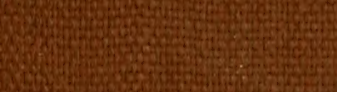


สิ 


1 




\title{
EUROPEAN AGRICULTURE
}

A N D

\author{
RURAL ECONOMY.
}

FROM PERSONAL OBSERVATION.

B Y

HENRY C $0 \mathrm{LMAN}$,

HONORARY MEMBER OF THE ROYAL AGRICULTURAL SOCIETY OF ENGLAND, OF THE NATIONAL AGRICULTURAL SOCIETY OF FRANCE, AND OF THE NATIONAL AGRICULTURAL SOCIETY OF THE UNITED STATES.

"For, in all things whatever, the mind is the most valuable and the most important; and in this scale the whole of agriculture is in a natural and just order; the beast is an informing principle to the plough and cart, the laborer is as reason to the beast, and the farmer is as a thinking and presiding principle to the lavorer." - BURKE.

\section{VOL. I. 2 in w w e}

FOURTH EDITION, WITH ADDITIONS.
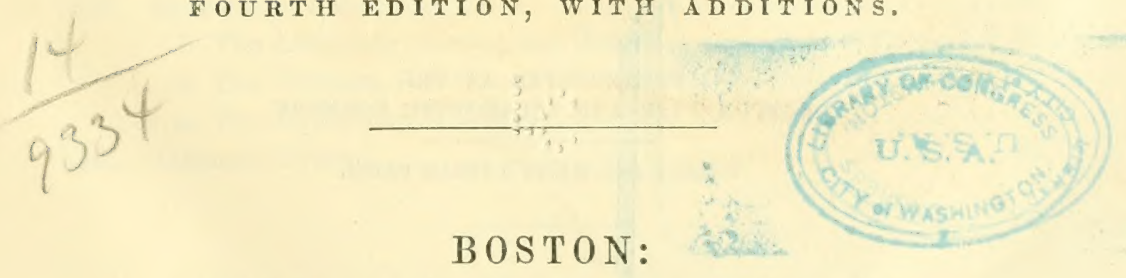

PHILLIPS, SAMPSON \& COMPANY.

NEW YORK: CHARLES M. SAXTON. PHILADELPHIA : THOMAS, COWPERTHWAIT

\& co. BALTiMORE: CUSHING \& BROTHER. CHARLESTON, S. C.:

M'CARTER \& ALLEN. CINCINNATI: H. W. DERBY

\& CO. BUFFALO: G. H. DERBY \& CO.

1851. 
Entered, according to Act of Congress, in the year 1849, by HENRY COLMA N,

In the Clerk's Office of the District Court of the District of Massachusetts.

STEREOTYPEP AT THE BOSTON TYPE AND S TEREOTYPE FOUNDRY.

WRIGHT AND HASTY'S STEAM PRESS. 


\title{
I N D E X,
}

\author{
or \\ TABLE OF CONTENS.
}

VOL.I.

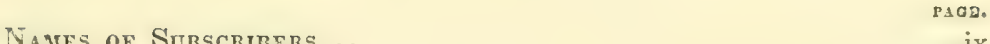

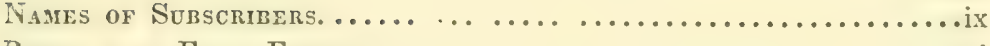

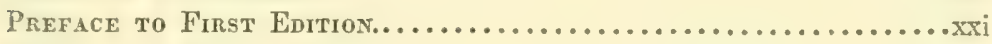

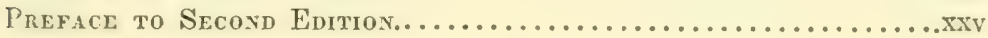

FIRST REPOR'T.

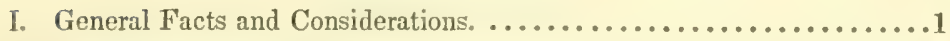

II. Particular Objects of Inquiry. . . . . . . . . . . . . . . . . .

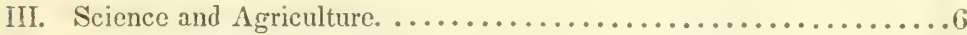

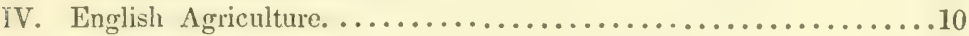

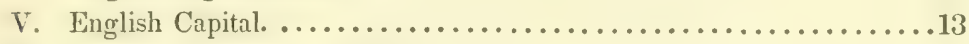

VI. General Appearance of the Country....................... 16

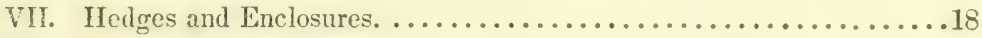

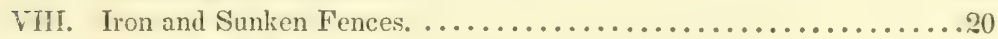

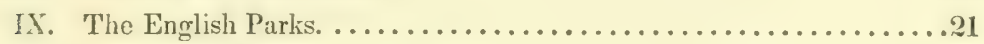

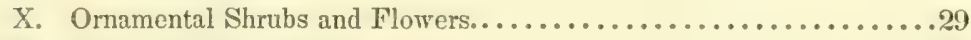

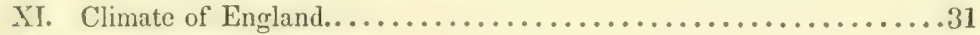

Y.1. Agricultural Population...............................

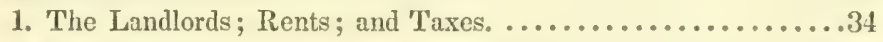

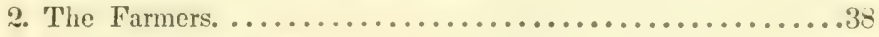

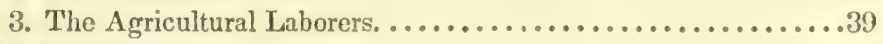

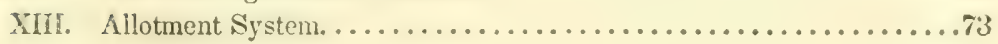

\section{SECOND REPORT.}

Xili. Allotment System, (continued.) ...................... 81

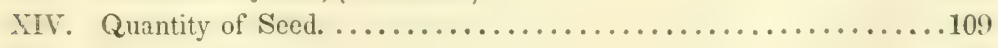

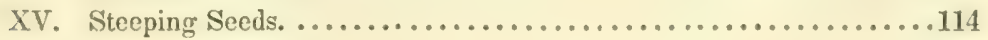

XVI. Spade Husbandry. ..................................

VOL. I. 
XVII. Condition of the Laborers..............................

XVIII. Progress of Agriculture, compared with other Pursuits. ......144

XIX. Actual Improvements in English Agriculture.............148

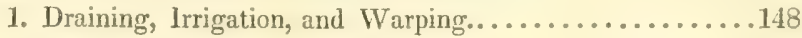

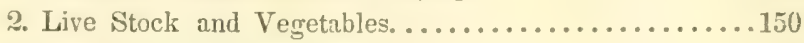

3. Agricultural Implements. ..................150

4. Application of Steam to Agriculture.............151

5. Increased Production. .................... 159

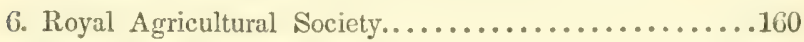

7. Agricultural Society of Scotland...................166

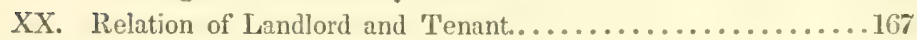

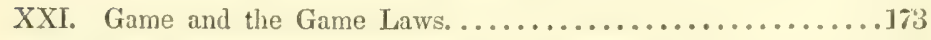

XXII. The Royal Agricultural Society of Ireland............. 175

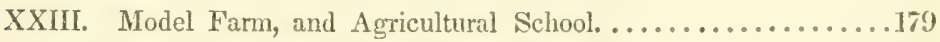

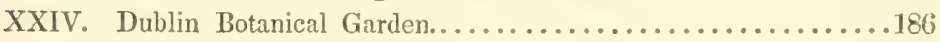

\section{THIRD REPOR'T.}

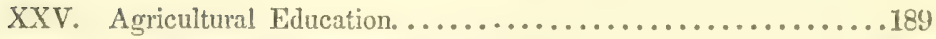

1. Glasnevin Agricultural School.................196

2. Templemoyle Agricultural School.............203

3. Brookfield Agricultural School.................210

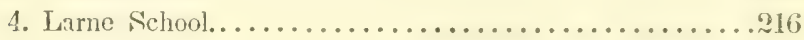

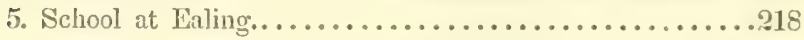

6. Agricultural College at Cirencester. .............219

XXVI. General Views of Agricultural Education..............220

XXVII. Influence of Knowledge upon Agriculture............223

XXVIII. Sciences to be taught..........................225

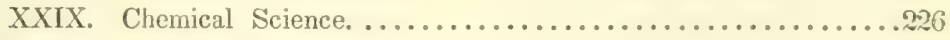

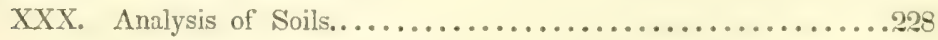

Soils of Heaths. .........................

XXXI. Natural Science............................237

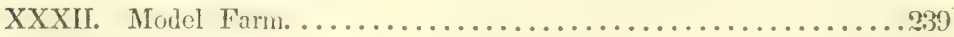

XXXIII. Experimental Farm..........................240

XXXIV. Economical Arrangements at the Agricultural College. .....210

XXXV. Plan of an Agricultural Institution for the United States. ...244

XXXVI. Elevation of Agriculture as a Pursuit and a Profession......248

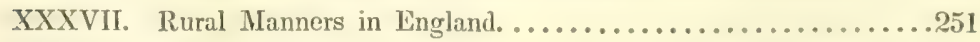

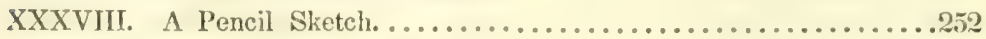

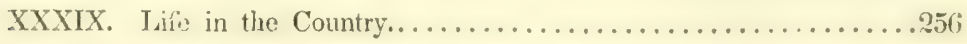


XI. Veternarv College.........................257

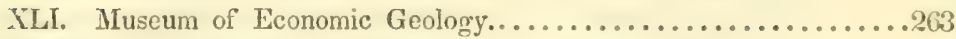

XLII. Chemical Agricultural Association in Scotland..............265

XLIII. Chemical Agricultural Lectures. ......................267

XLIV. Employment of Agriculturists. ....................268

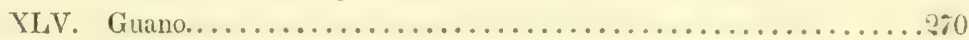

\section{FOURTH REPORT.}

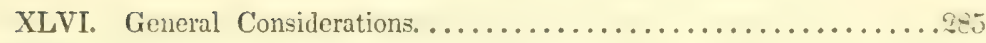

XLVII. Agriculture as a Commercial Pursuit. .................294

XLVIII. Markets. Cattle Markets.......................297

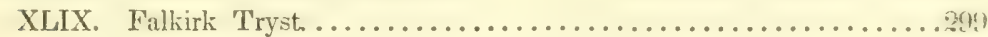

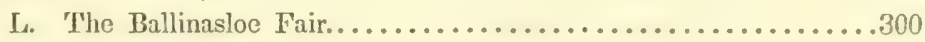

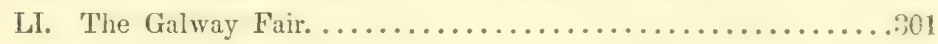

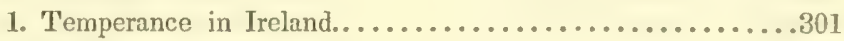

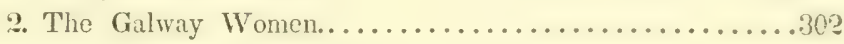

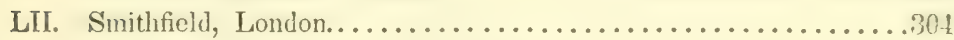

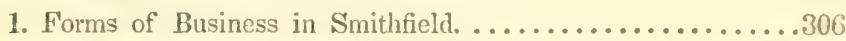

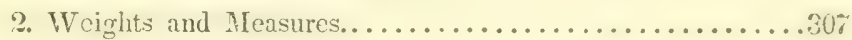

3. Weight of Animals, Mode of ascertaining...............308

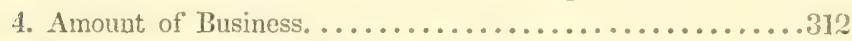

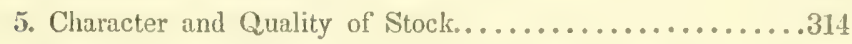

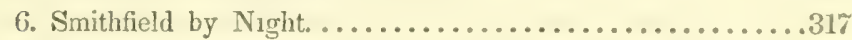

7. Attempted Removal of the Market from the City........319

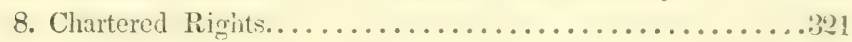

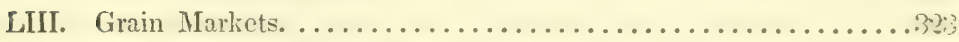

Kinds of Bread. Maize, or Indian Corn. ...............324

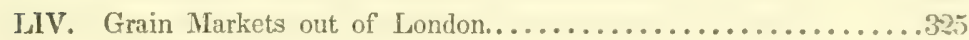

1. Forms of Business. ..........................

2. Advantages and Convenience of such Markets in the

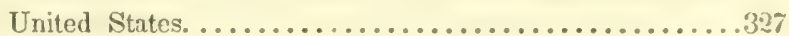

3. Modes of Selling................................

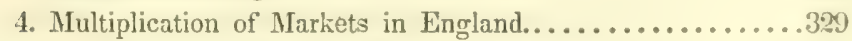

LV. The Corn Exchange in Nark Lane, London. ..............330

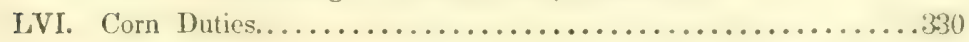

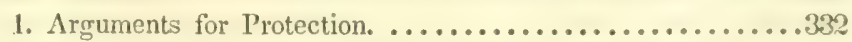

2. Arguments against Protection. .....................33

3. Moral Views of the Question........................

4. Patriotism and Philanthropy............................ 


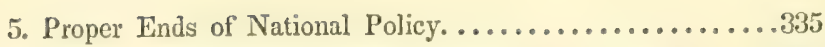

6. Bread regarded in a peculiar Light................336;

7. Peculiar Condition of the English Laboring Population....337

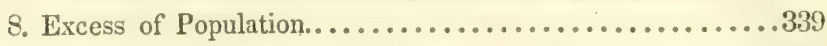

LVII. Mode of adjusting Labor and Wages........................

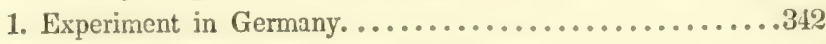

2. Claims of Labor, and Duties of Wealth..............343

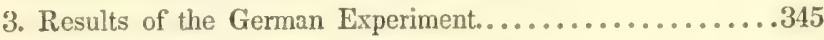

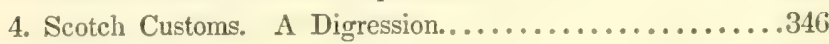

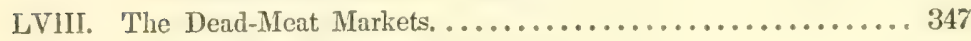

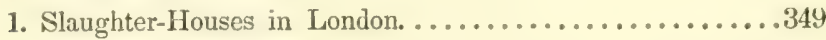

2. Customs of the Jews. ..............................

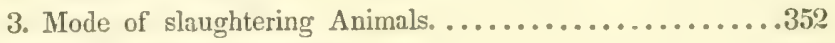

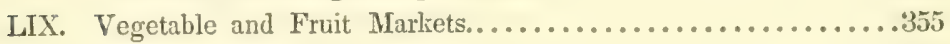

LX. Market Gardens................................. .

LXI. Covent-Garden Market............................

1. Fruits and Vegetables..........................

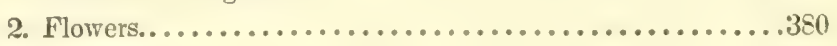

LXII. General Markets. . ..................................

\section{FIFTH REPORT.}

LXII. General Markets, (continued.).........................

LXIII. General Remarks and Divisions of the Subject of English

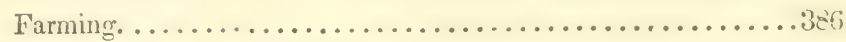

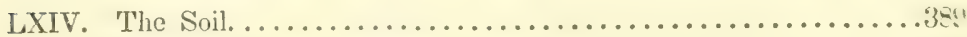

LXV. Theories of the Operation of the Soil. .....................

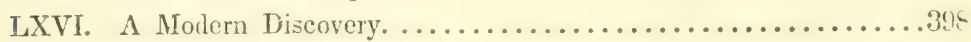

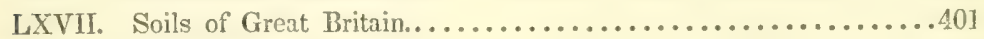

LXVIII. Classification of Soils...........................4

LXIX. Physical Properties of the Soil...........................

1. Wetness of a Soil. ........................404

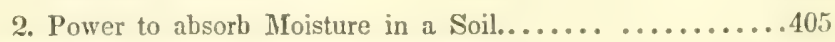

3. Consistency and Friability of Soils...............407

4. Temperature of Soils......................40

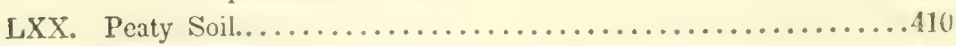

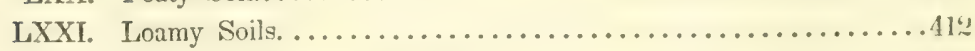

LXXII. Humus, or Vegetable Mould.. .......................

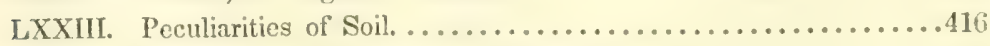

I.XXIV. Application of Chemistry to $\Lambda$ griculture................ 
LXXV. 'Theory of A griculture. ......................

LXXVI. Actual Improvements. ......................2?

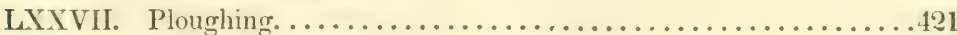

LXXVIII. The English Character. $\Lambda$ Digression..............422

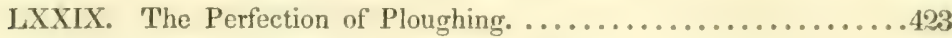

LXXX, Ploughing Match at Saffion Walden..............424

JXXXI. General Rules for Ploughing...................427

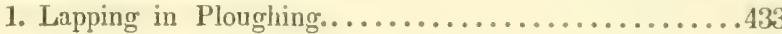

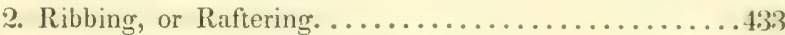

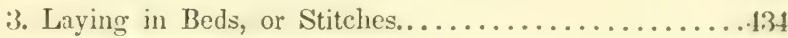

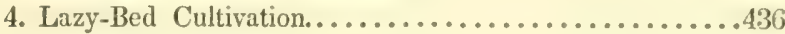

5. Correct Ploughing.......................440

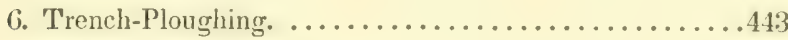

7. Subsoil-Ploughing......................448

8. Experiment in Subsoiling Heath Land............451

9. Subturf-Plongh. ....................... 45

10. Perfection of English Ploughing..................

11. Ploughing Matches...........................

12. Horses used for Ploughing................45y

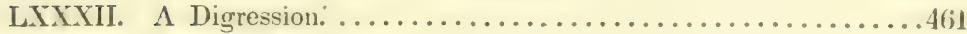

LXXXIII. Improved Machinery.........................

1. Machinery lightens Labor. ..................462

2. Machinery increases Production.................464

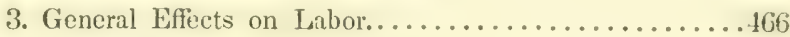

LXXXIV. Moral Considerations....................468

LXXXV. Harrowing. .................................. 46 ,

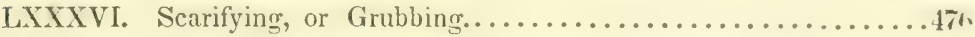

LXXXVII. General Remarks on the Use of A gricultural Machinery....45:

LXXXVIII. Particular Examples of Improvement..................485

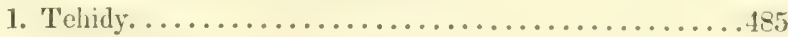

2. Scobell's Farm..........................

LXXXIX. Cornwall and the Land's End....................491

TABLE of Calculations on Ploughing. ....................492

$$
a^{*}
$$




\section{STEEL ENGRAVINGS.}

The English Cart Horse.............. Fronting title page to first volume. A First Prize Short-Horned Bull. ............. Frontispiece to Second Report.

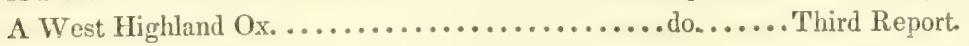

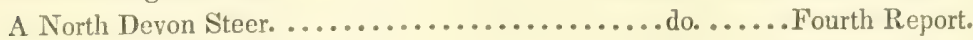
An Aberdeenshire I olled Bull. ....................... . . . Report.

\section{WOOD CUTS.}

Side Supports for Posts. ................................

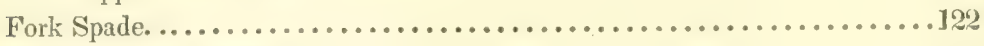

Smith's Subsoil Plough.................................. 455

Rackheath Subsoil Plough. ................................ 455

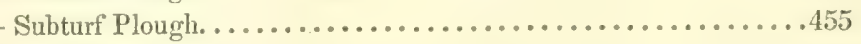

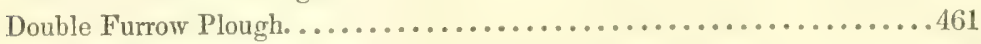

Gang of Light Seed Harrows. .......................... . . .

- Heavy Iron Harrows. .........................473

Biddell's Extirpating Harrow. .............................. 475

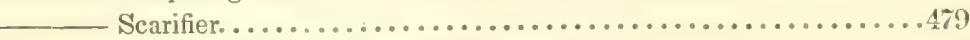

Chisel Point and Wide Hoe, to Biddell's Scarifier. ............... . 480

Finlayson's Self-cleaning Harrow. ........................ 481

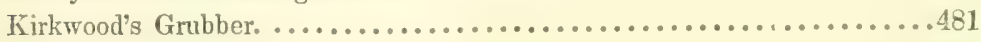

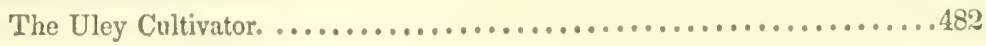




\title{
NAMES OF SUBSCRIBERS
}

\author{
TO THE FIRST EDITION.
} $\left.\begin{array}{cr}\text { Copies. } \\ \text { Massachusetts Agri- } \\ \text { cultural Society, }\end{array}\right\}$ Boston, Mass. 100

New York State Ag- $\{$ Albany, N.Y. 100 ricultural Society,

Vorcester County TWorcester, MIass. 40

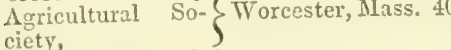
Philadelphia Agri- Philadelphia, Pa. 40 cultural Society, New York, N.Y. 40

American Institute, New Essex County Agri- Essex Co., Mass, 25 Essex County Agri-
cultural Society,

Massachusetts Hor- ? Boston, Mass. 25 ticultural Society,

Ionroe County Ag- Rochester, N. Y. 25 ricultural Society,

Plymouth Agricul- Plymouth, Mass. 25 tural Society,

Berkshire County? Agricultural So- $\}$ Pittsfield, Mass. 10 ciety,

IIampshire, Hamp- ? Northampton, den, and Franklin $\}$ Mass. $\Lambda \mathrm{g}$. Society,

Agricultural Society ? of Newcastle, Del- $\}$ Wilmington, Del. 10 aware,

Livingston County Geneseo, LivingAgricultural So- $\} \begin{array}{r}\text { seneseo, Livin Co., N. Y. } 10 \\ \text { ston }\end{array}$ ciety,

Library of Congress, Washington, D.C.10

Rhode Island Socie-? ty of Domestic Providence, R. I. 5 Man. and $\mathrm{Ag}$.

John P. Cushing, Watertown, Mass. Hon. T. H. Perkins, Boston, Mass.

Samuel Appleton,

Joshua Blake,

Hon. Abbott Lawrence,

Daniel P. Parker,

John Bryant,

TVilliam Appleton,

Henry Codman,

John A. Lowell,

Hon. Nathan Appleton,

B. B. Aussey \& Co.
Robert G. Shaw,

J. Breck \& Co.

E. B. Swett,

Hon. William Sturgis,

Hon. Jonathan Phillips,

George B. Blake,

James Jackson, M. D.

John C. Warren, M. D.

Hon. Josiah Quincy, Jr.

Lucius M. Sargent,

Israel Munson,

Wm. Prescott, LL. D.

Hon. Edmund Dwight,

E. H. Robbins,

Francis Skinner,

Henry Oxnard,

George C. Shattuck, MI, D.

Thomas B. Wales,

Hon. P. C. Brooks,

Hon. John Welles,

Hon. David Sears,

Hon. Samuel A. Eliot,

George Parkman, M. D.

Hon. Martin Brimmer, ? Mayor of Boston,

Francis G. Shaw,

Samuel P. Shaw,

Hon. John C. Gray,

Jordan \& Wiley,

Saxton \& Kelt,

Frederic Tudor,

James Munroe \& Co.

Isaac Winslow,

J. H. Francis,

WV. D. Ticknor \& Co.

Benjamin Guild,

Hon. Samuel Dorr,

I. B. Forbes,

George B. Emerson,

William Almy,

Benjamin 'I'. Reed,

John Parker,

George Hayward, M. D.

John D. Williams,

Thomas A. Dexter,

William P. Mason,

Sidney Bartlett,
Cupies.

Boston, Mass. 12

"6 11

10

"6 10

“6 10

“

“" 5

،

"6

.

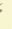

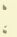

4

,

,

" 4

, 4

“. 4

. 4

$" 6-3$

.

.. 


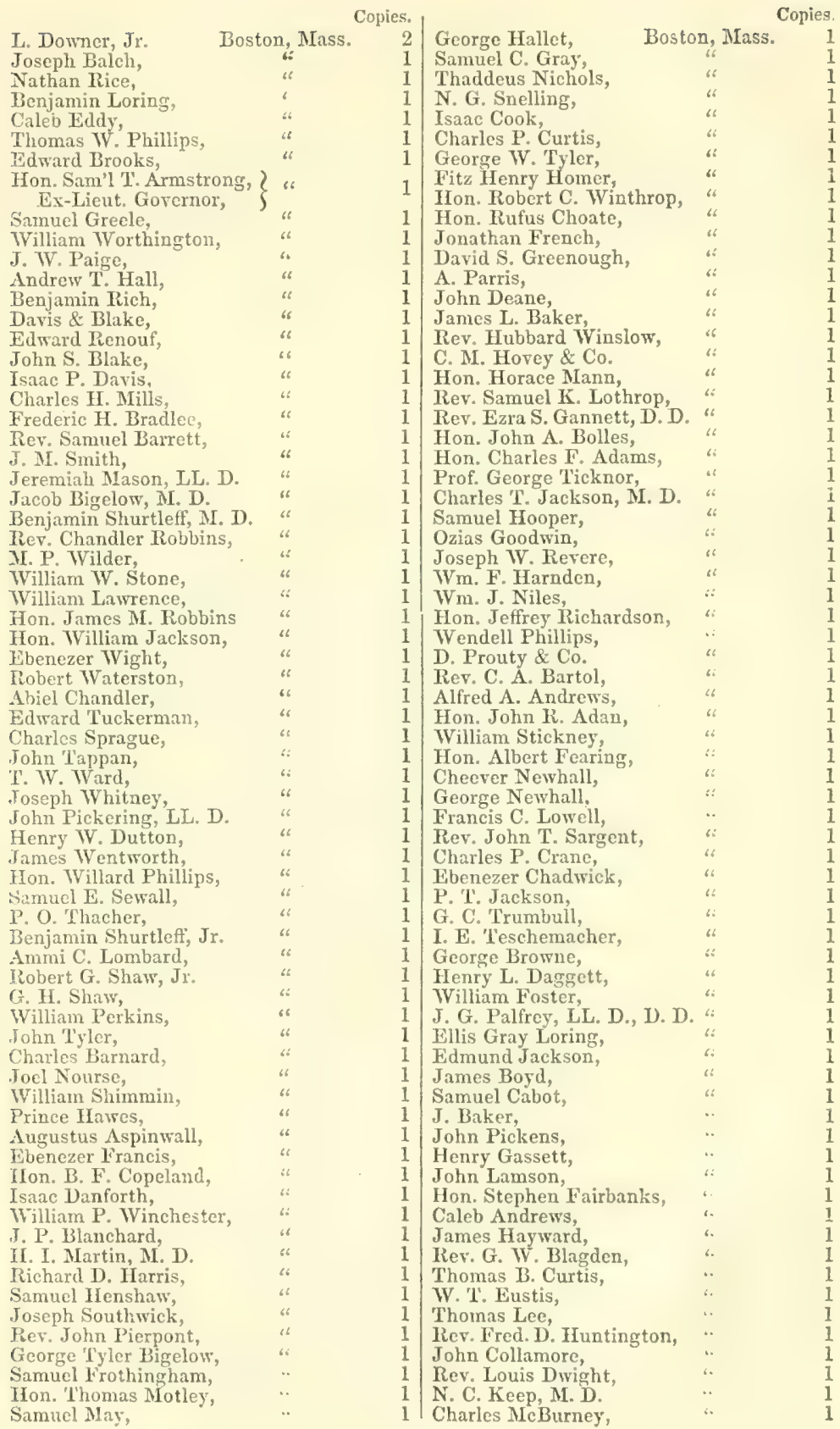




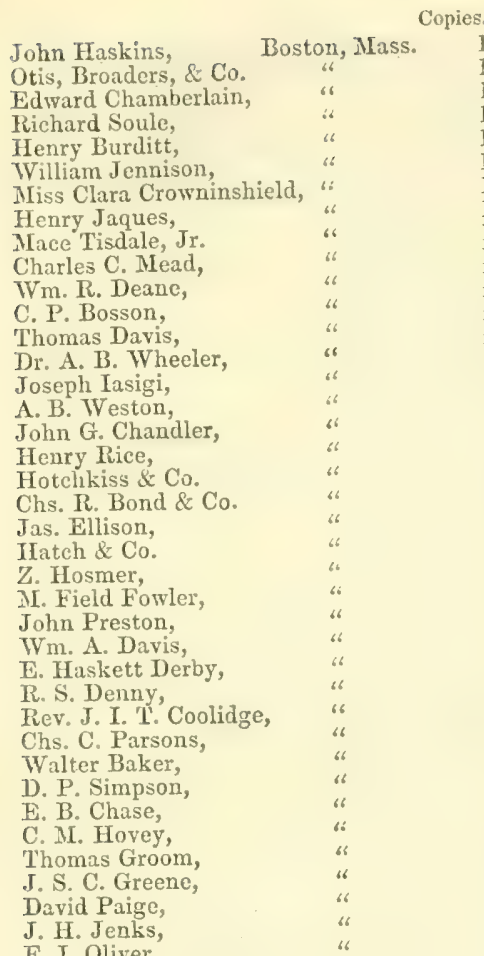

F. J. Oliver, S. G. Howe, M. D., South Boston, MIass.
Tames Brown, James Brown,

WT. A. White, "6

Joseph Story, LL. D., Cambridge, Mass. Josiah Quincy, LL. D. \ Pres. of Harv. Univ. Rev. Andrews Norton,

Villiam Pomeroy, Prof. James Walker, D.D.

N. J. Wyeth, O. S. Keith, Prof. Jared Sparks, Rev. R. M. Hodges, J. E. Worcester, Rev. Wm. Newell, Charles C. Little, Rev. Danicl Austin, Hon. Theodore Lyman, Brookline, Mass. Benjamin Goddard, John Howe,

Rev. John Pierce, D. D.

Ioses Jones, Samuel Philbrick, John Hayden, Samuel Veld, A. D. Williams, Jr. Roxbury, Mass.

Rev. George Putnam, Rev. Allen Putnam,

Hon. Sam'l H. Walley, Jr. "

George R. Russell, West Roxbury, Mass. Joseph H. Billings,

Francis Geo. Shaw, West Roxbury, Mass. 1 Aaron D. Weld, George Ripley, William Keith, John Parkinson, " " 1 Rev. Theodore Parker, " 1 John Prince, Jamaica Plains, Roxbury, 1 Francis C. Head, Gen. Wm. H. Sumner, " " Charles WV. Greene, "6 Stephen Mr. Weld, "6 John J. Low, M. W. Greene, Benjamin D. Emerson, "6 John M. Fessenden, " "6" F. E. Faxon, Isaac Parker, Waltham, Mass. 1 Benj. Wellington, " Rev. George E. Ellis, Charlestown, Mass. 2 Samuel Jaques, John Fenno, Chelsea, Míss.

Hon. Jno. Quincy Adams, ? Quincy, MIass. 1 Ex-President of U.S.

Rev. Francis Cunningham, Milton, Mass. 1 Joseph Rowe,

Danforth P. Wight, M. D., Dedham, Mass. 1

Rev. John White,

Rev, Alvan Lamson, D. D.

George Richardson, Dorchester MIass.

Increase S. Smith, "6

F. W. Macondray,

Joseph Peabody,

$\begin{array}{lll}\text { Hon. S. C. Phillips, " " } & 5 \\ \text { Nathaniel West, } & \text { " }\end{array}$

Salem, Mass. $\quad 10$

Hon. Nathaniel Silsbee, "6 3

Francis Peabody, "6 2

Hon. Leverett Saltonstall, " " $\quad 2$

Wm. H. Neal, 3 " " $\quad$ "

$\begin{array}{lll}\text { Robert Stone, } & \text { "6 } & 2\end{array}$

John H. Silsbee, " "

J. H. WVard,

Asahel Huntington,

Wm. F. Gardner,

Jno. Fisk Allen,

Jno. C. Lee,

Amos Choate,

D. A. Neal,

John G. King,

Oliver Hubbard, M. D.

Benjamin Merrill,

IVm. Deane,

Charles Saunders,

David Merritt,

John Jewett,

Erastus WVare,

Nathaniel Frothingham, Jr. "

J. Chadwick,

John Robinson,

J. S. Cabot,

Jno. F. Andrew,

Nathan Endicott,

Hon. G. Barstow

1 Joseph S. Leavitt,

E. Hersey Derby,

1 Gideon I'ucker,

1 D. \& J. Pulsifer,

1 A. \& D. Lord,

1 Benjamin F. Browne,

1


Robert Brookhouse, Salem, MIass.

liev. Charles TV. Upham,

Frederic Hotres,

Pickering Dodge,

George Choate, M. D.

Samuel Briggs,

Gen. TVm. Sutton,

Jos. G. Waters,

Hon. Stephen P. Webb,

Charles A. Andrew,

Caleb Foote,

WW. Ires,

John W. Pepper,

John G. Treadwell, NI. D. "

Joseph E. Sprague, "

N. W. Neal,

Uichael Shepard,

James Chamberlain,

B. K. Churchill,

Henry Whipple,

Henry A. Breed, Irnn, Mass.

$\left.\begin{array}{c}\text { Hon. Mareus Morton, } \\ \text { Ex-Gor. of Mass. }\end{array}\right\}$ Taunton, Mass.

Hon. Edward Barlies, "

Wm. A. Crocker,

Stephen Salisbury, TVorcester, Mass.

S. B. Woodward, AI. D.

Hon. Levi Lincoln, Ex- ? “

Governor of Mass.

Hon. John Daris, Ex- "

Governor of Mass. $\}$.

Daniel Waldo,

Joseph G. Kiendall,

Edwin Conant,

John W. Lincoln,

S. M. Burnside,

Tillliam Lincoln,

A. D. Foster,

W. A. Wheeler,

Isaac Davis,

Charles Allen,

Riejoice Newton,

Hon. Pliny Merrick,

I. A. Dowley,

Emory Vashburn,

H. S. Wheaten,

Oliver Dean, MI. D. Framingham, Mass.

$1 \mathrm{Wm}$. A. Lander, Danvers, Mass.

Ilon. Daniel P. King, "“

Jno. W. Proctor,

Benjamin Wheeler,

Nier, Andrew Bigelom, "

Benjamin Goodridge,

Charles Lawrence, North Danvers, Mass. 1

Enoch Silsby, Bradford, Mass.

Rev. Thomas B. Fox, Newburyport, Nass. 1

Edward Tappan, Jr.

Jno. Porter,

Micajah Lunt,

Jeremiah Colman,

Jno. Gras, Jr.

David Wood,

Hon. E. S. Rand,

B. B. Titcomb,

Daniel Adams, 3d, Newbury, Mass.

Moses Newell, West Newbury, Mass.

Wells Lathrop, South Hadley, Mass.

Ilon. Darid Cummins, Springficld, Mass. 2

Hon. W. B. Calhoun,
Conies.

1 Jas. W. Crooks, Springfield, Mass.

Copies

Justin Ely, TVest Springfield, Mross.

Hon. Benja. V. French, Braintree, Mass. I

1 Hon. James H. Duncan, Harerhill, Mass. 1

Joseph Howe, Methuen, Mass. 1

1 Hon.D. Webster, LL. D., Marshfield, Mass. 2

Hon. Nath'l B. Borden, Fall River, Mass. 1

A. Robeson, Jr. "

Wm. R. Robeson, "

1 John Flint, Andorer, Mass, 1

1 Joseph Kittredge, "6 1

Stephen Barker, "6

1 Jedediah H. Barker, " "

1 Samuel Farrar, " "

1 Hon. G. P. Osgood, " " I

1 J. J. Brown, "

1 Geo. Hndges, North Andover, Mass. 1

1 N. W. Hazen, South Andorer, Mass. 1

1 D. L. Child, Northampton, Mass. 1

1 Hon. Joseph Lyman, "6 1

1 Rev. Rufus Ellis, " "

Edward Clarke, " "

Wm. Clarke, " "

Wm. A. Hawles, " "

Daniel Stebbins, M. D. "

Hon. Isaac C. Bates, "

Hon. George T. Daris, Greenfield, Mass. I

Hon. C. K. Grennell, "6

Alpheus F. Stone, M. D. " "

Daniel Wells,

Wendell P. Davis, " "

Henry W. Clapp, " "

David Willard, " "

James Deane, M. D. "

Rer. Samuel May, Leicester, Mass. I

IV. B. Earle, "6

1 J. L. Moffat, Newton, Mass. I

ITilliam Kenrick, "6

1 G. B. Slater, Webster, Mass. I

1 Hon. F. R. Gourgas, Weston, Mass. I

1 Hon. Benjamin Estabrook, Athol, Mass. 1

1 Hon. Solomon Strong, Leominster, Mass. 1

1 Hon, George B. Upton, Nantucket, Mass. 1

1 George W. Wright, " " I

Henry Swift, "s

Barker Burnell, "

John P. Webber, Jr. Beverly, Mass. I

ReF. C. T. Thayer, " 1

Hon. Jesse Perkins, N. Bridgewater, Mass. 1

Hon. H. W. Cushman, Bernardston, Mass. 1

Horace Williams, Deerfield, Mass.

Arthur WV. Hoyt, " 1

Theodore G. Huntington, Hadley, Mass. 1

Col. David Wells, Shelburne, Mass. I

James N. Bates, Barre, Mass. 1

B. D. Whitner, Northboro' Mass. 1

Gen. Josiah Newhall, Lynnfield, Mass. 1

Hiram A. Morse, Holliston, Mass. I

WVm. R. Rodman, New Bedford, Mass. 1

S. W. Rodman,

Benjamin Rodman,

George Randall,

Charles W. Morgan,

John Henry Clifford,

George Howland, Jr.

William P. Grinnell,

William Rotch, Jr.

William R. Rotch,

Edmund Gardiner,

William C. Whitridge,

$\begin{array}{ll}\text { "6 } & 1 \\ \text { "6 } & 1 \\ \text { "6 } & 1 \\ \text { "6 } & 1 \\ 66 & 1 \\ 6 & 1 \\ 6 & 1 \\ \text { "6 } & 1 \\ \text { "6 } & 1\end{array}$


William IXathaway, Jr., New Bedford,

Matthew Luce,

J. H. WV. Page,

John C. Haskell,

'Thomas R. Robeson,

Frederic Robeson,

Joseph Ricketson,

Daniel Ricketson,

Abraham Shearman, Jr.

John W. Coggeshall,

Samuel L. Dana,

Jolnn Avery,

Samuel Lawrence,

William Spencer,

B. F. French,

Alexander Wright,

S. W. Stickney,

John Nesmith,

G. W. Larrabee,

John Clark,

Rev. H. A. Miles,

TVilliam Boott,

Daniel Bixby,

Amasa Farrier, Stoneham, Míass.

John Abbott, Westford, Mass.

H. C. Merriam, North Tewksbury, Mass. 1

N. B. Robbins, Plymouth, Mass.

Mrs. Susan Sedgwick, Stockbridge, Mass. 1

Elias M. Stillwell, Lancaster, Mass.

Paul Whitin, Whitinsville, Mass.

John Page, Hardwick, Mass.

S. B. Walcott, Hopkinton, Mass.

Johnson Gardner, M. D. $\left\{\begin{array}{l}\text { Vue de l'Eau. } 1 \\ \text { Mass. }\end{array}\right.$

William Jenkins, Providence, R. I. Alexander Duncan,

MToses B. Ires,

Rev. Samuel Osgood,

Joseph Mauran, M. D.

Samuel B. Wheaton,

William H. Hoppin,

Amory Chapin,

Edward Walcott,

Hartford Tingley,

Robert H. Ives,

Amasa Sprague,

R. WV. Greene,

Rev. F. Wayland, D. D.,

Pres, of Brown Univ.

Henry Anthony,

John I. Stimpson,

Benjamin W. Comstock,

Stephen H. Smith,

Hon. James Fenner,

Gov, of Rhode Island,

Owen Mason,

Matthew Watson,

Josiah Chapin,

46

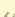

"

66

s

Adam Anthony, North Providence, R. I. Mark Antony De Wolfe, Bristol, R. I.

Wm. Bradford De Wolfe,

Jacob Dunnell, Pawtucket, R. I

James C. Rome, IVoonsocket, R. I.

Henry Whitney, New Haven, Conn.

Prof. B. Silliman, LL, D.

Charles Robinson,

Winthrop Atwill,

Prof. B. Silliman, Jr.

TVilliam K. 'Townsend,
Hon. W W B Bon Farmington, Conm.

Simeon Hart E. W. Carrington,

IV. Wadsworth,

Timothy Cowles,

S. H. Huntington, Hartford, Conn.

Horatio Alden,

A. II. Collins,

D. C. Collins,

Charles F, Pond,

Hon. Jno. M. Niles,

E. W. Bull,

George Tuttle,

T. C. Perkins,

Hon. J. 'Toucey,

Walter Mitchell,

S. G. Chaffee,

James Dixon,

Isaac Stuart,

George Brimley,

Solomon Porter,

Charles H. Olmsted,

S. E. Alden, Enfield, Conn.

Henry Thompson,

Leri Durand, Derby, Conn.

Charles A. Goodrich, Berlin, Conn.

Norman Porter,

Chas, W. Rockwell, Norwich, Conn.

Jacob W. Kinney,

Amos H. Hubbard,

William P. Green,

John A. Rockwell,

lialph H. Avery,

E. B. Brown, Mystic, Conn.

Joseph Griswold, Mystic Bridere, Conn

A. Woodward, M. D., Franklin, Conn. I

H. A. Dyer, Brooklyn, Conn.

IVm. G. Johnson, Uncasville, Conn.

J. S. Halsey, Preston, Conn.

Giles Taintor, IVindham, Conn.

Hon. C. F. Cleveland, $\}$ Hampton, Conn. I

Daniel Russell, Portland, Conn.

Joseph Hall,

"6

Joel Hall, 2d,

E. W. N. Starr, Middletown, Conn.

Sam'l D. Hubbard,

Alfred Hubbard,

Charles IIubbard,

Samuel Russell,

Joseph Hurlbut, New London, Conn.

Chas. A Lewis,

Wm. P. Clereland,

Wm. TV. Billings,

Lemuel Stoughton, East Windsor, Conn. I

Azel S. Bowe,

Erastus Eillsworth,

Henry Watson,

Ralph K. Phelps, Manchester, Conn.

E. Holcomb, Granby, Conn.

D. WV. Grant, Bloomfield, Conn.

Filley,

Bethuel Phelps, Warchouse Pt., Com.

Alvah Morrcli,

F. W. Wilcox, Salem, Conn.

Lucian 'T. Pearson, Collinsville, Comn. 

brary Association, $\}$ Bangor, Me.

E. C. Andrews, Portland, Me.

II. J. Little,

James Deering,

Joshua Richardson, "

William Willis, "

Neal Dow,

Joln Otis, Hallowell, Me.

Glazier, Masters, \& Smith,

Hon. Reuel Villiams, Augusta, Me.

Hon. Samuel M. Pond, Bucksport, Me.

W. A. Hayes, South Berwick, Me.

R. B. Allen, Belfast, Me.

E. Seymour, Brattleboro', Vt.

John H. Hopkins, Jr., Burlington, Vt.

Rev, Johx Wheeler, D. D.

Prof. Geo. W. Benedict,

E. 'T. Englesby,

H. B. Stacey,

N. B. Haswell,

Harry Bradley,

Hon. Geo. P. Marsh,

Jno. N. Pomeroy,

Carlos Baxter,

Luther Loomis,

N. A. Tucker,

David Read,

H. S. Morse, Shelburne, Vt.

L. S. White,

S. Grout, Bellows Falls, Vt.

Charles K. Field, Newfane, Vt.

Hon. Wm. Jarvis, Weathersfield, Vt.

Jos. P. Fairbanks, St. Johnsbury, Vt.

George IV. Palmer, Brandon, Vt.

Hon Levi Woodbury, Portsmouth, N. II.

Hon. Ichabod Bartlett,

Samuel Lord,

John Rice,

Jno. N. Sherburne,

HI. IV. Peirce,

Rev. John Parkman, Dover, N. H.

IR. B. David, Amherst, N. H.

Josiah H. Hobbs, Wakefield, N. H.

Levi Bartlett, Warner, N. H.

W. B. Walton, Schenectady, N. Y.

Rev. John Williams,

Jona. Crane,

Prof. Alonzo Potter, D. D. "

Prof. J. IV. Jackson, "

D. \& C. II Tombinson,

Alexander Walsh, Lansingburgh, N. Y.

Maj. Gen. John I. Viele,

Alfred Clarke, East Springfield, N. Y.

John B. James, Rhinebeck, N. Y.

John H. Walsh, Newburgh, N. Y.

Charles Downing,

A. J. Downing,

II. D. Grove, Hoosick, N. Y

Anthony Van Bergen, Coxsackie, N. Y. Inuis J. Van Derveer, Amsterdam, N. Y.

Willis Gaylord, Otisco, N. Y.

1). D. Campbell, Rotterdam, N. Y.

James 1R. Craig, Niskayuna, N. Y.

J. Strachan, Waterford, N. Y.

E. D. Windt, Fishkill, Landing, N. Y.

Peter C. Dubois,

William S. Ver Planck, "

John 13. Wakeman, Little Falls, N. Y.

John Caldwell, Salisbury, N. Y.
Dr. William Bristol, Utica, N. Y.

Copies.

E. WV. 'Teackle,

S. D. Childs,

Capt. William Mervine,

Edmund A. Wetmore,

Theodore P. Ballou,

Hamilton Spencer,

S. V. Aley,

John M. Sherwood, Auburn, N. Y.

John B. Dill,

Hon. Wm. H. Seward, ?

Ex-Gov. of New York,

James C. Derby,

E. Rhodes, Manlius, N. Y.

L. A. Morrell, Lansing, N. Y.

P. V. C. Miller, Shawangunk, N. Y.

W. A. S. North, Duanesburgh, N. Y.

L. W. Hall \& Co., Syracuse, N. Y.

P. N. Rust,

Rev, J. P. B. Storer, "

Russell Kniffen, Trenton, N. Y.

Elon Comstock, Rome, N. Y.

Benjamin P. Johnson,

Benjamin N. Huntingdon,"

Robert Sandford, Lenox, N. Y.

M. R. Patrick, Watertown, N. Y.

Henry S. Randall, Cortlandrille, N. Y.

George I. Pumpelly, Oswego, N. Y. 25 Hon. Gerrit V.
Sacket, Seneca Falls, N.Y. 46 William A. Sacket,

Samuel D. 'Tillman, "

C. M. Crittenden,

A. S. \& C. W. Dey,

Thomas H. Swaby,

C. L. Hoskins,

William Arnett,

H. C. Silsby,

George B. Daniels,

Edward Myndun,

Thomas C. Magee, Tyre, N. Y.

Jason Smith,

David Southwick,

J. W. Bacon, Waterloo, N. Y.

Richard P. Hunt,

Aaron D. Lane,

J. Lisk,

Junius, $\mathbf{N}$. Y.

John Carman,

Orrin Southwick,

William K. Strong, Fayette, N. Y.

John Johnstone,

Henry Reeder, Varick, N. Y.

John D. Cox, Romulus, N. Y.

G. Dickerson, Covert, N. Y.

Jeremiah Rappleye,

A. M. Farley,

Abraham Ditmus,

Anson Hopkins,

John L. Eastman, Lodi, N. Y.

P. W. Severance,

John De Mott,

Arad Joy,

6

A. B. Dunlap,

Ovid, N. Y.

IVilliam 12. Schuyler, "

Andrew Dunlap, Jr.

C. I. Sutton,

Henry Simpson,

Joseph Craven,

Hugh Chapman,

Daniel Scott.
1

1

1

1

1

$\frac{1}{5}$

5

2

1

2

1 
John I. Covert, Orid, N. Y. Henry M. Ward, Rochester, N Y. Samuel D. Porter, L. B. Langworthy,

Matthew Brown, M. D.

C. F. Crossman,

Henry I. Whitehouse, D. D."

Ébenezex Watts,

F. Whittlesey,

George F. Danforth,

E. Darwin Smith,

E. Pomeroy,

Graham H. Chapin,

Edward MI. Noore, MI. D.

E. G. Munn, MI. D.

W. W. Alcott,

James H. Watts,

Nathaniel T. Rochester,

Henry E. Rochester,

Thomas H. Rochester,

TVilliam Pitkin,

Samuel Miller,

Silas O. Smith,

Ellwanger \& Barry,

Maltby Strong, M. D.

Amos Sawyer,

Strong \& Dawson,

John Hawks,

John A. Pitts,

I. B. Bateham,

Lewis Thies,

Aristarchus Champion,

Josiah Snow,

Alexander Kelsey, M. D.

John Allen,

Fletcher M. Haight,

M. F. Reynolds,

A. Gardiner,

I. F. Mack,

Philander Davis,

Robert Wilson,

Moses Chapin,

Samuel G. Andrews,

E. F. Smith,

Hon. Thomas J. Patterson,

W. E. Lathrop,

John F. Bush,

John Haywood,

Prof. Chester Dewey,

N. B. Northrop,

James W. Sawyer,

John Rolph, II, D.

James Miller,

Darius Perrin

Rev. Tryon Edwards,

Charles Hendrix,

David R Barton,

Jasper W. Gilbert,

Everard Peck,

Frederick F. Backus, M. D

Elias Pond,

Isaac M. Hall \& Co.

Horatio N. Fenn, M. D.

Frederick Starr,

I. A. Ward,

Stephen Atwater,

David Hoyt,

Leander Wetherell,

George Shelton,

H. L. Sterens,
Copies.

.

To.

Jiriggs;

Hon. Thomas Kempshall, "

Joseph Hall, "-

Charles R. Babbett, " "

Hiram Smith, " "

1 Lewis Brooks, " "

1 Abelard Reynolds, "

1 Hiram Blanchard, " "

1 Reuben Sikes, " "

1 George Whitney, " "

1 Villiam W. Arumford, " "

1 W. A. Herrick, " "

1 John Fish, " 1

1 John Gifford, " "

I Aaron Errickson, " "

1 Allen Mason,

1 William Kidd, " "

1 William Buell, M. D. " "

1 John B. Elwood, M. D. "

1 Francis Brown,

1 Thomas H. Hyatt, " "

1 William Gerry, " "

1 William Brewster, " "

1 School District No. 15, "

1 William Law,

1 Lewis Denny, " "

1 Ephraim W. Bore, "

1 William H. Cheney, "

1 David Scoville, " "

1 Joseph Strong, " "

1 George A. Wilkins, "

1 J. Geurge Hodgkins, " "

1 Nathan B. Garnsey,

1 Hon. John Greig, Canandaigua, N. Y. 10

1 Hon. Francis Granger, "

1 Henry Howard, ":

1 John Rankin, " "

1 Charles B. Meek,

I. John A. Granger,

1 William R. Macao,

Henry K. Sanger,

1 Hon. Mark H. Sibley,

Thomas Hall,

Charles Shepard,

Francis W. Paul,

Thaddeus Chapin,

Walter Hubbell,

Alvah Worden,

Charles Seymour,

Isaac Pierson,

Thomas H. Johns,

Samuel H. Andrews,

Jos. Bull,

J. L. Stuart Mentcath,

Alexander MIurray,

William Burling,

Myron H. Clark,

Henry Howe,

1 Jared Wilson,

1 Robert Iigham,

1 G. R. Parbutt,

R. C. Pratts,

Oliver Culver, Brighton, N. Y.

1 Daniel P. Bissell, Moscon, N. Y.

1 S. B. Piper, Lewiston, N. Y.

VOL. I. 
Copies.

John S. Shuler, MI. D., Lockport, N. Y. 1 James D. Shuler, " " T'imothy Backus, Wm. A. Townserd, M. D. “

F. N. Nelson, "

T. T. Flagier, "6

Aaron Parsons, IIon. Washington Hunt, "

A. A. Boyce,

S. Scovill,

Edward Hardy,

N. Dayton,

O. P. Hoag,

J. Kilbourn,

Hon. Joel ÁcCollum, “

Trumbull Cary, Batavia, N. X.

Chipman P. Turner, "

H. M. Soper,

T. Fitch,

J. S. Ganson,

Junius A. Smith,

Frederick Follett,

Albert Smith,

J. L. Brown,

Ambrose Stevens,

Rufus Robertson,

James D. Merrill,

Shubael Dunham,

Lucius A. Smith,

James Brisbane,

Samuel Heston,

Byron Densmore, Kendall, N. Y.

Mioses B. Gage,

H. TV. Bates,

N. Whitney,

Henry Higgins,

Benjamin Gariss, Jr., Bloomfield, N. Y.

Ralph Wilcox,

Rev, Robert WV. Hill,

Frederick $\mathrm{F}$. Rice,

William H. Hall,

Myron Adams,

B. C. Taft, West Bloomfield, N. Y.

Jasper C. Peck,

John Dickson,

Joseph Hall,

O. Thompson,

William H. Olin,

Philo Hamlin, East Bloomfieia, Y. Y.

G. Collins,

Frederick A. Spalding, "

Sylvanus Emmons,

Mi. S. Newton, Lima, N. Y.

2I. W. Brown,

Henry Grout,

William Arnold, Jr

Gcorge W. Atwill

Irrastus Clark,

Ira Godfrey,

George E. King,

Alexander Martin,

liobert ' $T$. Leach,

Clitus TVolcott, Oakfield, N. Y.

P. M. Smith, Le Roy, N. '

Peter Snell,

John Lent,

"6

William sheldon,

A. B. Murphy,

J. H. Stanley,

Ebenezer Mcad,
S. W. Olmsted,

Noah D. Hart,

William W: Peck,

Cyrus Brown,

William Cathcart,

Rawson Harmon, Jr., Wheatland, N. Y. I

John J. Blackmer, " " I

Joseph Garlinghouse, Richmond, N. Y. I

Hiram Pitts,

J. C. Shelton,

Elias S. Gilbert,

Asa Nowlen,

Hon. Henry L. Young

Aron, N. Y.

"6

Luther Briggs, Brockport, N. Y.

Hon. E. B. Holmes,

Horace Wheeler, Honeoye Falls, N. Y.

Jahn A. Davis,

Stephen Barrett,

John Christopher, Gates, N. Y.

Charles Godfrey, Genera, N. Y.

Rt. Rev. Wm. H. Delancey,"

Robert C. Nicholas,

Jos. Fellows,

James Reese,

Gideon Lee,

Thomas D. Burrall,

Elisha Johnson, Hornby Lodge, N. Y. 1

TV. Patterson, Westfield, N. Y.

C. Robinson, Clarendon, N. Y.

Charles Lee, Farmingham, N. Y.

Isaac Colvin,

Henrietta, N. Y.

M. W. Kirby,

IVest Henrietta Library, “

William C. Cornell, " 1

James S. Wadsworth, Geneseo, N. Y. 10

W. W. Wadsworth, " "

James Wadsworth, "6 5

A. Ayrault,

E. A. Le Roy,

Thomas H. Newbold,

Daniel H. Fitzhugh,

George T. Olyphant

C. H. Bryan,

David Piffard,

H. A. Wilmerding,

William H. Spencer,

Samuel Fitzhugh, Nount Morris, N. Y I

Lucius Southwick,

J. R. Murray,

Villiam T. Cuyler, Cuylerville, N. Y. 1

N. W. Gardner, Royalton, N. Y. I

Anson Packard, Bristol, N. Y.

Lewis F. Allen, Black Rock, N. Y.

N. K. Hall, Buffalo, N. Y.

Hon. Millard Fillmore,

A. \& J. McArthur,

"6

N. Y

Luther Wilson, Wilson, N. Y.

John Robinson, Palmyra, N. Y.

Micah Brooks, Brooks Grove, N. Y.

Hon. Asher Tyler, Ellicottville, N. Y

Abiel Baldwin, Clarkson, N. Y.

Owen Edmonston, Phelps, N. Y.

F. Willard Frisbie

S. Hildreth,

Carso Crane,

Elias Cost,

\section{،}

"6

John Lapham, Farmington, N. Y. 1

A. Oliver, Penn Yann, N. Y.

Henry Welles, 
S. S. Ellsmorth, Penn Yan, N. Y. D. A. Ogden, George A. Shepard,

H. P. Sartwell,

Abraham Wagener,

Alfred Brown,

Uri Judd, M. D.

Jonathan A. IIall,

Nelson Tunnicliff,

P. S. Oliver,

S. R. Fish,

L. E. Lapham,

John Hatmaker, Milo Centre, N. Y.

A. B. Hull, Angelica, N. Y.

George Fisher, Oswego, N. Y.

George Dean, Westmoreland, N. Y.

Henry Chamberlain, York, N. Y.

David McDonald,

Edward Brown,

Hollowway Long,

G. O. J. Du Relle, M. D. "

Paul Goddard,

John Hollowway,

John P. Root,

F. A. Gray,

Campbell Harris,

J. B. Harris,

James Gilmour,

Roswell Stocking,

Angus McBean,

Artemas Blake,

Reuben Lafever, Reading, N. Y.

George Edwards, Bath, N. Y.

J. C. Fuller, Skeneateles, N. Y.

R. H. Foster, Lyons, N. Y.

James Dunn,

66

John M. Holly,

A. L. Beaumont,

A. Hyde Call, Albion, N. Y.

Asa Rowe, Sweden, N. Y.

William D. Dickenson, Victor, N. Y. John B. French,

IV. IV. Marsh,

66

George J. Jessup, Palmyra, N. Y.

Stephen Hyde,

Jonathan T'ownsend,

66

Samuel E. Hudson, Newark, N. Y.

Cyrus S. Bulton,

Daniel Kenyon, "6

John B. Crosby, Rush, N. Y.

Joseph Sibley, West Rush, N. Y.

Daniel H. Burtiss, Chili, N. Y.

Elisha Whittlesey, Brooklyn, N. Y.

Ledyard Lincklaen, Cazenovia, N. Y.

Hon. Leman Gibbs, Livonia, N. Y.

Hon. J. Larrowe, Hammondsport, N. Y. 1

Ralph Plumb, Buffalo, N. Y.

Abner Bryant,

Albert H. 'Tracy,

Samuel Hecox,

I. A. Blossom,

Lewis Eaton,

66
66
16
68

John Craig, Middleport, N. Y.

William $\mathrm{R}$. Gwinn, Medina, N. Y.

Silas M. Burroughs,

John \& George Kirby,

"6

Orrin Scoville,

Hon. R. II Smith, Perry, N. Y.

Josiah Andrews,

Mosely Stoddard,
Copies. Moses S. Cole, Parma, N. Y.

John Sargent, Mendon, N. Y. I

Joseph Cox, Scottsville, N. Y. 1

Isaac Cox, "6

W. W. Wilcox, Irondequoit, N. Y. 1

Alexander A. Hooker, " 1

D. II. Buel, Benton Centre, N. Y. I

Asa Foote, Middlesex, N. Y. I

Ira Merrill, West Avon, N. Y.

1 Saxton \& Miles, New York City, 60

I Charles A. Stetson, "6 10

1 D. K. Minor, " 10

J. Prescott Hall, "6 "6 5

James G. King, " "

James Lenox, " "

I. F. Sheaf, " "

R. B. Minturn, " "

1 Rev. John O. Choules, "6 " 2

S. Verplanck, " "

I Jonathan Goodhue, "6 "

M. H. Grinnell, "6 "?

Robert B. Coleman, "6 2

Rev. Joseph Penney, D. D. "
George Bird,

1 H. M. Hayes, " " 1

L. N. Fowler, " "

William H. Aspinwall, " "

Pelatiah Perit, " "

Curtis Holmes, 66

1. Joseph G. Cogswell, "6 " o

William Partridge, " "

David Felt, " "

IVilliam H. Cary, "6 "

William Emerson, "6

Lewis 'Tappan, "6

Orsamus Willard, " "

Rev. Henry W. Bellows, " "

Greely \& McElrath, " "

Joshua Brookes, "6 "

Jacob Harvey, "6

C. M. Olcott, "6

A. A. Low, "6

T. A. Morison, " "

John Halsey, Jr. " "6

H. T. Chapman, " "

Isaac II. Frothingham, " "

Charles G. Carleton, "6

Iyman Cobb, "6

J. Atkins, Jr. " "

Joshua Atkins, " "

George C. 'Thorburn, " " I

G. M. Haywood, " " I

Abraham Bell, "6 "

J. Smyth Rogers, " "

George D. H. Gillespie, "

J. C. Delano, "6

John Joyger, "6 1

Charles Congdon, " "

Rollin Sanford, " " 1

Jeremiah Brown, " "

IV. J. Cormell, " "

Isaac R. Cornell, " "

Charles Richmond, Jr. " " 1

N. D. Carlisle, " "

F. I. Betts, "6

William 'T. MIcCoun, "6

Danicl Stanton, "6

$\begin{array}{lll}\text { Jonathan Sturgis, } & \text { " } & 1 \\ \text { Charles M. Lcupp, } & \text { " } & 1\end{array}$ 
Shephord TKnapp, New York City, 1

Gilbert K. Lassee,

Henry Woods,

F. WV. Guiteau,

E. D. Gillespie,

Wiley \& Putnam,

J. S. Bartlett,

Luther Bradish, Ex- $\}$ New Rochelle, N.Y. 1

Lt. Goy, of N. Y. Y Neton, Staten Island, I

Nehemiah Denton, Brooklyn, L. Island, 1

John A. King, Jamaica, Long Island, 1

E. P. Prentice,

Henry O'Reilly,

Joln Townsend,

A. MeIntrre,

J. McDonald MeIntyre,

Erastus Corning,

Luther Tucker,

Hon. Wm. C. Bouck, ?

Gov. of New York,

Henry L. Webb,

John N. Wilder,

Caleb N. Bement,

Robert E. Temple,

A. French, Jr.

James M. French,

James Kidd,

Hon. D. D. Barnard,

Tames Hall,

II. Pumpelly,

Joel Rathbane,

A. E. Brown,

James Wilson,

Prof. E. Emmons,

Hon. J. Koons,

C. P. WVilliams,

Albany, N. Y.

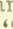

6

6

6

66

66

66

64

65

66
.66

.66

6 i

cc

66

68

68

ct

66

c6

66

66

66

J. P. Beekman, M. D.. Kin Jerhook, N. Y. 10

Iartin Van Buren, Ex- ? Lindenwald, President of U. S. $\}$ Iinderhook, Joel B. Nott, Guilderland, N. Y.

Edward C. Delaran, Ballston Centre, N. Y. I Georcre Vail, 'Troy, N. Y.

Hon. John Savage, Salem, N. Y.

Ezra Nre, Clinton, N.J.

Jas. Neilson, M. D., New Brunswick, N. J. 1

Hon. John 13. Aterigg, Pyramus, N. J. 1

J. W. Hayes, Newark, Y. J.

John S. Chambers, Trenton, N. J.

Samuel R. Gummere, "

Phil. Dickinson,

Richard S. Field, Princeton, N. J.

S. A. Hamilton,

Thomas Hancock, Buxlington, N. J.

Ira B. Underhill,

Bishop G. W. Doane,

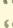

Edward B. Grubb,

James Thorn, Bordentown, N. J.

Josiah Tatum, Philadelphia, $\mathrm{Pa}_{\text {a }}$

Jacob Snider, Jr.

Peter Hulme,

Richard Peters,

Tames Mease, M. D.

John Hare Powell,

William Morrison,

A. Langdon Elwyn, MI. D.

Henry Lantzinger,

James Gowen,

Algernon Sidney Roberts,

Thomas Niclson,
Aaron Clement, Philadelphia, $\mathrm{Pa}$.

E. L. Cary,

Owen Jones,

Charles Magargee,

George WV. Carpenter,

S. Bradford,

John Farnum,

George Blight,

Athenæum,

Pennsylyania Horti-

Frederic Brown

Charles Chauncy,

Dr. George Uhler,

William G. Malin,

Charles Roberts,

Dr. Charles Noble,

Dr. J. Rhea Barton,

Samuel Bettle,

Stephen Colwell,

Adam Eckfeldt,

Charles Yarnall,

William E. Garrett,

P. A. \& S. Small, York, Pa.

John Erans,

Samuel Willis,

John Brillinger,

Samuel Wagner,

Henry Woods, Pittsburch, $\mathrm{Pa}$.

John S. Haines, Germantown, $\mathrm{P}_{\mathfrak{r}}$.

David George, Radnor, $\mathrm{Pa}$.

Samul

Daniel B. Smith, Harerford, Pa.

Ebenezer J. Dickey, Chester Co., $\mathrm{Pa} . \quad I$

Pennock Passmore, Westtorn, Pa.

Wilson \& Heald, Wilmington, Del. 2

Benjamin Webb, ..

James W. Thompson, M. D." 1

Samuel Canby,

Edward Tatnall, " "

John Andrews, " "

James Webb, "“ 1

John Jones, " "

Joseph Carr, " " "

Caleb Churchman, " "

Bryan Jackson, " "

J.S. H. Boies, "6 " "

James T. Bird, "6 1

Henry Dupont, “

Edward C. Hewes, "

Anthony Bidderman, " "

C. J. Dupont,

John B. Le Ferer, " 1

John W. Andrews, Stockford, Del. I

Edward T. Bellah, Brandytrine, Del. 1

William S. Boulden, Newport, Del. 1

Samuel Sands, Baltimore, Md. 9

William C. Shaw,

"

Gideon B. Smith, MI. D. " " 1

William Child, “"

Henry Mankin, " "

William G. 'Thomas, “"

William C Wilson, “
Ramsay McHenry,

Dr. R. Dorsey,

W. Cary, Fork-1Yeeting Post Office, Md. I

George Patterson, Sykesville, MId. I 
3. D. Mullikin, Good Luck, MId.

Botts \& Baldwin, Richmond, Va.

Hon. WV. C. Rives, Bentivoglio, Va.

Thos. S. Pleasants, Bellona Arsenal, Va. 1 Petersburgh Agri-
cultural Society. Petersburgh, Va.

Prof. Fred. Hall, M. D., Washington, D. C. 1

Hon. Henry L. Ellsworth,

I. A. Hall,

Rev. S. G. Bulfinch,

IK. L. Ellsworth,

J. S. Skinner,

Hun. E. Whittlesey,

J. L. Page,

Darius Lapham, IVest Liberty, Ohio,

Eli Nichols, Lloydsville, Ohio,

Charles Anderson, Dayton, Ohio,

Cyrus Holt, "

Robert W. Stcele,

J. WV. Smith, Maumee, Ohio,

II. L. Sullivant, Columbus, Ohio,

J. Sullivant,

Julius Brace, Cincinnati, Ohio,

II. Probosco,

Charles Duffield,

Charles Stetson,

L. Brigham,

Ely \& Campbell,

Cincinnati Horticultural Society,

J. MI. Trimble, Hillsboro,' Ohio,

Abraham Tappen, Unionville, Ohio,

William M. Dawes, Alexandria, Ohio,

Hon. John C. Calhoun, Pendleton, S. C.1

Sec'y of State of U. S.

Sanford WV. Barker, M. D. "

Charles Alston,

Ur. Benjamin Huger, "*

C. Cotes,

J. H. Hammond, Silrerton, S. C.

R. F. W. Allston, Georgetown, S. C.

II. C. M. Hammond, Hamburg, S. C.

Genrge Cross, Charlotte, S. C.

IR. F. Davidson, "6

Dr. William R. Holt, Lexington, N. C.

Hon. 'T. Spalding, Darien, Ga.

James H. Couper,
Copies.

1 Dr. II. W. Philips, Edwards Dépôt, Miss.

James Brown, Livingston, Miss. 1 Moses Liddell, Woodville, Miss. I John R. Liddell, Trinity P. O., La. I 3 Dr. John Calderwood, Mlonroe, La. 1 1 Branch Tanner, Cheneyville, La. I James L. Peacock, Bel- $\}$ near Clinton, La. 1 grade Plantation, ${ }_{\text {George Truit, Kinniconnick, } \mathbf{K} \text { y. }}$ 1 George Truit, Kinniconnick, $\mathbf{K}$. 1 Robert W. Williams, Tallahassee, Fa. 1 1 Richard Mendenhall, Richmond, Ind. I 1 Beadle; M. D. St. Catharine's, U. C. I 1 Adam Ferguson, $\left\{\begin{array}{l}\text { Woodhili, Water- I } 1 \\ \text { down, U. C. }\end{array}\right.$ I TV. Young, Halifax, N. S. 1 Thomas G. Taylor, Pictou, N. S.
Copies. Dr. TVilliam C. Daniell, Gainesville, Ga. 1 Peter L. Clower, Charles Barrell, Montgomery, Ala. 1 Beter A. Remsen, Mobile, Ala. I Rev. Basil Manly, D. D., ? " Pres. of Univ. of Ala. "\} " Charles MI. Foster, "6 1 Han. J. J. Ormond, "s James M. Crook, Alexandria, Ala. F. W. Siperly, Delavan, W. T. 1 Richard Williams, Constantine, Mich. I Gen. Calvin Jones, Bolivar, Tenn. 1 Benjamin Litton, Nashville, Tenn. I Dendy Sharwood, Ottawa, Ill. I Cyrus Bryant, Princeton, Ill. 1 (n) (1) William H. Whiting, Bloomfield, W. T. 2 J. H. Sherman, Carthage, Ill. 


\section{GREAT BRITAIN.}

Copies.

Lady Noel Byron, . . . . . . . . Esher, . . . . . 6

Sir Charles Morgan, . . . . . . . Tredegar, Wales, . . . 6

John Courage, Esq. . . . . . . . . Dulwich, . . . . . 6

Earl of Hardwicke, . . . . . . . . Wimpole, . . . . . . 5

Sir George Cayley, . . . . . . . . London, . . . . . . 2

Sir John Easthope, M. P. . . . . . . . " . . . . . . . . 2

E. W. W. Pendarves, M. P. . . . . . . Pendarves, Cornwall, . . . 2

Henry Morton, Esq. . . . . . . . Chester Le Street, . . . . 2

Countess of Hardwicke, . . . . . . Wimpole, . . . . . . 1

Lord Portman, . . . . . . . . . London, . . . . . . 1

Lord Ashburton, . . . . . . . . . " . . . . . 1

Lord Hatherton, . . . . . . . . Teddesley, . . . . . 1

Rev. Dean of Westminster, Dr. Buckland, . London, . . . . . . . 1

Miss Montgomery, . . . . . . . . . . . . . . . 1

Thomas Spencer, Esq. . . . . . . . Bransby, Lincolnshire, . . 1

John Giblett, Esq. . . . . . . . . . . Barnsbury Villas, London, . 1

R. J. Thompson, Esq. . . . . . . . Yorkshire, . . . . . 1

Jonas Webb, Esq. . . . . . . . . Babraham, . . . . . 1

Joseph Joy, Esq. . . . . . . . . . Boston, . . . . . . . . 1

Messrs. Drummond \& Co. . . . . . . Stirling, Scotland, . . . . 1

Messrs. Lawson \& Co. . . . . . . . Edinburgh, " . . . 1 


\section{P R E F A C E.}

I IAVE the honor of laying before the public my First Report on European Agriculture and Rural Economy. It is to a considerable degree, miscellaneous, and not so full of that practical information and detail which I design to give hereafter. I trust, however, it will not be found deficient in practical value. Many persons may think that I should particularly point out what is to be learnt from European agriculture; but I understand it to be my province to give an honest account of what I see, premising that there is nothing to be seen from which something may not be learnt, and that it is for others, and not forme, to say what they will learn from that which is placed before them. Where we find ourselves inferior to others, it may be desirable to ascertain how we may reach the excellence to which they have attained; and where the advantage is obviously upon our side, it may be a subject of honest congratulation. In circumstances, even the most different, a sagacious mind will gather instruction from contrast as well as from analogy ; and the success of any man, in any trade, pursuit, manufacture, or art, is in itself a porrerful stimulus to others to exertion; and, therefore, an instrument of excellence in any and in every other art or pursuit. I know no better way than to record my impressions of what comes under my notice in the field, which I have undertaken to explore, as faithfully as I can, and with as much detail as seems expedient; and to do my best, that every one who reads my pages with candor, will not close the book without finding something agreeable and instructive, something for improvement in the important art to which my labors will be particularly devoted, and something to make him wiser, better, or happier. These latter are the proper ends of knowledge and of life; and this honest aim will in itself sanctify and elevate the humblest efforts.

The objects of my inquiry are, of course, various and extensive, and embrace every thing connected with the cultivation of the earth, the improvements which are now going on in agriculture, and every branch of husbandry and rural and domestic economy.

Among these topics will, of course, be comprehended -

The Soils, and especially in their relation to different crops.

Manures and their application.

The Implements of Husbandry, and various Machines for facilitating ana abridging the labors of the Farm.

'The different great operations of Agriculture, such as Ploughing, Sowing, Cultivating and Cleaning, Harvesting and preparing the Crops for use or market, with the general application of the Produce of a Farm. 
Draining and Irrigation.

Enclosing and Fencing.

Redeeming Moor and Heath Land.

Warping and Diking.

The Crops grown - the Grasses, the Cereal Grains, and Esculent Roots for the food of man or beast, and plants cultivated for clothing, building, and fuel.

Live Stock of every description - Cattle, Horses, Sheep, Swine, Poultry; and their different breeds and classes.

The breeding, rearing, and fattening of Live Stock.

The Dairy.

The cultivation of Silk, Flax, Hemp, Hops, Madder, Woad, Mustard, Chiccory, Olives, Grapes, Figs; the production of Wool and Honey; of Wine, Oil, and Sugar; and various other crops and products which may come under my notice, and the production and growth of which may be possible and useful in any part of the United States.

Markets and Fairs; Farming Accounts.

Agricultural Labor; wages, condition, and service.

The Management of particular Farms - arable, dairy, stock, and wool farms.

Experimental Farms.

Veterinary Establishments.

Agricultural Societies, Museums, and Shows.

Agricultural Schools, Education, and Literature.

The Condition of the Rural Population.

Rural Life - Morals, Manners, and Customs.

These are among the topics which will claim my attention, and upon which, in the course of my tour, I hope to collect and to communicate much useful information. The field, I am aware, is a wide one, and no unaided individual could, under any circumstances, give a full and entire view of these varions subjects, so as to satisfy every inquiry; but I will do what I can to glean that which is most valuable, and to direct to more full sources of information the inquiries of those to whom further information may be desirable.

I do not know in what place, rather than here, I can better acknowledge the kindness and hospitality which I have received from gentlemen with whom it has been my happiness to become acquainted; add to this the ntmost readiness and courtesy in rendering every assistance in their power to my inquiries. The lindness is sensibly appreciated; and these acknowledgments are due to many noblemen of the lighest rank in the empire; and to many gentlemen of more humble condition, who, if they have not the nobility of rank, have even a higher patent - one without which the most brilliant insignia of external distinction become dim - the nobility of intelligence, wisdom, and most active and extensive usefulness. I should be glad here, if it were proper, to illuminate my page with the names of many distinguished individuals, of whose courtesy and lindness the recollection will not fail, while any record remains legible on the tablet of my heart; but this would be contrary to a rule which, with me, has alway been absolute in cases of this nature, lest I should be thought even to approach a violation of the confidence of social life. One may wound almost as much by public praise as by censure that delicacy of sentiment which, satisfied with doing good, shrinks from notoriety and ostentation. Nor would I in any 
way impair or hinder that frankness of communication and manners which constitutes the charm of social intercourse. 'This would be sure to be checked if we knew that a reporter for the public were constantly present; and, if the humble expression be allowed, it would hide itself in its burrow, as sure as it perceived that one of the feline or the canine race was always at the mouth of its hole waiting its coming out.

My agricultural tour, therefore, must not be expected to have much of personal and private narrative; though I am aware, that, from this very circum. stance, it may lack much of that interest which, with a large class of readers, it might otherwise possess. However strong, on these accounts, the temptation, I shall certainly not report many interesting conversations to which I have been a party; nor describe the eminent or the more humble individuals to whom I have had the honor of an introduction; nor, after the example of some tourists, tell of the private visits which I have made, and the charming families whose honored guest I have been; nor speak of the "accomplished men, and the delightful women, and the beautiful daughters, and the promising sons," in the houses where, to use the only term by which true English hospitality may be expressed, I have been domiciliated, and to do only justice to many of whom, and to a condition of society in the highest degree polished and improved, would not be for me an easy task. I say nothing of the impropriety of stealing for the public the likeness of a friend, without his consent, and without allowing him to choose his position, his dress, or his painter; for, as an agriculturist, this is not the species of live stock which I came to examine, and in which those for whose benefit I travel would be most interested. Yet, while I shall scrupulously avoid all personalities whatever of this description, I shall feel at perfect liberty to give, as far as I am able, a true picture of rural life in England, and of the condition and habits of the rural population; and if, in doing this, I shall, in any ca e, be thought to go beyond the strict line of what may be called the practical and the useful in an agricultural tour, with the candid I shall find an apology in my aesire to alleviate the dulness of dry details, by occasional topics more light and «maginative. It is not unreasonable for me to wish to attract to my pages, I h pe for their benefit, a class of readers who would be certain to be repelled from a mere skeleton, however accurately and beautifully all the bones were put together, and all the joints and articulations displayed; but who would be delighted to contemplate the same subject covered with flesh, instinct with life, radiant with health, and clothed in the habiliments of elegance and fashion. Every one lnows the variety of tastes every where existing. He who caters for the public will be, of course, anxious that each guest at the table should find something which he likes. Though, perhaps, a large portion of mankind might be best satisfied with plain boiled and roast, and content to eat their dinner out of pewter plates, and from a plain and coarse oaken table without a cloth, such as I have seen at Haddon Hall, nearly two centuries old; there are not a few who would prefer the refinements of modern life, a porcelain dish to a wooden trencher, a silver fork to the natural use of the ten digits, the French entrées to the more substantial covers; and who, little as it may contribute to the actual support of life, find as high a pleasure in the fittings-out of the banquet, its arrangements, neatness, order, beauty, and in the splendid pyramid of flowers which often crowns its centre, as in any mere gratification of the appetite. Under any circumstances it would be idle in me to presume to spread an elegant and splendid table for my guests; but while I shall be anxious to furnish that which is substantial and nutritious, I shall be equally desirous that at least the dessert 
shall be made up of the best fruits which I can gather. 'Though I am not able to present them in vases of gold and silver, or of diamond glass, or Sevrés or porcelain china; yet if the peaches and the strawberries should be seen blushing under a few of the leaves of their own foliage, or if a simple bouquet of the flowers of the sweetbrier and violet, or a handful of the half-unfolded buds of the moss-rose, the queen of flowers, should be sought to relieve the monotony of the table, I hope that my taste will not be condemned, but will be regarded only as in conformity to the rule sanctioned by a high antiquity, that of mingling "the agreeable with the useful."

There are other grounds upon which I claim the indulgence of my readers. We have often heard of the vexation of an artist, who is compelled to paint a picture to order; and, willing or unwilling, well or ill, under the most brilliant spell of poetical excitement, or in an hour of the most sleepy or prosy dulness, he must work at it, and have it completed, and varnished, and framed, and sent home to be criticized, by a certain time. To a degree, similar objections lie to all forced intellectual labor; and in many such cases, a porverfully excited desire to do well, and not to disappoint the wishes and expectations of kind friends, presents, in itself, no small hinderance to success, and, strange as it may seem, is sometimes the cause of failure. It must be obvious to any one what disadvantages I labor under in being obliged to give my reports before $I$ have completed my tour. In this case, I yield of necessity to an impatience of curiosity on the part of my friends, which I would neither condemn nor blame, but which certainly presents a strong claim upon their candor.

I am painfully aware of the greatness of the undertaking, and the sacrifices which, at my time of life, it demands of me, and the difficulties in the case of meeting even my own wishes. But the object being exclusively a public object, and one in respect to the utility of which, however imperfectly accomplished, there can be no dissent, $\tau$ look confidently for the aid and encouragement, so essential to my success, of the intelligent, disinterested, and public-spirited, among the friends of agricultural improvement. Such aid in any form will be gratefully appreciated.

In whatever light $\mathrm{I}$ regard the subject of the improvement of agriculture, my sense of its importance is continually strengthened. In its social, political, and moral bearings - in its connection with the subsistence of mankind, with their general comfort, and with the progress of civilization - no subject, purely secular, more demands the attention of the political economist, the statesman, and the philanthropist. If the familiar experience of half a century in all the labors and details of practical husbandry, a considerable acquaintaince with the agriculture of the United States, and an enthusiastic attachment to rural life and rural pursuits, give me any power to be useful in the advancement of this great cause, that power shall be exerted. I do not know to what object the short remainder of my life can be more rationally devoted.

HENRY COLMAN.

2 Spring Gardens, Charing Cross, London, 1844. 


\section{PREFACE}

\section{TO THE SECOND EDITION.}

IN presenting a second edition of European Agriculture to the public, I take the opportunity to acknowledge gratefully the patronage of my sukscribers, and the fivorable appreciation of my labors by a liberal and enlightened community.

I hope that the work will do some good by the information which it communicates; and I am happy in the assurance that it has already done, and will continue to do, much good in calling the attention of the public to this great and important subject, this most essential interest of the community. Every, even the most humble, effort to enlighten the public mind on this subject, to interest, if I may so say, their affections in it, and to elevate and ennoble it in the public estimation, is so far a contribution to the pest interests of society.

At the present time the world seems mad with the thirst for gold. The unexpected discovery of a large deposit of this precious metal in California seems at once to have carried this passion up to the boiling point, and brilliant dreams of wealth acquired without toil, and gold to be gathered in handfuls at pleasure, seem to have startled many sober minds, and to have moved them from their propriety, and to be drawing them away from the calm pursuits of honest industry and the certain gains of habitual diligence and wholesome economy, into a race to be suddenly rich, in which the competition will be crowded, the dangers to health and life many and great, and, under the best circumstances, the results to possession, enjoyment, and morals altogether uncertain. I firmly believe that, with no more expense than it now demands to reach this golden paradise, with no more toil in tilling the earth, with entire security and peace of mind, and with no danger to health or morals, many a young man might establish himself far nearer home in our beneficent country, on a small farm; and, in the wholesome 
pursuits of rural industry, would, in the end, become a far richer and happier man than nine out of ten of those who, under a burning sun, in a climate full of danger to life, among a population of the most heterogeneous character, and all burning with unmixed avarice, and entirely out of the protection of law, with the hardest toil, and amidst the most severe privations, seek for riches and happiness in the sands of San Francisco.

My work will be found in this edition considerably enlarged, and all pains have been taken to insure accuracy. There is some miscellaneous matter, but not wholly irrelevant to the subject; and as it has been my constant aim to make it so, the work will, I trust, be found of an eminently practical character; and as full and as exact details are given in regard to every agricultural operation or subject as the nature of the case seemed to demand.

In regard to the plates of animals some distrust has been expressed as to their accuracy. This, in a measure, grows out of an incredulity as to the extraordinary improvements which the British farmers have made in this matter. I have only to say that the drawings have been made from life by some of the best artists which the country affords; that every pains has been taken to render them correct likenesses; that $I$ have seen several of the animals of which cuts are given, and, as far as my judgment goes, know them to be exact; and in respect to those cases in which I have not seen the originals, having seen many animals of the same breeds and families, have not a doubt of their accuracy.

Boston, Mass. Feb. 1849. 


\section{EUROPEAN AGRICULIURE.}

\section{FIRST REPORT.}

\section{I. - GENERAL FACTS AND CONSIDERATIONS.}

Most of my friends are aware of the circumstances which have induced me to undertake an agricultural tour in Europe. The enterprise was suggested among some friends, at the show of the New York State Agricultural Society, in Albany, in September, 1842 ; and, upon proposals being issued for its accomplishment, the project met with so much favor as to warrant my sailing for England, in April, 1843.

Ploughing the sea is somewhat different from ploughing the land; but under an experienced pilot, and with favorable winds, we made a broad, a deep, and a comparatively straight furrow, throwing off continually floods of jewels from the mould-board; and in the short space of seventeen days, completed the brilliant line, and unyoked the team in the harbor of Liverpool. Here, for the first time, I set foot in England, the green isle in the ocean, the sight of which had been so long the object of my desire; the brilliant centre of so many youthful imaginations, the home of my fathers, and the advance-guard - if so it may be proper to speak - among the nations of the civilized world in the march of human improvement, in learning and civilization, in science and the useful arts, and in all the elements of social greatness and prosperity.

It would be impossible to describe my emotions on that occasion. If small things may be compared to great, then, if it were 
not - as with the bold and adventurous Genoese - the discovery of a new and unknown country, yet it was to me an unexplored country; and it was, in truth, almost the first time I had realized the greatness of the enterprise upon which I had embarked.

Some persons may smile at the application of such language to a mere agricultural tour. Things are great or small by comparison; and that work may be considered great to any one, which, in its proper performance, demands the exertion of all the talents which he may possess. I cannot but look upon an agricultural tour in Europe, in the present condition of the art and science, - for in both lights it has now come to be viewed, - as most important; combining a variety of inquiries and observations which would severely tax the highest powers that might be applied to this object. It is for me to assume only the humble office of a pioneer in this great work; and if I can be so happy as to render some essential service to my country, in facilitating the labors of those who shall come after me, in effecting a small clearing that others may more easily bring the field into a state of complete and productive cultivation, I shall be consoled under all the imperfections of my attempt with the conviction that I have not labored in vain.

I cannot help feeling that there is a high responsibleness attached to my undertaking - a responsibleness not merely to the lindness of friends, on both sides of the water, who with an extraordinary liberality and good will have favored the enterprise, but to the great cause itself of agricultural improvement; that the information collected and given might be drawn from authentic sources, selected and combined with judgment, and presented in a condensed, compact, and practical form.

A person who has had no experience in such a matter; who is not accustomed to such investigations, can form no just idea of the difficulties of accomplishing in this case what one would desire to do; and of the impediments, and, I regret to add, in many cases the vexations and disappointments, which, in its prosecution, he will be compelled to meet with. Before I left home, a friend - in many respects highly intelligent, and eminent for his sound judgment, and, withal, a liberal and devoted friend of an improved agriculture - said to me, "that there was nothing to be learned in England; that he himself had travelled much in England, by post, and had occasionally alighted and talked with 
laborers, whom he saw in the fields by the road-side, but he had learned nothing from them." And another friend, whose eminent position in the community should have saved him from an immature judgment, expressed an opinion that "the climate of England was so different from the United States, and the cost of labor in Eugland was so much less than in America, that the agricultural practice and experience of Great Britain could have no application to the United States." Now, entertaining as I do the high respect for these two gentlemen to which their intelligence and position in society entitle them, I have come, not without some reluctance, to an entirely opposite conclusion - it conclusion which my own observation, in the course of my progress, has daily more and more confirmed.

There is a great deal to be learned in Wugland, which can scarcely be said to be known in the United States. There is a great deal of agricultural practice in Fingland, which may with advantage be transplanted to America; and although, as is most obvious, every agricultural operation must be modified by the climate of a country and various local circumstances, yet, in respect to many facts of a practical nature, the knowledge that nnder any circumstances a thing is practicable is often of great importance, as it excites to inquiries and experiments which may evolve many other valuable facts; and inquiries and experiments will often suggest modes of operation by which even the difficulties of climate and situation may be counteracted or overcome. Plants and animals are often naturalized to localities very different and distant from their native homes. If the common history of the plant be true, one of the most valuable and nutritious of esculent vegetables, the potato, is an example of a removal from a warm to a temperate, and even a cold climate; and of a conversion from a root very inferior in size and quality, to a vegetable most productive in its yield, universally relished, in the highest degree farinaceous and nutritious, and, under the best cultivation, perhaps yielding per acre as much food for man or beast as any other plant which could occupy the ground. Then, again, to suppose that a knowledge of the agriculture of a country is to be acquired by a transit through it on the boxseat of a coach, or in a railroad carriage, or by a casual conversation with laborers by the road-side, who, especially in England, where labor is so much subdivided that the knowledge of a man 
in that condition of life seldom extends beyond the particular service to which he has been trained, is a judgment of which, upon further consideration, an enlarged mind would not be tenacious. In respect to any other matter of importance, it would not be the most likely way of obtaining full and authentic information. Why should it be deemed so in respect to agriculture? This art, in its improved condition, combines so many arts and such various subjects of inquiry and observation, that a close scrutiny and long-continued inquiry are as indispensable to a thorough knowledge of it as they are in respect to any of the branches of commerce or manufactures.

After travelling many hundreds of miles over this rich and highly-cultivated country, and seeing many of the landlords, and tenants, and laborers, in their own domiciles and homesteads, in their stables and fields, and enjoying the most free communications, I feel that I have, as it were, only begun to see what is to be seen, and to learn what is to be known, and that every step of my progress is developing new and valuable objects of inquiry and remark.

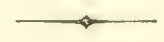

\section{II. - PARTICULAR OBJECTS OF INQUIRY.}

What should an agricultural tour embrace? To this the proper answer is, Every thing connected with the cultivation of the earth, the production of food for man and beast, and the condition of those to whom agriculture is a business and profession. In my preface I have enumerated generally the objects of inquiry. The various operations of husbandry, the implements by which these operations are carried on and facilitated, the plants cultivated, and the live stock produced and maintained, constitute the principal subjects to be observed and treated; but the subdivisions into which these great topies spread themselves are very numerous, and it is as important to consider them in detail as in the gross. It may be expected by some persons that I should merely point out in what respects foreign differs from American agriculture; or, otherwise, that I should only suggest for adoption in the United States such methods of culture as, in 
my opinion, would constitute an improvement upon American agriculture. 'This would be assuming too great a responsibility, and would display a confidence in my own judgment with which I would not willingly be chargeable. I design to give, as well as I am able, a full account of subjects which come under my immediate observation. I shall not hesitate to pronounce my opinion whenever I deem it proper so to do, because intelligent minds for whom I write will be no further influenced by it than as it appears reasonable; but I shall, in all cases, endeavor so fully to state any matter in discussion, that they will have the materials before them for making up their own judgment, and with that I shall not any further willingly interfere. Even agriculture, like every other subject not susceptible of mathematical demonstration, is not without its disputed and disputable points, into which, of course, something of the heat of passion may at times infuse itself. Political agriculture is full of such topics, and will be cautiously avoided by me so far as in any way it presents itself as matter of party contention. The different breeds of live stock, neat cattle, and sheep, have each their partisans; often influenced solely by their own honest preferences and convictions, founded - as they at least persuade themselves - upon experience and observation; and in some cases, it will not be denied, by private interests - a stimulus which is too seldom absent from most of the disputes and contentions in life. Now, if a man should pronounce a preference over all others for the short-horns, he must expect to be tossed by the longhorns; if he sides with the Herefords, the Durhams will shake their heads at him; and if he advocates, above all others, the claims of the polled Scotch, the Angus, or the Fife cattle, the West Highlanders will be down upon him with a vengeance. So it is with the South Downs and the Leicesters, meek, quiet, placable animals themselves, — who may be scen feeding peaceably together out of the same manger, and lying down without passion in the same pen; but not so their owners and breeders. A spirit of rivalry pervades every department of life. Under due restraints and discipline, it is productive of the most useful results; but it too often blinds the judgment, and becomes fierce and vindictive. We are not satisfied with the undoubted good qualities of what belongs to ourselves; but we resolve upon exposing the defects and faults, whether real or 
Imaginary, of what belongs to our neighbors. It is not enough that our own children are handsome, good-tempered, clever, and accomplished; but we insist upon it that those of our neighbors are ugly, morose, and ill-endowed. Perhaps agriculture presents a more limited field for any ill-natured emulation than almost any other department of life. Here men cannot conceal their discoveries and improvements. Here there cannot be long any monopoly of advantages. Here men perceive how rapidly and widely improvements and discoveries extend themselves. In the present condition of the world, for a man to pretend to keep any distinguished agricultural improvement to himself would be very much like his holding up his umbrella before the sun, so that it might not shine upon other people. All he can be sure of, in this case, is to keep himself in the dark. A liberal and intelligent mind perceives at once, that the light which his knowledge or improvements shed upon others, is always reflected back upon himself.

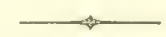

\section{III. - SCIENCE AND AGRICULTURE.}

It must be admitted, however, that although a good deal of selfishness and bigotry might remain, — for, alas! how can it be otherwise as long as human nature is human? - there is a spirit of liberal inquiry abroad in respect to agriculture, blazing in the valleys, and beaming from the hill tops, and every where diffusing an invigorating, a stirring, and a healthful radiance. One of the wisest of our race, who applied his heart, as he says, to understand wisdom, has told us that there is nothing new under the sun; what is, has been; and the human mind is not likely to spring suddenly a mine of truth, which has never before been touched; nor may it expect at once to accomplish the solution of recondite problems, which have baffled the most penetrating and puzzled the most sagacious minds. It would be the grossest injustice to many men of the brightest powers, of profound investigation, and of most liberal and disinterested views, - who, though they have gone out, have left a brilliant track behind them, - to say that agricultural science has never before been 
prosecuted with zeal, intelligence, and in the spirit of true philosophy.

I am not a believer in the immediate approach of an intellectual millennium; nor can I persuade myself that philosophy has just been born into the world, and that all preceding ages were ages of comparative barbarism. It is true that the natural sciences are now prosecuted with singular advantages and success; that, in a particular manner, chemistry has, in a measure, been created within the last half century; and that it promises to render the most essential aid to agriculture. Excepting, however, the stimulus which it has every where given to inquiry and observation, and the exact experiments which it is prompting farmers - even in the humblest departments of agriculture to make, it cannot as yet point to very many positive practical triumphs. Sanguine as I am, in common with others, in its application to agriculture, ultimately and perhaps speedily yielding the most beneficial fruits, it has not yet even approached a solution of many of the profound secrets of nature. Whether this triumph is ever to be achieved by human sagacity; whether, with our present faculties, we are capable of entering into these sacred mysteries, and of lifting up even a corner of the veil which Heaven has drawn over them, it wonld be idle to conjecture; but they are, as yet, a sealed book to us. In the spirit of the Book of books, "Let us wait at Wisdom's gates, let us wateh at the posts of her doors;" let us knock, humbly hoping that they may be opened to us. Those who have gone before us have done the same, and were favored with many lurgesses, which they have bequeathed to their children. Let us do them justice by gratefully acknowledging our debt to them; and not wrap ourselves up, as we are very liable to do, in the vain conceit that they knew nothing, and that we know every thing.

We talk about uniting science with agriculture, as if this were the first time of asking the banns, when we may be sure the marriage was consummated years and years ago. A science, technically speaking, is a particular branch of human knowledge, which has been systematized and drawn up in regular form; its particular principles and rules defined, its department circumseribed, and its peculiar vocabulary arbitrarily established. In this respect, chemistry, botany; and mechanics are sciences; but science, in an enlarged sense, is the observation of nature - the accumulation and comparison of facts, and the deduction of 
inferences from them, either for the acquisition of more knowledge, or for practical application and use. I venture to assert that, without any knowledge of the particular and technical terms of art, whose utility I am not disposed in the smallest degree to deny, wherever the mind is at work there is science; and many men, who hardly know the letters of a book, are yet profound observers of nature, and may be denominated scientific agriculturists; because they are full of knowledge, which they are constantly applying to practice. Now, without any disparagement of former times, I think it must be admitted that the universal mind of the agricultural world was never so powerfully stirred as it is at this present time. We must do what we can to keep it awake, and to direct the application of its powers. "Practice with science," is the terse and comprehensive motto of the Royal Agricultural Society of England. Philosophy now comes down from her high places, and takes Labor by the hand, that they may walk together among the works of God, and, with an enlightened and commendable curiosity, "search into the causes of things." This is the highest office of the human understanding.

Nature proceeds by fixed laws. She is not a confused jumble of things; to-day one thing, and to-morrow another. All the relations of the different parts of nature are mutual and exact, and every thing moves on in a beautiful agreement with every other thing. The ancients were accustomed to speak of the music of the spheres; this refers to the harmony which prevails throughout the universe, so that no discordant note is ever sounded. There is a reason for every thing; there is a rule by which every thing is directed and controlled. It is not enough for us to say, "This is a mystery ; it is in vain for us to inquire;" or, "Here is an arbitrary and miraculous power in nature which we can never understand." There may be many things beyond our comprehension; there is nothing which should be beyond our inquiry. There is a wonderful power at work always in vegetation. The development and progress of vegetable life, the relations of the soil to the plant produced, the effects of light and air, and dew and rain, and frost and electricity, the nature of manures, their uses and their results, may all be considered as mysteries as yet, to a great degree, unresolved; but from what we see in other parts of Nature, which have come under our observation, and where some portion of her laws has been fully 
revealed, an intelligent mind can have no doubt that all these things rest upon certain determinate principles, and are governed by laws as fixed as any which prevail in other parts of the system of nature. Whoever examines the minutest crystal, will find that in the same classes the laws of aggregation are the same; whoever examines any species of plants, perceives an exact similarity of formation and habit pervading whole classes and tribes. The established principles of gravitation and attraction, and above all that most wonderful discovery of chemical equivalents, all demonstrate the existence, throughout nature, of fixed laws and determinate forces, whose operation is universal and invariable. There is every reason to believe that the laws of vegetable and animal life, and growth and nourishment and decay, are equally well established, and equally miversal, and equally invariable. The ascertaining and discovery of any one of these laws is positive knowledge - is, properly speaking, science; and any mind, acute and observing, may, in the daily routine of humble life, become familiar with many of these great laws; and read, at first-hand, on the illuminated pages of external nature, the most useful and the most sublime truths, though it has never been taught to read by the alphabet of science, nor been allowed admission into the schools of philosophy.

It is said of one of the greatest of human intellects, a mind whose sublime discoveries constitute a divine revelation, second only to the written word, that he was led to the discovery of the great principle which binds worlds and systems in one harmonious bond, by the falling of an apple. The cultivator of the earth has before him not merely the fall but the growth of the apple, which, from the germination of the seed to the maturity of the tree, from the opening of the blossom to the ripening of the fruit, is full of lessons of wisdom; and, in every stage of its progress, reveals the power and the skill and the beneficence of that divine agent, who fills all in all.

England presents at this time a more brilliant example, than any age or country has before witnessed, of the application, I will not say of science, for that would not comprehend the idea which I wish to express, but the application of mind to agriculture. The practice of agriculture, and the philosophy of agriculture, are matters of universal interest. Men of all grades and conditions are laboring in this great cause, and are asking for the how, and the why, and the wherefore. The brighter intellects are 
directing their talents to agricultural inquiries; and the humblest in their humble, but not inefficient way, are seconding their efforts. So many minds concentrating their rays upon the same point, they must be sure to illuminate it with an extraordinary brilliancy.

Agriculture is now getting to be recognized as the commanding interest of the state: so it must ever be as lying at the foundation of all others. Few persons are apprized of their obligations to agriculture; and it is difficult to estimate the extent of these obligations. Every man's daily bread, his meat, his clothing, his shelter, his luxuries, all come from the earth. The foundation, or, as the French would say, the materiel of all commerce and manufactures, is agriculture; and its moral influences are innumerable and most powerful. It will be found likewise, upon an observation of the different conditions of different nations or communities, that a laborious agriculture is, in a high degree, a conservator of good morals; and that those countries are, upon the whole, and on this account, most blessed, not where the fruits of the earth are yielded spontaneously without care and without toil, but where its products come only as the reward of industry, and the powers of the mind, as well as the labor of the hand, are severely taxed in a struggle for the means of subsistence and comfort. Every one recognizes labor as the source of wealth. How few things have any value, which have not been either produced or modified by labor! and in what department is labor so productive, so essential, and so important as in that of agriculture?

\section{$\longrightarrow$ \\ IV. - ENGLISH AGRICULTURE.}

I will not dwell longer upon these considerations, with which every intelligent mind must be impressed; and which must, more or less, constantly present themselves to our notice in that field of observation which we have entered. I shall proceed to present some general views of the agriculture of England, and shall descend, in the course of my reports, to such details as may be deemed usefui and practical.

The condition of practical agriculture in Great Britain, as far 
as I have had opportunity of observing it, must be pronounced highly improved. Many parts of the country present an order, exactuess, and neatness of cultivation greatly to be admired; but a sky is seldom without clouds, and there are parts of England where the appearance is any thing but laudable, and where there are few and very equivocal evidences of skill, industry, or thrift. We are often told in America, that England is only a large garden, in which art, and skill, and labor, have smoothed all the rough places, filled up the hollow places, and brought every thing into a beautiful and systematic harmony, and into the highest degree of productiveness. This is not wholly true; indeed, though there are many farms to be altogether admired for the degree of perfection to which their cultivation has been carried, yet there are not a few places where the indications of neglect, and indolence, and unskilfulness are but too apparent ; and where, in an obvious contest for victory between the cultivated plant and the weeds, the latter triumph from their superiority both in force and numbers. I shall, however, most cheerfully admit that English farming, taken as a whole, is characterized by a neatness, exactness, thoroughness seldom seen in my own country. An American, landing in Liverpool, is at once struck with the amount of labor every where expended; the docks, and the public buildings, and the lofty and magnificent warehouses astonish him by the substantial and permanent character of their structure. The railways, likewise, with their deep cxcavations, their bridges of solid masonry, their splendid viaducts, their immense tunnels, extending in some cases more than two miles in length, and their depôts and station-houses, covering acres of ground, with their iron pillars and their roofs, also of iron, exhibiting a sort of tracery or net-work of the strongest as well as most beautiful description, indicate a most profuse expenditure of labor, and are evidently made to endure. He is still more overpowered with amazement when, coming to London, he passes up or down the River Thames, and contemplates the sereral great bridges, among the most splendid objects which are to be seen in Eingland, two of which are of iron and three of stone, spanning this great thoroughfare of commerce with their beautiful arches, and made as if, as far as human presumption can go, they wonld bid defiance to the decay and ravages of time. If to this, he adds (as, indeed, how can he help doing it?) a visit to the 'Thames 'Tunnel, - a secure; a dry, a brilliant, and even a 
gay passage under the bed of the stream, where the tides of the ocean daily roll their waves, and the mighty barks of commerce and war float in all their majesty and pride over his head, exhibiting the perfection of engineering, and a strength of construction and fuish, which leaves not a doubt of its security and endurance, - he perceives an expense of labor which disdains all the limited calculations of a young and comparatively poor country. He remarks a thoroughness of workmanship which is most admirable, and which indicates a boldness and bravery of enterprise, taking into its calculations not merely years but centuries to come. We have, in America, a common saying in respect to many things which we undertake, that "this will do for the present," which does not seem to me to be known in England; and we have a variety of cheap, insubstantial, slight-o'-hand ways of doing many things, sometimes vulgarly denominated "make-shifts to do," which we ascribe to what we call Yankee cleverness, of which certainly no signs are to be seen here. Agricultural operations and improvements are here in general conducted and finished in the most thorough and substantial manner.

The walls enclosing many of the noblemen's parks in England, which comprehend hundreds, and, in some cases, thonsands of acres, are brick walis, of ten and twelve feet in height, ruming for miles and miles. The walls round many of the farms in Scotland, called there "dikes," made of the stone of the country, and laid in lime, and capped with fiat stones resting vertically upon their edges, are finished pieces of masonry. The improvements at the Duke of Portland's, at Welbeck, Nottinghamshire, in his arrangements for draining and irrigating, at his pleasure, from three to five hundred acres of land, - without doubt one of the most skilful and magnificent agricultural improvements ever made, - are executed in the most finished and permanent manner; the embankments, the channels, the sluices, the dams, the gates, being constructed, in all cases where it would be most useful and proper, of stone or iron. 'These are only samples of the style in which things are done here. The important operations of embanking and of draining, especially under the new system of draining and subsoiling, are executed most thoroughly. 'The farm houses and farm buildings are of brick or stone, and all calculated to endure.

I cannot recommend, without considerable qualifications, these 
expensive ways of doing things to my own countrymen. We have not the means - the capital for accomplishing them; but we might gather from them a useful lesson; for, in general, we err by an opposite extreme. We build too slightly - we do not execute our improvements thoroughly - we have little capital to expend, without which, of course, no substantial improvements can be effected; and labor, with us, is with more difficulty obtained, with far more difficulty managed, and requires to be much more highly paid than here. I hope I shall be pardoned for adding, as my deliberate conviction, that we are too shy of investing money in improvements of this nature, however secure, because they do not yield so large a percentage as many other investments somewhat more questionable in a moral view, and vastly more so in respect to the security which they ofler.

There are circumstances in the condition of things here, which certainly warrant a much more liberal expenditure in improvements than would be eligible with us. Here exist the right of primogeniture and the law of entail, so that an estate remains in the same family for centuries; and a man is comparatively sure that the improvements which he makes will be enjoyed by his children's children. 'Things are entirely different with ushouses in our cities are continually changing hands, and are scarcely occupied by one life; and in the country, even in staid New England, few estates are in the hands of the third or fourth generation in the direct line of descent. I shall not at all discuss the comparative advantages, expediency, or propriety of one or the other system. I leave those inferences to others - my business is with the fact as it is; and, like short leases, it has an obvious tendency to hinder or discourage improvements of a substantial and permanent character, involving a large expense.

\section{V. - ENGLISH CAPITAL.}

Another marked distinction, already alluded to, between the condition of the proprietors of the soil here and with us, is in the amount of capital existing here. It is absolutely enormous, and almost distances the system of enumeration which we are 
tanght at our common schools. Let me mention some facts which have been stated to me on credible authority; and let me premise that a pound sterling is about equal to five dollars United States currency. Under a law of the present government, here, levying a tax upon every man's income when it exceeds one hundred and fifty pounds sterling a year, persons liable to taxation are required to make a just return of their income under a heavy penalty. A confectioner, in London, returned; as his annual income, the sum of thirty thousand pounds sterling, or one hundred and fifty thousand dollars, or six times as much as the salary of the President of the United States; which showed, at least, how skilful he was in compounding some of the sweets of life. A nobleman, it is said, has contracted with a master builder to erect for him, in London, four thousand - not forty not four hundred - but four thousand houses of a good size for occupation. In some of the best parts of London, acres of land. vast squares, are occupied with large and clegant dwellinghouses, paying heavy rents, in long rows, blocks, and crescents, and all belonging to some single individual. One nobleman, whose magnificent estate was left to him by his father, encumbered with a debt of some hundred thousand pounds, by limiting; as it is termed here, his own annual expenditure to thirty thousand pounds, has well nigh extinguished this debt, and, in all human probability, will soon have his patrimonial estate free of encumbrance. The incomes of some of the rich men in the country, amount to twenty, twenty-five, fifty, one hundred thousand, two hundred thousand pounds sterling - even three hundred thousand pounds annually. It is very difficult for New England men even to conceive of such wealth. A farmer in Lincolnshire told me that the crop of wheat grown upon his farm one year was eightecn thousand bushels. The rent annually paid by one farmer in Northumberland, or the Lothians, exceeded seven thousand pounds, or thirty-five thousand dollars. These facts, which have been stated to me by gentlemen in whose veracity I have entire confidence, and who certainly are incapable of attempting any "tricks upon travellers," show the enormous masses of wealth which are here accumulated. A gentleman of distinguished talents and fine classical attainments. and who adds to them a public spirit in agricultural improvement worthy of his education and his high standing in the community, has recently added to his property, by the purchase 
of lands, to the amount of two hundred thousand pounds sterling, that is, a million of dollars; and his estate, now in cultivation, and under his own personal inspection, and, with the exception of about four hundred acres lying in one body, amounts to six thousand acres. Another gentleman, of high rank, in respect to whom and to whose amiable family I have a constant struggle to restrain the open expression of my grateful sense of their kindness, and who - an example here not uncommon - to an extraordinary brilliancy of talent and an accomplished education unites the most active spirit of agricultural improvement, has, though not all in his immediate occupation, yet all under his immediate supervision, a tract of more than twelve thousand acres in a course of systematic cultivation or gradual improvement.*

The income of a single nobleman, from his coal mines, cxceeds one hundred thousand pounds sterling a year; and I believe this is not the largest of the coal possessions. With such wealth as this, men may make what improvements they please, and attempt what experiments they may deem worth trying; but should such imaginations ever visit a New England or a United States farmer in his dreams, if Esop's fable of the frog, who attempted to swell himself to the size of the ox, did not cure him, he might be deemed a fit subject for a lunatic asylum. There are other circumstances in the case which are to be added, and those are the cheapness of iron, the abundance of coal, and the admirable facility and skill with which the former material is wrought. Wood, and especially the soft woods, which are so much wrought among us, are here scarce and dear, and, therefore, seldom used for building purposes; bricks, and, in many parts of the country, good building stone, of the best quality, are abundant. Most of the cottages which I have seen have brick or stone floors, though many have only hardly-trodden clay and earth; and the entries of the best houses are generally

* 1 mention these examples — to which, from my own knowledge, I might add many others - in the form Ido, for the purpose, by the way, of showing my American friends that agriculture here takes its proper rank among the liberal professions, and that not merely as a recreation, but as a business; and in all its minute and practical details, it is not deemed incompatible with the highest distinctions of talent, education, and rank, but rather as a pursuit in which they all may most usefully and honorably lend their combined influence. 
paved, and the staircases made of stone. A fence of iron, affording a sufficient protection against cattle, is made here at a less expense than many wooden fences are made with us.

\section{VI. - GENERAL APPEARANCE OF THE COUNTRY.}

I may be allowed to put down marks of difference in the general appearance of the country, as compared with my own, as they strike my attention. I need not say that England is entirely devoid of a feature which strongly marks the newlycleared parts of my own country, and that is the stumps of trees, which have been cut down, or the large, naked, and dead standing skeletons of trees, which have been girdled, that the pionecr, in subduing the wilderness, might have a chance of getting bread for himself and his family, while he was endeavoring to tame the wildness of nature and to convert the forest into a fruitful field. England exhibits, of course, nothing of this, for the days of its youth have long since passed, and its agriculture reckons its patriarchal centuries. But there is another thing remarkable: the cultivated fields are entirely free from rocks and stones, excepting the limestone and flint pebbles in the chalk formations. In the clay soils and on the peaty moors, they, of course, are not to be looked for; but, where even they once existed, they have been entirely removed or buried, and there is nothing to interrupt or impede the progress of the plough. This is not so generally the case in my own country as is to be desired. It is, indeed, an affair of very difficult accomplishment in many cases, where, in a granitic region for example, the stones are often within stepping distance of each other all over a farm, and where every fresh ploughing seems to tum up a fresh crop of stones. On the other hand, there are too many cases where, with equal advantage to the purse as pleasure to the eye, such unsightly rubbish might be removed or buried; yet there are fields, within my own knowledge, where I may say, with confidence, the same piles of stones which were collected for removal, full half a century ago, retain their original position until this day; the plough, whenever they are broken up, being always 
compelled, at no small expense of time and trouble, (as il sailor would say,) to give these heaps a good berth; and only going near enough to them to refresh and invigorate the roots of the briers and bramble bushes, by which they are usually ornamented, and which, to rny taste, are quite as offensive in a farmer's field as the "mustachios and imperials" so often seen upon the monkey masque, which passes, by the mere indulgence and good humor of society, for a human face. Throughout those parts of England which I have seen, there are, as I have already remarked, an exactness, a finish, and a cleanness in the cultivation, which impress a stranger most agreeably, and deserve the highest commendation. There are, occasionally, immense tracts of uuenclosed commons, and heaths, and moors, where there is no cultivation, where nothing grows, and, in some cases, little can ever be made to grow; or which, otherwise, are abandoned to the growth of furze or gorse for the protection of the game, and for the pleasures of the chase. These are called preserves, and are leased to sportsmen occasionally, or, rather, the right to kill game upon them is leased, at a rate which we should deem a high rent, even for purposes of cultivation. An eminent agriculturist has shown that, in England and Scotland, there are full $10,000,000$ acres in heath or moor, all susceptible of being brought into productive cultivation. These lands, of course, remain as they are by voluntary neglect or design. But I refor to the cultivated and improved lands; and here there is every where a surprising neatness and finish - every thing is done, as it were, by line and measure; the corners and the head lands are thoroughly cleaned, the open ditches are kept unobstructed, the crops are drilled in straight lines, and a newly-plonghed field resembles a plaited ruffle from the ironing board of a good housewife. Such exactness is exceedingly beantiful, and, though it may appear, at first, to consume a good deal of time, will be found, in the long run, to be more economical than the slovenly way in which things are often done in many places, which I am reluctant to name. There is a pleasure afforded by such neatness which is very great, and which can be properly appreciated only by those who have been largely endowed by nature with the organ of order. 


\section{VII. - HEDGES AND ENCLOSURES.}

The green fences in England, by which the farms are sulrounded and divided, are often a beautiful feature in the landscape. Where they are complete, and neatly trimmed and formed, with here and there a single plant left to rise above the rest, which many deem more beautiful to the eye than a democratic level, and when seen whitened with their blossoms in the spring, or blushing deeply with their fruit in autumn, they are cxceedingly pleasing to the eye. In general, they are formed of the white thorn, and sometimes of the holly, and not unfrequently of these two plants intermingled. But I must confess myself somewhat disappointed in the condition of the hedges throughout England. Of course there are many exceptions, and perhaps the cases to which I refer should be considered as exceptions to the general fact; but in frequent instances they are greatly neglected. There are many vacancies in them; they are not well trimmed; they are intermingled with various weeds and rubbish; and, instead of being confined to a width of four or six feet, they are often seen with their pernicious accompaniments occupying more than a rod in width. I inquired why this was permitted; and why, when the rest of the face was so clear and bright, such dirt spots were allowed to remain: the answer was, "that they were left thus for the protection of the game, and that they made excellent covers for partridges and foxes." When so much care and expense are incurred in the protection of this kind of game, it is to be hoped that it may suggest always the higher duty of taking care of the human game, the hungry and ragged children, which in some parts of England are as numerous, and growing up as wild, and many of them as little taught, as the rabbits in a warren.

The enclosures in England are of varions extent, from ten to twenty and fifty acres. There are some farms with scarcely a subdivision, and in these cases the stock are soiled. In parts of England, however, they resemble the divisions of New England farms, and are of various sizes, but generally small, and of all shapes, and often not exceeding four or five acres. It is reported of a farmer in Devonshire, that he lately cultivated one hundred acres of wheat in fifty different fields. There must have been 
here a great waste of land and labor. One of the most competent judges of agricultural improvement in Fingland says, however, that "his tenants never wish to have more than one ploughed field on a farm."

The loss in land by too many fences, the loss of time in cultivating in small fields instead of large, on account of the necessity of more frequent turnings, and ploughing the head lands by themselves, and the actual cost of making and of maintaining the fences, not to add that these fences are a shelter for weeds, and a harbor for vermin, are serious considerations. The statement of an intelligent practical farmer in Staffordshire, on the highlyimproved estate of Lord Hatherton, whom I had the pleasure of risiting with Mr. P. Pusey, M. P., as given to Mr. Pusey, is well worth recording. Speaking of the farm called the Yew-Tree Farm, he says, "The turnip field is sixty-five acres; it was, two year's back, at the time I entered upon the farm, in eight enclosures. I have taken up 1914 yards of fence, and intend dividing it into three fields; it will take 800 yards of new fence. The field in which I was subsoiling is forty-two acres; it was in six enclosures. I took up 1264 yards of fence; if I divide this field, it will take 300 yards of new fence. The land Lord Hatherton mentioned on my Deanery Farm was originally in twenty-seven enclosures; ninety-one acres. I took up 4427 yards of fences; it will now lie in five fields, and will take 1016 yards of new fence."

"I cannot," he adds, "really say what land is gained by the different operations; but some of the fences were from three to four yards or more wide, that the plough never touched; my new fences are upon the level without ditches. In the whole of the old fences there was a great number of ash-trees, which are all stocked up, as well as a good part of the oak, only leaving a few for ornament and shelter. I think the greatest gain in land will be from getting rid of the trees." *

This is the experience and opinion of a sound practical farmer, and is entitled to great weight. In some of the counties large enclosures prevail. In parts of Lincolnshire the enclosures embrace about fifty acres each; and on the best managed farms which I saw, these fields were mostly laid either in parallelograms or squares. In the fens or redeemed lands of Lincolnshire, the

* Journal of Royal Agricultural Society, vol. ir. part 2, p. 306, note. 
ditches around and through the land form sufficient and the only fences. In the county of Northumberland, and in the Lothians, the enclosures are very extensive, and, excepting on the outlines, no fences appear. The plough, in such case, when it starts, takes its course, and runs to the end of these long fields without interruption.

Mr. Pusey, in Berkshire, on one of the best managed estates which I have visited, has induced many of his tenants to take away the inner fences and leave the fields open. Sheep are, of course, never suffered to graze or roam at pleasure over these large fields, but are fed in enclosures formed of movable hurdles in different parts of the field, where their manure is required. Cattle never go at large upon them; and the convenience of cultivating where the lands are thus open, to say nothing of the beauty of the appearance, in addition to other advantages already alluded to, is at once obvious and decisive.

\section{VIII. - IRON AND SUNKEN TENCES.}

I shall speak in this place of two kinds of fences which are common on gentlemen's seats, and one of which may be safely recommended to my own countrymen. The first is an iron fence, called here an invisible fence. This is made of stout iron wire, about one third of an inch in diameter, and consists of four or five bars or rods, with upright pieces of iron, about an inch and a quarter in width, and about one third of an inch in thickness, placed at about six feet distance from each other. Through these upright and flat pieces of iron the bars or rods are passed, and they serve to keep them secure. Every alternate one of these upright bars has a foot to it, and being sunk in the ground about a foot or more, serves as a post to keep the fence steady ; and occasionally these posts, if so they may be called, have side supports, thus; the fence, bit are very cheap, these, of course, increase the strength of they are not indispensable. These fences on account of the abundance of iron and? the facility with which it is wrought; and being kept painted commonly of a green color, they do not appear until you approach 
near them; but no animals attempt to pass them, and, when well taken care of, they are durable, and, it is obvious, may be easily removed from place to place.

There is another lind of fence often formed, called a sunken fence; or "ha! ha!" from its generally taking persons by surprise, as it does not appear until you reach it. A trench is dug as deep as it is required that the height of the wall shall be from the bottom of the trench; one side of the trench is perpendicuiar, and against this side the wall is erected; the other side is made slanting at an angle of about forty-five degrees, and the slanting side is grassed, and may be mowed clear to the bottom, so that no land is lost; but, in truth, a small amount is gained. The object is to conceal the fence, so that when placed round the grounds of a gentleman's house, the prospect of the lawn or field is not interrupted by an unsightly wall; and the grounds within the enclosure may be cultivated or embellished in any way with shrubs, or flowers, or fruit, and yet the cattle feeding beyond it, whom no visible obstruction appears to keep at a distance, are effectually excluded, as no animal attempts ever to leap such a fence.

\section{IX. - THE ENGLISH PARKS.}

I will take this occasion to speak of the extensive parks which are to be seen in many parts of the country, and which constitute a truly magnificent feature in English scenery. These are the open grounds, which surround the houses of the rich and noble in the country. By open, I do not mean entirely free from trees, because many of them are exceedingly well stocked with trees, sometimes standing single, at other times in clumps; sometimes in belts, sometimes in rows, and squares, and circular plantations; and more often scattered, as if they were carelessly thrown down broadcast. 'The ground under them is kept in grass, and depastured by cattle, sheep, and deer; and affords often the richest herbage. With some exceptions, a plough is never suffered to disturb these grounds; and in the neighborhood of the house, which is generally placed in the centre of them, the portion which is separated from the rest, as I have observed, 
by an invisible or sunken fence just now described, for the cultivation of ormamental trees and shrubs, is kept so closely and evenly shorn, that to walk upon it seems more like treading upon velvet than upon grass. Nothing of the kind can be more beattiful; and I never before knew the force of that striking expression of the prince of poets, Milton, of "walking on the smooth shaven lawn;" for it seems to be cut with a razor rather than with a scythe; and after a gentle shower it really appears as if the field had had its face washed, and its hair combed with a fine-tooth comb. It is brought to this perfection by being kept often mown; and I have stood by with perfect admiration to see a swarth mowed evenly and perfectly, where the grass to be cut was scarcely more than an inch high.

These parks which I have described abound, as observed, with trees of extraordinary age and size. They are not like the trees of our original forests, growing up to a great height, and, on acconnt of the crowded state of the neighborhood, throwing out few lateral branches; but what they want in height, they gain in breadth; and, if I may be excused for a hard word, in umbrageousness. I measured one in Lord Bagot's celebrated park in Staffordshire, and going round the outside of the branches, keeping within the droppings, the circuit was a hundred yards. The circumference of some of the celebrated oaks in the park of the Duke of Portland, which we measured together, when he did me the kindness to accompany me through his grounds, seem worthy of record. The Little Porter Oak measured 27 feet in circumference; the Great Porter Oak is 29 feet in circumference; the Seven Sisters, 33 feet in circumference. 'The Great Porter Oak was of a very large diameter, 50 feet above the ground; and the opening in the trunk of the Green Dale Oak was at one time large enough to admit the passage of a small carriage through it; by advancing years the space has become somewhat contracted. These indeed are noble trees, though jt must be confessed that they were thrown quite into the shade by the magnificent Kentucky Buttonwood or Sycamore, of whose trunk I saw a complete section exhibited at Derby, measuring 25 feet in diameter and 75 feet in circumference. This was brought from the United States, and indeed might well be denominated the mammoth of the forest.

In these ancient parks, oaks and beeches are the predominant trees, with occasional chestnuts and ashes. In very many cases 
I saw the beauty and force of that first line in the pastorals of Virgil, where he addresses Tityrus as "playing upon his lute under the spreading shade of a bech-tree." These trees are looked upon with great veneration; in many cases, they are numbered; in some, a label is affixed to them, giving their age; sometimes a stone monument is erected, saying when and by whom this forest or this clump was planted; and commonly some record is kept of them as a part of the family history. I respect this trait in the character of the English, and I sympathize with them in their veneration for old trees. 'They are the growth often of centuries, and the monuments of years gone by. They were the companions of our fathers, who, it may be, were nourished by their fruit, and reposed under their shade. Perhaps they were planted by the very hands of those from whom we have descended; and whose far-sighted and comprehensive beneficence embraced a distant posterity. How many revolutions and vicissitudes in the fortunes of men have they surveyed and survived! They have been pelted by many a storm; the hoarse and swift wind has often growled and whistled among their branches; the lightnings and tempest have many a time bent their limbs and scathed their trunks. But they, like the good and the truly great in seasons of trial, have stood firm and retained their integrity. They have seen one generation of men treading upon the heels of another, and rapidly passing away; wars have burst forth in volcanic explosions, and have gone out; revolutions have made their changes, and the wheel again returned to its starting point; governments and princes have flourished and faded; and the current of human destiny has flowed at their roots, bearing onwards to the traveller's bourn one family and one people after another; but they still stand, green in their old age, as the mute yet eloquent historians of departed years. Why should we not look upon them with reverence? I cannot quite enter into the enthusiasm of an cxcellent friend, who used to say that the cutting down of an old tree ought to be made a capital offence at law; yet I deem it almost sacrilegions to destroy them, excepting where necessity demands it ; and I would always advise that an old tree, standing in a conspicuous station either for use or ornament, should be at least once more wintered and summered before the sentence of death: which may be passed upon it, is carried into execution.

The trees in the park of the palace of Hampton Court are, 
many of them, the horse-chestnut and the lime, of great age and eminent beauty; several straight lines of them forming, for a long distance, the approach to the palace. On a clear, bright day, at the season of their flowering, I passed through this magnificent avenue with inexpressible delight. I passed through them again late in the autumn, when the frost had marred their beauty, and the autumnal gales had stripped off their leaves; but they were still venerable in the simple majesty of their gigantic and spreading forms. I could not help reflecting, with grateful emotion, on that beneficent Power, which shall presently breathe upon these apparently lifeless statues, and clothe them with the -glittering foliage of spring, and the rich and splendid glories of summer. So be it with those of us who have got far on into the autumn, or stand shivering in the winter of life!

The extent of these parks, in many cases, filled me with surprise. They embrace hundreds, in some instances thousands, of acres; * and you enter them by gates, where a porter's lodge is always to be found. After entering the park gate, I have rode sometimes several miles before reaching the house. They are in general devoted to the pasturage of sheep, cattle, and deer. In the park at Chatsworth, the herd of deer exceeded sixteen hundred. These deer are kept at no inconsiderable expense, requiring abundant pasturage in summer, and hay and grain in winter. An English pasture is seldom or never plonghed. Many of them have been in grass beyond the memory of any one living. The turf becomes extremely close and hard; and the fceding of sheep and cattle undoubtedly enriches the land, especially under the careful management of one eminent farmer, - and many more, doubtless, are like him, - on whose pasture grounds the manure of the cattle was daily collected and evenly spread.

In speaking of the parks in the country, I surely ought not to pass in silence the magnificent parks of London, as truly magnificent they must be called, including St. James's Park, Green Park, Kensington Gardens, Hyde Park, and Regent's Park.

Kensington Gardens, exclusive of private gardens, within its enclosures contains 227 acres; Hyde Park, 380 acres; Green Park, connected with St. James's Park, 56 acres; St. James's Park, 87 acres; Regent's Park, 372 acres; terraces and canals connected with Regent's Park, 80 acres - making a grand total

* Windsor Great Park contains 3500 acres, and the Little Park 300 acres. 
of 1202 acres. 'To these shonld be added the large, elegant, and highly-embellished public squares in various parts of London, and even in the most crowded parts of the old city, which, in all, probably exceed 200 acres. These magnificent parks, it must be remembered, are in the midst of a populous town, including upwards of two millions of inhabitants, and are open to the public for exercise, health, and amusement. 'They are, at the same time, to a degree stocked with sheep and cows.

It is impossible to over-estimate the value to health of these open spaces, and the amount of recreation and rational enjoyment which they afford to this vast population. In each of the large parks - Kensington, Hyde Park, and St. James's - there are extensive bodies of water, artificial lakes, in some places adorned with elegant bridges, and in St. James's Park studded with pretty islands and shrubbery. Here large varieties of aquatic birds are kept, to the great amusement of the thousands of children, who coax them to the shore with crumbs of bread and cake, the birds being so tame as almost to feed out of their hands, and for the instruction of older heads. There is likewise an exceedingly beautiful and tasteful cottage, of Gothic architecture, at the end of the lake in St. James's Park, for the residence of the keeper of the birds. There are always to be found in some parts of the parks, or at the keepers' different lodges, some cows kept, where a glass of milk, unadulterated and fresh from the fountain, can be had for those persons who, for health or plcasure, seck the delicious beverage in its purity. The numbers and tameness of the birds in these pleasure-grounds is a beautiful circumstance, which it might be well to consider in some other quarters. Their safety and lives are held sacred; and the birds gratefully, and, to a feeling heart, delightfully acknowledge this kindness by the most expressive confidence, alighting fearlessly in the path before you, as though they would invite you to cultivate their acquaintance. Man, in general, is a great savage, and a ferocious and insatiate animal of prey. He makes continual war upon many of the animals below him, not for subsistence merely, but for pleasure. His conduct towards the brute creation shows, too often, how certain he is to abuse unlimited power, and conveys a strong argument against despotic authority. Indeed, his war upon the birds merely as matter of sport, always makes me look upon him with a degree of shuddering, and feel that a man who can find his pleasure in the wanton destruction of little 
birds, the most humble of all animals in their claims, the most delicate, innocent, and pure in all their tastes and habits, and comparatively useless for food, puts himself beyond the pale of humanity, and could scarcely, with safety, be trusted with a child. It were worth considering always, how many of our pleasures are purchased at a most bitter expense of happiness and life to others! Two or three days' coursing, manly and healthful as the exercise on horseback undoubtedly is, and strongly exciting as the sport is, did not quite reconcile me to it; and the wailings and shriekings of the affighted and dying hares, in the jaws of the hounds, sounded in my ears, for several days afterwards, like the cries of expiring children.

I shall not be straying from my proper duty if I urge the beneficent example of London strongly upon my own countrymen. In Boston, excepting the Common - containing about forty-five acres of ground, exceedingly beautiful in its location and improvements - and some few openings upon a very limited scale, there is a large and constantly increasing population crowded together in one dense mass, with narrow streets and confined alleys, and basement stories, doomed to a comparative privation of Heaven's freest and greatest blessings - light and air. A Botanical and Pleasure Garden has been laid out, and is maintained by private subscription, accessible to subscribers or upon the payment of a light fee, which it is earnestly to be hoped, for the credit of this city, long distinguished by its liberality and public spirit, may receive every encouragement, so that its improvements and advantages may be greatly extended. New York, with a population of three times the extent of Boston, is scarcely more favored, excepting in the width of its streets; for, with the exception of those delightful grounds, the Battery, at the very extremity of the city, the open space in front of the City Hall, dignified, par excellence, by the name of the Park, and the open grounds attached to St. Johu's Church, and the University, but not accessible to the public, the city has no provision of this kind for public recreation and health. As there is little room in the city proper which can now be obtained, she ought at once, at any expense, to secure the charming grounds at Hoboken, to be devoted forever and exclusively to these objects. Having already, with the most loncrable enterprise, achieved one of the most extraordinary undertakings of the age, or indeed of any age, that of bringing, by a capacious tunnel of forty miles in length, a 
river of pure water into her city, and dispensing, with an unrestrained munificence, to those who cammot purchase it, this most important element, next to vital air, of human existence; let her go on and make the other provision, to which I have referred, for the health and comfort of a population already great, and destined to increase with an unexampled rapidity beyond any bounds which the imagination would now even dare to prescribe.

Philadelphia has set a better example than most other cities in this respect, in having laid out her streets of a capacious width, in having given to most of her houses yards or gardens of a good size, and in having formed, in different parts of the city, public squares of some extent, which are equally ornamental and useful. But she has done little compared with what she might have done; and it is to be hoped that she will be prompted to add to a city, the most convenient and beautiful in the Union, some public gardens and pleasure-grounds, admission to which shall be freely offered to her inhabitants; and more especially for the benefit of that class of them who can have no such indulgences but as the offerings of public beneficence. Baltimore has nothing that deserves the name of a square or a pleasure-ground, unless we are to rank under that designation the beautiful enclosure which she has recently purchased for a cemetery; a place, indeed, for a melancholy and instructive pleasure, but more properly devoted to silence and seclusion, and not at all of the character to which I refer. Lowell - destined to contain a large and laborious population, and of a character particularly demanding such places of recreation, with an unlimited extent of land at her disposal costing scarcely any thing, and with an investment in her manufacturing establishments of ten or eleven millions of dollars - has not a public square so large as a pockethandkerchief. This omission has always impressed me with painful surprise. Knowing, as I do, the high character of the gentleman who founded and built this flourishing city, now grown to manhood almost in a day, I can ascribe such an omission only to a want of consideration, and to the fact that the population has already extended far beyond any calculations which they could, with sobricty, have formed at its commencement. It is not too late to supply this omission, which interest, as well as philanthropy, most strongly dictates.

Cleanliness, fresh air, and pure water, and the opportunity and the means of relaxation and innocent recreation, are almost as 
essential to morals as to health. No one can doubt, in this respect, their direct and beneficial influence. The rich can take care of themselves, and can flee the sources of pestilence, and go after health and recreation where they are to be found. Not so with the poorer and humbler classes in society, to whose labor and service the rich owe all their wealth and many of their pleasures. Whoever goes into the low places in crowded cities, into the subterranean abodes where these wretched beings congregate like rabbits in a warren, or, rather, like swine in their sties, and enters into the melancholy statistics of mortality, in such cases will learn some measure of the suffering which is here endured. In London, and other places of a similar character, the presence of the police and the officers of the peace, always in such places in stroug force, will remind him that there is a comection not to be overlooked between condition and character, between destitution and crime, between outward filth and impurity of mind, neglect of person and neglect of morals. The most crowded parts of London are the most vicious parts; and a new should not neglect the experience of an old country. A city without public squares and public gardens should provide them, and on a most liberal scale. In a pecuniary point of view, as rendering a residence in the city the more desirable, and so increasing the value of estates in it, I have no doubt that it would yield ample advantages and profits. But health and morals are not to be measured by any pecuniary standard; and where wholesome water, and fresh air, and light, and sumshine, and cleanliness are concerned, no expense and cost are to be considered as exorbitant. To talk about the value of land in such cases, and to place this in competition with health, comfort, and morals, is equally short-sighted and inhuman.

The public parks and pleasure-grounds in London are highly ornamented with shrubs, plants, and flowers, and accessible to the public for exercise and recreation. In St. James's Park, and in some others, metallic labels are affixed to the foreign plants and shrubs, with the botanical and the vulgar name of the plants upon them, and the class and the country to which they belong. This is a beantiful arrangement, and well deserving imitation; furnishing instruction, as well as satisfaction; inciting to the study of botany, and opening a sealed book to the unaided and curious student of nature. Every one knows the advantage of teaching by example; and what an interest is given to the 
objects, which the natural and visible world presents, by the associations which science throws around them. 'This practice, I found, prevailed in other public gardens and pleasure-gronnds. It was the case in the beautiful and highly-cultivated botanical garden in the neighborhood of Liverpool, which, though created and supported by private subscriptions, and for scicntific purposes, is yet free of access to the public one or more days in the week. The same is the case with the very tasteful garden in Sheffield, a romantic and charming piece of ground, which, though on a small scale, combines many attractions; and likewise with the Arboretum at Derby, embracing, I think, about cleven acres, and formed into a garden and pleasure-ground for the public recreation. This last is the fruit of individual munificence. Mr. Strutt, an eminent manufacturer at Derby, employed Mr. Loudon - the late distinguished horticultural writer - to lay out, plant, and ornament these grounds, at an expense of ten thousand pounds sterling, or fifty thousand dollars; and then, with eminent liberality, gave them to the city of Derby for the public use and enjoyment of its inhabitants. Tens of thousands of pounds expended in the erection of a Corinthian column, or a marble mausoleum; would not have formed so durable or extended a memorial of him; and thousands upon thousands yet unborn, in the enjoyment of this beneficence, will invoke blessings upon his memory.

\section{X. - ORNAMENTAL SHRUBS AND FLOWERS.}

The cultivation of flowers and shrubs is a prominent feature in the landscape of England; and a circumstance which has given no little gratification to my national pride, has been the profusion of American plants, azalias and kalmias, magnolias and rhododendrons, and a large variety of pines and firs, which are seen in the shrubberies and plantations and pleasure-grounds, both public and private. A very large establishment in London is exclusively devoted to the sale of American plants; and they are every where admired for the splendor of their folliage and the beauty of their flowers. Greenhouses and conservatories are 
almost universal in the country, where any thing like a garden exists; and the better class of houses are surrounded and adorned with a great variety of flowering shrubs and plants, presenting, through the season, a charming succession of gay and brilliant ornaments. Even the laborer's humble cottage, ordinarily, I am compelled to admit, any thing but a picturesque object, will occasionally have its flowering shrubs adorning its door-way, and the ivy hanging its beautiful tresses over its window, forming, as it were, a mirror, set in a frame of the richest green. The village of Marr, in Yorkshire, not far from Doncaster, and the village of Edensor, in Derbyshire, near Chatsworth, and the village of Lord Brownlow, in Lincolnshire, the best built and by far the handsomest villages I have yet seen in England, to cottages of an excellent and tasteful construction, monuments of the liberality of their proprietors, add these beantiful rural embellishments of shrubs and flowers, and compel a reflecting mind to admit the moral influence of such arrangements upon the character and mauners of their inhabitants. Churches and ruins, likewise, are often seen spread over with the richest mantlings of ivy; and, among many others, the venerable and magnificent remains of Hardwicke Hall, for example, are covered, I may say, in the season of its flowering, with a gorgeous robe of it, matting its sides with indescribable luxuriance, climbing its lofty battlements, and fringing its empty windows and broken arches, as though Nature would make the pall of death exquisitely beautiful and splendid, that she might conceal the hideousness of decay, and shut from the sight of frail mortals these affecting monuments of the vanity of human grandeur and pride.

I have said and written a great deal to my countrymen about the cultivation of flowers, ornamental gardening, and rural embellishments; and I would read them a homily on the subject every day of every remaining year of my life, if I thought it would have the effect which I desire, of inducing them to make this matter of particular attention and care. When any man asks me what is the use of shrubs and flowers, my first impulse always is, to look under his hat and see the length of his ears. I am heartily sick of measuring every thing by a standard of mere utility and profit; and as heartily do I pity the man who can see no good in life but in pecuniary gain, or in the mere animal indulgences of eating and drinking.

The establishment of horticultural societies in Salem, Boston, 
Worcester, New Haven, New York, and Philadelphia, — and I speak of these societies in particular becanse I have attended the exhibitions of most of them, - has rendered an immense benefit to the country, not merely in the introduction of new and valuable fruits and vegetables, and in what they have done to improve and perfect the cultivation of those long known among us, but in the improvement of the public taste, and the powerful stimulus they have given to the cultivation of flowers and the formation of gardens and ornamental grounds thronghout the country. Few countries in temperate latitudes are richer in the floral kingdom of nature, and the luxuriance of vegetable growth and the splendors of vegetable beauty, than the United States. Why should not flowers be cultivated? Was the human eye, that wonder of wonders, that matchless organ of our physical constitution, that inexhaustible instrument of exalted and varied pleasures, made in vain? Are the forms of beauty in the natural world, infinitely multiplied as they are around us, made for any other purpose than to be enjoyed? And what better means can we take to strengthen the domestic affections, of all others the most favorable to virtue, than to render our homes as beautiful and as attractive as possible? Who does not see constantly the influence of external circumstances upon character as well as comfort ; and perceive how greatly order, exactness, and personal neatness contribute to form and strengthen the sense of moral exactness and propriety?

The horticultural establishments of England, their vegetable gardens, their flower gardens, their shrubberies and plantations, their greenhouses and conservatories, are upon the most extensive scale.

\section{XI. - CLIMATE OF ENGLAND.}

Another marked difference in the agricultural condition of England and the northern portion of the Uniled States, is in the climate. I camnot speak with any confidence of Scotland, but the climate of England must be pronounced highly temperate. It is favorable to the growth and the constant vigor and freshness of the grasses. It is not only temperate, but moist. 'The last 
season may have been peculiar. I landed in Liverpool near the end of April; and there was more or less rain for forty-six days in succession, until I became quite satisfied that an umbrella was as necessary as a hat. When the clcar weather finally set in, we had two months, or more, of as fine weather for harvesting as I ever knew, with scarcely the intervention of a day's rain; yet there was nothing of the parching heat of our summers, and I saw no land burnt up by drought. It is now December, and I have scarcely scen any ice, and not a flake of snow; and there is no frost in the ground. Many persons speak of this as the usual temperature, and say that the cold weather does not commence until after Christmas. The dews appear to me very light, owing, as I suppose, to the mildness of the days; and there have been none of those blowing clouds of dust with which our air is often charged, and which, with us, after long droughts, are very disagreeable. Of thunder and lightning this season I am unable to recall a single instance; and at no time of the day has the heat been in the slightest degree oppressive.*

Their insular situation exposes them to frequent and dense fogs, which interpose to prevent the earth being ever parched by drought; and the rains to which they are subject keep the earth, where it is of a retentive character, much soaked with water, and preserve an almost perpetual greenness of vegetation.

In many parts of England, the crops of turnips are never pulled until they are wanted for feeding in the course of the winter; in other places, they require a very slight covering to protect them from the frost. In most cases, sheep do not require to be housed; and in some cases, neat cattle get their chief living in the fields through a great part of the winter, though I cannot but regard this practice as very bad husbandry. Ploughing appears to be seldom interrupted for any length of time; and wheat is sown

* The annual average depth of rain in England is about two feet. In 1840, for instance, the depth at Aberdeen was 21.627 inches; at Empingham, 18.58; Epping, 20.767 ; Falmouth, 31.511; Gosport, 25.525 ; Greenwich, 18.24; York, 24.72 inches. That is perhaps not much below the average of the continent of Europe. Some portions of IV estern Europe, however, are exceedingly wet; 123 inches have been noted to fall at Coimbra, in Portugal, in a year. The fall of rain is still greater in the West Indies. At St. Domingo, 120 inches; at Cayenne, 116 inches ; at Maranham, 277 inches. So that even under the equator, a sufficient supply of rain water can be obtained for the service of the inhabitants. - Farmer's Almanac. 
from October to April. In parts of New Jersey, Pennsylvania, Delaware, and the states south, the farmers enjoy similar advantages of a mild temperature; but north of these, the despotism of frost and snow commences, and holds undisputed sway for four months in the year. Yet, notwithstanding this, our seasons are quite long enough for the perfect ripening of all the crops grown among us; and, with a little extra labor, even the valuable green crops, which here play so important a part in the feeding of stock and the enriching of the land, might, if deemed expedient, be raised and used among us. Of this, however, I shall speak hereafter. 'These remarks apply only to what has come under my own personal observation; and I can be said to have seen, as yet, only a small part of England. The winter management of farms here is a matter of as much importance as the summer husbandry, and will claim my particular attention. The disposal of the produce, the fattening of animals, the breeds or kinds of live stock most likely to make a good return to the farmer, and the whole management of the manure yards, are subjects in relation to which much useful instruction is to be obtained.

It would seem as though a country with so rough and severe a climate as New England, and with such long winters as prevail there, which, for more than a third part of the year, interrupt entirely all the out-door operations of husbandry, must be exceedingly unfriendly to agriculture, compared with one where the winters are open and field-labor is practicable through the whole of the year. This is, indeed, the case; yet there are some compensations for these privations and disadvantages, which in New England are duly appreciated, as the winter, when labor is to a great degree suspended, is the special season for the education of the young; for reading and mental improvement, and for the most friendly and social intercourse. If these circumstances may be thought to have no connection with agriculture, strictly so called, yet they are certainly to be considered in reference to the condition of the agricultural population; and in every circumstance which renders their condition more comfortable and happy, and, above all, which advances their intelligence, we may ordinarily look for a corresponding improvement in their cultivation and rural husbandry. $\Lambda$ New England village resembles, to a great degree, a united and happy family, where perfect equality prevails; where a friendly sympathy is every 
where active and strong; and where all seem bound to contribute, according to their power, to the general welfare, comfort, and improvement. Society exists in the United States under circumstances so entirely different from those in which it is found here, that a comparison can hardly be instituted between them. The intercourse to which I have here referred, can scarcely be said to exist in England; the general character of the laboring population being not many removes, as far as intellectual improvement is concerned, above that of the other animals which cultivate their fields.

In several respects, it must be admitted, the mild temperature of the English climate affords singular advantages. The winter season furnishes the best opportunity for draining and ditching; the active operations of the farm being, in a degree, suspended, labor is obtained at a low rate; and as a great portion of field work, in England, is done by the piece instead of the day, the shortness of the days makes no difference of expense to the employer.

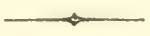

\section{XII. - AGRICULTURAL POPULATION.}

I have referred to some differences in the condition of society here, and in the United States, and those differences it may be well to understand. The agricultural population in England is divided into three classes - the landlord, the tenant farmer or occupier, and the laborer.

1. The Landlonds; Rents; and Taxes. - The landlord is the owner of the soil. Most of the landlords are noblemen or gentlemen, and are looked up to with a deference and veneration, on account of their rank, with which those of us who have been educated in a condition of society where titles and ranks are unknown, find it difficult to sympathize. They own the land. Some few of them keep portions of their vast territories in their own occupation, and under their own management; but, by most of them, their lands are leased in farms of different sizes, seldom less than three or four hundred acres, and in many cases eight hundred, a thousand, and twelve hundred acres. 'The rent of land varies in different places; in some being as low as five 
shillings; in others rising to almost as many pounds. Rents are in general paid in money. Sometimes they are valued in kind; that is, the tenant engaging to pay so many bushels of wheat, or so many bushels of barley, or such amount of other products; but in these cases, also, the landlord usually receives his rent in money according to the current prices of these articles. The rents are paid in semi-annual payments. The fair rent of land is sometimes estimated at a third of its products; by some, a different rule is adopted, which is, after all the expenses of cultivation and the usual assessments are deducted from the gross proceeds, that the balance remaining should be divided equally between the landlord and the tenant. In general, however, as far as my observation has extended, the rate of rent is not determined by any particular rule, other than that which prevails in most commercial transactions, that each party makes the best bargain for himself that he is able. It is only just to add that in all the cases, without exception, which have come under my remark, there has seemed to me, on the part of the landlords, a fair measure of liberality; the rents in general bearing a small proportion to the legal interest of the money at which the lands are valued, and for which they could be sold at once; lands costing $£ 60$ sterling, or 300 dollars per acre, being frequently let for 30 s. or $£ 2$ sterling per acre, that is, less than eight or ten dollars per acre. We are not well satisfied in the United States with a return from our land under five or six per cent. on its cost ; but the landlords here seldom obtain more than two and a half per cent. or three per cent. on the price which the land would command, if brought into the market. The low rents which are obtained show the abundance of wealth, and how greatly an investment in land is valued for its security; and the active competition for leases, which appears in almost every part of the country when farms are to be let, seems to imply that the rents are reasonable, and, more than that, liberal. As I shall not hesitate to put down my impressions of the country, of men and things, with the utmost frankness, avoiding all personalities, I must say that there has appeared to me on the part of the landowners, with many of whom, among the largest in the country, I have had the pleasure of becoming acquainted, the most marked libcrality in the management of their great estates, both in the terms and continumee of their leases, and in the aid rendered to their tenants in making improvements. The liberality and amount of the expenditures 
indeed strike an American with astonishment. In the United States, and especially in the northern parts of it, where there is a constant struggle to live, where men have to contend with a severe climate and a stubborn soil, and where money is comparatively scarce, the accumulations small, and the farms extremely limited, and where the first lesson taught to a child, even in his swaddling clothes, is a lesson of self-dependence, it is not surprising that men should be compelled with extreme care to husband their small means, and that a frugality, in itself highly commendable, should sometimes verge within the limits of meanness. This, indeed, is far better than that reckless expenditure, without regard to one's means, which we sometimes see, and which is almost sure to involve the individual who indulges in it in irretrievable debt and ruin. But there cannot be a doubt that in New England we often commit a great error in withholding a reasonable expenditure in the improvement of our lands; and that we are not sufficiently impressed with the obvious truth. that a proper expenditure of capital is as important to a successful and improved agriculture, as to the successful prosecution of any branch of manufactures, trade, or commerce.

Leases may be annual, or at will, or for a term of years. When land is taken by the year, it is understood that the tenant has six months' notice of the intention of the landlord not to renew his lease, if such intention exist. The lands in England are burdened with taxes from which the United States are free. 'These, in many cases, amount to a sum equal to the rent of the land. The tithes, or tenth of every article produced, are not now taken in kind, but are commuted and paid in money. The poor and parochial rates are often héavy; these all are paid by the tenant, unless a special agreement is made to the contrary.

Some persons are disposed to question the right of individuals to such extensive tracts of land, which, in many instances, they neither cultivate thomselves, nor suffer others to cultivate, and which deseend miminished through successive generations in the same family. The legal or constitutional right is determined by statute; upon the moral right, or the right founded upon principles of political justice, I am not disposed to enter, as this would lcad me to discuss the foundations of all property - a sul)ject foreign' from my purpose. 'The tithe system, as it exists here, strikes a foreign and umpractised eye as a singular feature in the condition of things. A tithe, or tenth part of the produce 
of the land, according to the provisions of the Levitical law in respect to the Jewish priesthood, was taken for the support of the established religion; and the priests and clergy of the different parishes were accustomed to levy it in kind, and to exact it to the extremity of every tenth portion of the honey made by bees in the farmer's hives, every tenth chicken in the good wife's poultry-yard, and every tenth egg laid by her fowls. Indeed, the monks, if reports be true, had always a remarkably keen appetite for honey, and poultry, and eggs. By one of the kings of England, the possessions of the church were seized and confiscated; and the right of claiming tithes, in many parishes or districts, was given to his friends, reserving a very small portion for the support of the clergy. A great portion of the tithes are now, therefore, held by laymen; and in some parishes, for example, where the tithes amount to several thousand pounds, the clergyman gets only as many hundreds; and the tithes of any particular parish or place, or rather the right to enforce and receive them, is as much a matter of sale or traffic as the land itself. It is not for me to quarrel with the institutions of a country of which I am neither citizen nol subject; but it is obvious that every burden upon the land must, to a degree, operate to the prejudice of agriculture; and the matter of levying a tax originally intended exclusively for the support of religious institutions, after it has long since avowedly ceased to be applied in any form to that object, is an affair for those to consider who are especially affected by it. I have not deemed it necessary to inquire into the amount paid in this way, which varies considerably in different places; but the amount stated to me by one farmer, the occupier of 250 acres of land, and whose rent is $£ 370$, is at least $£ 60$ sterling (or 300 dollars) per year in parochial rates, including all but specific taxes. The poor-rates are in many cases extremely burdensome upon the land, the wages of the laborers being in general so limited as not to admit, but in rare cases, of their laying aside any of their earnings for old age, or seasons of sickness and calamity. The support of the poor formerly rested, in a great measure, upon the religious houses, which were very largely endowed with lands and possessions for this very object; but when these houses were broken up and the property taken by the state, this burden was transferred to the backs of the landholders or occupiers. The individual possessions of the landowners are sometimes enormous, 
amounting in many cases to scores of thousands of acres, and in one instance within my knowledge, to seventy-five thousand acres; and in another, I believe, to more than a million acres.

2. The Farmers. - Next come the farmers, who lease the land of the landowners. These men are not like farmers in the United States, who themselves labor in the field; they rarely do any personal labor whatever. They are, in general, a substantial and well-informed body of men; and many of them live in a style of elegance and fashion. Many of them are persons of considerable property, as indeed they must be in order to manage the farms which they undertake. The capital necessary to manage a stock or an arable farm must be always estimated at double or treble the amount of rent; and, in general, cannot be set down at less than $£ 10$ sterling, or 50 dollars, per acre. The stock required for a grazing is, of course, much more than for an arable farm; but in no case can success be looked for without ample means of outlay. In no respect does the agriculture of England differ more from that of the United States, especially from that of the Northern States, than in regard to capital. Our farmers, in general, have little floating capital. They attempt to get along with the least possible expenditure. Under such circumstances, they operate to very great disadvantage. They can never wait for a market. They cannot bring out the capabilities of their farms; and the results of their farming are consequently limited and meagre. The difference between a new comntry contending, as it were, for existence, and an old country operating with the accumulations of years and centuries, is most sensibly marked; the expenses incurred on some farms in England solely for mantres purchased, exceeding thousands of pounds sterling, and the cost merely of grass seeds, are perfectly surprising to an American farmer; yet experience has demonstrated that, in these cases, the most liberal outlay of capital is the most sure to be followed by successful results.

The farmers in England, as far as I have had the pleasure to meet with them, are a well-informed set of men, especially on subjects connected with their particular pursuits. There, of course, is the variety among them which is to be found in other classes; but their manners, without exception, are courteous and agreeable, their hospitality distinguished, and their housekeeping - and I speak with the anthority of a connoisseur in these matters - is admirable. Indeed, it has not yet been my misfortune 
to meet, in England or Scotland, with a single instance of negligence in any private house which I have visited; but, on the other hand, the most exemplary neatness. I cannot say as much of all the hotels or taverns in the country, many of which are far inferior in all respects, and none of them superior in any, to our best hotels. There is one circumstance in English manners so much to the credit of their housekeeping, that I shall, for the besi of reasons, venture to remind my American friends of it, although I fear that any reformation in the case is hopeless. In no private house which I have visited have I been smothered or offended with tobacco smoke; and I have seen the offensive and useless habit of chewing tobacco since I came to England in but one solitary instance, and that was on the part of an American. At public dimners, the same reserve is not practised, and the atmosphere becomes as thick as a London fog. I will not interfere with any gentleman's private pleasures; but I will lose no fair opportmity of protesting against a practice which has little to recommend it, and in respect to which $I$ think we have good grounds to ask, What right has any man to indulge in any mere personal or selfish gratification, in-doors or without, at the expense of his neighbor's comfort? I know very well the value to my own country, as a branch of agriculture, of the production of tobacco; but I cannot look upon its cultivation with much complacency. Nor does the exhausted condition of the soil, where tobacco has been some time cultivated, reconcile me to its culture. Indeed, how much were it to be wished that instead of the production of an article useless for subsistence and pernicious to health, there could be substituted the cultivation of plants for the food and comfort of millions now suffering from the want of them!

3. The Agricultural Laborers. - Next to the farmers come the laborers; and these three classes preserve the lines of distinction among them with as much caution and strictness, as they preserve the lines and boundaries of their estates. These distinctions strike a visitor from the United States with much force; but, in England, they have been so long established are so interwoven in the texture of society - and men are, by education and habit, so trained in them, that their propricty or expediency is never matter of question. The nobleman will sometımes, as an act of courtesy and kindness, invite bis tenantfarmer to his table; but such a visit is never expected to be 
returned. The farmer would under no circumstances invite the laborer to his table, or visit him as a friend or neighbor. I do not mean to imply that there is, on the part of the higher classes of society in England, any insolence or arrogance in their treatment of their inferiors. Free as my intercourse has been with the highest and the middle classes, I have seen no instance of this, nor any thing approaching it, but the contrary; and the best bred men in the country - the true gentlemen - are distinguished by their courtesy and the absence of all ostentatious pretensions. While they naturally fall into the orbit, in which birth, education, and the political institutions of the country have accustomed them to revolve, the well-principled among them would, I am sure, be the last persons, by any assumptions, voluntarily to mortify one below them with a sense of his inferiority.

The farm laborers are, I will not say in a degraded condition, for that would not, in any sense, apply to them, unless where, by their own bad habits, they may have degraded themselves; but they are in a very low condition, and extremely ignorant and servile. They rarely, as with us, live in the house of their employers, but either in cottages on the farm or in a neighboring village. 'They are, usually, comfortably clad, in this respect contrasting most favorably with the mechanics and manufacturers in the cities and large towns; but they are, in general, very poorly fed. Their wages, compared with the wages of labor in the United States, are very low. The cash wages paid to them seldom equals the cash wages paid to laborers with us, and our laborers, in addition to their wages in money, have their hoard ; but the English laborers are ohliged to subsist themselves, with an occasional allowance, in some instances, of beer, in haying or harvesting. The division of labor among them is quite particular - a ploughman being always a ploughman, and almost inseparable from his horses; a ditcher, a ditcher; a shepherd, a shepherd only; the consequence of this is that what they do, they do extremely well. Their ploughing, sowing, drilling, and ditching or draining, are executed with an admirable neatness and exactness; indeed, the lines of their work could not be more true and straight than they usually are, if they were measured with a marked scale, inch by inch. They speak of ploughing and drilling or ridging by the inch or the half inch; and the width of the furrow slice, or the depth of the furrow, or the dis- 
tances of the drills from each other, will be found to correspond, with remarkable precision, to the measurement designed. But they appear totally destitute of invention, and have, evidently, little skill or ingenuity when called upon to apply themselves to a work different from that to which they have been accustomed. Their gait is very slow; and they seem, to me, to grow old quite early. The former circunstance explained itself to me when I examined and lifted the shoes which they are accustomed to wear, and which, when, in addition to being well charged with iron, they gather the usual amount of clay which adheres to them in heavy soils, furnish at least some reason why, like an Alexandrine verse, "they drag their slow length along." There are occasional instances of extraordinarily good management where they are cnabled to accumulate small sums; but in no case, under the best exertions, can they make, from the wages of labor, any thing like a provision for their old age and decay.

They are little given to change situations, and many of them, both men and women, live and die in the same service. Several instances have come under my observation of thirty, thirty-five, and forty years' reputable service; and many where persons, even upon the most limited means, have brought up large families of children without any parochial assistance. But, in this case, they are all workers; the children are put to some sort of service as soon as they are able to drive the rooks from the corn, and no drones are suffered in the hive. I visited one laborer's cottage, to which I was carried by the farmer himsell, who was desirous of showing me, as he said, one of the best examples, within his knowledge, of that condition of life. The house, though very small, was extremely neat and tidy; the Bible lay upon the shelf without an unbroken cobweb over its covers; the dressers were covered with an unusual quantity of crockery, suflicient to funish a table for a large party - a kind of accumulation which, I was told, was very common; and their pardonable vanity runs in this way, as, in higher conditions of life, we sce the same passion exhibiting itself in the accumulation of family plate. The man and woman were laborers, greatly esteemed for their good conduct, and had both of them been in the same service more than forty years. I asked them if, in the course of that time, they had not been able to lay by some small store of money to make them comfortable in their old age. I could not have 
surprised them more by any question which I could have proposed. They replied, that it had been a constant struggle for them to sustain themselves, but any surplus was beyond their reach. I cannot help thinking that the condition is a hard one in which incessant and faithful labor, for so many years, will not enable the frugal and industrious to make some small provision for the period of helplessness and decay, in a country where the accumulations of wealth in some hands, growing out of this same labor, are enormous.

'To the honor of several proprietors, the kindest provision is made for the decayed and superannuated. In some cases, the wages of the laborers are continued to the end of life; and in some, as I saw with great pleasure, comfortable cottages are provided for the old and infirm : they have their rent and fuel without charge, and a regular stipend as long as they live. This was the case at the seat of the late distinguished farmer, the Earl of Leicester, formerly Mr. Coke; and likewise on the estates of the Duke of Devonshire, where even the old schoolmaster of the vil-lage is pensioned, and has a house and a liberal allowance provided for him. Several other instances have come under my observation, where the superannnated and decayed laborers were kindly provided for and received a pension adequate to their comfortable support. This is as it should be. In every just community the rights of honest labor ought to be respected and secured. I confess it would be far better for them to be able to provide for themselves than to be dependent upon the precarious bounty either of individuals or the public; but I should be unwilling to overlook any act of justice or honor. It is obvions that the prospect of a supply from the bounty of the landlord can only apply to those who are in the direct employment of the landlord, and not to those who serve the tenant farmer, whose situation and permanency, where the lease of the farm is only for the year, are always, to a degree, doubtful.

It cannot be denied that those who labor with us are altogether a superior class of men to the English laborers; I refer, of course, to the natives of the country. A considerable portion of our labor is now performed by foreigners, who, when they unite sobriety and frugality with faithful industry, are sure of good treatment and success; indeed, I have known several instances of laboring men, and some of them in my own employ- 
ment, who, by good conduct, have supported themselves, and have accumulated, after a few years' service, their four and five hundred dollars and upwards, that is, their eighty and their hundred pounds - an acquisition which, in England, a laboring man would not dream of as the result of his labor, sooner than he would dream of receiving a pension of the same amount from the government. With us the laborer is vastly better paid than in England. With us the laborer always is, or always may be, the owner of the house in which he lives, and of as much land as he chooses to cultivate. Here the cottager is always a mere tenant, subject to the pleasure of his landlord; and, though there are many cases where allotments of small portions of land are granted them for a garden spot, and for the obtaining of some small supplies for their families, yet there are many where no indulgence of this sort is allowed, not even so much as a cabbage yard. The laborer here is doomed to remain in the condition in which he is born - he cannot rise above it. The provision for the education of the children of the laborers is, in most parts of England, extremely limited and meagre. There are some national schools, and there are, in many places, schools established and supported by the liberality of the landlords, for the benefit of the laborers in their own villages, and on their own farms. Sunday schools are likewise kept up in all the parishes which I have visited; and I should be happy, if it were allowed me, to adorn my page with the names of some noble women, who, with a benevolence truly maternal, take a deep interest in these institutions, and generously support them, and, better than that, personally superintend them. 'These are bright examples. In one case, at a small country village, on a Sunday, I saw more than four hundred of these children, cleanly and plainly dressed, entering the parish church, and taking their seats together, behaving with the most exemplary propriety. When they lifted up their voices in the solemn chants of the church, and their gentle and shrill tones were heard above all the rest, I could not help lifting up my own heart to God in thanksgiving, that the highest truths of religion can be taken in by the humblest minds: that here was at work an instrument of their elevation, which no human power could forbid; that here they were taught to recognize the dignity of their moral nature; and that there is one place, where all earthly distinctions betray their insignifi- 
cance, and every human being may, on equal terms and with equal confidence, invoke a common and a universal Father. This school was entirely supported by and under the care of a noble woman, who, to the highest distinctions of rank, education, fashion, and fortune, adds the far higher attributes of a deep sense of religions duty, and an earnest desire to be useful.

The Sunday schools do not, every where, confine themselves to religious instruction, but reading, writing, and the elements of arithmetic, are also taught, because, in many cases, the children of the poor are kept so constantly at labor as to have no other opportunity of getting this instruction. The education given them is of a very limited character, and does not extend beyond reading, writing, and the first principles of arithmetic, exclusive of religious instruction. The British and foreign schools, which are established by aid from the government which measures its bounty by what may be raised by private subscription in any parish or village - require the catechism of the established church to be taught, and the attendance of the children at the church, under the penalty of exclusion from the school. 'The National School Society allows the attendance of the children at such church as the parents choose; but the catechism of the established church, and no other, is allowed to be taught in their schools. The schools supported by the liberality of the dissenters are, comparatively, few ; and in most of these, without doubt, the same interest is active, and the same influcnces are at work, to attach their children to the particular sect by whose patronage the school is established and sustained. I speak now of England. I am not yet able to speak of the condition of things in Scotland, although it is constantly boasted of that the education of the Scotch laborer is always provided for, and that the Scotch laborer, in point of instruction, is far superior to the English. This remains for me to see.

'The condition of the laborers in this commtry is a subject of such deep concern to the community, on the ground of pecuniary profit as well as of philanthropy and justice, that I shall, in the course of my inquiries, revert again to it. I do not feel that as yet $I$ am sufficiently well-informed to speak with much confidence on the subject; but I shall not leave it without some further remarks. The common wages of farm labor vary, for men, from six shillings to twelve shillings per week; but I think 
a fair average would be eight to nine shillings sterling. A shilling may be reckoned at twenty-four cents, so that the monthly wages for a man may be put down at eight dollars and sixtyfour cents. This is the whole, where labor is paid for in money, cxcepting, as a matter of kindness, the farmer generally brings the coals for his laborer. There are cases, too, in which the farmer stipulates to supply his wheat to the laborer at a fixed price, which is to be unaffected by any changes in the market. Six shillings, only, a week are reported to be paid in some places, but I have met with no case less than eight shillings and sixpence a week.

It may be interesting to some of my readers to have a more particular account of the wages and condition of the laborers, and for that reason I will give some statements of their condition in that part of the country where wages are paid in lind.

In the neighborhood of Haddingdon, in East Lothian, I visited a laborer's cottage, being one in a range of six cottages, in a district of country highly cultivated and improved, and presenting some of the finest examples of agricultural improvement which I have ever seen. The wife, a very tidy and civil woman, about forty years of age, was at home; her husband and daughter laboring in the field. This was a very good specimen of a neat cottage, and its inmates had passed the greater part of their lives in it. It had no other floor but the hard ground; and two beds were fixed in the wall, like sailors' berths on board ship. The shelves were covered with crockery; and a Bible, and a few religious and other tracts lay upon the mantel-piece. A cake made of pea-flour and barley-flour was baking over the fire, of which I was asked to eat, but the taste of which did very little towards quickening my appetite. There was, besides the one in which I was, a small room for coal and lumber, where, in case of great emergency, a lodging might be made up. One of her neighbors in the same block, with no larger accommodations, had eight children to provide for. Two grown-up daughters, with one smaller one, occupied one bed; the parents, with one child, occupied the other; the two grown-up sons slept in the lumber-room or coal-house. There is often much closer lodging than this. The husband of the woman, in whose cottage I was, was a ploughman, and likewise a bondager - a species 
of service or contract which requires him to furnish a female laborer, at tenpence per day in ordinary work, and one shilling per day in harvest, whenever her services are required. If he has not a wife or daughter who will answer this purpose, he must keep a woman in his house to be always in readiness when required. His wages were -

18 bolls of oats, at 4 bushels per boll, . . . 72 bushels.

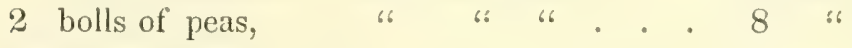

$4 \frac{1}{2}$ bolls of barley, " "6 "6 . . . 18 "

and $£ 1$ for "lint" - or shirts.

This payment of wages in kind, if the rate is fairly fixed, is certainly an equitable mode. Its effect upon the laborers, as in this case, as they themselves have grain to sell, is to make them the advocates of high prices, and, consequently, the friends of those restrictive measures by which foreign competition in the grain market is prevented. The employer likewise keeps a cow for the laborer; or if he has no cow, an allowance is made to him of five or six pounds in money. He is likewise allowed 1000 square yards of ground for potatoes, which the farmer ploughs and manures for him; but which he cultivates in extra hours. For the rent of his house he gives twenty-one days' work in harvest, if required; but should it happen that only twelve or fourteen are required, it is accepted as an equivalent.

For the woman's work he receives a fixed amount per day, whenever she is cmployed; and for her six months' service in the year he pays her three pounds. For the other six months he pays her nothing more than her board and some clothes. The farmer brings his coals for him, which he purchases at a small sum, being small coals, here called pan-wood. The value of three shillings and sixpence in coals will serve him through seven weeks in winter. Seven loads (one-horse loads, I suppose) of coals are purchased at the quarries for three shillings and sixpence. The farmer's shoes cost him ten shillings, and one pair will last him eighteen months. His daughter's working shoes last her a year: this is exclusive of her Sunday's shoes. In most parts of Scotland, the women, in the summer season, wear only their natural sandals and hose, which have, indeed, the advantages of being easily washed, and easily repaired; but in this part of Scotland they form the exception of wearing shoes and 
stockings the whole year. Their liring consists of bread made of barley and peas, neal or oaten porridge and milk, and potatoes; and they generally have a pig. They cannot, of course, lay up any money; and she added, in her own pleasant dialect, that "the lassies have muckle sair work in harvest." They depend on the sale of their surplus grain for what little money they need. I will do justice to her modest merit, and say, to the shame of thousands rolling in unstinted luxury, that she spoke of her condition as comfortable, and expressed strongly and religiously her contentment.

The wages paid in the county of Northumberland, where the Scotch system of farming is carried to a high degree of perfection, is as follows, as given by several gentlemen, familiar with the subject, to the parliamentary committee:-

\section{FIPST EXAMPLE.}

36 bushels of oats, 24 " " barley,

12 " " peas,

3 " "wheat,

3 " " rye,

36 to 40 "6 potatoes,
24 lbs. of wool, A cow's keep for a year, Cottage and garden, Coals carrying from the pit, $£ 4$ in cash.

SECOND EXAMPLE.

10 bushels of wheat, 30 " " " oats; $10 \quad 66 \quad 66$ barley; 10 " " rye, 10 ¿ : peas,

A cow's keep for a year,
800 yds. of land for potatoes, Cottage and garden,

Coals led, E3 10 s. in cash, 2 bushels of barley in lien of hens.

\section{THIRD EXAMPLE.}

36 bushels of oats,

24 "6 barley,

12 " " peas,

6 " " " wheat, $1000 \mathrm{yds}$. of land for potatoes,
A cow's lieep,

House and garden, Coals led, E5 in cash. 
The following, which is a specimen of the half-year's account between a large farmer and one of his laborers in a part of Northumberland, is worthy of observation :-

Dr. to

£. s. d.

Jane Thompson, (the bondager, ) 121 days at 10d., . 513

Catherine Thompson, (a child,) 24 harvest days at 1s. 140

Do., $\quad 73 \frac{1}{2}$ days at 5 d., . . . . $1107 \frac{1}{2}$

Elizabeth Thompson, (a younger child,) $7 \frac{1}{2}$ days, . . $01019 \frac{1}{2}$

Isabella Thompson, (a dress-maker at other times,) ? $35 \frac{3}{4}$ days at 1 s., $\} 1159$

Do., $\quad 20$ harvest days at 2 s. 3 d., . . . 250

Wife, 9 harvest days, . . . . . . . . 1003

His old father, 52 days, . . . . . . . . . 3180

John Thompson's half-year's cash, • • . . . $\frac{210}{2}$

This account, it will be seen, with the exception of the last item, does not include any portion of the laborer's own service, but that of his family only. The difference in the price of harvest work at different periods, as between one shilling and two shillings and threepence, is probably owing to labor becoming more scarce, on account of the general ripeness of the crop, or the hurrying state of the weather.

The Scotch laborers seemed to me, from a very limited observation, strongly attached to their employers. On one farm, where I had the pleasure of visiting, one of the laborers had been in the employment of the same family forty years, and another sixty; to each of whom, although their labor now was of very little value, the farmer continued the same rate of wages, which they had in early life. This indeed would seem to be no more than just, that the honest laborer, whose life had been spent in the service of another man, should not be turned adrift in his old age; but, alas! how rare is justice!

Of the extraordinary frugality with which some persons in humble life live, even where prices are high, I may give an

* Parliamentary Report on Employment of Women and Children in Agriculture. 1843. p. 297. 
example, which came under my observation. In Arbroath, near the magnificent ruins of the ancient abbey of Arbroath, I heard the movements of a hand-loom, and I took the liberty, with due ceremony, of going in. A middle-aged Scotch woman, of pleasing appearance and neatly dressed, was weaving. I asked her how much she was able to earn. She replied that if she rose early, at five o'clock, and worked all day through the week, after paying for the use of the loom and the cost of winding her spools, her week's work would amount to four shillings. She received no parish assistance. She paid three pounds sixteen shillings for the rent of her house. Her fuel cost her ninepence per week; and out of the remainder - less than two shillings she had to support and clothe herself and an aged mother, who was very infirm, and incapable of helping herself. What the support that either of the poor creatures could have under such circumstances must be left to conjecture. The woman spoke of her circumstances as being difficult, but she made no complaint. and presented an example of true Christian philosophy, which would have done honor to a superior education and the highest condition in life.

In all parts of the country, women are more or less employed on the farms, and in some parts in large numbers; I have freunently counted thirty, fifty, and many more in a field at a time. both in hoeing turnips and in harvesting. I have found them, likewise, engaged in various other services — in pulling weeds, in picking stones, in unloading and treading grain, in tending threshing-machines, in digging potatoes and pulling and topping turnips, in tending cattle, in leading out dung, and in carrying limestone and coals. Indeed, there is hardly any menial service to which they are not accustomed; and all notions of their sex seem out of the question whenever their labor is wanted or can be applied. The wages of women are commonly sixpence and cightpence, and they seldom exceed tenpence a day, excepting in harvest, when they are as high as a shilling. The hours of labor for the men are usually from six o'clock, A. M., to six: P. M., with an interval of an hour for breakfast and an hour for dinner. The women rarely come before eight o'clock, and quit labor at six, with the usual indulgence for dinner. Many of the laborers walk two and three miles to their work, and returu at night. Their meals are taken in the fields, and in the most simple form. The dinner is often nothing more than bread. 
In the season of harvest, immense numbers of Irish come over 10 assist in the labor, and this presents almost the only opportunity which they have, in the course of the year, of earning a little money to pay the rent of their cabins and potato patches. Nothing can exceed the destitution and squalidness in which they are seen ; starved, ragged, and dirty beyond all description, with the tatters hanging about them like a few remaining feathers upon a plucked goosen. At their first coming, they are comparatively feeble and inefficient; but after a week's comfortable feeding, they recover strength, increasing some pounds in weight, and, if they are allowed to perform their work by the piece, they accomplish a great deal.

I found in one case on two farms - which, though under two tenants, might be considered as a joint concern - more than four hundred laborers employed during the harvests, a large proportion of whom were women, but not exclusively Irish. 'The average wages paid the men in this case was one shilling sterling (or twenty-four cents) per day and their food, which was estimated at about ninepence (or about eighteen cents) per day. Their living consisted of oatmeal-porridge and a small quantity of sour milk or buttermilk for breakfast; a pound of wheaten bread, and a pint and a half of beer at dinner; and at night, a supper resembling the breakfast, or twopence in money in lieu of it. I was curious to know how so many people were lodged at night. In some cases, they throw themselves down under the stacks, or upon some straw in the sheds, or out-buildings of the farm; but in the case to which I refer above, I was shown into the cattlestalls and stables, the floors of which were littered with straw; and here the men's coats, and the women's caps and bonnets, upon the walls, indicated that it was occupied by both parties promiscuonsly. This was indeed the fact. Each person, as far as possible, was supplied with a blanket; and these were the whole accommodations and the whole support. This was not a singular instance. I am unwilling to make any comments upon such facts as these. T'hey speak for themselves. They are matters of general custom, and seemed to excite no attention. I do not refer to them as matter of reproach to the employers, who were persons of respectable character and condition, and whose families were distinguished for their refinement. But it presents one among many instances in which habit and custom reconcile us to many things which would otherwise offend us; and lead us 
to view some practices, utterly unjustifiable in themselves, with in degree of complacency or indifference; and as unalterable, because they have been so long established. I believe there is only one part of the United States where any thing resembling such a condition of things prevails, or would be permitted; and there only among a class of beings whose claims to humanity seem not very well established in all minds, and whose degradation, on account of their complexion, appears absolutely hopeless. But, even here, this indiscriminate consorting is not common; nor would it be permitted by any respectable planter.

This condition of things should certainly save this country from the reproach, if it be one, which some English tourists are disposed to attribute to American manners - that of treating the sex with too much courtesy and deference. I cannot bring myself, however, to view the subject with any lightness whatever. My confident conviction is, that the virtue of a community depends on nothing more than on the character of the women. In proportion as they are improved, and treated with deferenee on account of their sex, the women are brought to respect themselves, and the character of the men is directly improved; character itself becomes valuable to both parties. But in proportion as the condition of women is degraded, and they are considered and treated as mere animals, self-respect is not known among them; character is of no value; and the moral condition of such a class, or rather its improvement, is absolutely without hope. Nor is it without its pernicious influences, which must be too obvious to require to be pointed out, upon the classes in the community above them. Much fault as some persons have been pleased to find with the deference paid to the sex in the United States, I should be very sorry to see it in the smallest measure abated. I do not believe, taken as a whole, there is a more virtuous population upon earth, than are the women of New England and the Hiddle States; and nowhere is there a greater decency and propriety of conversation and manners. I speak of these portions of the country in particular, because with them I am intimately acquainted, and have a right to speak with confidence; but I have no reason to say that the same respectability of character does not prevail in other parts of the United States.

I do not claim for my country any thing like an immaculate condition of society; very far from it : but I do claim for them a highly-improved moxal condition; and have no hesitation in 
saying, that in most of our country villages prostitution is un. known, and an illegitimate child is a comparatively rare occurrence. I add with equal confidence, that under the influence of our free schools and universal education, and the disinterested and philanthropic exertions among all sects for the religious education of the young in Sunday schools, the beneficial and ameliorating results fully equal every reasonable expectation. This comes of the value of character, and the lessons early inculcated upon them to respect themselves as women. I would, if possible, strengthen this sentiment; and therefore wonld in no department of life render less prominent the distinctive barriers between the sexes. In all my intercourse with society in the United States, and with opportunities as large as any man of observing all classes among them in the various conditions of life, I have never known an instance of a woman going to a public bar for drink, or sitting down in a public bar-room with men, or alone, to regale herself. The ale-houses and gin-shops in England are as much accustomed by women as by men, and the results of such practices are exactly what might be expected -an extreme vulgarity of manners, and a large amount of drunkenness among the lower class of women. What, as a matter of course, comes with it need not be told; but the records of the police courts ieave no one at a loss.

My observations in this case must be understood as applying solely to the lowest class : these constitute a very numerous portion. They apply likewise mainly to cities and large towns. In respect to the deportment of the middle and the highest classes - with whom my intercourse, through their kindness, has been familiar and extensive - nothing in manners or conversation can be farther removed from that which is vulgar or offensive; and for propriety and the highest degree of refinement, nothing can be more exemplary and delightful.

In districts strictly agricultural, the low rate of wages does not admit of much expenditure in this way; and, if there are indulgences, they must be at home in the village ale-houses, and only occasional. For a considerable portion of the year, the farm laborers are not allowed any beer; in the haying and harvesting, their allowance seldom exceeds one pint and a half, which, as it is small beer, cannot be considered excessive. I could not learn that any allowance of whisky or spirit is ever given them by their employers, or that it is ever carried by them 
into the fields. The drinking, in this country, with the lower and laboring classes of people, seems, in a great degree, confined to the licensed houses, of which, certainly, there is nowhere any want. In passing through the village of Glossop, in Derbyshire, a modern and an exceedingly well-built village, in a distance, I should judge, of less than three fourths of a mile, I counted, as I passed along on the box of the coach, thirty-five licensed retail shops, most of which were probably for the sale, among other things, of intoxicating liquors. Indeed, the number of licensed retailers in every village in England is quite remarkable, and would seem, in many cases, to include almost every fourth house.

I am not disposed to object to the employment of women in some kinds of agricultural labor. The employment of them in indiscriminate labor is liable to the most serious objections. Nothing can be more animating, and, in its way, more beautiful, than, on a fine, clear day, when the golden and waving harvest is ready for the sickle, to see, as I have several times seen, a party of more than a hundred women and girls entering the field, cutting the grain, or binding it up after the reapers. In cultivating the turnips, they are likewise extremely expert. In tending and making hay, and in varions other agricultural labors, they carry their end of the yoke even; but in loading and leading out dung, and especially, as I have seen them, in carrying broken limestone in baskets on their heads, to be put into the kilns, and in bearing heavy loads of coal from the pits, I have felt that their strength was unnaturally taxed, and that, at least in these cases, they were quite out of "woman's sphere." I confess, likewise, that my gallantry has often been severely tried, when I have seen them at the inns acting as ostlers, bringing out the horses and assisting in changing the coach team, while the coachman went into the inn to try the strength of the ale.

As far as health is concerned, the out-door employment of women is altogether favorable. As far as virtue or moral purity is concerned, out-door employment in itself is not more objectionable than employment within doors. Indeed, from the inquiries which have been made into this matter, and the elaborate reports that have been given to the government, it does not appear that the agricultural districts, where the custom of outdoor employment for women prevails, are more immoral than the 
manufacturing àistricts. But the natural effect of such employment upon women is to render them negligent of their persons, and squalid and dirty in their appearance; and with this neglect of person, they cease to be treated with and deference by the other sex, and lose all respect for themselves. Personal neglect and uncleanliness are followed by their almost invariable concomitants, mental and moral impurity and degradation. The working likewise promiscuously with men, which is done contimnally, must cxpose them to rude jests, and to language and manners which, among the lower class of men, are too often grossly indecent and immoral. In all other respects, many kinds of ont-door agricultural employment must be, and is, as it is admitted, favorable to health and vigor. The general health and vigor of such women, so many hours engaged in reasonable exercise in the open air, contrast most favorably with the effeminacy, debility, and early decay of those who are confined in heated and close manufactories, or in sedentary employments within doors. Nor, in point of moral conduct, as far as mere occupation is concerned, is there any reason to suppose that the agricultural classes would suffer in comparison with the manufacturing classes, or with the host of young women in cities, employed in varions trades and in-door occupations. We have few instances, in the free states, of women being employed in field labor. The women in Wethersfield, Connecticut, have for years been accustomed to the cultivation of onions, doing every thing for the crop, excepting ploughing and manuring the land; even to preparing it for the market. They certainly have suffered no evil, but, on the contrary, have derived much benefit, from the occupation. Nowhere, it is believed, can men, dependent upon their own exertions for support, find wives better able to manage their household affairs, more frugal, more industrious, or more tidy, than among the industrious young women of Wethersfield. It must seem strange to many persons if I also add, as I know I may with truth, that many of these young women are persons of good education, and to a degree, allowing for the retired condition of society in which they have been brought up, even of refined manners: so totally different, indeed, are the conditions of the laboring classes in England and the United States. In truth, no comparison can properly be instituted between them. In general, among the laboring classes in England, their low condition, their ignorance, and want of education, and 
the almost absolute impossibility of rising above the estate in which they are born, render them, to a great degree, reckless and improvident. Character becomes consequently of far less importance than it would otherwise be. There are wanting, consequently, the motives to that self-respect, which constitutes the highest security of virtue; and under such a condition of things, it is not surprising to find a laxity of morals, which produces swarms of illegitimate children. This is attended by the usual consequence - an absence, on the part of the pirents, of that sense of obligation to support and provide for their ofispring, which is to be found in its purity and strength only in legal wedlock.

There are two practices tin regard to agricultural labor, not universal, by any means, but prevailing in some parts of Englaud and Scotland, which I may notice. 'The first is called the "gang system." In some places, owing to the size of farms being greatly extended, cottages being stiffered to fall into decay and ruin, laborers have héen congregated in villages, where have prevailed all the evils, physical and moral, which are naturally to be expected from a crowded population, shoved into small and inconvenient habitations, and subjected to innumerable privations. In this case. the farmer keeps in permanent and steady employment no more laborers than are absolutely required for the constant and uninterrupted operations of the farm; and relies upon the obtaining of a large number of hands, or a gang, as it is termed, whenever any great job is to be accomplished, that he may be enabled to effect it at once and at the smallest expense. Under these circumstances, he applies to a gang-master, as he is termed, who contracts for its execution, and through whom the poor laborers must find employment, if they find it at all; and upon whose terms they must work, or get no work. The gang-master has them then completely in his power, taking care to provide well for himself in his own commissions, which must, of course, be deducted from the wages of the laborers, and subjecting them, at pleasure; to the most despotic and severe conditions. It is not optional with these poor creatures to say whether they will work or not, but whether they will work or die - they have no other resource - change their condition they cannot - contract separately for their labor they cannot, because the farmer confines his contracts to the gang-master; and we may infer from the Reports of the 
Commissioners, laid before the government, that the system is one of oppression, cruelty, and plunder, and in every respect leading to gross immoralities. The distance to which these laborers go is often as much as five or six miles, and this usually on foot, and to return at night. Children and girls are compelled to go these distances, and consequently must rise very early in the morning and reach home at a very late hour at night. Girls and boys and young men and women work indiscriminately together. When the distance to which they go for work is ten miles, they are sent in carts. When the distances are great, they occasionally pass the night at the place of work, and then lodge in barns, or any where else, indiscriminately together. (To talk of morals in such a case is idle.) One of the gang-masters, who has been an overseer seventeen years, gives it as his testimony, under oath, "that seventy out of a hundred of the girls become prostitutes," and the general account given of the operations of the system shows an utter profligacy of mind in their general conversation and manners, when morals must follow of course. If they go in the morning and stay only a little while, on account of rain, or other good cause, they are paid nothing. The day is divided into quarters, but no smaller fractions of time are in any case allowed to them. Then the persons employed are required, in many cases, to deal with the gang-master for the supplies they receive, in payment for their labor. The results of such a system are obvious. The work being taken by the piece, the gang-master presses them to their utmost strength. The fragments of days, in which work is done and not paid for to the laborers, are all to the benefit of the gang-master, who, in such case, gets a large amount of work done at no cost. These poor wretches, being unable to contract for themselves, or to get any work but through him, he of course determines the price of the labor, and, one may be sure, puts it down to the lowest point. But his advantages do not end here, for there is no doubt that he gets a high advance upon the goods which he requires them to purchase of him, and thus their wages are reduced still lower. No just or benevolent mind, it would seem, can look upon any such system in all its details, as given in the Commissioners' Report, but with a profound sense of its injustice, oppression, and immorality.

One of the gang-masters says, "If they go to work two hours 
and a half, it is a quarter of a day. If they go a long walk, seven miles or so, and it comes on a wet day, there is the walk all for nothing. Children of the ages of four, five, and six, work in the gangs. They earn $9 \mathrm{~d}$. a day, the big ones; the small, $4 \mathrm{~d}$. ; children of seven years old, $3 \mathrm{~d}$. a day." "It is the ruin of a girl," says a parent, one of the laborers, "to be in such a place as that." "My children's hands are so blistered," says another of the parents, "pulling turnips, that I have been obliged to tie them up every night this winter. Pulling turnips blisters the hands very much - they are obliged to pull them up - they must not take turnip crones (a sort of fork) for fear of damaging the turnips."

"The gangsman, or leader," says another witness, "pays the wages of all employed in the gang, and, of course, makes his profit entirely from their labor, as the farmer takes care that the gang system shall not cost him more than the common system of individual laborers. The leader's profit, as I have heard, is sometimes $15 \mathrm{~s}$. per day. The assembling of twenty-five and thirty women and children and lads, of all ages and conditions and characters, together, has a most fatal effect upon their morals and conduct." Another respectable and reverend witness says, "The gang is superintended by a lazy, idle fellow, of profligate manners and a dishonest character — such, at all events, are the characters of two in my own neighborhood."

I will not dwell upon the evils of a management of this kind. It is obvious what a power such a man, the employer of these people, has over them; and it is as easy to infer what is likely to be the character of young persons, more especially, placed under his control. When are men to be just? and when are men, who live upon the hard labor of others, and who hold not merely their physical but their moral destiny in their hands, to feel their responsibleness as Christians and as men?

The most melancholy circumstance in the case is given in the testimony of one witness, a clergyman, who says, "that he fears the gang system will and must increase, especially upon large farms." It would not be unreasonable to fear that God would send blight and mildew upon fields where human life and virtue are thus sacrificed, and decency and morals thrown to the winds; and where the crops are watered with the tears of these wretched victims of injustice and oppression. 
There is another system of employment, which prevails in Northumberland and in some parts of Scotland, to which I have already alluded: this is called the bondage system; but it does not appear to me liable to the strong objections which the name would seem to imply. In this case, the laborer, when he contracts for his services, makes a condition that he will, as may be required, furnish a woman as an additional laborer; and he receives so much per day for her labor, according to the number of days she may be employed. In such case, if he has not a wife or daughter to supply the place, he engages some young woman who lives in his family, and to whom he pays such a sum by the year as may be agreed upon, in money, clothing, or otherwise, and she lives in his family as one of the family for the whole year. There are few forms of servitude which are not liable to abuses, and the greater the state of dependence and weakness, so much increased is the liability to abuse; but where the employer is a conscientious and just man, such a contract may be mutually advantageous.

In parts of Scotland, what is called the Bothie system prevails, and the support of the laborers is a very summary process. The wages are paid in money or kind, as may be agreed upon; and the laborers, if single men, are furnished with a room, fuel, and bedding; with two peeks of oatmeal on Monday morning, and with a daily allowance of new or of sour milk - occasionally they may have beer and bread for dinner instead of the porridge. Nothing more, however, is done for them. They prepare their porridge for themselves in such way as they choose; but this comprehends the whole of their living. It would not be true to say that this diet is insuficient for the support of a laboring man, as it must be admitted that few laborers exhibit firmer health, or more muscular vigor, or really perform more work, than many of these men. This mode of living would, however, I think, be a little too primitive for the New England taste, though on matters of taste we are told there is to be no dispute. Having myself visited a Scotch Bothie, I cannot, how much soever the economy of the arrangements may be praised, much commend the style of the housekeeping. Indeed, it is not difficult to infer that where young men at service are turned into a hovel together, and without any one to look after their lodging or prepare their meals, the style of living camnot have the advantages even of the 
wigwam of a North American savage; for there, at least, there is a squaw to provide the food and look after the premises.* The wages of a Scotch laborer are about $£ 12$ sterling per year, and living as above; and for a woman, as a field laborer, four shillings sterling per week, or about eighty-eight cents, out of which she provides for herself.

The condition of labor forms, as is obvious, a most important element in the agriculture of a country. Human labor, indeed, seems far more essentially concened in agriculture than in either commerce or manufactures. A few hands may manage a large ship, freighted with immense wealth, and performing voyages which equal the circuit of the globe. A child may superintend a large number of spindles; and a single power wheel sets in motion a vast and complicated machinery. Agriculture has already derived vast benefits from mechanical ingennity, and may confidently anticipate from this source an immense extension of her power; but there can be no question that she must, at least for a long time to come, continue mainly dependent upon human labor. The cost of labor, therefore, and the general support and condition of this labor, are alike interesting to the agriculturist and the philanthropist.

In an old country like England, where labor is so abundant, it is to be expected that the rules of labor should be exact and stringent ; indeed, without this the management of a large farm would be impracticable. 'The women usually begin work at eight o'clock, and, resting an hour for dinner, they work until five, or, in a pressure of work, until six. The ploughman must feed and clean his horses at four o'clock in the morning, and at six o'clock the plough must be under way. At two o'clock, his horses are put up for the day, and he devotes himself until six o'clock to their cleansing and feeding, and to the care of his plough and harness; eight hours in the field, and the plonghing an acre of

* Of the Bothie system, as it is called, or employment of unmarried men, living together in a bothie or hovel attached to the steading, it is hardly necessary to say, that a more effective means of demoralizing and brutalizing a peasantry could not be devised than that of crawding together a parcel of young men, half of them perhaps strangers, Irish, or bad characters, in a hovel by themselves, without even an attempt at moral superintendence. This is one of the worst evils that has attended the introduction of the large furm system.-Caing's Prize Essay. 
ground, being considered a full day's work. The other laborers begin labor at six o'clock in the morning, and work until six in the afternoon, with the intermission of half an hour for breakfast and an hour for dinner. No laborer leaving his employment before the termination of his engagement, without good and sufficient reason, can recover any portion of his wages; and no employer, without equal reason, can dismiss a laborer before the end of the term for which he is engaged. In general, however, laborers continue for years in the same employment, especially married men; and it is extremely interesting, speaking well both for master and servant, to see men and women who have remained in the same service twenty, thirty, forty, and even fifty years, and their children coming forward to take their places. In such cases, they become, as it were, an integral part of the establishment, and both parties are equally benefited.

In some parts of the country, as in Lincolnshire for example, twice a year, in the spring and autumn, are held, in some principal market towns, statute fairs, vulgarly called "Statties," where young men and women wanting service assemble, and persons wanting laborers or servants go there to supply their wants. Such arrangements have certainly many advantages; but they have also their evils, and the assembling of large numbers of men and women, in such cases, with, not unfrequently, the usual accompaniments of a Fair, are said to lead to much dissoluteness and dissipation. This is to be expected. This arrangement serves to average the rate of wages, and must be to all parties a great saving of time. In the present condition of female labor in the United States, there could be none but the worthless to offer themselves in this way; but with respect to young men seeking employment, there would be great advantages in having a day and place fixed in some principal town, when and where persons wishing for employment might be found by persons wishing to employ them; and such an "Exchange" might be annually held to advantage. An arrangement of this kind has often recommended itself to my mind for its convenience, and I have, before this, urged its adoption.

I have endeavored, with strict regard to truth, to state what I understand to be the condition of the agricultural population in this country. Further inquiries may serve to correct or modify my views on this subject. I am perfectly aware how difficult it 
is for a foreigner to obtain a correct knowledge or to form a fair judgment of the customs and manners of any country which he visits; and especially where his residence is limited, and his observations necessarily partial. Feeling no prejudices, anc? having no private interests or partialities in the case, other than those which are inseparable from an education in another condition in society, and under political institutions differing entirely from those which prevail here, I am desirous, above all things, to hold my mind open to the light of further and more exact inquiry.

It does not need any long experience to learn that first impressions are not always the most correct; and every intelligent and candid mind must allow that most men have some reasons which, to their minds, appear sufficient for what they do; that many customs which have prevailed for ages, however objectionable at first sight they may appear to us, have grown out of peculiar circumstances of time and place, which sanction their expediency at the time of their origin, if not the propriety of their continuance; and that, in respect to many acknowledged evils, it is far more easy to deplore the existence than to point out the remedy. While circumstances of this nature prompt to caution and forbearance in our judgments, they do not require us, at the expense of our moral sense, to regard these evils in any other than their true character, to palliate either their nature or extent, or to look upon them, under any circumstances, in utter despair of their removal or alleviation. Nor will they excuse any neglect of all proper and possible exertion to remedy an acknowledged evil.

The condition of the laboring agricultural class is certainly, in many parts of England, exceedingly depressed; and though in frequent instances it may be called comfortable, in few that I have seen can it be considered prosperous. Their labor is not extraordinarily severe; they are by no means treated with unkindness, or, excepting through the misfortune of the ill temper of their employer, with severity; they are decently clad, and there is a great amount of active benevolence every where at work to assist them, and to alleviate their distress in sickness and misfortune. But they are very poorly fed; with many exceptions, they are wretchedly lodged; their wages are inadecunate to their comfortable support; and their situation affords little or 110 
hope of improvement, - at least the power of making it better does not rest, where it should, with themselves.

It is a painful, though not an unheard-of anomaly, that, in the midst of the greatest abundance of human food, immense numbers of those by whose labor this food is produced are actually suffering and perishing from hunger; that where ten millions of acres of improvable lands, capable of being made productive lands, lie uncultivated,* millions of hands, which might subdue, enrich, and beautify this waste, from necessity remain unemployed; and that, in a country where the accumulations of wealth surpass the visions of Oriental splendor and magnificence, there exist, on the other hand, such contrasts of want, destitution, privation, and misery, as would surpass belief and defy the power of the imagination, but for the support of incontrovertible and overwhelming evidence. Under the present institutions of the country, a perfect remedy is hopeless, and an alleviation of these evils is all which can be looked for. An entire revolution in the institutions of the country, in the forms of society, and in the condition of property, could only be effected by violence; and the consequences of such a revolution it would be frightful to contemplate. But should a revolution occur, and the framework of society be broken up, and its elements be thrown into a state of chaotic confusion, what sagacity could predict the results, and what security is there that in any re-arrangement these evils would be rectified and the rights of labor any better protected? I say the rights of labor; for who, under any circumstances, will presume to deny that they, by whose labor the earth is made to yield her fruits, and all accumulations of wealth are obtained, have not, indeed, in common justice, a perfect claim to a full share of the products of their own toil? I care not what claims arbitrary and despotic power may set up; nor by what laws and rules she may seek to appropriate to her own use or luxury much the largest portion of these products; but I claim for the laborer an ample share of the fruits of his industry on the obvious grounds of natural right and justice, and the plainest principles of Christianity.

I am not at all disposed to quarrel with any of the institutions of this great and enlightened country - great and enlightened,

* Journal of Royal Agricultural Society, vol. iv. pt. ii. p. 308. 
as a whole, beyond almost any precedent. I am not disposed, in any offensive form, to profess my own preferences for institutions to which birth and education may have strongly attached me, founded as they are on the great principles of universal liberty as the birthright of every man, and of social equality as conformable to nature, and the only relation in which men can stand to their Creator, or under which they would dare to approach him. But, to my mind, it is obvious that no great improvement can take place in the character and condition of the lahoring population while they remain a distinct and servile class, without any power of rising above their condition. At present, the most imaginative and sanguine see no probability of their rising above their condition, of being any thing but laborers, or of belonging to any other than a servile and dependent class. The low state of their wages absolutely forbids the accumulation of any property. They cannot own any of the soil which they cultivate. The houses which they occupy belong not to themselves, and they may at any time be turned out of them. They must ask leave to live, or they must take it by violence or plunder when they will not be suffered to live. Their only home is the grave.

In a country where labor is superabundant, and the price of land places it utterly beyond the reach of those who have no means to purchase but from the scanty products of their own manual labor, the condition of the laborer is that of absolute dependence. In a condition of society where artificial ranks and classes exist, and where all the wealth and all the power are in the possession of the upper, or, as they are sometimes denominated, the favored classes, the barriers which hem in the lowest class - without property, without power, without education, without even a home which they can call their own - are, of course, impassable. In a country where labor is scarce, where land is cheap and free, and where the advantages of a good education are offered gratuitously to all, where no arbitrary distinctions of rank exist, and every man, by the force of his own talents and character, may occupy that condition in society to which he chooses to aspire, it is obvious how different is the situation of the laboring portion.

I believe it is impossible for a man who lives in a state of entire dependence upon others to have the spirit of a man; and 
who, in looking out upon the beautiful and productive earth, where God has placed him, is compelled to feel that there is not a foot of soil which, under any circumstances, he can claim for himself; that there is not a tree nor a shelving rock by the road side, where he can shelter himself and gather under his wing the little ones whom God may have cast upon his care, but he is liable to be driven away at the will of another - at the caprice of avarice, selfishness, pride, or unbridled power; that the use of his own hands and limbs is not his own; that he cannot, but at the will of another, find a spot of ground where he can apply them; and that even the gushings from the rock in the wilderness and the manna which descends from heaven are intercepted in their progress to him, and doled out too often in reluctant and scanty measure.

This will not be pronounced an exaggerated or colored portrait of the condition of the agricultural laboring pofulation of England. I suppose that, with the exception of some few rights of common, where some miserable mud-hut has been erected, and the possessor has a kind of allowed claim during his life, few instances can be found of a laborer's owning, in fee simple, a cottage, or so much as a rood of land. I recollect, in passing through a part of Derbyshire, in a region which forms the contiguity of several large estates, the coachman, by whose side I was seated, said to me, that this was the Duke of Devonshire's village, and this the Duke of Rutland's, and this the Duke of Norfolk's, and so on: and I could not help asking myself, with some sinking of heart, Where is the people's own village?

In a part of Lincolnshire, an excellent landlord and friend, distinguished for his integrity and philanthropy, was kind enough to take me to visit several of his cottages, that I might see, as he said, some of the best examples of this kind of life. It was on a Sunday evening. The houses were humble, but they were neat and comfortable. The inhabitants of one house which we entered were advanced in life, and alone; for, although they had children, their children had been under the necessity, as soon as capable of service, of leaving home in search of a livelihood. The appearance of these people was altogether respectable, but there were two incidents, which, though very small in themselves, at least furnished matter for grave reflection. The landlord had given notice, a few days previously, to some of his cottagers to 
quit, because, with a view to the small profit to be derived from their board, they had taken lodgers into their families, who were not agreeable to him. The old people whom I was visiting, though they had occupied the same place for perhaps more than thirty years, and felt themselves quite too far advanced to seek a new home, were suffering under the apprehension that they too might, in some way, have involuntarily incurred the landlord's displeasure, and might be turned out of their homes likewise; and the woman said that her husband, through fear of such an event, "had had no sleep for several nights." In another house, which we visited, we found the woman of the house had just returned from attending the accouchement of a neighbor, the wife of a laboring man; and she told us that when she announced to the father the birth of twins, he received the intelligence with saduess, and replied, that "it would have been a kinder act if Heaven had been pleased to have taken them both away." Where honest and laborious people, in advanced age; feel constantly that they may be turned adrift, at the caprice of their landlord, from the home of their youth, and where a father regards the birth of a child as a curse, the benevolent mind sees evils in the condition, which it must lament if it cannot remedy, and which it must lament the more, in proportion, as all remedy seems hopeless. The landlord in this case, as I am persuaded, was incapable of committing, knowingly, any act of injustice or unkindness; but it is obvious to what abuses such a power is liable, and to what evils a relation of such servile and abject dependence may subject one.

In the present condition of society in England, no material alteration, however, is to be looked for in the position of the laboring classes. Their lot seems to be sealed, and they must remain in this condition of servility and dependence. They cannot rise above it. They are not slaves; but they are not free. Liberty and independence, to them, are words without meaning. They have no chains upon their hands, but the iron enters into their souls. Their limbs may be unshackled, but their spirits are bound.

At the anniversary meeting of the Northamptonshire $\Lambda$ griculsural Society, several aged and respectable laborers were ealled in and advanced to the upper table to receive the premiums for grood conduct, "which they had merited," in the terms of the 
report, "by many years of faithful servitude." I confess, as I said on the occasion to the noble president, this term sounded harshly to my ear, and the more, if it expressed their true condition. Go where they will, the same barriers impede their advance; and if the ambition of wealth, or rank, or influence, of which they see such glittering examples continnally passing before them, should ever dawn in their minds, it would kindle only to be extinguished under inexorable circumstances.

There are persons who see in this condition no evil nor hardship. I am not about to expatiate upon its evils or hardships, if evils or hardships there be in it. If, in the present condition of society, pecuniary gain is to be the only worthy object of pursuit, and a pecuniary standard the only rule by which the goods of life are to be measured, and the human frame is to be regarded as only so much organized flesh and bone to be worked up at our pleasure into the means of wealth and luxury, then the improvement of the character and condition of the laboring classes is not a subject to attract the attention of the political economist, excepting so far as the perfection of the machine may conduce to the increased amount of the work to be accomplished by it. But, if a better rule is to prevail, and men are to feel their moral responsibility to each other, and the physical comfort of those by whose toil we live, and the moral improvement of those upon whom, as well as upon their more favored brethren, God has equally impressed his own moral image, are to be cared for, the condition of the laboring classes deserves the most serious attention and the most cordial interest of every man who has a spark of patriotism, public spirit, or philanthropy in his bosom.

This attention is now given, in various parts of the country, by many persons of distinguished benevolence and active usefulness, who know no higher pursuit, and find no richer pleasure, than in doing good. They are not willing, while they enjoy the loaf, to put their laborers off with merely the under crust, and not always enough of that.

The census of Great Britain reports the number of laborers employed in agriculture at 887,167 , and these, with their families, compose a population of not less than $3,500,000$, or one fifth of the whole population of the kingdom. 'The wages of labor, according to the reports of the committees of Parliament, vary, in different counties, from $7 \mathrm{~s}$. sterling to $12 \mathrm{~s}$. per week; and the 
rent of their cottages may be said to average about $1 \mathrm{~s} .6 \mathrm{~d}$. sterling per week, or $£ 318 \mathrm{~s}$. per year.* It may interest some of my American readers to learn the expense of some of the families of the cottagers, as they are given from authentic sources, as below:-

"H. Sopp, laborer, has a wife and four children; earns 9 s. $6 \mathrm{~d}$. a week; spends $7 \mathrm{~s} .2 \mathrm{~d}$. in flour and yeast; has been without tea, cheese, butter, soap, firing and candles, clothes and beer, for three months."

"- Slements, laborer, has a wife and four children; earns $11 \mathrm{~s} .6 \mathrm{~d}$. per week; spends $7 \mathrm{~s} .3 \mathrm{~d}$. in flour and yeast."

"- Pullen, laborer, has a wife and six children; wages $11 \mathrm{~s}$. $6 \mathrm{~d}$. ; flour and yeast, 9 s. 7 d."

I shall quote, further, the actual expenses of a laboring man with a wife and six children, in March, 1841; and "this will afford an average view of the manner of living of the agricultural population of the southern and midland comnties of England."

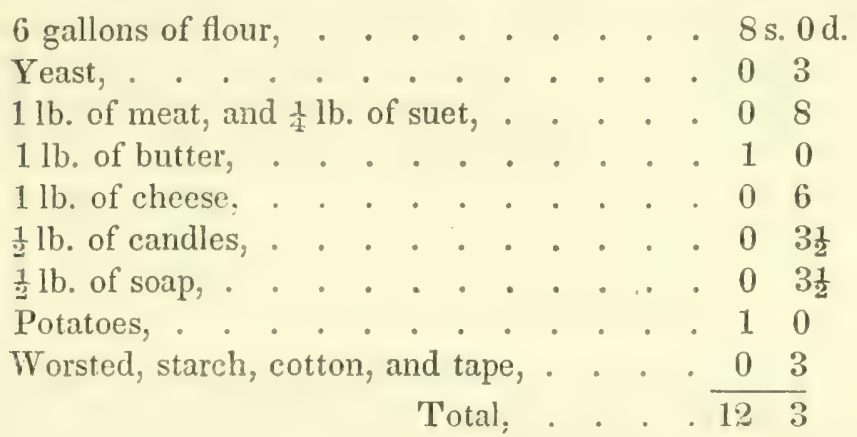

"This leaves nothing for rent, clothing, education, or any uther expenses, the only fund for defraying which consists of the extra earnings during harvest-time, a resource which, in many parts of England, is greatly limited by the periodical influx of Irish laborers. It is obvious, from a glance at this statement, that the bulk of agricultural laborers in the country are, at the best, just able to struggle on from hand to mouth, and that any suspension of employment, rise in the price of provisions, or

* One shilling sterling may be reckoned at 24 cents 4 mills; when a sover eign, as now, is estimated at $\$ 4.88$. 
unforeseen casualty, must, of necessity, compel them to resort to charity, or to descend to a coarser diet, and exchange the liabits of an English for those of an Irish peasant." *

* The condition of living among the poor agricultural laborers may, perhaps, find some strong illustrations in the subjoined note, which is for those only to read who take an interest in so humble a subject:-

"A poor man can seldom afford to purchase even the coarsest joint of mutton; but if he lives near a town, he can often get the sheap's head and pluck for less than 1 s. $6 \mathrm{~d}$., indeed very frequently for a shilling; and with these his wife can make up four liot meals. 'These substantial and truly savory meals may be eaten with potatoes only, as bread is not necessary.

"No instruction is necessary for the making of pies and puddings," (that is, because the laborer is never expected to have them, "whether of fruit or meat; but we may just remark that a meat-pudding (when a laborer can afford it) is one of the most substantial and savory dishes that can be brought to a hungry man's table; and if, instead of putting pie-crust over the meat, you cover it with mashed potatoes, and put it either into the oven or bake it by the side of the fire, it will answer quite as well as paste. In Cornwall, there is a common practice, among those cottagers who bake at home, of making little pasties for the dinners of those who may be working at a distance in the fields. They will last the whole week, and are made of any kind of meat or fruit, rolled up in a paste made of flour and suct or lard. A couple of ounces of bacon, and ta lb. of raw potatoes, both thinly sliced and slightly seasoned, will be found sufficient for the meal; the pasty can be carried in the man's pocket, but it costs $4 \mathrm{~d}$., as thus:-

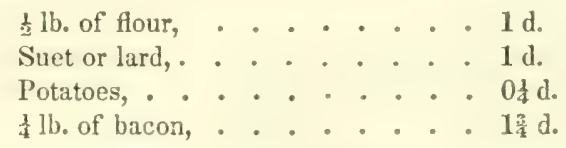

"Oatmeal is a frequent diet of the Scotch and Irish peasantry. The preparation is simply to put a liandful at a time gradually into a pot of warm water, and a little salt, simmering it over the fire and keeping it stirred with the other hand, until it becomes as thick as a pudding; or in about ten minutes time. It may then be eaten with a little treacle, or with a piece of butter put into the centre; but the better way is to cat it with cold milk, taking a spoonful of the stirabout with a mouthful of the milk; for if boiled in milk, it is not near so good. Fine meal does not answer the purpose, and the coarse ground 'Scotch oatmeal' is the best. Now, about half a pound of this, along with three pints of milk, will make a substantial and a very wholesome breakfast or supper for the family. It is indeed a hearty food; and the cottager, who seeks to support his wife and children both frugally and healthfully, should never be without it. The price in London is $4 \mathrm{~d}$. per quart, and the quart weighs nearly $13 \mathrm{lb}$.; so, supposing the milk to be bought at $1 \mathrm{~d}$. the quart, three good meals can thus be got for $8 \frac{1}{2} \mathrm{~d}$.

"Potatoes will ever be the peasant's standard vegetable; for, if of good mealy quality, they contain more nutriment than any other root; and three or four 
The following was given me as the wages paid on a farm in Lincolnshire, where the wages are more liberal than in

pounds are equal in point of nourishment to a pound of the best wheaten bread, besides having the great advantage of better filling the stomach.

"The liquor in which any meat is boiled should always be saved for the making of soup, and the bones even of fish should also be preserved ; for althoush quite bare of meat, yet if stewed down for severul hours, they will yield a species of broth, which, along with peas or oatmeal, will make good soup. A lot of bones may always be got from the butchers' for twopence, and they are never scraped so clean as not to have some scraps of meat adhering to them.

"This done, the bones are to be again boiled in the same manner, but for a longer time, and the broth may be made the next day into a stew with rice.

"Nor is this all; for the bones, if again boiled for a still longer time, will once more yield a nourishing broth, which may be made into pea-soup; and when thus done with (!)" (for, alas! every thing mortal has an end) "may either be sold to the crusher, or pounded by yourself, and used as manure for your garden."

These directions are extracted from a Treatise, of which I do not question the utility, on Cottage Economy, published in the Journal of the Royal Agricultural Society, and which certainly contains many valuable suggestions for the poor cottager. The perfect coolness and calm philosophy, however, with which the writer descants upon a single sheep's head and pluck making four savory dinners for a family; and a pasty made of any kind of meat or fruit rolled up in flour and lard, with a couple of ounces of bacon, and half a pound of raw potatoes thinly sliced, and slightly seasoned, carricd in a man's pocket when he goes to work a good distance from home, being ample for his dinner; and upon potatoes having the great advantage over bread of better filling the stomach; and the advice respecting the cooking of the same bones again and again, three successive days, make one think, to use Burke's expression, "that the Norfolk Squares must have dined" before they could have attained this high degree of philosophy.

The directions for eating the stirabout or oatmeal porridge seem likewise very kindly given to those who appear to have so little use for their mouths as hardly to know the way to them. "The better way is to eat it with cold mill, taking a spoonful of the stirabout with a mouthful of the milk."

The contrasts constantly presenting themselves in human life are often striking and instructive; and it may not be without its moral use if, with the laborer's "savory" viands, his sheep's head and pluck, his cold pasty, and his bones boiled three times over, together with the wholesome advice, given in the same treatise, "to pinch and screw the family even in the commonest necessaries," until he get a week's wages beforehand, that he may not run in debt, (query, what in the name of humanity does "pinching and scrcwing" mean in this case, unless it be to boil the bones again after they are pounded?) we compare the bill of fare at the dinner given to the council of the Royal Agricultural Society, by the mayor in behalf of the city of Derby, at the late agricultural show, holden in July, 1843, in that hospitable town. This bill, as well it may be, is printed on blue satin paper, in letters of gold, in keeping with the banquet. 
many places, and the farming of the highest order of excellence :-

\section{ROYAL HOTEL - DERBY}

The Mayor's Banquet to the Royal Agricultural Council, July 11, 1843.

\section{Bill of Fare.}

FIRST COURSE.

Three turbots and lobster sauce.

Three salmon and shrimp do.

Five dishes of filletted soles.

Five dishes of trout.

Ten tureens of turtle soup.

Eight do. of green pea do.

Eight do. of soup Julian.

SECOND COUNSE.

Four haunches of venison.

Four necks of do.

Five couples of boiled chickens.

Four hams.

Three calves' heads, stewed.

Four quarters of lamb.

Four geese.

Four veal fricandeau and ragout.

Four pigeon pies.

Two rumps of beef, stewed.

Four savory pies.

Five turkey poults.

Five tongues.

Three surloins of beef.

Three legs of lamb, and gooseberry sauce.

\section{ENTREFS.}

Lobster patties.

Stewed kidneys.

Sweetbreads.

\section{ENTREES.}

Mutton cutlets with tomatís.

Veal tendons.

Curried lobsters.

Veal cutlets and mushrooms.

Curried rabbits.

Lamb cutlets and cucumber sauce.

Eight leverets.

Eight couples of ducks.

Eight couples of roast chickens.

Eight plumb puddings.

Eighty dishes of Bakewell do.

Eight do. of apricot do.

Twenty do. of cheese cakes.

Thirty do. of maids of honor.

Cherry tarts, and currant do.

Jellies, blanc manger.

Rhenish cream, \&c., \&c.

\section{DESSERT.}

Ices, grapes, peaches, cherries.

Nectarines, strawberries, raspberries, pines.

Almonds and raisins.

Candied fruits.

Damson cheese, Tartarian cheese.

Orange marmalade.

Preserved ginger.

Sponge cakes, pound cakes.

Fruit, brandy, wine, biscuits, ginger cakes, \&c., \&c., \&c.

Wines at pleasure.

In these comparisons most certainly I mean no disrespect to any luman being. I myself, with a large party, had the honor to sit down at the hospitable and elegant table of the Mayor of Derby, who, in company with many of the citizens of that ancient town, spared no effort to make the visits of their friends as agree- 


\section{The Foreman -}

Has a house and garden (about 3 roods) rent free;

He keeps three young men, for which he has $£ 15$ a

$$
\text { year each, } £ 45 \text {; }
$$

He has 6 bushels of malt for each man,

- 1 quarter do. for himself,

- the best wheat at $48 \mathrm{~s}$. per quarter,

- seconds do. at $32 \mathrm{~s}$.

- four pigs kept in the yard with his master's.

He feeds and kills his own bacon, and has $\mathbb{E}_{24}$ in cash, and two cows kept.

\section{The Shepherd-}

Has a house and garden (about 2 roods) rent free,

- 2 quarters of wheat at $48 \mathrm{~s}$. per quarter,

-2 bushels of malt,

- a cow kept, and

- $£ 22$ a year in money.

Four laborers have the following yearly wages, from May-day to May-day : -

2 s. 3 d. per day, from May-day to Michaelmas,

$1 \mathrm{~s} .9 \mathrm{~d}$. " from Michaelmas to May-day,

2 s. $3 \mathrm{~d}$. per acre for grass and clover mowing,

$7 \mathrm{~s}$. " $\quad$ for corn cutting,

16 bushels of wheat, at $6 \mathrm{~s}$. per bushel,

1 bushel of malt, without charge,

1 cow kept, do.

able and comfortable as possible ; and certainly in this respect no persons could have succeeded better. Nor am I disposed to find fault with the luxuries with which any gentleman or company are disposed to entertain their guests. But the contrast here presented between the condition of the producer and the consumer - between him whose toil creates the food and him who eats it - cannot fail to read a most important and instructive lesson. What its moral uses are, I think, no fair and reflecting mind will be at a loss to perceive. I shall not, therefore, as in Nsop's fables, write the moral at the bottom, but I shall leave the whole to my reader, without note or comment; feeling sure that if it leads to no serious reflections, there must be a melancholy obtuseness of intellect; and if it stirs no pity and no humanity within him, there is reason to fear that all the springs are cut off, and the well is utterly dry. Such, alas! are but too often, though not always, the melancholy effects of luxury and prosperity. 
Each laborer pays $£ 44$ s. for a house, and has about 3 roods of garden.

\section{Calculation of what each man receives.}

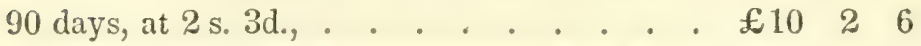

21 acres of grass and clover mowing, at 2 s. $3 \mathrm{~d}$. . 273

18 " of corn cutting, at 7 s., . . . . 660

172 days, at $1 \mathrm{~s} .9 \mathrm{~d}$., . . . . . . . . 1510

Cow keeping, . . . . . . . . . . 880

$\begin{array}{lll}42 & 4 & 9\end{array}$

Deduct house-rent, . . . . 440

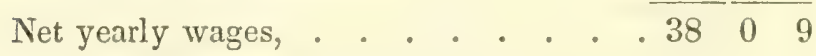

"The English laborer," says an assistant poor-law commissioner, "even if he has transcendent abilities, has scarcely any prospect of rising in the world, and becoming a small farmer. He commences his career as a weekly laborer, and the probability is, that, whatever may be his talents and industry, as a weekly laborer he will end his days." "This is the best side of the picture: what is the reverse? If he has no chance of rising in the world, how many chances has he of falling? If he is thrown out of employment; if he has a large family of girls or young children; if he yiclds to temptation, and becomes irregular in his habits; what is to become of him? The answer is obvious: for a time he will be assisted by casual charity, and struggle on against extreme privations; but if the causes of distress continue, one or other of two things will be his final lot - he will either be enrolled among the 1,072,978 paupers receiving parish relief under the new poor law; or he will be starved out of the country into some large town, and absorbed in the floating population who tenant the cellars and lodging-houses, and live by the worstpaid description of manufacturing industry, or by thieving, prostitution, and casual employment." **

As I have before remarked, it is much more easy to point out and deplore an evil, than it is to suggest a remedy. A republican would say that the evil is fundamental, and grows out of a constitution of society establishing different ranks, the appropriation

Laing's Prize Address. 
of the land in a few hands, the high price of land, the depressing sense of dependence, and the hopelessness of competition and of all attempts to acquire influence, respect, or wealth, incidental to, and inseparable from, such a framework of society. Persons born to affuence and distinction, and persons who have never felt their efforts checked or suppressed by a sense of a dependence which they cannot escape, can very imperfectly estimate the effect of these circumstances upon character. But whether desirable or not - and, in this matter, I would leave every man to the enjoyment of his own honest opinion - as all expectation of a change in the constitution of English society seems as vain as to expect to reduce the inequalities of the surface of the country to a common level - it only remains to consider what alleviations of the evils of the condition of the laboring classes can be successfully attempted. The inquiry is one which most deeply concerns religion and lumanity. It is only just likewise to remark, - and I do it with the highest pleasure, - that the subject is now interesting innumerable benevolent persons in the highest ranks and in the middle conditions of life, to a degree perhaps never before known; and that many of the brightest minds are now concentrating their energies upon its investigation and cure. It is with equal pleasure that I can say, that I have found among many of the landlords the most watchful attention to the welfare of their laborers, and every kind provision for them in sickness, decay, or misfortune. Alas! that there are so many who do not come within the reach of this provision, and so many who refuse or neglect to make it.

\section{XIII. - ALLOTMENT SYSTEM.}

'That which seems to be admitted on almost all hands to have operated to the most advantage, is what is termed the allotment system. In this case, the laborer hires of the landlord: a small piece of land, - and it is generally limited to one quarter of an acre, and seldom exceeds half an acre, - for which he pays such a rent as may be agreed upon; and he and his family cultivate it 
in their spare time, either before going to work or after having returned from their day's work. The manner in which this land shall be appropriated is generally determined or prescribed by the landlord; though, in some cases, it remains optional with the laborer. These small lots of land, though generally leased at a moderate rent, - in some cases, as at the Dule of Devonshire's village of Edensor, at a rent merely nominal, - bring at the rate of from one pound to eight pounds an acre, though, in the latter case, the land generally lies contiguous to some large manufacturing town, where the laborer finds an opportunity of disposing of many small products at a high price. In general, the land so taken, exclusive of some few garden vegetables for daily use, is applied to the growing of potatoes and wheat, and altcrnated with these two crops.

The effect of these allotments upon the character of the occipant is quite remarkable. He becomes himself, for the time. being, an owner of the soil; he has a feeling of independence which nothing else can give, and which at once exalts his character. He is able to avail himself to advantage of the labor of his wife and children, who in some cases perform most of the work on the ground in hours which would otherwise be wasted or misappropriated. His ground yields him a large supply of vegetables for his fumily, and enables him to keep and fatten a pig or two, and likewise some poultry, which very much conduce to his comfort, and that of his family. The cultivation of his ground likewise occupies hours which might otherwise be spent in the drinking-house, where nothing good is to be learned, and where the foundation of the ruin of many a laborer is laid; and the ruin of his family follows generally, as matter of course. Besides these advantages from the allotment system, his youngest children are here early trained to habits of industry and carefulness.

The mere keeping of a pig in such cases is a matter of serious profit, and not of that only, but of pleasure ; and I have been so much struck with the remarks of one of the commissioners on this subject, that I transcribe them for the gratification of $\mathrm{my}$ readers :

"Of such a pig, the first product of allotment, garden or potato headland, it is the fashion among political economists to speak disrespectfully. Now, whatever might be the superior profit, to 
the cottager, of saving the money which he spends on his pigs and buying his bacon in the market, this, as it never has been, and never will be so saved, we may dismiss. In the mean time, his pig, besides its usefulness, is also a real pleasure to him; it is one of his principal interests in life; he makes sacrifices to it; he exercises self-control for its salie; it prevents him living from hand to mouth, stupidly carcless of the future. I an persuaded that a greater act of cruelty could hardly be perpetrated, than the discountenancing this practice, or rather amusement and enjoyment, among the poor." *

So much for the moral effects of this simple matter of the poor man's keeping a pig, in which I perfectly agree with the writer, and honor the benevolence which discerns, even in these humble matters, a moral utility. It is difficult to say, why, when the rich man finds his pleasure in his hunters, his dogs, his game, his menageries, and aviaries, the poor man should not have his pleasure in his pig; an animal, indeed, not always of the most agreeable endowments, nor of very refined manners, but yet in temper and manner susceptible of a considerable improvement by education, and entitled to no small respect for his usefulness, since if his master feeds him when living, he returns the kindness, when dead, by feeding his master; a merit which cannot be ascribed to some other domestic pets far more expensively cherished and caressed.

Too much indeed cannot be said in favor of the allotment system, of its justice, its humanity, and its usefulness. Its influence upon the happiness of the poor, and its moral tendencies its tendency to prevent idleness and dissipation, and to produce sobriety, industry, and frugality, and especially to keep men at home, and attach them to their homes, most strongly recommend it. Many facts prove that the laborers in some instances pay full double the ordinary rent of the land, and find their account in it. In most cases, however, the lease of a farmer forbids his under-letting any portion of his land; and allotments can only be granted under special agreement, or by the particular consent of the landlord. This is not always to be procured; nor is it always without strong opposition from the farmers themselves.

It will perhaps be asked, by some of my readers, why do I

* Sir HI. Doyle's Report on Employment of Women and Children, p. 295. 
enter so fully into the condition of the rural population in England, when we have nothing which bears a resemblance to it in the United States. This latter is one of the very reasons why I do it; but I hope that others will present themselves, upon reflection, which will at least excuse, if not justify me. I may as well give some of those reasons in this place; then, perhaps, I may be heard with more patience.

I have promised my friends here, and in the United States, that they shall have my honest impressions of whatever comes under my observation connected with agricultural and rural affairs, and the condition of the rural population. In the next place, I see in the list of my subscribers the names of many, who will take a much stronger interest in such views, than in details of crops, accounts of live stock, and the practical operations of husbandry, which I shall go into at large in the course of my reports; certainly I am bound to consult, in some measure, their tastes. In the next place, we shall find in the management of small farms and small allotments, examples of successful cultivation, which cannot be without their use and application to farming on a much more extended scale. Lastly, I cannot think it will be without its use to compare the condition of a laborer, where to him land, under the present condition of things, is unattainable, and labor superabundant, with a condition of labor where, as in the free states, every industrious man can have land of the most fertile and productive character almost at his pleasure, and where the price of land places it within reach of his labor; where every man may have his home, and sit down quietly without the apprehension of removal ; where it is not a necessary study with him how often he may have meat, or how many days in the week he may have bread; but where, with industry, sobriety, and frugality, he may always have more meat and more bread than he requires, and something for the poor and the stranger.

I shall take the liberty here of inserting an account, sent me by a kind friend, of the working of the allotment system in a village within his neighborhood - I believe in Lincolnshire. It is an interesting and instructive account. His opinions respecting the size of farms must rest upon his own responsibility. I neither endorse nor deny them. On the subject of the size of farms I shall speak at large when my views have become matured by further observation. 
"Scampton is the property of a gentleman (Sir George Cayley, Bart.) of liberal views and enlarged benevolence. One of his first movements, upon succeeding to the estate some thirty years ago, was to provide for the comfort of those who, under his superior tenants, were to be the immediate laborers upon his land.

"To fourteen cottages allotments of land were made. A field of sixteen acres was set apart as pasturage, that each cottager might keep a cow; and another field of twenty-six acres was appropriated as mowing ground, that all might be provided with fodder for the winter. Each cottage had an acre of tillage land allotted to it in the field, and something like another half acre as garden ground, around its little homestead.

"A cow club, or insurance, was established, to enable those cottagers who lost a cow by casualty, to replace her immediately, and without loss of time.

"In the spring of the year, the cows are valued by a competent and disinterested person. Each cottager pays sixpence in the pound on the value of his cow. Cows above fourteen years of age are not insurable. If a cow dies within the year, the owner receives three fourths of her value. The dead cow is the property of the club.

"Sixpence in the pound, annually, has actually covered, to three fourths of the value, all casualties upon a run of twenty years.

"Under the inspection of a shrewd and spirited agent, the whole affair has worked to admiration, and been productive of peace and plenty amidst the little community whose happiness it was designed to promote. No burning of stacks here, because every man has one of his own. No invasion of the rights of property, because every man is a possessor of property, and anxious to guaranty his neighbor's rights, that he may hold his own in the better security.

"The rent that each cottager pays is something less than $£ 10$ per annum. 'The produce that is yielded, much to the credit of the humble cultivators, is abundantly ample to cover the outgoings, and leaves a surplus that makes them comfortable.

"The acre of tillage land is remarkably productive. It is divided into two allotments: half an acre is in wheat, the other half in potatoes; alternating the crops, of course, every year. On this short rotation, the land has not suffered, but actually 
increased in fertility. For the last ten years, the crops of wheat have yielded twenty bushels to the half acre. The twenty years preceding, eighteen bushels was the average. Instances of twenty-seven bushels to the half acre have been known. The half acre of potatoes, with others grown in the garden, are usually fed to pigs, and instances have been known where the cottager has sold twenty pounds worth of pigs and well supplied his own family with bacon. It is common for them to sell from ten to twenty pounds worth of pigs, or pork, per annum, and still keep a good supply for family use. Some of the cottagers, who have been blessed with careful wives and good cows, have sent twelve pounds of butter, per week, to market, during all the flush of the feed.

"It must be understood, that while the cottager's allotment of land is thus multiplying his comforts, he has a constant supply of work, and current wages, from the neighboring farmers. His own farming is done after his master's day's work is completed, with perchance a day now and then, as at seed-time and harvest.

"Happy, comfortable, and superior in condition, as these cottagers appear, yet the system that makes them so has often been called in question. It has been observed, that the children of cottagers, thus happily situated, are not over anxious to go to service, and not over apt to lieep their places when they do go. There appears a latent consciousness about them that the house of their parents is well supplied with bread and bacon.

"Perhaps the evil, if it be one, has a deeper origin than at first sight appears. May it not be traceable to our social system, the genius of which delights to keep property in large masses, under great proprietors? 'These proprietors have a similar predilection for large divisions of their property - large farms, and men of large capital to work them. All this may be wellvery well suited to the cast-iron consciences of the political economists; but it creates a chasm between the large farmerthe farmer of two hundred and fifty acres, with a capital of twenty-five hundred pounds, and the mere laboring cottager. The latter can never hope to pass so great a void. There are no intermediate resting-places. There are no farms of twenty, fifty, or a hundred acres, to which the succossful and deserving cottager can be promoted. The steps of the ladder are out. 
Having obtained the rare blessing of a cottage allotment. the language of his heart is, 'Let us eat, drink, and be merry, for in our present condition we must die.' His highest ambition being achieved, and the family little more to hope for, it is not to be wondered at that some little laxity should be observable. Let the great landlords of the land supply a motive by a more natural division of their property - let them encourage the aspirations of the industrious cottagers by small farms in prospective, and larger beyond them, and the energies of our peasantry will never be found to flag. But this is, perhaps, scarcely to be hoped for."

I shall go still more largely into the subject of allotments, as presenting one of the first and most efficient means of bettering the condition of the agricultural laborer. My own convictions are strong on this point; and they are sustained and strengthened by the testimony of many men of large experience and shrewd observation. The laborer finds, in an allotment, a means of turning his spare hours to advantage, and in a mode of labor which, from its very character, being in the association of his wife and children, under his own control and management, and for his own immediate and personal benefit, becomes a pleasure instead of a toil. He finds in it the means of eking out his scanty wages; of providing, to a degree, for an occasion of sickness, or other suspension of his employment and wages. He is enabled to bring from this source many rare comforts to his own frugal table; and has himself, if he is a man of feeling; - and why should he not be? - an opportunity of enjoying one of the richest of all pleasures, - that of making a small contribution to relieve an unfortunate or a sick neighbor. It presents a good school of industry for his children, under his own immediate inspection. It quickens his own intelligence in making agricultural experiments upon a small and useful seale, and rouses a spirit of wholesome emulation in his crops even with the master farmers. It removes him from strong temptations to gambling, low dissipation, and intemperance. It gives him an interest in the soil; it attaches him to his home; it involves him in all the risks of the public safety; and makes him the friend of public peace and order. It gives him the spirit of a man, raising him above the sense of slavish dependence, and the dread of becoming a pensioner on public charity. In so doing, it at once exalts 
him in the community; induces a most wholesome self-respect: inspires a just regard for the rights of property; attaches him the more strongly to his superior, who thus shows his willingness that he should walk erect instead of keeping him upon the ground with his foot upon his neck; and presents innumerable, constant, and powerful motives to improvement and good conduct. I wish it were in my power to convey to those, who have been born to affluence, rank, and authority, the force of these sentiments upon minds altogether differently circumstanced from themselves; but I know it would be difficult - I fear it might be impossible. A consciousness of absolute dependence, so extremely difficult to be engrafted in the human mind, seems indispensable to teach us our duty either to man or God.

That the whole of this subject has an important bearing in its economical and moral aspects upon my own country cannot, I think, be overlooked by a reflecting mind; and, in the course of my reports, will, I trust, be made more fully apparent. 



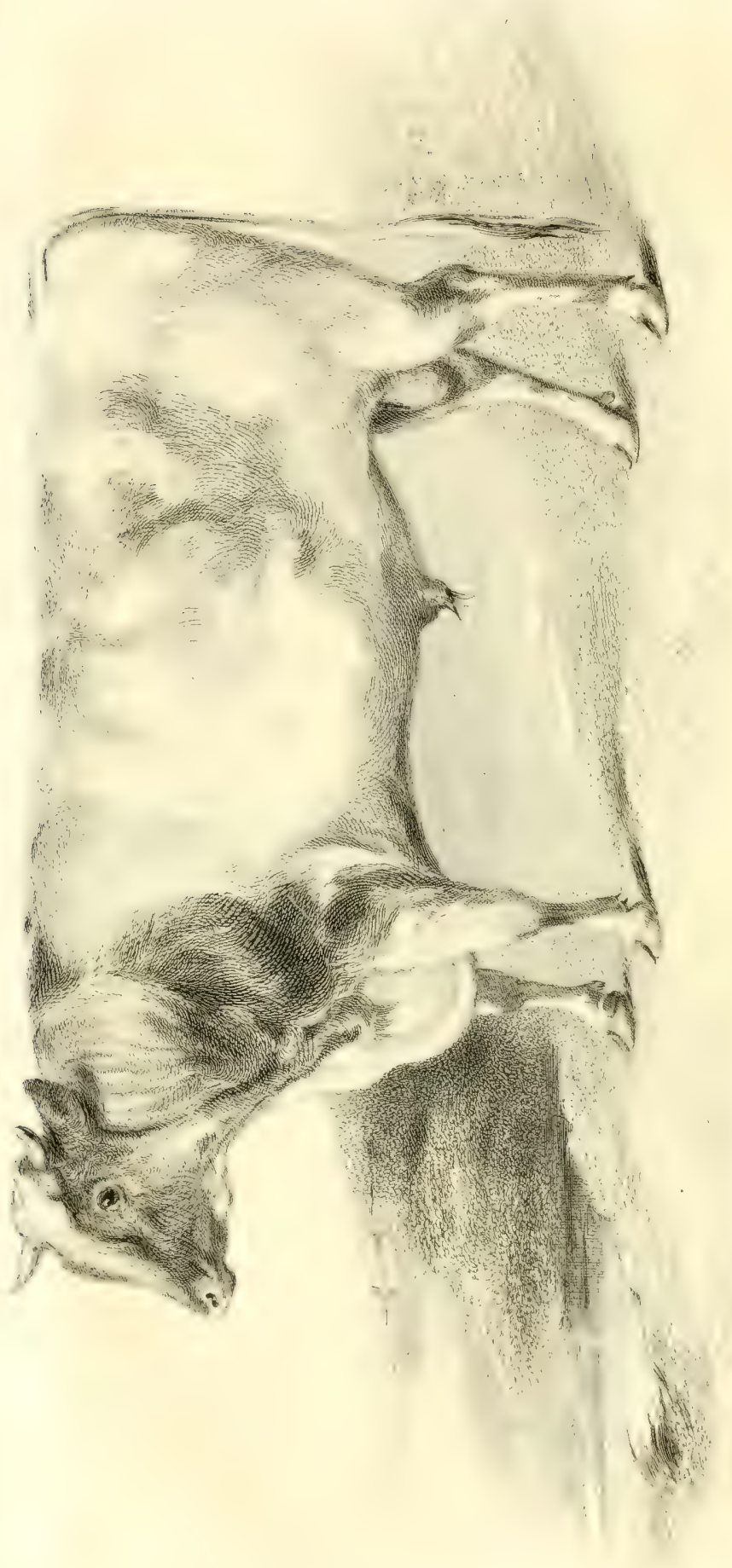




\title{
EUROPEAN AGRICULTURE.
}

\author{
SECOND REPORT.
}

\section{XIII. - ALLOTMENT SXSTEM. (Continued.)}

My First Report was concluded with the important subject of allotments of land to laborers. This subject, without an explanation, would scarcely be understood by a majority of the farmers in the United States. The agricultural laborers, or, as they are here termed, the furm-servants, are seldom or never owners of land. They receive their wages in money or produce, as I have already described; and some of them, living in compact villages, have not even a small piece of ground for a garden, though, in many parts of the country, the cottages have small gardens attached to them. The unmarried laborers sometimes live in the houses of their employers; but this is not now a general nor a frequent practice. The married laborers live in cottages on the estate, or in a neighboring village.

It is obvious how great advantages a poor family in the country may derive from a small pieee of land, and how much produce may be obtained from it for their support and comfort by the application of even a small amount of labor, which otherwise, without such opportunity of applying it, would be lost, or rather would not be exerted. Many persons, therefore, have leased to their laborers small portions of land, varying in size from a quarter of an acre, or even less, to an acre, and in some cases more than this, to be cultivated in such crops as the laborer may select, or as may be prescribed by the proprietor. One 
condition is usually made absolute in these cases - that the land should be cultivated with a spade, and not with a plough. The results therefore become the more interesting.

I shall give here an account of a successful attempt at the improvement of the condition of the poor rural laborers by allotments of iand, cultivated by the spade, uniting with these allotments, at the same time, a provision for the education of the poor children by whose labor these grounds are cultivated. The accounts have a twofold value, in showing the practicableness of meeting the expenses of education by the labor of the pupils, and the increased and extraordinary product which may be obtained from land under the spade husbandry.

"A friend to the more general diffusion of a sound education amongst the peasantry of the United Kingdom, who has long witnessed the success with which education may be, without cost, combined with instruction, in the best modes of cultivating the soil, begs to submit to those who are impressed with the importance of the effort, the few following facts:-

"A landed proprietor has established what are termed 'Agricultural Schools," upon the principle of uniting our present national with agricultural instruction, by making the labor of the little scholars, while under tuition in the art of husbandry in the afternoon, to compensate the master, in the way of salary, for the instruction they receive from him, in the usual course of our national education in the morning. Schools have already been established upon this plan at the villages of East Dean and Willingdon, and they are attended with the happiest results. The usual quantity of land required for the purpose does not exceed five acres; and for this the master pays a rent, certainly equal to, and in most cases beyond, that of the adjoining land, occupied by farmers. In the case of the Willingdon school, there is an appropriate house, for which the master pays an additional rent. The only payment in money to the master is the usual penny a week from each scholar.

"Nor can any reasonable objection be made to this plan on the ground of so employing the boys in the afternoon. The girls in our national schools are tanght, and for the same number of hours, to work with the needle, the use of which is not more important to them than that of the spade and the hoe to the boys. 
"As various questions will naturally suggest themselves to those who read this statement, the following answers, by the schoolmaster, to numerous inquiries already made, are inserted here:-

- Reply of the Master to Inquiries hespecting this School.

"I have twenty scholars, to whom I teach reading, writing, and accounts, the Church Catechism, Collects, and Psalmody on the national plan, with the approbation of the vicar, without any salary, for one penny per week from each boy, from nine to twelve o'clock; and from two till five in the afternoon cultivating the land. I have not lost one from dissatisfaction, but I am glad to say that they willingly assist me.

$\therefore$ I am satisfied that I can keep two cows on the same quantity of ground, stall-fed, where I could keep but one if I allowed her to graze; and grow more corn.

" 'I have no grass land, and all the first winter my cows had only straw, turnips, and mangel-wurzel, till green food came on in the spring; and now my hay is the clover I sowed with the grain crop last year.

"I I have experienced a great deal of good from the liquid manure from the two tanks, one from the cows and the other from the pigs.

" 'I have just lilled a pig weighing twenty-nine stone seven pounds, and one before about the same weight, which I have used in my family. I have a wife and four children.

" "It is allowed that my oats are the best sample in the parish. I. tied my oats in sheaves, and set them up the same as wheat, which saves a great deal of scattering: this is the general practice in Cornwall and Scotland, and, I hear, in some parts of Kent, and is particularly useful for barley to malt.

"I I thrash my corn over the cow-house, as in Cornwall, Switzerland, \&c., which keeps it perfectly dry, being thus kept from the damp ground.

" 'I am entirely supplied with water by the rain which falls on the house, preserved in a tank in the ground.

" "The quantity of land I rent is five acres, on the side of the South Downs, at $£ 3$ an acre; this with $£ 5$ for my house, makes $£ 20$, which I have paid for the year ending Michael- 
mas last, though I might have taken ofi my crops, and lived rent-free; but I preferred staying and teaching, though I have no salary; and so, I think, would many others.

"' I have now three cows, a heifer, and a calf, standing opposite to each other, with a road between their mangers for feeding these stall-fed cattle, which have never needed a farrier; and from skim milk I have made cheese like the Dutch cheese.

\section{" "George Cruttenden.}

“'Wiluingdox, near Eastbourne, Sussex, April, 1842.'

"At your request, I send the particulars of my produce last year, which I am perfectly satisfied with, leaving me a balance of $£ 40$ after every thing is paid, though the last was an unfavorable. dry summer.

"I am likewise happy to say, the principal farmers of the parish have taken into their employ six of my scholars, all under twelve years of age, into their service since Christmas, and two of them under nine; and all, after leaving my day school, where they paid me one penny a week in addition to their work, have each paid me fourpence a week out of their wages, for evening instruction; and their master is now using the liquid manure the same as I do, which $\mathbf{I}$ have found most beneficial.

"I have a wife and four children, whom I support in a comfortable way, and wish I could see many of my neighbors do the same; but that is not the case.

"G. CRuttenden.

“'Wilhryadox School, .April 1.4, 1843.

"A landed proprietor at Willingdon, seeing the success of this sehool, recommended the establishment of a similar school in the adjoining parish of East Dean, where, in the spring of 1842 , five acres of land were let to John Harris, an infirm man, who, two years before, had been in the Eastbourne Union House, with his wife and seven children, where, at three shillings per head, they

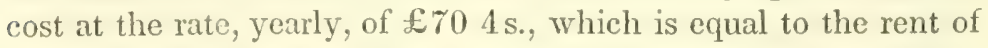
three hundred and fifty-one acres of sheep-walk: now he is supporting his fimily on only five acres, and, when recommended to give up his five acres, said, 'he had rather continue to pay rent, rates, tithes, and taxes, and teach without a salary, than have fourteen shillings a week withont the land.' 
"Harris, in the Union House, resembled a mouse in a granary devouring the fruits of labor; but does not this same Harris, on his five acres, resemble the mouse in the fable, releasing the famishing lion? for by his rent he is helping to support the owner of the soil, by his rates the poor, by his tithes the church, and by his taxes the state, which surprises those who have long been accustomed to hear it is requisite to let land in large farms, for the supply of food for large towns.

"But do not the Higher nents paid for allotments of land by the spade than the plough, show that, after supporting the cultivators and their fumilies, they send more to market per are than the great farmers?

"It was the eagerness of laborers in Sussex to hire land, that suggested the possibility of some men to obtain as much as five acres, undertaking to teach reading, \&c., three hours daily without a salary, without at all anticipating that twelve boys, averaging eight years of age, by their labor for three hours after noon, could well pay for their instruction in school before noon; but a trial of upwards of three years has put this beyond doubt, as dozens of signatures in the visitors' book testify, of clergymen and members of both Houses of Parliament, not only of this neighborhood, but also from Ireland and Scotland, amongst whom was Mr. Townshend Mainwaring, MI. P. for Denbigh, who inspected these schools April 29th, 1843, and entered in the East Dean visitors' book, that he was much gratificd by the complete success which appeared to attend the simple principle upon which the school was conducted.

"And these self-supporting schools require much less superintendence than where the master has a fixed salary, because, if he neglected or misused the boys before noon, their parents are not likely to send them back to work for him after noon.

"He is interested in cultivating the land well, as it is the only support of his family.

"Landlords are interested in letting land to masters who pay high rents.

"Rate-payers are interested in able-bodied men being enabled to maintain themselves.

"Parents are interested in sending their children where they rarly learn to earn their livings in that state of life unto which it has pleased God to call them. 
"'I'he farmers around, seeing the great produce from stallfeeding and liquid manure, are interested in taking additional hands into their service.

"The more food that is raised from the soil, the more there will be to exchange for clothing, and thus an increased home market be provided for our manufacturers; who, the more the earn, the more they have to lay out in meat, \&c.

"And to effect this, there is no deficiency in capital. There is no want of hands, as our Union Houses are overflowing with the able-bodied; nor is there any want of land, as the heaths, commons, and grazing land, even round London, show."

It is stated, likewise, - and it is a fact deserving of all remark, - "that, during a course of twelve years, out of four hundred rents, only three rents have been deficient, though the tenants were taken without reference to character, and told the rent would not be demanded if not tendered; but the desire of keeping the laud has secured the annual payment, and only one, during the whole of that time, has been convicted of a misdemeanor." ..... In fifty parishes in one county in which there are above three thousand allotments, after the most careful inquiry, our agent heard only of one commitment to prison in 1840 , and not even one in 1841, out of the whole three thousand families."

The general condition on which allotments are granted being that they shall be cultivated by the spade, the extraordinary product obtained in this way deserves to be remarked. The statements to which I shall refer are drawn from the reports of a committee of Parliament, and seem, therefore, entitled to confidence. I have myself visited several allotment grounds in different parts of the country, and am quite satisfied that the results under this system of management are not overstated. On this subject I shall say more hereafter; but it may not be out of place if I give here some examples which have been referred to.

Jesse Piper, in Sussex, holds an allotment of four acres. He obtained, in 1842. forty-two bushels of wheat from three quarters of an acre of land; he had two hundred and fifty bushels of potatoes fiom three fourths of an acre; he had ten bushels of barley from the other land, and kept two cows, and three and sometimes four pigs; he considers that there might be an acre of grass, and the cows were kept entirely upon the produce of the four acres; a portion of this was not arable, as some trees 
were growing upon it. A peculiarity in this man's management is, that he worlis one of his cows in his cart, and calculates that her labor saves him an expense of five pounds; she is milked in the morning before she is put to work, and, although worked, she makes eight pounds of butter a week, besides furnishing some milk for the family. This is a sort of Robinson Crusoe management, which is well deserving of attention. It would not be easy to find a reason why the female of one class of animals should be exempted from work, rather than of another; and there is no ground to suppose that, with grood fecding and careful usage, moderate labor would be injurious to the health of an animal; much more likely is it to be conducive to health, and even, in such case as this, to the more liberal secretions of milk.

Other circumstances in this man's economy are worthy of observation; he saves all his liquid manure in a tank by his own house, and mixes with it a proportion of soot and salt; he throws his land into heaps, and puts the liquid upon the heaps, and then spreads it abroad - "because," as he remarks, "his land is so near the chalk, that if he put his liquid manure upon the land, three fourths of it would be wasted - it would go clean away, so as never to get it again; but when put in a heap of mould it is retained."

\section{Produce of four Acres, held by J. Piper, in 1842.}

42 bushels of wheat, at $7 \mathrm{~s} .6 \mathrm{~d}$. per bushel. . . 15150 250 do. potatoes, at $15 \mathrm{~d}$. per do. . . . . . 15126 Food for one cow, which gave 4 lbs. butter per week,

at $1 \mathrm{~s}$. per lb. . . . . . . . . . . 1000 The other cow do. do. do. do. $\quad \begin{array}{llllll}10 & 0 & 0\end{array}$ Food for three pigs, at 20 st. each, and at $3 \mathrm{~s} .6 \mathrm{~d}$. per st. 10100

$£ 611 \% 6$

This example shows the extraordinary results of minute and exact cultivation, and the value of conomy in hushanding with extreme care all the resources for manure. The cow is an animal I have always looked upon with the greatest respect for her justice and her liberality: in this case she pays for her board by her yield in milk and butter, and adds to it her labor, or, as is said in case of a free passage on board ship, "she works her 
own passage;" but the good creature's usefuiness does not end here. When she has completed her round of beneficence, her benefactions do not close with her life; her hoofs are made into glue; her horns into combs; her bones into knife-handles and cane-tops; her hair worked up into plaster; her skin into shoes; and her meat into food. Who can wonder that the Hindoos always regarded her with a religious veneration?

The next instance presented by the Parliamentary Reports is that of J. Dumbrell. His allotment is six acres, and is managed by himself, his father, (scventy years old,) and a child of nine years old. "The soil is chalk, on a deep soil, in a valley."

His stock consists of two cows and a heifer, and from two to three pigs. His succession of crops is thus described: "First, Italian rye grass, cut four times, watering it each time with liquid manure after cutting it; then tares; then clover; then cabbage comes in, and mangel-wurzel; and second cut clover, and sometimes three; and that carries us all the summer through: then we begin upon the roots in winter, turnips and mangel-wurzel, and straw."

The following is the statement of his produce for 1840 :-

\&. s. d.

From two cows in nine months and a half, from the 16 th of Jan. to the 26 th of Oct., made $4001 \mathrm{lbs}$. of butter, which at $1 \mathrm{~s}$. per $1 \mathrm{~b}$.

The cow, all the year stall-fed, yielding a third more than the other, which grazed half an acre; and their two calves sold for

The skim milk, at 3 pints $1 \mathrm{~d}$., or given to the pigs, is estimated at

On one quarter of an acre he grew 18 bushels of oats, which, at $4 \mathrm{~s}$. per bushel, amounts to . . . . On 88 poles (i. e., a little more than half an acre) he grew 32 bushels of wheat, worth, at $8 \mathrm{~s}$. per bushel, (which is equal to the consumption of himself, his

wife, and three infant children, ) .
Besides pigs, potatoes, vegetables, and the butter to be expected to the end of the year, which may fairly be estimated on the whole of the land (including the foregoing, as I understand the account, which is rather imperfectly drawn up) at 
Out of this he paid -

Rent, rates, tithes, and taxes of one acre, . $\quad £ 17$

Rent of one acre and a half, . . . . . 70

Rent of half an acre of grass, . . $£ 210$

Lodge in it, . . . . . . 100

Rates, tithes, and taxes, . . . . 15

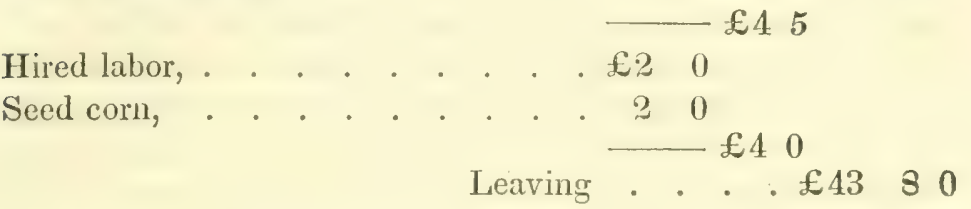

The two pounds paid for labor were paid for threshing.

There are two other accounts of the same individual subjoined.

Produce of three and one quarter Acres, in 1841.

f. s. d.

Wheat, $21 \frac{1}{2}$ bushels, at $8 \mathrm{~s}$. . . . . . 8120

Oats, 44 bushels, at $2 \mathrm{~s} .9 \mathrm{~d}$. . . . . . . . . 610

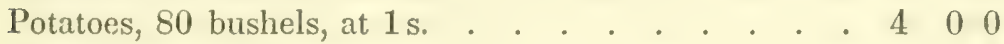

'Two calves sold for" . . . . . . . . . . 5100

Butter, $423 \frac{1}{4}$ lbs., at $1 \mathrm{~s}$. . . . . . . . . 2133

Milk sold, and given to the pigs, . . . . . . . . $\begin{array}{llll}10 & 0 & 0\end{array}$

$£ 55 \quad 63$

Produce of six and one quarter Acres, in 1842.

£. s. d.

Wheat, 40 bushels, at $6 \mathrm{s.} 6 \mathrm{~d}$. . . . . . . 1300

Oats, 93 bushels, at $2 \mathrm{s.} 6 \mathrm{~d}$. . . . . . . . . . 11126

Peas, 22 bushels, at $4 \mathrm{~s} .6 \mathrm{~d}$. . . . . . . . 4190

Potatoes, 150 bushels, at $1 \mathrm{~s}$. . . . . . . . 7100

Two calves, one fat and one suckled, . . . . . 370

Butter, $290 \mathrm{lbs}$, at $1 \mathrm{~s}$. . . . . . . . . 14100

Milk sold, and given to pigs, . . . . . . . 800

$£ 62186$

In 1842, he lost two cows by death, and the additional land was taken in bad condition.

At the same time, he presented a sample of his whent, on which were eighty-four stalls from one grain. There is another secret 
of this man's success - he had signed the temperance pledge; he is a tee-totaller, and drinks neither spirituous nor fermented liquor.

An inquiry was made of Mr. Dumbrell, "how it was possible to keep two cows, and maintain a family of five persons, on only three acres of land;" to which this is his answer - "The statement you saw was very true; half an acre of pasture, half an acre and eight rods in wheat, and one quarter of an acre in oats, the other part was green food for the cows, such as rye, tares, cabbages, clover, mangel-wurzel, turnips, and Italian rye-grass. But if you are surprised at my keeping two cows on this quantity of land, I must tell you that one crop a year will not do it : but my plan is to take second crops; that is, rye is the first thing I cut green in the spring; then I dig the land, and manure it with the liquid manure, as far as it will go ; then finish with rotten dung, and plant mangel-wurzel and turnips; and the part that I manure with the liquid is always the best. The next thing I cut is winter barley and turnips, and plant some cabbages for winter: by this time $I$ cut the grass and clover, which grows again in a short time, with a little of the liquid manure as soon as it is cut. Last summer I cut the Italian rye-grass and clover three times; and this year I have nearly cut it twice already, and there were really two good crops of the Italian rye-grass, and I think there will be two more this summer, with a little manuring. My early cabbages I always let stand to grow again all the summer, and they bring a great deal of food. I plant again in November, and put the liquid manure to them as far as it will go; but to the rest I use dung or ashes, which are not so good as the liquid, which any body may tell in the spring by looking at the bed of cabbages; so I hope it now appears how the cows are maintained in winter as well as in summer. During last winter, I had no hay, only turnips, mangel-wurzel, and straw, and they did very well."

I have already apprized my readers that my Reports must be, in a degree, desultory, from the necessity of giving them before the whole ground has been gone over. Compelled at once to begin the erection of my building, I must use such materials as I have; and which, I fear, under such circumstances, may appear incongrious and ill-assorted to an eye accustomed to order and exact arrangement; whereas, if every thing were at hand, I might 
better succeed in preserving the symmetry and adjusting the architectural proportions of the edifice. I shall therefore make no excuse for saying here something more of spade husbandry, and the extraordinary products of small pieces of land; and it must be admitted that it is by no means discomnected with the subject of cottage allotments.

The utmost productive capacity of an acre of land, in any crop, has not yet been fully determined. 'The amounts attained frequently surprise us; but we have not yet got to the end of the line.

One of the witnesses before the Parliamentary committee gives an account of a man who supported himself, and wife, and son, from two acres of land, for which he paid a rent for the two of $£ 9$ $10 \mathrm{~s}$; and in the course of seven years, he had saved enough from the produce of his two acres to purchase two acres of land, for which he paid about $£ 30$ to $£ 40$ per acre. He states, likewise, his own personal knowledge of six acres of land, which, under the spade cultivation, produced at the rate of fifty-two bushels of wheat to the acre. Another witness testifies that on the estate of Lord Howard, Barbot Hall, in Yorkshire, a rood of land was dug and planted with wheat by his lordship's direction, and twenty-eight bushels of wheat were obtained from this quarter of an acre, which would be at the extraordinary and unheard-of rate of one hundred and twelve bushels per acre.

The authenticity, or rather accuracy, of such a statement as this may well be considered as questionable; but I have the pleasure of presenting one, exhibiting a most extraordinary yield, on which full reliance may be placed.

In visiting Horsham, (the last summer, ) in the county of Sussex, my attention was strongly attracted by two small pieces of wheat in a garden by the road-side. exhibiting an extraordinary luxuriance; and I have been able to obtain a detailed history of its culture and yield, through the politeness of C. S. Dickens, Esq., of Coolhurst, near Horsham.

The seed of this wheat was brought from Australia, being the product of some wheat which had been sent there two or three years before. 'The quantity of land sown, in one of the pieces, was thirty-four square yards. The wheat was dropped in rows nine inches apart, and in holes six inches apart, and only one train in a place. 'The number of corns planted was 652, out of 
which 33 failed to germinate. The cultivator obtained four gallons of good wheat from the land, exclusive of several of the finest plants, which he saved. The usual number of stems from each seed was 18 to 20 ; a considerable number gave 30 to 35 , and one was counted which had 40 full-sized stems, and three of a smaller size. The straw from the 34 yards weighed 72 pounds, which would be 284 trusses of 36 pounds to the acre. The -weight of the 682 corns planted was 17 drachms. This being multiplied by 142, the land being the 1-142d part of an acre, gave about 91 pounds as seed for the acre; consequently one bushel of wheat, at 63 pounds per bushel, would plant more than six acres. The produce of 4 gallons, multiplied, as above, by 142 , gives the great quantity of 71 bushels, or 17 sacks 3 bushels, to the acre. The ground had borne potatoes the previous year, and had received no top-dressing, nor been in any way manured for the wheat. A sample of the wheat, which has been kindly sent to me, in the straw, and which I have deposited in the museum of the Royal Agricultural Society, was six feet in height.

These are remarkable facts. What has been done can be done. They forbid our resting satisfied with what has been accomplished; and they eneourage the hope that the productive powers of the soil are vastly greater than have yet been determined. Onward! is the watchword of the present day, in every department of science and art. Why should agriculture form an exception? Away with the drones! Do not let us mistake a fog-bank for land, nor think that we have reached the end of the voyage until our feet actually press the solid ground.

The allotments referred to above I have myself had the satisfaction of inspecting, and add, with great pleasure, my humble testimony to the skill, industry, and good conduct, with which they are managed. Indeed, in many respects, I do not know where they can be exceeded. The establishments presented striking examples of the most exact economy. Three of the parties had been driven by their necessities into the workhouses, principally, however, owing to accidental injuries and sickness; but now, instead of being dependent upon public support, they were paying punctually a full rent for their land, and were procuring an honest and comfortable living from their own industry. Another of the families, presenting one of the most beautiful and 
allecting examples of indefatigatble industry, wi serere economy, and of grateful and religious contentment, which I have ever witnessed, said, with their eyes flooded with tears, that they had been saved from the workhouse - a fate which many of the poor seem to dread almost as much as death itself — only by the kindness of their beneficent proprietor in leasing them the land, and in furnishing them with tools and with cows to commence their operations. Besides supporting theinselves and their child, they had also supported an aged father and mother; and had nearly paid a debt of twenty pounds to the physician, incurred by a sickness of three years, of the man himself, before he had the allotment; and the whole of which they were determined fully to discharge. They expressed themselves but too happy in being able to assist and succor their aged parents, who, in time of his illness, took the kindest care of them. In no condifion of life have I seen a brighter example, without any pretensions and without ostentation, of some of the highest virtues which can adorn the human character. An inflexible rule with them was, not to incur even the smallest debt for any thing. The matter of medical relief must, of course, form an exception. This same man, living in a poor village, where it would seem that education was nerer more wanting, had proposed, after the plan of the others, to keep a school, and assist himself by the labor of the children; hut a principal farmer in the neighborhood, disconcerted by the extraordinary success of this humble family in sustaining themselves independent of his aid, had threatened his laborers, if they sent their children to this school, they should be dismissed from his employment, and so prevented it. It is to be hoped, for the honor of human nature, that examples of such sold brutality are rare.

Three of these tenants have been kind enough to furnish me with their accounts of the products of the last year, (1813,) which will, I think, not be without interest to my readers.

Mr. Crittenden has five acres of land, of which the following is the produce for the year 1843. He adds, in respect to it, "I have not put in the corn, roots, and hay, which the cows and pigs consume, as they answer to them in their milk and flesh." 
"Willingdos, March 4, 1814.

"Whe produce of my land, five acres, the last year, (1843,) being the quantity and the price:-

£. s. d.

8 qt. 6 bu. of wheat, at 52 s. per qt. . . . . 22150

3 "6 0 " of oats, at 21 s. per qt. . . . . . 330

1 "6 " of barley, at 30 s. per qt. . . . 2126

1 " 0 " of peas, at 34 s. per qt. . . . . . 1140

120 bushels of potatoes, at 1 s. per bushel, . . 600

1 large hog sold for . . . . . . . . 4150

1 small do. . . . . . . . . . . . . 156

1 calf, sold young, . . . . . . . . 110

1 hog for self, 25 stone, . . . . . . . 3150

Butter and milk, . . . . . . . . . 1100

1 calf, reared for a cow, . . . . . . 2100

1 young sow, . . . . . . . . 200

$£ 6300$

Rent,

$3 8 \longdiv { 0 } 0$

$1 \mathrm{qt}$. of tail wheat, worth $£ 2$, which we eat, . . 200

Total, $£ 4 0 \longdiv { 0 0 }$ "

I subjoin the letter with which he has favored me:"Sir,

"I send you the rotation of cropping for six years, which I adopt myself; likewise the kinds and quantity which I sow, for two cows and a heifer, on my five acres. First, I sow about one and a half acres of wheat, which I drill in. about nine inches apart between drills. I sow two and a half bushels to the acre. Then I sow one acre with clover in the spring, - about three gallons of seed to the acre, - in order to cut for the cows green, and the rest for hay for the winter; this is the best food that I can get. It may be cut three times. Second, one acre of either oats or barley that I drill in, as every thing drilled is so much best for the boys to work amongst, and likewise a saving of seed. Third, I sow about twenty rods of rye, and sixty rods of winter tares, in September, for the cows in the spring, and they will come off sonn eluorgh for potatoes or turuips; after them, then it 
comes in for wheat. I sow the rye and tares broadcast, as it should be thick on the ground. Fourth, I sow the rest of the ground with swedes, turnips, mangel-wurzel, carrots, and potatoes, for winter food; the mangel-wurel produces a great deal of food for the cows, if the leaves are taken off properly.

"I leave a piece of ground for spring tares, to come in after the winter tares. I sow these in February.

"This will keep two cows and a heifer all the year round, if they are stall-fed.

"Rotation of Crops.

First Division.

Second Division.

1845. Wheat. . . . . Rye and tares.

-46. Clover. . . . . . . Wheat.

-47. Wheat. . . . . . Clover.

-48. 'Turnips and mangel-wurzel. Wheat.

-49. Oats or barley. . . $\left\{\begin{array}{c}\text { Turnips, mangel-wurzel, } \\ \text { carrots, }\end{array}\right.$

-50. Potatoes. . . . . Oats or barley.

Third Division.

Fourth Division.

1845. Oats or barley. . . . Wheat.

-46. Rye and tares. . . . . Turnips, mangel-wurzel.

-47. Wheat. . . . . Oats or barley.

-48. Clover. . . . . . . . Potatoes.

-49. Wheat. . . . . . Wheat.

-50. Turnips, mangel-wurzel, $\}$ Clover.

1845. $\mid \begin{gathered}\text { Fifth Division. } \\ \text { Spring tares and turnips. Division. }\end{gathered}\left\{\begin{array}{c}\text { Mangel-wurzel, carrots, } \\ \text { swedes, turnips. }\end{array}\right.$

—46. Wheat. . . . . . Oats or barley.

-47. Turnips, mangel, turnips. . Rye and tares.

-48. Oats or barley. . . . . Wheat.

-49. Potatoes. . . . . . Clover.

50. | Wheat. . . . . Wheat."

'The next account which I shall present is that of Mr. Dumhrell, at the village of Jevington. Sussex county, who occupies 
six acres and a quarter. The products of the years 1841 and 1842 are already given. The following is for 1843 :-

Six Acres and a quarter, 1843.

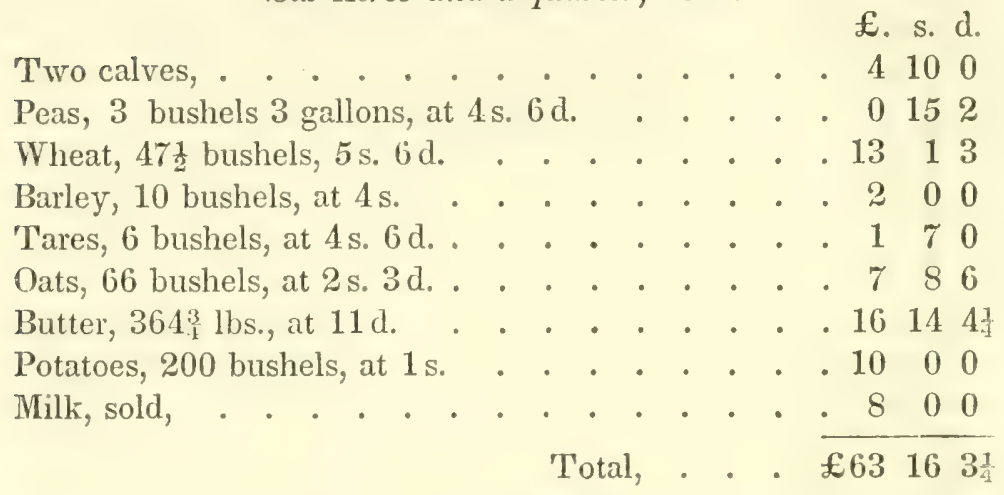

He adds, in his letter to me, "You may be surprised at PRT not making more from six acres and a quarter, than I did, in proportion, from three acres and a quarter; but it is to be understood that, since my farm was made up to six acres and a quarter; the products, as the two last tables show, have not sold so well, and the last three acres, which were added to my farm, were very poor soil."

I give next the report of last year's crop, which has been sent me by John Harris, as the products of the labors of himself and his scholars. He adopts the same system of spade husbandry, and the application of liquid manure to his crops. His allotment comprehends five acres only.

One acre and twelve rods of wheat produced . . 53 bushels.

Half an acre of oats, . . . . . . . . . 61 "

Thirty rods of barley, . . . . . . . . $13 \frac{1}{2}$ "

Twenty rods of peas, . . . . . . . . $4 \frac{1}{2}$ "

One acre of potatoes, . . . . . . . . . 404 "

Half an acre of turnips, . . . . . . . 150 "

Sixteen rods of carrots, . . . . . . . $3 \frac{1}{2}$ tons.

Fifteen rods of mangel-wwuzel, . . . . . . . 3 "

The rest of his land was occupied with green food for his cows; such as cabbages, rye, clover, tares, \&c. He kept two cows. He had from eight to twelve pigs all winter, and they 
consumed all his potatoes, and his tumips, mangel-wurzel, and carrots, were given to his cows. He fatted one hundred and twenty stone, or nine hundred and sixty pounds of pork, which he sold to the butcher. He sold six shotes, at three months old, for stores, and one pig for roasting; and he sold also one sow in pig, for $£_{2} 12 \mathrm{~s}$. He kept no account of the produce of his corvs.

Several things are remarkable in regard to these allotments and modes of management. In the first place, they are all cultivated by the spade. Where labor is abundant, as in England. and the great difficulty is to know how to employ it with advantage, this might be attempted even upon a large scale. The expense of horses upon a farm is always a great consideration: and especially upon small farms, the expense of horses, compared with the amount of product, is very great, and absorbs a large proportion of the income. It is estimated by many intelligent farmers in England, that the horse-teams require for their maintenance full one fourth of the produce of the soil. I propose presently to discuss this whole subject of brute labor upon a farm, and shall therefore go no farther at present than to add $\mathrm{my}$ conviction, that the expense of their horse-teams in England, the cost of their horses, which, after a certain age, is always a deteriorating capital, the expense of their maintenance, shocing: harness, \&c. \&c., constitute a most serious drawback to the prosperity of English farmers, and that some little of this may be charged to the vanity of display, and the ambition of extraordinary size. Whatever it may be, on these allotments it is all saved; the labor, with the exception of the working of the cow on one allotment, is all human.

The second observation, which occurred to me, was the extraordinary pains taken in saring the manure. Nothing was wasted. 'The animals were stall-fed, and kept constantly in the stable, and a small brick or stone tank, well cemented with lime, was sunk near the cow stable, and near the pigstye, which received all the liquid manure; and the contents of these tanks, on their becoming full, were pumped into a small cart, with a sprinkling-box attached to it, like that used for the watering of streets in cities. and distributed orer the crops, always with the greatest adrantage, and with effects immediately perceptible. The tanks in this case were quite small, because the stock was small, and 
made, with little expense, of common stone laid in lime, and having a wooden cover for security on the top. They were well cemented within, and might be emptied by a pump, or dipped out with a bucket.

An eminent farmer in Yorkshire has lately stated that he has, within the last ten years, made three tanks upon his farm, for the purpose of receiving the liquid manure. The first he made contained forty cubic yards of liquid, but he had enlarged it to one liundred and fifty yards, which was filled three times a year, by the produce of his farm. He is satisfied, from his experience, that thirty cubic yards of this liquid manure would cause it to produce as heavy a crop as any other manure which could be applied to it. With the manure which flowed into the tank, he had manured twelve acres; and this had produced heavy crops of grass, which he had mowed three times, and then there was an abundance, which he mowed late in the season and gave to his horses. This he had found to be the case upon land which had not been pastured for nine years, but always been mown.

I shall not offend any truly sensible person, if $I$ add that the most careful provision is made for the saving of all the human excrements, by a movable tub placed under the seat of the watercloset, and concealed by a door, which is carefully emptied and cleansed daily, and thus saved from being offensive. This is always mixed with soil, and, in the experience of one of the farmers, cannot be safely applied to the land until it is a year old. Of the value of this source of manure, now, in many cases, much worse than thrown away, I shall subjoin some curious calculations in a note, which my reader, being forewarned, may peruse or not, at his pleasure.**

* The committee for building a Lunatic Asylum, at Derby, proposed to Mr. Haywood, an agricultural chemist of much talent and experience, the inquiry as to the results which "the manure obtained from a given number of patients is capable of producing, in the growth of crops, supposing the entire drainage of the establishment to be applied to this use."

'To this Mr. Haywood replied in a very elaborate and scientific report, with a copy of which he favored me; from which 1 shall quote a few paragraphs.

"The great object of my inquiry is, to ascertain what quantity of arable land, in the present four-course system of cultivation, can be kept in a constant state of fertility by the application of all the excretions, both liquid and solid, which are produced by a certain number of individuals, together with the minor fertilizing substances which the proper management of a large domestic establishment is capable of producing; also to give, as accurately. as possible, the extent of land 
The third circumstance remarkable in the case was, that the cows are fed in the stalls, and never turned out. The principal food given them was clover, tares, or rye cut green; the leaves of mangel-wurzel, and, in the winter, turnips, mangel-wurzel, carrots, \&c., and straw. The cows were in good condition, and though evidently not of a character to promise much milk, yet the health of the animals was perfect. They were not selected,

which can be kept in the same state of fertility by the excrements of a certain number of horses, cows, and sheep.

"The course I have adopted in this inquiry has been, in the first place, to ascertain the average quantity of food, both animal and vegetable, consumed by a certain number of individuals in a given time, and from a knowledge of the composition of such food to deduce the composition of the excrements, and afterwards apply this to the composition of crops; for it is now universally admitted that all those elementary constituents which enter into the composition of plants or animals, are primarily derived from the air or the soil, and that whatever be the quantity of elementary constituents taken in the food of an adult man, in a given time, the same quantity of these constituents will again be eliminated from his system by the lungs, skin, kidneys, and intestines, in the same time. If, therefore, we preserve the whole of the excretions made by an individual in a given time, we preserve the whole of the elements of the food he has consumed in that time, and, by applying these to land, slould be able to produce again the same amount of food in the form of corn and potatoes, together with an extra quantity of vegetable matter, which, being consumed by a growing animal, would yield an equivalent amount of flesh; and these changes would be continued ad infinitum.

"It fortunately happens that those constituents of food which are eliminated by the lungs are derived solely from the atmosphere, and, as there is an inexhaustible supply of these in the atmosphere, no restoration of them to a soil is required. On the other hand, those eliminated by the kidneys and intestines, are derived exclusively from the soil, and, consequently, require restoring, in order to maintain its fertility."

"Thus we export from the fifty acres of wheat and barley, and the fifty acres of green crops, by one hundred young lambs, forty yearlings, four young cows, four calves, and two horses, the following quantity of those constituents of a soil which enter into the composition of plants:-

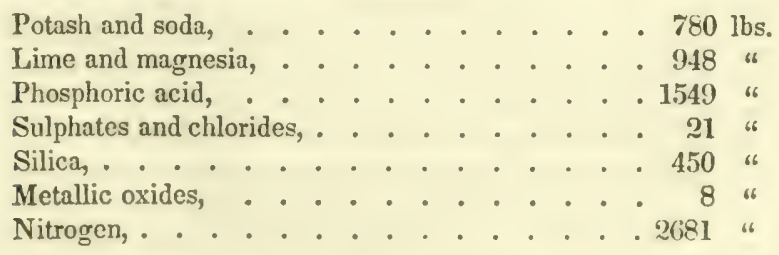

"It will be seen from the tables of the constituents of food, that the ingredients contained in the liquid and solid excrements of one hundred individuals, and the 
but chance animals; in one case, the yield had averaged seven pounds of butter each, per week; in another case, nine pounds had been obtained, when another cow, which was grazed in the pasture, yielded a very inferior quantity. The cows stood in well-ventilated stalls, in one case upon a stone pavement, in another upon hard-trodden earth; were well littered, and kept quite clean. The whole of the manure is saved in this way, and

bones preserved from their food, exceed the above quantity in every substance except nitrogen and silica; but the deficiency in these substances will be much more than compensated by the atmosphere in the former case, and by the soil in the latter; so that I should not have the least hesitation in saying that the excrements of one hundred inmates of your Asylum, or any other, where the supply of food is similar to the above, would keep one hundred acres of land on the common four-course system of rotation in a constant state of fertility. It appears from the calculations I have made, that for every two hundred and fifty pounds of flesh produced, the elements of one acre of ground are extracted annually on the fourcourse system, and assimilated by the animals consuming it; from which it follows, that for every additional two hundred and fifty pounds of flesh produced, above the quantity here given, the entire excretions of one man will be required. I have purposely omitted the pigs in the above account, as they would live entirely on the grains from the brewhouse and the refuse from the kitchen.

"Should you think it feasible to grow a succession of wheat crops, without any intermission of green food, then the above quantity of ingredients would very well supply sixty acres. The object of growing crops of turnips, clover, \&c., is to allow time for those constituents of white crops which exist in the soil, in an insoluble state, to become soluble by the action of the atmosphere in sufficient quantity to supply them. Were the whole of these added annually to a soil in the form of manure, no rest would be required, and a succession of white crops might thus be produced indefinitely. The cause of this not having been profitably accomplished hitherto, is not so much from any difficulty which attends it, as from unwillingness on the part of the farmer, or his ignorance of the mode of proceeding. Had a portion of those liquid manures, which are suffered to run to waste, from every town and farm-yard in the kingdom, been used for this purpose, success would in all cases have attended the experiment; for these contain the very elements, which are rentered soluble in every soil by the year's rest, and which, being assimilated by the plant, and afterwards removed in the grain, are allowed to run to waste in the following year."

I cannot with entire confidence endorse Mr. Haywood's views, especially on the theory of vegetation, in respect to the cultivation of the same crops in succession, on the same soil. It cannot be said to be yet determined whether a change of crop is rendered necessary by the abstraction of certain ingredients of the soil, which are again supplied to it by the influence of the atmosphere upon it when in a state of rest, or by the excretions of the crop, according to the notions of Decandolle, which are poisonous to a crop of the same kind coming in immediate succession; but the quotations which $I$ have given from his paper show the workings of a laborious and inquisitive mind, upon a homely, and at the same time an important subject. 
the amount is much beyond what would be thought, where the experiment had not been made.

There was another economical arrangement here, which attracted my attention. 'Two or three of the allotments, with their buildings, were on elevated land, where wells could not be sunk but at great expense, and a supply of water would be uncertain. In this case, tanks were formed about eight feet in diameter, by twelve in depth, into which the rain water from the roof of the house and the stable attached to the house was led; and thus, as experience had proved, an ample supply of pure water was obtained for the use of the family and the stock, at a small expense. These tanks were surmounted with a cast-iron frame, which furnished a strong cover and a small windlass by which the water was drawn. These tanks were formed of stone found upon the place, laid in mortar, and carefully cemented by gray lime mortar.

The cows were kept in a stable connected with the house, over which were the school-room and the threshing-floor. The grain, with the hay that was cut, of which there was very little, was stacked out of doors; and the cows were fed, almost exclusively, in winter, upon turnips or mangel-twurzel and straw. I have no doubt a more liberal feeding would have been found profitable, but they were under the necessity of getting along with the most limited and simple resources.

This management showed conclusively, in the fourth place, that, where the resources are all carefully husbanded, and the produce consumed upon the farm, the land is capable of keeping itself in condition. The grain which was grown here was mainly sold in order to pay the rent; but the rest of the produce was used for the animals within doors and without. The crops were certainly good; the wheat yielding about forty bushels per acre, and the potatoes from three to four hundred bushels. The clover was usually mowed three times in a season, and the first mowing was made into hay for winter resource; the lucern was fed green, and was mowed five times. The success of the crop depended much, without doubt, upon the immediate application of the liquid manure. A rotation of crops is made absolute by the conditions of the lease, so that two white crops may not follow each other without the intervention of a green crop. The clover erop of Mr. Cruttenden had suffered a good deal from the 
wire-worm, which he attributed to keeping the crop two years on the ground. I do not know how far the supposition is well founded, but it deserves attention. A great problem, then, is here solved, if, to any intelligent minds, it has been matter of question. that, where the product is consumed upon a farm, it may be made to furnish an ample supply of the means not only for maintaining but improving its condition. I do not say that manures may not often be purchased to a great advantage ; and undoubtedly a supply from other sources is indispensable where much: of the produce is sold from the farm. I have no doubt, likewise, that even these small farmers would find their account in extending their live stock, and purchasing oil-cake, which makes a mosi enriching manure, or other substances, for their consumption. A farmer in Lincolnshire, of whose successful management I shall presently give a full account, is of an opinion that his profits have regularly increased in proportion to the quantity of oil-cake which he has purchased for the consumption of his stock. There are, undoubtedly, many cases in which the application of mineral manures may be both useful and indispensable, and fully repay any reasonable ontlay which may be required for their purchase. It is not certain that even these small farmers had availed themselves of all the resources within their reach. Nor had either of them any advantage from the clearing out of ditches, from bogmud, or from deposits of marl. Nor had either of them, that I could learn, made any experiments in turning in green crops with a view to enriching the soil. The experiments, therefore, must still be considered as imperfect, and yet conclusive as to the recuperative power of the soil from the economical use and application of the results of its own products. This teaches a lesson to large farmers of the highest importance; for, while trade and commerce depend, to a considerable degree, upon large investments and successful adventures, the success of agricultural operations depends most essentially upon the limitation of unproductive expenses, and the most careful application and use of the products of the farm. In too many cases it happens, as Scott has described the farming operations of Triptolemus Yellowley, "the carles and the cart-avers make it all, and the carles and cart-avers eat it all."

It was another beautiful circumstance in the case, that three of these individuals, who, with their families, were now subsisting 
independently upon the fruits of their own labor, had been tenants of an alms-house, where their spirits were broken down, their children separated from them, husband and wife divided, and all power of mending their condition effectually taken away. New life was imparted to them as soon as they were uncaged, and an opportunity afforded of obtaining from the prolific earth, by their own willing labor, that support which Heaven formed it to yield to well-directed industry. Separate from all moral considerations, instead of being a burden and an expense to the community, they now became themselves aids to bear these burdens and to share in these expenses. This was an immense gain; and, regarded by a reflecting mind in all its various bearings upon the community and upon themselves, its value camnot be overstated.

There was another circumstance in the case, to which I cannot help referring with peculiar pleasure; and that is, the provision made by the labor of the boys for their own education. The education, it is true, is of a very limited description. It embraces only reading, writing, the first principles or rules of arithmetic, and instruction in the elements and formularies of the established religion. Even this was a great gain. To be taught even the use of their own minds, in the acquisition of knowledge, is a great gain; to have even a few scattered rays of intellectual light poured into the darkened soul, may call into powerful exercise the desire of knowledge, which will impatiently search for the means of further gratification, and invent resources for itself. Its effect must be to elevate a human being, from a mere senseless implement or machine, into a consciousness of his own intellectual nature, and bring with it a degree of self-respect, which; in its humblest form, cannot but be favorable to good conduct and virtue. But the children found at these schools, in addition to mental instruction, that which many schools of a higher deseription do not furnish. They were trained to habits of regular and useful industry, instructed in the arts of husbandry, and in the most intelligent and economical application of labor. To what better school could they be sent? Under what better discipline could they be trained? I can fully understand how much in this case, as in all others, must depend upon the character of the teacher; and I can easily suppose that it may be necessary often. especially in a first attempt like this, to work with very imperfect 
instruments. But while every proper precaution is taken to secure a good moral character in the teacher, and all practicable guards are placed over his conduct by his success being made entirely dependent upon its correctness, a good deal, certainly, is done; and better minds, and persons of higher qualifications, from the success of these experiments, may presently be induced to seek these situations, in a country where the means of subsistence and profitable employment are, from the redundance of the population, becoming every day more difficult.

It is to be regretted that the farmers in general-perhaps it would be more just to say, that many farmers - look with very illhumor upon the allotment system, and are opposed to granting land for these objects, even when their landlords desire it. I have found no instance of a landlord opposed to it, though I have found with them a prevalent disposition to limit the allotment to a very small size. I am not willing to impute motives where they are not avowed. I have seen too many instances of the highest and best minds acting under very partial and mistaken views, in a manner unworthy of them, to allow me to commit myself by any harsh judgment. The farmers, it is said, are prejudiced against allotments, because the crops obtained under this limited and minute cultivation throw their own inferior crops into the shade, or, by demonstrating what the land is capable of producing, may induce their landlords to raise their rents. It is alleged, further, that the farmers are not willing in any way to diminish the dependence of the laborers upon their favor, as it might give them the power of demanding a higher rate of wages. The farmers, in the next place, it is said, are not willing that their laborers should appear in the public markets as sellers of produce, which, if the competition was not to be regarded as affecting prices, yet it might inspire them with a hurtful sense of their own importance. I report here only the suggestions of others, and presume to hazard no judgment. The motives named are, alas! but too consistent with the weakness and the too often unrestrained selfishness of human nature. Every man, certainly, has a fair right "to live;" and the duty of every just man is "to let him live." Blessed will be the day, if come it ever should, when every man will learn that his own true prosperity is essentially concerned in the prosperity of his neighbor, and that no gratification on carth, to a good mind, is more delicious 
than that which is reflected from the happiness of another, to which he has been himself instrumental. I hope my readers will not consider these reflections misplaced. It is evident that the farmers have no direct pecuniary interest in the success of their laborers, as far as that success might save them from becoming a tax upon the public./'This tax, though always assessed by the farmers as guardians of the poor, is yet always paid by the landlord. It is collected from the farmer; but the amount of rent which he pays for his land is always regulated by the amount of taxes by which the land is burdened. If any of the motives which have been assigned do prevail with the farmers, one can scarcely exaggerate the meamness and unworthiness of such motives, and can only desire that these persons may have juster views of what they owe to themselves, and to those whom the dispensations of Providence have made in a degree dependent upon their favor.

I am sorry to add my strong conviction, that the education of the laboring classes is not viewed with favor by some who move in a higher condition of life; at least that they consider it of doubtful value, and are desirous of keeping it within the most restricted limits. There are, indeed, many noble minds, who, properly appreciating its immense value, are willing to impart as liberally as they have themselves received, and heartily aid all efforts to extend its advantages to every individual in the conmunity; but this feeling does not appear to me general. Every allowance is to be made for a condition of society where different ranks are established; where the lines of demarkation are maintained with extreme pertinacity; where there can be no high rank but as there is a low one; and where, according to the depression of the one, the elevation of the other seems increased. Every approach, therefore, in this direction, is likely to be resisted: and this feeling of superiority pervades, with an almost equal intensity, every class in society, above the lowest, from the master of the household to the most menial beneath whom there is any lower depth. Education is the great leveller of all artificial distinctions, and may, therefore, well be looked upon with jealousy.

There is wanting, likewise, that just appreciation of the value and benefits of miversal education, which can hardly be looked for but among those who have lived in a community where its 
facilities and advantages are enjpyed by every individual as freely as the sunshine and the rain. While I am writing, a highlyrespectable clergyman, not wanting in a benevolent regard for his fellow-men, has said to me that "the most limited education is all that is wanted for these persons, as more would make them discontented with their condition; and if they can read their Bibles and prayer-books, it is quite sufficient "'" and this same remark I have heard several times from others. I cannot say that I have not heard the education of the lower classes spoken of, by persons apparently respectable, in very harsh terms, and in terms with which I should be unwilling to stain my pages. I will only add that I deem such views entirely erroneous and unfounded. If, indeed, there are good reasons for the laborers being discontented with their condition, let the evils of it be remedied. But if it be a discontent arising from circumstances of hardship - if so they must be deemed - which no human power can remedy, education, besides furnishing in itself resources to mitigate these evils, will serve to give them more just views of human life, and to reconcile them to a condition which the divine Providence has made inevitable. If education has a tendency to make persons discontented with their condition, is it not equally objectionable in respect to other classes in the community who find others above them? and in truth, as far as my own observation goes, the rich and the elevated are quite as subject to discontent as the poor and restricted, from whom the luring baits of ambition and avarice are absolutely withheld.

That condition of society is of all others most favorable to improvement, and to the development of the best elements of human nature, where every means of improvement is furnished without restraint, and where men become the creators of their own fortune. 'The favorite maxim of the great French emperor was, "Let the career be open to talents." In New England, this great principle every where prevails; and here, where the advantages of education are freely offered to all, and the highest conditions of influence and honor are equally accessible to all, it may be safely asserted that no evils have grown out of it, and that its moral and social influences have been the best which the most philanthropic could have desired. In New England, where, even among the most humble classes of society, the literary attainments are often respectable, there will be found 
among those caasses the most devoted friends to public order, and the most stanch supporters of her social institutions. I trust I shall not be thought to speak with an undue enthusiasm in saying, that the time has now come when there should be recognized in every human form a moral and an immortal mind; that the ore in this quarry should be brought out and polished; and that the higher conditions of life will be themselves elevated, and the whole community advantaged, by all improvement of the lower classes. The subsoil plough is deemed the great discovery of modern agriculture; and by bringing the lower strata up, and mingling them with the surface soil, and exposing them to the same genial influences of sunshine and air, it will not be denied that the whole, without injury to any, has been rendered the more productive.

The experiments of the public-spirited proprietor of these allotments have been perfectly successful in a pecuniary view. I have seen the accounts. The rents have been paid with punctnality. There has been no distress levied, and, among upwards of four hundred tenants, scarcely an instance of failure to pay. The rents demanded have been fully equal to those received for lands in the vicinity, of the same quality, held in large farms; indeed, they have exceeded them. At starting, she has found it necessary to assist her poor tenants in the purchase of tools and stock; but these obligations are required to be liquidated.

The allotments are held in the following amounts :-

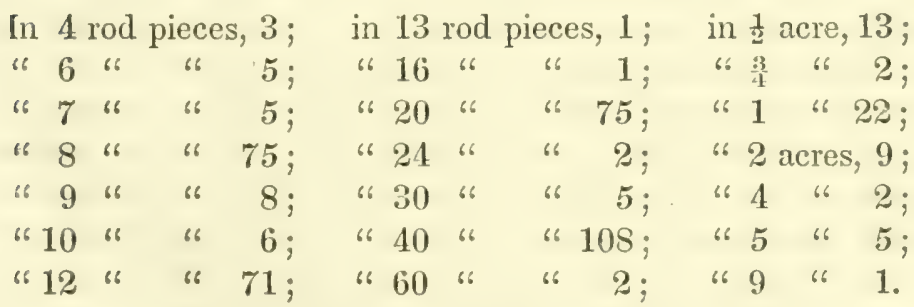

'Total, 421 allotments. Amount of rent received, $£ 4288 \mathrm{~s} .5 \frac{1}{2} \mathrm{~d}$. This is without houses or barns, the rent of which is a separate charge.

Of the occupants, the following are stated to be the number in the families supported from the land, with the exception of the small income from the instruction money. 
4 acres, 4 persons in family; 3 acres, 6 persons in family;

$\begin{array}{llllllllllll}6 & 66 & 7 & 66 & 6 & 6 & 5 & 66 & 9 & 6 & 66 & 66 \\ 5 & 6 & 7 & 6 & 6 & 6 & 5 & 66 & 6 & 6 & 66 & 66\end{array}$

39 persons ; 28 acres.

I submit these facts to my American friends as exceedingly curious. With us the land is not locked up by patents, entail, or mortmain. With us land is every where attainable, and at prices which bring it within the reach of every industrious and frugal man. But it will, I think, be interesting to look at these humble instances of domestic economy; and they must stimulate the most useful inquiry into the productive capacities of the land, which seem as yet to be very imperfectly developed. We are, likewise, not without our poor in the United States; and the vast influx of destitute emigrants is constantly augmenting the number. For idleness and profligacy there is no just claim upon public compassion; but I am convinced that a considerable portion of the poor would be glad to earn their own living if they could be put in the way of doing it. Whatever contributes to this object confers a public benefit.

It would be wrong for me to quit this topic without adding, that, since my First Report, I have visited portions of the country where, on the estates of some very large proprietors, (to one of whom the United States and Great Britain are under the highest obligations for adjusting their conflicting claims, and through whose beautiful grounds I rode eight continuous miles,) the cottages of the laborers were of the very best description; and their establishments, both within and without doors, indicated the greatest neatness and comfort. Gardens for fruit, vegetables, and flowers, were attached to all of them; and they were charming pictures of rural taste and embellishment. Many of these persons had likewise small allotments of land. The wages paid to the men were from $10 \mathrm{~s}$. to $12 \mathrm{~s}$. per week, and to the women $8 \mathrm{~d}$. per day while at work. This, of course, however, with the current expenses of living, did not allow them to accumulate any thing for sickness or old age. During the four weeks of harvest, by working by the piece, the laborer would sometimes earn more than 20 s. per week; and the women and children, by gleaning the scattered heads of wheat after the ficld is cleared of the crop, or, as 
it is here called, by leesing, not infiequently collect four or five bushels of grain. I have met with instances, where even more has been collected. Such are the fruits of the most exact frugalitv.

\section{XIV. - QUAN'III'Y OF SEED.}

The quantity of seed proper to be sown has been a subject of much debate. There may be an excess; and an error may be committed by sowing too small a quantity. An intelligent farmer makes the following calculation of the advantage and saving which would come to the country, if, instead of sowing two and a half bushels of seed to the acre, it should be found, as the maintains from his own practice and experience, it is sufficient to sow one bushel to the acre.

"Allowing," he says, "that, upon a fair calculation, $7,085,370$ ares are annually sown in the kingdom, in wheat, at the rate of two and a half bushels per acre, which is the ordinary allowance, there would be required 2,214,178 quarters (eight bushels per (quarter) for seed. But to sow one bushel per acre, only 885,671 quarters would be required; so that the amnual saving of seed would be $10,628,056$ bushels, or $5,901,192$ bushels more than the average importation of foreign com the last fourteen years. Though I merely take the instance of wheat, I am at the same time proving what may be done with all other corn; for the saving of seed, which I practise, is in equal proportions with all other kinds of grain, and with equal success."

The testimony of this farmer is so important that I shall be "':cused for speaking more at large on this subject. 'This gentleman has been a practical farmer of more than seven hundred anes of highly-rented, poor land; and what he recommends, he $\therefore$ s, he has long and suceessfully practised - that he grows crops much larger than the general average, and on soils of inferior (i.)seription, and with less than the ordinary expenditure of labor and manure.

I will allow him to speak for himself; and the results with inm, and the account of the proportion of seed for an acre used at Horsham, in the experiment which I have detailed above, afford 
the strongest reason, if for nothing else, for making further and more exact trials. The subject is clearly one of the first importance.

"The practice throughout England is to sow two and a hali and three bushels per acre, and the yield is seldom forty bushels, and more commonly only twenty bushels; and one tenth, at least, of the crop grown, is consumed in seed. These facts, and the knowledge that a single grain of wheat planted where it has room to tiller out, will readily produce four hundred fold, and often very much more, have induced me, in the course of the last eleven years, to make a variety of experiments, the results of which have shown me, that, independent of the waste, a positive and serious injury is done to the crop from so much seed; and the result is perfectly analogous to attempting to feed four animals upon a pasture sufficient only for one; and, in consequence, I have gradually reduced my proportion of seed-wheat from three bushels per acre, which was my practice, down to about three pecks, which reduction I have accomplished to the evident improvement of my crops.

"My practice is to drill every thing, (clover seed alone excepted;) to carefully horse-hoe, hand-hoe, and weed, so that the land may be kept perfectly free from weeds, and the soil between the rows may be stirred, and receive the benefit of fine tilth and cultivation, of which gardeners are sensible; but by farmers this is lost sight of, or not sufficiently attended to. My rye and tares for green feeding are sown in rows at nine-inch intervals; all my white corn at twelve inches; my pulse at twenty-seven inches; and my root crops, on the ridge, at twentyseven inches.

"My proportions of seed per acre are as follows:-

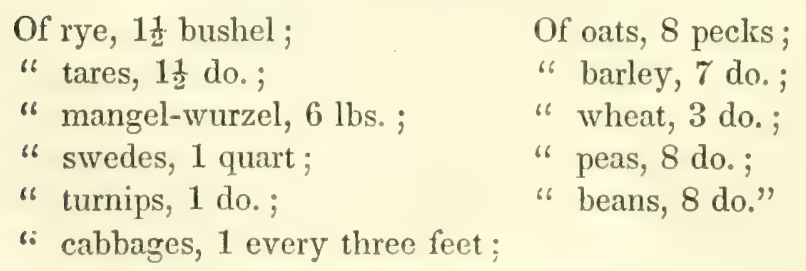

After detailing his mode of cultivation, to which I shall hereafter refer, he goes on to say, "I have frequently produced above 
five quarters (forty bushels) to the acre, and have grown above thirteen quarters of oats, (one hundred and four bushels,) and above eight of barley, (forty bushels.) Having shown the success, on an extensive scale, with thin sowing, I will explain why it is that three pecks of seed-wheat must be much nearer the correct quantity than ten or twelve pecks; and that any surplus of seed beyond a bushel must be very injurious to the latter growth of the crop. The produce of one ear' of thick-sown wheat yields about forty grains, (I say thick-sown, for thin-sown yields very much more, ) and, therefore, the produce of an acre (or twenty bushels, the ordinary average) must be, no matter how much has been sown, the growth of the ears from onc fortieth, or two pecks of seed, (and that, too, is allowing only one ear to grow from each grain, and forty grains from an ear.) This being the fact, of what use are, I ask, or what becomes of, the remaining eight or ten pechis of seed, which are commonly sown? But, in allowing one ear only to grow from a grain of seed, and each ear to contain only forty grains, I am far from taking what in reality would be the produce; for a single grain, having room, will throw up ten or twelve ears, and these ears will cach contain from sixty to eighty grains; and, supposing some of my small allowance to be lost or destroyed, the deficiency of plant is immediately met by the larger size of the ear, and by the tillering which is made, and the additional cars so produced, wherever room admits of the increase.

"Among the many proofs I have had of the advantages from thin sowing, the following is a striking fact: In the autumn of 1840 , I had to sow with wheat a field of eight acres, and I gave out seven bushels for the seed; but owing to an error of the drill-man in setting the drill, when he had sown half the field, he found that he had not put on half the sced; but that I might not discover, by the overplus, his error, he altered the drill, so as to sow the rest on the remainder of the field; and in this way one half of the field had little more than two pecks to the acre, while the rest had nearly five pecks. I did not know of the error, and was surprised, in the winter, by finding part of the field so thin, and, had not the rest of the field looked much better, should have ploughed it up; but at harvest the thinnestsown half proved the best; and I should never have lnown the error of sowing but for this fact having induced the carter to point it out to me." 
"At first, no matter how much seed has been sown, nearly every grain vegetates and finds space to grow; and in the early stages, when the air and soil are moist, and the plants small, there is food for all. But as the plants increase, a struggle for room and nourishment commences, which increases with their growth, and finally terminates by the destuction of the weaker by the stronger plants; but not until after a contest, lasting up to harvest, which leaves the survivors stunted, and the soil exhausted by having had to support three plants instead of one; and producing mischief, which is frequently the cause of blight, mildew, and the falling of the crop.

"It is to this I would principally ascribe the mildew, and blight, and falling, of the crop; for so far my practice proves it, that, since I have taken to sow only a bushel of wheat per acre, and I have done so now for some years, and on many hundreds of acres of wheat, - I have rarely found any portion affected by any disease." *

This is certainly strong and decisive testimony, and shows how deserving the subject is of the most exact and repeated experiments. Since the foregoing account of the Horsham experiment of the last season, I have received information of the result of a second experiment made this season by the same individual, Mr. Alman, nursery-man of Horsham, Sussex county. He has dug an acre of land with spade or fork, and dibbled it with the same kind of wheat which he sowed the previous year, and the crop is fast advancing to maturity. The amount of seed required for planting the acre, one grain in a hole, at the distance of nine by six inches, was a little more than one and a half gallon; the seed was covered about two inches in depth; the cost of digging the ground ten inches deep was $2 \frac{1}{2} \mathrm{~d}$. per rod; the cost of planting or dibbling the seed was $10 \mathrm{~s}$. per acre, and the expense of hoeing it was $7 \mathrm{~s}$. per acre. No manure has been applied to the land this year; but of the character of the soil I am not informed. I am assured that it promises to yield as well as it did the last season. A specimen which has been sent to me fully ripe, shows an equal growth both in the size of the stalk, which is more than five feet, and in the number of stems from a single seed. I shall presently have an exact 
account of the result, which my readers will receive with great interest. 'The expense of dibbling by hand has been accurately' kept, and, as above, in point of cost, would show a great saving in comparison with even the best machine. The increase from a single seed has been in some cases most extraordinary, and shows the prolificness - may I not properly say the unstinted beneficence? - of nature. I have myself counted, from a single grain of wheat, ninety-five seed-bearing stems; and I shall give the account of another experiment, the product of which I saw.

A farmer, B. King, at Eastbourne, Sussex county, on the 22d July, 1841, planted three grains of wheat; and one of them produced a root with upwards of a hundred ears.

One grain, the shoots of which were divided and transplanted twice, yielded, in 1842, three pounds twelve and three quarter ounces of clear grain; and the third grain, the shoots of which were divided three times, yielded seven pounds fifteen ounces and a half. The whole product of roots from this grain was 173 ; of ears, 3272; of grains, 97,028, and the weight as above. Half an ounce of this wheat, carefully weighed, contained 382 grains. This was the product of one grain in one season, which, according to what was required for the Horsham experiment, would be sufficient, in the second year, to plant two thirds of an acre. Of course, it is not to be expected that such an operation as taking up and dividing the plants could be cennomically practised to any great extent; but it shows how very easily and soon the seed of any valuable variety may be obtained with a little pains-taking. Some of the most esteemed varieties of wheat have been procured from the selection of a single head, which showed in the field an extraordinary predominance orer its neigbbors. This is understood to be the origin of the celehrated Chevalier barley, which was propagated from a single ear. found by a gentleman of that name in his field, and carefully cultivated. By the methods adopted above, a single head of wheat might be made, in the second year, to furnish a supply for acres; and the means of speedily introducing a new grain into a large district of country, might be transmitted thousands of miles in a letter. Such are the facilities of improvement which a !eneficent Providence oflers to those who are willing to use them.

An experiment of a similar kind was made, some years ago, by a Mr. Miller, and reported in the Memoirs of the Bath Agricul- 
tural Society, in which the result of the cultivation of a single season was even much more extraordinary than the above; but it is well known to the agricultural world, and need not be restated.

\section{XV. — STEEPING SEEDS.}

I may as well here as any where recur to an experiment exhibited at the Dundce Show, of the effect of prepared steeps for seed. It excited great attention on that occasion. I visited the grounds of the gentleman who made the experiment; and he has been lind enough to write me, on the subject, a letter, which I subjoin.

"Sir,

"Seminaries, Dundee, 13th September, 1843.

"Since I had the pleasure of meeting you in Edinburgh, I have thought a good deal about the way in which I ought to proceed as to concealing for a time, or at once revealing, my method of preparing seeds, so as to produce superior crops of grain. I have at last determined that the better way is to make the process known to the heads of agricultural societies.

"In accordance with this resolution, I have written to the Duke of Richmond, as president of both the National Agricultural Institutions of Great Britain, and to the president of the Royal Agricultural Improvement Society of Ireland, disclosing the processes which I have used; and I now do the same to you, as agricultural commissioner from the United States.

"I consider this plan better, in every respect, than sending prepared specimens of seeds, as the applications for these might soon become too numerous to be attended to.

"The specimens of growing corn, which I exhibited at the show here, were the produce of seeds steeped in sulphate, nitrate, and muriate of ammonia; nitrates of soda and potass, and combinations of these. It was objected by some that the tallest specimens of oats were too rank, and would break down before coming to the ripened seed. I should by no means be afraid of such a restilt, as the stems were strong in proportion to their 
height; but should there even be some reason in the objection, the result might be modified by a modification of the process. The tallest oats were prepared from sulphate of ammonia, and I am convinced, from experiment, that the addition of a portion, say one half, of sulphate of soda, or sulphate of potass, would so modify the growth as to make the stalks moderately high, and at the same time preserve the superior productiveness of the seed.

"The barley, which, you may perhaps recollect, consisted of an average of ten stems from one seed, and thirty-four grains on each stem, was the produce of seeds steeped in nitrate of ammonia. I may mention that the best illustration of the comparative productiveness of prepared and unprepared seed was exhibited by the contrast of wheat, sown 5th July, which, by the 10th of August, the last day of the show, presented the following results: the prepared seeds had tillered into nine, ten, and eleven stems; the unprepared into only two, three, and four; and both were from the same sample of seed, and sown in the same soil, side by side.

"The various salts above specified were made by me from their carbonates, and were exactly neutralized. I then added from eight to twelve measures of water. The time of steeping varied from fifty to ninety-four hours, at a temperature of about $60^{\circ}$ Fahrenheit.

"Barley, I found, does not succeed with more than sixty hours' steeping. Rye-grass, and other cultirated grasses, may do very well with from sixteen to twenty hours; but clovers will not do with more than eight or ten hours, for, being bilobate, the seeds are apt to burst in swelling.

"On the 16th ultimo, I caused four cart-loads of earth, dug from about six feet under the surface, to be laid over tilly ground, and spread there, and in this virgin soil, totally destitute of any organic matter, I sowed seeds of oats and barley prepared in seven different ways; but, having to leave on the 31 st, I conld not form a correct estimate of the comparative progress of the seeds, as the season is far advanced, and vegetation slow; but, if in health, I shall revisit the place in October, and shall then be able to judge better of the result. Along with the prepared seeds, I sowed also some umprepared, both in the virgin soil and in pure sand. They had all sprung 
well when I left. I hope soon to have the pleasure of writing you again on the subject. Meantime,

"I remain, sir,

"Your most obedient servant, "Jas. CAMPBELL.

"Hexrr Colmar, Esq. London."

There were exhibited, on this occasion, specimens of oats, barley, wheat, and rye-grass, raised from seed chemically prepared. Mr. Campbell adds in another letter as follows:-

"It is now a considerable time since I began to imagine that, if the ultimate principles, of which the proximate constituents of most of the gramineous seeds are composed, could by any means be made so to enter the substance of the seed, and at the same time not to injure its vitality, as thoroughly to imbue its texture with an excess of these principles, the end (viz., of superseding manures) would be accomplished; and it is by doing this to a certain extent that I am certain I have succeeded.

"The specimens of oats prepared from sulphate of ammonı are magnificent, both as to height and strength, being six feet high, and having stems like small canes, and consisted of an average of ten stems from each seed, and 160 grains on each stem. The oats from muriate of ammonia were vigorous and equally prolific, but not so tall; and those from the nitrate of soda and potass were nearly equally prolifie, but still less tall. Big, or bear, from a preparation of nitrate of ammonia, like that in which the barley was steeped, had an average of eleven and a half stems from each seed, and seventy-two grains on each stem."

Mr. Camplell states "that the ground in which his experiments had been made had received no manure for eleven years, and in it there was little organic matter of any kind." It was in a yard, or old garden, next to his house; but unless he had made an analysis of the soil in respect to the amount of organic matter contained in it, I should conclude that his judgment here was at fault. This circumstance, however, is of little consequence, since the experiments were comparative, and made in the same soil, and under the same circumstances. The plants had been principally removed from the ground when I saw it; and I had only to regret that the experiments, of which, from the apparent 
results, he could hardy, beforehand, have realized the importance, had not been made with more scrupulous exactness. They are, however, sufficiently interesting and decisive to induce other experiments, in which the results may be more defined. Mr. Campbell's disinterested conduct in communicating them to the public does him the highest honor.

Mr. Campbell has since sent the following communication to the Agricultural Society, as to the results of the unfinished experiments noticed in his former letter:-

"The salts were neutralized by adding the carbonates until effervescence completely ceased; and this was done that there might be no excess of acid." Mr. Campbell adds, with respect to his succeeding experiments, which he proposed to examine on the 12th of October, that they were completely successful, showing a decided contrast in favor of the prepared seeds. In the soil dug up from 6 or 8 feet under the surface, the prepared seed showed plants with seven and eight stems, while the unprepared had not more than three.

The preparation of seeds by steeping is not a new process. The preparation of wheat, by soaking in brine or in a preparation of arsenic, has been recommended, and, so far as my own experience and obscrvation go, may he considered as a sure remedy against smut. The steeping of Indian corn in a solution of copperas and of saltpetre has likewise been supposed to stimulate and promote its growth, though this is not so well established as might be desired. But a scientific attempt, like that of Mr. Canpbell, to combine, upon chemical principles, the ingredients or salts deemed essential to the growth of the plant, and to furnish them by soaking the seed in them, is a rare, though not wholly an unknown attempt. Its partial success, in this case, affords strong encouragement to further experiments. 'The steep may be supposed to operate in two ways - either as a stimulant, to cause the seed to develop its powers of germination more rapidly and fully than it otherwise would do, and thus gather more of the nourishment which it needs from the soil or the atmosphere; or as supplying that proportion of saline or inorganic matter which the plant requires. This is indeed very small, "though absolutely essential to the perfect condition of the wed, and to the healthy growth of the plant which springs from it." This is said to be, in wheat and barley, from $1 \frac{1}{2}$ to 2 per cent. of 
the whole weight; and in oats it is said to be $3 \frac{1}{2}$ per cent., though much of this is in the husk of the oat. In being applied at onctto the seed in a form to enter and saturate the pores of the seed, it may be expected to be taken up by the small roots of the plant as soon as they are developed; and its effects, therefore. must be immediate. But whatever may be the theory in the case, should Mr. Campbell's results be confirmed by further experiments, the fact will be obviously of great importance.

From some pamphlets translated from the German by Professor Johnston, extracts from which have been published in the Edinburgh Journal of Agriculture, it seems that great discoveries have been made in Germany, in the steeping of seeds: and, in the enthusiastic expectations of one of the discoverers, the application of manure may be dispensed with, and the rotation of crops on the same soil, in order to recruit the soil, will no longer be necessary. The confidence with which these experiments are given, and their results proclaimed, would seem to entitle them to attention.

I shall here take leave to quote from a paper of Professon Johnston some of these statements. Franz Heinrich Bickes, of Castel, Mayence, has published An Account of the Discovery of a Iethod of cultivating the Soil without Manure. He says, "It is twelve years since the discovery was made. The experiments have been made at various seasons of the year, and the same crop has been repeated on the same soil without regard to the usual rotation. The cost is trifling, and the supply of the materials to be substituted for manure is inexhaustible. The testimonies in its favor are said to be from practical men; and they assert that, from examples in the Imperial Garden in Viemna, in general the prepared seeds exhibited a very much stronger growth, were of a deeper green, had thicker stems, finer and fresher leaves, larger grain, and the grain was thimner skinned, and therefore contained more meal.

"The hemp was of a much larger size, and had many sideshoots bearing seed.

"The Indian corn had more ears. "

"The buckwheat was upwards of three feet high, and full of seed.

"Wheat, rye, barley, and oats, are thicker, and have more numerous stems, larger ears, and more grains in each. 
"The lucern was beyond all comparison stronger, had more shoots, and its roots were as thick again.

"The disks of the sunflower were doubled in diameter; the cabbage had larger heads, the cucumber larger fruit, while the unprepared seed yielded nothing."

Other testimonials are added from persons of respectable standing and condition. Other plants, besides those above mentioned, are said to have been equally benefited. One fourth only of the usual quantity of seed, of wheat and rye, was sown on a poor, unproductive clay; and yet the product was greater than on the newest land of good quality, though aided by manure.

"Ten or twelve potato plants gave, on an average, thirty large potatoes each, and had stems seven feet in height.

"Fifteen stalks of Indian corn had, on an average, five ears each, some having as many as eight or nine ears to a single plant.

"The buckwheat was four and a half to five feet high; the flax had four to five stems from each seed. The white clover was as large in the leaves and stems as the red clover usually is; the red clover and lucern three feet high."

The experiments of Mr. Campbell induced many farmers to try the effects of steeps upon their seeds. One of the most experienced and intelligent cultivators in Scotland informed me that his success had been partial. He had made numerous experiments, and in some instances with remarkable, in others with no effect. I am not yet in possession of the details, which I presently hope to obtain from him, and on which I shall greatly rely. As my Report is going through the press, I have been favored with a reply to a letter written to Mr. Campbell on this subject, which I annex.

"The accounts which I have received from various quarters are conflicting, some exceedingly good, and others equally bad; but this I have learned, that the greatest success has attended the experiments on a great variety of soils.

"I believe - and this is also the opinion of many others - that, where failures have taken place, they are due either to mismanagement or to the drought of the season. The results of my own experiments are highly favorable; and I have a variety of specimens for the exhibition at Glasgow."

He adds, "My nephew writes me as under." 
"I have just seen Sir John Ogilvie's overseer, and he states that the steeped oats sold by roup, yesterday, at $1 \mathrm{~d}$. per pole more than those which were not steeped on the next rig."

"N. B. The prepared seeds were sown much thinner than the unprepared, at least one quarter.

"Cranch \& Co., (Newcastle-upon-Tyne,) 30th July, write, 'We have received some good accounts of the steeps.'

"P. Bruce, (Hull,) 30th July, writes, 'I am glad to inform you that one or two parties tell me that they will buy the steep again, supposing that any falling off is attributable to the drought.' He has himself seen some that looks very well.

"I may add that any that I have hitherto seen looks exceedingly well, better than the unprepared, although sown thimer."

I cannot say that I am sanguine as to those extraordinary results to which, from the quotations which I have made, some persons look forward, when there will be no longer a necessity for a rotation of crops, and even the application of manure to the soil may be dispensed with. But I cannot help thinking that much remains to be achieved, and that much may be hoped for. We are not to be surprised that failures occur; but one wellauthenticated experiment, conducted in an exact manner, and in which the extraordinary results may be directly traced to the application, is sufficient to outweigh a hundred failures. The exhibition at Dundee, supposing Mr. Campbell's statements to be true, - and I know no reason to doubt, but, from his manly conduct, the best reason to believe them, - satisfied me that something important had been effected. I rely little upon mere opinion and conjecture, even of parties above suspicion of dishonesty, The mortification of failure, the desire of success, the ambition of notoriety, and especially any degree of personal or private interest, - all may serve to color the vision, to bias the judgment, and present grounds of hesitation, if not of distrust. With a full share of confidence in the virtue of men, I have been too often disappointed not to require the most ample evidence in all cases of moment. I was not a little amused in visiting, with several gentlemen, the farm of an excellent cultivator the last summer, that, when he showed us in his field of swedes, with an air of the most confident triumph, the surprisingly beneficial effects of a certain application upon some marked rows, every one of the party except himself was satisfied that 
the rows in question had no other distinction than that of absolute inferiority to all the rest. It would have been as useless as it would have been uncivil to avow our convictions to him, for men are seldom convinced against their will, and assaults upon an unduly-excited organ of self-esteem, if they do not arouse combativeness, inflict only needless pain. In agriculture, being eminently a practical art, and as yet, I believe, claiming not a single theoretical principle as established, excepting as first deduced from long-continued practice, experiments are of the highest moment. The careless and slovenly manner in which they are commonly conducted, the haste with which men jump to their conclusions, the variety of circumstances which belong to every case of importance, and the imperfect manner in which these circumstances are observed and detailed, are the just opprobrium of the agricultural profession. $\Lambda$ most intelligent and agreeable friend, in spealing of the best modes of fattening poultry, and in expressing her distrust of some which were recommended, said that her venerable grandmother always fed and fattened her poultry in a very difierent way. But upon being asked whether her grandmother's fowls were the best layers, brought up the most chickens, and produced the best poultry for the table of any to be found, she was compelled to answer that on this point she had no information. A learned naturalist, who, in many respects, was justly celebrated for his acquirements, was once asked why black-wooled sheep consumed more food than white, and proceeded gravely to give half a dozen philosophical reasons for it, without having once inquired whether the fact were so.

It is strongly hoped, that, under an enlightened system of agricultural education, for which the auspices now are most encouraging, and by the establishment of experimental farms, many important suggestions, in relation to agricultural practice, as yet only conjectural, may be determined, and much actual progress made in agricultural science, by the only infallible teacherexact and enlightened experiment. 


\section{XVI. - SPADE HUSBANDRY.}

The spade husbandry, to which I have already referred, has been undertaken by several gentlemen, in England, on a somewhat extended scale, for the purpose of giving employment to a numerous population in the vicinity of some large towns, suffering for want of the means, or the opportunity, of earning a subsistence. In one case, the extent cultivated by the spade has been fifty acres; in two other cases, over two hundred acres each; and the crops produced have been the same as in other field cultivation with the plough ; such as turnips, cabbages, beets, potatoes, barley, clover, and artificial grasses, oats, beans, peas, tares, and wheat. The crops have been cultivated at not an unreasonable expense, and the yield has been fully remunerating. Oats have given at the rate of forty and fifty bushels per acre, and, indeed, very much more ; and wheat thirty, thirty-two, and forty bushels. The instrument found by experience best for use has been a three-pronged fork, fourteen inches in depth, and seven and a half inches in width. By this instrument the ground has been stirred to the full depth of the prongs of the fork, but only about nine or ten inches of the soil have been taken out and inverted.*

The principle upon which this practice is recommended is the same with that of subsoil ploughing. The object desired is to loosen the substratum or under soil, so that, in the first place, all superfluous water may be drained off; in the second place, that the soil may be brought into a finer tilth, and rendered more permeable to the roots of the plants, in order that they may find the easier access to the nourishment which they draw from the soil; and in the next place, that it may become enlivened, if the

* Mr. Cruttenden has contrived a fork with a sharp blade of about an inch in width, which seemed an improvement on the common form, and which he deemed very useful. The annexed engraving exhibits the shape of the implement. The blade, like a spade, cuts off the roots with which it comes in contact, and the earth, when lifted, becomes broken by falling through the open spaces between the prongs, combining the advantages both of a spade and a fork.

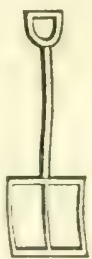


expression be allowable, and enriched by the admission of the air, by which all portions of it are thus visited, and gain from the atmosphere the elements of vegetation which it furnishes. Of the value of this circumstance no intelligent agriculturist can entertain a doubt. There is another advantage attending the spading of land. The tendency of drawing a plongh through the land is to render the ground more hard at the bottom of the furrow, where the shoe or bottom of the plough presses upon it, and to make it consequently more impervious to the roots of the plant than it would otherwise be; this is of course avoided in the spading of land. The subsoiling of land is deemed of comparatively little use, unless connected with a system of thorough drainage ; and this drainage would seem to be of equal importance upon land cultivated with a spade.

In Flanders, it is said that the cultivation by the spade prevails to a great extent, and is eminently successful. In the United States, where land is abundant and labor comparatively scarce, it would be idle to recommend to any great extent cultivation by the spade. Yet it would be curious to see what might be done in this way on a small scale. One of the most productive farms for its extent in New England, within my knowledge, - if farm it may be called, - consists of seven acres, from which the farmer or cultivator sells annually to the anomit of twenty-five hundred dollars, or five hundred pounds sterling. The industrious and frugal owner sustains his family in comfort and independence from this source only, and is actually growing rich. He resides within a few miles of a good market, and by his skill and industry he sometimes obtains five different crops in a season on the same land. The great question of the size of farms will come into discussion as I proceed; but I cannot now enter upon it. Such examples of what may be called cottage. economy, are not without instruction to those who hold and manage large possessions. In France, the farms are greatly subclivided, and the holdings are very small. It is estimated by a statistical writer, whose authority is respected, that, among 1,213,200 of small proprietors in France, their possessions do : iot arerage over five acres apiece. Political economists strongly (inject to such small divisions of land, as unfarorabic to the Iroduction of wealth, and not likely to lead to those improved 
modes of agriculture, which would be pursued under a system of large proprietorship.

There is undoubtedly a good deal of weight in the latter reason ; for implements and fixtures connected with an improved system of husbandry are themselves expensive, and few great and substantial improvements can be made without a considerable outlay of capital. Such improvements likewise demand systematic arrangements, and often extensive combinations, in order to their being eficeted. I have known numerous instances where lands required draining, and indeed were comparatively worthless without it; but this draining could not be effected, from the obstinacy of a neighbor, through whose land only could the water be made to descend. In other cases, where fields were held in common, the same evil has been suffered from a refusal on the part of the owners of the several pieces to enclose the land, and to unite in accomplishing the common object. It cannot be doubted, likewise, that the minds of men are greatly affected by the nature of their employments; and although there are many cases in which active and strong minds will rise above every barrier, and, in spite of the circumstances by which they are surrounded, will develop their native greatness, yet the constant confinement of the mind to a narrow and very limited sphere of action, will not be without its effect upon all its operations. The successful management of a large farm, like the management of any other large concern, requires a great deal of inquiry, calculation, reflection, and knowledge; and all this, from the necessity of the case, begets more inquiry, calculation, reflection, and knowledge. It is to minds only of this superior cast that we can look with confidence for enterprise and distinguished improvements.

The effect of such small subdivisions of land as those of which I am writing, and those which are said to take place in France, upon the production of national wealth, is another question, and must be put in an exact form before it can be answered. If we could suppose all these small farms to be cultivated in the most improved and perfect manner, the gross produce would be greater than under any other system. This, however, is not to be expected, and, for reasons already assigned, would hardly take place. In a pecuniary result, therefore, the subdivision of land into small farms is likely to fall much short of the product of the 
land cultivated in large occupations. But in reference to a general competence, and a more equal and just distribution of the prodicts of the land, and in its moral effects upon the character of the laboring population, the system of small fimms should dunbtless be preferred.* If pecuniary gain alone must be the paramount object of consideration, and the prosperity of a country is to be measured only by dollars and cents, or pounds, shillings, and pence, the cultivation of the land in large parcels would doubtless best effect the purpose; but if the true prosperity of a country is rather to be determined by the general comfort, improvement, and personal independence, of its population, we can hardly doubt that arrangements which most nearly connect an individual's interest with his own exertions and character, and, if the expression be allowed, make him the creator of his own fortune, are those which are most likely to effect these ends. The difference in the condition of an individual laboring always at the will of another, and having no other share in, or control over, the products of his labor, than that which he obtains from the willing consent, or wrings from the reluctant necessities, of his employer, and that of an independent freeholder in the soil, who has a personal stake in the producis of his labor, who applies this labor as he chooses, and has the absolute control of its results, can be best understood by those only who have seen mankind in these two different situations.

There are two cases in which the spade husbandry might have an important application in the United States. The English know nothing of, and can scarcely, as far as my own observation goes, be made fully to understand, a condition of things,

"No one," says the Baron de Stacl, "can compare the present state of France with that which prevailed in 1789 , without being struck with the great increase of the national riches. Throughout all France, the greater number of laborers and farmers are at the same time proprietors. Nothing is more common than to sec a day-laborer proprietor of a cottage, which serves as an asylum to his family; :I gaden, which feeds his children; a little field, which he cultivates at his leisure hours, and which enables him to sustain, with more chance of success, the terrible struggle between laborious poverty and engrossing opulence." +

"In 1838, the number of separate propertics taxed for the impút foncier, in Erance, amounted to the enormous number of $10,896,000$. The population of 1.... Ind proprictors, with their fimilies, is cstimated at $20,000,000$, or nearly two thirds of the total population. The average size of each property is about fourteen acres." † 
in which every man of common intelligence, industry, frugality; and sobriety, the great and certain elements of success in almost every department of life, may become a freeholder, that is, th: possessor in fee-simple of more or less land, according to his desires or wants. Here, in England, land is so dear as to be beyond almost the aspirations of men with small means; still less is it within the reach of those, whose whole wealth consists in the labor of their own hands; or it is held in large masses by men whose active capital corresponds with the extent of their possessions, and who, in such cases, would almost as soon sell their teeth as their land; or it is locked up by the laws of primogeniture and entail, so that even those who hold it have not always the power to alienate it.

It has been said more than once to me, since the publication of my First Report, that it is no evil that a man, and any man, cannot own a house and land, and that the condition of a freeholder is not preferable to that of a tenant. Certainly this must depend, to a great degree, upon the conditions under which the tenancy is held. But, without pronouncing it an evil, and leaving every one to enjoy his own opinion of the case as it is, I deem it a great good where such a blessing as a home of one's own, and a small farm of one's own, subject to no other conditions than such as the common laws of the land extend over it for protection, is within the reach and the early attainment even of the humblest member of the community. Now, we have in New England, and in other parts of the country, a great many instances, in which men and their families, pursuing some handicraft or in-door trade, and professional men, with small incomes, are the owners of houses in the country, with a few acres of land attached, on which they are occupied in their hours of recreation, or at scasons when the calls of their trade or profession do not press too strongly upon them. While these small farms furnish a large proportion of the supplies which they and their families require from the garden or the field, they are alike conducive to their physical, and, I add with equal confidence, to their moral health. To such persons the spade cultivation, and the minute and exact husbandry to which it leads. would be of great importance. Among the Romans, seven acres were regarded as an ample allowance for a family; and it woulci be extremely desirable to know what are, in fact, the productive 
powers of an acre. As yet, I believe, they are very far from being ascertained; but, in the course of my agricultural observations, many cases have come under my notice, in which the products from a very few acres, cultivated with all the care and liberality which such cases admit of, have far surpassed those of farms many times as large.

In one instance, which happens to be before me, the following was the result :-

Three men were employed one week in digging an acre with a spade, at $9 \mathrm{~s}$. per week, . . . . . . . $27 \mathrm{~s}$. The same amount of land, in ploughing three times, cost

7 s. per acre each ploughing, . . . . . . . . 21 Against the spade, . . $\overline{6 \mathrm{~s}}$.

At harvest, however, the spaded land produced fifteen bushels of wheat more than that under the plough. Here, then, was a clear profit, at the current price of wheat at the time, of $£ 419 \mathrm{~s}$. per acre.

Another example is given of a farmer in Essex, on a farm of one hundred and twenty acres.

"I have annually dug," he says, "from three to five acres, for the last five years. The soil I have operated upon is light, with a substratum of gravel, sand, and tender loam. The expense of the forking is $2 \frac{1}{2} \mathrm{~d}$. per rod $=33 \mathrm{~s}$. $4 \mathrm{~d}$. per acre; but I always dig under the furrow left by the plough, which adds one ploughing to the expense, viz., 8 s. By adopting this course, I do not bring up the inert subsoil until the second time of digging. The influence of forling on the crops seems to be, that all root crops are much increased in quantity; the cereal crops, which follow, are less injured by drought; and the land becomes much more free from annual weeds, as well as from those which are of a more permanent nature. I had recently a person with me who has made a series of very carefully-conalucted experiments, in which digging has been contrasted with ploughing. He thinks the produce of the forked land was nearly doutle that of the ploughed."

This farmer adds, "First, a man can dig a greater quantity" of land, in a given time, with a fork than he can with a spade. My experience shows one sixth; and it strikes me it must be so, becanse the pointed ends of a three-pronged fork can be more 
easily pushed into a hard subsoil than the continuous end of a spade; secondly, it does not bring up so much of the subsoil as the spade, but mixes the earth more, a great portion slipping through between the prongs; thirdly, the bottom is left more uneven and broken by the fork, which I consider a great advantage. One great objection to the plough is, the smooth, glazed surface which it leaves below, and which presents a resistance to the delicate fibres of the plant. If it is correct that, in most instances, the present surface soil is nothing more than a portion of the subsoil improved by cultivation, it must be right to increasc the quantity of corn-growing earth by subjecting more subsoil to the same operation."

"An instance is given of the spade husbandry of a farmer in Wurcestershire, who has cultivated four acres of very stiff clay land, two acres of it for seventeen years, and two acres for twenty-seven years. He grows, annually, wheat and potatoes; with about one quarter of an acre of beans, the crop being shifted altemately from one division to the other. His mode of cultivation is as follows: As soon as the wheat is off, he plough his stubble-ground, raking up the stubble to litter his pigs; he then digs it over with a fork, and plants on it potatoes in the following spring; this crop being kept clean, the land needs no further preparation for wheat. He does most of the labor himself; but he estimates it to amount to about $£ 46 \mathrm{~s}$. per. acre: his average produce has been rather more than forty bushels of wheat and twelve tons of potatoes per acre. The system he follows, as regards the cropping of the land, therefore, is evidently of the most trying description; and this is not all, for he sells all his produce, even his straw, excepting a few potatoes and beans, which he consumes in ammually fecding about thirty or forty score of bacon for his own consumption. He litters his pigs with the potato haulm and stubble; and the manure from this source, and from his privy, with some clay out of his ditches, which he gets occasionally and burns, is all that he has to fertilize the land with.

"Leaving out of consideration the small quantity of beans raised and bacon fed, valuing the wheat at $7 \mathrm{~s}$. per bushel, and the rest of his produce at the price he obtains for it, we shall have something like the following account of his farming :- 
f. s. d.

24 tons of potatoes, at $50 \mathrm{~s}$. per ton, . . . . 6000

80 bushels of wheat, at 7s. per bushel, . . . . 2800

2 tons of straw, at $50 \mathrm{~s}$. per ton, ..... 500

9300

Deduct from this, manual wages, at $£ 46$ s.

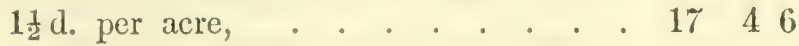

Seed potatoes for two acres, 25 bags of

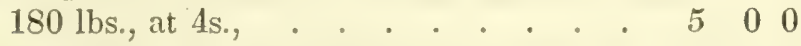

4 bushels of seed wheat, at 7 s. 6 d., . . 1100

$2314 \quad 6$

Leaves him, subject to rent and parochial payments, $\overline{£ 69 \quad 56}$

"This famer than gives strong and unanswerable evidence in favor of the fork or spade husbandry. He adds that he has pursued this system of cultivation during the period of the last twenty-four years, with the exception of the first three years, when his neighbors ploughed his land for him for nothing; that they are willing to do the same now, at any time, but he prefers soing to the expense of digsing it, to having it plonghed for. nothing." **

This is certainly an instructive example, and shows what may be done by very limited and small means. We have, in the United States, beyond a question, a large number of farmers, who, if they would cultivate, to the utmost of its capacity, a small extent of land, in the most thorough manner, would find themselves comparatively independent; whereas, now, without capital, spending their deficient labor over a large surface, and doing nothing thoroughly, they lead a life of vexation, toil, and disappointment, without any compensating result.

'To these examples I add the subjoined experience of a Scotel. farmer, who received a premium from the Agricultural Society fo: his skill and success.

"In 1831, I determined to ascertain the difference of the expense and produce, between trenching land with the spade. and summer-fallowing with the plough in the usual way. I

* These two instances are quoted by that able and industrious agricultural writer, Cuthbert W. Johnson, F. R. S., in Journal of Agriculture for January, 1844. 
therefore trenched thirteen acres of my summer-fallow break, in the months of June and July. I found the soil about fourteen inches deep; and I turned it completely over; thereby putting up a clean, fresh soil in the room of the foul and exhausted mould, which I was careful to put at the bottom of the trench. This operation, I found, cost about $£ 410$ s. per Scotch acre, paying my laborers with $1 \mathrm{~s} .6 \mathrm{~d}$. per day. The rest of the field, consisting of nine acres, I wrought with the plough in the usual way, giving it six furrows, with the suitable harrowing: I manured the ficld in August: the trench got eight cart-loads per acre, the ploughed land sixteen: the field was sown in the middle of September: the whole turned out a bulky crop as to straw, particularly the trenched portion, which was very much lodged. On threshing them out, I found them to stand as under:-

£. s. d.

'To two years' rent, at $£ 210 \mathrm{~s}$. per annum, . . . . 500

" expense of trenching, . . . . . . . . 4100

"seed, 3 bushels, at 6 s. 9 d., . . . . . . . . 103

" 8 cart-loads of manure, at $4 \mathrm{s.}$, . . . . . . . 1120

" expenses of cutting, threshing, and marketing, . . 1100

Profit, . . . . . . . . 3189

By trenched wheat per acre, 52 bushels, at 6 s. 9 d. . $\overline{£ 17110}$

E. s. d.

To two years' rent, at $£ 210 \mathrm{~s}$. per acre, . . . . 500

" 6 furrows and harrowing, at $10 \mathrm{s.g}$. . . . 300

"seed, 3 bushels, at $6 \mathrm{s.} 9 \mathrm{~d} .$, . . . . . . . . 1103

" 16 cart-loads" manure, at $4 \mathrm{s.}$, . . . . . . 340

" expenses of cutting, threshing, and marketing, . . 1100

Profit, . . . . . . . . 093

By ploughed wheat per acre, 42 bushels, at 6 s. 9 d. . $\overline{£ 14 \quad 36}$

"I now saw that, though it might be profitable to trench over my fallow-break during the summer months, it was by no means making the most of the system, as the operation was not only more expensive, owing to the land being hard and dry during the summer, but that it was a useless waste of time to take a. whole year to perform an operation that could as well be done in a few weeks, provided laborers could be had; and as, in all agri- 
cultural operations, losing time is losing money, - as the rent must be paid whether the land is carrying a crop or not; so that in taking one year to fallow the land, and another to grow the crop, two years' rent must be charged against the crop, or at least there must be a rent charged against the rotation of crops for the year the land was fallowed. As I felt satisfied that, by trenching with the spade, the land would derive all the advantage of a summer fallowing, and avoid all the disadvantages attending it, I determined on trenching thirty-four acres of my fallow-break immediately on the crop being removed from the ground, and had it sown with wheat by the middle of November, 1832. I may here remark that I did not apply any manure, as I thought the former crop was injured by being too bulky. As it is now threshed out and disposed of, the crop per acre stands as follows:-

£.s.d.

To rent of land, per acre, . . . . . . . 2100

" expense of trenching, . . . . . . . 400

" seed, . . . . . . . . . . . . . 110

" cutting, threshing, and marketing, . . . . . 1100

Profit, . . . . . . . 670

$\left.\begin{array}{c}\text { By average of the } 34 \text { acres, } 44 \text { bushels per acre, at } \\ 7 \text { s. per bushel, ........................ }\end{array}\right\} £ 1580$

"The advantages of trenching over summer-fallow are, in my opinion, very decided; as it is not only cheaper, but, as far as I can yet judge, much more effectual. I am so satisfied of this, not only from the experiments above noticed, but from the apparent condition of the land after it has carricd the crop, that I have, this autumn, cultivated about a hundred acres with the spade, and the crops at present are very promising."

There are various cases in which the spade husbandry might be most usefully introduced. In New England, especially in Massachusetts, for the support of the poor, several towns have purchased farms, to be connected with their alms-houses and pauper establishments, where there is an opportunity of using to advantage the labor of those persons among the paupers, who are able to do any work, and who are thus made to contribute, in a healthful and unexceptionable occupation, to their own support. This is an excellent arancemont, and the results have in many 
cases been highly successful. Here, in many cases, the land might be wholly cultivated with a spade, and the expense of a team be saved, which now oftentimes consumes a large portion of the products of a farm, especially where the farm is small, a full or complete team being as much required for the cultivation of a small as of a large farm.

In reference to this subject, though it may not be deemed exactly in place, I may be allowed to remark that, as far as my observation extends, nothing of this sort is done in England; no farm being ever connected with a pauper establishment, and only the smallest avails being had from the labor of the inmates Indeed, it is obviously judged best-a conclusion which regard with great distrust - to prevent rather than employ the labor of the paupers. At one of the Unions - for the poor-houses in England go by that name, being maintained and managed by several towns or parishes uniting together for this object - I saw a well-dressed and respectable-looking man employed in sweeping the walks, and trimming the grass-plats, in the front yard; and, upon my inquiring whether this man were a pauper, I was answered in the negative, and informed that he was hired as a laborer in the establishment, because it was deemed bad policy to employ any of the paupers in any such work, lest the place should be rendered too comfortable and attractive. I said to myself, - and I hope not to give offence in publishing my thoughts, - "The English certainly have their own ways of doing things." I am not, by any means, prepared to say, they are not the best that could be adopted. Indeed, we perhaps ought to think them the best, if we consider how much experience they have had, and how many means they have possessed for making the most full experiments. But they are certainly, in this respect, very different from what prevail on the other side of the water. It is an extraordinary condition of things, when, in the midst of want and suffering, human labor must be thrown away, or rather the exertion of it forbidden. 


\section{XVII. - CONDITION OF THE LABORERS.}

I have no disposition to obtrude my opinion, in any form, so as to give offence. Indeed, it has always scemed to me unreasonable in any case, or on any subject, that the honest opinions of any man should be the occasion of offence, as though we had the same control of our opinions as we have of our limbs; as though we should have any other object, in any matter, but the attainment of truth; and as if there were any way of attaining truth but by the utmost freedom of discussion; and, above all, as though men should, under any circumstances, feel at liberty to exercise the same tyranny over the mind which physical force and political stratagem give them over the person.

One cannot help seeing that wealth and prosperity are not always coincident; that wealth is not therefore the infallible index of prosperity. In many cases, - and perhaps it may only be rendered more striking from contrast, - the extraordinary accumulations of wealth on one side are followed by a corresponding depression on the other; while the rich are made richer, in the same proportion the poor are made poorer. As wealth increases, avarice is more powerfully stimulated, and labor more severely taxed. In the richest communities, the price of labor is always the most depressed; and with the increase of luxury the desire of indulgence is quickened with all classes: what might properly be termed luxuries and superfluities become absolute necessaries of life, and the expenses of living are proportionally increased to all. We may deplore such results, and deem it easy to suggest a remedy; but what remedy is of general or of practical application? The more artificial the state of society becomes, the more difficult it becomes to provide the means of living; and yet who would return to the state of nature, or abate one tittle in the actual refinements of life? Communities are growing up among us upon the principles of perfect equality of rank, the equal combination of labor, and an entire community of goods; and there are examples, where such communities, bound together by a strong religious tic, and subject to a most despotic government within themselves, have been maintained, and are still flourishing. But without this religious tie, or some strong 
personal and pecumiary interest, and without an absolute head, does any sober man dream that such communities can be sustained, excepting within the narrowest limits? or that such principles can be applied, to any great extent, to society at large, without an entire change in the whole structure of society; and, I may almost add, an entire renovation of human nature itself? Far be it from me, however, to suggest that the evils of society are without a remedy, or at least beyond alleviation. Our own country, under a free constitution of government, and with an almost unlimited extent of the most fertile territory, accessible upon the easiest terms, presents, perhaps, the most favorable condition, which has been known, for a security of the rights of labor, and the just fruition of its products; but it would be a great injustice to infer that there are not to be found in England many generous and just persons, devoted to the maintenance of the rights, and the welfare and improvement, of the humble and laborious classes. There cannot be a doubt, that, in a noiseless and unobtrusive way, much is, and infinitely more can be, done for these objects; and the aim of every good man, as far as he has any power, should be to diffuse, to the greatest extent possible, the means of subsistence and comfort to all, and to remove every impediment to the most equal distribution of the products of labor among those whose labor in their production gives them certainly a fair claim upon these products. Now, whether it be by large farms or by small allotments, by plough or by spade husbandry, that mode of husbandry by which the largest amount of product, and at the least expense, can be drawn from the soil, and with the least injury to its productive powers, is to be preferred. This great point is not yet ascertained; and its determination must necessarily be different in different places and conditions. But it is with England a question of tremendous importance, what is to become of the vast accumulations of people, which are continually increasing here at the rate of from seven hundred to a thousand per day. It is impossible to become accurately, though it may be slightly; acquainted with the condition of things in England, the actual suffering for a want of the means of subsistence, which prevails among large portions of the population, especially in some of the agricultural districts, and not to feel that there are powerful elements of disease at work in the social body, whose disastrous 
effects must presently be felt in all their violence. Men with families dependent upon their labor, earning not more than $7 \mathrm{~s}$, and in some instances even less, per week, and oftentimes with only occasional employment at that rate, present objects of deep interest to a philanthropic mind. Men living themselves upon a single meal per day, and that potatoes only, for the sake of keeping a wife and children from absolute starvation, - and there is ample evidence that such cases exist, - present a sad spectacle. What are the remedies for such a condition of things, if remedies there are to be found, it is not within my province, in this case, to discuss. It is a hard lot, where the most severe and unremitted labor will not avail to procure a subsistence for one's self and family, and where, with immense tracts of uncultivated land, the opportunity even of exerting this labor, however cheerfully it might be rendered, is, for any cause whatever, refused or prevented.*

The subject, it appears to me, - and perhaps wholly from my being unaccustomed to a condition of things in any degree resembling it, - is daily assuming a fearful aspect; I do not mean of danger to the government, - for the government of the country seems never to have been stronger, - but fearful in its bearings upon the public peace, the public morals, the security of property: and the state of crime. I make no apology for touching upon it, because the experience of an old cannot be without its advantages to a new country, and the condition of labor is a subject which materially concerns every just govermment. Any hopes of a government being founded or administered upon strictly moral principles are contradicted by all past experience. $\dagger$ 'The

* One can scarcely read, withoat a shudder, the following declaration of a celebrated economical writer:-

"A man born into the world already possessed, if he has no assistance from his parents, upon whom he has a just demand, or from society for his labor, has no claim for the smallest portion of food, and no busmess where he was. $\Lambda$ t Nature:mighty board there was no cover for him ; she tells him to be gone."

This passage, which appeared in the first edition of his great work, was afterwards suppressed, being, it is said, too strong for the temperature even of the rankest of the economical school.

$f$ "T'o provide for us in our necessities is not in the power of government. It would be a vain presumption in statesmen to think that they can do it. The people maintain them, and not they the people. It is in the power of government to prevent much evil; it can do very little positive good in this, or perhaps in any thing else. It is not only so of the state and the statesman, but of all the classes 
objects of almost all governments seem to be the security of life and property, the prevention of crimes which endanger life and property, and the aggrandizement of those in power. I do not know that more can be expected of them in the way of promoting good morals, excepting in the suppression of the direct instruments of vice, the support of religious institutions, and the provision for the education of the people. A citizen of the United States, from habit, if not from principle, at once resists and abjures any interference whatever with his religion, whether considered as matter of worship, or faith, or feeling, because, under the government of his own country, with which he has every reason to be satisfied, all such interference is absolutely prohibited. All attempts at enforcing moral duties by legal enactments would be futile and hazardous, since, as it is with human rights, many of them are imperfect, so it is with human duties, many of them are so undefined that it would be difficult to prescribe them with any practicable exactness; and laws of this nature are necessarily of a negative character. They may forbid that which shall not be done; but it is much more difficult to enjoin that which shall be done. They may determine by law that provision shall be made that no man actually perish of hunger in the streets; but what degree of provision short of absolute starvation, how much relief, and how much comfort, he shall have, is a matter far more difficult to be thus arranged. The provision for the education of the people is more clearly within the power and the duty of an enlightened government, on the ground, not simply of moral obligation, but of improving the national industry, increasing, consequently, the national wealth, and of elevating generally the character of the people, and so advancing the general improvement, and promoting public happiness and order.

and descriptions of the rich. They are the pensioners of the poor, and are maintained by their superfluity. They are under an absolute, hereditary, and indefeasible dependence on those who labor, and are miscalled the poor. Nothing can be so base and wicked as the political canting language, 'the laboring poor.' Let compassion be shown in action; the more the better, according to every man's ability, but let there be no lamentation of their condition. It is no relief to their miserable circumstances; it is only an insult to their miserable understandings. It arises from a total want of charity, or a total want of thought. Want of one kind was never relieved by want of any other kind. Patience, labor, sobriety, frugality, religion, should be recommended to them; all the rest is downright fraud. It is horrible to call them 'the once happy laborers." - EDMoND BURKF. 
But it is vain to look to any government for any thing like a paternal superintendence of its people. On a large scale it is not practicable. Those who govern can scarcely be expected to have virtue, and disinterestechess, and wisdom, sufficient for such a task; and those who are governed would not willingly submit to their injunctions or regulations. Any compulsory influence would be unavailing. But, then, it is the duty of every just government to afford to every one of its subjects, as far as depends on itself, the means of subsistence; and institutions or regulations, by which the right and opportunity for a man to exert his talents in a way not morally injurious to another, are taken away, or abridged, or in any degree interfered with, seem wholly wrong and unjust. It would be invidious in me, because perhaps out of place, to point out in any way how the institutions of this country so interfere, if interfere they do; but, as I have said before, the condition of a large portion of the population, - I speak of those in the rural districts, - being prevented the opportunity of applying the labor by which they might secure not only a subsistence, but the comforts of life, forebodes nothing but evil, and may, with strong reason, engage the anxious inquiries of those who have any power in the case, either of alleviation or remedy.

The population is increasing throughout the kingdom with amazing rapidity; and, strange as it may seem, the fact is beyond a doubt, that the increase is always greater among the wretched poor, whom extreme misery has made entirely reckless of consequences, than among that class whose circumstances are comparatively comfortable, and who have learnt that their comfort can be secured only by a wholesome and wise providence. The complaint is universal and continual, that the population is too numerous; but this does not prevent their increase. Few will be bold enough to hazard the question, Who is here who has not a right to be here? nor, like a party of shipwrecked sailors in a boat, to propose the decision by lot, as to which of the party shall be thrown overboard. But the great question must be met - not, How are the surplus population to be got rid of? but, How shall they be sustained? The insular character of Great Britain necessarily and absolutely limits its capacity of providing for its population from its own soil, although that capacity is yet fir from being reached. Idleness begets idleness; heggary produces and 
perpetuates beggary ; crime engenders crime. Sickness and neglect - a sad relief, alas! to the benevolent mind - may do something towards checking this rapid accumulation; for it is stated in the commissioners' returns, and has been asserted recently in the House of Peers, by a distinguished nobleman, that, in England and Scotland, fifty thousand individuals perish annually by disease, arising from the wretchedness of their habitations, owing to imperfect ventilation, and the want of sufficient drainage.* This, however, is a small number to be set against the annual increase. Emigration may somewhat alleviate the evil; transportation contributes its small share. It is a curious fact, however, that disease scems scarcely to produce any sensible impression on the population, and that the losses occasioned by severe and wide-spread epidemics are rapidly filled up and obliterated. The effect of the extraordinary improvements already made, and daily being made, in machinery, in the manufacturing districts, is to diminish the amount of human labor employed, and throw more destitute hands into the labor market. What, then, under these circumstances, is to be done, is a question, to the great moment of which I have already alluded. It is not, in such a case, for men to wrap themselves up in their own selfishness and indifference, and say, "Let things take care of themselves."

I was conversing with a friend on this subject, a gentleman of great intelligence, and not wanting in benevolence; and his remark was, that an increase of production would do little for

* This same nobleman, in discussing this important subject, stated that, in ten years, a larger number perished, in England, from these causes, than the whole number of slaves emancipated in their colonies ; and for which Great Britain paid, by a noble exertion, twenty million pounds sterling, or nearly one hundred million of dollars.

This is a curious fact, and every day's history of public beneficence presents analogous facts - cases in which thousands and millions are lavished upon objects, doubtless deserving of sympatly and kindness, thousands of miles distant from us, where the results are sometimes doubtful, and can never be known, but through the testimony of interested parties, while objects of mercy and kindness, whose claims are not less strong and urgent, and whose condition can be perfectly known, and where the results of our efforts may be watched and ascertained, perish in all their want, ignorance, wretchedness, and profligacy, at the very thresholds of our doors. Certainly, true charity, which extends its wide embrace to afflicted humanity every where, will not end at home; and it might often be as well for it to begin there. 
the lower classes, for they would get no more; with the price of bread, their wages, if lower be possible, were likely to be reduced; the advantages of such increased products would, of course, go into the hands of the land-holders and farmers, or the large manufacturers and mill-owners; and that, for his part, ho saw no ultimate remedy but starvation; that is, such an actual reduction of the means of living, that multitudes should gradually perish from want, and so thin off the surplus population. He said this, too, with all the coohness and indifference with which he would speak of brushing off the flies from the dimnertable. "Good God!" I said within myself, "has it come to this, that familiarity with want and misery can render the heart of man capable of contemplating such a result with calmness, and that human life on earth should come to be deemed utterly worthless? If there be any humanity, or any religion, left in the world, they must be roused to prevent such a catastrophe."

Whatever anxiety, however, the prospect may excite in a benevolent mind, there is no room for despair. It is not consistent with the nature of my present undertaking, to discuss this subject, in its various bearings and aspects, in this place. If life and health are spared me, I shall do it in another form. The people do not so much demand charity, as work. They do not so much require to be supported, as to be allowed to support themselves. The remarkable experiment, already referred to, of Mrs. Gilbert, a sagacious and benevolent woman, at Eastbourne, in Sussex county, who has four hundred tenants, on small allotments, and of whom not more than three have failed to pay their rent punctually, and who, on these small allotments, do, in many cases, all that is necessary, and in all, much for the support of their families, should command attention. There remains, as I have before stated, an immense amount of land, which might be cultivated and rendered productive. These considerations present the strongest inducements to an improved agriculture. More land should be brought into cultivation; that which is cultivated should be better cultivated. The laborers should have every encouragement and opportunity to help themselves. The interest of the farmers cannot be separated from that of the laborers; the interests of one class from that of another. Embarked in the same ressel, they must succeed or suifer, they must sink or swim, together. 
I have been, again and again, told that a material change has taken place in the condition of the farm laborers, within the last fifty years, or even a much less time. The practice of forming large farms, by uniting small ones, has tended to remove the laborer farther from the intercourse and superintendence of his employer. Being engaged in large numbers, individual interest and character have been lost sight of; and, cottages on the estates having been suffered to fall into decay, and not being renewed, the laborers have been driven into villages, with a great restriction of their comforts, and exposed to the temptations incident to such localities. The large establishments have lost that patriarchal character which used to belong to them; men are employed much more by the day, and the week, than by the year, as formerly; and are used, and thrown aside, as occasion may require, like mere implements upon the farm. Those strong personal ties, so favorable in their influence upon the lower classes; and not without most valuable moral effects upon the higher, have almost ceased to exist. It was a delightful circumstance, when, formerly, without any infringement of personal liberty, a laborer was considered as a fixture upon the place, and as having a sort of hereditary connection with the family and the estate of his employer, which only the most imperious reasons could dissolve; so men and women lived in the same service twenty, thirty, fifty years, and often for the whole course of their natural lives; their children and children's children were often born upon the homestead, and the interests of the master and the servants became identical. As they were paid, likewise, in kind, instead of money, they themselves, being, in a small way, sellers of produce, became personally interested in the state of the markets; and ties of familiarity, long vicinity, and connection, mutual dependence, and a mutual stake in the results of their joint labor, served to connect them the more closely together. No one, under these circumstances, can doubt the advantages of such a relation on both sides. There are many cases, which have come under my observation, where a similar connection exists, though in a form very much qualified by modern manners, and where individuals and families have been in the same service for many long years, and the aged among them are provided for, by those in whose service their lives have been passed, in the kindest manner, after all power of useful or active labor has ceased 
and they are staggering under the heavy burdens of age and decay. I have already, in my First lieport, referred to instances (I) this nature. But the system most previlent is perfectly heartless: labor is considered merely as labor; human muscles and sinews are regarded like the parts of any other implement; and when their power ceases, or their elasticity is destruyed, they are thrown aside, like worn-out machinery, into those melancholy receptacles of decay and poverty, which have, very properly, ceased to be called alms-houses, and which necessity, and not charity, provides. I cannot say that such sentiments are peculiar to England. 'They are, it is feared, becoming too common in the United States; not merely in the departments of agricultural, and manufacturing; and mechanical labor, but likewise reaching the domestic and household relations, where least of all they should have obtruded themselves. This comes, in some measure, from that narrow and mean utilitarian philosophy, which stimulates avarice into a diseased action, and measures every good in life by a purely pecuniary standard. Whatever tends to divide these different classes, either in interest or feeling, is, to a degree, and ultimately, I fear, it must prove in an equal degree, injurious to both parties. F'eclings of indifference, or contempt, or cruel disdain, on the one hand, are likely to be met with a sense of injury, a feeling of hate and revenge, on the other; and one of the greatest curses with which Heaven could have visited mankind, would have been to have made them in any sense independent of each other. 'There are no circumstances connected with the condition of society more to be regretted than such as separate different classes too strongly from each other, and create hostile or conflicting interests. A perfect equality of condition among men is a chimera; and if, by any conceivable or possible arrangement, it could take place, the carth, in its rapid revolutions, would not pass the half of a degree, lnat it must be interrupted. But an equality of natural rights is a position which, if I may be allowed to speak for one born and educated in a condition of society where it has been always acknowledged, would not be readily relinquished. Now, if there is any right which should be held sacred, next to that which every man has to his own person, it is the right of honest labor to an ample share of the products of that labor. The rights of the rich man to his possessions, honestly and honorably 
acquired, are as just as those of the poorest man to the crusi which feeds or the coarse garment which covers him; but, in every condition of society, the rights of the rich and the poor are reciprocal, and their dependence mutual and absolute. If the poor are compelled, under the arbitrary institutions of society, and I use the term arbitrary in no offensive sense, - more sensibly to feel their dependence, the upper classes in society, with that spirit of justice and kindness which constitutes the highest grace of power, and wealth, and rank, should be prompt to show their sense of how much they owe even of all this power, and wealth, and rank, to the labors, and services, and fealty, of the poor; and, without losing sight, as far as is consistent with the spirit of Christianity, of what is called their position in society, to endeavor to soften the severity of those distinctions, which, if they mark the elevation of their own condition, equally indicate the depressed condition of others. In that beautiful language, to which every serious mind will listen with profound reverence, "The eye must not say unto the hand, I have no need of thee, nor yet the head to the feet, I have no need of you;" seeing that even those parts of the body which are least "comely," are as essential to the perfect and healthy organization of the machine, as those on which the Creator has impressed the highest attributes of grace, expression, and beauty, and must be equally nourished from the great central reservoir of life and strength, or the whole must suffer from weakness or decay.

I do not mean to imply that there is any greater disregard of these principles than is to be expected in a condition of society so highly artificial as that which exists here, and where the accumulations of individual wealth, and of what, from its hereditary and inalienable character, may be termed class-property, are so enormous. I do not mean, as I have already said, to express any apprehension or alarm for the safety of the present institutions of England ; for, though the flood of population is rising witl a continually accelerated force, and in almost a geometrical ratio, yet wealth here is so strong, and poverty so powerless, and the safety of the whole is so essentially concerned in the maintenance of the integrity of its present form of society, and, above all, the experience of a neighboring nation, on the subject of revolution, is so admonitory and terrific, that almost every thing 
will be endured before any violence is hazarded or permitted. Still it is obvious to every reflecting mind how important it is to the public peace and the security of property, that the rights of the laborious classes should be fully acknowledged, and maintained in the spirit of kindness and equity, as well as of strict legal justice, and that every philanthropic effort should be stimulated and encouraged to protect and comfort them, and, more than that, by education, moral and intellectual, - for, without moral, intellectual too often proves a curse, - to elevate them ir their social condition. Next to the satisfactions of an honest conscience, the highest of all earthly pleasures to a good man, is that of conferring happiness upon others. I have seen, in England, with a gratification which it would be difficut to express, among persons of the most brilliant rank and the most commanding influence, many instances of a conduct which deserved and secured all this felicity. Every where men are to be found feching their high responsibleness, and, without any offensive assumption of superiority, devoting all their energies to the protection of the houseless, and to the comfort and improvement of those whom divine Providence has cast within the circle of their beneficence, and enjoying all that calm security which such conduct is sure to bring with it. I confess there has been no occasion in my life when $I$ have been so much disposed to envy the possession of wealth and power. On the other hand, I dare say I shall only be compassionated for my simplicity, when I add that the high stone and brick walls, with which houses, and parks, and properties, are here often intrenched and fortified, so high that even the nimblest jail-bird would look at them with despair, and the fences every where bristling with iron spikes and broken glass, and the sullen gates opening "with discordant jar." and the ferocious watch-dogs, to say nothing of other mastiffs, often stationed by them, from whose terrific growl even the honest applicant shrinks back with dread; and then the signs which meet your eye constantly, "All vagrants and beggars forbidden here," "All trespassers here will be prosecuted to the utmost rigor of the law," and "Steel man-traps set here," often bring a cold chill over me, and compel me to feel that property held under such cautions loses somewhat of its value. At the same time, it makes me estimate the more highly a condition of society where the road of aequisition is equally open to all, and 
where property being more equally distributed, and in almost all cases the fruit of personal industry, its rights are more readily admitted, and its protection becomes matter of equal and universal concern.

I return now to speak of the present actual condition of agriculture in England. I have dwelt largely, but I hope not too largely, upon miscellaneous and incidental considerations. I propose now to consider the actual condition and character of English agriculture; the improvements which it has effected; and those which remain to be devised.

\section{XVIII. - PROGRESS OF AGRICULTURE, COMPARED WITH OTHER PURSUITS.}

I have already said that the agriculture of England - and her: I include Scotland - is highly improved; but I may say, I think, with confidence, and certainly without censoriousness, that it has not yet reached that degree of excellence to which it is capable of being carried. In parts of the country, not much has been done; in the best cultivated districts, it would be presumptuous to say that the goal of perfection has been reached. Among the highest gifts with which Heaven has endued the human mind is a generous and insatiable ambition after excellence; an avarice of improvement, if so it may be termed, which characterizes a great mind; which knows in no case entire satisfaction; which no sooner mounts one summit than it essays to climb a higher; and which, if in any thing it should reach barriers that are absolutely impassable, would, like the celebrated hero of antiquity, "weep that it had no more worids to conquer." I am not willing to admit that this ambition, one of the noblest attributes of the human soul, can ever be stimulated to too great a degree. Cobbett, in his terse, energetic, but rather coarse manner, says that "he despises a man who is contented with his condition;" and in the sense in which he obviously designed to be understood, I quite agree with him, that no man should be satisfied with good while better is attainable; and that it would 
indeed be a sad condition of things, when the capacity, and still more the disposition, for improvement should cease.

It is, and, as long as I can remember, it has been, common to decry the farmers, as a stupid, ignorant, plodding race, satisfied always to jog on in the steps of their fathers, and averse to any improvements, such as are going forward in other departments of industry. I think I may confidently deny the allegation; and I regard the reproach with the disdain which it merits. My own observations, in England and the United States, lead me to the conclusion, that, after making every just allowance for the necessary difference of circumstances in the different cases, there is as much intelligence in regard to their art, and as strong a spirit of improvement, with the agricultural as with any class in the community ; and, more than that, the improvements, which have been actually accomplished in the agricultural art, are in no respect inferior to those which have been effected in manufactures and commerce, or in the higher professions, - if so we submit to call them, which I confess I do with great reluctance, - medicine or law; I would add theology, if I dared; but I am afraid I should get into hot water.

In medicine, if under that head we include surgery, one cannot go through the streets of London, and observe, at the shopwindows, the models of wooden legs, and artificial ears, and glass eyes, and mineral teeth, and the promise of a new nose, where the victim of misfortune has been deprived of his proboscis, without acknowledging that the triumphs of the surgical art are as brilliant as they are useful and humane. If one likewise should place any reliance upon the numberless pateit medieines and nostrums which decorate the pages of the newspapers, he would be led to infer that the reign of disease was broken up, and the elixir of immortality at length discovered. But wherer looks into the medical reports, and observes the variety of systems and modes of practice which prevail, and which different colleges of physicians seem to bring out as regularly, and in almost equal numbers, as the good housewife's hens bring out their broods in the spring, and especially reads the accounts of the various experiments, to which, for the benefit of science, their patients are unconsciously subjected, and by which, without the credit of inclination or consent, they are made, at their own personal exprose, suffering, and peril, to contribute to the most philanthropir 
discoveries, - it cannot be claimed for medicine, that it is altogether above the charge of empiricism, or that it has yet accomplished all that is to be desired in lessening the number or alleviating the virulence of diseases, or in restoring human life, with any confidence, to even a tithe of that longevity, which is claimed for it in those patriarchal ages when apothecaries' shops, and medical schools, and degrees, do not appear to have been established. It is scarcely better with the law. One of the most distinguished legal gentlemen in England has lately stated, in his place in Parliament, that such is the condition of the criminal law, that even the most learned in the profession cannot, in many cases, determine whether he is, by particular actions, committing an offence or not. The records of the courts daily show that the most. momentous decisions often turn upon points the most abstruse, and as yet absolutely unsettled; that even the most learned judges on the bench disagree in matters both of law and equity, involving property and life; and it seems but too often the test of legal eminence and skill to ascertain, not whether it be practicable to get "a camel," but whether the lawyer can get himself or his client, "through the eye of a needle," as being the most brilliant triumph of his art.* In theology, it cannot be said

* In a recent trial, a brute in human shape, or rather a demoniac, - for brutes are not capable of actions so malicious, - was indicted for wounding, maiming, and injuring, a horse. He, it seems, in the fury of his passion, had drawn out the tongue of the horse, and, by rubbing it against one of his teeth, had cut off four of five inches of it, which he threw at the horse's head. His counsel opposed the indictment, on the ground that there could, as defined by law, be no wounding but where some instrument was used; but the tooth was not an instrument; - there could be no maining but where some limb was injured; but the tongue was not a limb; - and that there was no injury, because, though the horse found some difficulty in eating his oats, he was otherwise as useful for labor as before his tonguc was cut off. On these grounds the prosecution failed, and the savage escaped. Under such an administration of justice, it would scarcely have been surprising, if the horse, had he not lost his tongue, had himself spoken out; and it would have been only fair if he had been allowed to bite off the ears of the lawyer, and of a magistrate who sanctioned such law.

At a court of assizes which I attended, and where the criminal calendar was heavy, a young married woman, of decent and respectable appearance, having a husband and children, and against whose character, in other respects, nothing was alleged, was sentenced to ten days' solitary imprisomment, for having taken for her fire, on the estate of a countess, near which her cottage stood, a stick of wood, valued at threepence, from a tree that had been felled and partly cut up. If the tree had not been cut down, and she had taken a piece as large, the act 
that much progress has been made in determining many questions which have vexed men's minds for centuries. I confess, when I was in the Bodleian library, at Oxford, that immense repository of the labors of so many burning brains and aching hearts, with its five hundred thousand volumes, and considered that, beyond all question, more than three hundred thousand of its thick octaros and ponderous quartos and folios were commentaries upon the Scriptures, or discussions of disputed questions in theology, and yet, in respect to most of them, that we are still at sea, and no land in sight, I could not escape the conviction, that here, too, man is still in leading-strings, and has yet scarcely taken "the first steps of infancy."

In respect to manufactures and commeree, if we compare the common operatives in either of these departments with those of the same class in agriculture, - the laborers in the mills, or the sailors on boardship, with the common laborers on the farm, - we shall find no great advantage, in intellectual progress, which the one has over the other; but, again, if we compare the highest class of farmers with the highest class of merchants and manufacturers, it will certainly be no disparagement to the latter classes to say that they are not in advance of the best-informed agriculturists; and that agriculture is now as much a matter of the mind, as much a matter of intellectual observation and in-

would have been a simple trespass, and she would have been mulcted in a fine only: as it was, however, it was a felony or crime, and she was punished accordingly. I could easily imagine the amazement of the poor unfortunate creature at so subtile and philosophical a distinction. I must add, though it may seem out of place, that a criminal prosecution for an offence of this nature can have no other effect than to engender a bitter malignity on the part of the poor towards the powerful, and that the generally severe administration of penal justice upon the humble and defonceless, (not, I must confess, peculiar to England, when the large flies so often break through the cobweb of the law, and escape by intrigue or influence, can have little effect in producing reformation; and its main tendency must be to nourish, on the part of the lower classes, a deep resentment of the partiality, and an utter hatred of the power, to which they are subjected. A patemal administration of justice is not, of course, to be expected; but what an infinite amount of guilt and wretchedness would be saved, if the circunstances of the guilty could be more mercifully considered; especially if lumanity and public justice could be more exerted in preventing rather than in punishing crime; above all, if society itself, by its omissions or its institutions, were not, in too many cases, the tempter, the minister, and the pander to crime, as well as its terrible avenger! 
quiry, as any one of the practical arts of life; and at the present moment, it is occupying as much attention from the highest class of minds as any other of the business pursuits of life.

I hope, viewed in this aspect, I shall not be thought to speak with undue warmth on this subject. I have, I am aware, already alluded to it; but I am anxious to assert the dignity of a pursuit which I regard among the most honorable, as it is among the most immocent and useful, in life; and I would, if possible, soften its aspect, and multiply its attractions, to a large class of persons, who have been accustomed to look upon it with indifference or disdain, but who would be sure to find in it, if ardently and intelligently pursued, health for the body, and peace and satisfaction - nay more, the strongest and most delightful interest - for the mind.

\section{XIX. - ACTUAL IMPROVFMENTS IN ENGLISH AGRICULTURE.}

But of what nature are the improvements which agriculture has actually made in Great Britain, which determine the present high condition of the art? A stranger cannot, of course, from personal experience, compare her present condition with what it was; yet the marks of progress are so obvious that the most transient observer recognizes them; and many are now in the process of accomplishment, which fill him with delightful surprise. Hany of these improrcments are among the noblest triumphs of art, and mark, as strongly as in almost any other cases, the power of mind over matter, the subjugation of physical elements to an intellectual sovereign.

1. Draining, Irrigation, and Warping. - Much of what has been done is entirely out of sight; whole fields, thousands and thousands of acres of land, have been underdrained by pipes and chamnels, spreading themselves like beantiful net-work under the surface, taking off all the surplus moisture, and converting cold, mfruitful, and unsightly morasses into productive and beautiful fields. It would be curious, if it were possible, to approximate 
the amount of this work which has been done: but there are no means even of framing a reasonable conjecture. It undoubtedly embraces hundreds of thousands of acres, and much more is in progress, since, importint and indispensable as moisture is to vegetation, nothing can be more jrejudicial than a superabundance of water, and especially stagnant water. Of the different modes of draining I shall speak hereafter at large. It is a subject of great importance and utility, and requires to be treated in the fullest and most exact manner. The next great improvement, that $I$ have witnessed in England, is in the fen-country of Lincolnshire and Cambridgeshire, where vast territories, embracing many thousands of acres, have been, it may almost be said, created, that is, redeemed from the sea, fortified by strong and extensive embankments, and now rendered as fertile and productive as any lands which can be found upon the island. These lands, likewise, are kept drained by immense steam engines, which move with an untiring power, and accomplish this mighty work with ease. In other cases, in Lincolnshire, another process is going on, here denominated warping, by which, on the banks of the Humber, immense tracts are enclosed, the tide shut in, and compelled to leave its rich deposit, thus forming, likewise, the richest meadows. Still another process is in progress, by which the crooked course of a river is straightened, its chamnel deepened by its own new current, and rendered navigable, and, by the erection of artificial banks, the soil within them continually raised, and hundreds of acres, where so recently the fish, at high water, sported with impunity, are rescued from the sea, and covered with thriving flocks of cattle and sheep. In Yorkshire, not only are various processes of redeeming and improving land going on, but the curious process of removing, by the aid of steam machinery, the rich deposit from the bed of a river, whose current has been diverted from its natural course; and this deposit, after being taken out, is laid, at not an inordinate expense, on a peat bog hitherto unproductive and worthless. By judicious management, it is spread on the land to the depth of eight inches, and the covering proceeds at the rate of five acres per day. In Nottinghamshire, a most splendid improvement has been effected in tuming the course of a small river, so as at pleasure to irrigate several hundred acres of land, which were formerly poor and comparatively umproductive, hut now yield the most 
abundant crops; and in Stafiordshire, the same results have been reached, not by a river, but by collecting the springs, and forming a grand reservoir, from which the water is carried over extensive fields, which are thus irrigated at pleasure.

2. Live Stock and Vegetables. - The next great feature m the improved husbandry of England is apparent in its live stock. I do not speak of it as seen at the cattle-shows of the different agricultural societies in the kingdom; for here the animals are all selected, or at a very great expense, and after a long time, fitted for the exhibition; but I speak rather of them as they are seen in Smithfield market, every Monday, and at the other smaller markets and fairs in various parts of the country. Here are the cattle and sheep of several distinct breeds, and all of remarkable excellence of their kind; I do not say perfect, - for that, in almost all cases, is assuming too much, _ but leaving very little to be desired beyond what has been attained. Their condition and form, their symmetry, their fatness, are all admirable and each breed is seen retaining its distinct properties, and, what is most remarkable, showing how much can be done by human art and skill in improving the animal form and condition, and bringing it to a desired model.

From Smithfield market, if he goes to Covent Garden market, in the infinite profusion and variety of fruits, and vegetables, and flowers, which are always to be found here, and in the perfection to which they are carried, and many of the finest fruits, in defiance of an uncongenial climate, he will find evidences of the same admirable slitl and art which are displayed in other departments of rural industry.

3. Agricultural Implements. - The next evidences of the improvement of the agricultural art are to be seen in the extraordinary display of agricultural implements at the great shows. The exhibition at the meeting of the Royal Agricultural Society at Derby, in July, 1843, was so remarkable, that I shall be excused for giving a statement of the number, and many of the kinds, of the machines and implements there exhibited.

Of Tillage Implements, then, there were, - of ploughs, 148 ; harrows, 31 ; scarifiers, 25 ; clod-crushers, 7 ; rollers, 12 ; couch rakes, 4. 
Of Drilling, Sowing, Manuring, and Hoeing Machines.of drills and bessers, and seed-sowing barrows, some designed for sowing manure with the seed, there were 61 ; of dibblers, for putting in the seed, 4 ; of horse-hoes, adapted to the cultivation of drilled crops, 20.

of Harvesting Machines. - For hay-making, 4; horserakes, 7.

Of Barn Machincry. - Horse engines, locomotive or stationary, 7 ; steam engines for threshing or grinding, 6 ; threshing machines, 15 ; winnowing and cleaning machines, 20 ; crushing and splitting mills, 36 ; corn and meal mills, 20 ; chaff-cutters, 51 ; cake-crushers, for oil cake, 14; corn weighers and measures, 2.

Field, Fold, and Yard Machinery. - Of turnip-cutters, 12; root-graters and cider mill, 3; potato-washers, 2; steaming apparatus, 5 ; feeding apparatus and fodder preservers, various; weighing machines for carts, cattle, \&c., 4; fire and garden engines, 11; inachines for stock yard, various; sundries, machines for breaking stones, iron field gates, hurdles, trucks, fences, \&c. \&c. \&c.

Agricultural Carriages, Harness, and Gear. - Wagons and carts for market, for harvest, for manures, (solid and liquid,) for family use, \&c. \&c., 38; breaks for carriages of all kinds; sets of wheels, axles, \&c. ; harnesses and horse-gear; drain tiles, and implements for forming tiles, 9 .

Dairy Implements. - Churns, 8; cheese presses, 6; curd mills, 4; miscellaneous and various implements, and tools and vessels for domestic and rural purposes.

It cannot be expected that I should characterize these machines, and point out their various properties; though this is what I propose to do hereafter, in respect to such of them as seem to me most desirable to be introduced into my own country; but the number and variety of them which have been produced, and the neatness and care with which they are made, evince great mechanical skill and knowledge, and show that here, as well as in other departments of industry, the mind has been at work, and has produced the natural fruits of intense and well-directed application.

4. Applichtion of Steni to Agriculiture.-There is, indeed, 
one giant power, of comparatively modern invention, which, it is thought, has not been as successfully or extensively applied in agriculture as in some other departments of the arts. Every one knows, at once, that I refer to the power of steam, which seems, wherever introduced, to defy all competition; and every day's experience appears to demonstrate that its extent is yet hardly conceived, and its application only begun. The experiments, which have been made in the application of steam power to the movement of ploughs, have not, as far as I can learn, been attended with success. It will not be safe to assert that this cannot be done to advantage; but certainly that is not the only application of steam to the purposes of agriculture, which is to be looked for. Indeed, besides the impossibility of an art, so intimately associated as agriculture is with almost all the practical arts of life. escaping its share of the general advantages which the community is enjoying from this mighty agent, it has already received many direct contributions from it. In the Lothians of Scotland, those beautifully cultivated grain districts, which, when seen in the season of their glory, with their green and their golden crops, so rich and delightful as to make the heart of an enthusiastic agriculturist beat as though he himself had a steam engine under his waistcoat, a steam engine is to be found on every principal farm, for threshing out all the grain, and for other economical purposes, to which, on a great farm, these engines are capable of being applied. The average size of these engines for threshing is from a six to an eight horse power, and the cost. which was formerly more than $£ 120$, or $\$ 600$, is now greatly reduced.

The advantage of steam, as a motive power, must be obvious. It is always available, at all seasons, and without reference to the weather. Its movements are uniform, whereas horse power is, to a degree, capricious and unsteady, and horses often suffer a great deal, both from too constant and long-continued pulls, and likewise from frequent stops and starts. The steam power never tires, and its operation may be continued to any length of time or quantity. These are all great advantages, especially when a farmer, from any sudden advance, wishes to bring his grain at once into the market. It is obvious, at the same time, what advantages he has in having his horses saved from the severe work of threshing, and fresh for other farm work. The saving of 
a pair of horses, on a farm, is estimated at $£ 100$ per year, (very much more, indeed, than it would be with us;) and intelligent farmers assert "that, with steam power, they save one fourth of the horse power on large farms."

The usual quantity of grain threshed by a six horse steam power is at the rate of from thirty to forty bushels per hour; though the quantity must vary with the condition of the grain and the straw. 'The average work of a threshing mill, driven by horse power, is 150 bushels per day, and by steam power may be reckoned at 250 bushels per diay, which is certainly a great preponderance in favor of the steam power. The wear and deterioration of the horses, and the expenses of keeping them, are most important considerations to a farmer. Indeed, so far as my observation goes, there is no single source of expense, none which abstracts so much from the profits of farming, and none of which the farmers in general are so little aware, as that of horse teams.

In the great experiment, or rather improvement, going on at Hatfield Chase, in Yorkshire, of emptying the deserted bed of a river, and spreading this rich alluvion over a peat bog, the earth carts are moved on a temporary railway by a steam engine, and carried to their place of deposit, so that, as I have before reinarked, five acres can be covered in a day, eight inches deep; and that which it would be perfectly in vain for any inferior power to have attempted, is accomplished with perfect ease by this willing but mighty agent. The fens in Lincolnshire, where the uncertain and capricious power of the wind was formerly depended on, and, of course, with little confidence and uncertain results, are now relieved, at pleasure, of their surplus water, by two steam engines, one of sixty and one of cighty horse power; and the quantity of water removed, the time required, and the expense incurred for doing it, are all matters of exact calculation. The workmanship of these engines - for I have had the pleasure of visiting the spot - is extremely beautiful; and the advantages of the whole arrangement can hardly be overstated. I can easily velieve that the same machinery, on a small scale, may be applied m many other similar cases; and a very intelligent and spirited farmer consulted me on the subject of his determination to erect a small steam engine, at his own expense, for the purpose of draining a part of his own premises. At the show at Derby, 
there was exhibited a movable steam engine, intended to be carried to a farmer's premises as it might be wanted for furnishing a threshing power, and other purposes. I have not yet learnt how it succeeds; but if success is not attained at a first attempt, it is ultimately certain. These machines are made of two, four, and six horse power. The cost of the two horse power is $£ 80$, or $\$ 400$, and a three horse power, $£ 110$. This does not include the threshing machine. A fixed steam power must have many advantages over a movable steam machine. It is never safe to calculate upon doing a great many things with any single machine. A self-directing machine would be a great discovery; but, short of man himself, we can hardly look for that, though it seems sometimes to be nearly approached. A great difficulty, in many cases, is, that the machinery must be trusted to the hands of the stupid, careless, and sometimes malignant.

Such a power as this, on a large farm, may be applied to a great many uses; and its advantages, in many cases, will be incalculable. The turning of a grindstone for sharpening scythes and axes, on a large farm, would save, in the United States, a great expense of labor and fatigne; and its application to cutting roots, and chopping long fodder for stock, to breaking and crushing corn and oats, and to grinding grain into flour for the family, as well as for cattle, would be highly useful, especially in those parts of the country where water power is difficult to be procured. This is the case in all flat countries, and particularly on the prairies in the Western States. There, in many cases, coal abounds; and there, if ever it may be expected, where miles almost may be run without occasion to turn the plough, steam may be applied for the purposes of draft.

Agriculture owes, also, a considerable debt to steam, for the advantages it affords in the construction of agricultural implements, in respect to cheapness and uniformity. In cutting, sawing, and planing wood, in grinding and fashioning metals, steam power is applied to great advantage. In one, if not more, extensive establishment, for the manufacture of agricultural implements in New England, steam power is used, so as greatly to reduce the expensiveness of plonghs, and other articles, which are here made. The same thing is done in England; and this application of this wonderful power is every day extending itself to a most extraordinary degree. I may well call it wonderful; 
for who conld have dreant, on first seeing a tea-kettle boiling over the fire, that there were the simple elements of a power destined to exert a greater influence in the progress of the arts and sciences, and consequently over the whole condition of society, than any other known; which was to rend rocks, and snap iron asunder, like bands of straw; which was to ride securely and triumphantly over the mountain waves of the sea; which was to drain floods and lakes, and lay open their fertile bottoms to the ploughshare; which should compel the deep places of the earth to disgorge their mineral treasures; and, disdaining time and space, plant distant countries, for all the practical purposes of commerce and friendship, of reciprocal supply and mutual improvement, in the immediate neighborhood of each other?

This brings me to another great benefit which agriculture has derived from steam power, which I should do injustice to pass over. I was in Smithfield market a few weeks since, and, in conversation with a very intelligent salesman, - whom, let me say by the way, I shall never remember but with a grateful sense of his kindness, and a high respect for his character,* - he said to me, "We have the contributions of seven hundred miles brought to market to-day, and without the slightest injury to their condition. We have beasts and sheep here from Sutherland, and from the southern counties of England;" and I believe he might have added, from Ireland and from Belginm. Steam vessels and railroad cars bring them at once to the great places of sale. It was always calculated, by the drovers of cattle from Connecticut River to Brighton market, near Boston, - an

* This gentleman, whose business, in the market, is of the most extensive and responsible character, presents an example so fuil of wholesome instruction, that I hope I shall be pardoned for enlivening my Report by a reference to it. He spends several days in the week in the most confused, noisy, and busy place in the world, faithful to the interests of his employers, and retires at night, a few miles from the city, to enjoy his cup brimful of domestic pleasures, at his own fireside, in a crowded circle, where mutual love reigns triumphant, where the table is covered with the literary gems of the press, and the walls of his drawing-rooms are adorned with the splendid products of his own pencil, displaying taste and skill. So true it is that men, if they will be but true to their own intellectual and moral natures, need not be utter slaves to the drudgery of business; and, if they will only look for them, may find, at the most moderate expense, within their own reach, in the hours of recreation, too often squandered or abused, sources of the richest and most elevated pleasures. 
average distance of about one hundred miles, and which occupied a week in its performance, - that a beef animal so driven lost one hundred pounds in wcight; and then he usually came into market foot-sore, sunken, in a state of fever, and looking like the victim of cruelty, and the picture of misery and exhaustion. Where steam power is employed, a journey of excessive fatigue and labor, which formerly occupied seven days, scarcely occupies now as many hours, and the animals are transported without fatigue or labor, or loss of substance.**

A farmer at Ware told me that the driving of a fat beast to Smithfield, about twenty-six miles, occupied, formerly, two days. The animal now goes by railroad in two hours, at a cost, I think, of not more than $2 \mathrm{~s}$, and comes into the market fresh and sleek, like a new bonnet from the band-box. But there is another animal benefited besides the quadruped; and that is th: drover himself, who, instead of spending eight or ten days or more upon the road, at a great expense of money, and not a little increased hazard of morals every day he is away from his family, finds his business now accomplished, and his money received, and himself returned to his home in three days. 'These are considerations of immense importance. $\dagger$

* I cannot say that they have not even some pleasure in the transit. This, perhaps, might be very well ascertained by an inquiry of the passengers in the third class cars, who, through the extraordinary disinterestedness of the railroad directors and corporations, are conveyed with the same advantages of the open air, the refreshing showers, and the full enjoyment of the rural scenery, and, in general, in the same affectionate aggregation, and in precisely the same circumstances of position and comfort, in which the cattle are transported.

f In a recent debate in Parliament, a member, otherwise of considerable cleverness, in referring to the practice of the railroads in rendering the transits of second and third class trains less frequent, and much slower than first class trains, was pleased to say that "it was well enough; for the time of the poorer classes was not of much consequence, and they might as well pass it in the cars as any where else." It would be difficult to say what, to any one but himself, is the value of the time of a man who could make so heartless an assertion. The poor man's time and labor are his only capital. Enable him to do as much again in half the time employed, and you quadruple his power of serving the community, and supportin:s himself and family. As for the rich man, who made this declaration, I wish him nothing worse than to travel in a third class car attached to a slow night freight train, so that, in one of the long tunnels between Liverpool and London, his pleasant imaginations might be rectified by sober facts, and himself have time for reflection and repentance. 
It will not do, then, to say that steam has done nothing for igriculture: perhaps no department of industry has been more essentially benefited. In its equalizing the value of landed estate throughout the country, it has conferred immense benefits. A farm, accessible to the great markets by steam conveyance, though two hundred miles from London, is now of equal value as if it wern within twenty miles. The farmer near London may complain of this; but it is proper for the community to remember how many more farms are at a distance from, than how many are near to, London; and how little the interest of a few individuals is to be brought into consideration, compared with the interest of a large community, who are to have the advantages of the extended competition. Singular as the result is, however, and contradictory as it may seem to all theories on the subject, it does not appear, in fact, that any parties are injured by the facilities given to the most distant to reach the market. In respect to all the great interests of society, which are in their nature fluctuating, or at all dependent on external circumstances, so many and sirch various elements are intermingled and combined, and so many new conditions present themselves, that the calculations of political economists are constantly at fault; and the results are deeply humbling to the pride of human sagacity. Into what a snarl of misery and confusion would every thing in this world be thrown, if man's providence were substituted for the divine providence! and so it constantly proves that, just in proportion as men attempt to interfere with the divine arrangements, to control the great natural laws of Heaven, and to create it perfectly artificial mechanism for the gorermment of society, tiicy find their plans defeated; and the certain result is any thing but unmixed or even general improvement. I remember, a few years since, it was confidently said, that, when the great Erie Ganal of New York should be finished, by which the agricultural treasures of the Great West should find an easy transmission to the Atlantic, farms in the neighborhood of New York city would become comparatively worthless. Yet, strange to say, they have much increased in value, and are now certain to hold their wwn. The vast increase of population throughout the country; the great increase of population in the city of New York, occasioned, to a considerable degree, by the amount of business which this very canal has produced; the multiplication of trades 
of every variety, and the influx of wealth to which it has contributed; with wealth, the increase of luxury, and the demand for fruits and vegetables, - articles in their nature perishable, and demanding a rapid and certain conveyance, - with various other circumstances, have conspired to keep up the value of farms, and, indeed, to increase their value in the neighborhood of New York, and in every point from which, by these improved facilities of conveyance, this great mart has been rendered the more accessible.

The poorest markets - those which are most poorly supplied are in general those where the prices are lowest. Competition and abundance create, and, to a certain degree, quicken demand; for the reason that they bring more customers, and create more wants. Peaches are now sent by steam conveyances from New Jersey to Boston, a distance of nearly three hundred miles; and strawberries from Providence, nearly two hundred miles, to New York. What has been the effect? To lessen price in a very small degree in any case, but in many cases not at all ; to increase the consumption greatly; and to induce the farmers, directly in the neighborhood of Boston, to go themselves into the cultivation of peaches, to take immense pains to guard against the evils of an uncongenial climate, and to cultivate, as far as possible, fruits of the best quality. Some trades may be overdone; they may be concerned only with articles not of necessity, but of mere fancy, and subject to the caprices of whim and fashion; but in all those for which the demand is necessarily permanent, and in a state of general prosperity in a country, the increased demand, growing out of an increased consumption, will be always likely to afford a remunerating price. But in any event, whatever tends to the improvement of the general condition of the community is to be encouraged. It may often be attended with partial loss or temporary inconvenience; yet, in all cases, unless conscience or morals are involved, individual benefit or advantage should yield to the public good. The farmer near a large town thinks himself injured by a railroad or canal which brings the farm of another man, a hundred miles distant, in competition with his own. Every one sees that the great public is to be benefited by the increased supply which is thus produced. Now, is there any grood reason why the distant farmer should not come to the market by any facility which he may create or obtain, as 
well as his neighbor, provided he does not hinder that neighbor from coming in the best way he can obtain, any more than there is why the distant farmer should be compelled to come on foot, and bring his load upon his back, instead of availing himself of his horse or his carriage?

5. Increased Prodection. - But in speaking of the advanced and improved state of English agriculture, there are, perhaps, stronger evidences of its progress than any to which I have referred, in the increased productiveness of the fruits of the earth, and in the increased population which are sustained by them.

In the ten years from 1801 to 1810 , the average annual import of wheat into the kingdom was such as to allow, if divided among $17,442,911$ souls, - the population of the kingdom at that time, - a small fraction over a jeck for the annual consumption of each person. The average amount imported between 1811 and 1820 , when the mean number of the population had advanced to $19,570,589$, would have allowed each person not quite one gallon and $\mathrm{a}$ half for the yearly consumption. The average amount of importation for the five years from 1831 to 1835 , when the mean number of consumers was over 25,000,000, if fairly divided, would have given to each person one gallon of wheat. Taking the three years 1833, 1834, 1835, the importation would have allowed only one pint and one fifth, or about fifteen ounces, of fine flour to each consumer.*

This is certainly a very small amount, and demonstrates the immense agricultural resources of the country. It shows as strongly the improvements in cultivation, by which, under a fastincreasing population, the dependence on a foreign supply for bread is continually growing less. This can only arise from two causes, the bringing more land into cultivation, and a more improved cultivation. Both causes have probably operated to a degree, and of the latter the cvidences are every where numerous and striking.

I was asking a farmer in Berkshire county, England, - venerable as an octogenarian, - whether he had seen any great im-

* Sce an admirable work, full of information-Porter's Progress of the Nation, Vol. I. p. 147 . 
provements in agriculture; to which, in spite of the prejudices which too often obscure or pervert the vision at so advanced a period of life, he replied, with perfect candor, "Immense improvements; we knew nothing; every thing is now better done; the crops are far more various and more abundant; the product of wheat has almost doubled; the tumip cultivation has been created; the implements are far better; the live stock is beyond all comparison better; every thing, every thing is better." The good old man had lived, like Simeon, in, indeed, a far humbler sense, to see the marked and strong tokens of the divine goodness in the progressive improvement of every thing around him; and he proclaimed it with the glowing enthusiasm of youth, and showed the fire still burning under the snow. Happy old age, when, instead of a mind soured under the accumulated burdens and infirmities of advanced years, and covered with mossy prejudices, it benevolently acknowledges good wherever good is found; progress wherever progress is made; and, instead of growling at the degeneracy of the present times, and sighing over the fading reminiscences of what it deems the superiority of years which are passed, delights in the actual improvements of the present, and sees in them the foreshadowing of far greater improvements in the distant prospect, when the advances now made, great as they may actually be, and still greater as they seem in comparison with those of days gone by: will be found to be only the first lessons of childhood! There is a good deal of this spirit or temper here, called by the gentle name, in England, of conservatism; but this man's mind was happily free from it. I have all reasonable respect for antiquity: but, if the presumption may be pardoned, I beg leave to say, with Lord Bacon, I reckon that to be antiquity which is farthest from the beginning. The present times are, therefore, more ancient than those which have preceded them, and are to be reverenced as imbodying the accumulated wisdom and experience of past ages. This spirit of improvement, now so rife and active, is the fomdation of all intelligent hopes of further progress; and I am happy in saying that in nothing is it more obvious than in agriculture.

6. Royal Agriculitural Societr. - In this progress the Royal Agricultural Society of England contributes its full share. 
This was established about 183\%, and embraces a large array of the highest rank and talent in the kingdom, and a vast body of farmers, landlords, and others interested in agriculture. Its funds are large, arising from donations and an annual subscription of a guinea from each of its members; but it has received no endowment from the government. Its objects comprehend every branch of husbandry and rural cconomy. It has a central oflice, or building, in Hanover Square, London, where the secretary of the society resides, and where the council of the society and other members hold weekly and monthly meetings, for the management of the business of the society, and the discussion of agricultural subjects, and the reception of agricultural information. This conduces very much to the interest felt in the projects and operations of the society, and is the means of diffusing a great amount of valuable information.

It has begun here the establishment of an agricultural library and museum, which presently must assume a considerable importance, and become curious and useful. The object of the library is to collect the most useful and valuable publications on subjects comnected with agriculture, in all its various and kindred branches, including likewise geology, botany, agricultural chemistry, engineering, and manufacturing, as far as they are connected with the making of agricultural implements, and the great agricultural operations of draining, conbanking, irrigation, and other important farming processes. The object of its museum is to exhibit specimens of agricultural productions, which are caprable of preservation, seeds, plants, grasses, samples of wool, mineral manures, models and drawings of agricultural implements, and whatever, in any way, may conduce to the advancement of the science or practice of agriculture. It is obvious how very important such an establishment must prove, by giving practical men an opportunity of inspecting, at their leisure, the most improved subjects of cultivation, the best grains, and the best wrasses and regetables, and, at the same time, the best tools and machines, with which to cultivate them. I have often urged the establishment of agricultural museums upon my countrymen, "epecially in the capitals of the states and of the United States: where the members of the clifferent legislatures assemble. ('oming, as they do, from differcnt and distant parts of the country: they will be enabled to carry home information of the utmost 
importance to the farmers, besides having their own knowledge advanced, and their own zeal quickened in this great cause. The commissioner of patents in Washington, distinguished by his indefatigable exertions for the advancement of agriculture, has already laid the foundation of such a collection, at the metropolis of the country, and in connection with his own department, where models of all patented agricultural machinery are always to be seen. It is to be hoped that the friends of an improved agriculture in the country will encourage and assist him in extending his collection of valuable grains and seeds. There are few ways so little expensive, in which they may render so much service to the country. It would be desirable that the government should enjoin it upon the commanders of all their ships of war, visiting different parts of the globe, that they should collect and bring home such seeds and plants, and such models of implements, as would be likely to be of use. That universal vegetable, the potato, furnishing so much food to man and beast, and scarcely second to any in value, considering the multitudes whom it supplies, and the quantity of food it affords, is said to be an importation from South America. The cotton plant, a source of enormous wealth to the country, is likewise esteemed a foreigiz plant.

Besides this, the Royal Agricultural Society issues a sem1yearly publication of valuable communications and papers, both on the science and practice of agriculture, which fall in its way, or are made to the society in reply to queries proposed for discussion and for information, upon which it offers premiums of a pecuniary or an honorary nature.

The society, likewise, at some place in the country, easily accessible, hold an annual show or exhibition of animals, implements, and agricultural products, upon the best of which it awards premiums. This occupies, generally, four days. Tuesday is exclusively assigned to the several committees for the inspection of subjects of premium, in the way of implements and agricultural machinery, when no persons whatever, excepting the committees and persons necessarily attendant upon them. are admitted to the yard, so that they have a favorable opportunity of quiet inspection, unintermuted by any interested or curious parties; Wednesday is devoted, in the same way, to the examination of the animals, and afterwards the yards are open 
to the public upon payment of a reasonable entrance fee; and on Fridays a public sale, at auction, is held of such animals, or implements, as their owners are willing to dispose of in this way. The collection of people, on such occasions, from all parts of the country, and, I may properly add, from all parts of the world, is immense. 'Two large public dinners are given on the occasion; the one called the council dinner, on Wednesday, and the other, called the society's dinner, on 'Thursday, when provision is made for fifteen hundred guests, in a pavilion erected for the purpose. These dimners are, in general, seasons of great hilarity, and promotive of sympathy in the great cause of agricultural improvement. If no other good comes of them to agriculture, they serve at least the purpose of consumption, and so quicken price and demand.

On these occasions, the prizes are ammounced to the successful candidates; and these premiums are given either in medals, plate, or money, and are received with no small degree of public and self-congratulation.

The arrangements, in general, are made with great care. The animals are assorted in distinct classes, with separate committees for the examination of each class; and the implements are placed according to their different designs and uses. It would be impossible to convey an accurate or adequate impression of the number and variety of the animals offered, in such cases, for exhibition and premium. I have already given a list and the number of agricultural implements exhibited the last year at the Derby show; but that conveys no idea of the ingenuity and skill evineed in their construction. One is led to conclude, from the inspection, that there is no operation or function, comnected with human life and labor, for which mechanical labor does not attempt, and may not presently succeed in furnishing an instrument or machine. In many cases, a machine is any thing but a facility; and not a few of the machines, both in their contrivance and the expensive and showy manner in which they are got up, evince pretty strongly the gauge which the contrivers and makers have taken of the understandings and pockets of the probable purchasers. They are seldom at a loss to put the pail under a full cow.

In many respects, the arrangements are admirable, and well 
worthy of imitation.* Every possible effort is made to secure an impartial decision anong the competitors; for besides that they are not suffered by their presence to influence the examiners, the examiners themselves are selected from among persons who are as far as possible disinterested, and not likely to be influenced. They are chosen, likewise, with a special reference, in their characters and qualifications, to the nature of the subjects submitted;

* The terms on which the premiums for seed wheat are to be awarded are well worth the observation of other agricultural societies, and I therefore subjom them.

\section{"SEED WHEAT.}

"I. Thirty Sovereigns, or a Piece of Plate of that value, will be given to the Exhibiter at the Meeting at Derby of the best $\mathbf{1 4}$ bushels of White Wheat, of the harvest of 1842, and grown by himself.

"II. Thirty Sovereigns, or a Piece of Plate of that value, will be given to the Exhibiter at the Meeting at Derby of the best 14 bushels of Red Wheat, of tho harvest of 1842, and grown by himself.

"III. Twenty Sovereigns, or a Piece of Plate of that value, will be given to the Exhibiter at the Meeting at Derby of the best 14 bushels of Spring Wheat, of the harvest of 1842, and grown by himself.

"Competitors are requested to send with their Wheat, specimens, fairly taken, of the same in the ear, with the whole of the Straw, in a bundle not less than one foot in diameter, and with the roots attached.

" $[12$ bushels of the Wheat will be sealed up by the Stewards, and one of the remaining bushels of each variety will be exhibited as a sample to the public; the other being kept for comparison with the produce of the next year. At the General Meeting, in December, 1844, the Prizes will be awarded.]

"The two best samples of each of these three classes of Wheat, without at that time distinguishing, in any of the cases, between the comparative merits of either sample, will be selected by the Judges, appointed for the meeting at Derby; and will be sown, under the direction of the Society, (the Winter Wheats in the autumn of 1843, and the Spring Wheat not earlier than the 1st of March, 1844,) by four farmers, who will make their report, upon which the prizes will be awarded, provided there be sufficient merit in any of the samples. Ten Sovereigns will be given at the Meeting at Derby to each Exhibiter whose wheat has been selected for trial.

"* * No varicty of zoleat which has been selcetcd for trial at any previous shozo shall be qualified to compete."

The following are the instructions to the Judges on other subjects:-

"As the object of the Society in giving the prizes for neat cattle, sheep, and pigs, is to promote improvement in breeding stock, the Judges, in making their itward, are instructed not to take into their consideration the present value to the butcher of animals exhibited, but to decide according to their relative merits for the purpose of breeding."

"In the Class for horses, the Judges, in awarding the prizes, are instructed, in adition to symmetry, to take activity and strength into their consideration." 
and every pains is taken in this way to secure the greatest aptness and talents. 'The name of the competitor is not given where it can be avoided, but only the number of the article presented. The rules of admission and competition are stringent and absolute, and no exceptions are, on any account, allowed. When, last year, a competitor attempted to introduce a machine out of season, or in some way contrary to the published rules, and wrote to one of the agents of the society, that, if - a silver liey should be found necessary to its introduction, he begged him to use it, this attempt at bribery was rejected with proper indignation by the society, and the individual concerned, though eminent as a machinist and a manufacturer, and offering every apology for his "indiscretion," was forever irrevocably excluded as a competitor for any of the premiums of the society.

The society likewise offers premiums for essays, which are deemed deserving of such reward, upon any given subjects, and for reports on the agricultural condition and habits of different comties and distriets. 'This has been the means of bringing out many valuable papers. Here, too, the decision is sought to be rendered as fair as possible; for the name of the writer is not given with the essay, but under a separate and sealed envelope, which is not opened until the successful cssay is announced; and then the seal is broken, and the writer's name declared, in the presence of the society.

The society likewise has a consulting chemist, a consulting engineer, a botanist, and a professor of the veterinary art, of whose services, in any desirable case, it avails itself. Some time since, it numbered on its lists more than 6.500 members; and has been, since that time, steadily on the increase. It is impossibl. to overrate the advantages which such a society brings with it $t$ the agricultural community; for, though it emrols among its members many gentlemen, who are mere anteurs in the profession. and take little interest, and have little knowledge of its practica! details, yet, on the other hand, it combines, among the highest men in the kingdom, a very large amount of practical talent and skill - men of the most accurate observation, who carefully enter into the whole subject. There is another great and good influence. which it powerfully exerts, and which must not he overlooked. It gives a high respectability to the agricultural profession, and presents it as a pursuit, not, as has been too often said, for mere 
dolts and clod-hoppers, but for minds of the highest order, anc for men of all conditions, from the prince to the peasant; for "the ling himself is served by the field." The prizes are contended for with an ardor little short of that which displays itself in the contests of political life, and received with a high sense of their value. I have seen, at the tables of some of the highest noblemen in the land, the premiums of agricultural success, exhibited in some form of plate, with more triumph than they would display in the brilliant badges of their rank.

7. Agricultural Society of Scotland. - The Highland and Agricultural Society of Scotland is an institution of a similar description, and of a longer standing, than the Royal Society of England. It is richly endowed, and as powerfully patronized. and has long rendered itself illustrious by its Journal, published quarterly, in Edinburgh. This Journal, for the ability with which it is managed, and which has been displayed also in the prize essays of the Highland Society, which are always published in connection with the Journal, has certainly no superior. The Scotch have been long distinguished for their acuteness and excellent management; and the evidences of the justness of their pretensions in these respects, were too obvious and numerous, on my transient visit to the southern portions of Scotland, to leave any doubt of their just claims to the highest reputation. The exhibition of the society at Dundee, the last autumn, was, in the character and condition of its animals, in no respect, in my judgment, inferior to that at Derby, though the Scotch cattle present different varieties from those which are fashionable and most estecmed in England. The short horns and the Leicesters ot England would be, as a stock, very poorly adapted to the bleak hills and cold climate of Scotland; while the hardiness and thrif of the Scotch cattle and sheep show how well suited they are to the homes where they are bred, and whence they are sent, in immense droves, in certain seasons of the year, to the southern. portions of the country. 'The general management of the Scotch Agrieultural Society does not essentially differ from that of the English Royal Agricultural Society. The general exhibition at Dundee passed off much in the same style as at Derby, excepting that I thought the Scotch drank their toasts with a little more heartiness than the linglish — a characteristic of the country- 
men of Burns. This is not the place for me to describe the different breeds of stock shown at either place, or the varions implements exhibited. This I propose to do in another part of my Reports, with all the particularity which my friends can desire. The stock shown at Dundee would bear a comparison with the best stock shown any where; and the fact is too well known to need any confirmation of unine, that in point of intelligence and agricultural skill, and in point of success, - the best test of intelligence and skill, - the Scotch farmers yield the palm to none.

\section{XX. - RELATION OF LANDLORD AND TENANT.}

The holdings of many of the Scoteh farmers are very large ; and their farms are generally held under leases of nineteen and twenty-one years. One would be led to infer that the terms on which the landlords live with their tenants, in Scotland, must be honorable and just to both parties, since renewals are common: the same estates have been, in many instances, in the same families for a century, and the expenses incurred, in some cases, by tenants, in the erection of permanent buildings and other fixtures, are very heavy; showing the confidence of the tenant in his landlord. One farm was pointed out to me where the tenant had recently died, leaving only one child, an infant son. In this case, that the lease might be retained in the family, three of the neighhoring farmers had agreed to take the whole management of the estate until the young man came of age. In such cases, there is very little difference between a lease and a freehold in fee-simple. I cannot say, however, that the tenant is raised above all dependence on his landlord, or that removals do not sometimes take place under circumstances of great hardship. In one case, which came under my knowledge, a farm had been withdrawn, or; rather, the renewal of the lease refused, though it had been in the occupation of the same family for many years, on the ground of political opposition and prejudice, the avowed opinions and votes of the tenant not coinciding with those of the landlord. It is easy to believe that this may often happen, though any 
direct influence of this kind would be likely to meet the reprobation of the public. In one case, in England, to my inquiries whether the tenant was not expected to vote with the landlord, the farmer replied that his own politics were opposed to the politics of his landlord; and that, when taking his lease, to his great regret, he had pledged himself to remain neutral, and withhold his vote - a course by which many overwise and prudent people think that they escape the responsibility of the duty, whereas, in truth, by so doing they virtually give a vote to their opponents. In another case, the reply of two very intelligent and substantial farmers was, that they were at liberty to vote as they pleased; but it was almost the only way in which they could show their respect to, and evince their sense of the kindness of, their landlord, and they felt it therefore a duty of gratitude to vote with him. We are not beyond this influence even in our democratic communities. The voting by ballot may seem to give a perfect security; but this is invaded or destroyed when the candidates of a party are publicly prescribed, and the votes given are in a printed form; so difficult is it, under any circumstances, to maintain a perfect freedom and independence, and in practical life to realize our ideal theories. But politics are not my province; nor should I have thus far ventured upon them, but as connected with the important relation of tenant and landlord, in which I know my countrymen feel the strong interest of curiosity. I shall, perhaps, excite some surprise in stating my belief that the manner in which farms are held here, on hire for a year, or on lease for a term of years, rather than being owned by the occupants, is itself a powerful instrument or incentive to agricultural improvement. In the United States, where farms are owned by the occupant, the farmer seldom keeps any account, and it matters not much to him what is the result of the year's management. The effect of this is to render a man negligent and indifferent to success or loss. But when, at the end of every six months, the rent must be paid, it is not a matter of indifference whether his farming turns out well or ill; for not only the labor employed is to be paid for, but the rent of the farm must be punctually discharged. This consequently compels him to make every exertion by which he may be assisted to meet his obligations. IIc finds no room for idleness or neglect ; and the continuance of his possession depends upon his good management and the punctual 
payment of the rent. This prompts to watchfulness, skill, experiment, and improvement; and especially it gives to farming a commercial or mercantile character, and obliges the farmer to keep accounts, and so to learn the exact pecuniary result of his operations - a matter in which the farmers of the United States, as far as my observation goes, who are the owners of the farms which they occupy, are almost universally deficient. The strict responsibility to which the farmers are here held by their landlords, is undoubtedly a material element in their suecess. At the same time, where the occupation is from year to year, and leases are refused on the part of the landlords, as is generally the case in England, - though in Scotland leases are almost muiversal, - the effect must be to prevent or discourage substantial improvements, as few persons will be inclined to make such improvements with an uncertainty of continuance. It is a fact, however, which may create some surprise, that many farmers are unwilling to take leases when landlords would be willing to grant them. But this happens only when there is a perfect confidence on both sides; the tenant has entire reliance upon the honor and liberality of the landlord, and the landlord is equally confident of the good conduct and management of his tenant. An excellent landlord, in Lincolnshire, says he considers himself bound to continue his old tenants and their children in possession, in preference to any other tenant, as long as they choose to remain, unless some extraordinary contingency presents itself; and virtually admits on their part a property in the soil. The great length of time during which families, on his estates, have held their possessions from father to son, shows that he acts upon the most liberal principles; and the condition of his tenants, and their great improvements, evince that his honorable conduct secures their entire confidence. It cannot be doubted, however, that the uncertainty of continuance, the absolute power of discharge on the part of the landlord, the risk of his caprice, and the possibility of a new one coming in possession, "who might not remember Joseph, but forget him," must have some effect in preventing or discouraging improvements.

I farm which is well managed cannot change tenants without great inconvenience and evil on both sides. On several very large estates, which I have visited, the occupancy had been in the same families for a large portion of a century; and there seemed not the 
slightest apprehension of any change on either side. A good tenant is evidently almost as important to his landlord as his continuance on the estate can be to himself; and where, under such circumstances, substantial and permanent improvements are to be made, the landlord himself bears a portion of the expense. In draining, for example, the landlord furnishes the tiles, and the farmer makes the drains and lays them. A skilful and intelligent farmer, worth having as a tenant, would hardly be found willing to take a farm for a year, without an expectation of a much longer continuance, and certainly would not, under such an occupation, attempt any improvements but at the risk or expense of the landlord. In Scotland, where leases are, in general, for nineteen or twenty-one years, if the farmer has seven years of unexpended lease, he is expected to pay a third of the expense of any permanent fixtures or improvements ; if fourteen years, he is expected to pay two thirds, and the landlord one; if the whole term, the whole expenses are deemed properly chargeable to him.

I confess, under the best circumstances, I should greatly prefer being an owner or freeholder, to being a tenant. There is an excessive caution which characterizes some shrewd calculators, who consider the value of a property diminished, where the lease is limited even to nine hundred and ninety-nine years; but, without any sympathy with such persons, there is, at least, a gratification to a man's self-esteem, to feel that he is "the monarch of what he surveys," and that whatever improvements he makes upon his estate will enure to the lasting benefit of himself or his heirs. In a pecuniary view, however, it is really matter of indifference whether the occupant pays a reasonable rent for the land as tenant, or, as the owner of it, loses the interest of the capital invested in the purchase of the soil. 'There are few cases, as 1 have before ohscrved, where the rents paid equal the legal interest of the money which the lands would command, if offered for sale. Certainly, as far as my observation goes, - and I have seen somewhat both of landlords and tenants, - there prevails a disposition, and there are the strongest inducements, to cultivate a mutuallygood understanding between the parties. There is, in general, no more reason to fear that landlords will be oppressive and mjust, than that tenants will be wasteful, negligent, and fraudulent. Power is always a hazardous possession, and always liable to abuse, and cannot, therefore, be too much guarded and 
limited in every condition of life. The abuses of power are not, however, peculiar to persons occupying a high condition in society, but are as often found among the lowest, who seem to have nothing else but the ability to injure and exert it most cruelly when they are most loudly claiming compassion for themselves, as the victims of injustice. I believe there is a great deal more abuse of power on the part of farmers towards their laborers, than on the part of landlords towards their tenants. The farmers can protect themselves; the laborers, in general, are without power. Indeed, the more cultivated and improved is the education of a man, and the higher the condition which he occupies in society, the stronger are the inducements to a just ano honorable conduct, not only in his enlarged mind, but in the increased value of character to such a man. In Ireland, the middle-man, who comes between the landlord and the poor tenants, who there are themselves laborers, and especially those middle-men who are themselves subletters of the soil, are always feared for their severity and oppression. How far a man's political independence is affected by his relation to his landlord, is another consideration. $\Lambda$ man living under such a constitution of government as that of England, unless he is himself an ofliceseeker, or dependent upon the emoluments of public office, will not deem this of so much importance as many might consider it ; and if he makes up his judgment from the representation which the minority in a republican or elective government always give of the character and measures of the majority, he may be led to conclude that his chance of being protected in his rights, and secured in his person and property, is as good under an hereditary government, or one chosen for him by others, as under one in the choice of which he himself, with others, is permitted to give his sufrage. I would not be thought to undervalue political liberty: and, in my opinion, human wisdom has never devised a constitution of government so just and so favorable to the happiness of its subjects as that of my own country. But I have been too often in the minority not to have learned that a majority composed of thousands may be as despotic as a single tyrant; and I an not unaware that the position occupied by the governments of all civilized countries, is, at the present day, very different from what it was a century ago. As the reformation, under Luther, gave a blow to the doctrine of the infallibility of the 
church, from which it can never recorer, so the successful asse"tion of the right of revolution against oppression, in 17t6, read : lesson to all arbitrary governments, which is not likely soon to be forgotten. Under any form of government, the great securit: for the subject is, that they who govern shall be equally affected by their own measures as they who are governed; and in countries so free and enlightened as Great Britain and the United States, whoever may rule, no measures of extreme injustice or wrong are likely to be long endured. There is a force in public opinion which can searcely be resisted, and which is more powerful than any mere legal enactments. What is mainly to be desire? is, that education should be so general in its extension, and so elevated and just in its character, that public opinion may be wisely formed, and be not only a commanding, but a safe and worthy guide.

The form or conditions of lease, in England, somewhat differ in different places; but the main terms are every where the same. Leases, generally, are drawn up in an exact form, and become sealed and legal instruments. The farm is entered upon in the spring, and the rent is made payable semi-ammally. The mod. of cultivation is generally prescribed by the landlord, from which the tenant is not at liberty to depart. Two white crops are seldom permitted to succeed each other without intervention upon the same land. The green produce is required to be fed upon the place; and if hay or straw is sold, an equivalent quantity of manure is required to be brought on. All substantial improvements are the subject of special agreement; and the tenant is nerer allowed to cut down any tree or timber upon the place, or otherwise to commit any waste. Where a farm is to be quit, or entered upon by a new tenant, the going-out tenant is at liberty to come in to gather the crops which he himself has sown.

There is a class of men, in England, of which we know nothing in the United States; these are called land surveyors or valuers. These are generally persons of experience and judgment, who examtive the condition of the place, and estimate what would be a fair rent to be paid; and by their opinion the parties are usually governed. Such a person is often employed to estimate the value? of growing crops, where an allowance is to be made by the incoming to the out-going tenant. This professional mon, if well qualified for his office, may he highly useful; and such a course 
likely to render the transaction more just than where it partakes wiore of an accidental or arbitrary character, where one party may i.e led by his caprice to demand too much, or be betrayed by his ignorance to obtain too little; or the other party may be driven by inis necessities, or led by a mistaken judgment of the capacities of the farm, to take it upon very hard terms. The taxes and tithes are usually paid by the tenant; but their amount is always considered in determining the rent, so that, properly speaking, they are paid by the landlord, and not by the tenant. The leasing of farms, in the United States, is quite rare, and but in few cases is it arranged by any established rule. In New England, in such cases, matters are conducted most loosely. Farms are frequently "taken to the halves," which is understood to imply that the farmer returns half of all the produce grown to the owner; but the landlord is almost entirely in the power of the farmer; and, after the farmer has, as is but too common, applied to his own use about half the produce, he divides with the owner the half which remains. If the owner furnishes implements, the farmer returns them as good as he received them; and, if he furnishes stock, as on a breeding or a dairy farm, the tenant pays the legal interest upon the cost, makes good the stock received when he "uirs the farm, which is generally settled by valuers or appraisers, and divides with his landlord one half the increase. Our practices, in this matter, are various and unsettled; and, as long as the hiring of farms continues with us to be so infrequent, - and it is likely to continue so while land remains as easy to be purchased as it now is, - no exact method will be introduced.

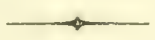

XXI. - GAME AND THE GAME LAWS.

The farmers in the United States are happily free from one evil which presses heavily upon the English farmers; and that is, the nuisance of what is here called game, and the curse of the game. lanss. Pheasants, partridges, grouse, hares, and rabbits, are here called game, and are protected, by the most severe laws, for the benefit of sportsmen who either own or lease the territory on 
which they find them, and pay a tax to the government for the privilege of shooting or coursing. The hares and rabbits are extremely destructive to the farmers' crops, and the complaints of them are universal. It is considered that five hares, or seven rabbits, consume as much as one sheep, besides a considerable amount of incidental damage; and it is stated that there were sold, from one farm, in one year, for the benefit of the landlord, no less than two thousand hares and rabbits, which was a tax upon the farmer equal to the support of three hundred sheep. 'They do great damage to much of the produce which they do not consume, in biting the turnips and in trampling down the grain. A farmer is liable to imprisonment or transportation if he destroys them, even when committing havoc upon his crops. An allowance is undoubtedly made, in some cases, though not in all, for these depredations and injuries. It is obvious, however, that, in most cases, an equivalent can hardly be made, not for the loss merely, but the immeasurable vexation, which they occasion. I entirely accord in the unanimous opinion of the farmers, whom I have met with, that, with the exception of feathered game, the game laws inflict a most serious injury upon the agricultural interest. Of their moral tendency this is not the place for me to speak; but the immumerable convictions for poaching - that is, entrapping or stealing game - with which the judicial calendars are filled, - and some trials for which charges I have attended, and the several murders of gamckeepers which have occurred even within the last year, present a subject of serious consideration for those who know that one great preventive of crime is to remove the facilities and inducements to it, and that whoever, voluntarily, and without necessity, presents a temptation to crime, necessarily shares in its responsibility. It is a subject which never can be too strongly urged upon just and reflecting minds, how much the manners and pleasures of the upper, the educated, and the influential classes, affect the morals of those beneath them. They inflict, oftentimes, an infinitely deeper injury than any injury to property can be. In the United States, though there are laws to protect from extinction races of birds and of fish, there are none which confer any exclusive privileges for the capture or destruction of that which Heaven has made as free as water and air, though any man would be liable to a penalty if he injured his neighbor in pursuing it. 


\section{XXII. - THE ROYAL AGRICULTURAL SOCIETY OF IRELAND.}

The Royal Irish Agricultural Society, for the general improvement of agriculture in Ireland, is of more recent origin than the English Royal Agrieultural Society, and is established upon the same general plan. It already embraces a large array of numbers, combining men of the highest rank and wealth with other's in more humble condition. It is intended to hold its ammual shows in different parts of the country; and it bestows large sums in premiums, - thirty sovereigns, or one hundred and fifty dollars, being the prize, for example, in the class of bulls, and other prizes of proportionate value for other objects. It has adopted one very wise provision: in the high prizes for the best live stock, it opens the competition to the whole kingdom, without restriction, so that specimens are brought from England and Scotland, of cattle, sheep, and swine; and thus the Irish are enabled to see, and compare with them, what has been done by others, and in what respects they exceed or fall short of them. 'This presents the most powerful stimulus to excel; whereas, if the competition were confined wholly to themselves, not knowing what has been done by othera, they might be satisfied with inferior attainments. At the agricultural show at Dublin, which I had the pleasure to attend, a good many animals were exhibited from Scotland and England, which were of a superior character, and which gave the Irish farmers a favorable opportunity, not only of seeing the favorite linds in the sister kingdoms, but the degree of perfection, to which, by careful breeding and kecping. they had been carried.

When I have recommended, as I have repeatedly done, the adoption of the same liberal practice among the county societies of Massachusetts, and with other societies in New York, I have always been met with the argument, that this would be sending the money paid in premiums out of the county, or out of the state, which is an objection unworthy of consideration; for of what consequence is the money, if we can get the improvement? The object of a society, in all its measures and premiums, should be the improvement of agrienlture and husbandry. The distri- 
bution of money is only an instrument to effect this end. By what means that object is most surely to be attained, is the only matter worth inquiry. Nothing is so likely to serve this end as seeing and ascertaining the degree of improvement to which the art has any where, at any time, or by any persons, been advanced; and how far, and how effectually, in our condition, we may adopt the same means of progress. There is, in my opinion, nothing less worthy of a liberal mind, nor less friendly to advancernent in any thing valuable and useful, than a miserable self-conceit, which passes often under the name of patriotism, but which is a spurious metal, and a mere counterfeit of that noble virtue. To value a thing because it is American, or because it is English, or because it is Irish, without regard to its substantial qualities, is worthy only of a child; and a mind bent upon improvement, and capable of any great progress, rises above such mean prejudices; values things according to their intrinsic merit: acknowledges excellence wherever excellence exists, and secks that which is good, wherever good is to be found. We should dismiss all pride in our own improvements when others have gone beyond us. The advances which others have made, be they who they may, should only be with us an incentive to new excrtions; and so far from indulging the slightest regret that they have surpassed us, if we discover that to be the fact, let us rejoice in what has been accomplished, and regard all improvements, of every description, as so much gained for science or for art, for general comfort or advancement, and as the common property of human nature and the world. This is the truest and noblest patriotism, which heartily exults in every good conferrec? upon its own community, or its orwn country, and, in the spirit of an enlarged philanthropy, seeks for its universal extension. To a good mind, the good is not diminished by being the more widely diffused.

No benevolent and just man can look upon poor, suffering Ireland, a land full of brilliant minds and generous hearts, and whose eventful history is resplendent with a galaxy of the most noble sacrifices and services of patriotism and philanthropy, without rejoicing in any good which comes to her, or offers itself in prospect. Ifer $\Lambda$ gricultural Society promises to prove of the highest benefit to a country, the soil of which is capable of a most productive cultivation, where labor presents itself in unlim- 
ited abundance, and where crowds, almost without number, of the wretehed, the half-clothed, and the hungry, demand, in tones which would touch any heart not made of stone, an opportunity of satisfying their own wants by their own labor, and of obtaining from the willing earth that which a beneficent Providence has formed it to yield for the subsistence and comfort of his creatures.

The exhibition at Dublin was, in various respects, creditable to the society. The collection of grasses and grains, dried specimens of which were exhibited by several nursery-men, were extremely beautiful, and highly instructive to the farmers. They were presented in a form which enabled them to compare with each other, and in some measure to determine, their relative qualities. Numerous specimens of flax, and of linen, and lawn which has been long a distinguished product of Ireland, likewise attracted deserved admiration. Specimens of soils, and mineral and artificial manures, and exemplifications of different modes of draining, and models of cottages and farm buildings, were also exhibited, and suggested improved and economical modes of construction. I saw, likewise, an American straw-cutting machine, very slightly varied from the original, and which had been patented in Ireland, of which I could not complain, after many instances of similar plagiarism, which I had seen, in my own country, exhibited as rare specimens of Yankee ingenuity. Of the morality of such tricks, if so they are to be called, I leave my readers to judge; but in other respects, from various things which have come under my notice, the account seems pretty fairly balanced between us.

The exhibition of poultry attracted much attention, and, though an humble object, was not unworthy of observation. It was principally confined to geese, ducks, and dunghill fowls. The Malay and Java fowls, specimens of which are to be found in the United States, were very large, and appeared almost to have some affinity with the ostrich family. It was stated that, when dressed, they would weigh from eight to ten pounds, whicis is the size of a common turkey. The valuable race of Dorkings was shown in great numbers, as being highly approved; and likewise some crested Spanish birds, which were reputed most abundant layers - a property which, in my opinion, depends as much upon plenty of feed, and houses where a mild tempera- 
ture is preserved, as upon any peculiarity of constitution. Of game-cocks I saw none. The inhuman sport, which once brought these animals into fashion, is, as far as I can learn, now not permitted nor known. The cause of humanity has certainly accomplished much in the abolition of the cruel games of cockfighting, dog-fighting, bull-baiting, and bloody boxing-matches. The various military dresses, most brilliant and magnificent as they were in themselves, and which were seen plentifully sprinkled about the show-yard, and in the streets of Dublin, indicated, however, that there were other game-cocks in training, for purposes far more cruel and unchristian, whom, with their glittering swords and bristling bayonets, I seldom pass without a shudder; and to the necessity, if there be any, of whose profession and employment, I can only desire as speedy and as effectual an end may be put. The fights of the lower orders of animals, for which they have been trained, and to which they have been spurred on by the brutality of a higher order of animals, assuming to be rational and moral, are, alas! but a melancholy counterpart of scenes which have covered human history all over with blood, and stained its pages with crimes of a demoniacal malignity and revenge, vulgarly, and by a misuomer which, in a Christian country, makes one's heart ache, called heroism and glory. The native race of cows, principally from the county of Kerry, which were exhibited on the occasion, was quite remarkable. They are much smaller than any thing of the kind which I have ever seen, and can have little value out of the country where they are reared, and to whose scanty pastures and bleak hills they are said to be peculiarly adapted. They are generally black, kept at a very small expense, and are said, for their size, to yield an extraordinary amount of milk. A bull of a year old of this stock, to which a prize of five sovereigns was awarded, was so diminutive, that I could, without difficulty, have lifted my leg over his back. The sight of this animal solved a problem in history which has always puzzled me. It is said of Nilo, that, beginning with a calf, and carrying him upon his back every day, the increase of weight was so gradual, that the limit of his personal strength could not be determined, and he continued to lift him after he became an ox. If it were a Kerry $o x$, the otherwise intrinsic improbability of the story entirely ceases This Kerry bull was little larger than a goat, and should 
form a part of the retinue of 'Tom Thumb, that distinguished American production, who has excited the most extraordinary sensation in England.

\section{XXIII. - MODEL FARM AND AGRICULTURAL SCHOOL.}

There is an establishment connected with the agriculture of Ireland, which is in the immediate neighborhood of Dublin, and which I have visited with the greatest pleasure, and that is a Model Farm and an Agricultural School. The national government have determined to appropriate seventy-five thousand pounds annually to the cause of education in Ireland, to be distributed, in proportions corresponding to the subscriptions of mdividuals for the same objects, in parts of the country where education is most needed. It is considered, and with good reason, that the great want, among the people, is a want of knowledge in applying and using the means of subsistence within their reach; that there is no indisposition on their part to labor; that there is as yet an ample extent of uncultivated land capable of being redeemed and rendered productive; and that a principal source of the wretchedness, and want, and starvation, which prevail in some parts of this country, often to a fearful extent, is attributable to the gross ignorance of the laboring classes of the best modes of agriculture and of rural economy. With this conviction upon their minds, the commissioners have determined to connect with all their rural schools a course of teaching in scientific and practical agriculture, communicating a knowledge of the simple elements of agricultural chemistry; of the best modes and operations of husbandry which have been adopted in any country; of the nature, and character, and uses, of the vegetables and plants necessary or useful to man or beast; of the improved kinds of live stock, and of the construction and use of the most improved and most approved farming implements and machinery. With these views, it is their intention to train their schoolmasters, and to send out such men as are apt and qualified to teach these most useful branches. For this purpose the government have established this model farm, which was begun in 
1838, and which has already, in a greater or less measure, quallfied and sent out seven hundred teachers. To my mind it seems destined to confer the most important benefits upon Ireland, ance I may add upon the world, for so it happens under the benignant arrangements of the Divine Providence, the benefits of every good measure or effort for the improvement of mankind proceed, by a sort of reduplication, to an unlimited extent; these teachers shall instruct their pupils, and these pupils become in their turn the teachers of others; and the good seed, thus sorvin and widely scattered, go on yielding its constantly-increasing products, to an extent which no human imagination can measure. Three thousand schoolmasters are at this moment demanded for Ireland, and the government are determined to supply them. Happy is it for a country, and honorable to human nature, when, instead of schemes of avarice, and dreams of ambition, and visions of conquest, at the dreadful expense of the comfort, and liberty, and lives, of the powerless and unprotected, the attention of those who hold the destinies of their fellow-beings in their hands is turned to their improvement, their elevation, their comfort, and their substantial welfare.

The Model Farm and Agricultural School is at a place called Glasnevin, about three miles from Dublin, on a good soil. The situation is elevated and salubrious, embracing a wide extent of prospect of sea and land, of plain and mountain, of city and country, combining the busy haunts of men, and the highest improvements of art and science, with what is most picturesque and charming in rural scenery, presenting itself in its bold momntains and deep glens, in its beautiful plantations, its cultivated fields, and its wide and glittering expanse of ocean. The scenery in the neighborhood of Dublin, with its fertile valleys, and the mountains of Wicklow, of singuiarly grand and beautiful formation, bounding the prospect for a considerable extent, is among the richest which the eye can take in; and at the going down of the sun in a fine summer evening, when the long ridge of the mountains seemed bordered with a fringe of golden fire, it carried my imagination back, with an emotion which those only who feel it can understand, to the most beautiful and picturesque parts of Femont, in the neighborhood of Lake Champlain. I have a strong conviction of the powerful and beneficial influence of fine natural scenery, where there is a due measure 
of the endowment of ideality, upon the intellectual and moral character; and I would, if possible, surround a place of education with those objects in nature best suited to elevate and enlarge the mind, and stir the soul of man from its lowest depths. It is at the shrine of nature, in the temple pillared by the lofty mountains, and whose glowing arches are resplendent with inextingruishable fires, that the human heart is most profoundly impressed with the unutterable grandeur of the great object of worship. It is in fields radiant with their golden harvests, and every where offering, in their rich fruits and products, an unstinted compensation to human toil, and the most liberal provision for human subsistence and comfort, and in pastures and groves animated with the expressive tokens of enjoyment, and vocal with the grateful hymus of eestasy, anong the animal creation, that man gathers up those evidences of the faithful, unceasing, and unbounded goodness of the divine Providence, which most deeply touch, and often overwhelm, the heart. The Model Farm and School, at Glasnevin, has connected with it fifty-two English acres of land, the whole of which, with the exception of an acre occupied by the farm buildings, is under cultivation, and a perfect system of rotation of crops. The master of the school pays for this land a rent of five pounds per acre, and taxes and expenses carry the rent to eight pounds per acre. Twelve poor boys, or lads, live constantly with him, for whose education and board, besides their labor, he receives eight shillings sterling per week. They work, as well as I could understand, about six hours a day, and devote the rest of the time to study, or learning. The course of studies is not extensive, but embraces the most common and useful branches of education, such as arithmetic. geography, natural philosophy, and agriculture, in all its scientific and practical details. They have an agricultural examination, or lecture, every day. I had the gratification of listening to an examination of fourteen of these young men. hrought out of the field from their labor; and cheerfully admit that it was eminently successful, and in the highest degree creditable both to master and pupil. Besides these young men, who live on the farm, the young men in Dublin, at the normal school, who are preparing themselves for teachers of the national schools, are refuired to attend at the farm and assist in its labors a portion of the time, that they may become thoroughly ac- 
quainted with scientific and practical agriculture in all its branches, and be able to teach it ; the government being determined that it shall form an indispensable part of the schoo! instruction throughout the island. The great objects, then, of the establishment, are to qualify these young men for teachers by a thorough and practical education in the science, so far as it has reached that character, and in the most improved methods and operations of agriculture. Besides this, it is intended to furnish an opportunity to the sons of men of wealth, who may be placed here as pupils, to acquire a practical knowledge of, and a familiar insight into, all the details of farming. This must prove of the highest importance to them in the management of their own estates.

The superintendent was pleased to show me his accounts in detail, which evinced, as far as I could ascertain, a successful and profitable management; but as there were several material elements to be taken into the calculation, I shall not speak with any confidence on this subject, without further information, which cannot now be had, but which I shall take pains to give in the fullest manner hereafter.

As the crops were uncommonly fine, and the whole cultivation and management, as far as it appeared, excellent, I shall detail some few particulars in a cursory manner.

The first object was to illustrate the best system of rotation of crops; and three systems of alternate husbandry were going on ; one of a course of three crops, one of five, and one of nine; and one especial object pursued in one department of the farm was to show the most eligible course of management of a single acre of land, so as to give an example of the best system of cottage husbandry for the poor man, who might have only a small allotment of land, and whose object would be to feed a cow and a pig, and to get what supplies he could for his family. Such lessons, it is obvious, must appear of the highest importance in Ireland, when we consider the condition of its peasantry, and cannot be without their advantages to every cultivator of land.

Another object aimed at is to show that a farm is capable of being kept in condition from its own resources, and from the consumption of the principal part of the produce upon the land. No manure is ever purchased here; and the manager professed to have an ample supply. Six years' trial, with crops of the 
highest productiveness, and indicating no diminution, but rather an increase of yield, seems to have satisfactorily established this point. The provisions for saving all the manure, both liquid and solid, for managing the compost heap, and for increasing its quantity by the addition of every species of refuse that can be found, are complete. The stock consists of seventeen cows, one bull, six young stock, two horses, and one pony; and they are all carefully stall-fed, in clean, well-littered, and well-ventilated stables, with ample space before and behind them, and turned out for recreation, in a yard, about two hours in a day. The manure heap is in the rear of the stables; is always carefully made up, and kept well covered with soil, or sods, or weeds, so as to prevent evaporation, retain the effluvia, and increase the quantity. The liquid manure is collected, by spouts, from the stables, into a tank, from which it is, as often as convenient, pumped up, and thrown, by an engine pipe attached to the pump, over the heap; and that portion of it which is not retained, but passes off, is caught again in another tank, and again returned upon the heap by the same process as before. The skilful manager of the farm prefers this method to that of applying the liquid manure directly from a sprinkling machine upor his fields. Either mode may have its peculiar advantages, which I shall not now discuss. The object of each is to save and to use the whole; and I am determined, so important do I deem it, never to lose a fair opportunity of reminding the farmers that the liquid manure of any animal, if properly saved and applied, is of equal value as the solid portions; but in most places this is wholly lost. The manure for his crops he prefers to plough in in the autumn; and the extraordinary crops of potatoes grown by him are powerful testimonies in favor of his management.

His potatoes give an average yield of eighteen tons (gross weight) to an English acre, which, allowing fifty-six pounds to the bushel, would be seven hundred and twenty bushels. He has grown twenty-two tons to an English acre. Either of these quantities, in New England and in Old England, would be considered a magnificent crop. He plants his potatoes either in ridges thirty inches asunder, with the potatoes or sets eighteen inches apart in the drills, or else in what here is called the lazy-bed fastion, which is a common practice, but which, as it respects the labor required, is altogether misnamed. In this case, the land is dug 
or ploughed, and thrown into beds of about three feet wide, first formed by ridging or back-furrowing with the plough, and afterwards covered with earth, thrown from a ditch between the beds about eighteen inches in width, and rumning between all the beds. After this bed is smoothed off, the potatoes are planted upon it, in rows, crosswise, at the distance of eighteen inches by thirty inches apart, and they are then covered with about four inches of earth taken ont of the intermediate ditch with a spade. After the potatoes are fairly above ground, they have a second covering of four inches of earth, as before, and this comprehends the whole of their cultivation in the lazy-bed fashion. When they are planted in drills or ridges, the space between the ridges is never suffered to be disturbed by a plongh, but is simply dug with a spade, as it is an important object to avoid injuring the young fibrous roots of the plant, upon which the tubers are formed. The potatoes are kept, in this way, with an occasional application of the hand to the weeds, entirely clean; and the luxuriance of their growth throughout a large ficld, as far as my observation goes, was never surpassed. By his management of his manure, sprinkling the heap with the liquid portions, and so lieeping up, through the summer, a slight but constant fermentation, not only all the weeds thrown upon it are rotted, but the seeds of these weeds are effectually destroyed. He says the largest crop of potatoes which he ever produced was had in a field where the sets were placed over the whole field, at a distance of a yard each way from each other. He prefers always planting whole potatoes, of a medium size, to cutting them. He showed me a portion of the field, which had been planted with cuttings of potatoes, sent him by a friend, of a new and valuable kind, and which he cut with a view to planting more land; but the difference in their appearance was most marked, and showed an inferiority of as one to three to those which were planted whole. 'Ten bushels of seed he considers suflicient for planting an acre.

His turnips promised extremely well. I remarked to him that they were sown in the drills very thickly. He replied that he had never lost his crop by the fly, and he attributed his success to two circumstances - the first, to planting his seed two inches deep, by which means the roots of the plant became extended and strong before the plant showed itself above ground; and the second, by sowing a large quantity of seed; if the flies took a 
portion of the plants, he would probably have an ample supply left. He suffers them to get somewhat advanced before they are thimmed, and then is careful to select the healthiest and strongest plants to remain. I must not be supposed ever to endorse the opinions of another man, simply because I give them; but certainly success is the best test of judgment and skill. However interesting and ingenious a man's speculations may be, his practice is always worth vastly more than his theory.

His crops of mangel-wurzel were magnificent; and he gets a great deal of green feed for his cows, by plucking the under leaves; though, if too severely stripped in the autumn, they are liable to be injured by the frosts.

He sows tares and oats together for green feed for his stock. The oats serve to support the tares, and the mixture seems to be greatly relished by the animals. His great dependence for green feeding of his stock is upon the Italian rye-grass, a most valuable grass, which is very much commended wherever it is cultivated, and which, I hope, will be introduced into the United States. I saw a field of this on the farm, which had already been cut twice in the season, and was nearly ready for another cropping. In Manchester, the last autumn, I saw specimens of three cuttings of Italian rye-grass, all cut from the same field in the same season, the combined length of which was thirteen fect. This was a surprising growth, and indicated the remarkable luxuriance of the plant.

His oats give an average yield of eighty bushels to an English acre; and the oats chiefly preferred here are the Scotch potato and the Hopetoun oat. The weight of the potato oat per bushel is stated to be about forty-four pounds. I have known it in the United States, the first year of its cultivation, to weigh as much, but the second year not to weigh more than thirty-five pounds per bushel. 'This must be owing to some error or defect in the cultivation ; for I can conceive of no natural hinderance, in many localities, to the most successful cultivation of this crop. He sows rye-grass with his oat crop, and gets a good cutting, after the oats are off, from the stubble. It might be thought that this is riding the horse "too hard;" but, as the rye-grass does not ripen its seed in the case, the soil is not exhausted. The next season it gives a full yield. I shall hereafter extend the account of this admirable establishment, if any thing presents 
itself, upon further inquiry, desirable to be communicated. The institution is one of great importance, and will serve as a model for others; and several, in different parts of the country, through the public-spirited exertions of several gentlemen, who are large landholders, are in the process of being formed. I shall conclude the account with the production, the current year, (1844,) of sixteen and a half acres of land upon this farm, which the manager, in whose established character I have entire confidence, has been pleased to give me. In my experience, the yield has not been surpassed.

From these sixteen and one half English acres, he has fed entirely, from the 4th of April to the 18th of August, seventeen milch cows, one bull, six young stock, two horses, and one pony. Of one acre in vetches, he has used one half the crop; the rest remains. Of one acre in cabbages, he has sold two thirds, and used one third; the two thirds having brought him by the sale $£ 13$ sterling; and from the same sixteen and a half acres he has cut and cured, and has in stack, twenty-eight tons of wellmade hay, from rye-grass. I took this statement down from his own mouth, with the stack of hay before me, the quantity of which was ascertained by cubic measurement, by a rule which is considered established and accurate.

\section{XXIV. - DUBLIN BOTANICAL GARDEN.}

In the neighborhood of Dublin is a Botanical Garden, comprehending twenty-seven acres, enclosed by a high stone wall, with a beautiful rivulet running through it, with ample and elegant conservatories and greenhouses, and in the highest state of cultivation and embellishment. It is supported partly by private subscription, and partly by donations from the government. It is a beautiful retreat, and open to all persons two days in a week, with intelligent and courteous superintendents to show and explain every thing. To my inquiry of the superintendent whether he suffered any injury from the visitors plucking the flowers, or breaking the plants, he replied, very little, if any ; none 
whatever from the highest classes in society, and none whatever from the lowest classes, who visited it in great numbers; and who, coming out of their damp cellars, and their confined streets, and their dark and offensive holes, and fastnesses, and common sewers, no doubt found in it, with their children, almost a transition from earth to heaven; and here breathed the perfumes of the divine beneficence, and contemplated, with a felicity which even princes might envy, the exuberant tokens of God's goodness in the flowers and fruits of the earth, radiant with a celestial beauty. There were other persons, whom he chose to denominate the vulgar rich, who were not so abstemious, and who required to be watched. It is to be hoped, as education advances, a higher tone of moral sentiment will prevail, and that every thing of taste or art, designed for general gratification, will be secure against injury or defacement, so that the odious notices and cautions, which are now so constantly seen in such places against depredation, may themselves be deemed a public insult, and the very idea of violating an honorable confidence, and abusing the public beneficence, may so trouble a man's conscience, that he shall desire to run away from himself.

This garden and grounds, and its conservatories, are designed to furnish specimens of all the most valuable and curious native and exotic plants and fruits; and, in addition to their present erections, the proprietors are now about to build a conservatory four hundred feet long, and seventy feet wide, with a height proportioned. The grounds are always open to the studious and scientific, and a course of botanical lectures is given, with the illustrations to be found here.

Botany may here be studied to great advantage, as portions of the ground are allotted to the perfect arrangement of the plants, according to the classification and orders of Linuæus, and in another part, according to the natural order; and for the benefit of agricultural students and farmers, specimens are cultivated and neatly arranged of all the useful vegetables and grasses, with their botanical and their vulgarnames affixed to them, with specimens likewise of the most pernicious weeds, that the farmer may see what to choose and what to avoid. The collection is already extensive, and is constantly becoming enlarged. It is difficult to overrate the value of such establishments, both for use and for pleasure, for their pecuniary, their intellectual, and 
their moral benefit. While penning this account, I hear, with extreme regret, that the Botanical Garden in Boston, a city so eminent for its public spirit and beneficence, is to be strangled in its infancy, and abandoned; and that the ground is likely to be appropriated to buildings, so that the rich prospect of the chamming environs of the city is to be shut out, and the fresh and salubrious breezes from the verdant fields and hills of the surrounding country are to be debarred an entrance for the refreshment of the inhabitants of this busy and crowded mart; and even the sight of the glorious western sky, which, with its gilded, and glowing, and gorgeous drapery, I have made, at evening, a pilgrimage, many hundreds of times, to contemplate and adore, is to be excluded by high walls of brick and stone. Should this be done? and how can such an injury, if once committed, be repaired? Surely they will forgive one of their own children, whom no distance of place and no length of absence can estrange from his honored and revered birthplace, in saying that even one half of the expense thrown away upon public dinners and parade, would secure to them permanent provisions for health, instruction, comfort, and delight, whose value no pecuniary standard can measure, and which can never be duly appreciated, but by those who have enjoyed and have then been deprived of them. 



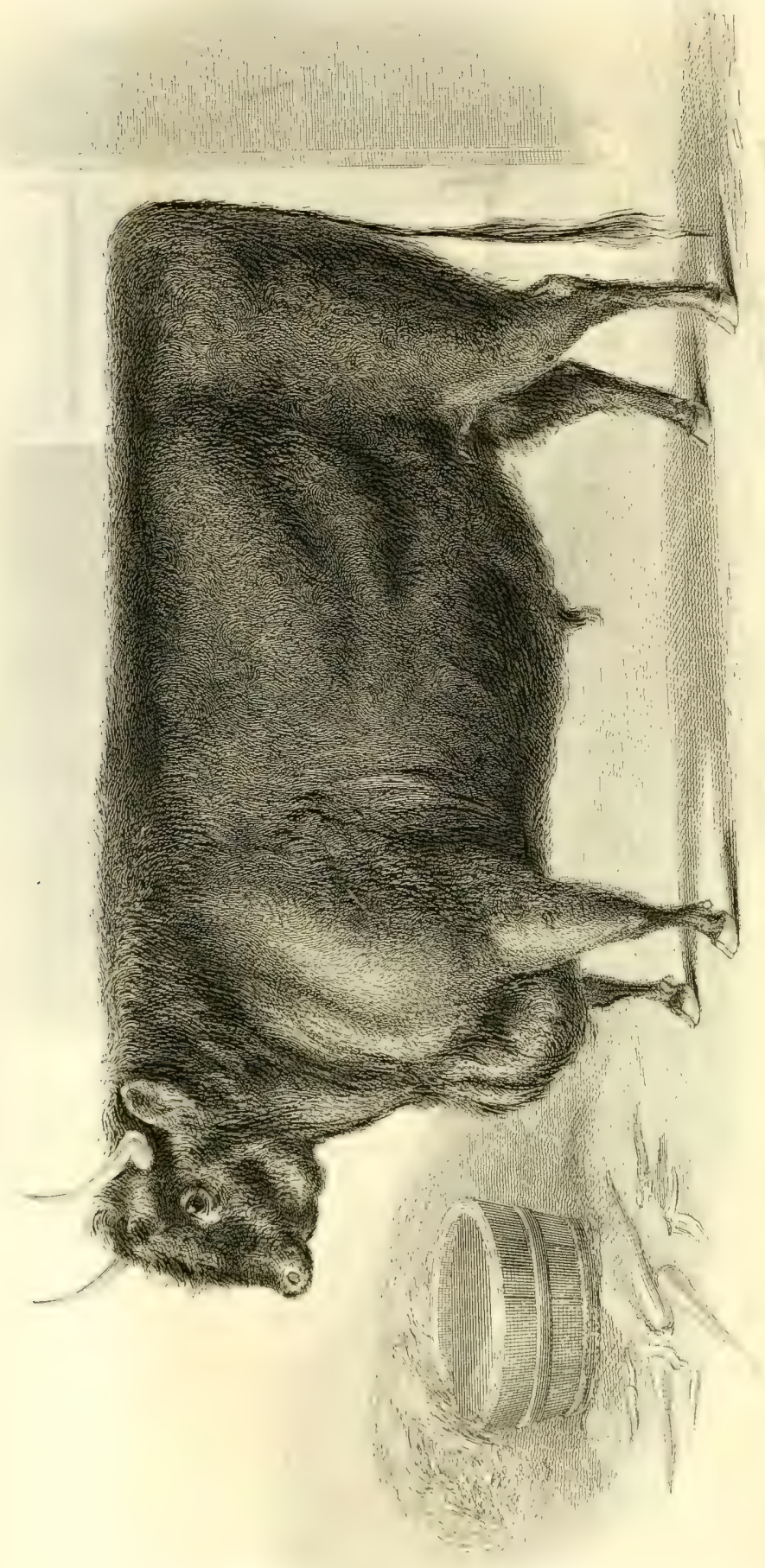




\section{EUROPEAN AGRICULIURE.}

\section{THIRD REPORT.}

\section{XXV. - AGRICULTURAL EDUCATION.}

Nix Second Report gave an account of the Agricultural School at Glasnevin, near Dublin, Ireland. I propose to add a notice of some other industrial schools, which I have had an upportunity of inspecting. The excellent establishment which I described, and three others, of a similar character, which I have visited, are in Ireland. Ireland, in this respect, has taken the lead of England and Scotland, where we might sooner have expected to find institutions of this nature.

That in a country where the waves of political agitation have for years been tossing all over it like the sea in a storm, and where, certainly in large portions of it, there exist a degradation and state of destitution utterly beyond any power which I possess adequately to describe, - in many parts, a struggle for existence which seems, to an inexperienced spectator, absolutely desperate, - and, in some parts, a ferocity, growing not out of any innate malignity, but out of unfortmate social relations, (for which the remedy is not obvious, scarcely to be paralleled even among camibals, - in a condition of society where all the elements of social life appear in a state of violent conflict, - that in the midst of all this there should be growing up institutions of this character, even in advance of places blessed with peace, plenty; quiet, and the highest measure of social improvement which has yet been reached, is not a little remarkable. 
But this beautiful and wretched country abounds with intelligent minds, glowing with the warmest philanthropy. They appear, indeed, like stars in a partially-clouded night, pouring, out of their own native fulness, rays of the purest splendor; struggling, as it were, continually, to penetrate the darkness which intercepts them; and appearing to shed a brighter radiance as the mists and black clouds sweep along, and, occasionally breaking open, leave, though only for a time, a way for the transmission of their light. They may, sometimes, seem to serve no other purpose than to render the darkness visible; but they inspire courage, and strengthen the hope of a wider diffusion, and the ultimate dawning of a full day.

These men rightly conceive that education is to be one of the great means of elevating Ireland; and that, an education of a practical character. In an education of a different character, Ireland is not wanting. Strange as it may seem, in some parts of Ireland, even the common people are familiar with the ancient classics; and the household deities of the heathen are enshrined in their cabins among their own numberless saints. When in Killarney, in the vicinity of the lakes of that picturesque and romantic region, I took leave to inquire of the hotelkeeper into the state of education among the people. He immediately called in a ragged, dirty, barefooted boy, - for, indeed, very few of the common people in the rural districts of Ireland are in any other condition, - and told him "to bring his books and show the gentleman what he knew." This boy was only ten years old, and the son of a shoemaker. He brought in his Greek Testament, and in the Gospel of John, in which I pretty thoroughly examined him, he recited with perfect correctness. I then examined him in the declensions and conjugations of nouns, and adjectives, and verbs, in which he was equally expert and correct. I found, likewise, upon inquiry, that this was the general course of education at the school which he attended. The next day, a lad passed me, evidently on his way to school, with his books under his arm. I inquired his age, which he said was fifteen years, and then desired him to allow me to see a book which he had with him, which was Homer in Greek; and he was studying the second book. To my inquiry if there were many in his class, he replied, yes; and to my question whether he was destined for the priesthond, his answer was 
in the negative. I leamed that classical learning was by no means uncommon in Ireland, and among some even of the poorest of the people. Schools, likewise, of a more humble character, abound in Ireland, and benevolent efforts are making to extend and improve them.

It would be wrong, however, to infer, from what I have stated above, that education in Ireland is every where of a high character, or that it is universal. I might do wrong to say even that it is general, though it is certainly much more general than is usually supposed. Many parts of Ireland are wrapped in thick darkness, with its usual concomitant, the grossest superstition. Indeed, without impugning the prevalent religion of Ireland, a fair proportion of the ministers of which are indefatigable in their pastoral labors, and disinterestedly devoted to the welfare of their flocks, it will not be denied that it discourages the general or extended education of the people. I speak of what strikes me as facts in the case, and neither attribute nor insinnate any unworthy motives. Nor would England, as far as my impressions go, gain much by a comparison with Ireland in this respect. In England the higher classes are not without strong, and it may be conscientious prejudices against the education of the lower and laboring classes. The course of education, at the national schools in England which I have visited, - and they are not a few, - is certainly of a meagre and limited description, cmbracing no more than reading, spelling, writing, and the study of the Bible, the catechism and the creeds, with the committal of hymns to memory. To my inquiry of a noble and enlightened woman, the benevolent patroness and supporter of a large school, and to whom, how much soever I might differ from her in opinion, it would be impossible to ascribe any want of kind regard for her dependants and beneficiaries, whether it would not be useful to teach these children some geography, and induce them to read some books of gencral knowledge, her reply was, that "she wanted none of the ologies, neither" geology, mineralogy, nor chronology, taught in her school; and that, in her opinion, it was quite enough of general knowledge for the children to know their prayers and the catechism; and of geography, for them to be able to find their way from their house to their work, to the school, and to the church." If I had not met with repeated instances of the same avowed sentiments, and of 
a practice conformed to them, I should hesitate in maling any general inferences. As it is, however, having stated the case, I prefer to leave it to my readers to form their own conclusions.

I could not help replying to this noble lady, that one of the ologies seemed to be pretty assiduously taught in the school, and that was thcology; for the catechism and creeds were inculcated with peremptory authority, and the Bible was the only reading hook in the school. She admitted this, but an exception of this nature needed no apology. I could not help thinking that the course might have been enlarged, and other branches of instruction have been introduced to advantage; that some good for religion itself might be gathered even from the simplest discoveries of geology, and the wonders, and uses, and splendors of the mineral world; that the great and settled truths of physiology, those which are directly practical in their character, might be of service both to the health of the body and the mind, and consequently to the moral health; that a general knowledge of anatomy, both human and comparative, could scarcely be without its use; and that it might be as serviceable, as it would be interesting, if children were taught to understand some of the marvels of their own structure, and led to see how this curious frame of their bodies is knit together and compacted by an allpowerful Architect; and the still more wonderful capacities and faculties of their own minds, where "the inspiration of the Almighty has given them understanding," - and thus be led to reverence the Divinity, who has made their own souls the temples of his indwelling spirit. I could not think that it would be straying far from the best objects of education, if these children were early accistomed to see every object and operation in nature instinct with lessons of heavenly wisdom. I cannot think that any thing would be lost. Are we not bound to believe that much would be gained by every advance in linowledge of this kind; if children were taught daily to consider the flowers of the field, how they grow; what causes the earth to yield its food for man and beast, and makes the dry seed spring up into a beautiful and fruitful plant, arrayed in a splendor surpassing that of Oriental luxury; and who takes carr. of the birds of the air, who, though they have neither storehouse nor barn, find their daily and hourly wants supplied by an invisible hand and a paternal and an inexhanstible bounty? 
Indeed, I have yet to leam that the acquisition of knowledge can ever be otherwise than favorable to virtue; or that whatever tends to enlarge and improve the mind does not, in an equal degree, tend to render character more valuable, moral obligations more authoritative, and inspire and strengthen that self-respect which is among the most powerful instruments and securities of virtue.

If I should be asked, now, What has all this to do with agriculture? I answer, Much every way. It will be found, with respect to agriculture, - what is true in reference to every other art, - that its proper exercise, and all the improvements which it has received, have been the eflects of the application of mind to the subject; in other words, of inquiry, observation, knowledge, and especially the results of intelligent experience. Who does not know the difference between a stupid and an intelligent laborer; between a man scarcely raised above the brute animal which he drives, and a man whose faculties are all awake, and who is constantly upon the alert to discover and adopt the best mode of executing the task which he has undertaken; between a beast altogether the creature of instinct, or a mere machine, moving only as it is impelled, and unable to correct its own errors, and a thinking, knowing, reasoning animal, always searching for the right way; maling all his actions subservient to his judgment, and gathering continual accessions of power and facility of action from his own and the experience of others? Every one will admit that the more intelligence, the more skill; the more knowledge, a man has, the better is he qualified, other things being equal, for the management of a farm. It holds equally true that the more intelligence, the more skill, the more knowledge, a laborer has, the better is he qualified to assist in that management, and to perform the part which belongs to him in the working of the whole machinery.

I believe I may safely say, that a New England laborer accomplishes in the same time much more than an English laborer; and this circumstance, in respect to agriculture, and especially in some of the manufacturing and mechanic arts, which more demand the exercise of the mind than the ordinary operatious of husbandry, is one among other circumstances which enable us to come in successful competition with the labor of Europe, so rery inferior in its cost. I camnot say they 
always execute their work as well. Certainly, in ploughing and draining, our operations are altogether inferior to what is done in England, where, in the perfection with which these matters are executed, nothing more seems to me either attainable or desirable. But this arises from several causes; - the more we have to do compared with the number of hands we have to accomplish it ; the extent to which a system of division of labor is carried in England, so that particular individuals are accustomed to do only particular things, and consequently acquire a precision and facility of operation, which such exact attention and long-continued practice are sure to give, attended with an almost utter disqualification for any other branches of labor. In many departments and operations of husbandry, this exactness is not necessary, though in many I am ready to admit its utility; but in the amount of work which an American laborer will accomplish in a given time, and in the facility with which he turns from one species of labor to another, he is far before an English laborer. This, I believe, is, in a great degree, owing to the difference in their minds; the one being educated, the other uneducated; the one being accustomed to depend upon himself, to inquire, to reflect, to observe, to experiment; the other scarcely exercising his mind at all more than the cattle which he drives, and accustomed to move in the line, and that only, which has been marked out for him. I hold that education, in every condition of life, is a great good. It sometimes gives facilities for particular crimes, of which, otherwise, men would have been incapable; but the viciousness of these men would have shown itself in some other form. It is in no sense attributable to their education. I believe, as much as I live, that every advance in the cultivation and improvement of the mind is an incentive and an anxiliary to good conduct; and although an education purely intellectual falls far short of the beneficial influences which it might yield, when the moral sentiments are cultivated conjointly with the intellectual, yet am I perfectly assured, that every quickening or cultivation of the mental faculties, every thing which contributes, in any measure or degree, to raise man above a mere machine, or a mere animal, is so far positive good positive good for his efficiency as a laborer, and for his happiness and moral well-being as a man. I am afraid I shall be thought to dwell too long on this subject; but I have felt such a burning 
indignation when I have heard the cause of popular education spoken of disparagingly, by those who were reaping its richest fruits; I have felt such a deep compassion for the very degraded condition, in this respect, of a large portion of the laboring population of England; I have seen with so much pain, on the part of some of those whose laps were overflowing with these richest blessings of Heaven, so strong a reluctance to communicate of their abundance to these benighted children of ignorance and want, in many cases, undoubtedly, springing from an honest distrust of their utility, - and, at the same time, I have felt my own heart swelling almost to bursting, with gratitude, for the privileges in this respect enjoyed by a large portion of my own countrymen, and the blessed fruits of which are every where seen among them in such rich abundance, — that I cannot refrain from speaking out; and too happy should I be if my feeble voice could do any thing towards commanding that attention to the subject which its importance demands.**

* 'That I do not express myself too strongly on this subject, may appear from the following remarks of a distinguished professor of agriculture, who is much employed in lecturing to the farmers about the country. They were made recently at a large agricultural meeting.

"I put no stress on the spread of knowledge, whether here, in Scotland, in Ireland, or elsewhere. I attach no importance to intellectual improvement amongst the agriculturists. I do not value that instruction which you saw those boys had received to-day, unless that knowledge furmishes you with the means of putting more money into your pockets."

And, indeed, is this all the value which this learned gentleman can see in education? One cannot help feeling that it is greatly to be regretted that he himself should have been put to so much trouble to acquire his own education, for an object in which it is not unlikely, with all his success, many a thimble-rigger, or dog-meat-seller, would beat him.

At the great meeting of the Royal Agricultural Society of Ireland, in Dublin, the last year, a peer of the realm, of high rank, and who (so much better oftentimes are men than the principles which they profess) is esteemed withal a very just and kind landlord, was pleased, after strongly proclaiming his interest in the improvement of the condition of the peasantry and the laboring classes, " to beg of his hearers not to misunderstand him, nor to subject him to the imputation of a desire to raise these people out of their proper condition - the condition which Providence had assigned them."

One would be glad to know, under such an interpretation of the designs of Providence, how any man should ever attempt the improvement of any body, or any thing; and whether he himself could by any compulsory process be induced to exchange his marquisate for a dukedom.

With great personal respect for both these gentlemen, whose publicly-expressed 


\section{GLASNEVIN AGRICULTURAL SCHOOL.}

I promised in my former Report to give some further account of the school at Glasnevin; and since that time the intelligent and obliging superintendent has been kind enough to furnish me with a copy of his farm accounts for two years, which $\mathbf{I}$ think must be interesting to my readers. It is obviously a great unestion whether an institution of this character can be made to support itself; and this question is affirmatively and emphatically answered by the result in this case. It is obviously highly desirable that education should be made as cheap as possible. I very well understand what often comes of making things cheap; that when the price is reduced, the quality of the article is made to correspond. A milkman in New York once told me that he always accommodated his customers as to the price; six and a quarter cents was the standard price for sound and pure milk; but if his customers wished to have it at five or four cents, he took care always to put enough water with it to bring it to the standard price. This honest fellow, who was a shrewd Irishman, by the way, (an evidence that all the wooden mutmegs are not made in New England,) was pleased also to tell me that, by straining water throngh some finely-gromnd Indian meal or flour, so as to color it, and adding to it a mere dash of skimmed milk, he was able then to afford it at three cents a quart to those who could not give a higher price. Most certainly I cannot recommend, in this sense of the word, a cheap education; but if the advantages of a good, solid, and enlarged education can be made universally acceptable; if they can be purchased by that which most young persons have, and besides which many young men have nothing else which they can give,

upinions are certainly just objects of animadversion, I can only express the wish, that they both might be transported, at least for a while, to a land of free institutions, where education is universal, - and learn there, that education, from its high moral influences, may have other uses than that of putting money into men's pockets; and that, where the road of advancement and promotion is freely and equally open to all, even the humblest in the community may ascend to a nobleness of merit, and character, and intellectual elevation, before which the tinsel splendor of coronets, and mitres, and maces, becomes dim, and they are seen in their proper character, as mere baubles for grown-up children. 
- their own personal labor, - a great point will be gained; and the price itself will be an eflicient instrument of their improvement. $I$ believe this can be done; that is, upon an adequate extent of land favorably situated, by an amount of labor which shall not interfere with their intellectual improvement, but, by conducing to their health, and by demonstrating the practical application of the principles and lessons which they are tanght, will most efficiently further this improvement, the pupils themselves may be comfortably sustained, and their instruction paid for. The school at Glasnevin certainly has gone far towards establishing this point. If this is too much to be expected, and the fees for instruction are to be paid in money, yet it will be a great object gained, if the labor of the pupils provides for their subsistence, and pays a fair rent for the land.

I subjoin the following extracts from the letters addressed to me by the intelligent manager of the establishment, Mr. Thomas Sliilling.

"I send you copies of my profit and loss account on the transactions of the farm during the last two years, ending the 31st March, 1844. The annual accounts and amount for the previous three years, from 1839, are somewhat similar, with this difference, that, notwithstanding the yearly reduction in the price of farm produce during the said time, there have been increased profits, from the increased products of the land, of course from high cultivation and fertility. 'The profits of last year would have been very considerable indeed, had I not suffered so much by the fatal disease among my cattle. This year I expect to realize a handsome sum, and you will recollect that these profit. are exclusive of the keep of my house and family in all kinds of farm produce."

"From what you will have seen and heard here, you will perceive that my system aims to show what land is capable of producing, when properly cultivated and managed; the greatest quantity of produce from the same quantity and quality of land; and the greatest amount of profitable human labor, an opposed to horse labor and expensive machinery. This I believe to be the system suitable for this, or perhaps any part of the United Kingdom, where we have a numerous population within small bounds, and even this small space of land not one 
third cultivated, nor one half of our people employed as they ought to be. The great evil of this country is monopoly, and the most pernicious and extensive is the land monopoly. The masses here have no right, property, or interest, in the soil which they inhabit. They are the most wretched of slaves. What we want is a middle class of small landed proprietors - virtuous, educated, and industrious. These would be Britain's strength; they are at present her weakness. I want the masses that are idle and starving, or driven into those sinks of vice, the large and crowded towns, spread over the face of the country, holding and cultivating their small farms, leading a comfortable, virtuous, and independent life. But our landlords say, "The people are poor; they have no capital; they are ignorant; they do not know how to cultivate and manage our land. We will not give it to them. We will keep it for grazing bullocks and sheep. 'They must look elsewhere for employment and sustenance.' It would be useless here to inquire, who makes these people poor and ignorant. We find the people as represented. 'This state of things we wish to remove, and take away all excuses on that head. We desire to educate them, and render them competent to manage the land."

\section{"Account of the Agricultural Establishment at Glasnevin, Ireland.}

Dr. ... Profit and Loss.

1843.

f. s. d.

March 31. To cows lost, . . . . . . . . 47149

"seeds, . . . . . . . . . . 277

"smith's work,. . . . . . . . 490

"servants' meat and wages,. . . . 4400

"laborers' wages, . . . . . . . 21910 \&

" coals for the year, . . . . . . 930

"turnpike" ". . . . . . . 1710

"general charges, . . . . . . . 22311

"year's rent, . . . . . . . . 25778

"profits for the year,. . . . . $12016 \quad 8 \frac{1}{2}$

$£ 51210 \quad 6$ 
1843.

$$
\text { Contra. . CR. }
$$

March 31. By bulls raised, . . . . . . . 1500

" heifers" . . . . . . . . . 400

" pigs, . . . . . . . . . . 30 \% 3

" oats, . . . . . . . . . 66187

" potatoes, . . . . . . . . . 89169

" vegetables,. . . . . . . . . 3314

" milk, . . . . . . . . . . $1996 \quad 5 \%$

" butter, . . . . . . . . . $54127 \frac{1}{2}$

"implements sold not required, . . $197 \quad 5$

$£ 51210$ 6"

"It will be perceived that there is a loss on cows in this year. 'This always happens, more or less. A large quantity of milk is required for the training establishment, ${ }^{*}$ and when a cow goes nearly dry, she must be sold, and another in milk bought in her place, at a higher price than that at which the former is sold. We have it in contemplation to take another farm, of larger dimensions, in addition to the present one, and of an inferior and different quality of land, in order to show a specimen of the improvement and management of that kind of soil ; and in this case the loss on cattle will be obviated, as the second will be more adapted to the raising of young stock and sheep."

1844 .

"Dr. . . Profit and Loss.

Tarch 31, To cows lost,

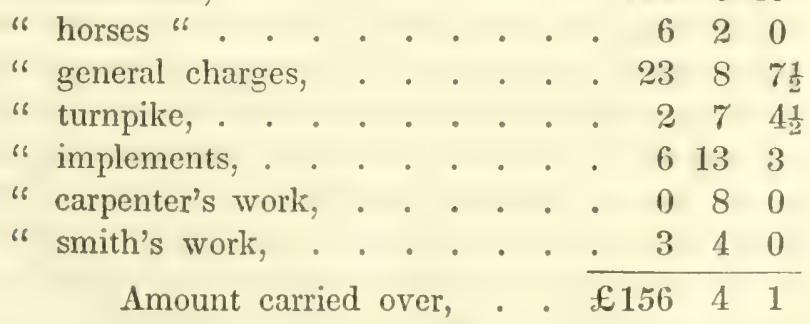

* This is the establishment of the Model School, where young men are trained as schoolmasters at the expense of the government. This place is supplied with milk and other things from the farm, by purchase. 
1844.

$$
\text { "Dr. . . Profit and Loss, . . (continued.) }
$$

March 31. \&. S. d. To servants' meat and wages,

" laborers' wages, . . . . . . . $519 \quad 11 \frac{1}{2}$

" coals for farm use, . . . . . 2100

" rent for the year, . . . . . 25778

" profits " " . . . . . . 4947

$£ 502 \quad 7 \quad 9 \frac{1}{2}$

1844.

Contra. . C $\mathrm{Cr}$.

March 31. By bulls raised, . . . . . . . 838

" heifers" . . . . . . 688

"potatoes, . . . . . . . . $8916 \quad 3$ 3

" milk, . . . . . . . . . . 18310113

" butter, . . . . . . . . . . $3252 \frac{1}{2}$

" pigs, . . . . . . . . . . 401110

" seeds, . . . . . . . . . . 1646

" vegetables, . . . . . . . . $90810 \frac{1}{2}$

"grain, . . . . . . $\frac{.34179}{£ 502791}$

"The great loss on cattle, this scason, principally arose in consequence of a fatal epidemic, which has prevailed in this neighborhood during the last two years, and carried off a number of mine."

"Besides the real cash profits every year, there is a very important advantage gained from the firm, and which has not been taken into account: I mean, the keep of the family and servants in farm produce, - nine individuals, besides occasional visitors during the year, - in milk, butter, cheese, eggs, poultry, pork, bacon, potatoes, vegetables, \&c. \&c. This, at a fair computation, may be reckoned at from $£ 80$ to $£ 90$ more."

"An addition is now being made to the buildings, to accommodate a superior class of twelve pupils, who will pay a moderate annual sum for their board, lodging, and education."

"You will understand that our farm was most injudiciously taken at an enormous rack-rent, double the sum that is paid for 
much better land in our immediate neighborhood; and when I agreed with the Board to manage it on my own account, and pay all rents, taxes, and other cxpenses, they agreed to supply me with a certain amount of labor; viz., at the rate of five men in the year; i. e. one ploughman and twelve pupils - the estimated work of twelve boys being equal to four men, or one man to three boys. This I find very near the mark. I would, however, prefer four steady, constant men, to the boys. The boys are difficult to manage; very ignorant at first, and neglectful; and, besides, they work only a part of the day, from ten until two o'clock, and from three until six in summer, and four in winter. 'This labor, at the present rates, would be equal to about $£ 96$, which, deducted from the profits of the year, leaves a remainder of about $£ 24$; add to which the keep of my family and servants in farm produce, which, at a low estimate, amounts to $£ 50$, with the former makes in all $£ 74$ per annum of clear profit, after paying labor and all."

"The accounts of servants' wages and labor" which you see, have nothing to do with the pupils. That I pay extra, for serrants, cowman, and laborers, occasionally employed in harvest."

"My salary from the Board is merely for scientific and practical instruction rendered to the National School masters and pupils, who are brought up in classes twice a year, (we have one hundred of them here at present.) 'The profits of the farm are considered an equivalent for its superintendence. This is as much as any farmer gets."

"I am happy to say that, since you were here, the commissioners have made a new arrangement with me, and a liberal one. 'They have raised my salary to two hundred pounds per' year. They pay me for the loss I sustained in my cattle from the epidemic, the last and the present year. They agree to build and make accommodation for a superior class of pay puipils. and give me the benefit of that. They will also encourage me to increase the farm by degrees, according as manure, stock, and capital increase, and some other advantages, which I did not before possess."

"I am paid eight shillings per week, for the board and washing of the pupils, and this is very near what it costs me. If there is a small profit, it arises from my having the farm produce within my power, not having to purchase. They are in genera? 
excellent fecders. They are at that time of life, from seventeen to twenty years, when they require most food; and at an employment of all others most likely to create an appetite."

"The dietary is as follows: Every morning, except Sunday, each boy gets one pound of the best bread, and a pint of new milk, cold or hot according to choice; and on Sunday morning they get coffee or tea, with bread and butter. For dinner, four days in the week, viz., Sunday, Tuesday, Thursday, and Saturday, they get meat; two days beef, and two days pork or bacon, three fourths of a pound, each, of good meat, not bone, with soup, and vegetables, and potatoes unlimited. Two days, viz., Mondays and Wednesdays, for dinner, one quarter pound of butter, with plenty of buttermilk and potatoes, and sometimes other vegetables, such as cabbages, \&c. One day, Friday, they get fish, with melted butter and potatoes unlimited. For supper, every day, oatmeal stirabout, well made, thick, and of the best meal, with a pint of new milk each; sometimes they choose potatoes for supper, instead of stirabout. By this you will perceive that they are good feeders. I have always been an advocate for good feeding and good working. The one promotes the other. It will perhaps be in your recollection that the boys, during your visit, were the very picture of a sufficient dietary. I had almost forgotten to mention that, on stated occasions, such as Easter, Christmas, Halloween, harvesthome, \&c. \&c., we give them an extra blow-out; roast beef, plum pudding, \&c. \&c., with porter and punch for those who are not tee-totallers. The school was formerly under a different regimen; and the doctrine then maintained was, 'Feed them too well here, and they will be discontented with inferior food when they get home.' My answer was this: 'Give them a taste for good feeding while here. Treat them as human beings, and as respectable members of society, and they will not relapse into their former wretched condition, but will work and exert themselves to obtain the comforts of life."

I have laid these details before my readers under the persuasion that they will be deemed both interesting and useful. It is not to be inferred, in any case, because I quote the opinions of another man, that therefore I make them my own. I do not know that it is necessary here, in giving this accomnt, to add a dissertation upon the value of total abstinence; though what my 
friend here terms a "blow-out," at harvest-home, \&c., must be a very gentle explosion, a mere flash in the pan, if we may infer any thing from what he calls, in the other case, a system of high feeding. I wonder what a Vermonter or a Connecticut River boy would think, to be cautioned against excess and indulgence over buttermilk and potatoes for dimner, and oatmeal stirabout, or hasty pudding, for supper; and whether he would not be a little surprised to hear a dimner of roast beef and plum pudding spoken of only as a feast for state occasions, which he feels that he can command every week at his pleasure. I give it, however, as a picture of manners, which, while it conveys a useful lesson in the wholesome example of sobriety which it exhibits, may at the same time impart not an unseasonable admonition of an extravagance with which many of us are justly chargeable, and of which, accompanied as it too often is even by ungrateful complaints, we have good reason to be ashamed. I am neither an advocate for high nor for low feeding, but for that which is plain and sufficient. It is certainly a fault with some of our laboring people, that they expend, in the indulgences of the table, too much of their hard earnings; and it might silence some of the repinings which are occasionally heard, even in the midst of comparative plenty, if they could see, as I have seen, the habitations of thousands and tens of thousands, where the sole and whole diet, for men, women, and children, three hundred and sixty-four days out of the three hundred and sixty-five, is potatoes and water, and by no means always enough of that.

\section{TEMPLEMOYLE AGRICULTURAL SCHOOL.}

The next agricultural school which I visited was that of Templemoyle, in the north of Ireland, and not very far from Londonderry. In point of situation, it is not easy to find a place more picturesque and beautiful. The soil, however, is of a hard and rather unfertile character, but not the less favorable for agricultural experiments. The farm consists of one hundred and seventy-two acres, and affords opportunities for experiments in draining, in the effects of various manures, and the common operations of ploughing and cultivation, and especially in the adaptation of the crops, and the mode of culture, to the climate, soil, and situation. 
The farm is under two different rotations of crops; one part being under the five-course rotation, the other under what is deemed the four-shift. The five-course system of cropping is,

First year; oats after pasture:

Second " turnips, potatoes, vetches, beans, or flax with manure:

Third " wheat, barley, or' oats, sown with clover and grasses :

Fourth " clover for soiling, or hay:

Fifth " pasture.

The four-crop rotation is the same, with the exception of the fifth year in pasture.

The department for in-door instruction consists of a head and an assistant teacher; and the course of instruction embraces spelling, reading, grammar, writing, arithmetic, geography, book-keeping, as applicable both to commercial and agricultural accounts, geometry, algebra, trigonometry, with its application to heights and distances, and land-surveying, together with the use of the water-level, the theodolite, and chain.

The agricultural department is intrusted to an experienced and skilful farmer, a native of Scotland, who has under him an assistant, a gardener, and ploughman.

Of the pupils, the one half are at their studies in the house, while the others are pursuing their agricultural instruction out of doors. This is the arrangement for the morning. In the afternoon, the arrangements are such that those in school in the morning are at work in the field in their turn.

The garden and nursery are objects of study and practice, and the lessons received in the house, in surveying and mapping, are applied in the field. Oral instruction and lectures are given in their proper place and time.

The buildings afford the necessary accommodations of schoolrooms, dining-hall, and sleeping apartments, and they furnish accommodations for seventy-six pupils. So far as I observed, there was no provision whatever for luxury or indulgence, and the fittings up were of the plainest description. One of the regulations of the school requires the pupils to wash their hands and faces before business in the morning, on returning from 
labor, and after dimner. I had my doubts whether some of the pupils, whom I saw. did it much oftener than this.

On Sundays, the pupils are required to attend their respective places of worship, accompanied by their instructors or monitors; and it is earnestly recommended to them to employ the remainder of the day in reading the Word of God, and such other devotional exercises as their respective ministers may point out.

This is a very commendable liberality, and rather remarkable in a country, - I speak of England as well as Ireland, - where the first principles of religious liberty are not unirersally understood, and where men of all parties seem quite as tenacious of their religious differences as of their moral duties. While no reasonable effort should be spared, in places of education, to instil and maintain in the youthful mind a profound and habitual sense of religious duty, nothing can be more unwarrantable than to take advantage of the influence which such places afford, to enforce the principles or peculiar practices of a sect or party.

It may be interesting to learn the general regulations of the school, which the intelligent principal was kind enough to give me in a printed form.

1. As the great object is to make the boys practical farmers, one half of them will be at all times on the farm, where they will be employed in manual labor, and receive from the head farmer such instructions, reasors, and explanations, as will render the mode of proceeding, in all the various operations performed on the farm, sufficiently intelligible to them. Every pupil is to be made a ploughman, and taught, not only how to use, but how to settle the plough-irons for every soil and work, and to be instructed and made acquainted with the purpose and practical management of every other implement generally used. And all are to be kept closely to their work, either by the head furmer or his assistant, or, in their unavoidable absence, by the monitor placed in charge of them.

2. Their attention is to be drawn to stock of all kinds, and to the particular points which denote them to be good, bad, indifferent, hardy, delicate, good feeders, good milliers, \&c.

3. At the proper season of the year, the attention of the boys is to be directed to the making and repairing of fences, that they 
may know both how to make a new one, and, what is of great advantage, how to repair and make permanent those of many years' standing.*

4. The head farmer will deliver evening lectures to the pupils on the theory and practice of agriculture, explaining his reasons for adopting any crop, or any particular rotation of crops, as well as the most suitable soil and the most approved modes of cultivating for each; the proper management and treatment of working, feeding, and dairy stock; the most approved breeds, and their adaptation to different soils. He will point out the best method of reclaiming, draining, and improving land; and will direct attention to the most recent inventions in agricultural implements, detailing the respective merits of each.

5. After the boys have been taught to look at stock on a farm with a farmer's eye, the committee propose that they should in rotation attend the head farmer to fairs and markets, in order to learn how to buy and sell stock. At the same time, the committee expect the head farmer will make his visits to fairs as few as possible, as his attention to the pupils of the establishment is always required, and he should therefore be as seldom as possible absent from Templemoyle.

An annual examination of the school is held before the committee and subscribers, and conducted by examiners totally independent of the school. 'The examination is attended by the leading gentlemen in the neighborhood, and many of these take a part in the examination, by either asking or suggesting questions - a practice which is deserving of recommendation, as adapted to give additional value and dignity to the examination.

Such are some of the principal regulations of the school, which I have copied, that its management might be fully understood.

Pupils, in order to be admitted, must be nominated by an annual subscriber, paying two pounds for the first pupil, and one

* This, of course, applies principally to live fences, or hedges. It could at present have little pertinency to the United States, where certainly there is very little mystery in making the fences, and as little labor expented in kecping them in repair. 
for each additional pupil. 'The school was established under the auspices of a society in 1827, and the whole number educated, since its foundation, is four hundred and ninetyseven.

The terms for boarding, lodging, tuition, and washing, are ten pounds, or fifty dollars, a year, payable quarterly, in advance. It may be interesting to see the dietary of the school, which I subjoin :-

Breakfast. Eleven ounces of oatmeal, made into stirabout, one pint of sweet milk.

Dinner. Sunday. Three quarters of a pound of beef stewed with pepper and onions, or one half pound corned beef, with cabbage, and three and one half pounds potatoes.

Monday. One half pound pickled beef, three and one half pounds potatoes, and one pint of buttermilk.

Tuesday. Broth made of one half pound of beef, with leeks, cabbage, and parsley, and three and a half pounds of potatoes.

Wednesday. Two ounces of butter, eight ounces of oatmeal made into bread, three and a half pounds of potatoes, and one pint of sweet milk.

Thursday. Half a pound of pickled beef, with cabbage or turnips, and three and a half pounds of potatoes.

Friday. Two ounces of butter, eight ounces of wheatmeal niade into bread, and one pint of sweet milk or fresh buttermilk; three and a half pounds of potatoes.

Saturday. Two ounces of butter, one pound of potatoes mashed, eight ounces of wheatmeal made into bread, two and a half pounds of potatoes, one pint of buttermilk.

Supper. In summer, flummery made of one pound of oatmeal, and one pint of sweet milk. In winter, three and a half pounds of potatoes, and one pint of buttermilk or sweet milk.

In lodging, the same system is strictly followed; the beds, bed-clothing, and all other necessary articles, being simple, though clean, and therefore within the reach of any industrious peasant. A proper degree of exercise is provided for by the distribution of hours into field and home occupation, so that each pupil is, in fine weather, half the day in the open air, as explained by the following table:- 
.Worl and Sithool Table, from the 20th March to the 23d September.

Boys divided into two equal divisions, $\mathbf{A}$ and $\mathbf{B}$.

Hours.

At Work.

At School.

$5 \frac{1}{2}$. All rise.

6-S. . . . . A, . . . . B.

S-9. Breakfast.

9-1. . . . . A, . . . . B.

1-2. Dimner and play.

2-6. . . . . B, . . . . A.

6-7. Play.

7-9. Prepare lessons for next day.

9. To bed.

. On Tuesday, B commences with work in the morning, and A with school, and so on, shifting upon alternate days."

The establishment was purchased for a term of years, and the buildings erected by prirate subscription, of one hundred and thirty-two shares, at $£ 25$ cach, and by the liberal donations of several useful societies and associations. The yearly expenditure is nearly met by the pay of the pupils, and the produce of the farm, beyond what goes to the support of the pupils. The amnual rent paid for the farm is put down at $\mathcal{E} S 0$, which would be less than ten shillings per acre for the land, and, as in the case of the school at Glasnevin, no charge is made for interest on the stock invested.

The copy of the accounts of the establishment, for 1841 to 1812, was given me by the superintendent, - some items from which will, I think, afford gratification to my readers.

House, \&c.

Salaries and Servants' Wages.

\&. S. d.

E. s. d.

Head master,. . . $50 \quad 0 \quad 0$ Matron, . . . . $20 \quad 0 \quad 0$

Second master, . . $2012 \quad 0$ Gardener, . . . . $17 \quad 0 \quad 0$

Head farmer,. . . S1 16 0| Servants, . . . $17 \quad 5 \quad 0$ 


\section{Provisions.}

\begin{tabular}{|c|c|c|c|}
\hline Grocel & $\begin{array}{rrr}\text { E. } & \text { s. } & d . \\
\text { (I) } & 17 & 111\end{array}$ & f'ish, & $\begin{array}{rrrr}£ . & \text { s. } & \text { d. } \\
5 & 1 \tau & 11\end{array}$ \\
\hline Beef, . & $1 \% 2+11 \frac{1}{2}$ & Sillt, & $\begin{array}{lll}0 & 17 & 6 \frac{1}{2}\end{array}$ \\
\hline Candles and soap, & $16 \quad 10 \quad 11 \frac{1}{2}$ & Wine and beer for & \\
\hline Potatoes, . . & 46 & examination, & 4 \\
\hline
\end{tabular}

The reason for the salary of the farmer being so much larger than that of the masters, is because, I presume, he provides for himself, whereas they live with the pupils. The charge for groceries is remarkable for its small amount. With us, the expense of tea, coffec, sugar, \&c., is considerable, even in the humblest families. I begrudge no man any of the comforts of life; but it is obvious that these must be classed among luxuries, contributing nothing to our strength and subsistence. In this case, it seems well worthy of reflection, how much is to be gained by a rigid cconomy; and how wise is the example of selfdenial, when, by cutting ofl the superfluities of mere personal indulgence, we secume the enduring and inestimable treasnres of the mind.

The farm and garden seemed very well managed, and in good order. Various experiments were being made, in the vicinity of each other, upon different manures; lut the results are not yet si) fully obtained a to afford grounds for confident practice. The nitrates of soda and of potash upon grass, at the rate of about one hundred weight to an Eluglish acre, gave a considcralile increase of grass over land which was not manured, but not sufficient to pay the expense of the application. Whether the efiucts of the application will last more than a year, remains to be determined. The second crop showed no benefit.

Fifty-two different varieties of wheat have been experimented upon by the punils, bnsides several rarinties of barley and oatSpecimens of the rarions products, prepared in a form to be partially compared with each other, were exhibited at the ammus! examination. These are certainly most useful lessons for the pupils. The pactire of thorough-draining and subsoiner hats been fully tested upon the farm; and it is stated that, on the land thus treated, the crops have been augmented full one third, besides the increased facility given to the cultiration of the land and the harresting of the crops. 
The frugality and excellent economy manifest in all the arrangements at Templemoyle, are much to be commended. 6. They discourage the admission to the school of lads from England, especially because the diet has not been usually found as well adapted to English as to Irish habits." In my opinion, it is much to the credit of the Irish to be satisfied and contented with a meagre diet. To a large portion of the Irish peasantry, it must be a paradise to get even a sufficiency of food to keep their waistbands from a most melancholy collapse.

This institution has already done much good. In 1843, about sixteen years after its commencement, it was ascertained that most of the young men who had received its benefits were settled in respectable and useful conditions of life. But, according to the present course of studies, the food for the mind is almost as simple and restricted as that for the body. The studies pursued should be greatly extended; and as the principal expenses are already incurred, and the fixtures, both for the school and the farm, are to a great degree complete, the additional cost for providing instruction, more especially in various branches of natural science, would not be large.

\section{BROOKFIELD AGRICULTURAL SCHOOL.}

This establishment, about twelve miles from Belfast, which I had also the pleasure of visiting, is an eleemosynary establishment, supported by the voluntary subscriptions of the religious society of Friends. It seems that many of this society, in Ireland, from one cause or another, had fallen into poverty and habits of neglect; and their children, many of whom had become orphans, were growing up without the advantage of rcligious habits, and without that kind superintendence which this remarkable society is accustomed to exercise over those who are connected with it. They took pity upon these stray sheep, which were wandering as it were at large and unprovided for ; and, with a spirit of charity, guided by the soumdest judgment and wisdom, they determined to gather as many of them together as their means would enable them to support, and, besides giving them a substantial and useful undertaking, to train them in habits of honest and useful labor, intending to make the products of that labor, as far as practicable, conducive 
to their support. 'They accordingly purchased the lease of a farm of twenty-four acres; and having erected and fitted up the necessary buildings, they prepared for fifty children; and the number of forty was soon found. The age at which children are admitted is between eleven and thirteen. On account of the condition of the funds, some have been admitted at an earlier age, for whom the friends who placed them there were willing to pay the full cost. In sex they are about equally divided. The establishment is under the direction of a man and his wife, who act as master and matron, and one schoolmaster, with a female assistant, who manage the literary department. The branches taught are "reading, writing, arithmetic, English grammar, geography, the catechism, and Scripture history." The oldest boys are taught likewise geometry and surveying. The children, with the exception of one ploughman, perform all the work on the farm and in the house; and the great object is to qualify them for useful labor and domestic service by a thorough knowledge of husbandry and house-work. An addition, since the first purchase, has been made to the land, so that the whole is now nearly fifty acres. "The boys have levelled about three hundred and forty-two perches of old ditches, which intersected the land, and have thus thrown nearly the whole of the farm into one field, portioned out into suitable sections for a regular four-course rotation of crops. They have also completed four hundred and eighty-eight perches of underground drain filled with stones. The drains are at the distance of from six to eight yards apart, according to circumstances; and in this way it is proposed to go gradually over the farm, as time and opportunity permit."

'The average cost of supporting a child at this institution is as inder:-

$$
\begin{aligned}
& \text { £. s. d. } \\
& \text { Provisions, . . . . . . . . } 5191 \frac{1}{4} \\
& \text { Clothing, . . . . . . . . . } 018 \text { 6 } 037 \\
& \text { Salaries, . . . . . . . . . } 100 \\
& \text { Other expenses, . . . . . . } \quad \begin{array}{r}
1 \\
\hline
\end{array} \\
& £ 9 \quad 1 \quad 10
\end{aligned}
$$

Deducting the profits on the farm, leaves the average cost of a pupil at . $\quad \begin{array}{llll}£ & £ & 6 & 9\end{array}$ 
The expenditure for the year in the family I shall give below; as it may be useful to compare it with some similar establishments in the United States.

Expenditure of the Brookfield Agricultural Scinool, for the Year ending 31st of Third Month, 1844.

$$
\text { \&. s. d. }
$$

Butcher's meat, (purchased,) • . . . 1580

Potatoes, meal, groceries, \&c., (pur-

$$
\text { chased,) . . . . . . . } 66 \quad 7 \quad 9
$$

Milk, 10,227 quarts, (supplied by farm,) $6318 \quad 4 \frac{1}{2}$

Potatoes, 1,150 bushels; . do. . . 42100

Vegetables, . . . . do. . . 6000

Fowls and eggs, . . . do. . . 2183

Oatmeal, . . . . do. . . 31130

Wheatmeal, . . . . do. . . 9138

Pigs, \&e. . . . . . . do. . . 23109

Fruel, . . . . . . . . 1317 2

Clothing: . . . . . . . 4017 \%

Salarics; . . . . . . . . . . 4400

Medicine, . . . . . . . . . . 515

Furniture, for wear and tear, . . 10190

Stationery and printing, . . . . : 16110

Contingencies, . . . . . . 738

I add likewise the Farm Account, for the year ending 31st II arch, 1S44, with which the superintendent was kind enough in favor me. The result is encouraging, and the good done is certain. The present superintendents and teachers are father and mother, son and daughter, of the same family; and their subsistence is included in the charges against the school. 
"Farm Account for one Yecer, ending 31st of Third Month, 1844.

Dr.

E. s. d.

'To stock, 31st of $3 d$ Month, 1843, . . . . . 13123

" rent and taxes, . . . . . . . . . 5026

" cattle, . . . . . . . . . . 46410

" seeds for sowing, . . . . . . . . . 809

"smith's work and repairs, . . . . . . . 876

"utensils, . . . . . . . . . . . 11190

" farm contingencies, . . . . . . 2426

" profit on farm, . . . . . . . . . $\frac{12124 \frac{1}{2}}{121}$

Cr.

$£ 401 \quad 1 \quad 8 \frac{1}{2}$

By produce sold, viz. -

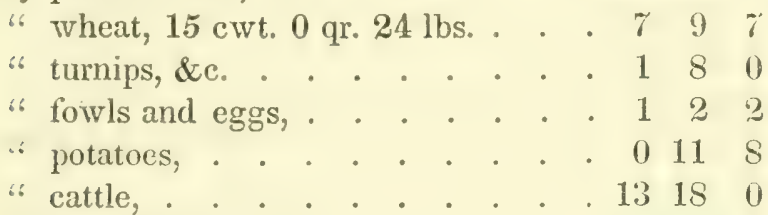

By produce supplied to house:-

" wheat, $25 \mathrm{cwt} .0$ qrs. 4 lbs. . . . $1210 \%$

" nats, 6 tons, 11 cwt. . . . . . 43356

"potatoes, 1,250 bushels, . . . .62 10 "

" pork, . . . . . . . . . . 2011

"vegetables, . . . . . . . . . . 4060

"fowls and eggs,. . . . . . . $218 \quad 3$

" milk, 10,227 quarts, at $1 \frac{1}{2} d$. . . $6318 \quad 4 \frac{1}{2}$

By stock :-

$211 \quad 13 \quad 6 \frac{1}{2}$

" hay and straw, . . . . . . S 0 . 0

" oats, $£ 6: 3: 6$; potatoes, $£ 1: 8 . \quad 7116$

"manure, . . . . . . . . 20000

"cattle, . . . . . . . . . 8400

"utensils, . . . . . . . . . 30 \% 0

"

"turnips, . . . . . . . . . 4100

" fowls, . . . . . . . . . 140

Value of boys' labor on the farm, $£ 35$." 
The farming was plain and creditable, the crops good and improving. The strictest economy, as it should be, was studied in every department. The cattle were all soiled — that is, fed in the stalls, as the limits of the farm did not admit of grazing. As an exact account was kept of the milk obtained from the cows, I was curious to ascertain the average amount yielded by each cow. Many circumstances, in such cases, which it is difficult to estimate, ought to be taken into the account; such as the precise number of cows in milk through the year, the length of time any of them may have gone dry, and the number of calves raised. Leaving these matters entirely out of the calculation, the yield was equal to five quarts of milk per day to a cow, for the three hundred and sixty-five days of the year. This is more than an average yield. What is called the Irish cow, the native cow of the country, is a very valuable dairy animal, and of a good character for grazing, but is, I am sorry to say, fast disappearing under the introduction of what are deemed improved breeds, but which may not be better adapted to the wants and condition of the country.

There is no charge in these accounts for what the superintendent at Glasnevin pleasantly calls a "blow-out" at harvesthome and other festivals; and no $£ 47$ s. $7 \mathrm{~d}$. for "wine and beer " at the examination, as at Templemoyle, — an omission, in a place of education, which will be looked upon with indulgence by at least one man in Ireland, who bears an infinitely higher title than "very reverend," - I mean the very excellent Father Matthew. I am certain I should be doing a great injustice if my allusions, in this case, implied any immoral excess either in the teachers or pupils of these institutions. There is no ground, within my knowledge, for any such inferences; but the influences of every kind, which bear upon the minds and habits of the young in places of education, are of the highest moment in regard to their welfare. The vinous "blow-outs" which occasionally occur at the anniversaries of some of our own literary institutions might, I think, be very safely dispensed with. But I leave the subject with wiser heads, and with men whose deep interest in the welfare of the young, and in the cause of good morals in the community, cannot be doubted, whatever may be their opinions of the doctrine of total abstinence. Few can have failed to observe that, if a person, who attempts 
blindfolded to make his way across a room to a particular point, at first setting out turns his feet but very slightly from the direet line, he finds himself, quite unconsciously, brought up at a very different comer from that at which he aimed. In a distance not great, I have seen persons, in this way, without their knowing it, completely turned round, and pursuing an opposite direction from that which they intended. I hope my readers will pardon this homely illustration of a point of infinite moment to the young; I mean, that of setting out right - what the French call "taking the first step." A misdirection, a slight aberration in the beginning, an indulgence in itself wholly venial, may carry them on blindfolded, and consequently without a consciousness of their error, and so without the disposition to correct their mistakes, until they find themselves at a result wholly undesigned, and as deeply as possible to be deplored.

I thought extremely well of this Brookfield School as a charitable institution. The course of literary education was indeed very limited; but how valuable was the training of these children to habits of industry! I think they might add to this institution, with great advantage, some of the useful mechanical trades, - such as tailoring, shoemaking, carpentering, and blacksmithing; and, for the girls, spimning and weaving; linitting and plain sewing they are of course taught. The mere giving of money to the poor is the cheapest of all charities, and in its expediency always the most doubtful. But to give these poor; neglected outcasts a useful education; to put into their hands, beyond the power of its being wrested from them, the means of getting an honest livelihood, and of being useful to the community; to give them, during the exposed period of childhood and youth, a comfortable home, and make them know that they have friends who feel the deepest interest in their character and good conduct; is a benefaction of the highest order, - as creditable to those who bestow as it is useful to those who receive it. "To seek and to save those who were lost" and perishing, was a mission of the divine mercy, which angels came from their celestial spheres to celebrate. How highly is man honored when he is permitted, in his humble measure, to imitate the beneficence of Heaven! When one looks here, daily and hourly, upon the thousands and millions, in Ireland, England, and Scotland, of umprotected, uncared-for, squalid, neglected, 
half-clad, half-fed, reckless, miserable, suffering children and young persons, growing up in this country of established churches and institutions called Christian, of arts the most polished, of learning the most cultivated, and of a wealth and luxury transcending even the wildest dreams of avarice; and reads in the ever-turning page their certain history, their sure progress from the cradle to the street, from the street to crimes so enormous, so extraordinary, as to make one's head grow dizzy at the recital, and one's hair stand on end with fright; and from these crimes to the prison, and from the prison to the transport-ship or to the gallows; the benevolent heart is ready to burst with grateful joy to see any green spot in the desert, to perceive even one brand plucked from the burning, even one unconscious or struggling victim rescued from the descending and overwhelming current.

\section{LARNE SCHOOL.}

My next excursion was to the Agricultural School at Larne, where I had the pleasure of witnessing the examination of a class of boys in agricultural chemistry and in practical agriculture. This is not, properly speaking, an agricultural school, but a national school, where the common branches of education are taught; and there is connected with it a department or class of agricultural study, and a small piece of land, which the boys cultivate, and on which, in the way of experiment, the principles of agriculture, and its general practice, are, within a very limited extent, illustrated and tested. The examination was eminently successful, and creditable alike to the teacher and the pupils. It was from this establishment that a detachment of five pupils was sent for examination to the great meeting of the $\Lambda$ gricultural Society of Scotland the last autumn, where their attainments created a great sensation, and produced an impression, on the subject of the importance of agricultural education, which is likely to lead to the adoption of some universal system on the subject.

I shall transcribe the account given of the occasion: "Five boys from the school at Larne were introduced to the meeting, headed by their teacher. They seemed to helong to the better class of peasantry, being clad in homely garls; and they appeared 
to be from twelve to fifteen years of age. They were examined, in the first instance, by the inspector of schools, in grammar, greography, and arithmetic; and searcely a single question did they fail to answer correctly. They were then examined, by an agricultural professor, in the seientific branches, and by two practical farmers in the practical departments of agriculture. Their aequaintance with these was alike delightful and astonishing. They detailed the chemical constitution of the soil and the effect of manures, the land best fitted for green crops, the different kinds of grain, the dairy, and the system of rotation of crops. Many of these answers required considerable exercise of reflection; and as previous concert between themselves and the gentlemen who examined them was out of the question, their acquirements seemed to take the meeting by surprise; at the same time they afforded it the utmost satisfaction, as evincing how much could be done by a proper system of training."

I confess the establishment at Larne afforded me, in this respect, very high gratification. The agricultural studies are not made compulsory, but voluntary; and one hom per day is devoted to agricultural labor. The Board of Education in Ireland have now under their control three thousand teachers; and it is proposed, wherever it may be deemed useful, to make agriculture a standard branch of common-school education. They already have seven agricultural training establishments; and it is in contemplation to have twenty-five, with which it is proposed shall be connected small model farms, so that every where, besides furnishing this most valuable instruction to the urils of the schools, the farmers in the vicinity may be excited and instructed to improve their cultivation. Thus diffusive is the nature of all beneficence. A good deed, like a stone thrown into the water, is sure to agitate the whole mass. Its strongest effects will be felt where the blow is griven; but the concentric circles are seen extending themselves on every side, and reach much farther than the eye can follow them. In the moral as well as physical world, the condition of mutual attraction and dependenee is universal and indissoluble. We have reason to hope that no good seed is ever sown in vain, but will sooner or later germinate and yield its proper fruits.

These establishments do certainly the highest honor and credit to the intelligence and philanthropy of Ireland, and their 
beneficent effects must presently be seen in alleviating the indescribable amount of wretchedness under which this beantiful country and fine-spirited people have been so long crushed to the earth - a wretchedness which, to be understood, must be seen.

\section{SCHOOL A'T EALING.}

An establishment of a somewhat similar character exists in England, perhaps many more than one, which I regret that accident merely has prevented my visiting. I refer to the school at Ealing, near London, and I believe there are others, supported by a noble woman, full of benevolence, Lady Noel Byron. At this school, three hours a day are devoted to labor on the farm; and in addition to instruction in cultivating the soil, the boys are taught to perform all the other operations necessary upon it, such as carpenter work, bricklaying, glazing, \&c. Each of the boys has a small plot of ground for his own cultivation, from which he derives a certain profit; and some of them had a pound or two in the Savings Bank at the end of the year. Such is the success of this institution, that there are now fifty applicants wishing to be received on the farm as boarders.

The principal objection suggested against the devotion of a portion of the day to agricultural labor at a place of education, is, that it would interfere with the progress of their studies. It is extraordinary to find intelligent minds overlooking the intimate relation between physical and intellectual health. There can be no doubt that a man will perform more intellectual labor, who devotes a portion, and not a small portion, of every day to healthful physical exertion, than the man who, neglecting such exertion, abandons himself in his study exclusively to his books. I am quite aware that many occupations, of a mechanical or a commercial nature, may so exclusively occupy the mind as to unfit it for scientific pursuits; but agricultural labors, quiet in their nature, and carried on in the open air, when pursued with moderation, so far from fatiguing, refresh and invigorate the mind, and prepare it for the more successful application to pursuits exclusively intellectual. The laboratory of nature, open always to the laboring farmer, is itself a school of philosophy to the intelligent, reflecting, and inquiring mind, and presents con- 
tinually topies of the most healthful, useful, and elevating character.

\section{Agricultural COLlEge A'T CIRENCESTER.}

In England, it is now proposed to establish a seminary exclusively agricultural in its character. The preliminary steps have been taken, and the foundation laid for an agricultural college. A considerable sum of money has been subscribed, a farm of about five hundred acres has been taken, and the accommodations for about two hundred pupils are in a course of preparation. It has been felt as a serious want that, while every other profession - law, physic, and divinity - has its exclusive means and institutions for education, and the army and the navy have their schools, - agriculture, the most important and extensive of all the arts, and without which it would be difficult to say where would be the sinews of war or the means of commerce, or what use there would be either for law, physic, or theology, should have no place for the teaching of those arts and scicnces, and for the making of those experiments, on which its success so mainly depends. The plans are not fully matured, nor the course of instruction prescribed; but the scientific qualifications of some, and the practical character of others of the gentlemen concerned in its establishment, and standing as its sponsors, warrant the best efforts for its 'success. The farm is taken at a moderate rent, through the liberality of its noble proprietor; and it is hoped that, aided by the resources of the farm, the expense of a pupil for boarding and tuition may not exceed twenty-five or thirty pounds a year - that is, one hundred and twenty-five, or one hundred and fifty dollars. 'Twenty thousand pounds, or' one humdred thousand dollars, were deemed the necessary capital with which to begin the establishment; and, to the great honor of England, there are few objects of determined public utility; for which, from its abundant resources and public spirit, ample funds may not be obtained. This is a sort of joint stock company, in shares of twenty-five, or thirty pounds each, in which the subscribers will have, as is right, the preference in reconsmending pupils to the foundation. 


\section{XXVI. - GENERAL VIEWS OF AGRICULTURAL EDUCATION.}

These details must all be useful to my own countrymen, among whom the subject of agricultural schools has been mucl discussed, and where a distinct proposition is already before the public for the establishment of an institution of this nature. Under these circumstances, I shall be excused if I extend my remarks on this subject. I shall do this with unfeigned diffidence, and especially from my ignorance of the various establishments for agricultural education upon the Continent. These are often referred to as examples of success, and some of them I hope to have an opportunity of inspecting.

It is quite certain that the course of education pursued at most colleges and universities is quite unsuited to qualify men for the common business and pursuits of life. Indeed, it would seem, in many cases, to operate as a positive disqualification; and men who may have distinguished themselves at our universities for their classical and scholastic attainments, are often thrown upon society as helpless and as incompetent to provide for themselves, or to serve the community, as children. We have small encouragement at present, I confess, to look for any thing better. The system of education at our colleges and universities has undergone little substantial alteration for a century; and what is called classical learning, and the subtleties and puerilities of scholastic divinity, occupy as much attention as formerly, and hold a place in these ancient seats of learning so high in the estimation of those to whom the management of these places is intrusted, that there is little hope of dislodging them. 1 am no enemy to classical acquirements, as a matter of elegant ornament and taste, as a source of delightful recreation, and as an essential element in a complete cducation. But to give them a preference in any way to learning more useful, substantial, and practical, is not to estimate things according to their real importance. The time and expense devoted to them might be given to studies infinitely more valuable. As to the time occupied in studying what is called divinity, I am not far from the opinion that the world would be no loser if every commentary 
upon the Scriptures, and every treatise upon the controversial subjects of religion, since the days of the apostles, were extinguished forever, and men were sent to the New 'Testament, and to the simple teachings of the Divine Master, only, to iearn their duty, and the only elements of true happiness and moral improvement. A college, therefore, of the practical arts, and of those sciences which directly bear upon practice, must be greatly desired by that portion of the community whose education must be to them a means of subsistence, and who have little time to cultivate the arts but with a view to apply them at once to the purposes of practical life.

It must be admitted, likewise, that many of these arts and sciences are, properly spealing, the creations of modern times, and could not be expected to find their place in schemes of education formed in a remote period. Chemistry, mineralogy, geology, and electricity, are all of modern date. There are those living, who may be said to have assisted at their birth, and have rocked the cradle of their infancy. All these are intimately connected with the practical arts, and especially with the advancement of the great art of agriculture; and we may confidently look for the most important benefits to agriculture from the study and application of these sciences. Botany, likewise, and the nature, habits, and uses of plants; comparative anatomy and physiology, the study of which may prove so useful in the improvement of the breeds of domestic animals, and in the treatment of the diseases and injuries to which they are liable; the art of measuring superficies and solids, an art so constantly in demand in practical agriculture; mechanics, and the construction of farming implements and buildings; hydraulics, a science so important in draining, irrigation, and the general management of water, and the uses of steam, that wonderful agent, which seems destined to exert a more powerful influence over the affairs and common business of the world than any or than all other agents besides; the principles of enginecring, in the construction of roads and embankments; - all these are matters to be learned and studied, as furnishing direct uses and aid in the practice of agriculture, and bearing immediately upon its advancement. These considerations demonstrate the importance of an institution, where such branches may be taught under the 19 * 
advantages of competent teachers, and means and apparatus adapted to their illustration.

A competent knowledge of these brauches should be considered as almost indispensable in those persons who would undertake the cultivation of a farm, or the management of large landed estates, either for themselves or others. It may be said that the style of farming in the United States is so wholly different from that in Great Britain, that, from the necessities of the one, we can make no inferences as to the wants of the other. I know that we have no class of land stewards, or persons employed for the management of the estates of other men; that our farms are comparatively small; and that a class of tenant-farmers is scarcely known among us. It appears to me, however, that it is quite as important that a man should be able himself to manage his own farm well, as that another man should be qualified to manage it for him; and that farms of a moderate size, where the farmers depend upon their returns for their support, have need of the greater appliances to render them productive, and furnish, upon the whole, a better opportunity for a successful agriculture, and for an agriculture of a highly experimental and improved character, than farms of a very large size, where the attention must be greatly divided, and the management - the mere daily routine of operations - requires the most incessant and absorbing care.

But there are considerations, of a more general character, which deserve attention. No one will pretend that agriculture, even in the more improved form in which it is any where to be found, has as yet approximated the perfection of the art. The perfection of the art of agriculture is that in which the largest amount of product is obtained at the least expense of labor and manure, and with the least exhaustion to the land. Indeed, there is reason to hope that we may presently reach a system of cultivation in which, though the crops may be large, the land itself shall not only not be exhausted, but be in a course of continual amelioration. I know well there must be a limit; but that limit no one can yet define. We know already that crops with large leaves, and therefore large powers of absorption, are commonly improving crops; and we know equally well that the growth of a forest upon land, so far from exhausting, is, in fact, 
an improver of the soil. There is every reason to hope, therefore, that such a system of husbandry may presently be found, when, without any extraneous aid, and from the resources of the farm itself, the largest crops may be obtained, and the powers of production extended. The system of nature every where, if man performs his duty, is a system of amelioration, and not of deterioration; it is every where a system of recuperative compensations, if man does not controvert or pervert its laws.

That our crops, for example, are not what they might be, is universally admitted. Within the last few years, crops of many linds have increased immensely. A few years since, fifty bushels of Indian corn, to an acre, was deemed a large crop. One hundred have been fiequently produced. Thirty bushels of wheat has heretofore been deemed more than an ordinary yield. Fifty is now not uncommon. I have known sixty, and nearly seventy, to have been grown, and, over a large farm, the crop to have averaged fifty-six bushels. Thirty tons of carrots per acre is the ordinary crop of a farmer within my lnowledge; and I have on my table before me the anthenticated statement of eighty-eight tons of mangel-wurzel to the acre. I am willing to admit that these are rare instances. Some of them may be considered as single instances; but it is obvious that one well-established case is as good as a thousand in demonstrating the practicability of that which is claimed to have been done.

\section{XXVII. - INFLUENCE OF KNOWLEDGE UPON AGRICULTURE.}

Here, then, there is an opportunity for the highest degree of intelligence, as applicable to the improvement of agriculture; for who can doubt that these extraordinary results are the cons:quence of that intelligence and enlightened skill, which are equally the instruments of success in every other art. But it seems idle to argue this point. All the improvements which have been made in agriculture are as much the result of the application of mind and of knowledge to the subject, as any of 
the improvements made in manufactures or the mechanic arts Accident has produced nothing. The dull, plodding laborer originates nothing, any more than the beast which he drives. The present advanced state of agriculture as a practical art, all the improvements which have been effected in it, are due to the highly-intelligent minds, the men of science, of learning, of observation, of skill, who have applied their attention, and have devoted their time, talents, and fortunes, to it.

The pioneer in the improved agriculture of the United States was Jared Eliot, of Connecticut - an educated clergyman, whose essays have a permanent value, and may be read with advantage even at the present day. The author of the New England Farmer's Dictionary, a most valuable book, published half a century since, and which has rendered an immense service to agriculture, was the Rev. Samuel Deane, of Maine. John Lowell, who contributed far more than any other individual to the improvement of agriculture in the United States, was an accomplished lawyer, a man of science and of taste, and as much distinguished for his intellectual rank and attainments as he was eminent for the highest virtues which could adorn his character as a man. Aaron Dexter, the beloved physician, an eminent chemist in the very imperfect state of the science, a man whose name was a synonyme for kindness, and to whose memory I shall be pardoned for here recording the humble tribute of my most grateful affection and respect, was an cminent friend and promoter of agricultural improvement. Fessenden, Buel, and Gaylord, were all men of highly-cultivated minds, stored with scientific lore, distinguished for their zeal in the cause of an enlightened agriculture, and honored with the power, which they used with so much zeal and efficiency, of conferring immense benefits upon the agricultural community. While even this Report is in progress, the grave has closed over the remains of a devoted friend to agricultural improvement in Massachusetts - a man of the highest order of intellect, of a mind rich in various knowledge, and of profound legal attainments; and for his personal worth, his public spirit, and private virtues, surpassed by none in his claims upon the affection and respect of his friends and fellow-citizens.* On the English side of the 
Atlantic, 'Tull, the author of the improved husbandry; Young: the eminent agriculturist, who kindled so great a zeal, and ditfused so great a mass of information, among his countrymen; and Sinclair, as great a benefactor to improved agriculture as England has known, - were all men of liberal education and distinguished scientific attaimments. Von 'Thaer, on the Continent, himself a host in agricultural skill and science, was bred to a learned profession. If I were at liberty to violate a rule which I have made absolute, I might refer to many living examples, on both sides of the water, of men of the finest genius, the most accomplished education, and rare scientific attainments, who have rendered, and are daily rendering, the highest benefits to practical agriculture, and which without their aid and enterprise would never be realized. It is, then, with agriculture as with every other valuable art; - its success and improvement must depend mainly upon the education of those who pursue it, and all hope of its progress must rest upon the science, in the most extended sense of that term, which is brought to bear upon it.

\section{XXVIII. - SCIENCES TO BE TAUGHT.}

The Agricultural College at Cirencester proposes a specific education in agriculture, and the cultivation of those sciences which bear directly upon it. Botany, not as a mere catalogue of names and classes of regetable productions, but as embracing the whole subject of vegetable physiology and the artificial improvement of plants, must of course be highly useful to a farmer. The cultivation of fruit and forest trees is necessarily included in it. The science of mechanics, so useful in the construction and improvement of agricultural implements, must be of constant and valuable application in the management of a farm. 


\section{XXIX. - CHEMICAL SCIENCE.}

But what seems mainly to be relied on, in this case, is chemical knowledge; and the high value of this knowledge it is at least safe to presume. Confident, however, as some persons seem to be in the discoveries already made, still it must be acknowledged that the application of these discoveries to practical agriculture has been hitherto so limited, imperfect, and doubtful, that we are compelled to consider ourselves as yet only in the infancy of the science. I do not mean in the smallest measure to undervalue the science; nor to disparage what has already been done; nor to discourage the sanguine hopes which some entertain for the future; but in the present state of agricultural chemistry, the extreme confidence of some persons may be at least pronounced premature. The application of sulphuric acid to bones seems as yet to be the only wellestablished case of the application of chemical science to the improvement of practical agriculture upon scientific principles; and this certainly atfords strong grounds to hope for much more. The operations of gypsum are still an insoluble mystery, and the explanations which have been given of its effects do not appear to be confirmed by facts. The application of lime to the soil, and its particular advantages and uses, are still among the vexed questions of agriculture. Its beneficial mechanical effects are often obvious, but its chemical operation is not so well defined. A farmer as eminent as Scotland produces, who has for a long series of years used lime most bountifully upon his farm, told me he remained entirely at a loss to determine whether it was of any service or not. The same uncertainty of explanation is applicable to various manures, in regard to their mode of operation and their precise chemical effects. I do not hold this as a reason for rejecting the aid of chemistry, but only as a ground for moderating a too sanguine confidence in its power. As it offers certainly the most probable means of solving many of the secrets of nature's operations, and as in many of the mechanical arts its triumphs are complete, there are the strongest reasons for pressing our inquiries by means of it, and for the best hopes 
of as much success as, in the present condition of the human mind, we have any right to expect.

The great value of chemical science is deemed to consist in its facility and power of analysis; but in this respect it seems to have advanced but little farther, excepting in changing the terms, than the ancient doctrine that all matter was resolvable into four elements - earth, air, fire, and water. The composition of albumen, fibrin, caseine, and gluten, and of each of them, is represented, by chemical analysis, as precisely the same in the nature and quantity of their original elements; as, for example, they consist of carbon, 48 ; hydrogen, 36 ; nitrogen, 6 ; oxygen, $15 ;$ - but to our senses, and in their uses, they are obviously altogether different. Now, chemistry explains the difficulty, - if explanation it can be called, - by stating that the difference in these substances arises from a different mechanical arrangement of the atoms or particles of which they are composed; but until chemistry can explain how this arrangement differs in the respective cases - until it can take the original elements, and compound or arrange them at its pleasure, so as to produce their different forms or substances - the explanation is certainly very far from complete. It is, indeed, not certain that even these four great principles - the existence of which is so well established and defined - are themselves ultimate elements; but admitting the fact, their precise nature is wholly unexplained, in the present state of human knowledge. Newton, in revealing the operation of a principle of gravitation, and in explaining its wonderful laws, has yet thrown no light upon the nature of the force itself; and, in dissecting the beautiful composition of light into its seven primary elements, has yet not advanced one hair's breadth in defining what light itself is. I know it is now the habit to believe that every thing in nature may be resolved into chemical or electrical agency, the laws of which are determined and explicable, and to discard all notions of what is termed the vital agency. I cannot myself doubt that every thing in nature is governed by determinate and general laws; laws, in respect to whose existence and operation science has already made very great advances, and, for aught that can be foreseen, may presently completely understand them; but as yet the goal is far from being reached; and human reason, with all its illumination, 
and in the hour of its loftiest pride, must abase itself in the dust, in the presence of that Omniscience before which all human wisdom seems little more than ignorance and folly.

Until Science will explain to me by what force I move my muscles at my pleasure, what mind is, what matter is, what knowledge itself is, and what are the records of memory, - or even afford me some means of conjecture, - I may be permitted to demur to her loud notes of triumph, and to feel that there are still many depths which the line of our philosophy has not yet reached, and imnumerable simple processes in nature, of daily occurrence, which are utterly beyond our explanation. That there is at work, in all animal and vegetable life, a vital agency, who can entertain a doubt? I do not know that it is not resolvable into the principles of chemical solution and affinity, or into electrical or galvanic agency; but the assumption, in the present state of science, would be, I think, premature, without stronger grounds on which to rest it.

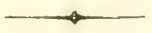

\section{XXX. - ANALYSIS OF SOILS.}

In the chemical analysis of soils, likewise, upon which so much stress is laid, there are dificulties, in the practical application of our linowledge, sufficiently discouraging. The complaint has been constantly and very emphatically made, that the analyses of former chemists, such as Davy, Chaptal, and other's, were all too gencral, and therefore of little or no practical value. It may be said of modern analyses, that they startle one by their precision and minuteness.

I shall be excused, I hope, if I endeavor to lessen somewhat the dryness and dulness of these discussions, to my readers, by a matter of fact, certainly not without its interest to me, and which may bear some analogy to the case before us. Some years since, when suffering under a severe illness for several months, I was sometimes amused, as far as it was possible for me, under such circumstances, to he amused, by the great, and I had almost 
said, endless variety of articles which entered into the preseriptions of my medical advisers in the customary form of grains, scruples, drams, and mixtures. So much of this article was for this specific purpose, and so much of that for another. This was to qualify that; that was to qualify this. This was to prevent such an article doing too much, and that was to prevent its doing too little. One was to operate upon the bile, another upon the blood; one upon the respiration, and another upon the digestion. And all this was to be going on, and to be accomplished, at the same time. I confess I was often in the situation, in respect to my physician, of the wondering pupils of Goldsmith's village schoolmaster, and marvelled "that one small head could carry all he knew." I had, at least, the consolation in the case of feeling that, as the surgeons often pleasantly term it, when amputating a limb, or operating for the extraction of the stone, I was furnishing at least a beautiful experiment in the way of medical science; and it must be said to the credit of my physician, whose kindness amidst all this I never can forget, that, although his philosophy and his scientific ardor carried him to the most extreme tests, and he might be said to have suspended me over a precipice by a twine string, confident that, if I dropped, it would at least prove that common twine was not strong enough in such cases, - a most important fact to be ascertained, - I was not quite used up, but was, after a while, cnabled to show myself erect again, a perfect monument of the triumph of his skill.

Let us now open at random upon some of the analyses given us in the work of the most distinguished chemist of the day, and inquire who has skill to prescribe for cases so complicated in their nature, or in any event what prescription would suit the case, but one as multiform and mixed as those of my own physician.

\section{SOILS OF HEATHS.}

"1. Soil of a heath converted into arable land in the vicinity of Brunswick. It is naturally sterile, but produces good crops when manured with lime, marl, cow-dung, or the ashes of the heaths which grow upon it." [It would be difficult, I think, to 
find many soils, where the climate did not forbid it, which would not produce good crops under such treatment.]

"Silica, and coarse silicious sand, . . . . . 71.504

Alumina, . . . . . . . . . . . 0.780

Protoxide, and peroxide of iron, principally com-

bined with humus, . . . . . . . . . 0.420

Peroxide of manganese, idem, . . . . . . . 0.220

Lime, idem, . . . . . . . . . . . . . 0.134

Magnesia, idem, . . . . . . . . . . . 0.032

Potash and soda, principally as silicates, . . . 0.058

Phosphoric acid, principally as phosphate of iron, - 0.115

Sulphuric acid, (in gypsum,) . . . . . . . 0.018

Chlorine, (in common salt,) . . . . . . 0.014

Humus soluble in alkalies, . . . . . . . . 9.820

Humus with vegetable remains, . . . . . 14.975

Resinous matters, . . . . . . . . . . 1.910

100.000

"Ashes of the soil of the heath before being converted into arable land:-

"Silica, with silicious sand, . . . . . . . 92.641

Alumina, . . . . . . . . . . . . . 1.352

Oxides of iron and manganese, . . . . . . 2.324

Lime in combination with sulphuric and phosphoric

acids, . . . . . . . . . . . . 0.929

Magnesia combined with sulphuric acid, . . . 0.283

Potash and soda, (principally as sulphates and phosphates,) . . . . . . . . . . 0.564

Phosphoric acid, combined with lime, . . . 0.250

Sulphuric acid, with potash, soda, and lime, . . 1.620

Chlorine in common salt, . . . . . . . 0.037

100.000

"2. Surface soil of a fine-grained loam, from the vicinity of Brunswick. It is remarkable from the circumstance that not a single year passes in which corn [wheat] plants are cultivated upon it, without the stem of the plants being attacked by rust. 
Even the grain is covered with a yellow rust, and is mucl: shrunk. One hundred parts of the soil contain -

"Silica and fine silicious sand, . . . . . . 87.859

Alumina, . . . . . . . . . . . . 2.652

Peroxide of iron, with a large proportion of protoxide . . . . . . . . . . . 5.132

Protoxide and peroxide of manganese, . . . . 0.840

Lime, principally combined with silica, . . . 1.459

Magnesia, idem, . . . . . . . . . . . . 0.280

Potash and soda, idem, . . . . . . . . . 0.090

Phosphoric acid in combination with iron, . . . 0.505

Sulphuric acid in combination with lime, . . 0.068

Chlorine in common salt, . . . . . . . . 0.006

Humus, . . . . . . . . . . . . . 1.109

$100.000 . "$

This analysis must surely be sufficiently close and serere to satisfy even the most fastidious; for here even six hundred thousandth parts of a particular ingredient in the soil, that is, of chlorine in common salt, were ascertained.

"This soil," it is remarked, "does not suffer from want of drainage; it is well exposed to the sun; it is in an elevated situation. and in a good state of cultivation. In order to ascertain whether the rust was due to the constituents of the soil, (phosphate of iron?) or to certain fortuitous circumstances unconnected with their operation, a portion of the land was removed to another locality, and made into an artificial soil of fifteen inches in depth. Then this barley and wheat were sown; but it was found, as in the former case, that the plants were attacked by rust, whilst barley growing on the land surrounding this soil was not at all affected by the disease. From this experiment it follows that certain constituents in the soil favor the development of rust."

But this inference does not appear to me to follow of course. We cannot deny that the rust may have been, in this case, the result of some noxious ingredients in the soil; this appears highly probable. But rust is often the result of influences mainly atmospheric. The fact that the barley grown on soil in the neighborhood of the remored soil was unaffected by rust, 
While that on the removed soil was aflected, is not conclusive. It is believed that plants are subject to rust only in particular stages of their growth. Now, on the supposition that the rust in this case was the effect of atmospheric influences, it is important to know whether the barley (for the wheat is not compared with any other wheat) growing on the removed soil, and that growing in its vicinity, were precisely contemporaneous in their growth, or in the degree of ripeness, or approach to ripeness, which they had attained. Further, it appears that the learned analyst was not himself able to say to what particular ingredient in the soil the rust was owing, nor what manure, if any, was used; and manure always seriously affects the plant to which it is applied.

" 3 . Soil of a heath which had been brought into cultivation in the vicinity of Brunswick. The analysis was made before any crops had been grown upon it. Corn plants [wheat] were first reared upon the new soil, but were found to be attacked by rust, even on those parts which had been manured respectively with lime, marl, potash, wood-ashes, bone-dust, ashes of the heath plant, common salt, and ammonia. One hundred parts contain-

"Silica with coarse silicious sand, $51.33 \%$

Alumina,

Protoxide and peroxide of iron, in combination with phosphoric and humic acids, . . . . . . 0.398

Protoxide and peroxide of manganese, . . . . 0.005

Lime in combination with humus, . . . . . 0.230

Magnesia, idem, . . . . . . . . . . . 0.040

Potash and soda, . . . . . . . . . . . . 0.010

Phosphoric acid, . . . . . . . . 0.066

Sulphuric acid, . . . . . . . . . 0.022

Chlorine, . . . . . . . . . . 0.014

Humus soluble in alkalies, . . . . . . . 13.210

Resinous matters, . . . . . . . . . . 2.040

Coal of humus and water, . . . . . . . 32.100

$\overline{100.000} . "$

Here it will be seen we come again to fractions as minute as hundred thousandths.

"The next analysis represents this soil after being burnt. 
One hundred parts by weight of the soil left, after ignition, only filty parts. One hundred parts of these ashes consisted of -

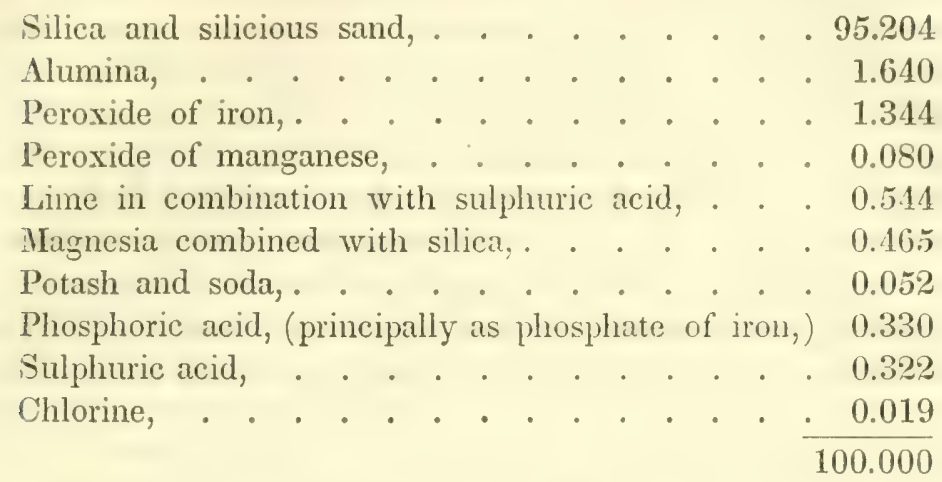

:By comparing this analysis with the one which has preceded it, an increase in certain of the constituents is observed, particularly with respect to the sulphuric acid, potash, soda, magnesia, oxide of iron, manganese, and alumina. From this it follows, that the humus, or, in other words, the vegetable remains, must have contained a quantity of these substances confined within it in such a manner that they were not exhibited by analysis."

Here it seems, then, admitted, that the most minute chemical analysis, even to hundred thousandths, failed to detect all the latent elements of which the soil was composed.

"Oats and barley were sown on this land the second year atter being reclaimed, and both suffered much from rust, although diflerent parts of the soil were manured with marl, lime, and peat-ashes, whilst other portions were left without manure. In the first year, all the different parts of the field produced potatoes; but they succeeded best in those parts which had been manured with peat-ashes, lime, and marl. In the second year, oats, mixed with a little barley, were sown upon the soil; and the straw was found to be strongest on the parts treated with peat-ashes, lime, and marl." [I have never known this to fail to be the case on any soil.] "Red clover was sown in the third year; and it appeared in best condition on those portions of the soil manured with marl and lime. Upon the divisions of the field which had been left without manure, as well as on those $20 *$ 
manured with bone-dust, potash, ammonia, and common salt, the clover scarcely appeared above ground." [Here, though so much stress is laid upon the infinitesimally minute divisions of the soil, we are left entirely at a loss as to the quantities or forms in which these applications were made.] "The divisions of the field, which had been manured in the first year with peatashes, ammonia, and ashes of wood, were sown with buck-wheat after the removal of the first crop of clover. The buck-wheat succeeded very well on all the divisions, yet a marked difference was perceptible in favor of the portion treated with ammonia. These experiments show us, that a dressing of lime did not completely remove from the soil its tendency to impart rust to the plants grown upon it." [But if the lime partially corrected the evil, is there not reason to infer that the error was in not putting lime enough upon it, and that more would have completely removed it?] "Nevertheless," the writer adds, "it is highly probable that, as soon as the protoxide of iron became converted into the peroxide by exposure to the atmosphere, lime would possess more power in decomposing the phosphate of iron."

I shall cite only one more example in this case.

"4. Subsoil of a loamy soil in the vicinity of Brunswick. It is remarkable that sainfoin cannot be cultivated upon it more than two or three years in succession. The portion analyzed was taken from a depth of five feet. One hundred parts contained -

"Silica, with very fine silicious sand, . . . 90.035

Alumina, . . . . . . . . . . . . 1.976

Peroxide of iron, . . . . . . . . 4.700

Protoxide of iron, . . . . . . . . . . . 1.115

Protoxide and peroxide of manganese, . . . . 0.240

Lime, . . . . . . . . . . . . . 0.022

Magnesia, . . . . . . . . . . . 0.115

Potash and soda, . . . . . . . . . . . 0.300

Phosphoric acid combined with iron, . . . . 0.098

Sulphuric acid, (the greatest part in combination with protoxide of iron,) . . . . . . . 1.399

Chlorine, . . . . . . . . a trace. 
"Now; the results of the analysis give a sufficient account of the failure of the sainfoin." [But it seems it can be cultivated upon it two or three years in succession.] "The soil contains one per cent. of sulphate of the protoxide of iron, (green vitriol of commerce,) a salt which exerts a poisonous action upon plants. Lime is not present in quantity sufficient to decompose this salt. Hence it is that sainfoin will not thrive in this soil, nor indeed lucern, or any other of the plants with deep roots. The evil cannot be obviated by any method sufficiently economical for the farmer, because the soil cannot be mixed with lime at a depth of five or six feet." [It requires some courage for a man even to think of such a thing.] "For many years, experiments have been made in vain, in order to adopt this soil for sainfoin and lucern, and much expense incurred, which would all have been saved, had the soil been previously analyzed. This example affords a most convincing proof of the importance of chemical knowledge to an agriculturist." *

Now, I think the strong impression which will be upon every practical man's mind, in looking at these analyses, will be, the utter impossibility of meeting the cases, and of adapting the cultivation and manuring with any very exact reference to the chemical condition of the soil; that is, of prescribing for the patient. I admit that the application of chemical analyses or tests to the soil may be of very great importance in detecting the existence of any substance, as in the latter case for example, which is poisonous to vegetation; though even here, the existence of the evil itself, and the remedy, are left somewhat in uncertainty. I believe it may be of great utility in determining the general and predominant characteristics of a soil; but with great respect for science, and for the labors of those men who, by their distinguished attainments, have conferred the highest benefits upon the community, I can come to no other conclusion than that any expectation of adapting our cultivation, upon any extended scale, to these minute diversities of soil, is illusory; and that the most illustrious chemist living may be challenged in vain to prescribe any practicable culture adapted to meet, with

* These examples of analyses of soils are by Sprengel, and taken from Liebig's Agricultural Chemistry, from the chapter on the Chemical Constituents of Soils. p. 208, 3d American edition. 
any degree of exactness, the cases given, or to recognize in his applications or prescriptions, with any jeculiar success, the minute diversities of composition which are here presented.

But suppose the application made, and even in the simplest form; what sagacity is acute enough to follow it in all its operations upon the elements, either simple or compounded, with which it comes in contact? or what skill can command the external circumstances of heat or cold, of drought or moisture, which must at the time affect its operation? No human skill has as yet been able to compound a soil, and say, This shall be more fruitful than any other. The hahits and nature of different plants require different conditions both of soil and of culture.

The Royal Agricultural Society of England has recently made a liberal grant to aid in the chemical analysis of the different vegetable productions, mnder the direction of one of the most able chemists of the age; and a good deal of valuable information will undoubtedly be derived from this source. The chemical analysis of different manures has been carried on with eminent zeal and intelligence, and is constantly going on, to the great benefit, without question, of agricultural science; but the extraordinary confidence which some persons indulge in the results of chemical science, in respect to agriculture, seems to me a little too sanguine, and the practical application of this knowledge by no means so easy as has been supposed.

I am quite aware that this may appear like a digression; but, in considering the subject of agricultural education, it was natural to advert to that which seems now to be more prominent in the minds of agriculturists than almost any thing else - the advantages which agriculture is to derive from chemical science, and the consequent importance of making it the prominent subject of instruction. Our expectations in this matter should be in some degree moderated by a remark of Liebig's: in speaking of the analysis of soils, and after having giren several examples, "It is unnecessary," he says, "to describe the modus operandi used in the analysis of these soils; for this kind of research will never be made by farmers, who must apply to the professional chemists, if they wish for information in regard to the composition of their soils." The science of chemistry has indeed now become of that enlarged character, and is occupied in such profound and difficult investigations and discoreries, that excellence 
in it can scarcely be looked for but with those persons who, to eminent taleuts of research, and an extraordinary enthusiasm in the pursuit, devote their time almost exclusively to this object.

A general knowledge of its principles and discoveries, and a fiacility in making some experiments in it, are all, perhaps, that call bo expected to be given in the education at an agricultural college; but it is desirable and most requisite, even for this object, that the institution, in a competent instructor, and all the necessary apparatus, should furnish the means of accomplishing it in the best manner, and to the greatest advantage This undoubtedly will be done.

\section{XXXI. - NATURAL SCIENCE.}

Lrery possible facility should be provided for the study of every branch of natural history, for every branch of natural history may be made subservient to agricultural improvement. There is, in my opiniou, nothing which so invigorates and strengthens the mind as earnest and deep inquiries into nature, the study of natural facts, the observation of natural phenomena. There is no knowledge, especially to persons residing in the country, which affords so many practicable uses and such raried and important application. The man who studies books exclusively is always liable to be the slave of other men's opinions; and his mind, losing by such restraints its native elasticity, never travels out of its prescribed limits. The man who goes himself to the original sources of knowledge, and draws water ont of the very wells of life, acquires a force of inquiry, maintains a healthful freshness of mind, which grow strong continually by what they feed upon, multiply for themselves the sources of knowledge, turn every object and occurrence which they meet with into an instrument of instruction, and find the world and nature no longer a dull, desolate, inanimate chamber, but its walls all over radiant with lessons of wisdom, and every object with which it is crowded vocal with the teachings of a divine spirit. 
I do not overrate the value of natural science to the agriculturist, the resident in the country. For him it is the proper study for use, for ability, for recreation, and for ornament. There is yet much to be done in agriculture. I believe that the quantity of the products of the earth from the same extent of surface may in most cases be quadrupled, and that the number of its productions for the sustenance of man and beast may be multiplied far beyond any present calculation. If we may argue from what has been done to what may be done, the perfection of agriculture is yet very distant, and vast improvements remain to be made. But this can only be effected by bringing vigorous and enlightened minds to bear upon the subject; and the natural sciences are those which of all others best prepare and strengthen the mind for such investigations. The best education which can be given to any man is not that which merely communicates knowledge, but that which enables and induces a man to acquire knowledge for himself. This is what the study of the natural sciences particularly prompt and compel a man to do. These studies, pursued especially in the country, where Nature in such a variety of aspects is continually offering herself for examination, give a vigor and activity of mind which particularly qualify men for practical objects and pursuits.

We are to look, then, to educated men, to men of active and cultivated minds, to men accustomed to study, inquiry, reflection, observation, and experiment, for any great improvement yet to be made in agriculture. These are the men who have always been the pioneers in human progress, and these men are still to lead the onward march. A school, therefore, which trains such minds, not for literary leisure, but for the active and business pursuits of life, must be regarded as one of the most valuable institutions in the community. No branch of art or business will be found to afford greater scope for the application of such an education than agriculture. 


\section{XXXII. - MIODEL FARM.}

To the departments which may be called literary and scientific, the Agricultural College at Cirencester proposes to add those which are strictly practical, by commecting with the institution a farm of five hundred acres. Practical experience is of the highest importance in every practical art. If it be true, that no man can be a thorough sailor who has not served before the mast, and who is not familiar with every rope in the ship, it may be as truly said, that no one should consider himself fully competent to the management of a farm, who is not thoroughly acquainted with every operation to be performed on a farm; and, though he may not always be able to execute it himself, he should know how it is to be done, and be able to determine when it is properly executed.

A model farm is intended to illustrate, as far as the nature of the soil and climate admit, the best practices in husbandry; to show the management of a farm in the details and in the whole; t) teach the arts of ploughing, sowing, harrowing, cultivating, reaping, harvesting, stacking, threshing, and preparing the products for market; to explain the management and treatment of all live stock on the place, whether designed for food or labor, for fattening or working, for beef, mutton, pork, wool, or dairy produce; to teach the whole duty of a shepherd or grazier, and the whole management of the stall and the dairy. These are the objects proposed; and it is intended that the labor of the farm shall be performed by the pupils, and its products go towards the support of the institution, so as to reduce the cxpenses of education. All this is well, and may be made eminently useful to the pupils. 


\section{XXXII. - EXPERIMENTAL FARM.}

It is further intended, besides presenting a model farm, that it shall likewise, in a measure, serve the purpose of an experimental farm. Besides presenting an example of the best management, and the performance of all the customary operations of a farm in the best and most approved manner, it is designed to afiord an opportunity of experimenting in various forms upon manures, seeds, plants, cultivation, and the feeding and fattening of animals, and upon every feasible subject, where practical information and exact results are important to be ascertained.

\section{XXXIV. - ECONOMICAL ARRANGEMENTS AT THE AGRICULTURAL COLLEGE.}

Such, as I understand, are the outlines of the plan for agricultural education designed to be pursued at the College at Cirencester. Its objects are not to teach its pupils how to labor, but to qualify a class of persons for the management of their own, or the estates of others. The farmers here are not, as with us, workers on their own estates; they are the managers or superintendents of the work; but it is obviously of the highest importance that they should understand how every branch of husbandry should be conducted. For the common laborer here, in the present arrangements of society, I see no hope of his ever rising above that condition in which he is born. There are some extraordinary exceptions; but they are very rare. Besides the impediments which lie in the way from his entire poverty, and the extreme dificulty of his ever acquiring more than six feet of the soil, and that six feet below the surface, and after all power of active improvement of it has ceased, any attempt to alter his condition in this respect, it is to be feared, as I think I have already shown, would be discouraged, certainly not aided, 
by those above him. I do not know that it is necessary for me to discuss the question whether such a condition of society is preferable to one in which the laborer is first to be served from the produce of his own toil; in which every man, by honest industry, may become the sovereign owner of the acres which he tills, and while he labors he may proudly feel that he is laboring for himself, and not for another. I shall leave all this to the dispassionate judgment of my reader, content even that it should be ascribed to the misfortune of birth, or the perverse prejuaices of education, that I immeasurably prefer a condition of society, where the rights of all men are, as far as possible, held equal; where no monopoly of wealth, or education, or rank, or power, limits or impedes the progress even of the humblest members of the community; and where, in a free and equal competition, without injury to his neighbor, every man, for himself and those dependent upon him, becomes the creator of his own fortunes.

No human institution is perfect. Every effort will doubtless be made to adapt the institution at Cirencester to its proper and valuable ends. It is obvious that some practical difficulties will present themselves, which it will require great skill to overcome. The distinctions of rank, which prerail in England, and form a part of its constitution, are as rigorously observed at places of education as in any other departments of society, and are marked there by differences of dress and of privilege. Will these distinctions prevail here? If they prevail here, will they not prove inconvenient in respect to the labors of the farm? or is the institution in no respect intended for the education of persous of rank? I am curious to know how this is to be arranged. Many noblemen in England, of the highest rank, are among the most intelligent practical agriculturists in the kingdom. Will they not desire all the adrantages of the institution for their sons? and will they consent to forego all the distinctions and privileges of their rank for the sake of the education? After all, the difficulty may be purely imaginary; for I confess, in my simplicity, educated as I had been in the plain democratic a republican habits of New England, nothing surprised me mon. than the perfect readiness, with which, in erery case, the claims of rank are acknowledged, and in most cases even the pride and pleasure with which this deference is paid, and their rights 
admitted, on the part of the inferior classes. So far from looking upon this as most of my countrymen are disposed to regard it, and as I should regard it in my own country, as a mark of extreme servility, in a country where such distinctions are established by law, and make a part of the government, it seems to me as much to the credit of their good sense, as it is conducive to their good manners, to conform to them. In any institution of this kind, in my own country, no such difficulties can arise; and it might seem idle for me to allude to them, were it not that an occasional, and I hope not unseasonable, illustration of the manners of England will interest the curiosity of a large portion of my readers.

In the next place, it seems to be designed, and certainly it is very desirable, that the farm shall be managed by the labor of the pupils; and it is proposed that the proceeds of the farm should go towards the payment of the rent, and the reduction of other expenses of the establishment. This is, in my opinion, as it should be; and, with the exception of one or two more experienced laborers, who, in their particular departments of ploughing, \&c., should be competent to act as instructors of the pupils, and with a few servants, (and they should be very few, for servants, in almost all places of education, are commonly a great evil, and the best of all training for the young is that which compels them, in a great degree, for all personal services at least, to depend upon themselves, ) the whole labor of the farm should be performed by the pupils. This would be, of all others, the most effectual way of making them acquainted with the subject, and the only way, indeed, in which they can become thoroughly acquainted with many of the operations on a farm. I am curious to know how this labor is to be had; whether it is to be voluntary or by compulsion; and how, among two hundred pupils, it is to be apportioned and equalized. If made voluntary, it certainly will not be equally rendered: some will not work at all; and preferences for some kinds of work, and distaste for others, which of course must be expected to exist, will be found inconvenient. If the labor is made compulsory, the enforcing of it will not be easy; and it would be diffienlt to find the young men, likely to resort to such a place of education, disposed to submit to any arbitrary exactions of this nature. How far it is practicable to make it mercenary, and 
to reward it by wages, or by a share of the products of such labor, is a subject which will require much consideration; but this mode seems to present the only alternative.

The large number of students - two hundred - to be provided for, seems to me to present another serious difficulty in the case. If any thing like a military discipline could be introduced among them, two thousand might be managed as easily as two hundred. As far as concerns their literary or scholastic improvement, the number presents no impediment in the way of their instruction by lectures or recitations; but when with this is to be combined the management of the farm by the personal labor of the pupils, a number so large, or indeed half that number, must be found exceedingly difficult of management. At the Gilasnevin school, the boys are regular apprentices to the farmer. and their work for certain hours of the day is compulsory. The schoolmasters, who come to the farm for instruction, come merely as spectators, and put their hands to the work, or not, as they please. The whole establishment, if indeed it were foul' times as large as it is, would not, under these circumstances, be beyond the personal superintendence of a single efficient manager. At Templemoyle, the number is limited to seventy, the farm is much more extensive than at Glasnevin, and the labor for half the day is compulsory. Is the pupils are almost entirely drawn from the poorest classes, and are persons who must depend for their success in life wholly upon their own efforts, they require no other stimulus to exertion. At Cirencester, the pupils may be divided into two classes - those who work, and are allowed in some form a compensation for their labor; and those who are not required or expected to labor, and pay an extra price for the exemption. Such an arrangement would have many disadrantages, and would be ill adapted to the condition of society in the United States. The number of two hundred seems to me quite too large, and immanageable with any view to the advantageous application of their labor, if that labor is to be voluntary.

In Scotland, the practical part of farming is learned by young men going to reside one or two years, or for a suitable length of time, with an intelligent and experienced farmer. In such case. the fee paid is about one hundred pounds. or fire hundred dollars. a year; and for this the apprentice is received into the family, 
and provided for at the farmer's table, and every operation on the farm is witnessed by him, and explained to him by the farmer. In such cases, labor with the pupil is wholly optional. Where the farmer is well-skilled and communicative, and the pupil capable and interested in the pursuit, few arrangements are to be preferred - this upon the supposition, however, that in other respects, and previously to his commencing his apprenticeship, he is well grounded in practical science.

The three things of which I have spoken ought to be viewed separately; but I fear, from the manner in which I have treated them, they may appear somewhat confused to my reader's mind.

\section{XXXV. - PLAN OF AN AGRICULTURAL INSTITU'TION.}

First, then, in every system of agricultural education, there should be an institution for the thorough indoctrination of the pupil in natural science, and in mechanical philosophy, so far as it can be made to bear upon agriculture. I have already treated fully of what, on this topic, should be taught in an institution of this nature.

Secondly, there should be a model farm, which should be accessible to the pupils, and where they might see an example of the best management, and the best practices in husbandry. It is obvious, however, that a single farm can present, excepting on a small scale, only a single kind of farming; and that it would be hardly possible to find a single locality presenting any considerable, or very instructive specimen of the different kinds of farming, such as arable, grazing, stock-breeding, stall-feeding, sheep-raising, and dairying. But the particular and careful observation even of one kind of well-conducted farming would qualify a pupil for understanding and receiving information on every other, whenever it came in his way, or wherever it might be attainable. Stall-feeding is intimately connected and often associated with arable farming, and dairying with grazing. The management of live stock, whether for work, for fatting, or for dairying, might, in a small degree, be exemplified on every well- 
managed farm. Such an appendage as this to a school of practical instruction, where the pupils might see and have explained to them the very best modes of husbandry, must be of the highest benefit. 'To these should be added an experimental farm. This need not be extensive, and it might be connected with the model farm; indeed, the model farm might itself be, to a degree, an experimental farm. It may be said that the premitums offered by agricultural societies, for various experiments in husbandry, are sufficient to meet the public wants in this case. I admit that they have in this way rendered immense benefits to the public; but there are still wanted various trials and tests of soils, manures, grasses, plants, implements, modes of cultivation, modes of feeding, breeding, dairying, - and on the effects of temperature, moisture, heat, frost, light, and electricity; - which common farmers can scarcely be expected to undertake, or, if undertaken, to follow out with that exactness which is most desirable, in order to render the results of such experiments worthy of confidence, and lessons for general application.

Connected with the whole should be most extensive gardens, - first, for purposes of botanical instruction, giving the pupils an opportunity of becoming acquainted with all the principal plants, grasses, forest-trees, fruit-trees, and weeds, which enter into their cultivation, to the advantage or injury of the farmer: and next, for making them thoroughly acquainted (a knowledge highly important to them) with the cultivation of all the varieties of vegetables and fruits which may be required for use, profit, or luxury.

Such is the basis on which I should be glad to see an institution for agricultural education rising up in every one of the United States, where the condition of society renders it expedient, and the population is dense enough to sustain it. The expensive plan on which it is proposed here to establish and conduct such institutions, would be quite unsuited to the state of manners and the condition of things in the United States. In their economical arrangements, Ireland has set.us an excellent example. With us, they might be made in a great measure self-supporting. The plan proposed for such an institution, some few years since, by the late lamented Judge Buel, who had the subject much at heart, involved an expenditure of one 
hundred thousand dollars, and might be said to have been crushed by its own weight.

Let us suppose that it were proposed to establish such an institution in the western part of New York. Certainly no location could, in respect to the external circumstances of soil. climate, access, society, and markets, be more favorable. A farm of five hundred acres might be taken, on farorable terms, on a long lease. I would under no circumstances suffer the number of pupils to exceed one hundred, and perhaps it might be expedient to restrict the number much more. Some goodsized hall or building would be requisite for public meetings, lectures, or recitation-rooms, and for a museum, library, and chemical laboratory; but I would erect no college building for the residence of the pupils. They should either lodge in the neighborhood, with such farmers as would be willing to receive them, or other persons who might be disposed to provide for them; or otherwise, I would erect several farm-houses on the place, sufficient to supply the needful accommodations; but in no case should more than fifteen or twenty be lodged in one place; and, whether on the farm or not, the lodging-houses for the pupils should be under the constant inspection or regulation of the governors or instructors of the institution. One or two instructors should be employed constantly for teaching the main branches of education, and a competent farmer should be employed to manage the agricultural department, and to give the necessary practical instruction. Beyond this, no resident instructors would be required, - but regular and full courses of lectures and experiments in geology, mineralogy, botany, comparative anatomy, the veterinary art, and chemistry, by competent professors of these sciences, who might be employed for these objects annually, without the necessity and expense of constant residence, - as is now frequently done at our medical schools. In this way, the best talents in the community might be commanded, and at a reasonable expense.

I would require, in the next place, that the pupils should be placed in a condition of perfect equality, and that a certain amount of labor should be made compulsory on all, at such a rate of wages as should be deemed just, according to the ability of the pupil, and the nature of the work done. An account 
should be kept for every pupil, and another by every pupil, of the labor performed by him, which should be passed to his credit. The farm account should be kept with faithful exactness, and be always open to the inspection of the pupils; and after the deduction of the rent, and the necessary burdens and expenses, and some small amount kept as a reserve or accumulating fund for the benefit of the institution, the remainder should be divided among the pupils according to the labor performed.

Their board and lodging should be settled for by themselves, without any interference on the part of the directors of the institution, beyond keeping the charges within a stipulated price; and the keepers of the boarding-houses should be required to purchase, at reasonable rates, from the farm, whatever supplies they might require, which the farm would yield. A tax should be levied upon the students for the payment of all the instructors and lecturers, and the use of the library, and chemical and philosophical apparatus; and likewise to meet any extraordinary experiments made upon the farm, with a view to the instruction of the school. Whether it would be advisable for every pupil to have an allotment for himself, either for the purpose of experiment, or for the profit, and in aid of his subsistence, would be worth considering; remembering always how important it is to give to every man an immediate interest in the result of his labors.

Such, in my opinion, is a plan for agricultural education which demands no great advance, and involves no risk. But the project is even much more feasible than I have already stated. Why, for example, should not such an institution be connected with the college at Williamstown, or Amherst, in Massachusetts, or with Dartmouth College in New Hampshire, or Burlington College in Vermont, or the college at IIartford in Connecticut, or Geneva in New York, where all the facilities for scientific instruction are at hand, residences for the students attainable, and suitable farms to be had, either on purchase, or lease, at very reasonable rates? I throw out these hints to my countrymen, not with a view of dictating to their superior judgment, but to show that an institution for a practical and seichtific education in agriculture may, without any hazardous expenditure, or any large investment, be made almost immediately attainable, and under every practicable advantage. 
A professorship in agriculture is attached to the university in Edinburgh, and the chair filled by an eminent professor, Mr. Low, who has rendered the most useful public services, in the publication of his treatise on agriculture, which is said to contain the substance of his lectures at this institution. He has likewise established an extensive agricultural museum, containing specimens of agricultural productions, and models of the various implements used in improved husbandry. The term required to complete such a course of education, might be matter of after consideration; but I would advise, in every case, that the residence should be absolute, the rules exact and stringent, and the annual or occasional examinations as severe as at the military school at West Point, so that an equal proficiency might be secured.

\section{XXXVI. - ELEVATION OF AGRICULTURE AS A PURSUIT AND A PROFESSION.}

Where it is practicable, I would make the education of a high and extended character; and, besides the art of measuring, and surveying, and mapping land, I would have the arts of sketching, and drawing, and landscape gardening, taught in the institution. The pursuit of agriculture is almost universally considered as merely a profession of commerce or trade, the farmer looking wholly to its pecuniary results. In a trading community, pecumiary considerations are always liable to control the judgment, and predominate over every other consideration. Where the means are limited, and the farm must be cultivated as the only source of subsistence, pecuniary returns must, of course, be the main object. Where, as in England, the cultivator is not the owner of the soil, but an annual rent must be paid; and he is liable, as in most cases, to be compelled to quit his occupancy at the pleasure or the caprice of his landlord, farming must be conducted merely as matter of business, and there is no inducement to pursue the profession as matter of taste or sentiment. In many cases in my own country, it must, of necessity, be 
followed wholly as a means of support and of profit, and in some cases as a struggle for life.

But there are inummerable other cases, in which men have the power, under the most farorable circumstances, and I am most anxious they should have likewise the disposition, to devote themselves to it as an elegant and liberal profession, worthy of a mind gifted even with the finest taste, and enriched by the highest cultivation. The United States present not many examples of very great wealth, at least when estimated by the standard of wealth which prevails in Englund, where, indeed, are to be found individual accumulations which distance all the dreams of Oriental magnificence. But, on the other hand, no country upon the globe, and no condition of things since the establishment of society, ever presented more favorable opportunities than the United States for any one, by active and wholesome industry, and a proper frugality, to acquire a competence, and that respectable independence, in which, with a full supply for the necessities of life, and an abundant provision for its comforts, there will be found within reach as many of the elegances, and ornaments, and luxuries of life, as a well-disciplined and healthful state of mind can require. I hare seen too frequently such beautiful examples in our country villages, and scattered over several parts of a land in many respects favored by Heaven above every other, not to be deeply impressed with a condition of life which, where its blessings are properly and gratefully appreciated, seems to leave little more on earth for a rational and reflecting, a benevolent and truly religious mind to ask. Happy is it where its waters are not poisoned by an insatiate avarice, nor disturbed and thrown into confusion by ambition of political office or distinction, or a feverish thirst for notoriety and excitement; but in a quiet, yet not stagnant repose, they reflect every where the tokens of that divine goodness, which seems in such examples to have poured out its richest earthly treasures. Now, I am anxious that agriculture should oceupy that place among the liberal professions, to which it can lee raised, and to which, from its importance, it is entitled. But this can only he done by improving the education of farmers as a class, - by multiplying, through the means of a most liberal and extended education, the charms of the comntry, and the subjects of interest which would be constantly more and more dereloped 
to a cultivated and inquisitive mind; and by showing that its successful pursuit, either as matter of business or recreation, where a moderate fortune is possessed or a moderate professional income is secured, is not incompatible with the highest improvement of taste, and even a vigorous and successful pursuit of learning; and that, where so pursued, under favorable circumstances, it affords as fair a chance of rational enjoyment and quiet usefulness as any situation which the most lucrative trade, or the most successful political ambition, or even the highest professional eminence, can command.

But I fear, how much soever I may satisfy the sober and reflecting minds on this point, my opinions and persuasions will scarcely be heard, and far: less heeded, in that rush for wealth, for office, and for notoriety, which, like a torrent sweeping over the country, carries every movable object in its course. It seems, however, not less my duty to record my strong convictions, which the experience of a life not short has served only to confirm. I see in my own country every where proffered to an honest industry, a wise frugality, and a wholesome selfgovernment, the most ample rewards: I see a wide extent of rich and beautiful territory waiting the improving hand of skill and labor, to be had in many cases almost for asking, with every man free to choose where he will pitch his tent, not only without injury, but to the advantage of his neighbor: I see the means of education, of competence, and of substantial independence, held out to all who will avail themselves of them. In the midst of all this, I see thousands and thousands of young men, blest with education and fortunes adequate to supply all reasonable wants in the country, rushing into cities, exhausting their small means in the extravagances and dissipations of fashionable life; crowding all the professions to repletion; pressing on, with vexation and disappointment heaped upon vexation and disappointment, into all the avenues of political office and distinction, and into all the bitter strifes of political controversy; forcing their way into the pursuits of trade without talents for their prosecution, and almost sure to involve themselves in bankruptcy and ruin; and, in one form and another, dragging on throngh life without satisfaction to themselves and without usefulness to others, and too often a ruinous burden upon those whom it is now their turn to succor and relieve. I cannot, 
therefore, help wishing that the pursuits of agriculture might be made attractive to such persons; and that, with education, and that moderate fortune which would give them the command of the best advantages of rural life, they might find in it, as far as rational happiness and humble usefulness are concerned, that philosopher's stone which in other places they are almost sure to search for in vain.

\section{XXXVII. - RURAL MANNERS IN ENGLAND.}

England presents many such examples. The true English gentleman, living, remote from the din of cities, and abstracted from the turmoil of political life, upon his own acres; managing his own estate; seeking the best means for its improvement, and superintending, under his own personal inspection, their application; doing what good he can to all around him; making those dependent upon him comfortable and contented; giving labor, counsel, encouragement, and all needful aid, to his poor neighbors, and causing them, and their wives, and their children, to look up to him as a friend and a parent, to whose kindness their good conduct is always a certain claim; whom when the eye sees, it sparkles with grateful joy, and when the ear hears his footsteps, the sounds go like melody to the heart; who is in his neighborhood the avowed and unostentatious supporter of good morals, temperance, education, peace, and religion; and in whose house you find an open-hearted hospitality, and abundant resources for innocent gratification, and for the improvement of the mind, with a perfect gentleness of mamers, and unaflected piety presiding over the whole; - I say, such a man - and it has been my happiness to find many examples - need envy no one save the possessor of more power, and a wider sphere, of doing good; and need not covet the brightest triumphs of political ambition, nor the splendors and luxuries of royal courts.

Whatever contributes, then, in any way, to elevate the agricaltural profession, to raise it, from a mere servile or mercenary labor, to the dignity of a liberal profession, and to commend it 
not merely for its profit and usefulness, but as a delightful resource and recreation for a cultivated mind, will certainly find favor with those who form rational views of life, who wish well to the cause of good morals, and would multiply and strengthen the safeguards of human virtue.

The class of individuals whom I have described - and I assure my readers I have drawn from real life, and deal in no fictions - find often their own efforts seconded and aided by those whose encouragement and sympathy always give new lifo and vigor to their exertions, and new pleasure to their pleasures, - I mean their own wives and children; and the farming operations, in all their history and details, and all their expediency and fitness, are as much matter of familiar and interested discussion at the fireside, as, in many other circles, the most recent novel, the change in fashion, or the latest triumph of party. Indeed, I have seen, in many cases, the wives and the daughters - and these, too, often persons of the highest rank and refinement - as well acquainted with every field and crop, their management and their yield, and with every implement and animal on the place, as the farmer himself; and I always put it down to the credit of their good sense.

\section{XXXVIII. - A PENCIL SKETCH.}

I must claim the indulgence of my readers, if I give them an account of a visit in the country so instructive, so bright, so cheerful, that nothing but the absolute breaking-up of the mind can ever obliterate its record, or dispel the bright vision from $m y$ imagination. I know my fair readers - for with some such I am assured my humble Reports are lindly honored - will feel an interest in it; and if $I$ have any unfair readers, $I$ beg them at once to turn over the page. But mind, I shall utter no name, and point to no place; and if I did not know that the example was not altogether singular, and therefore would not be detected, I should not relate it. I know very well, as soon as I return to my native land, if Heaven has that happiness yet in store for 
ne, a dozcin of my charming friends, - God bless them! - with their bright eyes, and their gentle entreaties, will be pressing me an a diselosure; but I tell them beforehand, I an panoplied in a stern philosophy, and shall remain immovable.

I had no sooner, then, entered the house, where my visit had been expected, than I was met with an unafiected cordiality which at once made me at home. In the midst of gilded halls and hosts of liveried servants, of dazzling lamps, and glittering mirrors, redoubling the highest triumphs of art and taste; in the midst of books, and statues, and pictures, and all the elegances and refinements of luxury; in the midst of titles, and dignities, und ranks, allied to regal grandeur, - there was one object which transcended and eclipsed them all, and showed how much the nobility of character surpassed the nobility of rank, the beauty of refined and simple manners all the adornments of art, and the scintillations of the soul, beaming from the eyes, the purest gems that ever glittered in a princely diadem. In person, in ducation and improvement, in quickness of pereeption, in facility and elegance of expression, in accomplishments and taste, in a inukness and gentleness of manners tempered by a modesty which courted confidence and inspired respect, and in a high iniral tone and sentiment, which, like a bright halo, seemed to encircle the whole person, - I confess the fictions of poetry bccame substantial, and the beau idéal of my youthful imagination was realized.

But who was the person I have described? A mere statue, to adorn a gallery of sculpture? a bird of paradise, to be kept in a glass case? a mere doll, with painted cheeks, to be dressed and undressed with childish fondness? a mere human toy, to languish over a romance, or to figure in a quadrille? Far otherwise: she was a woman in all the noble attributes which should dignify that name; a wife, a mother, a housekeeper, a farmer, a gardener, a dairy-woman, a kind neighbor, a benefactor to the poor, a Christian woman, "full of good works, and alms-deeds which she did."

In the morning, I first met her at prayers; for, to the honor (1) England, there is scarcely a family, among the hundreds whose hospitality I have shared, where the duties of the day are not preceded by the services of family worship; and the master and the serrant, the parent and the child, the teacher and the 
taught, the friend and the stranger, come together to recognize and strengthen the sense of their common equality in the presence of their common Father, and to acknowledge their equal dependence upon his care and mercy. She was then kind cnough to tell me, after her morning arrangements, she claimed me for the day. She first showed me her children, whom, like the Roman mother, she deemed her brightest jewels, and arranged their studies and occupations for the day. She then took me two or three miles on foot to visit a sick neighbor, and, while performing this act of kindness, left me to visit some of the cottages upon the estate, whose inmates I found loud in the praises of her kindness and benefactions. Our next excursion was to see some of the finest, and largest, and most aged trees in the park, the size of which was truly magnificent; and I sympathized in the veneration which she expressed for them, which was like that with which one recalls the illustrious memory of a remote progenitor. Our next visit was to the greenhouses and the gardens; and she explained to me the mode adopted there of managing the most delicate plants, and of cultivating; in the most economical and successful manmer, the fruits of a warmer region. From the garden we proceeded to the cultivated fields; and she informed me of the system of husbandry pursued on the estate, the rotation of crops, the management and application of manures, the amount of seed sown, the ordinary yield, and the appropriation of the produce, with a perspicuous detail of the expenses and results. She then undertook to show me the yards and offices, the byres, the feeding-stalls, the plans for saving, and increasing, and managing, the manure, the cattle for feeding, for breeding, for raising, the milking stock, the piggery: the poultry-yard, the stables, the harness-rooms, the implementrooms, the dairy. She explained to me the process of making the different kinds of cheese, and the general management of the milk, and the mode of feeding the stock; and then, conducting me into the bailiff's house, she exhibited to me the Farm Journal, and the whole systematic mode of keeping the accounts and making the returus, with which she seemed as familiar as if they were the accounts of her own wardrobe. This did not finisl? our grand tour; for, on my return, she admitted me into her boudoir, and showed me the secrets of her own admirable housewifery, in the exact accounts which she kept of every thing 
connected with the dairy and the market, the table, the drawingroom, and the servants' hall. All this was done with a simplicity and a frankness which showed an absence of all consciousness of any extraordinary merit in her own department, and which evidently sprang solely from a kind desire to gratify a curiosity on my part, which, I hope, under such circumstances, was not umreasonable. A short hour after this brought us into another relation; for the dinner-bell summoned us, and this same lady was found presiding over a brilliant circle of the highest rank and fashion, with an ease, elegance, wit, intelligence, and good-humor, with a kind attention to every one's wants, and an unaffected concern for every one's comfort, which would lead one to suppose that this was her only and her peculiar sphere. Now, I will not say how many mud-puddles we had waded through, and how many dung-heaps we had crossed, and what places we explored, and how every farming topic was discussed; but I will say, that she pursued her object without any of that fastidiousness and aflected delicacy which pass with some persons for refinement, but which in many cases indicate a weak if not a corrupt mind. The mind which is occupied with concerns and subjects that are worthy to occupy it, thinks very little of accessories which are of no importance. I will say, to the credit of Englishwomen, - I speak, of course, of the upper classes, - that it seems impossible that there should exist a more delicate sense of propriety than is found universally among them; and yet you will perceive at once that their good sense teaches them that true delicacy is much more an element of the mind, in the person who speaks or observes, than an attribute of the subject which is spoken about or observed. A friend told me that Canova assured him that, in modelling the wonderful statue of the Three Graces, from real life, he was never at any time conscious of an improper emotion or thought; and if any man can look at this splendid production, this affecting imbodiment of a genius almost creative and divine, with any other emotion than that of the most profound and respectful admiration, he may well tremble for the utter comption, within him, of that moral nature which God designed should elevate him above the brute creation.

Now, I do not say that the lady to whom I have referred was herself the manager of the farm; that rested entirely with her 
husband; but I have intended simply to show how grateful and gratifying to him must have been the lively interest and sympathy which she took in concerns which necessarily so much engaged his time and attention; and how the country could be divested of that dulness and enmui, so often complained of as inseparable from it, when a cordial and practical interest is taken in the concerns which necessarily belong to rural life. I meant also to show - as this and many other examples which have come under my observation emphatically do show - that an interest in, and a familiarity with, even the most humble occupations of agricultural life, are not inconsistent with the highest refinements of taste, the most improved cultivation of the mind, the practice of the polite accomplishments, and a grace, and elegance, and dignity of manners, unsurpassed in the highest circles of society.

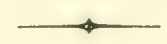

\section{XXXIX. - LIFE IN THE COUNTRY.}

To live in the country, and enjoy all its pleasures, we should love the country. To love the country is to take an interest in all that belongs to the country - its occupations, its sports, its culture, and its improvements, its fields and its forests, its trees and rocks, its valleys and hills, its lakes and rivers; to gather the flocks around us, and feed them from our own hands; to make the birds our friends, and call them all by their names; to wear a chaplet of roses as if it were a princely diadem; to rove over the verdant fields with a higher pleasure than we should tread the carpeted halls of regal courts; to inhale the fresh air of the morning as if it were the sweet breath of infancy; to brush the dew from the glittering fields as if our path were strewed with diamonds; to hold converse with the trees of the forest, in their youth and in their decay, as if they conld tell us the history of their own times, and as if the gnarled bark of the aged among them were all written over with the record of bygone days, of those who planted them, and those who early gathered their fruits; to find hope and joy bursting like a flood upon our hearts, as the darting rays of light gently break upon 
the eastem horizon; to see the descending sum robing himself in burnished clonds, as if these were the gathering glories of the divine throne; to find in the clear evening of winter our chamber studded with countless gems of living light; to feel that "we are never less alone than when alone;" to make even the stilhess and solitude of the country eloquent ; and above all, in the beauty of every object which presents itself to our senses, and in the unbought provision which sustains, and comforts, and fills with joy, the countless multitudes of living existences whic? people the land, the water, the air, every where to repletion, to see the radiant tokens of an infinite and inexhaustible beneficence, as they roll by us and around us in one ceascless flood; and in a clear and bright day of summer, to stand out in the midst of this resplendent creation, circled by an horizon which continually retreats from our advances, holding its distance undiminished, and with the broad and deep blue arches of heaven over us, whose depths no human imagination can fathom; to perccive this glorious temple all instinct with the presence of the Divinity, and to fecl, amidst all this, the brain growing dizzy with wonder, and the heart swelling with an adoration and a holy joy, absolutely incapable of utterance; - this it is to love the country, and to make it, not the home of the person only, but of the soul.

\section{XL. - VETERINARY COLLEGE.}

I must not quit the subject of agricultural education without adverting to some other institutions of great importance. The first of these is the Veterinary College, near London. I believe there is one of a similar character near Edinburgh; but that I have not visited.

The object of this institution was to qualify persons, by the study of comparative anatomy and physiology, and by opportunities for witnessing hospital practice and investigating the symptoms and phenomena of disease in the lower animals, to practise veterinary surgery and medicine; and to do what can be done, by skill and sminuer, for the relief of the sufferings and 
the cure of the maladies of quadrupeds of all linds - horses, cattle, sheep, dogs, \&c. For this purpose, a number of gentlemen associated, and, by a subscription for life of twenty guineas each, or an annual payment of two guineas, laid the foundation of this excellent and humane establishment. An extensive plot of ground, about three miles from the centre of London, was (1)tained, and the necessary buildings - consisting of stables and loose boxes; long piazzas for the purpose of giving the patients exercise in bad weather under cover; a room for lectures and dissections, and for a museum of anatomical preparations; and specimens of diseased organization, and a forge for shoeing, together with apartments for the resident professor, and for the accommodation of the servants of the establishment - have been erected; and already nearly or quite a thousand pupils have received diplomas or certificates of their qualifications for practice, and have gone to the business of their profession in different parts of the kingdom, in the army, and in foreign countries.

Subscribers to the establishment have the privilege of sending their horses, or diseased animals, to the institution, without any other expense than the actual cost of their food; but no animal can be admitted which is not the property of either an annual or a permanent subscriber. The horses of subseribers are sometimes prescribed for at their own stables, when it is inconvenient to send them, provided the medicines are compounded at the college. In case the disease of an animal is pronounced desperate, the owner, upon paying the expenses already incurred, may surrender him to the college; and if, by any treatment which they may see fit to adopt, the animal is recovered, the owner may have him again by paying the additional expenses since his surrender, or he will be considered the property of the college. Horses likewise may be shod at the forge of the college at the customary charges. Subscribers likewise, at a distance, have the privilege of procuring any medicines or drugs. which may be required, compounded at the college, and furnished at the actual cost.

A principal and an adjunct professor of veterinary science and practice, men eninent for their knowledge and skill, preside over the institution, and give regular courses of lectures and examinations; and the number of patients in the infirmary is generally 
such as to afford the students an opportunity of seeing a considcrable variety of practice, especially among horses, to which litherto the practice has been mainly confined. Besides this, through the liberality of the professors of the Medical College, the students at the Veterinary Institution have an opportunity of attending the medical and anatomical lectures gratuitously at these institutions; and, to guard, as far as possible, against ignorance and incompetency, no student can receive the diploma or recommendation of the institution to practise, until he has passed a regular and thorough examination, and has been found qualified for the duty.

This is a most excellent institution. In an economical view, it is highly important; for the amount of property in live stock is every where very great; and here, where, as in several establishments kept by a single individual, there are twenty and thirty, and sometimes forty horses for hunting, and in other cases as many more for racing, - and where, as in several cases within my knowledge, packs of dogs, of very great original cost, are kept at an expense of from fifteen hundred to two thousand pounds, or from seven thousand to ten thousand dollars, a year, and in many cases more than that, - it is easy to see what a large amount of property is at stake, and to what care it is entitled. I have been at one or two establishments where the horses in the stables, exclusive of horses for farm work, amounted to sixty or eighty. The large number of cavalry horses belonging to the army render the services of a veterinary surgeon, in such establishments, of indispensable importance.

Surgery, as an art, has been carried to great perfection; and in some circumstances hardly any thing more seems wanting than actually to breathe into some of the artificial anatomical preparations the Promethean fre, and sct the circulations in motion. Medicine, indeed, presents but few infallible remedies, but something has been done; and if comparatively little has been accomplished by physic, yet much has been done by a curative treatment and regimen. I am aware that it is quite customary to say of many novel, and certainly very gentle modes of treatment. of recent date, that the patients are cured by the imagination: and this is as agreeable a mode of cure as bloodletting, or powerful doses of calomel and jalap, or the exciting operation of Spanish flies. It is obvious, however, that, until we make 
much further progress in phrenological science, we can do littie by applications to the imaginations of horses or dogs. But, whatever imperfection attaches itself to medical science, something at least may be gained from it ; and it certainly presents the only practicable and probable means of learning the nature of disease, and combating its powrer. At any rate, medical science, and a thorough medical education, seem to aftord the only substantial security against the evils of empiricism or (quackery; and, to say nothing of experiments upon the human organism, I have myself seen, under the pretence of remedy or cure, such horrible cruelties practised upon dumb animals, as have filled me with indignation, and have made me indulge the inhuman wish of changing places with the operator - of putting lim in the position of his unhappy patient, and of being allowed to try some of his prescriptions upon himself. If they answered, well; but, in many cases, I think he would soon be past answering at all. The public have reason to congratulate themselves that medical practice is now every where assuming the character of prevention rather than of cure; and that the truly respectable part of the profession, dropping that profound air of mystery with which they formerly were accustomed to wrap themselves up, and which made one tremble in their presence almost as much as in the presence of the original professor of the black art. now prefer the more simple to the more artificial practice. They seem to be fast learning that Nature, like others of the sex, may be persuaded, but not forced; may be kindly led, but woe be to the man who attempts to drive her; and that, in truth, the great object of medicine is, not to give health, but to remove disease; to clean and adjust the machinery, and then it will go right of itself, barring accidents, as long as it is intended to go at all.

I have already spoken of the importance of the veterinary art in an economical view. A frightful disease has for some time prevailed among the cattle in England, Ireland, and the Continent. I met with one farmer who assured me that he had lost by it, in one season, ninety-seven cattle, and he feared his whole herd might perish with it, for he could find no remedy. Now: there is no hope of any remedy but from the investigations of medical skill and science. We want men, therefore, who by education are qualified for, and willing to devote themselves to, the 
inquiry into the causes and means of prevention of such direful calamities. The epidemic still prevails in England and on the Continent; and application has been made to the govermment to check the importation of foreign eattle, lest they should assist in the spread of the disease. Indeed, numbers of cattle are almost every week, as I have reason to believe, brought to Smithfield in such a state of disease as to be fit for no other purpose - and for this they are actually bought — but to make sausages for the poor Londoners. I hardly dare say that this is not to be complained of; but when one sees the extreme and indescribable misery and destitution of many of these poor wretches, apparently irremediable and hopeless, one almost hesitates, in sad desperation, to lament a mode of disposing of them after the Napoleon example of the treatment of his sick prisoners at Jaffa. I almost tremble while I write upon such a subject as this. It is indispensable to see, in order to believe. I have had the painful, I hope not improper, curiosity to penetrate many of these subterranean hiding-places and dens of misery; and it is my sober conviction that the human imagination cannot exaggerate the physical suffering, and, too commonly consequent upon that, the moral degradation in which many thousands, in this glorious and prosperous country, drag ont their wretched existence. But I advocate the establishment of veterinary institutions, and the cultivation of reterinary medicine, on the broad ground of humanity; and I hoje many such institutions will grow up in America, and that speedily. It is remarkable that, in the disease of one of our domestic animals, medical science has discovered the only effectual preventive for one of the most dreadful scourges which, in the form of disease. ever afflicted mankind. I refer, of course, to vaccination.

But these animals have bones to ache, and nerves to feel, as well as ourselves. They furnish our support ; they perform ou labors; they promote our pleasures; they are patient, enduring. and indefatigable, in our service. Has not God cast them upon our care, and put them under our protection? What a responsibility! Shall it be said that those who have no voice to speak for themselves, shall find no one to speak for them? What if they have no moral nature? Then they have not the vices of animals of a superior class, who, dishonoring, perverting, and outraging, that moral matr.re, degrade themselves fir below the 
class of beings guided only by instinctive impulses. It is said of the great emperor, that his heart was never more touched, if heart indeed he had, than on a certain occasion, when, three days after a sanguinary battle, when human victims were immolated to his dreadful ambition by thousands, riding over a field thickly strewed with the dying and the dead, he found a faithful dog lying by the side and licking the bleeding wounds of his dying master. The noble dog of St. Bernard, dragging the perishing traveller from the snow-drift to the hospitable convent, for warmth and comfort, and the poor spaniel dying with slow starvation upon the grave of his master, and refusing to be led away or to be comforted, are pictures of heroism and fidelity worthy of a place at the side of that of Regulus, deaf to the entreaties of his family, taking leave of the senate on his retum to fulfil his pledge, or that of the Grecian daughter nourishing her father in prison.

Humanity calls upon us to alleviate suffering, wherever suffering exists. I wish that veterinary instruction was connected with all our medical schools, and made an indispensable branch of study. We try all kinds of experiments upon these helpless animals for the benefit of science, and science should do something to repay the debt, by attempting, in every practicable form, to alleviate the sufferings of the race. In the country, a medical practitioner, who would add veterinary skill and practice to his other services, would confer immense benefits. It is lamentable that, by a false standard of moral duty, such an office should be thought degrading. In many cases, it might subject him to painful and thankless services; but the life of every benevolent physician is full of such services, and he has only to thank God that he has the power of doing so much good, often at so little cost. So far from such a practice being degrading, the physician who would be willing to render such services would be worthy of double honor; for the more humble, the meaner, the more friendless the sufferer, proportionately is the glory of the kinduess enhanced. There is no reason, however, why such services should be gratuitous, and in many situations it would form a profitable branch of practice. 


\section{XLI. - MUSEUM OF ECONOMIC GEOLOGY.}

This is a most valuable establishment, in the centre of London. Its whole object is utility, and principally in rendering geological discoreries subservient to the promotion of the useful and ornamental arts. It is a most singular, but a well-established fact, that the mineral treasures dug from the mines, in the islands of Great Britain, amount to the enomous sum of twenty million pounds sterling per year, or one hundred million of dollars, - of which eight million pounds, or forty million of dollars, are of iron, and nine million pounds, or forty-five million of dollars, of coal. It is easy to see what a vast interest is at stake in these matters. In another form, I hope to be able to give some account of a visit which I made to one of these immense excarations, where I descended, by a ladder, seven hundred feet, and then groped my way through rarious creviees, and chambers, and shafts, a distance of perhaps two miles under ground. I am disposed to think it would be misplaced in an agricultural report, where $I$ am afraid my friends will already find too many things out of place. I can only, in this matter, throw myself upon the indulgence of my readers, and remind them of the variety of tastes and appetites which I am compelled to consult. If, in spite of all this, a bill of indictment should be brought against me for making my Reports too miscellaneous, I shall at once allow a plea of guilty to be recorded, and throw myself upon the mercy of the court. I am indeed, in this way, an old offender, and I cannot express the gratitude which I feel for the mercy I have so often experienced.

The Museum of Economic Geology, though not founded principally for the benefit of agricultural science, is yet made subsidiary to this object. The geological structure of any portion of the earth's surface seems intimately related to the nature of the soil which rests upon it; so that, from knowing the structure of the rocky substratum of a country, you can infer strongly its fertility or its infertility, or the adaptation of its soil to various crops. The general opinion is, that all soils are formed from the crumbling or detrition of rocks, mixed with some vegetable or organic matter. This is the receired theory, 
but it is not without its difficulties. I have no disposition to controvert it, for a man who battles with the stones is quite sure to have the worst of it. The original form of the earth is wrapped in impenetrable obscurity. Science is doing every thing she can to unfold the leaves of this wonderful book; but where they have been most successfully separated and expounded, they are found so scratched, and torn, and blurred all over, that the letters are with extreme difficulty made legible. We soon leam that it was a much earlier specimen of printing than has been generally supposed, and some of it in a language that is lost. It does not appear to me more certain that the rocks were first formed, and then portions of them reduced to such a fine state of comminution as to form soils, than that the earth was originally in a state of fine atoms, and then, by the operation of fire, and water, and pressure from within and without, amidst violent terrene convulsions, rocks were formed, and the various strata arranged. It would seem not improbable that, from the earliest period of the reduction of its temperature to a degree that vegetable life could exist upon it, vegetable lif ${ }^{*}$ appeared; and by successive convulsions this vegetable life itself became overwhelmed, and was transformed into those immense beds of fossil deposits which occupy so large a portion of the surface, or upper portion, of the globe. How afterwards such vast deposits of earth took place over these beds of vegetable remains, can be explained only by some immense and utterly inexplicable convulsion and disruption of portions of the earth. It is admitted that the character of the soil often bears a direct relation to the rocks which it overlays, and evidently a considerable portion of it is formed from the detritus of these subjacent rocks; but the vast amount of drift or diluvium scattered over the earth's surface, and often at immense distances from places where, upon the common theory, it is supposed to have been formed, shows that the geological indications above referred to are not infallible.

The Muscum of Economic Geology is intended to exhibit specimens of various soils from the different localities in the country, with illustrations, as far as they can be obtained, of their peculiar adaptation to agricultural purposes; and connected with the museum is a chemical laboratory for the analysis of soils which may have already been obtained, of which may be: 
brought by farmers or land-owners for that purpose. 'The museum is open to the gratuitous inspection of the public, and is clearly the germ of an institution of great magnitude and importance. The establishment is at present under the management of Mr. Richard Phillips, F. R. S., a man deservedly eminent for his skill in chemistry and natural science, to whose indefatigable kindness I should do great injustice to my own grateful feelings if I did not here record my deep sense of obligation.

\section{XLII. - CHEMICAL AGRICULTURAL ASSOCIATION IN SCOTLAND.}

The farmers in Scotland, certainly inferior to none in agricultural enterprise, intelligence, and skill, and demonstrating this by a husbandry most exact and productive, have associated themselves together for the encouragement of the application of chemistry to the improvement of agriculture. Proprietors of land pay a yearly subscription of one pound or upwards to the association, and tenants ten shillings. This sum entitles each of them to two analyses a year at a certain fixed low rate. All above that number are charged half more. The analyst is required to give only such analysis as will answer the desirer purpose. Agricultural societies, by a yearly payment of five pounds to the association, are entitled to one lecture from the agricultural professor; for ten pounds, to two lectures, and so on; and the travelling expenses of the lecturer are likewise to be paid by those who employ him.

The society, more than a year since, proceeded to appoint, at a liberal salary, Mr. F. IV. S. Johnston, an agricultural lecturer and chemist, to the office of chemist and lecturer to the association; and a chemical laboratory and depository are established and in full operation at Edinburgh. Mr. Johnston is well linown to the agricultural community by his valuable works on agricultural chemistry, some of which have been reprinted in the United States, and in both comtries have had a very extended circulation. The success of the association, it is reported, has been 
such as to satisfy the original subscribers of its utility. It has led, through the lectures of the professor, to the establishment of several agricultural periodicals, and has throughout Scotland infused new spirit into the veins of the agricultural body, and quickened its pulse. One of the most substantial benefits as yet resulting from it has been the analytical examination of nimety different specimens of guano imported into Scotland; and that to secure the farmers from impositions, which, in cases before this, have not been infrequent.

After the remarks which I have made in a former part of my Report, it certainly is only just that I should subjoin the analysis made at this place of two soils from Renfrewshire, with the results of the application prescribed for them.

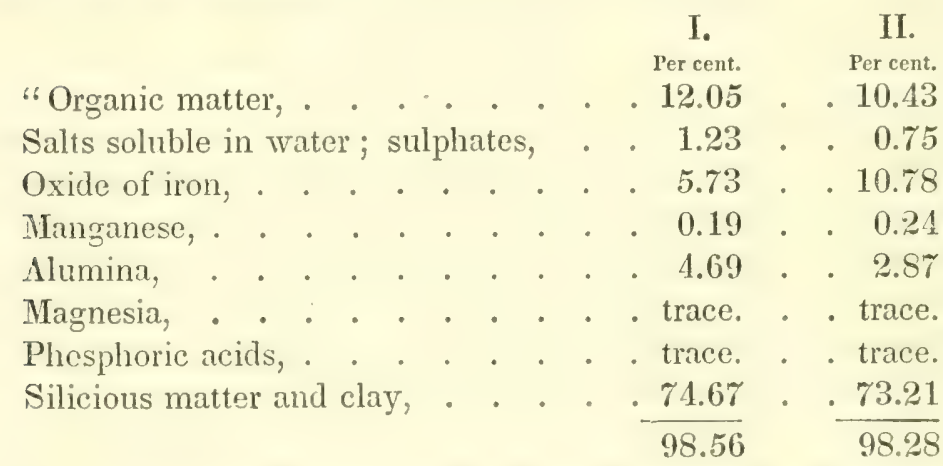

"But a mere trace of magnesia and phosphoric acid was found in either of these soils. It was therefore recommended to add to both of them the magnesia in the state of sulphate, and the phosphoric acid as bone-earth. The effect has been most wonderful and striking." - The letter with which I have been favored adds, "None of the analyses I have given are very claborate, but they are sufficiently so for practical purposes, and they do not confuse or mystify the farmer with hard names."

I had the pleasure of visiting this institution, and there was certainly no want of the indications of industry. I have only to regret that my friend's account of his two patients above is so short and imperfect. I should be glad to have been able to inform my readers what was the exact condition of the patients before taking the preseription, and their particular state of health after it. 
XliI. - CHEMTCAL AGRICUL'TURAL LEC'TURES.

During the last winter, a course of ten lectures, illustrated by numerons experiments, was given by Professor Brande, F. R. S., well known in the scientific world, on the chemistry of agriculture, at the rooms of the Royal Institution, - which, through his politeness, I had the pleasure of attending. They might be considered as almost wholly scientific, and were exceedingly interesting and instructive. Mr. Brande spoke of himself as having been a pupil or associate of the distinguished Sir IIumphry Davy, who lectured on the same subjects in this same institution, and who may be said to have taken the first step in the great movement, which is now so widely felt, of the application of science, properly so called, to agriculture.

Professor Brande's lectures were numerously attended, by ladies as well as gentlemen. Several of the ladies were always busy in taking notes of the lectures. I felt the highest respect for them on this account; and if I had been, as is said among the clergy, "a candidate for settlement," with my strong predilections for agricultural pursuits, I might have been tempted to inquire about some of them, whose high and capacious foreheads gave a noble indication of what was within, whether they also were in the transition state. Certainly here, as well as any where, I may claim for an American woman the honor of presenting from her own pen an excellent translation, from the French, of Chaptal's Agricultural Chemistry, to the American public. Her name is modestly withheld from the title-page, and therefore I have no right to give it.

I shall give below a syllabus of Professor Brande's lectures on these occasions, because I so strongly wish the example should be followed in my own country.

Ist. Lecture. Tre SoIL. - Its components; whence derived. -Inorganic Constituents of the Soil. Silica; alumina; lime; magnesia; oxide of iron; alkalies; phosphorus; sulphur; salts; water; decay of rocks; sand ; clay ; marl ; chalk ; other simple soils. - Organic Constituents. Humus or humic acid; their influences and uses. Absorptive power in regard to air, water, 
and gases. Radiating and receptive powers in respect to solar rays. Various physical conditions of the soil.

II. The Atmosphere. - Its composition; invariable and variable constituents. Influence of the moisture, carbonic acid, and ammonia, of the atmosphere.

III. The Vegetable. - Its Ultimate Constituents, and their sources; carbon; oxygen; hydrogen; nitrogen. The sources and importance of the so-called inorganic constituents of the vegetable; acids; alkalies; oxides; salts. - Proximate Constituents of the vegetable; sap; wood; starch; sugar; gum. Their metamorphoses; gluten; albumen; fibrine; caseine; legumine; proteine; resins; oils; acids; alkalies; fermentation; eremacausis; putrefaction.

IV. Functions and Growth of Vegetables. - Germination; general organization of vegetables; roots; trunk; branches; leaves; flowers; buds; functions of the roots and of the leaves.

V. Principles of the Improvenentr of Solis. - Mechanical, as influencing texture; chemical, as influencing composition manures, of inorganic, organic, and mixed origin. Draining; ploughing; burning; irrigation; green crops; interchange of crops; fallows.

I make no apology for giving to my readers this instructive syllabus in full. It is said of Queen Elizabeth that, being asked by one of her maids of honor for a book to read, she gave her an English dictionary. The lady presently returned it to her majesty with many thanks, and stated "that she had been much interested in the perusal." There was more wisdom in this reply than at first appears. 'To say nothing of its convenience, yet I have often found a copious index, or a well-digested table of contents, an interesting and instructive portion of a book.

\section{XLIV. - EMPLOYMENT OF AGRICULTURISTS.}

In the technical sense of the term, agriculturist means a teacher of agriculture. Under the excellent management of 
William Blacker, Esq., on the estate of Lord Gosford, in the county of Armagh, Ireland, an experienced and intelligent man, well skilled in communicating his ideas, is employed to visit the tenants on the property, to advise them in regard to the management and cultiration of their small farms, and to encourage then by some small premiums, and by reporting their condition and success to the principal manager. The occupations in these cases are very small, often not exceeding three, four, and six acres. As I understood Mr. Blacker, he has the care of twentyfive hundred tenants on the property of this nobleman. This number, I confess, seems very extraordinary; but the subdivisions on the place are quite small and numerous. I shall, on another occasion, give a particular account of Mr. Blacker's excellent managenent of small farms, becanse it is full of useful instruction, and does the highest honor to his judgment, perseverance, and benevolence. At present, I speak only of the cmployment of an agriculturist, which has been attended with the best effects. This person lives on the estate, and has a small amount of land in the neighborhood of his own house, which he is expected to keep in the best possible order, according to the system which he lays down for others, - so that he is called upon to teach by example as well as precept.

The same arrangement has been made, at the suggestion of Mr. Blacker, on the farm of Lady Bassett, near Camborne, in Cornwall, which $I$ had the pleasure to visit. Here, too, it works wvell. The farmers in Cornwall hold larger farms than in Armagh, and therefore have a higher idea of their own importance. They were at first very jealous of the direct approaches of the agriculturist to advise and instruct them. But by a little address, and by especially avoiding any thing like dogmatism or self-conceit, and by a frank mamer convincing the farmers that he was disinterestedly seeking their good, his success is becoming remarkable, and he is every day gaining upon their 'esteem and confidence. A horse, loose in a pasture, can rarely be caught if you approach him swinging the bridle, the emblem of his subjugation, before his eyes; but if you go to him shaking only the measure of oats before him, and concealing the bridle under your coat, you can generally take him without difficulty. I am no advocate for treachery under any form; but where the object aimed at is unexceptionable and excellent, I see no occa- 
sion for unnecessarily alarming the prejudices of those whom we wish to serve, or for awakening resistance by command, when we can easily enforce acquiescence by persuasion.

That the plan is sure to work well where the elass of tenants, as in Armagh, are very small tenants, and ignorant withal, is quite plain; but farmers on a large scale would be likely to reject any direct interference. Yet these men often need instruction. The knowledge of improvements, in some cases, extends itself by slow degrees; oral instruction, coupled with familiar illustrations, is always more interesting than books; and the employment of an agricultural missionary, of unobtrusive and kind manners, and perfectly competent to impart instruction, to visit a district of country, that he might point out errors and defects of cultivation, and explain the best modes of husbandry adapted to the climate and locality, would prove a most powerful means of awakening attention to the subject, of reforming errors, and introducing desirable and suhstantial improvements.

\section{XLV. - GUANO.}

Having now completed what I designed to say upon the provision for agricultural education in Great Britain, I shall beg the indulgence of my readers in reverting to a topic of a different character, and which, in a more methodical arrangement, wonld? have had a place in a different part of my work. $\Lambda$ strong and impatient desire has been expressed that I should give what information I possess on the subject of the recently-introduced and most extraordinary manure called guano; and I therefore speak of it in this place.

I do not deem it necessary to go into the history of a substance which has been made so familiar by the public discussions which have taken place in relation to it. That it is an animal deposit, is well established. It is the excrement of seabirds accustomed to frequent certain islands in the Pacific Ocean and other places in the tropical latitudes. Its use as a manure is not new in those comtries where it has been found. In Peru, 
the birds who caused the deposit were protected by severe laws, and the value of the manure was fully understood. 'The amount of the accumulations, considering the nature of the deposit, is immense, being represented, by travellers, as from three to seven hundred feet in depth. The number of birds is stated to be almost beyond calculation; and any person who will take the trouble to read, in that delightful book, Wilson's Ornithology, the accounts of the roosting-places of the passenger-pigeon in some of the Western States of America, will readily confide in well-authenticated accounts of the number of these birds, which would otherwise be deemed egregious exaggerations. To the gentlemen in England who are fond of what is termed a battue, a voyage to the Pacific to shoot the guano birds would afford excellent sport; and if in such case they would bring back loads of this valuable manure, it might not prove an unprofitable enterprise, and they would perform a double work of conciliation to the farmers. Their accounts of one or two days' shooting, or knocking down the birds with the butt-ends of their guns, would be read here with the greatest avidity, and eclipse all their former exploits of killing hundreds of game in a single day where the beaters were employed to drive them directly under the muzzles of their guns, and where occasionally they are obliged to knock down a poacher instead of a penguin.

These deposits are made in a climate where, for a considerable part of the year, little rain falls, and where the intense heat of the sun forms such a crust over the deposit, that it becomes almost insoluble. Supposing a deposit to be made of two inches a year, for three thousand years, this would give a depth of five hundred feet; and therefore the report of the depth of these deposits, though surprising, is by no means intrinsically ineredible. The extraordinary efiect of this manure is another remarkable circumstance. 'The dung of the domestic pigeon or fowl is among the strongest used, but it is not so powerful as guano. In the excrements of birds, the solid and liquid portions are combined. 'l'his is one secret of their strength. In the case of the guano birds, their food is wholly fish, and not, as with our domestie birds, mainly farinaceous; and therefore it abounds in nitrogen, and in bony substances, or phosphates.

The secret of the extraordinary success of this manure is not yet solved, however nearly a solution may have been approx- 
inated. This is evident from the fact that, after the most exact and minute analysis of this manure, conducted with all the skill and science which can be brought to bear upon it, no one has been able to form an artificial guano with any degree of its efficacy. Chemistry determines with wonderful accuracy its inorganic properties; but fifty per cent. of it is organic matter, and this being dissipated or lost in the process of analysis, nothing is known of it but its absolute quantity. Every common farmer knows that horse manure, cow manure, hog manure, sheep manure, are all specifically different, and their effects and uses are different; and I believe this depends not more upon a difference in their inorganic elements, than upon some specific effects of their organic elements; and though horses, and cows, and sheep, should be fed upon precisely the same food, their excrementitious matter would be specifically different, and the effects upon vegetation different. I pretend not to say in what this difference consists; this, chemistry has not yet reached, though I can but hope the goal will presently be attained. I am not therefore entirely satisfied with any account which chemistry has given of guano, so far as its operation is concerned. It has done much, and is clearly able to determine the different snecific values of difierent samples. This is of great importance to the farmer, and not less so to the honest dealer. But the specific qualities of this extraordinary manure, as proved by its effects, are, I presume to believe, with all possible respect for science, yet to be discovered. I know the consequences of questioning the infallibility of the pope, but I am no Catholic.

One, indeed, may well speak of its effects as extraordinary, from what I myself have seen. In Scotland, last autumn, two shrubs were shown to me, sweet-briers, growing in front of a two-story house, and trained upon its sides; one at one, the other at the other end. The soil in which they grew, the aspect, and other circumstances, were the same. One, in the season, had grown six or seven feet; the other, nearly thirty feet! It had actually climbed to the roof of the house, and turned and hung down, reaching half the distance down from the roof to the ground. I judged this could not have been less than thirty feet. 'This had been repeatedly watered with liquid guano, by the hands of its fair cultivator; for this was another experiment by a lady, (which I hope my American friends will 
bear in mind.) 'The other had received no special care or manuring. This charming woman, surrounded by her lovely children, was equally engaged in teaching the young idea as the sweet-brier how to shoot, and they too showed the beantiful results of devoted and assiduous culture.

I have seen the extraordinary effects of the application of guano all over the country, and I have met with very few instances of disappointment. I have been favored with a great many reports of its application; but my readers will, I think, be better satisfied with general results than with a long list of particular examples.

When I speak of its extraordinary effects, I yet do not consider them as so surprising as the effects of gypsum in many parts of the United States, whose operation, I venture to say, remains wholly unexplained. I do not, of course, mean to imply that one can be substituted for the other. The effects of half a bushel of finely-powdered gypsum, scattered over an acre of land, in some places, in increasing the crop of grass, and in respect to some other crops, is amazing; yet in all England, I have not been able to find a single well-attested example of its being applied with any benefit whatever. The applisation of guano has been made, in England and Scotland, to all kinds of plants, and in some instances with great success; indeed with rarely a failure.

It has been used for tumips, barley, wheat, oats, grass, gardeni vegetables, onions, asparagus, potatoes, flowers, and trees. I have seen its application in all these cases, excepting asparagus and trees; but the testimony which certifies its success in these cases is unquestionable. Comparisons made between gumo and other manures, are not quite satisfactory in respect to quantities, becanse it is obviously very difficult to institute any instructive comparison between so many pounds of guano, and so many loads of manure; manure is so various in its nature, quality, bulk, \&c.; but it will be quite easy to compare the two in respect to the ease or difficulty of their transportation, and of their application to the plant or soil. Comparisons, likewise, in respect to the cost of different applications, as made here, would be of little use in the United States, as prices of manure and of labor are totally different; and the one can afford no rule for the 
other. In this matter, the farmers of the United States must judge for themselves.

The quantity which it is deemed best to apply varies from two hundred weight to four hundred weight, or five hundred weight. Frequent cases have occurred of the application of five hundred weight and eight hundred weight, to a statute acre, with great advantage. Cases are on record of twenty-nine and thirty hundred weight being applied to grass-land with a great, but not, most certainly, a remunerating increase of crop. I met one farmer in Lincolnshire, who thought more than one hundred weight applied to tumips was umecessary; but the almost universal testimony is in favor of three hundred weight. A bushel of sifted guano weighs from fifty-two to fifty-four pounds.

In regard to the mode of application, it is well settled that it should seldom be applied alone. To garden vegetables, or greenhonse plants, it may be applied in a state of solution in water. In field cultivation, it may be applied by being mixed with four or six times its quantity of dry earth or mould. In this way, it may be sown broadcast over the field, and then lightly harrowed or turned in; or it may be sown first in the same drill where the seed is to be dropped; great care must be taken, however, that it does not come in contact with the seed, or it will destroy its vegetative powers. It is desirable that it should be covered as soon as may be after being sown. The best farmers give a caution against mixing it with lime, or bones, or wood-ashes, as these substances, coming in contact with it, will drive off its ammonia.

Where a portion of barn manure has been applied in conjunction with guano, the mixture has been found much more efficacious than the manure when applied alone. In an application which I saw, guano gave seven tons of turnips increase to an acre over an artificial manure which had been much praised, and was applied at the same time.

A good mode of preparing it for application is to mix it with fine earth, on the headlands of the field where it is to be used, forming it, with the earth, into alternate layers, in the proportion of earth to the guano of three to one; and after it has remained two or three days, thoroughly incorporating them together by turning over the heap. 
With potatoes, it should be placed in the drill or hole, but not in contact with the set or seed; and for Indian corn - a case in which I have had no experience - it would seem advisable to adopt a similar method.

The experiments of Mr. John Dudgeon have been given to the public at large. As I had the pleasure of visiting his farm, one of the best-managed in the kingdom, and saw some of the experiments going on, I feel at liberty to give them, and it may be interesting to my readers to have them in his own words.

"The following results, communicated by John Dudgeon, Esq., of Spylaw, to the Highland and Agricultural Society: in April, 1S43, show, first, the relative produce of turnips from guano applied at the rate of three hundred weight, four hundred weight, and five hundred weight, per acre, in competition with the produce from the farm-yard manure, applied at the rate of eighteen yards per acre; secondly, the trial of bone-dust with coal-ashes against guano alone, and guano mixed with a portion of sulphate of soda; thirdly, the trial of guano alone against bone-dust alone.

"The first experiment was in a field lying upon a slope, with a southern exposure, the soil consisting of a good loam upon a retentive sub-soil ; the upper part of the field, for about a fourth of its length, gradually becoming shallower in soil, and resting upon a hard muirland pan, so that the value of the lower portion of the field, as compared with the upper, may be estimated as three to one. This field has been but imperfectly drained. It was dunged in the usual way, immediately before sowing, with well-prepared farm-yard manure, at the rate of about eighteen cubic yards to the acre, with the exception of that portion to which guano was applied. Two ordinary drills for the latter were selected at random, and the guano distributed in them by the hand, without any mixture, at the rate of three: hundred weight per acre. Leaving an interval of three drills. which were manured like the rest of the field, two other drills were treated with guano, at the rate of four hundred weight per acre; and finally, with a similar snace intervening, two drills with guano at the rate of fully more than five hundred weight per acre. No difierence appeared in the turnips (which were the variety named Dale's hybrid) previous to singling or thinning the plants with the hoe; after that, however, the superiority of 
the drills with the guano became manifest, and continued to increase with the growth of the turnips, particularly in those drills which received the greatest quantity, till the whole were carted off in October, when the produce (topped and rooted) of the whole six drills were weighed, each two as differing in the quantity of guano applied, compared with two drills immediately adjoining, on which the farm-yard manure had been used. The following was the result :-

Kinds of Manurc.

Quantitics applied. $\quad$ Produce per Acre.

Two drills with Guano, . . 5 cwt. per acre, . . 25 cwt. 5 st.

" " " dung, .. 18 yds. " " . 18 " 7 "

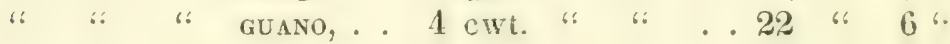

" " " dung, . . 18 yds. " " " 419 " 476

" " " Guivo, . $3 \mathrm{cwt}$ " " $"$ " . 20 " 6 "

"6 " d dung, . . 18 yds. " " . . 19 " 2 " 2

"In the second experiment, a comparative trial was made between guano and bone-dust mixed with coal-ashes. The ashes were sifted, and intimately mixed with the bones, some days before being applied, in the proportion of sixteen bushels of bones and eight of ashes, per acre. The quantity of guano applied was at the rate of three hundred weight per acre upon four drills, two and two together, at an interval of eight drills manured with bones and ashes. Then, at a similar interval, followed two drills, operated upon with guano together with sulphate of soda, (Glauber salts,) at the rate of four hundred weight per acre - being the only instance, in the course of these experiments, in which any foreign substance was used with the gruano. The turnips were drawn about the end of November; and on a comparison of the weight of the crop on two of the four drills done with guano alone, with the produce of the average of four drills, nearly immediately adjoining, manured with bone-dust and ashes, the result stood thus (the plants being topped and rooted) :-

Manures.

Produce per Acre.

Guano, alone, .......... 23 cwt. 2 st.

Guano and sulphate of soda, ....23 " 0 "

Bone-dust, . . . . . . . . . 19 " 2 " 
" In the third experiment, guano was used against bone-dust alone, applied, as is usual in that district, at the rate of sixteen bushels per acre. The guano was used at the rate of two hundred weight only per acre. The drills manured with the latter showed a very early superiority, and were ready for the hoe fully eight days earlier than the rest of the field. This more vigorous growth they maintained throughout; and when the turnips (the white stone globe variety) were weighed, on the 22d March, after standing throughout the winter, the result was as follows (the roots and tops being in this instance retained):" "Two drills guano, ....... 31 civt. 4 st. Two " bone-dust, .....2.24 cwt. 7 st." "

"The following table, extracted from the Scotsman, is the result of an experiment on a field which had, till the present crop, been in grass from time immemorial. The soil was a dry, friable loam. The turnips were sown on the 20th of May, and lifted and weighed on the 27th of November, 1843.

\begin{tabular}{|c|c|c|c|c|c|}
\hline $\begin{array}{l}\text { Kinds and Quantities of } \\
\text { Ifanurcs used per Acre. }\end{array}$ & $\left|\begin{array}{c}\text { Price of } \\
\text { Manurc } \\
\text { per } \\
\text { Acre. }\end{array}\right|$ & $\mid \begin{array}{c}\text { Weight of } \\
\text { Turnips without } \\
\text { Roots or Tops. }\end{array}$ & $\begin{array}{l}\text { Weight of } \\
\text { Roots and } \\
\text { Tops. }\end{array}$ & $\begin{array}{l}\text { Wcight of } \\
\text { rotten } \\
\text { Turnips. }\end{array}$ & $\begin{array}{l}\text { Weight of } \\
\text { total Produce } \\
\text { per Acre. }\end{array}$ \\
\hline & $\mathscr{E}$ s. & T. C. lb. & T. C. lb. & T. C. lb. & T. C. lb. \\
\hline 0,5 cwts..... & 215 & $\begin{array}{lll}29 & 17 & 13\end{array}$ & $612 \frac{1}{2} 11$ & $\begin{array}{lll}1 & 13 & 17\end{array}$ & $\begin{array}{lll}38 & 23 & 13\end{array}$ \\
\hline dung, 12 carts,. . & 312 & 2578 & $615^{2} 6$ & $\begin{array}{lll}2 & 12 & 13\end{array}$ & $3414^{27}$ \\
\hline Bones, 26.5 bushels, .. & 33 & $25 \quad 12 \frac{1}{2} \quad 12$ & $\begin{array}{lll}5 & 13 & 14\end{array}$ & $\begin{array}{lll}0 & 14 & 22\end{array}$ & $31 \quad 8 \frac{1}{2} 20$ \\
\hline Rape-dust, $12 \mathrm{cwts}$. & 30 & $2219 \frac{1}{3} 22$ & $\begin{array}{lll}5 & 9 & 0\end{array}$ & $\begin{array}{lll}2 & 81 & 6\end{array}$ & $3017 \frac{8}{4} \quad 0 . "$ \\
\hline
\end{tabular}

Guano has been applied to winter wheat, both in drills and broadcast, and with signal success. It has been applied, likewise, with great success, to grass and pasture land, as the following statement will show:-

"On an eight-acre field, sown with three hundred weight of guano, and three bushels of Italian rye-grass per acre, on the 29th of April, cut on the 3d of August, the produce weighed, when cut, eighteen tons, and when dry and ready for stack, four tons, per acre. Much of this crop was upwards of five feet long. So rapid was the growth, that, fifty hours after cutting, it had again sprung up to the height of three and one eighth inches. With such grass, and such manure, so easily convertible into liquid, I see no reason to doubt that the cottager, with his five roods of land, could supply his house with vegetables, and cow with winter and summer food, thereby providing for his family an almost entire subsistence." 
It las been questioned whether its effects will be permanent. I can only answer, that I have seen its obviously beneficial effects three years after its application upon grass. How much longer its efficacy may be expected to continue, experience only can determine.

Several kinds of guano have been brought into Great Britain; but the great distinction is between that from the Island of Ichaboe, on the coast of Africa, and that from the islands in the Pacific. The former seems entirely deficient in uric acid, and consequently lacks what is deemed a valuable element in vegetation. The comparative value of the two in public estimation, and in the opinion of a distinguished chemist, is supposed to be as four to five. The supply from Ichaboe is said to be exhausted, the enormous quantity of five to six hundred thousand tons having been taken, as is stated, from that single island.

I should do wrong to say that guano is always successful. 'There were many complaints this year of its failure, attributed to the excessive droughts which prevailed at the beginning of the season. A farmer likewise, in Cambridgeshire, communicates to the Royal Agricultural Society, in their last journal, his failure in two successive applications of it to crops of barley. In neither instance does any advantage appear to have been gained. IIe attributes this to something in the nature or character of the soil ; but this, without further trials, must be set down as wholly conjectural.

It is quite proper, likewise, that I should urge upon the farmers of the United States, that, however auspicious and brilliant may be the promises which guano holds out to them, they must not overlook the resources for enriching their own lands within their own reach. 'The following statement will strengthen this advice.

Philip Pusey, Esq., M. P., than whom, I believe, wherever his character for intelligent, accurate, and philosophical observation is known, it will be universally admitted, there is no higher agricultural authority in England, informed me that, the last season, he carted to the headlands of one of his fields a quantity of loam, mixed with coal-ashes and rubbish, and, having formed it into a bed, heaped upon it a quantity of barn manure, from the drippings of which the loam, \&c., became completely saturated. Upon the application of this to the land for a crop of 
turnips, by the side of the same crop manured with three hundred weight of guano, the advantage was very greatly in favor of the former.

Mr. James Smith, of Deanston, states that a friend of his manured three acres; the first with fifteen tons of stable-dung, cost $£ 4$; the second acre with three hundred weight of guano, cost $£ 1,6$ s. ; the third acre with eight tons of liquid manure, cost 2 s. 6 d. ; and the crop on the last was far the best. Dr. Playfair was kind enough to communicate to me this statement.

In an admirable lecture, delivered by the last-named active and intelligent friend of an improved agriculture, at the meeting of the Royal Agricultural Society, that gentleman saw fit to state that one pound of urine contained materials for producing one pound of wheat; and that the effete matter which runs into the Thames, annually, from the city of London, amounts to

$$
1,095,000,000 \text { pounds in one year, }
$$

and contains nitrogen sufficient to produce

$$
\begin{aligned}
& 1,600,000,000 \text { pounds of wheat, } \\
& 1,800,000,000 \text { pounds of barley ; }
\end{aligned}
$$

and, calculating this waste at a moderaie value, for agricultural purposes, London suffers a loss of $£ 1,000,000$ sterling, or $5,000,000$ dollars per year.

These curious statistics will, I know, give no offence to any sensible person; and they may suggest considerations of the very highest moment to the rising cities of the United States, where the sanatary and economical arrangements are not completed, and in many cases not begum. They especially enforce upon every individual farmer the duty of examining and husbanding, with a miserly frugality, all the resources of his own farm, even the most inconsiderable and humble. They have, I may be allowed to say, a far higher use by leading the reflecting and serious mind to admire and adore the never-ending cireles of the divine beneficence; the mixed and wonderful compensations and mutual subserviences which pervade the whole system of nature; and, above all, that constant miracle of miracles, going on contimually in the vegetable world, by which the most worthless and the most offensive substances are returned again to bless the animal creation, in those substantial products by which life is sustained, and comfort every where diffused, in fruits most delicious to the senses, and in plants, and flowers, which, in 
their variety, and beauty, and wonderful glory and splendor, infinitely surpass the highest triumphs of human art and luxury.

I think proper here to subjoin several analyses of guano with which I have been favored by a most accurate chemist, Mr. E. F. Teschemacher, to whose unremitted kindness, in various forms, I am most deeply obliged. Indeed, when I think of the debts which I have incurred, in this way, and which have been forced upon me, on this side of the water, I fear nothing is left for me but to take advantage of the act of general bankruptcy, with the mortification of feeling, from the number of my creditors, how very small a dividend can be made.

\section{"Dear Sir :}

"I have taken the first moment I had to spare, to fulfil my promise of giving you some details relative to guanoes - especially the analyses of the various kinds imported within the last eighteen months into this country, which have come under my cognizance. The analyses were performed by me during the course of my business, and are so arranged that a comparison may be easily made between them. Upon comparing these analyses with those of other analysts, I find them generally to agree in all their essential characters.

\section{"No. 1. Peruvian.}

" 100 parts consist of 9 parts of ammonia, combined with phosphoric, carbonic, uric, and organic acids, forming, of

Armmoniacal salts, . . 40

Animal organic matter, . $6 \frac{1}{2}$

Sulphate and muriate of potash and soda, . . 111

Phosphate of lime and magnesia, . . . 2 $29 \frac{1}{2}$ Sand, . . . . . 1 Water, . . . . $11 \frac{1}{2}$ $\overline{100}$

"The Peruvian contains $11 \frac{1}{2}$ parts of uric acid.

\section{"No.2. Bolivian.}

" 100 parts contain $10 \frac{1}{2}$ parts ammonia, combined as in No. 1, forming, of Ammoniacal salts, . . 36 Animal organic matter, . 5 Sulphate and muriate of potash and soda,. . . 15

Phosphate of lime and magnesia, . . . 2 $27 \frac{9}{4}$ Sand, . . . . . $1 \frac{1}{2}$ Water, . . . . . 14 100

"The Bolivian contains 3 per cent. of uric acid. 
"The uric acid is considered to furnish the crops with additional ammonia, which, after application, is given out by degrees.

"No. 3. Chilian.

" 100 parts containing 3 parts ammonia, combined with phosphoric, oxalic, carbonic, humic, and organic acids, forming, of

Ammoniacal salts, . . . $12 \frac{1}{2}$

Animal organic matter, - $2 \frac{1}{2}$

Sulphate and muriate of potash and soda, . . $7 \frac{1}{2}$

Phosphate of lime and mag-

nesia, and oxalate lime, . 53

Sand, . . . . . 2

Water, . . . . $22 \frac{1}{2}$

100

"This guano contains no uric acid.

\section{"No. 4. Ichaboe Guano.}

" 100 parts containing $7 \frac{1}{2}$ parts ammonia, combined with phosphoric, oxalic, carbonic, and humic acids, forming, of

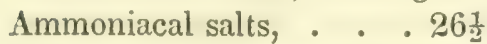
Animal organic matter, . $7 \frac{1}{2}$ Sulphate and muriate of potash, and phosphate potash, . . . . . . 10

Phosphate lime, and magnesia, and oxalate lime, 30 Sand, . . . . . 1 Water, . . . . . 25

"Contains no uric acid.
"No. 5. Angra de Pequena.

" 100 parts contain 5 parts ammonia, combined as in No. 4, forming, of

Ammoniacal salts, . . 20

Animal organic matter, . 5

Sulphate and muriate of potash, and phosphate potash, . . . . . . 11

Phosphate of lime and magnesia, and oxalate lime, . 32 Sand, . . . . . 2 Water, . . . . 30

"No uric acid. $\overline{100}$

"No. 6. Possession Island. "Very like that from Angra de Pequena, but very lumpy. "No uric acid.

\section{"No.7. Pedestal Point.}

" 100 parts contain $4 \frac{1}{2}$ parts ammonia, combined as in No. 4 , forming, of

Ammoniacal salts, . . 14

Animal organic matter, . 6

Sulphate and muriate of potash, and phosphate potash, . . . . . $6 \frac{1}{2}$

Phosphate of lime and magnesia, and oxalate lime, 37 Sand, . . . . . 7 Water, . . . . $\frac{.29 \frac{1}{2}}{100}$ "No uric acid. 


\section{"No. 8. Bird Islands; Algoa Bay.}

" 100 parts contain $2 \frac{1}{2}$ parts ammonia, combined as in No. 4, forming, of

Ammoniacal salts, . . . . . . . . . . . $10 \frac{1}{2}$

Animal organic matter, . . . . . . . . . $8 \frac{1}{2}$

Sulphate and muriate of potash, . . . . . . . $2 \frac{1}{2}$

Phosphate of lime and magnesia, (no oxalate lime,) . . . 62

Sand, . . . . . . . . . . . . . . . . $1 \frac{1}{2}$

Water, . . . . . . . . . . . . . $\frac{15}{100}$

"No. 8 contains no uric acid.

"No. 1 to 3 are South American guanoes.

"No. 4 to 8 are African guanoes.

"I have examined guano from other localities, but as I do not know those localities, I have omitted them in the list.

\section{"Guano 'T'esting.}

"1. A small portion, about 100 grains, mixed and rubbed with 10 parts of chalk to 1 part of quick-lime, should give out a strong smell of ammonia; and on holding over the mixture a glass rod moistened with muriatic acid, a dense white vapor should be given off. If this effect does not take place, the guano will contain very little ammoniacal salts.

"2. 100 grains guano, heated to redness in a Hessian crucible, should leave a white ash. This white ash should be nearly soluble in dilute muriatic acid. The residue shonld not exceed 10 grains; in good guano, the residue would be only 1 or 2 grains.

"The quantity of white ash will vary from 30 to 60 per cent., according to the nature of the guano.

\section{"Yours truly,}

"E. F. Teschamacher.

"No. 2 Park Terrace, Higniury, 24 January, 1845." 
I add to these some analyses forwarded to me from the Edinburgh Agricultural Chemical Association, by my esteemed friend, Mr. John P. Norton.

\section{"Two Guanoes from Ichaboe.}

No. I. No. II.

Water, . . . . . . . . 20.46 . 1800

Organic matter and ammoniacal salts, .44.96 . 52.60

Sulphate of soda and potash, with common salt, . . . . . . $\}$

$4.49 \cdot 4.89$

Phosphates of lime and magnesia, . . 27.31 . 19.22

Carbonate of lime, . . . . . . 0.07 ?

Silicious matter, . . . . . . . . . 2.15$\} \cdot 4.83$

3 per cent. free ammonia in No. I. . $\overline{99.44} \cdot \overline{99.54}$

"These are fair samples of the Ichaboe guanoes. Their only defect is too much water.

\section{"Two South American Guanoes.}

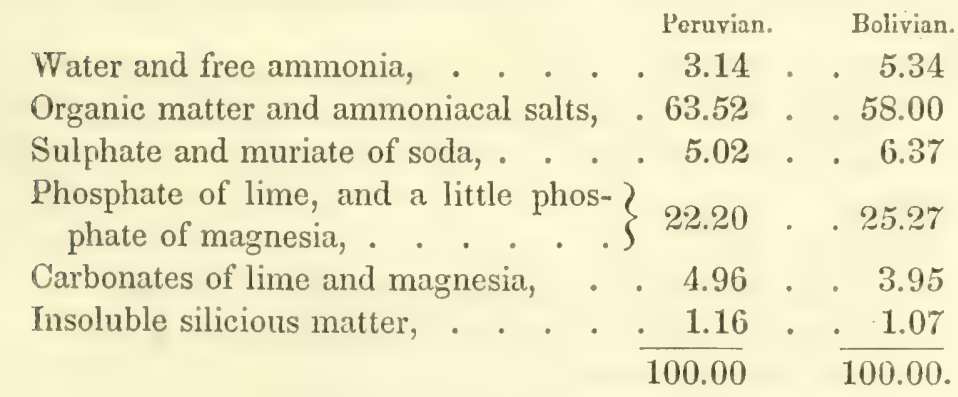

"These are both most excellent guanoes. The small proportion of water is remarkable, and the large quantity of organic matter and ammoniacal salts. This first, and then the phosphates, are the criteria of value. Carbonate of lime, sulphate and muriate of soda, \&c., are valuable manures, but may be bought lower than $£ 6$ or $£ 8$ per ton. 


\section{"Artificial Guano, (Potter's.)}

Water, . . . . . . . . . . 14.55

Organic matter, . . . . . . . . . . 17.32

Salts soluble in water, consisting of common salt and gypsum, with a small quantity of potash and ammoniacal salts, . . . . . . . . . . . . 40.43

Phosphate and carbonate of lime, . . . . . . 11.61

Coarse sand, with bits of gypsum, . . . . . . $\frac{.16 .06}{99.97}$

"This, therefore, contains 30 per cent. of water and sand. One by the same maker, previously examined, had about 30 per cent. of sand alone."

The following is from a chemist of the highest scientific character, Dr. Ure:-

"Reserving, for the present, the more particular analyses, the following may be offered as the average result of those I have made of genuine guano, in reference to its agricultural value :-

"Azotized organic matter, including urate of ammonia, and capable of affording from 8 to 17 per cent. of ammonia by slow decomposition in the soil, . . 50.0

Water, . . . . . . . . . . . 11.0

Phosphate of lime, . . . . . . . . . . 25.0

Ammonia, phosphate of magnesia, phosphate of ammonia, and oxalate of ammonia, containing from 4 to 9 per cent. of ammonia, . . . . . . . . 13.0

Silicious matter from the crops of the birds, . . . 1.0 



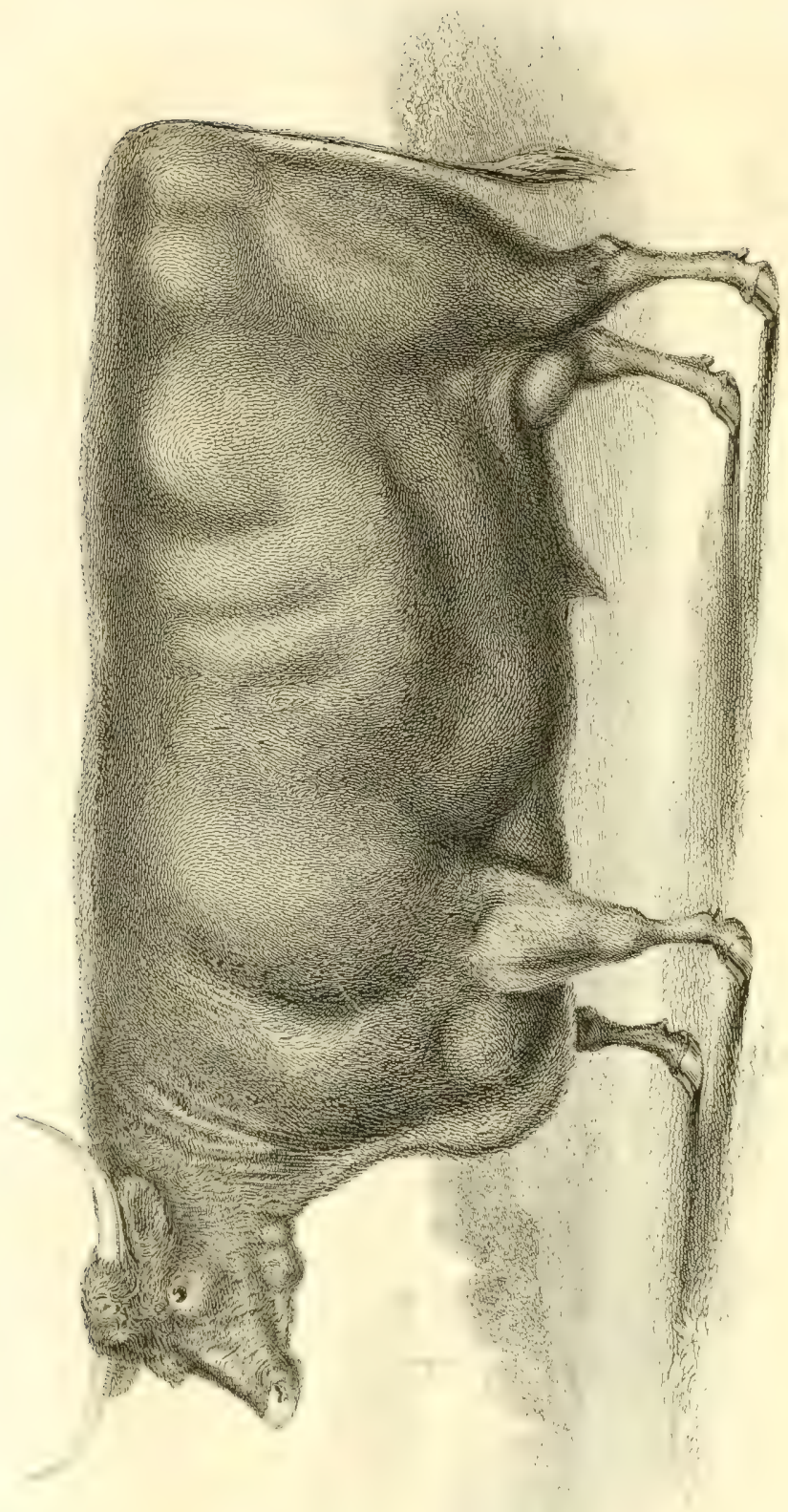




\section{EUROPEAN AGRICULTURE.}

\section{FOURTH REPORT.}

\section{XLVI. - GENERAL CONSIDERATIONS.}

Tue great incentive to all agricultural improvement is profit. The man who is satisfied with a bare subsistence will do little towards making his condition better. It is one of the prominent blessings of civilization, that it multiplies human wants and desires to such a degree as to call out all the powers of the body and mind to supply them. In proportion as civilization is advanced, human wants increase. From necessities we proceed to indulgences, from indulgenees to luxuries; until what were at first indulgenees and luxuries become themselves transformed into necessities. Out of these spring other indulgences and other luxuries, which go on by a sort of reduplication or spontaneous generation, to which as yet no limits have been reached, and we have reason to think that none are very near. When one class or species fails, or passes away, others come into its place, like sprouts springing from the living stump of a tree which has been cut down; or like the countless plants which come up where a single plant has been suffered to ripen and tc shed its seed.

Besides this effect of use or indulgence in increasing, and in griving an insatiableness to, human wants, there is an original and native element of the human mind, which the phrenologists designate as acquisitiveness, or a desire to obtain. This, when joined with secretireness, becomes a desire to keep or to accumu- 
late as well as to obtain, which, though liable to abuse, yet, like all other original tendencies of our nature, is designed for good. This operates as a continual stimulus to exertion, and rouses energies, and awakens an ambition, and strengthens and produces a perseverance and tenacity of purpose, which, in the creation and accumulation of wealth, lic at the foundation of most of the great improvements of society, and again in its turn creates a power or instrument of influence, which itself commands thousands of minds, and thousands of hands, to unite with an energy similar to its own in the accomplishment of its own objects.

All this does good; prevents the waters of society from becoming stagnant and unwholesome, and keeps them in a state of continued and healthful agitation. If human wants, having a sort of polypus vitality, are constantly increased by being supplied, it is no less true that the powers of the human mind and body are always increased and strengthened by being properly exerted. As the mind becomes enlightened and expanded, it is tempted to extend its dominion over matter and over other minds. In the spirit of an ambition never knowing enough, it goes out "conquering and to conquer." It invades other" dominions of nature, and makes every where the elements of the material world subservient to its purposes.

It is said that an Indian, when, on a certain occasion, he was brought from the solitude and destitution of his forest-home inte a busy manufacturing town, and saw windmills with their saiks inflated by the air, and water-wheels driven by the running stream, and steam-engines impelled by an agent of which befor. he had scarcely conceived, and the furnaces where, by the applications of fire, the iron-stones were made to flow in liquid streams, and to take the forms which the workman's pleasure dictated, exclaimed, in his amazement, that the white man made every thing work for him - the fire, the air, the water. Nothins could have been more natural than his surprise. Thus it is that human genius devotes itself to science; and every step in sciene. imparts a disposition and capacity to advance farther. It invent language and signs, that it may transfix, and hold fast, thoughts. and facts, and discoveries, for further use. It employs the powers of nature to increase, and multiply, and strengthen, other powers, and thus is constantly extending its sovereignty orer mind and 
matter, and assuming more and more to itself, in its humble capacities, the character of a creator. Thus it is that the fruitful powers of nature are called forth; the means of animal life and subsistence extended; the productions of the earth increased, diversified, and improved. Under an improved cultivation, ten men fiud ample and luxurious support, where, before, one would hare starved. New vegetables and new fruits are brought into existence and use, or others rendered more abundant; and with the increase of vegetable, the increase of animal life is immeasurably extended. Thus it is that new forms of comfort, luxury, and ornament appear with corresponding wants on the part of those who are to enjoy them; new means of subsistence are supplied; new forms of habitation are demanded; new articles of clothing are provided. All the wonders of art spring up; the multiplied embellishments of refined life present themselves: and the progress of society is in all respects advanced and contiunally advancing.

All this grows out of that original element of the human mind to which I early alluded, - acquisitiveness, the desire of gain, or advance, or betterment, or profit, - which thus stimulates men to the continual improvement of their condition. But all this, we are told by some men, springs from selfishness, and they denounce it as criminal. Their denunciations are without reason, and they make no just discrimination between the different conditions of a principle which in its original nature is wholesome and useful, and becomes wrong and pernicious only by its extravagance and abuse.

What would man be without any regard to his own interest? It is an instinctive impulse which prompts us to take care of our lives. Self-preservation is the first law of our nature. But the same law implies the most diligent care of our health, and all that varied and extended provision for health and comfort. necessary to the continuance of life, and to its continuance under circumstances most favorable to its activity, usefulness, and reasonable enjoyment. But who is to take care of us, if we do not take care of ourselves? If every man, instead of providing for his own wants, gave himself up to the care of his neighbor it is not easy to see that any advantage would be gained by it. Fvery one would find that, besides multiplied inconveniences, the provision for himself would be far less complete and satis- 
factory than when under his own immediate superintendence and control. The evils of selfishness do not lie in a man's appropriating to himself that to which he has a just claim, and which he may enjoy without injury to his neighbor, but in the appropriation of that to which he has no fair title, and which he cannot so appropriate without injury to his neighbor, and without an invasion of the just rights of other men. That meanness of selfishness, which some men exhibit, and which seeks the exclusive enjoyment of whatever it can accumulate, irrespective of the comfort, and at the expense of the toil, of others, - that dogin-the-manger selfishness, which accumulates without imparting, and seems to experience its highest zest in contrasting its own fulness with the destitution and misery of others, - is as odious as it is criminal. On the other hand, that rational regard to one's own interest which prompts a man continually to take the best possible care of his body and mind; to secure his health, that his physical activity and vigor may be increased, and to cultivate and improve his mind, that it may resemble, in its fruitfulness, a well-tilled and enriched field; to increase likewise his estate, and embellish and adorn it; and to accumulate wealth that he may multiply the sources of good to others, stimulate others to exertion, and lead to those generous improvements which wealth is capable of producing, and to which it may be beneficially applied, - this is a sentiment, which, so far from being to be condemned, is to be commended and cherished as the great instrument and spring, as much of social and public, as of personal and individual good.

Improvement of every kind lies in action. The happiness which never satiates or wearies is to be found in the consciousness of progress. Who that has experienced a dead calm at sea, - not a breath of wind to ruffle the wares, the ressel tossing from one side to the other like a cork upon the water, the rigging shaking, the sails flapping, the crew idle and listless, no progress reported, and the whole company wearied, impatient, desponding, ill-humored, - and compares this with a brisk gale blowing. - every rope straightened, every sail spread and filled, the planks of the ship creaking as it were with intense exertion, the masts bending almost to breaking under their burden, the crew awake. the passengers all animated with hope and delighted with the certainty of progress, and the molle ship, with her priceless cargo 
of human life and fortune, moving like a thing of life over the billows, and, as she ploughs her proud path through, as it were, a flood of liquid silver, throwing the glittering and brilliant tresses of jewels from her neck, - who has had this experience, and will not feel how little to be desired, either for the body or the mind, for health or enjoyment, for the animal or the moral man, is a state of inanity and sluggish repose?

The poets - those ethereal beings, who deal in fiction, and whose imagination becomes a sort of ignis fatuus, a "Will-of-thewisp," leading them they know not where - love to descant upo: the Golden Ages or the Paradisiacal state, when men, without care for food or clothing, had nothing to do, but, under a calm sky and a soft air, to lie down on banks of fragrant flowers, by the side of gurgling streams, under the shade of spreading aromatic trees, and let the richest fruits fall into their laps, and listen to the Eolian strains of the winds whispering among the branches, and the melodious songs of birds of the gayest plumage fluttering around them, and abandon themselves to the charms of a purely animal and sensual existence. But what reflecting man would desire such a life as this for himself, and would not feel an intolerable restlessness, and especially a mortifying consciousness that it falls, one may almost say, infinitely below the capacities of his nature and the purposes of his being?

I cannot look out of my window, where I am now writing, in Trafalgar Square at Charing Cross, without seeing a world of indescribable life, and bustle, and activity. The night in London is seldom longer than from half past two o'clock until four o'clock: in the morning, when the flood-gates begin gently to open, and gradually the rushing torrent of life pours through in a turbiul and boisterous flood. After the waters begin to move with force, there is perhaps not a minute in the day when more than a thousand, or rather thousands, of people cannot be counted from my window. Here are carriages without number, from the splendid chariot with its noble linrses, its gorgeous equipage, its liveried servants, and its precious cargo of figured porcelain, down to the lumble gig, the dray-horse, the wheelbarrow, and the donkey-cart with its precious load of garbage or of dog's-meat. Here are shops without number, replete with all the most exquisite productions of science, genius, art, and mechanical contrivance, and fuli of buyers and sellers. Here are crowds of men, women, and chil- 
dren, passing and repassing, sauntering, walking, rumning, and jostling each other, waiting upon and being waited upon, entertaining and being entertained, carrying and being carried, laboring and enjoying. Here are caravansaries for the travellers, banks for merchants, monuments to heroes and princes, schools of science, galleries of art, and temples to God, adorned with the funest embellishments of architcetural skill, and lifting their beautiful spires to the skies, as if, from the glittering vane upon the top, they would emulate the brilliancy of a fixed star, and as if, like the star which stood over the sacred spot of a divine nativity, they would present Heaven's brilliant cmblem of mercy to encourage man's faith and piety. Here, too, are fountains of water throwing up their liquid treasures over their heads, and coming down in constant showers of brilliants. Here are men, and the busy and exciting concerns of men, under all the varying aspects of human life and activity. Here are the magnificent triumphs of human art and skill; here are the fruits of centuries of toil and labor; and here is one continued intensity of action, as if it were the very heart of the great world beating with violent emotion. But none of this, properly speaking, is mechanical ; it is all intellectual; it is all under the dominion of mind to excite, to urge, to direct, to control it. There is a far mightier power at work within than appears without. If you could take off the roof of some of these moving tabernacles; if you could see what is there lying beneath, the burning thoughts, the anxious desires, the resolute purposes, the beating affections; and the ficry passions, which are there at work, and as it were mingling in one common flame, you would indeed see objects more curious and wonderful, an exhibition far more extraordinary, than any thing ever before presented to your senses, or even to your imagination. But what is the secret spring, the great pwer-wheel which sets all these things in motion, which excites and quickens all this activity? It is acquisition, the desire to acquire subsistence, pleasure, profit, wealth, or power.

Would it be better that all this should cease, and society become a mere stagnant pool ? Would it be better that all the itecessity of labor should be taken away, and men shonld have no other destiny than to repose in quiet, with all their wants supplied, and all their senses gratified; and that down conches thoult he spread round these gushing fountains, and instead of 
water they should send forth the delicious juices of the grape, though perhaps, to suit the English taste, it should be ale or beer, or what is vulgarly called "half and half," for that is the Englishman's nectar, - and that men should have only to drink it in at pleasure, or, in common parlance, to enjoy themselves? I think not. I believe Heaven could send no greater curse than to exempt mankind from all necessity of labor.

If we look at the condition of the inhabitants of tropical countries, where the richest fruits of the earth grow spontaneously. where clothing and shelter are searcely required, and where men are exempted from the necessity of labor, we shall find them sunk in sensuality, abandoned to animal indulgences, and in intellectual and moral condition at the lowest scale. If we compare them with the inhabitants of temperate regions, the disparity will be seen to be great, but vastly in favor of the latter. Whe intellect is sharpened, as well as the muscular vigor increased, in proportion to the difficulties with which it has to struggle, and the labor by which it is taxed, provided that labor is not excessive and unnatural. Though there may be a severity of toil wholly discouraging, and difficulties which are perfectly hopcless and insurmountable, - which cases we must of course except, - yet, in point of actual enjoyment, there cannot be a doubt on which side the advantage lies; and that the necessity of exertion, and every wholesome stimulus to useful and honest labor, is a blessing from Heaven.

The condition of the Irish peasantry likewise strongly illustrates and confirms these truths. Nothing can exceed the destitution and wretchedness in which millions of these people live. I have been into many of their cabins, and have seen the habitations of thousands and thousands of these miserable people; and, in regard to external accommodations, I can scarcely think that there is upon earth a lower condition of human existence. Certainly the wigwam of an American savage may often be regarded with envy for its comforts, compared with many an Irish cabin. I have been into those which were mere holes dug into the side of a peat bog, and have put my haud upon the wet and velvety walls, that I might be certain my senses did not deceive me. In these caves, covered with sticks, and straw, and sods ; without chimney, window, or tloor; with a fire of turf slowly burning upon the ground and filling the place. 
with smoke; without bed, table, chair, or plate, or knife, or fork; with, indeed, no article of furniture save a kettle in which to boil their potatoes, and a basket in which to take them up; with no other seat but a bit of dried turf or peat, and no bed to lie down upon but a flock of straw, which was frequently shared in common by the children and the pig, - I have found a crowded family, with rags for clothing that scarcely hid their nakedness, living from one year's end to the other upon potatoes and water, and never more than once a year tasting either bread or meat.

This is not the place for me to enter into the political considerations comnected with this condition of things in a country which, in respect to its climate and soil, and resources for useful industry, and means not only of comfortable subsistence to a population quadruple of that which exists there, but in means of abundance and wealth, is eminently favored of Heaven. But I refer to the example of Ireland to show that where persons can remain satisfied under privation and extreme penury; where they are content to live upon the meanest fare, and to occupy habitations scarcely fit for the shelter of the lowest of the brute creation; where, with only a mud-cabin and a potato patch, without even money enough to pay the wedding-fee, (for this is made out by the contributions of friends on the occasion, ) they are willing to take upon themselves the responsibilities of marriage, and become the founders of families to be born only to inherit a similar destitution and wretchedness, it is difficult to find motives to rouse them to exertion and industry. Until a revolution can be effected in their feelings, and a set of wants created within them, any strong hopes of the improvement of their condition seem idle.

The wants of men, then, are the great incentives to exertion; and the stimulus of profit, the desire of gain and of accumulation, is that which induces enterprise and effort, which excites inquiry and leads to knowledge, which prompts to labor, and thus urges men on to new acquisitions and continual progress. We may appeal to higher motives than self-interest, where there are minds capable of appreciating a higher class of motives; but it is absurd to consider inferior motives as wrong, where better cannot be had; and self-interest and the desire of gain are not only innocent, but commendable, where we do not seek gain or pursue our own interests to the injury and loss of others. 
I fear I may be thought to have gone out of my way by such a preface as this; yet I hope I may have the indulgence of my readers for an honest endeavor to enliven a subject of dry details with matter which, though it may seem distant from, is certainly not irrelevant to my purpose. I have not always found it a hinderance, though it may appear like an interuption, in making a tour of business, sometimes to dismount, and, throwing the reins over the neck of my horse, that he too might regale himself by the roadside, lie down on a green bank, under a quiet shade, by some sparkling stream, and abandon myself for a while to the charming thoughts which then come fluttering round the mind, like fireflies upon a meadow in a quiet evening of summer; or at other times to leap the fence, and rush into the fields or the neighboring forest, and return with a handful of golden grain, or a bouquet of wild flowers gathered fresh from the bosom of nature, and showing the exuberant bounty of Heaven, or the triumphs of artificial culture. I could then mount my horse, refreshed by the indulgence, and pursue my joumey with new speed, with senses more alive to the beauties of the country through which I was passing, and with a more grateful sense of the goodness of the great Author of nature, who, by this varied mixture, by alternations of light and shade, of labor and rest, of toil and indulgence, and by an endless succession and diversity of objects, makes life, which would be otherwise deplorably monotonous and tedious, not merely agreeable, but delightful.

I should be happy, in my humble way, in any degree to accomplish so desirable a purpose in respect to my kind readers, and render the journey which we have undertaken to travel together as pleasant as I could wish to make it useful and instructive.

Some men, very much addicted to great refinements in casuistry, and especially in respect to the motives of human actions, would condemn every motive, but such as are purely disinterested, as criminal. I agree with them that the highest of human actions must have its origin in the highest and purest of all motives; but I cannot deny the innocence, and, more than that, the positive virtue and worth of many actions and pursuits, that are prompted by motives which some persons would designate as inferior, but which, nevertheless, have their origin in our own nature and constitution. Self-interest, profit, 
accumulation, are all of them reasonable and commendable objects, when they do not lead us to invade or infringe upon the rights of others, and when our accumulations are used for useful ends.

I am anxious to vindicate the profession of agriculture from every aspersion which may be cast upon it, and to contribute my mite to place it in that rank, in the seale of human pursuits, which it may justly claim for itself. I may say, with Bacon, "that it has the divine sanction," for in the beginning God placed man upon the earth to cultivate and make it fruitful. I may claim for it, further, that it is an innocent pursuit; that it can do no injury to any one; and that it invades no man's just rights, and prejudices no man's safety, health, peace, or reasonable enjoyment. I will add to this, that it is a beneficent employment. Whoever cultivates the earth, and covers it with rich and golden crops, renders it more beautiful; whoever causes the earth to yield its fruits, increases the means of human comfort and subsistence; and in proportion as this cultivation is improved and skilful, and by such improvement, and such skill, the products of the earth are many times increased, so the means of human subsistence and comfort, and of subsistence and comfort to a very large portion of the brute creation, are correspondingly extended.

I will make no invidious comparisons between agriculture and other professions and pursuits of life; but certainly none is more innocent, more honest, more useful, or more rational. That happens, in respect to agriculture, which does not equally appear in many professions, that its improvements caunot be monopolized; they are of necessity exposed. Emulation or competition, so often productive of the worst results in many pursuits of life, in the improvement of agriculture can produce nothing but good.

\section{XLVII. - AGRICUITURF AS A COMMERCIAL PURSUIT.}

Men, then, may lawfully pursue agriculture under the stimulus of profit. In many cases, the gains of one man are made at the expense or loss of another. 'The celebrated Madame Roland 
used to say "she was always sorry to hear that a man had matce a good bargain, because she knew, in that case, that some jerson must have made a poor one." It is not so in agriculture. The more a man increases his wealth by increasing the products of the earth by a skilful cultivation, so much the more is the whole community benefited, excepting only where human laws interpose to intercept the widest possible diffusion of the bomnties of Heaven.

Agriculture, in order to excellence, requires as much the stimulus of profit as any other pursuit in life. In England and Scotland, it has had that stimulus. It has had governmental protection and indulgence, the propriety and justice of which are questionable with many men of distinguished wisdom, observation, and patriotism, and the expediency of which is capricious, being dependent upon circumstances ever liable to fluctuation and change. The protection which it has received has been in laws prohibiting, under heary duties, the importation of agricultural produce from foreign countries, and affording relief from various forms of specific taxation, to which other professions or conditions are subjected. The horses, dogs, servants, and carriages, of all other classes of the community here are taxed; but those of the farmer are exempted from taxation. In the tax upon income, the farmer's income is fairly assumed from the rent which he pays; but in levying the assessment, only half his rent is reckoned, so that a farmer paying in fact $\& 400$ rent, would be considered, for the purpose of taxation, as paying only $\mathbb{E} 200$. In some respects, it must be confessed that what is called "protection" is of a suicidal character. A duty is laid, for example, upon imported clover-seed, whereas the amount produced in the country, or likely to be produced under all the encouragement which its cultivation receives, bears a very small proportion to the amount used by the farmers, and used in fact by no other persons; so that the duty paid upon this article is a heavy tix upon the many farmers, for the exclusive benefit of the few. Great complaint is likewise made, by the farmers, of the introduction of fat cattle from abroad, which come into injurious competition with their own stock, and of the admission of foreign salted provisions. At the same time, the very provisien upon which these cattle might, if imported lean, be fatted at home, is prohibited. The Indian corn from the United States can be 
admitted only by the payment of a duty which is almost prohibitory. It camnot be grown in England, though, under some extraordinary circumstances in accidental localities, it has occasionally ripened. If, instead of importing fat cattle from the Continent, to supply their markets, they would import lean cattle, and at the same time import Indian corn under a low or nominal duty, to fatten them with, (and it would be difficult to find a : :ubstance which, in proportion to its cost, is more nutritious, ) it is ubvious that, besides the profit upon the labor of fattening these catile, they would have the great advantages of their manure certainly a most serious consideration.*

Agriculture in England appears altogether as a commercial pursuit. Where heavy amounts of rent are to be periodically and punctually paid, men are compelled to look carefully at their expenditures, purchases, and contracts, and their pecuniary results. It is by no means so with us in the United States, where most farmers are their own landlords and the owners of the estates on which they live, and where, if their sales from their farms are sufficient to meet the expenses of labor, the light taxes of the govemment, and those supplies for their families which the farm itself does not yield, they feel themselves at least secure, if they are not satisfied. I design presently to give some example of the manner in which farm accounts are kept here by the most careful farmers, and which show all the exactness of mercantile transactions. Irdeed, it must be so, or they would become involved in inextricable confusion, which would surely terminate in bankruptcy and ruin. I know farmers here who pay their two hundred, four hundred, six hundred, and one thousand pounds' rent; I have been credibly informed of a farmer in Scotland, or on the borders of Scotland and England,

The alteration of the tariff, allowing the admission of fat cattle, and foreign cheese, \&c., under a reduced duty, does not appear, at present, to have produced so great results as was expected, whatever may be the case hereafter.

'The report made to Parliament this present scssion, (1845,) returns, as imported into the country from abroad the last year, of cattle, 2,241 , (which, if we suppose them to average 800 pounds per head, would give only about three fourths of a pound of meat to each individual;) of sheep, 1,063, (which, at 80 pounds per head, - a large average, - would give half an ounce of nutton to each individual ;) of cheese, 11,000 tons, (which would give about one pound per individual.) At the same time, the minister in Parliament states that, during the last year, the population of the kingdom has increased by 380,000 !! 
whose amnual rent, at one time, was seven thousand pounds, or thirty-five thousand dollars; and it is quite obvious how disastrous must be the consequences, if such properties are managed otherwise than with the most scrupulous commercial exactness.

It cannot be denied that our habits in this respect are altogether diflerent from what they should be; that perhaps a majority of our farmers keep no accounts whatever, and many who keep accounts exhibit only imperfect and slovenly examples. It is said, - and it is certainly much to his honor, - that a distinguished individual here, possessing immense estates, but who had become somewhat perplexed, not to say embarrassed, in his pecuniary affairs, and whose education had not been, in this matter, of a character to enable him to manage his affairs to advantage, employed an accurate accountant in his house for some time, for the sole purpose of learning from him the science of book-keeping by double entry. With a natural love of order, and a firm resolution, having acquired this knowledge, he was soon enabled to bring order out of confusion, and rescue himself from embarrassment, and its attendant and inevitable mortifications. Such an example as this is certainly worth recording.

Many farmers, more systematic than others, keep not only an account of cost and expenditure, and the amount of sales and profits, in the form of a cash account, but likewise a regular account with every field and every crop, and I had almost said with every animal, taking, as every careful trader or merchant will do, a yearly account of stock at a fair valuation. Every thing is accounted for ; not so much as a quart of milk is used in the family, but it is charged at the current price. I should be doing great injustice not to say that I know many examples of such carefulness in my own country. Besides the great satisfaction springing from this exactness, the sense of security and integrity, which it brings with it, is invaluable.

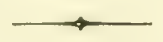

\section{XLVIII. - MARKETS. CATTLE MARKETS.}

The English farmers have gieat advantages in their markets and exchanges; and in this matter, to a certain extent, we ought 
to follow them. I do not say these markets are an unmixed good; but the benefits arising from them, I am convinced, greatly preponderate over the evils; and, taking advantage of the long experience of others, some of these evils we may either remedy or avoid. It would prove highly beneficial to our farmers if they could have certain established markets for the sale of their produce when it is ready for sale; if prices could be fairly adjusted and equalized; and especially if the markets could be for cash; and that credit, in all cases excepting for very short periods, could be abolished. It would be equally useful to them to know where they could buy as well as where they could sell; for they often want lean or store stock for fattening, a change of sced for sowing, horses for farm service, young stock for grazing, and corvs for dairy use.

With the exception of three or four of our large towns, - as Boston, New York, and Philadelphia, - we have no established cattle market in the comtry; and markets such as Brighton near Boston, and the Bull's Head near New York, are almost exclusively for the sale of fat cattle, sheep, and swine. Our farmers sell, as they can, to agents or purchasers travelling through the country, and buy as they can, and where, by chance, after taking, in many cases, long and expensive journeys, they may find the stock which they need. In frequent cases, stock, both cattle and swine, are driven through the country and sold to those who wish to purchase, as accident may direct. A wool fair or market, is not, within my knowledge, held in the country; nor a corn or grain market. In the purchase of wool, agents scour the country, and in general the farmers are quite at their mercy. In respect to grain, the farmer carries his wheat, or other grain. to the miller or the trader, and must make the best bargain that he can. In such case, in the first place, there is no competition; and no possibility of calculating the quantities on hand for sale; and no mode of fixing any general or equal price; and, indeed, no

* Howard Strcet, in Baltimore, affords the only place in the United States resembling an exclusive market for the sale of grain or flour; and this is only attended by individual purchasers, and is not a mecting of farmers, grain-dealers. and millers, coming together on particular days in the week, and at a particular hour in the day, to exhibit samples, to collect and impart information respecting the grain prospects of the year, to discuss prices, and to afford to all partics the advantages of comparison and competition. 
certanty to the farmer of finding any market at all. 'These evils might be remedied, and a change effected, to the great advantage of buyers and sellers, by the adoption of the system of weekly or periodical markets, which prevails throughout England and Scotland. Here are wool fairs, for the sale of wool, of which samples are exhibited; and corn and grain markets, where wheat, barley, oats, rye, beans, and peas, samples of which are exhibited, are sold; and markets for the sale of fat cattle, and markets for the sale of lean cattle, and markets for the sale of horses, and markets for the sale of sheep and lambs, and markets for the sale of cheese and butter; these markets sometimes uniting several objects, or otherwise limited to some single object.

I have attended several of these markets, and some general account of them may have an interest with my readers.

\section{XLIX. - FALKIRK TRYST.}

The largest cattle mirket in the kingdom, uniting sheep and cattle, takes place three times a year, - on the second Tuesday in Iugust, September, and October, - at Falkirk in Scotland, about equidistant from Edinburgh and Glasgow. This is called the Falkirk Tryst, and is held on an extensive plain about three or four miles from the town. Here are congregated a vast number of horses, cattle, and sheep, and of buyers and sellers. It was estimated, when I was there, that the number of cattle then on the ground exceeded fifty thousand head, and of sheep seventy thousand; and the banker informed me that the money employed in the negotiation wonld exceed $£ 300,000$, or one million and a half of dollars. The cattle and sheep exhibited at this tryst are almost altogether of the Scotch breeds, and many come from the remote Highlands. They are purchased to be distributed, in the neighborhood and the sonthern provinees, for wintering, or for fatting for the winter and spring markets. Besides cattle and sheep, a large number of horses are brought ior sale at the same time; as many as three thousand horses are 
sometimes offered for sale, and the field presents the appearance of a grand military display; indeed, I have seldom seen a sight more imposing. For a week or more before the tryst, the roads leading to Falkirk will be found crowded with successive droves of cattle and sheep, proceeding to this central point; and it is extremely curious, on the field, to see with what skill and care the different parties and herds are kept together by themselves. In this matter, the shepherds are greatly assisted by their dogs, who appear endowed with a sagacity almost human, and almost to know every individual belonging to their charge. They are sure, with an inflexible pertinacity, to follow and bring back a deserter to the flock. Purchasers come in great numbers from various parts of the lingdom. Some cattle are bought to be re-sold at other and smaller markets. The larger number are bought in order to be fed or fatted on the arable farms at the south. Cattle which have thus been driven from the extreme north are afterwards to be found even in Cornwall, at the Land's End.

The sales in these cases are, of course, for cash. Bankers are always present, or near at hand, to facilitate the transactions. Here, at a distance little less than four hundred miles from London, bankers go down from London, carrying their funds with them, and occupying, during the time of the market, (which continues at least four days, ) a temporary stand or office in the field.

\section{L. - THE BALLINASLOE FAIR.}

At Ballinasloe, in Ireland, a similar fair is held; though here the fair is usually confined to the sale of sheep, and they sometimes number as many as eighty thousand sheep. A very large fair is held in the southern portions of Scotland, for the sale of lambs, where the collection is immense. 


\section{LI. - THE GALWAY FAIR.}

A very large fair is held at Galway, Ireland, in the county of Galway, called the Fair of Rose Mount, at which I was present. This was chiefly for the sale of ponies, or horses of a small breed, with some few cattle. On this occasion, the collection of people was surprisingly great; and I could then well understand what was intended by the public meetings in Ireland, called "monster meetings," in respect to which, until I saw this collection of people, I had always supposed the account of the numbers assembled had been much exaggerated. There were here, on this occasion, some cattle and sheep; but there were, also, four thousand ponies, the catching of which, for examination or sale, as they had, in general, neither bridle nor halter, was sufficiently amusing, and I was about to add, sufficiently Irish. The fair was held on the sea-shore, where the receding tide left a large bed of mud. 'The ponies, when required to be caught, were surrounded and driven into this mud; and here, in a very ignoble way, they were secured, though it was not always without some difficulty they were extracted after being caught.

1. Temperance in Ireland. - There were two circumstances connected with this fair at Rose MLount, a reference to which, though not having an immediate connection with the principal object of my Reports, yet having a direct bearing upon rural manners and customs, may not be considered wholly out of place. Here, as well as at the fair at Donnybrook, where immense numbers of people were congregated, I could observe most distinctly the beneficent effects of that powerful reformatory movement, which, under the ministry of a good man, worthy of the name of an apostle, has effected a glorious moral triumph throughout Ireland, such as the pages of history scarcely record. I cannot say that at either place there was no drinking and no quarrelling; but there was comparatively little; and knowing, from report and from the natural excitableness of the Irish temper, what had been usual on such occasions, I could not but feel how much had been accomplished, when a foreigner might truly say, of such vast and mixed assemblages, they were quiet, orderly, and kind; and a well-behaved man, disposed to keep his elbows 
to his own sides, might feel an almost equal security as he woulà feel in church.

2. The Galway Women. - There was another circumstance, perfectly unique in its character, to which I shall be pardoned for alluding. There was another species of live stock exhibited at the fair, which I cannot say is never seen at such places, but which does not always present itself under the same frank circumstances. The kind nobleman who accompanied me, and who, like many others, noble and simple, whom it has been my good fortune to meet with on this side of the water, left no effort unessayed for my gratification, after looking at the various objects of the fair, asked me, at last, "if I would like to see the girls." I confess my natural diffidence at once took the alarm; and my imagination cast a few furtive glances over the sea at some precious objects I had left behind. However, upon a voyage of curiosity, why should I not see what was to be seen? and, confident that my good friend could have no sinister design, I gave him an affirmative reply. Upon inquiring of one of the trustees, or masters of the fair, "if the girls had come," we were informed they would be there at twelve o'clock. At twelve o'clock we went, as directed, to a part of the ground higher than the rest of the field, where we found from sixty to a hundred young women, well dressed, with good looks and good manners, and presenting a spectacle quite worth any rivil man's looking at, and in which, I can assure my readers, there was nothing to ofiend any civil or modest man's feelings. These were the marriageable girls of the country, who had come to show themselves, on the occasion, to the young men and others who wanted wives; and this was the plain and simple custom of the fair. I am free to say that I saw in the custom no very great impropriety. It certainly did not imply that, though they were ready to be had, any body could have them. It was not a Circassian slave-market, where the richest purchaser could make his selection. They were in no sense of the term on sale; nor did they abandon their own right of choice; but that which is done constantly in more refined society, under various covers and pretences, - at theatres, balls, and public exhibitions; I will say nothing about churches, - was done by these humble and unpretending people in this straightforwarl mamer. Between 
the noble duchess, who presents a long train of daughters, rustling in silk, and glittering with dianonds, at the queen's drawing-room, or the ladies of rank and fashion, who appear at public places with all the beauty and splendor of dress and ornamen: which wealth, and taste, and art, and skill, can supply, incanine nothing else but "Admire me!" and these honest Galway nymphs with their fair complexions and their bright eyes, with their white frilled caps, and their red cloaks and petticoats, - for this is the picturesque costume of that part of the country, - all willing to endow some good man with the richest of all the gifts of Heaven, a good and faithful wife, I can see no essential difference.

"Let not ambition mock their usefiul toil, Their homely joys, and destiny obscure."

I hope I shall be excused, if I say something more of these Galway women. I never saw a more handsome race of people. I have always been a great admirer of beauty - natural beauty, personal beauty, mental beauty, moral beauty. For what did the Creator make things so beautiful as they are made, but to be admired? For what has he endowed man with an exquisite sense of beauty, but that he may cultivate it, and find in it a source of pleasure and delight? As I have grown older, this sense of beauty - and I deem it a great blessing fiom Heaven has become more acute; and every day of my life, the world and nature, nature and art, the animal, the vegetable, and the minera! creation, the heavens and the earth, the fields and flowers, men, women, and children, wit, genius, learning, moral purity and moral loveliness, decas of humanity, fortitude, pationce, heroism. disinterestedness, have seemed to me continually more and more beautiful, as, at the setting of the sun, man looks out upon a world male richer and more glorious by his lingering radiance. and skies lit up with an unwonted gorgeousness and splendor. But the human countenance secms in many cases to concentrat all of physical, of intellectual, and of moral beauty, which car be combined in one bright point. Why should it not, therefore: be admired? In the commingled beams of lindness and goodhumor brightening up the whole face, like heat-lightning in summer on the western sky; or in the flashes of genius sparkling in the eyes with a splendor which the fires of no diamond can rival; or in the whole soul of intelligence, and noble thoughts, 
and heroic resolution, and strong and lofty passion glowing in the countenance, - there is a manifestation of creative power, of divine skill, unrivalled in any spot or portion of the works of God.

The extraordinary personal beauty of these Galway women was not mere imagination on my part, nor the result of any undue susceptibility. I said to the coachman, as we passed through this part of the country, that I never saw a handsomer people. "That," said he, "travellers always remark;" and when I left the country, in casting my eye over a recent book of Travels in Ireland, I found the author's impressions corresponded with my own. Tradition says that a colony of Milesians formerly settled in this part of the country, and that the remains of this race, or the offspring of the intermixture of them with the native tribes, present these results. This is a remarkable fact, and not without its bearing upon one great branch of agricultural improvement.

\section{LII. - SMITHFIELD, LONDON.}

The great market for cattle, in England, perhaps the greatest in the world, is at Smithfield, in London. This market is principally for fat cattle and sheep, and for cows. It is held weekly, in the centre, and in one of the most crowded parts, of this great metropolis. Monday is the day of general sale for fat cattle and sheep; Tuesday for hay and straw; Thursday is again a day of sale for hay and straw ; and Friday for cattle, sheep, swine, and particularly for the sale of milch cows, and at 2 o'clock for scrub horses and asses. This day is not so large a market as Monday, and embraces the cattle that were left over on the Monday's market.

The market opens at daylight, at all seasons of the year, and closes at 3 o'clock in the afternoon, at which time every thing, sold or unsold, must be removed. The sheep and swine are enclosed in pens, railed in with wood, and containing scldom more than fifteen sheep in a pen. The cattle, as far as the 
accommodations will admit, are tied, by the horns or neck, to long railings, which extend on the outside of the market-place, and likewise down the centre of the area. Between the rows of animals tied to these rails and facing each other, there is a passage-way; and there are, likewise, open spaces behind them and between them, so as to enable the purchasers to see the stock. In respect to the supernumerary animals, or those for which, for want of room, no tying-place is to be had, they are often driven into small circles, and, by a great deal of severity and cruelty, they are made, after being dreadfully beaten over the head and eyes, to stand with their heads turned in towards the centre of the circle. The poor animals, finding themselves in so novel a situation, stunned with a din and noise which no language can describe, and exhausted by fatigue and terror, are often glad to be let alone, and to remain quiet in situations, into which they may be forced, which would otherwise be scarcely endurable. Man is almost sure to be a tyrant, when possessed with absolute power; and there is good reason to belicve that he will have a heavy account to settle hereafter with the brute animals which he has most cruelly abused.*

It is obvious that it would be difficult to make any exact assortment, or classification, of the animals in the case, according to their different breeds. The sheep are placed in one part of the market. 'The cattle occupy another. The cows, and calves, and swine, occupy other separate positions. But no classification if the beasts into the different breeds of Short-Horns, IIerefords, Devons, or West Highlanders, or Scots, is attempted, although, from the fact that individual farmers generally limit themselves: to one species of stock, the contributions of different individuals, standing by themselves, present a sort of classification; and si. give a better opportunity to an intelligent observer to compare the different breeds with each other.

* It is said that much of the cruelty, which was formerly practised in these case. ,s now prevented by the influence of the $\Lambda$ nimal's Friend Society, an associatiori ryute numcrous, whose exclusive object is to prevent cruelty to dumb beasts, ant vilus to protect those who are unable to protect themselves. 'They have numerous agents, and prosecute, without fear or favor, every case of inhumanity, - for it is a great misnomer to call such cases brutality, - which comes under their notice, deserving censure or punishment. It is, undoubtedly, greatly owing to their exerions, that the odious practices of cock-fighting and dog-fighting are now not practised; or, if practised, conducted in the most secret manner. 
1. Forms of Business in Suitufield. - It is not here, as it is with us, that a drover goes through the country collecting, on his route, cattle from the different farmers, as he may chance to find them; but usually the farmer himself sends them to Smithfield, where they are put for sale into the hands of an accredited agent, whose commission for sale is established and understood. This commission is not a percentage upon the amount of sale, but so much per head. These, of course, are persons well known, and whose shrewdness and skill are undoubted. In the most extensive transactions of buying and selling, no paper is passed; but the price of the stock on sale being inquired, if the bargain is struck, the buyer and seller merely touch each other's hand, and there is no retraction. It is highly creditable to the commercial character of the country, and to the general integrity which prevails among the persons concerned in this great market, that, as I am. informed by an individual familiar for years with the most extensive transactions in this place, a failure to fulfil these engagements, though no paper is passed between the parties, is of very rare occurrence.

In the sale of sheep and cattle, the business is always transacted through an accredited and established salesman, who has his regular commissions upon every animal sold. The sales are always for cash, unless the salesman himself chooses to assume the responsibility of giving credit, and there are always banking houses in the vicinity to render the usual facilities for business.

The customary commission for the sale of an ox of any value is four shillings, or about ninety-six cents; of a sheep eight pence or sixteen cents. The city receives a toll, upon every benst exposed to sale in Smithfield, of one penny per head, and upon sheep at the rate of one shilling or twenty-four cents per score.

The value of the services of an intelligent, experienced, and honest salesman, is very great to the farmer, and much beyond the compensation ordinarily demanded. He is familiar with the state of the market, with the supply to be expected, with the prices generally taken, and with the characters of the persons with whom he has to deal, who know him as well. The farmer, going into the market to sell his cattle for himself, is liable to various impositions, of the extraordinary ingenuity an? coolness of which, many experiments will not be necessary to 
convince him. It might happen, that, instead of returning home with bank notes and sovereigns in his pocket, he might, like Moses in the Vicar of Wakefield, bring back only a quantity of green spectacles.

The state of the market, the current demand, the supply to be expected, together with the state of the dead-meat market, and what supplies of meat already killed are to be expected, are all matters to be taken into calculation. These are all inquired into, and well known to a thoroughly intelligent and experienced salesman, but are very imperfectly understood by any other persons than those who make it their constant business to become acquainted with them. The division of labor is carried to a great extent in all the business pursuits of this great country, and, while it seems unfriendly to that general tact with which persons among us apply themselves to a great variety and diversity of pursuits, must obviously contribute to a high degree of skill or improvement in the particular art or profession where it is applied.

2. Weights and Measures. - Animals in Smithfield are almost always sold on the hoof; yet an estimate is formed of their weight, and the price given is calculated upon the number of pounds the animal is computed to yield after being slaughtered. The gross hundred weight of one hundred and twelve pounds is still used in England; but the calculations are generally made in stones of eight pounds. By an act of Parliament, the stone of fourteen pounds is required to be adopted in the reckoning in the market; but custom in this, as in many other cases, defies the authority of the government, and eight pounds continue to be reckoned as the Smithfield stone.

The different measures and weights used in different parts of the kingdom are extremely inconvenient, and sadly perplexing to a stranger. The English, the Scotch, and the Irish acre are each different from each other. Grain is, in different places, sold by the bushel, by the quarter, by the comb, by the boll, and by the load; and a load is in some places four, in others three bushels. A Scotch pint is two English quarts. In Covent Garden market, two pottles of strawberries, containing little more than a pint each, are called a gallon. Potatoes are sometimes sold by weight, and sometimes by the barrel; in some 
places by the stone of fourteen pounds, in some by the stone of sixteen pounds. $\Lambda$ dozen of eggs is in some places fifteen. I may perhaps be asked, if this is not in Ireland; but I shall not say, excepting to add, as far as my experience goes, fifteen to a dozen would be a very proper index of Irish hospitality and kindness. In one market, in Yorkshire, a pound of butter is twenty ounces avoirdupois; in Staffordshire, eighteen ounces. In Norwich, butter is sold by the pint; in Cambridge, it is literally sold by the yard, being made into rolls of a certain size, and measured off in feet and inches. In one of our hot days in July, with the glass at $95^{\circ}$, our market-men, at this rate, would have little difficulty in giving full measure. I have already alluded to the force of custom. It has many advantages, but why should it stand in the way of improvement? The prevalence of an unmeaning or a useless custom has nothing to recommend it. Yet I believe I shall be doing no injustice to the English, - the last thing certainly which I should wish to do to a people whom I so highly respect and love, - if I were to say, many of them greatly prefer antiquity to utility, and will hold on to an ancient custom with the pertinacity of a drowning man, though its meaning has entirely ceased, and its observance is on -very account inconvenient and burdensome. With such persons, all argument on the subject of improvement is idle; the conception has never yet dawned upon them.

Such a varying standard of weight, or measure, or value, renders many statements quite unintelligible to a stranger or one ignorant of local customs, and comparisons and calculations all but impossible.

3. Werght of Animals, Mode of ascertaining. - The weight of an animal in Smithfield is reckoned by the weight of the four quarters. The hide, rough tallow, and ofial, are not taken into the account. There are rules given by which to determine the weight of animals, when slaughtered, by external measurement of them when alive. The salesmen in Smithfield do not rely upon these rules, but estimate the weight of cattle by the eye; and mere judgment, founded upon long practice, evinces most extraordinary approaches to exactness, seldom varying but few pounds. 'The rules, however, to which I refer, have a value to persons who are not accustomed to estimate by the 
eye; and a series of tables have been constructed upon these rules, which, if they could be relied upon, would be of considerable use in private practice.* The girth of the ox (for it does not apply to cows as well as to oxen, as their shape is much less regular) is to be taken directly behind the shoulder, and the length is to be measured from the front of the shoulder-bone to the end of the bone on the rump, where a line dropping down at right angles with the line on the back would just clear the thigh, or buttock. Then, according to a rule given me by Lord Spencer, "Reduce the feet into inches; multiply the girth by the length, and that product by the fraction .001944, which will give the weight in pounds;" or, in another form, as the rule is quoted by Mr. Hillyard, "Estimating the weight of a cubic: inch of meat at 171 grains, then girth 7 feet 6 inches, and length 5 feet 4 inches, gives $41,235_{100}^{84}$ cubic inches, which. multiplied by 171 , gives $7,051,328$ grains, equal to 125 stones. 7 pounds, of 8 pounds to the stone." Another mode of estimating the weight of cattle is to ascertain their live weight upon a platform balance, common enough in the United States. Then. according to some authorities, every 112 pounds live weight will produce 72 pounds of beef; but a coarse, large-boned ox will not produce so much. Another way is to deduct one third of the live weight, which is commonly deemed a fair allowance; and also, if the beast is not quite fat, from $2 \frac{1}{2}$ to 5 per cent. in addition. Another able authority states, "that the proportion which the dead weight bears to the live weight of animals was reckoned at one half the live weight; but subsequent experiments in the more improved breed of animals show that this is much too small a proportion, it being more correctly represented by the fractional quantity .605 , the weight of the animal being assumed as 1. This would be about three fifths for the dearl weight. The gross weight of the animal being then multiplied by .605 , will give the result in the same denomination in which the gross weight is given." It is obvious, however, that such rules can be little more than an approximation to exactness: since the circumstances under which the animal is weighed,

* These tables are to be found at large in Mr. Hillyard's useful and sensible hook, entitled "Practical Farming and Grazing," a fourth edition of which appeared in London in 1844. 
whether upon a full or an empty stomach, must essentially affect the result. It will be interesting, I am persuaded, to many of my readers, if $I$ give an account of the weights of some of the most remarkable animals which, within a few years past, have been exhibited at the show of the Smithfield Club, which takes place annually in December; and the account, besides giving the weight of the animals, will show, at the same time, how nearly the weight calculated by rule, and the weight estimated by the judgment of experienced men, corresponded with the actual weight, ascertained upon the animals' being slaughtered.

\begin{tabular}{|c|c|c|c|c|c|c|}
\hline \multirow{2}{*}{ 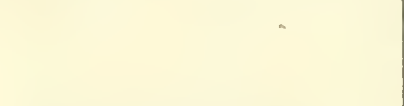 } & \multirow[b]{2}{*}{ YEAR. } & \multirow{2}{*}{$\begin{array}{l}\text { GIRTH. } \\
\text { Ft. In. }\end{array}$} & \multirow{2}{*}{$\begin{array}{l}\text { LENGTH } \\
\text { Ft. In. }\end{array}$} & \multicolumn{3}{|c|}{ STONE OF EIGHT POUNDS } \\
\hline & & & & $\left|\begin{array}{c}\text { Computed } \\
\text { Weight. }\end{array}\right|$ & $\left|\begin{array}{r}\text { Estimated } \\
\text { Weight. }\end{array}\right|$ & $\begin{array}{l}\text { Butcher's } \\
\text { Weight. }\end{array}$ \\
\hline Lord Spencer's Durham ox, . . . & 1828 & 9. 2 & 6. 0 & 211 & 210 & 210 \\
\hline The Scotch heifer,........ & 1830 & 7. 8 & 5. & 138 & 140 & 138 \\
\hline Mr. Townsend's Durham heifer, & 1833 & 8. 3 & 5. & 164 & 175 & $176 \frac{\pi}{4}$ \\
\hline Mr. Baker's Durham ox, . . . . . & 1833 & 8. $9 \frac{1}{2}$ & 6. & 195 & 205 & 206 \\
\hline Mr. Buckley's Hereford ox, . . . & 1833 & 7. 11 & 5. & 143 & 150 & 144 \\
\hline Lord Spencer's Durham ox, . . . & 1834 & 9.7 & 6. 1 & 236 & 240 & 236 \\
\hline Lord Oxford's Hereford ox, . . . & 1834 & 9. 4 & 5. 10 & 214 & 222 & \\
\hline Mr. Hillyard's do. heifer, . & 1834 & 8. 7 & 5. 7 & 175 & 184 & 192 \\
\hline Lord Brownlow's do. do. . . & 1834 & 8. 0 & 5. & 155 & 164 & \\
\hline Marquis of Exeter's do. do. . . & 1835 & 7. 11 & 5. & 134 & 138 & $142 \frac{1}{2}$ \\
\hline Lord Spencer's do. do. .. & 1835 & 7. 8 & 5. & 130 & 138 & \\
\hline Lord Spencer's Durham ox,... & 1835 & 9.2 & 6. & 211 & 218 & 210 \\
\hline Lord Spencer's do. do..... & 1836 & 9. 2 & 6. & 215 & 222 & 218 \\
\hline Marquis of Tavistock's do. do. & 1836 & 8. 10 & 5. & 187 & 196 & \\
\hline Lord Leicester's Devon ox, . . . & 1837 & 8. 1 & 5. & 142 & 145 & 152 \\
\hline Mr. Giblet's one year old Devon, & 1837 & 8. 4 & 5. & 158 & 162 & 166.4 \\
\hline Mr. Baker's heifer,. . . . . . . . & 1837 & 7. 11 & 5. & 148 & 152 & 152.3 \\
\hline Mr. Hillyard's Devon ox, . . . . & 1838 & 8. 1 & 5. & 142 & 142 & 139.6 \\
\hline Marquis of Exeter's Durham ox, & 1841 & 8. 9 & 5. & 185 & 185 & 185 \\
\hline Duke of Bedford's Hereford ox, & 1841 & 8. 9 & 5. 9 & 185 & 185 & 180 \\
\hline
\end{tabular}

The practice at Brighton, Massachusetts, is to sell the animal at a certain rate per pound, or per hundred pounds. 'The anima? is then slaughtered, and the return of his weight made to the owner or drover. The owner or drover does not see his animal killed or weighed. 'The market takes place on Monday, but he is commonly detained until Thursday, before the weight of the animal is ascertained, and he receives his pay. This, besides its expense, is on every account a serious evil. It cannot be denied, likewise, that the temptations to a fraudulent return of the 
weight are very strong, and that much dissatisfaction, very often without question groundless, frequently arises. It is surprising how near to exactness the judgment of an intelligent and experienced man approaches; but as this method is liable to the objection of a man's being judge in his own case, it would seem very desirable that some less exceptionable method should be adopted. I can think of no one more eligible than that of ascertaining the live weight on a platform balance, and then adopting some general rule as to the allowance to be made for the difference between the live and the dead weight. A rate of discount or allowance, founded upon repeated and exict experiments, would be equally fair for both parties. The adoption of such a rule would be of the greatest service in enabling the drover or owner to close his business in one day, and would, in general, be much more satisfactory to the farmer; who sends his cattle to market, and is not always without his suspicions of an imperfect return. I offer these suggestions with great diffidence, especially when I read, in a letter addressed to me by a practical man, "that there is no mathematical rule upon which he places any reliance; that he has often been invited to test the correctness of measuring beasts, and also to determine their dead, from ascertaining their live weight, but has found that no confidence can be placed upon such rules." He adds, "that after handling beasts to ascertain their fatness, the mind, by practice, is intuitively impressed with about the weight of the four quarters, exclusive of any offal; and that experienced men can tell the weight of beasts, on an average, within three stone of eight pounds, and of sheep within two pounds." I believe all this ; and it presents a beautiful example of what the mind is capable of, and of what it may be brought to under careful trainiug and long practice. We certainly know that the mind is a very good clock, and measures the time with wonderful exactness, both sleeping and waking. I have been often struck with the extraordinary precision with which the poor blind horses, which move the ferry-boat between Troy and the Albany side of the river, measure the distance which they have come, and after making a pause just before they touch the opposite shore, seem to kuow exactly how many more strokes or turns to give to the paddles, in order to reach it. I hope I shall not offend the pride of any of my readers, by this comparison of the hrute with the human 
mind. Man is very apt to think himself the only knowing animal upon the earth; and I have no doubt that some of the lower animals have the same self-conceit. It is interesting to see reason and moral sentiment, the noblest gift of Heaven, any where diffused, and even in the most humble forms. Such indications strengthen the claims which all sentient beings have upon our kindness and respect; and several of the lower animals - if any being is to be considered inferior who accomplishes the true purposes of his creation - read many striking moral lessons to mankind.

The character of a salesman in Smithfield Market, for judgment and integrity, is of immense importance to him. He is forbidden by law to purchase on his own account; and it is clearly most important that his private interest should not conflict with that of his employer. But it is easy to see the futility of all laws to make men honest, where evasions in a variety of forms are so practicable. Personal character, and a healthful state of public opinion, form, in such cases, the great security.

4. Amount of Business. - The amount of business transacted in Smithfield is enormous. It is estimated at not less than $\$ 100,000$, or half a million of dollars, every week. The Smithfield Market is certainly one of the great sights of London. The returns of the market on the Christmas week of 1844, when I was present, gave 5000 beasts and 47,000 sheep. 'This was considered the largest market ever remembered; and the extraordinary quantity of stock was doubtless, in some measure, to be attributed to the severe drought of the preceding summer, and the consequent scarcity of fodder, which compelled the farmers to lessen their stock. The largest return of stock ascertained for any year, between the years 1821 and 1842, was in the year 1838, and was,

Of cattle, . . . . . . . . . . 183,362

Of sheep, . . . . . . . . . 1,403,400

In the year 1830, there were sold in Smithfield,

\begin{tabular}{|c|c|c|c|c|c|c|}
\hline Beasts, & & & & & & \\
\hline Sheep, . & • & • & • & . & & \\
\hline Pigs, . & - & • & & & & \\
\hline Calves, & • & $e^{\circ}$ & • & & & \\
\hline
\end{tabular}


In the year 1842 ,

$$
\begin{aligned}
& \text { Of cattle, . . . . . . . . . . . 175,347 } \\
& \text { Of sheep, . . . . . . . . . . 1,468,960 }
\end{aligned}
$$

The supplies since that have not diminished. But this by no means comprehends the whole supply of provision to London, as immense amounts of slaughtered meat are brought constantly to the dead market, from distant parts of the kingdom, by the innumerable steam conveyances, which have so much increased the facilities of access to the metropolis. We need scarcely be surprised at any distance from which it may be brought, since I have seen Leicester or Southdown mutton, killed and dressed in England, for sale in the market at Boston. In spite of the doctrines of restricted or free trade, the benevolent mind cannot help rejoicing in a facility of intercourse, which renders the mutual interchange of the respective adrantages and blessings of different countries and climates so convenient, and thus does away forever with all that fear of want or famine which, in former times, so often followed any extraordinary contingency of the seasons. The quantity of meat, and that principally mutton, brought from six different ports in Scotland to London, was ascertained, in one case, to be about 2364 tons in six months; besides a very large amount of live stock. It has probably greatly increased with the opening of every new means of conveyance.

The friend to whom I am indebted for much of the above information, in regard to Smithfield, states the average weekly sale of beasts in Smithfield at about 3000, and of sheep, about 30,000 ; of calves, about 300 ; of pigs, about 500 . At the dear market, about 3000 sheep are sold weekly. Of the live stock, the beasts average from $£ 15$ to $£ 18$ per head, and sheep 30 shillings. $A$ pound in this case may be most conveniently reckoned at fire dollars, and a shilling, therefore, at a quarter of a dollar. The average age of beasts sold in Smithfield is from two to three years, and of sheep from fifteen months to two years. It is not to be supposed that these returns by any means embrace all the beasts slaughtered, or the meat consumed in the metropolis and its vicinity; for great numbers are sold before they reach the market, and are therefore not reported. Vast amounts, likewise, are imported from Ireland; and the cotters of this fertile. 
but wretched country, where a large portion of the inhabitants are, for a considerable part of the year, upon the borders of starvation, are obliged to see their only pig - the companion and pet of their children - and their only calf or steer, sent off to other markets to fill other mouths. Smithfield, though much the largest, is only one of the markets of the country; but the immense supplies which are here furnished must give some idea of the improvement and degree of perfection of the agriculture of a country from which they are drawn.

The poultry markets, and the markets for game, are also most extensive. The fish markets in London seem to me unsurpassed for their excellence, and certainly embrace a great variety of the very best kinds. These, of course, furnish their full proportion of the supplies of London.

5. Character and Quality of Stock. - The quality of the cattle exhibited in Smithfield market, of sheep in particular, is extraordinary for its fatness. The show of the Smithfield Club, which is held in December, under the patronage of some of the first noblemen in the kingdom, may very properly be denominated a show of monstrosities in the way of fatness. They are moving elephantine masses of flesh, and if, as according to modern chemical philosophy, all fat is the result of disease, they are far from being attractive to any but the grossest epicure. No advantage can come from rearing animals to such an inordinate degree of fatness, save in the matter of showing what the art of man can accomplish in respect to the animal economy, and also that of testing the mutritious and fattening qualities of different kinds of food.

In respect to the weight of the animals in Smithfield, an individual familiar with the subject, and in whom I have great confidence, states that the beasts from two to three years old will average from 85 to 100 stone of 8 pounds, or from 680 to $\$ 00$ pounds, when dressed - that is, the four quarters. Others place it not higher than 82 stone, or 656 pounds; of calves, 150 pounds; of pigs, 100 pounds; of sheep, 90 pounds. Calves are seldom sent to market under six or eight weeks old; and large hogs are never seen in the market. If we may rely upon ancient authorities, within a century past the weight of animals in Smithfield Market has nearly doubled; perhaps more than 
doubled. It is said that, in 1710 , the arerage weight of beasts was 370 pounds; of calves, 50 pounds; of sheep and lambs, 28 pounds. 'This increase of size is probably attributable in the main to two great causes, which deserve serious consideration. The first is, the improvement of the breeds of cattle. $\Lambda$ person has only to go into Sinithfield Market to remark the perfection to which the art of breeding has been carried, and the distinctness of the lines by which the different breeds are separated from each other. 'Three great points seem to have been gained. The first is, great size and weight have been attained; the second is, the tendency to fatten, and to keep in fat condition, has been greatly cultivated; the third is, that the animal arrives early at maturity. All these are most important points; the last certainly not least; for if an animal can be brought to the same size and weight, without doubling the expense, at eighteen months old, that he could formerly be made to reach not sooner than at three years of age, the quick returns, so essential in all commercial transactions, are secured, and as the expenses are lessened, the profits are greatly increased. Nothing strikes one with more surprise than to see what, in the improvement of the appearance and constitution of the stock, intelligence, skill, and perseverance can effect. I may here with propriety quote what my friend, before referred to, says in relation to the quality of the stock in Smithfield. "I fear many of our breeds of beasts and sheep are becoming worse than they were, from an excessive attention to neatness and symmetry of form, so that bulk and quantity of good flesh have been too much overlooked. Our Hereford beasts are much inferior to what they were; also other breeds of beasts; and particularly some breeds of sheep. Some persons are so very particular about purity of blood, that they often run into great error; their stock losing flesh, constitution, and size. This is particularly observable in Leicester sheep. So wedded are some persons to this breed, and to what they call purity of blood, that their sheep keep dwindling into very insignificant stock. I am satisfied that we cannot go on breeding in and in, without losing size, quality, and worth." I give these opinions of a very practical man, as familiar with the Smithfield Narket as any man in England, without endorsing them, and leave them to speak for themselves.

The second great cause of the improvement of the stock in 
Smithfield Market is, the improvement of the husbandry of the country, particularly by the introduction of what is called the alternate husbandry, and the cultivation of green crops. The cultivation of turnips and swedes is comparatively modern; and perhaps no single circumstance has effected so great an improvement in the agricultural condition of the country. Formerly, cattle were fatted, if fatted at all, upon grass and hay, and these of inferior kinds; the store stock were wintered upon straw, and came to the spring in such a condition that the greater part of the summer was required, in order to recover what they had lost in the winter. Now, the introduction of the artificial grasses, clover, and rye-grass, the growing of vetches, rape, turnips, swedes, carrots, and mangel-wurzel, and the use of oil-cake, have multiplied in an extraordinary manner the resources of the farmer; and the practice of folding his sheep, and stall-feeding his fatting beasts, give him a command of feed, and, if I may so say, such a control over the season, that the results are most remarkable in the supply of the market, at all times of the year, with animals of the finest description.

I may be inquired of, what I think of the English meats. The fatness of the beef and mutton is most remarkable. I have seen single beasts in the United States as fat as any I have seer here; but these are comparatively rare exceptions; and here the general character of the beasts and sheep is, in this respect, most striking. It would, however, I fear, be hopeless to attempt to persuade an Englishman of that which is my honest conviction that our meats are sweeter to the taste than those which I have eaten here. Our poultry is incomparably better. An Englishman will be likely to set this down as mere prejudice, which possibly it may be, for who can escape such prejudices, or be fully conscious of them when they exist? - but I believe it is not prejudice, but Indian corn, (the grain upon which our animals are fatted,) which gives to their meat a peculiar sweetness, which is not produced by other feed. Our beef animals are not killed until from five to seven years old, and our sheep seldom unti! three years old. Here sheep are killed at about fifteen months; and beasts at two years and upwards. The flesh of these young animals is wanting in that consistency which more age would give, though an extreme on the other side, and the hard-working of our oxen until eight and ten years old, is liable to give a 
toughness to the meat, which would not be found if fatted at an earlier, though not a very early, period. If price is to be taken is a correct index of quality, then it will be found that the beef of the small West Highland cattle, and the mutton of the Welsh sheep, are decidedly superior to any other, the prices which they command being always higher than others. The smaller size, and the better intermixture of lean and fat meat which they present, render them more convenient for family dishes, and more attractive than those immense rumps of beef, and saddles and legs of mutton, covered with an inordinate thickness of fat, which, by their grossness, repel any but the most inveterate epicure - the animal who seems to live only to eat.

My conviction is, that there is no agricultural improvement in England so great and striking as that which has been effected in their live stock: I refer particularly to its size, aptitude to fatten, early maturity, symmetry, and beauty. Of the milking and dairy properties of their stock, I shall speak hereafter. I must include, likewise, in my commendation, their horses - working, carriage, pleasure, and race horses. It could scarcely be expected to be otherwise. 'The highest degree of skill has been concentrated upon these objects; and this skill has been stimnlated by premiums of the most honorable and liberal character, and by expenditures absolutely enormous. The splendid and magnificent premiums of gold and silver plate for successful competition, which one sees on the tables and sideboards of the fortunate wimners all over the country, and which are exhibited with an honest pride, while they display the highest triumphs of artistical skill and taste, serve only to fan the flame which they enkindle, and to quicken an ambition, which never can be quiet while a more distant point remains to be attained. How happy would it be for the world, if human ambition were always directed to objects so imnocent and commendable; to purposes which benefit, instead of those which curse, the world; to the triumphs of genius, industry, and science, over the elements of nature, instead of the bloody conquests of power, avarice, and despotism, over human comfort, liberty, and life!

6. Smitheiem by Nigit. - Smithfield by night, and in a ark night, presents a most extraordinary scene, which, though I bave witnessed it, it would be very difficult for me adequately 
to describe. A large proportion of the stock arrive in the neighborhood of London either on Saturday or early on Sunday, where they are fed in the fields, or the extensive lairs prepared for their reception. These lairs, especially Laycock's at Islington, are well worth a visit, being composed of open yards and most extensive sheds, covering fourteen acres of ground, furnished with watering troughs and mangers, and divided into different compartments. Here the farmer or drover is supplied with hay or straw for his stock, not by the day or night, but by the truss, the hay which is sold in London being always put up and tied in bundles of 56 pounds each - certainly an excellent arrangement, which, while it prevents all temptations to waste, requires a purchaser to pay only for that which he has. The cattle here get a little rest and refreshment in these stalls after their long journeys; and here they are visited by the salesmen preparatory to their appearance in the market on Monday. It would not be surprising, likewise, and not altogether unlike some occurrences on the other side of the water, if some purchasers, with an acquisitiveness not disturbed by religious scruples, should occasionally make their way there and anticipate the bargains of the ensuing day.* About midnight the different detachments, almost treading upon the heels of each other, begin to make their way to the place of rendezvous through the winding streets of this wilderness of houses, and enter the great market-place by different and opposite avenues, and, like hostile parties, often meet each other in the very centre. Then comes the conflict : the driving of so many thousand of sheep into their several pens; the assorting and tying up, or arranging, so many thousand of cattle, driven into a state of terror and frenzy by the men and dogs; the struggles of the different owners or drovers to keep their own and prevent their intermingling with others; the occasional leaping the barriers, and the escape of some straggler, who is to be brought back by violence; the sounds of the heavy blows over the heads, and horns, and sides, of the poor crazed animals; the shrieks of the men; the yelling and barking of hundreds of dogs, who look after the sheep and

* I will say, however, by the way, and as an act of simple justice, that London, as well as every other part of England which I have visited, is remarkable for its sober and decorous observance of the Lord's Day. 
cattle with a ferocity perfectly terrific, and a sagacity almost human; the bellowing of the cattle, and the bleating of the calves; forming, if the expression is allowable, a concert of discordant sonnds utterly indescribable and hideous; and in the midst of all this confusion, the darting about of hundreds of torches, carried in the hand by men looking for their cattle and sheep, and seeking to identify their marks, - all together present an exhibition for which it certainly would be difficult to find a parallel, and sufficiently gratifying to the lovers of the picturesque in human affairs. The calves and pigs enter the market in a more aristocratic style, in carriages and vans, with the regular attendance of out-riders and footmen; but in spite of this luxury, after the example of some of their betters, these indulgences do not appear to lessen or quiet all their complaints, and they add their portion to the general harmony. Their owners are quite wise to carry, instead of attempting to drive, them; for I think no human power would be sufficient to drive and assort a herd of pigs, coming into a scene of this description. When the day dawns, however, every thing is found in order; all the different parties at their respective posts; and the immense business is transacted with a despatch, an efficiency, and precision, which are quite remarkable.

\section{Attempted Removal of the Market from the Citx. -} It certainly is not a little surprising that a market of this description should be held in the midst of such a city as this. Its name implies that, in former times, it was held in the outskirts of the town; but that time must have long since passed away, and the "field," so called, is now surrounded with miles of houses in every direction, and in the very centre of a most densely-packed population. It would seem, at first sight, that the obvious and innumerable discomforts of such an arrangement, and the danger to human person and life from driving so many beasts through the crowded strects, were sufficient reasons for transferring the whole business to a more retired and convenient situation in the neighborhood of London. A wealthy individual by the name of Perkins, under the influence of the best of motives, made an attempt to do this, and erected an establishment for a marliet at Islington, about two miles from the centre of London, which is well worth looking at for the completeness and excellence of its 
arrangements. The cost of the establishment is said to have been $£ 100,000$, or half a million of dollars. It forms a hollow square, and embraces a space of more than twenty acres, com pletely enclosed by high brick walls, which form the backs of deep sheds, slated, and open in front, furnished with mangers and with water troughs supplied from two very large tanks in the centre of the yard, which are kept constantly filled by machinery from wells sunk in the neighborhood. The sheds are capable of accommodating 4000 beasts; and here they might remain from day to day until sold, without inconvenience. In the centre of this immense quadrangle are four extensive squares, all neatly paved with flat stones, and divided into several compartments, railed in with neat iron railings, and capable of accommodating 40,000 sheep. Other pens are constructed for calves, pigs, and other animals usually brought to market; and all are arranged in the most simple and convenient method, with ample passages furnishing easy access to every part of the enclosure. Besides these, there are convenient and ample offices for all the various clerks, salesmen, bankers, \&c., connected with the business; and it was designed to erect commodious hotels for the acommodation of persons attending the market, and extensive slaughterhouses for the killing of the cattle, directly in the neighborhood. The whole space is entered under a handsome archway; and for its particular purposes, it would be difficult to conceive of any thing more commodious or better arranged.

In spite of all these obvious advantages, the market could not be removed from Smithfield. The persons in the neighborhood of the old market whose business and profits were intimately connected with it, opposed its removal. There was fear of a rival market being got up on the other side of the city. The city wonld lose the tolls, which are now received at Smithfield, and which, in the course of the year, make up no inconsiderable revenue. The meat, if the animals were slaughtered out of the town, would, of necessity, have to be conveyed to the city in carts, whereas, now, much of it is killed directly in the neighborhood of the market. These and many other reasons were urged, but, perhaps, would not have availed, excepting for the fact that Smithfield was discovered to be a chartered market, for the sale of cattle; and the twelve judges of the high courts decided, upon consultation, that this charter could not be 
abrogated; and eren 11 spite of an act of Parliament, which was obtained in the case, this great public nuisance must be continued.

8. Chantered Riguts. - When the vast amounts of property: which are here locked up, by the disposal of generations long since departed, for the most frivolous, useless, and obsolete purposes, and under the most absurd tenures, are considered, and that even public and acknowledged nuisances cannot be abated, while maintained under the plea of chartered rights, it is quite well worth considering whether this doctrine does not admit of some qualifications, which would render its operation less burdensome and offensive. Many cases, which are constantly occurring, would do much towards reconciling one to an occasional and general revolution, under which, freed from the rusty fetters of ancient prejudices, superstitions, follies, and crimes, society might take a new start, and avail itself of the improved experience and enlightenment of modern times. The right of a man to dispose of property, after his death, other than that which is the direct fruit of his own skill and industry, is, in my mind, quite questionable on moral and economical, however well established it may be upon legal grounds; and I hope I shall not give offence by an opinion, however crroneous, yet very honestly held, that no man, under any circumstances, has a right to appropriate property to any object which the state may not annul when that object becomes either pernicious or useless; above all, that no man, under any circumstances, has any right in the soil, which is not entirely at the disjosal of the state, always premising that the state make adequate compensation for individual cases of hardship or injury, and for any substantial improvement, which may have been effected in the property by the labor or skill, or at the personal expense, of the occupier. Let us suppose, for example, that Smithfield had been, by some ancient charter, appropriated exclusirely for public executions, - as it was indeed the melancholy site of the martyrdom of Rogers, and other heroic rictims to bigotry; - and that the government determined that executions should cease to be public, or should take plasc in the prison-yard; or, what is infinitely to be desired, that, under the mild influences of Christianity, the punishment of death should be abolished: must this field therefore forever remain 
useless and unoccupied? The English, as I have before had occasion to remark, - and I do it certainly as far as possible removed from any spirit of censoriousness or ill-humor, - are excessively conservative. Their judges still swelter under their full-bottomed wigs; and their courtiers and civilians, in the midst of crowds of gentle ladies, wear swords on state occasions, when there is reason to think that some of them, if called upon to draw and defend themselves, would scarcely know which end to seize upon. I am not for indiscriminate changes; but I go for miversal improvement, wherever the improvement to be made is obvious, decided, practicable, and remunerative. If otherwise, what is the value of experience and of education? and how idle it is to talk of the progress of society! Even in this matter of chartered rights, the government, with an inconsistency not uncommon, does not hesitate to take private property for public uses, and to invade the property even of charitable trusts for the passage of railroads, which, whatever may be said of their public uses, can scarcely be considered in any other light than as private corporations. I should be glad to know what business has a dead man with the affairs of the living; and what has a man to do with the earth after he has left it? He has had his day, and is of no further use in it, excepting in the good example which he may have left behind him. Indeed, as Goldsmith remarks, he takes care to rob it of what little he might return for its benefit, by ordering himself to be buried six feet below the surface. 'The earth belongs exclusively to those who nccupy it. It seems to me to behoove us much more to take care for the good of those who are to come after us, and may be essentially affected by what we do, than for the wills of those who have gone before us - whom what we do, or are, cannot affect at all; and who themselves, if they were now living, would see, in a change of circumstances, the absurdity, or uselessness, or inconvenience, or hardship, of the arrangements which they propose, and be among the foremost to condemn and alter them. If public faith requires that the wills of those who have departed should be observed, it should take care that the objects for which those wills provide should be in themselves just, reasonable, and useful, as loug as that provision may continue; but the locking up of land in perpetuum, for private or public uses, seems of very questionable right and expediency. 
It is quite obvious that I am no lawyer; and I give my opinions with the more freedom, knowing that they will not be quoted as authority.*

Besides Smithfield, markets for the sale of live stock, botn lean and fatted, are held in various parts of the country. These being held in determined places, and at established and wellknown times, the farmers and others have always an opportunity of disposing of cattle, for which they wish to find purchasers. and of obtaining such as they require for keep or fattening.

\section{LIII. - GRAIN MARKETS.}

Next to the cattle markets, in England, the grain markets deserve attention. They perhaps should have a higher place, as the value of the grain crop of the country must very much exceed that of its live stock. 'The amount of grain produced in

* I might get upon forbidden ground if I ventured to speak of chartered opinions, and of the variety of artificial and stringent contrivances to regulate what men shall think in all times to come. I have my own notions on these subjects, with which I shall not trouble my readers, further than to say that I hold mental elavery as the most ignominious of all kinds of bondage, and thank God, every day of my life, that attempts to inthral the mind are, in the end, as idle as to attempt to chain the wind, convinced as I am that all hopes of human improveinent, and the moral advanccment of society, must depend upon the utterly free. unrestricted, and independent inquirios of the human mind after what is good, and useful, and true.

I trust I shall be pardoned these reflections, which otherwise might seem inopportune, when it is considered that, in some respects, Smithfield is classical and consecrated ground. I think it was one of the Oxford martyrs, who said to his heroic companion at the stake, that "they should kindle such a fire that day in England, as he trusted in God would never be extinguished." Such were the fires kindled in Smithfield, which, as they were reflected from the surrounding objects, showed the grim, and hideous, and bloody features of bigotry and intolerance, in all their deformity and hatefulness, and still send up their light to Ileaven, as the signal of that liberty of judgment, opinion, and conscience, which constitutes the glory of the human mind, and which every true man should claim, at any and every peril, as his independent and inalienable birthright. 
England is immense, as is quite evident from the great population which is fed.

Kinds of Bread. Matze, or Indian Corn. - In Scotland, a considerable portion of the bread is made of oatmeal. In Ireland, a large portion of the poorer classes live upon potatoes; and many scarcely taste bread from one year's end to another. In some parts of the country, meal from pease, and barley meal, are mixed with a portion of wheat meal, and used for bread. But the vast majority of the people use wheat bread exclusively. There is very little or no rye consumed for bread. Indeed, I have not known it used in a single instance. The poor are extremely tenacious of the kind of bread which they eat ; and I have seen, in more instances than a few, where the farmer was under an obligation to supply his laborers with wheat at a certain rate, and was using wheat of an inferior quality for his own table, and sending the best to market, the laborer insisted upon that of the best quality, though he might have had an inferior quality at less than the stipulated price. I certainly do not deny their right to do this; and I begrudge the poor none of their small round of comforts and luxuries. I wish they whose toil, under the blessing of Heaven, produces the bread, may never want an ample supply, and that of the finest kind. As a general rule, likewise, I believe it sound economy to use the best of every thing. But I refer to this fact, as showing to a degree, in my pinion, the hopelessness of introducing our Indian corn as breac? fir the English poor - a scheme which many persons have advocated on both sides of the water, as reciprocally advantageous to both countries. They will not eat it. If the rich should adopt it as a luxury, (and, if they understood its proper use, they would with reason deem it so, ) their example or estimation of it might have its usual efiect; but to commend it to the exclusive use of the poorer classes as a cheap kind of bread, acknowledged inferior, though it were as sweet as the ancient manna, would be met with that pride of resentment, which any thing short of absolute starvation would scarcely be able to overcome. With Arthur Young, I decm Indian corn, or maize, as among the best. and most useful crops ever yielded by the earth. Nothing within my knowledge is grown at so little comparative expense. 
Nothing furnishes by the acre more nutritions food for man or beast. Nothing, as grain or grass, is capable of more varied and useful application. No plant cultivated returus more to the land, in manure, by way of compensation for what it takes from it. The dampness of the English climate, the deficiency of sunshine, and in general the coldness and heaviness of the English soil, forbid its production here.* If it were introduced here without duty, with a view to fatting swine and cattle, there would he, in my belief, a clear gain, on the part of the farmers, of the manure. I am not conscious of any interested views to bias my judgment in this matter; for, besides an absence of all commercial interests, from which my pursuits in life are entirely foreign, I think there is reason to believe that, if its admission into England were free, the supplies of this article from the shores of the Mediterranean would nearly preclude the competition of the United States.

\section{LIV. - GRAIN MARKETS OUT OF LONDON.}

Grain markets are established in all the principal towns of the country, and are generally held weekly. In almost every town where a regular market is held, there is held a corn market,

* In some few cases, where the locality and the season have been peculiarly favorable, the earliest kinds have ripened; but it cannot be depended on, and any attempt to cultivate it on an extensive scale would doubtless prove a failure. I am not certain that it may not succeed as a green crop for fodder. If so, it would be found that no crop would yield more, or more nutritious feed for stock: or make more milk, beef, or mutton; or furnish a better feed for horses. It is confidently stated, upon authority which I cannot doubt, that it has yielded, in New England, at the rate of thirty-nine tons of green feed to an acre; and some persons have assumed that double this quantity can be grown. $\Lambda$ distinguished agricultural friend here is now making the experiment of growing it for green feed. We must wait for the result. I imported the seed for him; but the various expenses attending it almost forbid a repetition. 'The unfortunate man, who has to run the gantlet through salesmen, and freighting agents, and commission agents, and wharf agents, and carriers, and above all custom-houses, finds himself, at the end, much in the situation of the man who went down from Jerusalem to Jericho; but without even a kind Samaritan to pity his destitution, or assuage his wounds. 
althongh the grain market is always distinet from the general market, sometimes in the same place but at a different hour, but: in most cases, on the same day but in a different place. All grain here goes under the general denomination of corn. In a great many towns, large and elegant halls are erected for what is called the Corn Exchange, where the farmers, millers, cornfactors, and grain-merchants, assemble for this particular object exclusively. In some cases, these buildings have considerable pretensions to architcctural elegance; and many of them larger pretensions to utility and convenience, as there are comnected with them extensive rooms and chambers for the storage of grain.

1. Forms of Business. - The general standard of measure is at quarter, which consists of eight imperial bushels, though still, in some markets, the reckoning is by loads of three bushels. The markets are of two kinds, one by sample - the grain to be delivered on a future day; the others are in some parts of the country called pitch markets, where the grain is brought into the market, and sold and delivered at the same time. In these market-houses, the factors, or sellers of grain, have their respective stands, with the necessary appurtenances of counting desk and writing implements, and with the various samples of grain exhibited in boxes or bags before them. In some markets, I have found many of the factors and farmers bringing their samples of grain, in small bags, in their hands and pockets. In most cases, the markets are opened and closed at fixed hours, and this is notified by the ringing of a bell, to which there is universal submission. Such habits of punctuality, in the transaction of business, are of the highest importance; and should there be occasion, I beg leave strongly to commend them to my own countrymen. 'The rules of commercial transactions cannot, in my opinion, be too stringent and absolute ; yet certainly nothing is more loose and slovenly than the ordinary modes of transacting business in my own country; and the necessary consequence is, a great want of punctuality, and that dreadful curse of the community, angry and interminable litigation. A fixed time to begin and to close the market quickens both buyer and seller; but how often have I seen, especially in the comntry, men wasting the whole day, and chafiering, hour after hour, with all the 
necessary amount of trickery and prevarication, about that which might be much better determined in fifteen minutes!

\section{Advantages and Convenience of such Markets in the.} United States. - The convenience of these markets, scattered all over the country, is very great. They would be very useful with us, and I think cannot be too soon established, especially in our grain-growing districts, such, for example, as Western New York. The farmers in this part of the country would certainly derive great advantages from regular and quick sales, and from the extended competition to which such established markets would certainly lead. Once a week, however, in the same district, would be too often, as they would be likely to take the farmers too much from home; and at the breaking up of the winter, when the state of the roads renders travelling difficult, or during the busiest season of summer, it might be advisable to suspend them. In any event, the hour of opening and of closing them should be fixed and absolute. Mutual agreement might determine this; and the custom, once established, would be as imperative as any laws on the subject. If it should be asked how these markets might be established, I think the agricultural societies in the different counties could easily arrange the matter; and that it would be a very useful object of their attention. I would advise, further, that a grain market, and a cattle market, should be always a cash market; and that all giving or taking credit in such cases should be considered disgraceful both to buyer and seller, and entirely out of the question. If bread should not be paid for in cash, what should be? I am afraid my advice may be deemed a work of supererogation, but it is well intended; and whoever contributes in any way to limit (I am sensible the abolition is hopeless) that system of private credit and long accounts, which prevails to so great an extent all over the country, does a public benefaction. With honest men who mean to pay their debts, nothing, in the end, is erer gained by it; and the frequency with which a man's own integrity is undermined by it is not the least of its evils. I am strongly of the opinion that it would be better for the community if there were no laws for the recovery of debts, excepting cases involving fraud either in the act or the representation; and all such instances should be punished as other crimes. The value of 
integrity would then be better appreciated; economy in the modes of living would prevail much more; and industry and frugality would be greatly stimulated.

3. Modes of Selling. - The sale by sample seems, on many accounts, more eligible than by bringing the whole quantity at once to the market. The sample, in such cases, is divided between buyer and seller, for there should be a guarantee of fair dealing on both sides, as, in case of a fall in price, the purchaser might substitute a better sample than that which he had received, and in this way evade his engagement. In all cases, the selling by sample is liable, however, to objections of this kind, and more especially as the seller himself is likely to separate from a small sample what might injure its appearance; and a small sample is always likely to be cleaner, and appear better, than a large quantity. One cannot say of wheat what the shopkeepers say of their silks and calicoes, "They appear better in the piece than the pattern." While it is very desirable, in all commercial transactions, to avoid, as much as possible, occasions of misunderstanding, much must, after all, be left to personal integrity, and that sense of honor and right which commercial men would find it for their interest to guard with as much tenacity as they would their lives. But alas! if commercial transactions were so exact and explicit as to be incapable of misconstruction or evasion, and men were always under the influence of a strict principle of integrity and justice, what would become of the lawyers, the paid moral police and the strict guardians of justice always on one side? Hany of them would make very good farmers, - a transmutation from which, in some cases, the community might suffer no inconvenience.

Where grain is sold in quantity, or by the load, and delivered at the time of sale, these occasions of misunderstanding are avoided, and the whole business is concluded at once. The farmer leaves his corn and takes home his money; and any anxiety respecting the rise or fall of the market, and the fulfilment of the engagement, coupled as it may be with the usual contingencies of the future, is prevented. But the farmer or seller is placed somewhat at the mercy of the buyer, when, as the close of the market approaches, he finds himself with a load of grain, which he must either sell, or carry back, or store, if it 
be practicable, at considerable trouble and expense. In large markets, however, where the sellers are numerous, and competition is in proportion, the prices become soon settled by common consent; and the seller may calculate, if he does not, through timidity or greediness, overstay his time, upon getting the current price, if the quality of his grain justifies it. "The tide, if taken at the flood," to borrow the simile of a great authority, "leads on to fortune;" but with those who neglect the opportunity, the ebbing tide often leaves the vessel stranded, high and dry upon the shore.

4. Multiplication of Markets in England. - There are circumstances of difference, in the condition of things here, and in the United States, which it may not be uninteresting to remark upon, as a special reason why the grain markets prevail all over the country. Here there is an immense population to be fed, scattered every where; and there are many more, in proportion to the whole number, who are buyers of bread than with us. The manufacturing villages are crowded with a population who are to be fed by other hands than their own. The villages and small towns are full of tradespeople, mechanies, and professional men, who are to be supplied with bread. The laboring agricultural population, too, are buyers of bread. With us, every farmer raises his own bread, and feeds his laborers in his own house. With us, there are comparatively few married laborers employed at all, and of those, there are scarcely any who have not small farms of their own, on which they raise their own bread, and commonly much more. Here the laboring population, excepting in the case of some small allotments, grow no bread for themselves; and the expense of fuel is so great, likewise, that they depend upon public bakers, rather than bake their own bread. In consequence of this, markets are held at all the principal towns, where the millers and bakers supply themselves. Purchases are made, likewise, in these markets, for the supply of London, where the facility of carriage allows its being sent. 


\section{LV. - THE CORN EXCHANGE IN MARK IAANE, LONDON.}

The supply of London itself is an immense affair. The ordinary population of this mammoth city is estimated at about $1,800,000$; and during the session of Parliament, in what is technically called "the season," when the legislature may be said to be in full blast, all the places of public amusement opened, and the court in the plenitude of its luxuries, it is supposed that the population of London does not fall much short of $2,500,000$. Nothing impresses a reflecting mind with more force, than the consideration how such vast numbers of people, all of whom are consumers, are to be fed. Yet they are fed, and the cases of want and starvation do not arise from any deficiency in the supply of bread, of which there seems always enough and to spare.

"The total importation of corn and grain of all kinds into London averages, at the present time, about 28,000,000 bushels annually, besides about 50,000 tons of flour and meal - the weight being at least 530,000 tons." The Corn Exchange, in Mark Lane, is the great place of trade in corn and flour, and in all kinds of grain and pulse. There are two spacious buildings adjoining each other for the transaction of business and the exhibition of samples, and the market is holden three times a week, - on Monday, Wednesday, and Friday, — Monday being the principal market-day. The business done here is immense in home-grown and in foreign grain.

\section{LVI. - CORN DUTIES.}

Grain is not admitted into England from foreign ports, Canada excepted, free of duty, excepting when the price reaches its maximum. The highest duty, of 20 shillings per quarter, is paid when the price is 50 shillings per quarter, and the scale of duties is a descending scale, in certain determinate proportions, 
until the price reaches 80 shillings per quarter, when it is admitted free of duty. In consequence of these regulations, large :mounts of foreign grain are stored in warehouses, waiting for admission, when, by the variations of the market, the duties are at the lowest. The amount of duty payable on the introduction of foreign wheat being regulated by the current price of wheat, it becomes obviously of the highest consequence to determine what is the current price of wheat, since this price has no reference to the cost of the wheat, and, as is plain, the price may vary in different parts of the kingdom. With a view to determine this, returns are received weekly, at one of the govermment offices in London, from the different counties in England and Wales, comprising reports of the sales in two hundred and ninety-two market-towns, designated by law, upon which the mrice is averaged, and by this the duty is regulated for six weeks at a time; the current price, with the duty payable, being announced in the public papers, by authority of the government. This variation of the duties is called the "sliding scale," and has been the cause of much warm political controversy.

The whole subject of restrictive duties is now constantly before the public mind; and while it will not be denied that there are interested partisans on both sides, who hare only some private and personal ends in view, it can as little be doubted that there is a fair proportion, on both sides, of men of intelligence, honor, and integrity, who, in the measures which they advocate, are governed wholly by their convictions of what is due to great and valuable interests, concerned in the question, and of what they deem best for the country. I know how difficult it is to acknowledge this; how easy it is to impute corrupt motives to even the purest minds; and how our own views may be affected by circumstances, of whose influence we are not aware, but which are certain seriously to bias our judgment. Men who think that the corn laws should be abrogated, and those who think that they should be maintained, may be equally honest and equally patriotic; but nothing can be more disgraceful and unvorthy of an intelligent and honorable mind than that bigotry and intolerance, which would stifle inquiry on any subject of public interest; which would prevent the free utterance of an honest judgment, and impute sinister intentions or interests for any difference of opinion. It is to be regretted that examples of this 
intolerance, both in respect to politics and religion, are not wanting on both sides of the water. One is almost discouraged to perceive, in many cases, that the only adrance made upon the intolerant and ferocious spirit of the dark ages, is the immunity from personal violence and suffering. Men are not now, for their religious or political convictions, burned at the stake; but to a sensitive mind, a penalty scarcely less bitter is often administered, in the opprobrium which follows the profession of unpopular opinions. The tiger, though muzzled, still growls, and beats the bars of his cage with his tail, showing what he would do if he could. It is a singular and instructive fact, that formerly it was the great aim of the municipal and the national government to keep down the price of bread, but that the present policy of the government is to keep it up. Two centuries and thalf ago, the city itself provided large stores of grain, imported irom the Continent, and even established and maintained several public ovens, in order to prevent a scarcity of wheat, and to save the poor from suffering by a high price, consequent upon a deficient supply. The several livery companies of London were required by law to have several thousand quarters of grain always on hand, for the same object. It contrasts strongly with such provisions, that, a few years ago, two thousand quarters of wheat, that is, sixteen thousand bushels, were thrown into the river, because the owners would not pay the duties or keep it longer, subject to expenses of storage and port charges. Whether the policy of the present day is an improvement upon the wisdom and good government of former times, I shall leave to the calm judgment of my readers; but such a fact as that detailed above, occurring where so many thousands are constantly suffering, and many dying by slow degrees, from a deficiency of food, can hardly fail to bring a cold chill over a man of common sensibility, though he be cased in the triple brass of the most orthodox school of political economy, and seems such a resentment and defiance of the goodness of Ireaven, that one can scarcely trust himself to speak of it.

1. Arguments for Protection. - The protectionists, who are opposed to the introduction of foreign grain, maintain that a free competition in their own market by supplies from abroad would so reduce the price of grain as to render its cultivation not 
merely profitless, but ruinous; and that the result would be to throw much land out of cultivation, and consequently deprive the laborer of his present resources; and though the price of bread were reduced, yet such would be the scarcity of employment, and the reduction of his wages, that he would be without the means of paying even a reduced price.

2. Arguments against Protection. - The opponents of restrictions in the introduction of foreign grain maintain, on the other hand, that, from the necessities of the case, the land will continue to be cultivated; that the introduction of foreign grain will induce the farmer to cultivate more land, to introduce improvements in cultivation, to bring into a productive condition much land which is now waste and profitless, and thus increasing the amount of his crops by a more skilful cultivation, this excess will be very much more than an equivalent for any diminution of price. The saving of the expenses of transportation, incident to the importation of grain from abroad, must be considered, in its very nature, as virtually a considerable protection to the English farmer.

I do not deem it necessary further to discuss this great question. It does not appear probable to me that, even if the ports were thrown open, much larger amounts would come in than what are now brought ; and one effect is certain - that of increasing the price of wheat in the exporting countries. If more wheat is cultivated in foreign countries for exportation, then it must be obtained from territories more distant than those from which it is now brought, and the expense of transportation would be proportionately increased. The production of wheat would be in no case, as many persons secm to imagine, without limit. The United States have vast markets growing up among themselves for the consumption of their surplus products; and in a free trade, the wheat from the United States must come into severe competition with the continental wheats. Every one must see that the financial bearings of the question are quito complicated; and under such a change in the policy of the country as the abrogation of all duties or restrictions, many new circumstances would spring up to affect the results, little thought of by even the shrewdest calculators. How limited is human prescience! and what countless and complex influences are con- 
tinually intermingling themselves in the affairs of nations, as well as of individuals, which defy equally man's sagacity to understand, and his power to control!

3. Moral Views of the Question. - Having stated, with what impartiality I am able, the principal commercial and financial arguments in the case, on both sides, I feel that there are views of this subject, of a moral character, to which I may without impropriety refer. The question is considered by many as a great question of humanity, which I shall endeavor to look at in the light of a calm philosophy, if I may make any pretensions - and I am certain they must be of the most humble character - to such a lofty gift. I hope my readers, even among the parties most deeply interested, will approach it in the same spirit. I believe, from my personal knowledge of many of them, that there is as ample a share of real benevolence for the poor, among the advocates of the corn laws, as among their opponents; and men of this high character will listen with patience and with eagerness to any discussions of the subject which may serve to correct wrong impressions, if wrong impressions exist, or to make the path of duty more plain, if at present it is in any degree misunderstood or overshadowed.

4. Patriotism and Philanthropy. - It may be supposed that, as the citizen of a comparatively young and growing country, anxious to extend its profitable commercial relations in all directions, and spurred on with an eager and breathless avarice, - stimulated, by an enterprise every where left free to be exerted, and by natural and social advantages of an extraordinary character, to enrich itself by the wide disposal of the products of its industry and its virgin soil, - I should be most anxious for the admission of these products into England under the most favorable circumstances, and should be the strenuous advocate of free trade, certainly on the English side of the water, which is about as far as any man's impartiality may be expected to go. I plead guilty to a strong attachment to my own country, and a most ardent desire for her prosperity; neither of which sentiments has suffered the slightest abatement by my protracter? absence, and my familiarity with other countries and other institutions. But I am not conscious of any interested views 
which should unduly bias my judgment in this case; and I will assert, in all the strength of the most heartfelt conviction, that I regard patriotism as a very mean virtue compared with philanthropy, and that the mere interests of trade are to be trampled under foot with scorn and disdain whenever they conflict with the interests of humanity. I know very well that they are oftentimes coincident. Some time ago, in the United States, at a public celebration, where I am aware that sentiments occasionally get a little colored by the wine in which they are drank, a distinguished public character gave, as a toast, "Ou country!" which would have been very well had he stopped there, and I should have had no objection to emptying my glass, if that had been necessary to sanction it; but when he added, "Our country, right or wrong!" I regarded the sentiment with inexpressible detestation, to which the wine, if I had drank it, would only have added intensity. Some apology may be made for him as a military man; for what has a military man to do with right or wrong? His duty is only to obey orders; and, as a facetious divine said in another case, he has neither the trouble nor expense of keeping a conscience.

5. Proper tinds of National Policr. - When, under the blessing of Heaven, will mankind cease to estimate the prosperity of individuals or nations by a mere pecuniary standard? When, will they learn that the true glory of a nation is the glory of justice and humanity, and that the only legitimate and worthy objects of a good government are, - not the mere accumulation of wealth, the triumphs of military ambition, the extension of territory, the multiplication of pageants and of luxuries, the intrenching of power already too arbitrary and despotic in its exactions, the higher elevation of ranlis already too high for sympathy with the wants, and sufferings, and privations, of the depressed and low, - but the far nobler purposes of giving to all the opportunity and the means of exerting an honest industry, and an ample share, and a perfect security in the enjoyment, of the fruits of that industry; allowing 110 individual to be above the reach of that law which inflicts its penalties upon the most humble and down-trodden, and suffering no person to pine in obscurity, uncared for and unpitied; but, in the exercise of an "xact and impartial justice, seeking to protect the defenceless, to 
succor the oppressed, to raise the fallen; by a wise education, and a paternal care, to inspire even the lowliest with the ennobling consciousness of his own moral and immortal nature; and, in the spirit of true Christianity, to regard all men as one family, and to seek to impart to every man, without stint or abatement, his full share of all the advantages and all the goods which God, when he made men for each other, and endowed them with human sympathies, designed that they should find in the social state? - When, indeed, are these celestial visions of philanthropy to be realized ? when is the bleeding victim to be plucked from the jaws of an unrelenting avarice? when is the imprisoned bird to be let free to breathe the clear air of heaven, and pour out his songs of ecstasy upon the floating breeze? when is humanity - in too many cases oppressed, degraded, plundered - to be allowed to stand erect in the conscious dignity of freedom and of manhood?

6. Bread regarded in a peculiar Light. - In civilized states, bread has always been considered in a different light from almost any thing else, and has been the subject of special regulations. For many years, speculators in grain were looked upon with peculiar suspicion and odium, and were the subjects of particular legal restrictions. They were considered as the creators of scarcity, by their hoarding up large stores of corn; whereas, in fact, it was through their providence that these times of suffering were anticipated and mitigated, or avoided. They are not disinterested, but are as useful and important as any class of persons, employed as agents in any branch of trade. They are most useful in enabling the grower of grain to dispose of it to the best adrantage; and it would be difficult to say how a large community could be supplied without them; as if, for example, London itself were left to the precarious supply of individual farmers. They perform, indeed, a most essential and important service, and are entitled to a fair remuneration. The indispensable importance of a character for fair dealing, and the competition to which they are exposed, are securities against that compensation being excessive. As speculators in grain were regarded with peculiar vigilance, so were bakers, and so are they still, held to a strict responsibility, and the weight of their loaves subjected to an assize. In Turkey, a baker giving light weight is nailed by the 
ear to his shop door - a most awkward position, certainly, to be placed in, and sufficiently admonitory.

'The corn laws are regarded by some persons with a sentiment of similar distrust or dislike. They are considered as a tax upon the bread of the poor, or a reduction of the size of their loaf, to which they ought not to be subjected. The effect of the duty upon corn is obviously to increase the price of bread, as the abrogation of the duty would be to lessen its price, or otherwise it would be of no importance whatever. In two respects, bread differs from other articles which man wants or desires. In the first place, its supply is indispensable to human subsistence; in the second place, though to a degree the product of human industry, its production is not controllable at human pleasure. Of other articles, in regard to which man's only province is to work up the raw materials, he may manufacture a large or small quantity, at his will. In respect to bread, man can only sow the seed, and then wait with humble hope for that blessing, "which shall give the increase." These circumstances have undoubtedly had their influence on the exertions which have been made every where to prevent a monopoly of bread, and to keep it, as far as possible, within the reach of the most destitute.

\section{Peculiar Condition of the English laboring Popula-} TION. - But there are circumstances, connected with the condition of English society, which give peculiar severity to these laws. A large portion of the laboring population depend wholly upon their labor from day to day, for a supply. If wages were paid in kind, the price of bread would not so much affect the laborer. If wages rose or fell with the price of bread, the case would be different from what it is. But this is not the case; labor is superabundant; the competition for employment is severe; and constant employment difficult to be procured. Land, for the purpose of growing bread for themselves, is a matter wholly beyond the reach of the greater part of the laboring population. They might as well think of getting possessions in the moon. 'The soil is locked up in comparatively few hands. It is stated confidently that, from the year 1775 to the year 1815, the number of landed proprietors in England was reduced from 210.000 to 20,000 , and that the process of absorp- 
tion has been continually going on from that to the present time. Labor here, then, is wholly dependent upon capital. Emigration, from the insular character of the country, is extremely difficult, and not as in the United States, where a man has only to take his axe upon his shoulder, and find for himself a home. Though the price of bread, therefore, should increase, the rate of wages would not be affected; the laborer would get no more; and, from the advance in the price of that which is indispensable to his subsistence, his wages would virtually become of less value, though the nominal amount remained the same. Add. to this, that the increase of the population of Great Britain is going on at a rapid rate, the increase for the last year, as stated upon the highest authority, being no less than 380,000 . These considerations, as connected with this subject, cannot fail to have their weight upon reflecting and benevolent minds. Whether any restraint, therefore, should be put upon the supply of food to the people, is a matter which I submit to the opinion of those whom it concerns.

If "property has its rights, it has also its duties," and those of a most responsible character. The condition of the laborer is sufficiently striking. His labor creates the product, but this product passes immediately into other hands; sometimes into the hands of those whose skill, and care, and enterprise, combined with his labor, did their full share in the creation of this product, but often into the hands of persons "who produce nothing, and live only to consume and to enjoy. He must be satisfied if a very small portion of it is returned to him by way of compensation for his toil ; but it would seem at first blush a hard case, if even a portion of this must be abstracted in its progress to him, or otherwise he will not be allowed the opportunity of laboring at all. Our horses and oxen are well fed and cared for, in proportion to the labor which they are compelled to perform. What should we say of the man who refused them this? But alas for the poor men! I have seen hundreds and hundreds of the laborers, who, after a most scanty breakfast, in the midst of their labors, sometimes severe and always unremitting, had nothing for their dinner but a bit of dry bread and a draught of water, and who would retum at night, when the toil of the day was over, to a supper as scanty. Even the inferior butter is not suffered to reach them, but is mixed with tar 
at the custom-house, that it may be destroyed as human food. What an extraordinary fact this is! In one of the great breweries in London, where, I think, forty of the magnificent London horses are kept, they are worked but six years, and are then sent into the country to enjoy rest and comfort the remainder of their lives. What an enviable condition is this compared with that of many of the human laborers, in a country enriched by their toil, and flooded with a wealth unknown before in the history of the world. I should do the greatest wrong if I did not say, however, that there are many bright examples of a justice and humanity towards those by whose toil they live, of the noblest character - a conduct which is sure to be followed by its appropriate reward; and that the evils are deplored by many more, who have not the sagacity to discem, nor the power to apply, a remedy. But the condition which I have described is but too common, and must afford a most instructive lesson to the laboring portion of the people of the United States.

8. Excess of Population. - The constant complaint here is, that there are too many people. This is an extraordinary complaint, while there are several millions of acres of productive lands lying waste and uncultivated. But what is "the preventive check"? Poverty and hunger are not found effectual. It is an extraordinary remedy adopted at Manchester, where, according to the returns, seventy-six out of every hundred of the children born die before the usual age of weaning, a large proportion of whom are dosed ont of existence by the excessive use of opiates. Such a mode of disposing of a surplus population is certainly as little to be commended as Defoe's Short Method with the Dissenters, advising to hang them all! A valued friend of mine, a celibate, and so likely to continue, whose great passion is statistical science, very gravely asserts, that if men and women would not marry until they were twenty-seven years old, there would be no surplus population. The only reply to be made to such practical theories, is in the words of the old proverb, "When the sky falls, we shall catch larks;" and it would not be surprising to find such a man as gravely recommending the old method of catching birds, by putting salt upon their tails. I was one day, in London, importuned for charity, by a healthy-looking woman with a young infant upon her arms; 
and it is not at all uncommon to find them with two, often, no doubt, hired for the occasion. "Why," said I, "do you beg? Why do you not work?" "Because," said she, "I can get no employment." "But," said I, "if you have no means of supporting them, why do you have children?" "Sir," said she, with a simplicity which was irresistible, "Providence sends them." It would have been much more true had she said, improvidence; but it was evident she was no adept in the Malthusian school. Children, then, will be born into the world. The improvement of the lower classes by education, the general elevation of the standard of living, the increase of what may be termed the artificial wants of life, and the influence of the higher class of religious and moral considerations, giving a deeper conviction of responsibility, and rendering the domestic affections more elevated, and the social interests and the parental relations more sacred, as far as they can be brought to bear upon the mind, are among the only certain remedies for this improvidence. These considerations, however, can only be expected to have their proper influence where the mind is in some measure prepared for them by a rational and virtuous education. But it is in no case a sufficient reason for subjecting the poorer classes to any new hardship or privation, to say that there are too many people; because there are other questions, which inevitably arise in the case, to which a reply might not be very easy; - namely, Who is here who has no right to be here? and, Whose duty is it to retire? or, Who should be put out? I do not say that society is bound to support gratuitously any man, other than such as by the providence of God are made incapable of providing for themselves. Here the obligation is imperative. I hold the obligation on society to be equally imperative to afford to every man, as far as possible, the opportunity, by his own honest labor, of providing for himself and those whom the divine Providence has cast upon his care. Now, wherever the appropriation of the soil, or the institutions of society, are such as to deprive a man of this power, or to prevent him the opportunity of its exertion where otherwise he would use it, it would seem, without the most cogent reasons, a measure of great severity to live upon his labor, and to take even from the small pittance which enables him to render that labor; to see him reduced to the borders of starvation, and then to demand a piece of his last crust. I do 
not speak of motives in this case at all, but only of what seems to some minds to be the tendency or character of certain measures. I do not believe there is any prevalent want of compassion among the strongest advocates of restriction, or any disposition to drive the laborers to the wall. Indeed, I shall utter only my honest conviction, founded upon the closest personal observation, that the laborers of England have no warmer friend than in the public-spirited nobleman * who has taken the lead in the protection societies; and this likewise applies, as I well know, to many associated with him. No man in England is surrounded with more contented and attached laborers. But we cannot all see the same subject in the same light; and while nothing is easier or more congenial to a mean temper, nothing is more foreign from a generous and honorable mind, than the imputation of mean or unworthy motives to those whose opinions or measures differ from our own.

I have spoken thus at large, and given, as well as I am able, the opinions prevalent with different persons on the great subject of the corn laws - first, because it is intimately connected with the agricultural condition of England; and next, because I know the strong interest which is taken in the subject in the United States. It certainly is not for us to complain of the restrictive laws of England. I give no opinion as to the policy or impolicy of such restrictions on either side; but, while we barricade our own doors, we cannot, with a very good grace, require of others to leave theirs open.

\section{LVII. - MODE OF ADJUSTING LABOR AND WAGES.}

Every circumstance, which tends to widen the distinction or separation between the rich and the poor, the employer and the employed, and to create opposing interests between them, is alike unfriendly to both parties. The rich and the poor, the employer and the employed, are equally essential to each other.

The Duke of Richmond, president of the $\mathbf{A}$ gricultural Protection Society. $29 *$ 
Formerly, the laborer lived in the family of the employer, and sat at the same table. This custom is now almost entirely done away with; and laborers, instead of being members of the same family, live wholly by themselves. It used to be much more the custom than now to pay the laborers in kind; and then the laborer had a special interest in the crop, and high prices were quite as much for his advantage as for that of his master. This practice still prevails to a degree in Scotland, but nowhere, that I have found, in England. Under present arrangements, however, where wages are paid in money, the two interests, as in all other cases of commercial trading, become distinct, and, I may add, opposed to each other. What one receives, lessens, of course, the gains of the other. The employer gives as little as possible; and where labor is abundant, and competition severe, it is obvious he has the laborer very much at his mercy. The laborer, on the other hand, will not be likely to return any more than the strictest interpretation of his obligation requires. This may be the occasion of a matter to which $I$ have before alluded - that, in my opinion, an English laborer does not accomplish nearly so much in the same time as an American laborer. I speak of cases in which the American is working for himself, the Englishman for another. In cases where work is taken by the piece or job, as in harvest for example, there seems to be no want of application or success, on the part of the English laborer.

Philanthropic minds are now every where anxiously at work devising means or schemes for the benefit of the laborers, and to mitigate the evils of their condition, which otherwise are likely to be increased rather than diminished, as the population increases. In Austrian Poland, where the peasants are themselves occupiers of land, the landlord or proprietor of the soil claims from them a certain number of days' work, each week, exclusively for himself ; but no such arrangement would be possible in England; nor would it obviate the difficulty to which I have referred.

1. Experiment in Germany. - A German baron, with whom I have the pleasure of a friendly acquaintance, has given me an outline of his arrangement with his laborers, which, as far as it is practicable, deserves much consideration, as, aceording to his 
own account, it secures their industry, fidelity, and contentment. No human arrangements are perfect, and no human laws can be framed which the ingenuity of men will not contrive to evade; but as there appears in this plan every motive to good faith, grood faith on both sides would seem to be all that is necessary to its successful operation.

First, from the products of the place, the customary ront is paid, and the wages of the labor employed. The surplus remaining is then divided into five equal parts. Two of these parts are claimed by the proprietor for his skill, intelligence, and care, in the superintendence and management of the property; one part is retained as an insurance upon that part of the property which is liable to loss or destruction; one part is devoted to actual improvements upon the place; and one is divided among the laborers themselves, according to the rate of wages which they receive for their work. Whether these proportions are properly adjusted or not, I shall leave to the judgment of my readers. It is obvious that any others might be adopted which should be deemed more just. It is certainly an approach to an equitable arrangement; and my friend assures me that it works well. He says, he leaves his estate at any time with a perfect confidence that his interests will be cared for and protected, and that there will be no waste of time, and no squandering of property, and no neglect of duty. Success is, in proportion, as much the interest of the laborers as of the proprietor.

2. Claims of Labor, and Duties of Wealth. - This has always impressed my mind as only an equitable adjustment, and must be equally as soothing to a good man's conscience as to a poor man's stomach. Contradicted, as I have often, and severely reproached, as I have sometimes, been for the assertion, I nevertheless maintain as my sober conviction, that in all business where success depends on labor, - whether it be in the case of manufacturing industry, in agricultural labor, or in the toils and hardships of a seafaring life, - the person who does the work, who endures the hardships, who encounters the exposures, has the first claim upon the proceeds, and should come in for an equitable share of the profits. I admit that there is much labor and anxiety in mental application, and in the active cuterprise and care on the part of the manager of such concerns, which are 
often as serere as any bodily toil, and which deserve to be fully compensated. In general, this enterprise is perfectly competent, however, to take care of its own interests, and seldom fails to provide for itself. But it is said, these people take no risks; they are sure, in any event, of their stipulated wages; they have no right to any more. I know they have no legal right. But I do not understand that they take no risks. There is always a risk of losing their wages, which is something; but in all employments there is a risk of health, and in many a constant exposure to disease, to accidents of various kinds, to loss of sight, or loss of limbs, or loss of life. There are many trades and professions where health is almost certain to be impaired, and life to be prematurely cut off. There are peculiar dangers in mines, among complicated machinery, in unhealthy climates, on the open seas, and on the ice-bound and rock-bound shores, bristled with pointed cliffs and ruffled with foaming waves.

I know very well the great rules of trade, as they are called "Buy as cheaply as you can; sell as dearly as you can; get your labor performed for the least possible wages; and accumulate, accumulate, accumulate, as your great end and aim." 'This men call Christianity; I think, to give it such a name is a libel upon a religion which teaches us to do justly and to love mercy, and which enjoins it upon us, as the highest law of social duty, to do to others as we would that others should do to us. I admit that, if men could enter into a perfectly free and equal competition, unmixed self-interest, though an inferior, might yet not be so objectionable a rule as in other circumstances; but how seldom is the competition equal between capital and labor, wealth and poverty, skill and ignorance; and especially in a country like England, where wealth is enormous; labor superabindant; the professions, and trades, and occupations crowded to repletion; the lower classes extremely ignorant and dependent; and the population increasing with a rapidity perfectly astounding. I complain of no man's wealth, if that wealth be the fruit of honest industry and enterprise. I envy no man's power, if that power be justly acquired. But I do envy - with no desire, however, to pluck a single jewel from his crown - that man's honor and felicity, and equally his wisdom and goodness, who, in the possession of ample power, whether of wealth, or learning, or talents, finds his highest honor in being just, and his purest 
happiness in using this power 11 doing good; in succoring those who need succor; in helping those who are trying to help themselves; in encouraging and stimulating self-respect, and a virtuous ambition to make their condition better, even in the most humble; in proving himself the friend of the friendless; in protecting and rewarding industry, sobriety; and frugality, not in a niggardly, but a generous manner; in sharing some liberal measure of his abundance with those by whose labor, under the blessing of Heaven, this abundance has been created; and in sending light, and comfort, and plenty, into the cottages and hearts of those who have sowed his fields, and brought on their toil-worn shoulders the fruits of their cultivation to his stores. The golden harvests of such a man in every wave reflect Heaven's purest sunshine; his dew-bespangled fields glitter with a radiance brighter than ever shone in a regal diadem; and the happiness and joy, which he sends into the homes and hearts of others, return in gushing streams to flood his own home and his own heart.

I know my poor words will find a warm response in many a kind bosom, and, by Heaven's blessing, may throw a spark into that smoking flax, which too much of what is called prosperity may not yet have quenched. There are many such hearts; but in general we see "who gets the lion's share." To reason with avarice, is well nigh desperate. If it were an iceberg, we might hope that, under the rays of a clear sun, it might be made to trickle; but it is a mass of granite, which, like the monitmental column in Trafalgar Square, stands wholly unmoved by the forlorn and pitiable objects of destitution and wretchedness, whom I have often seen, in a winter's day, sunning themselves at its base; and remains alike impervious to heat or cold, to calm or storm, to summer's fires or winter's frosts.

3. Results of tile German Experiment. - The friend, to whom I have referred, has three hundred laborers in his employment. He says, the system works well; and that every year's experience gives him stronger confidence in its justice and advantages. First, his work is done; secondly, it is done in the best manner in which his laborers are able to execute it, because it is the interest of all that it should be done, and well done. The laborers have a system of rules and fines amons 
themselves, always subject to his approbation, and, after once approved, always rigidly enforced. They inquire, of their own accord, into the best methods of doing what is to be done; they point out mistakes which have been committed, and improvements which may be made, subject always to his judgment. If men are found unskilful or incompetent in the particular branch of duty assigned them, he is advised of it, and persons more suitable are selected by their judgment who best understand the capacities of their fellow-laborers for the work. They are held jointly responsible for any injury to the property, unless the offending person is found. An individual guilty of any neglect of duty, or any improper conduct, or any violation of the established rules, is mulcted in a pecuniary fine. The names of the offenders are always amnounced at the close of the year; and these fines, go towards a general entertainment and festivity. The proprietor himself hears all complaints, and a laborer, whose bad habits are judged incorrigible, is discharged.

I have been somewhat amused by his telling me that the great evil which he has to contend with is the use of tobacco. Smoking upon his premises he absolutely forbids, for three good reasons - first, the danger of fire ; secondly, for the time which it occupies, and the lazy habits which it induces; and thirdly, because he deems its effects upon the stomach extremely pernicious to health, and incapacitating men in a degree for labor. In other words, he views it as a poison. So do I. I wish it was as quick and fatal in its operation as arsenic, or prussic acid, always premising, however, that those who now use it in any form should be fully and reasonably forewarned.

4. Scotcr Custons - a Digression. - My readers will, I hope, be indulgent to my infirmity, which has been, even in this country, sometimes put to a severe test. In Scotland, for example, they take snuff with a spoon. A small silver spoon, or one made of bone, is filled from the horn, and then thrust up the nose. To complete the refinement, there is also a small brush to clean the upper lip, and edges of the nostrils. 'The reader may judge of my sensations when the spoon and the horn were botls actually offered to me in church. There may, however, in this case be some claims to indulgence, for in one of the Scotch meetings which I attended, the extempore prayer was actuilly 
one hour, and the sermon which followed, two hours in length; both, I admit, excellent in their way. But then, although the argument and the doctrine were sufliciently stimulating to a stranger, yet veterans accustomed to such engagements might get to sleep, from pure exhaustion, under the discharges even of musketry and camnon, and might require extraordinary applications to keep their sensibility alive. I will say, however, in justice to the Scotch, that I never witnessed more decorum, and more wakeful attention, in time of service, than in the Scotch meetings; and they bore these inflictions or penances, as less serious minds would consider them, with a philosophic submission, worthy of the pillar saints in the dark ages.

While speaking of the manners of the rural population, I may allude to another practice prevailing in some of the rural districts in Scotland, which some persons in the rural districts in the United States may feel an interest in knowing. I attended worship, in Scotland, in a most quiet and delightful district of country, and among green fields cultivated with the highest skill, and loaded with the richest crops, where, when the first regular service was through, and all done, after an interval of about ten minutes, during which the minister never left his pulpit, nor the congregation their seats, the minister began and went through another whole service, and gave a second sermon on a different subject, as long as the former. This finished for the day, and, as I was informed, was so arranged that the farmers, and farmers' wives and daughters, who lived at some distance, might get home in season to milk their cows, and tend their cattle. I had likewise a slight impression come over my mind, that they meant to have their money's worth of instruction, and did not choose to let their spiritual laborer off with half a day's work for full wages. It required, however, a healthy intellectual digestion to dispose of two full meals at once.

\section{LVIII. - THE DEAD-MEAT MARKETS.}

Besides the cattle and grain markets, there are other markets, to which I have already alluded, comnected with agriculture, 
which are sometimes called by the startling designation, the dead marlicts, by which is only intended markets for the sale of slaughtered animals, beef, mutton, pork, lamb, veal, \&c. \&c., and which in London are quite worth a visit. The largest of these, in this great metropolis, are Newgate and Leadenhall Markets; and it is a curious fact, that the former occupies a building (the magnificent entrance of which still remains, with its high and ornamented archway, and its aisles, with the old columns, form the meat-stalls) which was formerly a literary institution, or college. Instead of food for the mind, it now furnishes food for the body; and instead of the purveyors of intellectual provisions, - poetry, philosophy, eloquence, and science, here stand the purveyors of mutton, pork, and beef-a very ignoble office, and a very humiliating descent, as some refined and sensitive persons would deem it: but alas! what would become of science, philnsophy, eloquence, or even poetry itself, without mutton, pork, and beef? The philosophical Edward Search, in his most admirable work, "The Light of Nature," says, "that he has found a draught of Daffy's Elixir, on getting up in the morning, a powerful means of grace, dispelling doubts and despondencies, and strengthening and brightening his faith;" and though, through a foolish pride, we may be disposed to deny or not to recognize our relations in humble life, as citizens sometimes "cut" their country cousins when they meet them in town, yet the stomach and understanding are near neighbors, and the one absolutely dependent on the other. What nature hath joined no man can put asunder.

The markets in London display their meats to considerable advantage; and besides the great markets, meat shops prevail all over the town, and are found in some of the best streets intermingled with other kinds of shops of the most splendid description. Even Bond Strect, the very emporium of fashion, elegance, and taste, has its meat shops, where whole carcasses of mutton are suspended before the doors in long rows, as, under the bloody code of former years, prisoners at the close of the sessions used to be suspended at the Old Bailey, - except in this case in an inverse order, the heads of the sheep being downwards, as mutton-heads are apt to get inverted. A fine lady, in passing from one milliner's or jeweller's shop to another, must take very good care, lest, instead of encountering a fine bean, to 
which she might not object, she encounters a fine quarter of beef, or a fine sheep, which certainly, if taste only were consulted, she would prefer to meet in another form and place. The incongruity is at first offensive to a stranger, and seems in very bad taste; but an amateur finds some compensation in the beanty of the objects thus exhibited. I do not mean the ladies, of whom possibly I may speak in another place, but the meats. Mutton is always the prevailing meat, for this seems to be the favorite dish on English tables. It is a remarkable fact, that mutton is the prevalent dish at the public schools and colleges. At the Blue Coat School in London, for example, it is the sole meat for the eight hundred boys, four or five days out of seven. The same is the case, I am told, at Eton; and this not, as I supposed, from its comparative cheapness, but from experience, and the opinion of nedical men, that it is the most wholesome diet, and lcast likely to interfere with intellectual application and health.

The Southdown and the Leicester sheep are generally preferred, though the small Welsh mutton, for its exquisite flavor, is most esteemed; and the fatuess of the beef, and mutton, and lamb, is every where most striking. Indeed, in the English markets, lean meat is hardly to be seen. If it is sold, it is certainly seldom displayed. The meat-shops are eminently clean; this, indeed, is the universal characteristic of the English people above the lowest classes, who in London are eminently dirty. The salesmen, however, with their blue woollen frocks and aprons, in tidyness of appearance would hardly bear a comparison with the salesmen and women in the Philadelphia markets, with their white linen frocks and aprons. Indeed, in this respect, Philadelphia, as far as my observation goes, stands preëminent. Cleanliness, it is often said, and with a good deal of reason, is next to godliness. I confess to this creed. I think it should be inculcated as a religious duty, and for its useful moral influences. The sect of Friends regard it as such; and it is doubtless much owing to their influence and example, that Philadelphia is so proverbially neat. Many of the English butchers and salesmen are distinguished for their intelligence, and the great extent of their concerns.

1. Slaugiteir-Houses in London. - I have already said that a great deal of the meat which is exposed for sale in London is 
killed in the country, and at some seasons of the year brought cven from remote parts of Scotland. But I shall perhaps surprise some of my readers by informing them that London is full of slaughtering-houses. The police of London is so exemplary, and many of these places are kept with such perfect neatness, that even the nearest neighbors are not apprized of their existence.* This fact may be recommended to the attention of the butchers in the vicinity of Boston, and some other of our large towns. Their neighbors certainly will join in this recommendation, for most of these slaughtering establishments are an intolerable nuisance. In some of the best streets in London, where the meat-shops are found, will be found behind these shops the slaughter-houses, where this meat is killed. You will sometimes see cattle and sheep brought in by the front door of very respectable looking houses, (for the yards of the houses are otherwise inaccessible,) like acquaintances of the family. Back of these shops, I have been introduced into elegantly furnished drawing-rooms, and did not discover that the slaughtering establishment was immediately adjoining, until I looked out of the window. There is not the slightest odor perceptible, to offend the senses. The animals come out in a very difierent form from what they go in. The blood goes at once into the common sewers, and the offal is carefully removed. In the neighborhood of the

* One great means of the extraordinary cleanliness of London is, that no swine are ever allowed to be kept in it. The lower class of Irish, who migrate to London in vast numbers, (for where, indeed, do not these laborious creatures migrate?) are thus obliged to abandon the tender familiarities of their early years, which have "grown with their growth, and strengthened with their strength." As the ruling passion, however, is always strong, and the Irish heart, even in the humblest condition, is distinguished by warm affections, they contrive, as some of the gentlemen of the health commission have informed me, many times in a very adroit manner to evade the law, and the pig and the donkey are often regularly installed lodgers in their rooms, and free sharers at their humble board. It is said that when the terror of the Asiatic cholera prevailed, and a health committee visited the premises of the poorer classes in Edinburgh, with a view to remove the incitements of disease, they found in one of the upper chambers of one of the very high-storied houses of that city, inhabited by an Irish family, a large hog among the children. Upon inquiry how he could have been got up there, the owner replied with genuine Hibernian simplicity, "Plaze yer honor, he was never got up here at all at all ; but he was barn here." I do not know why an Irishman should not be attached to his pig, as well as a nobleman to his dog. In substantial usefulness, the pig would not suffer by the comparison. I cannot say as much of his moral developments. 
great markets, however, the slaughter-houses are in cellars under ground, and are not managed with equal neatness. It requires some courage to enter these places. In the extensive market at White Chapel, the slaughtering establishments are above gromi in the rear of the stalls, and the gutters of the streets literally flow with blood.

2. Custous of the Jews. - The market at White Chapel is in the immediate neighborhood of the quarter of the city where most of the Jews reside. The Jews will never eat or buy any meat, which is not killed by some one of their community deputed or appointed for that express purpose. He comes at the time fixed and kills the animal; and after the meat is dressed, if he finds upon it the slightest blemish or indication of disease, the meat is condemned, and no Jew will buy it, though the Christians betray no scruples of this sort.* If the meat is found perfectly sound and healthy, a clasp or token is put upon the leg, and the Jews are at liberty to purchase it.

Any person who has the curiosity to go into the Jews' quarter, and see how they live, behold the filth of their streets, the wretchedness of their habitations, remark a squalidness which no description can exaggerate, and inhale the odors of which the place is redolent, which seem to be the very compound of

* 'The subjoined note is of a nature scarcely to be read by any person of a very sensitive and delicate mind. I advise such persons, therefore, by all means to pass it over. I give it in self-defence, and to show that $I$ do not intend to make statements without authority.

In my Third Report, page 261 , I said that "numbers of cattle are almost every week, as I have reason to believe, brought to Smithfield in such a state of disease as to be fit for no other purpose - and for this they are actually bought — but to make sausages for the poor Londoners." This statement a lind and intelligent friend complained of as unwarrantable, and not well founded. 'The form of expression might, I admit, have been better chosen; but the reason I had to believe the fact, was the direct assertion of some respectable salesmen in Smithfield Market, who spoke of the practice as undoubted. This was particularly applicable to the time when an epidemic prevailed among the cattle. 1 do not believe any city officer would permit or connive at it, if known; but cases of a strongly suspicious character are yet established with so much difficulty by what would be deemed legal evidence, that parties notoriously criminal often escape with impunity.

But the following statement, given under oath to Dr. Playfair and Sir Henry de la Beche, of the IJealth of 'Towns Commission, during their inquiry into the 
corruption and pestilence, and of all that is odious and disgusting, will feel no little surprise at their particularity and fastidiousness in regard to their meats. But these are among the inconsistencies and anomalies of human nature, which are to be found among persons in almost every condition. The same inconsistency is seen, for example, among the lower class of Irishwomen in their own country, however humble in condition, with whom it seems to be the ruling, and an indomitable passion, to have a clean and handsome cap, though in most other respects one would be half inclined to think they were laboring under a species of hydrophobia. You will see them, the head surmounted with an elegant frilled cap, emulating the whiteness of the drifted snow, while the lower parts of the person, in a state of nudity, (for the drapery of the statue of an Irishwoman seldom extends below the knee,) though, as pieces of sculpture, exhibiting: originally the highest artistical skill, are yet so rough, and torn, and begrimed and stuccoed with mud and dirt, that you can hardly believe that both ends belong to the same person, and that the head has not by some awkward mistake got upon the wrong shoulders.

3. Mode of slaughtering Animals. - I have felt it a duty of humanity to inquire into the mode of slaughtering animals,

state of Bristol, may serve to clear up some of my friend's doubts on the subject. Report on Lancashire, p. 30.

"Have you resided some time in this house?" "Yes, for several years."

"What occupation does your neighbor pursue?" "He kills pigs, which he gets over from Ireland. Often the pigs, in coming over in the packet, die, and I have scen as many as thirty dead pigs at a time brought into the yard. They are thrown into the shed there until there is time to cut them up; and by that time I have seen the magrots fairly dropping out of them. Then they are cut up, and, I believe, are made into salt bacon, or sold for sausages." * * * * * * * * * *

"Have you not complained of this nuisance?" "Yes, we have ; but we were told it was of no use complaining, for doctors agreed that these smells were very healthy. Besides, the owner of the yard is a very good neighbor, and tries to keep things as clean as he can; but his occupation beats him in that."

What can go beyond this? But why, it may be asked, refer to such cases? Because, in order to correct an abuse, and to guard against it, that abuse should be exposed. Nor is it without a melancholy instruction, to see to what extremes avarice will hurry its votaries; nor without a moral use, to hold up the perpetrators of such wickedness towards the poor and ignorant to the execration which they descrve. 
with a view to discover if there be any way of lessening the suffering necessarily inflicted. When it is considered that from thirty to forty thousand animals, poultry and game not included, are put to death weekly, for the supply of the city of London alone, it becomes a grave question of humanity whether any, and if any, what amount, of the physical suffering necessarily incident to such operations, can be saved.

"The poor beetle, that we tread upon,

In corporal sufferance finds a pang as great

As when a giant dies."

The moral influences of the employment, in this case, are certainly deserving of consideration. The notions of former times were such, that a butcher was not allowed to sit as juror in a trial of life and death. I cannot sympathize in these prejudices; but any practice, which tends in any degree to render us indifferent to the infliction of pain, even in the case of a dumb animal, - any practice bordering upon cruelty, - cannot be without its pernicious efiects upon the temper and character of persons accustomed to it. It may seem to some persons a ridiculous squeamishness, but I confess that I never see cooked animals brought upon table as near as possible in the form of life, whether it be game or any thing else, without a painful disgust, which I find it impossible to overcome. It is a mysterious law of nature that animals should feed upon each other; and certainly, as we cannot doubt, like all the laws of nature, a beneficent law; but it is the ferocity of a tiger, and not becoming a man, which delights to regale itself with the warm blood of his victim; and though I am no Bramin, I wish always that the food which I eat should be as far as possible separated from al associations of life.

Sheep are slaughtered by thrusting a straight knife through the neck, between its bone and the windpipe, "severing the carotid artery and jugular vein on both sides," by which they bleed freely, and life soon becomes extinct. They are kept fasting twenty-fom hours before leath, as it is said that, if killed upon a full stomach, the meat is not so agrecable to the taste, and sooner passes into a putrid state. Sheep are placed here upon a cradle or stool, to be killed, as with us. I am not very well able to describe the mode of cutting up and dressing, further than to say, that it exhibits a remarkable neatness: that the 30 * 
meat, as far as I can observe, is never blown; and that the calcass is not, as with us, slit down by the back-bone, and so divided into four quarters; but a piece nearly square is cut from the loins, termed here a saddle of mutton, which is esteemed a more choice part for roasting than the leg, and is always a favorite dish upon an elegant table. The butchers, or coolss, have likewise a habit, not certainly general with us, but much to be commended - that of separating the joints before the meat is cooked, which greatly alleviates the difficulty of carving.

The mode of slaughtering cattle differs from that of slanghtering sheep. Some gentlemen, a few years ago, interested themselves much on this subject, on the sole ground of humanity, and experiments were made of killing the animal, by driving a sharp instrument directly into the spinal cord, back of the horns; but, although the animal fell instantly, yet the convulsions continued much longer than when he was killed by being stunned, by the former method, and it was reasonably inferred that the suffering, therefore, was much greater. This is said to be the mode adopted in the great slaughtering establishments in the neighborhood of Paris, "where a sharp-pointed chisel is driven, with a smart stroke, between the second and third vertebræ of the spine; insensibility immediately ensues, and the blood is let out by opening the blood-vessels of the neck." Besides the objection made above to this mode of slaughtering, it is said the animal does not bleed so freely and entirely as when stunned on the forehead, as by the former method. The present mode of killing is by bringing, by means of a ring on the floor and a rope passed round the foot of the horns, the ox's head to the ground; and he is then struck on the forehead, not, as with us, by an axe with a flat head, but with a similar instrument, with a pointed end, two or three inches long, of the size of the small finger, this point being hollow, and with sharp edges, - and this is driven directly into the upper forehead. The animal falls at once: this point is immediately extracted, and a wooden pin, of about the same diameter, is driven into the wound, and forced into the brain or spinal marrow, and the animal dies at once. I am not certain, that this is an improvement upon the mode of killing which prevails with us; though the killing of an $o x$, with us, requires great adroitness and great strength; otherwise, the blows require to be repeated. and much suffering is inflicted. which. it would seem. 
might be avoided. The English method might be tried; and if it has any advantages to the sufferer or the executioner, I cannot doubt it would be adopted.

Calves, as I have observed, are not killed under six or eight weeks old, and they are bled daily for a week before they are slaughtered. I do not know that this is a very painful operation, but very little seems to be gained by it. They are killed, as with us, by cutting the throats across. The manner, however, in which they are often conveyed through the streets, piled into a cart, lengthwise, by dozens, with their heads hanging down as they are jolted over the pavements, is perfectly shocking to humanity, and deserves the interference of the benevolent society for the prevention of cruelty to animals. It is sufficiently humiliating to feel, that in nothing does man more need watching and restraint, than in his treatment of the helpless and defenceless.

It is a subject certainly worthy of concern. It is no affectation of sensibility, though by some it may be deemed a morbid sensibility, to say, that the subject is a painful one. The passion which one sometimes sees excited in the killing of animals, and the utter callousness and indifference with which some persons go about it, to whom the work is familiar, are very far from being agreeable features, either in temper or conduct. The sight and smell of blood excite an instinctive horror even among the inferior animals; and any man, who contributes, in any way, to alleviate pain and suffering, even among the lowest of sensitive existences, and to prevent cruelty, more especially to the dumb and defenceless, need not feel that he has lived wholly in vain.

\section{LIX. - VEGETABLE AND FRUIT MARKETS.}

England may with reason boast of the fineness of her fruits, espccially as, in this matter, she has to contend with the adverse influences of temperature and climate. The country abounds in greenhouses, hothouses, conservatories, and foreing-beds. All the appliances of art, and the highest measure of horticultural skill, are exerted to counteract the unfavorable circumstances 
under which their cultivation is carried on; to protect plants whose frail nature requires protection; and by every possible means to stimulate and bring to perfection those plants and fruits which seem to demand the same assiduous and parental care as the young of the animal creation.**

Few of the country houses belonging to persons whose means allow of such indulgences, are without forcing-beds, greenhouses, and conservatories. Many persons, whose means are restricted, with a high refinement of taste, sacrificing the common pleasures of a frivolous and inferior character, prefer this far higher class of enjoyments and luxuries. In these greenhouses and conservatories, the gayest flowers, the most precious exotic plants, and the richest fruits, are cultivated. Many of these conservatories, filled with the choicest varieties of flowering

* I wish we knew more of vegetable life. Indeed, what branch of science is there, of which we have not reason to wish we knew more? The microscope, under those modern improvements which have increased its power, and consequently extended the field of its triumplss in a most astonishing degree, is constantly bringing new wonders to light; disclosing the curious and complex structure of the vegetable world; and enabling us to watch in some plants, in their wonderful frame-work, the rapid circulation of the streams of life. Such discoveries almost make us feel that the man who would wantonly pluck a lily from its stem, and scatter its leaves to the winds, or would trample a damask rose upon the ground, offers an offence to conscious life, and casts an indignity upon some of the most beautiful expressions of the divine skill and beneficence.

I have recently had the pleasure of looking through as powerful an instrument, of this kind, as human art has perhaps as yet been able to produce. Leaves, woods of different kinds, and different insects, were presented upon the ficld of vision, and exhibited a structure so various, complicated, and exquisitely finished, that one seerned endned with a new sense, and almost born into a new world.

I often hear it said that divine revelation is complete and full, and that we must look for nothing more. It may be so with a written word; though I know of no right which any human mind has to limit the dispensations of Infinite iVisdom; and with the most reverential gratitude for what has been given, I confess there are many more things, than have been revealed, which my impatient curiosity is thirsting to lnow. But the revelations of the natural worla secm only just now begun. 'The telescope and the microscope are unfolding many a book hitherto closed and sealed, and pouring a flood of light upon ficlds of wonders which have not before been brought within the reach of human vision, and disclosing objects, forms, structures, contrivances, modes of being, of actuvity, of life, and of enjoyment, which force upon the mind a sense of the Creator's skill, goodness, and power, absolutely oppressive, and awaken a feeling of reverence and adoration wholly incapable of utterance. We may presently come to understand the organization, for respiration and digestion, of the regetable 29 we do of the animal world; and one is scarccly less mysterious than the other. 
shrubs and plants, are at the side of, and immediately accessible to, the drawing-rooms of the houses, furnishing, besides the most beautiful objects of sight, an attractive recreation and delight to the female menbers of the household, and a refreshing retreat from the dissipations of society, or the harassing cares of domestic life.*

The hothouse or greenhouse productions of England (such as pine-apples and grapes, the natives of climates of a higher temperature) are not surpassed by any which I have ever tasted. The pines, or pine-apples, appear to me in size quite equal, and in

* In one of the most beautiful parts of England, endeared to me by the hospitalities of friends whose kindness I cannot too highly appreciate, I found even a right reverend bishop, a man eminent for his intellectual powers and his literary attainments, entering, with all the enthusiasm of Bacon, into the cultivation of his garden, as " one of the purest of human delights." He was then considered as among the warmest patrons of a religious party, whose eminent piety no one questions, who have, at least for a while, converted the Established Church into the church militant, broken up the dead calm in which it had for years reposed, and lashed its waves into a tempestuous foam. When I visited him, he was anxious to show the friend who accompanied me, and myself, his rosary, as he termed it, where, in a separate and extensive enclosure, he was cultivating a great variety of roses, with something of the enthusiasm which is said to have characterized the cultivation of tulips some years gone by. I could not resist the inclination to tell him, without any intentional discourtesy, that he had been for some time suspected of certain heresies, but I hardly supposed matters had gone so far with him that he would openly show his friends his rosary. He was then in the midst of a religious war, if it be not an abuse of language to call any sort of war, or any angry contest whatever, "religious," and in the very heat of the fight. I could not avoid thinking, at the same time, what a refreshment to the soul, as well as to the body, must it be thus to retire from the field of theological controversy, bristling with points of angry dispute, like the bayonets of an opposing column on a field of battle, to the charming quiet and delightful occupations of rural life. Soothing it must have been, to cease for a while a well-nigh hopeless struggle for a perfect unity of opinion, form, and faith, to contemplate the infinite and harmonious variety which pervades creation, and reflect, at the same time, what an abatement of utility and enjoyment it would have been, had God comprehended all this infinite diversity in one, and made all animals of one form, all vegetables of the same kind, and all flowers of the same color and fragrance. Though I was far from being willing to censure this venerable man for anxiously and devoutly turning to the east, when he recited the articles of his creed, if he deemed it important so to do, I could not help thinking that he must sometimes turn his face to the west, to offer his evening sacrifice, when, standing upon the threshold of his door, he saw before him the wide-spread ocean glittering with matclless splendor, and the setting sun bathing in a flood of glory, and throwing his slanting beams over, a landscape as diversified and as beautiful as, within my observation, the pencil of nature has delineated. 
flavor superior, to any which I have seen brought directly from then own native region, - for the reason, perhaps, that the latter, as is understood, are gathered in a green state, and are left to ripen on the passage, usually crowded in bulk in the hold of a vessel. The grapes are magnificent in size, and delicious in taste. I cannot say that there are no native grapes, and none growing in the open air; but I do not recollect meeting with any. It seems to me to be the humidity of the climate of England, rather than its low temperature, which prevents the ripening of many fruits and plants, which can be grown in an equally high latitude on the western continent. It remains to be seen what will be the result of that remarkable system of drainage, which is here prosecuted in different parts of the country with great spirit and resolution, and which bids fair, as soon as any such great operation can be expected to be effected, to become general, if not universal. Its sanatary effects upon the human, as well as the brute animal, are said to be already in some places determined.

The smaller fruits - such as strawberries, raspberries, gooseberries, and currants - are cultivated with great success. Of a kind of strawberies, called the Alpine Pine, and more properly the Elton Pine, the size is most remarkable, ten of them, as I saw in the market of Dundee, where they are cultivated in perfection, actually weighing a pound avoirdupois. I saw others as large at the horticultural exhibitions, called by a different name; but those were forced in pots in greenhouses.

The gooseberries which I have seen on private tables, and in the markets, are of a very extraordinary size, the purple varieties being preferred. I cannot learn that they are as much subject, as in New England, to a species of mildew, or bluish mould, which soon becomes black, and ruins the fruit. Here they are always cultivated upon a single stem, in the form of a small tree, kept trimmed high, and entirely clear of all rubbish or weeds at the bottom. The disease, or blight, to which I refer, is not unknown here, but it is not common; and the fruit is grown in the highest perfection. 'This disease may come from an unhealthy condition of the soil, or the application of improper manure; but the general and most probable conclusion is, that it is atmospherical. It has appeared to me, that the climate of England, where they have far less sunshine, and much more dampness, than in the Northern United States, does not produce mould in the 
houses upon plate, furniture, and books, so soon as it does with us, and provisions, both raw and cooked, appear "to kecp sweet" longer. I do not undertake to give any scientific reason for this; but it seems probable, that it arises from a more even temperature, and the absence of that intense heat which, with us, often follows rain and dampness. The black currant is almost as much cultivated as the red and white, and quite commonly eaten. Raspberries are cultivated; but I have seen none to be compared with the fine kinds common in the United States. Blackberries I have not seen cultivated. I have met with them in the southem parts of England, but ripening so late in the season that they have no richness of flavor.**

Of plums there are several kinds: damsons are common; the Orleans plum, the large egg-plum, resembling what $I$ think is called, with us, Bolmar's Washington, are the most esteemed; but they are not abundant, and I cannot say that those which I have seen are equal to those seen in the best markets of the United States, and especially, of all other places, at Albany, in New York, where this fruit is found in a degree of perfection and abundance which I have seen nowhere else. Cherries are

* I am quite aware of the old proverb, "that there should be no dispute about matters of taste," and that it is perhaps quite too late in the season with myself, for me to discuss these matters. I remember very well when a half-grown, green, hard, sour apple, was as much relished by me as now a delicious Muscat grape; but, alas! "the times change, and we change with them." I will not complain. To complain would be ungrateful. There are tastes for all ages, as there are fiuits and flowers for all seasons. I thank God every day of my life for the beantiful world in which he has placed me; but I would not wish to be always young; any more than I would desire to be always old. I cannot say that I ever sighed for a perpetual summer ; for nature every where abounds in compensations. I exchanged the bright, sunshiny days of my own country for the foggy and humid climate, and the cloudy and weeping skies, of England, where sometinies l have scarcely scen the moon and stars for a month, and where, when the sun shows himself, one seems to recognize an acquaintance of former times. But what of that? Habit and use reconcile us to various and ever-changing circumstances. I have become amphibious, like a true Englishman, and take a good wetting quite naturally. The moderate temperature of the climate has become agreeable; and even the cloudy skies seem better for my eyes than the bright anci dazzling snows of New England, in the clear days of winter. Age itself, if it has not the vivacity of youth, and is sometimes oppressed with the consciousness of having not even half accomplished our duties and desires, brings with it many delicious treasures of memory, which, like good wine, lose nothing of their sweetness by time; and hopes, which we would not exchange for all the pleasures of the whole of life's brightest summer, are daily approximating their fruition. 
plenty in the market, and in great perfection; the Tartarian, the bigarreau, and the large black-heart and mazard, predominate.

Peaches, nectarines, and apricots, are seen occasionally at private tables; and in great perfection, though in very small quantities, at the great market, and at some of the splendid fruit shops in London. Peaches are grown in favorable situations on open walls, but in general under glass, and early in the season are forced by an artificial climate. They are brought to great perfection in appearance, and command, when first they appear in the market, two guineas, or about ten dollars and a half per dozen, as pine-apples cultivated here, at some times of the year, bring a guinea or thirty shillings sterling apiece, - that is, from five and a quarter to seven and a half dollars each!

One, in such cases, ceases to have any solicitude to know where the peaches or the pines come from, but is curious to learn where the guineas come from. To most of us, however, unindoctrinated in the financial contrivances and complex laborsaving machinery of society, this inquiry seems hopeless, and generally ends in the conviction that wealth is very unequally distributed in this world, without any possibility of devising any practicable scheme for a more even and impartial adjustment. Suppose we could at once level all the waves of the sea, and produce a dead calm, and a perfectly even surface; still it would seem that, while the drops on the top are glittering and radiating in the sunshine, a vast proportion of the drops must be underneath, or near the bottom, sustaining those at the top. The only hope in such case is that, in the continual fluctuations of the whole mass, amid the conflicts of under-currents and upper-currents, the spontancous effervescence, and the turbulence of winds and storms, the lowest may often be brought to the surface, and the uppermost descend, and this continual change of place and position may give to all, in the long run, an equal chance.* This analogy, perhaps,

* It is by no means the case, I am aware, that the low position is always to be commiserated. The place of humble obscurity is, in general at least, the place of safety, and is quiet and peaceful, while the surface is swept and disturbed by the violence of every storm. There is a measure of selfishness and narrowness in the conception of a charming poet, which is not to be approved, when, in the tones of pity and complaint, he says, -

"Full many a flower is born to blush unseen, And waste its sweetness on the desert air ;"

as if the beauties of nature were made only for man's eyes, and as if the hum- 
can scarcely be said to apply to a country, where the masses of wealth are the accumulations of centuries, and are fortified and hedged in by the strong iron fences and the bristling chevaux-defrise of laws of entail and rights of primogeniture. It may serve better to illustrate a condition of society like that in the United States, where the paths of competition in the various departments of life are equally open to all - the condition of the laws and the habits of the country favor the more equal distribution of wealth, and seem to forbid any extraordinary permanency to any large accumulations. Which condition is to be preferred, my reader must determine for himself.

'The luxury in which the higher and wealthier classes in England live is, probably, unequalled in any comntry, and is, perhaps, not surpassed in the history of Roman grandeur or Oriental magnificence. They expend, whether willing or unwilling, with a profusion which it is difficult for those of us brought up in the school of restricted and humble means to understand; and in respect to true liberality, there is probably the same diversity of disposition and character to be found as among those, who, instead of dispensing guineas, are obliged to keep their reckouing in pence and farthings. I do not forget that excessive wealth, as well as extreme penury, have each their peculiar moral dangers. But the liberal expenditures of the rich, eren upon many articles of pure luxury, are a great public benefit. Certainly, no immoral indulgence is ever to be justified or excused. I do not say that it is the best appropriation of the money; that point I shall not now discuss; but certainly the person, who gives his two guineas for his dozen of peaches, encourages industry, rewards horticultural skill, stimulates improvement, excites a wholesome competition, and would, surely, be doing much worse with them if he kept them parsimoniously and uselessly hoarded in his coffers.

The apples, in England, are in general inferior, excepting for cooking purposes. The superiority of our Newton pippin is every where admitted and proclaimed. Of other of our fine apples, - such as the golden russet, the Baldwiu, the blue pearmain, and many others, - I have seen none, though it is not to be confi-

blest flower did not perform its proper part in purifying the air, the great element of life to all animated existence, and regale many a sentient being by its fragrance, and fecd myriads upon its leaves, and yield to many a busy insect the precious honey from its expanded bosom. 
dently inferred, from that circumstance, that none are imported. Large quantities of apples are sent from the United States to England, and sold to advantage.**

The English have not yet learned the value of apples as food for stock. Many of the farmers in the United States, after repeated trials, both for fatting swine, for neat stock, and even for milch cows, rate them in value in the proportion of three bushels of apples as equal to two of potatoes. There are many forts of England, where apples might be cultivated to advantage for this very purpose, where the finest kinds might not ripen, but where the inferior sorts would be likely to yield abundantly. 'There are many hedgerows where they would grow to advantage; and they certainly might be substituted, without loss to beauty, and with a clear gain to utility, for many thorn-trees, ash-trees, and others, which now stand in the parks and open grounds of the country.

Of pears I have seen several good kinds, but none comparable to the Seckle or the Bartlett. This, however, may be mere matter of personal taste. Melons are grown only under glass, and by artificial heat. The English walnut grows abundantly, and is used both dried and for pickling; and chestnuts are plentiful. The common shagbark, or hickory nut, I have not met with, though it is sometimes imported. Filberts are cultivated in the county of Kent for the market, on a gravelly soil, where they are raised on small bushes, or trees with one stem, and suffered to grow not more than five or six feet high. They grow together on the same ground with hops, and pear or apple-trees; and the proportionate number of each to an acre, is stated at 800 hills of hops, 200 filberts, and 40 apple or pear-trees. "The

* Small adventures sent in this way, as presents from friends to friends, are often so badly packed at home, and so adroitly unpacked on the passage, and withal, are tixed with such a variety of charges in the transit, that one is compelled, from bitter experience, to give up a much greater pleasure than that of eating the fine fruit - the pleasure of enabling one's friends to eat it. The Christians, as we are called, have, at least many of them, very little honesty, and, one would be half inclined to think, live upon a system of piracy, or privateering, or reprisals, among themselves. 'The Turks have more; for all travellers assert that what is intrusted to their lieeping, under a pledge of fidelity, is sure to be held sacred. The violator of such a trust, upon conviction, would be likely to find himself a head shorter. But then the Christians have a great deal more, and a truer, faith; and after all, common honesty is a very homely virtue, which any body can practise if he would. 
hops are said to last twelve years, the filberts thirty, and after that, the apples and pears require the whole ground."

The vegetables grown for table use are many of them in appearance of the finest kinds. The potatoes grown in England are in general of a superior quality, though I think them inferior to the potatoes grown in Nova Scotia. In Nova Scotia, they have not only the advantage of a climate as cool as that of England, but likewise of a virgin soil, which circumstances seem particularly favorable both to the growth and the quality of the potato; and nothing of the kind, which I have ever eaten, is equal to a fine Nova Scotia potato. In our old soils, surcharged with manure, the potatoes are always inferior in quality. In Ireland, deemed of all other countries the adopted home of the potato, I was seldom able to find one that was even eatable. This arose, however, not from the quality of the root, but from the mode of cooking - the Irish always desiring, to use their own expression, "to have a stone in the middle ;" so that the aim of the cook was only to boil, or rather scald, the outside of the potato, and leave the inside as hard as when it went into the pot. The advantage of this, as gravely stated to me, was that they were longer in digestion, and therefore gave more support. This may be sound philosophy in Ireland, where the stomachs of the poor find an equal difficulty in getting, as they do in keeping what they get. It would be inhuman to treat the extreme destitution of these poor wretches with any levity; but I found this mode of cooking prevailing also at the tables of the rich and noble; and after seeing such an abuse of one of the most useful and nutritious plants which come out of the earth, I was half inclined to advise them to try a few granite pebbles of a size to pass through a McAdam ring, and see whether they would not serve the digestive organs still longer. It was a curiosity to me in London, likewise, to see them selling in the market, by the quart, the small, not half-grown, not quartergrown potatoes, not even so large as cherries, and many not larger than peas; and these were bought up as luxuries. I should quite as soon think of sitting down to a dish of boiled bullets, or duck-shot; and I should suppose with almost equal chance of nourishment. If it were such potatoes only, at which Cobbett launched his anathemas, one would not be surprised at his indignation. 
It is a very great point to bring the earliest potatoes into the market, and I have seen them offered in Covent Garden Market as early as March. Indeed, by a method which I will presently explain, there would be little difficulty in having them at the coming in of the new year. In Penzance, in Cornwall, at the very south of England, where there are some parcels of most excellent soil, and great skill in its cultivation, where the winter is open and the climate very mild, and where, for this purpose, land is let at twenty pounds, or one hundred dollars per acre, large supplies of early vegetables, potatoes especially, are raised for the London markets. In this case, they are sprouted under and upon warm horse-dung, or under glass; and are planted as early as Febrnary, and carefully attended, pains being taken to select the earliest kinds. The mode of sprouting them in this case is similar to that adopted by the excellent and spirited cultivators at West Cambridge, near Boston, where the sets are started, under a bed of fresh horse-dung, on the sunny and protected side of a hill.

I will here quote the directions of the celebrated Mr. Knight, president of the Horticultural Society, for raising early potatoes; which, it is obvious, can be applicable only to our mild and southern latitudes, where the winters are open.

"Drills may be formed in a warm and sheltered situation, and in the direction of north and south, during any of the winter months, two feet apart, and seven or eight inches deep. Stabledung, half decomposed, should be laid in the drills, and combined with the earth four inches downwards, and covered with some of the mould which had been thrown out in forming the drills, by the rake, to within four inches of the surface. The sets uncut are then to be placed, with the crown-eye uppermost, in the centre of the furrow, four inches from each other, and to be covered with only an inch of mould at first, and afterwards with an occasional quantity of sifted ashes, until the plants are so vigorous and advanced as to require the usual earthing, of which, however, very little is necessary." Mr. Knight also used leaves as a lining at the side of the drills, in the early periods, to preserve as much warmth as possible, and better to guard against the effects of frost. 'The soil in this case should be light and dry, and not tenacious of water. It is recommended by some gardeners, early in the season, to lay the sets upon a floor in a 
warm room, and occasionally sprinkle them with water, which will cause them to germinate. As soon as they have sprouted, cover them with some finely-sifted mould; and the sets will be. ready for transplanting at the earliest period.

Another mode of obtaining early potatoes, not new potatoes, which is, I am told, sometimes practised, is to plant potatoes only so carly in the season, as that they shall be about halfgrown at the usual time of taking them up. These may be taken up in the autumn, and replaced in earth; and early in the succeeding spring they may be sold as new potatoes. I should be sorry, by any account of the deceptions and tricks practised in this old country, to be in any degree instrumental in corrupting the simplicity and true-heartedness of any of my own countrymen, who, good souls, may possibly never have heard of any such thing as trick or deception! but excepting the lie in this case, the potatoes would be quite as good as the half-grown, waxy, new potatoes usually brought to market.*

Potatoes are sold in the market by weight, fourteen pounds constituting a stone weight; in Ireland, a stone of potatoes weighs sixteen pounds. In Ireland, the crop is measured by barrels, and an acre of ground is stated to have yielded so many barrels. Then the Irish acre differs very much from the English statute acre, being, I think, the former compared with the latter, as 196 to 121 , or nearly 5 to 3 . A barrel of potatoes in Ireland may contain five, or only three bushels, and the weight of the bushel of potatoes is not determined, though customarily estimated at 56 pounds. Few beans are cultivated for the table, excepting the Windsor bean, which is a coarse vegetable; and a small bean, used like our string beans, and called the French bean. Our Lima bean, and other rich pole-beans, I have not met with. Peas are abundant in market, are brought in early, and continued late, and are of several different kinds, the Charlton pea (so called from the town where the earliest peas are

* Nor, if they should be tempted to practise any such fraud, will I go so far as to recommend them, by way of encouragement or consolation, to read the cliapter on Lying, in Paley's Moral Philosophy; nor, above all, that celebrated treatise of the same exquisite master in casuistry, that perfect anodyne for weak consciences, the Letter on Subscription, in which he shows, with admirable skill, in how many different ways an honest man may subseribe the thrrty-nine articles of the church without believing one of them. 
grown) being preferred as an early pea. In order to bring peas to early maturity, or rather to a state for sale, a ridge of land or high furrow is thrown up in a direction from east to west, and the peas are planted on the south side of this ridge at the bottom of the furrow. In this way the young plants are protected from the cold winds on one side, and enjoy the warm rays of the sun reflected on the other. This is a simple and excellent arrangement, especially in a climate where we may say, with some truth, that a handful of sunshine is worth much more than its weight in gold.

Carrots and turnips are of the finest quality, and always sold in bunches. 'The orange carrot seems preferred for the table; the Belgian white for stock. Onions are generally eaten small. They are planted early in the autumn, and gathered in July and August. Spinach, endive, cresses, lettuces, are always in the market, either forced or grown in the open ground. Bloodbeets I have scarcely seen, either in the markets or on table, unless pickled in vinegar. The fine egg-plant, so common in the New York and Philadelphia markets, does not appear to be known here. That most luscious vegetable, the sweet potato, of course cannot be grown. I have once seen some for sale at a shop window, and, thinking $I$ would indulge in a reminiscence of home, I found, on weighing, at the price asked, a single potato would be $1 s .6 d$. or $37 \frac{1}{2}$ cents. Of course it ended in inquiry; and I was obliged to be satisfied with other forms of remembrance. Of squashes, they can scarcely be said to have any. They have a very inferior kind, which they dignify with the name of vegetable marrow; but of our fine crook-neck and Canada squashes, or our autumnal vegetable marrow, nothing is seen, and their exeellence cannot be appreciated without being tasted. Of our delicious green Indian corn, of course they have none. Cucumbers are always in the market. In the early part of the season, they are forced; in the latter part of the season, they grow out of doors. Every possible pains is taken to protect their plants, as may be seen by the hundreds of handglass frames and bass mattings which are to be found in every extensive vegetable garden.

There are four species of plants, or edible vegetables, in which, it must be admitted, the English markets cannot be surpassed, at least in the size of their products. They are asparagus, 
rhubarb, cauliflowers, and cabbages. The asparagus and rhubarb are gigantic, the rhubarb more especially, which is often brought to market three and four feet in length, and of the size of a woman's arm - some women of course excepted. The early asparagus is forced under glass; the later is forced in the open ground by all the appliances of manure. The quantity of rhubarb consumed is enormous, for it comes not in baskets, but piled up in four-horse wagons in bulk. The asparagus shows the want of sun, and appears as if grown in a cellar, the mere head of the early kinds being the only part eatable. I think Cobbett somewhere says, that "the English do not know how to eat asparagus, for they always begin at the white end." I have not myself observed among them any remarkable deficiency of gastronomical science; but certainly, in this case, they have not far to go to find a white end. Sea-kale or Scotch kale is very miuch eaten early in the season. It is blanched under cover, and is a delicious vegetable, that is, for those whose taste agrees with mine. The Jerusalem artichoke secms a favorite vegetable with most persons.*

One of the principal vegetables founa in the market, and this at all seasons, is cauliflower; and it is certainly grown here in perfection. 'They are sown, for the next year's use, some time in August, in hotbeds, and are transplanted into the open ground in February. They, of course, before being transplanted, are cultivated under glass, and for some time after they require protection. They are a frequent, and almost an invariable dish at well-furnished tables. Cabbages likewise are brought into the market with a profusion absolutely astounding, which itself

* In this case I am in the minority. I have not studied under Mrs. Briggs, or Dr. Kitchener, or I would inform my readers how they are cooked. Under modern refinements, meats, and vegetables, and fruits, come to table as much disguised, as were men and women at the late bal-costume of the queen, when nothing nearer than engagés or attachés knew each other, - and that, either by magnetic clairvoyance or previous arrangement; and it is said, (I do not vouch for its truth, ) some nobleman addressed his valet as "my lord;" and some gentlemen, like the Smitlfield drovers in penning their cattle at night, as I have described, had to look carefully for some private mark, to be sure that they had got their own wives to carry home with them. I would not insinuate that the English wives, exemplary as they are for their fidelity, were not as anxious to be found, as their husbands were to find them. Sometimes I agree in a remark, often quoted by persons who are not very abstemious in the use of strong language, that "Heaven sends us meats, but" _ I had rather not say who _ "sends us cooks." 
shows how much they are eaten. One would be disposed to consider them as the favorite vegetable of the English. The early ones of course are forced in hotbeds and transplanted; and a constant succession is kept up. I have sometimes seen in the market, at one time, very early in the morning, many large fout-horse wagon-loads of cabbages, lettuces, and rhubarb, all distinct, and piled up in the most beautiful manner, with a precision which is admirable; and when $\mathbf{I}$ have had the curiosity to inquire how many heads of cabbage were on a single load, the answer has been, two hundred and twenty-five dozen.

The celery brought into market is, like the rhubarb, gigantic. The solid-stalked is greatly preferred. It is finely blanched. It is not so agreeable for eating as a smaller-sized plant, but it shows the perfection of cultivation. The celery, like the rhubarb and the lettuce, is brought into market in the neatest manner. Nothing is tumbled into the carts, or thrown out upon the ground topsy-turvy, or indiscriminately. Even the heads of lettuce are every one of them tied with a string of bass matting; and when presented in the stalls, the various articles are arranged with great care - I may add, with taste, and a view to effect.

In looking down from the high bridge, in Edinburgh, upon the vegetable and fruit market below, and observing the arrangement of the different articles in the stalls, the intermingling of the white cauliflowers with the purple cabbages, the orange carrots, the yellow turnips, and the red beets, and other articles of various hues, like the colors in a Turkey carpet, the effect is really picturesque and beautiful. I have gazed at them repeatedly with much pleasure. The same remarks apply to the arrangements in the London markets. I know some will say, What is the use of all this? I have just given the answer. It gave me, and it gives others, pleasure. That is reason enough, if there were no other. I think in this respect we have a good deal to learn. There is a natural concord or harmony among all the senses, and the stomach seems better satisfied when that which enters it gives pleasure to the eye. Suppose that our fine rare-ripe peaches were a dingy black, instead of presenting, as they now do, a sample of that most lovely and perfect intermingling of colors to be found in nature - such as the soft blending of red and white in the leaf of the damask rose, or, in a still more radiant form, on the cheek of virgin beauty and innocence; 
I think in such case we should eat them with a far infericr relish.

Grapes of the very finest deseription are produced in England, but wholly, as I have already remarked, by artificial culture. This, of course, places them beyond the reach of the great mass of the people; but they are always found on the tables of the wealthy and noble. In the stalls of Covent Garden Market, they present themselves in such a rich and luscious display, as to tempt a visitor to break at least one of the commandments; and, if it were not for the plate glass, which protects them, it might be, another also. This interposition is certainly humane, as a violation of the latter commandment referred to, under the lynxeyed system of espionage necessarily practised here, miglit place one in an awkward position. 'The violation of the commandment of not coveting what we cannot possess, must be settled in another court. I can only hope that human weakness will be considered; for, in passing from one part of London to the other, and among the shops crowded with the splendid productions o: nature, refined and embcllished by the highest art and slitl, with all the means of sensual gratification, with every thing to minister to luxurious indulgence, to feed the animal appetite, and the often more hungry intellect, and to delight and gratify the fastidious and cultivated taste, it requires a most rigid self-control, sc far as our desires are concerned, to keep the peace, from day to day, with one's own conscience.

One of the best gardeners in England has given me some instructions on the manazement of grapes, which some of my readers may be glad to receive:-

"With regard to the best way to manage the vine, when fuiting, I invariably stop the shoot one eye above the bunch; and it is the practice of the best gardeners in England. I genmally leave one shoot not stopped without fruit, and to fruit next season, and cut the shoots ont that have borne fruit this year. On the short-spur system, every shoot is stopped an eyc above the bunch, except the top one, and then it must be managed like the rest; all the lateral shoots must be stopped one cye above another, until they cease growing, as, the more leaves you get, the fruit will swell larger."

I should add more on the cultivation of this delicious fruit, but I know it is very well understood in the United States, 
where the best grapes grown are not, within my knowledge, surpassed for size, abundance, and flavor. So, at least, I thought them before I left home; but in my long exile, in order to keep down a dreadful homesickness that sometimes makes sleep almost as much a stranger to my pillow as though it was stuffed with McAdam's angular stones, I try to think, like the fox in the fable, that the American grapes are sour. But I cannot do it. Affections, which no time nor distance can quench or abate, defy every such idle effort; and memory returns, with all its sensibilities quickened, and all its delicious colorings heightened and embellished, to triumph over the impotence of the resolution.

There is another article abounding in the markets here, which, though by no means unknown in the markets of the United States, is not common; and therefore, from the same intelligent gardener, I shall give the best account I could obtain of the mode of cultivating them. I mean, mushrooms. There are few extensive gardens without a mushroom-house, which is a dark room fitted up with shelves, and with the means of producing the desired temperature.

"The cultivation of mushrooms in the winter months, in order to have a daily supply, requires a house for the purpose. The house at Welbeck is divided into four tiers of shelves, three shelves in each tier. The shelves are ten inches deep, [that is, a sort of boxes, like the berths on board ship. - H. C.]

"The first three shelves are generally filled about the beginning of September, as the field mushrooms begin to go out then. The material used to fill the shelves is pure horse-dung droppings, without any straw. It is suffered to ferment a little before being put in, and beaten quite hard with a wooden mallet. $\Lambda$ s soon as the heat decreases to $65^{\circ}$ by the thermometer, or ascertained by a piece of wood thrust in, to see that the burning heat is gone off, the bed may be spawned, by opening holes two inches deep in the dung, and putting in bits of spawn about the size of a walnut, nine inches each way, all over the bed. It is then covered with two or three inches of good fresh loam from a pasture field. If a little road-scrapings is added to the loam, it helps to bind it, which is important, as a great deal of the success of the crop depends on the soil and dung being incorporated into one solid mass, not liable to crack, or get too dry. The soil 
must be beaten with the mallet, like the dung, quite smooth and hard all over. In eight days after spawning, the bed will be covered with a whitish substance, which shows that the spawn is rumning all through it, and that the heat is right.

"Mushrooms generally appear in six weeks after making the bed, if the temperature of the house is kept from $55^{\circ}$ to $60^{\circ}$. They are very impatient of too much water; and water is required to be put on them only with a fine watering-pot rose: and that when the bed gets dry; and it should be always of the same temperature as the house, or it chills all the young ones, and the crop never lasts so long. If hot-water pipes are used to heat the house, there is no occasion for watering. We generally make fresh beds every month, to keep up a succession all through the year, excepting the months they come naturally in the open fields.

"Mushrooms may be grown in winter in a dark cellar, where there is no artificial heat, by covering the top of the ridges, or box, with good dry hay, at least ten inches thick. They will not come in so quickly as in a house kept at a steady temperature, but will keep in bearing a great deal longer, so that one good bed will last all through. As a good deal of the stuccess of growing mushrooms depends on the goodness of the spawn, it is necessary to get it from some respectable nurserymen, who generally sell it in the shape of bricks. Its quality may easily be ascertained, if good, by breaking it, and seeing it full of white threads, and the smell is exactly like a mushroom. If it smells musty, it has lost its vegetative powers. It will keep good for a year or two, if kept dry, and out of the power of frost. The best is made in London about Battersea, where many cows and horses are pastured in the fields. The old droppings are taken from the surface where the natural mushrooms grow, and mixed with fresh horse-dung, and cut into the shape of bricks. There is always good spawn in the old beds, which may be preserved to put into new ones."

I have gone thus fully into this, as it may appear to some, unimportant subject, because, as a vegetable, this plant is esteemed a great delicacy; and next, because of the great quantities of ketchup which are used, and which may be manufactured in the country, and of which mushrooms are the principal material. 
Pines, or pine-apples, are, as $I$ have remarked, cultivated to a large extent, and with the greatest success, in the hot-houses of the afluent, where fire heat is employed; but in Cambridgeshire I found them cultivated, with great success, in common hotbeds. The beds were formed in the usual way; and in order to keep up the heat, or renew it when it declined, additional supplies of fresh stable manure were applied, from time to time, to the sides of the bed. The plants were healthy, and fruited well; and so far as the quality of the fruit goes to approve the mode of growing, I will say, on my own knowledge, better need not be desired.

I have one remark to make in regard to English vegetables and fraits, that will not, I hope, be deemed ill-humored, - which is, that, though cultivated with extraordinary skill, with the exceptions I have above named, they are tasteless, and without that fine relish which one would like to find. I think it is Voltaire who says "that the only ripe fruit to be found in England is a baked apple." I cannot accede to a censure so sweeping; but it is plain that their fruits and vegetables want xipeness and flavor. 'This may arise partly from a deficiency of heat from the sun, and partly from the excessive forcing of their vegetables, in the vicinity of large markets, by unlimited quantities of manure. I know how difficult it must be to make an Englishman believe this statement; for under the national peculiarity of a large endowment of self-esteem, which their Anglo-Saxon descendants over the water seem to have inherited, (and sometimes, I think, with a considerable enlargement of the organ, from long cultivation,) a genuine Englishman thinks that nothing out of his own country can possibly be so good as what is to be found in it. Now, in intellectual fruits, and the products of art and science, I will not dispute their preëminence - only hoping that, while they are reposing upon their laurels, a young and ambitious rival, in a fair and generous competition, may be up with them as soon as possible, and distance them, if he can. But climates and sunshine are not under human control; and the fact which I have stated is in my mind established, and not the result of mere prejudice, of which, on any subject, if I were conscious of it, I should be ashamed. 


\section{LX. - MARKET GARDENS.}

My remarks above have chiefly referred to the supply of vegetables in London. There are large markets in all the principal towns; but it is difficult to conceive the amount required for the supply of this mammoth city, with its two milliou hungry mouths, not one of whom, scarcely, in any direct form, produces a single mouthful for himself.

The extent of the vegetable gardens in the neighborhood of this great city is enormous, and the multiplied facilities of conveyance make even remote places, now, in many articles the suppliers of London. Fifty years ago, it was calculated that there were two thousand acres cultivated by the spade, and eight thousand by the spade and plough conjointly. The extent of cultivation must, of course, be at present much greater. It is said of one individual that he had eighty acres in asparagus, and of another that he had sixty, and that the forming of the beds was estimated at $£ 100$ per acre. This undoubtedly was under the old system of growing asparagus, when the soil was to be taken out to a depth of some feet, and a bed of stones placed at the bottom, and other expensive arrangements. Now, asparagus is grown almost as easily as carrots or celery, it only requiring to be first grown in a nursery or seed bed, and then transplanted in the bottom of deep furrows or trenches, made two feet distance from each other, well bedded with manure, and the bed itself kept constantly clean, and annually covered with a loading of manure in the autumn, which must be dug in with a fork in the spring. This, in three years from the seed, gives as good and abundant a plant as under the old method of trenching and bottoming with stones, and laying a foot of manure on the stones.

The amount of vegetables sent by some individual salesmen is enormous. The principal market-days are three times in a week, but Saturday is the principal day; and it is confidently stated - though in relating it I fear that some persons may think the credulity of their too-confiding countryman has been practised upon - that a single grower has been known to send, in one day, more than nineteen hundred bushels of peas in the pood, and seven or eight loads of cabbages, averaging eighteen hundred cabbages each; and at another season, from the same farm, four- 
teen or fifteen hundred baskets of sprouts will be sent in one day, and in the course of the year from five to six thousand tons of potatoes. In his account of the agriculture of Middlesex, Middleton says, that in 1795, in the height of the fruit season, each acre of the gardens cultivated in small fruits gave employment to thirty-five persons, among whom were many women, who were employed in carrying the fruit to market on their heads; and that the gathering of a crop of peas required forty persons for every ten acres. The account given of the sum of money received from the produce of a single acre is quite worthy of remark, it being the statement of a market-gardener. Radishes, $£ 10$; cauliflower, $£ 60$; cabbages, $£ 30$; celery; first crop, $£ 50$; second crop, $£ 40$; endive, $£ 30$, - making a total of

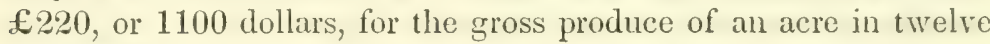
months.*

Besides the market which London presents for the disposal of the products of these immense gardens, it is to be remembered that labor may be procured at an hour's notice, at any season and for any term, and at a low rate of wages. The farmer or gardener is therefore saved the burden of keeping up an expensive establishment for any longer time than their services are needed; with this addition, that he makes no provision whatever, at any time, for housing or feeding them. Any person, who has had the management of a large farm in the United States, knows quite well, that the sum of all its difficulties is in the feeding

* What some persons may deem the intrinsic improbability of such accounts, will disappear, when one considers that, in London, every thing, and any thing, may be sold, and may find purchasers, excepting only, I believe, children. These are to be given away; for it is a sober truth, that in the streets of London I have been repeatedly offered the present of children, and that from the breast too, though none the better for that, if I would take them. Whether it is, by a sort of natural phrenological skill, they discover my philoprogenitiveness to be large, or from a destitution, the bitterness of which extinguishes the maternal affections, or from a profligacy even more bitter, and more deeply to be deplored, (in too many cases the pitiable consequence of this destitution, ) this is not the place for me to consider. But it is for my own countrymen to consider, with the deepest religious gratitude, the difference between a condition of things in which children are felt to be a burden, and almost a curse, and that in which a healthy and perfect child may be looked upon always as a choice blessing from Heaven; and the more hungry mouths, and sparkling eyes, gather round the well-filled board of the humblest cottager, morning, noon, and night, so much the more, in fact, are the means of supply increased, and the parental heart filled to overflowing with joy and love 
and management of the human machinery. In the next place, here there is no want of capital with persons who undertake such occupations; and it is applied with liberality wherever there is a chance of using it to profit. This is a great consideration, wherever capital may be safely and advantageously applied to land. We often hear the counsel given to cultivate a little land well, rather than a large extent of land imperfectly. In the main, this is sound advice on the score of profit. But in agriculture, viewed as a commercial transaction, the profits will correspond with the amount of capital invested or employed. Large returns are to be expected only from cultivating a large extent of land; or, in other words, pursting agriculture as a man, who would command suecess, pursues any other branch of trade, by devoting his time, talents, and zeal to it, and applying all the means within his reach to its advancement. While

\section{"Little boats should keep near shore, \\ Vessels large may venture more."}

The man who, as above, can cultivate one acre of ground with such eminent success, may cultivate one hundred with similar profit, provided he can give to it the same requisite attention, provided a sufficiency of labor aud manure are equally attainable, and provided, likewise, the market is equally sure and favorable for the disposal of his products. Whether capital can in any particular case be profitably applied to agriculture, must depend upon a great variety of local and temporary circumstances. It is so with commerce, and with most other branches of business. No human power or skill can control the vicissitudes of the climate and the weather; but the contingencies on which the success of agriculture depends are perhaps not so great as those on which the success of mercantile transactions depends. It is idle to expect reward without labor, fruit without seed, profit without risk, success without effort, - unless in those games of mere chance, of which sober men will beware, and in which there are always vastly more losers than winners, and many more blanks than prizes. The great want with most of our farmers is clearly want of capital, to apply to the land in labor, or manure, or in the way of permanent improvements of drainage and irrigation, which change at once the whole fice of a country. The main elements of success in agriculture are the same as in any other profession,-_skill, judgment, application, 
industry, and capital, either in the form of education, money, oi credit; the risks are not greater; the road to a reasonable com petence, which is all to which a good mind should anxiously aspire, is as certain as is common in human aflairs; extraordj nary success - which $I$ do not say it is criminal to desire, but even lawful to aim at - is not unfrequently attainable: but, what is better than all, the gains of agriculture, where the labor by which those gains are secured is honorably and justly providec. for, and its products disposed of without any betrayal of conscience, are so unalloyed, so untainted by corruption, so clearly in themselves not the occasions of privation, but the very instruments of good to others, that one reposes on them with entire and grateful complacency, and their value to the winner is more than quadrupled. My friends, I know, will pardon my enthusiasm, which, like a half-smothered fire, is continually bursting out in this way. If it sometimes sheds a flickering light by its blaze, it never burns to destroy; and if, in respect to that noble pursuit which Heaven first ordained for man, it awakens in any pure and honest minds, not crazed with speculation nor hardened and corrupted by the too common tricks of trade, any gentle vibrations of sympathy, I shall feel that my two mites have found their way into the great treasury of public good.

The eminent success of the market-gardeners near London depends on several circumstances in their management, which I will point out. In the first place, the land is thoroughly drained, so as not only to cut off the springs which might render the wetness of the land permanent, but likewise to carry off speedily the rain which falls. In the next place, the land is completely trenched, to the depth of from two to three feet, with the spade. This serves two purposes; first, to assist in the drainage by giving a free passage into the principal conduits of the rain as it comes down; and next, to enable the roots of the plants freely to extend themselves in search of food. In trenching, it is necessary to keep the top soil at the top, and not to bring the lower stratum to the surface, or to suffer a large portion of the cold earth to be mingled with the rich mould. This requires some little calculation. The soil of the first trench made across the field must be completely thrown out; and so likewise the top soil of the second trench. The bottom soil of the second trenching is then to be thrown into the vacant space of the first, and the top soil 
of the third line upon that. Things will then come rightly into their places, the bottom soil being always thrown upon the bottom, the top soil upon the top, while at the end of the piece trenched, that which was first thrown out must be brought and replaced. The third point particularly attended to, is ample manuring. For this object they have always plentiful stores on hand, to be applied as may be desired; the old hotbeds, when broken up, furnishing large quantities in that decomposed state, in which only is its application safe in respect to many kinds of plants. Manure is sometimes applied in a solid and somctimes in a liquid form. Sometimes, when the ground is dug, the manure is dug in with it; sometimes it is laid on the surface; sometimes it is used with every successive crop, at other times with the first crop only: but all these are matters directly dependent upon expericnce and practice, and which it would be impossible, in such a report as this, particularly to define. Manure, in its coarsest state, is seldom applied to garden vegetables; and it is found expedient, in respect to liquid manures, to apply them in a diluted and mixed form. The next point aimed at, is to avoid the immediate repetition of the same crop on the same ground; for, though manure may be had in abundance, yet the second and third crops gradually become deteriorated. Chemistry has not yet determined with precision how this evil, if so it is to be regarded, is to be counteracted. It is strongly hoped that this may be one of its first achievements. Most of what it has yet given us in the case is theory. What we want is practical and efficient rules by which the health and strength of the declining patient may be at once and with certainty recovered. The next object is, to have a succession of crops, one crop often growing between the rows of another, and prepared to take its place as soon as it is removed, so that there is no respite of the cultivation, while the season allows of it; and near London, with the help of straw covering, and mats, and glasses, some plants are on the ground all the year. For this object, and to counteract the effect of the seasons, the most extensive preparation is made; articles are prepared of brush, of matting and straw, and hand-glasses, or boxes with glass tops, and, to guard against insects, boxes with coarse ganze tops are prepared in the greatest abundance, and changes of the temperature and weather are watched with the most sedulous care. Hot and forcing beds, likewise, and conserva$32 *$ 
tories, and hothouses, are made ready in the most extensive forms, for the purpose of forwarding plants to be set out at proper seasons, and for the growing of those plants which require artificial heat. Lastly, irrigation is as much as practicable attended to, and engines, and watering-pots, and other contrivances, are in constant requisition for these purposes, and as far as they can be applied. The science of gardening is here a substantial science; and young men are as carefully educated in its various departments as in any of the learned professions, and receive a patronage according to their skill and merit. Under such circumstances, the market gardens near London are managed with a skill and enterprise worthy of all praise, and sure of rewards much more substantial.

\section{LXI. - COVENT GARDEN MARKET.}

The great market in England for vegetables, fruits, and flowers, is the market of Covent Garden, without question a corruption for Convent, as this place is understood to have been formerly the garden of the convent, and connected with the establishment of Westminster Abbey. The whole square included in the marketplace is said to embrace five acres; but this, I think, must take in the buildings, dwelling-houses, hotels, shops, \&c., forming the exterior boundary of the square. In the centre of this square is the market-house, of which no verbal description can convey a very exact idea to the reader. It combines open stalls and close shops, sellers within and on the outsides, with a long hall or arcade, running through the centre, sixteen feet in width, and fitted up with shops on each side, and with shelves projecting into the passage, which are spread out with all the fruits and flowers of the season.

1. Fruits and Vegetables. - The outer stalls are for the coarser vegetables, potatoes, cabbages, \&c., and for the common foreign fruits. This is by no means the only vegetable and fruit market in London, but it is the principal one; and some of the other markets, and many of the fruit-shops, scattered over Lon- 
don, receive their supplies from Covent Garden. There is hardly any season of the year when every variety of fruit and vegetables, which can be forced, is not to be found in this market; and in the proper seasons a great variety is to be found, the product of natural and artificial culture, in the highest perfection. 'The sale of dried foreign fruits is here likewise immense. England can scarcely be considered as a fruit country, and the high prices charged for the finest fruits place them beyond the reach of all but the most wealthy classes. Two shillings, or half a dollar, for a single peach, - and at no season are they much less than half that sum, and many other fruits in proportion, - render them forbidden fruit to the great multitude. In quantity, Covent Garden is limited compared with the city of London, which it is intended to supply; but it is high tide here on a market-day, at daylight in the morning, when the wholesale market-men supply the retailers, and the streams from this fountain flow into and permeate every part of the city and its neighborhood. The market in Farringdon Street occupies as much ground as Covent Garden, but this embraces butchers' stalls as well as fruits and vegetables.

Covent Garden presents an interesting spectacle on a great market-day, at 4 o'clock in the morning, when the wholesale business commences, and the retailers, seeking supplies for their difierent stalls, and the occupants of stalls in other markets, and the keepers of vegetable shops in the town, and the various itinerant dealers, who penetrate all the by-places and strects in different parts of the town and the vicinity, come to make their purchases. This occupies two or three hours; and a busier scene is hardly to be witnessed. All the smaller articles - gooseberries, currants, peas, beans, new potatoes, apples, \&c. — are brought in baskets; cabbages, lettuces, rhubarb, celery, \&c., in bulk, as I have described. Peas, in Covent Garden Market, are shelled before they are sold, and after they come out of the hands of the wholesale dealer. These come frequently in sacks. It is an interesting sight to see the poor and symalid women and young girls, who come to carn a few pence by shelling the peas, sitting about in different squads, (and I have counted at one time as many as eighty in one party,) all busily engaged in this occupation at about one penny, or two cents, per quart. Raspberries and strawberries are brought in small cone-shaped baskets, containing little 
more than a pint; and these are usually brought long distances on the heads of women. It is said that these women, who carry such heavy loads upon their heads, are principally from Wales, and that many of them, for example, come into market twice a day from Brentford, where great quantities of strawberries are raised, and return; and this is a distance of more than seven miles, making at least thirty miles in a day. To such endurance may even a woman's frame be trained. Many of the milkwomen in London, who carry their milk in large tin cans slung from their shoulders, and containing from six to eight gallons each, travel long distances in the course of the day. But the most remarkable instance of strength and endurance is perhaps to be found in the fish-women of Edinburgh, who attend the market from New Haven and Musselboro'. Their load, which is in two baskets, one over the other, containing different kinds of fish, slumg upon their backs, often weighs $150.1 \mathrm{bs}$, and has been known to weigh $200 \mathrm{lbs}$. The distance from New Haven to Edinburgh is more than two miles, and in this distance they stop to rest but once only; and after their arrival they are to be found crying their fish in all parts of the town. How many of the Chestnut Street, or Washington Street, or Broadway belles would it require to lift even one of these loads from the ground? Yet these market and milk-women, and the fish-women of Edinburgh, are perfect models of health and strength. The latter - with their elephantine arms and legs, their bright, clean caps, and fair complexions, their firm tread, and their stentorian lungs, with their gay costume of various colors, and their five petticoats, so arranged in different lengths that a portion of each may be displayed - are among the most picturesque, and not unpleasing, objects of that beantiful city.

The advantage of bringing the finer fruits to the market in this way is, that they come in the best possible condition. The wholesale business being completed, the growers of the produce return home, and the marketing goes at once into the hands of the shopmen and retail dealers, who are, in general, residents in the city.

2. Flowers. - Having said so much of the vegetables and funits, I must not omit another article in Covent Garden Market, of which the sale is immense, - that is, flowers. In the winter 
they are sent here from the greenhouses; at more genial seasons, from various gardens and conservatories in the neighborhood. They are displayed in the greatest profusion and perfection, and are, undoubtedly, a large source of income to the cultivators. The English appear to me to have a strong passion for flowers, and I commend their taste. A country house, without its plantation of flowers and flowering shrubs, would be quite an anomaly; and many of the humble and moss-grown cottages have their small gardens of flowers, their doors trellised with woodbines and honeysuckles, and their outer walls covered with a thick mantling of ivy, and made gay with the sweetbrier and the monthly rose. The door-yards of the English, in the country, their windows, their halls, their palaces, are all decorated with flowers; they are among the most beautiful ornaments at their festivals; and even the highest charms of female loveliness are studiously augmented by these innocent and splendid adomments.

Looking out of my window a short time since, I saw that the laborer wheeling his barrow before the door had his button-hole decorated with a beautiful geranium. I went into the street, and the driver of the omnibus, whom I first met, wore a handsome nosegay. I met a bridal party, and, bosides the white favors worn by all the servants in attendance, each one had a bunch of flowers at his breast. I met the crowd of magnificent equipages hastening to a drawing-room to pay their courtly homage to a sovereign queen, whose virtues and most exemplary demeanor render her worthy of the homage of true affection and respect; and every lady bears in her hand a magnificent bouquet; and the coachmen and the footmen seem to emulate each other in the gayety and beanty of the flowers which they all wear. At St. Paul's, at the opening of the term of courts, the long procession of grave and learncd judges, who then go in state to church, appears, each one, with an elegant nosegay in his hand. At the opera, upon the breathless and successful competitors for public favor, in the midst of a tempest of applause, descends a perfect shower of floral wreaths and rich bouquets.

I sympathize heartily in this taste of the English for flowers, which thus pervades all ranks, and, flowers being accessible to all, and among the most inuocent and the cheapest of all pleasures, diffuses a vast amount of enjoyment. They are, indeed, among 
the richest adornments of God's beantiful creation, and every where, in the tangled forest, in the most secluded thicket, on the ocean prairies, and even upon the desolate heaths, are scattered about in such an endless variety and profusion as cannot fail to impress a reflecting and devout mind with the most grateful veneration and delight.

As for those persons who can see no good and no utility in any thing beyond that which fills the belly, or covers the back, or puts money into the pocket, they are of the earth, earthy. Such grovelling selfishness and animalism I trample under foot with ineffable scorn. But the cultivation of flowers does much for the benefit of the mind. $A$ taste for objects so pure expels a taste for others, which are unworthy. A passion for what is beautiful and refined in nature often secures the mind from the intrusion of passions low and hurtful. Every advance, which is made in any direction for the improvement of the taste or the refinement of manners, is so much done for the general comfort of social life and for good morals.

\section{LXII. - GENERAL MARKETS.}

Besides the markets to which I have referred, there is a market in London exclusively for the sale of raw hides and leather; and in various parts of the country markets are held, at fixed times and places, for the sale of wool, and of butter and cheese. These generally go under the name of fuirs; and I do not think they can be too soon established in the most populous districts of our country. There may be evils, but there are great and overbalancing advantages, attending them. The large dealers attend in numbers to make their purchases, and both sides have equal henefits from an extended competition. Prices assume an equal and a fair rate. The farmer may feel, ordinarily, quite sure of a market for his produce at a fixed time, and to receive his money, instead, as now, of depending almost upon accident for a purchaser. Last, but not among the least of the benefits of the markets in question, is the wholesome emulation which is created by bringing different articles of produce into comparison 
with each other. The producer of an inferior article is stimulated by the success of his neighbor to produce a better; agricultural information becomes generally diflused; and thus agricultural improvement is essentially advanced. Should such markets be established, the most stringent rules should be adopted for their management; but, above all things, all trickery and fraud should be eschewed and denounced. A man guilty of it should be so branded with infamy, that he should never presume to show himself there a second time. Men, under such circumstances, would be sure to discover that "honesty is the best policy."

In London, there are markets for the exclusive sale of poultry and game, and in Dublin, I found one wholly deroted to the sale of eggs. The amounts here collected and disposed of almost surpass belief. The statement of a respectable witness and custom-house agent, recently, before a parliamentary committee, is quite remarkable. He said that there were five vessels annually cngaged in that trade between Normandy, on the coast of France, and London, which bronght about 3700 tons of eggs in the year. Ten cases went to a ton, and from 1000 to 1200 were in each case. This trade was between Cherbourg, Harfleur, Caen, and Portsmouth. Forty millions of eggs were annually imported through this channel alone. Some one asks very emphatically, "Why should they not be produced at home?" *

* "The value in moncy of one seemingly unimportant article, eggs, taken, in the course of the year, from Ireland to the ports of Liverpool and Bristol, amounts to at least $£ 100,000$. The progress of this trade affords a curious illustration of the advantages of commercial facilities in stimulating production and equalizing prices. Before the establishment of steam-vessels, the market at Cork was most irregularly supplied with eggs from the surrounding district; at certain seasons they were exceedingly abundant and cheap, but these seasons were sure to be followed by scasons of scarcity and high prices; and at times, it is said to have been difficult to purchase eggs in the market at any price. At the first opening of the improved channel for conveyance to England, the residents at Cork had to complain of the constant high price of this and other articles of farm produce; but as a more extensive market was now permanently open to them, the farmers gave their attention to tine rearing and keeping of poultry; and at the present time, eggs are procurable at all seasons in the market at Cork; not, it is true, at the extremely low rate at which they could, formerly, be sometimes bought, but still at much less than the average price of the year. $\Lambda$ like result has followed the introduction of this great improvement in regard to the supply and cost of various other articles of produce. In the apparently unimportant article feathers, it may be stated, on the respectable authorit $y$ above quoted, that the yearly importation into England, from Ireland, reaches the amount of $£ 500,000$ sterling." Porter's Progress of the Nation, vol. iii. 83. 
Markets of a general character are held once or twice a week in all the principal towns; and in those cases where the farms are small, the farmers' wives and daughters will be seen going six or eight miles on foot, or in vans, (i. e. lumber and freight coaches or wagons, ) to sell the week's product of their dairy or their ponltry-yard. In this case, they are always found, with their neat baskets upon their arms, in a particular part of the market assigned to them. Their neatness of dress and person commend them to attention. It requires some courage to elborv your way among them, if you do not design to be a purchaser; and their chaffering and courteous solicitations to buy, with the emphatical recommendations of the articles for sale, together with the usual chatter and gossip to be expected among such a collection of gude wives and bonnie lasses, are sufficiently amusing. 



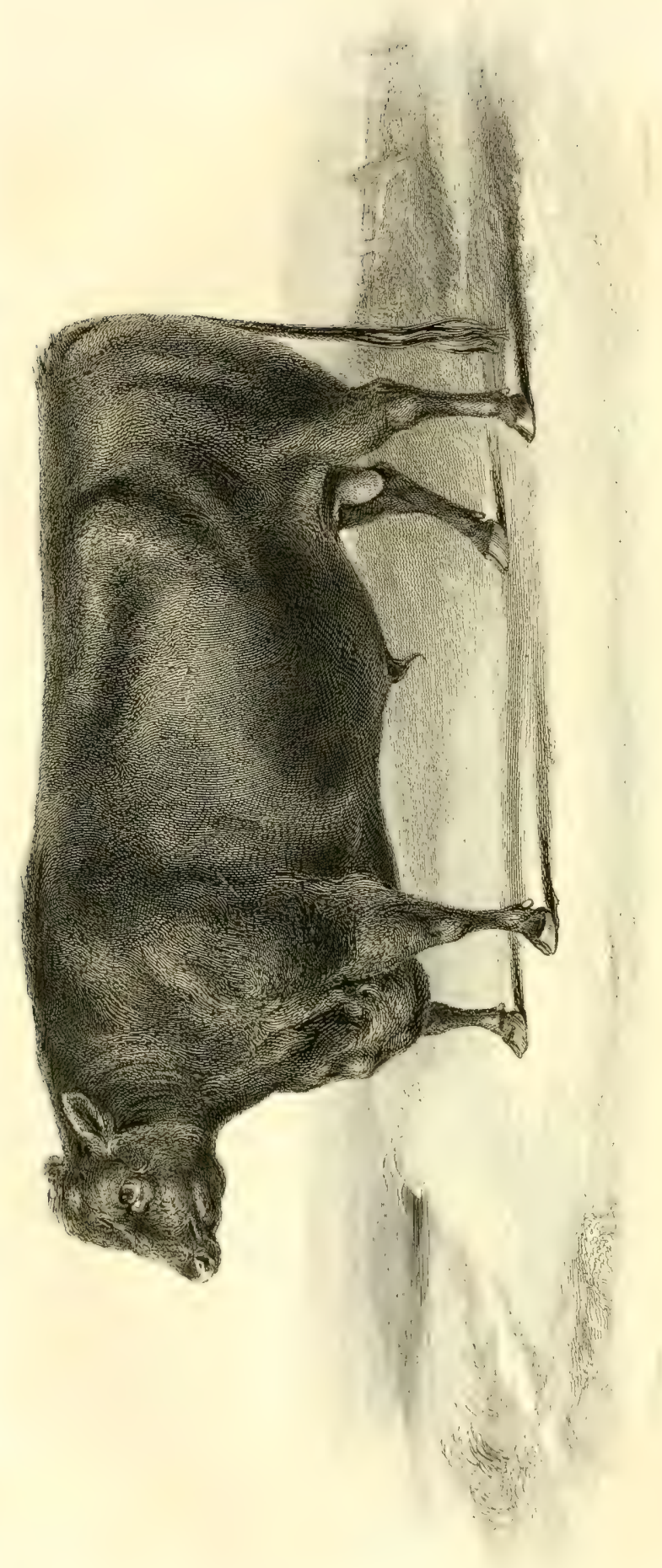




\section{EUROPEAN AGRICULTURE.}

\section{FIETH REPORT.}

\section{LXII. - GENERAL MARKETS. (Continucd.)}

1. Market at Derby. - Nothing can be more miscellaneous than an English country market; and my readers may be gratified with the partial account which I took of one of them as I went through it. This may be considered as a fair sample of others. Many of the goods are spread upon the ground, or under temporary stalls or booths erected for the purpose. Every seller pays a certain tax to the town for permission to sell, or for the load of goods brought into market. This toll is generally collected at the entrance of the town, as it is to this day in London, from every loaded vehicle which enters the city.

This market was held in the open square at Derby, and the stalls were chiefly attended by women. 1. Nails and tacks. 2. Otd iron, chains, \&c. 3. Cutlery of various sorts. 4. Shoes and boots. 5. Hats and caps. 6. Hosiery. 7. Millinery. 8. Iron ware. 9. Tin and copper ware. 10. Various kinds of female dress, caps, laces, Ec. 11. Household furniture, old and new. 12. Brushes, mops, \&c. 13. Bread. 14. Bacon and salted pork. 15. Muslins and caps in upturned umbrellas on the ground. 16. Children's toys. 17. Combs and paste. 18. Flour. 19. Butter and cheese. 20. Fish of various kinds. 21. Baskets. 22. Old books. 23. Sofas, bureaus, and tables. 21. Crockery ware and glass ware of various kinds on the ground - a great many sellers. 25. Glass ware in abundance. 
26. Rabbits and game. 27. Poultry. 28. Meats of various kinds. 29. Vegetables and fruits. 30. Straw bonnets. 31. Refreshments, gingerbread and ginger beer. 32. Wool in large packs. 33. Oranges, \&c. 34. Sieves, wire-baskets, and birdcages. 35. Bandboxes and trunks. 36. Dolls. 37. New books and stationery. 38. Live birds. 39. Confectionary of various kinds. 40. Shoes, combs, \&c. \&c. 41. Saddles, bridles, collars, \&c. 42. Rakes and agricultural tools. 43. Ginger pop, as usual. 44. Garden seeds. 45. Patent medicines, and especially worm lozenges, with about fifty bottles of worms preserved in spirit to evince the efficacy of the medicine - a terrific exhibition. 46. Meats of various kinds. This comprehends but a small portion, and by no means all the varieties of stalls. The whole are dispersed by 3 o'clock in the afternoon. The population of Derby is about 37,000 , and is chiefly a manufacturing population.

\section{LXII. - GENERAL REMARKS AND DIVISIONS OF THE SUBJECT OF ENGLISH FARMING.}

The agriculture of England presents itself under three great divisions - that of arable farming; breeding and grazing, or feeding; and dairying. I propose, in a great degree, to arrange my observations conformably to these three parts.

There may be, with some of my readers, a misconception as to my plan, and, in consequence, expectations which will fail to be met. I do not undertake to give a complete system of farming, and specific and exact directions in detail for the cultivation of every crop, and for every department of farm management. This would oblige me to execute a work vastly more extensive than that which I have undertaken. With respect to many of my readers, it could prove only a work of supererogation, for much of these details must be as familiar to them as the roads over their farms. I have always found, likewise, in respect to snch directions, with which many books are crowded, extending: as they frequently do, to circumstances the most minute and insignificant, that they are often inapplicable, from the infinite diver- 
sity of circumstances which different cases present. Most men have their peculiar methods of accomplishing an object, which are in truth the best for them, because the most natural; they would be hampered and embarrassed by other modes, less familiar, which might be prescribed. Unless, therefore, there is some striking originality, or some obvious and peculiar convenience, in the method suggested, it is only necessary to say in general what is to be done, and leave it to every man's own ingenuity to find out the best method of effecting it.

IIy principal object is to point out, in European agriculture, such circumstances of difference between it and our own as may serve for the improvement of the agriculture of the United States, and to give such an account of the modes of management which prevail abroad, and which have been sanctioned by long practice and experience, as may facilitate their adoption, as far as the circumstances existing among us would render their adoption eligible. Every country, differing from other countries in its climate and temperature, in its soil, in its facility for procuring manures, in the character and supply of its labor, in its commercial and political relations, must be expected to have an agriculture in some respects peculiar to itself; and the practices of another country can only be partially adapted to its own. At the same time, the general principles of agricultural practice are every where the same; and these, with the various modifications, which they may be expected to assume under different degrees of civilization, or different degrees of improvement in science and the arts, and their general and special application, cannot be too fully discussed and illustrated. We may learn much from others, who do things which we are never called to do; who cultivate crops which we never cultivate, and never can cultivate; and we may learn much from persons who do the same things which we do, but in a different way from ourselves - who cultivate the same crops, but by their own peculiar methods. We may learn much from those who cultivate better, and from those who do not cultivate so well as ourselves. There is little hope in any thing, so far as any great improvement is concerned, for the man who implicitly follows any guide whatever. He must exercise his own reason, experience, observation, and judgment, in the application of rules which may be laid down for his direction.

The celebrated Bakewell, whose name occupies a distinguished 
place in the annals of agricultural improvement, advised farmers, who would improve their cultivation and management, "to go abroad and see what other people were about." Every observing man, who acts upon this advice, will find its advantages. I have often heard it said, and, if I thought it of any value in the case, I should say that my own experience confirmed it, that one of the best modes of understanding a book written in a foreign language is to read different versions or translations of it. The different forms of expressing the same thought adopted by different persons, or the different conceptions which different minds gather from the same expressions, whether in themselves right or wrong, may give us a clew to the true meaning, and correct many a misconstruction, or reveal and make light many a hidden or obscure passage. 'This analogy suggests the true mode in which an inquisitive mind may gather instruction and knowledge from the practices of other men.

Three things seem to me absolutely essential to human progress in any and every art, in any and every science. The first is a profound conviction of the imperfection of all human knowledge; the second, an entire distrust of all human infallibility; the third, a perfect docility of mind, and a readiness to receive light and instruction from any and every quarter where it may be gathered, or by which it may approach us. Self-esteem, which, when combined with a good measure of benevolence and conscientiousness, and so leading men to admit and respect the just claims of others, is a useful and harmless sentiment, and prompts to many valuable enterprises, - when found excessive, and in a great degree unqualified, becomes an almost hopeless impediment to improvement.

I was told, before I left the country, by some American friends, that there was nothing in the way of agriculture to be learned in England, and that American agriculture was as improved as English agriculture. I had been but a short time in England before I heard, from various quarters, that in no country on the grlobe had agrirulture reached that degree of improvement which it had attained in England; and really in some cases, at public dinners, when, in the language of modern agricultural chemistry, the gases of the wine began to stimulate the brain, one would be almost led to infer that agriculture itself was a recent invention of British genius; and England presented herself to the en- 
cunuted magination leaning upon the handles of a plough, with piles of scientific books spread open at her feet, weeping, like the Macedonian hero, that she had no more worlds to conquer. A Flemish gentleman informs me that the agriculture of the Low Countries is altogether superior to that of any other part of the world. The Chinaman puts forth his claims to superiority, and shows pretty conclusively how much justice he has upon his side, when he points to the extraordinary and unquestionable fact, in his own country, of the largest amount of population supported upon the smallest extent of land. In the midst of all this comes a German, of wide possessions, of long practical experience, and of much intelligence, and says to me, "The English are the most arrogant and conceited people under the sun; and, in respect to agricultural improvement, they are far inferior to the Germans." Now, I do not feel it necessary to buckle on my armor and defend my good friends the English against language which, it must be admitted, is sufficiently peremptory and harsh. Nor do I deem it necessary to enter the lists with either of these parties, and endeavor to force him from his position. A diseased or inordinate self-esteem brooks no argument, and, in contending with national prejudices, the result can only be as it is, to use the rather coarse metaphor of Dr. Franklin, with a man who spits against the wind - that he spits in his own face. The first conclusion to be drawn from these confident assumptions is, to distrust them all; and the second is, by looking calmly and impartially at the improvements in which each claims a superiority, to gather instruction from the results of each one's experience, and new facilities and motives to enterprise, inquiry, and exertion.

\section{LXIV. - THE SOIL.}

Agriculture rests, first of all things, upon the nature of the soil which is to be cultivated. The soil is the basis on which the plant is to be supported, and the medium through which it is to receive the food by which its life is to be sustained, its growth promoted, and its progress advanced to matu$3: 3 *$ 
rity. Some scientific persons assert that the principal, if not the only, use of the soil is for the support of the plant, and that the fool of the plant is derived wholly from the atmosphere. In the heat of their imaginations, they have even asserted that a man's fields may be emriched, or rather his growing crops may be fed, by the exhalations from his neighbor's manure-heap in an adjoining field. This would be very much like a man's being fed by standing over the grating of a hotel, or a cools's shop kitchen, in London, and inhaling the odors from the savory viands which are there in the process of preparation. How much flesh might be gained, and how long life might be sustained, in this way, we shall know when the experiment is once successfully tested. That plants receive a large proportion of their nourishment from the air, does not admit of a doubt. But the calculations of the philosophical chemists as to the amount of carbon which the atmosphere, taking it at its estimated height of forty-five miles, is capable of supplying, (equal, according to some calculators, to the sum of seven tons to an acre;) and the discussion of the great question how the atmosphere was first supplied with this great element in vegetable life; and the apprehension which some persons express, on account of the supposed actual diminution of carbon, - though there appears to be enough, according to the most rigid calculations, to last several thousand years longer, are, to say the least of them, sufficiently amusing; but of what practical use they can be to the common farmer, is not so easy to determine. If the animal creation is to be starved out some thousands of years hence, it need not give the present generation, whose average of life does not much exceed thirty-five years, any great personal concern. It will not be a harder fate than that which certain of what are called the higher order of animals seem disposed to anticipate for some of their fellow-beings now living. But, whatever may be the part which the atmosphere performs in the food or nourishment of vegetables, it is beyond human power to affect or control it, unless we can grow our crops under bell-glasses or in greenhouses. The duke of Devonshire, in his magnificent conservatory at Chatsworth, three hundred feet long, seventy-five feet wide, and sixty-four feet in height, heated by seven miles of pipes, and covering, with its appurtenances, a full acre of ground, might manage to charge the atmosphere in which his plants respire with gases exactly suited to 
their wants, and of the most nutritious character ; but, beyond this: gigantic experiment, to which few can aspire, nothing certainly is to be hoped for. The farmer's whole business, as far as cultivation is concerned, lies with the soil; and upon the soil, and the skill and intelligence with which he manages it, must depend entirely his success. The notion, that plants receive a large portion of their nourishment through their leares, - although some experiments, in my opinion not sufliciently decisive to determine the question, seem to favor it, - appears to me about as probable as that animals receive a large portion of their nourishment through their lungs. If they absorb carbon and discharge oxygen by day, they reverse the process, and absorb the oxygen of the atmosphere, and discharge the carbon, by night; and what portion of the latter in this way is assimilated, and made to form a part of the plant, (as far as I can understand the experiments which have been made, ) does not as yet seem to be determined. I know the confidence with which this is affirmed, and, as a philosophical fact, I admit that it is of great interest and extremely worthy of inquiry. A friend, a few days since, said to me that he was conscious, when immersed in water, of absorbing considerable water by means of the pores of the skin, and wished me to believe it. With great respect both for his intelligence and honesty, I still remain skeptical. What may be the case after death, when decomposition has commenced, is an entirely different matter. At present, I believe that the only way in which the food, by which the body is nourished, is received, is by the month ; always excepting the case of the soldier at Washington, so fully reported in the medical journals, who had a hole in his stomach, by which, in order to watch the process of digestion, food was supplied, as a servant puts away cold meat in a cupboard. The fact is undoubted that plants by day absorb carbonic acid and cxhale oxygen, and that by night the process is reversed, and they inhale oxygen and expel carbonic acid; but it does not seem so well established that in this way they obtain the carbon which is assimilated in their organism. At least, the supposition is so little favored by analogy, that I hope it may be lawful still to doubt.

That the atmosphere contributes essentially to vegetation - that plants derive much of their nourishment and substance from the air, as I have already remarked, does not admit of a question: 
but, so far as any practical use whatever is to be made of this fact, we must consider this nourishment as received through the roots, and consequently through the medium of the soil in which these roots spread themselves, and the manures by which it is enriched. The soil therefore, as the basis of all vegetation, is the great object of the farmer's consideration.

\section{LXV. - THEORIES OF THE OPERATION OF THE SOIL.}

Soils may be considered in two points of view ; first, in reference to their intrinsic or absolute character, and next, in reference to the plants to the growth of which they are adapted. In a preceding number, in speaking of the chemical analysis of different soils, I think it appeared how little practical advantage had as yet been derived from any experiments in this way which had been made. The common properties of soil may be distinguished by the eye or the feel with persons of experience and practical observation; but chemical examination may often be of the highest importance in detecting the presence of some mineral ingredient by which the cultivation of particular crops may be hiudered or wholly prevented. A friend, eminent for his agricultural knowledge, pointed ont to me a particular field, in which all attempts to grow wheat had been unsuccessful, while no such incapacity existed in the adjoining fields. In such a case as this, one would look to the chemical analysis of the soil to determine what ingredient was deficient, or what unfriendly element existed or predominated in the soil to prevent the growth of the plant; and, this being ascertained, perhaps a remedy might be found. But the extraordinary and minute exactness to which the chemical analysis of the soil is sometimes carried, and upon which many scientific persons insist, it would seem, can serve little other purpose than that of producing despair of adapting our cultivation to such diversified and minute variations.

What portion of the soil is abstracted for vegetable food is not yet determined; and it is a singular fact, that, though analytical chemistry has demonstrated that certain mineral substances 
are taken up in the organism of plants and are essential in composing its structure, and has proceeded to calculate the actual amount in pounds' weight abstracted by the growth of crops of a particular quantity, it has never yet, by an analysis of the soil before the planting, and as exact an examination after the crop has been removed, determined the loss in such case. Why this has not been done, or whether it be beyond the present power of chemical analysis to accomplish, - extraordinary as is the degree of perfection to which the science has been advanced, must be left to others to answer. I am perfectly aware, of course, that the same identical soil cannot be subjected to the process of analysis, and then employed for the purposes of vegetation, with a view of ascertaining what has been lost or abstracted; but an equal weight taken from the same place with that employed for growing the plants might be examined, and afterwards that in which the plants were grown, so that, by this kind of comparison, the truth might be to a degree approximated. I am quite aware that it may be said, in this case, that the amount of mineral ingredients found in the produce would show the exact amount abstracted; but it would be extremely interesting to know, by an examination of the soil, that these results exactly or nearly corresponded. But it is found that land left to itself for a length of time recovers its fertility, and, after a lapse of two, three, or more years, the same crop, which failed when grown in immediate succession to another of the same kind, can be adrantageously cultivated again. It would be highly curious, then, by retaining a portion of the land in which the plant had been grown, and leaving it exposed to the ordinary influences of light and heat, and rain and frost, to ascertain in what length of time the soil would recover its exhansted elements of fertility. This has not, within my knowledge, been attempted.

The ingenious theory of Decandolle, that the exudations or excrementitious matter from one kind of crop unfitted the ground for an immediate repetition of the same species of plant, seems now to be generally abandoned. It is a well-established principle, which practical men understand quite as well as the scientific, that a rotation of crops is indispensable to a successful agriculture; and the theory is altogether probable that a particular crop exhausts the soil of certain elements essential to its lmarluction, which must be somehow supplied before a second 
crop of the same kind can be grown on the same land; but it would be extremely interesting if the fact of such exhanstion, and its extent, could be more particularly determined by a chemical examination of the soil which has been cultivated. The beautiful theory of the great agricultural oracle of the day, that certain mineral ingredients which are always found in the ashes of plants, and which are carried off when these products are removed, and, being essential to vegetation, require to be either artificially replaced or supplied by a natural process, - and that, the land being suffered to rest, or applied to a different production, the ordinary influences of air and moisture in decomposing the rocks of the soil will renew the supply of these mineral elements which have been removed, - seems to offer the desired explanation; and the experiments to which this theory has led, and which, under its influence, are now going on in various parts of the country, must presently determine it, and, what is better, show its proper application, and greatly simplify the processes of agriculture, reducing its expenses and giving comparative certainty to its results.

The operation of air and moisture upon the soil, the effects of light, and electricity, and frost, upon vegetation, all admit to be powerful; but they are as yet only partially understood, and present subjects of the most interesting inquiry. In the progress of science, technically so called, we have much to hope for; but in what it has already accomplished, enough has been gained to quicken, but very far from enough to satisfy, the appetite. One of the most eminent agricultural chemists of the present day, Boussingault, second perhaps to no other, has said,* " $\Lambda$ great deal has been written since Bergman's time upon the chemical composition of soils. Chemists of great talent have made many complete analyses of soils noted for their fertility; still, practical agriculture has hitherto derived very slender benefits from labors of this kind. The reason of this is very simple; the qualities which we esteem in a workable soil depend almost exclusively upon the mechanical mixture of its elements; we are much less interested in its chemical composition than in this; so that simple washing, which shows the relations between the sand and the clay, tells, of itself, much more that is important to us than

* Rural Economy, Law's edition, p. 266. 
an claborate chemical analysis." This is certainly a great confession for an eminent chemist to make.

To exemplify the different results to which the most scientific men arrive in these cases, I will refer both to Boussingault and Von Thaer in respect to a simple point, the presence of the carbonate of lime in the soil as essential to the growth of a crop of wheat, on which subject the public mind has been solong, so generally, and so confidently made up.

Von Thaer says,* "The richest argillaceous soil that I ever analyzed, the fertility of which was regarded as of the very richest quality, was taken from the right bank of the Elbe, some few miles from its mouth; it contained eleven and a half parts in a hundred of humus, four and a half of lime, a great quantity of clay, a little coarse silica, and a considerable portion of very fine silica, which could only be separated from it by ebullition. It certainly possessed a great degree of cohesion, but, when moderately moistened, it was not very tenacious. It was made to bear the richest crops, as cabbages, wheat, antumual corn, beans, \&c. : but every sixth year it was necessary to manure it thoroughly, and to give it a fallow."

On the preceding page, he says, "The richest land I ever analyzed, and which was taken from the marshes of the Oder, contained $19 \frac{3}{4}$ parts in 100 of humus, 70 of clay, a little fine sand, and an almost imperceptible quantity of lime; but the situation of this land was too low, and it was too damp, to admit of a correct estimate being formed of its fertility."

Boussingault says, $†$ "I may remark generally, that, from the whole of the analyses of good wheat lands which have hitherto been made, it appears that carbonate of lime enters in considerable quantity into their composition; and theory, in harmony with practice, tends to show that it is adrantageous to have this earthy salt as a constituent in the manures which are put upon soils that contain little or no lime."

On the next page, $\ddagger$ he says, "M. Berthier"s analysis is still far from proring that the presence of lime in a soil is indispensable, inasmuch as beautiful wheat crops are grown in the neighborhood of Lisle without lime. In proof of this fact, I shall here cite the analysis of one of the most fertile soils in the world,

* Vol. i. pp. 355, 354. † Rural Economy, p. $291 . \quad \ddagger$ p. 295. 
the black soil of Tchornoizem, which Mr. Murchison informs us constitutes the superficies of the arable lands comprised between the 54th and 57th degrees of north latitnde, along the left bank of the Volga as far as Tcheboksar, from Nijni to Kasan, and stretching over a still more extensive district upon the Asiatic side of the Ural Mountains. Mr. Murchison is of opinion that this land is a submarine deposit formed by the accumulation of sands rich in organic matters. The Tchornoizem is composed of black particles, mixed with grains of sand; it is the best soil in Russia for wheat and pasturage ; a year or two of fallow will suffice to restore it to its former fertility after it has been exhausted by cropping; it is never manured.

"M. Payen found in this black and fertile soil,

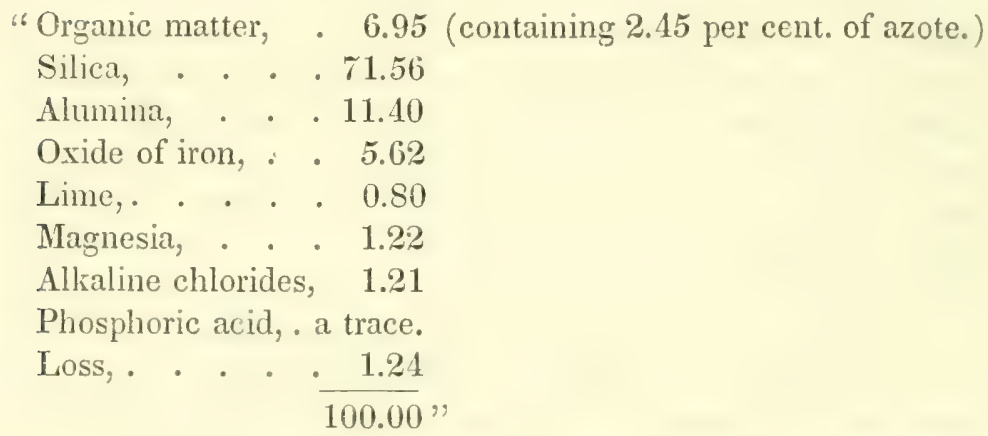

It is a little remarkable, judging from the analysis here given, that not only is the quantity of lime extremely minute, but even the phosphates, deemed so essential and indispensable to success, are also absent.

Such are the diversified results to which even the most scientific are led; and they are well adapted to admonish us of the imperfection of human knowledge, and the limitation of human powers. In Lincolnshire, where some of the best farming in England, as is universally admitted, is to be found, on a soil where the whole substratum was chalk, or the carbonate of lime, and where the mould or loam was not more than three or four inches deep, I found the farmers manuring the land, from pits dug in the field, with the very chalk by which the whole soil was underlaid. Upon my proposing the question to an eminent geological professor, then with me, much interested in agriculure, why this was done, he replied that the lime in the surface 
soil had probably become exhausted by sinking down, through its greater specific gravity; but I could not see that there could be any difficulty in the plants reaching it, where the whole body of lime lay within so short a distance of the surface. My own belief is, that, in this case, its operation is chiefly mechanical, and that its use was merely to consolidate the upper surface, and make it more adhesive for the roots of the plant, and that any other substance or marl, equally firm and consistent, would have served the same end.

One of the most eminent chemists of the present day, distinguished for the splendor of his attainments, seems to entertain, with no small confidence, the opinion that chemistry, including probably electricity and galvanism, is destined to solve all the secrets of vegetable and animal life; that the various processes going on in nature are mere chemical processes; and that any thing like a vital power above or beyond them all, and incapable of being solved by scientific investigation, is an hypothesis unworthy of an enlightened mind. It is certainly not for the human mind, as yet, to say what cannot be done; and it would be quite premature for Science to assume that she has reached the ultimate boundaries of investigation, as it would be impious for her to claim the prerogatives of omniscience. But if I may in the case adventure the remark, - admiring as much as any one can the actual and wonderful achievements of science, - there still remains beyond even the farthest advances an impassable barrier, a terra incognita, which the most adventurous have not yet penetrated. It is easy to ascertain that certain substances have an affinity for each other, and science, with wonderful ingenuity, has determined the forms of combination under which they become united. The action or force by which they are hrought together and there held may hereafter be explained, and may be ranked under some unknown chemical foree; but as yet any attempts to define, or even conjecture, its nature, have been wholly abortive. The simple and familiar fact, that the muscles are obedient to the will in moving the limbs, every one admits; but in what this will consists, and how it is exerted, and how it effects its purpose, seems as yet as far from being reached, as on the day that the first child was born into the world.

We are very apt to exclaim, in the ecstasy of the Grecian philisopher in the successful investigation of an interesting prob- 
lem, "I have found out! I have found out!" when, with all the apparent and flattering loosening of the strings, the Gordian knot remains as firm as ever. The processes of nature must be all simple enough to the great Mind which established them, but that is not the human mind. To compare a rushlight to the sun would fall infinitely short of expressing the difference between them. But it is obvious that so many circumstances must combine to accomplish even the simplest and most familiar results in nature, that, to a finite understanding, the simplest processes must be complicated. Any person of common observation, who will go into a meadow or pasture, and observe the different varieties of plants which cover the ground, and remark how every one preserves its own peculiar distinctive character and form, and, though all growing upon the same soil and under the same external influences, each one extracts for itself, and for itself alone, that which its own peculiar character and constitution require, - and that in size, and form, and color, and odor, and stem, and leaf, and fruit, and seed, there are essential, and inviolable, and invariable distinctions, - and that each one appropriates to itself that which is required to form the stem, and to expand the leaves, and to throw in the coloring, and to mature the fruit, preserving always the perfect identity of the species, and furnishing in some cases a nutritious, and in others a poisonous compound for animal life, - will, I think, be very far from considering the phenomena of vegetable life as simple, or resolvable into those few chemical laws which have been established in what must at least be still considered as only the infancy of the science.

\section{A MODERN DISCOVERY.}

It is lately stated, as one of the great discoveries of the age, that an eminent agricultural chemist has invented (or rather determined how they should be compounded) a variety of manures specially adapted to the particular crop to be cultivated, furnishing in exact measure and lind the food which is required. The professed object is to supply those mineral and alkaline sub- 
stances to the soil of which it has been exhausted in the process of cropping, and to furnish them in such form, and so combined, as that they may be best taken up by the plant, and jresented to the plant only so gradually as the habits of the plant may require. This eminent chemist claims, to use his own words, "to have found means to give to every soluble ingredient of manure, by its combination with others, any degree of solubility without altering its effect on regetation. I give, for instance, the alkalies in such a state as not to be more soluble than gypsum, which, as is well known, acts through many years, even as long as a particle of it remains in the soil. The mixture of manures has been adapted to the mean quantity of rain in this comtry, (Fingland;) the manure which is used in summer has a greatcr degree of solubility than that used in winter. Experience must lead to further results, and in future the farmer will be able to calculate the amount of produce of his fields, if temperature, want of rain, \&c., do not oppose the manure coming fairly into action. I must, however, observe that the artificial manures in no way alter the mechanical condition of the fields; that they do not render a heavy soil more accessible to air and moisture; for such fields the porous stable manure will always have its great value; it can be given together with the artificial manure." *

With the highest respect for this eminent man, whose scientific labors have given a spur to agricultural inquiry and experiment unknown in any former time, one cannot but remark the convenient reservation afforded by the qualification "if temperature, want of rain, \&c., do not oppose the manures coming fairly into action;" and the recommendation to apply the stable manure together with the artificial manure, and the statement, in another place, that certain manures "act far more favorably on the production of grain crops, especially if they are added to the animal excrements, and are given to the fields at the same time," present sagacious and certainly very safe advice. They slightly remind one of a custom formerly prevalent in some Catholic countries on the Continent, when, at the opening of the spring, the priest was accustomed to go over the fields of his parishioners to give them his blessing; but when he came to fields which were cxhausted and sterile, he was very careful to add, "This needs manure." 'The doctrine of the occasional and temporary

* Liebig on Artificial Manures. 
exhaustion of the soil, by the continued repetition of the same crop, of ingredients or elements important to its growth and maturity, certainly seems reasonable and well established; but the dread which seems to possess some minds of an exhaustion which would doom the soil to perpetual barrenness, without some extraordinary supply of the materials of which it has been deprived, may have more ground to rest upon, when the birds in any country or locality are unable to find lime to form the shells of their eggs, and animals become mere lumps of gum-elastic for want of material to form their bonés.*

There is a recuperative power in nature by which it would seem that any soil, originally adapted to the growth of any particular plant, by rest, or by the growth of other and different plants, becomes again fitted for the original cultivation. That this may be hastened by artificial manures, there can be no doubt. That science may at last achieve the great discovery of a way by which the same plant may be cultivated uninterruptedly year after year on the same soil, is certainly to be hoped for. Whether this object is already accomplished by this distinguished philosopher, is now to be submitted to actual experiment by those who can afford to purchase this artificial manure.

* The fears which seem to haunt some minds, lest, by cultivation, the exhaustion of the soil should proceed so far as ultimately to put even the existence of the human race in peril, from famine, may be useful enough in exciting men to frugality in the saving of manures, and enterprise and industry in their application; but seem as little warranted as the sanguine expectations of the Millerites, who looked for the end of the world in April, 1843, and some of whom, having got their white robes fitted, and their wings spread, seemed to be rather out of temper that their predictions failed, and that Heaven in its mercy granted the "poor dogs," the unbelievers, a short reprieve. Voltaire, when admonished that coffee was a slow poison, remarked that it must be very slow indeed, for he had drunk it constantly for seventy years. Mr. Lyell, in his late 'Tour in the United States, (which, let me remark by the way, is written in the calm spirit of a philosophical observer, and does honor to his candor and sense of justice, as well as to his scientific attainments, ) is of opinion that the time occupied in the recession of Niagara Falls from the shores of Lake Ontario, where they once were, to their present position, could not have been less than 35,000 years; and that the fossi] remains, both vegetable and animal, now found there, show that even this period. startling as it may seem, belongs to a modern and not a primeval era. How idle in respect to these matters, seem, then, the calculations of beings, who

As dreams are made of, and whose little life

Is rounded with a sleep!" 
These compounds are advertised for sale at $£ 10$ sterling, or $\$ 50$, per ton, and a ton, it is said, will be sufficient for manuring four acres. Some agricultural friends, who have applied them, have promised me the results of their experiments. My readers shall have them when they are received. Such a discovery would certainly constitute a great advance in agricultural improvement. I shall not venture to predict, but patiently wait the issue, not deeming it necessary to caution those, whose funds are limited, against large investments. It seems, from some examples already given, that, with time, the soil itself, hy its own inherent energies, for which we cannot be sufficiently grateful, will recover its exhausted fertility. In the mean time. its use is never to be abandoned; for the improved agriculture of modern times has certainly made one great advance in utterly zondemning a naked fallow, and the soil may be occupied with equal advantage, both to itself and its cultivators, by a succession of tenants.

\section{LXVII. - SOILS OF GREAT BRITAIN.}

The soils of Great Britain, in two or three respects, differ essentially from the soils of the United States. In Great Britain, or rather in England, - for I believe the formation does not extenc into Scotland or Ireland, - there is a rast amount of chalk, coming, in some cases, directly to the surface, and turned up by the plough; in other cases, formed a few inches below a surface of mould or loam, interspersed, in some cases, with an infinite number of small or broken flint-stones. We have much calcarcous soil in the United States, much of the primitive and secondary limestone formation, but I know of no deposits of chalk. I have not seen in Great Britain any soils of pure sand, such as we find on Cape Cod, in Massachusetts, on the eastern shores of New Jersey, and in the South Atlantic States. Nor de I know in the United States of any such mountain peat, or bog. as is to be found in parts of England, and in vast tracts of Ireland. In the latter country there are many hills, of very considerable elevation, and in Scotland and England likewise, covered with. 
pure bog-peat to the depth, I have seen in some instances, of ten or twelve feet, and holding water like a sponge. Of course, these must have formed, in some distant period, vallevs, or level surfaces, where vast forests once stood, and, falling down, passed into decay, succeeded by those plants which constitute the principal substance of which these beds are composed; and then afterwards have been elevated above the surrounding country by some great convulsion of nature. These hills are entirely destitute of trees, and covered only with furze, or heather, or moss. 1 know of no examples in the United States of deep deposits of peat being found upon elevated summits; but there are likewise in Ireland, as in the United States, very extensive tracts of level peat-bog shut in by high grounds, saturated by water, and of unascertained depth. There are likewise in England some extensive peat-bog meadows, of the improvement of which I shall presently treat; but such tracts, within my observation, are not common.

There are likewise in England immense extents of alluvial soil. The valley of the Thames, for a great part of its extent, is clearly alluvial; so are the flat lands upon the Humber and its various branches; so are the immense tracts, denominated fon lands, in Lincolnshire, Bedfordshire, and Cambridgeshire; so is the beautiful valley of the Trent, and the valley in which York is situated; so likewise is the rich White Horse Valley, as it is termed, in the county of Berkshire. Some of these are a stiff, adhesive clay, of the most tenacious character; others a deep, rich loam; and some of them have been redeemed from the sea by a process called warping; which I shall presently describe. These are composed of what is here called silt, which consists. of a very fine sand, and muddy or aluminous matters, held in suspension by the water of the tides, and brought down likewise by the waters of rivers coming from the interior and swollen with rains, which have swept down the cultivated hills, and lobbed them of some portion of their riches. These lands are justly deemed some of the most fertile in the kingdom.

There are likewise extensive tracts of soil resting upon the red sandstone, like some of the soils in New Jersey, producing large crops of the richest herbage in pasture, and fine crops under tillage; but of the common granitic soils of New England I have met with few examples. There are, however, I believe; 
extensive tracts of them, especially in the north. A geological survey of the Island of Great Britain has been executed with great skill, and the various geological formations distinctly indicated on a map; but such have been the extraordinary convulsions on the earth's surface, that the geological lines are not an infallible guide to the character of the soil. It may be safe, in general, to infer the character of the soil from the nature of the rocks prevalent in any particular locality; but the diluvial and alluvial deposits often differ entirely from the character of the rocks which lie beneath them. No knowledge of the geological formation of a country, therefore, - so far as its cultivation, and the general character of the crops to be raised, are concemed, will supply the place of personal observation and experience.

If the nature of the soil were the only circumstance to be taken into consideration in determining the character of the agriculture to which it is adapted, the mode of cultivation, and the crops to be grown upon it, the whole subject would evidently be greatly simplified; but the climate, including heat and moisture, and the aspect and elevation of the land, are quite as much concerned in every question connected with this subject.

\section{LXVIII. - CLASSIFICATION OF SOILS.}

For all practical purposes, soils may be ranked under five different heads - sandy, clayey, calcareous, peaty, and loamy. I purposely avoid all scientific distinctions, and use such terms as even the commonest farmer will understand. A sandy soil is that in which sand abounds; clayey, in which clay; calcareous, in which lime in some form prevails; peaty, in which peat; loamy, in which a rich loam abounds. These soils are sometimes found so combined, that it might be difficult to designate their character by any one of these general terms. In some places, they are found in almost a pure state. In general, where there is found in a soil 80 per cent. of sand, it must be pronounced a sandy soil ; and so the clay, the peat, or the lime; but it is not always easy to class a soil which is of a mixed char- 
acter, and say what kind of element predominates. By sight and feeling, however, practical men are able to form an opinion of a soil upon which it may be safe to act. Besides the principal elements, to which I have referred, there is often found some mineral ingredient, which may scriously affect the character of the soil, and the degree of the presence of which can only be determined by scientific examination. Iron, copper, or mineral coal, is in general sufficiently indicated to the eye, or shows itself in the water which percolates the soil. The different forms, too, in which lime presents itself in the soil, whether as chalk, or gypsum, or magnesian limestone, are all to be considered in determining the character of a soil.

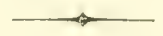

\section{LXIX. - PHYSICAL PROPERTIES OF THE SOIL.}

In addition to the characteristics of a soil of which I have spoken, there are other circumstances, usually denominated the physical properties of a soil, by which its fertility, or the kind of cultivation to which it may be proper to subject it, are to be in a great degree determined. These are its wetness or dryness, its power to absorb or retain moisture, its consistency or friability: and its temperature. All these matters are essentially connected with the fertility of a soil, and the kind of crops to which it is to be applied.

1. Wetress of a Soll. - Wet soils, or soils a considerable part of the time under water, produce a coarse herbage of little value to stock - in many cases scarcely sufficient to support life, and rendering scarcely any nourishment. The manure of animals fed upon the produce of such soils is comparatively worthless. It has been found, likewise, by repeated experiments, that water allowed to remain upon land for any length of time is injurious to vegetation, when the rapid transition of water over the land might be highly beneficial. An exception, of course, is to be made where the passage of a turbid stream or flood is arrested long enough to afford opportunity for the depo- 
sition of the enriching matter with which its waters are charged. The effect of too much water is to reduce the temperature of the soil, to obstruct the access of the external air to the roots of the plants, and, in fact, to macerate and destroy the texture of the finest linds of herbage. Perhaps it would be a more simple statement, and equally just, to say that the aquatic plants are, with some exceptions, not adapted to the nourishment of animal life, and that those which are most suited for the food of man or beast, are not suited to be grown under water. Water is of great importance to their sustenance and growth. They cannot live without it; but they cannot live in it. As to the human being, it may be of the highest benefit, both as an internal and external application; but there is soon an end to the matter when man is plunged into water, and kept under it.

All hope of cultivation or improvement must be abandoned, where land is under water any considerable portion of the time. or where it is fully saturated with water, like a sponge.

2. Power to absorb Moisture in a Soll. - I may remark, in the next place, that the fertility of a soil very greatly depends upon the power of the soil to absorb and to retain moisture. Some very distinguished men have maintained that the fertility of a soil may be measured by this power, an opinion which, it may be said, (without meaning a pun,) has much ground to rest upon, but which cannot be admitted without considerable qualifications. Moisture and wetness are in this case to be carefully distinguished. A soil consisting almost wholly of sand possesses no retentive powers; and though of all other soils the most absorbent, yet the water passes through it as through a sieve. Clay, on the other hand, is extremely retentive of water, often to the prejudice of the vegetation which grows upon it. Liebig: in a recent treatise upon artificial manures, to which I have alrealy referred, seems to be of opinion that the system of drainage now prosecuted with so much enterprise in England may be carried to an injurious extent, so as to induce the too rapid passage of the soluble manures which are applied, and before they can be taken up by, or have performed their proper office to, the growing plants. As every thing which this distingnished gentleman asserts is now deemed oracular in the agricultural world, I will quote his observations at large. 
"The reason why, in certain years, the influence of the best and most plentiful manuring is scarcely perceptible, is that, during the moist and rainy springs and summers, the phosphates and other salts with the alkaline bases, as also the soluble ammoniacal salts, are entirely or partially removed. $\Lambda$ great amount of rain and moisture removes, in the greatest quantity, the very substances which are inost indispensable to the plants at the time they begin to mature and form seeds. The system of draining which of late has been so extensively followed in England brings the land into the state of a great filter, through which the soluble alkalies are drawn off in consequence of the percolation of rain, and it must, therefore, become more deficient in its soluble efficacious elements. Attentive farmers must have observed that, after a certain time, the quality of the grain on land laid dry according to this principle deteriorates; that the produce of grain bears no due proportion to the produce of straw."

"What is more evident, after these remarks, than that intelligent farmers must strive to give to the soil the manuring substances in such a state as to render possible their acting favorably on the plants the whole time of their growth. Art must find out the means of reducing the solubility of the manuring substances to a certain limit, - in a word, of bringing them into the same state in which they exist in a most fertile virgin soil, and in which they can be best assimilated by the virgin plants."

"The attention which I have paid to this subject has been crowned with success. I have succeeded in combining the efficacious elements of manure in such a manner as that they will not be washed away; and thus their efficacy will be doubled. Owing to this, the injurious consequences of the present system of draining are removed; agriculture is placed upon as certain principles as well arranged manufactories; and, instead of the uncertainty of mere empiricism, the operations of agriculture may be carried on with security; and, in place of waiting the results of our labors with anxiety and doubt, our minds will be filled with patience and confidence."

Such are the brilliant visions which are held up before the mind of the farmer; and such is the distrust which this great man would throw over the enterprising practice of draining. It is not quite easy to understand how the plants are to take up their food but in a condition of the most minute solution; nor 
how, if they are dissolved, they are to be kept from being washed away. It is not for any finite mind, in cases which admit of any doubt, to say what is possible or what is impossible; and it would be premature to condemn that which comes recommended upon such high authority, and is yet to be made the subject of experiment. After the extraordinary and most beneficial results which have been effected by the thorough draining of all superfluous wet from the soil, the agriculturists may, however, pursue the system with a good degree of confidence, especially if a mode has been discovered of combining the alkalies and the phosphates, that they shall not be so dissolved by rain and wet as to be washed away, and yet that they shall be so dissolved that they may be taken up by the plant as its wants may require. Within the last month of writing this, I have seen, on a thin, dry, and light soil, in which sand abounded, the beneficial effects of thorough drainage, where, on a field of turnips, the crop of the drained portion, with no other diflerence than the drainage, was evidently better, by one half: than that on the undrained part. If it be the fact that soils of a friable or porous nature are, in this way, liable to lose these beneficial elements by rains and wet, it would seem extraordinary that the fact had not been sooner discovered, and their deficiency and destitution made evident. I would not express these doubts in any captious spirit, knowing how much agriculture must, in the end, owe to science, and being ready to hail with the highest satisfaction any triumph it may achieve.

3. Consistency and Friability of Solls. - The next point to be considered, in the character of a soil, is its consistency or friability. A soil, if too closely packed, - which soils of almost pure clay are liable to be, - not only forbids the passage of water. which it holds stagnant upon its surface, but is impervious to the roots of plants, especially of those plants which send their roots downwards in search of nourishment. It is likewise extremely difficult to be worked in wet weather, being not easy to move upon, adhering to the feet of the workmen and the horses, and to the implements, and in dry weather being sunburnt and hard, and, when tumed up, remaining in large and unmmageable clods. In the northern parts of the United States, where the frosts are severe, plants are always liable to be thrown out, and 
their roots torn asunder, by the violent disruption of the clods. On the other hand, soils may be too fine, powdery, and friable, being subject to be blown by the winds, being too little retentive of moisture, and therefore liable to be severely affected by drought, and failing to furnish a sufficiently strong hold for the roots of those plants which spread themselves upon the surface. A soil neither excessively consistent and close, nor excessively friable, is undoubtedly to be preferred. All pent-up or stagnant water, either on the surface or within the ground, is unquestionably prejudicial to a healthy vegetation; and a freedom or porosity of soil, so as to admit the free access of the air, is an important and valuable feature. It seems to be a well-established fact, that a newly turned up surface attracts moisture from the atmosphere; and the more friable a soil is, the more surface it exposes to the external air. In condensing the aqueous particles floating near the surface, it thus procures for the plants growing upon it some of the most important elements of vegetation. This is undoubtedly the secret of the success in forwarding vegetation by frequent stirring of the earth around plants even in time of drought, especially plants with broad leaves, such as cabbages and lettuces, which, by means of their expansive foliage, protect the earth underneatl them from the direct rays of the sun.

4. Temperature of Solls. - It is not my intention to give a treatise on this subject, nor to extend my remarks beyond such notices as will best explain the great improvements in cultivation, or the management of soils, which have been undertaken and accomplished here, and which may properly be said to constitute the glory of English husbandry. I proceed, then, to observe, that another important property of soils may be said to be their temperature. This is a matter of great importance in respect to vegetation. Heat, as well as moisture, are both equally essential to vegetable life and growth. The temperature of a soil would seem to be very little under human control; yet undoubtedly much may be done in some ways for this object. At certain seasons of the year, on the approach of frost, vegetation is arrested, and at all seasons, in certain altitudes, cultivation is hopeless. In Great Britain, this limit is reckoned at fifteen hundred feet above the level of the sea; but the cultivation of wheat cannot be recommended above six hundred feet. The main source of heat to 
the soil is the rays of the sun. Whatever may be thought of that immense internal fire of liquid matter supposed to exist within the centre of the globe, and occupying a large portion of it, while we are resting only upon a thin outward crust, yet little of this heat is felt at the surface; and animal and vegetable life is dependent upon that magnificent orb which the Creator seems to have placed in the firmament as the emblem of his own inexhaustible, impartial, and widely expausive goodness, which bids the sleeping earth, in the spring time, arise as it were from the dead, and put on the habiliments of vegetable splendor and beauty, which fills the luscious vine of summer with its rich clusters, and gilds the autumnal harvest with a beneficent and matchless glory.

The temperature of the soil is then dependent upon external influences, - upon the sun primarily, and the atmosphere as affected by the heat of the sun. This temperature is, of course, affected by the condition of the soil as to wetness or dryness, and somewhat by its inclination and aspect.

The more direct are the rays of the sun, the stronger the heat produced by them; and the lighter or brighter the surface on which they fall, the less strongly are they absorbed, and the more strongly reflected. In judging of the fertility of a soil, with some persons its color is always matter of consideration; black soils absorbing heat much more strongly than white or light-colored soils. A rich garden black mould is a great absorber of heat. $\Lambda$ sandy soil, or soil composed mainly of silex, becomes soon heated, first, from its dryness, the water passing directly through it, and, second, from the smooth surface and crystalline form of the particles of which it is composed; the heat is increased by being reflected from one side to the other, as in a tin oven. The temperature of a soil is materially affected by its condition as to moisture or dryness. This is obvious to every one. Buzi there is another curious fact in this case, not so generally observad - that water is a non-conductor of heat downwards. It: woald be difficult to make a kettle of water boil by making a fir $\Rightarrow$ over it. So the sun's heat upon a wet surface is repelled, and not transmitted; and while evaporation may be going on it the surface, the lower strata remain cold. 'The temperatur if a soil is materially affected by its aspect. Hence soils $1 \because g$ g to the south, receiving as they do the more direct 
rays of the sun, are much warmer than those to the north, and, in both cases, the temperature is affected by the angle of inclination at which the land presents itself towards, or recedes from; the rays of the sun; the steeper it is towards the south the warmer - the steeper it is towards the north, for obvious reasons, the colder the temperature. It is well known, in respect to the tonderer fruits - such as peaches, for example - in high northern latitudes, that the crop is generally more certain on the northern than on the southern side of a hill, for the reason that, the frost continuing longer and more constantly, they come into flower at a later period, and therefore are less liable to the dangers of being repeatedly frozen and thawed, and to be cut off by the late frosts in the spring:*

\section{$\longrightarrow$ \\ LXX. — PEATY SOIL.}

There are two other varieties of soil to which I have referred, upon which I shall take leave to make some passing remarks. The first is the peaty soil, which is composed wholly of vegetable matter, and is sometimes found of a great depth. It is evidently formed of the deposit and decay of vegetables, and in different stages of decomposition, - some being reduced to a fine and compact pulp, which cuts like butter, other being only partially decayed, and retaining the original forms of its leaves and stems. If vegetable matter were, as is often reckoned, the best food of plants, it would seem as though no soil could te so fertile as that of peat. This is not found to be the case, however, but for reasons not so well established as the fact. The plants of which peat land is composed have perished under water. It may be said, therefore, that they are rather in a state of preservation than decay, and this is quite obvious from the fact, that the water is required only to be drained out, or dried up in them, and they furnish a fuel equal to wood. "From the

* "In the country in which 1 reside, it has been remarked, that those portions of land which receive the first rays of the morning sun are more apt to suffer from the effects of white frosts than others, because the sudden transition from cold to heat sensibly affects delicate plants." - French Trans. of Von Thaer. 
nature of its formation under the surface of water, it acquires a portion of tamnin, which has the property of preserving animal and vegetable matter from decomposition." It may be, likewise, that the species of plants of which, in general, these preserved plants are composed, being of an aquatic nature, they do not form the most suitable nourishment to plants of a different description. I speak in this case according to the vulgar apprehension of the manner in which plants are fed, well knowing that the received doctrine is, that the organic portions of plants are obtained wholly from the atmosphere, and that the soil supplies only their mineral ingredients. Yet it must be admitted that, in ordinary cases, the fertility of a soil essentially corresponds to the amount of vegetable matter found in it, whether it supplies, in any degree, the actual substance of the plant, or, by its gradual decay, be merely the vehicle of transmitting for its nourishment the gases out of which its substance is to be composed. It is certain, however, whatever may be the philosophical reason in the case, that pure ummanufactured peat does not form a nourishing soil or substance for plants, other than those to which a wet soil is particularly congenial, and that it cannot be made so, but under a particular management; which I shall presently describe. The vegetable matter of which peat consists, being once thoroughly reduced, and mixed with other substances of an alkaline character, is rendered a most enriching manure for most kinds of land, though a much less substantial one than is generally supposed. One of its great uses is that of an absorbent, taking up the liquid matters which would otherwise be lost.

Immense bogs have been redeemed, and brought into a state of productive cultivation, in England; and, of late, these improvements have been going on with greater success than usual. In Ireland, such improvements have proceeded to a great extent, and the Waste-Land Improvement Company have at this time, in one place, five thousand acres of bog in the process of improvement. This place I had the plcasure to visit, and shall presently speak of what has been, and what is proposed to be, accomplished. The peat-bog, under favorable circumstances, as I have seen in the United States, as well as in England, may be rendered in the highest degree productive and profitable. The bog of salt marshes is of a different character from the fresh 
water peat-bog. This, however, is composed of vegetable matter in the main, being altogether marine plants, which have served as a kind of net-work to collect the earthy matter brought among them by the tide. The quantity of salt intermixed with these deposits gives them a peculiar character. They are favorable to the production of plants congenial to them; but other plants cannot be made to grow upon them until they become thoroughly decomposed; and, in that case, no soils yield a more luxuriant or richer vegetation. In truth, they require to be reduced to the state of fine mould, and the greater portion of the saltness exhausted, which time itself will effect where they are kept from the access of the tide, in order to be in a condition favorable to the growth of other than marine or saline plants.

\section{LXXI. - LOAMY SOILS.}

Next to peaty soils, I have to speak of what are called loamy soils. These are not very well defined. There has been much debate as to what constitutes loam or mould; but if it be difficult to define it with exactness, there is no great difficulty with practical men in understanding what is intended by it. I suppose the proper definition of mould to be decayed vegetable matter, and of loam to be that portion of the soil in which this mould, or decayed vegetable matter, (or humus, as it is technically called,) is mixed up with other common mineral elements, such as sand, clay, and lime, and in a state of fineness and equal or diffusive commixture. I do not know that any great error would be committed by considering mould and loam as synonymous, and by saying that mould or loam is a rich, unctuous, dark-colored matter, abounding in vegetable as well as mineral substances, found usually on the surface of fields, especially of those which have been cultivated, or those which are entirely in a state of nature; and of various depths, from inches to feet. In the rich valley of the Mississippi, I have seen it extending to a depth of twelve and eighteen feet, and of extraordinary richness. In cases of pure sand or clay, little or nothing of this is to be found. In chalk 
soils, its depth is usually very small. It constitutes the rich and fertile upper stratum of a soil which is usually cultivated by the plough; and it becomes gradually deepened as the land is cultivated and manured. The depth of this loam or mould may be considered, in general, as the best test of the goodness of the soil, or its productive character. I know that this is sometimes donied. The dark-colored condition of the upper stratum is not always an indication of mould, for occasionally there is met with an upper stratum of deep sand, colored with some mineral substance, which is almost utterly barren, and very difficult of improvement; but ordinarily, other circumstances being equal, the surest test of the fertility of a soil is the depth of the vegetable mould or loam on the surface.

Loamy soils receive their particular designation from the mincral substance with which they abound; thus we speak of sandy loams, or clayey loams, from the predominance of either of these substances in the soil ; and undoubtedly the richest of all soils is that in which there is an intermixture of various elements - some one says, where lime, clay, and sand, are mixed in equal proportions with mould, or decayed vegetable matter; but it is not certain that the exact proportions are ascertained.

\section{IXXXII. - HUMUS, OR VEGETABLE MOULD.}

'The substance designated as vegetable mould, or humus, in its pure or unmixed state, is not an infallible indication of the fertility of a soil, as I have already stated in respect to peat formations. Liebig refers to the soils in the neighborhood of Mount Vesuvius, composed wholly of matter thrown from the crater, as highly fertile. "The land in the vicinity of Vesuvius may be considered as the type of a fertile soil, and its fertility is greater or less, in different parts, according to the proportion of clay or sand which it contains. The soil which is formed by the disintegration of lava cannot possibly, on account of its origin, contain the smallest trace of vegetaile matter: and yet 
it is well known that, when the volcanic ashes have been exposed for some time to the influence of air and moisture, a soil is gradnally formed in which all kinds of plants grow with the greatest luxuriance. This fertility is owing to the alkalies which are contained in the lava, and which, by exposure to the weather, are rendered capable of being absorbed by plants. Thousands of years have been necessary to convert stones and rocks into the soil of arable land; and thousands of years more will be requisite for their perfect reduction - that is, for the complete exhaustion of their alkalies."

This is a very extraordinary statement, and, without implying any distrust of the authority on which it is made, is certainly not consonant to general experience. General experience would seem to show that soils without any vegetable mould are not productive, and most practical farmers would prefer, of all others, a soil where the vegetable matter, well compounded, existed in abundance, forming, as it is termed, a deep and rich loam. But it would seem that, in the case to which Liebig refers, thousands of years are necessary to render a mass of lava fertile, and in such a case it might be fairly presumed that some vegetable matter might accumulate and produce the desired mixture. I do not presume to call in question an authority so distinguished, and for which no man has more respect than myself; but I could wish that we had more facts in the case, or that they were more definitely stated.

Until recently, almost all agriculturists, both the scientific and practical, have considered the quantity of vegetable matter contained in a soil as the test of its fertility. A prejudice so universal, and so long established, would seem, on those grounds, strongly entitled to respect. It has been as well understood that vegetable matter alone, as in the case of peat, and this but partially decomposed, was not fertile. But the opinion of the connection of vegetable mould with fertility applied to vegetable matter in a state of comminution and intermixture with other elements of a soil, and here the fertility of the land has been understood to bear a very close relation to its predominance or deficiency. Peat itself, when thoroughly decomposed, has been found a most efficient manure. The effects constantly accruing from the application of decayed vegetable matter to the 
soil, from the application of the dung of eattle, which is in the main decomposed vegetable matter, and the extraordinarily luxuriant vegetation always appearing upon duug-heaps left on the field, or upon places where dung heaps have been formed, seemed to speak the same language. The supposition has been, that this vegetable matter constituted, in fact, a part of the food of plants, and went to assist in forming their substance.

The doctrine of Liebig denies directly the supposition that this humus, or vegetable matter, is taken up as the food of plants, because, where a forest grows, the vegetable matter in and upon the soil actually increases, instead of diminishing; but then, although, in the case above referred to, of the volcanic soils near Mount Vesuvius, one might be led to infer that he considered it of no moment, yet this I think would be doing him an injustice. $\mathrm{He}$ does consider the humus of the soil as furnishing, in its decay, a necessary supply of carbonic acid to the plant in the process of germination, though of no use after the plant gets above ground; and he supposes that the manures of animals ied upon the product of the land return to the land those mineral elements which they took from it, and which are indispensable to their perfect formation. This may be so; and in this view he does not deny the value of vegetable mould, or humus. But certainly there was nothing improbable in the supposition that plants might have found some portion of their food in those decayed substances which once constituted a part of the substance of their predecessors. Indeed, I see as yet no sufficient grounds to conclude that their office in supplying carbon to the growing plant ceases as soon as the plant is above ground, and able, as he supposes, to gain its own supplies for itself from the atmosphere. It is quite certain that the growth of a forest would be checked, and the amount of humus in the soil be diminished, if all the decayed leaves and limbs, which fall from the trees, were constantly removed; and it is as certain that the continual cultivation of land, without supplies of manure, exhausts its vegetable mould; and that the application of vegetable manures to crops in a growing state is often as efficacious as when applied, or ploughed in, with the seed. 


\section{LXXIII. - PECULIARITIES OF SOIL.}

There are some characteristics of different soils which seem to be generally admitted by practical men, but not very well defined. Thus some soils are deemed much better than others for the production of beef, others for that of butter, others for that of cheese ; and I found farmers, in some of the dairy districts, going so far as to assert that cheese could not be made on some soils, or rather, as I inferred from their remarks, could not be made to so much advantage as on others. But this, it seemed to me, could only be an indirect inference. That these products, both in quality and quantity, depend much upon the nature of the plants upon which the animals are fed, is an obvious fact; and that some soils may be more favorable than others to the production of such kinds of plants as are particularly suited to particular uses or objects, I could easily understand; but any other connection of the products with the nature of the soil secmed to me far from being established. To speak, therefore, of a cheesy soil, as I heard in some dairy districts, seemed to me of questionable propriety, as, under an intelligent agriculturc, I could hardly doubt that a different species of herbage might be cultivated upon the same soil which now produced that which was unfavorable.

I have given these brief notices of the general character of soils in England, of which the connterparts may be found in the United States. I have given them in terms which will, I think, be understood by the commonest farmer. I could without any difficulty have borrowed learning enough for the occasion, and have talked philosophically in the case; but in all I have read on the subject, I have as yet discovered no practical advantage to the general mass of readers, from so viewing it, beyond what is secured by more simple statements. The importance of the nature of the soil to the husbandman, who spends his labor upon it, is very great. Some of the mineral ingredients, which are found in the soil, are indispensable to vegetation. Those which are found in the plants can only be received from the soil; but it is a singular fact that, in case of a deficiency, one may sometimes be substituted for another. "Potash is not the only sub- 
stance necessary for the existence of most plants; indeed, it has ween already shown that the potash may be replaced, in many cases, by soda, magnesia, or lime."*

\section{LXXIV. - APPLICATION OF CHEMISTRY TO AGRI- CULTURE.}

It must not be inferred, from any remark which has fallen from me, that I overlook the value of chemical science and inquiry in respect to agriculture. An inference of that nature would do me a great injustice. Our obligations in this matter are already very great, and more and wider triumphs are to be looked for. But two or three things, in this case, appear to me deserving of consideration, and likely to moderate an excessive confidence. The first is, that vegetation, and consequently cultivation, in the most scientific sense of the term, is not so simple a matter as some persons would have us imagine. How, for example, particular plants from the same soil are capable of extracting entirely different substances, according to their own peculiar and individual characters, each one preserving its own identity in form, taste, odor, color, fruit, and use, is not yet explained. The explanation is not even approached. In the second place, it scems assuming quite too much to suppose that all the processes of vegetation are to be resolved into mere chemical processes - understanding by chemical processes those laws or operations of which chemistry has attained a knowledge. The remarks which I have just made seem to demonstrate this. In the next place, the lnnowledge which chemistry has already furnished, either of the nature of soils or manures, or of the phenomena of vegetation, has not as yet been of so practical a character as is to be hoped for; and it would seem extremely dificult, not to say impossible, so meet on any extended scale the diversities of soil which it has illustrated. The newly-invented manure, to which $\mathbf{I}$ have above referred should it be found to equal what it seems to promise, may fully meet this objection, and thus effect an important stricie in agricultural improvement. 


\section{LXXV. - THEORY OF AGRICULTURE.}

The present theory of agriculture assumes that plants consist of two species of matter - vegetable and mineral ; that the former is derived wholly from water and the air, and the latter from the soil. The plant is not perfected without the conjoint aid of both. The former consists of oxygen, hydrogen, carbon, and nitrogen ; and the latter of at least eight different kinds of mineral substances. The latter are found in the ashes of plants, and are indestructible. They consist usually of four acids and four alkalies; - silicic acid, phosphoric acid, sulphuric acid, and muriatic acid; and, of the alkalies, potash, soda, lime, and magnesia. Other mineral substances are found; but these which I have enumerated are the principal. Boussingault thus designates them: "The residue left by the combustion is commonly composed of salts; alkaline chlorides, with bases of potash and soda; earthy and metallic phosphates; caustic or carbonated lime and magnesia ; silica; and oxides of iron and of manganese. Several other substances are also met with there, but in quantities so small that they may be neglected." *

The mineral substances found in the ashes of plants may be supplied by art; yet whether to be applied to the land in a direct and simple, or in a combined or mixed form, and, if so, how combined and mixed, are points not as yet determined. It is certain that there is only one form in which they can be taken up by the plants, and that is, in as extreme a degree of solubility as they are capable of being reduced to. Whether they shall be so reduced before they are applied, - whether, for example, they shall be presented to the plants in a solid or a liquid form, or whether they shall be by any art prepared, or it shall be left to the vital operations of the plant to prepare them, - are points yet to be determined. These questions will naturally present themselves again when the subject of manures is considered.

In respect to the organic parts of vegetables, - those which form their largest portion, and consisting of oxygen, hydrogen, carbon. and nitrogen, - the two former are understood to be supplied by water, the carbon by the atmosphere, and the nitrogen, consti- 
tutming the nutritious part of the vegetable, from ammonia, which is itself a compound of nitrogen and hydrogen, and supplied partially by rain, by the decay or putrefaction of animal matter, and in the excrements of animals. In the escape of ammonia from our dung heaps, it is supposed a great portion of their most valuable material passes off; and attempts have been made to fix this volatile substance, so as to secure it for the service of the plants, to be taken up by them as required. For this purpose, gypsum has been strongly recommended to be sprinkled in stables, and to be spread upon manure heaps. It is quite doubtful whether its effect has met the sanguine expectations which were formed of it. In the report given by Professor Henslow, which he has been kind enough to send me, of fifteen attempts to fix ammonia by the application of gypsum to dung, the result seems to leave the question wholly undetermined. His conclusions from these experiments are given in this result: "It will be seen that, with turnips, the eflect has been uniformly in favor of gypsumed dung. With the straw of wheat, the result is twice in favor of the gypsumed dung, once against it, and in one case there is no difference. In respect to the wheat itself, it is six times in favor of the gypsumed dung, and six times against it. The practical inference to be deduced from this part of the inquiry favors the idea of using gypsumed dung for a turnip crop, but shows that it produces no better effect than ungypsumed dung upon a wheat crop." Such results certainly lead to no very strong conclusions. But the beneficial effects of covering manure heaps with mould, in order, in the first place, to prevent the escape of the volatile parts of the manure, and, in the next place, to absorb the gases, — so that the soil used for a covering becomes itself a valuable mantre, - are points long ago determined by the practice of many enlightened farmers.

Whatever may be the success or the ill success of dealing with the mineral qualities of the soil, or with those subtile gases of which vegetables are composed, there are processes of a practical nature to be applied, the propriety and utility of which are established. The practice of agriculture is still rery much in advance of the theory of agriculture. I do not undervalue scientific agriculture. Science may do as much for agriculture as for any other department of business, or art, or health, or comfort, or enjoyment. In no department is success more 
desirable, or would it prove more extensively beneficial. The human mind finds the greatest of all delights in the acquisition of linowledge, and is impelled by an instinctive impulse "to search into the causes of things." A man, if familiar with the place and route, may find his way, if the lamps were not lighted, even of a dark night, in the labyrinthine streets of London; but he must proceed slowly and doubtingly, and may tumble into an open sewer, or run against a post, or encounter other obstructions more yielding than the post, yet twice as dangerous. But since science has kindled the beautiful and far-reaching silver flame of gas, and converted night into day, he walks in security and confidence; he escapes, if he has wisdom so to choose, all perilous obstructions; and he reaches his destination by the most direct, the most expeditious, and a certain route.

\section{LXXVI. - ACTUAL IMPROVEMENTS}

'The soil must be the great object of the farmer's attention; and here he may accomplish much. I mean much relatively, and with a due consideration of the limitations by which human power is always hemmed in. Light and heat, sunshine and rain, wind and frost, and many other influences most important to vegetation, of which as yet the human imagination has not, in all probability, taken cognizance or conceived, are wholly beyond his control or dictate. Arrogant and presumptuous as he is, the earth could not contain him, if he were not chained down by the fact of his absolute dependence. There is a beautiful moral in the mythological fable of Jove's having given the reins to Phaeton, and the disastrous consequences which followed. But the ameliorations which an improved agriculture may effect are great, and sufficiently encouraging to the loftiest self-esteem. $\Lambda$ wet soil may be drained; a dry soil may be irrigated. A barren soil may be enríched; a rich soil may be made more fertile and productive. A thin soil may be deepened; a heavy soil may be made lighter; a loose soil may be made more compact. $A$ bleak soil may be sheltered: and an unfarorable aspect 
may be alleviated. Waste lands may be converted into fertile fields, and a growth of nauseous or unnutritions weeds supplanted by bending sheaves of golden grain. Rivers may be diverted from their tortuous courses, now rendering vast tracts of land inaccessible, and made to flow in straight lines, leaving their recovered banks open to the plough; and immense extents of the richest alluvial lands may be rescued from the sea - the feeble arm of human art and industry drive back the spoiler, and stay even his proudest wares. All these noble triumphs English agriculture has achieved; and I shall take pains to lay them before my readers. What I propose to do then further, in this number, is, to detail their various improvements, and then to speak of the adaptation of particular soils to those purposes for which experience has shown them best fitted.

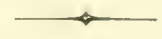

\section{LXXVII. - PLOUGHING.}

The first and most general operation, to which the soil is subjected, is ploughing. Man must have been early taught that, in order to render the earth productive, it must be tilled; and it would be extremely curious, if the materials of such history were attainable, to trace the progress of improvement fiom the first instrument employed to stir the earth to the present beautiful and ungenious implement, by which acres, and miles of acres, are at pleasure inverted. It would be interesting to know how the North American Indians eultivated their corn (maize) when the country was discovered; tradition has not preserved the traces of the method which they adopted. Their implements must have been few, and of the most simple description. The smooth stones, some of which I have myself found in places known as their favorite haunts, of a wedge shape, may have been used for digging the gromd for the deposit of the seed, and perhaps for keeping the soil loose round the plants: near the sea-shore a clam-shell may have answered the same purpose. Of weeds, probably they had few to contend with, as the land was new and rot surcharged with manure, of which perhaps they did not know 
the use, since, within the memory of persous now living, farmers in the vicinity of Albany were accustomed to cart the manure from their barns on to the Hudson when frozen, and in the neighborhood of Montreal on to the St. Lawrence, that, at the breaking of the ice in the spring, it might be carried away by the stream. Even much more recently, in some parts of the country, larmers, when they have found the piles of manure round their barns accumulated to an inconvenient size, have preferred to desert them, and build other barns, rather than be at the trouble and expense of removing these heaps. One is often amused at hearing people boast of "the wisdom of our ancestors;" and, to be consistent, we should expect to see such persons adjusting the equilibrium of a bag of grain upon the horse's back by putting the corn in one end and a stone in the other.

When I come to treat of the implements of husbandry, I shall describe an English plough; at present I have to deal only with the operation itself.

I think I may say that, in England and Scotland, the art of ploughing has reached perfection, and that it is unrivalled and unsurpassable. This at least is my opinion, which nust be taken at what it is worth. I caunot conceive how it can be improved; and this not in rare instances, and at ploughing matches, but $\mathbf{I}$ may say universally. In some cases, the work has been done better than in others; but I have not seen an example of bad ploughing in the country; I have not seen one which, in the United States, would not be pronounced superior.

\section{LXXVIII. - THE ENGLISII CIIAACTER - A DIGRESSION.}

It may be thought a little out of the way, but I will take this occasion to say, that the English know what right lines are. It is but just to say of them that of which I am convinced, after a familiar and close observation, - that they are an upright people: that they have, with as few exceptions as are ordinarily to be expected in a commercial community, none of that slyness which some men chuckle orer as a commendable quality, but 
which, though it may mount a fine beaver and wear the best Saxony broadcloth, is only a soft name for villany; that their habits, like their ploughing, are direct and straight-forward, and are opposed to all balks and all tortuous windings. I thank God that the blood of such a people flows in my veins; for I look upon honesty as the true nobility of man, and the only aristocracy to which my heart burns to pay always its spontaneous and unclaimed homage. "An honest man is the noblest work of God;" a passage, of which a facetious divine, a man as true as he was witty, once said, "If it were not in the Scriptures, it ought to be."

\section{LXXIX. - THE PERFEC'TION OF PLOUGHING.}

The perfection of any art consists in its accomplishment of its particular object in the best mammer, and by the simplest means. The perfection of ploughing consists in its performing its work exactly as you wish or require to have it done. You wish the surface soil of your field completely inverted. You wish this to be done at a particular depth, and the furrow-slice to be cut in perfectly direct lines. You desire it to be of a certain width and certain thickness, and the same in every part of the field. You require that it should be raised without breaking, and either laid completely flat upon its back, or made to recline upon its neighbor at a particular angle of inclination; and you wish it so done that, if it be greensward, every portion of the herbage shall be completely shut in, and not a spire shall dare show its head between the furrows, any more than a straggling Frenchman on the field after the battle of Waterloo. And you want this performed at the rate of about an acre a day of eight hours work, with your team moving at the rate of two miles or two miles and a quarter per hour, so that they may work comfortably every day in the week. You desire your ploughman to follow his team, and execute his part with entire attention to what he is about, without perturbation, without sweating, without fretting. and especially without swearing, which some men whom I have known, both at ploughing matches and in their own fields, have 
deemed indispensable to the proper performance of their work: in which matter I beg leave to say I always entirely differed from them in opinion, having never yet discovered any reason why men, who assume to belong to the order of rational animals: should, by their passion and the indecency and profaneness of their language, degrade themselves below the brute animals which they undertake to govern. Now, in all the particulars which I have pointed out, the ploughing here will be done exactly according to a prescribed form. I said, in my first report, that the ploughed land resembled a rufle just come from under the crimping iron. The representation is perfect.

\section{IXXX. - PLOUGIING MATCH AT SAFFRON WALDEN.}

I attended, among several others, a ploughing match at Saffron Walden, where there were at least ten competitors, with lots of an eighth of an acre; and, as well as I can remember, the furrow-slices were to be seven inches in width and five inches in depth. It was not a match against time, although the work was required to be completed within a certain time. I do not misstate when I say that I do not believe there was the variation of an inch, in the whole field, in the width or depth of the furrow, or a single crooked line, or even one solitary balk. The fields or lands were struck out before beginning. Two horses composed a team, and the ploughman was his own driver. Some boys under eighteen were allowed to enter as competitors for boys' premiums. I went over the field in an ecstasy of admiration at its uniformity, neatness, exactness, and beauty.

There were some peculiar regulations adopted on this occasion, to which I may properly refer. Ploughmen who had obtained a first-prize premium on any former occasion, for ploughing, were disqualified, by the rules of the society, from entering into the general competition. But, with a view "of giving such merito. rious ploughmen another opportmity of showing that their skill and energies remain unimpaired," a special competition was offered to them, and seven prizes were proposed - the first 
amounting, in money and clothing, to $£ 810$ s., or abont $\$ 43$, the lowest to $£ 210 \mathrm{~s}$, , or more than $\$ 12$, and the unsuccessful competitors, to the number of seven, were to receive $£ 1$ each. This was putting them through a fine sieve, so as to come at the best quality. $\boldsymbol{A}$ premium of five guineas was likewise offered to the farmer who had employed the greatest number of ploughboys on his occupation, in proportion to acreage, for the preceding year, provided one of the boys in his employ should have obtained a prize for ploughing at the Ammal Necting. Such a premium as this seemed well suited to induce the farmers to give particular attention to the improvement of the lads in their service. Two circumstances contribute strongly to the perfecting of this most essential art. The first is, that boys are trained to it as early as they can possibly be employed with safety. The second is, the division of labor which generally prevails, so that individuals devote thernselres, to a degree exclusively, to one particular object; a ploughman is constantly employed at the plough, and a herdsman in the pastures, or stalls.

'There are two points, which have seemed to me always particularly to test the skill of a ploughman. The one is the mode in which he lays out his land, and strikes the first furrow; and the second, that in. which he finishes the last furrow. In the case to which I have referred, the last land remained, at the close, a single unbroken strip of equal width, from one cnd of the field to the other, lying like a stretched-out ribbon, which, as the ploughman came down the course, he turned without breaking, and with perfect precision, from one end to the other. In this instance, the horses seemed almost as well trained as the driver, and inspired with an equal emulation. The finishing of the ends of the lands is always a work of great care; they are crossploughed, and the whole affair is completed with an equal neatness throughout.

I have seen very good ploughing in the United States, and perhaps in no department of agriculture has greater improvenent taken place than in ploughing, and in the construction of ploughs. Formerly, nothing could be more slovenly executed. A straight line was not to be seen. The land was not half turned over. The furrows were of such depth or thickness as they might chance to be; and the plough itself, when in action, resembled very much a live animal, with a sort of grasshopper 
motion, which one man at the stilts, and often two men riding upon the beam, were struggling to keep down, and, like police officers, to prevent its escape. A man was always required, likewise, with a hoe, to assist in turning the furrow-slice at the end of the share, or in the discouraging duty of raising again, and turning over by main force, those furrow-slices which, notwithstanding they had been raised by the plough, like a reluctant boy pulled out of bed in the morning, with his eyes half npen, insist upon getting back again as soon as the master's back is turned. I remember many a thump on the breast from the handles of the plough, and many a sudden jerk, which has thrown me upon the furrow, when I have been riding on the beam, and many a splitting of a beam, and many a breaking of a share; and have looked back with dismay upon a long furrowslice obstinately turning back into the furrow, after I had supposed it securely laid over. Somewhat of this experience may have been necessary, to enable me to estimate properly the excellence of English ploughing, when the implement seemed to move through the ground with as much quietness, directness, ease, - I may almost add grace, — as a boat through the water, with its sails spread to a favoring breeze, and an accomplished steersman at the helm. Some allowance is to be made for the condition of our fields, compared with the English fields. Here there are no stumps of trees, and no stones, to impede or derange the plough. With us, alas! in many cases, the stumps and stones remain in resolute opposition, to dispute our entrance, and, like bad tenants, can be dispossessed only by main force.

I know that some may ask, What is the use of doing things with so much care? I answer, in particular, that, the field being more thoroughly worked, the advantages to the crops, both in the suppression of weeds and in furnishing a more favorable bed for the extension of the roots of the plants, and its after cultivation and management; are quite sufficient to recommend it. But I answer, in general, that the labor in the end is less, and more easy, in doing things well and regularly than in half doing them, and that in a slovenly manner; and that habits of order, neatness, and regularity, in one brauch of labor, lead to the same habits in other branches, and are of eminent advantage; and, according to an excellent proverb, a thing which is well done is twice done. 


\section{LXXXI. - GENERAL RULES FOR PLOUGHING.}

The depth of ploughing, the width of the furrow-slice, the number of ploughings which should be given to land, and the season at which it should be executed, depend on such a variety of circumstances, that it would be difficult to prescribe any universal rules.

The objects of ploughing are, to loosen the soil, and to render it permeable to the roots of plants, that they may extend themselves for nourishment and support; to make it accessible to the air and rain, from which, according to modern theories, it gathers both oxygen and ammonia, for the food of plants; and, lastly, to give an opportunity of incorporating manures with the soil, for their support and growth. It has another object, of course, where greensward is turned over, which is, to bury the herbage then on the ground, and substitute other plants.

The depth of ploughing varies in different soils, and for different purposes. The average depth may be considered as five inches, but no direction on this subject will be found universally applicable. Three of the most eminent practical farmers with whom I am acquainted here plough not more than three inches; but the surface mould, in these cases, is very thin, and the understratum is a cold, clammy chalk. One farmer, whose cultivation is successful, and who cultivates "a light, poor, thin, moory scil, with a subsoil of either blue or white clay, peat, or white gravel," carefully avoids breaking up the cold subsoil, and cuts up the sward with a breast-plough, which is a kind of paring spade; and, after burning the turf, and spreading the ashes with a due application of artificial manure, consisting of equal quantities of lime, wood and turf ashes, at the rate of sixty bushels to the acre, and sowing turnip-seed, cultivates between the rows with a single horse-plough, which cannot, of course, take a deep furrow. 'The second year of the course, when he sows wheat. he ploughs it very lightly with a horse, after having first breastploughed it, so as thoroughly to cover in the manure which the sheep who have been folded upon the land have left upon it. The third year it is breast-ploughed, sown in turnips, and cultivated between the rows with a horse, as before described. The 
fourth year it is simply breast-ploughed for barley. The fifth and sixth years it is in grass. Thus, in the whole course of a six years' rotation, this land is only ploughed four times by men, and three times with a single horse-plough. Another farmer in the same neighborhood says that, upon this description of land, any other than the breast-plough would not leave the ground sufficiently firm for wheat. Mr. Pusey, M. P., whose excellently managed farm I have had the pleasure of repeatedly going over, in remarking on the above accounts, says, "Occupying similar land, I may add that I never plough it deeply, but I repent of so doing; and am falling more and more each year, by the advice of neighboring farmers, into the use of the breast-plough, instead of the horse-plough. This manual labor is quite as cheap, for a good workman can pare such hollow tender land at $4 \mathrm{~s}$, or even at $3 \mathrm{~s}$. per acre. It is possible that the drought of our climate in Gloucestershire and Berkshire may be one cause of the success of this practice in those counties, and that the same soil, if transferred to Westmoreland, would require deeper working. Therefore, without recommending shallow cultivation in districts where deep ploughing has been hitherto practised, I would merely warn begimners against plunging recklessly into the subsoil." These examples are certainly well worth considering. I do not understand that these practices at all militate against the doctrine of the advantages to be obtained from subsoiling. In cases where subsoiling and thorough draining are not applied, this shallow ploughing may be preferred, as the mingling of the cold and inert subsoil with so thin a surface of vegetable mould would doubtless be prejudicial, at least for a length of time; but the improvement of such land by a system of thorough draining and subsoiling is another matter, to which I shall refer in its proper place. There are considerable tracts of this moorish land - that is, a thin, black, coarse peat, not half decomposed, resting upon a cold and hard pan of gravel or clay, or what some persons have mistaken for marl, in Massachusetts, and other parts of the country, the improvement of which, so far as my experienco has gone, has been almost hopeless.

While upon this subject, I may as well give the results of the management of the first farmer referred to, and therefore subjoin them. "By this mode of management, an economical system is followed up through the whole course, by being nearly all 
performed by manual labor, by which means a remunerating crop will be produced, and the land always kept firm, which is the only difficulty to bc overcome on this description of soil. The farm, when first taken by me, was wet; as much out of condition, and as light and weak, as it well could be-parts of it being merely held together by the roots of grass and weeds, natural to moory land, but which must be very projudicial to the production of those crops that are to benefit the farmer. I commenced by draining, and then pursued the foregoing system of cultivation, by which my most sanguine expectations have been realized, though I was told that the land would be too light and too poor to plant wheat after turnips. I have never found any ill effects from paring and burning, experience having taught me that it produces a manure particularly beneficial to the growth of turnips; thereby enabling me to firm the land by sheep." ** This farmer speaks of performing a great portion of his work with manual labor. I think some part of it might rather be called pedestrian than manual; for, if he ploughs his land by men, he treads it out by women. He says, "Before the horseroll can be used, I send women to tread it, and, if occasion require, tread it again; after which, I have it twice hoed. I have found more benefit from this mode of pressing than any other, being done at a time when wheat, on this description of soil, requires assistance." $\dagger$

I have found other farmers, who, with their wheat crops on light, chalky soils, plonghed in a very shallow manner, and then were accustomed to tread their land with sheep, in order to give the wheat plant a firmer footing; as, otherwise, in a very light soil, it might be thrown out by the wind. These cases, how-

* Journal of the Royal Agricultural Society, vol. vi. p. 1.

† 'This is a use to which women have not as yet been put in our "half-civilized" country. I dare say, however, many persons think that it is very well to make such clever animals serviceable; their "keep," agriculturally speaking, is somewhat expensive; and, as they have their share in the pleasure of consuming, they may as well take their part in the labor of producing. Whatever any persons may think, however, I will say no such uncivil thing; but, since the celebrated danseuse, Fanny Ellsler, returned from the United States, after a two years' tour, with a gain of twenty thousand pounds, or one hundred thousand dollars, it cannot be denied that the Americans are quite willing to pay for the use of women's feet - in a way, we admit, more elegant, tasteful, and classical, but certainly not more respectable, and not half as useful, as that of treading the wheat-ground. 
ever, must all be deemed exceptions; and the general rule in England, where the soil admits of it, and manure is abundant, is that of rather deep ploughing. Five or six inches is the average depth; in many cases, much more than this. The loam, or vegetable mould, is, without question, the great source or medium of nourishment to the plants. Be it more or less deep, it is always safe to go to the bottom of this, and, by gradually loosening a portion of the subsoil, or lower stratum, and incor porating it with the mould, and rendering it accessible to the air and light, it acquires the nature of mould, and the whole arable surface is enriched. The deeper the soil, the more deeply the roots are permitted to descend, and the more widely they are enabled to spread themselves, - unless they penetrate a substratum unhealthy from wet or the too great prevalence of some unfavorable mineral substance, - so much the more luxuriant and productive is the vegetation likely to prove. The depth to which the roots of plants will go down in search of food or moisture, where the soil is in a condition to be penetrated by them, is much greater than a superficial observation would induce us to suppose. It is confidently asserted that the roots of some plants - such, for example, as lucern and sainfoin go to a depth of fifteen, twenty, and even thirty feet. This seems scarcely credible. Red clover is known to extend its roots to the depth of three feet, and wheat to the depth of two or three feet, where the condition of the soil is favorable to their extension. Von Thaer, the distinguished agriculturist, says, "he has pulled carrots two and a half feet long, the tap-root of which was probably another foot in length." The tap-root of a Swedish turnip has been known to extend thirty-nine inches; the roots of Indian corn full six feet. These statements may appear extraordinary; but, by the free and loose texture of the soil, it is obvious a good husbandman will give every opportunity for the roots and their extremely fine fibres to extend themselves as far as their instincts may prompt them.

Next to the depth of ploughing, the width of the furrow-slice is to be considered. This, of course, depends mainly upon the construction of the plough. A plough with a wide sole or base, in the hands of a skilful plonghman, may be made to cut a narrow furrow-slice; but a narrow-soled plough camnot be made to cut a wide furrow-slice, though it may sometimes appear to do 
so by leaving a part of the ground unturned, which the furrowslice is made to cover. Where, as in old ploughed land, the object is solely to leave the ground loose and light, it is advisable to take a very narrow furrow. Where, otherwise, the object is to move greensward or stubble ground, and to cover in the vegetable matter, such a width of furrow must be taken as will cause the slice, as it is raised by the share, to turn over easily. This width may generally be reckoned at nearly twice the depth, though less will answer; but a furrow-slice of equal sides would not turn, but stand on end. The manner in which the furrow-slice will be turned depends somewhat upon the form of the mould-board, but more, in general, upon the skill of the ploughman. Two modes are adopted; the one to lay the furrow-slice entirely flat, shutting its edge exactly in by the edge of its neighbor; the other, to lay it at an inclination of 45 degrees, lapping the one upon the other. The former mode, where land is to be sown with grass-seed, and, as the phrase is with us, laid down, is, undoubtedly, to be preferred. Perhaps, in any case where a grain crop is to be cultivated, it should be preferred, as its beneficial effects have been well tested in the United States. In the United States, however, from a higher temperature, the vegetable matter thus pressed down may be expected sooner to be decomposed, and thus sooner furnish a pabulum for the growing plants, than in a climate where, in a much lower and more even temperature, the decomposition cannot be expected to take place so rapidly. In other cases, and for vegetable crops, - I mean in contradistinction to grain crops, - a different mode of ploughing, that is, laying the furrow-slices one upon the other at an angle of 45 degrees, or half turned over, would leave the ground more loose, as well as expose a larger surface of the inverted soil to be enriched by the air. In this way, by harrowing and rolling, the vegetable matter will be completely buried. This mode of ploughing is evidently preferred throughout the country, as I have seldom seen the sward completely inverted and laid flat, though I know the practice prevails in some counties. To avoid having any of the grass protrude itself between the furrow-slices, they have here, what I have never seen in the United States, a skim-colter, that is, a miniature ploughshare, or blade, placed under the beam, and 
so adjusted as to cut an edge from the furrow-slice as it is tuned over; this picce, so cut off, at once dropping down, and being buried under the furrow-slice as it goes over. 'The consequence is, that there is no grass on the edge of the furrow-slice to show itself, and great neatness is therefore given to the whole work. There is another mode of ploughing, which I have sometimes seen practised, by which the furrow-slice is not merely lifted, but may be said to be rolled over, or twisted in a sort of bagfashion. This seemed to me to be principally owing to the concave form of the mould-board, for no workman could have done it with a straight or convex form of mould-board. It would seem to render the soil more friable and loose; but every departure from a straight line, or wedge form of the mould-board, evidently much increases the draught. The skim-colter, to which I have referred above, somewhat increases the draught, but in a very small degree.

The great object of the English farmers, in ploughing, scems to be the thorough pulverization of the soil; and they are therefore very seldom satisfied with one ploughing, but their land is repeatedly ploughed, scarified, and harrowed. They cross-plough their land, and think it desirable to reduce the sward land to a fine tilth, tearing it to pieces, and bringing all the grass, and roots: and rubbish, to the surface, that they may be raked up and burned, or carried to the manure heaps. The propriety of this practice is, in my mind, quite questionable. It would seem to me much better to turn the sward completely over, and then cultivate on the top of it, without disturbing the grass surface, leaving that, when thus turned over, to a gradual decomposition, that it might in this way supply food to the growing crop, whereas the abstraction of so much vegetable matter must greatly diminish the resources of the soil. Where, however, the field is infested with twitch grass, (triticum repens, ) - in which, indeed, many of the fields in Englind abound to a most extraordinary extent, - there may be no getting rid of it but by actually loosening and tearing it out; but where it is a mere clover ley, or an old grass pasture or meadow, the taking out and removing the vegetable matter seems to be a serious waste. Even the twitch might be managed where the crop is to be hoed, though, in grain crops, its presence is extremely prejudicial. 
Haring thus described the general style of ploughing, as it prevails in Lingland, I come to speak of particular processes which are occasionally practised.

1. Lapring in Ploughing. - A field of greensward, or stubble, is often, in the autumn, only half ploughed; that is, a furrowslice is turned over directly upon an unploughed surface; and then another furrow is turned upon another unploughed surface; until the whole field, being thus ploughed, presents a succession of open furrows and of lapped lands, and only half of it is in fact stirred. In the spring, these intermediate places are brolien up by the process being directly reversed. Some advantage may come, in this case, from the decomposition or rotting of the vegetable matter placed between the two surfaces thus brought together, although this can hardly be expected to proceed at a rapid rate, if at all, during the winter season, and the furrows may serve as drains to carry of the water from the land; but, excepting the saving in time by half doing instead of wholly doing the work, I see no advantage in this process over the regular mode of ploughing the whole field at once. It is advised, however, in performing this operation, that the part of the sward which is laid over should be wider than that upon which it is laid, that, by its weight, it may be broken, and the whole rendered more friable.**

2. Ribbing, on Raftering. - There is another mode of ploughing called ribbing; or raftering, differing scarcely from the method just described, excepting that two furrow-slices are laid upon one, instead of one upon one. In this case, an open furrow and an alternate ridge present themselves over the whole field; the furrows serve to keep the land from stagnant water: and the turned-up land is exposed to the ameliorating processes of

* "When land has become very full of twitch, it is a good plan to half-plough it - that is, turning over one furrow and then another opposite, to meet it. If this is done in November, it will check the growth of the twitch during the winter. The land, when ploughed in a contrary direction early in the spring, will lie in heaps, and thus become quite dry, when the twitch may easily be got out, and a good turnip fallow be made. Scufflers are now made, which will answer the purpose of stiring land that has been ploughed, and thus save the labor and expense of a ploughing: Finlayson's harrow is a most useful implement." - Hillyard's Practical Farmer, 4th edition, p. 36. 
the air and the frost. The field, when done in the best possible manner, as it often is, presents a beautiful example of artistical skill. In the springing, preparatory to after cultivation, the whole is broken up and levelled, by reversing the operation. I am not able to see any decided advantage which this mode has over tho regular ploughing of the whole field at once, except in the saving of time, and this saving is at the expense of only two thirds of the land being ploughed.

3. Laying in Beds, on Stitches. - There is another mode of ploughing, or rather of laying the land, which prevails in England and Scotland to a great extent, and is nearly universal upon low and wet soils; that is, the practice of laying the land in beds, or what are here commonly called stetches. In this case, a ridge is formed in the centre, by laying two furrows back to back, and then ploughing up to them on each side, until a sufficient land is gone over to form a bed. These beds vary much in width, from five to eighteen and thirty-six feet. In some cases, under a system of plonghing which is called two in and two out, four beds are formed into one bed, of perhaps sixty feet in breadth. In Essex county, on the lowlands, they are only five feet in width. An open furrow is of course left for the water to flow off, which runs down the sides of the beds. The object is to lay the land dry; but it is obvious there is a loss of land in the furrows, and, while there is a constant accumulation of rich soil on the centre of the bed, the mould must gradually become thinner as you approach the furrow, and the furrow is always indicated by an absence of product, or the growth of coarse and worthless grasses.

These ridges, in English cultivation, are seldom altered, but (though often, far from being bounded by a straight, are bounded by a winding or crooked furrow) remain the same as they have been doubtless for a century. Indeed, they are in many places regarded with a lind of superstition, as though the land would lose its fertility if they were broken in upon; and some writers on English husbandry assert that water flows better in these winding gutters than it would in straight furrows, which is certainly a new philosophy. Though, where they are not properly ploughed, there is liable to be a continual accumulation towards the centre, yet I cannot say that I have ever seen so great an 
increase of them as is described in Von Thaer's Agriculture, which has been rocently translated into English, and published in two volumes in London. "In places," says this author, "where, as is frequently the case, there have been no ditches between the lands of different proprietors, or where these ditches have been filled up for the sake of gaining additional surface, all the ploughmen have avoided throwing the earth to the outside, from fear that, if they did so, their neighbor might carry off that which was thus placed within his reach. In this manner, ridges of considerable breadths have become elevated in the middle to such a degree, that two men, walking in the parallel furrows which bound them, will not be able to see each other." * This seems to be a regular piece of Munchausen; and if all book agriculture were of this description, one could hardly be surprised at some little incredulity and distaste on the part of common practical farmers.

The advantages of laying land in this form, in cases where land is wet and heavy, or where the rain does not pass off readily, are obvious. Where the ridges or beds, likewise, are made equal, and with care, the ridges and furrows furnish a convenient measurement of land in sowing, reaping, or harvesting. There is a considerable loss of land in the furrows, where the beds are, as in some cases, made very narrow, as for example when formed of ten furrow-slices, and two furrow-slices are taken for the drain, the amount of land taken for the drains will be equal to one sixth of the whole, or one acre in six - a very considerable loss, it must be admitted; but then, in every system of ploughing, there must be open furrows left at the sides, if not in the centre, of the fields; and where the beds are large, as described above, throwing, for example, four common beds of fifteen feet each, so as to form one of sixty feet, the loss by open furrows would be greatly reduced. In countries subject to much snow, and severe frosts, it is objected that, the snow being naturally blown from the elevated into the lower parts of the field, the ridge, or highest part of the bed, is more exposed to the alternations of freezing and thawing, and so the grain plants on the ridge are liable to be

* Principles of Agriculture, by Von Thaer, vol. ii. p. 84, as translated from the French by those two most intelligent and industrions agricultural writers, William Shaw and Cuthbert W. Johnson, Esquires. 
thrown out and destroyed. I do not know that this objection is entitled to much consideration. Where the furrows are made from east to west, instead of from north to south, - and the latter ought always to be the direction, - there will be a considerable difference in the temperature of the two sides of the ridge, as the difference in the effect produced by the sun's rays, when falling directly upon a surface inclined towards the sun, or upon one directly the reverse of this, must be considerable. It is urged, likewise, as an objection to these ridges, that the rain, as it falls, passes too rapidly into the furrows, and is carried off without gradually soaking into the land, as on a flat surface, and giving the whole its full advantage. These are some of the objections urged against this system of laying the land in ridges; and, since the introduction of the system of subsoiling and thorough-draining, Mr. Smith, the introducer of this immense and extraordinary improvement, and in general those persons who follow out his notions in other respects, disapprove altogether the plan of laying out the ground in ridges or beds, and leave an even and unbroken surface. In cross-ploughing fields laid in beds, there is likewise an inconvenience arising from the furrows; and the same dificulty likewise applies to the harrowing of such fields, especially if it is attempted to be done across the furrows. Harrows formed with a concave under-side, to adapt them to the shape of the bed, are sometimes used lengthwise with the ridge : but they are ill adapted to cross-harrowing these ridges, or to be used upon land with a flat and even surface.

The beanty which is given to the cultivation, where such ritges prevail and are well formed over extensive fields, is certainly some recommendation of them; but this supposes them to be made evenly and with care. Upon as fair a view of the subject as I can take, I should recommend them, not for their beauty, but for their utility and convenience. But in this case, excepting where the land is very wet and low, I should insist upon a width certainly not less than forty feet; and I should avoid by all means too much accumulation of earth in the centre of the ridge, which an expert ploughman is very capable of doing.

4. Lazx-Bed Cultivation. - There prevails in Ireland a mode of ridging land, diferent from what I have deseribed, and called 
- with what propricty I am unable to see - the lazy-bed system. It is done, in general, only in wet and low lands, thongh I have seen it upon other lands. In this case, the whole land may be either plotghed or dug over by the spade, before the formation of the beds, or it may be left in grass, and the process proceed in this way: Beds of four feet wide are marked out, and divided by a furrow-drain about one foot wide. The potato sets or seed are laid upon the ground or bed, at such distances as are deemed best, generally in lines across the bed, and the earth in the furrow is cut down to the hard pan, even a foot and a half in depth, by a spade, and taken out and thrown upon the seed which has been deposited on the bed, and the whole is carefully smoothed off with the shovel. The fresh earth thus taken from the furrow-drain brings no seeds of weeds with it, and the after cultivation is easy. The potatoes in the autumn being dug with a spade, the whole ground is pretty thoroughly forked, or dug over, and, when it is used the next year for a crop, - it may be of potatoes again, or of oats, - the furrow-drain is filled up, and one made in another place, or in the centre of that which was the bed, so that, in truth, the whole field becomes pretty thoroughly cultivated.

A very intelligent farmer, whom I had the pleasure of meeting in Ireland, was kind enough to give me an account of his management of some of his land on this plan, a system which he considers as extremely well adapted to a cold, wet soil, not yet carefully drained, or to a dry soil which may have become exhausted by constant cropping and shallow ploughing.

"I lined out the ground to be tilled, in ridges four feet wide; and furrows two feet wide. I then dug out of the parts lined off for the furrows, and put on the ridges, all the active soil which could be taken up by the spade. The sets were then planted, and covered by the earth which had remained in the furrows, and which was for this purpose cleanly shovelled. By this mode I obtained a dry seed-bed in moist gromd - a fresh, artive soil in cxhausted ground, and a depth of surface in light land.

"In one instance, on a cold, retentive soil not drained, where there had been a very poor crop of potatoes the previous year, and the soil not stirred from the time the potatoes had heen dug out until the oats were sown, a good crop of oats was obtained. In the other case, a second crop of oats was taken off the same 
field, the stubbles having been ploughed in October. This crop was much superior to the former. It produced fine grain, and was so luxuriant that the greater part of it was lodged previous to reaping on the 9th of August. Should the surface or active soil be very shallow, the breadth of the ridge may be narrowed, or the breadth of the furrow increased. The wide furrows allow of loosening the subsoil, either with crow-bars, picks, or spades, and I carefully reserve all stones which appear, for drains, where draining is necessary; and where it is, I now drain wherever I find the stones at hand - sometimes before tilling. I make the drains at forty or sixty feet apart at first, and put in my intermediate drains in each succeeding year, as I obtain stones in loosening the subsoil.

"I lay out my ridges for potatoes, the breadth as for oats, putting the sets in rows across the ridges, five sets in each row, and the rows varying from eighteen to twenty-two inches apart; - thus saving seed, being enabled to keep the plants free from weeds, to dig out the potatoes at less cost without injury, and increasing the produce, over the old lazy-bed system, in the proportion of one sixth."

'The object of this farmer is to till his low land, in a way to avoid the evil of excessive wet, by this simple method, before he can go to the expense of completely furrow-draining. The method of managing land by complete drainage, which I shall presently describe, would undoubtedly be to be preferred, where there is a sufficiency of time and capital; but in the mean time the other system may be adopted as a temporary substitute.

This gentleman gave me, at the same time, an account of an experiment made as to the distance at which potatoes should be planted, which seems worth recording, and which I will insert here, though not exactly in place.

The potatoes were cultivated in the lazy-bed fashion described. Six ridges were laid out four feet wide, with two feet furrows; an equal quantity of manure laid down for each. Two ridges were planted, the cuttings being laid thick, without any regularity; two ridges had the cuts placed in rows across the bed, fourteen inches apart, five sets in a row; and two ridges, seventeen inches asunder, five sets in each row. The manure was spread over the entire of the ridges tilled in the old lazy-bed way, and immediately over the sets planted. The quantity of 
seed required by the first mode of planting was six and a half stone, or 91 pounds; by the second method, 77 pounds; and by the third method, 70 pounds. The quantity of ground, in each case, was seven square perches. The produce was as subjoined :-

In the first method, . . . . . . . 1218 pounds.
In rows at 14 inches, . . . . . . . 1358 "6
In rows at 17 inches, . . . . . . 1442 "

He adds that the advantage of the latter method is not only a considerable increase of produce by the acre, amounting to 5152 pounds over the first method, but there is a decided advantage in every operation which takes place, from the planting to the digging. The ridges take less seed; require less labor; can be freed from weeds with greater ease and less danger to the tender stalk, and dug with greater facility, and without injury from the spade. Another advantage is, in those places where there is but a light surface, they may be "moulded up," or the dirt brought to the plants, with much benefit.

I give this as an example of spade husbandry. As such, it will have its value with many of my readers. "It is not adapted to cultivation upon any extended scale; but there are small pieces of low, wet land throughout the country, which the owners cannot afford at once to drain thoroughly, but from which, in this way, good crops may be obtained, and the land brought into a condition of productive improvement. The experiment. in regard to quantity of seed, is certainly worth considering. Potatoes are never cultivated in England or Ireland, as with us, in hills. I have known as large a production from a field cultivated in hills three and a half feet apart each way, as in almost any other mode; but the expense of gathering them is more than upon one planted in drills, so as to be easily turned out by the plough. A distinguished farmer in England has invented what he calls a hog's-head plough, for the purpose of turning out potatoes which are planted in drills, without injuring them. It resembles a hog's snout attached to the front part of a plough, without a colter, by which the potatoes are raised and turned out of their bed. 'This may be said to be copying nature, for it is clearly the way that profound race of investigators, the swine. would turn out the crop, if they were sent into an undug potato 
field; but it has no great advantages, in this matter, over a double mould-board plough.

5. Correct Ploughing. - The proper and best mode of ploughing is so exactly and well described by a recent and eminent Scotch agricultural writer, that I think I cannot do better than to give it in full to my readers.

"Whatever mode of ploughing the land is subjected to, you should take special care that it be ploughed for a winter furrow in the best manner. The furrow-slice should be of the requisite depth, whether of five inches on the oldest lea, or seven inches on the most friable gromd; and it should also be of the requisite breadth of nine inches in the former case, and of ten in the latter; but as ploughmen incline to hold a shallower furrow than it should be, to make the labor easier to themselves, there is less likelihood of their making a narrower furrow than it should be, a shallow and a broad furrow conferring both ease on themselves, and getting over the ground quickly. A proper furrow-slice in land not in grass, or, as it is termed, in red land, should never be less than nine inches in breadth and six inches in depth on the strongest soil, and ten inches in breadth and seven inches in depth on lighter soils. On grass land of strong soil, or on land of any texture that has lain long in grass, nine inches of breadth, and five inches of depth, is as large a furrowslice as may possibly be obtained; but on lighter soil, with comparatively young grass, a furrow-slice of ten inches by six, and even seven, is easily turned over. At all seasons, but especially for a winter furrow, you should endeavor to establish for yourself a character for deep and correct ploughing."

"Correct ploughing possesses these characteristics: The furrow-slices should be quite straight, for a ploughman that cannot hold a straight furrow is unworthy of his charge. The furrowslices should be quite parallel in length; and this property shows that they have been turned over of a uniform thickness, for thick and thin slices, lying together, present irregularly horizontal lines. The furrow-slices should be of the same height, which shows that they have been cut of the same breadth; for slices of different breadths, laid together at whatever angle, present unequal vertical lines. The furrow-slices should present to the eye a similar form of crest and equal surface; because, where one 
furrow-slice exhibits a narrower surface than it should have, it has been covered with a broader slice than it should be; and where it displays a broader surface than it should, it is so exposed by a narrower slice than it should be, lying upon it. The furrow-slices should have their back and face parallel; and to discover this property requires rather minute examination after the land has been ploughed; but it is easily ascertained at the time of ploughing. 'The ground, on being ploughed, should feel equally firm under the foot at all places; for slices in a more upright position than they should be not only feel hard and unsteady, but will allow the seed corn to fall down between them and become buried. Furrow-slices in too flat a state always yield considerably to the pressure of the foot; and they are then too much drawn, and afford insufficient mould for the seed. Furrow-slices should lie over at the same angle; and it is demonstrable that the largest extent of surface exposed to the action of the air is when they are laid over at an angle of $45^{\circ}$, thus presenting crests in the best possible position for the action of the harrows. Crowns of ridges, formed by the meeting of opposite furrow-slices, should neither be elevated nor depressed, in regard to the rest of the ridge, although ploughmen often commit the error of raising the crowns too high into a crest - the fault being easily committed by not giving the feered" (that is, the first, or marking-out slices) "furrow-slices sufficient room to meet, and thereby pressing them upon one another. The furrowbrows should have slices uniform with the rest of the ridge; but ploughmen are very apt to miscalculate the width of the slices near the sides of the ridges; for if the specific number of furrowslices into which the whole ridge should be ploughed are too narrow, the last slice of the furrow-brow will be too broad, and will therefore lie over too flat; and should this too broad space be divided into two furrows, each slice will be too narrow, and stand too upright. When the furrow-brows are ill made, the mould-furrows cannot be proportionately ploughed out; because, if the space between the furrow-brows is too wide, the mouldfurrows must be made too deep, to fill up all the space, and vice versa. If the furrow-brow slices are laid too flat, the mouldfurrows will be apt to throw too much earth upon their edges next the open furrow, and there make them too high. When the furrow-brows of adjoining ridges are not plongled alike, one 
side of the open furrow will require a deeper mould-furrow thar the other." *

There is no more accuracy and exactness prescribed in these directions, in the execution of this first great operation of husbandry, than what is actually attained and practised both in England and Scotland. The Lothians, in the vicinity of Edinburgh, - and which may indeed be considered as the garden of Scotland, - the counties of Northumberland, Lincoln, and Norfolk, in England, exhibit this perfection of cultivation. It may be seen in many other places, but in these on a more extended scale than in others. But such excellence, however, is not attained without very great pains, and, with expert ploughmen, a long course of practice. I shall be asked, perhaps, what advantage comes from this exact mode of performing the work. It might be enough to answer, that, in every species of labor, and in every practical art, what is done should be well done, and perfection, how far soever he may fall short of it, should be every man's great aim. It might be enough to say, that the moral influences upon a man's own character, and life, of habits of exactness, order, care, and neatness, are always great, and of very serions value; but I may confidently add, that the perfection with which land is tilled is of great importance to the crops, and directly conducive to their perfection and abundance. The man, too, who studies to plough and cultivate his lands in the best manner, will be anxious to have his implements of the best kind, and to keep his team in the best order and condition. Indeed, multiply as we will the excuses for slovenliness, irregularity, and carelessness, there cannot be a doubt that habits of order, exactness, and carefulness, in all respects, are directly conducive to, nay, are the true foundations of, all profitable arrangement. I may add, likewise, that where every thing is kept in order, and all work proceeds by rule and system, though these rules may sometimes appear extreme or severe, affairs are managed at less expense of labor and time than in a more negligent and reckless mode.

The great object of ploughing is to pulverize the soil, to open it to the admission of those great enrichers of the land, and those great instruments of vegetation, heat, light, air, and moisture; to furnish a penetrable bed in which the roots of the plants may

* Stephen's Book of the Farm, vol. i. p. 633. 
establish themselves, and stretch themselves out in search of food; and, by bringing the stony portions of the soil under the influence of external agents, to produce a chemical decomposition, and supply of those mineral ingredients, a portion of which is indispensable to the healthy growth and productiveness of the plants which are cultivated. It is important, therefore, to reduce the soil to as fine a tilth as possible. It is important to do this, likewise, that the manures which are applied may be thoroughly intermixed with the soil. In gardens, and in small plats, this is done by the spade, which in fields is attempted by the plough; the object in both cases being to render the soil loose, fine, and friable. The more care is exercised in the ploughing, the more certainly will these ends be accomplished.

6. Trench-Ploughing. - I come next to speak of what is called trench-ploughing. This term is applied to a deeper ploughing than usual, or to a double ploughing, where one plongh follows directly in the furrow left by a preceding plough. In trenching land with the spade, which I have before described, the object is completely to invert the soil, laying the surface soil underneath, and covering it with that stratum of soil upon which it had previously rested. The object obviously is, to deepen the cultivatable soil, - if I may coin a word which will be very well understood, - and, by bringing the lower stratum to the surface, expose it to influences by which it may gradually become enriched. Soil taken from almost any depth, after lying upon the surface for a length of time, will ordinarily of itself acquire a productive power, and may be cultivated with success. I have known this to be the case with earth taken from the bottom of a deep well, which, after a length of time, became productive. There is always, in such cases, an accumulation or accession of extraneous matters, which come one hardly knows whence, how, or when. The surface of the coral reefs, of which the istands in the Pacific are examples, after being raised above the water, are gradually decomposed and enriched; seeds of plants, floating in the air, or brought by birds, or cast ashore by the waves, gradually establish themselves. The lichens, or mosses, and an humble class of vegetation, present themselves, until presently, from their decay, and the deposits of animal life in various forms, a rich mould is formed, and this barren rock becomes, in 
time, the fertile abode of animal and vegetable life. 'I'he recuperative power of nature is every where seen most active. Lands exhausted by cultivation are restored by the skill and labor of the faithful and enlightened cultivator. Even left to themselves, to the spontaneous efforts of nature, they recover their exhausted fertility; and soils, which have never yet seen the sun, by being brought to the light and warmth of day, and to the refreshing and renovating influences of sum, and air, and rain, become productive, and stand ready to perform their part in supplying the wants of the vegetable, and through them of the animal creation. Trench-ploughing, which aims wholly to assist this operation of nature, and take advantage of its ready benevolence, is done by a single plough, which goes to a depth of at least fourteen inches, completely inverting this quantity of soil; or the land is first ploughed in the ordinary mode, and a second plough follows in the same furrow, at a depth determined at the plcasure of the ploughman. In the former case, it is obvious that the surface soil is completely inverted and buried; in the latter, the substratum is rather mixed with the upper soil. In the former case, it is clearly a very bold operation. On the Island of Jersey, famous for its cultivation of esculent roots, parsnips, and the white carrot, and other crops, they have what is called a trench-plough, which, going to the depth of fourteen inches, and throwing out a wide furrow, requires a heavy team. In this case, the neighbors club together, uniting their teams so as to assist each other.* The subsoil, unless there is a super-

* I will give here the account of this operation, from Colonel Le Couteur, whose high reputation is well established in the agricultural community.

"In most cases, in the month of October or November, a slim-ploughing is given to an old, or two years' lea, which is left exposed to the winter frosts. It is well harrowed and cross-harrowed previous to carting out the manure, which is spread on the ground at a rate ranging between 12 and 20 tons per acre. In some cases, the above previous skim-ploughing is deferred until January or February, in order to allow the cattle to feed off any herbage that may be left on the land, so that the two ploughings now to be described take place in the same month.

"A short time (the shorter the better) previous to putting in the crop, the land receives its second, and generally last plourghing. The trench-plough then comes into play, preceded by its pioneer, the two-horse-plough. A trench is opened through the middle, or length of the field, in this manner. The two-horseplough is made to cast off a furrow up and down, so as to assist in forming the trench; the trench is then neatly sunk 18 inches deep, more or less, according to 
abundance of manure to be applied and mixed with it, cannot be brought at once into a state of active productiveness. Where there is a sufficiency of manure, however, there is, no doubt, some advantage gained, to what extent it is not easy to say, from the freshness of the virgin soil which is brought up. Otherwise, time and cultivation will be required to bring this fresh and comparatively inert soil into a condition of productiveness. In this case, however, the farmer must exercise his own judgment, and consider his own means. He may be sure that the deeper and the richer is the soil, or monld, which he has to cultivate, 5: much the more abundant will be his crops. To create a soil, however, is not a sudden operation; and, in cases where the

the depth of the soil, and squared off two feet with spades, the earth being thrown off to a distance on each side.

"A man with a spade should then be placed at each end of the furrow, to dig and square it out half the length of the trench-plough, as wide as the furrow intended to be taken, in order to enable it to plunge into its depth at once, on turning in to work; this is made at the left-hand side of either furrow, after the small two-horse-plough has made its start.

"This two-horse-plough (one that will take a width of furrow one inch wider than the trench-plough) then precedes and turns in the manure and turf, together with three inches of soil, into the botton of the furrow, or prepared trench. The trench-plough, drawn by four, six, or eight horses, according to the depth desired, then turns over from ten to eighteen inches of clean soil on the turf, which is so completely buried as to destroy all vegetation, even in the freshly-broken sod. When the sod is quite fresh, as little soil as possible should be taken up by the small plough, so that the couch or weeds may be more completely covered by a great mass of clean soil. When the ploughed land becomes so wide as to render it inconvenient for one man, at cach end, to open the furrow for the plough on one side, and square up the other side neatly, one man is placed at each corner to perform this work, so that two additional men at each end of the land, or fcur in all, are now digging, levelling, and squaring up the corners. Two acres or more may thus be turned up in a day, as the trench-plough takes a wide furrow from eleven to thirteen inches, and, by its excellent construction, moves and turıs the whole soil.

"'This operation is performed by joint-stock labor by all the farmers in Jersey, who bring their teams to assist each other. It is appropriately denominated, no a great ploughing, but a GREAT DIGGING; indeed, no spade husbandry is so efficient, as most men, in digging, merely turn the secondspit upon the under, or trench-slice, whereas the whole soil is shaken and broken by the trench-plough."

Certainly the soil, in this case, must be very rich to bear being inverted at this depth. I give the whole account, rather as matter of agricultural curiosity, than with any notion of its being adapted to our husbandry. These very great operations, in which so many men and so many horses are employed at one time, I have always found of doubtful expediency, and should deem it prudent to seek more simple means of accomplishing the end, if more simple could be found. 
surface is completely inverted, the rich soil is buried, and the undersoil brought to the top, he may labor in a sure hope of an ultimate compensation; yet he must in such case wait with a manly patience; and it may be advisable in some instances to have some regard to the length of his purse, and the time of his life; perhaps, in England, it would be as well to add the terms of his lease, which may not always be such as to encourage substantial improvements. Such improvements, being intended to be permanent, can hardly be otherwise than expensive.

I do not know where I can better introduce to my readers an experiment upon soils, which I witnessed in progress in that admirable establishment, the Agricultural Museum and Nursery-Grounds of the Messrs. Drummond, in Stirling, Scotland, which I strongly recommend to the notice of every intelligent traveller in that picturesque and most interesting locality, whether his objects of pursuit be of an agricultural nature, or otherwise. If the experiment leads to no practical results, it is deserving of attention, as matter of philosophical curiosity. I give it from their own written communication to me.

"Notice of a Comparative Trial of the Qualities of various pure Earths for supporting Vegetation, made in the NurseryGrounds of W. Drummond and Sons, Stirling.

"Garden pots eight inches in diameter were filled each with a pure earth, reduced, by pounding, to the consistency of grarelly sand, where it had previously existed in the indurated or rocky state. Oats were then sown about the middle of April, three plants being allowed to remain in each pot. The pots were plunged to the rim in an open border, cinders of coal being put under them, and care otherwise taken that the roots of the oats should obtain no extraneons nourishment. The plants were watered with common spring water, a few times, in very dry weather.

"The stalks attained, in general, to the height of two and a half to three fect. The grain fully ripened about the beginning of September.

Earths.

"PRODUCE.

"Granite, (Aberdeen,) .

Ears. Grains.

Clay slate, (primitive,) . . . . . . . . 11 . 241 
Earths.

Ears. Grains.

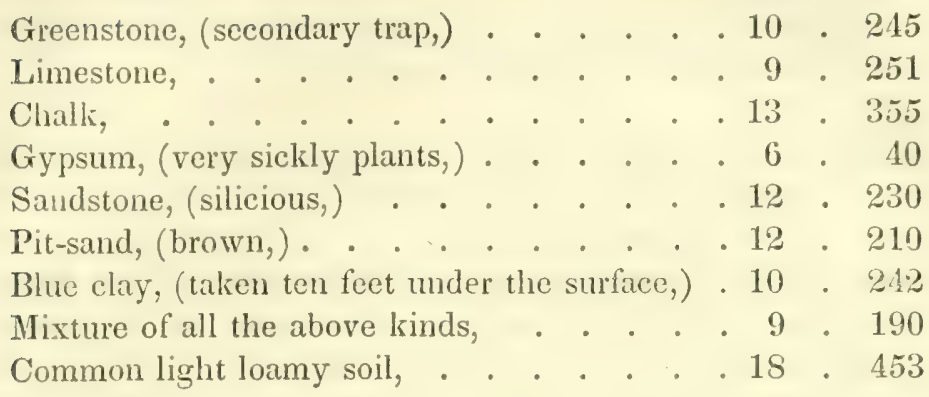

"Experiments of this nature seem worthy of further prosecution, particularly relative to the respective influence of the atmosphere and soil in the nourishment of plants. When the oats were sown, scientific as well as practical men predicted, that in most of these earths they would not grow ; and when they saw them growing, predicted that they would not ripen seed. The results have proved otherwise."

A single experiment, in such case, can hardly be considered as decisive, excepting as to the possibility of plants living and maturing in an unmixed soil. The fact of their not succeeding, with one exception, so well in a soil composed of the several varieties as in a simple soil, is likewise noticeable. The superior success of the plants in loam is also to be observed, to show that their growth was not wholly rependent upon the atmosphere, as some would have us believe, and that the soil furnishes something more than a mere support for the plants. 'The growth, in each case, must be considered as inferior; and, without deducing any general conclusions, which might be premature, or endeavoring to fit the facts to any received theory, I submit it to the further inquiries of those who have the curiosity and talent to pursue these interesting investigations. If it prompts to other well-conducted experiments, my object will be answered.

The bringing of any considerable quantity of inert soil to the surface is obviously attended with uncertain results, so much depends upon the nature and condition of the soil so brought up. At the Duke of Portland's, at Welbeck, places were pointed out to me where the surface mould had been removed, a portion of the subsoil taken away, and the mould, or top soil, returned to 
its place; but in no instance was its previous fertility restored. Deep cultivation will undoubtedly in the end recover such places, but time and patience are indispensable.

7. Subsorl-Ploughing. - The next great operation, performed with the plough, is here called subsoiling. The object of this is similar to that of trench-ploughing - that of loosening the substratum, and deepening the soil to be cultivated. But it differs in this respect: trenching, either by the spade or the plough, buries the surface soil, and covers it with that which is turned up; but subsoil-ploughing aims to loosen the substratum to the depth required, without bringing it to the surface or covering the mould, and, by the gradual intermixture of the lower stratum with the upper soil, to enrich it, and ultimately convert the whole into an equally arable and fertile condition. Subsoiling is performed by a plough of a peculiar construction, following in the furrow of a common plough. If we suppose the first plough to have turned up the land to the depth of seven inches, the next plough loosens it to the depth of nine inches more, so that the whole land ploughed is in this case equal to sixteen inches. The great objection to trenching land, either by the plough or spade, is, that it brings the inert soil to the surface in a condition unsuited to the purposes of vegetation, and that thus much time is necessarily lost before it can, without great expense, be restored to its former fertility. The advantage of subsoiling is, that it so gradually raises the substratum to mingle with the top soil, that the cultivation of the latter is not interrupted, but the soil is benefited by the slight intermixture. Another and very great advantage derived from subsoiling, is in the admission of air and heat to the loosened soil, by which it is improved, and better subserves the purposes of vegetation, and at the same time opportunity is given for the free expansion of the roots of the plant. On many descriptions of soil, the surface, or vegetable mould, rests upon a hard pan at greater or less depth, and which is impervious to the roots of the plant, and does not suffer even the water to pass off freely. However long this may have existed, as the plough has usually gone only to a certain depth, this substratum has become the more indurated by the treading of the horses in the ploughed furrow, and the constant sliding of the sole of the plough over it. It is the object of the subsoil- 
plough always to break up this pan, which, after being broken up and exposed to the air, gradually crumbles and becomes mingled with the upper soil.

This is subsoiling, as it is here termed, of which every modern treatise of English husbandry is full. It can scarcely be said to be an absolutely new practice,* for passing a second plongh in an open furrow may be considered as a species of subsoiling; yet the credit of introducing the practice, and establishing it upon just principles, as connected with draining the land, must be fully accorded to Mr. James Smith, of Deanston, in Scotland, a man of whose sound understanding and practical skill I might speak in the highest terms, if my humble voice would add any thing to the distinguished and substantial reputation which he enjoys throughout the kingdom. I have been over the estate in Scotland which was under his care; and, though the land may be considered as inferior, yet its fine appearance, the regular arrangement of his fields, the condition of his fences, and the perfect cleanness and productiveness of his grounds, present an eminent and beautiful example of the most improved husbandry. A great portion of his labors are indeed under ground, and out of sight; but the results of them are obvious.

Mr. Smith was the active manager of an extensive cloth or cotton factory, in the neighborhood of which was the farm on which he effected such improvements. The condition of the factory in all its departments, the buildings for the persons who are employed in the factory, the whole arrangement of the factory village, the condition and reputable conduct of the operatives, and the measures taken for their educational improvement, are very much in advance of what is to be found in many places both in England and the United States, and, while they do Mr. Smith himself the highest honor, present a beautiful example for imitation. Mr. Smith is entitled to the high merit, not of applying

* Worledge, in his Mystery of Husbandry, describes (A. D. 167\%) very clearly the first rude attempt to construct a subsoil-plough. He tells us of "an ingenious young man of Kent, who had two ploughs fastened together very firmly, by which he ploughed two furrows at once, one under another, and so stirred the land twelve or fourteen inches deep. It only looseneth or lighteneth the land to that depth, but doth not bury the upper crust of the ground so deep as is usually done by digring." Quoted in Ransome's excellent work on the Implements of Agriculture, p. 12. 
the subsoil-plough to the land merely, (by which the most valuable improvements have been effected,) but to the interesting community of several huudreds, over which, as the agent of the Deanston works or factory, he presided. By education, and by paternal care and interest in their welfare, he has done what he could for the improvement of their condition. He may be said to have broken up and elevated the lower strata, that, by bringing them from a degraded condition to the light and air, and by degrees preparing them to intermingle with the higher strata, he might alike benefit both parties, and substantially improve the character of the whole.

Mr. Smith invented a plough for the express purpose of subsoiling, of which I design presently to give a plate. It is without a mould-board, but it has a feather on the share. Several other ploughs have been invented for the same purpose-one made under the direction of Mr. Pusey, called the Charlbury plough, which proposed to perform both the operation of ploughing the land and subsoiling at the same time. It was therefore a common plough, and, several inches below the sole of the plough, and behind it, there was attached a turned-up or crooked tine or foot, calculated to descend into the soil in the furrow to the prescribed depth. The draught of this plough must be of course, by such an arrangement, considerably increased, and the instrument would appear rather clumsy in its operation. If it did its work well, this is all that could be required. One of its great merits is stated to be a considerable superiority over the Deanston plough, in lightness of draught. I have never seen it employed. Another subsoil-plough, which has been recommended, is a single iron tine or foot, attached to a proper frame with handles, and which, being drawn through the furrow after the other plough, loosens the soil in a single line. It would seem to be an instrument of small expense, as well as simple construction; but it executes the work very imperfectly, not stirring the whole ground, but dividing it only in single lines. Mr. Smith's plongh, having a small feather on the share, not only moves the whole bottom of the furrow, but it raises a small portion of the subsoil, and lays it against the side of the furrow already turned over, thus mingling the subsoil and the upper soil in some small portions together. This may be considered as a decided advantage. Jut, to describe the practice of subsoil- 
ing land without that of thorough-draining, which forms a part of the same system, would be unjust to Mr. Smith. This, however, I shall do most fully under the subject of draining, which will come as matter of course.

To subsoil without draining is not to be indiscriminately rccommended. In heavy and clay soils, it would be of little use, as they would soon settle down into their former compactness. In some soils it would only serve to increase their wetness, as the water, sinking deeper into the ground, without any provision for its escape, would pass off less quickly by evaporation than if nearer the surface. In lighter soils, where its only effect would be to loosen the soil, it would undoubtedly be beneficial.

\section{Experiment in Subsoluing Heatu Land. - An example} of success in the application of the subsoil to heath land, which is within my knowledge, is so remarkable, that I will give it to my readers at large. The gentleman to whom I shall refer, Sir Edward Stracey, is himself the inventor of a subsoil-plough, known as the Rackheath plough, after the name of the property which he occupies, and which is much lighter of draught than the Deanston plough.

"On my coming to reside on my estate at Rackheath, about six years since, I found 500 acres of heath land, composing two farms, without tenants, - the gorse, heather, and fern shooting up in all parts. In short, the land was in such a condition that the crops did not return the seed sown. The soil was a loose, loamy soil, and had been broken up by the plough to a depth not exceeding four inches, beneath which was a substratum (provincially called an iron-pan) so hard, that with difficulty could a pickaxe be made to enter in many places; and my bailiff, who had looked after the lands for 35 years, told me that the lands were not worth cultivating; that all the neighboring farmers said the same thing; and that there was but one thing to be done, viz., to plant with fir and forest-trees. To this I paid little attention, as I had the year preceding allotted some parcels of ground, taken out of the adjoining lands, to some cottagers, to each cottage about one third of an acre. The crops on all these allotments looked fine, healthy, and good, producing excellent wheat, carrots, peas, cabbages, potatoes, and other regetables, in abundance. The question then was, How was this to be done? 
On the outside of the cottage allotments, all was barren. It could not be by the manure that had been laid on, for the cottagers had none but that which they had scraped from the roads. The magic of all this I could ascribe to nothing else but the spade; they had broken up the land eighteen inches deep. As to digging up 500 acres with the spade, to the depth of eighteen inches, at an expense of six pounds an acre, 1 would not attempt it. I considered that a plough might be constructed so as to loosen the soil to the depth of eighteen inches, keeping the best soil to the depth of four inches, and near the surface, thus admitting air and moisture to the roots of the plants, and enabling them to extend their spongioles in search of food, - for air, moisture, and extent of pasture, are as necessary to the thriving and increase of vegetables as of animals. In this attempt I succeeded, as the result will show. I have now broken up all these 500 acres eighteen inches deep. The process was by sending a common plough drawn by two horses to precede, which turned over the ground to the depth of four inches. My subsoil-plough immediately followed in the furrow made, drawn by four horses, stirring and breaking the soil twelve or fourteen inches deeper, but not turning it over. Sometimes the iron-pan was so hard that the horses were set fast, and it became necessary to use the pickaxe, to release them, before they could proceed. After the first year, the land produced double the former crops, many of the carrots being 16 inches in length, and of proportionate thichness. This amendment could have arisen only from the deep ploughing. Manure I had scarcely any, the land not producing then stover sufficient to keep any stock worth mentioning, and it was not possible to procure sufficient quantity from the town. The plough tore up by the roots all the old gorse, heather, and fern, so that the land lost all the distinctive character of heath land, the first year after the deep ploughing, which it had retained, notwithstanding the ploughing with the common ploughs for thirty-five years. Immediately after this subsoil-ploughing, the crop of wheat was strong and long in the straw, and the grain cloie-iosomed and heavy, weighing 64 pounds to the bushel; the qu* otity, as might be expected, not large, (about 26 bushels to the an re,) but great in comparison to what it produced before. The milwers were desirous of purchasing it, and could scarcely inlieve it was grown upon the heath land, as in former years it 
was difficult to get a miller to look at a sample. I.et this be borne in mind, that this land then had had no manure for years, was run out, and could only have been meliorated by the admission of air and moisture, from deep ploughing. This year the wheat on this lind has looked most promising; the ears large and heavy, the straw long, and I expect the produce will be from 34 to 36 bushels per acre. My Swedish turnips on this land this year are very good; my pudding and sugar-loaf turnips failing in many parts, sharing the fate of those of my neighbors. having been greatly injured by the torrents of rain which fell after they had shown themselves above the ground. Turnips must have a deep and well-pulverized soil, in order to enable them to swell, and the tap-roots to penetrate in search of food. The tap-root of a Swedish turnip has been known to penetrate 39 inches into the ground. I will add only two or three general observations.

"1st. The work done by the plough far exceeds trenching with the spade, as the plough ouly breaks and loosens the land all around, without turning the subsoil to the top, which in some cases (where the subsoil is bad) would be injurious to the early and tender plants; and if the subsoil is good, it would be rendered more fit for vegetation after the air and moisture had been permitted to enter. The ploughing is also far preferable to trenching by the spade, ever for planting, (i. e. trees, ) as it may be done at one fourth the expense.

" 2 dly. It were very preferable, if possible, to work the horses abreast, pair and pair; but, in using this plough, the horses must work in a line, for, if abreast, the horse on the land ploughed would soon be fatigued, by sinking up to his hocks; and, to render the draught more easy, the second horse from the plough should not be fastened to the chains of the horse next the plough; but the chains of the second horse should be made long enough to be hooked about two feet behind the back-band of the chains of the horse next the plough, so that the second horse will draw at an angle of about 33 degrees; otherwise, were the chains of the second horse hooked in front of the backchain, he would pull the whole weight of his draught, together with that of the horses preceding him, on the back of the horse inext the plough; and the strength of the horse would be lost in 
the draught, as his whole powers would be exerted in his endeavors to prevent being brought down upon his knees. By so arranging the chains, the power of three horses would be equal to that of four."

Such were the favorable results of this bold experiment. In many other cases, however, the result has not been so successful ; and when the state or character of the land is such as to retain the water, as (to use the expression of one highly intelligent farmer, who subsoiled his land without first draining it) "it sometimes does like a sponge," the subsoiling is as likely, and perhaps more likely, to be injurious than beneficial. 'The Deanston system, as it is here called, of subsoil-ploughing and furrowdraining will presently be fully stated to my readers.

9. Subturf-Plough. - The same gentleman last referred to, Sir Edward Stracey, is the inventor of what is called a subturfplough, which is fitted for use in lands where it is desirable to stir the soil beneath without breaking the turf. It does not differ much from the subsoil-plongh ; and, being once inserted into the ground, breaks it up to the depth of about ten inches, leaving no other marks of its operation than the lines cut in the turf, which very soon, by the natural growth of the grass, become obliterated. The lines are at the distance of about fourteen inches from one another. It loosens the soil underneath, admits the air and rain, and permits the roots to spread themselves. He says, "after a trial of it, that the quantity of the aftermath, and the thickness of the bottom, have been the subject of general admiration. Another advantage from this subturf-ploughing is that, before that took place, water was lying stagnant on many parts, (after heavy rains,) especially in the lower grounds, to a great depth; now, no water is to be seen lying on any part, the whole being absorbed by the earth." This supposes that the lower strata, below where the plough has reached, are porous, and easily transmit the water, or, otherwise, it might be liable to the objections to which I have referred above.

10. Perfection of Englisil Ploughing. - I have spoken of the various modes of ploughing, and of the extraordinary exactness with which it is executed. It would be curious to trace 


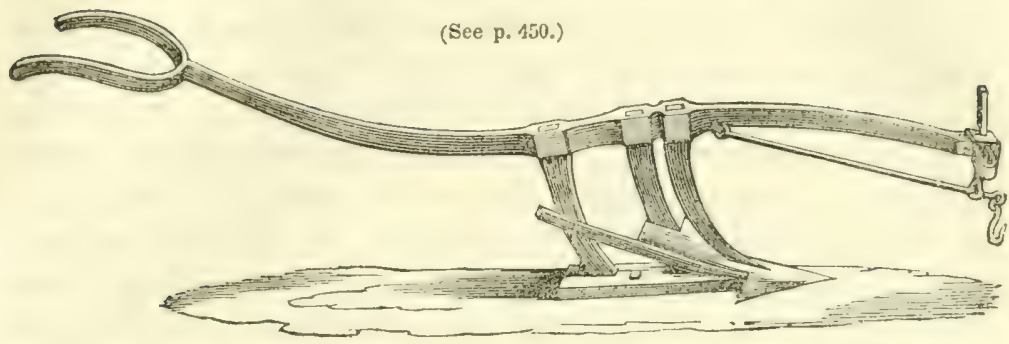

RACKHEATII SUBSOIL-PLOUGH.

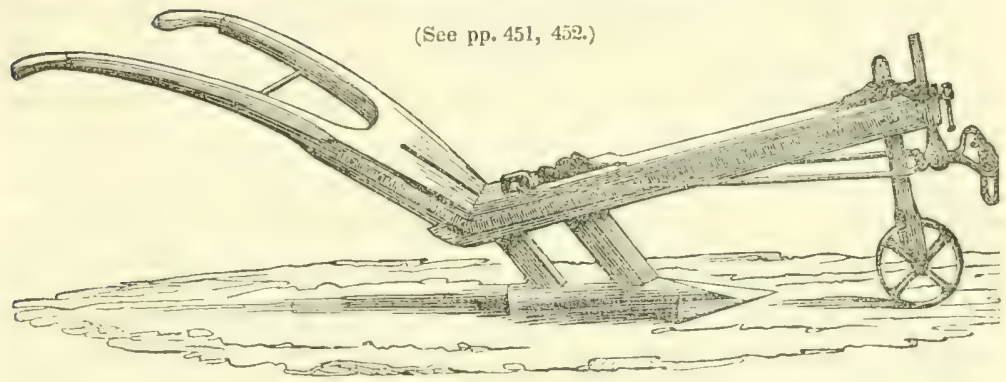

"This performs the operation of subsoil ploughing, to the depth of from ten to sixteen inches below the surface, and, when preceded by the common plough, which is the plan recommended, the depth reached below the surface ground is just so much the more than the first plough effects."

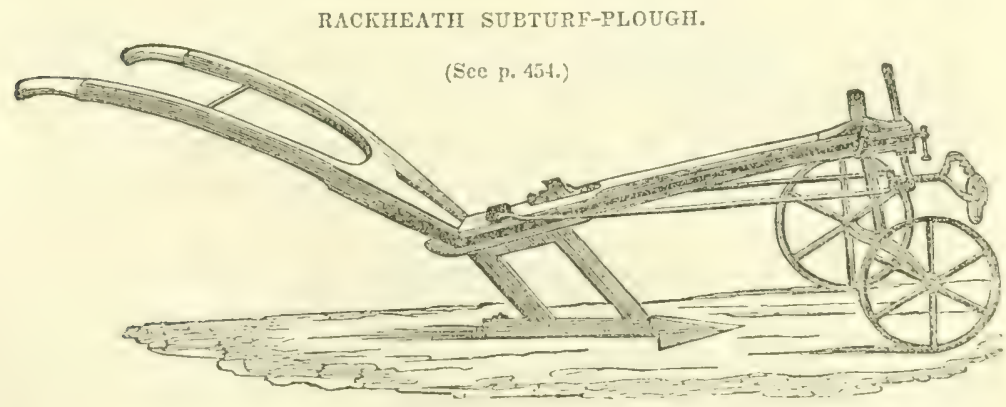

"This plough answers admirably for under-ploughing grass lands, and is made into a subturf-plough by changing the wheel gear in front to that of a carriage and two wheels." 
the progress of this art, from its rudest stages, to the beantiful and facile manner which distinguishes its performance in the best cultivated districts of England and Scotland. I do not like to say that no further improvements can be made. No reflecting man, who has witnessed the extraordinary changes, and inventions, and improvements, of half a century, and seen the continually-shifting scenes, and the new actors presenting themselves on the stage, and bringing the treasures of their wisdom and skill to the vast accumulations which genius and science have already heaped up, will assert this of any human art; but it is safe for me to say, that I do not know how, in the best cases, the execution of the work can be improved. Under the direction of an experienced and well-skilled ploughman, and an eflicient and well-trained team, the implement itself moves like a thing of life, and performs its office with the precision of the lighest intelligence.

This is not the effect of accident; it is the work of severe and careful training. Boys are early accustomed to stand behind the plough, and stimulated by the strongest motives which can be addressed to their cupidity, their love of approbation, or their ambition of excellence. Under the prevalent subdivision of labor, to which I have before alluded, the advantages arising from practice, and a fixed attention to one particular object, are obviously secured. The man who ploughs, and does little else except ploughing, is far more likely to execute his work thoroughly and well than the man whose attention is divided among a multitude and diversity of pursuits.

11. Plovghing-Matcues. - The ploughing-matches, likewise, in which most intelligent and severe judges are appointed, the rules of competition are stringent and absolute, and the golden rewards most liberal, have contributed essentially to the improvement of this art.

We have witnessed the same results in the United States. I recollect the first ploughing-match at Brighton, under the auspices of the Massachusetts Society for promoting Agriculture. The gradual proficiency, from these early and comparatively rude trials, to the triumphant and beautiful results which, more than a quarter of a century afterwards, with honest pride, I have witnessed at Worcester, shows that there is no deficiency of talent 
and skill, and no lack of an honorable ambition of improvement, and that in the various departments of the arts, and in spheres of improvement and progress higher than those of the mechanical arts, all that is wanted among us, to the development of power and skill, is "a fair field and no favor."

The regulations of the English ploughing-matches difler in some respects from those in the United States. The judges in the English ploughing-matches never come on to the field until the work is done and every team withdrawn. With us, they are present from the commencement to the close of the work. Our practice is, in my opinion, to be preferred. In the former case, no party is known, and impartiality, therefore, may be said to be perfectly secured. So far it is well. The work is accurately surveyed and measured; the depth of the ploughing, the width of the furrow-slice, the mode of laying it over, the straightness of the liues, the manner in which the first furrow-slices are brought together if it is ploughed back to back, or the funishing of the last and middle furrow if the piece is ploughed from the outside to the centre, the freedom from balks and breaks, are all carefully considered in the verdict rendered. In the United States, every effort is made to secure impartiality, consistently with other arrangements, inasmuch as that no names, but only numbers, are given to the judges, and the different plats of ground to be ploughed are drawn for by lot. Then the judges on the field observe the whole progress of the operation; measure the different portions, as the work goes on; and watch the temper and conduct of the ploughman and the training of his tcam, the manner in which he treats his team, and the condition in which they come off from the work. These circumstances all deserve consideration, and should come in as elements on which a judgment is to be made up. In both cases, it is understood, as it should be, that no party having any personal or pecuniary interest in the result shall have a place on the bench. The English are exact and positive in prescribing the depth of the ploughing, and the width of the furrow-slice even to a half-inch, and insist upon a uniform width throughout the whole. I have urged this same thing often upon committees, in my own country, on which I have had the honor of being placed, and have been met with the objection, that this was requiring too much, and would operate as a discouragement. In my opinion, you 
cannot require too much, provided you make your preminms in proportion liberal. Excellence is never attained by presenting an inferior standard. Let your rewards be as liberal as possible; require the work to be done as well as possible; and make your rules reasonable, but as stringent as possible; and hold conformity absolute and inevitable. In every such competition, there are minds in which the superior value and splendor of a triumph under such circumstances will rouse a powerful and noble ambition; fire will be brought out of stone, and, as in some beautiful chemical experiments, you will see the blaze burning under the ice. But if you must have a scrub race, have it in another part of the field, and after the noble-spirited horses are withdrawn, and the donkeys and the Rosinantes are brought forward. I have never known a case, in which this loose system of accommodation and indulgence prevailed, and where the rules were narrowed or expanded to fit the occasion, that the decision of the judges gave general satisfaction, or ought to give satisfaction.

It is very mortifying to fail in an object for which one has had a hard struggle. Many a noble fellow, after having reached the upper limbs of the tree, as he was upon the point of putting his hand on the fruit, has fomd himself, with every effort and strain, not quite high enough to reach it, and perhaps has come tumbling down, with his clothes torn, and his face scratched, to the ground. Upon such a mind, the only effect was to xouse his ambition to a stronger pitch, to give new vigor to his muscles and new energy to his determination. This was as it should be.

I have been told of an Irishman, - an Irishman he was, of course, for none but this clever people ever do such pleasant things, - that he called to demand the payment of the highest prize in the lottery, which he said he had drawn. Upon presenting his ticket, he was told that it was the number next above his to which the prize had fallen. He said "he knew that very well: but he did not suppose that such great folks would stand out for a single number." In all cases of competition, the prize should only be paid to the number which has actually drawn it. It may, in many cases, be expedient to give prizes for effort, and for partial excellence; but if the fremium is amounced for accomplishment, to accomplishment only should it be paid. 
12. Horses used for Ploughixg. - Plonghing here is almost universally done with horses. 1 saw some oxen plonghing at Holkham, with leather harnesses and breastplates, instead of yokes and bows, as employed in New England, and I have found oxen used in some few other cases, but, within my observalion, these cases are very rare. The question of the comparative expediency of employing horses or oxen in farm work will come up for discussion presently.

The horses are extremely well trained, and usually groomed with the greatest care. I have found one remarkable exception to this practice, and that of a very large farmer of high repute. He never suffered his horses to be curried or sheared, or confined in stables. When brought home from their work, they were turned into open yards, with capacions sheds, and the stable doors, without any division of stalls, were always left open. The mangers were plentifully supplied with food, and the troughs with water, and they ate and drank, stood or reclined, or walked about, as they pleased. The yards and stalls were always most abundantly littered. I should have scarcely thought proper to mention a case of management, which some might pronounce careless and slovenly, and of which, in riding through some parts of New Eugland, one would hardly be at a loss to find examples, were it not that this was the practice of a very large farmer, extremely skilful and intelligent, and the favorite tenant and model of one of the largest proprietors, and one of the greatest agricultural improvers in the comitry, (the late Lord Leicester, ) and that he pursued this practice from choice, and becanse he deemed it most conducive to the health and comfort of the animals. He maintained that the animals, not being kept in warm stables, but familiar with the changes of the weather, bore them with less inconvenience and suffering than they otherwise would have done; that a great deal of time and trouhle was saved in the care of them; that, being at liberty to lie down when they pleased, their rest was more refreshing than if confined and tied in a stall; that, the hair being given them for a covering, it was wrong to strip them of their flannels at a season when they most needed them; and that the dirt itself, matted among their hair, assisted in retaining the warmth. These were all philosophical reasons, which did uot quite convince me of the wisdom and expediency of this mode of managing. The last 
argument, in respect to the dirt lieeping the animals warmer, seems well understood, and practically exemplified, by many of the lower classes in London, Ldinburgh, and Dublin, and, if well founded, might do something towards lessening the compassion which one must otherwise feel for their suffering from the want of fuel. The horses in possession of the farmer spoken of appeared in good condition, and were strong for labor; and the practice pursued was of several years' standing.

The usual practice is for the ploughman to be at the stables at four o'clock in the morning; to clean, water, and feed his horses, and to be in the field at work at six o'clock. With a short time to rest occasionally, he continues his plonghing until two o'clock, when he returns to the homestead, the horses are thoroughly cleaned, and rubbed, and watered, and fed, and at last littered for the night — eight hours being considered as a day's work; and, in ordinary cases, an English statute acre, of the same size as an American acre, is his allotted stint. There are cases of heavy land, in which only three quarters of an acre are considered a day's work; and others, of lighter land, in which upwards of an acre and a quarter are accomplished. In Scotland, a pair of horses are ordinarily considered sufficient for any kind of land, and they are worked side by side. If three are employed, two walk upon the land, and one in the furrow. The practice of employing only two horses to a plough is beginning to prevail in Fngland; but, in many instances, three and four horses are used, drawing at length. This practice is not so entirely without reason as some travellers represent it, for in some land it is desirable and necessary to avoid trampling it, and consolidating it the more, by the horses' tread; but when, as it has occasionally happened, I have seen five horses harnessed lengthwise to a single plough, with two men at the plough, and three men or boys with the horses, my own admiration has sometimes bordered upon the ridiculous. The affair of turning at the end, in such a case, is somewhat like wheeling a battalion of undisciplined militia at a country muster, and, unless the field be very long, a large portion of the day must be occupied by these evolutions. The Scotch ploughman, with only two horses, and the reins over his neck, turns a corner like an officer's charger, and requires no aid.

In some cases, ploughs with double mould-boards are used, 
which regularly tum two furrows at the same time. In light land, and where the ploughing is shallow, they save time and expense. In stronger lands, where three horses are sufficient, it is obvious that the expense of one horse is saved. In heavy lands, where four horses would be required on account of the double mould-board, it is obvious nothing would be gained. In parts of Lincolnshire, on the chalk formation, where the ploughing for wheat was not more than three inches, these plonghs were much approved. I give below a cut of a double furrow-

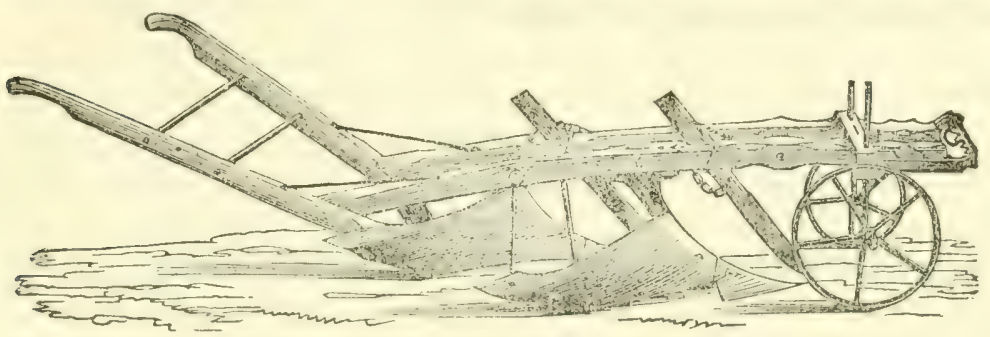

plough. The invention of this plough is by Lord Somerville: and it is certainly creditable for the ingenuity of its construction.

\section{LXXXII. $-\Lambda$ DIGRESSION.}

Progress of Improvement. - I have gone thus at large into the operation of ploughing, because it is the great operation of husbandry; and having finished the ficld, let us stand aside, and, looking at the work, indulge a moment the reflections which suggest themselves.

A ruffle from under a crimping iron does not present a more beantiful object than a well-ploughed field from under the hands of an English or a Seotch artist. 'The lines are all straight; the furrows well turned; the headlands cross-ploughed; the comers finished. A well-disciplined mind enjoys the highest pleasure from seeing an operation of any kind, even the most humble, well performed, and perfected according to its proper measure.

There is something, likewise, extremely gratifying in witness- 
ing the progress and advancement of human skill and art. From digging the ground with a stick, that a hole might be made for the deposit of the seed, to the perfect inversion of it by the plough, what an immense stride! That is now done in a day, which, in the rude ages referred to, could scarcely have been accomplished in a year; and that is now performed with ease, and without any unkind tax upon the health of man or beast, which could not otherwise have been eflected without the most severe exactions of human toil, and often at the expense of the premature shortening of human life.

\section{LXXXIII. - IMPROVED MACHINERY.}

There are persons continually complaining of the introduction and use of machinery in the place of human labor, and as therefore prejudicial to the interests of the poor. At an agricultural dinner, I listened with a good deal of interest to a distinguished nobleman, who was defending machinery against this charge, by endeavoring to show that, so far from machinery lessening the demand for labor, it was the ordinary result of it to cause the employment of more persons than were occupied before its introduction. This may be the fact; but if this were the only result, or if this result stood alone, it would not be a very strong recommendation, and should be classed with the kind of argument used not long since in Parliament, in commendation of the corn laws, that they encouraged labor by rendering agricultural produce dear, when it is obvious that, just in proportion as the price of agricultural produce increases, the value of the wages of the laborer decrease, his supplies are diminished, and, though labor is more in demand, it is worse paid.

1. Machinery lightens Labor. - The value of improved machinery rests upon different grounds. Its first effect is to lessen the severity of human toil. Through the ingenious application of the mechanical powers, that is effected by the hand of a child, which the united force of hundreds of men, strained 
to an intensity most painful and injurious, could scarcely accomplish. 'The wheel, and the lever, and the pulley, and the indefinite multiplication and curious combination of powers which art invents, execute works of a magnitude, before which the armies of an ancient or a modern Alexander might sit down in despair. Instead, according to the fashion of ancient monarchs, of throwing golden fetters into the torrent, to stem its force, modern science puts an iron bit into its mouth, and rides triumphantly upon its crested waves. The victories which human art has achieved over the elements of nature, once deemed untamable, adorn with matchless splendor the aunals of our times; and yet, like the crepuscular light, like the first darting up of the morning rays upon the eastern horizon, they only presage the full light of day. Fire, water, air, in various forms, stand ready to do mau's bidding; and, as the miracle of modern art, the winged lightning presents itself to his service, and becomes the instantaneous bearer of intelligence between places the most distant - between places whose distance, be it what it may, will make no perceptible difference in time or certainty, where once the means of an uninterrupted continuity of communication shall have been discovered. These are great achievements, and their effects are felt in every department of labor. In agricultural operations, if the mechanic arts have not yet done as much as in many other branches of industry, yet they have rendered no small contributions; and it is not to be forgotten, that the agricultural interest, if not specifically served, shares as largely as any other class in the general benefits which the improvements of the mechanic arts confer upon society. The plough is an immense advauce upon the spade; the cultivator, upon the hoe; the horse-rake and hay-tedder, upon the hand-rake and the common fork. The steam-engine performs the work of many men and many horses in the threshing of grain, and the pumping of water, and various other operations to which it is applied. In the fens of Lincolnshire, two immense steam-engines, one of eighty, and one of sixty horse power, under the care of one or two individuals, completely drain an extent of surface of many thousands of acres. They bring these hitherto waste tracts of country under the dominion of productive cultivation, and, by its magical influence, bid these unsightly and barren sands adorn thernselves with the glittering tresses of a golden harvest. 'These 
are among the miracles of machinery, under the guidance of an intelligence which is an emanation from the Divine Spirit. One hundred and fifty thousand acres, in the neighboring fens, are now in the process of being redecmed from the sea, and completely drained, by a similar machinery. The courtiers of the king may now safely challenge him to place his chair upon the beach, and bid the waves retire. What could human labor effect in such cases without the aid of machinery? For all the men, and women, and children, in England, to have attempted to accomplish such a work, without such help, would have been as wise as to undertake to dip out Lake Superior with a tablespoon.*

2. Machinery increases Production. - The second effect of machinery is, to multiply production to an unlimited extent. A cotton manufactory at Manchester turns out in a day as much cotton cloth as, under the old system of household spinning and weaving, could have been made in all Lancashire in a fortnight, perhaps a month. With improved machinery, twenty acresmay I not say fifty? - can be ploughed, harrowed, manured, drilled, cultivated, and the produce harvested, and threshed, and

* "If reference is made to the evidence given before the House of Commons, to which the numerous petitions complaining of agricultural distress were referred in 1821, it will be seen that, at that time, almost the only grain produced in the fens of Cambridgeshire consisted of oats. Since then, by draining and manuring, the capability of the soil has been so changed, that these fens now produce some of the finest wheat that is grown in England ; and this more costly grain now constitutes the main dependence of the farmers in a district where, fourteen years ago, its production was scarcely attempted."

"It has been found that an engine of the power of ten horses is sufficient for draining 1000 acres of land, and that, on the average of years, this work may be performed by setting the engine in motion for periods amounting in the aggregate to 20 days of 12 hours each, or 240 hours in all. Several engines have been erected for this purpose within the last threo or four years, some of them having the power of 60 or 70 horses : each of these large engines is employed in draining from 6000 to 7000 acres of land. The cost of the first establishment of these engines is stated to be $£ 1$ per acre, and the expense of keeping them at work $2 \mathrm{~s} .6 \mathrm{~d}$. per acre. 'This plan is found to bring with it the further advantage that, in the event of long-continued drought, the farmer can, without apprehension, admit the water required for his cattle, and for the purpose of irrigation, secure in the means he possesses of regulating the degree of moisture, if the drought, as is frequently the case, should be followed by an excess of rain." - Porter's Progress of the Nation. 
prepared for food, where, under the rude system of the aborigines of the country, the cultivation of only one could be carried on, and its produce secured. Indeed, all such comparisons seem idle, because, without machinery of some kind, no cultivation whatever could take place. The human hand is itsclf a machine, and one of the most perfect description. If there is any advantage in having two hauds rather than one, then there must be a correspondent advantage in any contrivance hy which one hand can be made to do the work of two, or two hands of four, and still more when one can be empowered to do the work of thousands.

From the manner in which some men speak of machinery, whe would suppose that the world would be better and happier if men and women were to go back to simple fig-leaves for aprons, and undressed shecp-skins for coverings, and find shelter and repose at night under some overhanging rock, or on a bed of hemlock boughs, in a wigwam of birch-bark. I have no sympathy with such "simple and primitive" notions. I will say nothing of the charms and blessedness of a state of perfect innocence, because I would not offend any honest man's prejudiees, nor thrust my fice ant hands against the porcupine armor of controversial theology ; but I confess I have always had some misgivings as to the happiness of what poets describe as the golden age, and theologians depict as the paradisiacal statc: when the human race lad nothing to do but to enjoy themselves; and to enjoy themselves in doing nothing - an experiment which, whenever I have tried it, Ihave always found extremely monotonous and wearisome. Strength is to be found only in the exertion of the muscles; food yields its nourishment only when the machinery of digestion is in full operation; and health, and power, and hippiness, are compatible only with the highest activity of the physical and the intellectual faculties.

When the ignorant and vulgar, whose views do not extend beyond the first immediate effects, burn factories; and breals threshiug-rinils to pitces, an enlightened and generous mine? would fecl compassion for their ignorance and infirmity; but when minds of a different order, professing to be enlightened, become, as we sometimes see them, the cavillers against improved machinery, and prate about the "simplicity of the goorl old times," when mon! nert clam-sholls for spnons, and thoms 
for pins, and goat-skins for glass bottles, and wooden bowls instead of china, - and, in some instances, do far worse by fostering the vindictive prejudices of the vulgar against those inventions of art and genius which relieve the severity, facilitate the cxertion, and immensely increase the productive power of labor, I hold them as without excuse, and could wish them no worse lot than to be exiled for a season to some parts of Ireland, where these prejudices against improved machinery are as fierce as theirs can be, and where they may find millions living in a state of destitution as complete and absolute as seems compatible with the continuance of life.

3. General Effects on Labor. - I confess, however, there is one view of this subject which I must not pass over, and which I cannot take with equal complacency. The effects of improved machinery should be to alleviate and to shorten human toil, and, in multiplying production, to extend more widely the supply of food, and the common comforts of life. The laboring man should, on every principle, be the first to share in these benefits; but far too often he is the last. Food is greatly multiplied both in quantity and variety; but, in a country where labor is superabundant, the wages of labor become proportionately reduced, and the power to purchase restricted. There can be no doubt that, in respect to clothing and furniture, the condition of the laboring population is greatly improved above what it formerly was. An American clock, for example, made in Connecticut, - that home of industry and the useful arts, - an article both useful and ornamental, and in which the "gude" housewife is sure to take an honest pride, may be purchased in London for a pound. A century ago, this would have been an article of furniture which a nobleman might covet.

But it is too true that improved machinery scarcely diminishes - in many cases it increases - the demand for human and brute labor. Two men only are required to thresh grain with a flail; from five to eight, besides the horses, or the attendants npon the steam-encine, are employed at the threshing-machine. Wuch more is threshed, and, in consequence of these increased facilities, much more is grown, and therefore requires to be threshed. "But for the invention of the steam-engine, a large proportion of the coal mines now profitably worked could not 
have been opened, or must have been abandoned. It is well known that, by the consumption of one bushel of coals in the furnace of a steam-boiler, a power is produced which, in a few minutes, will raise 20,000 gallons of water from a depth of 350 feet - an effect which could not be produced in a shorter time than a whole day through the continuous labor of twenty men, working with the common pump. By thus expending a few pence, an amount of human labor is set free, to employ which would have cost fifty shillings; and yet this circumstance, so far from having diminished the demand for hunan labor, even in the actual trade where the economy is produced, has certainly caused a much greater number of persons to be employed in coal-mining than could otherwise have been set to work." *

It certainly is matter of congratulation, rather than of complaint, that more food is produced to be eaten, more clothing to wear, and more fuel with which to warm our habitations and to apply to other purposes of utility, necessity, or enjoyment; but, in looking at the severity and long continuance of toil to which a large part of the laboring portion of the community are subjected, and how, in many of the arts and operations of manufactures and trade, human health and comfort are wholly disregarded, and human life is used up with as much indifference as fuel is thrown into the furnace of the steam-engine, one cannot help deeply lamenting that the burden camnot be lightened on the back of the hard-driven animal, and that they whose toil produces every thing are put off with the smallest and meanest portion of the fruits of their own industry. How far government should interfere, in such a case, between the employer and the employed, is a question not without great practical difficulties. Human society is such a complicated web, that the extreme tension of any single thread disorders the whole piece. Every provision should be made for the protection of the young and helpless; opportunity should be afforded for the full development of their physical powers, and for the education of their minds. No pains should be spared to protect good morals and decency, and to secure human life against any extraordinary perils. The hours of labor should not be too long extended, nor the hours of seasonable rest encroached upon; and, in any case

* Progress of the Nation, vol, i. p. 335. 
where they are wholly dependent upon others for the provision which they require, that provision should be at least as kind and liberal for the human bipeds as for the domestic quadrupeds. It might be extremely difficult to effect this; but, until this is done, our condition is not half Christian. Avarice, by force, or cumning, or art, - openly sometimes, but more often covertly, is constantly triumphing over humanity and justice ; and it may be regarded as the Juggernaut of civilization, crushing with indifference all who come in its way.

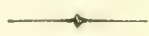

\section{I.XXXIV. - MORAI CONSIDERATIONS.}

Before we turn from the ploughed field which we have been contemplating, I have but one or two more remarks to make, which will not, I hope, be deemed out of place. The ordinary operations of nature aie so familiar, that we cease to look at them with surprise. We choose to wrap ourselves up in our own conceit, and, certain facts regularly occurring under certain conditions and circumstances, we satisfy ourselves with saying that it is according to the laws of nature, and think therefore that we understand it. I do not perceive that we understand it any the better because it is according to the laws of nature; since these laws themselves, in their ultimate causes and operations, are utterly insoluble to the human understanding, and the frequency and uniformity of their results, so far from lessening; actually increase the miracle. I say miracle, for in no other light than as miraculous can we regard the changing scene which is now to pass before our eyes. The field; as we now look at it, presents but a naked surface of inert dust; but there are porvers and influences at work, within and around it, of the most subtle and amazing character. The earth has opened its bosom, and the children of men are to receive nourishment and life from the bounty of their common mother. Man casts the dry seeds upon these naked furrows, and they are at once quickened into life. The earth, the air, the sun, the rain, all lend their combined aid, in exactly such measure, and at such time, 
as is needed for the perfection of the work. The plants rise out of the ground with a spirit and beanty which no human art can rival. The hand of an invisible artist is at work to expand the roots, to train the stem, to mould the leaves, to protect all with a net-work of the finest web, to throw in colors of exquisite beauty, and to fill the pendent seed-vessels with bread, for the sustenance and nourishment of animal life. In a few weeks, or months, the field so lately naked and desolate is laden with treasures far richer than gold, and for which all the glittering diamonds of Peru, and all the shining pearls of Orient climes, would be no substitute. Man gathers what, with strange presumption, he calls the products of his skill and labor, and fills his garner with the golden treasures of the fields. Now, because this happens so regularly and so frequently, shall it cease to excite his surprise, and touch his heart? In my humble opinion, its frequency, and its comparative certainty, vastly expand the miracle; and if the rich fruits of a beneficence, so entirely beyond his command and control, yet withal so constant, so faithful, so liberal, call out no aspirations of piety, if "harvest home" awakens no anthem of thanksgiving and reverence in his soul, he must not claim an equality even with the animals which he drives, for "the ox knoweth his owner, and the ass his master's crib."

\section{LXXXV. -- HARROWING.}

There are various operations to be gone through with, after the ploughing. The first object in English cultivation is to reduce the soil to as fine a tilth as possible. Tull, who is sometimes called the father of English arable cultivation, deemed the loosening, and stiming, and reducing the soil, as all that was necessary to its productiveness, and that manure might be dispensed with. The first position was the foundation of great improvements; but the latter was soon discovered to be an error. His practice, which was tried by many persons, laid the foundation of what is called the New Husbandry, and may be 
considered as constituting an era in English agriculture. It is curious to observe, that oftentines, in human history, great mistakes lead to great improvements and discoveries; and in the complicated course of human affairs, a divine Providence, in comparison with which human sagacity can scarcely be considered other than as arrant folly, converts the errors of man into instruments of truth and knowledge. Experiment is the highway to science, and it is as desirable, in many cases, to know what will not, as to know what will succeed. Men are always ready, through self-estecm and the love of approbation, to detail and magnify any fortunate results; but he is a brave man, and more entitled to respect, who, by way of caution, will expose his failures, and guard the sanguine and adventurous against the errors in which he himself became involved. This is a noble disinterestedness; but many men, like the fox who lost his brush in a steel trap, wish nothing so much as to see their neighbors subjected to the same mortification.

The Romans, in their husbandry, prescribed four distinct processes of arable culture. The first was to break the land; the second to turn it over; the third was to break it again; the fourth was to turn it again.* 'They understood perfectly the use and advantages of thorough and deep tillage. The English farmers are fully aware of this, and follow repeated ploughings, with various other processes.

The first is that of harrowing. This is done lengthwise with the furrow always in the first instance, and then crosswise, until the surface is completely mellowed and pulverized. With us, in general, harrows are made single, and the teeth set in wooden frames, and, though they are usually made square, yet the chain is generally attached to one of the corners, which gives them a diamond shape, and is supposed to lessen the draught. We seldom take a breadth, in such ease, of more than four and a half or five feet. Here the best harrows are made, both frames and teeth, of iron. The teeth, or tines, work to a depth of five to eight inches, and follow each other in lines about four inches apart. Seed harrows, or harrows for covering the seed, have tines about four inches in length, and are made proportionately light.

* 1. Fringere. 2. Vertere. 3. Refringere. 4. Revertere. 
I do not know that I can do better for my readers, than to subjoin the remarks and illustrations of one of the most eminent implement makers in Great Britain, Mr. J. Allen Ransome, in his valuable treatise on the "Implements of Husbandry."

"It is admitted, by all acquainted with the subject, that harrowing, especially on heavy soils, is the most laborious operation on the farm, - not so much, perhaps, on account of the quantum of power requisite for the draught, (though this is sometimes considerable,) as for the speed with which the operation js, or ought to be, accompanied; and yet it is frequently left to the charge of mere boys, and sometimes performed by the worst horses on the farm.

"If we examine a field, one half of which has been harrowed with weak, inefficient horses, and whose pace was consecuently sluggish, the other half with an adequate strength and swiftness of animal power, we shall find the former will be rough and unfinished, the latter comparatively firm and level, and completed in what would be called a husbandry-like manner. Scarcely any thing in farming is more unsightly than the wavy, serpentine traces of inefficient harrowing. The generality of harrows appear too heavy and clumsy to admit of that despatch without which the work cannot be well done; and though it is evident that different soils demand implements of proportionate weight and power, yet, for the most part, harrows have been rather over than under weighted, particularly when employed after a drill, or to bury seeds of any kind.

"Harrowing has been so long regarded as an operation which must be attended with considerable horse-labor, that attention does not appear to have been sufficiently turned to the inquiry whether this labor might not be greatly reduced, by lightening the instruments with which it is performed. Many would be surprised at the amount of reduction of which seed-harrows, at least, are capable, and, where land is clean, to see how effectirely a gang of very light small-toothed harrows may be used.

"Having noticed, in some parts of Norfolk, the perfect manne" in which seed corn is covered by a common rake with wooden teeth, a friend of mine constructed a gang of harrows on the following plan, and he states that it proved the most popular and useful implement of the kind to the farm. 
Gang of Light Seed-Harronos.

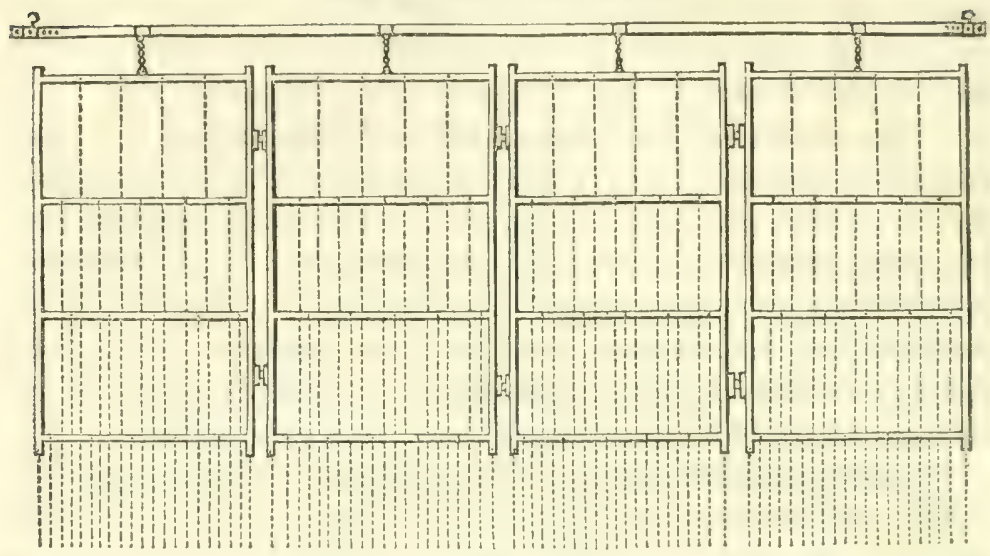

"The frames are of ash, and as light as possible, with iron teeth, being but three inches long, exclusive of the part which enters the wood-work. They screw into the balks in the manner shown in

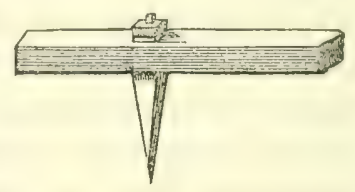
the annexed figure.

"It should be observed that the above four harrows are amply sufficient to cover a twelve-furrow stetch or ridge, of 108 inches, but three will be wide enough for a three-furrow stetch of 90 inches, exclusive of a small portion of the furrows. If for some purposes the teeth be found too thick, every alternate tooth may be taken out; but for general purposes this will hardly be necessary. The two horses require, on this plan, to be kept quite level; for, if one be suffered to go in advance of the other, a diagonal line is produced, by which the teeth will be made to follow each other, instead of cutting fresh ground. I am aware that, by the usual construction of harrows, a diagonal line of dranght is required, in order to throw the teeth into a proper working position; but I am strongly inclined to the opinion, that the correct working of the implement ought to depend on its constrnction, and not on any particular mode of working it. Besides, the system of keeping one horse in advance of his partner is bad in principle; it is an unequal division of labor, the fore-horse being compelled to do more than his share of the work, which, under any circumstances, is always heavy enough. 
The balks of the above set of harrows were made of wood, in order to insure extraordinary lightness; but, for general purposes, i prefer those made of iron, the weight of which can be increased to any reasonable degree, without adding much to their substance. This is important in working tenacious clays, which, by adhering to the common clumsy wooden ballis, considerably increase the labor, and at the same time impede the proper execution."

Sometimes harrows are made in two parts, that is, two small and complete harrows, placed side and side, and united by flexible hinges. In such case, the harrow can be reduced to half its width, by one part being doubled over on the back of the other; or, when the land is in ridges, and the harrow travels on the summit of the ridge, the two parts, by the flexible junction in the centre, are able to accommodate themselves to the curvature of the ground upon which they travel. Sometimes three or four harrows are attached first to each other, by these hinges, side and side, and then to a single beam, to the ends of which the traces of the horses are appended, and in this case they sweep a breadth of nine feet. This carries on the work with great rapidity. A pair of good horses might carry such a breadth without difficulty, upon light land; but upon a heavy and tenacious soil, the labor would be too great for them.

\section{"Gang of Heavy Iron Harrows.}

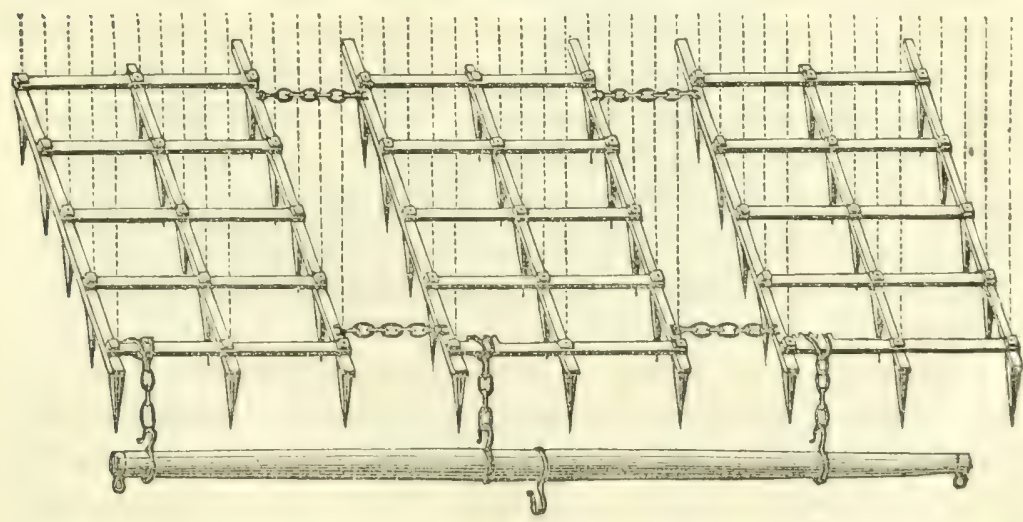

"The above engraving of iron harrows is introduced to show the form in which they are usually made; they are used in 40 * 
gangs of three, four, or five, as may be required to suit the lands on which they are used, and may be made to any weight required." * No intelligent farmer, however, will ever think of harrowing his land, unless it be of the lightest description, in a wet state. It has been by some persons deemed an improvement to make the front tines of a harrow shorter than the back ones; but 110 advantage comes from this. By many the practice and in my opinion with reason - is condemned, as the instrument, in such case, unless brought too near the horses, will be found to dip in front, by which means the draught is considerably increased. Teeth of a uniform length throughout are to be preferred. The flexibility given to a harrow, by a hinge in the centre, is a great improvement. In many cases, one harrow is attached to another so as to follow it, but so far removed to one side or the other, that the teeth follow in different lines. In such case, it is obvious that the draught must be very much increased, both from the distance of the last harrow from the moving power, and from its lying flat and dead upon the ground, and having no advantage of the lift which is given to the forward harrow by the chain which attaches it to the horses, and which it would have, if it were set in the same frame.

There are several varieties of harrows, but, excepting the frame being made of iron instead of wood, and their being connected by hinges, so as that the frame becomes, so to speak, flexible, I see no prominent excellence to be pointed out. "In an experiment made between a pair of wooden harrows and a pair of iron ones constructed on the same plan, and having the same number, and precisely the same disposition, of the teeth and frames, although those of iron were found to be 20 pounds lighter than those of wood, yet the former worked decidedly better and steadier than the latter; in fact, the iron harrows cut into the land, while those made of wood rode, or rather danced, upon the surface."

A harrow, called a web or chain brush harrow, invented by Mr. Smith, of Deanston, I have seen, but not in operation; and its effect must be to reduce the surface to a very fine tilth, but it is not its object to penetrate the soil. If we take a number of small iron circular plates, perhaps three inches in diameter, with 
thin or sharpened edges, and string them upon iron rods, upon which they will revolve freely, and arrange them in squares like the panes of a window or sash, and with enough of them to form the desired size of a harrow, we shall have formed the instrument to which I refer. As they revolve vertically, and are drawn over the surface, their tendency is to cut all the lumps into fine pieces, and to leave the surface well reduced and pulverized.

At Lord Hatherton's well-managed farm, at Teddesley Park, Staffordshire, I saw a revolving harrow, somewhat resembling a hay-spreading machine, the long and curved teeth of which penetrated the ground deeply, thoroughly stirred it, and brought the weeds and rubbish to the surface. It was moved upon low wheels, and performed its work most effectually.

I shall borrow, for the benefit of my readers, an account of Biddell's extirpating harrow from Mr. Ransome's valuable book, before quoted. I have not seen the instrument at work, but its efficiency will be understood from the account.

"Biddell's Extirpating Harrow.-This is a new implement, invented by Arthur Biddell, of Playford, and similar to the scar-

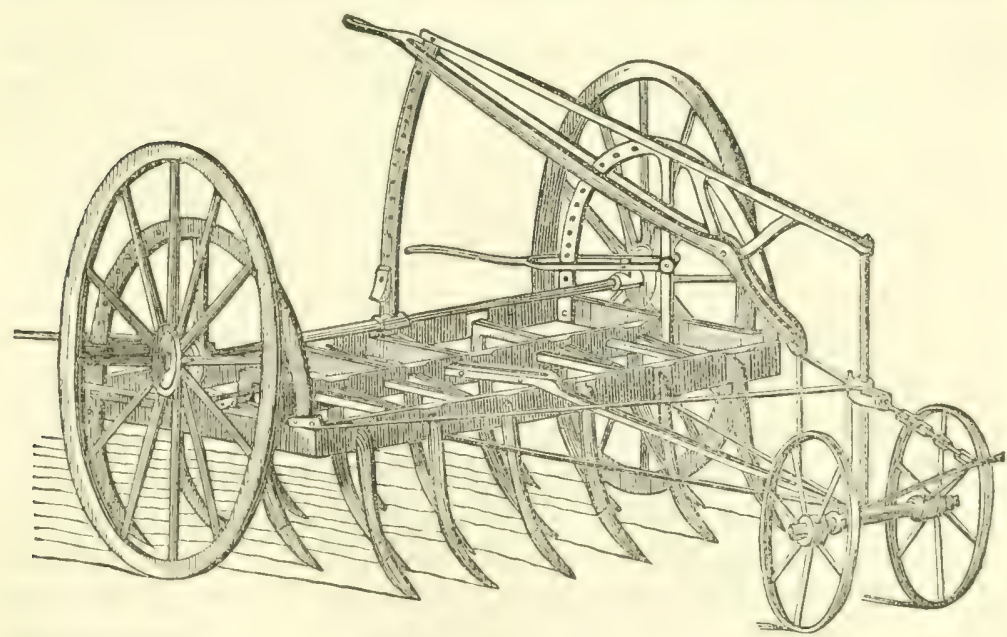

ifier which bears his name. It is intended for breaking up land when it is too hard for the heaviest harrows, and for bringing winter fallows into a state of fine tillage. In working summer- 
lands, it is calculated, by the shape of its tecth, to bring to the surface all grass and rubbish. The teeth are placed in three rows, in order to allow sufficient distance fiom each other to prevent choking, and the implement is so constructed as that, by means of levers, the teeth may be elevated or depressed at pleasure. According to the form of the lands it may be required to operate upon, it may either be used perfectly parallel, or the fore teeth may be made to penetrate deeper than the hinder ones, whilst those at either side may, when one wheel is required to run in the furrow, be instantly adjusted to the level of the land, so that every tine shall penetrate to a uniform depth of six inches, if required; and they will work equally well at any less depth.

"I have frequently seen this implement at work on very foul land and on stubbles, when it has been too hard to allow the use of the plough. As the interval between the lines formed by its teeth does not exceed four inches, the soil has been completely stirred. The tines may be either used with points or with steel hoes; and with the latter the skimming, or, as it is frequently called, the 'broadshare' process, may be quickly accomplished. The weight is not found to be a disadvantage, but, from the stability it gives, the contrary; and, being borne on high wheels, it does not require so much horse-labor as might be supposed, two horses, on most soils, being generally sufficient."

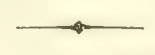

\section{LXXXVI. - SCARIFYING, OR GRUBBING.}

What is called, in England, the scarifying or grubbing of land, is little else than harrowing it with a deeper and stronger instrument than a common harrow, with a view to reduce it to fine tilth, and to bring up the roots and weeds which may iufest the land. The English and Scotch aim, in their husbandry, at an extreme cleanness of cultivation. There are - as it would be strange if there were not-examples among them of slovenly cultivation ; but cleanness is the prominent and almost universal characteristic of their husbandry. The late Lord Leicester, (Mr. 
Coke, of Ilolkham) used to make it his boast, that not a weed could be found in extensive fields of his cultivation, and offered a high reward for the discovery of one. The couch grass, (triticum repens,) and the common charlock, (wild mustard,) and the poppy, abound, in some districts, to a most extraordinary degree; and in cleaning the fields, in the autumn, of conch grass, the piles of it which are sometimes seen would lead one to suppose that it was the only crop grown on such places. In some cases, where the land is very dirty, and the cleansing very thorough, the heaps of weeds have been as numerous as cocks of hay in a mown field.

The general practice is, to bum these heaps upon the field, to the expediency of which I strongly demur. The amount of ashes obtained in such case is altogether inconsiderable. The couch grass being extremely vivacious, and propagated from every joint, it is not easy to bury it so deep as to extirpate it. Some of the Scotch farmers pile it up at the outside of their fields, and mingle with it quicklime, which of course soon consumes it. I cannot help thiuling it would be much better to use it as litter in the cattle-sheds or stalls, and fold-yards, where, by the trampling of the stock, it would soon become decomposed, and, without danger of starting again into life, it would go to essentially increase the compost heap.

'The operation of scarifiers, or grubbers, will bc seen at once by a reference to the plate. Many of them are certainly very efficient instruments, and, when the team is sufficiently powerful, stir the land most thoroughly to a great depth. There is a considerable variety of them; and the peculiar excellences of each of them are always fully set forth by the inventor or maker, in doing which, there seems to be no want of talent or address among the English, and some of them may fairly challenge competition with Peter Pindar's razor-seller, or with any of the vivacious and voluble tribe of Connecticut pedlers.

The infunite variety of machines and mechanical contrivances exhibited at the great agricultural shows in this country, covering literally acres and acres of ground, strikes a visitor with astonishment. As, in reading the accounts of patent medicines in the public newspapers, one is led to think that the reign of disease is abolished, and the victory of health, life, and perpetual youth, on earth, secured, so, in looking at the number and variety 
of agricultural implements presented on such occasions, and the diversity of purposes which they are most certainly and effectually to accomplish, one is almost persuaded that human labor and superintendence may be dispensed with; and that the farmer, as he would wind up his clock on Monday morning so that it may run all the week, so he has only to set his agricultural machinery in motion, and may then leave the field with a quiet confidence that every thing will proceed as he desires it should. After having visited, likewise, the establishments of many large proprietors, and seen the broken and condemned implements, and the piled-up, useless lumber of this description, in their implement-rooms and sheds, I cannot help thinking that there is, among a great many men well informed in other matters, a fair share of susceptibility to imposition; that "razors made to sell" meet with no want of purchasers in England; and that the manufacturers perfectly understand themselves, when they have got their pail under a full cow. The human tongue is certainly an extraordinary piece of machinery, and its flexibility camnot be sufficiently admired. I see, in the papers of the week when I am writing, an advertisement of a potatopowder, recommended to families to be put into the pot with the potatoes to be boiled, so as to correct the evils of the diseased potato, and not only to neutralize its pernicious influences, but actually to convert the diseased portions into useful nomrishment. The price and place of sale are both given. There will be many to buy, beyond all question. When will the reign of empiricism cease on earth? When the last man has left it ; and not sooner.

The operation of scarifying will be better understood from a picture of some of the principal instruments in use than from any verbal description.

'The first to which I shall refer is called, after the name of its inventor,

Biddell's Scarifier - and I shall allow the manufacturer to speak for himself.

"This implement is for the purpose of cultivating land under a variety of circumstances, and bringing it into a proper state of tilth much more effectually, and at less expense, than can be done by the means generally employed for that purpose. 
"It may be successfully used to clean wheat, bean, and pea stubbles, directly after harvest;

"To break up such parts of clover layers as may have failed in the plant, and to break up land after green crops, in May or June, in preparation for turnips, coleworts, \&c.; thus accomplishing fine and deep tillage, without bringing fresh earth to the surface-land, in preparation for barley and oats.

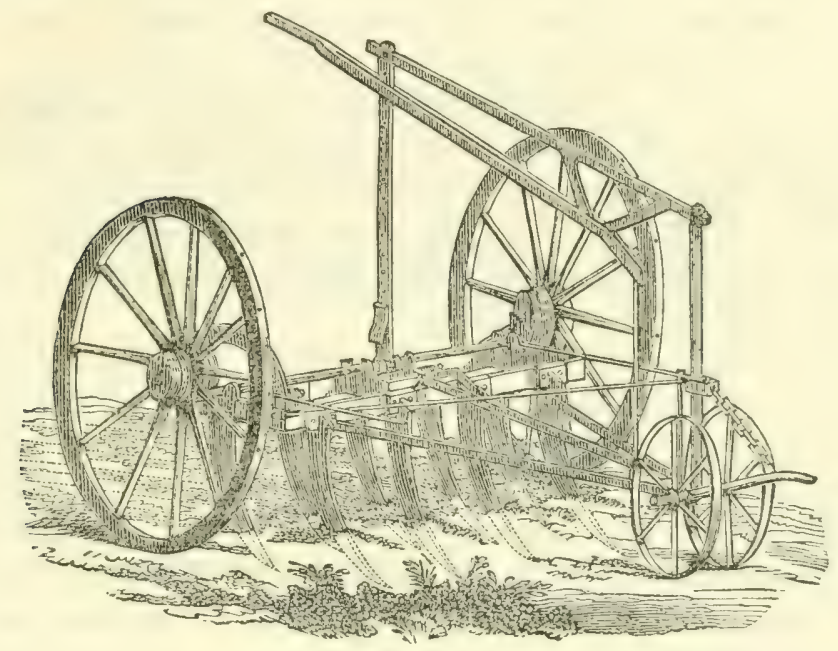

"Its Advantages are - Saving, in Tillage, of half the labor, both manual and horse, over the ordinary method of cleaning land.

"Saving of Time. Lands may be broken and stirred, with this implement, in much less time than with the plough.

"Improved Cultivation. The operation of this searifier is much more effective for spring crops on strong lands than ploughing; as it occasions less treading by horses, produces more mould, and allows the moisture to be more advantageously retained; and the seed will be deposited in the soil which has been exposed to the winter frosts.

"Less harrowing is required, as the land is broken up, and left much finer than after the plough.

"The couch grass (if any) is brought to the surface without breaking it. 
"The land is left by this implement in a state to be immediately harrowed, which may be done in time to break the clods before they become too hard.

"In all cases, where it is desirable to give tillage to the land without turning down the surface, this implement may be used with great advantage.

"Directions for using the Scarifier. - In using the scarifier, attention should be paid to set it level, and the depth of scarifying may be varied from one to ten inches, which is done by means of the two levers.

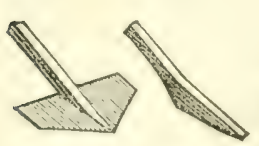

"When the land is very hard, and required to be cut clean, first use the chisel points, and then follow with the wide hoes.

"The chisel points only should be used on clover leys; the roots of the clover being too tough for the hoes, and are not required to be cut up.

"The horses should be kept in a direct line, and the implement not suffered to turn without taking the fore part out of the ground by means of the long lever. Particular attention should be paid to this; for, although the slanting direction in which the tines are set will bear the dranght required while the horses go straight forward, they cannot stand against the twist, if the scarifier be turned round before the front tines are taken out of their work. It is also needful to observe, that the draught iron from the fore wheels, upon which the whippletrees hang, should be suspended by the draught chain higher than where the three draught irons (when in work) go upon the upright part of the fore axletree; otherwise, this may bend or give way.

"The wheels, on either side, may be made to go higher or lower by shifting the coupling irons, where holes are made for that purpose, where one wheel has to work in the furrow; which may be the case when a stetch is scarificd by going on one side of it, and coming back on the other.

"It is essential to have whippletrees adapted to the implement; if otherwise, it will fail to scarify up the foot-marks of the horses."

The next implement for the purposes described, and which has been a long time in use, is called 
Finlayson's Self-Cleaning Harrow. - "This is an efficient imnlement for cleaning lands under tillage from couch grass and other weeds; the curvature of its teeth being so formed as to bring to the surface all weeds and vegetable rubbish."

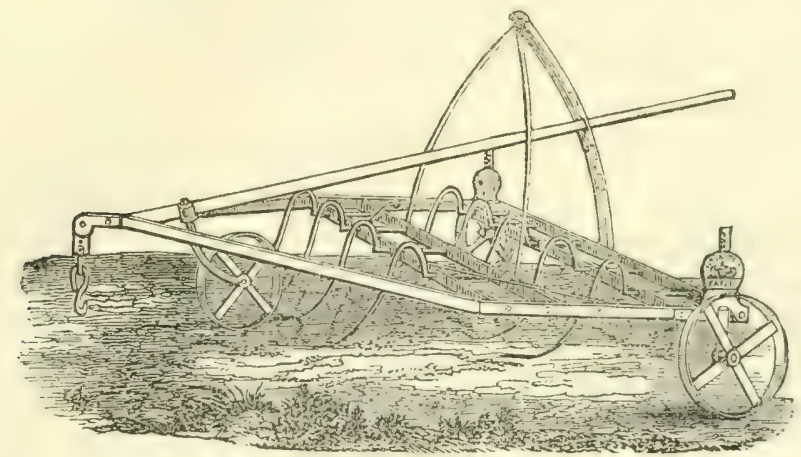

This was among the first improvements of the kind, and has been followed by a great many other inventions, of which 1 shall offer only two other examples. The first is,

Kirkwood's Grubber. - "The leverage that is obtained by pressing on the handles or stilts of this machine, whether in action

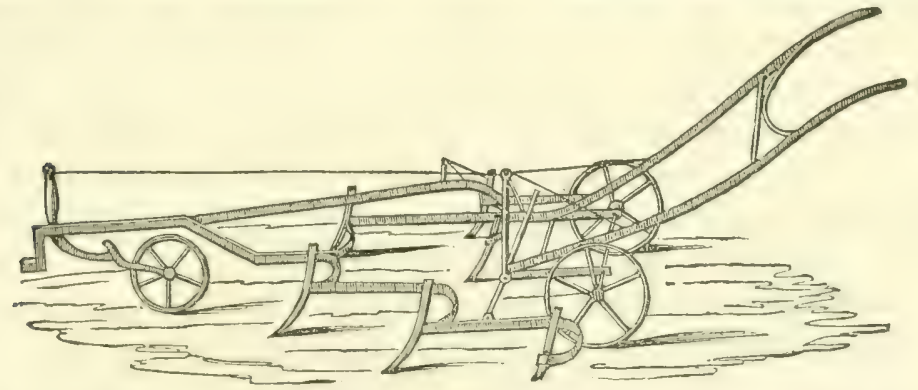

(1) at rest, is so simple, and yet so powerful in its effect, as to regwlate the depth of the tines to the greatest nicety; or, in cases of obstruction, to throw them ont altogether. It is an admirable implement, and well deserving the high commendation generally bestowed on it." Objections have been made, however, to the form of its teeth.

The next instrument which I shall notice is called the Uley cultivator, and made at the iron and agricultural implement 
works of the Earl of Ducie, at Uley, in Gloucestershire, and under the direction and management of a highly intelligent and practical machinist, Mr. Richard Clyburn, a visit to whose establishment afforded me the highest gratification.

The Ulex Cultivator. - "No. 1 size, with 5 tines, covering a space of 40 inches.

"No. 2 size, with 7 tines, covering a space of 56 inches.

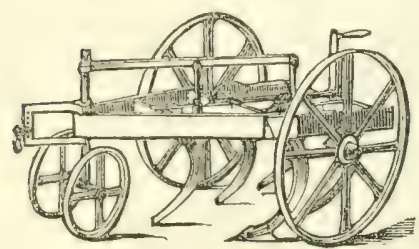

"The improvements consist, first, in a new method of fastening the tine into the frame, so as to insure a sufficiency of strength to the upper end of the tine, where the greatest strength is required; secondly, in making the scarifiers and grubbers concave on the under side, which causes them to wear to a sharp edge, and enter the ground better, where it is very hard; thirdly, in constructing them in such a way, they can be made of wrought iron.

"The frame is of cast-iron, made to receive five or seven tines, each tine covering a space of eight inches, and so arranged that, although drawing lines only eight inches apart, they are two feet from each other; this, with their curved shape, and length, prevents its clogging in the foulest land. There are three sorts of points; one, two inches wide, for grubbing up or breaking land; another, nine inches wide, for working stubble; the third set has steel blades, and are used for paring, instead of the breast-plough : these points all fit the tines without pins to hold them. The tines are fastened into the frame with a split key and cotter; and, in case of breaking, they can be taken out and others put in, as easy as the colter of a plough. The height of the frame from the ground is about two feet; the wheels are of cast-iron, the front ones 1 foot 6 inches diameter, and the back ones 3 feet 4 inches diameter. The machine is raised and lowered by turning a handle, the axle of which has a worm fixed on it, working into a wheel fixed in the crank-axle of the back wheels. This wheel has a projecting arm, in which a stud is fixed: to this stud is attached a connecting-rod, the upper end of which is comnected to the long lever which has its fulcrum in the centre, and is connected with the frame by a joint; the other end of the lever 
is cunnected to the top of the $\mathrm{T}$ axle, on which the front wheels work. It will be seen by this arrangement that, if the handle is turned to the right, the machine is lifted up; and if to the left, let down: this is indicated by the dial-plate on the right-hand side of the machine, marked in inches, in and out of the ground; one rotation of the handle raises or lowers the machine one inch."

This instrument, wherever it has been used, has been highly approved.

It will be obvious to my readers, that the object of these sevcral inventions is to put the ground into a fine and deep cultivation; and, in many cases, the scarifier will be substituted with great advantage for the plough. In the spring of the year, especially, where land has been ploughed in the autumn, it would be most injudicious, in many cases, to reverse the sward with a plough, and at the same time, as the wetness of the land may require that it should be cultivated lightly, a harrow or scarifier presents the most proper implement.

As a matter of curiosity, a Table of ingenious, exact, and somewhat useful calculations, in regard to the business of ploughing or scarifying land, will be inserted on the last page of this Report.

\section{IAXXXVII. - GENERAL REMARKS ON THE USE OF AGRI- CULTURAL MACHINERY.}

In presenting these different examples to my readers, they will not expect me to recommend them, nor to mark a preference of one over the other. That I must leave wholly to their judgment. I have only to say that the best results are to be expected only from the most careful and thorough cultivation; but with the best feelings towards those ingenions mechanies and artisans who have done so much to alleviate and facilitate labor, my own experience, and that of many friends, would lead me to advise to caution in the purchase of any machines whose 
utility has not been thoroughly tested, and especially those of a complicated or expensive character. A machine which promises much may greatly disappoint us in the results. Some of the most complex machines perform only that which the most simple would accomplish with half the trouble, and it is often quite as difficult to manage the machine as to perform the labor. A machine constructed upon the most sound and philosophical principles requires, many times, a philosopher to guide it. Agricultural machines of a complicated nature are constantly liable to get out of repair, and at times when the inconvenience and loss, occasioned by the stoppage of the work from such accidents, are excessive. Then the conduct and management of the machine must go into the hands of persons who are ignorant and stupid; who have a prejudice against the success of machinery, because they erroncously suppose that it interferes with their labor; who generally resist all innovations, and who but too often find a malicious gratification in the failure of all attempts at improvement. The remedies for this very common evil, it is not easy to determine. The first is, if possible, to give the laborer a direct persoual interest in the success of the machine in use. The second is less direct, and can only be looked for in the future; that is, the better education of the laboring classes, which shall enable them to take more just views of their own private interests, and understand their inseparable identity with all measures of general improvement, with the progress of the mechanic arts, by which, if labor is not abridged, production is greatly increased, and with the interests and welfare of every sther class in the community. Happy will it be for the world, when the true principles of political economy - so well illustrated in the well-known Latin fable of the revolt of the limbs against the stomach, and as clearly in the sacred writings, when the apostle reminds us that "we are members one of another, and if one member suffer, all the members suffer with it, and if one member rejoices, all the members rejoice with it" - shall be every where understood, and, if we may dare hope for such a result, conscientiously applied and practised upon. 


\section{LXXXVIII. - PARTICULAR EXAMPLES OF IMPROVEMLNT.}

I have spoken of the preparation of the land, by culture, for the deposit of the seed, under the heads of ploughing, subsoiling: paring, deep-stirring, scarifying, and harrowing; but there were two processes going on, in Cornwall, of so peculiar a character that I deem it proper to detail them.

1. Tenidy. - The first was at Tehidy, the residence of Lady Bassett, under the direction of an intelligent and accomplished agriculturist, a gentleman well established in the principles, and familiar with the practices, of agriculture, in the best cultivated districts of Scotland, and who was employed not merely to put the home-estate under a proper course of management, but, by example, counsel, advice, encouragement, and rewards, to assist and induce the tenants on the property to abandon the objectionable and profitless modes of husbandry which they had long followed, and introduce a better system, which the experience of the most improving and best farmers in the country had sanctioned.

An extensive tract of land on the sea-coast was underlaid, about three inches below the surface, with a compact bed of flint stones, of four and six inches in depth, and might indeed be very properly called macadamized. Vegetation on such land was almost hopeless, for the mould, or vegetable matter, on the surface, had little depth, and no plough or cultivator conld penetrate this obstinate mass of stones. But this farmer undertook to remove with pickaxes this entire mass of stones, and had accomplished a considerable tract when I had the pleasure to visit it. The piles of stones lay as thick, as and very much larger, than cocks of hay, upon the field, preparatory to their being carted away, for the making or repairing of roads. Under this layer of stones was found a soil which could be brought into, and, under proper manuring, would liberally reward, good cultivation. The Cornish men, who, in the capacity of miners, are accustomed to face difficulties of no ordinary magnitude, and will march up against the brazen walls of a copper mine, where they may pick and hammer away for weeks and months with- 
out reward, with as much indifference as they would cut away upon a loaf of stale bread, performed this service with a labor and perseverance worthy of all praise. Under this layer of stones was a soil capable of productive cultivation, and the reward was found in the crops which were growing on a portion of the recovered land. After the stones were removed, the land was subsoiled, and a crop of turnips, manured with guano, was taken. The effects of guano; when the land manured by it was compared with a part of the field manured only with the ashes of the furze, were here most remarkable. The experiment was a brave, and, though labor was at a low rate, it was an expensive one; but as the land was comparatively without value in its former state, the only question in the case was, whether the land, after being redeemed in this way, would be worth the expense of the recovery. Heavy as this expense was, the land became worth a great deal more than it cost. In fact, it was so much land literally created by the process; and its situation, where it was easily accessible, greatly enhanced the value.

2. Scoberl's Farr. - The other experiment to which I referred was going on between Penzance and Land's Fnd, on the farm of Colonel Scobell - a farm, in respect to parts of which the culture would seem like going upon a forlorn hope, the land presenting a most forbidding aspect; and yet in its results exhibiting a conclusive test of the best husbandry, by its permanent improvements, and its ample returns for the labor and expense bestowed upon it.

Some parts of Cornwall - where the hospitality of the inhabitants is in an inverse ratio to the quality of the soil - reminded me of a tract of country very well known to many persons in the United States, through which the turnpike-road passes between Lynn and Salem, in Massachusetts, which some one facetiously called the "abomination of desolation," and of which the British prisoners, in passing over it on their way to Boston, in the last war, demanded, with considerable cmphasis, "whether that was the " (here using a theological phrase, which it would be quite improper to repeat out of the pulpit) "country for which the Americans were fighting." There is this remarkable difference, however, in favor of Cornwall, that, like some old miser, who seeks to conceal his riches under an appearance of 
extreme squalidness and destitution, it is underlaid with inexllanstible mineral treasures, as I myself, in a dress befitting the infernal regions, with a lighted torch in my hand, descending by the slippery rounds of a ladder seven hundred feet, and traversing two miles under ground, had the gratification - for so I may call it, since I am once more on the surface - to witness. In this part of the country there is little wood, and no coal, and, for fuel, the inhabitants pare the surface of the land, which seems corered with a thick matted moss and heather, and which, when taken off, leaves under it a mixture of white gravel, and black, peaty mould. This being taken off in spots, the country resembles the face of a man reduced to a skeleton, with his skin pitted and blotched all over with the small-pox. It will be understood that I am speaking only of a part of Cornwall, and, in particular, the mining districts; for in some parts there are spots of eminent fertility, of which the culture is singularly skilful, and the productiveness nowhere exceeded.

Some of the land owned by Colonel Scobell is of the description of which I have spoken. He sells the moss and heather, taken off by, what a native American may properly call, this scalping process, at twenty-four pounds per acre; and then, by deep and brave cultivation, and by most ample manuring, at an expense of ten pounds an acre, he brings this very land into productive cultivation. This is what, in New England, we should call adroitly, and, certainly, most honestly and creditably, "turning a penny;" here it is evident it might be designated by a denomination two hundred and forty times larger. After this land is in this way brought to, it would readily let at thirty or forty shillings per acre. After the land has been pared, his process is to drain, subsoil, and manure it, and then he gets excellent crops of turnips, barley, and wheat.

All circumstances considered, the whole management of this farm seemed to me excellent, and it will not be deemed out of place if I now speak of it, since the subject is before me.

The farm embraces an extent of some hundreds of acres, of a gravelly soil, and much of it composed of rotten and decomposed granite rock. It required no small resolution and courage to take such a tract of country in hand, with a determination to make its cultivation profitable; for, though I have referred to some cases in which the returns from the sale of the furze and 
heather upon it were very large, it could scarcely be expected that such a process of profit was applicable to a large extent.

The farm is not in what would be called "pink style," and nothing is done for show. The fixtures, though very convenient, are of a plain and inexpensive character. He keeps 150 head of neat stock; he raises all his calves; he fats a large number of swine, of which he has an excellent breed, being a mixture and cross of the Essex, the Neapolitan, and a boar procured from the United States, which appeared to be a chance animal with excellent points. His cattle are of the improved Durham, which seemed not the kind best adapted to the short pastures of the country, and were not in good condition, having, as he said, suffered from the extreme drought which had prevailed during the summer, and of which it was quite evident the stock in all that country had felt the severity.

His stock are kept in the house the greater part of the year, and fed upon steamed food. His swine are generally killed at one year old, and weigh from fifteen to seventeen scores of pounds; and when kept until two years old, he calculates them to weigh about thirty-five scores of pounds. He has killed those which weighed thirty-six score. They run in the pasture upon grass only, "with no meat," — that is, no grain or meal, - from April until October. They are then put up and fed with steamed potatoes. mixed with barley meal, and given to them while warm; and twelve gallons of barley meal are deemed sufficient for the fattening of a hog. His swine, when put up for fattening, are fed several times a day. Indeed, the hind watches them constantly, and supplies them with food as often as their troughs are emptied.

The cattle are tied in stalls with chains. Provision is made. by a movable trough, to let in water to them, so that they are not turned out except for occasional airing. The stable and barns are upon the side of a hill, and the cattle are kept upon a lower story.

The upper part of the barn is devoted to the washing and steaming of the food; for all of it, the chaff' as well as the vegetables, are steamed for the stock. The turnips and potatoes are placed in a large trough or tub, directly under a full current of water, coming from a drained field, which falls some short distance directly upon them, and immediately passes off', carrying the dirt with it. The potatoes are steamed in barrels. The 
barrels are suspended in an iron half hoop, and are swung back and forward by a clane. They turn upon a pivot, and have but one head in. They are easily swung round to the trough, where the potatoes are washed, and then filled. A movable bottom, full of holes, is then placed in the open head, to prevent the potatoes from falling out, and they are again swung round and dropped upon a platform, and a steam-pipe, opened by a cock, introduced under the bottom, which effectually steams them in fifteen minutes. 'They are then again attached to the lever, swung round, inverted, the movable head taken out, again inverted, and the cooked contents poured into a trough, and the barrel again filled and cooked as before; so that, from the beginning to the end of the process, they can scarcely be said to be tonched with the hand.

'The turnips, with their tops on, are dropped from the cart into the washing trough, and, when washed, are shoved along, and thrown into steaming boxes level with the floor, on which they are washed. 'These boxes have a false bottom, or grating of iron, under which the steam is introduced by a pipe, and, after being sufficiently cooked, the end of the box is dropped, and they are easily shovelled into a cooling box, set still lower than the other, for their reception. The chaff is steamed in a large closet. All the hay for the cattle is cut by a machine, on an upper floor, and easily shovelled into this closet, where it is steamed by a pipe introduced from the common steam machine. Every thing is contrived to simplify and relieve labor. The food is then put into barrows, and wheeled, through the passages, to the different stock to be fed. The water, which comes from the turnips when steamed, is always saved, and, being mixed with a small quantity of barley meal, is given to the store hogs. It will ferment if left to stand, and is deemed quite nutritious. Oatmeal is used for the stock, when barley meal cannot be obtained, and is deemed much better.

The potatoes and turnips are all washed, and shovelled, and steamed, by a single young woman, stout, healthy, active, and energetic, not in appearance much to my taste, as "a fine gentleman," but entitled to respect for her cheerfulness and goodlummor, and for the spirit and fidelity with which she performed her humble duty. Her master spole of her in the kindest man- 
ner, and, in looking at her in her laborious service, I could not help thinking of that noble line, -

"Act well your part; there all the honor lies."

The manure of the stock is thrown into the yards. Different kinds are mixed, and some hogs are kept among it, who, by stirring it constantly, prevent its fermentation. The liquid manure is all saved in tanks, and, in some cases, is, with great success, led over the fields.

With the water obtained from the drainage of the land, Mr. Scobell has created a mill-power, which turns a wheel twenty-eight feet in diameter. With this is connected a threshing machine, a wimnowing machine, and a flour and grain mill, for the purposes of the establishment; and the same power is applied to a mill for crushing and sifting bones, to a chaff-cutter, and to a grindstonc.

From the situation of the ground, likewise, on the side-hill, Mr. Scobell is enabled to irrigate portions of his land, which he does with great advantage. From the rocky character of the country, the fences on the farm are stone walls, a very desirable mode of disposing of the surplus stone in the fields; and his gates upon the farm are of iron, at the moderate cost of $7 \mathrm{~s} .6 \mathrm{~d}$. per gate. They appeared, however, quite too light and frail for endurance.

The fixtures on the farm are of the rudest description, and no pretensions are made to neatness or exactness; but every thing seemed well cared for; and for economical arrangements, for effecting the purposes intended, for a management combining the lowest scale of expenditure with the highest scale of profit; few more successful examples have ever come under my observation. The courageous enterprise, which could boldly face the obstacles to be encountered in this most inauspicious tract of country, would qualify a man for a much higher military commission than that which its proprietor had borne, and the sound judgment and skill which suggested and planned the improvements, and carried them out with such a creditable economy of labor, are well worthy of commendation. 


\section{LXXXIX. - CORNWALL AND THE LAND'S END.}

Many of the practices prevailing in Cornwall, with the modes of speaking, and forms of expression among the people, are so nearly allied to those of New England, as to satisfy me that we must have imported them from this part of the world, and that scions from Cornwall are thickly ingrafted in our pilgrim land. I wish we might inherit, in the fullest measure, the spirit of fullsouled hospitality which I found among them. I have only to regret that the rules which $I$ have prescribed to myself forbid my saying what I would. But the feelings of grateful and affectionate respect are not the less strong for being suppressed; and my Cornwall friends, from their own generous natures, may be assured that my sense of their constant and disinterested kindness is all which they themselves would desire it should be.

On this excursion into Cornwall, I went to the Land's End, and planted my foot on the very last rocky point, extending into the sea, which I was able to reach. I had but a few moments before passed a traveller's home, with the significant sign, "The First and the Last House in England." Nothing can be more picturesque than this rude and rock-bound shore, with its whitefringed ruffle of surf, as far as the eye can reach, and a few scattered rocks at a distance, over which the swelling waves were profusely pouring their showers of diamonds, so treacherous to the home-bound mariner, so picturesque and beautiful to the landsman, as he suns himself upon the grassy shore, watching the distant sails scattered upon the wide expanse, full-freighted with human life and hopes, glittering in the sunlight, and floating like water-fowl in their native element.

As I stood upon the far-jutting point of the promontory, and felt that no intervening country separated me from the land of my birth, and the home of what is most dear to me, I found my head growing dizzy, my heart beating as though it were struggling to get out, and my cheeks quite wet, perhaps with the spray; and I could only find relief in sending a thousand unspoken messages of affection, and in more earnest prayers for the prosperity of the land, and the loved ones whom I had left behind. May the winds waft the former to their oljects, and the last find a response in heaven! 
'T A B L E,

$$
\text { By Jон MORTox, }
$$

Showing the Distance truvelled by a Horse, in ploughing or scarifying an Acre of Land; also the Quantity of Land worked in a Day, at the Rate of sixteen and eighteen. Miles per Day of nine Hours. - Johnson and Shaw's Farmer's Almanac, vol. i. p. 191.)

\begin{tabular}{|c|c|c|c|c|c|c|c|}
\hline $\begin{array}{c}\text { Breadth of } \\
\text { Furrow-slice } \\
\text { or Scarifier. }\end{array}$ & $\begin{array}{c}\text { Space trav- } \\
\text { elled in } \\
\text { ploughing an } \\
\text { Acre. }\end{array}$ & \multicolumn{2}{|c|}{$\begin{array}{l}\text { Extent ploughed per } \\
\text { Day, at the Rate of }\end{array}$} & $\begin{array}{c}\text { Breadth of } \\
\text { Furrow-slice } \\
\text { or Scarifier. }\end{array}$ & $\begin{array}{c}\text { Space trav- } \\
\text { elled in } \\
\text { ploughing an } \\
\text { Acre. }\end{array}$ & \multicolumn{2}{|c|}{$\begin{array}{l}\text { Extent ploughed per } \\
\text { Day, at the Rate of }\end{array}$} \\
\hline Inches. & Milcs. & \multicolumn{2}{|c|}{$\begin{array}{c}18 \text { Miles. | } 16 \text { Miles. } \\
\text { Acres. }\end{array}$} & Inches. & Mites. & \multicolumn{2}{|c|}{$\begin{array}{c}18 \text { Ailes. } \mid 16 \text { Miles. } \\
\text { Acres. }\end{array}$} \\
\hline 7 & $14 \frac{1}{8}$ & $1 \frac{1}{4}$ & $1 \frac{1}{8}$ & 34 & $2 \frac{9}{10}$ & $6 \frac{1}{5}$ & $5 \frac{1}{2}$ \\
\hline 8 & $12 \frac{1}{4}$ & $1 \frac{1}{2}$ & $1 \frac{1}{4}$ & 35 & $2 \frac{4}{5}$ & $6 \frac{1}{3}$ & $5 \frac{3}{5}$ \\
\hline 9 & 11 & $1 \frac{3}{5}$ & $1 \frac{1}{2}$ & 36 & $2 \frac{3}{4}$ & $6 \frac{1}{2}$ & $5 \frac{4}{5}$ \\
\hline 10 & $9 \frac{9}{1 \sigma}$ & $1 \frac{4}{5}$ & $1 \frac{3}{5}$ & 37 & $2 \frac{2}{3}$ & $6 \frac{2}{3}$ & 6 \\
\hline 11 & 9 & $\stackrel{2}{ }$ & $1 \frac{3}{4}$ & 38 & $2 \frac{3}{5}$ & $6_{\text {IV }}^{9}$ & $6 \frac{1}{8}$ \\
\hline 12 & $8 \frac{1}{4}$ & $2 \frac{1}{5}$ & $1 \frac{9}{10}$ & 39 & $2 \frac{1}{2}$ & $7 \frac{1}{8}$ & $6 \frac{1}{3}$ \\
\hline 13 & $7 / \frac{1}{2}$ & $2 \frac{1}{3}$ & $2_{\frac{1}{10}}$ & 40 & $2 \frac{1}{2}$ & $7 \frac{1}{3}$ & $6 \frac{1}{2}$ \\
\hline 14 & 7 & $2 \frac{1}{2}$ & $2 \frac{1}{4}$ & 41 & $2 \frac{2}{5}$ & $7 \frac{1}{2}$ & $6 \frac{2}{3}$ \\
\hline 15 & $6 \frac{1}{2}$ & $2 \frac{3}{4}$ & $2 \frac{2}{5}$ & 42 & $2 \frac{1}{3}$ & $7 \frac{2}{3}$ & $6_{\frac{3}{4}}$ \\
\hline 16 & $6 \frac{1}{6}$ & $2_{10} \frac{9}{10}$ & $2 \frac{3}{5}$ & 43 & $2 \frac{6}{20}$ & $7 \frac{4}{5}$ & 7 \\
\hline 17 & $5 \frac{3}{4}$ & $3 \frac{1}{10}$ & $2 \frac{3}{4}$ & 44 & $2 \frac{1}{4}$ & 8 & $7 \frac{1}{10}$ \\
\hline 18 & $5 \frac{1}{2}$ & $3 \frac{1}{4}$ & $2 \frac{9}{10}$ & 45 & $2 \frac{1}{5}$ & $8 \frac{1}{6}$ & $7 \frac{1}{4}$ \\
\hline 19 & $5_{4}^{1}$ & $3 \frac{1}{2}$ & $3_{\frac{10}{10}}$ & 46 & $2 \frac{1}{6}$ & $8 \frac{1}{3}$ & $7 \frac{2}{5}$ \\
\hline 20 & $4 \frac{9}{10}$ & $3 \frac{3}{5}$ & $3 \frac{1}{4}$ & 47 & $2 \frac{1}{10}$ & $8 \frac{2}{3}$ & $7 \frac{3}{5}$ \\
\hline 21 & $4 \frac{7}{10}$ & $3 \frac{4}{5}$ & $3 \frac{1}{3}$ & 48 & $2_{\frac{1}{1}}^{\frac{1}{2}}$ & $8 \frac{3}{4}$ & $7 \frac{3}{4}$ \\
\hline 22 & $4 \frac{1}{3}$ & 4 & $3 \frac{1}{2}$ & 49 & 2 & $8 \frac{9}{10}$ & $7 \frac{9}{10}$ \\
\hline 23 & $4 \frac{1}{4}$ & $4 \frac{1}{5}$ & $3 \frac{7}{10}$ & 50 & 2 & $9 \frac{1}{10}$ & $8 \frac{1}{10}$ \\
\hline 24 & $4 \frac{1}{8}$ & $4 \frac{1}{3}$ & $3 \frac{9}{10}$ & 51 & $1 \frac{9}{10}$ & $9 \frac{2}{5}$ & $8 \frac{1}{4}$ \\
\hline 25 & 4 & $4 \frac{1}{2}$ & 4 & 52 & $1 \frac{9}{10}$ & $9 \frac{1}{2}$ & $8 \frac{2}{5}$ \\
\hline 26 & $3 \frac{4}{5}$ & $4 \frac{3}{4}$ & $4 \frac{1}{5}$ & 53 & $1_{\frac{9}{10}}$ & $9 \frac{3}{4}$ & $8 \frac{1}{2}$ \\
\hline 27 & $3 \frac{3}{5}$ & $4 \frac{9}{10}$ & $4 \frac{1}{3}$. & 54 & $1 \frac{4}{5}$ & $9 \frac{4}{5}$ & $8_{\frac{9}{10}}$ \\
\hline 28 & $3 \frac{1}{2}$ & $5 \frac{1}{8}$ & $4 \frac{1}{2}$ & 55 & $1 \frac{4}{5}$ & 10 & 9 \\
\hline 29 & $3 \frac{1}{2}$ & $5 \frac{1}{4}$ & $4 \frac{3}{5}$ & 56 & $1 \frac{3}{4}$ & $10 \frac{1}{4}$ & 9 \\
\hline 30 & $3 \frac{1}{3}$ & $5 \frac{3}{5}$ & $4 \frac{4}{5}$ & 57 & $1 \frac{3}{4}$ & $10 \frac{2}{5}$ & $9 \frac{1}{5}$ \\
\hline 31 & $3 \frac{1}{5}$ & $5 \frac{3}{5}$ & 5 & 58 & $1 \frac{7}{10}$ & $10 \frac{3}{5}$ & $9 \frac{1}{3}$ \\
\hline 32 & $3_{\frac{1}{1} \bar{U}}^{1}$ & $5_{5}^{1}$ & $5 \frac{1}{4}$ & 59 & $1 \frac{7}{10}$ & $10_{1}^{3}$ & 93 \\
\hline 33 & 3 & 6 & $5 \frac{1}{3}$ & 60 & $1 \frac{3}{5}$ & $10 \frac{9}{10}$ & $9_{1}^{7} \overline{0}$ \\
\hline
\end{tabular}

END OF TIIE FIRST VOLUME. 



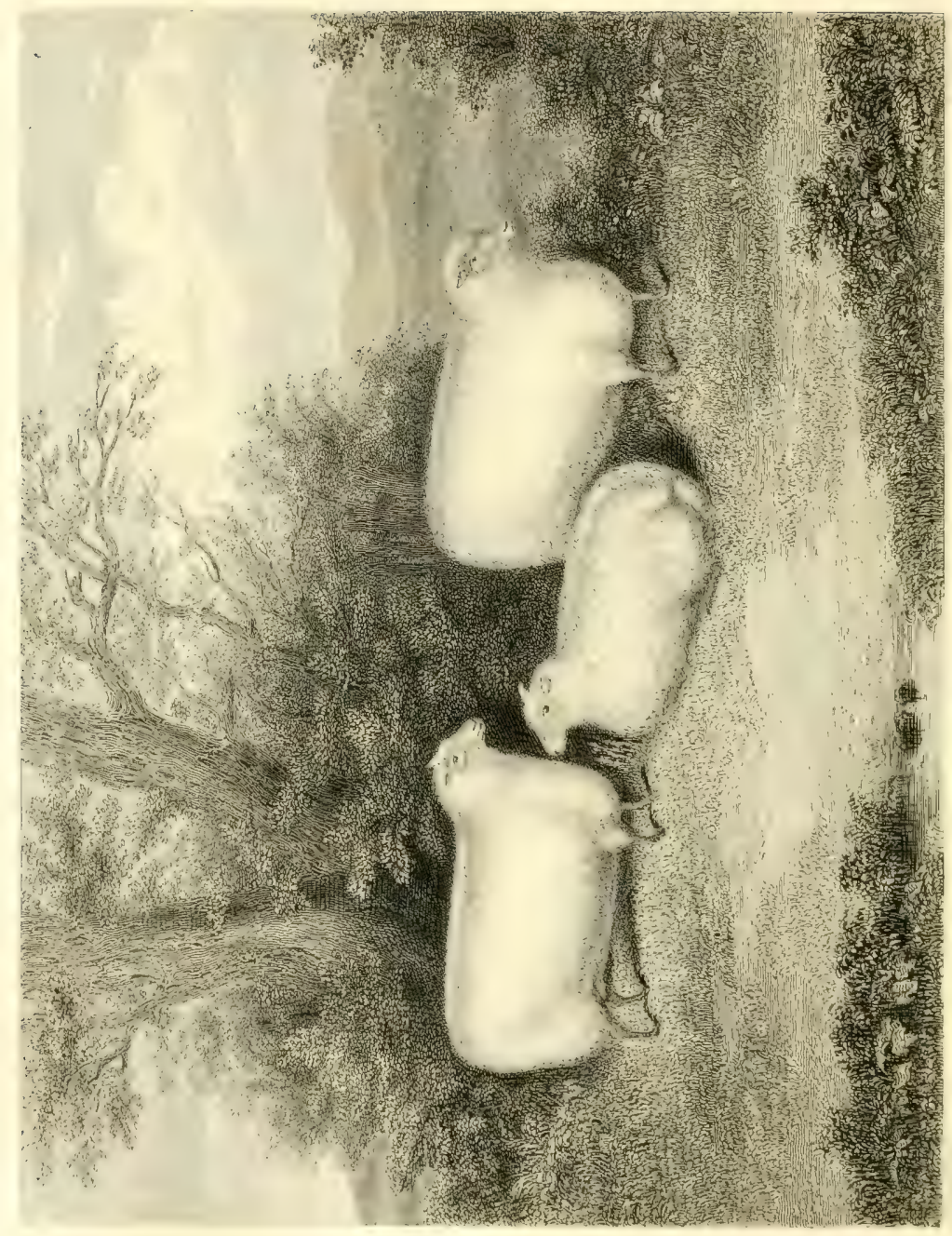




\section{EUROPEAN AGRICULTURE}

A N D

\section{RURAL ECONOMY.}

FROM PERSONAL OBSERVATION.

B Y

HENRY C COLMA ,

IONORARY MEMBER OF TIIE ROYAL AGRICULTURAL SOCIETY OF ENGLAND, OF THE NATIONAL AGRICULTURAL SOCIETX OF FRANCE, AND OF THE NATIONAL

AGRICULTURAL SOCIETY OF THE UNITED STATES.

"For, in all things whatever, the mind is the most valuable and the most important; and in this scale the whole of agriculture is in a natural and just order; the beast is an informing principle to the plough and cart, the laborer is as reason to the beast, and the farmer is as a thinking and presiding principle to the laborer." - BunkE.

\section{VOL. II.}

FOURTH EDITION, WITH ADDITIONS.

\section{BOSTON:}

PHILLIPS, SAMPSON \& COMPANY.

NEW YORE: CHARLES M. SAXTON. PHLADELPHIA: THOMAS, COWPERTHWAIT

\& CO. BALTIMORE: CUSHING \& BROTHER. CHARLESTON, S. C.: M'CARTER \& ALLEN. CINCINNATI : II. W. DERBY

\& CO, BUFFALO: G. II. DERBY \& CO. 
Entered, according to Act of Congress, in the year 1819, by HENRY COLMAN,

In the Clerk's Office of the District Court of the District of Massachusetts.

STEREOTYPED AT TIE

BOSTON TYPE AND STEREOTYPE FOUNDRY.

WRIGITT AND HASTY'S STEAM PRESS. 


\title{
I N D E X,
}

\author{
OR \\ TABLE 0 F C ONTENTS.
}

VOL.II.

SIXTH REPORT.

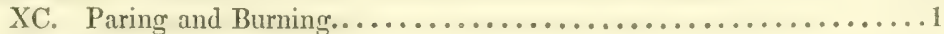

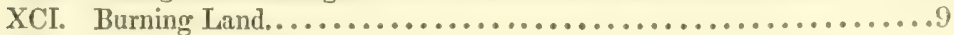

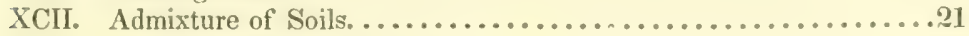

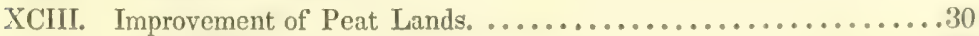

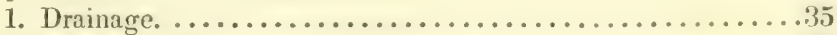

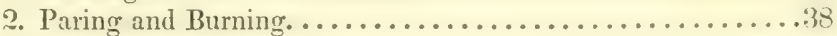

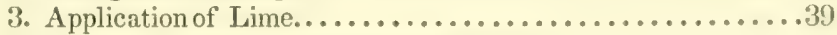

4. Rules in Ireland for Redemption of Bog. ........... 41

5. Application of Gravel or Sand.................. 41

6. Application of Clay or Marl. .....................

7. Application of Mud or Loam....................... 45

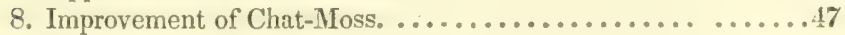

9. Depth of Ploughing on Peat Soils.................. 49

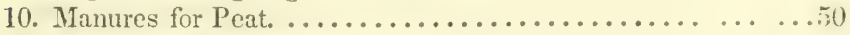

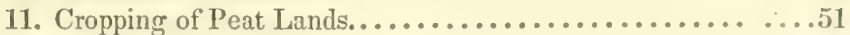

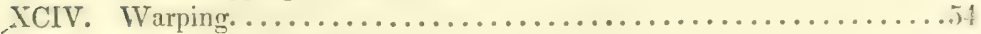

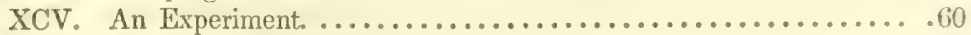

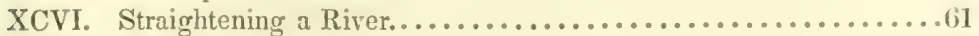

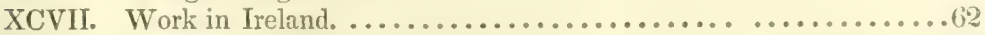

XCVIII. Drainage. ................................. 63

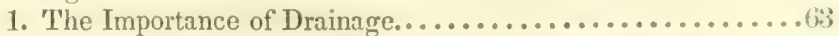

2. Extent of Drainage, and Embankment against the Sea......65

3. The Ancholme Drainage.......................66

4. Embankments against a River, and Discharge of Water

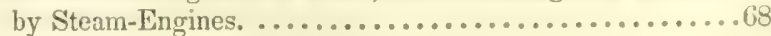

5. The Deeping Fen.........................69

6. The Muston Drainage, .....................69

7. Drainage at Scampton. .......................... 0 
8. Draiage in Nottingham PaGE

8. Drainage in Nottinghamshire. ..................... 73

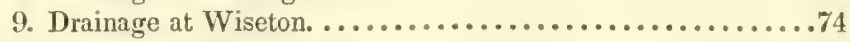

10. Grandeur and Value of these Improvements..............75

11. Relation of these Improvements to the United States. .......75

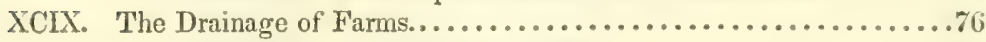

1. Climate, and Condition of the Soil. ................... 6

2. Modes of Draining. Open Ditches. Covered Drains........77

3. Elkington's System of Drainage....................

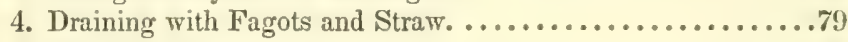

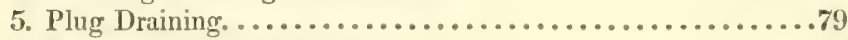

6. Draining with Turf Covering. ..................... 81

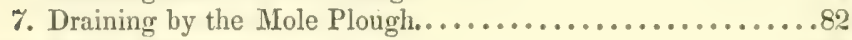

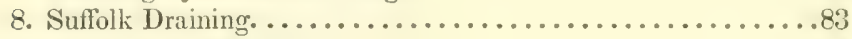

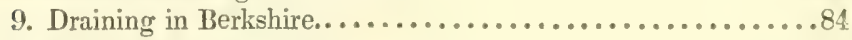

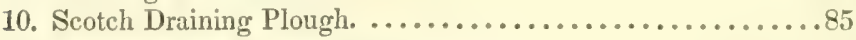

11. Draining with Broken Stones. .......................

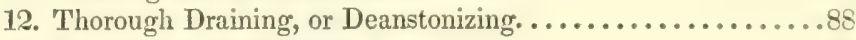

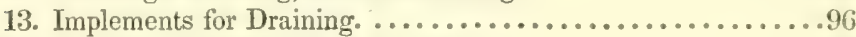

C. National Characteristics. - A Digression. ..................98

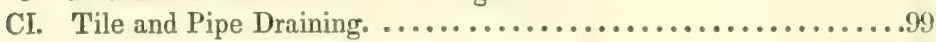

1. Improvements in Form of Draining-Pipes. .............99

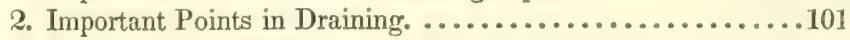

3. Results and Experience in Pipe Draining.-Depth of

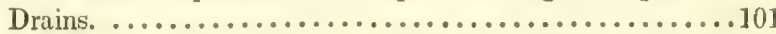

\section{SEVENTH REPORT.}

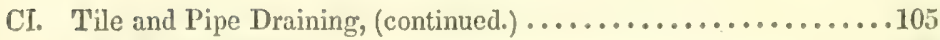

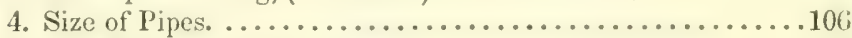

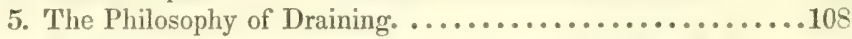

6. Magnificent Agricultural Improvements, and their Moral

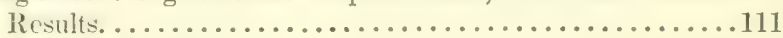

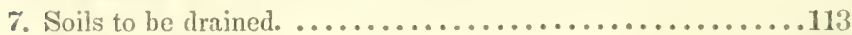

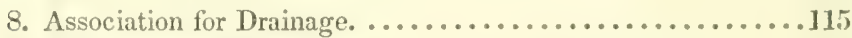

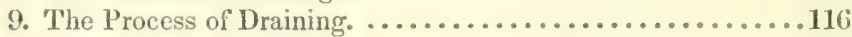

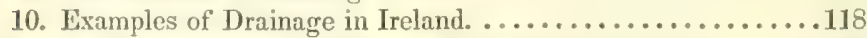

CII. Subsoil Ploughing connected with Thorough Draining. ........125

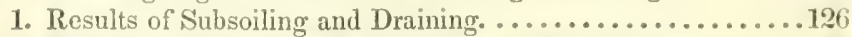

2. Failures in Subsoiling in Adhesive and Heavy Soils........

3. Success in Subsoiling Sandy and Light Lands...........128

4. Success of Subsoiling on Thin, Peaty Ground............ 132

5. Importance of Subsoiling and Draining, and their Applica-

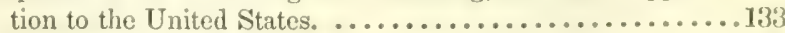

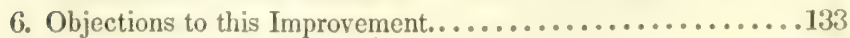

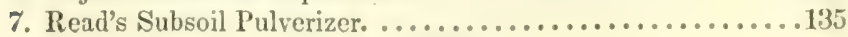




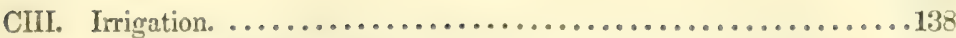

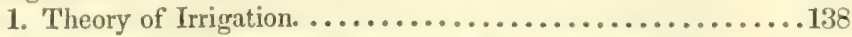

2. General Principles and Directions for Irrigation. .........140

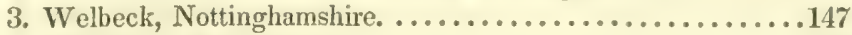

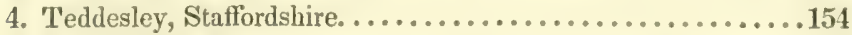

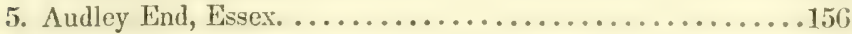

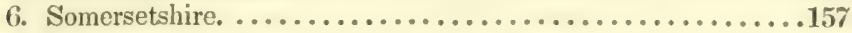

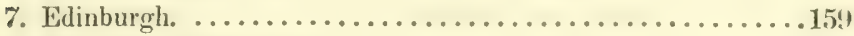

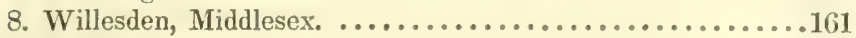

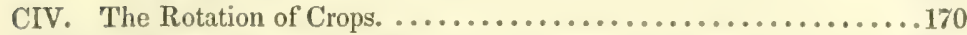

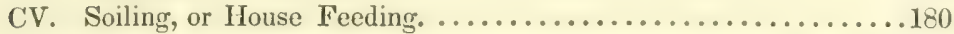

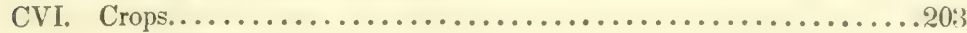

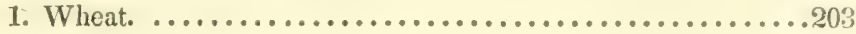

EIGHTH REPORT.

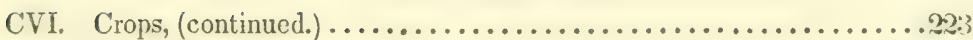

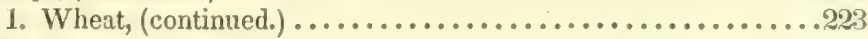

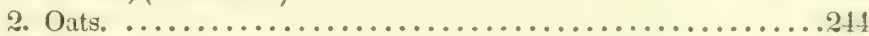

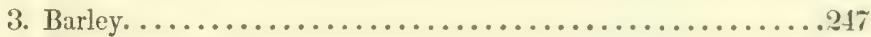

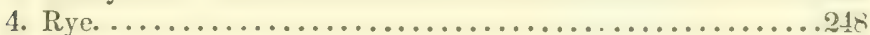

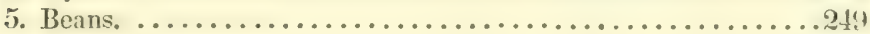

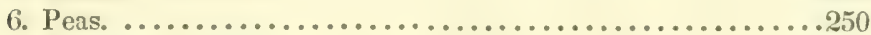

7. Vetches or Tares.............................251

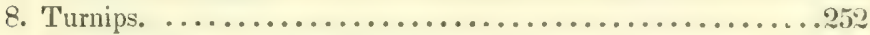

9. Potatoes, Beets, Carrots, Parsnips. .................257

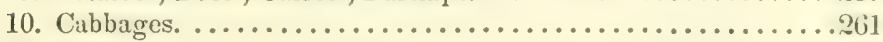

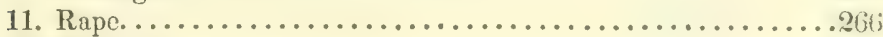

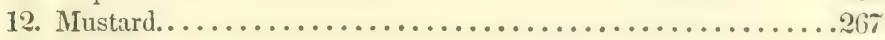

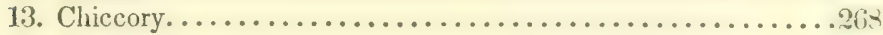

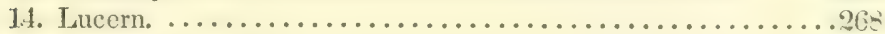

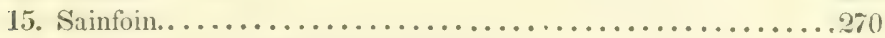

16. Crimson Clover, (Trifolium Incarnatum.) ............272

17. Whin, Furze, or Gorse, (Ulex Europaus.) ...............272

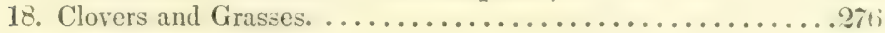

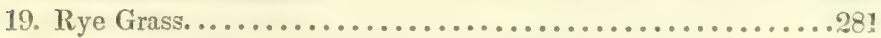

20. Orchard Grass, or Cocksfoot, (Dactylis Glomerate. .........282

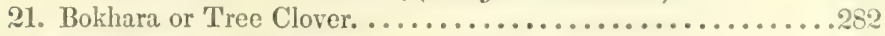

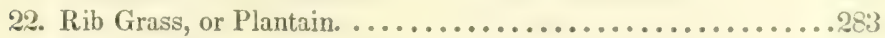

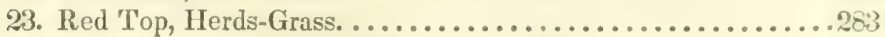

24. Millet. ...................................

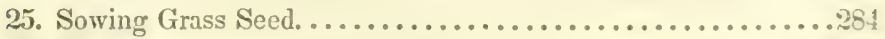

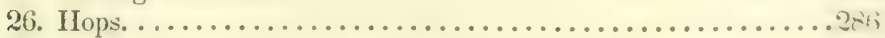

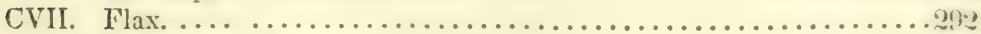

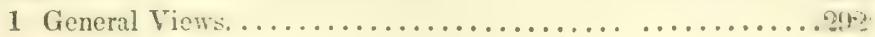

$$
a^{*}
$$




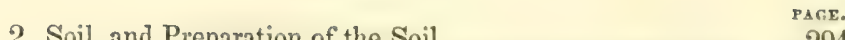

2. Soll, and Preparation of the Soil. .....................294

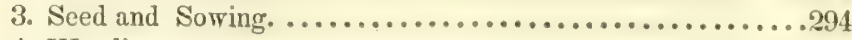

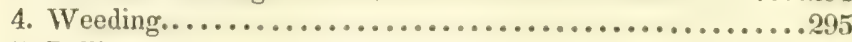

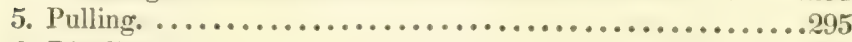

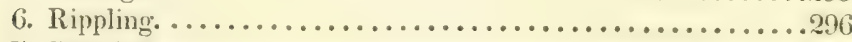

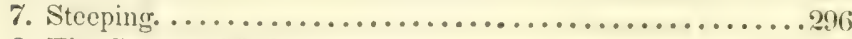

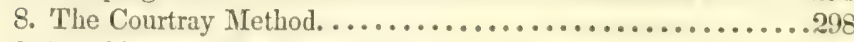

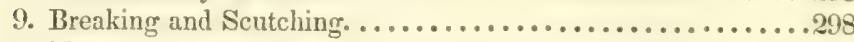

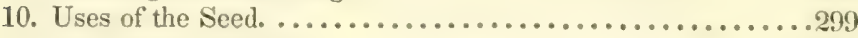

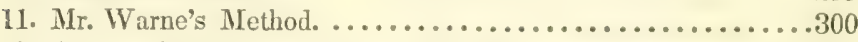

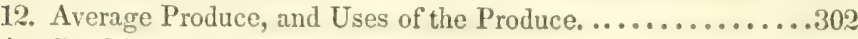

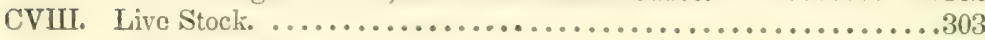

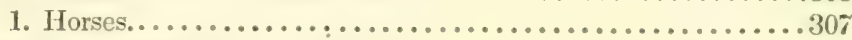

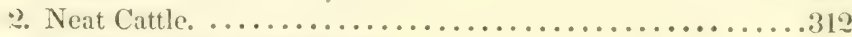

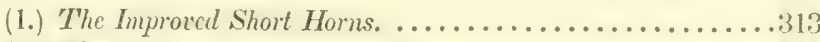

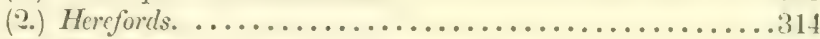

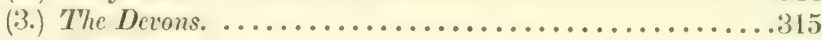

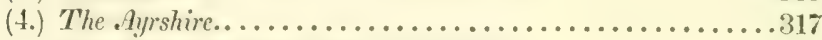

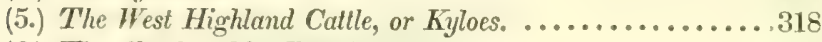

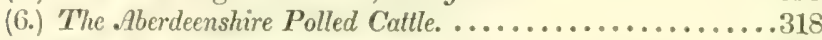

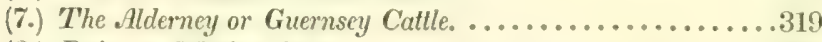

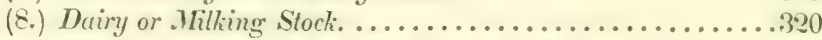

(9.) Improvements in Relation to the Lnited States. ...........399

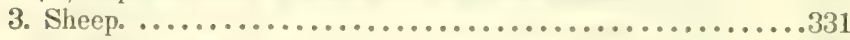

(1.) Farious Brceds. ................................

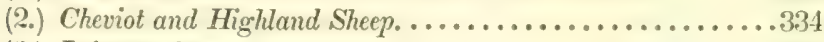

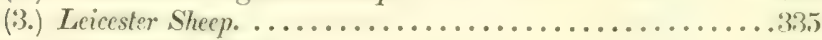

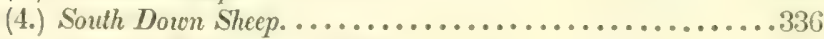

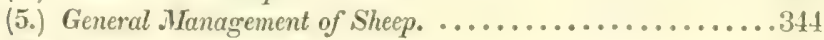

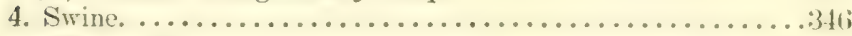

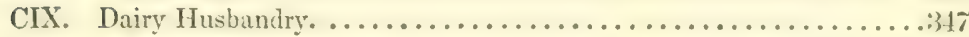

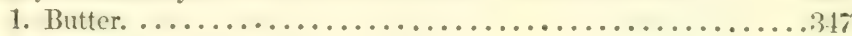

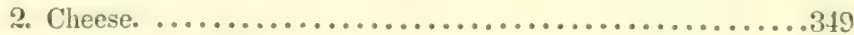

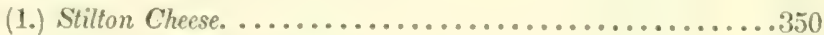

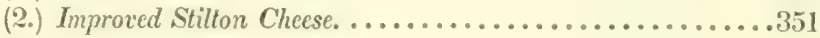

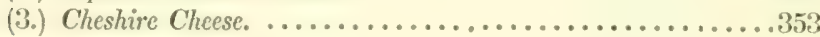

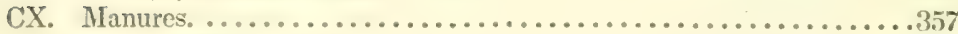

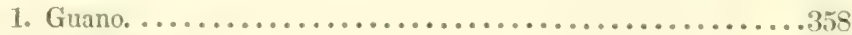

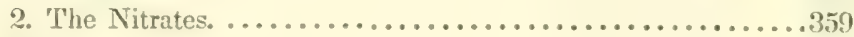

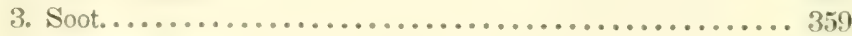

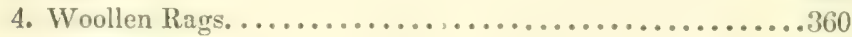

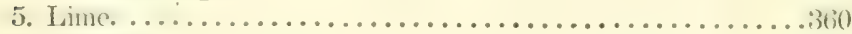

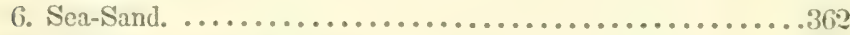

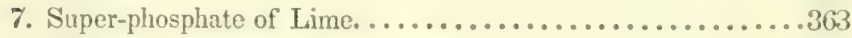

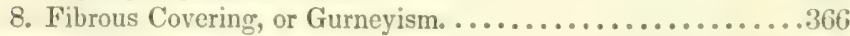

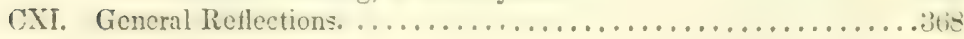




\section{NINTH REPORT.}

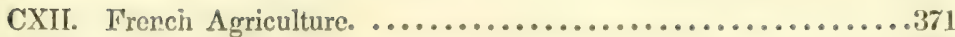

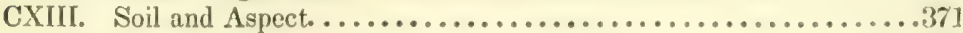

CXIV. Crops.................................. $37 ; 3$

CXV. The Forests of France. ......................... 373

CXVI. A French Landscape. ............................. . . .

CXVII. The French Peasantry. .......................... 37.7

CXVIII. Size of Farms and Division of Property. ................ 377

CXIX. Measures of the Government for the Improvement of Agriculture. ..............................

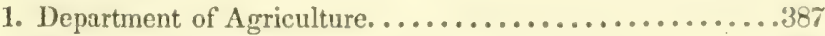

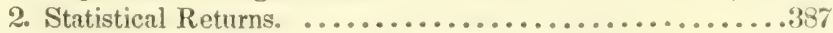

3. Inspectors of $A$ gricultural Districts. . . . . . . . . . . . 388

4. Importation of Improved Stock. ... . . . . . . . . . . . 388

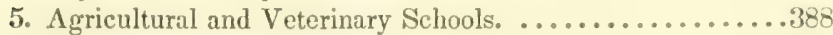

6. Agricultural Societies and Show........................ 389

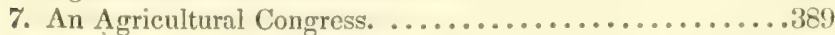

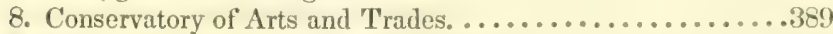

9. Society for the Improvement of Wool.................. 390

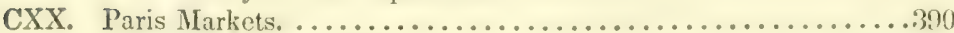

1. Corn Market. . . . . . . . . . . . . . . . . . . . . . . . . $3 ! 0$

2. Meat Markets...........................................

3. Markets for Eggs, Butter, Cheese, Vegetables, Fruits,

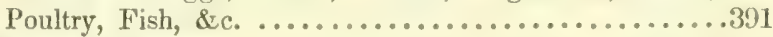

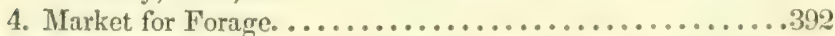

5. Ilorse Market. . . . . . . . . . . . . . . . . . . . . . . . . . . 39:3

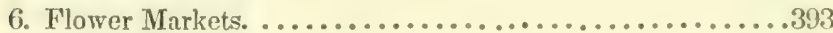

CXXI. The Culture of Flowers. - Botany. ....................394

1. The Floral Magnificence of England. . . . . . . . . . . . . 397

2. The Flower Gardens of Paris. - The Garden of Plants... . . 398

3. The Gardens of the Palaces. . . . . . . . . . . . . . . . . . 399

4. Rural Embellishments in France, Holland, Belgium, Ger-

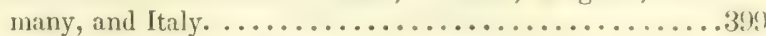

CXXII. Abattoirs, or Slaughtering Houses. ...................406

CXXIII. The Filth of Paris. ........................410

CXXIV. Night Soil. Poudrette. .........................414

CXXV. Agricultural Education............................419

1. School at Grignon. . . ........................ 419

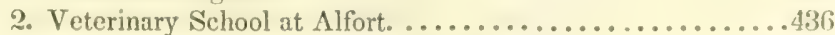

3. Agricultural Colony at Mettray...................440

4. Colony at Petit Bourg. ........................443

CXXVI. Crops........................................

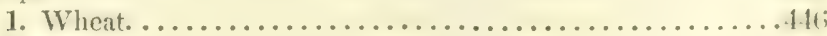

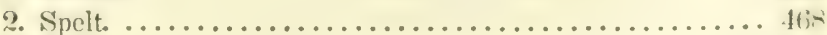

3. Ryc. .............................

4. Barley. ................................ 472

5. Oats................................ 47

6. Meslin, or Méteil. ............................... 477 


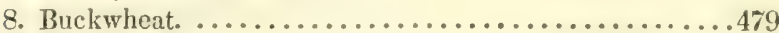

9. Millet...............................479

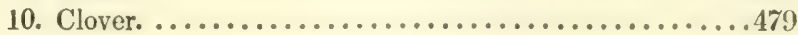

\section{TENTH REPORT.}

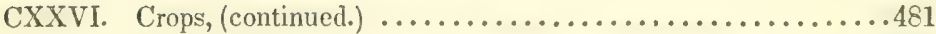

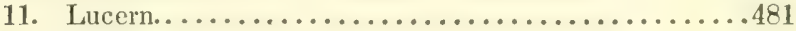

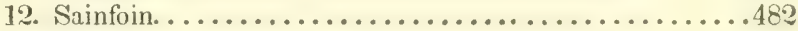

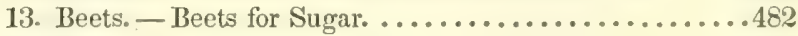

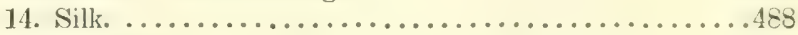

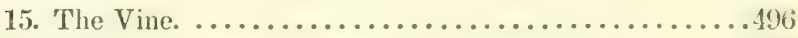

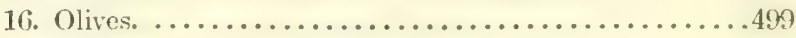

CXXVIr. General Views of French Agriculture. ................50

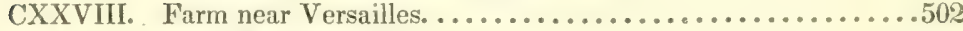

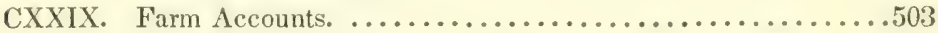

CXXX. Agriculture of Belgium and Holland.................506

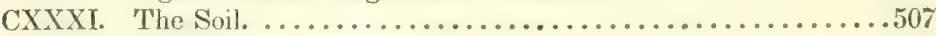

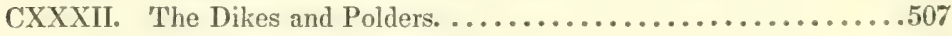

CXXXIII. The Water Machinery or Mills. ...................510

CXXXIV. Flemish Agriculture............................

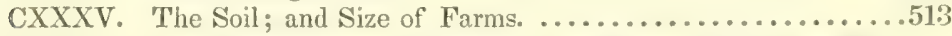

CXXXVI. The Cultivation of the Soil, Trenching, Ploughing, Ma-

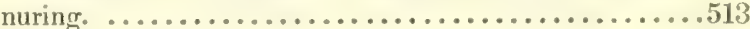

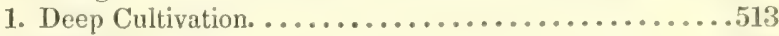

2. Subsoiling...........................

3. Draining. .................................

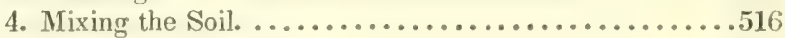

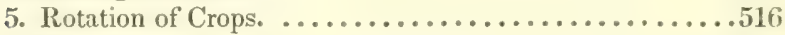

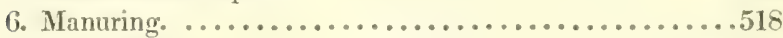

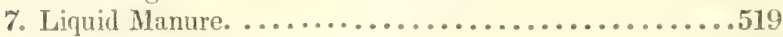

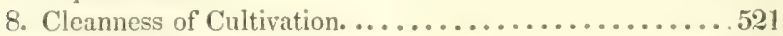

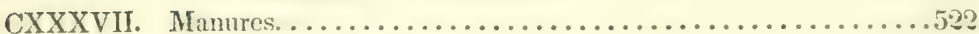

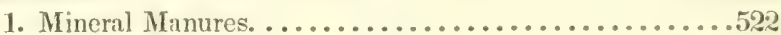

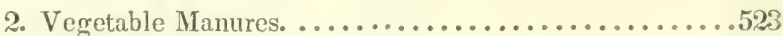

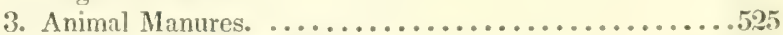

4. Liquid Manures, and Means of saving them. .........529

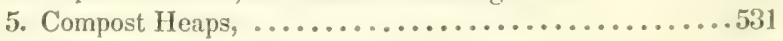

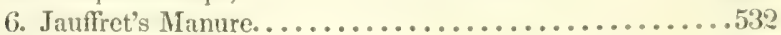

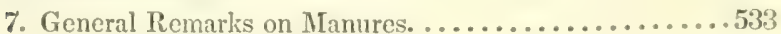

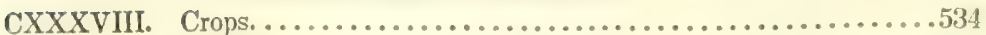

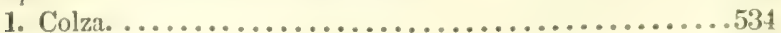

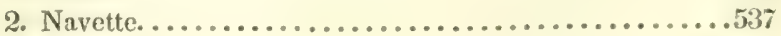

3. Poppy................................. 


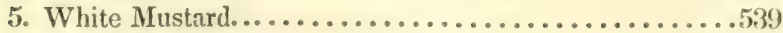

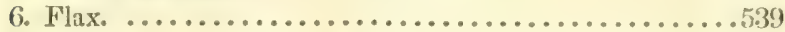

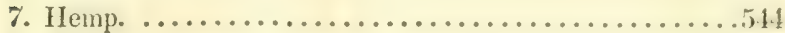

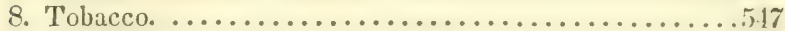

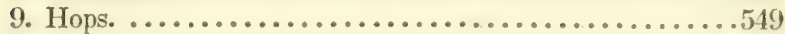

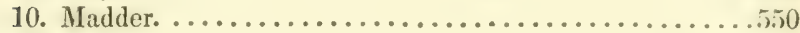

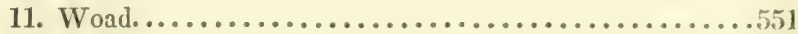

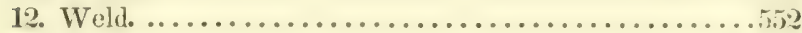

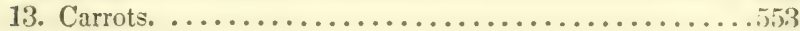

CXXXIX. Implements of Husbandry. .......................

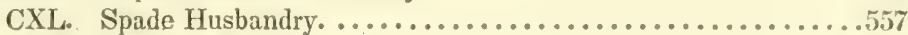

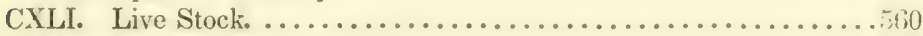

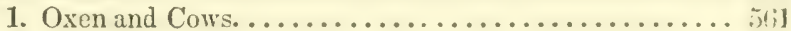

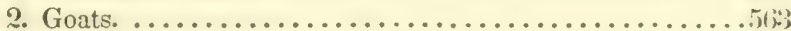

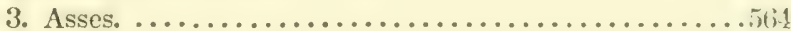

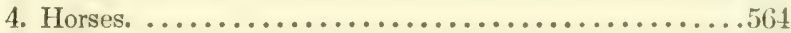

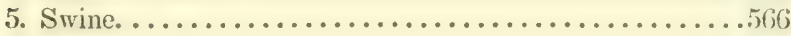

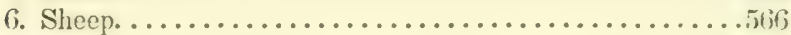

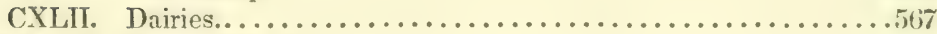

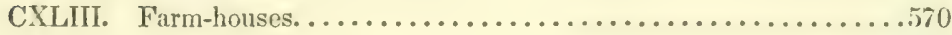

CXLIV. Swiss Farming. ..............................

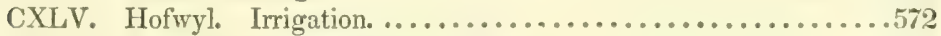

CXLVI. Lodi's Benevolent Establishment..................... .574

CXLVII. Institution for reclaiming Vicious Children............576

CXLVIII. Condition of the Poor and Laboring Classes. ............576

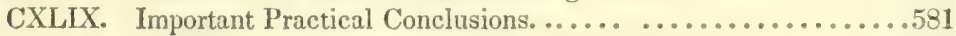

1. Thorough Draining and Deep Cultivation............581

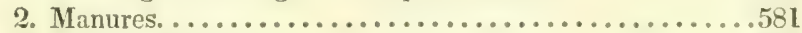

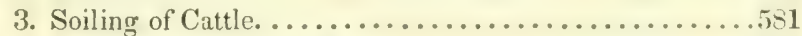

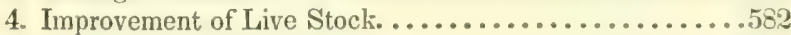

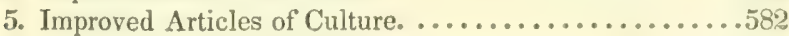

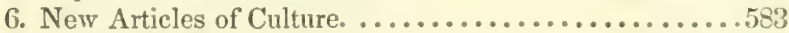

Aprexdix - I. II. Select Farms.............................. 587

\section{STEEL ENGRAVINGS.}

Three South Down Wethers. ........... Fronting title page to second volume. Three South Down Rams................. Frontispiece to Seventh Report.

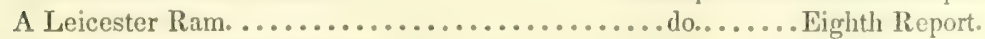
Three new Leicester Wethers. ..................... Ninth Report.

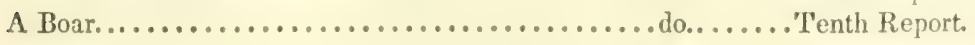




\section{WOOD CUTS.}

PAGE.

Plans of Draining at Scampton. ......................... 72

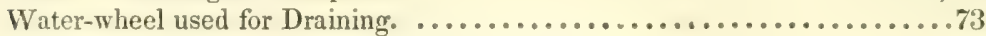

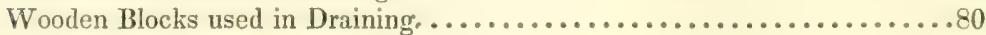

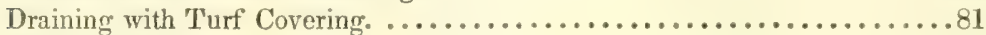

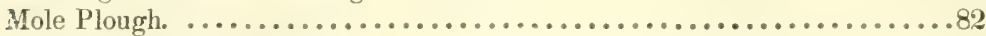

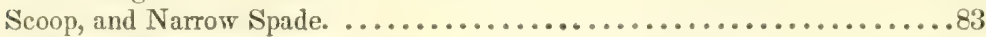

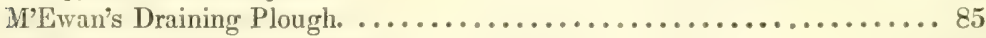

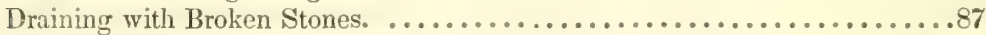

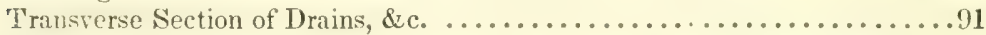

Transverse Section of Drains, \&c., with Sketches of Implements used in

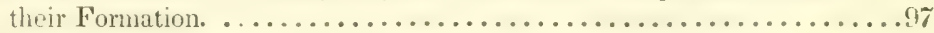

Plan of the Thorough Draining on Part of the Townland of Carnesure. ....120

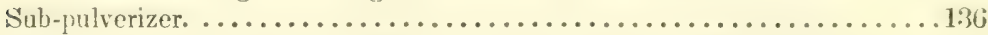

Plan of a Part of the Irrigated Meadows in the County of Nottingham. .....149

An Elevation of a Shuttle or Gate, for the Regulation of the Passage of

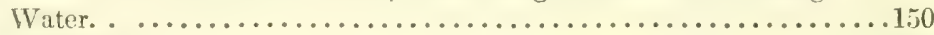

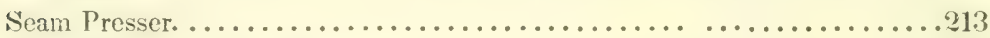

Crosskill's Patent Clod-crusher. ............................214

Garrett's Patent Horse-hoe. ...............................223

Garrett's Patent Drill for General Purposes. .....................225

An Implement for Dibbling. . . . . . . . . . . . . . . . . . . . 229

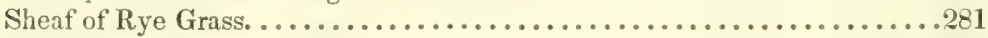

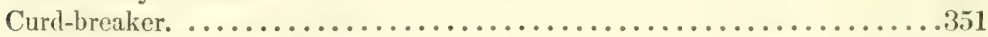

Agricultural Colony at Mettray..............................

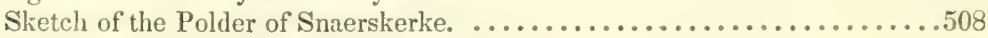

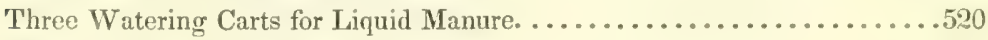

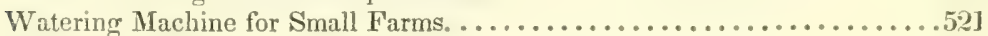

Plan of Urine Cistern. ....................................530

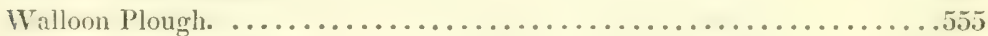

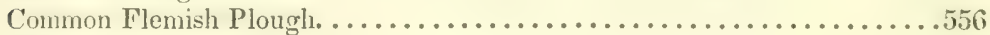

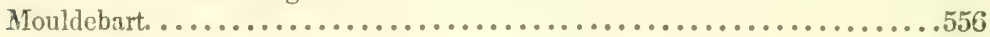




\section{PRELIMINARY OBSERVATIONS.}

AGriculture is the first and most important of all arts. Though not more honorable nor more innocent than many other arts and professions, yet it is perfectly innocent, and is as honorable as any. That likewise may be said of it which can be said of few others, - it is essential to human subsistence. We shall find few persons in the community who do not at once assent to this ; but often the assent is merely formal, and is not that deep and established conviction which should, much more than it does, prevail throughout the community; and especially amongst those who, gifted either by talents or station, have most concern in moulding human destinies, and in adjusting the interests and forming the condition of society.

The affecting and extraordinary events of the last two years should have their due influence upon every reflecting mind. In a single country, by the loss of a single crop, at least five hundred thousand persons have perished, amidst the accumulated horrors of starvation, or the diseases engendered and aggravated by fumine. Ireland has its millions of fertile acres untilled, and its millions of strong hands unemployed. Had the agriculture of Ireland been what it should be, this terrible event - and one more terruble does not darken the pages of history - could not in all human probability have happened.

The essential character of the agricultural art is constantly pressing itself upon our attention. I have had from my childhood an inclination for rural pursuits. I have followed the plough many a day, with a freedom and a buoyancy of spirit which seemed to have no counterpart but among the winged denizens of the air, who hovered around me, and with their thrilling notes cheered me on my way, and made the woods echo with their melody. I have cast the dry seed into the teeming earth, and watched its first bursting above the ground, and its gradual progress to maturity, recompensing every grateful attention bestowed upon it, until it poured its ripened treasures into my lap, with a grateful, and, I may add without presumption, a religious elevation of soul, which no language could adequately express. 
We may be told that agriculture is a purely material and sensual art, and does not deserve a place among the humane arts. To a mind material and sensual in all its habits, every thing becomes material and sensual in the lowest and most degrading sense of those terms. But its rational pursuit is not incompatible with high intellectual attainments and the most refined taste. Whatever occupies and absorbs the mind exclusively, is, of course, unfavorable to any great excellence in other pursuits. Agriculture, pursued as a mere branch of trade or commerce, or a mere instrument of wealth, will be found to have influences upon the mind, narrowing and restricting its operations and aspirations, corresponding with any other of the pursuits of mere avarice and acquisition, and which even those of the learned professions, when pursued wholly with such views, are sure to have. But when followed without exclusive views to mere gain or profit, it is far from being incompatible with a high state of intellectual cultivation. Many of the sciences are the handmaids of agriculture, and serve as well as ennoble it. Its practical pursuit, though it occupies, yet it does not exhaust the mind; but, within certain limits, inspirits and invigorates all its faculties. A spiritual mind may spiritualize all its operations; a religious mind sees, in its wonderful and curious processes and their marvellous results, many of the adorable miracles of a beneficent Providence. That a profound study of the agricultural art, and an intimate acquaintance and familiarity with its practical details, are not incompatible with a high degree of intellectual improvement and cultivation, we have too many living examples of this union to leave us to doubt; and the immortal names of Cicero, Bacon, and Washington, show, from their own assertions, that minds highly gifted of Heaven have found their richest pleasures in rural and agricultural occupations and pursuits; and in company with many others, in ancient and modern times, form a magnificent constellation of learning, genius, and taste, shedding their splendor upon this useful art.

When I hear this art spoken of with a sort of disdain, as wholly sensual and material, I would ask, What is there with which man has to do which is not material and sensual? All his organs of perception are material and sensual; all of that which he calls purely intellectual or spiritual, without the power of giving any intelligible definition of what he intends by it, is directly connected with, moved by, controlled by, and dependent upon, his physical organization; and is vigorous as that is vigorous; healthy only as that is healthy; lives only by being well fed and well cared for. Even the pious clergy, who caution us so strongly against secular pursuits, and against seeking things earthly and temporal, without the labors of the husbandman, without beef and bread, without wool and silk, without milk and honey, since manna has ceased to come down 
from hearen by night, and the rock no longer pours forth its crystal treasures at the touch of the prophet's wand, could give us neither their prayers nor their exhortations; the pious hands could not be raised to IIeaven for its benediction, and the eloquent lips would become dumb.

I believe the agricultural profession is highly favorable to good morals; I shall not presume to say more so than any other; but it will not be too much to say more so than many others. Perhaps it will be said, that the agricultural districts of England and other countries yield their full proportion of crime. I will not peremptorily deny what is often confidently asserted; but I am not ready to concede to it until other proof than $I$ have yet received is furnished. As far as my own personal observation and experience go, my conviction is the reverse of this. Two fruitful sources of crime are to be found in excited passions and in powerful temptations. Agricultural occupations, so far from exciting, tend to exhaust and allay the passions; and the retirement and seclusion of the country present fewer temptations than the tumultuous life, the opportunities for vicious association, the disorderly hours, and the infinite variety of attractions and engagements of city life. Among, however, a degraded population, poor and half-fed, without education, without any interest in the soil, without friends to take an interest in their welfare, without any sentiment of the value of character, without self-respect, accustomed to pass their moccupied time in drinking-houses and in degrading pleasures, and treated and lodged without distinction of sex, and without any regard to the common decencies of life, it is not surprising to find a nursery and hot-bed of crime, where it shoots up in startling luxuriance. My acquaintance with many of the villages and rural districts of England and Scotland satisfies me that the firorable moral influences which might be looked for from rural life and agricultural pursuits, are there found in full operation; and under a system of more general and improved education, and especially under institutions which would give those encouragements to labor which are the most powerful motives, as well as the proper rewards of industry and good conduct, these influenees might be expected to be even more general.

Let me speak of a district or country with which $\mathbf{I}$ have been many years familiar: * it is a purely agricultural district; it contains about three hundred thousand inhabitants; its climate is cold and severe; its soil, with some exceptions, of molerate fertility, and requiring the brave and strong hand of toil to make it productive. It has public and free schools in every town and parish, and several seminaries of learning of a higher character, and where the branches of it

VOL. II.

* The State of Vermont, United States.

\section{$b$}


useful and literary education are taught, at an expense so moderate, that it is placed within the reach of persons even of the most humble means. It has every where places of religious worship, of such a variety that every man may follow the dictates of his own conscience, where religious services are always maintained with intelligence and decorum, sustained wholly by voluntary contributions; and sects of the most discordant opinions live in perfect harmony, recognizing in their mutual dependence the strongest grounds for mutual forbearance and kindness. Taken as a community, they are the best-informed people I have known; and they have numerous and well-chosen circulating libraries in almost every town. 'They have no connection with any large market; and the produce which they have for sale goes through intermediate hands to the great marts. They have few or no poor, and those only the emigrants who may stroll there from neighboring provinces. The sobriety of the people is remarkable; they are every where a well-dressed people; their houses abound in all the substantial comforts and luxuries of life; and their hospitality is unbounded. They understand their rights and their duties, and have often distinguished themselves by an extraordinary bravery and manliness in their vindication and defence. No where is public order more maintained, or public peace better preserved; large portions of the inhabitants never boit a door, nor fasten a window, at night; and in a village of some thousand inhabitants, I have known a garden stored with delicious fruit, with no other fence than one which served as a protection against cattle, as entirely secure from intrusion or plunder, as if it had been surrounded even with a prison-wall bristled with chevanx-defrise. In this state crimes are comparatively rare; courts of penal justice have little occupation; the prisons are often without a tenant, and there has been scarcely a public execution for half a century. From such an example of a community almost exclusively agricultural, I have a right to claim for agricultural and rural life all the beneficial moral and social influences to which its enthusiastic aủmirers pretend.

The present excited state of the civilized world ought more than ever to call the attention of philanthropic individuals and of governments to the immense importance of agriculture. I have been in France during the exciting scenes of a political revolution, in which I have seen very many thousands of workmen without the means of support from their labor, and large bodies of them actually dependent upon public charity for their daily bread. It is not the dangers to public liberty and order, growing out of such large unemployed and destitute multitudes, which so much disturb me, as the actual suffering to which they are exposed, and the melancholy future that lies before them. In London I have encountered, with an extreme depression of heart, thousands of squalid, ragged, 
nuserable poor, without resource but from crime or charity. $\Lambda$ distinguished manufacturer in one of the most industrious counties in England, states that there are at least five hundred thousand operatives without employment, and many on the borders of starvation: tradesmen and professional men will tell you that every trade and profession is overstocked; and one is daily saluted with the melancholy, not to say presumptuous exclamation, that there are too many people. This reminds one of the sad shipwreck of the French frigate, the Alceste, when many of the wretched survivors, who were floating upon a raft composed of fragments of the ship, deemed it necessary to their own safety to drive by force a large portion of their suffering companions into the seaa sad and horrible alternative.

It would be more than absurd in me to attempt to prescribe a remedy for evils upon which so many sagacions heads and philanthropic hearts have concentrated without success their powerful energies. But I will point out what I deem the true cause of this great evil, and leave to wiser minds to suggest a cure. One thing is certain ; as matters go on, the evil must extend itself, and become every day more aggravated and terrible, unless some remedy is devised. The remedies for the wretched, or, if not wretched, the unfortunate condition of the laboring classes, which have been proposed in Paris by men whose good intentions I would not distrust, and which have been so fully and publicly discussed, are absurd, impracticable, and mischievous. The interference of government in limiting or fixing the hours of adult labor; in attempting to establish a rate of wages irrespective of the time employed; in proposing to equalize the wages of all trades, and determining the same rate for the skilled and the unskilled, the active and the indolent; the proposition to furnish the unemployed with work at the national expense, and to destroy private competition by the establishment of national workshops, - are all of them attempts which are sure to defeat themselves, and which are as impracticable for the end which they propose, as to attempt to chain the wind, or to stop the flowing of the tide. None of them touch the true cause of the evil.

Must we affirm, then, that there are too many people in the world? and that thousands and millions are born into it for whom there is no place at the table of a beneficent Providence? Why, in France there are more than nineteen millions of untilled and unoccupied acres, and in England more than cight millions, all capable of yielding food and clothing to countless human beings; and here and in other lands there are millions of acres, for the want of labor which might be applied, that produce not a moiety of what they might be made to produce. In ancient Rome, seven acres were the ordinary size of furms on which a family might be sustiined. In Flanders, on a soil which was once 
sterile, but which human labor has made productive, two and a half acres will give ample support for a man and wife and three children, or what is considered equal to three grown-up men and a half; and add to it three acres more, which this amount of labor is more than sufficient to cultivate, and you add a considerable surplus for other purposes.

'The great cause, then, of the evils complained of, is, that the cultivation of the earth is deserted; and that such innumerable multitudes pour into cities and towns, and, filling every profession and every mechanical art and trade, destroy each other by a competition in articles of which the demand is necessarily limited. There may be too many physicians, too many lawyers, and too many ministers, for them all to get a sufficient and an honest living; and too many hatters, and too many printers, and too many shop-keepers; for, besides that these persons furnish more of a particular article or service than the community require, their work is in general only formal; they only manufacture, - they do not produce; they do not, like the grower of bread and of clothing, create that which may be said to have a substantial and permanent value. For when was the time when there was too great an abundance of the materials - I mean particularly of those which can be kept from year to year - for food and clothing, for human subsistence and comfort? As long as this state of things continues, there must be misery in the community; as the population increases, this misery must increase.

In cities, money becomes the standard of prosperity. Wages are paid in money; money is the instrument of subsistence, of gain, and of pleasure. Avarice, under these circumstances, becomes stimulated to excess, and often leads to crime. Men's happiness becomes dependent upon that which has no intrinsic, but only an arbitrary value, - a value which is always capricious, and continually changing. If men could be induced to cultivate the earth, and, trained to the simple habits of laborious and rural life, be satisfied with what that affords them ; if they would measure their prosperity and wealth, not by so many shining picces of gold or silver, which they have hoarded in their closets, but by the produce of their labor in bread and clothing, and the various and innumerable simple luxuries of life, with which a kind Providence so often blesses the labors even of the most humble, how changed would be their condition! If they could be as well satisfied to breathe the fresh air of their native mountains and forests as the corrupt and pestilential atmosphere of crowded streets and confined dwellings, from which both sun and light are shut out; as well content to enjoy the simple and healthful sports of the country, as the exciting and exhansting pleasures of city life; if their taste conld be better satisfied to contemplate the verdant fields, waving with crops or enamelled with flowers, 
than carpeted and gilded halls; if they could be tuught to prefer slies painted with clouds of brilliant hues, and studded with stars whose lustre never grows dim, to palaces blazing with artificial lustres and adorned with the far inferior magnificence of man's genius and taste; if, indeed, by any possible means, you could induce men and women, and, above all, the young, to love the country; if, in a word, you could keep them in the country by an attachment to its simple labors and recreations, and prevent their crowding cities to repletion, and thus destroying by competition the ordinary professions and trades which prevail there, where so many vigorous young men, and so many fair and blooming maidens rush in, like flies in a summer evening into a blazing taper, to find too often the grave of their health, hopes, happiness, and virtue, $\rightarrow$ what an immense gain would be achieved for morals and for humanity!

But while matters continue otherwise, while such millions of acres remain unoccupied, while such thousands upon thousands crowd into the learned professions, and into the mechanical arts and trades, and fill cities to repletion, under the powerful stimulus of a vain ambition, an inordinate avarice, or a love of excitement, luxury, and pleasure as inordinate and unrestrained, we shall continue to complain of a superabundance of population; and that superabundance, wherever the wave accumulates, will bring with it crime and misery. The decrees of Divine Providence cannot be violated with impunity. Every inordinate and unrestrained passion will yield its bitter fruits. Every infaction of the laws of man's moral constitution will be followed with its just and inevitable penalty.

To my mind, then, the great causes of the evils of which society, especially in the old countries of Europe, is every where complaining, are primarily those which are now pointed out, - an excessive crowding of the professions, trades, and mechanic arts, creating a most baneful competition, and an entirely false assumption, which every where fixes itself in men's minds, that pecuniary wealth is the true standard of prosperity. Competition, which, when excessive, is so hurtful and serious in the mechanic arts ard trades, :s, in agriculture, always a good. Under proper management the earth cannot be made to produce too much. It is a generally received theory, that as yet there has veen no sur r $: 13$ produce; that what is grown in one year is, upon an average, only sufficient ior that year; and that one year's entire failure of the crops would cause the destruction of the human race. I shall not speculate upon this theory, which, possibly, may be well founded, but which Heaven forbid that it should be put soon to experiment. In some years there may be a surplus of some products, and then there may be a deartl of others. But $I$ have never known too much grown: I have never known the great mass of mankind enjoying too much bread, 
or too much clothing, or too many of the substantial comforts of life. If they get the conforts, or their substantial necessities are supplied, then certainly we should desire that they should have the luxuries of life in addition, - above all, those simple luxuries which are the produce of their own honest labor, and to which that circumstance alone will always give a peculiar zest.

Can any thing be done to remedy or abate this great evil, and to turn aside this rushing current, which threatens to accumulate in such masses of frightful misery? This is a great inquiry for the philanthropist, and for all governments which have at heart the only proper object of government, that is, the welfarc of the governed. The Divine Providence often punishes human cupidity and madness by its judgments; but war, disease, famine, and floods, which sweep away their tens and hundreds of thousands, are dreadful curatives. They seem only temporary in their operation. They lay waste instead of fertilizing. They make man's heart sink within him; and they leave behind them nothing consolatory or hopeful. No reflecting mind, at least no mind with any experience of human life, will suppose for a moment that any effectual remedy can be at once discovered or applied. It is only the madness, or enthusiasm, if the milder term is more fitting, of a French revolutionist, which dreams that the whole form and relations of society can be suddenly changed, and that the next morning's sun shall rise upon a cloudless sky, bringing back the golden age, dispelling all the fogs and mists of night, drying up all the sources of human misery, and pouring out a flood of universal peace, plenty, and happiness.

While human weakness and passions remain what they are, no complete remedy is ever to be even hoped for. It does not yet appear that Heaven designed that man should realize an optimism in this world. To our humble views it seems to be the aim of Divine Providence, by the limitations, uncertainties, imperfections, and trials of this state, to stimulate a virtuous ambition, and to arouse the minds of the well-disposed to all possible exertion to ameliorate the condition of their fellow-men. There is one great encouragement to every philanthropic attempt. Little as any individual, or any combination of individuals, can effect, yet I believe truly that no benevolent exertion, however humble, ever failed to produce some good; and experience constantly shows that seed, which has been cast into the ground, may lie long concealed, may not show itself above the surface even during the lifetime of those who planted it, to gladden their eyes, yet it may yield, though a late, an ample harvest.

Every one knows the power of public opinion, and how all the world are influenced by fashion, or what is called general sentiment. I have heard of a man who was asked, as is common on leaving church, "how he liked the preacher." His honest reply was, that "he did not know; he had not heard any body 
say." This homely anecdote illustrates a striking element in the human character, and shows how much our judgments, and consequently our actions to a certain extent, depend upon the rank which most things hold in public estimation.

I wish to see an agricultural life, much more than it is, the choice of men of fortume, of influence, of talents, occupying the higher positions in society; and this, not as mere dilettanti or amateurs, but as plain, active, practical husbandmen; men, not merely to come on deck in some fine sunshiny day, to admire the ship with all her canvass filled, and all her streamers flying, as a beautiful object of art, and, in a spasm of poetical frenzy, to enjoy the deep green of the ocean, and its graceful undulations, and its ruffled waves; but who understand perfectly the art of navigation, who "know every rope in the ship," the nature and stowage of the cargo, and the place and duties of every man in the company.

I have devoted weeks, and montls, and years, in my humble way, to recommend this noble art, to vindicate its claims to the attention of those who have at heart their own and the welfare of the community, to show that it is a source, if not of large, yet of reasonable profits; that as an occupation it is as honorable as it is useful ; that it conduces to health of body and peace of mind; that rural pleasures are, to a well-disciplined mind, among the last to cloy and exhaust it, and wholly pure and innocent; but especially, that a strictly agricultural life, under those reasonable limitations which apply to every other pursuit, is not incompatible with the pursuit of science and the cultivation of a refined taste; so that men of fortune, talents, and liberal education, who now sacrifice their fortumes in the idle pastimes and frivolities of city life, and their health and peace of mind in its feverish excitements, and the competitions of a diseased vanity and ambition, would find in the simple and hospitable habits of rural life, health and vigor of body and mind, and that independence of money and of time, and opportunities for general reading, or the prosecution of any favorite science, which it is almost impossible to find in the crowded haunts and the eternal and ever-varying round of city engagements and pleasures. The most gifted minds .ccompish comparatively little, and fall far short of what might be hoped and expected. The most humble contributions may not be without avail in affecting the mass of public opinion and sentiment. $I$ am happy in thinking that I have sometimes struck a sympathetic chord in some generous minds; and under any and every discouragement, I console myself with the perfect and serene consciousness of having labored at a purpose wholly disinterested, innocent, and useful.

What governments should do in the case, is a most important question. A 
great portion of the governments which have existed, have been little else than an unmitigated curse to mankind. The accumulation of wealth, the acquisition of territory, family aggrandizement, purposes of purely selfish ambition, the mere pomp and luxuries of life, military domination and despotism, have been almost the sole purposes aimed at by the governments of the world. The only legitimate purposes of government are the security and welfare of the governed; but how little have these been regarded! how often entirely overlooked! Holding, as I do, all offensive war, of every description, and under any pretext, as a crime against humanity and against God, one's heart bleeds at the recitals of history, which seem little else than recitals of bloody conquests and human slaughter, of wasted fields, of famishing millions, and of sacked and burning villages. If the millions and millions of laboring hands, of sacrificed lives, and of hardly-earned treasures, which have been worse than squandered upon these wicked objects, had been devoted to the subjugation and cultivation of the waste places of the earth, and, instead of attempts to destroy, society had devoted itself to attempts to save life, and to the production of food and the multiplication of the comforts and innocent luxuries of mankind, how different would have been the result!

What an extraordinary moral anomaly, if so it may be called, does France at this moment present - a nation on the verge of bankruptcy, burdened with excessive taxation, with an army of four hundred thousand men, and more than nineteen millions of acres of unoccupied land, all susceptible of cultivation, and of feeding and clothing millions! Does Great Britain furnish no parallel to this monstrous fact? With an increasing national debt, whose payment is perfectly hopeless, a weight of taxation the subject of universal complaint, millions upon millions lavished upon her armies and navies; worklouses and prisons filled to repletion, thousands and hundreds of thousands upon the verge of starvation; and in the two great islands, resplendent with the brightest lights of civilization, more than thirteen millions of acres of unoccupied land, and even her cultivated soil, with an improved agriculture, capable of sustaining in plenty three times the number of those who now draw nourishment from her breast. What a singular conjuncture of circumstances!

Are not these monstrous facts, deeply distressing to philanthropy, deeply wounding to human pride? We may well ask, If in two of the most enlightened, the most civilized, and the most polished nations which have ever existed, nothing better has been attained, or rather so much remains unaccomplished for human comfort, such a mass of human crime and misery remains unreached and unalleviated; have we not some reason to ask, what are the blessings, and what are the triumphs of civilization? IVe have a right to demand whether the true 
ends of government and society have been answered; - whether it has really reached the limits of its power for good; and whether it has not yet to study the arts of peace and the public welfare. The expenses of fortifying Paris and of providing its arnaments, would have converted a whole department into a garden, teeming with the substantive comforts and luxuries of life. The enormous expenses of the wars, under the empire, of which now little remains but triumphal arches stained all over with hunan blood, and splendid monuments to the glory of one of the great butchers of the human species, would have converted the whole of France into a fruitful field; planted every where schools, churches, colleges, and smiling villages; filled her every where with the industrial arts, and with monuments of taste; banished, under the blessing of Heaven, all want, where there was industry to collect, and frugality to use the products of nature's bounty; and put it in the power of every one of her thirty-six millions of people to sit down in peace and comfort under his own vine and fig-tree. The moneys expended in the naval armaments of Great Britain, in the preparations of munitions of war, in the support of her navies and armies in any year of her history, what would not they have done in subduing and making her waste lands productive! The sums expended for her defence of Ireland, for the repression of disorders, in a great measure consequent upon her wants and miseries, and the vast sums bestowed upon that wretched country in charity, the necessity of which springs directly and wholly from its neglected and wretched agriculture, what would not they have accomplished in draining her bogs, in enriching her meadows, in changing her mud hovels into comfortable cottages; in warding of the grim horrors of famine, and in raising millions of human beings, sunk, as I myself have witnessed, in a lower degradation than that in which it seemed possible that human life could be sustained, to the common level of humanity, and even to a high measure of comfort and civilization!

What, then, shall government do to remedy the dreadful evils under which civilized society is now groaning aloud; and one part of God's family is impiously complaining that IIe permits another portion, though with equal rights as themselves, to come into the world; and our cities, from an excessive competition or production in the pursuits of mechanical industry, or in the learned professions, are every where teeming with masses of misery and crime? I do not say that an extended and improved agriculture would prove the only remedy: nor that it would prove a certain remedy; but I believe it would prove effectual to a certain and large degree; and I demand to know what single remedy will prove more efficient. To whatever degree, be it more or less, to which it is extended, it increases national wealth; it multiplies the means of subsistence; 
it withdraws men from the competitions of trade and manufactures; and, above all, it attaches men to the soil, and so far gives a pledge of order, loyalty, and patriotism.

The efforts of government, then, should be directed to give every possible facility and protection to this art or pursuit; to render land accessible; to break up those tenures under which, by various provisions, worthy only of a barbarous age, land is kept out of cultivation; to alleviate, as much as possible, the burdens upon land; to assist in all those great improvements, which are too vast for individual effort; to diffuse agricultural knowledge; to promote agricultural education; to learn and translate the improvements and crops of other countrics: and by honors and premiums to encourage an emulation in the only art in which emulation is not only innocent and harmless, but always useful to all parties; and thus to stimulate cultivation and improvement in every branch of this art, and induce habits of domestic economy, by every practicable means. What governments can do on a large scale, landlords and proprietors may do perhaps more efficiently and successfully within their own domains. May they feel the great responsibility which their situation imposes on them! If any one of the great nations of Europe would give but half the attention and half the expense to the improvement of its agriculture, which it now bestows upon its military preparations and improvements, we might expect an equal proficiency in the one art as in the other. Which should be preferred - whether it be better to save life or to destroy - I leave to the judgment of my readers.

It is now only a few months since I passed a day at Waterloo. I saw, waving with their luxuriant crops, the fields which had been enriched by torrents of human blood: I stood upon the grassy mound under which tens of slaughtered thousands lay entombed. I have a profound reverence for that heroism which bares its bosom in defence of right, justice, and freedom; but I have no respect for that tiger ferocity which delights in human carnage, and that mad enthusiasm which follows, reckless of its own and of other lives, the phantom which men call military glory. The cannon's roar, the waving plumes, the burnished helmet, the bristling bayonets glittering in the sunshine, have no charms for me. I took in my hands a skull pierced by a ball, which the plough had recently turned up. I thought for a moment of the burning passions, the fiery hate, the thirst for revenge, for conquest, and for blood, which had filled and swelled in this little casket, - the noblest production of divine power, - when death instantly demanded the account. Other associations rushed upon the mind. I thought of some once cheerful fireside made desolate; of some aged mother robbed of her staff; of a widow cast friendless upon the world; of orphan children, and of 
weeping friends. And this, said I to myself, is military glory; these are the trophies of war. \& touna the springs of feeling beginning to be deeply moved. I turned my eyes at once to other neighboring fields of conquest, which $I$ had recently left. I had seen millions of acres, by an enterprise truly grand, a courage most heroic, a labor most indomitable, rescued from the sea, and its proud waves repelled; barren sands converted into fruitful fields; and where the ocean held its profitless sway, and the winds, and waves, and tempests were accustomed to spend their mingled and destructive violence, the calmness and security of rural life every where triumphant; fields crowned with plenty, and speckled every where with rejoicing herds; and cities and villages swarming with busy and happy thousands, and rich in all the arts and luxuries of civilized and refined life. I did not need to ask myself, What conquests are the most noble?

I hope my kind reader will not deem these reflections misplaced, as preliminary to the somewhat dry task and the plain matters of fact to which I now invite him. One of the most distinguished agriculturists which England ever produced said, "that the best way of improving agriculture was to go abroad and see what other people were doing." I have been now some time in Great Britain and on the Continent, that I might see what other people were doing, and learn from personal observation the true state of the agriculture and the rural economy of the old world; that I might present to the agricultural community in my own country, and in other places, matters of instruction and examples for imitation, if such were to be found; or subjects of congratulation if their own improvements have already placed them in advance, and left them nothing: to learn. A full survey of European agriculture is a task for many minds, for many years of observation, and for higher talents and acquirements than I could bring to the work. Yet I shall deem it no mean honor to contribute any useful service to so important an object. It will be understood that I enter the field only as a gleaner. It is said that the gleaners often bring home the heaviest and the ripest heads of grain, because these are the first to drop from the stalks. I shall be but too happy if the analogy should be found to hold in my case.

The sketches of French agriculture commence at the ninth report; and these will be followed by, and sometimes intermingled with, sketches of Flenish and Swiss agriculture, and other observations which have suggested themselves in the course of my tour. There may be found some deficiencies, because I mean to state nothing, unless otherwise declared, which has not been verified by personal observation; but, on the other hand, there will be this advantage, that such statements rest upon a responsible authority. My great object will be to 
give, almost exclusively, information of a practical character; but if occasionally there may appear some slight digressions, my kind reader will regard them only as watering-places on the journey, where the traveller loosens the reins and dismounts for a moment in a dry and dusty road, that he may renew his progress with more freshness and vigor 


\section{EUROPEAN AGRICULTURE.}

\section{SIXTH REPORT.}

I PROCEED, in this Report, to treat of other processes than those which I have described in the management of arable land.

\section{XC. - PARING AND BURNING.}

The process of paring and burning the surface of the land has veen practised with great, thongh not always with equal, success in many parts of the country. The objects of it are threefold: the first, to reduce the coarse vegetable matter on the surface to a state of decomposition, that it may be supplanted by a more profitable vegetation; the second, to destroy grubs, insects, and the larve of insects, which infest the soils, and are pernicious to the cultivated crops; and the third, to convert the coarse, vegetable matter on the surface into ashes, for the nutriment of the crops which are to follow. This process is not to be confounded with that, which I shall afterwards describe, of burning clay fo: the purpose of manure and of rendering the soil friable and pervious to the roots of plants.

In the operation of paring and burning, a thin slice, or turf, varying from one to three inches, is taken from the surfice, and, after being sufficiently dried, is cut into pieces of a convenient length, and then piled in heaps preparatory to being burned and reciuced to ashes. 'The turf is cut sometimes with a plongh with a broad share, of the width of the slice desired to be raised, or,

VOL. II. 
otherwise, with a spade made thin, with a flange or wing on one side of the blade, resembling, in this respect, a spade for the cutting of peat, and with a long and curved handle, with a crosspiece at the end, by which it is forced under the sward by a pressure against the thighs of the workman. The work, when performed with the spade, is deemed severe, and it is considered a sufficient day's work for a man to accomplish a quarter of an acre.

The sods, when collected, are piled in heaps of a larger or smaller size, according to the convenience of the operator, pains being taken to form a sort of furnace beneath, in which are placed some brushwood, fagots, or coal, as in the oven of a brickkiln. The sods are piled over this; and, fire being kindled, attention is paid to prevent its blazing out, so that wherever a hole is found, by which the fire might escape, it is immediately filled up with fresh dirt; and, as the fire advances, new sods are occasionally heaped upon the pile; the object being to reduce the whole to ashes by a smouldering fire. It is surprising to find to what a fine state the sods and vegetable matter may be reduced, and how the burning will continue to go on, though the whole seems to be in a state of perfect quiescence. A thorough burning requires frequently a month, or a longer time, for its completion.

'The headlands of a field are occasionally burned without the rest of the field being subjected to the same process. Here there is always an accumulation of soil, and a collection of rubbish, coarse grass, weeds, or bushes; and all these are dug up occasionally to the depth of six or ten inches, and piled in heaps, and burned as I have above described. In cases where the whole is not consumed, the part which is not sufficiently reduced by the action of the fire is transferred to another heap. Two or three pieces of advice are commonly given in regard to the management of this burning. One is, not to make the heaps too large in the beginning, as the weight of the incumbent mass is liable to extinguish the fire, but to heap it up gradually as the firo goes on; the second is, not to allow the fire to blaze out, as clse it would soon burn itself out; and a third is, not to make the fire too hot, as otherwise much of the earth, instead of being made to crumble, and reduced to a friable state, wonld become baked hard, like bricks. 
The ashes, then, of these heaps are evenly spread over the fields operated upon; and this is generally followed by a green crop, such as vetches or turnips, which, under good management, are consumed on the field. Then follows the usual course of wheat, barley, and grass. The amount of ashes, obtained by the ordinary process of paring and burning, has been made the subject of exact calculation, and is so remarkable that I deem it worth stating. "An acre of land, from which the turf was taken in the common mode of paring and burning, appeared to have produced an average of 2660 bushels of ashes, which, at their mean weight of 65 pounds to a bushel, when dry, would give 172,900 pounds, or rather more than 77 tons, per acre."

The subject of paring and burning land has been long matter of warm discussion. Of its advantages, in many cases, there can be no doubt. In the well-cultivated county of Essex, it is a constant and successful practice. $\mathbf{A}$ distinguished farmer states that he has practised it for more than twenty years; and where, when he began the practice, he was able to keep only one, he now keeps six sheep. It has been said that the destruction of the vegetable matter in the soil must necessarily impoverish it; and that it would be much better to bury this vegetable matter: where, by a slow decomposition, it might serve to afford uutriment to the crops to be cultivated. There are, in the first place, some mechanical difficulties in the case. Where a piece of heath land, covered with coarse grasses and low bushes of furze or fern, is ploughed, it is extremely difficult, even by the most severe process of pressing or rolling, to make it lie flat, and so consolidate it that it can be cultivated to advantage. This is stated to have been the fact, on an extensive heath in Surrey, where cultivation, under the practice of paring and burning, succeeded well, but very ill where the land was only turned over without paring and burning. "In the former case, the land was immediately fit for turnips, tares, barley, and clover; in the latter, the tough wiry-bent heath, and divarf furze, kept the land too light and spongy for any crop. Even rolling could not leep it down, for its elasticity raised the soil soon after the roller had passed over it, and it is of so imperishable a nature, that it is likely to plagne the farmer for many years." There are certainly strong reasons, in such cases, for paring and burning fields of this description; but they do not apply to those lands where the regetable matter 
is of a different description, and would, by being covered over, be speedily brought into a state of decomposition. Here the expediency of paring and burning is more questionable.

In the process of burning, it is evident that none of the earthy or mineral constituents, or what are called the inorganic portions of the soil, are consumed. But all the vegetable matter, with the exception of that portion which has become charred in the process, is destroyed. The extreme doctrine of some eminent chemists is, that the humus, or vegetable portion of the soil, is of no importance to vegetation; but universal experience and observation seem to attest that the fertility of soils, with some exceptions, may be ordinarily determined by the quantity of decayed vegetable matter or mould in which they abound. If plants, in fact, derive nothing from the soil but the mineral ingredients which are found in them, yet the humus of the soil may itself be the means of abstracting from the air, and conducting to the plants, the nourishment, the carbonic acid, and the ammonia, which they are to obtain from thence.* The humus of the soil serves to render it more friable; it absorbs moisture from the atmosphere, and it retains heat, and, in these respects, if in no other, contributes to vegetation. $\dagger$ In dissipating this

* "Humus, in contact with air, gives off carbonic acid." . . . . "The capital fact which results from these experiments of Saussure, the deduction directly applicable to the theory of manures, is this - that humus is dissipated when it is exposed to the air ; and that, during the slow combustion which it undergoes, it is a constant source of carbonic acid gas." - Boussingault, p. 323.

"Potash and soda dissolve humus almost completely, causing an evolution of ammonia." - Ibul. p. 321.

$\dagger$ "'There is an important element, which must always be taken into the account in estimating the value of soils, no matter what their special composition; this element is their depth, or thickness. In running a deepish furrow in a cultivated field, we generally distinguish at a glance the depth of the superficial layer, which is commonly designated as the mould, or vegetable earth; this is a layer generally impregnated with humus, and looser and more friable than the subsoil upon which it rests. 'The thickness of this superficial layer is extremely variable. It is frequently no more than about three inches; but it is also encountered of every depth, from three or four to twelve or thirteen inches. It must be held an exceptional and unusual case, when it has a depth of three feet, or more. Nevertheless, we do meet with collections of vegetable soil of great depth, deposited by rivers, washed down into the bottoms of valleys, or accumulated on the surface, as in the virgin forests or vast prairies of America. Depth of mould or vegetable soil is always advantageous; it is one of the best conditions to successful agriculture. If we have depth of soil, and the roots of our plants do not penetrate 
matter, then, by burning, we must look for some compensation in the ashes which are produced, or in the mechanical effects which this burning operates upon the soil. The ashes themselves are powerful absorbents and retainers of moisture, and they answer a valuable purpose in the disintegration, or loosening, of the soil. They certainly, in many cases, operate as an efficient manure. I have seen their effects often, both upon old and new land. In examining the returns of nearly four thousand different wheat crops in Massachusetts, in which, with a view to secure the premium offered by the state upon the cultivation of wheat, it was required to give the mode of culture in detail, I. found, in every case where ashes were applied to manure the crop, the beneficial effects were emphatically affirmed. In clearing new land, it has been the custom to fell the standing wood, and, after it has become sufficiently dried, to burn it completely upon the land. This always leaves a large deposit of ashes on the ground. It is common to plant Indian corn directly upon these ashes, without ploughing the land, and, at the close of the season, at the last hoeing of the corn, or indeed its only hoeing, to sow wheat among it, which, to use the common phrase, is then "hacked in" by the hoe. Some of the largest crops of Indian corn and of wheat, which I have ever known, have been grown in this way. In one case, upon a very large field, the product of wheat averaged sixty-four bushels to the acre. What is the chemical effect of ashes, I believe, is not well ascertained; but I shall presently let those give their opinion who assume to understand their operation. It seems natural to infer, that that which once formed a constituent element in a plant may serve as food for another plant of the same species. 'There may be other uses, which are not so direct and obvious, but equally efficient.

The expediency of paring and burning land must, as I have remarked, depend upon the nature of the soil which is to be

sufficiently to derive benefit from the fertility that lies below, we can always, by working a little deeper, bring up the inferior layers to the surface, and so make them concur in fertilizing the soil. Independently of this great advantage, a deep soil suffers less either from excess or deficiency of moisture; the rain that falls has more to moisten, and is therefore absorbed in greater quantity than by thin soils; and, once imbibed, it remains in store against drought." - Boussingou?t, p. $29 \%$. 
subjected to the process. On light, sandy, or gravelly soils, where the vegetation is thin and sparse, it is strongly objectionable. I will subjoin here an extract of a letter, with which I have been favored, from the intelligent steward of the excellentlymanaged farm of Lord Hatherton, at Teddesley, Staffordshire. "With respect to the trial we made, of paring and burning some of the high heath lands at Teddesley, we prepared two small patches, about half an acre each, in the usual way, in the spring of 1844, upon the highest part of the 'Teddesley common, and the ashes were spread and harrowed when the turnip seed was sown. The other part was ploughed and dressed with about five tons of lime to the acre, and sown with turnips at the same time as the above; but, in consequence of the summer of 1844 being unusually dry, both experiments were deficient. We again sowed the land with turnips last June, and the land prepared with lime has now a decided advantage, and I have not the least doubt it will be much more apparent in the next crop, which will be oats. I have frequently witnessed the experiment of paring and burning waste lands, when they are first brought into cultivation; but in no instance should I recommend its adoption upon dry, sandy soils, which are already deficient in vegetable matter, which is the case with most of the common lands in this neighborhood, particularly the high lands. The crop of oats was grown upon the highest part of the common, after a crop of turnips, for which the land was broken up and limed, as I have before stated." "The crop of oats on this land, of which there were sixty acres, were at the rate of full sixty bushels to the acre - the result of heavily liming the land when first broken up, and then twice eating turnips off it;" (that is, eating them on it, by folding the sheep upon it. - H. C.) "On no other plan than that of taking nothing out of the land, and putting as much as possible in, could such a produce of oats have been obtained from such a soil." **

The lime, in this case, if it were copiously applied, as I saw

* Since writing the above, a very competent friend writes to me thus: "I'he experiment of burning did not answer. All my experience has satisfied me that it will not do on my ground. Nor do I believe that it is a good thing any where, where other means of reducing vegetable matter can be had. I have pared and burned a good deal formerly. It brought good crops, but the land was clearly impoverished afterwards." 
preparations for doing on another part of the farm, may have assisted, as the fire would have done, in the decomposition of the vegetable matter. The lime is advised to be applied always with the ashes, when the surface is pared and burned. They are stated to work well together. A certain gentleman, abont to undertake the office of a judge, was advised, by another very shrewd and experienced magistrate, to give his decisions without giving the reasons for those decisions. Perhaps he saw that his causality was deficient, or knew how often it happens in life that for many exceedingly well-established facts it is very difficult to give any reasons. I avail myself, in this case, of the same sage advice. The effects of lime are in a degree capricious and uncertain. I know that they must follow the general and established laws of nature; but, in spite of the confidence of some men, it does not appear that these laws are yet fully understood. A deficiency of lime in the soil implies the necessity and advantages of its application; but the "quantitive philosophy," as it is called, leaves me sometimes at a loss, when I am told, on the one hand, that the ashes of a crop of clover, on an acre, contain full three bushels of gypsum; and know, on the other hand. that half a bushel of gypsum sown broadcast, in a rainy day; upon an acre of clover, will often very much more than double the crop. In this case, whatever may have been the effects of the lime, or whatever, in any case, may be the advantages of mixing lime with ashes, where land has been pared and burned, (and I am not disposed to deny them,) the advantages of consuming the crops of turnips upon the ground, by folding and feeding the sheep, are not matter of question. A high authority, on the treatment of land which is pared and burned, advises "to apply the whole of the manure produced by the crops to the ground; and to manage it, generally, in the usual course of regularly-cultivated arable land." This corresponds with the shrewd advice. to which I referred in a former number, given in respect to the application of a new artificial manure, which was, that, in addition to the artificial manure, you should apply to the errond the quantity of other mamure ordinarily used in such cultiration : and somewhat reminds one of the mode adopted by the Irish servant, (an Irishman, of course,) whom his master desired to get rid of a light guinea, and who reported to him, with much self- 
gratulation, that he had done it most adroitly by passing it, unobserved, at the turnpike-gate, between two sixpences.

The paring and burning of peat land is always advised, and the ashes to be spread. Here there is an excess of vegetable matter, which, perishing under cold water, and that water usually impregnated with an excess of iron or some pernicious mineral substance, is in an unfit condition for the purposes of vegetation. The coarse grasses, likewise, customarily found upon peat meadows, forming a thick, matted sward, require to be either entirely removed, or thoroughly reduced and decomposed, before a better kind of vegetation can take their place. Peat ashes are stated to have a specific value, which I shall speak of presently. The burning of peat ground, however, requires very great care, as I have sometimes seen very deep and inconvenient holes made in the surface, by the fire having been suffered to proceed too far.

In all cases where it is attempted to bring a soil into cultivation by paring and burning, it is considered indispensable to success, that the land should be drained and laid thoroughly dry. This rule applies to other cases, besides those of paring and burning. I may, as well as not, here, though I shall have occasion to repeat it hereafter, urge upon farmers the importance of laying their land dry, or rather of having the command of the water upon it, in order to a successful culture. Without this, it is idle to expect success. Water, one of the great elements in vegetation, may, by excess, become thoroughly pernicious and destructive, except to those coarse aquatic plants to which it is the natural condiment and home.*

* After writing the above article, I met with some remarks of the distinguished writer on rural economy, Boussingault, to whom $I$ have before referred, which had not before met my eye, but which I know my inquisitive readers will be glad that I should present to them.

"The effect of the imperfect combustion of these pyritic turfs, the product which results from it, explains to a certain extent the beneficial efiects of the practice of paring and burning - an important and widely-spread practice, the utility of which it would be difficult to understand, were it not connected in some way with the production of ammoniacal ashes.

"The useful effects of paring and burning are, in all probability, connected with the destruction of organic matter, very poor in azotized principles; in the transformation of the surface of the soil into a porous, carbonaceous earth, made apt to condense and retain the ammoniacal vapors disengaged during the combustion; 


\section{XCI. - BURNING LAND.}

The burning of the soil is a process somewhat different from that of paring and burning, and, properly speaking, for different objects, though the latter process tends in some degree to the same end. No operation in husbandry, which I have seen this side of the water, surprised me so much as this. Of its expediency, or rather of its remunerative character, I must leave others to judge. In the last particular, the difference between two dollars a week for labor without board, and three dollars a week with board, will be found material. In either case, it will be found that there are few operations more expensive.

'The question which an English farmer, or improver of land, often proposes to himself, is very different from what an American farmer in similar circumstances would propose to himself. The price of land in England is often most exorbitant, £60 sterling, or 300 dollars, per acre, being frequently paid for large farms, and, not seldom, much more than that. The annual rents paid in Great Britain for extensive farms would, in some

lastly, by the production of alkaline and earthy salts, which are familiarly linown to exert a most beneficial influence upon vegetation. These conditions seem so entirely those, the object of which it is to realize by paring and burning, that, in order to make the operation favorable to the soil which undergoes it, the vegetable matter which it has produced must of necessity be transformed into black ashes; when it goes beyond this, when the incineration is complete, and the residue presents itself as a red ash, the soil may be struck with perfect barrenness for the future. The burning, therefore, that was not properly managed, that led to the complete incineration of all the organic matter, would, for the same reason, have a very bad effect in the preparation of the Picardy ashes; which might, indeed, act in the same way as turf ashes from the hearth and oven, but which, deprived of all azotized principles, would not ameliorate the ground in the manner of organic manures."

"I have frequently seen the process of burning performed in the steppes of" Southern America. Fire is set to the pastures after the grass which covers them has become dry and woody; the flame spreads with inconceivable rapidity, and to immense distances. The earth becomes charred and black; the combustion of those parts that are nearest to the surface, however, is never complete; and a few days after the passage of the flame, a fresh and vigorous vegetation is seen sprouting through the blackened soil, so that in a few weeks the scene of the desolation by fire becomes changed into a rich and verdant meadow." Rural Economy, p. 374. 
cases, almost buy the fee simple of lands in the United States, lands much more fertile, and, in the old and settled parts of the country, subdued, well fenced, and with good buildings. Where land now is waste, and produces little or nothing, it is obvious that it would be wiser to expend a sum equal to what would be the full value of the land after its improvement, than to suffer it to remain wholly unproductive; such improvements may, in fact, be considered as creating so much land, as adding so much productive land to an estate. In the United States, where land is abundant and cheap, such expensive improvements, unless on a small scale, and in some most favored localities, cannot be recommended. It would be wiser to abandon land so worthless, and have recourse to better soils, which are easily accessible for prices vastly less than the expense of such improvements.

The process of burning land, of which I am speaking, is applicable only to stiff, clay soils. 'The objects of it are, first, to render it friable, and destroy its adhesiveness, and the second is to create a supply of manure in the ashes of the soil thus burned. The first I can understand; the second seems more difficult of credence.

The process consists in digging, either with a plough or spade, the whole top-soil of a field, and placing it in small heaps, with a furnace or oven under them, where a fire of coal, or fagots, or brushwood may be kindled, and continue to burn until the whole pile is, properly speaking, reduced to an ash-heap, as far as the nature of the substance so reduced admits of being so designated. Where I have seen the process carried on, the depth of soil so dug and burned did not much exceed a foot; but I have been made acquainted with one experiment, where the depth so moved and reduced was three feet. Those of my readers who are fond of mathematical calculations may amuse themselves with calculating the gross number of tons of earth which, on a single acre, must be moved in such an operation; and I think they will be surprised at the result. I know of scarcely any thing like it, except in the case of the old man in the fable, who bequeathed to his two sons a valuable treasure buried in the field, for which they were to dig. Whether avarice or curiosity prompted them in the case to go deeper than this, and to accomplish a more Herculean task than this, we are not informed.

In one case, which I saw, the pieces of clay were baked 
into hard lumps; and a good deal was completely vitrificd, the whole presenting the appearance of the floor of a brickliln after the burned bricks had been removed. The process here had evidently been carried too far, and the experiment disappointed the enterprising undertaker - a failure, for which he suggested many causes besides the true one. I have always found that the strong back - for very strong it must be to bear all that is put upon it - of a certain nameless personage in theology was an exceedingly convenient repository for certain persons to put their sins upon, which their own inordinate self-esteem would not allow them to ascribe to the proper source; so my friend, in this case, had half a dozen reasons to give respecting the season, and other extraneous hinderances, in place of the true reasons why his experiment failed; and, like a brave veteran, the hero of many fights, in the midst of his discomfiture, his heart still glowed with the confidence of ultimate success. Such courage and perseverance deserve a better reward than $\mathbf{I}$ fear he will obtain. There are soine chemists, learned in the highest degree, who speak with confidence of pounded glass being used as a manure; and another, eminent in his peculiar science, spealis of the power of a plant, in its wonderful action of growth, to decompose the sides of the glass vessel in which it is grown, and appropriate portions of it for its nutriment. I believe it. $\mathrm{He}$ is a brave man who will presume to say what cannot be done. A single imprisoned drop of water, by the power of fire or of frost, may rend a mountain asunder. 'The power of vegetable action is as tenacious and indomitable as the Creator could make it, for the purposes for which he designed it; and it is only another form in which that wonderful Power, which can command stones that they shall be made bread, displays itself, that enables the plant, which is itself to become bread to man, to extract, even from the inert stones themselves, its own proper nutriment and substance, and convert them into a principle of life.

I do not know where better than in this place to insert a letter received from a most intelligent and practical farmer in Staffordshire, which will be read with interest, and which relates particularly to this mode of improvement.

"I fear it will not be in my power to give you any satisfactory or decisive information as to the result of burning the Needwood Forest clay sand. What I have done has not been by 
paring and burning the surface, which is, I belicve, pretty extensively done in some parts of England. In that case, I presume, a great portion of the substance burned is vegetable matter, which almost of itself furnishes the fuel for burning the soil. I have ploughed up a fallow-field as deep as the plough would go, perhaps a foot deep, of which three or four inches were clayey soil, and the rest pure clay, and have then with coalslack burned the whole in small heaps, or in rows. This is the third season since it was done; but the two which have elapsed have, from drought, been extremely unfavorable for the cultivation of land out of which every particle of moisture had been burned."

"I have also very imperfectly succeeded in having the burning effected as I should have wished. The clay breaks up in large, rough, solid lumps, and it is extremely difficult to subject the whole to the action of fire, without having a large portion of it reduced to brick, or brick-dust. Under the most favorable circumstances this is difficult, and the difficulty is constantly increased by weather. A violent wind drives through the heaps, rapidly consumes the fuel, bricking the clay in contact with it, and leaving the rest untouched; or a soaking rain, for a day or two, interferes equally unfavorably. The object, I presume, should be to get the fire to smoulder through the whole mass, which no doubt would be more easily effected if it were somewhat of a more loamy character, and had any tendency in itself to carry on the action of the fire."

"In 1843, I had a very full crop of barley from the first half acre, which was burned and spread down early in the spring; and received a good soak of rain. From the next portion $I$ had a very bad crop of potatoes, and from the rest of the field a poor crop of turnips, which were sowed very late, and, from want of moisture, did not come up till they should have been half grown. They were a healthy crop, but very small. Last year I sowed barley, which came up very partially, from want of moisture; and in June, I ploughed it up and sowed turnips, which in all this part of the country (as well as in that field) were, last year, (1844, ) a complete failure. These two years of non-return from the burned land indisposed me to try it for another without the aid of manure. I dunged it, and have now on one half a good growing crop of oats, and on the other a beautiful crop of wheat. 
One land of the wheat was left without manure. It was worse than the rest, but not bad. In the working of the land a vast improvement has been effected by the burning. I sent specimens of my unburned and burned clay to be analyzed by Professor Johnston, in Edinburgh; who wrote to me, after the analysis, that he was quite unable to assign any chemical reason for the fertilizing eflects attributed to it. I told him that I had not any experience myself of its fertilizing effects; and I then sent him specimens of clay, burned and umburned, from Newhall, a colliery distant about seven miles from this place, where I have been shown fields, which are said to have borne six and seven successive lixuriant crops withont a particle of manure, after being burned, having previously been exceedingly unproductive. The clay is in appearance very different from mine, and burns into a very different substance, apparently not having any tendency to burn into brick, but into black and red loam. I have not yet received Professor Johnston's report upon them."

"In the last two years I have burned a great deal of clay, but it has been under different circumstances, and with different objects. In draining my land, nearly the whole material taken vut is pure clay, which I consider unfit to be put in again, in that state, over the tiles. I therefore burn it, and then fill the drains with burned clay, of which about one half then remains, which I cast upon my plough-land to improve its texture, in which way I find it very useful."

Experience is always a valuable instructor, when that experience is intelligent, and carefully detailed. The letter which I have given is, on every account, entitled to respect. I shall proceed to give some other details from another source, the Jomuals of the Royal Agricultural Society.*

Mr. Charles Randell, who speaks of having had much experience in the improvement of cold and heavy soils, by the application of burned clay, has given the particulars of several experiments of this nature.

The first was made with a field of eleven acres of the worst ilescription of clay on the side of a steep hill, "inaccessible to the dung eart, to which it had always been a stranger." It was ploughed in the summer, and he, with the scufle and drag,

* Vol. v. part i. p. 113.

VOL. II. 
brought the clods of couch grass and wiry turf to the surface, which, with the quantity of soil necessary to procure a good dressing of ashes, were shovelled and forked together, and burned in heaps of abont a cart-load each, with wood from the neglected hedge-rows in the vicinity. The weather, he says, was unfavorable, and the work not well done, but the result was satisfactory. The field, after the ashes were lightly ploughed in, was planted with vetches, and these were eaten off the succeeding summer with sheep, and then planted with wheat, which produced more than thirty bushels per acre. It was afterwards laid down to grass, and carries a much heavier stock than before. He says "that, if he finds it go back, he shall plough it again for vetches, having no doubt that it is now capable of bearing a crop sufficient, when consumed upon the land by sheep," (I beg my readers particularly to remark this qualification,) "to enable it to grow as good a crop of wheat as the last."

His next trial was upon a field of sixteen acres, fifteen of which are a strong clay, the remainder fair turnip land. The clay part of the field was exceedingly foul, so that he had two objects to attain - first, to get rid of the conch by burning it in the clods; next, with the ashes so obtained, to render the whole field capable of bearing a crop of swedes. In this case, likewise, he speaks of his success. "The whole, after draining, was limed and manured alike, and the crop was quite as good upon the clay as upon any part of the field. All the swedes were consumed upon the land by sheep; the succeeding barley crop was much better upon the part which had rarely, if ever, been planted with barley before; the seeds (that is, the grass seeds) were equally good; but the wheat crop this year, (1843,) from the excessive growth of straw, went down early, and became mildewed, and, though more bulky than the rest of the field, will not be so productive. 'The field is now ploughed for swedes again; and the clay part is as healthy, and as likely to grow a crop, as that which has always been considered turnip land."

It will not escape observation, that this land last mentioned was drained, and limed, and manured, and all the swede turnips consumed upon it by the sheep, who were, of course, folded upon it. This certainly cannot be considered as niggardly treatment of the land, whatever may have been the effects of the burning. Two other fields are mentioned, in order to show more satis. 
factorily the fertilizing power of ashes, because, to use his own expression, they were not assisted by any other kind of manure. What Mr. Randell means by not being assisted with any other kind of manure, will appear from his account. The field of five acres was a foul bean stubble; the English horse-bean is undoubtedly intended, which, when not cut close, leaves a large amount of stubble. In May, it was skim-ploughed to the depth of about one inch and a half, and all that the plough raised burned with fagots, and the ashes spread. It was then ploughed and scuftled, and rendered perfectly clean; planted with vetches in October; and fed off, the ensuing summer, by sheep folded upon it; and this followed by wheat at more than forty-five bushels per acre. Another field adjoining, of three acres, under similar treatment, produced nearly equal, results, the difference in the wheat crop, which was not quite so heavy, being attributable to the vetches having been eaten off by horses tethered on them, instead of sheep. The difference of the results in the two cases - of feeding with sheep on the ground, or with horses - is quite worthy of remark; but it is much to be regretted that the amount of difference should not have been exactly ascertained, instead of adopting the terms, "nearly equal results," and "not quite so heavy," which imply that the result was matter of conjecture, not of measurement, or at least admit of considerable latitude of construction.

Another experiment of the power of ashes, unaided, to restore exhausted land, (more conclusive, he says, than the former,) was a field of ten acres of exceedingly stiff clay, "in 1839, an awfully foul piece of two years old in grass." He ploughed and planted it with wheat, which was dibbled in, and twice hoed, and gave only sixteen bushels per acre. Afterwards the stubble was skim-ploughed, and attempted to be dragged, but so matted and heavy, it would seem, that this was found impracticable; "it was then parted with forks, and burned; and the quantity of ashes burned could not have been less, upon the far greater part of the field, than from 150 to 200 yards per acre." What is meant by yards, in this case, I must leave it to my readers to conjecture, - I suppose, however, cubic yards. It was then planted with vetches; but such a crop of crowfoot, charlock, and rubbish of all descriptions followed, that it was mowed and carried to the fold-yard. It was then fallowed and drained, and then, in 
the ensuing spring; sowed with barlcy, which produced fifty-six bushels per acre.

The next field consisted of thirteen acres of stiff, but tolerably productive wheat land. It was foul, burned equally well, was drained, limed, and manured, and produced an excellent crop of swedes, no turnips having been grown upon it before. "It has since grown barley and seeds, as good as I could wish," rather an indefinite mode of measurement, "and is now planted with wheat."

All these pieces of land had the ashes burned and spread upon the land, with wood cut from the adjoining hedges, or with inferior coal, and the cost of the process estimated at $£ 310 \mathrm{~s}$, or about $\$ 17$, per acre.

In another case, the same farmer adds, "upon fifteen acres, which were dressed in like manner during the winter, where no attempt was ever before made to grow turnips, in consequence of the tenacious quality of the land, and without the aid of manure of any description except the ashes, and I have had a very excellent crop; and the most extraordinary part of the matter is, that, although the greater part has been eaten of in the months of October and November last, which were very wet, by nearly four hundred sheep, constantly kept upon them, the nature of the soil has been for a time so changed by the ashes, that I have been enabled to plough close behind the sheep, and drill the wheat as fast as ploughed."

He remarks, likewise, what I deem of much importance, that, if the soil be dug and "thrown with the spade in large pieces, a double quantity of coal will be consumed, and the ashes of no more value than so many brick ends. The proper mode is to move the soil with a pickaxe, breaking it all the time as much as possible; it is then put lightly on the fires with a shovel."

What he says of the value of ashes is quite worthy of attention. "That the mechanical effect of ashes, in rendering heavy land friable, has a great deal to do with increasing its powers of production, there can be no doubt; but it is unfortunately as certain, that their effect in this way is not so great in subsequent years as in the first two or three, though it will always be considerable. This is accounted for by the natural tendency of ashes, like lime, to sink into the soil. In a few years, they become incorporated with a larger proportion of earth than at 
first; and their effect in rendering it more easily workable then sradually diminishes; but that their virtues are not to be attributed to their mechanical eflect alone, I have proved by wheeling ashes upon the surface of part of a crop of vetches, when the part so dressed showed, in the succeeding spring, a superiority which was distinguishable as far as the field could be seen, and where the crop was cut (green) while the whole was heavy, that part to which the ashes were applied was completely rotten at the bottom."

"For those who, like myself, have to get a considerable tract of foul and poor clay land into a tolerable state of cultivation, there are, to my knowledge, no means by which it can be accomplished in so short a time, and with so great a certainty, as by burning. Let it be accompanied in all cases by draining; let the first crop be a green one consumed upon the land, and the land will be at once established, and may ever after, at the least possible expense, be maintained in a productive state, provided it be kept clean, and cropped in a fair and reasonable manner."

We have likewise, in this case, the testimony of Mr. Eli Tabrum, who spealss of having practised the burning of land for thirty years, and of having made it a regular course of farming. He commenees on the land by sowing ten to twelve pounds of the best trefoil seed, and from four to six pecks of rye-grass per acre, on the exhausting wheat early in the spring, having it harrowed and rolled in, the expense of which is amply repaict by the autumn and spring feed it produces, enabling a much larger flock of sheep to be liept. There is a twofold advantage in being liberal in the quantity of seed sown; that is, in the quantity of feed, and in the increase of herbage, which materially assist the burning, and much improve the quality of the ashes. It is highly necessary to have the land well underdrained before burning. He adds, afterwards, that if the cultivation "is followed up by effectual burning, about once in six or eight years, with an intermediate coat of yard manure, or folding, it would double the returns of much of the land of whirh he speaks, both in stock and crops.

Another farmer, Mr. Eli Turvill, speaks of burning land as much practised in his vicinity. "The fuel generally used is a good wagon-load of haulm per acre, or brushwood from the hedges, and a portion of bean-straw. Some burn the heaps at $2 *$ 
4 perches square, 40 per acre, and each heap is expected to contain three yards of ashes; some in heaps, at 8 yards square, at $75_{2}^{1}$ per acre, and each heap is expected to contain two yards of ashes. The whole of the ashes are spread, and the land fallowed in the usual way. It is repeated every four or six years, as may suit the rotation of crops. It is an excellent preparation for all kinds of corn, (wheat, barley, \&c. ;) on the thin-skin land, white turnips are grown well after burning; it absorbs the water; the land dries earlier, and can be sown sooner in the spring. The improvement on the crop amply pays for the outlay, as well as leaving the land much better for the following crops. Burning is a fertilizer of the soil, and the oftener it is burned, the more it improves the staple and quality of the land; so far from destroying the soil, it acts greatly to its improvement, and is highly conducive to the growth of the cultivated crops; the effects may be seen more particularly in the clover." *

Such are the accounts of practical farmers, on this important process. Let us now hear what lessons science inculcates in relation to the subject.

Dr. Playfair, the learned consulting chemist to the Royal Agricultural Society, says, -

"By this process of paring and burning, injurious organic matter is consumed. Plastic clays are quite changed in their character, not only by having all their constituents brought into contact with the oxygen of the atmosphere, and thus undergoing change, but the clay itself acquires another character; it becomes absorbent, taking up from the atmosphere ammonia, carbonic acid, and watery vapor, as well as affording more ready access to the nutritious substances which may be dissolved in water. But in this you see nothing is destroyed, and the inorganic elements of the soil are only brought more fully into contact with the absorbing organs of the plants." $\dagger$

We may next refer to the great agricultural oracle, Professor Liebig, on this subject.

"The advantage of manuring fields with burned clay, and the fertility of ferruginous soils, which have been considered as facts so incomprehensible, may be explained in an equally simple

*: Journal of Royal Agricultural Society, vol. iv. part 1, p. 267.

if Lecture before the Royal Agricultural Society. 
manner. They have been ascribed to the great attraction for water exerted by dry clay and ferruginous earth; but common dry, arable land possesses this property in as great a degree; and, besides, what influence can be ascribed to a hundred pounds of water, spread over an acre of land, in a condition in which it cannot be serviceable either by the roots or leaves?

"The true cause is this: The oxides of iron and alumina are distinguished from all other metallic oxides by their power of forming solid compounds with ammonia. The precipitates obtained by the addition of ammonia to salts of alumina or iron are true salts, in which the ammonia is contained as a base. Minerals containing alumina, or oxide of iron, also possess in an eminent degree the remarkable property of attracting ammonia from the atmosphere, and retaining it. Vauquelin discovered that all rust of iron contains a certain quantity of ammonia. Chevalier found that ammonia is a constituent of all minerals containing iron; and that even hematite, which is not at all porous, contains one per cent. of it. Bouis showed, also, that the peculiar odor observed on moistening mincrals containing alumina is partly owing to their exhaling ammonia. Indeed gypsum, and some varieties of alumina, - pipe-clay for example, - emit so much ammonia, when moistened with caustic potash, that, even after they have been exposed for two days, reddened litmus paper held over them becomes blue. Soils, therefore, which contain oxides of iron and bumed clay must absorb ammonia - an action which is favored by their porous condition. They further prevent the escape of ammonia, once absorbed by their chemical properties. Such soils, in fact, act precisely as a mineral acid would do, if extensively spread over their surface; with this difference, that the acid would penetrate the ground, enter into combination with lime, alumina, and other bases, and thus lose in a few hours its property of absorbing ammonia from the atmosphere. The addition of burned clay to soils has also a secondary influence. It renders the soil porous, and therefore more permeable to air and moisture. The ammonia absorbed by the clay or ferruginous oxides is separated by every shower of rain, and conveyed in solution to the soil." *

I have gone thus at large into the subject of paring and burn- 
ing land, and of burning clay, and the value of the ashes of clay, deeming that it would at least be found interesting to my American readers, where the process is certainly rare, if not unknown, excepting on peat lands; and because, likewise, it is a process belonging to English agriculture; but not with any strong expectation of its being adopted to any great extent in my own country, where land is cheap and labor is dear.

The scientific solution of the operation of bumed clay, and of ashes generally, I submit to those who are interested in, and competent to deal with, such discussions. The practical farmer will not fail to observe how much stress is laid in every case, with scarcely what may be called an exception, on the quantity of vegetable matter consumed in the burning, and going to increase essentially the amount of ashes to be applied. He will not fail to observe, likewise, the connection, in some cases, with the burning, of liming, manuring, and folding sheep upon the land, and consuming the produce grown upon it. If he should undertake to burn his soil, it is hoped that his attention will be specially arrested by these points. The value of ashes, the ashes of consumed vegetable substances, is not a thing now to be learned; and how much soever pains may be taken in burning clay, it is quite safe at present to assume that the more of vegetable matter is consumed with it, so much the better for the ashes of the clay. The opening of clayey and adhesive soils by burning them, so as to make them easily worked, and rendering them accessible to air, and moisture, and light, and heat, is an obvious and decided advantage. In their ordinary condition, the cultivation is a work of great labor.

The burning of the grass and rubbish upon the American pairic grounds is always followed by a thickening, and increased Inxuriance, of the succeeding crop. This burning, however, rarely does more than skim the surface, and, except in cases of excessive drought, does not destroy the roots of the herbage. The burning of the fallen trees in the new parts of America, and the successful culture of crops upon their ashes, I have alrcady referred to. In the management of broom coin, (sorghum saccharatum,) on Commecticut River, a crop which leaves a large amount of haulm, many farmers have long been accustomed to burn the stubble upon the ground for the sake of the ashes, rather than either plough it in, or carry it into their barn-yards to be added, in its 
decomposition, to their manure heaps, or to talse pains to cure it, and use it as feed for their stock, for which, when saved in a proper condition, it is as good as the stubble or stover of Indian corn, (zea mays.) The farmers of Long Island, New York, have for years been in the habit of sending to the towns on the sea-shore in New England, for the purchase of the spent or wasto ashes from the soap-boilers and others, and for which they pay what is deemed a high price. They apply it to their wheat lands, sown broadcast upon the young wheat, and say that, without it, they are not sure of a crop. The farmers in New England err in allowing it to be taken from them at any price, unless they can find a substitute in guano, or some other manure as portable. I speak of these facts, however, as showing the universally admitted value of ashes as a manure, a subject to which I shall refer again, when the important subject of manures is treated, as designed.

\section{XCII. - ADMIXTURE OF SOILS.}

One of the most common and obvious suggestions, in the improvement of the soil, is that of rendering, as far as practicable, plastic and adhesive soils free and permeable; and, on the other hand, that of making those soils, which are loose and light, close and compact. In the former case, in order to effect the desired object, draining has been applied with grcat success, and must be regarded as the basis of such improvements. Without draining, indeed, and a complete riddance of the superfluons wetness and moisture, little is ever to be hoped for in any case. In order to effect the latter object, rolling with heavy rollers, and especially treading with sheep, have been resorted to; and several farmers, with whom I have had the pleasure of forming an acquaintance, abandon all expectation of a crop, unless the ground, after being sown, is thoroughly trodden by sheep, which treading, for the purpose specified, may be considered even as more effectual than the application of the roller.

But an improvement of a more substantial and permanent character is attempted by what may be termed an "admixture of 
soils;" by the addition of elay to sandy soils, and of sand to clayey soils. In agricultural books and addresses, I have often seen this method recommended, with a great air of sagacity and confidence, as an obvious process of improvement, of very easy accomplishment, by persons who understand little of practical agriculture, and very imperfectly appreciate the difficulties of such a process. The transportation of soil is among the most expensive operations in husbandry, and can scarcely be expected to be carried on, on a very extensive scale. To convert a clayey soil into a siliceous soil, or, on the other hand, a siliceous soil into a clayey soil, so as deeply and permanently to change their character on any extensive surface, must be left to those great geological changes which are alike beyond human prescience, command, or control. Amendment, rather than change, is all that human skill and ability are likely to effect; and I shall detail in this matter such examples as have come under my observation.

The application of sand to clay, like the application of sand to lime in the making of plasterers' mortar, has, in general, especially if the clay is wet when the sand is so applied, a tendency to give it hardness, rather than to render it friable and open. Where the land is in a state of dryness, and newly ploughed, the application of a limited quantity of sand might serve to render it more open. That this would be the whole effect to be expected from it, and this to a degree uncertain, and that it would effect no chemical alteration in the soil, seems generally agreed. That a portion of silica is essential in the formation of all the cereal plants is established; but in all clays there is presumed to be a sufficiency for this purpose. In peat lands it may be otherwise. A distinguished practical and scientific farmer, the late Mr. Rham, states that he has never known an instance in which the application of sand to clayey soils has been found to succeed in rendering them more porous. The expense of laying on the large quantity of sand that would be required must probably swallow up any profit that could be derived from it. Mr. Pusey, however, showed me an example in which a clay land field in grass had been decidedly benefited by a top-dressing of sand from a neighboring hill. Whether the sand, in this case, had any peculiar chemical properties, from which the benefit of the application was derived, did not appear. 
It is not so, on the other hand, with the application of clay to light soils; and this has been practised in England so extensively, and with so much success, that I shall detain my reader with some prominent examples. Of the application of clay in the improvement of peat lands, I shall speak presently; I now refer only to its application to sandy and light lands, with a view of giving them compactness. The object of applying clay, indeed, may be twofold; the first to produce a closeness of soil; and the second, that of obviating their too great dryness, the property of clay being to absorb and retain moisture both from the atmosphere and that which falls in rain.

One of the most extensive applications of it, which I have witnessed, was on the farm of the Duke of Bedford, at Woburn, a place distinguished, under the care of its present noble possessor, as under that of his eminent predecessor, for a most intelligent, scientific, extensive, and successful busbandry; in all its various arrangements, and the completeness and extent of its operations, surpassed perhaps by no one in the kingdom, or hardly, indeed, rivalled.

The intelligent manager of the place, Mr. Burness, states that he finds "the application of clay to his light soil of great advantage. It makes the straw much stronger, with a better ear, and standing much better up in wet seasons. When the land is highly manured, without being clayed, the crops are liable to fall down, become lodged and spoiled." $\mathrm{He}$ adds, likewise, that he finds claying of great advantage to the turnip crop.

The practice is to put the clay on the clover leys as early as the crop is off, and get it broken in pieces as much as possible before the land is ploughed for wheat. It is also Jaid on land that is under fallow for tumips early in the winter, that is, on land which has been ploughed preparatory to its being cultirated in turnips the ensuing season. This is done that it may have the chance of the winter and spring frosts to become well pulverized before it is ploughed down; and this he prefers to spreading it upon clover leys.

He goes on then to speak of some experiments. "We clayed last summer four acres, and left two acres not clayed on an old sward and light soil. T'he clay was put on in July, and lay all the summer; was ploughed up in November, and pressed," (an operation which I shall describe presently,) "and the wheat 
dibbled into the pressed grooves. In February, we top-dressed the six acres with good farm-yard dung; and, as late as the beginning of Nay, I thought there would not be half a crop, although plenty of ends; but toward the midule of the month the clayed part began to look of a much darlier appearance than the two acres which were not clayed; and, at the present time," when he gave this account, ) he thought, "there was one third part more on the clayed than on that which had not been clayed, although managed in every other way the same."

$\mathrm{He}$ goes on to say that, in Jantury, 1841, he clayed some land which was going to be a turnip-fallow the following summer; and in the month of April, when he began to harrow and plongh the land, the elay broke down and slacked like lime, and worked in with the soil. There was not much apparent difference in the turnip crop that summer, as the other part of the field was sown at a different time, and he was not able to tell the difference; but the ensuing year, he says, "the barley looks much stronger and stiffer in the straw, and stands much more upright, than in the land which was not clayed, where the greater part of the crop is down on the ground, and exposed to be rotted by the rain."

The quantity applied to the acre is generally ahout fifty loads; 1 suppose single-horse cart-loads are meant. If more is to be applied, it is adrised to make the application at sucessire times, as, in his opinion, more given at once would do harm: Nearly all the light soil on the farm of the Duke of Bedford, near Woburn Abbey, has been clayed, and a great deal of it twice; and, in every instance, its beneficial effects have been established. I myself can bear witness to the neatness and:excellence of the cultivation, though I had not the pleasure of being there when the crops were standing upon the ground. The clay may be dug from the pit at any time most convenient for the farmer, and, if turned over once or twice, will mix much better with the soil, though, of course, the expense of the operation must, in such case, be increased. Mr. Burness says, his plan is to dig and cart it on to the field at once.

Mr. Pusey is of opinion that this substance, denmminated clay: contains a great deal of lime, and is, in fact, a stiff marl.

Another eminent Bedfordshire farmer, whom I have the pieasure of knowing: speaks of the application of elay or marl, 
customary in his neighthorhood, as varying from 50 to 150 cubie yards per acre. He deems the smaller quantity preferable at one operation, as it mixes more steadily with the soil, and, though it may not last so long, comes sooner into operation. He has applied it to clover leys in summer, and to turnip fallows at different times. He advises to have it dug in winter, and to cast it upon the turnip land in the spring, when it has had time to dry, and has become lighter of carriage.

We have the testimony of another skilful farmer, a tenant of the Duke of Bedford, who has pursued the practice of claying land to a great extent. Not satisfied with the quality or quantity of his produce, he has clayed 420 acres, in every instance with good efiect. Upon the gravel and sand land he has put forty loads per acre, containing forty bushels per load. On. the moorland, covered with rushes, he has put seventy loads. The time of applying it is directly after harvest, or in winter, if there has been a frost. At the former time, it is done with less labor to the horses and less injury to the land. The clay gets dry, and, as soon as rain comes, it may be harrowed about, when, according to his opinion, it will begin to act beneficially to the land by correcting the acidity, of which most lands have too much, thereby making food for plants of what was inert in the soil, and giving the land that solidity which it required. In one case, he speaks of witnessing the decided advantages from it, after a lapse of fourteen years from its application. He speaks further of having both marl and clay upon his land. He tests their different qualities by applying vinegar, and determines their gookness by their effervescence. In the case above referred to, the clay which he applied would not effervesce on the application of an acid; but, on drying it before the fire, and then applying the vinegar, he found the desired result. This determined him to use it on the land, giving it all the benefit of the sun in summer.

In another case, he applied, in September, 1835 , screnty loads per acre of marl, blue, with some chalky particles among it, nzon seven acres, and left seven acres adjoining ummarled. 'The next year, the oats were very good where the clay was; the succeeding year, with turnips, the crop was good where the land had been clayed: on the other land the crop appeared, and soon perished. In 18.40, the whole field was clayed, and a large crop of barley was obtained throughout. Ife remarlss, "that land will

vol. 11 . 
not always show the benefit in the first crop after the application. Some farmers," he says, "prefer lime to clay, on light land." He deems this an error. Lime will correct the acidity in such land, but it does not give solidity or compactness to the soil, but makes light land still lighter. Besides the advantages to which I have above referred, he considers the application of clay as serving to strengthen the straw of wheat, and to increase the quantity and improve the quality of the grain ; and likewise certainly a most material point - to prevent mildew in wheat, to which the farm was formerly subject. $\mathrm{He}$ is of opinion, likewise, that it prevents a disease to which turnips are subject, called, vulgarly, fingers and toes, which I think is more doubtful; and that it supplies to the soil an element favorable to the growth of clover, of which I believe there can be no question.

It may be thought, in this case, that advantages may arise from the application of marl - in which, of course, there is a considerable portion of calcareous matter, more active than the aluminous element - which are not to be expected from the application of pure clay. This would probably be the case ; but I have seen repeated examples of the application of pure clay, both spread upon grass land, as a top-dressing, and otherwise applied, which have been highly beneficial; and where the material is at hand, and can be procured without a heary expense, the practice may be confidently recommended.

On the farm of Mr. Pym, in Bedfordshire, a very skilful and practical agriculturist, "the whole farm," Mr. Pusey says, "which is a light yellow sand, and which was covered with heath and a gray lichen, the gray moss of trees, - a kind of vegetation indicating a great degree of sterility, - the whole farm has been made. fertile by means of a dark gray clay, which is full of lime, situated at the foot of the sandy hill, and the moderate dose of sixty cart-loads per acre is found to last at least twenty years. On this sandy farm, both turnips and swedes were ridge-drilled, and looked remarkably well."

This practice of marling or claying light land has been long and most extensirely practised in the comnty of Norfolk, a comty which yields, perhaps, to no other in its agricultural improvements, which was the residence, and the scene of the labors and improvements, of that ackinowledged prince of farmers, Mr. Coke, (the late Lord Leicester,) of Ilolliham, and which now presents, as 
I have had the pleasure to witness, some of as good examples of intelligent, exact, and successful farming as are to be found in the United Kingdom. In the cases of marling, to which I shall refer, while the upper stratum, or surface, is light and sandy, yet there is found, at not a great depth, a deposit of clay or marl, which is proved to be highly beneficial, and which, from its being so accessible, is applied easily, and at a moderate expense.

The substance applied is a bluish clay, and found from four to six feet under the surface. Pits are dug, about six feet by three, in rows, in a part of the field most convenient for the application of the material, and least inconvenient on account of the injury done to the fields, and two or three spades' depth of the clay is taken out; the top soil, which in many cases is peat, being thrown back into the open pits. The whole piece thus dug over is sometimes converted into a plantation, where, the roots of the trees extending themselves, and the ground being covered with the waste of the trees, the soil thus dug over becomes consolidated, and ultimately brought into a condition for use.

In most parts of the country, and universally where the land is inclined to wetness, at least before the introduction of $\mathrm{Mr}$. Smith's system of under-draining and subsoiling, in. which all cultivation in ridges is disapproved of, fields are cultivated in beds, or, as they are here called, stetches, varying in width from six furrows to thirty. The practice of one farmer, in Norfolk, whose admirable cultivation is second to none, I have had the pleasure of observing, is to plongh two of these beds outward, leaving a deep trench, or wide double furrow, in the centre, and here, where the clay is near the surface, obtaining it to spread upon the land. In the instructive Report on the Agriculture of Norfolk, published in the Journal of the Royal Agricultural Society, an account is given of one enterprising farmer in Norfolk, who had applied 54,055 loads to a little more than 286 acres of land, or at an average rate of 189 loads per acre. In another case, a farmer clayed a thousand acres twice over, at the rate of forty loads per acre, in the course of eight years. Another farmer applied at the rate of fifty loads per acre. In another case, a great improvement has been effected by trenching, so as to bring the bottom soil to the top, and bury the top at the bottom. "In this case a trench is opened three or four feet wide, 
and two spades deep; the bottom of the trench is then turned up with a spade or three-pronged fork." The surface earth is then thrown back, and a complete inversion of the soil takes place.

In some cases, men are employed, at a season when labor is to be had most cheaply, to marl or clay the lands with wheelbarrows, where the material is near at hand. 'The nearness of the material to be applied, its quality and abundance, and the price of labor, are all elements to be taken into the calculation, where any such improvements of land are to be undertaken, as well as the return to be expected, and the value of that return, when obtained. I give in this case no accounts, which are stated, of the actual or probable costs of such improvements, because little or no practical use could accrue from such calculations in the United States, where the price of labor and the value of produce are so entirely different from what they are here.

The application of chalk to the improvement of land is often and successfully made; but, as I know of no deposits of chalk in the United States, such a process can have little interest with us. I have already referred to the practice, in Lincolnshire, of chalking liberally chalk lands, or lands with only two inches or more of decayed vegetable matter or soil, underlaid by pure chalk. The same practice prevails in Hampshire; but I know no satisfactory reason to be given for it beyond that of giving closeness and adhesiveness to the loose and light surface soil. The effect of chalk is to bind land, without increasing its weight. The same may be said of lime, and of mixtures of lime with clay, as in calcareous marl. Though we have no deposits of chalk in the United States, yet we have an abundance of lime, and without doubt much calcareous and rich marl, yet to be discovered. The green sand of New Jersey, underlaying a large portion of that arid and siliceous soil, and extending along the eastern shores of Virginia, has already, in some cases, effected wonderful and valuable ameliorations, and those too of a permanent character; and when its ultimate, and, if I may so say, its moral as well as its chemical influences are considered, nay be deemed much more valuable than an underlaying of gold dust.

Of the chemical influences of clay upon the soil, as yet, but little seems determined. "Potash," says Liebig, "is present in all clays; according to Fuchs, it is contained even in marl ; it 
has been found in all the argillaceous earths in which it has been sought. The fact that they contain potash may be proved, in the clays of the transition and stratified momtains, by simply digesting them with sulphuric acid, by which process alum is formed. Land of the greatest fertility contains argillaceous earths and other disintegrated minerals, with chalk and sand in such a proportion as to give free access to air and moisture."

The remarks of Boussingault on this subject are, in my opinion, well worth giving to my reader. "The qualities which we esteem in a workable soil depend almost exclusively upon the mechanical mixture of its elements. We are much less interested in its chemical composition than in this; so that simple washing, which shows the relations between the sand and the clay, tells, of itself, much more that is important to us than an elaborate chemical analysis. The quality of an arable soil depends essentially on the association of these two matters. Sand; whether it be siliceous, calcareous, or felspathic, always renders a soil friable, permeable, and loose. It facilitates the access of the air and the drainage of the water; and its influence is more or less favorable, as it exists in the state of minute subdivision, or in the state of coarse sand or of gravel. Clay possesses physical properties entirely opposed to those of sand. United with water, it forms an adhesive, plastic paste, which, once moistened, becomes almost impermeable. With such characters, it will easily be conceived how it is impossible to work to advantage a soil that is entirely argillaceous. The proper character, or, if you will, the quality of soil, depends, then, essentially on the element which predominates in the mixture of sand and clay that composes it; and between the two extremes, which are alike unfavorable to vegetation, viz., the completely sandy soil and the unmixed clay, all the other varieties, all the intermediate shades, can be placed." "*

An account is given in the Journal of the Agricultural Socicty of the application of bituminous shale to land, with very beneficial effects. This shale may be considered as an imperfectlyformed coal, a slaty stone, which is found on the opening of coal itarries, and is generally deemed an indication of the neighborhood of coal. A quantity of this substance had been thrown out

* Rural Economy, p. 266 . 
in digging a watercourse. An application was made, by the tenant to the landlord, for an allowance for removing this shale, which incumbered the land. The owner, upon examining the spot, found around each heap a circle of dark green and luxuriant grass, such as would have surrounded a heap of rich manure, and observed that the frost was reducing the shale to powder. These circumstances indicated a fertilizing property in the substance, and he recommended to his tenant to apply it to the land. The result of such an application was a heavy crop of hay, and after-grass.

I am mainly induced to quote this account for the sake of showing the beneficial results often to be expected from experiment and observation. It is too frequently that we neglect valuable resources within our reach, as this farmer, in truth, proposed to remove and throw away that which proved a beneficial manure; and the casual glance of an eye accustomed to observation perceived its valuable but hitherto unknown properties, from the luxuriance of the growth of the grass around the edges of the heaps. Mrs. Barbauld, in her admirable lessons for children, presents a striking contrast between two boys taking a walk, one with his eyes open to see every object as he passed along, and the other sauntering along, as it were, with his eyes closed, without observing any thing. The moral of such a story is quite obvious. It would be of use to many others than children, who might find the means of all sorts of improvement constantly within their reach, if they would look after them, where now every thing appears barren and hopeless, and not go through the world with their eyes closed, or blind through stupidity or prejudice.

\section{XCIII. - IMPROVEMENT OF PEAT LANDS.}

The improvement or redemption of peat lands is the topic upon which I shall next treat. This subject essentially ennecrns the farmers of the United States, as, in many parts of the country, there are extensive tracts of peat land, now producing nothing valuable, which might be made eminently productive, as advan- 
tageously to the health of their vicinity as to pecuniary profit. Upon a small scale, great improvements have already been made, in this way, in several parts of New England, within my own knowledge, with a skill, intelligence, and success, highly honorable to those persons who have accomplished them.

One of the greatest enterprises of this kind, probably, ever undertaken by individual effort, was that of Lord Kames, sixty or seventy years since, at Blair Drummond, in the neighborhood of Stirling. This was not an improvement of the peat soil, but an actual removal of it. Underlaying the peat was a bed of deep and rich alluvion. From the walls of peat, or the cuttings which appear at the sides or bounds of this improvement, - for, though an immense body was taken away, an extensive tract is still to be found, - the depth of peat removed, as it appeared to me, must have been six feet or more. It is stated to have been in some places full sixteen feet. It was necessary to obtain a command of water sufficient to carry the turf into the River Forth. A wheel twenty-eight feet in diameter, and eight feet wide, was employed to raise the water, which it did at the rate of six and a half tons per minute. The water thus raised was directed into channels cut in the moss, along the sides of which men were stationed, cutting the moss into pieces, and tumbling it into the current of water, by which it was floated into the river, and thence much of it into the sea.

This was really a vast undertaking. Whether the expenses were met by the advantages gained, I am not able to say; but a large tract of most excellent land was uncovered and brought into cultivation, and which, as I had the pleasure of witnessing, now yields as good crops as are ordinarily grown in the country.

Enterprises of this nature must, of course, be rare, and in but few circumstances practicable; but such a work does infinite honor to the boldness which conceived, and the perseverance and labor which executed it. The interesting and extremely picturesune neighborhood of Stirling is all classic ground, made memorable by acts of prowess and heroism in the civil wars which prevailed here, and by dreadful and bloody affrays. In looking at this magnificent improvement of Lord Kames, in comparison with these memorials of revenge and hate, of misery and murder, (for agresessive war deserves no milder name, I could wet help feeling how infuitely higher is the honor of subduing 
the carth, that it may be rendered more fruitful, and serve the purposes of life and happiness, than any of the triumphs of military glory, any of the bloody conquests of revenge and unbridled ambition. These serve no other purpose than that of scattering abroad agony and desolation; glutting the most hateful passions of a depraved nature; and marking their progress, not by the displays of genius and skill, and the brilliant and rich fruits of civilization and humanity, but by laying waste the improvements and refinements of science and art, and pouring out every where a turbid flood of unmitigated wretchedness and death.

In England, Ireland, and Scotland, vast amounts of peat land have been subdued and redeemed, and, from being wholly waste and unproductive, are converted into well-tilled and fruitful fields. Thousands and tens of thousands of acres have been recovered in England; and, in Ireland, improvements of this nature are in progress on a most extensive scale. The single territory of Gleneaske, near Ballina, consisting almost wholly of peat bog, and which was to me the object of a most interesting visit, embraces about 3500 Irish acres, or upwards of $5600 \mathrm{Eng}-$ lish acres.* This, a public-spirited company, called the Waste Land Improvement Company, and possessing an ample capital, have undertaken to reclaim and cultivate, and have already made a considerable progress. There is, indeed, in Ireland, ample scope for this species of improvement, as the area of peat bog is estimated at no less than 2,833,000 acres, almost the whole of which is deemed capable of being redeemed, and brought into productive cultivation.

I know nothing in the United States resembling the bog land of Ireland and England. Much of it, indeed, is on a level surface, but extensive tracts of bog are elevated into hills of considerable height, composed wholly of peat, and that often, as I have seen, to the depth of six, and even ten feet on the summit.

Peat, properly so called, as my readers well know, is a deposit of vegetable matter, composed, in general, of a particular kind of plants, which have decayed under water, and containing much of the element which is called tannin, which preserves it in the state in which it is found, often impregnated with iron, or

* An Irish is to an English acre as 121 to 196. 
other minuml substances, and charged with acids unfriendly to vegetation. In its natural condition, it produces only a coarse lind of herbage, distasteful and innutritions, or is covered with a short moss; in Ireland, in many cases, by heath, alike worthless for any purpose of feed. It is retentive of water like a sponge, and is very difficult of being reduced, so as to furnish a good bed for a sweet and healthy vegetation. In a wet condition, it is scarcely accessible; in a dry state, it becomes too light and hard; and, though composed wholly of decayed vegetable matter, is in an inert condition, or deficient in some elements essential in order to render it productive. It is found of very different depths; in some cases, only a thin stratum of decayed vegetable matter, of six inches or a foot in depth, overlaying a bed of white sand or gravel; in others, a bed of black spongy matter, of many feet, and often of unascertained depth.

IIuch of this land in Eingland, Ireland, and Scotland, has been redeemed, and made highly productive. An eminent Scotch farmer, to whom I had the honor of letters of introduction, states that land which, in its natural state, was not worth more than sixpence an acre, in its improved condition is now fully equal to three pounds per acre. This refers to the annual rent or income of the land. This farmer has recovered two hundred acres of peat bog. Much of it was redeemed at a great expense, as it had been cut over for fuel, and it was deemed important to fill up the holes which had thus been left. Much of it was reclaimed at the expense of $£ 30$, or $\$ 150$, per acre ; but the farmer considered himself amply remunerated by the improvement. Other lands, which gave him not more than 1s. 6 d., or $37 \frac{1}{2}$ cents, per acre, now give him 12s. to $14 \mathrm{~s}$., $\$ 3$ to $\$ 350$, per acre, annually. A similar improvement is stated by a farmer in West Somersetshire, whose peat land, before comparatively valueless, now lots for' $£ 3$ to $£ 4$ per acre. The improvements in the fen land of Lincolnshire and Cambridgeshire, which is in many parts a species of peat land, have been followed by results equally valuable.

The extensive tracts of bog land in New Jersey, lying between the city of New York and Newark, in New Jersey, over which both the turnpike and the railroads now pass, open a field for improvements of the same kind and of the most valuable description. Partial attempts have been made already, and their success is sufficiently encouraging. But when the whole of this 
great extent shall be dyked against the tide, and the power of steam applied to its effectual drainage, the obtaining of a soil of the richest description, so near to some of the best markets in the country, will be likely to afford an ample compensation for any expense which may be incurred. It may be said that such improvements must be very distant in a country where immense tracts of unoccupied land, of the richest description, remain to be had at very low prices; but the proximity to a great city, and to several large and thickly inhabited towns, continually increasing, in population, business, and wealth, with almost unparalleled rapidity, must give a value to such lands which can scarcely be calculated, and keep far in advance of the competition of even the most fertile lands in a remote interior. Indeed, a slight inquiry will satisfy any one that the value of lands in the neighborhood of our cities, for agricultural and horticultural purposes, in spite of all the predictions founded on the improved and unlooked-for modes of conveyance by canals and railroads, has been continually rising, and has by no means reached the zenith.

Three difficulties may be said to present themselves in the redemption and improvement of all peat lands; the first is their wetness, and draining must be the first operation to be applied to them; the second is their want of compactness, for they are often too light and spongy for the growth of plants, though this defect will be partially remedied by the draining of them; and the third is the removal of some pernicious quality, some mineral acid, which is prejudicial to the growth of the best vegetazion, or the supply of some element of vegetation which is requisite in the cultivation of any other plants than that of which the moss itself is formed. Peat, though wholly a vegetable substance, and, properly speaking, a compact mass of humus, - in itself fumishing, under a proper form of preparation, a useful manure, - is still deficient in the elements necessary for the growth of the finer grasses, the esculent vegetables, and the cereal grains.* What, in particular, these elements are, remains for

* Professor Kane, in his instructive work on the Industrial Resources of Ireland, remarks, that " it is by the gradual formation and decomposition of this body (nitrogen) that the organic matter of the soil becomes so powerful an agent in its fertilization. 'The roots and fibres of a crop, left in the soil, gradually rot, and become thereby the means of absorbing from the atmosphere a quantity of nitrc- 
agricultural chemistry to discover. The philosophers have approached the promised land, but have not yet got possession.

1. Draindae. - Drainage is the first step in the progress. The land should be pierced by deep ditches of at least four feet in width, and the depth, and distance from one to the other, to be determined by circumstances. Peat lands, or bogs, vary greatly in depth — from a foot to a depth, in some cases, of twenty feet, or indeed much more, and beyond being sounded, and which, in our improvements, it would be hopeless to attempt to reach. The only rule to be given is to make the drains of such a depth as to take of the water completely from the bog as low as three feet. It seems generally advised to leave the great, and, if so they may be called, the central drains open. If they are not sufficient to effect the perfect drainage of the land, then side drains, not sunk so deep, but emptying into the main drains, must be made. It is impossible to lay down rules, applicable to all places, for the distances at which these drains must be made from each other - so much must depend upon the extent of land to be drained; the quantity of water ordinarily to be removed, whether it be water from permanent springs or only flood-water from the hills; and, likewise, the descent or fall by which it can be carried off. Two eminent farmers in Lincolnshire, one of whom I had the pleasure of visiting, speak of making their ditches eleven yards apart, from centre to centre, and of four feet width; but no arbitrary rule can be adapted to all situations; and this must be left to the judgment of the improver. These ditches are left open; and perhaps, here, this is the only eligible mode; yet, on two farms in Massachusetts, where, I am proud to say, the improvements in redeeming peat bog, though on a comparatively very small scale, for the intelligence and success with which they have been made, would do honor to

gen, which is rendered available for the sustenance of the next generation of plants. In estimating the fertility of a soil, therefore, it is most important to deternine the quantity of these organic matters, and particularly the amount of nitrogen which they contain. The mere presence of organic matter indicates nothing; thus a peaty soil may be absolutely barren, if the decomposition of its organic matter has been carried on under water, where the oxygen and nitrogen of the air have not access, and consequently only inert ulmine, destitute of the power of crolving carbonic acid and ammonia, be produced." - p. 270 . 
any country, - the bog to be drained, in these cases, being a sort of basin surrounded by hills which were covered with stones, - a ditch of considerable width was dug, at the edges of the bog, to a depth of six feet, and filled in with stones of various sizes, gathered from the adjoining fields, to within about thirty inches of the surface, and then the bog earth returned upon the top, and the whole levelled. Thus a double purpose was answered - that of draining the bog, and clearing the neighboring land of unsightly and useless stones.

With respect to the position of the drains, some reference is to be had to the sources of the water by which the land is drenched. If it be flood-water from the hills, then it would be advisable, as far as practicable, to intercept it by cutting a ditch at the margin of the bog. If it arises from springs, whose source can be ascertained, then it would be desirable to reach these springs directly by a drain into which they might flow. If the springs are too numerous, and cannot be ascertained, then the best judgment must be exercised in laying out the main and the side drains. Here, the side drains emptying into the main drains are recommended to be made with tiles, and $I$ have seen tiles of a very large bore, on the farm of one of the best farmers in Scotland, - and that is perhaps as high praise as I can bestow, - employed for the centre drains into which all the side drains entered, so that the whole work was completely covered in. The bore of these tiles was, I think, about eight inches by six, and considerable ingenuity was displayed in forming them by a method which I should find it difficult to describe so as to render myself intelligible. They were designed to be used with a sole, and holes were formed for the entrance of the side drains. They presented an example of extremely neat husbandry, and were effectual in relieving the land of a large amount of water. Where a solid substratum, whether of clay or gravel, is reached under the peat, tile may be used for drains without the soles, or the drains may be formed of broken stone, directly upon the hard bottom, as I shall presently describe; but where the deptli of the peat is such that a hard bottom cannot be found, tiles withont soles, or drains formed of broken stone, would soon become useless. In the Lincolnshire improvements, open ditches are made so as to include areas of twelve or fifteen acres; and these, without any under-drains, are found sufficient for the ob- 
ject intended. Open drains are made, likewise, on Chat-Moss, so as to include about an acre of land.

It is well known that open drains are liable to be constantly worn away by running water; and the overhanging surface breaks down by its own weight, and fills up the ditch. The severe frosts which occur in the northern United States, and which heave the ground deeply, and the sudden thaws which are consequent upon them, do much to disturb and break up the sides of open ditches. To guard against this as much as possible, it is advised to make the top of the open ditches very wide, and the slope of the sides very gradual. At Lord Ducie's model farm, under the care of that highly intelligent and practical farmer, Mr. John Morton, the slope to the drain (or the sides of the main ditch) receded so far, and was made at so small an angle of declination, that a cart might be driven upon it without danger of overturning. In most cases this could be done only at the expense of removing a large body of the peat. Whether this might not be advantageously pared and burned, and the ashes spread upon the land; or made into piles, and, by a proper intermixture with other matters, such as night-soil, stable manure, or lime, be reduced into a fine enriching manure; or carried into the stable or fold-yard to increase the compost heap; or, otherwise, be dried and employed as fuel, _ must be left to the judgment of every individual farmer, according to the circumstances of the particular case. In such a mode of spreading and forming an open drain, which declines gradually to the centre, the very current of the water is a security against all injurious wear and tear of the sides; and it is obvious, if the land is devoted to grass, either in pasturage or mowing, it may be made productive to the water's edge. Upon the beanty of the appearance of such easy slopes, when made with the neatness and exactness with which all such operations are performed here, in Great Britain, I need not remark. The lines of all ditching and draining here are made with mathematical precision, and are in general as straight as they can be drawn. I am unwilling to say where I have seen such operations performed in a way to induce one to suppose that he who made them always wallied backwards, and, after starting, gave himself little concern however zig-zag his course might be or at what point he should come out. Many of us, it would seem, have yet to learn that the voL. II. 
most perfect mode of doing a thing is ultimately found to be the best mode, though, in the beginning, it may be neither the quickest nor the cheapest. There may be, in some cases, an extreme or excessive particularity or precision; and we are often told of people who are more nice than wise, though I have not found this class very numerous; but the exceptions may serve only to prove the value of the rule.

Farmers are not entirely agreed as to the degree to which the water, in draining, should be taken off. Some persons contend that the land should be rendered as dry as practicable, while others maintain that it is quite enough to reduce the level of the water to a depth of three feet below the surface, and that the land will be benefited by the presence of water at such a level, as it will serve to keep the soil moist - I suppose, by capillary attraction, and by evaporation. There seems to be some reason in this argument ; and it is conformable to the opinion and practice of one of the best farmers whom I know. It perhaps admits of one qualification. If the water of the meadow is strongly impregnated with iron, or some mineral acid, as may in general be easily discovered from its rusty or colored appearance, its presence may be injurious to the roots of the growing plants. If it is clear or rumning water, it is obviously not liable to the same objection. By most farmers, however, it is recommended to make the ditches deep rather than numerous.

I shall return presently to the subject of drainage, and now proceed to speak of other processes customary in the improvement of peat land.

2. Paring and Burning. - The land being drained, the next process usually advised is to pare and burn the surface, and spread the ashes. This practice is not without its opponents. If the land is to be covered, as I saw in one case, with six or eight inches of mud or soil, the removal of the coarse vegetable matter from the surface would be an unnecessary, and perhaps some would think, a wasteful process; for, under such a mass of soil, its decomposition would be, though slowly, yet certainly effected. But where a sufficient covering is not intended to be applied to accomplish this purpose, the expediency of paring and burning the surface is, in my opinion, determined. There is always a large amount of the coarsest vegetation, which, if 
tumed up by the plough, would remain diflicult of manaegenent, and very slow of decomposition, and much interfere with any crop which might be cultivated. But this being pared and burned on the ground, the ashes, which are stated to coutain the element of potash, so useful in vegetation, furnish in themselves a valuable manure. In paring and burning, great care is to be used lest the burning should proceed too far, and burn deep holes in the peat, which would be both unsightly and inconvenient.

3. Application of Lime. - The next inquiry is, What application shall be made to the soil? Lime is very generally recommended, in places where it is accessible at a reasonable rate; but farmers are not unanimous as to its necessity or utility. The effects of lime are understood, in what must be considered the present imperfect state of the science, to be four-fold. It operates, first, as a mechanical divider of the soil; and this eflect is undoubted and valuable. The application of sand to peat effects the same purpose. Secondly, the lime operates, by a chemical process, to decompose and reduce the peat; but on this point, chemists seem to hold a double doctrine - maintaining that, in some circumstances not very clearly defined, it dissolves and consumes, but, under other circumstances, it tends to harden and preserve, the woody fibre. This may be true in both respects, though we may find it as difficult to understand as the satyr, in the fable, did to understand how the traveller should blow in his hands to warm them, and blow in his broth to cool it. Lime is supposed to be beneficial in a third respect, that of furnishing to the plant a portion of food which it actually requires, an element of which its substance consists. 'This is not, of course, required in all plants which may be cultivated; nor to the same extent in plants of the same family. There is another advantage supposed to arise from the application of lime: and that is, its chemical effects in correcting the mineral acids which often abound in peat bogs. An excess of iron, which may be seen in the color of the stagnant water or drainings of these lands, is a common fault. 'The application of lime, in such a case, converts the sulphate of iron into the sulphate of lime, or gypsum, - that is, from poison into food, and wholesome nutriment, for vegetables. "Turf, or turfy soils," says Boussingault, 
"yield rich crops when we succeed in converting the turf into humus. By a happy coincidence, turfy deposits frequently alternate with layers of sand, of gravel, of clay, and of vegetable earth, which have been accumulated at the same epoch. By a mixture, by a division, of these different materials, preceded in every case, however, by proper draining, mere peat bogs may be turned into good arable soil. Pyritic turf, however, shows itself more intractable; it rarely yields any thing of importance. To improve such a soil, it is absolutely necessary to have recourse to substances of an alkaline nature, such as chalk or lime, wood ashes, \&c., which have the property of decomposing the sulphate of iron which is formed by the efflorescence of the pyrites." "*

The experience of a distinguished farmer in Scotland, in the use of lime upon peat lands, is well worth quoting. He has improved two hundred acres of peat bog, which certainly gives him a right to speak. "The farmers in Scotland think that they cannot raise good crops of grain without lime, as the greatest part of the south of Scotland is composed of new red sandstone, grauwacke and granite, and therefore devoid of lime, which forms a considerable portion of every fertile soil ; indeed, it was found that the soil in Dumfrieshire did not produce well-filled barley-crops until the farmers employed lime, which they now do to a great extent, and find it equally useful for potatoes and turnip crops, which is amply testified by the farmers' purchasing lime to the amount of $£ 3000$ aunually from my lime-quarry at Close Farm." This value of lime to turnip and potato crops is a new fact. Certainly, I would hint not the slightest distrust upon the authority of this intelligent witness; but matters not half so weighty as $£ 3000$ worth of lime, purchased annually, at one's own quarry, may, without our own consciousness, somewhat affect the judgment.

This farmer adds, "I have employed lime, as it is practised in Derbyshire, to great advantage upon the surface of moor land, (i. e. bog;) but as it requires a very large dose of lime, it can only be done where lime is cheap, as it requires from 200 to 300 bushels of lime, per acre, to destroy the great quantity of vegetable matter in moor soils, which it soon accomplishes, as is 
shown by the land being soon filled with moles, which are drawn to it by the decayed vegetable matter producing worms, the food of moles."

"In Craven, in Yorkshire, lime is employed very extensively, as a top-dressing, even upon a limestone soil. I have found that cattle feed upon pasture, well top-dressed with lime, much quicker, and that the meat is much richer and better mixed, than upon pastures equally productive of herbage."

4. Rules in Ireland for Redenption of Bog. - The directions given in Ireland for the reclamation of bog under very judicious and successful management, are as follows:-

"The first essential in reclaiming bog lands is, that they should be sufficiently drained.

"The second, that they should receive an ample covering of clay, soil, or gravel, not less than three or four inches deep.

The third, that they should be well limed, and that the lime should be applied immediately after being slacked, and mixed with clay; if lime cannot be had, ashes are a good substitute.***** So soon as the ridges shall have had time to dry, forty barrels of fresh-powdered lime may be applied to the acre, and covered over with clay taken from the trenches." *

I believe that a dressing of lime for peat may always be safely recommended; but the expense would be, in many cases, enormous, and put its application quite out of question where a pecuniary return is expected.

5. Application of Grafel on Sand. - Other applications are made with success. Common coarse gravel is sometimes applied; but the only effect to be looked for, from such an application, seems to be merely the mechanical division of the soil, and the hardening of the surface. The late Earl Spencer, $†$ a high authority in all agricultural matters, in the improvement of a tract of peaty meadow, which he had drained by means of a steam-

* Principles for the Reclamation of Bog Land on the Cloghan Estate, by J. P. Kennedy, Eseq.

$\dagger$ The unlooked-for death of this distinguished friend, and active and generous promoter, of agricultural improvement, has been deeply felt, and has left a sensible void in the agricultural community. To the memory of his personal kindness, his beatiful simplicity of manners, and his eminent, attractive, and amiable 
engine, found that a thick top-dressing of sand improved the pasture more than lime, or any other dressing which he had tried.

6. Application of Clay, or Marl. - But one of the great improvers of peat land is clay, or marl. By marl, in this case, will be understood a substance composed of clay and lime, or a soft, unctuous earth, which indicates the presence of lime by its effervescing with acids. This, so far as my observation or knowledge goes, has been found invariably beneficial. A simple dressing of clay, to the depth of two inches, has given a desired compactness to the soil, and by degrees has, in the progress of cultivation, converted the dry, fibrous, and spongy matter into a rich black loam. This is represented to have been the effect upon the Lincolnshire fens, which have been repeatedly clayed or marled, though I saw small indications, although they are represented as peat, of that coarse, fibrous, light, and spongy character, which, by way of eminence, goes under that name. and which constitutes, it is said, nearly three million acres of the surface of Ireland.

In many cases of peat bog there is found, underlaying the peat or turf at varying distances, a substratum of clay or marl. By taking this out of pits, or out of the ditches which are dug for the purpose of draining the land, and spreading it on the surface to the depth of two or three inches, the best results follow. The soil is brought into a condition for cultivation. It is comminuted, or decomposed, and made fine; it is rendered compact; it retains that degree of moisture which is useful to vegetation, and furnishes a tenacious substratum for the roots of the growing plant. Its chemical effects may be considerable; but as yet these are rather conjectural than ascertained.**

virtues, it will not be deemed misplaced that I here record the humble tribute of my grateful and most sincere respect.

"His saltem accumulem donis, et Fungar inani munere._- 22

* It may be interesting to my readers to have the opinions of Mr. Anderson, of Scotland, on the Uses of Lime in Agriculture, whose essay on this subject was rewarded, by that distinguished body, the Highland and $\Lambda$ gricultural Society, with a prize of ten sovereigns.

"Of the leguminous crops, we may say unhesitatingly, from what we have observed, that they cannot be cultivated with any success without the previous application of lime, unless where abundance of native calcareous matter exists in 
The practice of one of the best farmers in Lincolnshire, whom I have the pleasure of knowing, is described by him as follows: He resumed the occupation of a farm which had been let to a tenant, and which had been all clayed over once. He fallowed it thoroughly, and, after getting some crops of cole or rape, he clayed it again, putting on about 300 cubic yards to the acre. Clay dilies are formed eleven yards from the centre of each, and are dug about three feet wide and four feet deep, which furnishes a large amount of clay to be applied to the land. $\mathrm{He}$ then went through a regular course of cropping, and clayed a third time, and obtained highly productive crops - forty bushels of wheat to the acre, and from sixty-four to seventy bushels of oats. He began to clay a fourth time, but not with the same success as before; from which he inferred that the land hat been

the soil." (Yet it seems to be a conceded fact that the application of lime is most beneficial where there is most lime in the soil. This is a remarkable, and, in a measure, an inexplicable circumstance.-H. C.) "The bean, indeed, and, so far as we have observed, the potato crop, are exceptions to this rule; although we have seen lime, in compost with earth or old turf dikes, give a most productive and valuable crop of potatoes."

"Whether spread on the surface of pasture-land alone, or in compost with earth, or applied with a crop and grass seeds, with a view to pasture, it never fails to call into existence the dormant seeds of the superior grasses in the soil, and to nourish and facilitate the growth of those that may have been confided to it by the agriculturist. This is a fact beyond all dispute. It is a never-failing fertilizer of grass land. The effects of lime on peaty soils are the following :-

"Peat is known to contain two substances inimical to vegetation, and eminently preventive of the changes and interchanges, the compositions and recompositions, necessary to aflord a supply of genial nourishment to a superior class of vegetables. These injurious substances are tannin and gallic acid. But let us consider for a moment the composition of these inimical compounds, and we shall find that we have it in our power, by a simple process, to convert them into substances most friendly to the advancement of superior vegetation, and in this form contributing highly to the fertility of soils. We find, on analysis, that they are composed of the following constituent proportions :-

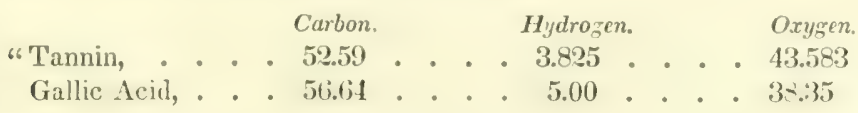

"IVe have shown that quicklime and hydrate have a powerful affinity for carbonaceous matter and oxygen. This known, with the assistance of the above analysis, it is at once clear how they operate beneficially on peaty soils. It is evident that, by appropriating a portion of the carbon and oxygen, lime neutralizes the acid in both these substances, itself becoming a carbonate; and, by this change, substances that were formerly destructive to fertility, combining in 
sufficiently dosed. Indeed, in such cultivation it can scarcely be called the culture of the peat, but the actual bringing up of a new soil, wholly different from the peat, and the cultivation of that. It would be a great error to suppose that the land in this case was not manured. 'Two or three of the crops of cole or rape grown upon the land were eaten off by sheep, folded on the land; and other dressings of manure were liberally applied. Other examples of the advantages of claying peat might be referred to as equally decisive. But I shall quote the account given by Mr. Morton, to whom I have already referred, and the proofs of whose skill, and science, and success, I have witnessed with the highest pleasure, on that which deserves to be called a pattern farm.

"The fens of Lincolnshire," he says, "have been increased in

part with the lime, are resolved into their simple elements, and, assuming a new character, gradually become capable of sustaining an improved vegetation. Of course, as we have already shown, the lime will act on the fibrous vegetable remains in the soil, combine with them, and convert them by degrees into soluble and fructifying nutriment for vegetables. If, after peaty lands have been once limed, it should be found advisable, for any cause, to break up a lea, (and this should be as seldom as possible, such lands being better laid to grass,) it would be an improvement to do so by paring and burning, as, by the application of heat, a portion of the lime now converted into carbonate, from being so long buried and in close contact with the soil, would be freed from its acquired acid, and restored anew to its original purity when first applied - or, in other words, be reconverted into quicklime, and would thus be rendered capable of exerting a renewed action on the peaty substances present, and, from its recovered causticity, again promote the various processes of decomposition and recomposition, so favorable to the development of healthful and luxuriant vegetation." - Journal of the Highland and. Agricultural Society, for October, 1843.

"The decay of woody fibre," says Liebig, "is very much accelerated by contact with alkalies or allialine earths; for these enable substances to absorb oxygen which do not possess this power themselves. Alcohol, gallic acid, tannin, the vegetable coloring matters, and several other substances, are thus affected by them. Acids produce quite an opposite effect; they greatly retard decay." Page 361, Boston edition.

I give these quotations for the benefit of my readers. 'They are among the best scientific explanations, which we have had, of the effect of lime upon peat. It would be quite presumptuous in me to say that $I$ endorse or deny them. Some of my readers will think that the explanations need explaining; and I am not without some sympathy in their difficulties. Most of us get on as far as the Oriental philosophy, that the earth rests upon the back of an elephant, and the elephant stands upon the back of a tortoise. But what does the tortoise rest upon? Here we are obliged to stop; and here, too, science, in all its pride, is often compelled to stop with us. 
productiveness, at least 100 per cent., by applying to the surface of the peat the clay which is found at depths varying from two to five feet below it. The application is made thus: 'Trenches parallel to one another are made eleven yards apart, and three feet wide down to the clay; and then two feet in depth of the clay is thrown out, one half on each side. The effect of this, after the second year, is greatly to increase the productiveness of the soil ; in many cases, to double it." **

7. Application of Mud on Loay. - There is another application to the improvement of peat soils, of mud or loam, which is, of course, beneficial. An example of this kind, which I visited at Hatfield Chase, in Yorkshire, is so remarkable for the boldness of the enterprise, that I must not fail to notice it. Mr. Gossip, having purchased 4000 acres of peat bog, in its natural condition comparatively worthless, has undertaken the reclaiming of it. In the neighborhood was the deserted bed of a river, which had been laid dry by the making of a canal, into which the waters had been turned; and a deep body of silt, or rich mud, deposited in the river, was now rendered accessible. By constructing a temporary railroad, on which a steam-engine was at work, he was drawing out in carts this mud, and spreading it eight inches thick over the bog. The carts were drawn up an inclined plane by means of the steam-power, and were then carried along to the place of deposit, and their contents spread so as to cover the ground to the depth of eight inches. The rails on which the engine and its train of carts moved were formed by two pieces of heavy timber, on which an iron bar, forming the rail, was laid; and, by a machine or crane, suspended from a frame or triangle, these timbers were taken up as occasion required, and, being suspended, were swung round and placed in the desired direction for the carts to proceed upon. The cost of covering the land in this way was stated to be $£ 14$, or $\$ 70$, per acre; but, when accomplished, an ample remuneration seemed sure. It was, indeed, a gigantic enterprise; and the spirited improver had bravely orereome many immense difficulties and dis-

* This is an extract from a letter of Mr. Morton to Philip Pusey, Esq., M. P., given in Mr. Pusey's admirable Essay on the Improvement of Peaty Ground.Sorwna! of Royal Agricultural Society, vol. ii, part 3. 
couragements in the undertaking. This was, however, in truth, the creation of so much land for cultivation, of which the bog might be said to form merely the floor, or substratum. In the cultivation of the land, portions of the bog would be brought up and mixed with the soil which had been laid upon it, and both would be improved. Such enterprises as these, undertaken by an individual, indicate the great amount of capital which exists in this country, ready to be applied when it may be advantageously brought out.

There was another operation, in the way of improving bog or meadow, by the application of loam or clay; which I saw on my way to examine the one described. It was on a small scale, indeed, compared with that, yet, for the mode in which the earth or clay was conveyed on to the bog, was quite deserving of notice. The earth or clay to be applied was dug from a bank or side-hill, on the margin of the bog. Cars or carts were made, about four and a half or five feet long by about three feet in width; and these were so contrived as to run upon two wheels, placed very near to each other under the centre of the carriage, and so fitted as to preserve the balance of the cart. In this way they were made to run easily upon a single rail, formed, by a flat bar of iron, or two bars placed very near each other, upon a thick plank, a foot or fifteen inches in width. This, it is obvious, was easily removed by hand from place to place, and, once being laid flat, required no further adjustment; whereas a railroad of two separate rails, on separate pieces of timber, requires a good deal of arrangement in order to bring the two rails even. In the case of which I am now speaking, the carts were guided by hand; and, upon being emptied, were shoved back again by hand, in order to be filled. The softest bog, which had any consistency, could be easily reached in this way, and the simplicity and inexpensiveness of the operation seemed quite worthy of remark, because within the reach of persons of very limited means.**

\footnotetext{
* I find, since writing the above, that a similar process was adopted, in reclaiming Chat-Moss, by the distinguished Mr. Roscoe, in 1797.

"Mr. Roseoe gave it as his decided opinion, that the best method of improving moss-land is that of the application of a calcareous substance, in sufficient quantity to convert the moss into a soil, and by the occasional use of animal, or other extraneous manures, such as the course of cultivation, and the nature of the crops,
} 
Sand is stated to have been applied to a drained bog in Scotland, at the rate of a single-horse cart-load to every square yard of surface; but the land was so soft that, in order to prevent sinking, the horses had wooden clogs or pattens on their feet that is, a wooden shoe much broader than the foot. The simple method, above described, of using a single railway easily transferable, would obviate all the difficulty mentioned.

S. Improvement of Chat-Moss. - I shail insert here the answers which I received from a very extensive improver of bog land on Chat-Moss, to questions which I proposed to him, acknowledging, at the same time, my obligations to his kindness.

(1.) The condition of the bog or moss? - It was originally a sterile, wet soil, wholly unproductive.

(2.) How drained? - By close drains, four and a half yards from each other, using no other material but the sods to make the close drains, which are from thirty to thirty-six inches deep. The fields are one hundred and fifty yards wide, by three hundred yards in length, divided by open drains four feet deep, into which the close drains discharge themselves.

(3.) What applications are made? - - After the drainage is complete, it has been usual to lead, upon each acre of land, one hundred and twenty tons of marl, from the margin of the moss; and afterwards to spread forty tons of Manchester night soil.* 'The ground is then fit for cropping.

may be found to require. The cost of marling was stated by Mr. Roscoe at £10 per acre, at which cheap rate it would not have been possible to have performed the work, but for the assistance of an iron railway, laid upon boards or sleepers, and movable at pleasure. Along such a road the marl was conveyed in wagons with small iron wheels. Each wagon, carrying about 15 hundred weight, was drawn by a man; and this quantity was as much as, without the employment of the railway, could have been conveyed over the moss by a cart with a driver and two horses."

This, to some of my readers, may seem an early use of the iron railways. Some form of them was adopted ten years before this, at some of the coal quarries.

* It may be interesting to my agricultural readers to know something of the amount of this manure collected in Manchester. My other readers, being forewamed, are of course forcarmed.

The night soil of Manchester is taken into the country by carts, and must be removed before 9 o'clock in summer, and 10 o'clock in winter. (In Boston, U. S. A. they order these things better. The night carts are not suffered to 
Instead of the marl and night soil, Mr. Bell (the tenant) has tried four tons of lime, five hundred weight of salt, and ten hundred weight of guano; and this he thinks, from his experience, answers equally well, at less than half the cost.

(4.) What crops are grown? - Wheat, oats, potatoes, turnips, and hay.

(5.) What is the amount of produce per acre? - About the same quantity as from land of the ordinary kind of average quality.

(6.) What is the condition of the land afterwards? - Much the same as of other land after cropping.

(7.) In what state are the manures applied? - In the state in

enter the town before 10 o'clock in the evening, and must be beyond the limits of the town before 5 o'clock in the morning.) Sometimes it is carried in boats, on the Mersey and Irlwell, and on the Bridgewater and other canals. It is mixed generally with coal ashes, and is sold at about $1 \mathrm{s.} 6 \mathrm{~d}$. per ton, and applied to the growth of potatoes and other vegetables.

It is ascertained that more than one thousand tons of this manure passed by the Cheshire road, alone, weekly, to be used for the growth of potatoes. It is deemed excellent as a preparative for the succeeding crops of wheat and clover.

From the 16th to the $22 \mathrm{~d}$ of August, inclusive, 1843, there passed through the Cornbrook bars 647 loads, averaging two tons each, making 1294 tons. The amount of stable dung which passed through the same bars, in the same tirne, was 113 loads, averaging two tons to a load, making 226 tons.

During that time the farmers were busily engaged in harvest, and of course few of them could leave home. When the dung carts. were last counted in the spring, they were found to be double the number here stated; and the annual return of potatoes from this source may be safely taken at 300,000 loads.

The amount sent by the Combrook bars is supposed equal to all that goes by other roads and conveyances out of Manchester.

Value and Use of Night Soil. - One ton of night soil, mixed, as it generally is, with coal ashes, is considered sufficient for manuring three Cheshire rods, of 64 yards each, or 192 square yards, for the usual course of crops, followed by the best farmers, on land of ordinary quality; viz., potatoes, wheat or oats, clover and other artificial grasses.

Thus one ton of manure will, on an average, produce, on 192 yards of land, nine bushels of marketable potatoes, of 80 pounds each, which will be one Manchester load of three bushels, or 240 pounds, on every rod of ground; so that 1000 tons of night soil, passing the Cornbrook bars, may be expected to send back to market 156,000 loads, or 468,000 bushels of potatoes, annually.

These facts and calculations, with which my valued friend, Dr. Playfarr, has furnished me, are curious and striking; and, if they do not fill a man with profound and grateful adoration for what Mather calls the wonder-workings of the Divine Providence, there can be little difficulty in determining, whatever may be his pretensions, in what class of aximals such a being should be ranked. 
which they come out of the marl pit, and out of the middens, the marl being pulverized and spread pretty equally on the surface of the land, after it has fallen to pieces by influence of the frost and the sun.

(8.) How many years or sensons since the application was first made? - The estate has been in my hands twenty-five years, and during that time it has been progressively improving. The marl requires to be renewed about every ten or twelve years; and the other manures as upon other land.

9. Depth of Ploughing on Peat Solls. - On the depth of ploughing or cultivation, to be adopted in respect to peat soils, a diversity of opinion prevails among the English farmers. Where the depth of peat is small, and this overlaying a hungry, cold, white gravel, to bring this matter to the surface, and bury the vegetable matter beneath it, is to pronounce a sentence of long and almost hopeless barrenness upon it. Where the peat is deep, and the top is pared and bumed, many farmers are satisficd with simply harrowing or scarifying it, and sowing the first crop. Where the land has been pared and burned, and a dressing of clay or marl applied, it will be safe to go deeper with the cultivation. Here, however, the course to be pursued must be regulated by circumstances. If the crop to be grown is a grain or grass crop, it is not necessary to cultivate as deeply as in the case of a potato or turnip crop, or of any tap-rooted vegetable. The great danger to be apprehended, in the cultivation of peat, is, that it will lie too high and open, and not be sufficiently compact. Mere rolling will not bring it to a proper consisteney. and consequently it is, after being sowed, often trodden by men and women. This method is not likely to be adopted in the United States. If the land is to be sowed with grain, or laid down to permanent grass, either for mowing or pasturage, and has been well dressed and manured, it is advisable to plough only so deeply as thoroughly to intermix the matter so applied with the peat. The roots of the plant sown in such casc, extending themselves into the peat, will dissolve and reduce it; and when it comes, after a while, to be cultivated for other crops, it will be found in a fine and reduced state. This fact has been strikingly verified within my own observation. In a case where a deep salt marsh, a bed of almost pure fibrous matVOL. II. 
ter, had been enclosed and embanked from the sea or tide, and was then, having received a dressing of loam of two inches thickness, from a neighboring bank, sown with a mixture of grass seed, and afterwards constantly depastured by stock, it was found, after a lapse of several years, to be completely decomposed; and the spade which I thrust into it brought up what appeared to be nothing else than a bed of rich vegetable mould, without any appearance of fibrous matter, other than the roots of the grass on the surface. It is found, here, that the tendency of clay or marl is to sink down into the peat, and therefore the dressing requires to be occasionally renewed. They recommend to apply the (urantity, which may be deemed ultimately sufficient for the reclamation of the bog, in successive small quantities, rather than at once. Sand and gravel, from their greater specific gravity, will, of course, have a greater tendency to bury themselves than any other applications.

10. Manures for Peat. - Of the manures applied to the improvement of peat land, night soil is deemed to stand at the head. This is not usually applied alone, but mixed, as above stated, with coal-ashes, or otherwise compounded with loam or with peat itself. In the latter case, it is advised that the peat should be dry, and then reduced to a fine state, so as to absorb the liquid portions of the night soil. By whatever means heat can be produced in a heap of peat, whether by the interleaving of layers of fresh horse-dung, or otherwise, the peat will be reduced to a fine condition for composting. The subject of forming peat compost will more properly come under the head of manures. Bone-dust is stated to have been applied with advantage to peat lands, but I am not in possession of any detailed facts or trials on the subject. Mr. Cooke, an intelligent farmer, recommends this application; and Mr. Pusey, M. P., an agricultural authority entitled to the highest confidence, has tried it with success. The application referred to above, of four tons of lime, five hunred weight of salt, and ten hundred weight of guano, is quite worthy of notice. The use or advantage of the salt I am unable to explain. This subject has been greatly controverted, and seems still left in doubt. Sir Humphry Davy inculcates that a certain amount of salt tends to promote decomposition; but, heyoul that, its effects are directly the reverse, being preservative, 
and preventive of decay. The limit, however, is not defined. Others think that the advantage of salt is to be found in its absorption of moisture from the air. This seems a highly probable advantage in the case referred to, as peat lands, when thoroughly drained, are liable to suffer from drought; and the good effects of guano are supposed to be considerably affected by the presence of moisture. Salt is certainly conducive to the destruction of insects. In a manuscript lecture of Dr. Playfair, with the perusal of which he has kindly obliged me, in speaking of common salt as a fertilizer, he says, "Liebig ascribes its action to a decomposition of the sulphate of lime in soils, by which sulphate of soda enters into the plant. Without hazarding an opinion as to the truth of this view, I would simply remark that, if this be so, salt should act most beneficially on the cereals and on the leguminous plants, because they are the great generators of the constituents of blood, gluten, albumen, and casein; and these are the parts of plants for which sulphur is absolutely necessary." These conjectures, to whatever credit they may be entitled for their ingenuity, seem little else than floundering in the dark. The day may presently dawn upon us. It is clearly advisable and wise to draw the curtain back and let in what little light may come. This little word "if" is certainly one of the most convenient words in the language, and performs, in science, a similar office to "charity" in morals - that of covering a multitude of errors.

The example given above, of the application of guano to peat, and its salutary effects, is the only one which has come to my linowledge. 'This extraordinary manure seems destined to produce the most beneficial effects upon agriculture. What a pity it is that we cannot induce these useful birds to make their home among us, and save us the trouble and danger of a voyage round Cape Horn! But they know our savage propensities too well; and, if the doctrine of transmigration be true, they may have heard the story of the avaricious gourmand, who killed the goose that laid the golden egg.

11. Cropping of Peat Lands. - The course of cropping of peat lands, in this country, is somewhat variable. In the fens of Lincolnshire, which, though peaty, can hardly be treated as bog; an eminent farmer states that, the land heing brought into 
condition, the first crop sown is rape or cole, a plant very much resembling mustard. This is twice fed off', in the season, by sheep which are folded upon it. To my American readers let me say that by folding, in this case, is meant that a certain portion of the field is enclosed by a light fence, - it may be of hurdles or of twine net-work, (which is somewhat dangerous, from the sheep getting their heads into the meshes and becoming strangled, or tearing the fence down,) or of light rails, which are movable from one part of the field to the other, - so that, when one part of the crop is consumed, another portion of the field is enclosed, into which they are driven, until the whole field is gone over. 'This gives it a thorough dressing, especially as the sheep, in such cases, generally receive some grain with their feed. After this the field is clayed again, and then sowed with oats; second year, wheat; third, cole with manure; fourth, oats; fifth, wheat; sixth, cole or turnips, well manured; and then clayed again. In the same time, the farmer, of whose cultivation I am speaking, consumed six or eight tons of oilcake, with about twelve acres of meadow-land hay, to assist in converting his straw into manure; all which was divided, upon his cultivated land, on a farm consisting of 100 acres. With this very thorough cultivation, he obtained forty bushels of wheat to the acre, and about seventy bushels of oats. In other cases, the course of crops has been - first, turnips; second, oats; third, wheat; fourth, seeds mown or grazed, - that is, the land laid down to grass; fifth, wheat again.

How far such a course of crops could be advantageously introduced upon the peat lands of the United States, I am not prepared to say. The culture of rape, within my observation, is unknown; but the practice of consuming a crop upon the land, by folding sheep upon it, is an admirable foundation for good husbandry, and will be, I hope, one of the earliest improvements that we shall adopt.**

* A curious circumstance is mentioned in a letter from Mr. Wingate to Mr. Pusey, in his thorough essay upon the Improvement of Peaty Ground, to which. I acknowledge myself much indebted, which I shall quote:-

"In Lincolnshire they never sow rape so early as May, but chiefly in the middle and latter end of June, and stock it as soon as the weather becomes sufficiently cool, so that it will not injure the lambs, which in warm weather are subject to have the blood-vessels of the ear much enlarged, and often lose a part 
In Ireland, the first crop usually taken from peat lands is potatoes; and these are generally grown in the lazy-bed method, to which $I$ have referred in a former report. In this case, where the peat rests upon clay or a hard subsoil, the ground is first laid out in beds varying from four to six feet in width, and divided lengthwise by trenches which empty into an open drain; dirt, or bog earth from these trenches, being, as it is dug out, laid upon these beds. The seed potatoes and manure are then placed upon them, and covered with another digging of earth, or clay from the trench. When the potatoes, which are planted crosswise of the bed, in rows about a foot apart, have shown themselves above-ground a few inches, they are then covered with a second digging of earth, or soil from the trenches. This completes the cultivation. The land is the next year sown with oats, and sometimes laid down to grass; or, in some cases, a crop of wheat is taken. Sometimes the old trenches are filled up, and a new laying out of the ground, and a new trenching, is made, and the process, as at first, repeated. Where the means of improvement are so limited as in Ireland, and the social disadvantages so great, Irish husbandry can be in but few cases referred to as a model. This remark, however, must not be received, as I shall presently show, withont strong exceptions in some parts of that country.

I have gone thus fully into the subject of the improvement of peat lands, because, in parts of New England and New Jersey, and other parts of the country, there are vast bodies of this kind of ground, waiting the resuscitating hand of intelligent cultivation. I know of many distinguished examples of the most judicious and successful improvement in my own country, to which I have not deemed proper, in this place, to refer. The strong conclusions to which I have come in the case are, first, as the indispensable basis of the improvement of such soils, they must be well drained; secondly, that, in most cases, paring and burning, and spreading the ashes, are advisable; in the third place, that, although lime may be useful, a dressing of clay of

of the ear, if not taken off the rape for a few days, which generally sets them right again. It is generally consumed in the months of October, November, and December, before it is injured by severe frost."

This is literally a rape of the ear, and is probably owing to some acrid matter belonging to the plant, which in its general character resembles mustard. 
moderate thickness would be still more useful; in the fourth place, that the depth of ploughing should be seldom greater than thoroughly to mix the dressing applied with the soil, but not to bury it; fifthly, that there is little danger of being too liberal in manure, and the stronger and the more active the manure, so much the better; and, lastly, that, whatever crop is grown, the most advisable course is, as soon as possible, to bring the lands into permanent mowing or pasturage. Some of the largest crops of timothy or herdsgrass, which I have ever seen, have grown upon such lands; and, where well reclaimed and managed, few lands will carry a heavier amount of stock.

In speaking of the crops which may be cultivated on these lands, I should have added that barley is generally discouraged, the grain produced being represented as inferior in quality. I have no authentic facts in the case; and this, after all, may be mere prejudice.

\section{XCIV. - WARPING.}

In giving an account of the agriculture of England, it wonld be wrong for me to omit the practice of warping land - an operation which has taken place in Lincolnshire, and on the borders of Yorkshire, in the neighborhood of the Humber, a considerable river, which, at its mouth, opens into a large estuary, or arm of the sea. It consists in introducing the tidal waters of this river upon lands lying lower than the tides at their flood, and there detaining them until they have deposited a considerable portion of the fine matter, or silt, commonly called warp, which they hold in suspension. In this way, by degrees, a deposit of one, two, three, and sometimes more feet is made, which forms one of the richest soils that can be found, easily tilled, requiring at first little or no aid from manure, and producing the richest crops and the most abundant pasturage. I went over these grounds with singular pleasure, admiring the skill and energy which could boldly triumph over many obstacles, and wrest from the dominion of the sea a vast body of soil, before this utterly profitless, but now converted into rich fields, loaded 
with an exuberant vegetation. Three thousand six hundred acres have already been recovered, with a prospect of a considcrable accession. These are certainly among the most beautiful triumphs of human art, and compel one to reverence that intellectual power which lies at the basis of such improvements.

The River Humber, formed by the contributions of the Ouse and Trent, and several smaller rivers, opens into a large bay at its mouth. At its junction with the sea, its waters are said to be quite clear; but within they are quite turbid, and a large quantity of fine silt, siliceous and aluminous matter, is heid in suspension by them. Extensive tracts of low bog, and other lands, lie above on the river or rivers emptying into the Humber; and the object has been to introduce this muddy water upon these lands, and there keep it long enough to give time for it to deposit a considerable portion of this floating substance.

In order to approach these lands, a deep canal, in one case, was cut, at first for a distance of three miles, and since that time extended to six miles. The dimensions of the canal were 30 feet wide at bottom, 90 feet wide at top, and $11 \frac{1}{3}$ feet deep; and a sluice-rvay built of stone, with two openings of 16 feet each, and four strong opening doors, was made at the entrance of this canal, to admit and control the tides. Most substantial banks were made on the edges of this main drain, and it answers the purpose of a canal for the admission of vessels of 70 and 50 tons burden, which ascend it for the purpose of bringing down the produce of the country to be conveyed to market. The lands now intended to be flooded are banked in by strong embankments, and a sluice-rvay is cut to the main drain, so that, when the water is admitted to the main drain, it may flow into these enclosed spaces. Here it remains in a stagnant state for a time, and at ebb tide is let off again, preparatory to the reintroduction, at another tide, of a fresh supply. When the deposit has become sufficient, the sluice-way is filled up, and the embankment rendered complete and efficient against the irrujtion of the tide. ant the land placed under a course of cultivation. A good deal of ingenuity is required, in order to give the water a proper direction, and enclosures are made within other enclosures; and great care is requisite to prevent a too sudden irruption of the water, and to avoid opposing currents meeting each other, which is apt to occasion irregularities of surface and sand-banks; and skill is 
required so to conduct the water, that the most abundant deposits should be made in the lowest place, in order to bring the bottom to a uniform level. The work requires to be done substantially, and the banks made very strong, lest they should leak, or be burst through by the violence of the water.

A well-informed man, familiar with the process, gives the following account of it: "The water conducted by the main drain into the embanked allotment is more or less divided into smaller ones, called 'inlets,' (which vary much in size, ) and conducted to different parts of the compartment; for, wherever the current, leaving a drain, expands itself, there the greatest quantity of warp is deposited. As soon, then, as the plots of land next the mouth of the inlets have a sufficient quantity of warp deposited, the inlets are extended by what are called 'call banks,' which, though much smaller than the others, still conduct the current onwards to parts not acted upon by the currents before, and so on, as required. One of the greatest niceties in warping is to have the land finished as level as possible, which can only be done by the strictest attention, and by proper judgment in conducting the different currents, which must not be suffered to cross one another, or to meet, as, in such a case, the deposit of the warp is less, not so regular, and of an inferior quality."

"Care must also be taken that the currents should not be too strong, for in warp there is a considerable portion of sand, which, being the most heavy of all the particles floating in the water, sinks first, the lighter particles being carried on by the violence of the current ; consequently, a sand-bed is formed. These sandbeds, however, if covered afterwards with warp, generally are found to crop better than warp, which may be too strong.

"With respect to the depth of warp deposited, it depends much upon the level of the land to be warped; for, should the land be very irregular, in some places there would be a great deposit, and in others only, comparatively, a small one. It is generally advantageous to have the land to be warped as level as possible. A deposit may then be obtained, of from one to three feet, and in some favorable situations it has been considerably more; but it cannot be generally calculated on." **

* R. Creylie's Account of WVarping. - Journal of Agricultural Socicty, vol. v. part 2, p. 402. 
The amount of mud thus deposited in a single season was, as I was informed, as much as eighteen inches. Mr. Creyke says, "that in one spring, during ten or twelve tides, he has known 10 or 15 acres to have been warped the thickness of from one to three feet; and that in June, 1829, a compartment was commenced of 160 acres, which was finished in January, 1830, a period of only seven months. During that period, a general deposit took place of between one and three feet; but that was an extraordinary season, and the compartment lay in a favorable situation for being warped."

The value of such land is very great. Bog lands, that were worth only $1 \mathrm{~s} .6 \mathrm{~d}$., annual rent, became worth $50 \mathrm{~s}$, per acre. The crops obtained on such land are very large, and it is considered as too rich for wheat, until it has been severely exhausted by other crops, such as potatoes, flax, rape-seed, and clover. It has been known to yield ninety bushels of beans per acre, and from three hundred to nearly six hundred bushels of potatoes; and three tons of clover at a first cutting, with a good second crop, and abundant pasturage afterwards.

This is another specimen of what may justly be called the creation of a soil; for, where there is a rich deposit of three feet depth of alluvion, it is of little importance whether the substratum on which it rests be sand, or bog, or stone. 'The turbidness of these waters, and the quantity of earthy matter held in suspension, are remarkable circumstances. It has been the subject of much curiosity whence it could arise. It has been said that it comes from the abrasion of a long extent of sea-coast by the waves; but this would hardly account for it, for the water is said to be clear at the junction of the river with the sea. By others it is said to be the washings of the cultivated soils in the interior, brought down by the several rivers and streams which pour into the Humber; and the fact that the warp is most productive of weeds, and of white clover, establishes the fact of its obligation to these sources. The mouth of the Humber has, without doubt, for years and centuries, been the great receptacle of the washings of the upper countries; and there they collect, and remain in a state of constant excitement and suspension, - at least the upper portions, - from the waves, and currents, and tides. This is undoubtedly the source of this vast body of silt, which is floated backwards and forwards by the flux and the reflux of 
the tides. In some cases the deposit is made at successive periods; as, where the productiveness of a field has begun to flag, the tide is readmitted, and a new dressing of mud is given, to recruit its energies. This can only be done until the surface has reached the height of the highest spring tides.

It has been objected "that there is a species of rich loam: which, under the name of alluvial soil, is understood to mean land which has been gained, in low situations, by the overflowing of streams from higher grounds, or, by the artificial process of warping, from the turbid waters of muddy rivers, as well as by slimy matter thrown up by the tides, and afterwards embanked; that this contains a large proportion of vegetable and animal matter, which gives it a dark color, and produces almost inexhaustible fertility: but the quality of its products, though luxuriant to the eye, is not equal in nutriment to those grown on drier land." This may be so; but it is an objection which I did not hear stated among the cultivators of these lands; nor have I ever heard it from the cultivators of those beautiful lands, in the United States, which lie upon some of our fine rivers, and are flooded and enriched by the deposits from their amnual overflowings.

The substance called warp has been found, upon analysis, to contain mucilage, with a minute portion of saline matter; a considerable quantity of calcareous and aluminous earths; and the residue, mica and sand - the latter in by far the larger quantity, and both in very fine particles. That is to say, it is, and is likely to contain, a mixture of whatever has been brought down, by the rains and rivers, from the cultivated country of the interior.

The Delta of the Nile, and its rich banks and meadows, annually overflowed, are composed, without doubt, of the same materials, and their extraortinary fruitulness is proverbial. On the Mississippi, at the junction of the Ohio with this mighty father of waters, there is an immense tract of land, annually overflown, of the same rich description; and when, as it may happen in the progress of time, those now vast solitudes shall be teeming with population, these great spaces of rich alluvion - when the overflowings of the river, by embankment, shall be excluded, or occasionally admitted, at pleasure - will exhibit an unsurpassed productiveness.

On the smaller rivers, - the Connecticut, for example, - when- 
ever, in its occasional inundations, any portion of its waters is arrested and held stagnant, a marked increase of productiveness is sure to follow. The very superior richness of the meadows on the Deerfield River, a small tributary of the Connecticut, is doubt. less attributable to the fact that, when the Connecticut is at its height of flood, the waters of the Deerfield are driven back and held for a time stationary, when they copiously deposit the enriching matters which they have gathered from the higher lands, and hold in suspension. 'The great river, in its swift passage over the lands, leaves little behind it; but it has occurred to me that, when capital has become more abundant, and the spirit of improvement more bold and active, there may be many situations on the river where, at not an exorbitant expense of embankment, advantage may be taken of the flood to arrest some portion of the waters, and hold them fast until they have dropped their wealth upon the land. In most cases, probably, the great hinderance to such improvements would be the vast masses of ice which come down in the spring floods, defying almost every barrier, and sweeping every thing before them in their progress.

Many of the rivers in England, which I have visited, are extremely discolored and turbid. The amount of cultivated land may be a principal cause of it. All the rivers which enter into the Humber, - for I have crossed them all, - the Avon, near Bristol, the Severn, at Gloucester, the Usk, near Newport, Monmouthshire, are all copiously charged with mud in suspension. The Ex, in Devonshire, the Mersey, and the Clyde, are very much of the same character. The 'Thames is a floating mass of impurity and filth. In order, upon the present system of warping, to effect an improvement, it is necessary that the land to be warped should be lower than the tide by which it is to be covered. But it does not appear to me irrational, or premature, to look forward to the time when this difficulty shall be obviated. As I shall presently show, two immense steam-engines, one of sixty, and one of eighty horse power, which I had the pleasure of seeing, and of admiring their mode of operation, clear thousands of acres of land (at a moderate expense, compared with the good achieved) of the drainage water. Why, by the same mighty power, which is fast effecting immense changes in all the departments of lahor, may not this mass of turbid water be thrown upon lands higher than the highest tides, and there held fast until it lets go the 
riches which it holds; and thus, in all accessible places, this improvement be successfully carried on? It must be long before we may look for such great enterprises in the United States; yet the extraordinary value of land here, and the immense amount of capital seeking a profitable investment, warrant almost any expenditure; and the permanent utility and beauty of such improvements - I had almost said, their moral sublimity - ought to stimulate ingenuity, labor, and skill, in every quarter. If he is to be pronounced a public benefactor who makes two blades of grass grow where but one grew before, what shall be said of him who, by the boldness of his enterprise, stays the proud waves of the ocean; arrests the impetuous current laden with plunder, and compels it to disgorge; and rescues thousands of acres, over which the waters of the sea spread only waste and desolation, and compels them to glitter with golden grain, - instead of the hoarse voice of the beating sea, to resound with the glad notes of harvest-home, - and the extensive plains to swarm with an industrious population, and the fields to be crowded with bleating and rejoicing herds!

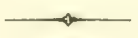

\section{XCV. - AN EXPERIMENT.}

I ought not to pass over an experiment I witnessed, in Eastbourne, Sussex, of making a productive field on a bed of shingle. By "shingle," it may be necessary to explain, for some of my readers, that I mean the heaps of small and worn round and flat stones, which are thrown up by the sea, and constitute often the upper portion of a sea-beach. A considerable piece of such land was enclosed by a stone wall, and mud and clay, to the depth of more than a foot, evenly spread over it. It was then, after being properly manured, sown with wheat, and produced a good crop, and, when I saw it, was covered with a good yield of grass. The material being near, the expense, though considerable, was not over-large, and an ample remuneration was obtained. It did not appear to suffer from drought, as one would have supposed; though, ordinarily, few things suffer from drought in Eng- 
land; and it was done by a benevolent individual, the late Mrs. Davies Gilbert, who was full of works of active gond, by way of showing that even the most barren spots might, by labor, be made productive; that this might be done, in many situations the most unpromising, with a full return for the labor and exfrenditure; and that, in many cases, all that is necessary, to enable the poor to provide for their own necessities, is to give them the opportunity of exerting their own powers.

\section{XCVI. - STRAIGHTENING A RIVER.}

On the eastern shores of England, near where the boundaries of Lincolnshire, Cambridgeshire, and Norfolk, come together, and running for some distance to the north, is a place called the Wush, being a shallow and muddy deposit, which is left bare, to a great extent, at low water. Considerable portions of this have already been reclaimed. Where the River Nene, at the southern part of this Wash, entered into it, its channel was narrow, and crooked, and inconvenient for navigation. By laying bunches of fagots, at low water, in two lines at a proper distance from each other, so as to form two walls, - leaving a proper width for the river, and turning the channel of the river between them, the course of the river itself deepens the channel, the mud collecting among these fagots fixes them down, and forms two solid banks; and the silt, or deposit, collecting on the outside of these walls, soon rises above high-water mark, and presently, being protected against the irruptions of the sea by cross embanliments, will be converted into productive fields. The channel of the river is, of course, now made perfectly straight. As the silt, and slime, and mud collect among these walls of fagots, they are gradually raised to a sufficient height; and, by the time they are decayed, the banks will have become consolidated and permanent. The river is navigable for vessels of a considerable size; and the force of the current, being now confined and directed between these artificial banks, is sure to keep the channel free and deep. A large tract of valuable soil will thus

VOL. II. 
be redeemed from the sea. The Rev. Dr. Buckland and myself were conveyed, by the politeness of the superintendent of these works, in a boat, three miles down this artificial river, and sympathized in warm admiration of the ingenuity and success of this noble enterprise. The result of this great work is not merely to deepen the river, to render it navigable, and to redeem a large extent of land from the sea, but the channel furnishes a natural drainage for the very extensive fen lands above on the river, and in the vicinity into which their waters will naturally be poured.

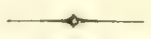

\section{XCVII. - WORK IN IRELAND.}

In Ireland, on the River Foyle, below Londonderry, where it widens into a lake, a great work is going on in redeeming a large extent of land from the sea. At the recession of the tide, an extensive surface is left exposed. The plan is simply to enclose the land by a strong stone wall, or embankment, which will effectually exclude the sea. The work is as yet in embryo, though a large extent of wall is visible. I was told it would include full 2500 acres; but the source of my information was more casual than authentic. After it is once securely enclosed and brought into cultivation, it appeared to me there would be no difficulty in irrigating at least a considerable portion of it, by water from the neighboring hills. I do not know that this is a part of the plan.

The example is one of bold enterprise, and is undertaken by one of the city companies in London, who have large funds at their disposal. I refer to it, hoping to induce my readers to reflcet for a moment upon the essential difference, in the investment of capital, between that which is accumulative and productive, and that which is unproductive and deteriorating. If a man spends one hundred thousand dollars in the erection and adornment of a house far beyond his needs, the capital invested makes no return; the house is liable to continued wear and decay; and a large expenditure is required, not only to live in keeping with the establishment, but to licep up the establish- 
ment; and, if some allowance is to be made for the pleasure enjoyed in this display of the owner's vanity, and gratification of his pride, it must be regarded as a pleasure not of a high character, and almost purely selfish. On the other hand, capital expended in the redemption of land from the sea, or in the improvement of waste lands, becomes at once recuperative; the crops soon give a greater or less return; production quickens and increases production; power in this case, as in many others, grows by the action of its own energies; useful labor is called out; human food is increased, and human comfort is provided for. The eye of the observing traveller rests with grateful delight upon these beneficent triumphs of human art and industry. The performers of such good and, oftentimes, grand works, in the works themselves, erect to their own honor monuments far more glorious, in the estimation of true philosophy, than equestrian statues, or marble mausoleums, or even the mighty pyramids of Cairo - the altars where human toil and life were recklessly and criminally sacrificed to despotic pride, and to an ambition of renown which has no place among those virtres which truly adorn and elevate our nature; a desire of a vain immortality, which, in this case, seems to have met with a remarkable moral retribution, in that even the names of the founders of these wonderful erections remain beyond the deciphering of human' skill.

\section{$\rightarrow$ \\ XCVIII. - DRAINAGE.}

I come now to speak of one of the cardinal improvements in English husbandry. I mean the drainage of the soil.

1. The Importaxce of Drainage. - It happens with water, as with that other most important and useful element in nature, fire, that, while under certain conditions it is indispensable and most beveficial, under others it becomes prejudicial and destructive. Water is an essential element in vegetation, and, supplied under proper and favorable circumstances, is most conducive to 
its luxuriance and productiveness; but in excess, it is either wholly destructive, or produces only that which is worthless or pernicious. Every one knows this; but it does not come within my province to go into a philosophical discussion of the properties of water as a constituent of vegetation, or of the modes in which it is supposed to operate. An excess of water in the soil pievents the access of the air, which is essential to the health of the plants. It reduces the temperature when it becomes stagnant in the soil. It favors the approach of frost, so that crops are often cut off, in low places, which, but for the wetness of the soil, would otherwise have been fully and seasonably matured. It renders the working of the soil difficult and laborious, and very often impossible.

The removal of an excess of water from the land is the object of drainage, as the throwing of water over the land is the object of that other great and most beneficial operation of husbandry, irrigation, of which I shall speak in its proper place.

Lands may be injured from excess of water in three different ways; first, from being flooded by the tides of the sea; second, by permanent springs in the land; and, third, from the retentive character of the snil, holding fast, like a sponge, the rains which fall; and perhaps from the formation of the land - the water having no chance to escape. These causes may operate singly, or, to a degree, in combination. ' There are cases in which, where the sea itself does not reach the lands directly, yet it forces back sometimes a fresh-water stream, by which the land is flooded, and the same injurious effects are produced.

Much land in every country is perfectly useless and worthless from these several causes. The question, however, whether the drainage of it will prove remunerative, involves a variety of considerations, and many of a strictly local character, which must be taken into view by persons who propose to undertake the drainage of their lands, but upon which it would be impossible for me to enter. There are considerations, connected with the subject, which are not to be measured by a pecuniary standard, but whose importance cannot be over-estimated. I mean, for example, such as refer to the health of the country. The fogs and dampness, arising from wet and undrained lands, are a prolific source of ill health and sickness. Tracts of land in England, which were liable to fevers and agues, and consumptions 
by a complete drainage have become salubrious, and are now upon an average standard of longevity with other parts of the country. The question of the expediency of draining, in some eases, resolves itself, as in the case of the redemption of peat or other waste lands, into a question of the value of the land after being reclaimed. The cost of drainage may, in some instances, be more than the land is worth after the drainage is effected, or it may be quite equal to its value; but, if it be worth nothing in its undrained condition, the operation may be considered as an actual purchase of the land; and the real satisfaction which a good mind finds in effecting such improvements, and the nseful employment of labor, and the productive investment of capital, may all operate as reasonable and strong inducements to such undertakings.

2. Extent of Drainage, and Embanhment against the Sea. - The tracts of land which have been redeemed by drainage of the first kind referred to, in England, are very great. I mean now to speak of lands which were either covered by the sea at every tide, or by occasional overflowings, or by the rivers which bounded these liuds being, at occasional high tides, forced back, to the overflowing of the adjacent lands, or, otherwise, by the waters, from higher grounds, which flowed into these lands, not finding a ready exit into the sea. 'T'hese lands, which were thus rendered mere bogs, in many cases scarcely accessible, or: otherwise, only wastes producing nothing, have, by drainage and cultivation, become the most productive in the kingdom.

I have a good deal of diffidence in stating the extent of these redeemed lands, because I have not found it possible to authenticate, as fully and as exactly as I could wish, the statements which have been made to me, and I am a little at a loss as to the geography of the district. The level of Ancholme district is represented as containing 50,000 acres.* This amount is

* "The level of Ancholme consists of a tract of low land, situated on the south side of the River Humber, about ten miles below its junction with the River Trent, and contains about 50,000 acres of land, of which only about 17,000 acres are subject to taxation. 'The district is bounded on the east by an elevated ridge of chalk hills, extending from the Lumber, for a distance of nearly twenty-four miles north and south; about 100,000 acres of the land of this ridge drain into the Ancholmc. On the west them is an inferior ridge of oölite and andy lime- 
liable to be covered by the streams flowing into it in time of flood. "The Ancholme valley, for the most part, lies below the level of high-water mark of spring tides. It is probable that at no very distant period it was overflowed by the tide. The mouth of the River Ancholme, emptying into the Humber, would frequently become blocked up by the deposit of alluvial matter, and thus the drainage water from the interior would be obstructed, so that, at times, the level would be completely inundated, and, even under the most favorable circumstances, would never be properly drained, and necessarily become a vast stagnant marsh, more or less intersected with streams and pools of water, according to the particular state of the season, and the ever-varying condition of the River Humber, into which it discharges its water." The Bedfordshire level is stated to contain 300,000 acres; and a company is now formed, who propose to redeem 150,000 acres more. They have already begun their operations. All these tracts are on the north and north-eastern side of England, and adjacent to each other.

I have been through a very considerable portion of this district; and, where formerly the lands were covered with the tides, or otherwise rendered inaccessible or incapable of cultivation from their wetness, populous villages are now found, and farmhouses, surrounded with cultivated fields in a state of the highest productiveness, meet the eye continually. The whole amount drained and redeemed is stated to be full 500,000 acres.

3. 'The Ancholme Drainage. - The commencement of the qreat work by which these lands have been drained dates back to an early period. There are said to exist in England, particularly on the banks of the Thames, works of embankments, to exclude the water from the land, which were made by the Romans. The plan for redeeming these fen lands was laid, and its axecution commenced, as early as the middle of the thirteenth century. Its most important improvements were commenced

stone hills, which divides it from the valley of the Trent; about 50,000 acres of this ridge drain also into the Ancholme. On the south it is bounded by a low ridge of diluvial hills, which divides it from the valley of the Witham; and on the north is situated the River I Iumber; so that the total quantity of land draining into the Ancholme may be said to be about 200,000 acres." -- Journal of Society of Civil Engineers. 
later than the middle of the last century. Some of the earliest improvements were the work of individual enterprise. $\Lambda$ gentleman of capital undertook the draining of a large extent of land, upon condition that, if he effected the drainage, according to his contract, a certain amount of the land so redeemed was to accrue to him, by way of remuneration. Later improvements were effected under the direction of companies associated by an act of government for that purpose, and empowered to assess a tax for the accomplishment of their object.

If we take the district of the Ancholme River, and describe it, it will present a favorable opportunity for considering the whole subject. The Ancholme is a small and sluggish river, emptying into the Humber at some distance from the sea, but not above the influence of the tides. The Humber, being a larger river than the Ancholme, in its high course of tides forced back the River Ancholme on to the flat lands in its neighborhood, to their min as far as cultivation was concerned; and the level was often flooded by water from the hills, brought down by several streams which emptied into the Ancholme. The River Ancholme was likewise used for purposes of navigation, several villages being reached by it. Three points were then to be kept in view, in any improvement which should be undertaken. The first was, to preserve the navigation of the river; the second, to exclude the tides; the third, to prevent the land from being flooded from the rivers or small streams which came from the neighboring hills upon the level. Under the direction of scientific and skilful engineers, these objects have been accomplished.

By a sufficient embankment at the mouth of the river, the entrance of the tides was effectually prevented. But a sluiceway, or lock, was constructed here for the admission of ressels of such size as the river was capable of receiving, and the bed of the river was straightened and enlarged. In order to receive the waters from the high grounds, canals of a suitable size were formed on each side of the level, which intercepted the water in its descent, (and are vulgarly called catch-drains,) and conveyed it to a point where it was poured into the Humber, and so reached the sea. In order to prevent the dirt washed from the neighboring high lands from being poured into this canal, weirs. or dams, were raised across these small streans, in the course of their descent, where this mud would be deposited: and it mirht 
then be taken out by the farmers for the purpose of enriching their land. These "catch-water drains," as they may be called, afford another singular advantage. The water received in them is fresh water, and they furnish an ample supply, in their whole course, for purposes for which it may be wanted. It has been suggested that, in some cases, it might be used for purposes of irrigation, though I saw no examples of this application of it. An eminent engineer, Mr. Smith, of Deanston, has suggested that "it would be practicable to make use of the high land water, collected in the catch-water drains, for working water-wheels, either for draining the lower fens, if any existed, where natural drainage was impracticable, or for other useful purposes, either of agriculture or manufactures."

At the sluice-way or entrance into the Ancholme, large gates are erected, which open with the ebbing, and close with the flooding tide, thus preventing the access of the tide, excepting at pleasure, and favoring the egress of superfluous water at the descent of the tide. It is deemed desirable, in these cases, that water in the main drains should never rise higher than within four feet of the surface of the soil. This, while it leaves an ample soil for cultivation, gives an opportunity of cutting cross drains into the main drain, and at right angles with it, where there is any superfluous water in the soil to be drawn off.' To this kind of drains I have already referred, in speaking of the redemption of peat lands in Lincolnshire.

4. Embankments aganst a River, and Discharge of Water my Steam-Engines. - There are cases in which a river requires to be embanked out, and its overflowings upon the adjoining lands prevented, by what, in a similar case at New Orleans, is called a levee. Here the great River Mississippi flows high above the city; and the city is protected from its invasion by a high cmbulinent, partly natural - that is, made from the deposits of the river, - and partly artificial, and extending high above the city, and guarded against being broken in upon with the greatest care. In a similar way, a river is sometimes conducted through a drained fen, the surface of which is below the river. The course of the river is straightened by high embankments being thrown up. The earth to form these embankments is taken from the drained side of the embankment; and thus a deep 
ditch is formed, at its base, through its whole length. 'This ditch itself serves to receive the waste waters from the drained land; but as they have no chance of escape, unless, in some cases, by a tumnel formed under the river, and conreying them to a lower locality, and when rising nearer than within four feet of the surface of the drained land, affecting injurionsly its condition, a steam-engine is employed to raise and discharge the water, and thus relieve the land from it. This was formerly attempted by windmills, which could of course not be depended on, and were both expensive and ineffectual. It is now done by steam-engines. These move a power-wheel of large diameter, which revolves in a chamber walled with stone, resembling the lock of a canal, in which it moves with great precision, and so as barely to clear the sides. The water is forced up on the paddles, and, at a surficient height, is thrown over the bank or gate into the river.

5. The Deeping Fen. - At Podes-hole, which I visited, there are in operation two steam-engines of the most beautiful construction - the one of sixty, and the other of eighty horse power: and these are effectual to the draining of 40,000 acres of what is called the Deeping Fen. The upper part of these lands, which are thus drained, was peat meadow; the lower part was salt marsh. These lands are now in the highest degree productive; producing fine crops of wheat, oats, potatoes, and swedes, besides furnishing the very best of pasturage and hay land. There is found to be a difierence in the qualities of the grass; the lowest lands are fed with sheep, and the highest with cattle. Barley is not cultivated on these lands; but, besides the crops above mentioned, mustard, woad, and chiccory, are extensively cultivated. Four crops of wheat have been taken in succession from these lands, without manure. As the last crop was less than the former, the land was then laid down to grass. The rent of these lands is $38 \mathrm{~s}$. and $40 \mathrm{~s}$. per acre; but this must be considered as a moderate rent for lands so valuable. By means of these steam-engines, the water is kept down to the desired level. It is not found necessary to work them at all times, and the power is sufficient to meet any extraordinary emergency.

6. The Muston Drainage. - These improvements are so extraordinary, and I may say so truly magnificent, that I shall 
be exeused for dwelling longer upon them, and for giving some communications, with which my personal friend, Sir George Cayley, who has been largely concerned, has been kind enongh to favor me.

"The general plan of the Muston drainage, intended to drain about 10,000 acres, near Scarborough, might be thus stated. The small rivers, Hartford and Derwent, with several brooks, held their courses through an extensive marsh, and, in times of heavy rain, they overflowed their banks, and flooded the land to a great extent. No expense whatever was incurred for cutting channels deep enough to convey away the flood-waters of these rivers or brooks; but they were allowed to keep their ancient lcvels, and embankments were made near them on each side, by cutting deep back drains, for carrying the dead water from the lands, and casting up the soil, excavated from them, on to the sides next the rivers or brooks. By this process, all the great body of water was conveyed in times of flood, within these cmbankments, to the lowest outfall; and the deep cutting which was considered the sine qua non of an efficient drainage, and the expensive part of it, was entirely confined to such moderatesized drains as were sufficient to convey the dead water from the land. Another practical advantage of the deep back drains being contiguous to the embankments, was that, when they received any injury from cracking, after long droughts, or the burrowing of moles and water-rats, and thus permitted the floodwater to pass in some degree through them, the back drains interrupted it, and preserved the land from injury."

7. Drainage at Scampton. - In addition to the above, I will give the account, with which he has also favored me, of the draining of his own private estate at Scampton.

"With respect to the leading features of drainage, on the great scale of operations, I sent you some reports of the Society of Civil Engineers, in which, near the end of the papers, you have a short account (given alove) of the principle I previously named to you as having been applied in draining my own estate at Scampton, of which place you had spoken in your first number, with reference to other matters. $\Lambda$ s there is no plan or section of these drains given, and as the subject is of first-rate agricul- 
tural importance, I will give you these in a rough way, suffieient to make the matter intelligible at a glance."

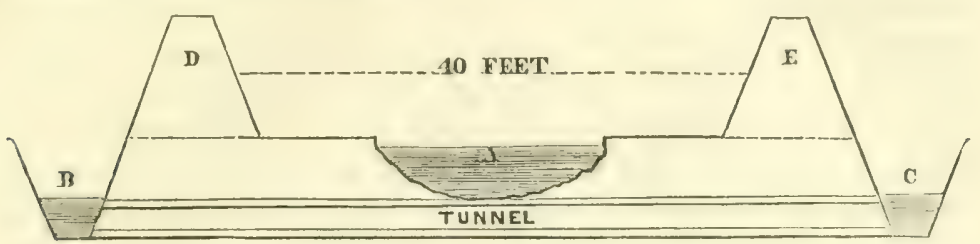

"Suppose A to be the section of the bed of a brook of living water, running through a marsh, which ordinarily keeps within its banks, and that this section contains any given number of square feet - say 30. Then estimate, from the best authority, what section would convey its highest floods, and suppose it, for example, to be four times the usual bed, or 120 square feet. Then, as the banks should not be calculated to hold more than four feet depth of water, they must be placed at 120 , or 40 feet apart; and the back drains, B and C, will be placed so as to form the embankment $\mathrm{D}$ and $\mathrm{E}$, thrown up from their excavation at the required distance from each other. It is, however, better in practice to give most ample room between these, as it is much safer, in times of flood, to permit the water to spread over more land, and be shallow against the banks, than to spare the land, and have deep water ready to take fearful advantage of any flow or derangement in them, consequent upon cracks from long periods of dry and hot weather, or the burrowing of water-rats and moles, \&c."

"The meandering nature of the rivers and brooks, in low marshes, often leads them into courses disadvantageous for conveying the whole mass of the dead water, collected in the back drains, from the lands drained into them; and althongh it is best to let them pretty strictly accompany the rivers or brooks, yet, when there occurs a better outlet at the termination of the drainage on one side of the river or brook than on the other, it may be necessary to connect these drains, under the brook or river, by a circular or other brick tunnel. Cases also occur where brooks, with their accompanying embankments and side drains, have their natural course into rivers with the same accompaniments as in the sketch" on the next page.

"Here it becomes necessary to lay a tumnel of sufficient size to 
convey all the water of the back drains, on the side next the brook, under it, as shown in the former sketch, and here by dotted lines."

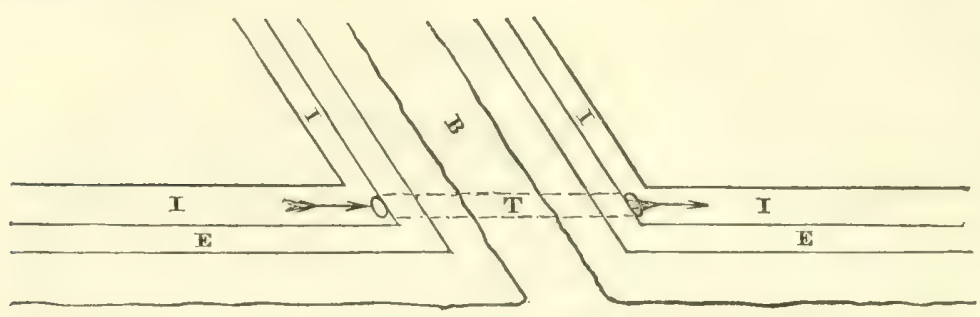

R

$\mathbf{R}$

\begin{tabular}{lll}
\hline & \\
\hline $\mathbf{N}$ & $\mathrm{E}$ \\
\hline & $\mathrm{K}$ \\
\hline
\end{tabular}

I.... Back Drain.

B..... Brook.

EXPLA N A TION

\begin{tabular}{l|l} 
T....T'Tunnel. & R.... River. \\
E.... Embankment. & N... Natural Soil.
\end{tabular}

"These tunnels are rather costly; but being, in most cases, few in number, form $n$ great objection to what, in all other respects, is the most cheap, and often the only effectual plan of drainage in extensive marshes. When the back drains, in ordinary seasons, have the surface of their water about four feet lower than the natural soil, it gives sufficient fall for effectually draining the adjacent land by the usual ditehes, under-draits, de. Where, on a minor scale, bogs are fed, at the foot of rising grounds, from springs below the surface, it has been found impracticable to drain them, but by intercepting, by a very deep catch-water drain, the springs from entering the bog. No drains, however deep or large, below the bog, will dry the land, for it has to pass through the land, and cause it to be a bog before it is led ofl."

"P. S. It has occurred to me that you ought to be aware how extensively steam power has been employed, in Lincolnshire and other flat comties, in draining land where the natural fall is insufficient. My own case at Scampton reminded me of this; for although, when I first drained that estate in the way I have described, there was a sufficient outfall, yet, when my neighbors began to find out the benefits of draining their land, they embanked against me; and thus, in time of flood, my old 
outlet was inefficient, and I have been obliged to eke out my former drainage by expending six or seven hundred pounds in a twelve-horse power steam-engine, which has proved quite sufficient to keep the estate dry in the highest floods. I believe there are about 400 acres of land subject to flood, without the means of keeping it out. The steam-power is applied to a simple water-wheel turning freely in a walled watercourse, which terminates in a curve, which rises over the top of the embankment, necessary to keep out the flood-water of the river that flows below the estate."

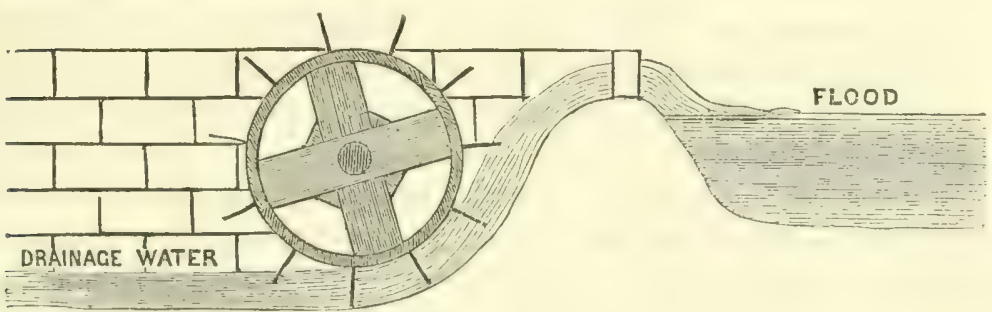

"The power is so adjusted as to give the water in the drain just sufficient velocity to rise over the embankment; and the wheel does not touch the walled trough in which it works, either on the sides or bottom, so that there is no friction but on its axis. I am informed, where these engines have been employed extensively for otherwise unreclaimed morasses, the expense is triling, compared with the profits of the land thus brought into cultivation."

8. Drainage in Nottinghamshire. - A tract of land of abont 6000 acres, in Nottinghamshire, on the northern boundary of this county, called The Cars, has been drained in a similar way. The general impression is, that the sea once flowed over this territory. Half a century ago, this morass was first attempted to be brought into cultivation. At that time it was absolutely a bog, and no horse could be used in ploughing it. The first attempts at draining it were not successful. "In 1828, a steamengine was erected, of forty-horse power, at a cost of $\mathfrak{E} 6000$, for lifting the water by a wheel. The engine is placed upon the main drain, about three quarters of a mile from the River Trent, into which the drainage of these Cars empties itself; but, unfor-

VOL. II. 
tunately, when high tides flowed up that river, there was freguent interruption to the drainage, from the water in the river being higher than that in the drain; and it would have flowed in upon the Cars, had not flood-gates prevented it. By placing the engine at some distance from the Trent, a reservoir was then formed in the main drain, within that space flanked by high banks; and so, by lifting the water into this reservoir, to a higher level than the water of the Trent, it is enabled to fall into that river at all times." *

9. Drainage at Wiseton. - I will insert here a brief notice of a drainage effected by the late estimable Lord Spencer, on his estate at Wiseton, in Nottinghamshire, by means of an eighthorse power steam-engine.

"Five hundred acres of swampy meadow land, lying on both sides of the River Idle, and nearly as low as the bed of it, bearing only coarse aquatic grasses, of little value, not worth more than $15 \mathrm{~s}$. an acre, to rent, are now worth full $25 \mathrm{~s}$. The cost of the engine was $£ 520$; the necessary buildings, and iron pipe (twelve inches in diameter) lying under the bed of the river, $£ 400$. For this outlay of capital, and the annual expenses of coals, and labor to work the engine, not exceeding $\& 60$, there is an increased annual value of $£ 250$, on this part of the estate. Besides this, the engine, whilst throwing up the water to conrey it into the river, grinds the corn; cuts turnips, hay, and straw ; pumps water for the cattle, in the yards and houses, - and would, if required, thresh all the corn. Had there been a thou-

\footnotetext{
* "The wheel for lifting" the water revolves between two stone walls, in a space of about 27 inches wide, through which the whole of the water is driven. The wheel itself is formed of cast metal sides, with wooden paddles between, placed ingeniously at a certain angle, which enables the wheel to lift the water above its own centre: thus a wheel of :33 feet diameter creates an artificial drainage equal to more than its radius of $16 \frac{1}{2}$ fect. Flood-gates are again placed immediately before the wheel, to prevent the water ooming back on the wheel ceasing to revolve. Absolute command of the water is now effected; and a provision has been made, of incalculable value to the occupier of these Cars, by introducing, during the summer months, water, from the adjoining River ldle, as a supply for the stock."

"The total cost of two engines, for the purpose of this drainage, has been little less than 112,000 , and the annual expenditure of working the engines, and cleansing the drains, is from $3 \mathrm{~s}$. to $4 \mathrm{~s}$. per acre." - Corringham's Report of Agricul ture of Nottinghamshire.
} 
sand or more acres of the land, the engine would have drained it, with scarcely any additional expense." *

10. Grandeur and Value of these Improvements. - I have had peculiar pleasure in giving my readers an account of these magnificent improvements. They present most striking and beautiful examples of the application of eapital, labor, and skill, in the actual creation of wealth, and of wealth itself of a reduplicative character, and full of beneficent and enduring results. Thousands and millions, the produce of severe toil, are often wasted upon useless bawbles, upon idle pageants, upon objects of mere luxury and parade; and, when the sun goes down, the show passes away as a mere dream. I say nothing of the moral results of such exhibitions, which are but too often not indifferent merely, but pernicious. But here we witmess the glorious and enduring triumphs of art and science; the useful application of labor; the means of human subsistence and comfort largely extended; the waste places enriched, the barren made fruitful; the solitude peopled; a wide territory peacefully rescued from the sea, and converted into the abodes of industry and plenty; and desolate sands and sunken bogs transformed into cultivated fields, waving with golden harvests.

11. Relation of these Improvements to the United States. - It may be thought that such improvements as these can hardly be looked for in the United States for centuries to come, and while so many millions of public and unappropriated lands, of the richest description, remain to be had at the cheapest rates. I am not of this opinion. The value of lands is materially affected by their situation. Excepting in extraordinary fluctuations, or seasons of inflated speculation, prices have always a tendency to equalize themselves, and to become conformed to actual values. If land in the immediate neighborhood of a city is worth three hundred dollars per acre, while land in one of the Western States may be purchased at the government price of one dollar and a quarter per acre, it is because the advantages growing out of the position of the one or the other differ in a corresponding degree. In the nerghborhood of some of our large and growing cities, - of 
New York, and it may be said, too, of Boston, for example, - there are extensive tracts of land, (in some cases constantly saturated with water, and rendered comparatively worthless; in others, visited regularly by the tide, and producing an inferior herbage, that might be exchanged for what would be far more valuable,) which might be embanked and drained, and reduced to cultivation, for an expense which, under such circumstances, their enhanced and constantly-increasing value would much more than repay. Such exampies as I have described, if they have no direct application to the United States, cannot be without a most salutary influence in stimulating inquiry and effort; in inducing reflecting and inquisitive minds, and men of bold enterprise, to look about them, and discover, if possible, what means are within their reach of remedying evils under which they labor, of honestly improving their own condition, and with that, of course, the welfare of the community.

English husbandry, on account of a diversity of climate and soil, and because, likewise, of many circumstances in our social condition, may not be well adapted to the United States; and to follow out its rules, without a just discrimination, would be quite sure to end in disappointment and loss; but, in the perfection to which the art is carried, in the application of the most enlightened and scientific inquiry to its improvement, in the strong and indefatigable interest taken by persons of the highest influence in its advancement, and in the actual gains and various improvements which it has already accomplished, it reads a most important lesson, to the farmers of the United States, to remit no exertion, and to apply all their energies to the advancement of an art involving the most wholesome and an unexceptionable application of labor, and constituting the great source of subsistence and comfort, and the basis of national wealth.

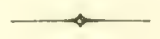

XCIX. - THE DRAINAGE OF FARMS.

1. Climate, and Condition of the Soll. - The climate of England, from its high latitude and insular character, is not damp merely, but wet. On the western coast, and far to the 
north, they are much more subject to rain than on the eastern coast. The frequency of rain, and the suddenness with which the showers collect and compliment the unsuspecting traveller or pedestrian with a bath, and the many days - and I may almost add weeks - during which the sun never makes his appearance, or, if seen at all, it is with a veil over his face, as though he were distrustful of his welcome or ashamed of his long absence, forcibly remind the visitor, if he has come from the other side of the Atlantic, any where south of the British provinces, that he is from home. There is a compensation for this in an equable temperature, which is cxceedingly grateful; in the indifference with which the habits of the people, most of whom seem as regardless of a good ducking as so many water-fowl, soon induce you to look upon it; in the brilliant and deep verdure of the country, which in many cases remains unchanged, and converts February into June; and in the fine, clear, ruddy, and transparent complexions which characterize the English ; - I mean, of course; those who are not overworked, and who are well fed; the class, as a member of Parliament significantly denominated them, of two meals a day.

The effect of such a climate upon their land is what we should expect; and a large portion of it is fully saturated with water, rendering it difficult of cultivation, and endangering or injuring the crops. To cultivate wet lands is quite out of the question; and, therefore, efforts to drain the lands have been made, with more or less skill and success, probably as long as the land has been cultivated.

2. Modes of Dranning. Open Ditches. Covered Drains. - The rudest mode of draining, and that, without doubt, first adopted, was that of open ditches. 'The unsightliness of such ditches, where they are numcrous, the inconvenience of crossing them, the actual loss of land incurred in their formation, the constant wear and falling in of the banks, the labor required in keeping them open and in repair, with many other obvious oljections, are quite sufficient to prove them ineligible. Covered drains were early substituted for them, and various forms of these have been adopted, all of which I shall not micrtake to describe.

It is desirable, in drains, that they should, as speedily as pos- 
sible after xains, or from whatever source the wetness may come, relieve the land from it. Several things are therefore to be considered - such as the capacity, the depth, and the direction of the drains, the distance at which they should be placed, their outlets. and the mode of their formation. The expense of draining must, in all cases, be considerable. The materials employed in their formation, and the permanency of the work, are essential points to be considered. The great improvements made in draining land, in England, have been the work of the past few years; in no branch of husbandry has more been gained; and the results have been in the highest degree valuable and important. I believe I am safe in saying that, in what it has done, and what it promises to do, for the advancement of agriculture, no other process of improvement can be compared with it.

3. Elkington's System of Drainage. - It is but few years since Elkington - a name well known in English husbandry effected a great improvement, by what might be termed tupping the springs. It was generally supposed, at least much more generally than at the present time, that the wetness of land proceeded from springs, gushing up spontaneously, and supplied from internal sources, much rather than from water falling upon the surface. It is well known, likewise, that a large portion of the earth's surface is in layers, or distinct strata, somewhat like the leaves of a book lying upon its side, and, in some cases, not flat, but with its side raised up, and, as the geologists term it, dipping one way or the other, at different angles of inclination. In effecting the drainage of a low piece of land, Ellkington's first plan - and this was the plainest dictate of common sense - was to cut off the water by a drain formed at the foot of the elevated ground, and round the whole margin of the meadow. By this drain the water from the high lands, whether proceeding from permanent springs or from the infiltration of occasional rains, was intercepted, and, if possible, conveyed away. I have. seen this done repeatedly and successfully, and the meadow, when thus insulated, made quite dry.

But there were other cases, in which it happened that the water failing mon the land, though it might pass through one or two of the upper strata, would meet, in its passage down, with an indurated and impermeable stratum or layer, by which it would 
be held fast, and presently the whole surface become saturated with wetness. In such cases, by piercing forcibly through this stratum, or by digging wells in different parts of the field, which would go through it, a more open stratum would be reached, and, in this way, the whole land be completely drained. This plan would sometimes succeed, where the geological structure of the land favored it, and obtained for him great celebrity and most extensive patronage; but, for obvious reasons, it must sometimes fail, and large expenditures were occasionally followed by severe disappointments. The discovery of this mode of drainage, which excited great attention at first, seems, like many other important inventions and discoveries, to have been the result of mere accident; the circumstance of a laborer having forced a crowbar, through a solid stratum of earth, into an open, porous, and gravelly subsoil, by which means a large quantity of water was made to disappear, having induced to other experiments, which proved successful. There can be no doubt that Elkington's practice might still be adopted with success in many cases; but it is not now regarded, as at first, like the patent medicines which we sec every day advertised as certain to cure all diseases.

4. Draning witu Fagots and Straw. - Various methods of draining land had been practised for a great length of time before this, and many of them are still continued; and, though they may not come in competition with the most improved modern methods, yet they frequently may furnish a useful substitute, and in some circumstances, and in certain localities, may be most eligible. In some cases, after the drain had been dug, it was filled in with fagots, over which the soil was returned and pressed down. In some cases, a rope of straw was placed in the bottom of the drain, and the drain filled in over it, so that, when it decayed, it left a passage for the water. These were, of course, imperfect modes of draining, and the drains could not be considered as very permanent. The filling up was merely intended to remain until the earth had become consolidated, and an arch was formed.

5. Phig-Drmavig. - In some places a mode of draining, which is called plug-draining, is still in use in stiff clay soils; is executed at a comparatively small expense; and, though not so 
permanent as some other modes of draining which I shall presently describe, is yet considered sufficiently enduring fully to remunerate the expense. In this case, after the drain has been fully opened, some wooden blocks, chained closely to each other, of the shape and size of which it is desired that the drain should be, are placed at the bottom of the drain. The clay

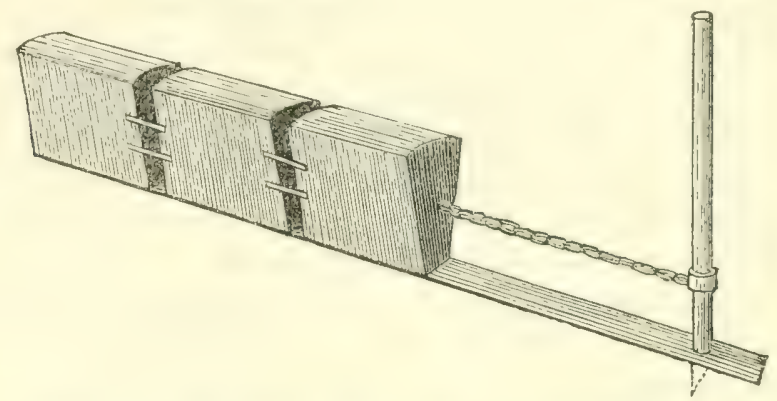

is then filled in carefully over them, and hard rammed, and then the turf and other dirt returned upon the top of that. The plugs are then drawn forward by means of a stake in front of them to which they are attached, and the filling in proceeds until the whole is completed. This drain, if well made, will last many years. I see no advantage in this matter of having the plug in different blocks, unless in a case of the drain varying from a straight line; and it would seem as though a single solid plug or stick of the proper size and form, which is sometimes used, would serve the purpose in view still better. It is always safe to infer, however, in respect to any practice which has long prevailed, when other modes may have suggested themselves as preferable, that it has some good reasons to recommend it. The size of the plugs may vary according to the size which it is desired the drain should be; but I will give the size which is sometimes recommended. 'The blocks, then may be eight inches in height, six inches in length, four inche", wide at the top and two inches wide at the bottom, and fastened together by strong links of iron. To the forward block an iron chain is attached, by which the whole is drawn forward by means of the stake or lever in front. I found one of the best farmers in England engaged in making drains, upon at considerable fick of this deseription, derming them econemical and effectual; and it is said that "one farmer has, within four 
years, made 300 miles of this kind of drain," and is satisfied with its operation. A section of the drain is represented in the engraving.

6. Draining with Turf Covering. - Another mode of draining, somewhat similar, is, after having made the drain tunnel-shaped, as above described, leaving two shoulders at the height from the bottom it is desirable the drain should be made, then to take the sod

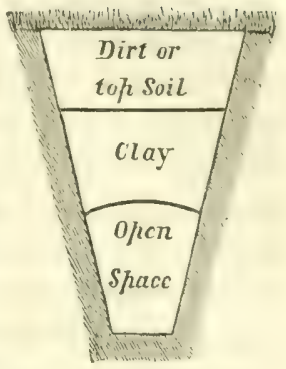
which was taken from the top, and, inverting it, place it upon these shoulders in the drain, and then fill up with the dirt which has been taken out. Both these methods of draining, however, thongh comparatively cheap, can scarcely be considered as permanent. They are liable to be much worn by any considerable amount of water flowing in them, and may easily be pressed down by the passage of a loaded wagon over them.

A farmer in Cambridgeshire, on a soil of tenacious loam, shallow, and upon a subsoil of cold clay, makes his drains five yards and a half apart, and, having first opened them with a double mould-board plough, making a deep furrow, a spade follows, and, after taking out to the depth of the spade, the drain is dug with a suitable instrument twelve inches farther; the width of this aperture is about three inches at the top, and gradnally reduced to one inch at the bottom. The drain is then perfectly cleared by a hoe or a scoop. Peat-turf, procured froin the fens, and cut into lengths of from twelve to sixteen inches, and about three inches in thickness, is then pressed into the lower part of the drain its whole thickness, leaving a passage for the water, undemeath, of abont nine inches in depth. 'The peat expands by moisture, and becomes very firm. It is said these turf drains have been found in a sound state after having been laid for sixteen years; but it is recommended to renew them every eight years. This is certainly a very simple and economical mode of draining. The durability of the drainage depends upon the somulness of the clay; the depth in the earth at which the turf is buried; and the quality of the turf, its strength, and firmness.* 
7. Draining by the Mole Plough. - Another mode of cutting a drain is by what is called a mole plough. This plough consists of a straight and strong beam, to which two handles are attached, and a single piece of iron or straight colter, passing throngh the centre of the beam, and capable of being graduated, like a common colter, by means of wedges, to such a depth as it is desired to go. To the foot of this iron is attached a piece of iron, round like a gun-barrel, or round at top and flat at bottom, of the diameter of which it is intended to make the watercourse, and pointed at the end.

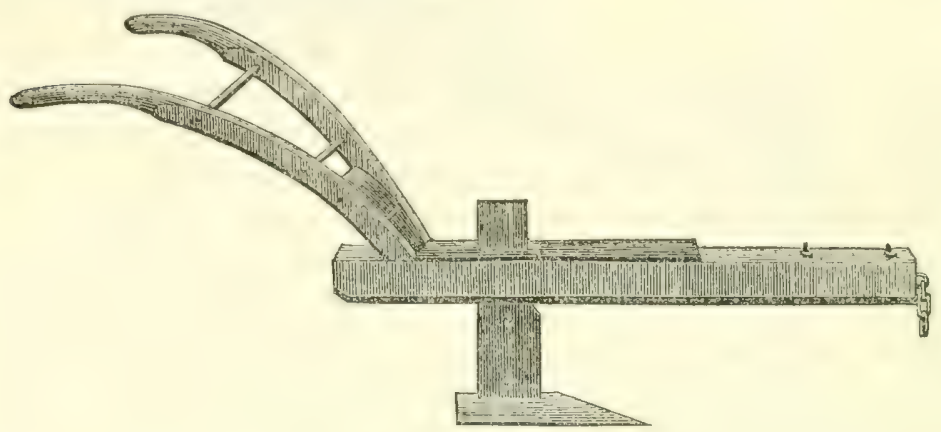

After being once placed at the proper depth, this is forced through the land by a strong team; but a better way is to force it on by a movable windlass, which is made to revolve by a horse attached to the lever. The chain being thus wound up, the plough is forced through the ground a short distance, and then the windlass is moved forward, and another purchase is taken. I met with this machine only on one farm; but I could rasily infer that the diificulties attending its use were not small. It could only answer upon clayey land. Upon stony ground it would meet with insuperable obstructions; upon gravelly or sandy soils, the drain would often be filled up as soon as the instrument had passed. Upon clayey and adhesive soils its effect would be more permanent; and the space made by the narrow colter; or iron bar, to which the mole itself is attached, heing narrow, would soon close. I cannot say much in commendation of this mode of draining; but it seems to be one of those make-shifts to which people often resort with a view to saving xpense, and which yct fails to accomplish its olject; while a more thorough and effectual mode, adopted at first, would have proved in the end as little expensive. 
8. Suffolk Draining. - I will now allow an intelligent farmer in Suflolk to speak for himself, and describe the modes of draining adopted in that improved county.

In the first place, the line is marked out by a plough going and returning, and forming a furrow eighteen inches wide and five deep. This is followed by another large plough, which turns out another furrow ten inches wide by five deep; and thus the plough has formed a drain ten inches wide by ten inches decp. The workman, in the next place, with a common spade, digs a trench nine inches deep; and the next step is with a narrow spade to go eleven inches deeper, and with a scoop take out the loose dirt.

The narrow spade is $1 \frac{1}{2}$ inches wide at bottom, and $2 \frac{1}{3}$ inches wide at top. It is in depth (the blade) 13 inches, but, working in a slanting direction, it only digs out about 11 inches.

"After the digging, a small quantity of stubble is laid along the narrow drain, and is pressed down about three inches by the spade into the narrow drain. The stubble is not pressed to the bottom, but a free passage for the water is left under it. Earth, heavy or light indiflerently, is then shovelled in over the haulm," and the plough is used to assist in covering the drain.

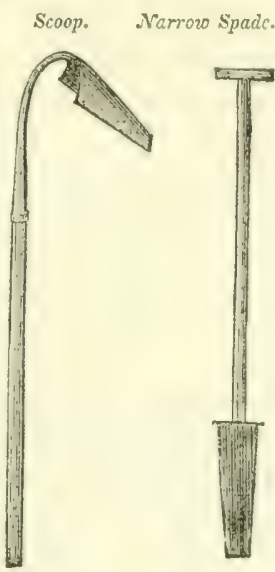

"Sometimes heath is used instead of stubble; sometimes hopbinds twisted; sometimes a 'scud of straw' is made to fit the upper part of the narrow drain. Occasionally a wagon-rope is laid along the bottom of the drain, before the filling up is done: and the rope is afterwards drawn along, thus securing the drain from the crumbs of earth at the bottom; but this precaution is unnecessary. At other times all filling up is dispensed with, and a board (or piece of plank) of the same dimensions as the narrow drain is fitted into it; the earth is then rammed down on to the edge of the beard, and the board is drawn along the drain, leaving an arched water-way behind it." An cxample is given of some drains, formed six years previous to the account. continuing to do well.

"Sometimes fagot-wood is laid along the bottom of the drain, 
with haulm over it, the water finding its way through the wood;" but this mode is deemed expensive. "But, better than all, peat cut for the purpose in the fens, in length fifteen inches, and three inches square, is pressed gently into the top of the narrow drain, and the earth thrown in upon it. The peat swells speedily, and becomes firmly fixed, and is very durable; and has this advantage over the methods already specified, and also over tile-draining, that a fold-stake driven into it commits no damage. In peat-draining, when we come to stony or gravelly spots, two pieces of peat instead of one, or one and a half, are placed side by side, or, in bad cases, the sides of the drain are built with turf, as well as the top. Stubble, heath, hop-binds, straw, are quickly decomposed and washed away; peat remains. Sir IIumphry Davy says, "Inert peaty matter remains for years exposed to water and air, without undergoing change." *

9. Draining in Berkshire. - Mr. Pusey, whose operations I had the pleasure of witnessing, is now draining extensively after the method which I have described - the plug method. The field in which this process was going on was a stiff, adhesive clay. I do not understand him to prefer it to tile-draining, excepting on the ground of cost. The objection - want of permanence - is met by the small comparative expense. "Where the whole of a large farm requires to be drained, and the means both of landlord and tenant are limited, there can scarcely be a doubt which is best for both of them, - to drain 100 acres for forty years, or 300 acres for twenty years." All this must be matter of personal calculation, which is likely to be affected by in great variety of circumstances. The farmer must calculate the length of his lease, and the landlord the length of his life. I cannot most certainly commend the selfishness of the man who said "he shonld do nothing for posterity becanse posterity had lone nothing for him;" but improvements are sometimes made so unnecessarily substantial and expensive, that the mere interest of the sum expended would build them in a way to be effective, and rebuild them as often as might be necessary to do so. Mr. Pusey refers to one fact well worthy of remark: His drainer, an experienced man, traced out the drain with a plough, and the

* Journal of Royal Agricultural Society, vol. iv. part 1, p. ‘ 9 . 
saving of expense, by adopting this simple expedient, he calculates at $2 \mathrm{~d}$. per rod, which would be equal to $£_{2}$ per acre. The plough opened the soil to the depth of 8 inches. These drains are made at $\mathbf{1 1}$ feet apart and 30 inches in depth. This kind of draining can apply only to heavy clay lands. In gravelly soils, stones or tile must be used.

10. Scotcu Draining Plough. - At the interesting and admirable museum of the Messrs. Drummond, at Stirling, Scotland, I saw a mammoth plough designed at one operation to open a drain and sink it almost to its required depth. It was the invention of Mr. M'Ewan, of Blair Drummond, and upon low alluvial lands, or clay land, which is not too stiff, or upon what is called carse land, (which much resembles the alluvial lands on the Connecticut River,) it "effected the opening of drains to a depth of from 18 to 22 inches in the most perfect manner, and at the small cost of about $2 \mathrm{~d}$. per rood of 36 yards. The size of the implement was perfectly Brobdignagian, and I had almost said terrific.

A'Euan's Draining Plough.

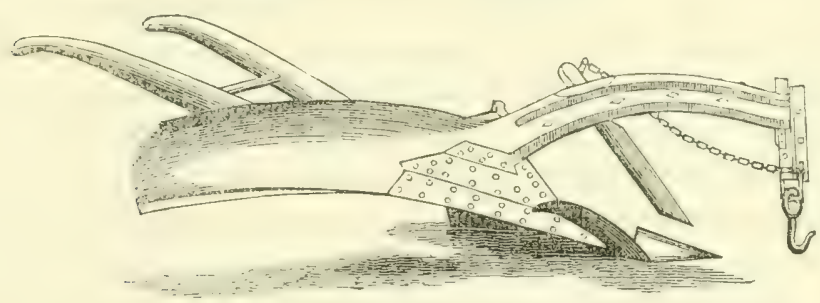

"The leading principles of the construction of MIr. M'Wwan"s draining plough are, - having it of such large dimensions as 10 turn out at once the full depth of the drain, which is the more easily accomplished by having the furrow of a wedge shape, and ample in its width, so that, when separated from the soil, it shall lift freely out; having the mould-board or inclined plane of the plough of great length, and consequently of easy slope, so that the great and weighty furrow shall be gradually raised, while, by the same form, the plough is rendered more stendy and easy to hold. The furrow is taken clear out, and laid along the drain at one foot distant from the margin. From eight to twelve horses are necessary to work this plough in carse land, according VOI. II. 
to the nature of the soil; and it is probable that sixteen may be nccessary in some obstinate clays. The pace of the horses must be slow, say two miles an hour; and the plough is easily directed by one man. After the plough has done its work, men follow with small spades, to take out a space for tiles or for broken stones, and to correct any deviation from the uniform fall of the bottom, caused by any unevenness in the ground. The tiles or stones are then put in, and the furrow turned in over them by the same plongh."

"If the horses were to move continually, at a rate of two miles per hour, they would turn ont 782 roods, of 36 yards, in eight hours; but in so heavy an operation, much time is lost in turnings and otherwise, so that one third may be deducted to cover loss of time, which will leave 521 roods of work done."

"The horses go on each side of the line of drain, the near horse of the off-side division going in the furrow, all being yolsed to a strong main bar, or master-tree, ten feet long, and arranged in fours and sixes abreast, as may be necessary; four abreast when eight horses are used, and six when twelve are used. The leading horses draw from a second main bar attached to the muzzle by a chain passing along betwixt the middle horses behind. When the plough reaches the end of a line of drain, and is abont to be turned, the draught chain of the leading horses is detached; and a man taking hold of the chain, the bar, resting on the ground, follows round till in a position to be yoked for the next line of drain, the plough following draw by the rear horses. When working, each pair of horses is led by a man; one man to each range of horses, going in the middle, and leading a horse in each hand, and a man going on each flank, leading the horses next him - the steadiest man being put in the middle, to keep a direct line for the drain. The man who lifts the chain assists the ploughman in raising the plough from the drain just completed; and in going round and entering for the next drain."

With striking simplicity the writer of this account adds, "The drain plough, like all things else of the same magnitude, and when in the hands of inexperienced persons, requires great patience and perseverance, especially when applied in a land of a hard and stony nature, and can never sueceed in the hands of impatient and carcless people. But to those who take time and 
pains to have their men and horses fully broken in to the work, there will be an ample reward in the cheapuess and expetition with which the drains shall be executed."

I have given the account of this implement to my reader, if indeed he has had breath enough to get through it, rather as matter of curiosity, than with even the slightest expectation that such a machine could, with any possible advantage, be introduced into my own country. Yet there are persons who bear testimony to their having used it to accomplish a large extent of drainage. In my opinion, such persons are of the right nerve to be sent upon a forlorn hope; and the proper team for such a machine is not a team of horses, but of elephants.

11. Draining with Broken Stones. - Underground draining has been practised, in several counties, for more than a century; and the construction of drains, by filling the bottoms with small stones, is by no means a new process. In such case, the drains were dug and filled in, somewhat after the subjoined cuts.
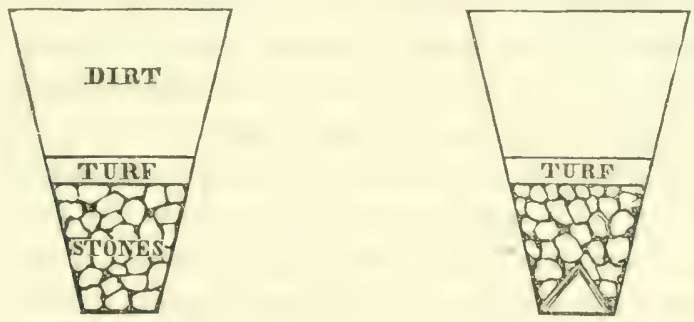

They were dug to the depth of perhaps 20 inches, and filled in with small or broken stones to the depth of about six inches; the stones were covered with an inverted turf, or with straw, and the dirt was thrown in upon it, and the land levelled. It must be admitted that these drains have proved of an efficient and permanent character; and, where stones are easily to be had, this form of draining, all circumstances considered, may be himhly eligible, the shallowness only excepted. In some cases, the broken stones fill the whole bottom of the drain; in others, two or three flat stones are sometimes set up, thus,
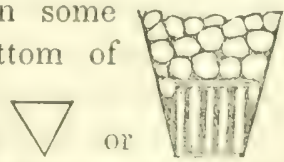
with a view of forming a more ready passage for the water. It is obvious that the second form is more likely to keep itself clear than the former, from the water being compressed into 
a narrow space; and that, in the latter case, as well as where the stones are thrown in promiscuously, the entrance of vermin is completely foreclosed. Experience has suggested, in such drains as these, two or three rules of great importance. The first is, that every caution be taken against the dirt sifting in among the stones; the second is, that the drain should never be filled with large and small stones, thrown in promiscuously, but that only small stones be used; and they, as far as possible, of a uniform size.

12. T'horough Draining, or Deanstonizing. - I come next to speak of operations in draining which, in connection with subsoil-ploughing, may be said to constitute an epoch in agricultural improvement; and the effects of which upon the agriculture of England appear destined to be of the most extensive, permanent, and valuable character.

Mr. Smith, of Deanston, near the village of Doune, in Scotland, (of whom I have before spoken,) conceived the plan of laying his fields thoroughly dry by a careful system of drainage, and next by subsoiling his fields - that is, a mode of deep-ploughing, which, as I have described in a former number, consists first in ploughing with a common plough, and following in the same furrow with a plough of a peculiar construction, called a subsoilplough, being a plough without a mould-board, by which the lower stratum is thoronghly broken up, loosened, and stirred, but not brought to the surface. The active soil is still kept upon the top; the lower, or subsoil, is rendered permeable to the roots of the plants; the air has access to it, and enriches it, and, by being loosened, the water filters through it, passing off by the drains. His operations attracted so much attention, and have led to such great improvements throughout the country in draining, that his name as a great improver is destined to be long remembered, and his system is sometimes, after the name of his residence, called "Deanstonizing." I have had the pleasure of going over the farm on which his operations were carried on, and of admiring its improved condition.

According to the method adopted by Mr. Smith, the first step is to ascertain the level of the land, so as to form a main drain in the lowest part of the land, into which the side drains may fall, and the water be led off. He recommends that the bottom 
of the main drain should be $3 \frac{1}{2}$ or 4 feet below the surface; and says that a drain ten inches wide, and twelve inches deep, will discharge the water from a hundred acres. Many persons, in undertaking the draining of flat lands, are discouraged by the difficulty of finding an outfall for the water; but he deems that one foot fall in a hundred yards, with a drain of the above dimensions, may be relied on. "It has been proved, in practice, that a watercourse 30 feet wide and 6 feet deep, giving a transverse sectional area of 180 square feet, will discharge 300 cubic yards of water in a minute, and will flow at the rate of one mile per hour, with a fall of no more than 6 inches per mile." It is his advice that this main drain should be covered as well as the side drains; but others recommend that it should be left open, that it may be always easy to watch the running of the side drains which empty into it. Three objections, which, among others, lie against leaving the main drain open, - such as the falling in of the sides, the loss of ground, and the danger of the access of vermin to the side drains, (where they are formed with tiles, ) - are obviated by Mr. Morton, in an ingenious manner, as I saw on Lord Ducie's model farm. I have already slightly referred to it. The main drain, in this case, runs through the lowest part of the land; but it is made so broad and flat that the grass can be mowed down to the very watercourse, or a cart could be driven, without overturning, on the very edge or sides of it, though this would never be advisable, for fear of injury to the drains. The farm road, in this case, is made at about the distance of sixteen feet from the centre of this open drain, or brook. In this case, then, there is no loss of land, and no bridges are required in the crossing. Where the side drains enter the main drains, one link in the chain of pipes is omitted, and the remainder of the distance is laid with small broken stone, which allows of the passage of the water, but forbids the access of any vermin into the drain.

The main drain having been formed, Mr. Smith advises, next, the cutting of a drain at the top of the field, and across the whole breadth of it, from which all the side drains are to commence, and thence run exactly parallel with each other into the main drain. The depth of this transverse drain must not be more than that of the drains which may be said to take their rise from it, and lead into the main drain. Besides the great main drain, 
which forms the principal watercourse, the condition of the land is often such as to require submains, into which the side or parallel drains empty themselves, and by which the water is conveyed into the principal drain. This matter is so entirely dependent upon the shape and situation of the land to be drained, that no universal rule can be laid down. The number of submains, and their position, must depend wholly upon the shape and condition of the land to be drained; but the submains should be covered as well as the parallel drains which run into them.

The mains and the submains being completed, the next step is to lay out the parallel drains; and the frequency of these drains, or the distance which they should hold from each other, depends upon the character of the subsoil. "If," says Mr. Smith, "it consists of a stiff and strong till, or a dead sandy clay, then the distance from drain to drain should not exceed from 10 to 15 feet; if a lighter and more porous subsoil, a distance from 18 to 24 feet will be close enough; and in very open subsoils 40 feet distance may be sufficient. The drains," he adds, "should be run parallel to each other, and at regular distances; and should be carried throughout the whole field without reference to the wet or dry appearance of portions of the field, as uniform and complete dryness is the object; and portions of the land, which may be considered dry in their natural state, will appear wet when compared with those parts which have been properly drained."

Of the general form of the drains recommended by Mr. Smith, I subjoin a sketch, (p. 91, ) which will need no illustration. The eye will at once discern the different forms which may be eligible under different circumstances.

The depth of the parallel drains should, according to Mr. Smith, be at least two feet and a half, - and he deems three feet more eligible, - so that the land may be subsoil-ploughed to the depth of sixteen inches, and the plough certainly should not pass nearer to the drain than two inches; that is, there should be at lcast eighteen inches of workable soil above the stones with which the drain is filled. A less depth, as far as injury to the drain is concerned, might answer; but experience has proved, most strongly, that a much greater depth than this is to be preferred for the perfect drainage of the land. The main drains and 
TRANSVERSE SECTION OF DRAINS, \&C

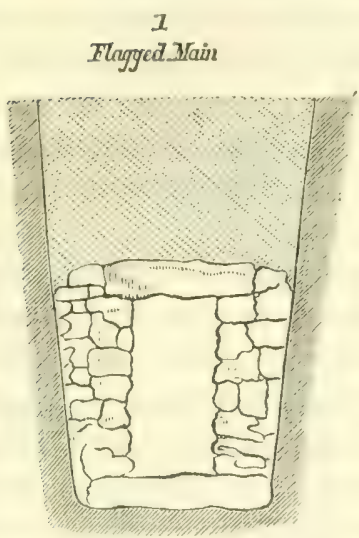

3

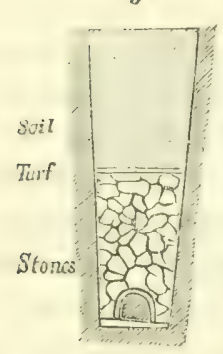

Small
1.

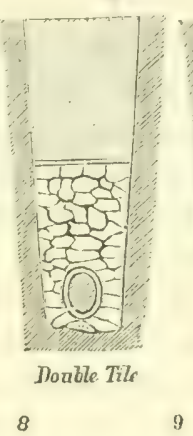

2

Archedarain

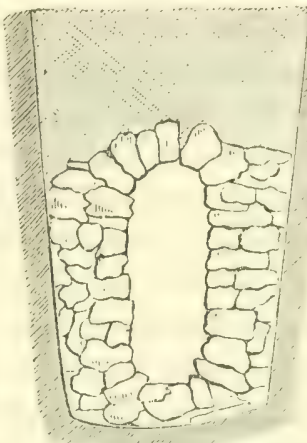

5

6

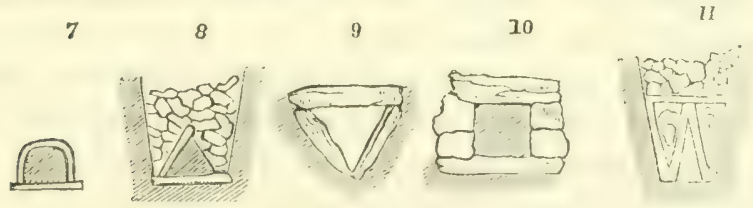

submaius should be at least six inches lower than the parallel drains, so as to secure a sufficient fall. In speaking of the inclination of the drain, so as to secure a sufficient fall for carrying off the water, I have given the minimum which should be relied on. Mr. Morton is of opinion "that 1 in 200 is the least that can be advised; 1 in 140, or 1 in 100, would keep the bottom clear of sediment." The width of the parallel drains at top should be fifteen inches; at bottom, it may be from four to five inches, according to the width of the tile with which they are to be filled, or the quantity of stones which may be at hand to fill in with; but 
it will be found that a much less space than this will be ample for the discharge of all the water from the land under any circumstances; and where round tiles, of an inch bore, are used, (which are getting to be decidedly preferred,) no more width at bottom will be required than merely to place the tile. Where broken stones are employed, no stone larger than will pass through a two and a half inch ring should be employed; large stones ought by no means to be used.

Practical men advise that the length of a drain should never exceed 300 yards; and, where it crosses springs of water, it should not exceed 200 yards. The rule, in making drains, is, to begin with the complete formation of the main drain, and then proceed with the parallel drains, from the point where they enter the main drain to their upper extremity. In filling up, the order is to be reversed, and the completion of the drain is to commence at the upper end, and proceed to its termination with the lower end, or with its entrance into the main drain. It is extremely desirable to have, if possible, all the drains opened before any portion of them is filled in, that their partial working may be watched, and a right inclination secured; and a very eminent and successful improver advises, where draining is attempted in a stifi soil of clay, for example, after the tiles are laid, to fill in but partially at first, leaving the land to be swollen and cracked by the winter frosts, - for, such fissures being once opened, the water will make for itself through them communications with the drain which will become permanent.

It is now an established point, and one of great importance, that, with the exception of the main drain and the submains, which must conform to the character of the land, and the point where a discharge of the waters is to be sought, all drains should be made as straight as possible; and that, where they are made on a side hill, they should proceed straight down the hill in the direction of its inclination, and never be made round it, or cut it diagonally, for the obvious reason that, although a drain made round a hill, or cutting it diagonally, might take the water from the land above it, or intercept any spring which might be found higher up on the hill, yet it would do nothing towards relieving the land below from any wetness which might proceed from rain or from springs situated below it. It is obvious, likewise, that a drain cut round a hill, or diagonally 
upon its side, will not empty itself so soon as one which is in a direct line down it, and that the water in such a drain is noi likely to be wholly emptied by the mouth of the drain; but some of it will find its way through the side of the drain, as it flows on, and, instead of serving to drain, do something torvards lieeping the land below it wet. In making drains on a side hill, which empty into a main drain, though it is important always to make them straight, it would not be advisable, or even possible, to make them parallel; but, following the formation of the ground, they may, as it were, radiate from the top, and reach the main at the nearest point. This plan I saw adopted on one of the best-managed farms which has ever fallen under my observation - that of Mr. Stirling, near Falkirk, in Scotland.

Mr. Smith refers to two very important advantages in having the drains made in a direct line down the steep; that it is a security against the lodgment of any sand or mud in the drain, and that, in case of any obstruction presenting itself in the drain, the water will, by its downward pressure, force itself through, or, bursting out upon the surface, from its accumulation, indicate at once the seat of the difficulty. "Cross drains, having little declivity, are often filled high up with water, before the insidious cause of mischief is discovered." Arguments for the construction of drains straight down the hill, instead of passing round or across it, are often referred to, from the geological structure of the ground; but this varies so much in different situations, that such arguments can have only a limited application. There are cases in which the existence of some spring between the drains may require to be led into one of the parallel drains; but, in general, the water, under such circumstances, will find its own way; where this is not the case, however, a short cut or branch down the incline may bring the water from the spring directly into the side of one of the parallel drains. The tendency of water to force its way along by its own gravity, and its extreme mobility, must be obvious to every one. That which is nearest the drain being first drawn off, the neighboring portion immediately takes the empticd place, and is forced onwards, and so on, gathering accessions continually, beyoud any limits which we cun affix to it. $\Lambda$ well, sunk to a more than ordinary depth, will often affect all the other wells in a very extensive neighborhood. Such are the general and most important principles laid down 
by the most experienced men, in regard to the system of thorough draining, with a view to subsoil-plonghing.

Mr. Smith's directions for forming the drains are so clear and "xplicit, that I am persuaded my readers will be gratified to have them in his own words.

"The lines of drains having been marked off" in the field, the drainer begins by cutting with a spade on a line, then removing a first spading of about 13 or 14 inches wide all along; another follows with a narrower and tapering spade, made for the purpose, taking out another spading; and, when picking becomes necessary, a third man follows with a pick, and a fourth with a large scoop-shovel, to cast out the earth; a smaller scoop-shovel is used to clean out the bottom, which should be cut as narrow as will allow the last drainer a footing, generally about 3 or 4 inches. From 2 to $2 \frac{1}{2}$ feet from the surface are the best depths for such drains, the latter always to be preferred. The bottom should be cut as straight and uniform as possible, so that the water may flow freely along at all places, and it is better to cut a little deeper where there is any sudden rise of the surface, than to follow it; and where sudden hollows occur, the cutting may, on the same principle, be less deep: attention to this also admits of after straightening or levelling of the surface, without any injury to the drains. The workmen, in cutting, should throw the earth to the right and left from each alternate drain, as that allows the plough to go regularly and fully occupied boutings, in filling in the earth, whilst each alternate ridge or space is left for getting in the stones, free from the earth thrown out. The stones may either be laid down at intervals by the sides of the drains, to be there broken, or, being broken in masses at some convenient spot, and at such convenient seasons as best suit for the employment of spare labor, can be brought by the carts ready to be filled in. No stones should be filled in till the whole line of drain has been cut ont and inspected; but the sooner drains are completed after having been cut, the better, and they should always be filled from the higher level downwards. Sometimes, when there is much tendency of the sides to fall in, it becomes necessary to fill in going along. Cutting in the summer, when there is little water in the soil, or in any dry season, saves much of this. In soft or sandy bottoms, by cutting the drains to half the depth in the first instance, and allowing them 
to remain so till the water has been voided from the upper stratum of the soil, the lower part may then be cut ont with more safety from falling in. The stones should not be filled nearer to the surface than 18 inches, leaving 16 inches free for deep ploughing.

"The upper surface of the stones having beon made straight and uniform, the whole should be neatly and closely covered with a thin thatch or turf, cut from the adjoining surface or brought from some suitable place. Strict attention to the correct execution of this operation is of the greatest importance, as many drains are ruined at once from the running in of the loose earth. Thick turfs are objectionable, from the dificulty of getting them to fit close. Straw, rushes, broom, whins, and other like materials, are very objectionable, affording no certain or uniform security, and forming a receptacle for vermin; peat moss, in a thin layer, well beat down, may be used to advantage. When the deepest ploughing has been executed, there should always remain a firm crust of earth nndisturbed over the stones of the drain; and un surface water should ever have access to the free way of a drain by any direct opening, but should find its way by percolation or filtration through the subsoil, and should always enter by the sides of the drains. It may be of advantage to tread or beat down closely the first two inches of soil put orer the turf, iu order to form the permanent crust."

The making of drains is a matter which requires great skill and experience. So important and expensive an operation should be executed with the greatest care. The most thorough and permanent mode of doing it will be found, in the end, the most satisfactory and the least cxpensive. The science and skill of an experienced engineer will be often found requisite to lay out the work, and to determine the levels, where it is to be undertaken to any great extent, either by individuals or companies; and this class of men, now so rare among us, may, I hope, presently appear. 'The supply of such professional men, whose services would be of the greatest utility in many cases, is a prominent object, to which I should look forward in the establishment of seminaries for agricultural education. There has hecn, many times, a great waste of labor and money, and most inortifying disappointments, where such operations have been imperfectly and hastily executed, or undertaken without expe- 
rience or skill. Instances can be cited, where, indeed, the necessary taking up and removal of an imperfect drainage has actually cost more than the reconstruction of the whole work. The art likewise of using to advantage the common draining tools by the laborer himself is the result of training and long experience. In England, where the division of agricultural labor is carried to an extent, of which, in the United States, we hardly know any thing; there are professional drainers almost exclusively devoted to this branch of patient and severe toil, who have reached a perfection in the art and the use of the tools quite deserving of admiration. It must be a long time before we can have such a set of laborers, unless we import them.

13. Implements for Draining. - I subjoin, (p. 97, for the benefit of my reader, a plate of the various implements customarily used in draining, which, I hope, will put him upon the inquiry whether he can devise any better.

EXPLANATION OF THE FOLLOWING PLATE.

Frg. 1. - Section of the Frequent Drain, with its filling of broken stones and its $S_{\text {n.t. }}$.

a First Spade, common shape.

$b$ Second Spade, which follows the first, and is narrower.

c Pick, used when the subsoil is stony.

$d$ Large Scoop-Shovel, for removing the loose earth after picking.

Frg. 2. - Section of the Wedge-Drain, with its Set, as used in the carse or clay soil.

a First or opening Spade, same as above.

$b$ Second do. (Some use this and the following with a spur attached; but the best drainers prefer pushing with the toe on the shoulder of the spade.)

c Third or narrowest Spade.

d Narrow Scoop for cleaning out the bottom.

Fig. 3. - Section of the Tile-Drain, with its Set.

a First Spade.

$b$ Second do.

c $\Lambda$ flat Scoop, with turned-up edge, for cleaning out the bottom.

Fig. 4. - A Flauchter Spade, used for cutting turf to cover the small stones in the frequent drain. 
TRANSVERSE SECTION OF DRAINS, \&C., WITII SKETCHES OF IMIPLEMIENTS USED IN THEIR FORMATION.

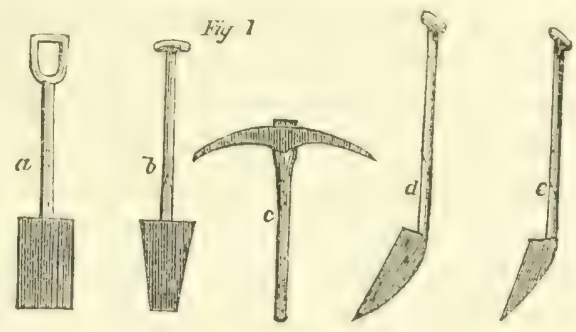

Fy 2
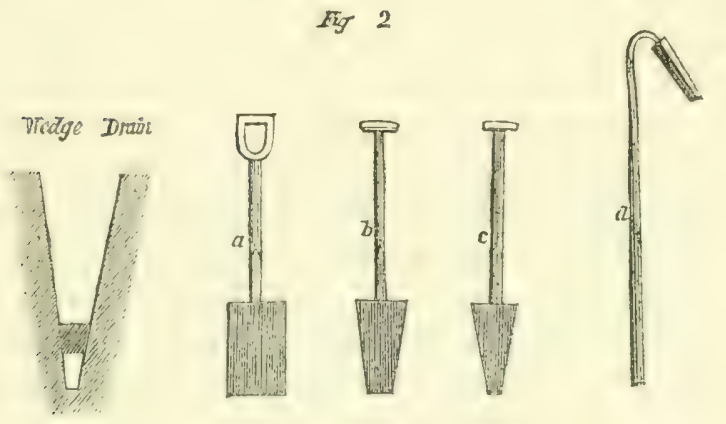

Fig. 3
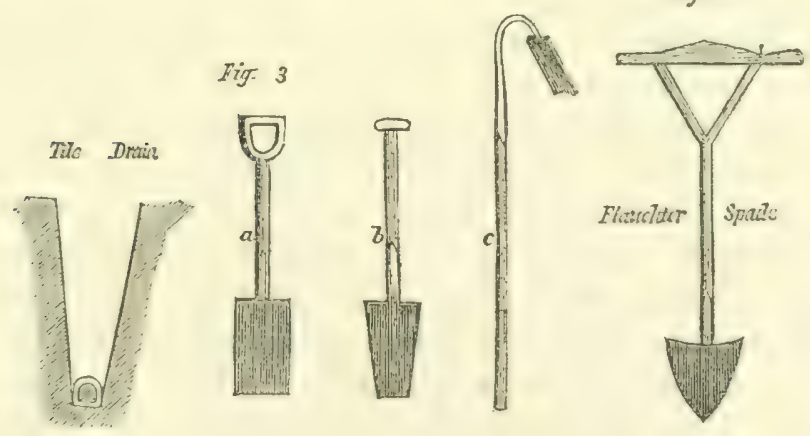

VOL. II. 


\section{C - NATIONAL CIARACTERISTICS. - A DIGRESSION.}

All hope of finding a Yankee skilled in the use of the spade, or able, or willing, whether able or not, to cut a drain with the same neatness and exactness as an Irishman, or a Scotchman, or an Englishman would do, must, I think, be given up, at least for the present. 'I'hey are not accustomed to apply themselves so steadily to a minute object. I have never yet found one, who could, or, if he could, was willing to make a straight drain. There are about them a hurry and carelessness of operation, what is vulgarly called an independence of temper, a conceit of their own superior sagacity and knowledge, and an impatience of being taught, - a necessary result, I believe, of our free institutions, and the general diffusion of a moderate education, which refuses to be commanded or directed. This is a temper of mind, which, I acknowledge, has its advantages, and is a great spur to improvement, but which is often excessively discouraging and inconvenient to other parties, who may choose to have their own work done in their own way, and who, when they pay liberal wages for services required, might with some reason expect to find a servant instead of a master. But servant does not, I believe, belong to a republican vocabulary. I am content.

In executing, as I have done, some miles of underground draining, I should have utterly despaired of accomplishing it, hut for the aid of some Irishmen and Scotchmen; and, I believe, I shall do no injustice by saying there is this difierence between the two: For patient labor and the free expenditure of his strength in such cases, the Irishman cannot be exceeded; and his skill in the use of the spade, and the pickaxe, and the shovel, is unsurpassed. But he needs always direction; he only imitates, and follows a lead. The Scotchman goes himself. He is equally severe and laborious as the Irishman; but he has a judgment of his own to guide him, and he always brings that judgment to bear upon his work. 


\section{CI.-TILE AND PIPE DRAINING.}

The thorough drainage of land now occupies the attention of the agricultural community in Great Britain more than any other branch of improvement connected with the soil. I know of none from which more important and beneficial results have been received, or may still be looked for. It will not be pretended that all soils equally demand it, or will be equally benefited by it; but, among the many instances which $I$ have seen, scarcely any have failed to meet the expectations of those persons who have adopted this means of improvement. 'The drainage of land, as I have before remarked, has been a practice of long standing; but, as connected with subsoil ploughing, it must be considered as of modern date.

I have spoken already of various modes of forming drains. That of draining with tiles or pipes remains to be treated, and in several respects the experience of the last two or three years has effected extraordinary improvements, especiatly in the construction of the tiles or pipes, and in the reduction of the expense of the operation. The expense was at first of a character to render the improvement quite formidable; but from an outlay of $£ 5$, or in some cases even $£ 10$, it is now reduced, under favorable circumstances, to $£ 2$, or even less, and the great hinderance to its general adoption is removed.

1. Improvenents in Form of Draining-Pipes. - Tiles were formerly made singly, and by hand. The clay was rolled out, and then pressed over a block into the shape of a horseshoe. In laying them in, it was deemed only necessary to lay them on a hard bottom of clay. But the running water constantly wore the bottom, and softened the clay; and the tile would sink into the clay, and the drain be rendered useless. The next improvement was to make them with feet; that is, to spread the bottom edge, on which they stood, outside, from a half of an inch to an inch in width, - thus, $\Omega$ - which served to prevent their sinking into the earth or clay upon which they rested. The next improvement was to construct a flat sole, to be laid in the bottom of the drain, which should be a little wider than the tile itself, and upon 
which it should be carefully placed. This sort of tile is still used in many parts of the country; and it is universally advised, as the result of the best experience, wherever this horseshoe tile is used, that it should always be placed upon a sole or bottom. For this purpose, the sole might be formed and baked like the tile itself. Where slates are plenty and easy to be had, they answer well as a substitute for the clay tile. The next step in the improvement of the form of a drain tile was to bend it in the form of a pipe, bringing the edges almost together, but leaving a seam at the under part for the admission of the water, as it was then deemed indispensable for this object that it should be done. The last improvement is that of making a complete pipe, of such a diameter in the bore as is deemed necessary; and these are now made by machines, of which there are several of very ingenious construction, and some of which produce eight or eleven pipes at a single operation, of a uniform thickness and bore, and all cut to the same length. Different matcrials have been used for the formation of draining tiles; some have been a mixture of various substances, principally lime and sand, and called concrete; but perhaps no better material can be found than the best of brick clay; and this, when properly prepared and well baked, will be found to endure for a length of time as yet unascertained. The proper preparation of the clay requires that the stones should be picked out of it, and that it should be finely ground and pulverized. Some persons insist that it should be washed; but the best machines are so made as to avoid this necessity. 'The speed with which some of these machines are operated, is quite remarkable; it being asserted, on authority which may be relied upon, that Hatcher's machine, when worked by a man and three boys, will turn out nearly 11,000 pipe tiles, of one inch bore, in a day of ten hours, and so in proportion for pipes of a larger liameter. $\Lambda$ machine invented by Mr. Scragg; of Calveley, Cheshire, "is equivalent," says Mr. Parkes, the engineer of the Royal Agricultural Society, "to the easy manufacture of more than 20,000 pipes of an inch bore per day of ten hours, and so on in proportion for other sizes. It is also worked," he adds, "at a less cost of labor, and with greater ease to the workmen, than any other machine with which I am acquainted." It must be admitted that this is a great advance in mechanical invention and improvement. 
2. Inportant Points in Draining. - Some most important points in draining seem to have been but recently established. 'The first is, that water enters the drain from the bottom, rather than from the top; that is, its tendency is always to seek the lowest level. The second point, which seems well determined, is, that pipes of an inch bore are sufficient, when laid down at proper distances; for the rapid and effectual removal of any quantity of water from the land, which is the eflect of rain upon the land. The third point is, that deep draining, though the drains be less frequent, is much more effectual than shallow draining, and that where drains of two feet deep have failed to run, or even drains of three feet have been ineffectual, drains of four feet on the same land have shown the presence of large quantities of water in the land, which otherwise would not have been removed. I have seen this completely demonstrated; and the testimonies on this subject are so multiplied within my own knowledge, that it may almost be affirmed that a single drain of four feet in depth will be more effectual in the drainage of a soil, than two drains of the same size laid at any depth less than three feet. 'The Duke of Portland, when I had the pleasure of examining his magnificent improvements at Welbeck Abbey, pointed out to me some land, which had been deemed sufficiently drained, and indeed much more deeply than was usual, but which, notwithstanding, continued to occasion rot to the sheep which were fed upon it; and the evil was not effectually removed until the drains were sunk to the depth of eight feet.

"Several respectable and intelligent farmers in Kent, who have laid drains very deeply in clays and stiff soils, assert that the flow from the deepest drains invariably commences and ceases sooner than from shallower drains after rain." 'This is a curious fact. That it should flow more copiously in such deep drains is to be expected, from the fact of a deep drain's affecting a larger extent of land than a shallow drain; but, as the gentleman who states this fact suggests, it is not so easy to account for the water falling upon the surface appearing in a drain four feet deep sooner than in one two feet deep. The fact, however, seems well established.

3. Results and Experience in Pipe Draining. - Depth of Drains. - I shall now proceed to state some facts, both in 9 * 
regard to the depth of draining, and the sufficiency of pipes of a small bore for the perfect removal, in a short time, of all the water that falls upon the surface. I must premise, however, that these are but a few of those which have come within my own personal knowledge; but, these being stated with accuracy and exactness, I shall avail myself of them.

Mr. Hammond, of Penshurst, in Kent, states that he has drained ten acres with the round tiles, and that he is "quite satisfied that they act better than any other yet made, as they are not liable to be disturbed by moles or other vermin, which the other sorts admit, and can be laid with greater nicety in the drains than in any other shape. The effect of draining I have experienced for twenty years, and am quite satisfied that no expenditure on the land will make so good a return; as the effect of relieving the soil of the stagnant water to the depth of three fect instantly admits the atmosphere, and what before had been inert becomes active soil, and the root will penetrate it, and rain afterwards will pass through the soil into the drains with beneficial effects, where before it was injurious." *

Mr. Parkes, in his capital papers upon draining, says, "Several farmers have under-drained lands again, which were previously shallow-drained; and they agree in stating the beneficial result, in every case, to have equalled their expectation, and to have quickly repaid the cost." Mr. Spencer, of Wrotham, in Kent, has successively drained two feet, three feet, and four feet deep, and has invariably found an increasing fertility to result, in the same field, from the removal of the water to a progressively greater depth below the surface.

Mr. Arbuthnot gives the subjoined account of his success in laying land dry by drains sunk to the depth of four feet. Two pieces of grass land, containing about seven acres together, had been attempted to be drained, but without success, by the ordinary process of shallow drains. He then undertook to sink deep drains to the depth of four feet, at distances varying from 25 to 45 feet apart, and to lay pipes at the bottom of each drain. At the time the work was in progress, there was scarcely any rain; but upon its completion there were some heavy showers, and the effect of the four feet drains was soon established. The

* Journal of the Royal $\Lambda$ gricultural Society, vol. iv. part i. p. 47. 
pipes in the furrows were $1 \frac{1}{2}$ inch in the bore; the pipes in the main drain were 3 inches in diameter. The rain rushed rapidly out of the new main drains, but none came out of the old shallow drains into the main drain. The lands soon became perfectly dry, which was very far from being the case under the shallow drains. Mr. Arbuthnot adds, "that he is so convinced of the effect of deep drainage, that, although the whole of the land which he occupies has been drained, partly with stones and partly with tiles, and, as was thought, to a tolerable depth, yet he designs to cross the old drains with deeper ones, in order to do all in his power to free the land from excess of water. Instead of using pipes of $1 \frac{1}{2}$ inch diameter, he would prefer the pipes of the cross drains rumning into the main drain to have been only 1 inch, being convinced that inch pipes would have answered every desired purpose." * *

On a subject so curious and important as this, I deem it proper to quote from a letter from Mr. Hammond (to whose experience I have before referred) to Mr. Parkes. "I found," he says, "after the late rains, that a drain eight feet deep ran eight pints of water, in the same time that another three feet deep ran five pints, although placed at equal distances. The circumstances under which this experiment was made, as well as its indications, deserve particular notice. The site was the hop-ground before referred to, which had been under-drained thirty-five years since, to a depth varying from 24 to 30 inches; and though the drains were laid somewhat irregularly and imperfectly, they had been maintained in good action. Mr. Hammond, however. suspecting injury to be done still to the plants and the soil by bottom water, which he knew to stagnate below the old draits. again under-drained the piece in 1842 , with inch pipes, in part to 3 feet deep, and in part to 4 feet in depth, the effect proving very beneficial. The old drains were left undisturbed, but thenceforth ceased rumning, the whole of the water passing below them to the new drains, as was to be expected. The distance between the new drains is 26 feet, their length 150 yards, the fall identical, the soil clay. The experiment was made on two drains adjoining each other, i. e., on the last of the series of the three feet, and on the first of the series of four feet

* Journal of the Royal Agricultural Society, vol. vi. part i. p. 130. 
drains. The sum of the flow from these two drains, at the time of the trial, was 975 pounds per hour, or at the rate of $19 \frac{1}{2}$ tons per acre in 24 hours; the proportionate discharge, therefore, was 12 tons by the four feet, and $7 \frac{1}{2}$ tons by the three feet drain. No springs affected the result. Hence we have two phenomena very satisfactorily disclosed - first, that the deepest drain received the most water; second, that it discharged the greatest quantity of water in a given time, the superficial area of supply being the same to both drains." 



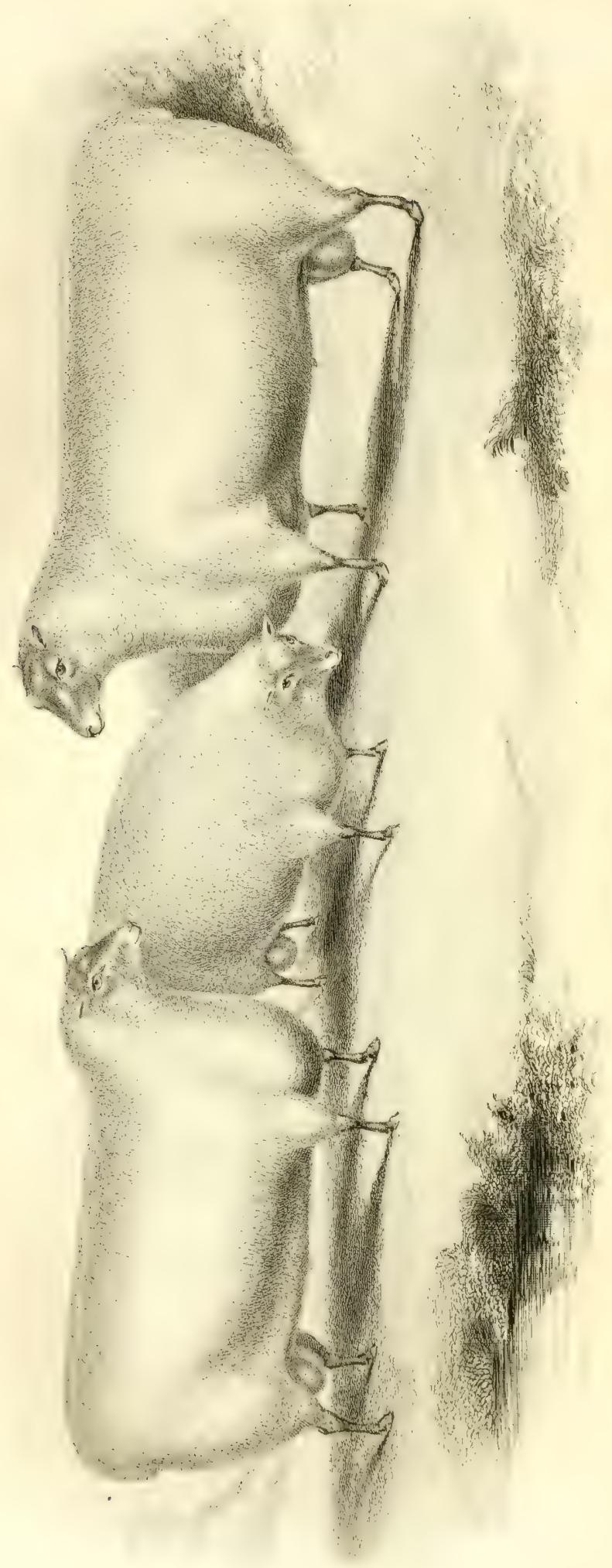




\section{EUROPEAN AGRICULTURE.}

\section{SEVENTH REPORT.}

\section{CI. - TILE AND PIPE DRAINING. (Continued.)}

ON this subject Mr. Parkes continues his remarks:- "The phenomenon of a deep drain drawing water out of a soil from a greater distance than a shallower one, is consistent with the laws of hydraulics, and is corroborated by numberless observations on the action of wells, \&c.; but the cause of the deeper drain receiving more water in a given time, is not so obvious. An opposite result, as to time, would rather be expected, from the fact of water, falling on the surface, having to permeate a greater mass of earth, both perpendicularly and horizontally, in order to reach the deep drain. A natural agricultural bed of porous earth resembles an artificial filter; and it is unquestionable that the greater the depth of matter composing such filter, the slower is the passage of water through it. In stiff loams and clays, however, but more particularly as regards the latter earth, the resemblance ceases, as these soils can permit free ingress and egress to rain water only after the establishment of that thorough net-work of cracks or fissures, which is occasioned in them sy the shrinkage of the mass from the joint action of drains and superficial evaporation. These fissures seem to stand in the stead of porosity in such soils, and serve to conduct water to drains after it has trickled through the worked bed; it is possible, too, that, in deeply-drained clays of certain texture, the fissures may be wider or more numerous, in conse- 
quence of the contraction of a greater bulk of earth than when such soil is drained to a less depth." *

The fact to which this very able writer refers has its difficulties, as I have before remarked; but it is to be considered that, as a larger surface is drained by a deep than by a shallower drain, the streams through the pores or the fissures of the earth, which empty into it, are, of course, larger, and so acquire an increased momentum in their progress. If the descent of the water in the soil was altogether perpendicular, the drain nearer the surface would, of course, be reached first; but in a drain inuch more water must come diagonally or obliquely, than perpendicularly. The more land to be drained, the farther the water must flow; the farther the water has to flow, the greater the volume of stream which is collected; the larger the stream, the more its momentum and velocity will be increased. This supposes, however, that the passages are already opened and formed. In the case of the artificial filter referred to, the water, descending perpendicularly, would of course reach the bottom later than it would reach any higher portion; but, supposing the filter to have been so long made that the liquid poured upon it had formed various passages, it seems to me not improbable that the mass of water poured upon it would reach a central point at the bottom where it was to make its exit, or a basin in which it was to be collected, as soon as any small quantity would be collected, at a point somewhat higher up; and that the larger the size of the filter in this case, the more surface it covered, from the increased quantity, and the increased rapidity of flow giren to the streams flowing to this point, the sooner it would become full, and even sooner than a point higher up, which would, of course, affect a proportionately less mass of surface to be drained.

4. Size of Pipes. - There has been so much conversation and discussion on the size of pipes, and the efficiency or capacity of small pipes of only one inch bore, in effecting the drainage of land, that I know I shall agreeably tax the attention of my reader by quoting further from Mr. Parkes's excellent essay on this subject.

"It was on the 9th of Norember that I inspected the drainage

* Journal of Royal Agricultural Society, vol. v. part ], p. 150. 
of Mr. Hammond's farm, recording the ficts, that, after a min of about twelve hours' duration, on the 7 th, I found the draius, on the 9th, in a nine-acre piece, three feet deep, just dribbling, and those in a hop-ground adjoining, four feet deep, exhansted; Mr. Hammond having observed, previously to my arrival, that the greatest stream at the outfall of each drain amounted to abont the half-bore of the inch pipe."

"The rain-gauge informs us that 48 of an inch in depth of rain fell upon each square foot of surface in the observed time of twelve hours. This quantity is equivalent to $69 \frac{1}{10}$ cubic inches, or $2 \frac{1}{2}$ pounds, which, divided by twelve hours, gives little more than $\frac{2}{x^{2}}$ of a pound per square foot of surface per hour for the weight of the rain."

"The drains were 24 feet asunder, and each pipe a foot in length, so that each lineal foot had to receive the water falling on 24 square feet of surface, equal to 60 pounds, or 6 gallons; and as the time which this quantity occupied in descending through the soil and disappearing was about 48 hours, it results that $1_{\frac{1}{4}}$ pounds, or one pint per hour, entered the drain through the crevice existing between each pair of pipes. Every one knows, without having recourse to strict experiment, how very small a hole will let a pint of water pass through it in an hour, being only one third of an ounce per minute, or twice the contents of a lady's thimble."

"The weight of rain, per acre, which fell during the 12 hours, amounted to 108,900 pounds, or $48_{\frac{1}{1}}^{6}$ tons, which on the whole piece of nine acres, is equal to $437 \frac{4}{10}$ tons; and each drain discharged 19 tons, equal to about $\frac{4}{10}$ of a ton per hour, on the mean of 48 hours; but when the flow was at the greatest, I find that each drain must have discharged at the rate of five times this quantity per hour, which affords proof of the faculty of the pipes to receive and carry off a fall of rain equal to $2 \frac{3}{2}$ inches in 12 hours, instead of half an inch - a fall which is quite unknown in this climate. Half an inch of rain in twelve hours is a very heavy rain. I learn from Mr. Dickinson that his rain-gauge has never indicated so great a fall as $1 \frac{1}{2}$ inch in 24 hours, and from Dr. Ick, the curator of the Birmingham Philosophical Institution, that only on five occasions has the rain there exceeded one inch in 24 hours, during the same period of eight years. We may, therefore, consider the fact of 
the sufficiency of inch-bore pipes for agricultural drainage to be fully demonstrated, both by experience and experiment."

5. The Philosophy of Draning. - The drainage of land is of such vast importance, that, although my remarks on the subject have been much extended, I may safely longer claim the indulgence of my reader. It may be safely laid down as an established principle, that, in order to the successful cultivation of the soil, the cultivator must have, as far as it can be acquired, the command of the water by which that soil is affected. I have already said that wetness may be ascribed to two causes; the first, arising from what are called permanent springs in the soil, which, of course, are more or less affected by the rain which falls, but whose origin may be sometimes traced to a considerable distance from the ground, which is covered or saturated by them; and secondly, from rain falling directly upon the field. The former can be remedied only by cutting off the spring or the channel in which its waters flow. The latter evil can be remedied only by a system of drainage, so frequent and so formed and laid, as to convey the water away in the shortest possible time. I call it an evil ; but, in the main, the rain which falls is, of course, an immense good - a great and powerful instrument of vegetation, without which no vegetation could prosper, or even survive. It becomes an evil only when it becomes stagnant. The effects of stagnant water in land are destructive to vegetation; or rather, under certain conditions, it may even produce a greater luxuriance of vegetation, but the plants produced in a very wet soil are unpalatable, imnutritious, and insubstantial. Animals fed upon them always lose condition, and the manure of animals so fed is almost worthless. I saw this strikingly illustrated in the magnificent park of the Duke of Bedford, at Woburn Abbey. Here there were many spots where the grass was luxuriant and abundant, on account of their excessive dampness, and which were entirely neglected hoth by the sheep and the deer; but wherever these places, once ivet, had been thoronghly drained, they became the farorite resorts of the animals, and were fed as closely as possible. I have witnessed similar results in many other cases.

Water is an element in the food of plants, composing, in some instances, as in the tumip and potato, a large proportion of their 
substance; the former, it is stated, containing nearly 90 per cent., the latter varying from 70 to 80 per cent. Water, filtering through a soil, opens its pores to the admission of air, which is most essential to the growth of the plant, or perhaps, more properly speaking, to the fertility of the soil. Humboldt observed that argillaceous soils and humus deprived the air of its oxygren. He satisfactorily ascertained that earth taken from the galleries of mines at Salzburg only became fertile after having been exposed to the atmosphere for a considerable lengti of time. These observations established the necessity of the presence of oxygen in the interstices of the soil, or, as he then said, and as may still be maintained, the utility of a previous oxidation of the soil. All our agricultural facts, indeed, confirm this view of the necessity of air in the interstices of the soil that is destined for the growth of vegetables. When, by ploughing very deeply, for example, we bring up a portion of the subsoil into the arable layer, in order to increase its thickness, we always lessen the fertility of the ground for a time: in spite of the action of manures, and of any treatment we may adopt, a certain time must elapse before the subsoil can produce an advantageous effect; it is absolutely necessary that it have been exposed to the atmospheric influences; and it is then only that deep ploughing, which gives the amble layer a greater thicliness, pays completely for the expense it has occasioned.*

Water contributes, in the next place, when filtering gradually through the soil, to dissolve the manures, and prepare them to assist in the growth of the plants - in some cases, for the elements of these manures to be taken up by the plants. But water in too great abundance destroys these manures, and carries them away. Rain water, falling upon the surface, when the temperature of the air is higher than that of the soil, contributes to increase this temperature of the soil. Water, when stagnant in a soil, diminishes its temperature. The extreme wetness of a soil renders it diflicult to be worled; impedes the sowing or planting; often destroys the seed and the crop; occasions it to become poached or inaccessible to animals; and in many other ways may be said to make the cultivation of such soils hopeless. 
The rain water which falls upon land may be detained by two circumstances - the first by the impervious nature of the upper soil, which may be an adhesive and strong clay, through which the rain cannot percolate; the second, by an impervious or indurated subsoil, either of clay or of hard pan, which holds fast the water when it reaches it, and consequently the upper portions become saturated or flooded. In respect to the former, the adhesive clay, though there have been some failures, yet there are many remarkable instances, where, by a system of under-draining and subsoil-ploughing, the hardest soils have been opened and rendered comparatively dry and friable. When a ditch or drain has been dug, the tenacity of the neighboring soil has been loosened, and the drying of the soil in the hot sun of summer has, under such circumstances, caused it to crack in various directions, and, these fissures being once opened, channels for the trickling of water have been formed; others have followed from contiguity, and these adhesive soils, by a course of cultivation, have been loosened and reduced to a condition of unlooked-for dryness and fineness. Where the wetness of the soil has been occasioned by a hard and impervious subsoil, this evil has found no other effectual remedy than in deep draining, and the thorough breaking up of this hard layer by the subsoilplough. The stratum below is often found pervious to the water, which makes for itself a ready exit, when it once reaches it. Some persons are of opinion that, if it were possible to prevent it, it would not be desirable to draw off the water beyond a depth of from four to five feet, - regetation ordinarily not extending beyond this, - thinking that, in time of drought, the upper surface might be benefited by the evaporation of the water at this depth, or its ascent by the process of capillary attraction. It is useless to speculate in this case, as such a matter must be almost wholly beyond our arrangement or control. I ought to add that, where this adhesive soil is once loosened, its porosity - if I may borrow a hard word - is often much assisted by the common earth worms, who penetrate it in various directions, and, directed by natural instinct, aim especially at the drains or places where the water is found. Thus it is that we are often served by our most humble friends, and in circumstances where we never think of recognizing the obligation. 
6. Magnificent Agricultural Improvements, and their Moral Results. - These may be considered as the general principles of draining; and, as I have before remarked, it must be placed almost at the head of British agricultural improvements. Much as it has already done in commection with subsoilploughing, it may be said only to have begun its work; and it seems destined to double, in many cases to quadruple, the agricultural products of the kingdom. The scale on which it has been carried on, by some distinguished improvers, may well excite surprise on the other side of the water. The Duke of Portland, it is stated, had some time since completed more than 7000 miles of drainage on his estates, although much of this was done before the system of subsoil-ploughing was introduced. The Duke of Bedford informed me that he made about 200 miles of drainage on his estates in a year, and about 50 miles in his Park grounds. This was all executed in the most excellent manner.* Lord Hatherton at Teddesley Park, whose

* The Duke of Bedford was kind enough to give me, while enjoying the unaffected and princely hospitalitics of Woburn Abbey, an account of his draining operations for three years, which I shall here subjoin. It will interest an intelligent reader, by showing him the extent to which agricultural improvements are carried in this country; and it will illustrate another point, to which I have more than once referred, the accuracy with which, on such estates, the farming accounts are kept - a matter which cannot be too much insisted on.

"An Account of Draining on the Duke of Bedford's Bedfordshire Estatcs, in the Years 1841, 1842, 1813, and 1844.

\begin{tabular}{|c|c|c|c|c|}
\hline & Acres. & 'Tiles. & Cost. & $\begin{array}{l}\text { Average } \\
\text { Cost per } \\
\text { Acre. }\end{array}$ \\
\hline "In winter of 1841 and 1842:- & & & $f \quad s . d$. & f s. $d$. \\
\hline Woburn Park and Grounds. . & 90 & 254,950 & $864 \quad 57$ & 9120 \\
\hline Woburn District. ............ & 90 & 240,300 & 618175 & 740 \\
\hline Bedford District ............... & 203 & 392,760 & 109585 & 10 \\
\hline "In winter of 1812 and $1843:-$ & & & & \\
\hline Woburn Park and Grounds... & 71 & 194,505 & 61240 & 8120 \\
\hline Woburn District........... & 277 & 625,750 & 1587147 & 5150 \\
\hline 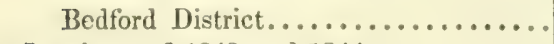 & 232 & 492,845 & $1409 \quad 09$ & 610 \\
\hline "In winter of 1843 and $1844:-$ & & & & \\
\hline Woburn Park and Grounds.......... & 100 & 180,000 & $636 \quad 05$ & 6120 \\
\hline 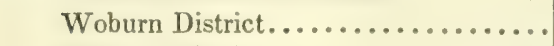 & 243 & 494,150 & 1411181 & 5160 \\
\hline Bedford District............ & 228 & 430,300 & $1391 \quad 1 \quad 1$ & $\begin{array}{lll}6 & 0 & 0\end{array}$ \\
\hline
\end{tabular}

"Note. - The greater cost per acre of draining in the Park than upon the 
admirably improved estate I have had the pleasure of repeatedly visiting, had, some years since, completed the drainage of more than 467 acres, at an expense of $£ 150817$ s. $4 \mathrm{~d}$.; and had increased the rental of his land, by these operations, to the amount of $£ 4352 \mathrm{~s} .4 \mathrm{~d}$. per year, or at the rate of 29 per cent. upon the capital expended. The main drains here were laid about three fect deep, with tiles about five inches wide by twelve inches long. The branch drains are about two feet six inches deep, and are laid with tiles about four inches wide by twelve inches long. In some of the valleys, the substratum is of a loose mixture of sand and gravel; and in those places it was found neccssary to adopt drains varying from five to eight feet deep, which pour forth large bodies of water, both in summer and winter.

It may be said, such is the rapidity with which agricultural improvement is advancing in this country, that a great revolution has been effected in the system of draining since these splendid improvements were accomplished; and that draining fully as efficient as the above is now reduced to one half of the expense.

The country abounds with examples of agricultural improvement on the part of individual proprietors, if not upon so extensive a scale, yet, in proportion to the ability and means, quite as enterprising and spirited. It is truly delightful to witness such an application of wealth; and the benevolent mind is never more disposed to envy the possession of power than when it is this beneficently exerted. The erection of magnificent houses or palaces in a city, far beyond one's needs, I am not disposed to deny, does good, as it creates a demand for ingenious, industrions, and, to a degree, useful labor, and circulates a large amount of

estate, arises from the carriage of tiles and soles being included in the former, which in the latter is done by the tenants without charge.

"The saving in Park draining, in 1842 and 1843, was in labor chiefly, that being lower in 1812 and 1843 than in 1841 and 1842 .

"The additional saving in 1843 and 1844 was, by putting the drains one yard further apart, viz., 6. yards, instead of $5 \frac{1}{2}$, as in former years. The depth of the drains was increased, and the labor also, but the value of the tiles saved in quantity was considerably more than the increase of labor.

"The difference in cost of draining, between one part of the estate and another, is occasioned by the various sizes of the lands, as, in high-ridged and crooked lands, the drains follow the water furrows, at whatever distance they may be." 
wealth where it is needed. There is a pleasure, likewise, in contemplating the skill and architectural taste displayed in their structure, the beanty of their arrangements, and the luxury and splendor with which they are adomed and furnished. But often they are mere monuments of vanity and display; they are a serious drawback upon the resources of the proprietor; they are much beyond his wants and convenience; they involve a necessity of a style of living which sometimes brings with it as much vexation as pleasure; and the wealth which is expended upon them is locked up, to a great extent, in a profitless disuse, or otherwise may be considered, as far as it exceeds the necessities, or convenience, or uses of the proprictor, as irrecoverably thrown away.

But how different are the results of the application of wealth to the purposes of agricultural improvement ; in converting land which is waste into that which is productive; in the employment of the poor in useful and healthful labor; in increasing the means of human and brute subsistence; in advancing the real wealth of the community; in the actual creation of wealth without loss or injury to any one; in making improvements, which have in themselves a reduplicative energy, so that the more improvement is made, the more the power of improving is extended and enlarged; in exhibiting an example of skill and success. which excites no ill-will, becanse it injures no man's interest, but is every where beneficial, and prompts to a wholesome emulation; which leaves behind it not traces drawn in the sand, to be obliterated by every wave which time rolls upon the shore, but which are to endure for generations and centuries to come; and which, in truth, constiutes one of the most honorable and enduring monuments, which a reasonable and well-disciplined ambition of posthumons reputation and fame can desire or seek after!

7. Sorls to be dranen. - In revicwing this important subject of the drainage of land, - one, certainly, of the most important connected with the art of husbandry, - I deem it best to recapitulate some points, which have been partially noticed, and are to be deemed established.

The removal of water from the land is, then, in all cases, indispensable to a successful cultivation. Where it proceeds 10 * 
from permanent springs, they must either be cut off or led away by a drain which shall directly reach them. There are very few lands which would not be benefited by draining. Wherever a spot is discovered in a field, where the water is accustomed to lodge, or which, from the coarseness or character of the herbage growing upon it, indicates the presence of water, we may feel sure that there the operations of draining are required. In the next place, it is desirable that the wetness arising from rain should be removed as soon as practicable. All the advantage which plants derive from rain are obtained from its immediate passage through the soil. Whenever its passage is arrested, and the water becomes stagnant, its presence is injurious, excepting to plants which are, like rice, for example, of an aquatic, or, as it may be termed, an amphibious character.

That soils of a light and sandy character are benefited by draining, I have had the fullest demonstration, and shall presently show. That soils of a most retentive and adhesive character have been greatly improved by it, seems to be established in many cases, though there are instances of failure in this respect; and an intelligent and spirited agriculturist in Yorkshire, with whom I have the pleasure of an acquaintance, has proposed that analytical experiments should be made, to determine what proportion of aluminous matter in a soil should discourage any attempts at improvement, by draining and subsoiling. Perfect success has followed the operation where the amount of clay or alumine has been as great as 24 per cent.; and failures have occurred, where the proportion has been 43 per cent., which induces the conclusion with him, that the boundary must lie somewhere between these two points. This, he thinks, experiment alone can decide. It must not be overlooked, however, that other circumstances besides the actual composition of the soil, may have affected the results. Mr. Hammond, before quoted, has been suceessful in draining heavy and adhesive soils, where, after the drains have been opened, and the pipes laid and but slightly covered, the frost has had an opportunity of operating upon the land, and occasioned fissures, which have been converted into permanent pores or chamnels for the water falling upon such land to reach the drains. There is always some encouragement in the simple fact, that one drop of water is sure, in its natural course, to follow another. There are. 
however, undoubtedly, some soils, where, from their impervious character, draining would be almost hopeless. It is difficult to pronounce beforehand what soils come under this description. It is certain that many soils, which were considered beyond the reach of this species of improvement, have been subjected to it with great and permanent advantage. In many cases, the character of the soil, whether suitable or unsuitable for drainage, might be easily ascertained by sinking a hole of the depth to which it is proposed to drain, and, securing it from the access of rain, or of water running upon the surface, ascertain whether any water would filter into it.

8. Associntion for Drainage. - The drainage of land upon the most improved principles and method, may be considered in England as a branch of engineering, to the successful application of which both science and much practice and experience are requisite. For an individual to undertake it upon any extensive scale, without sufficient knowledge and skill, would be likely to terminate in disappointment and loss. It would seem as though no better plan could be adopted than that which has been recently undertaken, viz., the organization, with an ample capital, of a draining association. This company, under the name of the West of England and South Wales Land Drainingry Company, propose to establish, in different and convenient parts of the country, where the clay is abundant and suitable, tileries for the manufacture of pipe tiles; they mean to secure to themselves always the services of accomplished and practical engineers, and, having proper tools and experienced workmen, they will undertake the effectual drainage of whole farms, guarantying that the work shall be executed in a correct and perfect manner; and in this way at a great saving of trouble, and at a great deal less expense than it could be effected by individual effort and cuterprise. It is difficult to conceive of an arrangement from which, if skilfully and liberally managed, more advantages may result. An extensive and thorough system of drainage will, beyond all question, effect for England the greatest and best improvement, in an agricultural view, which can possibly be looked for. "The effect produced on the crops of close, retentive soils, after they have been perfectly drained and subsoilploughed," says Mr. Morton, "is most astonishing. The prod- 
uce is so much increased, that it will, in many instances, pay the expenses in a year or two; and wet soils, which seemed to be strong clay when wet, become friable, and even light, when completely subsoil-drained, are easily cultivated, and light enough for producing turnips to be fed off with sheep. Complete or perfect drainage is the foundation of all improvements in husbandry; it should, therefore, be the first step which we take in attempting to improve or ameliorate the soil."

9. Thie Process of Dranning. - In looking at a field or piece of land, which is proposed to be drained, the first thing to be ascertained is, what fall can be had for removing the water. A fall of one in two hundred is stated, by practical men, to be the extreme on one side; but it is desirable to get, if possible, one in a hundred. With such an inclination, the drains are more likely to be kept free from sediment. The next step to be taken is, to lay out and form a main ditch or drain, into which all the small drains shall empty themselves, and the water be carried off. This, of course, must be in the lower part of the land, and it is generally advised to let it remain open, that the months of the small drains may be observed and watched. Where left open, as at the model farm of Lord Ducie, there the inclination of the sides is so easy that they are cultivated to the water's edge. It is advised, in other cases, to let the side drains empty into a common main drain, which is to be covered; and this main drain is to empty itself into an open ditch. The principal reason assigned for having all the underground parallel drains empty themselves into the main, and through that into the ditch, instead of each emptying itself into the ditch, is, that while, in the latter case, a hundred months would require to be kept open and clear of rubbish, in the former only one has to be attended to ; and also that, duriug the summer months, some of the parallel drains wonld become dry, and allow the entrance of moles and rats, which would soon stop them up; but that the quantity of water which always issues from a main drain would forbid their entrance, and thus hinder them from injuring it or the others.* Where the bottom of the drain, however, is formed with broken stones, there is no danger from this circumstance; and where the 
pipe drains of only one iuch bore are used, they do not admit of the entrance of vermin. On Mr. Smith's plan, however, the main drains are covered as well as the side drains, and the entrance or ontlet of the main drain may be protected by an iron grating, or a foot or two of broken stone laid down at the end. It is advised that the main drain should be sunk six inches lower than the side drains; but where pipes are used, the side drains may enter directly into the main drains, the pipes being made with a hole in the side, for this express purpose. It has been found quite effectual, in some cases, to lay two pipes for a main drain, side by side; but it would seem most desirable to have a pipe of a large bore for the main drain, and of a sufficient size to receive all the water which should be emptied into it from the side drains. Such pipes, at Mr. Stirling's, near Falkirk, were of a very large bore, and made in three parts, so as exactly to fit each other when brought together. The advantage of a concave or circular bottom for the water to flow in, in preference to a flat sole, must be obvious at first thought. Tiles have been constructed with a circular bottom, like a horse-shoe set upon its front edge, and a flat cover to rest upon it; but 1 can see $n$ advantage which this has over a pipe; unless it might be that, by the removal of the cover, the seat of any obstruction might be ascertained without lifting the whole.

It is often found necessary to make what are called submain drains, which of course communicate with the main drain. This must depend upon the nature of the ground, and where these submaius are made on the side of a hill, they are best made obliquely, crossing the small drains diagonally, and thus giving an impulse to the water received into them. It is advised, in all cases, to make the parallel drains, which connect with the main or the submain, straight, whether runuing on level land, or on a side hill; and it is deemed best that no small or parallel drain should ever exceed two hundred yards in length, without emptying into a main or a submain drain. The distance at which the drains should be placed apart may vary with the nature of the soil, from a rod to forty or sixty feet. It may be interesting to know the length of drainage, or of pipe, which may be required in an acre, at the different distances which are customarily adopted. I subjoin, therefore, the following table:- 


\begin{tabular}{|c|c|c|}
\hline $\begin{array}{c}\text { Distance between } \\
\text { Drains. }\end{array}$ & $\begin{array}{c}\text { Length of Drains } \\
\text { in Furlongs. }\end{array}$ & Feet of Pipes. \\
\hline 66 & 1 & 660 \\
44 & $1 \frac{1}{2}$ & 990 \\
33 & 2 & 1320 \\
22 & 3 & 1980 \\
$16 \frac{1}{2}$ & 4 & 2640 \\
\hline
\end{tabular}

"On the heavy lands of Suffolk, and the adjoining counties," says one farmer, "under-draining at a distance of $16 \frac{1}{2}$ feet, and at a depth of 26 or 30 inches, is as much a matter of routine as hedging and ditching." This depth would now be deemed quite insufficient.

The mode of covering drains is various. Where the drains are filled with broken stones, it is advised to lay upon the top of the stones an inverted sod, and then return the dirt which has heen taken out. Where a pipe or tile and sole are used, the same advice may be given. In adhesive or clayey soils, it is deemed quite objectionable to return the clay, and ram it in closely upon the pipe. It has been deemed important, by some persons, that alternate pipes of a large and a small bore should be used, so that the small pipes may enter the larger ones, and that there shonld be no interruption of continuity between them. In some cases, rings of clay have been formed, into which the ends of the two pipes might enter, so as to close the interstice, and retain the pipes upon a level. This is not, however, deemed necessary. Where the bottom is hard, and the pipes carefully placed, there is no danger, afterwards, of their getting, if the term may be allowed, misfitted; in cases where the bottom is sandy or loose, more pains must be taken to prevent this, which is easily done by an experienced and careful drainer.

10. Fxamples of Draynage in Ireland. - I have now, I believe, enumerated the principal points to be observed in draining a piece of land according to the most improved system. With a view the better to illustrate this important subject, I subjoin a plan of the drainage of a farm in Ireland, belonging to Messrs. Andrews, of Comber, county Down; (see p. 120,) together 
with their general account of the process. 'This was executed exactly according to the directions of Mr. Smith, of Deanston, with tiles, and a foot of broken stone laid in upon them; and before the pipe tiles had received so much of the public approbation as has since been deservedly bestowed upon them.

"The accompanying map represents that portion of the lands in the townland of Carnesure, which has been thorough-drained up to the present time. Another part of the farm, in the townland of Comber, containing $19 \frac{1}{4}$ acres, was drained in 1841. The specification on the map exhibits the quantities drained in the respective years 1841, 1842, 1843, and 1844, each of which comprised the portion which the course of cropping enabled them to manure, and to place under green crops in the succeeding year.

"In the year 1843, they completed the thorough-draining of 58 s. 3 R. 7 P. statute measure, by the execution of 7172 statute perches parallel, 793 perches submain, and 128 perches main drains; and in 1844,58 A. 1 R. 37 P., by 7720 perches parallel, 781 submain, and 20 perches of main drains, being, in the years 1843 and 1844, 117 A. 1 r. 4 P. statute measure, viz. 14,892 perches statute of parallel drains.

$\begin{array}{rlll}1,574 & \text { " " } & \text { " submain " } \\ 148 & \text { " }\end{array}$

"The mode of execution has been precisely the same as that which Mr. Smith characterized as 'most thoroughly following out the Deanston system.' In the whole of the land drained, there is not one open channel for water; all the water passes away under ground, and the wheat seed on the potato land has this year been covered with the grubber, without any ploughing, after the removal of the potatoes, leaving the land perfectly flat, and without a furrow, as recommended by Mr. Smith, so that every stalk of grain will benefit equally from both the soil and the atmosphere; and during the late rains, even on sloping ground, not a particle of the fine soil has been washed from the land, while, in the undrained lands around, the roads and ditches are filled with the fine deposits from the streams of water which have rolled down the furrows, and the rivers are red with the still finer matter which they are hurrying to the bottom of the sea. This advantage is attained without any attendant evil; they look to the total abolition of every water-furrow from the fields" 
Plan of the Thorough Draining on Part of the. Townland of Carnesure, the Property of Messrs. Andrews, of Comber, County Down, to which the Gold Medal of the Society was awarded for 1844.

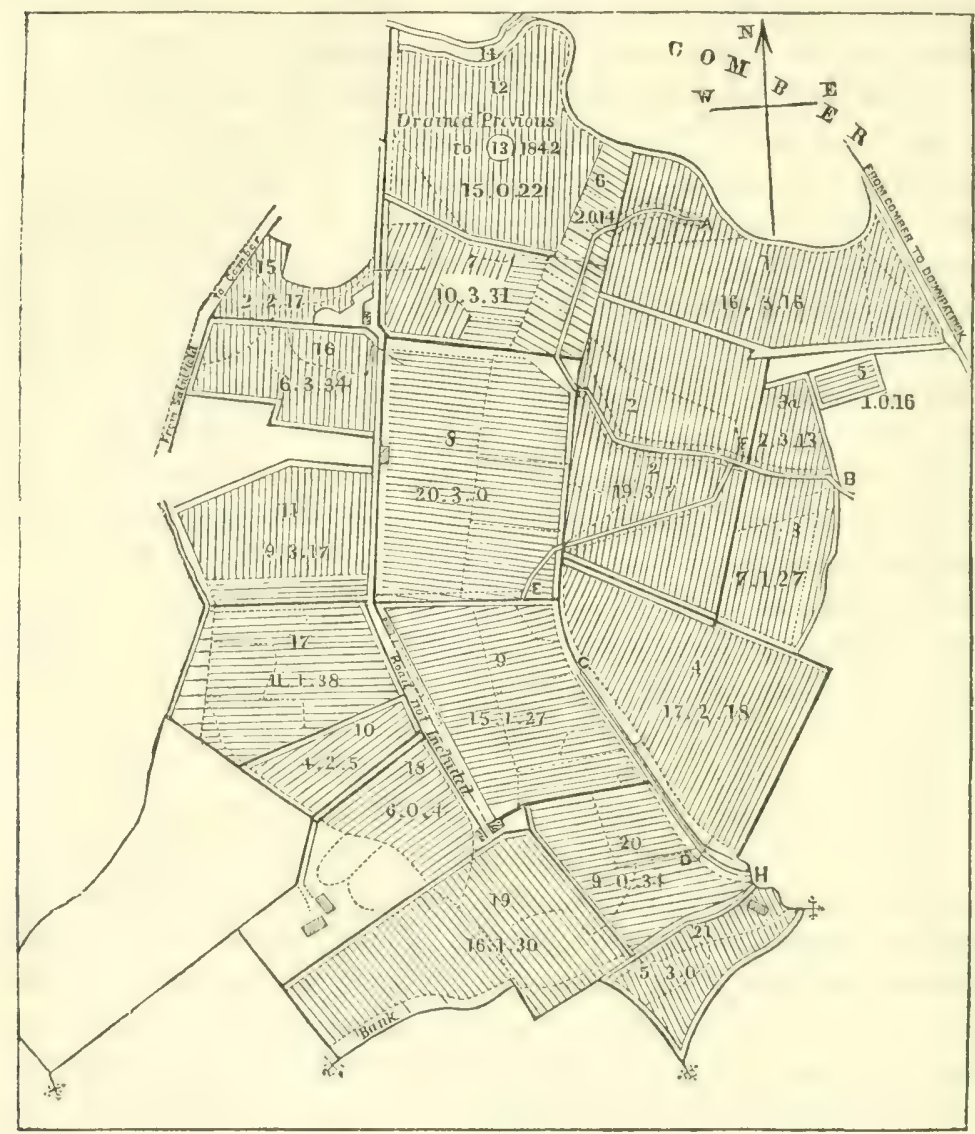

REFERENCE.

\begin{tabular}{|c|c|c|c|c|c|c|}
\hline & A. & R. & P. & $\begin{array}{l}\text { Length of } \\
\text { Main Drains. }\end{array}$ & $\begin{array}{l}\text { Length of Sub- } \\
\text { main Drains. }\end{array}$ & $\begin{array}{l}\text { Length of Par- } \\
\text { allet Drains. }\end{array}$ \\
\hline \multirow{5}{*}{$\begin{array}{l}\text { Ground drained in } 1841, \text { contains } \\
\text { Do.... do... in } 1842, \ldots \text { do. .. } \\
\text { Do... do... in } 1813, \ldots \text { do. } \\
\text { Do... do.. in } 1811 \ldots \text { do. . }\end{array}$} & 15 & 0 & 22 & - perches. & $15 t$ perches. & 2018 perches. \\
\hline & 70 & 1 & 14 & $148 \ldots$ do. . & $715 \ldots$ do. . & $8370 \ldots$ do. \\
\hline & 58 & 3 & 7 & $128 \ldots$. do. . & $793 \ldots$. do. . & $7172 \ldots$ do. \\
\hline & 58 & 1 & 37 & $20 \ldots$ do. & $781 \ldots$ do. . & $\pi 20 \ldots$ do. \\
\hline & 202 & 3 & 0 & 296. & $243 \ldots$ & 25280 \\
\hline
\end{tabular}

NotE. - Main Drains are shown thus, Submain Drains,...... thus,

Parallel Drains, ....... thus, 
"The parallel drains are at least 30 inches deep, with 12 inches of small stones; the submains are 6 inches deeper, laid with slates and tiles, and filled with stones to the level of the parallel drains, and both are carefully levelled, turfed, and firmly cramped; and the mains, flagged in the bottom, built with dry masonry, and covered with coarse flags, are placed at depths, and constructed of dimensions, in all cases exceeding what Mr. Smith has considered sufficient to carry off the entire water from the submains, during and subsequently to the heaviest falls of rain.

"The soil, as stated in last Report, rests on the grauwacke slate formation, and the subsoil, as described by Mr. Smith, 'consists chiefly of a clay drift, with gravel stones thickly interspersed, and occasional boulders of considerable size.'

"The work of thorough draining of every year has been followed up in the succeeding year by subsoil-ploughing. All the land drained in 1843 was subsoiled and in green crops in 1844, and that drained in 1844 has been undergoing the process of subsoiling, which will soon be completed."

"As regards the profits to be derived from capital expended in thorough-draining," these gentlemen say, "our experience fully realizes our largest expectations. In green crops the increased return is most conspicuous. In undrained land in a wet year, potatoes and turnips have ever proved wretched crops; and all attempts to clean the ground have invariably failed. In 1840 , our crop of potatoes on wet land did not exceed 200 bushels per Cunningham acre; this year we ascertained, by actually weighing, on the weigh-bridge, the entire crop of potatoes, of the kind called cups, from field No. 4, containing above 17 statute acres, (excluding the head lands from the calculation, both as to crop and measurement,) that the produce was,

Tons. Cwt.

Per statute acre, 472 bushels, of $56 \mathrm{lbs}$. each, or $11 \quad 16$

Per Cunningham or Scotch acre,610 . . $15 \quad 5$

Per Irish acre, 766 . . . . . . . . . . 193

"Aud on field No. 7 , several trials were made of drills dug the length of the field, the kiuds being lumpers and other coarse varieties; and the produce was at least one sixth greater than that of the cups.

"This we regard as very great produce, and the difference 
between such a crop and the starved produce of 1840, on land equally good, would more than doubly repay the entire cost in one year. On the average of wet years, we think it may fairly be reckoned, that the increased return of one green crop would amply repay the costs of draining. Of the increased return from white crops we cannot yet speak so definitely; but the crops on our drained land have been very luxuriant and satisfactory, and the weight of the wheat which was threshed for seed in November this year, was $633^{3}$ lbs. per bushel, which exceeds what we have ever before experienced, in the best years, on our farm.

"The clover and grass seeds have all succeeded much better than we have been accustomed to for many years, and are now luxuriant, and thickly planted on lands which have for some years appeared clover sick; probably owing to the treasures of the subsoil being laid open to them, and possibly also to the higher temperature of the dry soil preventing the injury by frost to the crowns of the clover plants, to which some observers have attributed the failure of clover.

"That the subsoil is so laid open, is abundantly proved by the roots striking downwards, as far as the depth of the drains admits air to the subsoil; for we have extracted from our drained land the tap-roots of Swedish turnips more than two feet in length, Nature having doubtless taught them to search in the subsoil for that inorganic food, of which the upper soil, by long cropping, had been largely exhausted, but which subsoil they would not have dared to penetrate, had it been saturated with stagnant moisture, to the exclusion of atmospheric air.

"We do not feel it necessary to enter into any further details or observations; we can confidently recommend all who may read this Report to embark in the same course of improvement, which we at first commenced with caution, and have pursued and extended with increasing confidence and satisfaction as we proceeded. The expenditure has been serious; but we entertain no doubt of an ample remuneration."

To this I shall subjoin the statements of another eminent improver in Ireland, who has very successfully drained land to a large extent.

"The character of the land drained is mostly an adhesive clay, and the subsoil of a bluish-yellow clay, with a mixture of large stones, forming a very retentive and impervious mass. 
The rock, which is of the grauwacke slate, comes near the surface, and in some instances prevented the drains being eut as deep as might have been wished. The average height of the land drained is about 200 feet above the level of the sea, with a western aspect. The higher portion of it, previous to being drained, was wet, shallow, and sterile, and the lower part a heavy, stiff clay, which, in unfavorable seasons, was almost impossible to prepare for drilled crops. The effect of the drainage on all this land is very conspicuous, particularly on 140 acres which have been subsoiled. The land is now a deep and free soil, producing excellent crops of potatoes, turnips, and carrots, when previously it was quite unsuited to drilled crops.

"I would, however, from any conclusions I can draw from experience, beg to recommend, in ordinary cases, where the rock does not interfere, and where sufficient fall can be obtained, that the drains should be cut at least three feet deep, and that tiles and soles, or pipe-tiles, should be used in preference to stones, both as to efficiency, and above all to permanency.

"I am fully satisfied, in the greater number of instances, that much expense may be spared in materials for filling, by increasing the distance between, and adding to the depth of the drains. One great advantage in favor of the deep drains is, that they are calculated to be more permanent, and that, while in wet weather they discharge fully as much water, they continue in operation a much longer time, and in many instances continue to give out water for weeks after the shallow drains have ceased to discharge upon similar soils.

"The following is a description of the manner in which the drains at Ballyleidy have been executed: The submains are laid off on a considerable declivity, and cut six inches deeper than the parallel drains, with a slate and a large tile laid in the bottom of each, with stones carefully conpled over the tiles, and six inches of broken stones placed over all, then neatly turfed. Iron grates are built in at the mouths, where these submains discharge, so as effectually to prevent the entrance of any kind of vermin. I am now satisfied that the most permanent submains are two tiles reversed, forming a pipe, and thus confining the water so as to give it force and pressure, to clear away all obstructions.

"The parallel drains were neatly cut, and, where stones were 
used, filled 13 inches deep, the stones regularly levelled, which were all screened, and broken, to pass through a three-inch ring; then covered with a thin sod, which was well tramped down.

"When the tiles and stones were both used, about 25 tons of well-broken stones were put over the tiles to the acre, and the drains well sodded.

"It was also found necessary to build a large main drain for conveying the water from about four hundred acres, through a large tract of ground, which added considerably to the expense.

"In May, 1844, preparation for turnips was commenced upon it, and all parties previously acquainted with it were astonished at the change. It had become deep, free, and open, one ploughing and harrowing being quite sufficient to prepare it for drilling. Fifty barrels of lime to the acre was applied, after the first stroke of the harrow, and then well harrowed in with a heavy iron harrow, mixing it minutely with the soil, to the depth of 5 or 6 inches. It was then drilled and sown with Swedish turnips on the 6 th and 7 th of June - part being manured with $4 \mathrm{cwt}$. of guano to the acre, and part with 2 cwt. of guano and 12 bushels of crushed bones: the result has been a superior crop - the medal given by the Royal Agricultural Society to local societies. for the best cultivated 5 acres of turnips, having been awarded by the Bangor Farming Society for this crop. I have every reason to believe that all kinds of crops usually grown in this neighborhood may in future be grown on it successfully; that they may be sown or planted at times, particularly after heavy rains, which would have been impossible before draining, and that in all cases, with the same manure and labor, there will be fully one third of an increase in the crop."

'This gentleman proceeds with some observations, which are quite worth recording.

"It may be proper to remark why it is that I recommend drains to be made deeper and farther apart than those which have been executed at Ballyleidy; and why I prefer tiles, while a large portion of the drains at Ballyleidy have been made with stones.

"In the first case, it is from the experience obtained by a careful examination of the effects produced by drains of diflerent depths, that I have become convinced of the superierity of deep over shallow drains. With respect to stones, it was a matter of 
necessity using them here, as I have been long satisfied that tiles or pipes are preferable. It was only the difliculty of obtaining tiles in time at a reasonable price, which prevented them being used in all cases. I may also observe, that I have in many instances put stones over tiles, but now believe that even in the stiffest clay this is unnecessary, the drains which have been made with tiles alone being equally efficacious. The tiles, where stones are not put over them, are less liable to be injured or broken, and of course calculated to be more permanent - an object which, in such an important improvement, should never be lost sight of.".

\section{$\longrightarrow$ \\ CII. - SUBSOIL-PLOUGIING CONNECTED WITII THOROUGH-DRAINING.}

I have given these general examples of thorough-draining, which might be multiplied, under my own observation, to a very great extent, and have to add that this improvement is preparatory to subsoil-ploughing, and intimately connected with it.

I have already fully described the nature of subsoil-ploughing. Trench-plonghing is sometimes mentioned. By trench-ploughing, the under soil is brought to the surface, and, in fact, it is no other than deep ploughing, and is created by passing a second time in the ploughed furrow. In subsoiling, the lower stratum is stirred and broken, but not inverted.

Subsoil-ploughing is never to be recommended without first draining, muless in cases where the lower soil is extremely loose and porous, so that the water can pass immediately off. The late Mr. Rham, a distinguished farmer, attempted this upon an adhesive soil, but found that, to use his own expression, it held water as a sponge, and becane quite ummanageable, until he proceeded completely to thorough-drain it with tiles. "Until there is an escape for the water through the subsoil, any epening of it but provides a greater space for holding water, and will rather tend to injure than improve the soil." 
1. Results of Subsoiling and Draining. - The improvements effected by the process of thorough-draining and subsoiling have been most remarkable. The manager of the farm of Sir Robert Peel says, "that he can confidently state, that the crop of turnips, after the above treatment, was four times the quantity in weight ever produced in the same field at any previous time." Mr. Smith says, in an early treatise on this subject, that which has been fully coufirmed by subsequent experience, that, "when land has been thoroughly drained, deeply wrought, and well manured, the most unpromising, sterile soil becomes a deep, rich loam, rivalling in fertility the best natural land in the country, and from being fitted for raising only scanty crops of common oats, will bear good crops of from 32 to 48 bushels of wheat; 30 to 40 bushels of beans, 40 to 60 bushels of barley, and from 48 to 70 bushels of early oats, per statute acre, besides potatoes, turnips, mangel-wurzel, and carrot, as green crops, and which all good agriculturists know are the abundant producers of the best manure. It is hardly possible to estimate all the advantages of dry and deep land. Every operation in husbandry is thereby facilitated and cheapened; less seed and less manure produce a full effect; the chances of a good and early preparation for sowing are greatly increased - a matter of great importance in a precarious climate; and there can be no doubt that even the climate itself will be much improved by the general prevalence of dry land."

Mr. Smith further remarks upon the improvement of the soil upon his own highly-cultivated and conditioned farm at Doune, which I had the great pleasure of inspecting, that, "when he commenced these operations upon his own farm, on a part of it he had not more than from four to four and a half inches of surface soil ; but having applied the system of thorough draining to it, and used the subsoil-plough, he can now turn up more than sixteen inches of good soil, and it is not more than twenty years since he began."

2. Farlures in Subsoiling in adhesive and heaty Soils. I cannot say that this process within my observation has been withont failures. Mr. Swarfield, the intelligent manager of the beautiful estate at Chatsworth, informed me that it had not been 
successful with him. My respected frend, Mr. Spencer, on his well-cultivated farm at Bransby, in Lincolnshire, complained of its being ineffectual, from the soil being too adhesive and heavy, and soon rumniug together, and becoming as compact as before breaking up. Mr. Black, in Yorkshire, the steward of the Earl of Zetland, says that one of his subsoiled fields produced thirty-five, and the other twenty-seven and a half bushels of wheat per acre; the field that produced the greatest number of bushels per acre was subsoiled across the drains, the other parallel with them; ploughing across the drains he deems decidedly the best method. This was in 1838. In December, 1839, one of the fields was ploughed, but no traces rcmained of the subsoilplough having been used. "I expected," he adds, "from the complete breaking up of the subsoil, that the parts would have remained distinct for years; but such was not the case; they had all run together, and were as compact as when first moved by the plough, without even the appearance of a water-shake or fissure. This I was not prepared to expect. Separated by a fence only is another field of a similar description, which was fallow at the same time, but not subsoiled; the crop on this field was quite equal to the other. A neighbor subsoiled one acre of a field, which was sown with beans; this field I frequently saw through the summer, and, during that period, the part subsoiled was by no means superior to the other." Another farmer of Kirkleatham, in Yorkshire, whose experiments were conducted in a judicious and effectual manner, says that he is satisfied that subsoiling is of no permanent use upon his soil. The quality of the land in all these cases is the same, and consists of a level, uniform tract, of a peculiarly tenacious soil, called the lias clay, containing, by analysis, more than 43 per cent. of alumina, or pure clay. Mr. Black remarks, that "the soil which will receive the most permanent improvement from subsoil-ploughing is one in which silica predominates; indeed, all shallow soils of the lighter kinds will be improved by it, and particularly so if there is any moorland pan, or indurated incrustations, formed by the weight of the plough going for a number of years at the same depth, or from other causes. If the subsoil is of good quality, and a greater depth of furrow is wished for, the subsoil-plough may be used with great advantage; the percolation of water prepares the subsoil for amalgamation with the surface. Strong 
clayey land cannot be permanently improved by subsoilploughing."

I have felt bound to give these statements of intelligent practical farmers, though I might show many opposite results, which would lead one to suppose that there may have been something peculiar in the execution of the work. The same result has followed to a degree at Wimpole, the estate of the Earl of Hardwick z, a farm, which, in many respects, for careful management, and especially for the admirable arrangement and order observed in every thing connected with the farm premises, is not surpassed by any which has come under my observation.

It may, however, be considered as to a degree settled, that the very strong and adhesive clays in the application of this system of thorough-draining and subsoiling are to be looked at with a good deal of distrust; yet the certain success which has attended many attempts to drain a strong soil, by very deep and frequent draining, and by giving a fair opportunity, after the drains were opened, for the operation of excessive heat or excessive cold, in loosening and rending the soil, scarcely permits us to despair of some improvement in almost any case.

3. Success in subsolling sandy and Ligit Lands. - The application of this mode of improvement to light, sandy land may excite some surprise; and yet its beneficial effects, in such cases, have been, within my own knowledge, so fully established, that I think proper to dwell upon them at some length.

At the estate of Sir John Easthope, in Surrey, where many discouragements in the way of soil have been skilfully and suecessfully contended with, I saw the beneficial effects of subsoiling and draining strongly exemplified, in a soil of a sandy, gravclly, thin, porous character; the part so operated upon presenting a striking and beautiful contrast to another part of the field under the same cropping, which had not been so managed. To this experiment I have already referred. But more fully to illustrate this subject, I shall quote from a communication made by Mr. Denison, of Kilnwick Perey, Yorkshire, to II. S. Thompson, Esy. and given by him to the public in a valuable paper on subsoilploughing, in the Transactions of the Yorkshire Agricultural Society for 1840.

"Few have been hitherto met with who would not ridicule 
the idea of applying the operation of subsoil-ploughing and thorough-draining to light, blow-away sand; and as it is to this latter description of land that I have chiefly turned my attention and experiments, I will confine myself to what I really know and have experienced.

"I will now mention the mode in which I have brought a considerable tract of sandy land into cultivation; and I feel so thoroughly grateful to the subsoil-plough for the share it has had in my success, that I cannot do sufficient justice to it without fully explaining the system upon which I worked.

"The tract of land upon which $\mathbf{I}$ began was in extent about 400 acres, the principal part of which was rabbit warren. The general character of this tract was, that although, upon the whole, it was nearly a level, yet the surface was undulating; the sandy swells being covered with heather, and the hollows; a bed of aquatic plants, being for many months in winter entirely covered with water. Of the sandy hills, the soil, as far as I am able to judge, was a sterile, impalpable sand, having been heretofore cultivated, and again abandoned. About six or eight inches below the surface, this sandy soil seemed to become hardened into almost a sandstone, with the occurrence occasionally of an impervious bed of ironstone; presenting, wherever it did occur, a complete obstacle to the entrance of the ploughshare: generally speaking, however, these nodules, or beds of ironstone, lay at a depth somewhat below the ordinary ploughings. The marshy hollows were of a totally different nature; and their cultivation had never been attempted; an idea apparently having prevailed, that they were below the reach of drainage. When become dry, the soil of these hollows appeared to be a black vegetable mould, extending to a considerable depth; in some places peaty, in all containing a large proportion of inert vegetable matter.

"Upon considering the character of this tract of land, I thought that the principle of subsoiling would be equally applicable to the light, sandy hillocks and the marshy levels. Upon the higher grounds, it was obvious that, when under cultivation, the sun had very great power over the six or eight inches of stirred soil, and that thus vegetation was either burnt up, or, if a strong ground-wind came, there was danger of the contents of one field being hlown juto another. If, therefore, by stirring to 
the depth of sixteen instead of six inches, a greater volume of soil conld be obtained, the power of retaining moisture would be proportionally increased, although the constituent parts of the surlice remained unaltered; for I never contemplated that which by some is confounded with, and by others preferred to, subsoiling; I mean trench-ploughing. I am of opinion that in very few cases, if any, is the soil underneath more fitted for vegetation than that of the surface; least of all in a case like the present : a hungry, ferruginous subsoil could be no amendment upon a surface however sterile. Experience has shown that this theory is correct, and that, on sandy soils, the advantage to be derived from subsoiling is from obtaining a greater depth, and consequently a greater power to absorb moisture. On the level, marshy portions of this tract, the benefits, though not so obvious in theory, have proved equally clear in practice. The subsoilplongh has broken through the mass of tough vegetable matter: tearing up the roots of rushes and other fen weeds, which were beyond the reach of the common plough.

"My first operation was to carry a main drain through the whole estate; and this was not only an expensive job, but one also which requiled considerable precision; for upon the accuracy of its level depended the success of the whole drainage. Nor, when the drain was made, and the surface water conveyed away, was half the requisite treatment effected; for it proved that the sandy elevations, of which. I have so often spoken, were the receptacles of springs, so that, in the whole of the estate I purchased, though termed a sandy waste, there was hardly a single acre which did not require draining previous to subsoiling.

"The main open drain being carried through, the next thing was to make main hollow drains, leading into it, bottomed with tiles, of the width and height of six inches, and covered with a sod, four inches thick, taken from the nearest hedge-side. I prefer sod to sticks, ling, or straw, for it allows the water to percolate freely, and does not shrink. The depth of these leading tiled drains varies much, according to the undulations of the surface. In some cases, it was necessary to cut them between six and seven feet deep, - altogether at an average of four feet. Into these drains were brought the smaller ones, laid with tiles of the width and height of three and a half inches, placed at every twelve yards apart, and of the same average depth as the others. 
I consider it prudent to have in every five acres one leading drain, with au outlet into the main open one: the mouths of the outlets should be of wood kyanized, with a swing-door for the sake of preventing the possibility of the outlet being trodden up, or destroyed by frost acting upon the tiles.

"The above particulars have been given somewhat at length. fiom the conviction of the great importance of effectual drainage, and that, without it, subsoil-ploughing will do more harm than good.

"The first process, after the drains were complete, was in the months of March and April, to pare and burn, and to sow rape and turnips, drilled with half-inch bones and soot in the following month. The crop was not at all regular, being good where the soil was deep and black, but very bad where it was sandy; the sole being hard, and the action of the sun having great power to the very roots of the plants.

"In the winter of the same year, after the turnips and rape were consumed, I ploughed the land in the direction of the old furrows; and the subsoil-plough followed, worked by two oxen and four horses, loosening the hard, sandy sole on the higher ground, and tearing up the roots of the rushes, \&c., on the low. In this state the land lay till the month of April following, when Finlayson's drag-harrow was applied across the ploughings, which brought up all the roots and rubbish to the surface: these were then raked off and burnt. I then sowed the black Tartarian oats, and ploughed them in: the ground was then harrowed and pressed down with a clod-crushing roller, made by Mr. Croskill, of Beverley, which implement has been of the greatest service to me in almost every stage and crop. It has been the means of consolidating the earth, which would other. wise have been too light, and it has kept the moisture in also. It has a decided advantage over every other kind of roller in this respect, becanse it leaves an uneven surface instead of a flat one, from which the rain, in sandy land especially, is apt to run off without nourishing or refreshing the crop.*

"The oats came out very healthy, and had no check: in sixteen weeks from the time of sowing, they were reaped, and, when threshed, yielded $10 \frac{1}{2}$ quarters per acre, 8 bushels per

\footnotetext{
* I shall hereafter describe this valuable agricultural implement. - H. C.
} 
quarter, which were sold at $26 \mathrm{~s}$. per quarter, - and this from land that was let two years before at $2 \mathrm{~s} .6 \mathrm{~d}$. per acre.

"I sowed forty acres with oats, of the same flat of land that had been pared and burnt, but not subsoil-ploughed, from want of time. The produce of this was not more than 3 qrs. per acre, and straw small and short - a very fair proof of the advantage of subsoiling.

"I have now 100 acres of wheat and oats growing on what was the very worst part of the whole property, and considered perfectly useless. It has been drained, pared, and burnt, and subsoiled exactly after the mode above detailed; and it looks as promising as what was so good last year. The land upon which I had potatoes, exhibits as decided a superiority."

4. Success of subsoiling on thin, Peaty Ground. - I thinl proper to subjoin the account of a Mr. Croft, of his operations upon a different kind of land.

Mr. Croft, of Hutton Bushel, who occupies some moorland on the calc-grit, thus describes the effect of subsoiling:-

"The surface soil is little more than half a spade deep, not positively peat, but next akin to it; at this time of year, (November,) it was always fetlock deep: under this is the pan, about two inches thick, and as hard as iron. We broke a pickaxe in getting a specimen. Below the pan is the rubbly soil, of which I also send a specimen for analysis. On this land nothing would grow. In summer, the crops would appear healthy and good, but before harvest, always ảwindled away. I found it impossible to use the subsoil-plough with four horses; but by fixing a whecl to it, (which made it work much steadier,) and using six horses, we got on tolerably well, though it was very hard work for both horses and man. Immediately after subsoiling, I sowed oats with Sinclair's grass seeds. I had a full crop of oats, so heavy, indeed, that they were all flat on the ground. and not ripe till November: the seeds have been hard stocked all this year with sheep and young horses, which, as you kuow. are the worst of all stock for year-old seeds; but the herbage is good, and the land quite firm. Before subsoiling, the land was not worth $5 \mathrm{~s}$. an acre : it is now let at a guinea."

"In this case, the advantages of subsoiling were great and immediate, and evidently arose from the drainage effected by 
breaking up the pan, which was impervious to water; whilst the rubble below was highly porous, and aftordsd a ready passage to the stagnant water which caused the previous sterility."

5. Importance of Subsolling and Draining, and their Application to the United States. - I hope no apology will be required by my readers for having gone so much at large into this subject. The thorough-draining and subsoil-ploughing of land constitute, in my judgment, the great modern improvement of English husbandry; and in their more extended application to lands which are now comparatively waste and profitless, or at best very restricted in their produce, and to lands which have been long cultivated, the productive capacities of which have been very imperfectly brought out, and to lands which have been productive, and hitherto supposed to have reached their maximum of yield, they seem destined to increase the products of the country beyond any calculations which have yet been made.

That such an improvement is applicable to many parts of the United States, - I mean especially the older states, where land has already reached a high value, - cannot be doubted. I know many farms and many tracts of country, where, by such a process, the product of the land might be expected to be doubled; and I have a confident hope that, in parts of the country where wheat now is liable to be thrown out by the severity of the frosts, or to suffer blight from the wetness of the soil, to which, in many cases, blight is to be attributed, we may, by means of this great improvement, be enabled to grow wheat with success. Our crops of potatoes, which we generally plant by preference in low lands, are often destroyed by excessive wetness arising from heavy rains, which remain on the top of the soil, for want of ready and sufficient drainage. I have known, in repeated instances, the seed to be destroyed in the spring; and the crop in the autumn to be rotted. in such cases, after it had become ready for the harvest.

6. Objections to tuis Improvement. - I foresee only two or three objections to the adoption of this improvement in the United States. In laying drains of clay pipes or tiles, the very severe frosts, especially in the northern parts of the country, are liable to break them to pieces at the outlet of such drains; but 
this may be guarded against by laying three feet of the ends of the drains with broken stones, through which the water would find its way. The pipes or tiles laid three feet, or even two feet, below the surface, would not be affected by the frost.

The next objection is in the difficulty of finding suitable persons to execute the work. An extensive system of draining, to be well executed, - and unless it can be well executed, it is better that it should not be attempted at all, - requires, in the laying out of the work, skill, and science, and experience; and as yet, a class of skilful, scientific, and experienced drainers can scarcely be said to exist among us. Time and demand, as in all other cases, may, however, soon produce them. The laborers, to execute the work, likewise, are not so readily found. No native American laborer, among the thousands whom I have known or employed, would have had patience, application, perseverance, and constancy sufficient to execute drains after the perfect and scrupulously exact manner in which they are made in England. Our habits of haste, our anxiety to arrive at our object by the shortest possible way, - for a genuine Yankee may always be known by his crossing a street, in spite of mud or dirt, diagonally, rather than going to the corner and crossing at right angles on the regular flagging, - our habitual conceit of our superior judgment, corresponding, in general, in a direct ratio with the ignorance of the party, which disdains to be directed or taught, are all national peculiarities, which operate against any minute, precise, and exact labor. There would be no difficulty, at any time, - such are the accustomed habits of the division of labor, - in finding any numbers of Englishmen, ten of whom are content to be employed during the whole of their lives in the formation of one pin at a time; but a Yankee would at once undertake to do the whole himself - with what advantage, as it respects the perfect execution of the article itself, I must leave others to judge. In many cases, however, we may take advantage of the labors and experience of those emigrant laborers who are planting themselves in vast numbers in a country affording singular advantages to a poor man, who is at the same time frugal, temperate, and industrious. Unless the work can be executed in the most careful, thorough, exact, and skilful manner, I strongly advise - if I may be allowed, with all possible respect and good-will, to give my advice - that it should not be undertaken. The half execution, 
or the imperfect execution, of it often brings many a good thing into disrepute, and proves a great bar to improvement.

But the great objection which will be urged will undoubtedly be the want of capital, and the expensive character of such improvements. That they are expensive there can be no doubt; but in all such cases there are only two questions to be asked. First, have $I$ the means of executing them? If the means are not within a man's reach, of course he should remember the fate of him who fell under general reproach, because "he began to build, and was not able to finish." The second question is, "Will the improvement pay? Will it produce an adequate return?" Then the cost of it is only to be considered in reference to the return which it will make; and the agricultural improver, in such case, is to be governed by the same principles by which the conduct of shrewd men is directed and regulated in other business transactions.

I can only say, that, in England, with scarcely an exception, as far as I have seen, the improvement is sure to be remunerative in a very high degree; and for that reason the government are proposing a most beneficent measure in offering the loan of capital, upon adequate security, for the accomplishment of such improvements, and in other cases allowing the owners of entailed estates to raise a certain amount upon the mortgage of such estates for the same purpose. Within my own observation, in my own country, where such improvements have been judiciously effected, though on a comparatively very limited scale, the result has afforded an ample compeusation. I know quite well how all agricultural improvements, involving a considerable outlay of expense, and attended with some necessary delay in the returns, are commonly sneered at in our active and bustling community, by some persons, who are constantly in a state of the most feverish anxiety to find a shorter way to wealth, to reach it, if I may so say, on a railroad line, and by an express train; but I believe I may add with confidence, and that after not a short experience, that judicious investments in the profitable improvement of land, though they may have been at first expensive, have, in the course of time, proved as profitable as, and always much more secure than, most of the moneyed speculations in which the business public have been engaged.

7. Read's Subsorl Pulverizer. - I ought not to close this 
subject of subsoiling and draining, without notice of an implement which has, in these cases, proved of great utility; I mean Read's subsoil pulverizer. I have already given a description of two subsoil-ploughs. This instrument, which can scarcely be called a plough, is intended to accomplish the same purpose. I have not seen it at work, but $I$ have the testimony of several persons in its favor. The great advantages claimed for it are, that it does its work effectually and with much less expense of labor, on account of its suspension upon wheels, than other ploughs, requiring only two horses to use it. "The improvement," says the inventor, "consists in carrying the weight of the machine on two pairs of wheels of equal diameter, and placed in the same line, so that the implement offers no greater resistance to the cattle than is required by the action of the shares or tines to break up or stir the subsoil." It is represented as highly useful, when fitted with tines or hoes, for scarifying between rows of beans, turnips, mangel-wurzel, or potatoes, requiring one or two horses, and also for working hop-gardens. I subjoin an engraving of it. It is, of course, when used for subsoiling, designed to follow in the furrow of a common plough.

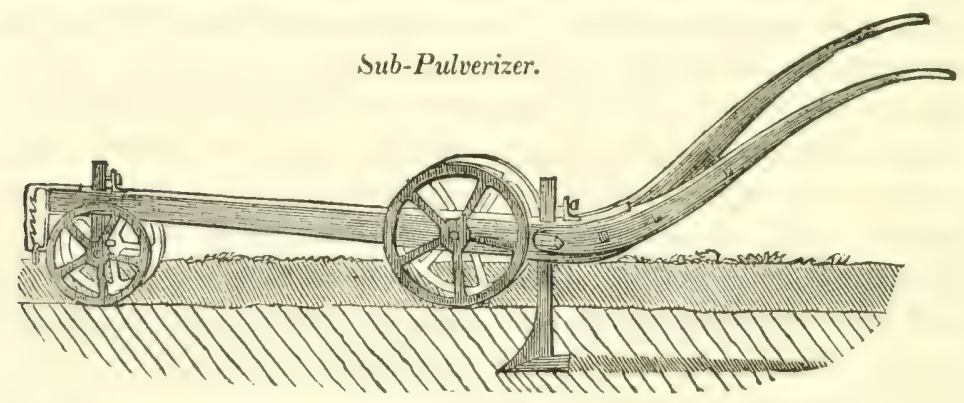

It will be interesting to my readers, if I subjoin the report of Mr. Parkes, the eminent engineer of the Royal Agricultural Society, upon the merits of this implement.

"An implement was produced at the Southampton meeting, with the merits of which the writer afterwards became fully acquainted. It was put to the test by the judges in a hardbaked soil. The pan, or old plough-floor, of this field, had evidently never been invaded by agricultural tools; below six inches it was as solid as centuries of ploughing and trampling can be conceived to have made a tenacious loam, aided by a 
drought of several weeks' duration. Mr. Read's pulverizer was put into the furrow opened by a plough, and set to work about six inches under it. 'The effect was 'perfectly beautiful,' to use the judges' words. The old floor was split up into fragments, like broken tiles; the soil was separated and pulverized, not heaved up in great masses, and let fall again to its original berth - the common defect of the ponderous subsoil-ploughs; the depth was maintained invariably uniform, and a holder for the implement would be nearly unnecessary but for the circumstance of its coming out at the end of a furrow, and of setting in again. The uniformity of depth and regularity of motion are owing to the construction of the implement, which is as simple as it is novel. A straight beam, furnished with the usual pair of handles, is carried on four wheels, the leading pair being placed near the bridle, and the following pair near the after end of the beam. The stirrer or miner is let down through a mortise in the beam, immediately behind the after pair of wheels, and fixed to cut at any required depth. By this arrangement, the entire weight is carried on the wheels, which also preserve the action of the stirrer at all times parallel with the bottoms of the furrows on which they travel. This instrument required considerably less force of draught than any which had come under the observation of the judges. A mole-share has been applied to this implement, and used in Kent with excellent effect in making mole drains with a force of four horses; and by reason of its manageableness and accurate working, the implement has been found, by farmers in the same county, to facilitate drainage in clay soils, in a remarkable manner, if used with due caution. They recommend that newly-drained clays be not broken up, in the first instance, to a depth beneath the furrow greater than six inches; that the share be set another season two or three inches lower, and so on gradually decpening the pulverized mass, rather than disrupting the whole at once."

Since this report was made, this implement has been much more extensively brought into use, and with universal approbation. It is a much less costly instrument than the subsoilploughs before described. It seems to me quite worth considering how far the application of such wheels to a common plough would be practicable and desirable. It would seem likely to facilitate very much the even holding of the plough, to 
diminish its fruction in some measure, and to make it easier to preserve an equality of depth in ploughing, than by the common instrument. There are parties who will perfectly understand this, and who, if they deserve attention, will avail themselves of these suggestions.

\section{CIII. - IRRIGATION.}

1. Tifeory of Irrigation. - Irrigation, or watering land under growing crops, can scarcely be called a very frequent operation in English agriculture; yet I cannot imagine the process to be more beautifully or successfully carried out than in some examples which have here come under my notice. These I shall describe as well as I can.

When a sterile and unproductive waste is converted into a fruitful field, and land which yielded nothing is made to produce the most abundant crops, - when the simple element of water, which Heaven, in its unlimited goodness, pours out in most situations in such abundant profusion, becomes the kindling instrument of life and energy to the vegetable world, to be used or applied by human art at its pleasure, - a reflecting mind contemplates the beneficent results with an elevated and grateful admiration. In such cases, one sees the highest encouragement to further efforts; the limits of progress and improvement the imagination has not yet descried; and past victories prefigure future triumphs in this humble but most useful field of exertion.

That water is an important and indispensable element in vegetation, every one knows. That its elements constitute a portion of every plant, is well established. But in what particular way it operates to produce its effects, is not so well determined. Its operation, say some persons, is purely mechanical. It reduces the matters in the soil, the manures, and the mould, into a condition to supply the plants with the food which they require; yet, if the water becomes stagnant in the soil, its effects are pernicious. It serves, in the opinion of one eminent person, to wash the roots of the plants, relieving them from that excrementitions matter which exules from their roots, and which, if suffered to remain, injures their health, and impedes their growth. 
This may be so, but it is obviously purely conjectural. It opens a passage for the access of the air to the roots of the plants. This must be beneficial. It increases the temperature of the soil ; but this must depend upon the relative condition between the soil and the water applied, which must vary under different circumstances. In the opinion of Sir Humphry Davy, "In the artificial watering of meadows, the beneficial effects depend upon many different causes, some chemical, some mechanical." This is certainly a safe opinion; but its chemical effects are not so easily determined. Let us hear the great authority.

"The atmosphere and the soil offer the same kind of nourishment to the leaves and roots. The former contains a comparatively inexhaustible supply of carbonic acid and ammonia; the latter, by means of its humus, generates constantly fresh carbonic acid, whilst, during the winter, rain and snow introduce into the soil a quantity of ammonia sufficient for the development of the leaves and blossoms."

"The complete, or, it may be said, the absolute insolubility, in cold water, of vegetable matter in progress of decay, (humus,) appears, on closer consideration, to be a most wise arrangement of nature. For if humus possessed even a smaller degree of solubility than that ascribed to the substance called humic acid, it must be dissolved by rain water. Thus the yearly irrigation of meadows, which lasts for several weeks, would remove a great part of it from the ground, and a heavy and continued rain would impoverish a soil. But it is soluble only when combined with oxygen; it can be taken up by water, therefore, only as carbonic acid.

"When kept in a dry place, humus may be preserved for centuries; but when moistened with water, it converts the surrounding oxygen into carbonic acid. As soon as the action of the air ceases, - that is, as soon as it is deprived of oxygen, - the humus suffers no further change. Its decay proceeds only when plants grow in the soil containing it; for they absorb by their roots the carbonic acid as it is formed." *

"It is because the water of rivers and streams contains oxygen in solution, that it effects the most complete and rapid putrefaction of the excrements contained in the soil, which it penetrates, 
and in which it is continually renewed. If it was the water alone, which produced this effect, marshy meadows should be most fertile. Hence it is not sufficient, in irrigating meadows, to convert them into marshes, by covering, for several months, their surface with water, which is not renewed; for the advantage of irrigation consists principally in supplying oxygen to the roots of plants. The quantity of water necessary for this purpose is very small, so that it is sufficient to cover the meadow with a very thin layer, if this be frequently renewed." *

These are the opinions entertained by different eminent individuals on the subject of irrigation. They cannot be said to contradict each other; but whether or not they reach the whole of the case, must be left to the judgment of my reader. The beneficial and productive influences of this process in an agricultural view are perfectly established. Any person may perceive it at the breaking up of the spring, when the snow water is turned into a restricted channel down a bank, that there the verdure and the growth of the grass will sometimes exhibit a month's advance over other parts of the field. Every one perceives its effects, when a drought is followed by a copious rain, and the whole aspect of the fields is immediately changed. Whatever may be the theory, which we deem most reasonable, in respect to the operation of water upon vegetation, it is enough for all practical purposes to know the fact; and the knowledge of this fact, and the practice founded upon it, are almost coincident with the art of cultivation. The amounts of the annual and fertilizing inundations of the Nile, and the plans for watering the fields after the dry season has commenced, must be well known to my readers. The productive influences of the overflowing of several of our great rivers upon their bottom and alluvial lands, are perfectly understood by the agricultural community. These, however, are usually charged with an enriching deposit, which is often made in considerable quantities, and the effects of which are always remarkable.

2. General Principles and Directions for Irrigation. Some points respecting irrigation may be considered as well established, to which it is proper that I should refer. It is set-

* Liebig's Agricultural Chemistry, p. 168. 
thed that simple water, without any admixture, is in itself a great enricher of the soil, or perhaps, more properly, a great promoter of vegetation. If the water of irrigation is charged with enriching matters in a state of solution, its beneficial effects are of course increased. Waters charged with mineral substances, such as water strongly impregnated with iron from peat bogs, or water from copper mines, is pernicious to vegetation, as any one may see, who will visit the outlets of the copper mines of Cornwall. It is established, likewise, that water in irrigation, in order to produce its best effects, must not be suffered to stagnate upon the land, but must pass in a steady progress over it; and that this progress should be comparatively gentle, and not sudden and rapid. It is equally well established, that lands which it is proposed to irrigate, should be thoroughly drained, so that the water poured upon the land should not be suffered to stand in the land, nor upon it. 'The effect of stagnant water upon the surface, or' the complete saturation of the soil, is to change the nature of the herbage, and to produce those grasses, which are coarse or innutritious, in place of the finer, sweeter, and more healthful. Yet it is not the mere transition of the water over the surface that is to be sought. It is desirable to have it soak into the ground, but not to remain there. Its speedy transition over the surface is to be effected by the inclination of the land from where it is received to the trench, furrow, or ditch, by which it is to be carried off. Its passing into the ground, and finding a speedy passage off, is to be effected by a system of thorough draining and subsoiling; for if the subsoil is impervious, the irrigated field becomes converted into a marsh. One of the most eminent farmers in Scotland, whose hospitality I had the pleasure of enjoying, but whose death since that time is deeply to be lamented, - Mr. Oliver, of Lochend, near Edinburgh, who had a large extent of meadow, irrigated by the sewerage water from the city, found that, after his fields were thorough drained, the benefit of the irrigation was greatly increased; for by the descent of the sewerage water into the soil, as well as over it, the enriching portions of the manure in a state of solution were carried to the roots of the plants. In the irrigated meadows of the Duke of Portland, - for its extent one of the most beautiful and finished agricultural improvements which can be found, and which I shall presently fully describe, - he showed me, that por- 
tions of his irrigated lands, which had even been drained, continued to affect his sheep with the rot; and this evil was not remedied until the draining was carried to the depth of eight feet or more. Before that, without doubt, the stagnant water at the bottom prevented the water of irrigation from passing off, and may be said to have poisoned the whole ground.

In irrigation skilfully managed, the increase of product is often very great - twofold, fourfold, in many cases even fivefold. Even sands, which were barren, have, by irrigation, been made productive. Plants, in such cases, having once found a footing, by the spread and decay of their own roots, have at length formed a soil, and created around themselves the elements of fertility. The effect of pure water, I have already said, is considerable; but when this water brings with it the refuse of the streets and habitations of a town, in a state of solution, the effects, as we shall presently see, are most remarkable. I have seen it stated, that water issuing from a limestone soil, and strongly impregnated with lime in the form of a sulphate or other combination, has been employed with great success in irrigation. Such instances have not come under my observation; but I cannot doubt the effect, where the soil was of a nature to require that element. In respect to manures, or any of the constituents of plants, it is evident they can be taken up only in a state of the finest solution. Here homœopathy triumphs, and no human sense is acute enough to discern, no human scales are fine enough to measure, those infinitesimal atoms out of which the rough substance of the gnarled oak is formed.

It would be idle, in a work of this nature, to attempt to lay down any thing more than the gencral principles of irrigation. In the accomplishment of any particular work, all the localities are to be considered, and the effecting it upon any large scale would require considerable engineering skill.

Irrigation of land and inundation are not the same. The inmatation of land resembles what I have already described under the process of warping, where, the land being enclosed by embankments, the water is admitted to flood the land, and is held fast until its floating riches are deposited. This can seldom be done without disadvantage upon a growing crop, unless when in its carliest stages of growth. Irrigation is the gradual filteriug 
and spreading the water over the soil, and, where not too rapidly applied, may be done with safety at any period of the crop. This, however, can only apply to pure water. The application of turbid water, where a considerable amount of inud and earthy matters is held in suspension, or the application of sewerage water to a growing crop, would be liable to the same objections as inundation. I am referring, as must be obvious, to fields in grass, to which irrigation is applied; and not to fields under arable culture, to which it may be, but to which I have never seen it applied. What are called catch-meadous, is a form of irrigation upon side hills, where the water, after passing over a certain portion of the land, is caught in a trench, and again used for the irrigation of other portions of land. In a plan of irrigation, the first thing to be considered is the command of an adequate supply of water, and this, of course, at a level above the land to be irrigated. This may be obtained from a brook, whose course may be turned, or a portion of whose waters may be diverted for that purpose; or, as it is here sometimes obtained, by the collection of the water of springs bursting out upon the high lands into a common receptacle or reservoir, which may be tapped for the purpose of letting out the water, as it may be required. I recollect at Canterbury, in New Hampshire, at the establishment of the United Brethren, or Shaking Quakers, - certainly among the best farmers in the world, - that these industrious people, for the sake of establishing a mill power, much needed among them, had, by an embankment or dam between two high clay hills, formed a large basin or reservoir, which the melting of the snows in the spring, the rains, and some springs on the sides of these hills, would completely fill with water, furnishing a supply for the season; and which, passing into successive basins as it descended the hill, was used five times for mill purposes; such as a flouring mill, a threshing mill, a mill for sawing wood, a mill for grinding bark, and a mill for the dressing of leather. I could not help admiring the ingenuity of these people in creating a mill power where none existed before; and it is perfectly plain that, by such an arrangement, they might have executed an extensive system of irrigation, had it been thought proper so to apply the water. In some situations, where fuel and labor are not expensive, steam power might be employed with advantage to force water, and to form a reservoir at the 
height necessary for irrigating the land below. On a farm in Dedham, Massachusetts, situated upon an acclivity, at the foot of which ran a small brook, I saw that the farmer had formed a reservoir above his house and barn. Into this reservoir, through leaden pipes of a small bore, the water of the brook was forced up, by means of an hydraulic ram and forcing pump, itself operated by the running brook; and a supply of water was always maintained in the reservoir amply sufficient for the domestic purposes of the family, and the supply of the cattle in the yard. The water was forced a considerable distance, and the expense of the machinery was very trifling. The cost and labor of keeping it in operation were nothing, excepting that of opening and shutting the gate. The expense of the whole apparatus, excepting the reservoir, did not exceed five pounds, or twenty-five dollars. The farm would, in England, be considered a very small one, not exceeding one hundred acres; but it shows, just as much as a larger one, to what advantage the most simple contrivances may be applied. This water, thus raised, might have been used for the purposes of irrigation.

Where the supply of water is sufficient, it is carried along on the upper margin of the land to be drained in a trench or furrow ; and, when it is required to throw the water over the land, the end of this trench or furrow is to be stopped, either by a gate or a damming up for the occasion, so that the water entering it may flow gently and evenly over its sides. It is plain that the water trench or furrow should be carried nearly upon a level; first, that the flowing of the water over the sides of the furrow or gutter may be equal and uniform; and, next, because any variation from a level would force the water to a particular point, either to prevent its equal diffusion over the field, or to occasion, perhaps, a rupture of the side of the trench, and an injury to the field itself. The variation from a level, recommended by some persons with a view to giving the water an easy flow in the trench or gutter, is only one inch fall in every ten feet.

Besides the formation of the trench or furrow, the surface to be irrigated requires to be made even, the knolls reduced, the hollow places filled, and the holes, occasioned by vermin of any kind, stopped, that the water may flow evenly over the whole. The degree of inclination, desirable in a field to be irrigated, is stated to be about ten feet in ninety; but although this may be 
found desirable, it is obvious that it cannot be under the control of the farmer, to any considerable extent, but at a very great expense. We must take the land as we find it; for few things are more costly than attempts materially, or to any great extent, to alter its shape. It would be prejudicial to undertake to irrigate our lands without the means of getting rid of the water, and without having a gradual, though not a rapid, transmission of the water over the surface; but in cases where the inclination is too great, the supply must be more gradually rendered.

The frequency with which water may be applied to meadows, and the length of time which it may be suffered to remain on them, are points to be considered. At Welbech, at the Duke of Portland's, after the prepared land was sown with grass seeds, the water was brought upon them as soon as it was thought they would bear it; i. e., after they had become sufficiently rooted, and the ground consolidated around them. This would vary, according to the season, from one month to six. The great danger to be apprehended upon newly-sown lands is the washing away the dirt from their roots. The duke himself remarks that, "short of that, they cannot be watered too soon, or too long at a time, unless the land has very recently been drained, in which case it would not be well to increase the natural strength of the springs until the land had forgotten its wet propensities. On really dry iand there are only two limits to the length of irrigation, viz., the want of water, and the want of consistency in the soil, so that it shall not be washed away from the roots of the grass."

After the grass had become sufficiently strong, the water was kept going over it for about four days, and then taken off. The grass was mown as soon as it was ready for the scythe, and the water again turned over. The same course was pursued upon the old grass land. About once a month, the water is turned on for three or four days at a time, according to the supply, and this throughout the year. When the water is abundant, it is applied oftener than once a month; but how long it should be kept on, is somewhat matter of judgment in reference to the weather and the state of the ground. The manager of the works chooses to keep it on until he sees its effects upon the grass.

Lord Hatherton, on his meadows at Teddesley Park, informs me, that they commence irrigation about the 1st of Norember, vor. II. 
and the water remains three or four days on the land. If the supply is sufficient, it should be renewed once a fortnight. In a dry season, it is advisable to apply it immediately after cutting the grass; but it must not then be allowed to remain many hours in the same place, especially if the sun is powerful.

Mr. Oliver, at Lochend, where the sewerage water of the city was used, deemed it unsafe to apply the irrigation immediately after the cutting of the grass, but considered it altogether advisable to wait until the grass had acquired some growth. The sewerage water, in this case, was of great strength, and a different rule was applicable from a case where the water of irrigation was pure.

Mr. Roals, who farms some cold land one thousand feet above the level of the sea, in Somersetshire, and who has improved a considerable tract by irrigation, says, that "the water should never be suffered to remain in one place over the grass more than two or three days at a time without being changed; nor be turned upon the land in order to remain there during frost; but should the frost set in while the water is on, by no means alter it until the frost is gone; for if the surface is exposed, and the frost continues, it will most likely lift the land and kill the grass." *

These observations will have peculiar value in New Eugland, where the frosts are severe, and where grass lands, upon which water stands in the winter, or lands upon which grain has been sown in the autumn, if particularly wet, are sure to suffer most severely from freezing.

I have already spoken of the quality of the water used for irrigation. At Lord Hatherton's, it is the water gathered from the different drains, in different parts of the farm, whose position was such that their supplies could be turned to this purpose. At the Duke of Portland's, a small river, called the Mam, rumning through the neighboring town of Mansfield, supplies the water of irrigation. After strong rains, when the washings of the streets and sewers of this town are poured into the river, its waters become quite turbid, and have a superior efficacy. The sediment deposited by a single watering, in such cases, is very

* Journal of the Royal Agricultural Society, vol. vi. p. 520. 
observable. I shall presently speak more at large of the application of sewerage water.

"In the management of the crops of grass upon irrigated meadows," says one whose practical linowledge of the subject allows him to speak with authority, "experience has shown that to let the grass grow to be too old, viz., mutil the seed of it is in a forward state, is productive of very great injury to the land. When the grass has been cut for hay in this state, and brown at bottom, the land does not recover for a great length of time. It is also found very desirable, after beginning any meadow, or portion of a meadow, which receives the water from one carrier, and at one time, that the consumption of it in a green state should be carried on as quickly as possible, so that in dry weather the water may not be kept off of it too long; for in that case it requires so much water before the land is saturated, and will allow the water to flow evenly over it, that much loss of time occurs in the next crop of grass."

I have thus touched upon the principal points comnected with this great agricultural improvement, though there are some others to which I shall recur before I quit the subject; and I now proceed to speak of some principal experiments, which have come particularly under my observation.

3. Welbeck, Nottinghamshire. - The most extensive and most finished work of irrigation, or, as they are here called, of water-meadows, and to which I have repeatedly referred, is at Welbeck, in Nottinghamshire, at the residence of His Grace the Duke of Portland.* The water-meadows at Welbeck at first embraced

* The Duke of Richmond, for whose constant kindness I should find it difficult to express my sense of obligation, did me the honor of a letter of introduction to the Duke of Portland, which I duly forwarded; and he, learning I was in his vicinity, was kind enough to send a messenger twenty miles to meet me, that I should appoint a time for my visit, when he would be at home, that he might himself, to use his own expression, "have the pleasure of personally showing me his improvements." The rules which I have prescribed to myself, and which I hold inflexible, do not allow me to speak further of my most instructive and delightful visit to that noble residence; yet it seems but just that I should, as I wish to do with the most delicate respect, allude to such examples as only illustrative of the uniform and universal treatment with which I have been honored during my protracted residence in this country, by the higher classes, both titled and untitled. These persons constitute a body, of whom I may say with truth, and I hope with- 
more than threc hundred acres; but they have since been considerably extended, and, when I was there, the improvement was still going on.

The land, before the improvement was commenced, was in part a thin, gravelly, and barren soil, and in part a peat bog, or swamp, and full of rushes and aquatic plants. The River Maun, which we should scarcely deem entitled to much more than the name of a brook, after sweeping through the town of Mansfield, a town of a population of a few thousand, made its way through the lower portion of these grounds. At what may be called its upper end, a portion of its water was diverted from its natural course, and, by an artificial channel, led along the margin of the meadows, which were to be irrigated, varying, in its passage, as the shape of the land varied; and this for a distance of five miles and a half, until, from the nature of the land, the artificial channel was brought into contact with the old channel; and here, a new dam being formed, the artificial channel crosses the bed of the river, and goes down on the other side, a distance of two miles farther.

At successive places, in the course of the artificial channcl, sluice-ways are opened on the side, for the purpose of letting out the water; and these sluice-ways, besides being furnished with gates and valves, all of a perfect description, are most substantially laid with stone, wherever the inclination was more than one inch in five yards, so that no injury might be done to the mearows by too rapid a current of water. From these sluice-ways lateral gutters extend at right angles, into which the water is received, and thus diffused over the whole grounds. I subjoin a partial sketch of the general plan of the improvement, (p. 149,) which will render my description much more intelligible, and likewise an elevation of one of the shuttles, or, as we should call it, one of the gates, for the regulation of the passage of the water, (p. 150,) the construction of which appeared to me somewhat novel and ingenious, and so may be to some of my readers,

out offence, that, taken together, a class of men more polished and courteous, better educated, more enlightened, or more moral, has adorned no country and no period. The kindness which I have experienced has not, however, been limited to any class; and my numerous friends, in a condition of life more humble, may be sure that their strong claims upon my grateful respect are most cordially acknowledged, and can never be forgotten. 


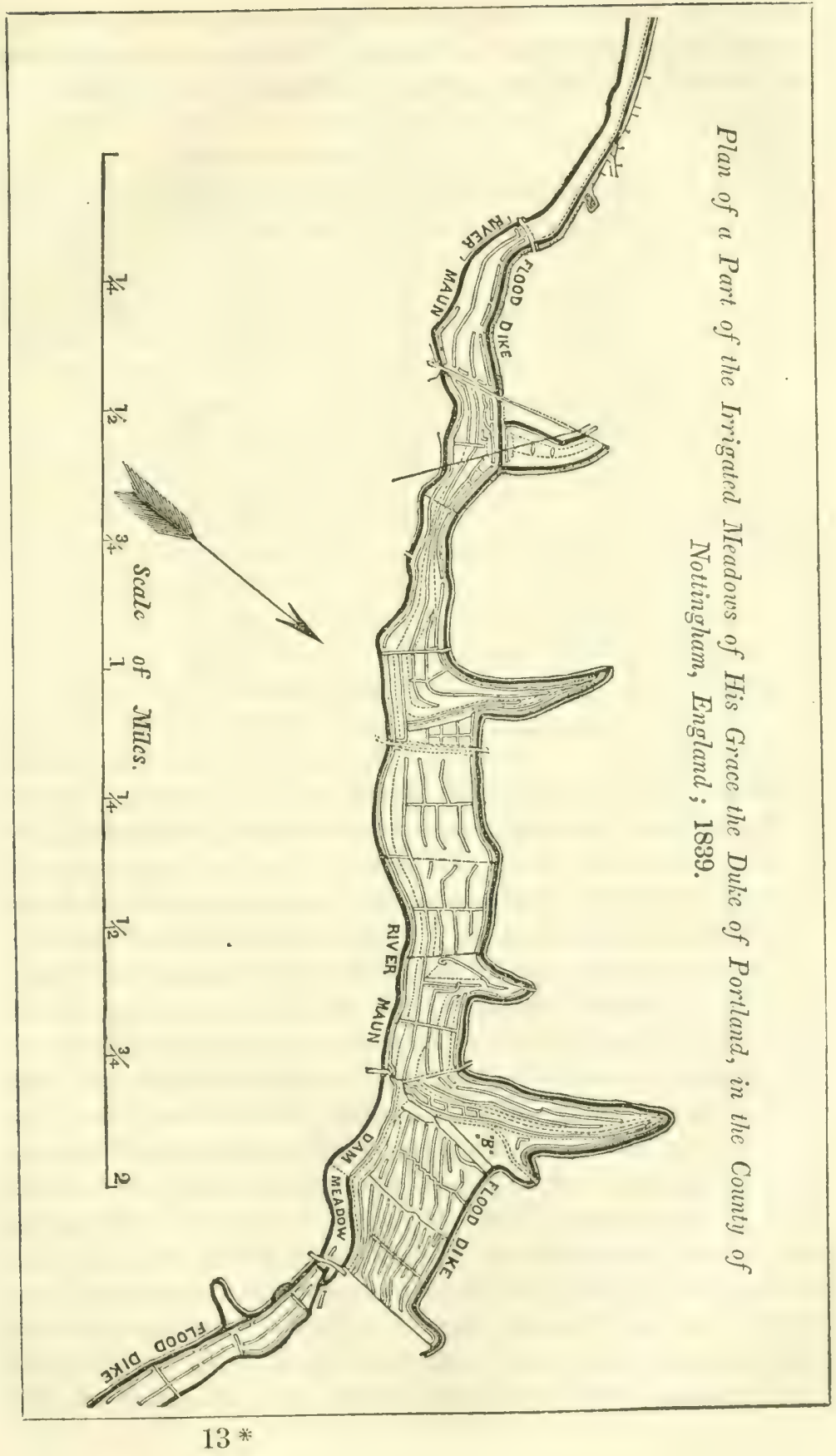


though in its nature altogether simple, and probably familiar enough to every practical mechanic. The sketch is copied from the Journal of the Royal Agricultural Society, vol. i. p. 359.

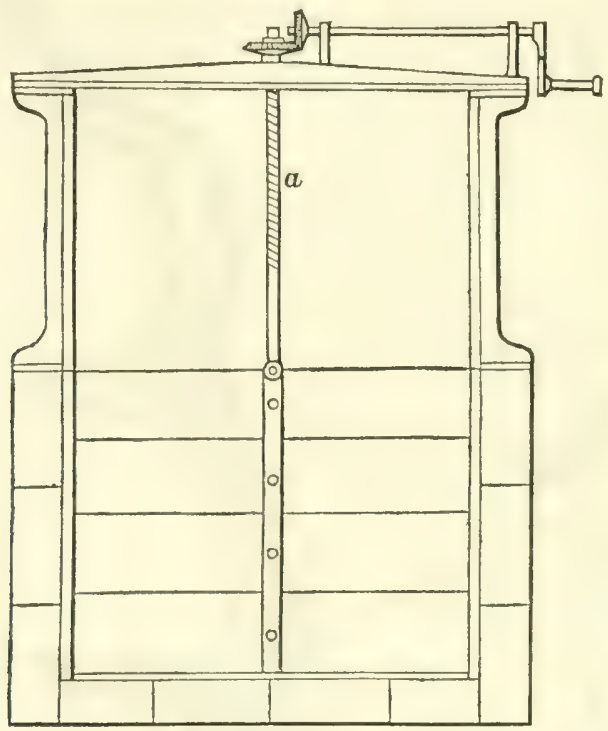

But the conveyance of the water, and the formation of this artificial channel or canal, for so great a length, were only a part of this magnificent work. In order to render the irrigation of these lands easy, their whole surface was to be reduced to an equal flatness or inclination; consequently, knolls of even six and seven feet high were to be cut down, low places and holes filled up, and all the inequalities of the land corrected; and this was mainly done by the spade and wheelbarrow. The great point aimed at was, to render the slopes easy and equable; and, in order that, in cases where considerable elevations were levelled, a perfectly dead earth might not be left exposed, the top soil was first taken off, and then returned upon the places which had been dug down. This process had not been effectual to render these places as fertile as those parts which had not been subjected to so severe an operation; but time, under the continual influences of a rich vegetation, will probably effect that. The improvements, which were in progress when I visited the place, showed what an undertaking had been accomplished, and 
what an immense amount of labor expended. It was not merely that these grounds were to have their faces washed and their hair combed, but the levelling of these various inequalities required an extraordinary skill and an indefatigable and heroic perseverance. But the beauty of the whole work, as it presented itself to the eye, so nicely formed, and so bright and rich in its verdure and productiveness, was delightful; and this perfect and magnificent trimmph of art and industry over adverse circumstances, most strikingly exemplified by a comparison with the adjoining land, which remained in its original inferior state, and had not been brought under the resuscitating and beautifying hand of improvement, compelled the highest admiration.

But the work which appeared was by no means the whole that had been done. The land had been all thoroughly drained, and, in solne cases, to the depth of five feet. In some cases, the work had required to be twice done, because, when the land became saturated with the water of irrigation, new force was given to the natural springs, which then were rendered too strong for the outlets provided. The duke was kind enough to point out to me how indispensable it was to get rid of the bottom water in order to bring the lands into a sound state; and in one case, where the ground had been drained at the depth of five feet with tile-drains, the ground could not be laid dry until a spring at the side of the land was completely cut off, and a channel formed, so that the water might be conveyed quickly away. In one case, it was found necessary to sink a drain to the depth of twelve feet, in order to cut off a copious spring, which pressed upon the land. The system of thorough-draining, which I have already very fully discussed, may be sufficient to convey away all the rain water which follows, but not the water flowing from powerful springs in side hills, whose waters often press upon lower grounds in the neighborhood, and completely saturate them.

New evidence was given, in the progress of the work, that lands subjected to the process of irrigation, always suffer if there is too great flatness, and that it is of the highest importance to the full benefit of the operation, that, although a too rapud transmission of the water of irrigation is to be avoided, yet its progress should not be interrupted or delayed.

Besides the amount of labor expended in draining the lands; 
levelling inequalities, filling up hollows and holes, forming the channels, sluices, and dams, it will be considered that a great deal was required in grubbing the land, getting rid of the gorse, and heather, and rubbish, that covered considerable portions of it before the improvement was undertaken; and, previous to the levelling, the ground was ploughed, and a crop of turnips grown upon it, which were fed off by sheep. This was followed by a crop of barley, and then a second crop of turnips. The improvements having been completed, and the land levelled, these first crops, which were contemporaneous with the process of improvement, having been taken, the lands were regularly laid down to grass, and so have remained, requiring now no further manure, and yielding a most abundant product.

It has been found that the supply. of water has been inadequate to the wants of the land in seasons of drought; and, to remedy this, the proprietor has formed, above the town of Mansfield, a reservoir of seventy acres, which is designed to do double duty, being first used to drive some mills in the town, and afterwards for the purposes of irrigation.

The productiveness of these meadows has much exceeded the expectations formed; and I shall quote from Mr. Denison's interesting account of them in the Journal of the Agricultural Society, of which I have already to some extent availed myself.

"These meadows are farmed in the following manner. Early in January, Southdown ewes, with lambs bred early for this purpose, are turned on the meadows. In this early season, they are assisted with cabbages; but the ewes and lambs always do well on the meadows; and they appear to be particularly healthy for the lambs, very few dying suddenly, as will often be the case on fresh seeds, [i. e., land newly laid down to grass. H. C.] Ewes are put on with their lambs as they are born, and gain strength, and in this way, from January to the end of March, and in some parts till much later in the spring, even till late in May, they are devoted to ewes and lambs, feeding the lambs fat, which are sold, at that early season, at from $24 \mathrm{~s}$. to $30 \mathrm{~s}$. each. The land is then shut, some at the beginning of April, other portions later in rotation. The most forward meadows will be ready for cutting green by about the middle of May, and will yield from sixteen to twenty good cart-loads of green fodder per acre, which is carried to cattle in yards. In about six weeks, 
a second crop is ready, which, with the allowance of time necessary to clear the first crop from the ground, and to apply the water, will carry this second cutting to the middle of July. After this, an eddish [called in the United States after-feed or fallfeed. - H. C.] will be left to be eaten by sheep and cattle in the autumn and early winter. The meadows which are first cut will frequently allow of a third cutting of green food; but the eddish will, of course, in that case be of less value. Speaking, therefore, of the whole range of meadows, to say that, besides the sheep-feed in the spring, they will afford two green cuttings and an eddish, is to be rather under than above the mark. Some portions are allowed to stand for hay, and are mown, after having been stocked late, early in July, yielding two tons to the acre, and leaving, as in the other case, an eddish for the early winter." *

But it must be remembered, that this is not the whole of the profit gathered from these meadows. They require no manure to keep them in condition, beyond the water which is supplied to them, if that is to be called manure. But every acre of this irrigated land, in its produce consumed by cattle on the farm, supplies manure for five acres of other land; and this, on every account, must be considered an invaluable advantage.

The expense of these improvements has been very great; and the more especially, as every part of the work has been executed in the most substantial and beautiful manner. It seemed to me impossible to find a more finished work. The scale of expense here could form no rule for any such work in the United States, even should one in a much more humble form be in any case attempted. As to the result here, although, wherever these improvements are spoken of, I have heard the expense objected to, it was enough for me to know that the noble proprictor expressed himself entirely satisfied. $\dagger$ At the current value of land in this

* 'The Duke of Portland, speaking of the quality of the produce of these meadows, says, "There is reason to believe that water-meadow hay is not good for horses working on wind; but for all other purposes it is quite good. On account of its succulency, the grass is difficult to be made into hay, and requires much time. Horses of every description, and cattle, thrive greatly on the meadors themselves; and I should say that, unless they give the rot to sheep, they are the most wholesome pasture for them, as well as for horses and cattle; but my meadows are all perfectly dry."

$\dagger$ "The value of the land has been raised from the annual sum of $£ 80$ to that 
country, and of land which, from its own resources, without further expense than that of ordinary attention, is capable of keeping up its fertility, and, at the same time, to such an extraoldinary extent administers to the fertility of other lands, and, to a degree, may be said almost to defy the seasons, it would seem that such an improvement would almost justify any expense incurred in effecting it. In any event, I could not help reflecting, with the highest delight, upon so useful, instructive, and beautiful an application of wealth; upon the important agricultural lessons which it explained and illustrated, upon the powerful stimulus to improvement, which such an example at once supplies and applies to all who witness it; and upon so striking a monument, which the proprietor has thus erected in honor of himself, adapted, not to astound, but to instruct; not to provoke envy, but to awaken gratitude; to carry down his memory to posterity in letters of universal respect, and more eloquent in his honor than the loftiest Corinthian granite column, or even the proudest regal mausoleum of ancient Egypt. But putting the actual pecuniary profit out of the question, the sum total of the expense of all these improvements, the actual creation of all these three hundred acres of most productive lands, with all its collateral and reduplicating advantages, does not half equal the expense of many a contested election, as formerly conducted, squandered in drunkenness, profligacy, and riot.

4. Teddesley, Staffordshire. - The next great improvement in irrigation, which I had the pleasure of witnessing, was at the highly and most judiciously improved estate of Lord Hatherton, at 'Teddesley Park, in Staffordshire.*

Here he has undertaken, under the superintendence of a most competent manager and steward, to drain completely between five and six hundred acres of land, and has managed to convert

of $£ 3660$, at a cost (from their commencement, in 1816 , to their completion in 1837) of $£ 40,000$. The profit upon each acre, after defraying all expenses, is computed at nearly $\mathrm{A}^{* 12}$ a year, without taking into consideration the great benefit they are to the arable land adjoining them." - Corringham's Report of Nottinghamshire.

* 'To this gentleman's constant kindness, and, I may be allowed to add, intimate personal friendship, I am indebted for many of the advantages, and very much of the pleasure, which have attended my visit to England. 
the water of drainage into a valuable mill power; and then leads it off for the purpose of irrigating about eighty-nine acres of land, taking in its way much of the drainage of the barn-yard, (where a stock of about two hundred head of cattle are constantly soiled,) which is collected in a large reservoir for this purpose, and sometimes carried out in a cart for the purpose of irrigation, and sometimes pumped upon a mixed heap of materials composted for manure, that it may enrich and decompose them. The water, in order to form the mill power, is first collected into a small reservoir, half a mile distant from the farm buildings, and then conveyed in covered drains to the mill honse. In order to bring the water out at a proper level, it was necessary to sink a channel through a hard sandstone for a distance of about five hundred yards. "The stream of water was not sufficiently powerful to turn an undershot wheel; and to enable it to act with force, it was necessary to bring it out to the upper part of a wheel of thirty feet in diameter. This wheel has been placed in the rock thirty-five feet deep, and the head-way has been carried from the bottom through the rock, which comes out in a valley below, at the distance above mentioned of five hundred yards."

This mill power is applied to drive a threshing machine; to the cutting of hay and straw ; to the crushing of oats and barley; to the grinding of malt, and to the turning of a circular saw ; and it is obviously capable of further application. This is an immense advantage. The water, having performed this duty, is then conducted into the fields which are to be irrigated, where, by varions channels, it is made to overflow and enrich these extensive grounds. The whole number of acres embraced in the farm is about thirteen hundred, only a portion of which is subjected to drainage ; the number actually irrigated is eighty-nine. This land was originally of little comparative value, but is now highly productive. No manure is ever applied to these lands other than what is carried by the water in its mixture with the liquids from the barn-yard. The year before the last, notwithstanding the severe drought of the summer, they produced at least two tous of hay per acre. They are fed in the spring with sheep, and with cattle and sheep after being mowed. It would not be easy to estimate too highly the value of lands of such 
cheap and permanent productiveness, after they are once formed, and especially in reference to the means which they furnish of enriching other and less favored portions of the farm. The improvements on this farm are of a most substantial and complete character. The accomplishment of the object in view, in the most useful, thorough, and least expensive mode, is the governing principle pervading the whole establishment. Certainly one more judicious could not be adopted; and in this respect they present an example capable of being followed by farmers of limited means, whose improvements must be restricted to such ouly as will pay. The water obtained by drainage, in this case, happens to be favorable for irrigation. The whole expense of under-draining the land, of erecting water-wheel and machinery, and of irrigation, is estimated at $£ 27332$ s. 2 d., and the increased annual value of the estate is rated at $£ 10132 \mathrm{~s}$. 4 d. This results from draining 467 acres, and employing the drain water for mill purposes, and the irrigation of 89 acres of land; "affording a clear annual interest on the outlay of full 37 per cent."

5. Audlex End, Essex. - The next improvement by irrigation I had the pleasure of inspecting was at Audley Eud, near Saffron Walden, the elegant residence of Lord Braybrooke. The improvements here, in this way, are upon a comparatively small scale, but extremely productive. They are on the lowlands, in the vicinity of a small stream or river. I cannot do so well as give an account of them in his lordship's own words.

"The water-meadows at Audley End were formed in 1841, from old pastures, without disturbing the surface except for the purpose of adjusting the levels, and cutting the ditches; but in consequence of the inequality of the ground, many hollow places were filled up with fresh moulds; and the product was not much increased the first year of irrigation.

"Although it was not possible to ascertain the exact amount of the crops for the succeeding three years, two of the three crops having been consumed in a green state on the ground, yet occasionally single rods taken indiscriminately from the first growth of grass have been weighed, in order to obtain a tolerable estimate of the general produce, and they afford the following result:- 


\begin{tabular}{|c|c|c|c|c|c|c|}
\hline First Time of Cutting. & $\begin{array}{l}\text { Weight of Grass } \\
\text { per Rod. }\end{array}$ & $\begin{array}{l}\text { Weight of Iray } \\
\text { per Rod. }\end{array}$ & $\begin{array}{l}\text { Weight } \\
\text { per }\end{array}$ & $\begin{array}{l}\text { frass } \\
\text { Acre. }\end{array}$ & $\begin{array}{c}\text { Weigh } \\
\text { per }\end{array}$ & $\begin{array}{l}\text { of Hay } \\
\text { lcre. }\end{array}$ \\
\hline & $l b s$. & $l b s$. & Tons. & Cuct. & Tons. & Cuch \\
\hline May 1,1843 , & 143 & 39 & 10 & 4 & 2 & 15 \\
\hline May 30, & 201 & 51 & 14 & 7 & 3 & 12 \\
\hline April 22, 1844, & 152 & 38 & 10 & 17 & 2 & 14 \\
\hline May 15, "6 & 211 & 62 & 15 & 1 & 4 & 8 \\
\hline May 23,1845, & 170 & 44 & 12 & 2 & 3 & 2 \\
\hline June 3, & 218 & 56 & 15 & 11 & 4 & 0 \\
\hline
\end{tabular}

"In the end of July and beginning of August, 1844, a second cutting was made of the grass growing on the land above referred to, and carried to the homestead in a green state for consumption; and this crop appeared nearly as heavy as the first.

"It must be remembered that no deduction has been made for any waste of ground arising from the carriers and troughs; but it may be presumed, after allowing for this loss of surface, that the average produce yielded the three last years has been about thirty-one tons of grass, or eight tons of hay per acre. It appears, from the different periods of the year at which the crops arrived at maturity, that, even on irrigated meadows, the temperature of the atmosphere in the early part of the spring exercises considerable influence over the growth of the grass, where water is not always at command to apply to the meadows.

"Italian rye grass seems suitable for irrigation, as a patch at Audley End measured three feet two inches in height on the 30th of April, 1844." *

6. Somersetshire. - I have already referred to Mr. Roals's account of his forming some catch-meadows, or meadows to be irrigated on very high lands, by collecting the water from some springs high up, and then bringing it down by successive gutters or trenches. "The water gutters were made to take the water that was drained from the springs above. He set out the watering gutters by a level, giving them one inch fall in every ten feet. They were cut nine inches wide and three deep. If the land has a gentle slope, the gntters may be put sixty feet from each other; but if it be very steep, and there is a good flow of

* Journal of Royal Agricultural Society, vol. vi. p. 5*2.

VOL. II. 
water, they may be put seventy or eighty feet apart. When he finds the water sink too fast into the land, he spreads fine earth or road scrapings over the surface, in order to fill it up, that the water may pass over to the next catch-gutter. He has drained and formed into meadows, for irrigation, thirty acres, which yield from a ton to a ton and a half of hay per acre annually." This land, which, previous to these improvements, was valued by authority at $2 \mathrm{~s}$. per acre rent, would now let for $25 \mathrm{~s}$. This demonstrates the extraordinary value of this improvement.

His remarks subjoined to this account are too valuable to be omitted. "The sides of the mountains, in the north of England and Wales, might be converted into catch-meadows, in the same way that I have done mine, provided the water is of good quality, and the land can be made porous, to let the water filter gently down. I have never found turning water over old pasture do much good, as the grass that comes up is coarse and thin, and the hay, if mown, is not of good quality. If, therefore, old pasture is intended for meadow, it will answer best to break it up first, work it well, and sced it down with those grass seeds which are most congenial for water meadows."

The judgment of this farmer, in respect to the management of old pasture, seems at variance with the experience of Lord Braybrooke. But I suppose they are speaking of entirely different qualities of soil. The former is speaking of high mountain pasture, the latter of alluvial lands, which have been greatly enriched.

I shall conclude this part of my subject with the remarks of Philip Pusey, Esq., M. P., which are always deserving of tho highest attention, and which are as applicable to many parts of the United States as to those places to which they immediately refer.

"I have known Mr. Roals's farm for many years. It stands alone on the summit of the wild Exmoor range of mountain land. If any one asserted, that, for a trifling outlay, he could cnable heath-covered steeps to rival, in produce and value, the old grazing grounds of Northamptonshire, he would be regarded as a dreamer. But if any owner of moors will visit Somerset, or North Devon, he will ascertain the literal truth of the statement, as I did five years ago. All that is required is a streamlet tricling down the mountain side, or a torrent descending rapidly 
along the bottom of the glen. The profit of under-draining old arable land appears trifling when compared with the profit of thus forming catch-meadows, which, according to Mr. Roals, is more than one pound interest for two pounds invested. The two pages of this report, which state no more than Mr. Roals has himself done, contain a talisman, by which a mantle of luxuriant verdure might be spread over the mountain moors of Wales and Scotland, of Kerry and Cannemara."

New England, especially, and many parts of the other states, are full of sites and means for such improvements; and in many cases the expense and labor of levelling the land, bringing the water into a body, and placing it under control, would be met many times over by the profits of such improvements.

7. Edinburgi. - I come next to speak of a system of irrigation established in Edinburgh, which I looked at with a good deal of interest, where the sewerage water from the drains of the city are applied to grass lands in its neighborhood, which by this means are rendered most extraordinarily productive.

The drainage water from a large portion of the city of Edinburgh is collected into covered carriers and drains, and from these emptied into a small stream of water, very properly, as one may suppose in such case, called the Foul Burn, the term burn being the Scottish name for a small stream or brook. Here it passes along, in an open brook, among some flat lands, which, by proper arrangements, it is made to overflow. I should state that, before it reaches the places where it is thus diffused, it is received in tanks, where the more solid parts are deposited. It does not require any extraordinary acuteness of smell, on approaching these irrigated lands, to become satisfied that the waters, even after passing from the cisterns or tanks, are sufficiently charged with odoriferous particles held in suspension. Indeed, in visiting some parts of the old town in Edinburgh, of Glasgow, and of Dundee, it is difficult to persuade one's self that the inhabitants of those parts are not absolutely deficient in one particular sense. Whether, with the present habits prevailing in those places, this deficiency is to be considered an evil or a good, I shall not undertake to decide.

This water, thus received, is diffused over three hundred acres of land; and these lands are rendered productive to a most extra- 
ordinary degree. One of the principal proprietors, who held his land, under a long lease, at a rent of $£ 5$ per acre, and sub-let this irrigated land at $£ 30$ per acre, informed me that it was sometimes cut seven times in a season. The grass is carried into the city, a distance of two and three miles, for the support of the cows, which supply the city with milk. Different channels or gutters are formed for the admission of the water, so that the whole may be flooded. It is applied generally after every cutting, where the situation admits of it ; but it is found advisable not to apply it immediately upon the grass being cut, nor before it has obtained some small growth.

The offensive exhalations from meadows thus treated have been the subject of prosecutions at law, as nuisances to health, by parties who derived no benefit from the operation, and whose sense of smell, therefore, was not, as I have known in some similar cases, benumbed or bribed by any pecuniary advantage. In the testimony adduced on these occasions, it has been stated that the rent for which some of these meadows are leased in small portions to cow-feeders, varies on an average from $£ 20$ to $£ 30$ per acre. Some of the richest meadows were let, in 1835, at $£ 38$ per acre; and in that season of scarce forage, 1826, $£ 5 \%$, or $\$ 285$, per acre, were obtained for the same meadows. "The waste land, called Figget Whins, containing thirty acres, and ten acres of poor, sandy soil adjoining them, were formed into water meadows, in 1821 , at an expense of $£ 1000$. The pasture of the Figget Whins, containing thirty acres, used to be let for $£ 40$ per year, and that of the ten acres at $£ 60$. Now, the same ground, as meadows, lets for $£ 15$ or $£ 20$ an acre per year, and will probably let for more, as the land becomes more and more enriched;" that is, land which, before the irrigation, let for about 500 dollars per year, now, under this improrement, yields an anmual rent of from 3000 to 4000 dollars. The irrigation is continued at different times, from the 1st of April to the middle of September.

The parties interested in defending the use of this water for irrigating these lands maintain that the grass produced in these meadows by this process supports in Edinburgh 3000 cows, and in Leith 600 cows. It is added, "that the parties interested in the lands estimate the compensation which would induce them to discontinue the practice, at $£ 150,000$, or $\$ 750,000$. 
This is stated as the stum which the proprietors at the west side of the city would be entitled to, exclusive of those at the east, were the practice abolished by government."

These are certainly most extraordinary results. The estimate of their pecuniary value may be exaggerated; and yet this would be difficult. The subject is of such immense importance, that $I$ shall presently again refer to it. I may be allowed to add, in passing, that which I know will not be disdained, but the more highly appreciated, by the most cultivated mind - that the process, however humble, by which that which is offensive and poisonous may be changed into that which is agreeable and nutritious, and that which is loathsome be converted into the highest forms of fertility and beauty, is among the most affecting wonders of a beneficent and divine Providence.

8. Willesden, Middlesex. - The next example of irrigation, to which I shall refer, is of a different kind from those of which I have spoken; but it may properly be classed under the same head; and its character is so extraordinary, and its practical bearings so important, that $I$ am anxious to present it to my readers. Having repeatedly visited the farm, and being personally acquainted with the enterprising proprictor, I am prepared to affirm the statements, however remarkable, which I shall present.

Mr. William Dickenson is the proprietor of a very large establishment of horses in London, which are kept for what is here called jobling; that is, supplying noblemen, gentlemen, and others, with horses of the best description, and at their pleasure, for daily use or for journeys, by the week, or month, or year. In this case, the contractor furnishes as many horses as are agreed upon; and in the erent of lameness, or disease, or incompetency, or at the hirer's own caprice, the latter may change his horses as often as he pleases. Whether these horses shall be kept by the contractor when the hirer is in the town, or by the hirer at his own stables, is matter of agrecment. Such an arrangement is common, even with some of the richest men in the kingdom, whose fine teams are jobbed or hired; and who, in such case, are at least saved from always a disagreeable and most commonly a dangerous intercourse with those geese-pluckers, the horse-jockeys - a race of men pretty well known in all countries, who, when 
a favorable subject falls into their hands, will not leave willıngly even a pin-feather, and who value such a bird, not for the fineness of his flesh, nor the beauty of his plumage, but for the richness of his notes.

These engagements oblige Mr. Dickenson to keep always on hand a large number of horses; and his stables in London may be considered as model stables, from the manner in which they are arranged, the condition in which the animals are kept, the perfect cleanliness which prevails in every department, and the admirable provision for securing an equable temperature and a thorough ventilation. Among other things, likewise, an ingenious provision is made for the saving of the urine of the animals, and, as far as possible, for preventing the escape of the ammonia, which high anthorities deem its most valuable ingredient, in its transition from the stall to the tank in which it is finally collected from the various stables. To effect this, the floors of the stalls are laid either in brick, or stone, or a composition of the hardness of stone, with a gentle inclination of the floor from each side to the centre of the stall. . Here an iron pipe is sunk, the whole length of the stall, similar to half a gun-barrel, with its concave side up, of course, into which the urine finds its way; and this is covered the whole length with a thin strap of iron, which can easily be lifted when the conduit needs cleaning. The urine goes into this channel unmixed with straw, and is conveyed by this pipe into a larger whole pipe in the rear of the stable, and is thence carried to the tank, which is placed in the outer yard. This tank is very securely covered, and is emptied into a watering cart by a pump, whenever occasion requires. Mr. Dickenson conceives there is great advantage in the liquid being thus, as far as possible, secured from the evaporation of its most valuable gases. The stalls are six and a half feet wide; ten feet in the whole length, with seven feet behind the mangers. The inclination of the floor from the sides to the centre, and from the front to the rear, is as little as possible, consistently with securing the passage of the urine. The number of horses lrept here is, I believe, from 150 to 200. The liquid manure is, as far as possible; all saved for the use of his own farm. The solid parts of his manure are sold to farmers. This fact deserves particular notice. It is a point of the highest eonsideration. The stale of a horse is equal to about three gallons 
per day. If it were all saved, it would amount to about three and one half gallons.

Mr. Dickenson has a farm about five miles from his home in London, to which all his liquid manure is carried, and there distributed upon his growing crops, from such a cart as is usually employed for watering the streets of cities. When taken out there, it is mixed, before application, in the proportion of one part of urine to two of water; and the proportion to an acre is estimated at $\mathbf{1 1 0 0}$ gallons of urine to 2200 of water ; and this is applied as often as and soon after the grass is cut.

The plant which he cultivates on this land is the Italian rye grass, (lolium Italicum, which he sows, in the autumn, say in September or October, formerly at the rate of four bushels per acre, but now, by an improved drill machine, at the rate of two bushels per acre; and upon looking at the two sowings, the one of four bushels per acre, the other of two bushels, the plants upon the latter sowing appeared to me more even and thick than where four bushels were sown in the usual way.

Mr. Dickenson thinks he has obtained, almost by mere accident, a very superior species of this valuable grass; and upon comparing various specimens, which he had under cultivation, and learning his own experience in the case, there seemed good reason for the belief.

"The Italian rye grass," says Mr. Lawson, "compared with any of the varieties of common rye grass, affords a stronger braird, arrives sooner at maturity, has a greater abundance of foliage, which is broader and of a lighter or more lively green color, grows considerably taller, is more upright, or less inclined to spread upon the ground; its spikes are longer; spikelets more thickly set; and, upon the whole, producing a less bulk of seed, which is smaller, has the awn adhering to it, and is generally little more than half the weight per bushel of that of common perennial rye grass (lolium perenne) when grown under similar circumstances." It is added, "If it be sown with clover, or lucern, its growth is so rapid that it will quickly choke them. It is eaten greedily by cattle, whether green or dry, and yields fifty per cent. of hay. After the field is harrowed, it is sown at the rate of from 16 to 18 pounds per acre, and the seed rolled in."

"The Italian rye grass will be valuable as an early grass; it 
retains its powers of growth to a late period in the season. A patch of it, which had flowered and ripened its seeds, was cut over in the first week in November; and, notwithstanding the frosts we have since had, occasionally pretty severe for the season of the year, [This is at Hamburgh. H. C.] at which period vegetation is nearly dormant, these plants have put forth new leaves, which at present (24th December) have attained the length of above a foot, showing a superiority to any other grass in producing herbage. This grass, too, is found to be more hardy than the common rye grass; for in the vicinity of Hamburgh, the common rye grass will not stand the winters when very severe; whereas the Italian rye grass withstands the severities of winter even when sown in September, and, consequently, the plants are young and tender when the frosts prevail."

Lord Hatherton sows amnually, at Teddesley, about one hundred acres of rye grass. His letter to me states "that common rye grass is always sown with clover, about one peck of rye grass seed to the acre. Italian rye grass is generally sown alone, three bushels to the acre, and may be mown three times."

At Mr. Littledale's, Birkenhead, near Liverpool, I saw the Italian rye grass in a state of great luxuriance, the second year's growth; but it had been irrigated from the stable. Mr. Dickenson says to me, "I should continue the field two years under grass, and then plough up for grain; but the plant will continue stronger or weaker according to the treatment, and whether you take seed or not. The grower must judge a little for himself. The grass is excellent food for working horses, and makes an abundance of milk from cows. Ewes and lambs do better upon it than upon any thing I have ever given them."

The soil of Mr. Dickeuson is a stiff elay, with which he mixes the rubbish gathered from the removal of old buildings in London, and consisting of sand and lime. In 1844, he mowed his rye grass ten times -

First in March, with about ten inches of grass;

April 13, a second time;

May 4, a third time;

May 25, a fourth time;

June 14, a fifth time;

July 22, a sixth time; with ripe seed and three loads of hay straw to the acre. 
Immediately after each of these crops, the land was watered once from a London street water-cart, with one part of pure urine from the stables and two parts of water, the produce of each crop increasing with the temperature of the atmosphere from three quarters of a load per acre as hay to three loads per acre. The crop having shed a quantity of seed, he was doubtful the urine might injure its growing; so discontinued to water, but well harrowed it with iron harrows, and left it, expecting nothing more from it. It produced, however, three or four light crops afterwards.

In 1845, his first cutting was on the . 6th of April ;

his second, . . . . . 3d of May;

his third, . . . . . . 9th of June.

On the 22d of September, the fourth crop on the land measured three feet; the sixth crop, on land which had been previously mown five times, measured one foot and a half.

On the 26th of January of this year, 1846, I saw some rye grass, which had been cut two or three days previously from his fields, which measured 16 inches in length. This same field was mowed October 30 th of the last year. It has been cut again the 8th of this month, (April,) 22 inches long.

Mr. Dickenson says that, when he has wished to relieve the tanks in the winter season, he has put on pure urine with excellent effect. He has also put on two parts urine and one water; and one part urine and one water, and two parts water and one urine. He is disposed to think, if there is such a quantity of urine as to render it indifferent how much is used, it may be applied pure to that description of grass, on almost all occasions. with success; but the effect would be greater on the land and plant in proportion to the temperature of the atmosphere. He advises to dilute more as the temperature rises, and for ordinary grasses to the extent of five or six parts of water. For the clover he thinks it ineffectual.

I was solicitous to know the actual amount of grass or hay probably obtained from an acre. He took the trouble to weigh accurately the produce of a yard square, of the fifth crop of grass of the season; and the following is his reply to me:-

"A yard of grass, cut in the presence of Captain Buller, weighed . . . . . lbs. $5 \frac{3}{4}$

Dried 12 days in the open arr. . . . . . " 23 
Dried further 3 days in a room heated to $59^{\circ}$ Fahrenheit, and weighed (standing weight). lbs. 23

Dried 3 days in a kitchen at $70^{\circ}$ of heat, and weighed . . . . . . . . " 210 oz.

Roasted 2 hours before the fire, and weighed . " $26 \frac{1}{2}$ "

"This was the third crop of grass with the second crop of seed, and it is the only instance I have been particular to measure, cut and dry the produce, and this to satisfy one who had seen the previous crop cleared from the field; and this would be at the rate of about 5 tons 3 cwt. to the acre."

I saw in Manchester the produce of three cuttings of one season of Italian rye grass, the united length of which was more than 13 feet.

Such are the important statements, which I have verified upon my own repeated personal observation, and which I have the greatest pleasure in communicating to the farmers of the United States. I have no hesitation in saying that the verification of such extraordinary facts as these, and their communication to a wide extent, are infinitely more than a compensation for the toil, and labor, and expense, of my visit to this country; indeed, are not to be put for a moment in comparison with them; for if properly improved, this information must be worth millions to the country. I claim no priority of discovery, and I cannot presume that this information may not have reached the country in a hundred forms, in these days when the press pours out its treasures, as, in its great inumdations, the Mississippi pours out its floods over an immense country, and sends its waters into every creek, and crevice, and fissure, of that wide expanse. But I know my friends will value a personal confirmation of these facts, and will feel, with me, greatly obliged to Mr. Dickenson for the full communication of the results of his experiments.

These experiments are most important in showing, first, what an amount of stock may be kept upon a small space of ground when under the best cultivation, and by means within the reach of many farmers. Where a piece of ground is devoted to this object, within an easily accessible distance from the stables or yards, it is very easy to see what a quantity of produce may be obtained for feeding animals in the stall, either horses, cows, or sheep. I put this question to Mr. Dickenson, asking his deliberate opinion, "How many horses, in a good season, may be fed 
from an acre, and for what length of time?" To which he replied, "Four horses in a straw yard consumed in one day seven yards by five and a half of the Italian rye grass, having no other food, and not being in work, but running loose in the yard at their own pleasure." The answer, I am aware, is indefinite, because the condition of the grass and the actual weight gathered at the time of cutting are not given; yet the fact is worth something as the foundation of a conjectural estimate. My readers may be curious to know the army allowance for a horse of dry feed per day - $14 \mathrm{lbs}$. of hay, $10 \mathrm{lbs}$. oats, $7 \mathrm{lbs}$. straw, each horse; with hard work, less hay and more corn ; with little work, less corn and more hay.

But more important than any thing else is the illustration which these results give of the extraordinary value of urine as manure. I asked Mr. Dickenson if he would add the solid manure, if it were at hand; to which he replied, "No."

This is a very homely subject, I am aware; but it is one of the most important in the whole range of agricultural inquiry. In cities, it essentially concerns decency, cleanliness, and health; and $I$ have yet to learn that to a mind with its moral taste not depraved, and not cursed by a habit of vile associations, there is any thing indecent in speaking of any of the processes of nature, which are all recuperative, wonderful, and beneficent. "Honi soit qui mal y pense." Neither in Boston, New York, Philadelphia, nor indeed in any other city in the United States, have I known any systematic attempt to save the sewerage water for agricultural purposes; and yet I believe, at a very small expense a vast amount of the urine might be collected and carried out of the city by the neighboring farmers, without offence to any body, and with very great public and private advantage. I believe that, in many cases, it might, with a little pains, be collected from private and public houses, from stables, and from public urinals established in different parts of the city, which are rery much wanted in the great thoroughfares, on grounds of health and comfort as well as decency; and that the farmers, who are now in the habit of buying solid manure, at the stables of the city, at very heavy prices, would find even a much greater advantage in removing the liquid manure, after proper arrangements for its collection and removal should have been made. A very high authority states that "human urine is particularly rich in 
nitrogen; and that it has been ascertained by analysis in this respect that one hundred parts of the urine of a healthy man are equal to thirteen hundred parts of the fresh dung of a horse, and to six hundred parts of the fresh dung of a cow."

"The urine of men and of carnivorous animals contains a large quantity of nitrogen, partly in the form of phosphates, partly as urea. Urea is converted, during putrefaction, into carbonate of ammonia; that is to say, it takes the form of the very salt which oecurs in rain water. Human urine is the most powerful manure for all vegetables containing nitrogen; that of horses and horned cattle contains less of this element, but infinitely more than the solid excrements of these animals." *

I do not deem it necessary to cite any other authorities on this subject. Mr. Dickenson's experience in the case is conclusive; and he finds it for his advantage to save all the urine of his stables, to carry it in carts a distance of five miles, and is content to sell to those who will buy it his solid manure.

Next to the introduction of fresh water into a city, the disposition of its waste or sewerage, in respect to the sanatory condition of the population, is most important, and ought to occupy intensely the consideration of the public men, and men of influence, and the municipal authorities, in the United States. 'The influence of cleanliness upon health, comfort, and morals, in all cities or large aggregations of people, is of immense moment. In all public works of drainage, extreme care should be taken to gnard against hurtful mistakes in the beginning; and to make, under the direction of the highest and most practical and experienced engineering skill, such arrangements as will be effectual and substantial without any mean reference to expense. Where any portion of the sewerage of a city can be saved without offence, and without danger to health, the results at Edinburgh, as evineing the value of such savings, show to how much consideration the matter is entitled. The agricultural value of one portion of this saving is estimated in Edinburgh at $£ 150,000$ sterling, which would be equal to a sum yielding an interest of $\$ 45,000$ per year. This, we are to understand, is already obtained with very imperfect arrangements. After making a deduction of all the miscellaneous matters which go to swell 
the heap, "it is calculated that, in a city containing 100,000 inhabitants, there is produced of human manure 24,440 tons a year, sufficient, according to Liebig, to manure 50,000 acres of land, and, if conveyed to the soil by irrigation, worth at least $£ 12,000$ a year, [or $\$ 60,000$,] and probably much more." If even one half of this could be so saved and applied, it is obvious how much would be gained.

The subject is now, in England, occupying, to an intense degree, the minds of many of the most distinguished men - politicians, magistrates, agriculturists, and philanthropists - in the kingdom. A company has been formed, with a capital of one million pounds sterling, and by men who are entirely above any plan of mere speculation, for the purpose of supplying towns with water, and availing of the drainage of large towns for agricultural purposes. Some of the first engineers in the kingdom are actively engaged in their service. One of them, Mr. James Smith, of Deanston, the eminent agricultural improver, whose system of thorough drainage and subsoiling may be said to constitute an era in agricultural improvement, has laid before the public a plan for conveying the sewerage of towns into the comntry for agricultural uses, by means of pipes, which is now being carried out in the city of Aberdeen, Scotland. His plan is, having collected the sewerage water of a town into a convenient receptacle, to force it, by means of a pump, to a sufficient altitude to send it into the country through large pipes, to be used for the purpose of irrigation of lands below the level where it is received, or of applying it to other lands by means of a pipe and hose.

I do not deem it necessary here to give all the elements of his calculation; but the result is that, in supplying an equal amount of the elements and requisites of vegetation, the cost of manuring one acre

with sewerage water, upon his plan, would be $£ 012 \mathrm{~s} .9 \mathrm{~d}$.

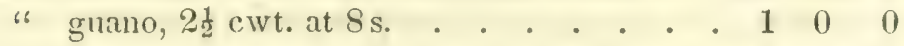

" farm-yard manure, 15 tons, at $4 \mathrm{~s}$. . . . 300

It is added that, "by an experiment made last season on a portion of meadow in Lancashire, applying at the rate of 15 tons of farm-yard manure per acre, and $3 \mathrm{cwt}$. of guano to another equal portion, their effects were found to be inferior to the 8 tons of sewerage water applied to a similar extent of ground. The amount of fertilizing matters contained in the water was vor. II. 
not ascertained, but, assuming a similar quantity to that found in the Edinburgh sewer-water, the amount applied must have been about 1792 gallons per acre, which is less than the quantity which Mr. Smith proposes to apply to tillage land under his improved method of conveyance.

The proposition at first is startling, and may awaken incredulity. I can only say that the plan is proposed and approved by men of as much engineering skill, and of as much practical experience, as are to be found in the world. It certainly should not be condemned, unheard, in a day when cities are every where lighted with blazing air; information is communicated hundreds, and soon will be thousands, of miles, instantaneously, by means of electricity; and men are conveyed from one end of a continent to another, over wide-spreading lands, and heaving and boisterous oceans, with the swiftness of a swallow's flight, under the wings of a steam dragon.

Having now treated at large some of the prominent operations in English husbandry, I shall proceed to speak of other points in their management, which deserve attention.

\section{CIV. - THE ROTATION OF CROPS.}

The rotation of crops implies the alternation or succession of different crops on the same land. It is well ascertained by frequent and long experience, that where the same cultivated crop is frequently repeated on the same land, and allowed to perfect itself, its product will be diminished, and in some cases will fail altogether. 'The grasses would seem to present an exception in this case; but they are commonly mowed or depastured, and so do not ripen their seed. Where grasses proceed to perfection, certainly it may be said, in respect to many of them, that they are subject to the same rule. Forest-trees likewise may be considered as forming an exception, though it must be remembered that they supply their own nutriment from the decay of their own foliage, and that, although they bear fruit while young, yet they are many years in reaching a perfect maturity; and even 
in respect to forest-trees, nature, in many cases, clearly indicates the necessity of a change of production, in that where you cut down a forest of oak, it is usually followed by a growth of pine, and where you remove a forest of pine, there will spring up a growth of oak; the soft and the hard woods thus alternating with each other.

Sometimes it is found that the substitution of a single different crop is sufficient to prepare the land for the repetition of the former one. In some cases, the crop can be repeated with advantage after an interval of two, three, or more years. In some instances, the land, if left to itself, or what is called a naked fallow, becomes, after a year or more, prepared for the repetition of the first crop. The regular and plentiful manuring of the land will enable the land to bear the repetition, though there are cases in which even this ceases to restore the land to its former condition. It is found likewise that crops of the same fanily, though not of the same kind, will not follow each other to advantage. Thus the cereal grains, wheat, rye, barley, and oats, are considered improper to follow each other in immediate succession. The English divide their crops into two kinds, white and green crops. The grain crops are white crops; the green crops are the esculent vegetables, such as turnips, ruta-baga or swedes, carrots, parsnips, beets, cabbages, peas, beans; although the two latter, which are cultivated for their seeds, would seem more properly placed among the white crops. There is, however, another distinction between the narrow-leaved and the broad-leaved plants, which is to be considered in this case. The narrow-leaved plants, such as the grains and grasses, receive their nourishment mainly, as is supposed, from their roots, which are numerous and fibrous; the broad-leaved plants, such as turnips, cabbages, beans, and peas, and the clovers, receive their nourishment chiefly from the atmosphere, and do not therefore so severely tax the soil. This difterence, it is supposed, allows of one of these crops being alternated with the other without prejudice to either. I am giving, in this case, the theory of others, which certainly, to a casual observer, seems plausible enough. I trust I may be allowed to demur to it, or at least to hold my judgment in suspense, because, to my mind, the proof is wanting. It remains, in my opinion, yet to be established that any plants receive their nourishment through their leaves. 
It would be presumptuous to pronounce it impossible, but the proof does not appear conclusive. Two other theories have been suggested to account for the necessity or expediency of an alternation or change of crop. The first is, that every plant throws out from its roots, as excrement, that which is unfavorable to the growth of, or poisonous to, any plant of the same kind that may succeed it, but which, on the other hand, may be favorable to the growth, or be the proper food, of a plant of another kind. It is maintained, that by the cultivation of another kind of plant, of different wants from the former, this pernicious excrement is used up; or even by the suspension of cultivation, by what is termed a naked fallow, by the stirring or ploughing of the ground without cultivation of any crop, this offensive matter is destroyed, and the former plant may be again successfully cultivated.

The second opinion is, that different kinds of crops make demands of different elements from the soil ; that the cultivation of a particular crop tends to exhaust the soil of the ingredients or elements which it particularly requires; that this element may be sometimes artificially supplied by manuring; or that the land being suffered to remain without cropping, or by a succession of different crops, nature itself will provide for a renewal of the deficient or exhausted element. The former theory is in a great measure abandoned; the latter is the prevalent opinion with those who claim a right to speak with authority.

The latter theory, however, is not without some difficulties or exceptions. Onions, for example, are cultivated successfully, year after year, on the same land, from preference, because it is found that the longer the land has been accustomed to this crop, the more favorable does it become to the growth of it. I have known cases in which Indian corn has been successfully cultivated forty years without interruption on the same land. A distinguished agricultural traveller and observer, ${ }^{*}$ says that he has seen, "in the table lands of the Andes, wheat fields which had yielded excellent crops annually for more than two centuries; and that potatoes may come again and again upon the same soil; they are incessantly cultivated at Santa Fé and Quito, and nowhere are they of better quality." 
In all these cases, which seem to militate against a theory perfectly rational in itself, there may be circumstances undetected or unobserved, which, if known, would fully explain the exception. I do not mean to deny this theory, and certainly not to throw any discredit upon the aid which science may give to agriculture; but these matters are not so simple as we are disposed to think them.

The confidence and presumption of knowledge abate the desire of further attainment, and remove the stimulants to inquiry. Science has yet a great work to perform for agriculture; and when chemistry can, by analytical examination, show precisely what is wanted in any particular soil for the growth of any particular crop, and how it may be supplied, we shall hail the discovery as one of the highest importance, and the noblest triumph which it can achieve. We believe, at least we confidently hope, that this may be done. We know what has been promised in this matter, and wait patiently its fulfilment. Agriculture will then be reduced to a system of rules so simple and exact that the plainest mind camnot mistake the course to be pursued.

At present, we must be guided by practical experience. Most crops are found to diminish in their yield the more frequently they are repeated in immediate succession upon the same land. Manuring for every crop will not always prevent this, although it will commonly do it where an ample supply is to be had. Some crops, it would seem, will bear a repetition much less frequently than others. Red clover bears to be repeated only once in four or six years, and some farmers would introduce it into the course of crops only once in twelve years; yet here we are not without dissent, for an experienced and observing farmer says, it may be cultivated as often as we please, provided the soil is sufficiently consolidated. Flax, it is constantly said, camnot be successfully cultivated oftener than once in five years; yet in one of the comnties of New York they cultivate it with advantage every other year, and the experiment in Ireland has been equally successful. There cannot, however, in spite of these exceptions, remain a doubt, that, in the present state of agricultural knowledge, there should be an alternation or rotation of crops, as the surest mode of obtaining the largest product from the ground, and of keeping up the condition of the soil. I have 
known rye sowed, year after year, on the same land, for a length of time, with a constantly-improving product; but in this case, clover was always sowed with the rye; and this clover, in a state of luxuriance, was always turned in by the plongh with the rye stubble, or, as it is here termed, "smothered," preparatory to the land's being again sown with rye.

One great object in any rotation of crops, which might be adopted, should be to make the intermediate crop, which is supposed to be fed upon the land, prepare the land for the crop, which is to follow. Thus it is that a green crop, which is manured, will itself do much in manuring the land for a white crop. While the amount of manure which is applied to a green crop can hardly be excessive, the same manure, if applied to a white crop, would be likely to increase the straw at the expense of the grain, and render its growth so luxuriant, or, if the term be allowable, so plethoric, that it would be liable to disease or blight, or to perish by being lodged.

The course of crops varies in different localities, according to the nature of the soil and the climate; and the kinds of crops grown depend likewise much upon local circumstances, such as the vicinity of a market, and the demand which that market creates. The most common rotation, and that which goes, by way of eminence, by the name of the Norfolk system, is called a fourshift rotation, and consists of, 1st year, turnips; $2 d$, barley; $3 \mathrm{~d}$, clover; 4 th, wheat. In this case, there is usually but one manuring or dunging for the course, and that is given to the turnips. But, then, under the best husbandry, the turnips are fed to sheep which are folded upon the land, the tumips generally being cut and given to them in troughs, the fold being formed of hurdles, and changed frequently; and the clover likewise is fed upon the ground by sheep. The wheat and the barley go to market; and the straw is reserved for feeding and for litter in the barn-yards and stalls. On an English farm, no straw is ever suffered to be sold or carried off the place, unless an equivalent in dung or other manure is brought on. In some parts of Kent, it is stated that wheat and beans are alternated contimually. On a farm in Gloucestershire, much celebrated for its good management, turnips, potatoes, and wheat, constitute the alternation of crops, though sometimes a crop of vetches or rape intervenes, which is fed off upon the land. In this case, a great deal of 
manure is purchased and brought upon the land. In some places, in the county of Kent for example, a six year's' course is recommended: thus, 1st, swedes, [ruta baga, well manured, and fed off with sheep, who at the same time have a plentiful allowance of oil cake, than which nothing contributes more to the enriching of the manure; $2 \mathrm{~d}$ year, barley or oats; $3 \mathrm{~d}$, clover; 4 th, wheat; 5 th, peas or beans; 6th, wheat. In this case, the wheat, the beans, and the peas, have a dressing of duug; and in some cases, in the third year, beans are substituted for clover; and in the fifth year, clover for peas and beans.

"On land of a second rate quality, the five-field course is common: 1st, turnips; $2 \mathrm{~d}$, barley; $3 \mathrm{~d}$, clover ; 4 th, wheat ; 5 th, oats. 'This is found to bring the clover tilth too often; to remedy which the following course is sometimes adopted: 1st, turnips; $2 \mathrm{~d}$, barley; $3 \mathrm{~d}$, half clover, half peas or tares; 4 th, half wheat, half oats; 5 th, half oats, half peas. This brings the clover round only once in ten years, when the crop becomes much more certain."

A very experienced farmer has beeu kind enough to communicate to me what he deems an eligible rotation for a "farm, of a heavy soil, varying from foul to eight inches in depth, resting on a stratum of strong brick clay from two to three feet in thickness, the substratum being the red crumbly or dried marl, intermixed, in some places, with thin slaty stone, and containing occasionally gypsum. All the arable land has been drained with tiles, in the furrows or divisions of the land, which vary from five to nine yards in width, about eighteen inches deep. The cold springs, pressing beneath the stratum of clay, in the greater part of the farm, have been cut off in an effectual manner by a few large under-drains, varying from ten to sixteen feet in depth. About half the arable land is considered to be totally unfit for the growth of turnips; on the other half the cultivation of tulnips has for several years been part of the rotation, and lately with considerable success, for the purpose of carting off into the farm-yards and pasture-grounds; but no part of the land is dry enough, or properly calculated for feeding off the turnips with sheep."

Each division of the farm consists of twelve fields or enclosures, and is worked on a double rotation of six years. The rotation has been, 1.st, common turnips; $2 \mathrm{~d}$, barley; $3 \mathrm{~d}$, white 
clover and rye grass, pastured; 4th, ditto ; 5th, wheat ; 6 th, winter tares; 7th, Swedish turnips; 8th, barley ; 9 th, red clover; 10 th, wheat; $11 \mathrm{th}$, beans; $12 \mathrm{th}$, wheat.

In this case, the turnips, the first year, are manured with ten two-horse cart-loads of manure to the acre, well turned in in the spring. The crops of the third and fourth year are fed off by sheep on the land. The sixth year, the tares have a moderate dressing of manure. The seventh year, the Swedish turnips, besides twelve two-horse loads of manure, have likewise applied forty bushels of ashes and bone dust. The ninth year, a slight dressing of manure is applied to the land after the first crop is taken off for soiling. The eleventh year, the land is manured with seven or eight two-horse cart-loads of manure, applied before sowing in the spring.

The rotation of crops pursued by Mr. John Morton, on the Whitfield Example farm, which I had the pleasure of visiting, is for a clay soil, as follows: 1st year, swedes and mangel-wurzel; 2d year, wheat and beans; $3 d$, clover; 4 th, wheat and oats, that is, part of the land in each; 5 th, vetches, rye, early turnips ; 6th, wheat.

On a sandy soil, the rotation is as follows: 1st, swedes and mangel-wurzel ; 2d, barley; $3 \mathrm{~d}$, clover ; $4 \mathrm{th}$, oats ; 5 th, cabbage, potatoes; 6th, wheat.

On a limestone soil, 1st year, rye and turnips; $2 \mathrm{~d}$, barley; $3 d$, clover; 4th, oats; 5th, turnips; 6 th, wheat.

I do not deem it necessary to cite any more examples of the rotation of crops; and my object has been, not to prescribe any particular rule of management, but merely to illustrate the practice which prevails here. How far it would be eligible, or adapted to the condition of agriculture, in the United States, is quite another question, and must receive a very different answer in different localities. Many of the crops which are cultivated here are not, within my knowledge, cultivated at all in the United States, such as vetches or tares, though I have myself tried them upon a small scale, and have known one or two farmers to experiment upon them in the same way; and, in the next place, there is here an incapacity to grow a crop which is common with us, - the maize, or Indian corn, - a crop, which, in my honest opinion, all its uses being considered, is the most valuable product that ever came out of the ground. 
The examples which I have given will serve to illustrate the systematic form in which agriculture is pursued here. According to the rotation determined on, the farm is divided into portions, and each one comes, in its turu, into a regular course of cropping. With the tenant farmers, this is not a matter of choice, but is commonly strictly prescribed in the lease, and is not suffered to be departed from. The great principles of cultivation and management which they suggest must be obvious; first, that a regular change or rotation of crops is always advisable in order to secure the largest product from the land; next, that the white and the green crops should alternate with each other; that two white crops should not follow each other, and seldom two green crops; that the manure should be applied for the green crops, and that the green crops should always be consumed by stock upon the farm; and, where the nature of the land admits of it, by stock, sheep in particular, folded upon the land which it is desired to put into a condition for a grain crop.

Formerly, it was deemed indispensable to introduce into the course what is called a naked fallow, in which a season was lost; for, though the land was cultivated, no crop was grown. 'This was done for two reasons - first, because it was supposed that, in a course of cropping, the land occasionally required rest; but secondly, with a view of exterminating the weeds; or noxious plants with which the land was infested. The former doctrine is now exploded, and it is considered that, by the substitution of a different crop, the land may be occupied continually; and clover crops by their tap-roots, and all crops which are fed and expended upon the land on which they are grown, so far from being considered as cxhausting, must be regarded as enriching crops. The second reason for a fallow must be admitted to have much force. The degree to which many fields here are infested with weeds, with charlock, dock, poppy, and, above all, with twitch grass, (Iriticum repens,) is most remarlsable; and the latter, propagating itself, as it does, from even the smaliest fibre or joint, cannot be got rid of without extreme pains, by harrowing, grubbing, and picking it out by forks and by hand. On a piece of ground under the process of being cleaned I have seer the collected heaps of it as thick and large as haycocks on a newly-mown field. A hocd crop, of course, presents an opportunity of cleaning the ground as effectually almost as a naked ballow. 
It will be for the farmers in the United States to consider how far the rotation of crops deserves their attention, and, if any particular course be adopted, what is best suited to their particular condition or locality. The same course is obviously not alike adapted to soils of different character, or to places varying in climate and in their demands for particular articles of produce. I am quite aware that, at present, in the United States, there are few examples of what may be called a systematic agriculture; and in many parts of the country, especially in the new states, where the virgin soil is unexhausted, and in some cases its exuberant riches would seem almost inexhaustible, - for in parts of the western territories, in the prairies and bottom lands, I have seen the rich alluvial soil exposed to the depth of eighteen feet, - it would seem to be of little consequence to present generations by what course the land should be cultivated. But to the perfection of the art of agriculture, to the realization of its greatest products, and, above all, to the attainment of that great point of good husbandry, the obtaining of the largest and most profitable return from the land at the least expense of labor, at the least injury to the soil, and, as it may be hoped in many cases, with an actual benefit or improvement to the soil, without doubt an exact system of cultivation and a regular course of crops will be found indispensable. The climate of England and the southern parts of Scotland presents advantages which we in the Northern and Middle States, perhaps in most other parts of the United States, cannot enjoy. The mildness of the winters here enables them to fold their sheep, and to feed the crops to them in the ficlds where they grow, during any part of the season. In very rare instances are the sheep ever housed, or even sheltered or protected; and in many parts of the country the turnips are eaten by the sheep where they grew, or are pulled as they are wanted and given to them in the fold. Where this is not the case, the turnips are either pitted or placed where they grew. "To "pit" them is to place them in heaps in the field, sometimes digging a hole of a foot deep to receive them, and, after bringing as many loads to the heap as is deemed convenient or jroper, shaping the pile like the steep roof of a house, and, after putting on a layer of straw over the turnips, adding to this a layer of dirt of a sufficient thickness to secure them from frost. "To " place" the turnips, is to pull two rows of tumips, and, wath- 
out removing the tops or the earth from the bottoms, to place them close on each side of the intermediate row that is left in the ground. A plough is then passed down on each side, and the whole are covered by the earth being turned upon them. These are secured from frost, and are accessible at pleasure through the winter, and given to the stock as wanted.

My own conviction, and that founded upon no little personal experience and observation, is, that the farmers in the United States, where circumstances favor it, would find a great advantage in growing esculent vegetables for their stock, especially turnips, swedes, and mangel-wurzel ; and where these are properly pitted in the fields, they may be preserved from the most severe frosts, and at the same time be accessible, in the coldest weather, at the southern end, which may be secured by bundles of straw, to be removed and replaced at pleasure. That, during our long winters, a supply of such vegetables would very much conduce to the health and comfort of our stock, that they would be found most valuable for cows in milk and in calf, and for fatting cattle and sheep, is certain; and the cultivation. of them would yield an ample profit, and the return of manure from the consumption of them upon the farm would prove most valuable. In this way, likewise, the straw of the farm wonld be converted into rich manure.

It will be observed that, in any rotation of crops to which I have referred, there is little provision for hay. Comparatively, very little hay is grown, excepting for market, or for the horses on a farm; and what is grown is husbanded with the most exemplary care - with a care which would much astonish many of our farmers, whose habits in this respect are extremely wasteful. On many farms there are meadows in permanent grass; some portion of the clover crop is usually dried and cured; and when rye grass forms a part of the rotation, it is almost always converted into hay. The main dependence for the stock, with the exceptions above named, is upon the esculent vegetables and the straw. As soon as the spring advances, there is a supply of rye sown for the purpose of being fed green to the stock, or of winter vetches, and the farm horses are usually soiled through the summer upon the latter crop, of which I shall presently give a more particular account. 


\section{CV. - SOILING, OR HOUSE FEEDING.}

THE practice of soiling stock prevails to some, but not, within my observation, to a great, extent in England. The soiling of stock implies the keeping of them in stables or yards all the season, and bringing to them green feed, when it is to be obtained, cut fresh from the fields. I have not been able to get that exact information on the subject, which I should have desired; and perhaps it would be vain to look for it.

Work horses are almost universally soiled in England upon clover, rye grass, rye, vetches or tares, or rye and vetches sown together. These are sown expressly for this purpose. The horses are frequently kept upon them without any additional feed; but when on the road, or when the farm work is severe, they require grain of some sort in addition.

Sheep, as I have before said, which are in a course of preparation for the market, and sometimes store sheep, especially those which have lambs by their side, that are designed for market, are folded, and the tares cut green and conveyed to them, which may be considered as soiling. A large stock on Lord Hatherton's admirably managed farm at Teddesley Park, in Staffordshire, are soiled; and their good condition evinced the excellent care which was taken of them. In many cases, in small holdings, I have found the system pursued with great success. On Lord Gosford's estates in Ireland, under the judicious and excellent care of Mr. Blacker, who has the superintendence, as he informed me, of several hundreds of tenants, (such are the subdivisions of estates in that country, ) I found that among many of these small tenants he had introduced the practice of soiling their cows. Several, whom I visited, were keeping in good health, and with great advantage, three or four cows, where formerly they kept but one, and that one in a half-starved condition. It is said that in Ireland a cow is sometimes recommended for her capacity of getting her own living by leaping hedge and ditch, and foraging any where at her pleasure. Under a system of soiling, that branch of her education might well be dispensed with, much to the advantage of the peace of the neighborhood.

That a great saving of food is effected by soiling there can 
be no doubt; no one rates it at less than two to one; many say that three animals, some assert with confidence that four animals, can be well kept upon the produce of land, if soiled, where not more than one could be kept if depastured. The difference, undoubtedly, in this respect, is very great in favor of soiling; but its expediency upon the whole, in any given case, will be affected by a variety of local circumstances.

The soiling of work horses on a farm is always to be advised. They require the most particular superintendence; but this can be given to them only when they are near at hand. They should be protected agaiust those extreme changes of temperature from which they are likely to suffer if turned into a pasture at night after a hard day's work. They require to have their food prepared for and brought to them; otherwise much of the time, which should be given to sleep and repose, is necessarily devoted to obtaining their food; and a horse turned empty at night into a pasture, will be likely to pass a great part of that night in filling his stomach. The same remark applies also to working oxen. It is highly creditable to the English farmers that their work horses are attended to with the most particular and faithful care, as to cleaning, littering, feeding, working, and watering. I have referred already to the practice of one distinguished farmer, who never allowed his horses to be trimmed, or curried, or housed, against their inclination. He was of opinion, that Nature, in this respect, was the best guide; and that she gave the animals their thick and matted coat, in winter, when they required it, and it was, therefore, wrong to deprive them of it; and in the spring she took equal care in divesting them of the covering, which then became oppressive and superfluous. There may be some reason in this; but whenever I see either horses or men in this shaggy and wild-bear condition, I cannot help thinking that nature.may be somewhat improved upon. It cannot be said of this farmer, however, that he did not give his horses the opportmity of sheltering themselves if so they chose: for he had warm sheds and open stalls, most amply littered, to which they might have recourse at pleasure. This latter circumstance, of leaving them loose, was a feature in his management much to be commended; for it seems a great cruelty, though not an infrequent practice, to tie a hard-working horse in

voL. 11 . 
a close box or stall, with a short halter, where he cannot stretch himself, nor lie down but in a constrained position.

Nothing, indeed, is more remarkable throughout England, as far as my observation has extended, than the care and kindness bestowed upon the horses; excepting always the omnibus and cab horses in London, who seem, like galley-slaves, to be sentenced to hard labor as a punishment, and the hunting horses, who, especially in what are called stceple chases, which are in fact only trials of speed under the most unfavorable circumstances, are subjected to a severity of usage absolutely barbarous. I had the pleasure of enjoying the hospitality of a family of high rank, at whose residence forty or fifty carriage and hunting horses were kept, and where it was the custom for the principal members of the family, and their guests, to visit, by a covered passage way, the stables late in the evening, to see that every thing was in order; that the grooms and their respective charges were in their places, and in proper condition; and that the noble animals, who contributed so essentially to their pleasure and comfort, were duly cared for. The establishment was a model of neatness and good management. I have had the pleasure to find many a farm stable, where the comfort and health of its occupants were provided for with a carefulness equally exemplary. I confess I never witnessed such kind, and only proper care bestowed upon these noble animals without a strong desire that some other animals employed in the labor of the farm, certainly not less noble, and whose toil is equally severe, were the objects of a similar care and kindness.

With respect to the soiling of sheep, it could rarely be practised on any extensive plan; but the folding of sheep for fattening, and with a view to enrich the land in the fields, where the produce grows, which may be considered as one form of soiling, is universally practised. Experiments have been made on the feeding of sheep entirely within a yard; and the result, with respect to an eminent firmer in Yorkshire, whose establishment I had the pleasure of visiting, seemed to show that much was gained by this process, inasmuch as the animals consumed a much less quantity of food, in the proportion of 30 to 50 , than animals which had a free range; but later experiments, by other individuals, do not confirm these results. Mr. Pusey, for exam- 
ple, states, that he "Kept ten Down lambs in a shed, and ten out of doors, weighing each lot regularly; but found the gain of weight rather on the side of the lambs fed out of doors." It is extremely difficult to say why one experiment succeeds, and another of the same kind fails or gives an entirely different result; but this is a frequent occurrence, and requires us to draw conclusions from single or from few facts with extreme caution. We can presume to be confident only when these facts are multiplied, and often repeated under the same circumstances, and always with the same results.

With respect to the soiling of cattle, it is the case with some farmers that their calves are never turned into the field until they are a year old, and that many cattle may be said to be wholly reared in the stall. The fat stock, which are sent to the Smithfield cattle-show, and much of what is designed for the market, are kept altogether in the stalls or in loose boxes, as they are here termed.

In regard to milch cows in the country, they are commonly depastured; but in the large dairy establishments of London and its vicinity, they are wholly soiled. After being once placed in the stalls, they are never untied, excepting in some cases where they are loosened for the purpose of being watered, until their milk ceases to be sufficient to meet the expense of their keeping. They are then fattened and sold to the butcher. The feed is cut and daily brought to them in a green state, sometimes from a considerable distance. In such a city, cows, if kept at all, must be kept in the house; and during the season when green feed is attainable, it is of course obtained, for its advantages in increasing the milk.

Two great advantages of soiling cattle are, first, the increase of manure; and second, the lieeping of more cattle on the same land.

The increase of manure from soiling is very far beyond what would be supposed by any one not experienced. Where proper provision is made for this purpose, all the manure of the animals is saved, instead of being left and scattered either on the road side, or in the fields, to be dried up by the sun, or washed away by the rain; and it is at hand to be applied as the farmer shall choose. It gives him an opportunity of converting all his long litter, and the straw of his farm, into the most valuable of ma- 
nure, by using it as an absorbent for a large amount of the liquid portions of the excrements of his cattle. It affords him likewise the power, by properly-constructed gutters and tanks, of saving his liquid manure - the best portion, if well managed, and, aceording to the estimation of many eminent farmers, compared with the solid portions of the manure, in point of value, full two to one.

'The next great advantage of soiling is the increased stock which may be kept upon the same land. From the various facts which have come under my observation, where the soil is carefully and judiciously cultivated, and duly mamured, and a proper rotation observed, I believe that on land under artificial grass or esculent crops, three animals may be soiled where one only is now grazed. I believe this may be done with equal or superior advantage to the health and thrift of the animals, and that, in most cases, the increase of valuable manure obtained in this way, will much more than pay for any extraordinary trouble of attendance.

Another advantage is in the saving of interior fences upon a farm. Where cattle are kept constantly in barns or yards, the necessity of enclosures is of course done away; and, separate from the saving of expense in the case, the convenience of cultivating in long lines and open fields, the saving of land, and the superior neatness of the cultivation, are great and obvious advantages.

The trouble of cuting and carrying the fodder for a large stock presents to many persons an insuperable objection to soiling. This, however, must depend on local circumstances, which every farmer must take into consideration for himself. Without doubt, in some cases it might be such as to render the experiment ineligible. The difficulty of finding a supply of green feed sufficiently early in the spring, is likewise made an objection. This may be an objection in many localities; but in England proper, where an ample supply of Swedish turnips, carrots, and mangel-wurzel, are grown, and where winter vetches, rye, Italian rye grass, and lucern, afford an early cutting, this objection does not apply. It has been objected that cows soiled will not give so much milk as when grazed; on the other hand, the testimony of some individuals, with whom I have become acquainted, establishes the contrary. At Teddesley, in Staflord- 
shire, where a large stock is soiled, the opinion is, that the cows do not give so much milk as when grazed. At Glasnevin, Ireland, the opinion of the intelligent superintendent of that establishment is, that then production of milk under the soiling system is much greater than when grazed. In a trial lately reported upon the comparative advantages of feeding cows with malt or barley and other articles of food, it was found that, upon being taken from the fields to the stalls, the milk of these cows was considerably increased. It is difficult to make a comparison in the case upon which the matter may be confidently determined. The quality of milk must, to a degree, depend upon the nature, and its quantity upon the supply, of the food which the animal receives. Some animals naturally and constitutionally, from peculiarities or circumstances which have never yet been explained, secrete milk of a much richer quality than others. The Alderney or Guernsey cows are remarkable examples of this kind, their milk being much richer than that of any other breed of cows known. Yet that the quality of the milk is not wholly constitutional, but depends to a considerable degree upon the nature of the food on which the cow is fed, is well established. Its quantity, of course, depends upon the supply of food which the animal receives. It seems to be determined by experiments which have been made here, that, of all food, grass fed green will produce the largest secretions of milk. It is found, likewise, by experiment, that in order to the largest secretions of milk, the temperature in which the animal is placed must be comfortable; she must be free from external annoyances; and she must be "at ease in her mind." These things being equal, it is not easy to see why, under an ample supply of fresh grass eaten with a good appetite, there should not be an equal production of milk in the stall, as in the pasture.

In illustration of some of my remarks, and because I think it may gratify the curiosity of my readers, I will here quote from a report just presented to Parliament in relation to the trial of different articles of food upon two cows, with a view to determine the result upon the quantity and quality of their milk.

"The intestines are the reservoir in which the food is placed for the purpose of being absorbed into the blood. The rapidity with which the dissolved or digested matter is taken up must, it is obvious, depend upon the rate at which the vessels destined 
for this purpose act : these being set in motion by the heart, this again by the nervous system, and the latter by respiration, there is discernible a beautiful chain of connection between the oxygen of the atmosphere and the absorbed food. If the system described were always in equable movement, if no influences were occasionally present to interfere with its proper equilibrium, animals would be in the condition of plants, which possess absorbing apparatus, but are destitute of one powerful interfering agent in the animal economy; this is the brain and nervous system, upon the condition of which depend passions and emotions of the mind. It is principally by the study of this important apparatus that we derive our knowledge of what is peculiarly termed the constitution of animals. Without this system, animals would be merely chemical machines, and we might then predicate, in every case, the effects of particular influences, as one animal would then differ from another merely in the extent of its mechanism. This remark is to be kept in view in considering the subsequent experiments. The cows were very different in reference to their nervous condition. The white cow was quiet and steady, generally eating equal portions and producing equable quantities of milk. 'The brown cow, on the contrary, was fitful in her appetite, and, of consequence, was variable in the amount of her products. In proportion to her weight, she consumed a larger amount of food than her fellow, but always afforded less milk, and a greater amount of butter. The variable action of her organs is well exhibited in the first series of tables. When at pasture, she had given two pints less than the white cow, and immediately before the experiments, she gave the same quantity as her fellow. On her arrival in Glasgow, her milk greatly increased; but it soon began to diminish, although the same amount of food was continued. That the change was not produced by any alteration in the food is obvious from the steadier result afforded by the white cow, which was also supplied with an equal weight of fodder. The amount of milk given by the brown cow was as much as 26 lbs. per day, when she was fed with grass, and upon the same kind of food the quantity declined to $22 \mathrm{lbs}$.; while the milk produced by the white cow was, at the commencement of the experiment with grass, $23 \mathrm{lbs}$., and at the termination of the trial $21 \mathrm{lbs}$. ; so that there was a falling off, in the case of the brown cow, to the 
extent of $4 \mathrm{lbs}$, and with the white cow only to the amount of 2 lbs. That this result was not merely owing to a deficiency of water was proved by experiment, which gave the same amount of water in the milk of both cows; but the quantity of butter afforded by the brown cow anounted to 11 l lbs., while that of the white cow was $S_{\frac{1}{3}}$ lbs., in fourteen days, from $142 \% \mathrm{lbs}$. of grass supplied to each animal. Again, when the animals were fed on steeped entire barley, the brown cow's milk fell from 22.1 lbs. to $17 \frac{1}{2} \mathrm{lbs}$, while that of the white cow's only declined from 22 lbs. to $19 \frac{1}{2}$ lbs. ; the brown cow falling off to the extent of $5 \mathrm{lbs}$, and the white only to the extent of $2 \frac{1}{2} \mathrm{lbs}$. These facts are sufficient to show that the two animals were constitutionally different. The occasional wild look of the brown cow, her tendency to gore those who approached her, her frequent startled aspect, all indicated a nervous state of excitement; the probable cause of which has been already alluded to. The result of these experiments seem to countenance the idea that, although a handsome external figure is not necessarily an indication of the highest capacity in a cow to produce milk and butter, yet that it may conduce to afford a steady supply of milk, inasmuch as it appears to indicate a proper relation between the organs." *

'That stall-feeding does not necessarily tend to reduce the quantity of milk, seems satisfactorily established at the various milk establishments which I have visited, where it is often found that the quantity is increased by the improved system of feeding under which they are placed. One milkman, of large experience, has assured me that he can almost at pleasure, in some cases, increase the quantity of milk full an eighth by a change of feed, as, for example, by giving them an extra supply of raw potatoes in addition to their other food. In a comparison. likewise, between the two modes of feeding, it must be remarked: that cattle wholly grazed are liable to the changes made in their feed by the variations of the seasons, the grass being at one time abundant and most succulent; at another short, or dried up by drought. In the stable, their feed may be kept uniform throughout the season. Cows, with us, that are depastured, give a flush of milk in May and June, when the feed in the pastures is most luxuriant, but "fall away" greatly in their yield in August;

* Parliamentary Report on feeding Cattle with Malt, 1846. 
from which decline they but partially recover, when turned into the mowing fields in September and October, upon the aftermath, or rowen. Now, although they may not, at any time, in the stall, give as much milk as when turned into the pasture at the very height of the feed, yet, their keep being equal throughout the season, the yield of milk will be longer kept up; and the whole amount given throughout the year will probably be more than that obtained from animals which are wholly grazed, and left to encounter the vicissitudes of the seasons.

In any system of soiling, it would seem most important that the animals should be occasionally tumed out into an open yard for some portion of the day, as essential to their health, rather than to remain tied in the same position, as they are compelled to be in many of the large dairy establishments in the cities, not only from one week or one month to another, but from the beginning to the end of the year. "It is known," say the commissioners on the state of health in large towns, "that tubercular consumption is very prevalent among the cows which supply milk to the inhabitants of some large towns, where they are immured during part of every year in dairies perfectly closed; and which, being too small for the number of animals which they contain, soon become filled with heated, vitiated air, for the removal of which no provision is made. This is remarkably the case with the cows belonging to the milkmen of Paris, which are annually carried off by consumption in considerable numbers. A confirmation of the influence of this cause is afforded by the exemption of the horse from consumption, although frequently placed in the same circumstances with the cows, but with intervals of exposure to fresh air, and the enjoyment of exercise. Where a number of horses, however, are collected together in ill-ventilated stables, they may become consumptive. $\mathbf{A}$ discovery of this kind was only lately made, as to the effect of defective ventilation on the cavalry horses in some of the government barracks in England; and it is stated that a saving of several thousand pounds per annum was effected by an easy improvement of the ventilation of the barracks near the metropolis." These statements seem to me to have a very important bearing upon the construction of our stables and barns, and the greneral treatment of our live stock. The health of our live stock is, I fear, not sufficiently regarded. I have already alluded to 
it; but the subject is of so great importance, that I may be allowed to reiterate my admonitions. Though they camnot tell their complaints, these are not the less severely felt; and the animal constitution is liable to the same irregularities within, and to the same injurious influences from without, in one cuse as in another, in the brute as in the human animal.

I have seen, as I have already remarked, several instances of soiling in this country; but, with the exception of large milk establishments in the towns, and one or two large farms in the country, they have been upon rather a restricted scale. I have said that horses are almost universally soiled; the same may be said of much of the fat stock, which is in preparation for an early market, and especially for the agricultural shows. Fattingsheep, in England, are generally folded, and in most cases the feed is cut or pulled for them, and they are fed from mangers or troughs. Other stock is generally grazed, as with us. Indeed, in parts of the country, especially in Scotland and Ireland, there is a large portion of the country which does not admit of, or would not pay the expense of, cultivation, and this is devoted to grazing, as the only beneficial use to which it can be applied.

I am bound to say that soiling is not universally approved. Mr. Stephens, the eminent author of the Book of the Farm, says that he has tried twice the experiment of soiling his horses, but failed in both cases; at one time for want of cutting grass, the second cutting having entirely failed that year; and the other time, for want of straw for litter, until the arrival of the new crop.* The latter reason seems to me about as appropriate and valid an objection against soiling, as it would be to have said that his experiment of soiling failed because he had no stalls in which to tie his cattle, and no troughs from which to feed them. Litter is indispensable in order to reap from soiling all the advantages, which it may afford in the production of manure; but it is difficult to understand with what propricty it can be objected to the practice of soiling, that it fails, when that failure is not in any way the fault of the system, but grows out of the deficiency or neglect of him who makes the experiment. The former objection has a good deal of force; and it would be great imprudence or improvidence to under-

* Book of the Farm, vol. iii. p. 851. 
take a system of soiling without an ample preparation against such contingencies. Mr. Dickenson's experiment, which I have so fully detailed in a preceding part of this Report, (p. 161,) and the experiments of the cow-feeders near Edinburgh, most clearly show what can be done.

It does not come within my province, in this case, to detail what has been done in the United States in the way of soiling. The experiments of Josiah Quincy, Esq., on his estate in Quincy, Mass., made with great intelligence and acuteness, are detailed most fully in the Reports of the Massachusetts Agricultural Society. I have in other publications referred to a dairy of Robert Smith, Esq., near Baltimore, where a hundred milch cows were soiled. Another similar establishment I have visited on Long Island, N. Y., where an equal or larger number of cows are soiled. I have likewise, in former reports, mentioned the admirable experiment of a small farmer, in Waltham, Mass., who, from three cows carefully soiled, and allowed to recreate themselves for two hours a day in the barn-yard, produced at the rate of thirty pounds of butter per week, for three months. But I will refer to some cases which have come under my observation here, always finding occasion to regret the extreme difficulty of obtaining from farmers in general very exact accounts of any of their farming operations.

I shall give first the experience of Mr. Skilling, the intelligent and skilful manager of the school farm, at Glasnevin, near Dublin.

At first, he was a country schoolmaster, having the management of four and a half acres of land. "When I adopted the house-feeding system," he says, "my neighbors laughed at me, and predicted that my cattle would die; others said the cattle would give no milk. I lived near a village, through which I led my cows twice a day to water. They had a good appearance, as they were well fed; and they ran through the village wild and full of spirit. This showed they were in no danger of dying; and when they saw (for I was closely watched) firkin after firkin of butter going to market, they began to think there could be no great deficiency in the milk. I fed them on mangel-wurzel and turnips; and when other cows were dry, mine were giving milk. During three years, I kept three cows, and 
sold $£ 6$ worth of butter each year, from each cow, besides having a sufficiency for a family of six persons."

When I visited Mr. Skilling's well-managed establishment, he was then soiling sixteen cows in clean, well-ventilated, and convenient stables. He states that these cows, upon an average, give him $£ 1510 \mathrm{~s}$. a year, each, and this principally from the sale of the milk. He estimates "that a cow fed in the house will make twenty-five tons of liquid manure, which will be suthicient for an acre of ground." I am afraid in this case my friend overrates the quantity. He says, he can, "on an average, keep a cow on every two English acres of land." I believe that, with proper pains and cultivation, a cow may be kept upon less than two acres. I have known a cow very well kept upon one acre through the year, and a portion of hay annually sold from the same ground. "Such," he adds, "are the advantages of housefeeding. There may be dificulties in keeping cattle in houses; but people should have patience, and not let difficulties overcome them. The advantages that arise from house-feeding are a larger quantity of manure, and much more milk; and, such being the case, it would appear strange that men should continue to practise the old plan. The system is applicable to a large farm, as well as to a small one. In England, the farmers do not keep half a sufficient stock upon their farms. They keep a great number of sheep, but not sufiicient to compensate for the short stock of cattle. But it may be objected that, on a very large farm, say 1000 acres, it is difficult to erect a cow-house sufficiently large to accommodate as many cattle as would be necessary. The difficulty can be casily obviated. Let a number of cottages be erected on the farm; and beside them let cow-houses be built, so that the persons residing in the cottages can take care of the cattle in the houses next to their own. Let the young eattle be in one house; the milch cattle in another; the fat cattle in another; and it will be found, at once, that the system is as applicable to a large farm as to a small one." Mr. Skilling, it will be seen from these statements, is of a sanguine temperament; but the observations of a man so experienced as he is are entitled certainly to a respectful hearing.

He goes on to say, "The house itself must be airy, well ventilated, and perfectly clean. The animals must be well curried and brushed every day." Ifis stables and their occupants gave 
ample evidence that he practised what he preached. "There ought to be one particular person to superintend and pay attention to the feeding; and one of the most important parts of his duty is, to ascertain the appetite of every beast. Cows, like other animals, will eat less or more; and they ought to be supplied according as they require it, being kept rather with an appetite, than otherwise. As soon as the animal has eaten its food, all refuse should be immediately taken away, and nothing suffered to remain in the stalls before it. The cattle will know the hour of feeding as correctly as the clock tells it, and will be disappointed and fretted if neglected. This neglect is prejudicial both to milking and fattening. Every farmer who cultivates his land in a proper manner, will have plenty of food for his cows in the house, summer and winter, and of various kinds. Cows, like other animals, are capricious in their appetites; they will not agree with being constantly confined to the same kind of food. No matter how nutritious in itself, there ought to be a variety; a change, if possible, for every feed." This is the mode of feeding which, he says, he himself has found eligible. "I give six feeds in the day, summer and winter, beginning at 6 o'clock in the morning, and ending at 9 in the evening: viz., at 6 , at 8 , at 12 , at 3 , at 6 , at 9 . They get water in their stalls at 10 in the morning, and at 5 in the afternoon; they are likewise turned ont one hour, from 10 to 11, where they exercise, and drink if they choose. The kinds of food I use chiefly are the following: In summer, at $6, \mathrm{I}$ feed with perenuial or Italian rye grass and clover; at 8, with cabbages or leaves; at 12, with cut hay and straw; [this feed is to prevent the action of too much green feed upon them; a cow in health ought never to be purging; if she is, both milk and flesh are running off; ] at 3 , upon vetches; at 6 , upon mangel-wurzel leaves, rape, cleanings of ditches, or other refuse of the farm or garden; at 9, clover or grass, or this may again be dried feed, if the state of the bowels requires it. In winter, at 6, first foed with steamed food; at 8 , with turnips, raw ; at 12 , with cut hay and straw; at 3 , with mangel-wurzel raw; at 6 , with steamed food; at 9, with hay and straw. Water must be given or offered, and plenty of salt used in the steamed food. 'This mode, after much experience, I have found highly advantageous for all my cattle." He adds, "I have ascertained that when my 
present farm was in pasture, it pastured eighteen cows in summer; but now it feeds sixteen cows and three horses, all the year round, and I have as large a proportion of grain crops on the same land as most other people, besides."

I have thought that these details, all of which came under my own observation, would be interesting to my readers; and I will refer to some experiments on a small scale, on the estate of Lord Gosford, in the comty of Armagh, Ireland, already spoken of, under the management of William Blacker, Esq., who may be considered as the author of house feeding in Ireland.

I had the gratification of a most instructive visit with this gentleman, among several of his small tenants, who every where greeted him with a warmth of welcome which showed their deep sense of his kindness. Indeed, many of them, through his judicious and beneficent agency, had been recovered from a condition of want, discouragement, suffering, and debt, and placed in circumstances of independence, comfort, contentment, and improvement; and I know not who are more to be envied than those persons who have it in their power to confer such benefactions, and who are permitted to see the beneficent fruit of their labors.

I shall be excused if I interrupt the course of my subject to speak of the means by which these changes, which here meet the eyc and warm the heart, and form such an affecting contrast to the indescribably wretched condition of many of the cottier of Ireland, have been brought about.

The numerous tenantry among whom he was placed, and a large proportion of whom were the occupiers of very small holelings, labored under two great difficulties, - ignorance of the best mode, and the want of the means, of cultivating their grounds, difficultics which press hearily upon a great portion of the Irish population. The best of all charities is that which helps the unfortunate to help themselves. To understand the condition of Ireland, - mnlike, it is said, that which exists in any other part of the civilized world, - it is necessary to go into Ireland. My eye never before rested upon, my imagination could scarcely exaggerate, the state of destitution and degradation, as far as their condition was concerned, in which I saw millions of these people living The whole blame of this condition is not to be charged: as is too often done, upon the landlords. If, as is well known, 
there are too many landlords who neglect, there are those who seek to perform, their duty, and to discharge their high responsibilities, and who, actuated by an ardent spirit of philanthropy, are sincerely anxious to ameliorate the condition of their dependents, and to raise them from their low estate. But what can be done with people who are satisfied to burrow in a mud cabin, or a mere hole in the earth, and to marry, and live, and to bring children into the world, upon poverty and potatoes? Mr. Blacker, with the coopperation of the nobleman whose estate he manages, has effected the most beneficial changes among his tenants, by stimulating their pride, by multiplying their wants, by calling out their self-respect, by teaching them the best modes of management, and assisting them to pursue these modes.

His first plan was to employ some respectable and skilful farmers from Scotland, well qualified to teach, who were to serve as agricultural instructors. They were themselves to occupy a small farm, on which they were to exhibit an example of the best mode of management and cultivation; and, within a prescribed district, they were to visit the cottiers and small tenants, and instruct them in these improvements, looking after them frequently, reporting them, and encouraging them by the promise of handsome premiums for superior skill and industry, to be bestowed at the annual agricultural meeting, at the close of the year. In addition to this, through his Scotch agents, or by himself, Mr. Blacker offered the tenants aid in the form of seeds, artificial manures, improved implements, and sometimes a cow, the expense of which was all to be ultimately reimbursed. The plan has succeeded admirably. One of the first visits was to a small farmer, who had been at one time negligent, addicted to intemperance, deeply in debt, and wholly discouraged, and without even a cow, so important a blessing in a poor man's family. His hahits were now changed; he had applied himself most diligently to the cultivation and improvement of his little farm; he had paid his debts; he was keeping two or three cows, and now felt the pride and wore the port of a man. It would be difficult to say what superior benefaction he could have bestowed upon such a man; and the beneficence was gratefully appreciated; for there is a chord in the human heart from which the touch of disinterested kindness seldom fails to bring a response.

I will give the returns of some of these small tenants. 
A. B. has fourteen acres. He keeps four cows and a horse. The sales from the produce of his cows amounted in the year to $£ 17$, beyond the supplies of his family. Under the system of house feeding, he says he can keep four cows where he could keep only one before. Such a place as this, it is clear, should not be burdened with a horse. Each acre of his land, he stated, gave him a profit of $£ 5$.

C. D. cultivated eight and a half acres, in potatoes, flax, oats, turnips, \&c. \&c. He kept two cows, but had wisely sold his horse. He paid $£ 915$ s. rent, and had cleared, in the previous year, $£ 43$, exclusive of butter used in his family. His oats were a magnificent crop; and where they had been manured with the water in which his flax had been rotted, the beneficial effects of the application were most striking. He raised two pigs.

E. F. occupies nine acres. Had last year three cows; this year he is keeping four; sold last year about $£ 40$ of produce, exclusive of butter. His cows produce about seven pounds of butter each per week.

All this is spade husbandry and house feeding. I shall proceed to give some other statements, which did not come under my particular observation, but with which Mr. Blacker was kind enough to make me acquainted.

G. H. stated that he had fed his stock of four cows and two calves upon one acre and two roods of land * all summer, being about one rood and four perches for each cow, after allowing for the calves, and had three roods of turnips, and one of rape, for winter. His whole occupation amounted to eight acres and three roods of land. His stock, of four cows and two calves, he stated, late in the autumn, had been fed, through the summer and up to that time, upon clover and vetches, on the same piece of ground which formerly, in grazing, kept only one cow, and that poorly. This man added that he was satisfied that there was no way in which land could be made to produce so much, or by which it could be brought into such heart, as by the soiling system, and four-course rotation of crops. He was just beginning to feel the benefit of it, his land being now all perfectly clean, every inside ditch levelled, not a spot in the whole that was not productive, and not any of it whatever in pasture.

* I suppose, in these cases, the Irish acre is intended, which, to the English statute acre, is as the square of 14 to the square of 11 , or as 196 to 121 . 
I. J. states that, when he came to his farm, four years ago, he could only keep one cow, and two acres of such pasture as it atiorded was only sufficient to summer-feed her; that he had gradually increased his stock from year to year, until he had now three good cows, and a horse, on his eight acres of land, and had now more acres manured than he then found roods.

K. L. states that where formerly he had only two cows, a heifer, and a pony, he now had five cows, two heifers, and one good horse, upon his sixteen acres, kept on clover and vetches in summer, on cabbage in the autumn, and turnips in the winter and spring.

M. N. occupied twenty-three acres of land. His stock was seven corvs, two heifers, one calf, and two horses, which were kept in good condition; and besides this, he had nine hundred stooks of excellent oats, and an acre of flax.

O. P. occupied six acres of land. Two acres and two roods were in potatoes, one acre in turnips, and he produced about thirty barrels of oats. He house-fed three cows, three calves, and an ass; he made three firkins of butter; he had two pigs; he had to support a family of eleven persons; and yet he had twenty barrels of potatoes to sell.

Q. R. held four acres, one rood, and twenty perches of land. He had two acres of potatoes in arable land, and three roods in reclaimed bog, of which he had reclaimed two acres; he had one acre of turnips; he had ten barrels of oats to sell; he had made three firkins of butter during the summer; he had house-fed two cows and two heifers. He had thirteen in a family to support, and he expected to sell ten barrels of potatoes; had already sold three pigs at a profit, after paying their cost, of $£ 5$.

S. T. held five acres of land. He had two acres of potatoes, three roods of turnips, twenty perches of flax. He had housefed three cows and a genet. He had made three firkins of butter, and had twenty-four barrels of oats and fifteen barrels of potatoes to sell.

I do not deem it necessary to multiply these cxamples, although more are within my reach. I need not point out the conclusions to which they lead. Two things, however, deserve particular attention. The first is, that none of the product of the land is lost or wasted. The second, which reveals the whole secret of suceess, is in the large quantity of manure which is obtained 
upon this system. It is confidently stated that, where every thing is well managed and saved, a single cow will furnish ample manure, in the course of the year, to be applied to an acre of ground. I do not recollect that, in any of the cases which I visited, any provision was made for saving the liquid manure in a tank, so as to be applied by sprinkling to the land. This, if properly done, as may be seen from Mr. Dickenson's example, would have greatly increased the resources of these small farmers.

How far the system is applicable in other cases, every farmer must determine from the circumstances in which he is placed. I have no hesitation in saying that there is no farmer, who keeps live stock, to whom the subject is not worthy of attention. Perhaps there is no farmer with whom it may not very advantageously be to a degree applicable. The moving spring of every farmer's success is his manure heap; and how the manure heap is to be created and enlarged every one knows.

The great matter to be considered is, how to obtain a supply of succulent food throughout the whole year. With us in the United States, the plant of Indian corn, for a part of the season, cut green, and as early as it will bear cutting, furnishes the richest and most abundant of all provision. It may be sown broadcast or in drills, and so as to furnish a succession of feed until the frost comes. This advantage cannot be had here.

The Italian rye grass, which I have already so fully described in speaking of Mr. Dickenson's management, is an admirable plant for this purpose. In addition to this, there is a species of rye, called $S t$. John's day rye, lately introduced here, which grows luxuriantly, and comes into a state fit to be repeatedly cut very early. I saw this plant cultivated on Mr. Pusey's estate, and there brought into most advantageous contrast with the common rye, which was sown in the same field. I shall give Mr. Pusey's account of it.

"Some farmers do not approve of rye, for while young it gives but little food, and shoots up rapidly to a harsh stalk, which stock do not relish. This does not apply to the St. Johu's day rye. This plant, if sown in proper time, and on a suitable soil, presents itself to the scythe in a state palatable to horses for full three weeks or more. It will grow from six to seven feet high. 
The time to sow it (in the climate of England) is the 24th of June, at all events before July. The condition of the soil must not be poor, and the produce will pay for good land. The soil needs to be compressed after sowing, if the land be at all light, by rolling or sheep treading."

In June of the following year, the farmer whom I have quoted above sent Mr. Pusey an account of his further success in the growth of this rye. The stalk was six feet in leugth, though it had not then flowered. He began to soil eight cart horses witr. it on the 13th of May, then three feet high, and four cows a week later. Both these kinds of stock ate nearly the whole of it with scarcely any waste; it had then been twenty-two days in use, and he expected its eatable state would extend through a month. He thinks he should have begun a week earlier, not waiting until it was three feet in height.

Mr. Pusey, whose growing crop I saw, "sowed some in July, 1843 , on some poor, moory soil, without manure; it was fed off in the autumn, and again in the spring, yet produced, on little more than a quarter of an acre, thirteen bushels of seed. The seed was sown again last year, (1844,) in August, as soon as harvested. It produced on a sandy loam very good feed in the autumn; and in this backward spring, $(1845$,) it realized the description given of it, and established its character by covering four or five acres with a thick coat of herbage, in which the lambs were browsing breast-high, while there was little or no other feed in the neighborhood."

It is said to be called St. John's day rye "because it grows so rapidly that, if sown about St. John's day, it will be fit to mow green by the middle of September; and in favorable seasons, may be fed off again in November, without preventing its giving ample feed the next spring, and a good crop of grain at harvest."

This rye, in Belgium, is deemed inferior to the common rye in yield of grain, but "it has evidently two advantages over the common rye. It tillers so much as to produce double the quantity of herbage on the same space of ground. In one field, where the two varieties were growing together, the common rye, after twice feeding off, became so thin that I ploughed it up, while this new rye covers the ground with its third crop, as with its 
first. It is sweeter than the common rye when young, as is shown by its being preferred by the hares and rabbits. Its principal merit is, however, its superior sweetness in advanced growth, and the consequently longer time during which it remains fit for use as spring feed."

Mr. Baker, a distinguished farmer of Essex, speaks of having obtained seed from two different seedsmen, and having found that, for spring feed; one was a fortnight earlier than the other, and yielded double the amount of produce. By the use of this plant, he says, he is now able to support all his horses and neat stock for two or three weeks before his neighbors commence. From the middle of April last, (1845, ) he has been enabled to maintain upwards of forty horses and colts, and fifty head of neat stock, the former up to the present time, (24th of May,) and the latter until the 14th of this month, almost without the assistance of hay. The chief difficulty he had to contend with, was, to remedy the great waste occasioned by the horses and stock in foddering; for, as the rye advanced in stem, the stock would eat only the most tender portion, and, if tares were sown in conjunction, would waste the greater part of the rye in the endeavor to extract them while feeding. 'To remedy this, he cut the whole into chaff, and, by the addition of a small quantity of hay, and about one half of sweet wheat or oat straw, which he gradually diminished as the season advanced, he obtained a description of food for which, for early use, he knew of nothing as an equivalent, in point of cheapness or utility, besides the advantage of gradually adopting the change from dry to green food without risk or inconvenience to the animal. The number of acres consumed, to the present time, did not exceed nine; and the land upon which it was grown was already in a forward state for turnips. The rye grown by Mr. Baker is understood to be different from the St. John's day rye.

For house feeding, likewise, lucern is sometimes cultivated, although not so extensively in England as I had expected to have found it. This requires to be sown on rich soil ; broadcast. if the land is clean; but in narrow drills, so as to admit of being hoed, if it is likely to be infested with weeds, which, in truth, constitute a principal obstacle to its cultivation. It is believed there is no more nutritious food to be found for cattle and horses. 
and none from which so large a product can be obtained from an acre, save only Indian corn, in a favorable climate and soil. It is stated confidently, but perhaps extravagantly, that an acre of good lucern will keep four or five horses from May to October, when cut just as the flower opens. It requires a dry, rich, loamy soil. The climate of Scotland is said to be too cold for it; but I have known very good crops of it produced in the neighborhood of Boston, New England. Clover - the common red clover-furnishes an excellent article for soiling, scarcely inferior to any thing which can be found; but its cultivation is too familiar for me to enlarge upon it.

The article mainly depended on in England for soiling, especially for horses, is vetches or tares. These furnish a very large amount of feed, and there is at least one kind which may be cut more than once in a season. Of the vetches which are cultivated for the purpose of soiling in England there are two kinds; one, which will bear to be sown in the autumn; the other, which is sown in the spring, to afford late summer or antumn feed. As well as I could learn, there is no observable difference in them, but that one will endure the winter, and consequently will afford early spring feed, and the other kind will not endure the winter; and the general impression is, that these peculiarities are the result of cultivation and habit, rather than of original constitution, if the term may be so applied.

After the early and trying part of the season is past, the crops of turnips, swedes, mangel-wurzel, and various tribes of cabbage, under industrious and good cultivation, will furnish an abundant supply of food; in respect to some of them, first in their leaves, and next in their bulbs and roots. Rape is likewise cultivated very extensively, especially in Lincolnshire, for the folding and feeding of sheep. As far as my observation extended, it is not usually cut for sheep; but a temporary fence is put up round a portion of the field, and they are turned in upon it. This being eaten, another enclosure is made; and in this way they successively enter upon the different portions of the field.

That a variety of food is conducive to the health of the animals, and to the increase of the milk of the cows, seems well established by general opinion and by actual experiment. Dried food is much less conducive to milk and to fatness than green; 
and the effect of dry straw is to produce almost immediately a great diminution of milk. Hay is conducive to health, and to milk, in proportion to the succulent state in which it has been cured, provided, however, it has attained some substantial growth before being cut.

I think it will be interesting to my readers, if I quote here from the report to which I have alluded, on a trial of some different kinds of food upon cattle, made under the direction of the government, and just published by their order. I cannot say that the report, as a whole, is altogether satisfactory, or that the conclusions arrived at are very definite. The remarks, however, which I shall quote, are very worthy of attention.

"That a change of diet is necessary for animals which are kept in a confined condition, is proved by the tables accompanying this report in a striking manner; and the results now obtained amply sustain the idea, supported by us some time ago, in reference to the dietary of human beings shut up in poorhouses and places of confinement. It was then argued that, in order to retain the human constitution in a healthy condition, variety of food should be properly attended to, and different species of diet were suggested as well calculated to supply a series of dishes to the poor. In the Asylum for the Houseless and in the IIouse of Refuge, at Glasgow, the recommendations wcre followed out, and, according to the report of the treasurer, the dimer meals being varied two or three times every week, the change in the dietary is much relished by the inmates, and may have had some effect in the greater degree of health which has been evident among them of late. The analogy subsisting between the physical nature of human beings and of many of our domestic animals, would lead us to the conclusion, upon physiological grounds, that their dietary should be conducted upon precisely similar principles. To prove this by exact experiments, is a point, it will be admitted, of considerable importance to the agriculturist, although it may have been, as might be expected, surmised by many intelligent observers. Not only, however, is varicty of food requisite for an animal in an artificial state, - it is found also to be beneficial to one in a condition more akin to that of nature; for it is upon this principle that we are able to account for the superior influeuce of old natural pastures, which 
consist of a variety of grasses and other plants, over those pas tures which are formed of only one grass, in the production of fat cattle and good milk cows. To any one who considers with attention the experiments which have been detailed, there cannot remain a doubt in the mind, that cattle, and especially milk cows, in a state of confinement, would be benefited by a very frequent and entire change in their food. It might not be too much to say, that a daily modification in the dietary of such animals would be a sound scientific prescription."

I have deemed it important to go thus largely into the subject of soiling or house feeding, because I think it will enable many of the farmers in the United States, especially in the older states, to keep three times the amount of stock which they now keep, and to very much more advantage with regard to produce and profit, and especially to the improvement of their farms, than the system which they now pursue. The great means of improving our farms are in the amount of stock which we keep upon them, always premising, however, that that stock, to be profitably kept, must be well kept; and while every farmer loses who does not keep all the stock which his farm will carry, he perhaps loses still more who keeps more stock than he can keep well. But every effort should be made by a good farmer to increase the capacities of his farm to their utmost extent; and by the number of cattle and sheep which he can amply provide for, may be determined his means of enriching his farm and enlarging the profits of his husbandry.

I foresee two objections that may be argued against the adoption of the system of house feeding in the United States - the one, the expense of labor; the other, the trouble of undertaking it upon any extended scale. The first is a simple question of profit and loss; if its profits will be more than an equivalent for its expenses, the application of any amount of labor under such circumstances cannot be reasonably objected to. The trouble and care which it may bring with it are no further a reasonable objection to its adoption than to every other project of improvement. No good in life is obtained without its proportionate price; and to men who live by their farms, and therefore have an interest in making those farms as productive as possible, as to enterprising men engaged in trade or manufactures, it resolves 
itself into the simple question, whether it will prove sufficiently remunerative to compensate the labor and attention. The reply to this question will of necessity be qualified by many local circumstances, and must be left to every farmer's own decision.

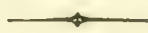

\section{CVI. - CROPS.}

The island of Great Britain produces, of bread crops, wheat, oats, barley, and rye; and perhaps in no other part of the world has the cultivation as yet reached a greater degree of perfection. I am, however, far from believing that it has attained its highest point ; and, if the extraordinary crops produced in some parts of the country evince what can, the inferior yield in other parts, without any ascertainable hinderances of climate or soil, show what should, be done. I believe there is no part of the island in which wheat may not be successfully cultivated. In the north, oats are more cultivated than wheat, and constitute there the principal bread of the people at large. Oaten bread, however, in that country, is found under certain forms at the tables of the rich and of the higher ranks, as well as among the lower classes; and though I consider it altogether inferior to the bread of Indian corn, - and such, indeed, is my honest opinion of wheat bread also, - yet it is agreeable to the taste, and its nutritiousness is undoubted. In Ireland, where fine wheat is grown, and where also a considerable portion of oatmeal is consumed, the food of a large mass of the people is potatoes, and of this not always a full supply.

1. Whent, however, is to be considered as the standard grain, and the great crop of England, upon which the arable farmer mainly depends for his money returns from his farm, and for the payment of his labor and rent, and to which, therefore, his attention is constantly and principally directed.

Of wheats there are great varieties. In the Agricultural Museum at Edinburgh, first established by the most commendable enterprise of Mr. Lawson, but now the property of the Highland 
and Agricultural Society of Scotland, a vast number of kinds are exhibited; and his account enumerates more than eighty different sorts. The common divisions are into bearded or beardless wheats, into thin skinned, or white, and hard or flint wheats, or into white or red wheats. The botanical distinctions would be of little consequence to my general readers. The white wheats, or thin skinned, yield the largest proportion of flour or starch ; the flint wheats of gluten, which is the most nutritious part of the wheat. The colors white and red are not permanent distinctions, but are considered as attributable to the soil in which these two kinds are grown; the white wheat sometimes changing into a red, and the red into a white. No advantage would come from my enumerating the various kinds cultivated. Every district has its favorite wheat ; and it is with wheat as with most other popular favorites - public opinion is continually changing. The results, too, with respect to the same kind of seed, are different under different cultivation, and are likewise materially affected by the season. Different markets, likewise, have their preferences for different kinds of wheat. 'The baker wants one kind of flour; the confectioner requires another. I shall presently specify some of the principal ones cultivated. The analysis of different wheats has shown a remarkable difference in the quantity of gluten in each; but it probably will be found that this more depends upon the soil and the species of manure applied, than upon any peculiarity in the seed itself.*

* "A sack of Italian, Sicilian, or Russian (Odessa) flour, when tough in lineading, or, according to the baker, 'full of proof,' or gluten, takes up, in consequence, from five to six gallons more water than a similar quantity of British flour, and makes, in consequence, from four to six more quartern loaves. When the wheat, in England, is not well harvested, it is frequently necessary, in order to make a loaf 'which will stand up in the oven,' and sell, to mix with it flours of the above description. Starch is perfectly white, while albumen, the same substance as white of egg, is of a grayish color; and gluten, by exposure to air, becomes brown. The flours called fines and extrafines are made from Dantzic wheats, when to be had. From their whiter color, and their taking up, in the formation of bread, less water than wheats from the south, they must contain more starch and less gluten and albumen. Our British wheats, used also for fines and extras, in which the former is known to abound, are also whiter; and, as articles of Iuxury, it is true that the whiter wheats bear a higher price. But flours from the south, from containing more gluten, are browner, and, seeming to be less well dressed than they are, and to contain more bran than they do, sell at a lower price: still they go farther, and make a more wholesome and nutritious bread. The intel- 
There is another distinction of wheats - into autumn, or those which are sown in the autumn, and spring wheats, those which are sown in the spring. But this is undoubtedly an accidental and not a permanent or constitutional distinction. With care in the selection of the seed earliest ripe, after a succession of seasons, what was winter wheat may be converted into spring wheat; and by sowing spring wheat in the autumn, its season of ripening will be retarded, and after a while it will take its place among winter wheats.*

Of the average yield of wheat per acre throughout the kingdom, it is difficult to speak with any confidence, as no exact returns are collected, and conclusions of this sort must be almost wholly conjectural. Nor do I see what useful lesson is to be learned from combining the results of poor and negligent with those of the most liberal and skilful cuitivation, and striking a general average between them, except to afford an excuse or palliative for the neglect and indolence of those who do not cultivate their lands as well as they might. What we require to know is, what can be done; and this is determined beyond all

ligent laborer who bakes his own bread from seconds knows this well; it keeps him better up to his work than whiter flours." - W. H. Hyelt, Esq., Royal Agricultural Journal, vol. i.. pt. i. p. 144.

"Proust found French wheat to contain 12.5 per cent. of gluten; Vogel found that the Bavarian contained 24 per cent.; Davy obtained 19 per cent. from winter, and 24 from summer, wheat; from Sicilian, 21, and from Barbary wheat, 19 per cent. The meal of Alsace wheat centains, according to Boussingault, 17.3 per cent. of gluten; that of wheat grown in the 'Jardin des Plantes,' 26.7 ; and that of winter wheat, 3.33 per cent. An increase of animal manure gives rise, not only to an increase in the number of seeds, but also to a most remarkable difference in the proportion of the substances containing nitrogen, such as the gluten which they contain. One hundred parts of wheat grown on a soil manured with cow-dung (a manure containing the smallest quantity of nitrogen) afforded only 11.95 parts of gluten, and 64.34 parts of amylin, or starch, while the same quantity grown on a soil manured with human urine yielded the maximum of gluten, namely, 35.1 per cent." - Liebig, p. 94.

* We must guard here against a mistake which, I know, has been made, and with much loss and vexation. The Whittington wheat is called a spring wheat, but it must be sowed in February. We on the other side of the water, hearing of its excellent qualities, and supposing it to be a spring wheat in our sense of the term, sowed it in the last of March and in April, and it did not come into head, as the season was too short. Many persons blamed the seedsmen for having deceived them in selling them a winter for a spring wheat; but the mistake arose, as errors and fuults often arise, from a different use of the terms in the two countries.

VOL. II. 
question when we learn what has been done. No good cultivator should willingly stop short of what has been reached by others, nor should even this satisfy him, if there is a possibility of going beyond it.

In statistical works, 26 bushels are put down as the average yield of wheat through the kingdom; a few years since, 18 bushels were named as the customary yield. This would argue a very great improvement. There are not a few who even now insist that 14 bushels are the average product, taking the whole kingdom together. This seems to me much too low. Among all the farms which I have visited, I have not found a single farmer who has rated his product so low. On the other hand, under good cultivation, I have scarcely ever found it less than 32 bushels. I have very frequently found it full 40 bushels. In the fens of Lincolnshire, on the redeemed land, I am informed, on the best authority, that the yield is very often from 7 to 8 quarters, that is, from 56 to 64 bushels per acre. A much higher amount than this has been named. One of the best farmers in the kingdom, in the county of Berks, assured me that the crop upon his large farm, in 1844-5, averaged 56 bushels to the acre; and it is well attested that a crop grown in Norfolk county, in the same year, produced 11 quarters 2 bushels 3 pecks per acre, that is to say, 90 bushels 3 pecks per acre - the largest crop on record, within my knowledge.

When I received from most credible authority the account of the last crop, so very extraordinary as it is, I felt the strongest desire to ascertain, if possible, by what means it was produced, and especially whether there was any peculiarity in the soil, to which so great a yield was to be ascribed. This desire was felt as strongly by other members of the Royal Agricultural Society; and they directed the very eminent chemist of the society, Professor Playfair, to make an analysis of the soil and report it. I shall give my readers this report at large, which has been published in their Journal.

Two portions of the soil - one of the surface, the other of the subsoil - were placed in his hands. "I place," he says, "for the information of the council, the analysis in two forms, one of these giving the actual statement of the analysis, the other indicating the probable method in which the ingredients are associated in the soil. 


\section{"1. Surface Soll.}

In 100 parts as actually found. Organic matter, . . . . 2.43 Hydrate water, Carbonic acid, $2.60^{*}$

Sulphuric acid, 0.92

Phosphoric acid,

0.09

Peroxide of iron, . . . 3.41

Alumina, . . . . 3.58

Lime, . . . . . . 1.28

Magnesia, . . . . . 1.12

Potash, . . . . . 0.80

Soda, . . . . . . 1.50

Chlorine, . . . . a trace.

Loss on analysis, . . . 0.63

100.00
In 100 parts as contained in the soit.

Organic matter, . . . . 2.43

Hydrate water, . . . . 2.60

Silica and silicic acid, . .78.27

Peroxide of iron, . . . . 3.41

Carbonate of lime, . . . 2.10

Sulphate of lime, . . . 0.15

Phosphate of lime, (as in bones, ) . . . . 0.08

Phosphate of magnesia, . . 0.58

Magnesia, (probably as a silicate, ) . . . . . 0.88

Alumina, (probably as a silicate, ) . . . . 3.58

Silicate of potash, . . . 1.58

Silicate of soda, . . . 3.71

Chlorine, (in combination as salt, ) . . . . a trace.

Loss on analysis, . . . 0.63

100.00

"2. Subsoll.

In 100 parts as actually found.

Organic matters free from ammonia,

Hydrate water,

Carbonic acid,

Silica,

Peroxide of iron,

Lime,

Magnesia,

Alumina,

Potash,

Soda,

Chlorine,

Sulphuric acid,

Phosphoric acid,

Loss on analysis,

1.20

82.55

0.69

$1.5,5$

4.48

0.60

1.10

1.26

0.16

a trace.

0.07
In 100 parts as contained in the soit. Organic matters free from ammonia, . . . . . 1.20

$2.60 t$

0.04

3.70

100.00
Hydrate water, . . . . $\quad 2.60$

Silica and silicic acid, . .81 .96

Peroxide of iron, . . . . 3.70

Carbonate of lime, . . . 0.09

Lime, (probably as a silicate,) 0.58

Magnesia, (probably as a silicate, ) . . . . 1.55

Alumina, (principally as a silicate, ) . . . . 4.48

Sulphate of lime, . . . 0.27

Chloride of sodium, . . 2.05

Silicate of potash, . . . 1.19

Phosphoric acid, a mere trace.

Loss on analysis, . . . 0.30
100.00

* Water which is not driven off at the boiling point, $212^{\circ}$.

$\uparrow$ Water not expelled by long-continued exposure to a water bath. 
"The subsoil may be viewed as representing the soil in its natural condition, and, as such, is rich in every constituent essential to fertility, with the exception of phosphoric acid, of which substance scarcely a trace could be detected. All the iron in the soil exists in the state of peroxide, so that the plants may appropriate its constituents without injury. The presence of so much common salt in the subsoil is only explicable on the supposition that it has been washed by the rains from the upper to the lower soil, for we find it absent, except as a trace from the surface soil. The vicinity of the soil to the sea explains the origin of the salt."

"The upper soil has obviously been improved by manure containing phosphates, and perhaps also silicates. I regret that no information on this point accompanied the letter from the secretary of the Statham Farmer's Club. The soils, from the presence of the alkalies and the alkaline earths, and of all the proper acids in the subsoil, are admirably calculated to furnish plants with their proper food."

I give this account of the soil, upon which this extraordinary crop was produced, from a gentleman truly eminent for his science, with feelings of no little discouragement, as showing, in a case where the curiosity was most reasonable and intense to get at the secret of this remarkable success, and where chemical analysis seems to have done its best, that we are still in as much darkness as ever. His conjecture how the ingredients were probably mixed in the soil, as appears from the second part of each table; his supposition, in the absence of all information on the subject, that phosphates, and perhaps silicates, may have been supplied in the manure; the utter want of the phosphates in the soil, deemed so essential to vegetation and to the growth of a grain crop; and the impossibility, which I think every farmer must fecl, of deducing from the result any practical conclusion whatever, - are circumstances in the case which can scarcely escape observation, and which I submit to the judgment of my readers without comment.

That, under any circumstances, we can command a crop, or insure any given amount, need not be said; but the extraordinary pains taken here in the preparation of the land and the culture of the crop are followed with all the suecess which is to be expected. I have a great many returus of 32 bushels and 
40 bushels produced on an acre; and I am strongly inclined to believe that the average of good cultivation, in ordinary seasons, is seldom less than 32 bushels per acre. The product of good cultivation should be considered therefore as the standard crop, without reducing it by the much smaller crops of those who either cultivate negligently, or manure sparingly, or suffer their crops to be stifled with weeds.

In an experiment carefully made by a distinguished farmer * in Northamptonshire, who has given to the world, in a plain and practical manner, the results of his agricultural experience, the products per acre of six different kinds of wheat sown were as follows :-

The Essex brown yielded at the rate of 40 bush. ; 64 lbs. per bush.

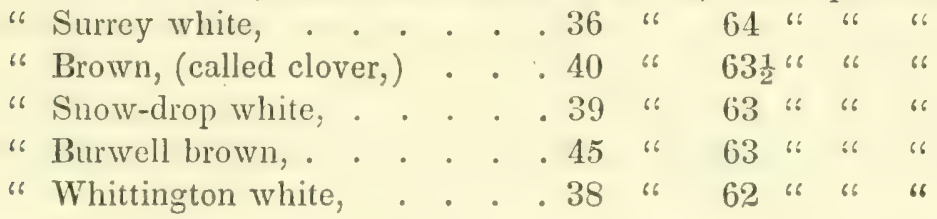

Here were six different kinds, of which it must be admitted the yield was large, and shows what may be done.

In an experiment made by W. Miles, Esq., M. P., the produce, per acre, of sound wheat was 48 bushels; 42 bushels 2 pecks; 47 bushels; 35 bushels 3 pecks; 49 bushels.

The crops on a farm of P. Pusey, Esq. were, on one acre, at the rate of $37 \frac{3}{4}$ bushels; on another, $45 \frac{1}{2}$ bushels; on another, $47 \frac{1}{2}$ bushels. "This, it will be remarked, was not a garden experiment, but applies to a whole field of wheat, and the amount was given by the occupier of the land."

W. L. Kidd, M. D., of Armagh, Ireland, informed me that he obtained at the rate of 50 bushels of $62 \mathrm{lbs}$., or about $28 \mathrm{cwt}$., per acre, and that there were persons in the neighborhood whose crops were still larger. The wheat was red wheat; the quality such as to command the highest price. The soil was a stiff clay recumbent on limestone.

Mr. 'Theadstow, of Booth, near Liverpool, informs me, that in 1844-5, on a piece of land less than a statute acre, he pro-

* C. Hillyard, Esq., Thorpelands. 
duced 64 bushels of wheat of 70 pounds the bushel. I will subjoin his statement in this case. "The soil is very light, consisting of a great portion of sand, and lying close to the sea-shore. 'The land, the previous year, had been trenched to the depth of about three feet, by hand labor, and well manured with horse and cow manure, and planted with potatoes. When the wheat was sown, the ordinary mode of cultivation was pursued. Something short of two bushels of white Dantzic wheat was sown. The seed had been produced on land of a heavier nature than that on which it was sown here. The mode of sowing was broadcast; the time of sowing, the 1st of December. This is a mode of cultivation adopted generally on my farm, universally with vegetables, - and produces sometimes uncommon roots. Some of the cabbages, which I have weighed, weighed 45 lbs. each." In some experiments made in Gloucestershire, the products were as follows, per acre, of good wheat:-

Brown's white prolific, 48 bush. 3 pecks; weight, $62 \mathrm{lbs}$. per bush. " red prolific, . 46 " 2 " 2 " $600 \frac{1}{2}$ " " " " Whittington white, . 48 " . . . . " 59 " " " " Old Herts white, . . 46 " . . . . " " 61 " " " " " " " Golden drop red, . . 49 " . . . . " " $61 \frac{1}{2}$ " " " " Creeping wheat, (red,) 46 " 1 peck; " $62 \frac{1}{2}$ " " "

The above were planted on a gravelly loam, (clover lay,) in a high state of cultivation.

In the same county, in another case, the products were as subjoined. Cobham wheat, per acre, 42 bushels; Brown's white Chevalier, 14 bushels; yellow Chevalier, 36 bushels; Whittington white, 383 bushels; Hertfordshire white, 39 bushels ; Golden drop, 40 bushels.

The above were grown after peas, which is considered a bad preparation for wheat.

In Worcestershire, a crop of wheat, in 1843-4, was at the rate of 45 bushels to the acre; and as much was expected the succeeding season. It was of a kind called Burletta wheat, and was sown by drill at the rate of two bushels per acre.

In another part of Worcestershire, in 1844-5, on 130 acres, the crop was nearly 47 bushels per acre, and the sample represented as excellent. 
These are remarkable fucts, and well worthy the attention of the farmers.

Wheat is sometimes grown here upon a summer or naked fallow, especially where the land is much infested with weeds; but naked fallows are well nigh exploded in any improved system of English husbandry. Wheat generally comes once in a four years' rotation; sometimes twice in five years, and in some cases twice in seven years; in some every alternate year, beans forming the intermediate crop. The latter course, for sixteen years, has been the practice of an eminent farmer in Norfolk, whose admirably-managed farm I had the pleasure of visiting. The land subjected to this treatment is a deep rich alluvion, formed from the deposits under the sea, and the beans are most thoroughly manured.

The preparation of the land for wheat is made with extraordinary pains. The crop preceding it is usually turnips, or some green esculent, which is consumed by sheep upon the land. The turnips are of course most amply manured, and are generally cultivated in drills. When the season for sowing wheat arrives, these drills are opened by the plough, and the decomposed manure very thoroughly distributed. It is considered bad husbandry to apply green manure, or manure of any kind, excepting from the folding of sheep upon it, to the land, the year the wheat is to be sown; but the result is always better, when the sheep so folded, besides the turnips or other green feed with which they are supplied, are liberally furnished with oil cake. One of the most skilful farmers in Lincolnshire, who, by a successful husbandry, has risen from small beginnings to wealth, and has established in comfort several sons upon farms in his vicinity: ascribes his success wholly to the liberal use of oil cake for his stock, considering it of the highest value in enriching his matnure. I had the pleasure of witnessing the most ample evidences of his good husbandry. This system of enriching land by folding sheep upon it in movable folds - a custom long linown in England - might in many instances be adopted in the Northern United States, especially when the market for mutton is inproved. This, I think - after carefully watching its progress for some years past - it is destined to be; especially when our breeds of sheep, grown for this express object, are improved. Here mutton may be considered as the favorite dish with all classes 
who consume meat, and is the principal meat to be found in the markets, where it is exhibited in extraordinary perfection.

The soil preferred for wheat is a strong soil, with a large proportion of clay; but experience has, of late years, contrary to early and strong prejudices, determined that even the light and loamy soils are capable of bearing heavy crops of wheat, provided they can be sufficiently consolidated. This is done often by driving sheep over the land after sowing, and by an implement which I shall presently describe, called a presser.

The first process is, thoroughly to clean the land from weeds and rubbish; but the green crop previonsly cultivated, if it has been properly managed, will have done much towards this. The twitch grass (triticum repens) abounds in the lands here to a most extraordinary extent, and this is raked out and pulled out, and generally piled on the land and burnt, and the ashes spread. Some persons adopt the method of mixing the piles of it with quicklime, and thus forming an enriching compost for their land. Others carry it into their barn-yard, to be trodden under the feet of the cattle, and to absorb the liquid of the yard.

But wheat is often sown after clover, or upon what is called a clover lay; the first crop in the course being turnips, the second barley, the third clover; if cut the first year for hay, then depastured with sheep the second; or otherwise fed and ploughed in, and the wheat sown on the inverted sward, and the land not harrowed so deeply as to tear it to pieces. When the clover is designed to stand only one year, it is mowed and made into hay in June, and then sheep are folded upon it; and in this way they go over the field twice before it is ploughed for sowing. It is deemed of great importance, in this case, that the soil should be in as compact a state as possible, and a heavy roller is passed over it. The greatest stress is laid upon this matter of consolidating the soil, where it is of a light or spongy character; and in some soils the ground is simply harrowed, where the preceding crop allows of such a process, or otherwise ploughed not more than three or four inches in depth.

An instrument much used for consolidating the soil, and very much approved of by those who use it, is called a seam-presser. This implement passes over the land in the direction of the furrow, and it forms on the furrows two deep drills at a time, the two rollers being eight or nine inches apart, and the blade of the 
roller, if so it may be called, or the rim, being $\square$ thin at the edge, and growing wider above the edge, thus, $\square$, and forming, as it revolves, two furrows, hardened by its weight, into which the grain drops as it is sown; and when it comes up, it appears as if it had been regularly sown in drills of eight or nine inches apart, according to the width of the revolving presses from each other. "The seam-presser is, in fact, an abstract of a drill-roller, consisting of but two cylinders of cast iron, which, following the plongh in the furrows, press and roll down the newly turned-up earth."

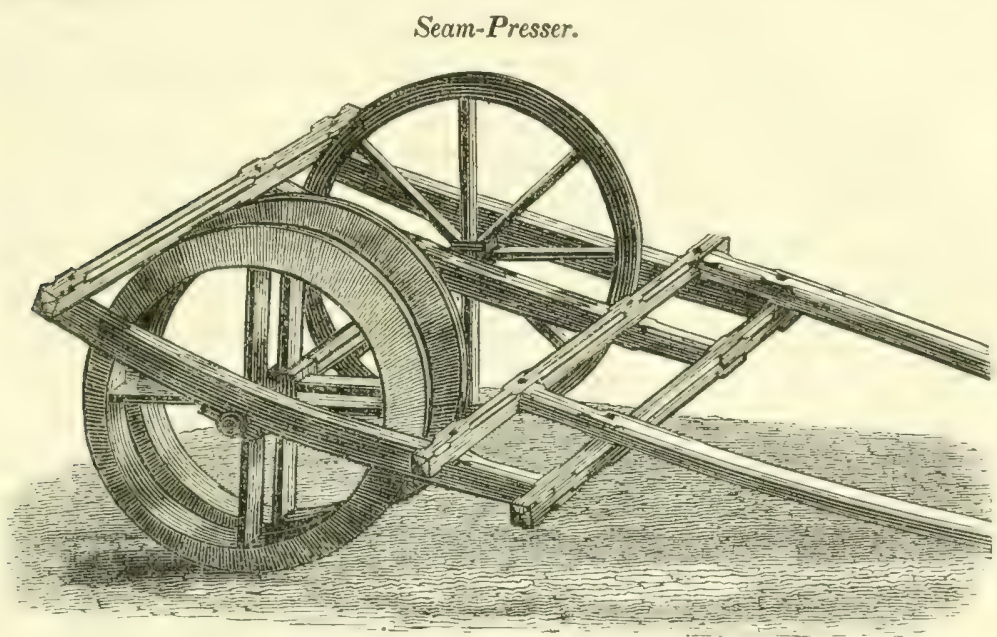

On heavy or clay soils much more work is rendered necessary to bring them into condition. The first of all requisites is, that the land should be thoroughly drained or freed from wet. In all cases of heavy land, it has been the custom to throw the field up into beds, or, as they are here called, stitches, with an open furrow between them. In many cases which I have seen, these are even less than six feet wide; and wherever they are made by every sixth furrow or every eighth furrow, it is obvious that every acre in six, or every acre in eight, is lost ; for nothing grows in the intermediate drains. The practice of cultivating in beds or stitches is, I may say, almost universal throughout Fugland and Scotland; in general, however, these beds are from three to six yards wide; on dry lands, more than this. Since the introduction of the Deanston system of thorough-draining and subsoiling, it has been shown that they are not at all necessary for carry- 
ing of the wetness of the land; and that on a perfectly flat surface, which has been drained and subsoiled in an effectual manner, all the water falling upon the surface, will, by a direct descent into the ground, find its way to the drains. In this way the loss of land is prevented, and the condition of the land over the field is more equal; for the practice of forming beds or stitches by continually turning the furrow towards the centre of the ridge, is to rob the part of the land nearest the furrow; and the plants growing near the margin of the furrows are always inferior to those upon the centre of the ridge. Under these circumstances, the only consideration upon which these stitches can be recommended is, that they assist the sower and the reaper in the measurement of their work.

Another instrument is used on hard clay soils, - which often remain after ploughing, and even harrowing, quite lumpy, — called a clod-crusher, which not only reduces these lumps to fineness, but serves likewise to consolidate the soil. It can only be applied with advantage where the lands are dry and the clods hard.

\section{Crosskill's Patent Clod-Crusher.}

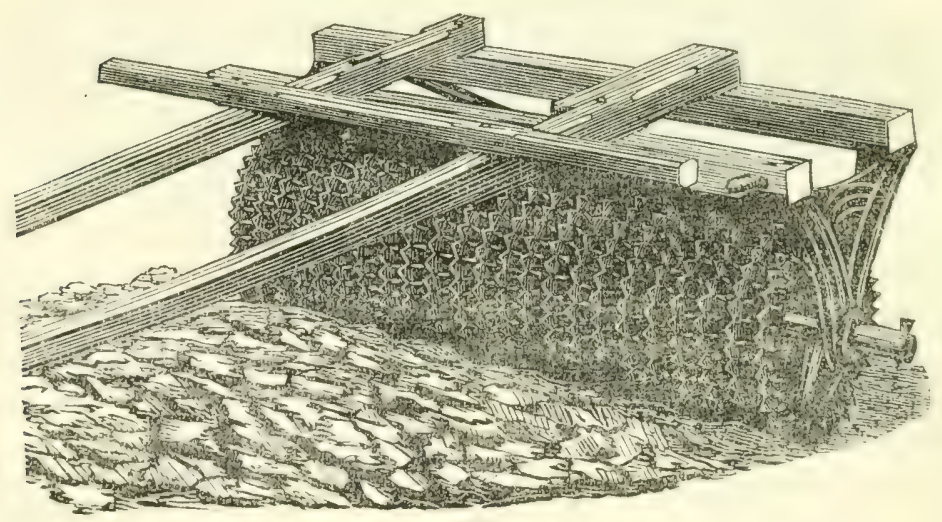

"Clod-Crusher. - This valuable implement is composed of a series of iron rings, with notched edges set apart from each wher about three or four inches. Small crossbars, or knives, are placed at frequent intervals on the faces of these, and near their outer notched rims, so as to intersect every portion of land over which it passes. Its construction, combined with its great weight, renders it very effective for the purpose which its name 
denotes. It has been aptly said to be 'a roll and a harrow combined.' Its use has been found to prevent the ravages of the wire-worm - no small recommendation to it."

"Further improvements have been made in its construction, the principal features of which consist in an improved form of tooth, for breaking, rather than grinding, the clods; and in arranging for each cylinder independently to revolve upon its own axis - an advantage which not only increases its efficiency, but materially lessens the power required for its draught."

"The roller is an implement which requires more than usual judgment as to the time of its use; and this remark applies with increased force to the one under consideration."

Perhaps there is no agricultural implement in use in England, at the present time, save only a plough, that is so much approved of by practical farmers as this clod-crusher. It is used sometimes before sowing, to get the land into condition and produce a fine tilth. It is used, likewise, after the plant has come $u p$, to consolidate the land and fix the roots of the plant; and it is used also with much advantage on the wheat, in the spring. It has proved of very great efficacy in the destruction of the wire-worm, frequently at once arresting its ravages in a wheat field. It is used likewise with great advantage upon light soils, in consolidating them, and as a substitute for the treading of the wheat-ground by sheep; for which purpose, when they are used, it is considered, in most cases, very much to their injury. The implement is heavy, and is generally drawn by three horses.

The quantity of seed to be sown has been matter of much discussion and experiment. 'The amount, with different farmers, varies from three peclis to three bushels per acre; and some persons contend for four and even five bushels. The saving of two, or even of one, bushel of seed per acre, upon the whole extent of land cultivated throughout the lingdom, would be indecd an immense saving. The saving in seed of two bushels. to a farmer who cultivates his fifty or his hundred acres of wheat; would certainly deserve much consideration; but if this saving is to be made at the loss or diminished product of three or five bushels in the crop, it would prove a kind of economy not much to be commended. Among the various conflicting statements which have been made to me on this subject, and which. 
have been publicly reported, it is exceedingly difficult to arrive at any satisfactory conclusion. A very eminent Scotch farmer, of large experience, says that, "in some seasons, a moderately thin plant - that is to say, a small number of the young plants of wheat standing upon a given space of ground - is found to be advantageous both to quantity and quality of grain, and in others highly injurious."

IIr. Davis, of Croydon, to whom I have before referred, claims, liom a sowing of three pecks to the acre, to produce an average crop of forty bushels to the acre. The last season, on visiting his lam, though the straw was of a very large size, and the heads long and full, it seemed to me impossible that it should have proluced even thirty bushels per acre; and much of it was certainly extremely foul with weeds. I regret that, though I have attempted, I have been unable to ascertain the actual yield; and I in quite ready to admit that one is very liable to err in judgment upon such a crop, not making proper allowance for the length of the heads, which was quite remarkable.

'The experiments of Mr. Barclay, M. P., given in the 6th volume uf the Jourinal of the Agricultural Society, seem to go strongly against the thin sowing of wheat.

23 bushels of seed drilled, $9 \mathrm{in}$. apart, gare 37 bushels per acre.

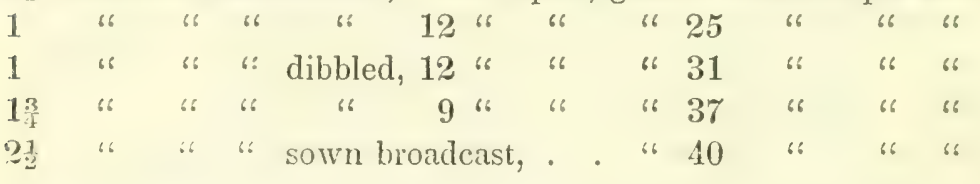

The value of the grain, as estimated by the miller, was $3 \mathrm{~d}$. inore per bushel, in the first and last case, than in the others, and the straw, in the last case, was considerably more, in quantity and value, than in either of the former.

In an experiment which I myself saw upon a very small scale, wheat, dibbled at the rate of six quarts to the acre, produced at the rate of seventy bushels to the acre.

In some experiments reported by W. Miles, Esq., M. P., made it his beantiful farm at King's Weston, near Bristol, the yield of the drilled wheats, at two bushels, and one bushel three pecks, per acre, was very much superior to those dibbled at two pecks and one quart per acre. 
CROPS.

The wheats produced as follows :-

Drilled Wheats.

\begin{tabular}{c|cc|ccc|cc|c|c} 
No. & $\begin{array}{c}\text { Quantity of Seed } \\
\text { per Acre. }\end{array}$ & \multicolumn{3}{|c|}{ Product in Good Wheat. } & \multicolumn{3}{|c}{ Product in Tail or Imperfect } \\
Wheat.
\end{tabular}

Dibbled Wheats.

\begin{tabular}{|c|c|c|c|}
\hline No. & $\begin{array}{l}\text { Quantity of Seed } \\
\text { per Acre. }\end{array}$ & Product in Good Wheat. & $\begin{array}{l}\text { Product in Tail or Imperfect } \\
\text { Wheat. }\end{array}$ \\
\hline 1. & 2 pecks. & 21 bushels 3 pecks. & 3 bushels 0 pecks. \\
\hline 2. & $2 \quad 61 \mathrm{qt}$. & $\begin{array}{llll}30 & 6 & 2\end{array}$ & $\begin{array}{lll}66 & 1\end{array}$ \\
\hline 3. & 16 & 19 & "6 \\
\hline 4. & $2 \quad 6 \quad 16$ & $34 \quad 66$ & 66 \\
\hline
\end{tabular}

Mr. Miles's remarks, subjoined to this statement, are well worth repeating.

"Notwithstanding the dibbling in this trial must be considered, as far as regards Nos. 2 and 4 , a failure, yet I cannot but state my thorough conviction, that upon light, flat land, free from stones, this system ought to he universally adopted. I should, however, recommend not less than a bushel to be dibbled to an acre, and that the process should take place earlier in the season, as when, from the quantity of grain grown, there camnot be a superabundance of plant, it is of great moment that it should be fully established before the alternations of frost and thaw commence. The tillering of the plants is extraordinary, as well as the strength of the straw; and what is saved in seed may be most beneficially applied to liceping the land perfectly clean, with advantage to the laborer and certain profit to the cultivator. If, indeed, we take two instances of the same species of corn from the above tabular results, we cannot fail to be struck with the much greater return from the small than from the large quantity sown; for instance, I find that No. 2, drilled at two bushels per acre, produced forty-six bushels two pecks; whilst No. 1, dibbled at two

voI. II. 
pecks per acre, gave - say, twenty-five bushels per acre. Two pecks of seed, however, were only tried in the latter, whilst four times that quantity was used in the former case; proportionally, therefore, instcad of forty-six bushels two pecks, it should have given one hundred bushels. I throw out these hints for serious consideration, as, without doubt, such a saving of seed as the general introduction of the dibbling machine would produce must be esteemed of national importance."

These are, certainly, very remarkable results; yet Mr. Miles gives, in the same paper, an account from a book of husbandry written some years since, in which an experiment is detailed of sowing ten pounds to the acre, and twenty pounds to the acre, in which the advantage appears to have been greatly in favor of the thin sowing. In Mr. Miles's case, a good many of the wheat plants were destroyed by the frost. In the thickly-sown, a loss could be afforded, as a sufficiency of plants would remain for a crop; in the thinly-dibbled wheats, there was no such reserve to fall back upon, and the loss was fatal.

In this matter, many things are to be considered. Some kinds of wheat tiller much more than others; that is, a single plant of one kind of wheat will throw out more shoots than a plant of another kind. The time of sorving is a material point. The earlier sown wheat has much more time to thicken, and throw out bearing shoots, than late sown wheats. The condition of the land, likewise, is to be considered. Highly-enriched and manured land will nourish more plants than that which is poor and scantily manured. The state of the land, in the next place, as it respects weeds, must be taken into view. On land which is foul, thin sowing will give an opportunity for the weeds tu spread themselves, very much to the disadvantage of the crop.

I have already treatod this subject, to some extent, in my second report, to which I must refer my readers. I cannot help thinking that, with early sowing upon well-manured and well-cleaned land, and the faithful hocing of the crop, so as to keep it free from weeds, a much less quantity of seed than what is usually applied might be safely and strongly recommended. But, as these furorable circunstinces cannot always be secured, certainly; in ordinary cases, a liberal allowance of seed is to be advised. The only saving to be calculated upon, in this matter, is in the quantity of secd; as it does not appear, from any experiments 
which have becn reported, or which have come under ny notice, that the crop has, in any case, been lessened by too much sced.

This subject is, certainly, one of great importance. The farmer, who has most strongly advocated thin sowing, or a great ieduction of the usual quantity of seed, from a letter which I have recently received from him, remains confident of the soundness of his views. On the other hand, the opinion of another eminent practical farmer is, "that these new doctrines are calculated to do greater and more extensive mischief, not only to the growers but to the consumers of com, than any other theory he ever remembered to have been broached."

In some experiments given in the able report on Norfolk farming, in the Royal Society's Journal, it appears that wheat sown at the rate of ten and a half pecks per acre produced nearly two bushels per acre more when sown in 7 inch than when sown in 9 inch drills. In another case, there were three and a half bushels in favor of the 7 inches. In another case, wheat drilled at $4 \frac{1}{2}$ inches exceeded 9 inches by nearly two bushels, and 7 inches exceeded 9 by eleven pecks and three pints.

In another experiment,

S pks. seed produced more than 7.1 plis. by 5 plis. 14 pts. per acre.

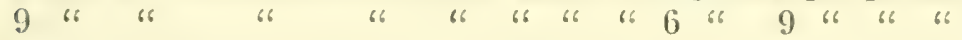

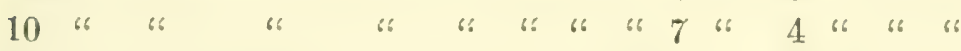

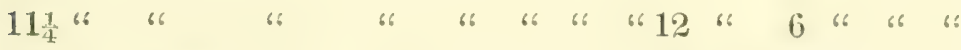

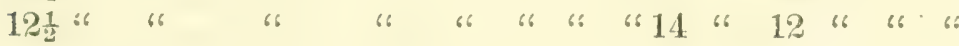

These statements do not determine the case, but they are strongly entitled to consideration. It would be wrong, however, not to state that, in a subsequent experiment of this same farmer, the difference between sowing eight pecks or twelve pecks, after deducting the seed, was only a few quarts. Thus,

8 pks. of seed produced at the rate of 39 bushels 2 pks. 2 qts.

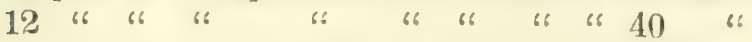

And in another case, three bushels of seed actually produced less than two bushels and a peck. 'Thus,

9 pecks of seed produced 40 bushels 2 pecks 2 quarts.

12 "6 $66 \quad$ 6 $66 \quad 40 \quad 66$ 
It is admitted that crops standing thickly ripen the soonest; and the grain produced by them is said to be of a superior quality to that which comes from thinly-sowed crops.

On Lord Leicester's estate, in Norfolk, (who, more than any other man in the annals of English agriculture, distinguished himself for his successful husbandry, the practice was to sow three bushels per acre. On Mr. Dixon's farm, in Kent, whose crops are said to average forty-two bushels per acre, the custom is to sow two and a half, and sometimes nearly three, bushels per acre.

The time of sowing wheat in England admits of a long range, from the middle of September until December, and sometimes even into February. Where circumstances favor it, an early sowing is preferred; and very forward wheats are fed down, in the spring, by sheep, which are folded upon them. In cases where a crop, to be followed by wheat, is to be used upon the ground, the wheat is not sowed until that crop is fed off; or where wheat follows potatoes, the sowing is carried forward far into the season.

Wheat follows turnips, mangel-wurzel, carrots, potatoes, and clover. The last is universally approved. Mustard is likewise sown, as a preparation for wheat, sometimes at the rate of seven, and sometimes at the rate of sixteen, pounds to the acre, to be fed of by sheep, or otherwise to be covered in as a green dressing. A matter is stated as a fact in this case, which deserves attention; that the white mustard will not remain in the soil after being once ploughed up; that the black can hardly be cradicated, but has been known to remain in the soil for ages. We must be cautious what guests we entertain.

I have already said that, in a rotation of crops, only one out of the four is manured, and that green barn manure is never applied to the wheat crops. But the wheat crop cannot be said to be not manured, for the folding of sheep upon the ground, by their consumption of the green crops, furmishes a most effectual manuring. Besides this, artificial or saline manures are applied to the crop, and guano has been used with great success. The nitrates have mainly served to increase the amount of straw, but not of grain; and although some experiments seem to have produced a great increase of grain from their use, yet they are not very often applied. I have, however, the assurance of one extensive farmer of his success in the use of the nitrate of soda when 
applied to oats upon a clay soil, increasing the crop in the proportion of 12 to 5, and this in repeated trials. I regret that I could obtain from him.no further and no more exact particulars. There are many instances given, and some from farmers with whom I have the pleasure of an acquaintance, of the very successful application of nitrate of soda to wheat; yet, in spite of these, it is not very extensively used, and its application is viewed with great distrust. Further, and more exact, and longer-continued experiments are greatly to be desired.*

There are three modes of sowing wheat - the first, broadcast : the second, by drilling; the third, by dibbling. "The last two methods are generally done by machines; the last not always; however; unless women and children, who drop the grains in the hole made by a dibble of the most simple construction, are to $b c$ considered as machines, and the human hand the most perfect of its parts. Drilling and dibbling are methods certainly to be freferred, as the seed is more evenly sown, and an opportunity is offered of hoeing and weeding the crop, which is here most carefully done, and undoubtedly to great advantage. When wheat is drilled, likewise, there is an opportunity of cultirating between the rows by implements for that purpose, the advantages of which are unquestionable. These implements are denominated horse-hoes, or scufflers.

In my next Report, I shall give a plate of a horse-hoe much in use; but I cannot, among the many varieties exhibited, pronounce it the best. I shall give it as a specimen of the imple-

* "With regard to nitrate of soda, from which so much was once expected. there are the most undoubted proofs, from numerous quarters, of an enormou: increase of the produce after its use; there are as undoubted instances of it: utter failure. Nor have we any clew to the mystery. On the same land, where it gave me eight bushels one year, it gave barely three in the following; and having tried it largely, at that time, on different farms, nowhere with success, I have given it up. Still, there is evidently a principle of fertility in it, which will some day be found out; and some farmers continue to use it; but in several cases it has produced mildew in wheat and barley, by forcing the crop beyond the strength of the land. By the side of the nitrate, I tried, on several fields, the sulphate of ammonia, extracted from gas-water the first time. It acted precisely as the nitrate of soda, darkening the color of the plant, and strengthening the straw and the ear even more than the nitrate; but it certainly did not pay. Again, we have the principle, and we must learn to combine it." - P. Pusey, Esq., M. P. 
ments used here, thinking, if it has no other benefit, it may furnish some useful suggestions to some of our inventive manufacturers of agricultural tools, who, in the ingenuity and skill of their productions, and especially in the excellence of the workmanship, (and it is no disparagement to the English manufacturers for me to say it,) need not fear a competition with the best mechanics on this side of the water. The implement has received the highest premium of the Agricultural Society, with rery strong commendations. 



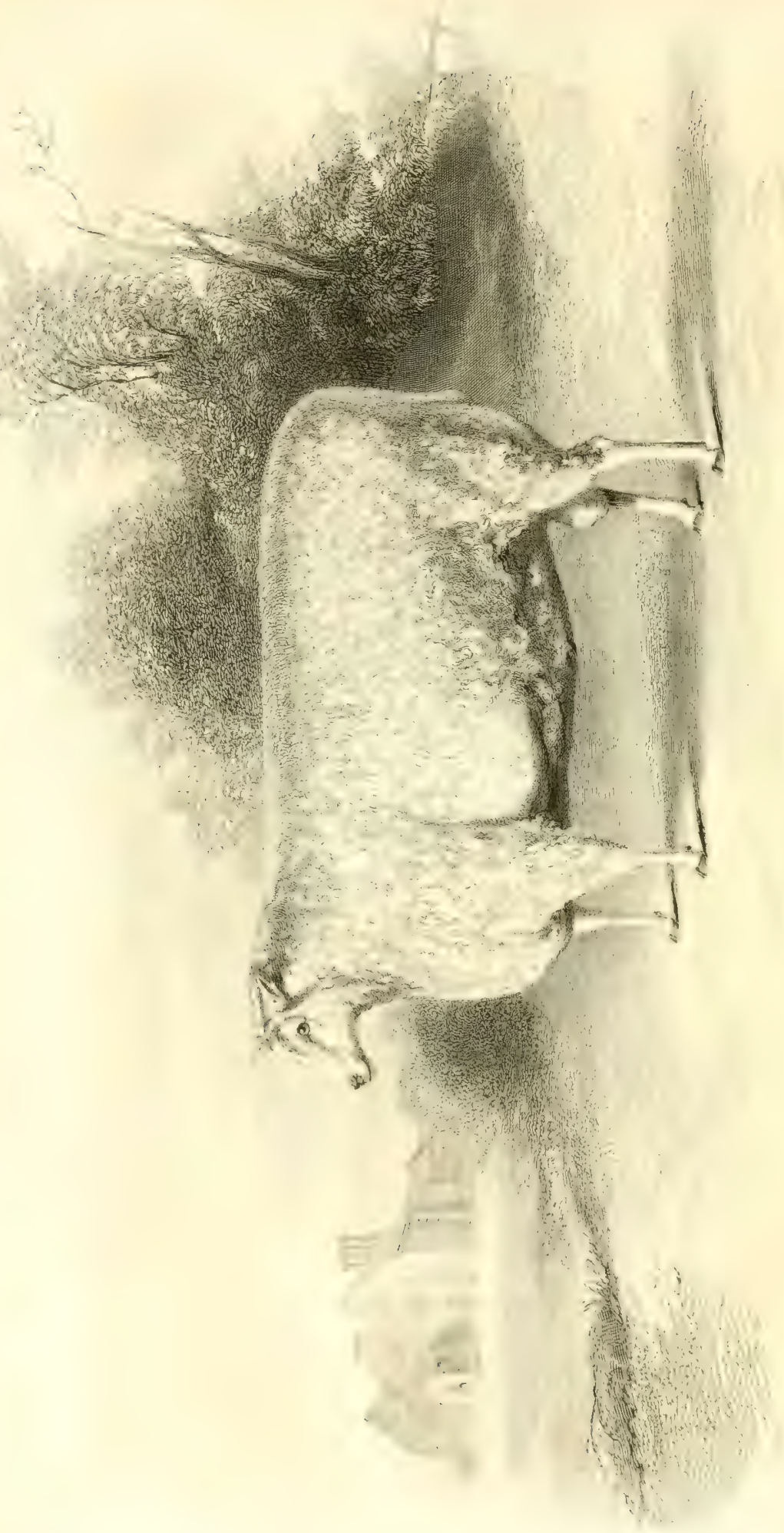




\title{
EUROPEAN AGRICULTURE.
}

\author{
EIGHTH REPORT.
}

CVI. - CROPS. (Continued.)

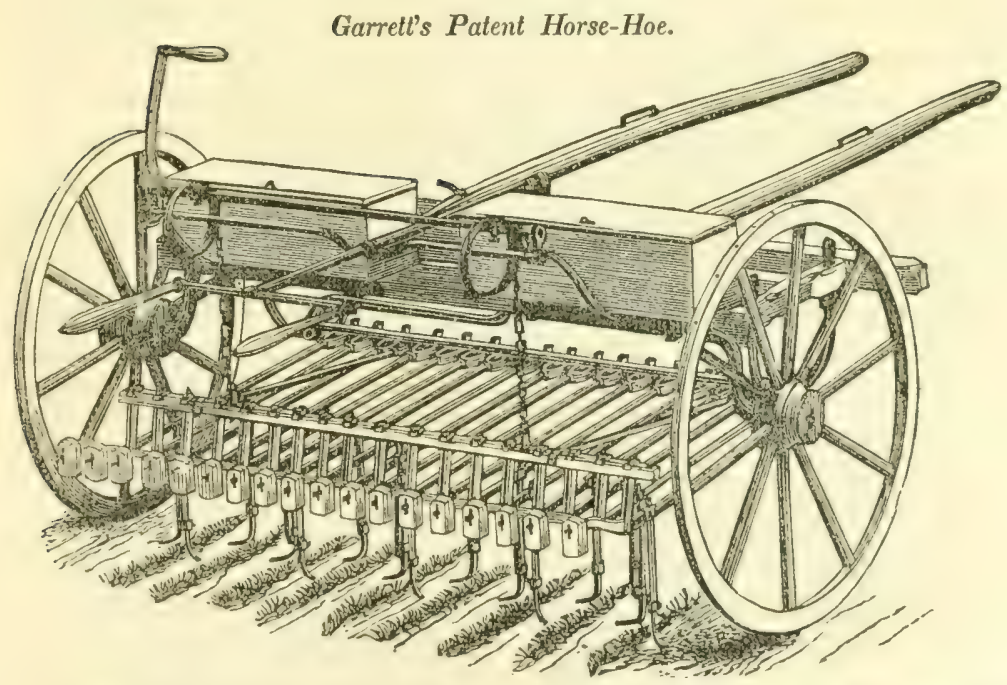

" Trus horse-hoe, invented by Garrett and Son, of Leiston, is suited to all methods of drill cultivation, whether broad, stetch, or ridge ploughing, and is adapted to hocing grain of all linds, as well as roots. The peculiar advantages of this implement are, that the width of the hoes may be increased or diminished, to suit all lands or methods of planting; the axletree being movable at both ends, either wheel may be expanded or contracted, so as always to be kept between the rows of plants. 
"The shafts are readily altered and attached to any part of the frame, so that the horses may either walk in the furrow, or in any direction, to avoid injury to the crop.

"Each hoe, or each pair of hoes, works on a lever independent of the others; so that no part of the surface to be cut, however uneven, can escape; and in order to accommodate this implement to the consolidated earth of the wheat crop, and also the more loosened top of spring grain, roots, \&c., the hoes are pressed in by different weights being hung upon the ends of each lever, and adjusted by keys or chains, to prevent their going beyond the proper depth.

"That which has hitherto been an objection to the general use of the horse-hoe, in this is avoided by adopting a mode of readily shifting the hoes, on a plan similar to that of the steerage adopted in drills, so that the hoes may be guided to the greatest nicety. This implement is so constructed that the hoes may be set to a width varying from seven inches to any wider space; the inverted hoes are preferred, when the distance between the rows is sufficient to admit a pair of them; otherwise, triangular or arrow-shaped hoes may be substituted, or any other form that may be considered best for the purpose.

"Two points in this hoe are worthy particular notice; the one being that the blades of the hoes are made entirely of steel, and are attached to the stalks so readily that, as they may become damaged or worn out, they may be replaced, by the operator, without difficulty; the other, that the position of the frame admits of easy adjustment, so that, according to the texture of the soil, the cutting edges of the hoes may assume a position more or less inclining to the work." *

Wheat is drilled when it is sown in a continuous line, and in general the distance of these drills or rows from each other is about nine inches. A greater width is preferred by some persons. When the ground is marked out by a seam-presser, as before described, the seed then comes up in continuous rows, as if it were sown by a drill-machine; but there are several machines in operation expressly for the drilling of wheat and for depositing, at the same time, in the drill, such fine manure as it may be desired to sow with the grain. Indeed, to such perfection have 
some of these machines been carried, that even coarsely-chopped manure is likewise deposited by them in the row, as is done in the case of sowing turnips or other roots.

At first sight, these machines appear extremely complicated and unwieldy; and one would be inclined to think that a spinning jenny might be managed with equal ease in the field. They are cumbrous, and to a degree complicated; yet they are much in use, and they certainly perform their work extremely well. This, perhaps, is all that is to be asked of them; and mechanical ingenuity, which, under the stimulus of large premiums and a powerful competition, is now, every day, becoming more active, may presently succeed in rendering them more simple and light, without reducing their efficiency. I give below, merely as a specimen, the engraving of a drill machine

\section{Garrett's Patent Drill for General Purposes.}

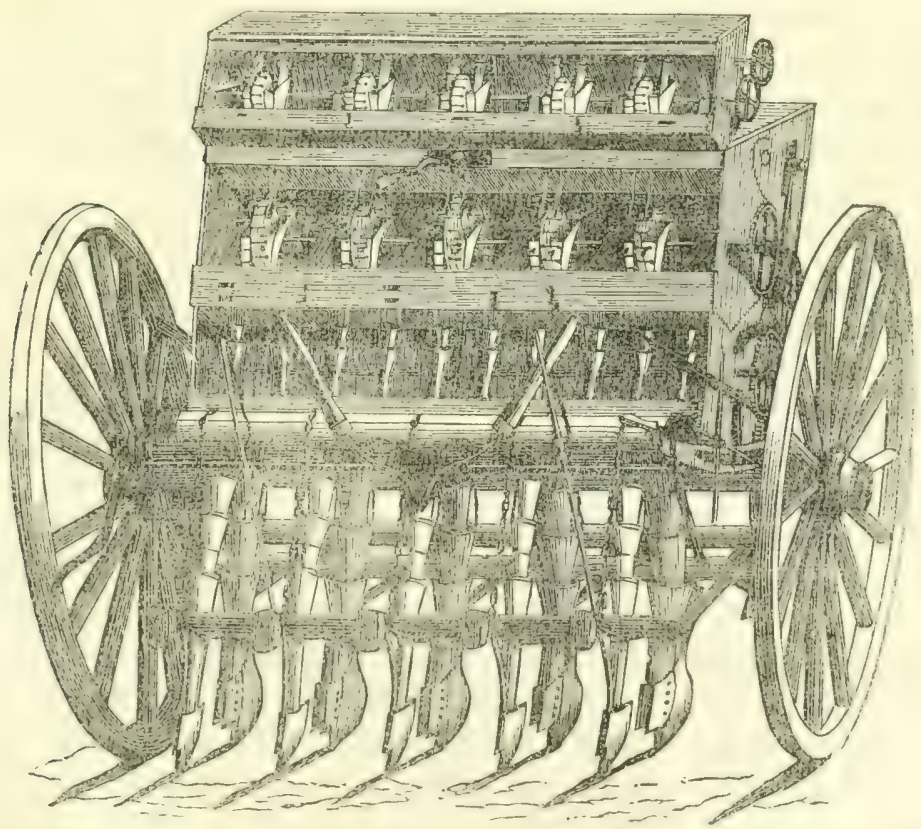

to which the Agricultural Socicts awarded its premium of thity pounds; it is said to have a deserved popularity. I harc see: several different linds in operation, but with rery imperfect means of making a comparison between them ; and, from a neressarily cursory observation, it would be presumptuons in me to 
pronounce a decision upon their merits. As every man, with a common endowment of philoprogenitiveness, deems his own children the handsomest; and, though they may be blear-eyed or bandy-legged, will come at last to look upon these defects and deformities with indulgence, or even with complacency and admiration, and will insist that others shall have the same opinion; so, if we take the accounts which the inventors and makers give wf their own machines, we shall find the correspondent exaggerawons of self-esteem and vanity, and shall be called upon to believe that each one supplies the defects, and surpasses the merits, of every other.

"The Suffolk drill is the kind in most general use throughout the kingdom, and is adapted for drilling corn either on level lands or on ridges, and on all descriptions of soil. It is furnished with independent levers, by which the colters are each readily ind separately made to avoid any rocks or irregularities of the yround, and a press-bar, extending over the entire width of the inachine, to force the colters, in case of need, into hard ground, with a varying degree of pressure, according to the texture of the soil.

"The colters can be set so as to drill the corn at any width, from four inches to a greater distance. They also, if required, readily allow of the introduction of the horse-hoe; and, from being placed in double rows, they admit, when at work, large stones to pass between them, of a size that, under the old plan of placing the colters in one line, would break or stop the machine. The most complete drills are furnished with the 'swing steerage,' by which the drill-man keeps the rows at exact or even distances from those which have been previously drilled. 'The 'corn barrel' is made to deliver from two pecks to six or seven bushels of seed, per acre; and they are furnished with an additional barrel for drilling turnips and mangel-wurzel. These barrels, by a simple yet efficient 'regulator,' are kept, on unequal, hilly ground, at the same level; so that the grain is evenly delivered, in whatever situation the drill may be placed.

"A 'seed engine' is also sometimes added to the common corn drill, by which the grass seeds and clover are sown at the same time as the corn, and each kind of seed, if required, separately. By this plan, any quantity, per acre, of the seeds may be much more evenly distributed than by mixing them up together. For 
these seeds, being of different sizes and weights, are, in the ordinary seed engines, very apt to separate in the boxes; and thus the brushes too often deliver them in unequal proportions.

"The weight of these drills necessarily varies with the number of colters, ranging from three to ten hundred weight; they are drawn, according to circumstances, by one, two, or three horses; the sliding axletree, allowing the addition of any number of colters, adapts the drill to different breadths of land.

"The manure-box may be taken on or off at pleasure. It is a simple yet accurately-working apparatus for delivering the manure, which it does with great evenness, and in quantities varying, as the 'slip' is placed, from six to eight bushels per acre. In the best drills, also, a very important improvement has been made within the last few years, which consists in the use of separate colters for manure and seed. The manure is now deposited, according to the mode preferred by the cultivator, not only from two to three inches deeper in the ground than the seed, but from ten to twelve inches in advance of it, so as to give the soil time to cover the manure before the next colters deposit the seed; whereas, on the old plan, of depositing the seed and the fertilizer together down one pipe, an evil was liable to arise; when it was used with some of the more powerful artificial manures, the seed and the manure were too close together, and the manure was not dropped with certainty in its best position, under the seed." *

At the Shrewsbury meeting of the Royal Agricultural Society, a drill, or seed-depositing machine, was exhibited, of which the approbation of the judges of implements is so emphatical that I shall quote it in full. It was the invention of Mr. William E. Vingoe, of Penzance, Cornwall.

"This implement enlisted the judges' earnest attention and unqualified admiration, from the simplicity of its acting parts, the accuracy of its deposition of seed, and the mechanicallygood adaptation of means to ends. Although simple, it is difficult to describe. It travels on three wheels, the leading pair being attached to the shafts, from which pair is derived the small power required to effect the measurement and deposition of the seed. The machine is capable of sowing six rows of

* Ransome's Implements of Agriculture. 
corn, (grain,) or other seed, at a time. The apparatus for forming the drills consists of six pressing wheels, immediately followed by as many narrow boxes or shares, which maintain the little trenches clean and open, and each trench perfectly distinct, until the seed falls into them. Through these shares, the seed is conducted by small tubes from the seed-box or hopper above them; and immediately behind the shares is placed a peculiarly-simple and effective kind of hoe, for covering the seed. 'The seed is received upon sliders resting upon the bottom of the hopper, and furnished with proper recipient holes, the size of which determines the number of seeds desired to be planted. Means are provided for striking off excess; and it was found, on repeated trials, that no greater difference took place, in the number of seeds deposited, than was fairly attributable to the difference in the magnitude of the corns. The entire apparatus is readily raised out of the ground at headlands, or when turning. If the preparation of a firm seed-bed be a good principle, this machine effects it as well as any presser; pressing and drilling six rows at once, with an adjustment for shifting the width of the rows from five to any other number of inches apart desirable for grain; and it either distributes the seed in a train or drops it within a small compass." *

Such a machine as this would seem to meet its objects perfectly; but there are many others, which claim for themselves equal advantages. It would be idle to attempt to enumerate the various forms of drill machines which I have scen at worls in the country, and to the value of which I can bear a strong testimony, not so much from an inspection of the construction of the machine as the excellent manner in which, so frequently: the work appears to be executed. The practice of drilling wheat is in my opinion greatly to be preferred to that of sowing wheat broadcast ; first, in the much more equal distribution of the seed; next, in the better opportunity which the wheat has of spreading or tillering; and thirlly, in the opportunity of clearing and cultivating the crop, which latter is of great importance. I am of an opinion, borne out very strongly by facts which have come under my observation, that wheat in the early periods of its growth is as much benefited by cultivation as any plant which

* Report of Committee on Implements, at Strrewsbury, 1815. 
is grown; and the injury which is done, both to the growth of the plant and to the sample of grain, by the weeds which ripen their seeds among it, renders the weeding or clearing of the crop of great importance. 'This is often done here, even when the crop is sown broadcast; and it is not uncommon, in the spring, to see a large party of women in a field, employed in weeding; but it is obvious to what disadvantage this is done when the plant is sown broadcast, compared with it when sown in drills.

The next mode of planting wheat is by dibbling. Drilling is sowing the wheat in rows, in continuous lines; dibbling is planting it, in these rows, at intervals, sometimes, of six inches to a foot. This is sometimes done by hand: a laborer goes forward, with an instrument with two or three teeth, making holes, into which children, who follow him, drop one or more seeds as they go on, and cover them with their hands or feet. Labor is here so

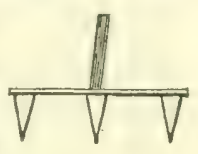
abundant, and parents, in order to eke out their narrow means of living, are so ready to avail themselves of the labor of their children, that this operation is not expensive, and indeed is often compensated by the actual saving in seed; and abating the irregularities in the sowing, which may be expected from the common recklessness of children, may be considered as a good mode of executing the work. But machines have been invented for dibbling as well as for drilling; and one called Nexberry's machine, from the name of its maker, is exceedingly ingenious in its construction. I should find it difficult to describe it intelligibly. A machine calculated to sow only one row has one wheel, to sow five rows has five concentric wheels, hollow, and with a box in them to contain the seed, with dibbled points upon the rim of these wheels, at such distances as it is desired the holes should be made. As the machine revolves, these dibhles or pins, which are in fact hollow, force themselves into the gromnd, making a place or hole for the deposit of the seed; and, as they are being raised from the hole, they divide and drop the seeds into it, which is covered and pressed down by the machine. The machine is calculated to sow from four to five pecks an acre. It is drawn by $\mathrm{two}$ horses, - in some cases more are required, and in general performs its work well. It is an expensive machine;

voL. If. 
and its weight has been objected to by many persons; but by some farmers this, on light lands, is considered an advantage.

There are several other kinds of dibbling machines, which I need not describe, and, among others, a machine carried in the laborer's hand, which makes the hole and drops the seed by the same operation. It is ingenious, but is adapted to cultivation only on a very small scale.

On one of the best cultivated farms in England, - that of the Duke of Bedford, at Woburu, - Mr. Bumers, the farm manager, states (1845) that he employed boys to dibble one hundred acres of wheat. The holes were made with a stick or dibble, three inches asunder in the row, the distance between the rows being nine inches; and the number of "dibs," per acre, amounted to 232,320. He states that he has some boys who would make one hundred and fifty-one holes in a minute; but of course they could not long continue such a rate.*

A great diversity of opinion prevails on the subject of drilling and dibbling wheat; and, from the respectability of the differing parties, there is reason to believe these different opinions are held in equally good faith. 'The invention of a patent machine for any particular object, like that of a patent medicine, always develops in the artist or inventor a wonderful facility in procuring authorities in its favor. The advantage of being able to weed and cultivate the plant applies even more to wheat which is dibbled than to that which is drilled, and the product is likely to be as good. In all these cases, the main saving calculated upon is in the quantity of seed to be sown. This may vary from one bushel and a peck to two bushels and upwards per acre. This is, certainly, where any large quantity is to be sown, an important consideration. Where the land is in good condition, enriched and free from weeds, and where the planting can be

* On this excellent and admirably-managed estate, I found that thirty boys were constantly employed in farm work, for which they received sixpence per day. Their wages were never raised, but whenever they could improve their condition, they were at liberty to avail themselves of the opportunity. They' were thus furnished with regular work, and were serving an apprenticeship to agriculture under the most favorable circumstances. This was real and most judicious philanthropy. This may not be understood on the other side of the water, where there is an urgent demand for all the labor that can be supplied; but it will be appreciated here, where employment, at any rate, is often very difficult to be procured. 
done very early in the season, and carefully done, dibbling may be considered safe, and perhaps to be preferred; but, in all cases, against the advantages of dibbling a small quantity of secd, are to be set off the danger from insects and frost, and the imperfect germination of the seed. To save two bushels, or even one, per acre, in all the seed sown throughout the kingdom, would be an enormous saving, and come very near meeting all the demands which are made for foreign supplies; but on the other hand, from the omission to sow sufficient seed, to experience a loss or deficiency of four or more bushels per acre, as some pretend would be the result, would be a much more serious matter. I have known a good many persons to hold to some particular opinions or faith in religion, because they say, notwithstanding their conviction of their inconsistency or absurdity, if they should prove wrong they still would be safe; whereas, if they adopted other opinions, to which they feel strongly inclined, and of which they perceive the reasonableness, if they should not prove true, they wonld find themselves in an unfortunate condition. The state of opinion, in regard to the thick or thin sowing of wheat, is quite analogous. Farmers may be safe, and save their seed, by sowing little. They do not save their seed, but they are sure to be safe, - so far as this goes, - in regard to a crop, by sorving a good deal. Different minds will view the matter differently; but, having fully stated the case, like a wise judge, I submit it to those whose province it is to decide. I have known a great many persons, who have enjoyed an extravagant reputation for wisdom, who never gave a decisive and unequivocal opinion in any case. Like the Delphic oracle, they were always sure to be right, because the prediction would fit any result. Without any pretensions to wisdom, it may be safe in me to adopt the same course.

The increase which, by painstaking, may be obtained from a single seed is very remarkable. I have already spoken of some instances, but I shall refer to others, for two reasons; first, for the curiosity of the fact, and showing how prolific, under gnod cultivation, a plant may become; and next, as evincing with how little difficulty a new and improved variety of grain may be obtained, by selecting from a field even a single head.

$A$ farner in Cambridgeshire, in 18.10, gathered, from one of his fields, eighteen very fine ears of wheat, (which were five, sis, and 
seven set,) the proceeds of which filled a common wine-glass. The above was planted the following antumn, and produced one peck, which was planted November 8,1841 , and produced seven bushels and one peck: planted the same, November 2, 1842 ; the produce one hundred and eight bushels and two pecks ; which was planted in the autumn of 1843 , and produced one thousand eight hundred and sixty-eight bushels. This was the increase from the eighteen ears, in the short space of four years.

We have another account of the product of a single ear, grown hy an excellent and spirited farmer, Mr. Jonas, of Cambridgeshire.

In 1838, dibbled in 50 kernels, ( 30 of which only grew ;)

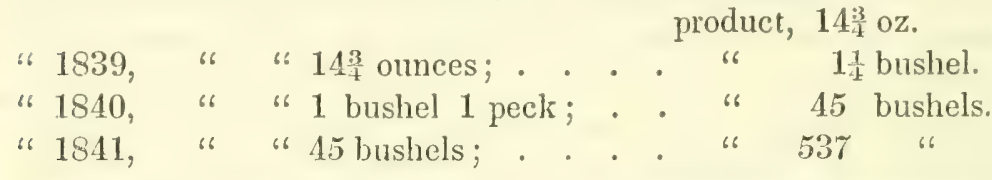

A wheat in Scotland, known as the Hopetoun wheat, and deemed an excellent and prolific variety, owes its origin to the accidental circumstance of an observing farmer, Mr. Patrick Shirreff, having, in 1832, remarked a very superior ear, from which he picked out ninety-nine corns; and from their product came this celebrated variety. A similar origin is ascribed to the Chevalier barley, a popular and favorite variety, which sprung from an extraordinarily fine head, gathered from his fields by a gentleman of the name of Chevalier, and sedulously propagated. It is thus seen "what great effects from little causes spring," and how often an improved variety may be obtained, in the vegetable as well as in the animal creation, by a careful, repeated, and persevering selection.

The preparation of seed wheat, with a view to prevent smut, is by immersing it in brine sufficiently strong to bear an egg, and then sprinkling it with lime. Some persons recommend a solution of arsenic; but this is always attended with danger. An eminent farmer in Gloucestershire is of opinion that he always secures his crop against smut, by sowing newlythreshed seed, the produce of the preceding year. In his cultivation, he sows from three and a half to four bushels; his average crop is stated to be from twenty-eight to thirty bushels, and sometimes forty bushels, per acre. The depth of sowing 
is a point upon which all farmers are not agreed. Where the land is liable to be heaved by the frost, deep sowing of three and four inches is recommended; and in such cases, the wheat is often ploughed in, and the land left in a rough state, which is supposed better to shelter the plant. By the best farmers, great pains are taken in the selection of the seed-wheat. It was once held - and upon as high authority as that of Sir John Sinclair that imperfectly ripened and scarcely merchantable wheat, since it would germinate, would answer equally well the purpose of sowing as the best formed and best ripened wheat. This was even recommended as being a saving of secd, since more liernels in number would be contained in a bushel of shrivelled or halfripened wheat than in one of full and jlump grain. This notion, however, is exploded; and wheat is understood to follow the universal rule, that, to produce the best, it is necessary to propagate from the best. Many farmers take pains, in selecting their seed, to take the best sheaves in their hands and strike them against some hard body, without threshing them either by machine or flail, thinking that, by this process, the fullest and ripest grains will drop out, which they save carefully for seed.

It is deemed of great advantage, in the spring, to drag or harrow the crop; or, where it is in drills, to scuffle it, as I have already described; or to hand-hoe and weed it, which, being light work, is generally done by women. I was about to say by old women; but I am not positive in that matter; for field-work, and poor clothing, and poor living, give an appearance of old age which is premature. Wheat is sometimes rolled in the spring before harrowiug; and when far advanced in the autumn, it is sometimes fed down by sheep; the effect of which is supposed to be, to strengthen the stalk and to cause it to tiller or spread more.

The time of harvesting wheat has been matter of much discussion; but the results of repeated experiments, with a view to determine the best time, all point to an early rather than a late cutting. The best rule for harvesting is not merely when the stalk below the head has changed color, and the circulations have consequently ceased, but when the grain, though it has ceased to yield any milk upon pressure, is yet soft. It then ripens well in the sheaf; it yields more and better flour; and none is lost by shaking out, as when it is suffered to stand until it has become dead-ripe. Some farmers recommend that the wheat should be 
cut seren days, others fourteen, before it would be perfectly ripe. I do not hold that the middle path is always the preferable course; but there may be an error, as my own experience satisfies me, in cutting grain too early, as well as in cutting too late. In one respect, the farmers here have a great adrantage on their side, in the number of laborers they can, at any time, bring into the fields; so that the largest crops may be cut and gathered in a comparatively very short time.

Wheat here is seldom put in barns; it is generally made into stackis. Staddles are formed of wood, - in some cases the feet are of cast iron, - about eighteen inches or two feet in height; sometimes the frame is of iron as well as the feet. On these the grain is stacked with the most extraordinary neatness, and well thatched. In this way, it will keep any length of time. When placed on iron staddles, the stack is inaccessible to rats. In parts of Cambridgeshire where the stacks were placed upon the ground, I found them plastered with lime-mortar, about two feet from the ground up, and whitewashed, which was regarded as a preventive against vermin. 'The stacks, in general, are made round; but this is objected to in Norfolk county, where the stacks are made long, as being made at less expense and more conveniently removed, in parts, for threshing. The stacks, generally, are calculated to contain from eighty to one hundred bushels; but, in Lincolnshire, I found them of an immense size - at least twentytwo feet in height, and more than fifty feet in length. In Norfolk, I found stacks of grain more than seventy feet loug, and surrounding the homestead like a vast encampment. On one farm in the Lothians, I counted sixty-seven staddles; and more than those were filled every year. Many of the large stacks which I saw were estimated to contain from eight hundred to one thousand bushels each. The neatness with which a skilful thatcher will form, and finish, and frequently ornament, his stacks, is surprisingly beautiful; and the conscious dignity with which one of these large farmers displays his magnificent stack-yard, and leads you about his premises, is sufficiently- to be admired, and eertituly not by me to be condemned. At the example farm at Whitfield, Gloncestershire, there was a small railioad from the stack-yard to the threshing-floor, by which the sheaves were very conveniently transported. The great advantage of stacking grain. over storing it in barns, is, that it is not so liable to injury from heat; but the 
thatcher's art is a matter of great skill and experience; and as long as wooden barns are erected among us at so small an expense, and with our off-hand modes of doing things, it can scarcely be expected that we shall have patience to adopt it. I can ouly add, that I know no agricultural picture more beautiful than a neat farm-house in the midst of a crowded and wellthatched stack-yard.

I was to have said something of the different kinds of wheat; but it would not be possible to find any universal or unanimous preference, as different linds are popular in different localities. IImuter's wheat, in the Lothians, "may be considered the most extensively cultivated of any genuine or unmixed variety in Scotland." It takes its name from the person who first propagated it by selection; and it is said to have been cultivated on one farm more than sixty years. It weighs from sixty-four to sixty-five and a half pounds per bushel, and has produced at the rate of forty-six bushels to an English statute acre. It is a winter wheat.

Mr. Skirving, the eminent secdsman of Liverpool, writes to me that he considers the Chidham wheat as the best to cultivate. This is known in Scotland as the pearl wheat. The grain weighs about sixty-five pounds per bushel. "It is a prolific variety, a free grower, and tillers freely in the spring."

The Whittington wheat presents a very beautiful grain. It was here called a spring wheat, becanse it had been sow'n in February, and was mistaken for what is called a spring wheat in New England, and not sown there until April, when it universally failed. It is, however, a late wheat, and, with us, should certainly be sown in the autumn.

The Talavera wheat is an early wheat, and much valued. "The bread made from it," says Colonel Le Couteur, whose careful experiments on the cultivation of different linds of wheat are well known to the agricultural public, "is incomparably the best that $I$ have met with. It is light, very white, and preserves its moisture almost as long as bread made from spring wheat. It is, moreover, so sweet and well-flavored as to appear to some palates mor̈e like cake than ordinary bread." It has yielded at the rate of fifty-two bushels per acre, weighing sixty-one pounds per bushel. Under the cultivation of another farmer, it produced thirty-six bushels per acre. Its cultivation has, however, been 
abandoned in Scotland. It is not deemed sufficiently hardy for their cold and wet springs, and is complained of as not tillering freely.

The Egyptian wheat, with its compound head, - appearing as though several heads of wheat, with the longest in the centre, were brought together, - is sometimes cultivated; but its produce and quality are not such as to encourage the cultivation of it.

I might enumerate many other varieties which are cultivated here; but I have, in truth, seen none superior to kinds common in the United States, especially the white western wheats. Indeed, the bakers here, for the purpose of producing the finest bread and confectionary, prefer the best American flour; and it would be difficult, at any time, to find any superior to the best Howard Street, from Baltimore, the best Philadelphia, and the best Genesee flour.

The seed having been sown, every pains is taken to keep the ground entirely free from standing water or puddles, which are always hurtful to the plant; and where the land has not been thoronghly drained, furrows are run across the field, for the purpose of intercepting and carrying off any water which might otherwise stand upon it.

Where wheat is to be followed by grass, or, as it is here termed, by seeds, clover and Italian rye grass are sown in the spring and harrowed in. Wheat sometimes follows potatoes; but this is not generally approved. It often follows clover which has been mowed or depastured, and then ploughed and rolled and harrowed, and the seed sown on the inverted sward without disturbing it. 'This practice is much commended. Some farmers have found an advantage in sowing white mustard, and either feeding it off by sheep folded upon it, or ploughing it under, in a state of succulency, as a green dressing for the land. About twelve or sixteen pounds, in such case, are sowed to an acre. A case is stated where the farmer, after ploughing in a crop of white mustard, obtained six or eight bushels more of wheat, per acre, than from land which was manured with rape cake. The land in this case, as I understand, was not manured for the mustard. 'The land is usually manured for mustard with seven or eight loads of manture per acre. 'The mustard is considered as a great preventive of wire-worms.*

* Almack's Report of $\Lambda$ griculture of Norfolk. 
I particularly refer to this practice, for the purpose of bringing before my readers an account of the experiment of John Keely, of Massachusetts, illustrating the beneficial eflects of ploughing in a green crop as a preparation for a grain crop. To some of my readers, I am aware, it will be familiar, as I published it, some years since, in my first report of the Agriculture of Massachusetts; but I must claim their indulgence, on account of other of my readers, on both sides of the water, to whom it may not be known, as the experiment seems to me of great importance, and directly bearing upon the subject which I am now treating. I shall abridge it as much as possible.

"The land on which this experiment was made lies on the Merrimack River. The soil is a sand, approaching to loam as it recedes from the river. It is altogether too light for grass. Oats might probably be raised upon it to advantage, were it not that the land is completely filled with the weed commonly called charlock, (wild mustard,) which renders it unfit for any spring crop, excepting such as can be hoed. The crops of rye, on the neighboring soil of the same nature, vary from seven or eight to twelve or thirteen bushels per acre, according to the cultivation and their nearness to the river.

"In the summer of 1827, we sowed three bushels of winter rye, near the river, on about two acres of land, which produced twenty-eight bushels. In 1828, we sowed four bushels on four acres, rumning the whole extent of the plain from the river. This piece was sowed in the spring with oats, but they were completely smothered with charlock; and about the middle of June, the whole crop was mowed, to prevent the charlock seeding. By the middle of August, a second crop of charlock having covered the land, it was ploughed very carefully, in order completely to bury the charlock, and then suffered to remain until the 15 th of September, when we began sowing the rye in the following mamner: A strip of lind about twelve yards wide was plonghed very evenly, to prevent deep gutters between the furrows, and the seed immediately sowed upon the furrow and harrowed in; then another strip of the same width; and so on, until the whole was funshed. We found the oat-stubble and charlock entirely rotted, and the land appeared as if it had been well manured, thongh none had been applied to this part, since it had been in an: possession. 'The rye sprung up rery quiclily and rigorously, 
having evidently derived great benefit from being sown, and hasing sprouted, before the moisture supplied by the decaying vegetable matter in the soil had evaporated to any considerable extent. This crop produced one hundred and thirty-three bushels.

"In 1829, the charlock was suffered to grow on the land appropriated to rye, until it had attained its growth, and was in full blossom. The land was then ploughed, and the charlock completely covered in. In a short time, a second crop appeared, more vigorous than the first. As soon as this had attained its growth, it was ploughed in as before. A third crop appeared, which was covered in when the land was ploughed for sowing, about the middle of September. This piece of land was a strip parallel with the other, and contained two acres. The crop produced seventy-four bushels and a half.

"In 1830, the land appropriated to rye included nearly all the lighter parts of the soil, and, owing to a pressure of business, was not attended to as we could have wished. It was ploughed, in the early part of the summer; but harrowing, to destroy the weeds, was substituted for the second plonghing. This, and the unusual blight which affected all the grain in this part of the country, led us to anticipate a small crop. It yielded fifteen bushels to the acre.

"The land on which the crop of rye was raised the present season had, for three or four years previous, been planted with Indian corn; and owing to the extent of our tillage land, we have not been able to apply more than four or five loads of manure to the acre this season. The charlock was suffered to attain its growth as usual, and on the 18th and 19th of June, it was carefully ploughed in. The second crop was ploughed in on the 6th and 7th of August. On the 14th and 15th of September, it was sowed in the usual manner; viz., a small strip of land was ploughed, and the seed sowed immediately upon the furrow, and then harrowed in. Then another strip of land was ploughed, and so on, until the whole was completed. One bushel per acre was sowed, as usual. Owing to the unusual severity of the winter, the crop was much injured, but recovered soon in the spring. The rye was reaped at the usual season. 'The land contained one acre and thirteen rods, and yielded forty-six bushels and three pecks - a remarkably fine sample."

This is certainly an extraordinary result. Mr. Kecly remarks, 
that he "would not turn a furrow after the dew had evaporated. I have no doubt that a large portion of that fertilizing quality in the soil, which during the summer months is constantly exhaled from the earth, is by the dew b:onght again within our reach; and it would be wise to avail ourselves of the opportunity of again burying it in the soil.* In the second place, I would by all means use a heavy roller after each ploughing. It would fill all the cavities left by the plough, and, by pressing the soil more closely upon the weeds, would hasten their decomposition and much retard the evaporation from the soil." An eminent judge was advised, when he gave his decisions, never to give the reasons for them: his decisions might be right, but the reasons for such decisions might not be the true ones. Mr. Keely might have benefited by the same caution. His facts, without question, are as stated, but the causes which he assigns for the result may not be those which have produced it; yet the suggestions of such a man are entitled to consideration.

'The harvesting in England is performed in three modes; by the sickle, by the common scythe, or by the Scotch bow or cradle. The sickle is fast yielding to the other instruments. 'The wheat is cut higher by it than by other modes, and there are therefore fewer weeds or foreign substances gathered anong the straw, to fill the manure with pernicious seeds; and the straw, being clean, is not liable to be heated in the stack. But, if the seeds are not carried into the manure, they are left in the field, and in some cases with equal disadvantage. The grain being cut high, more straw is lost upou the ground; and reaping with the sickle is comparatively a slow process. Where the crop is much lodged, however, or matted, the sickle is almost indispensable. Mowing the grain with a common seythe is practised in many places. A skilful mower lays the grain with great precision, so that it is easily gathered and tied. The crop is, of course, cut very low, and the straw is much mixed. The Scotch bow, which is merely a hoop, extended upon the handle of the scythe so as to receive the grain in falling, that the workman may deposit it evenly for the binders, is much used, but, I may be allowed to say, is very inferior to the cradle, with its four or five fingers, in use in New England and New York.

* It will be recollected that this is the opinion of a plain and practical farmer, some years before Liebig detected the presence of ammonia in rain-water. 
The wheat being harvested and removed, it is customary iv leave the field for the gleaners - the women and childreu of the vicinity. $\Lambda$ farmer who does not do this, or who rakes his fields after the removal of the crop, usually renders himself obnoxious to the ill-will of his neighbors. This has now become, from long use, matter of prescriptive right. It is often, but not always, limited to the wives and children of the laborers in the service of the farmer. This privilege is worth more than one would at first be disposed to consider it, as a single expert gleaner will collect, in the season, three or four bushels. One woman assured me that she had sometimes obtained, by gleaning, to the amount of six bushels, in a year, of wheat; but I deemed this statement, as perhaps peculiar to the sex, a little poetical. Such results exemplify, in a striking manner, the extraordinary amounts of small savings; and if, as it is natural to suppose, they correspond to the accumulations of small expenditures, an experienced traveller or resident in England ceases to be surprised at them. The gleaners in a field, the women and children, from the peach-bloom of two years old to the sallowness and decrepitude of an old age withered by toil and want, present an interesting spectacle. I am not certain that this form of charity is unobjectionable; but it is gratifying to contemplate; when a benevolent farmer, by not suffering his reaped fields to be closely raked, himself shares in the pleasures of the gleaners: acquisitions, and thus strengthens the bonds of good-will and kindness which connect him with his humble dependents.

I have gone thus largely into the cultivation of wheat, because in England, and perhaps throughout the world, it must be considered, as a bread plant, the most important of all agricultural products. I myself believe, when all its uses and all the circumstances of its culture are considered, - what it requires and what it returns, - that Indian corn is more valuable ; but it would be difficult to persuade others of this, who have not been brought up to its use. To the arable farmer here, and in the United States, where it can be grown, wheat must be the great object of attention.

I suppose there is no country where the average yield of wheat is so large as in England; and this product has nearly doubled within the last thirty or forty years. I am quite aware that, in many parts of England, the crops are still small, and do 
not exceed sixteen bushels to an acre; but on the estate of the late Mr. Coke, afterwards Lord Leicester, _ where, when he cane to reside on his property, it was thought, on accomut of the thinness and poverty of the soil, wheat would not grow, - the average yield is from forty to forty-eight bushels per acre; and I have already referred to a large farm where the crop on the whole farm, in 1811-5, — a most favorable season, — averaged fifty-six bushels per acre. These are most encouraging results; but since, beyond all question, in an instance referred to, eighty bushels have been produced, who will say that the limits of improvement have been generally even approached? All this too has been, without doubt, the effect of improved cultivation.

I have gone so fully into this subject that my readers may deem a recapitulation unnecessary; but the subject is so important, and bears so strongly likewise upon other crops, that 1 must claim their indulgence for a few remarks.

The success of no crop whatever can be commanded; there are agencies and elements concerned in the production far beyond the power or skill of man to command or control. But that culture may do much, is equally certain; and the circumstances under which it succeeds are those in which we are mainly concerned. The soil on which the improvements on Lord Leicester's estate have been made, was originally a thin, gravelly, and light soil ; but it has been decpened by ploughing, and thoroughly pulverized, and enriched by manure. The manure has been applica to the green crop, the tumips or swedes, in a most liberal manner, at the rate of fourteen loads to an acre, when ten are ordinarily considered an ample allowance; but in addition to this, the crops have been consumed on the land by sheep folder upon it, and these sheep, dming the folding, have been themselves liberally supplied with linsecd oil cake, than which, excepting the flaxseed itself, nothing contributes more to enrich the manure. In some cases, Mr. Coke was accustomed to use rape cake as a manure, and this was ground fine and sowed in the drills with his wheat. There is no donbt of its efficacy, but it is not safe to use it without some mixture. The Dutcls farmers dissolve it in their tanks of urine, and then apply it with great alvautage. It is sometimes used as a top dressing between the rows of the growing crop. I have not found its use extensive.

vor. II. 
Guano was not known as a manure in the time of Mr. Coke, but is now applied, properly mixed, by many farmers, with great advantage. The manure, however, which comes from animals folded on the land and fed liberally with linseed oil cake, is, beyond question, one of the most safe, one of the most enriching, and one of the most permanent in its beneficial effects, which can be applied. I believe the soil for wheat cannot be too deep; though, as I have already stated, it may be too loose at the top, and, in such cases, requires shallow ploughing and treading, or pressing on very light soils, in order that the roots may be firmly fixed in the soil, and the dirt not liable to be blown away from them. In Lord Leicester's cultivation, the seed was always drilled, and the crop most carefully horse-hoed, in which operation the dirt was thrown towards the plants. In the third place, the land was thoroughly cleaned of weeds. A gentleman, who visited the estate during the life of the former proprietor, states that in travelling over, and observing most carefully, a field of wheat of seventy acres, he discovered but one single weed, and that of charlock, which one of the workmen pulled up with a good deal of indignation. I will add only that success is always uncertain unless the land be thoroughly drained. Standing water upon the soil, or in the soil, is always prejudicial, and often fatal, to the crop. With respect to other matters connected with this cultivation, I have treated them so fully that I may leave it to my intelligent readers to form their own conclusions.

I believe that the average crop of wheat here may be fully doubled. I shall quote, rather as a curiosity, the following statement, which has been furnished me. $\mathbf{A}$ cultivator, in the end of Angust, 1843, planted in his garden thirty-two grains of wheat, of the very best quality, at six inches apart, and at the depth of an inch and a half. In 1844, this seed produced thirty-two plauts, having from ten to twenty-cight stems and ears each; the average number of ears was sixteen; the average weight of each plant was one and three quarters of an ounce. An acre of land would contain, at six inches' distance, 174,240 plants ; the prodnce, 304,920 ozs., or $19,000 \mathrm{lbs}$, or about 320 bushels, per acre. When a farm can be subjected to a most careful garden cultivation, though the expcetation of any approach, upon any extensive scale, to a crop even of one third of this amount, would be 
deemed pure lunacy, it is apparent that a large increase of product may be confidently looked for. One would not be surprised at a great exteusion of spade husbandry, since I have been over a field, on one farm, of one hundred and fifty acres, thoroughly trenched to the depth of eighteen inches by the spade, and where the growing crops presented a promising appearance. 'This was done in a place where, and at a time when, labor was most abundant; the undertaking was a substantial benefaction to the poor: and the cost was not more than it would have been by brute labor.

I might speak of the diseases and accidents to which this crop is liable; but this would be to compose a treatise rather than a notice, and my readers will not expect it. One experiment made in the destruction of slugs upon wheat, by the application of salt, is highly important. Where slugs have appeared on the wheat, a farmer in Norfolk has been in the habit of sowing one hundred weight of salt to the acre, which, without injury to the wheat, has proved effectual to their destruction. In one case, where the operation of sowing was in progress, on discovering shugs, he sowed as above, and in two days they wholly disappeared. An application of lime to slugs proved harmless.* I have known, in New England, the application of salt mixed with manure prove effectual for the destruction of wire-worms, in a cornfield. Calculations respecting the amount of injury often done to the wheat crops by the wire-worm, rate it at more than $£ 60,000$ per year. Indeed, it may be much more than that, and is scarcely a subject of calculation. Many insects affecting the grain crops are considered as wire-worms, which belong to a different tribe of insects; and there are insects which prey upon other insects, and thus check their destructive ravages. The reflections of Mr. Curtis, an enlightened naturalist, on this subject, are so striking, that I know I shall gratify my readers by their quotation.

"Let us now pause for a moment, and reflect upon the extraordinary fact, that our com, the staff of life, is placed in the nower of this pygmy race; and that, destined as man is to earn his bread by the sweat of his brow, yet famine, accompanied by its concomitants, disease and death, may overtake him, (notwithstanding his industry, and let his prospects be ever so promising, )

* Almack's Report of the Agriculture of Norfolk. 
through the united operations of the insect race. How wonderfully displayed, therefore, are the wisdom and goodness of the Creator in so nicely balancing the destroyer and his parasitic enemies, as to keep man, naturally prone to indolence, ever on the alert! and yet, when the countless hordes of noxious insects fall like an irresistible plague upon his crops, that Hand which is ever ready to befriend mankind arrests the scourge. Myriads of parasitic insects are let loose, multiplying as their prey increases; the threatening scourge passes over with less loss than could have been anticipated; and in the succeeding year, to the astonishment of the farmer, instead of the mischief being increased, not an insect enemy is to be seen." *

2. OAts. - Oats are cultivated largely in Great Britain. In Scotland and Ireland, they are cultivated extensively for food for the population; and, when the meal is of the best quality, in some forms in which it is cooked, it is not only palatable, but extremely agreeable. Porridge is prepared merely by boiling it in water, with some salt thrown in, until it reaches a proper consistence, and in this form is ordinarily eaten with milk. Brose is prepared simply by scalding the meal with boiling water, and throwing in a little salt. This is likewise eaten with milk. Oatmeal cakes are made of oatmeal, and spread out to a thinness not exceeding a quarter of an inch, and baked to a crisp. In many cases, I found a bitterness in the flour, which I apprehended arose from the seeds of some weed having been ground up with it; but, with this exception, the porridge and the brose, when eaten with a plenty of cream and sugar, (a little, as I thought, to the consternation of some of my Scotch friends, was a most agreeable dish. A coarse quality of meal, in such cases, is preferred to that which is fine. It will not do to say that it is not a nutritious substance. The allowance, formerly, of a Scotch laborce was a peck of oatmeal per week, and two Scotch pints, or four quarts, of milk per day; and this comprehended the whole of his subsistence. Where more hardy or more skilful laborers are to be found; where we are to look for a finer race of people than the Scotch, - more erect, more muscular, more energetic, with more of physical or of intellectual power, - I know

* Curtis on Insects affecting Corn Crops. 
not; and this dish is, perhaps, never absent from a Scotch table. and, with a large portion of the Scotch, constitutes their principal diet. In Englaud and Scotland, oats and beans form the chief food of their horses, with a comparatively very small portion of hay : and so many are liept for labor, sport, or pleasure, that the demand is immense. A pound of good oats is understood to give as much nourishment to a horse as two pounds of hay.

Oats are not cultivated very differently from the methods prevailing with us. 'They are most commonly sown broadcast, but sometimes are drilled, where the land is foul with weeds, and sometimes dibbled. When drilled, four bushels of seed are sown to an acre; when broadcast, it is not uncommon to sow six bushels: for though oats, like wheat, throw out side shoots, or, as it is termed here, tiller, yet the heads from the side shoots are seldom of much value. 'The crop varies from thirty to sixty, and sometimes eighty, bushels. It is strongly advised to cut oats early, as soon as the stalk turns yellow under the head, and even while the other parts of it are green. None are lost, in such case, by shaking out; the grain itself is brighter, and the straw is saved in a much more palatable condition for the animals to whom it is fed.

When grass land is broken up, oats are almost always the first crop taken. In this case, the land is ploughed and the sward completely iuverted in the antumn, and then harrowed or lightly ploughed in the spring. In this way, the oats have the benefit of the decaying vegetable matter turned under. The oats, when sown broadcast, are most often harrowed in; but when ploughed, it is done with a light furrow, as they will not germinate when deeply covered. Oats are sometimes sown after turnips which have been fed to sheep folded on the ground. In this case, the ploughing is very light. . Those, however, which are grown upon old grass or pasture land broken up, give generally much the largest return. Oats are grown upon soils of almost every description, but certainly not with equal success; and a strong, rich loam may be expected to give the best crop. The poorer the soil, in general, the more seed is advised.

In the admirable Agricultural Muserm of the II ighland Agricultural Society there are specimens of forty different kinds of oats; but it would be useless to give a mere list of names. What is called the common oat is the oat which, without any 
particular selection, happens to be cultivated in some particular district.

The potato oat, which I have often met with, is much esteemed The grain is short and white, the panicles well filled, and it is usually without beard or awns. But it is said to become bearded, from being cultivated too long on dry soils without changing the seed. The specimen in the Museum weighed forty-six and a half pounds per bushel. I have known this oat cultivated in the United States; the first year with success; but the second year the crop was much less in the number of bushels, and in the weight of the grain. I cannot think there are any insuperable obstacles to its successful cultivation in the Northern United States, unless they should be found in the intense heat of our summers. This sort is said to have had an accidental origin among a field of potatoes, and from that circumstance obtained its name.

The Hopetoun oat is another celebrated Scotch oat, which had its origin in an accidental selection. It is stated to be not so liable to be shaken out by the winds as the potato oat, and to be a few days earlier; its straw longer and stiffer, and not so likely to become lodged. It is esteemed better adapted for light than for strong clay soils; but is more liable to smut than the potato oat. For low meadows and newly-reclaimed lands, it is much esteemed. The sample in the Museum, which was selected from that exposed in the Edinburgh market, weighed forty-six pounds per bushel.

The black Tartarian oat is much cultivated in England, the white to a considerable extent in Scotland. 'The straw sometimes reaches six feet in height. These kinds are late, and require a very rich soil. They are well known among us, having all the panicles on one side; not often found unmixed, but, within my knowledge, successfully cultivated by an eminent farmer, in New Hampshire, on Connecticut River, whose crops average from sixty to seventy bushels per acre.

I have seen here a very superior oat from Archangel, in Russia, and greatly esteemed by Mr. Dickinson, at whose extensive and beautiful stables, in London, I met with it. He informed me it was cured by fire in the plant, and weighed thirty-eight pounds per bushel. He valued it for feeding, weight for weight, more than any other. It was a small oat, but long in proportion. 
3. B.refey. - This crop is very largely cultivated in England. It often follows turnips; and then, clover being sown with it, a good preparation is made for wheat. 'The uses to which it is applicd in England are principally for malting and making into beer; of which the cousumption is great beyond all ordinary calculation, malt liquor being the favorite drink of all the lower classes, and seldom absent from the tables of the rich and luxurious. In Scotland, much barley is used for distillation into spirits. Barley was formerly, and is now, in some countries, used for bread; but in this respect it yields to the finer grain, wheat, and even to rye and oats. It is used to some extent for feeding cattle and swine, but mainly for the purpose of malting.

Barley is of various kinds. One kind has two rows, and another has six rows, to a head. That which has two rows only is generally preferred. There are two kinds, distinguished from the time of sowing, as winter and spring barley, the former being sown in autumn. The alternations, in winter, of freezing and thawing, are prejudicial to winter crops, and an early sowing of the spring crop is strongly recommended. There is a coarse kind of barley, known as bere, or bigg, which is advised to be sown where the crop is to be cut for green feed. There is a kind, called the naked barley, which somewhat in appearance resembles wheat, and from which the corolla is spontaneonsly separated. This kind is said to be much esteemed on the Continent, but is not much cultivated in Great Britain. The bere, or bigg, ripens much earlier than other kinds, and is consequently adapted to a late climate.

Barley is sown broadcast or by drill, and harrowed in. It is advised that it should be sown always upon a newly-ploughed and fresh soil, and that it should be carefully rolled, either immediately upon being sown or after the plants are above gromind. When barley is drilled, and it is intended to sow grass seeds among it, they may be sown after the barley is hoed, and then rolled; or, if the barley is sown broadcast, they may be sown with the barley. There is almost always danger, in such cases, however, of burying the grass seeds too deeply.

The cultivation of barley is so well understood in the United States that I need not enlarge upon it. One of the best farmers in England, whose premises I have had the pleasure of inspecting, drills in about three bushels and a half per acre, at seven 
inches apart, and then harrows it with a light harrow, and sows clover and other grass seeds upon it with a machine drawn by a horse, that it may be the more evenly spread. The barley under his management is always carefully weeded. A double-rowed barley, called Chevalier, from the name of the person who first selected a single head in his field and grew ultimately a crop from its product, has for many years been greatly preferred in England, and continues to maintain its high reputation. The average weight of barley is from forty-five to fifty-five pounds per bushel, and a crop on land well prepared is from thirty to fifty bushels. Its proportion of nutritive matter is sixty-five per cent.; that of wheat being seventy-eight per cent. On good loamy soils, barley is more profitable than oats. It is not so eligible on stiff and cold clays. It is considered not so great an exhauster of the soil as oats. A good deal is sown in the neighborhood of London, to be cut as green feed for milch cows in the large milk establishments. Machines are in use for hummelling barley, - that is, breaking off all the awns close to the grain, - and likewise for hulling it, so as to form what is called pot or pearl barley, a very nutritious and agreeable ingredient in broths and in drinks for invalids.

4. Rye is very little cultivated in Great Britain, and I have never seen it used here for bread. It is, however, sown for green fodder, and with great advantage, as it comes early. I have described already an early and extraordinarily-useful kind under the designation of St. John's day rye, which produced, besides being repeatedly cropped, thirty-six bushels to the acre. I believe that rye might be more extensively cultivated in England, to great advantage, for human food, if its proper use was understood, for the feed of dairy cows in the spring, as nothing will produce greater secretions of milk than rye meal, - and also for the fattening of swine. In the best dairy districts of the United States, where the amount of cheese made to a cow is nowhere exceeded, nor within my knowledge equalled, - a dranght of about three quarts of rye meal per day given to a milch cow, in the spring, before the grass is abundant, is amply compensated by the increased amount of milk and cheese produced; and $\mathbf{I}$ have known it applied to the feeding of swine with great success.

Having thus far treated the cereal or bread grains, called white 
crops, I come next to consider another class of plants, much cultivated and of great value in English husbandry.

5. Beans. - Beans are of several kinds. The first division is into garden and field bcans. Of garden beans very few are cultivated. String beans, otherwise called French beans, are common enough; but I have not met with our finest kinds of shell beans, such as the cranberry, the pole, kidney or caseknife bean, and, above all, that rich and delicious vegetable, the Lima bean. If they are known in England, it has not been my fortune to meet with them, either in the markets or at private tables.

Beans may be considered, in England, as a most important field crop, and are principally used for the feeding of horses, to which they are given, usually, broken and. mixed with oats, - a quart of beans being considered as quite equal to two quarts of oats, or with cut hay and chaff. They are likewise used in fatting swine; but they are considered to give too much hardness to the pork, excepting when it is to be used for bacon. They are deemed valuable likewise for fatting oxen, and increase much the milk of cows. They may be said to take the place with the English which Indian corn takes with us. Some quantity of beans are mixed with new wheat to be ground, as the millers say "that soft wheat will not grind well without them; and, as one shrewdly observes, they take care that in this matter there shall be no deficiency." I have eaten, in Scotland, bread made with a large proportion of bean flour, but I cannot say with much relish. The nutritive qualities of beaus, as compared with wheat, are as sixty-eight to seventy-eight per cent. The ordinary weight of a bushel of beans is sixty-six pounds.

There are several kinds cultivated, which are known by different names; but the kind most approved is a small, round bean, of a dark color, and of nearly twice the size of a marrowfat pea. A well-cultivated field of beans is, in its early stages, a beautiful object. The land most suited to beans is a strong, rich loam, and a clay soil is congenial to them. Nearly seventy bushels have been obtained from an acre; sixty is a large crop; ordinarily, however, they do not exceed thirty bushels. Here they are sown early, - in February or early in March, - and ripen late. 'They are sometimes sown broadcast, and large crops have been obtained in this way; but it is not recommended, firom the difi- 
culty of keeping the crop clean, which is of the highest inportance, where a wheat crop is to follow. They are usually drilled ten or twelve inches asunder, and the intervals hoed; and sometimes two feet, or two feet and a half, apart, and then carefully cultivated between the rows. 'The land, in such case, is commonly highly manured, the manure being rotted barn manure, spread and ploughed in; and, being liept as clean from weeds as possible, there is a fine preparation for wheat. In this way, wheat and beans are made to alternate on the same land for years, with advantage; though the land should be strong, to bear so severe usage, and the bean crop must be liberally manured. The rotation often adopted is, turnips, barley, clover, beans, wheat; where the land is very rich, it is, turnips, barley, clover, oats, beans, wheat, beans. The quantity of seed sown by drill for beans is two and a half and three bushels. Peas are sometimes sown with beans for a green crop, for the purpose of soiling; in which case, three bushels of beans and two of peas are sown; and this produces a nutritious and well-relished food for cattle and for pigs. Of crops which ripen their seeds few are less exhausting to the soil than beans. Beans, at harvest, are shocked in the field until dry, and then placed in stack to be, after a while, threshed out, either by flail or by a machine. The fodder, cut up with other fodder, in the spring of the year, is eaten by stock. Caution is advised in giving horses new beans, as they are very likely to founder them. The crop of beans here is certainly most valuable, in a climate where Indian corn will not grow; but it seems, in all respects, much inferior to that inestimable and useful product, the value of which, in my estimation, and the more I see of foreign husbandry, is continually rising. The small, white, kidney or round bean, so common with us, and so much eaten in some parts of the country, is not, within my observation, grown or used here.

I tried the cultivation of English horse-beans more than once in the United States; but they were always, in the time of flowering, destroyed by a small, black fly, which they seemed to attract in an extrandinary degree, and which stripped the stems completely of their foliage.

6. Peas do not appear to be extensively cultivated in England, as a field crop. The yield, when successful, varies from twenty 
to forty bushels; but there is nothing peculiar in the cultivation. It is considered a valuable food for horses and for swine, and large quantities, raised or imported, in the form of split peas, are consumed in soups, \&c. The garden culture of peas, in the neighborhood of London, and other large cities, to be sold green, is most extensive; but there is nothing remarkable in the process. With a view of forwarding them, the land is thrown into ridges, rumning north and south, and the seed is dropped on the south side, at the bottom of the ridge. High manuring increases very much the growth of the stalk, but postpones proportionately the forwarding of the pods. For five different and valuable kinds of peas, "the country," Mr. Lawson says, "is indebted to T. A. Knight, Esq., the late distinguished president of the London Horticultural Society, who obtained them by crossing or hybridizing some of the most esteemed varieties. From their remarkably-wrinkled appearance, together with the peculiar sweetness which they all possess, Knight's marrows may be said to form a distinct and most valuable class of garden peas." 'These are, certainly, most honorable contributions of eminent skill and science to the public good. The haulm of peas, as well as that of beans, is carefully saved, and much valued as fodder for cattle, and especially for sheep.

7. Vetches or 'Tares. - This plant is extensively cultivated in Eugland, and considerably in Scotland; and, in my opinion, its cultivation may be strongly recommended in the United States. It is not much cultivated for the seed, as the permitting it to ripen would tend to exhaust the land; but the seed is usually imported from the Continent. The principal object of its culture is to furnish green food for stock, horses and milch cows, which are soiled. Tares supply an immense burden of most nutritious food. They are cut only once; but they are sown at different times, and sometimes as late as August, that the supply of green feed may be uninterrupted.

Tares are of two kinds, - winter and spring, - which differ in no respect, excepting in the habit of ripening; and the tares sown under favorable circumstances in the spring will not lag far behind those which are sown in the autumn.

The land should be brought into a state of fine tilth, and should be well manured. Sometimes they are sown upon a grain stubble, 
which must be carefully ploughed in and reduced. Three bushels is the quantity of seed to be sown to an acre where they are to be consumed green; two and a half where they are grown for the seed. They may be sown broadcast, or drilled, or dibbled; and the latter modes are recommended where the lands are foul with weeds. With winter tares it is recommended to sow rye; with spring tares, which are to be cut for feed, oats or barley may be sown, to improve the value of the crop. The crop is cut daily and fed to sheep, which are folded upon the ground, or cut and carried into the stables for horses and cows. Vast quantities are cultivated, in the neighborhood of London and other large cities, for the milk establishments, and for a change of diet for the horses which are kept there. The cutting of the tares may be begun as soon as they come into flower, and continued until the pods are fully formed; and if there is then a surplus, they may be cut and made into hay, so as to avoid the exhaustion of the soil by the ripening of the seed.

I am not able to give the amount of product which may be obtained from an acre, but from observation I know it must be very large. I do not know whether a larger yield ean be obtained from it than from the improved Italian rye grass, of which I have given an account; but, as an article for soiling, it is easily cultivated, and would prove invaluable. The winter tares wonld scarcely endure our northern climate. The value of some portion of green feed to our horses kept in stables, in cities, would be very great; and a mixture of this with the dry feed upon which many of them are now exclusively kept from one year's end to another, would be greatly conducive to their health and comfort. Many a poor mechanic or laborer among us, with a small piece of land attached to his domicile, would find it quite easy to keep a cow, and obtain an ample supply of milk for his family, by the cultivation of some such crop as this. This plant is an annual. There are vetches which are biennial, but they are not recommended for cultivation. The seeds of tares are deemed vaulable for poultry. They will increase the flesh of horses, but are considered hurtful to them.

8. Tunnirs. - The next great crop in English husbandry is turnips. Of these there are several botanical varieties; but $I$ avoid those distinctions, as of little value to general readers. 'Ihere 
are two great and well-known classes; the common turnip, of which there are three varieties, - the flat, the globe, and the tankard turnip; and the Swedish turnip, or ruta baga. The common turnip requires a shorter season, more quickly decays, and is a less substantial food, than the Swede turnip. The common turnip is usually white; but there are yellow varieties, which are nearly as solid, and almost as enduring, as the Swedes. Such, for example, is the yellow Aberdeen turnip, which will keep late into the spring, when the common white turnip has become corky and vapid.

The turnip has been cultivated for conturies in England; but it is within a comparatively recent date that it became a matter of general field cultivation upon light lands, and may be said to have effected a revolution in husbandry. The great value of it is in feeding stock, especially in the return which it makes to the land when it is fed to sheep folded upon the land; in the manure, likewise, which it produces when fed to cattle or sheep in stalls or yards; in the increased number of stock which its production puts it in the power of farmers to keep; and in its intermixture with dry feed, enabling them to make use of that dry feed to advantage, to which, otherwise, cattle could not be confined but at the expense of health and comfort. Thongh other articles may be useful and expedient - such as grain, and oil cake, and hay, - yet many sheep and cattle are now actually fatted upon turnips and straw. It is said that this is done with more difficulty at the south of England than at the north; the turnips in Northumberland, and at the north, being accounted richer, or more nutritious, than in the southern counties; thus sceming to confirm a strong opinion entertained by some persons that the colder the climate, the more nourishing the esculents grown in it. Another great advantage arising from the cultivation of turnips is in the cleanness of cultiration to which it leads, and which thus forms is suitable preparation for wheat, or the grain crop which usually follows them.

The land for turnips, if not stiff and hard bound, cannot be too rich for them; thongh the application of an excessive quantity of manure would be prejudicial, in some cases, to the suceceding crop of wheat, causing too rank a growth, and occasioning it to lodge. The common preparation for turnips is by a thorough ploughing in the autumn: then the land is amply VOI. II. 
manured, by manure spread on the furrow and lightly plunghed in. The manure, however coarse, in such case, will become fully decomposed by the spring. In the spring, this land is laid into ridges about twenty-seven inches apart, and the seed sown on the top of the ridge by a machine. In other cases, where the cultivation is more complete, furrows are opened in the spring, and the manure placed in the furrows; back furrows are then turned so as to form a ridge, upon which the turnips are sown by a drill machine, which, as it deposits the seed, deposits, at the same time, a quantity of ground, or dissolved bones, or some other artificial manure. Sometimes the bones are sown broadcast; and from twenty to twenty-five bushels of ground or broken bones are considered an ample dressing. On the application of bones as a manure, and their solution by sulphuric acid, - that great contribution of chemistry to agricultural improvement, - I shall speak under another head. About two pounds of turnip seed are sown to an acre. The practice of sowing broadcast, which formerly prevailed, is nearly abandoned; but it is still a vexed question whether they should be drilled in upon a flat surface, or upon ridges. Where the land is thin and liable to suffer by drought, the flat surface is to be preferred; but otherwise, in my opinion, ridges, with the manure placed under the plant, are much better. The ridges, for Swedes especially, shonld be at least twenty-seven inches apart,- - for the common turnip a less distance; and the land may then be thoroughly cultivated between them. After the last hoeing, if the condition of the land admits of it, cabbages may be planted between the rows. The interval at which the plants are left on the ridge is, generally, about a foot. Mr. John Bloomfield, of Holkham, one of the favorite tenants of Lord Leicester, and from whose experience and excellent farming I derived much valuable instruction, states that he gets a better crop when his Swedes are left at eighteen inches apart. Six inches apart is enough for other turnips.

Turnips, in the first part of their season, cannot be cultivated too much. The fly is the great evil, in the turnip crop, with which the farmers have to contend. A preventive is found by some farmers in late sowing. The flies are accustomed to appear at a season when, ordinarily, the plants are in readiness for them. By postponing the sowing ten or twelve days, the flies will have passed therr period, and the crop is safe. 
The turnip crop is to be considered, as I have already remarked, as the foundation of the improved husbandry of England, in the means which it affords of supporting an increased stock, in the abundance of enriching mautre which it thus supplies, and in the cleamness of cultivation to which it leads as a preparation for other crops. They are usually fed off in the field; the white turnips, often, as they are grown, in the ground, - which I cannot help thinking a slovenly mode of husbandry. But in most cases, they are pulled and topped, and tailed, and cut by a machine, and fed to the sheep in troughs on the field where they grew; the fold, which is composed of movable fences, being changed from one part of the field to the other, until the whole is gone over, and the crop consumed. 'They are sometimes spread upon grass lands, both for cattle and sheep, but are most commonly given to cattle in stalls. Many of the best farmers pull all their turnips, and feed them to their cattle and sheep in their straw yards; which enables them to convert their straw into enriching manure. The Scotch farmers in the Lothians, and the farmers in Northumberland and the northern counties, who grow immense quantities of turnips, sell them to feeders of sheep and stock, as they stand in the field, upon the condition that they are to be consumed where they grow. The sheep and cattle are brought, in such cases, from the Highlands in the north, and are here prepared for market. The climate of England enables the farmers to leave their turnips, for the most part, in safety, in the ground, during the winter, and to gather them as there may be occasion. 'The Swedes, if not pulled, and if left to thaw in the ground, suffer little from frost. Various modes are adopted for protecting them, in parts of the country where it is deemed necessary or expedient; and they must, of course, be removed, where a grain crop is to be sown in the autumn or early winter. I need not describe these modes, as few of them would be applicable to my own country. Swede turnips may, as I know by repeated experience, be kept well during our coldest winters, by being laid upon the gromud, where the bottom is dry, and piled up in a long ridge, like the pitched roof of a house, being first eovered lightly with straw, and then with dirt, - holes being left in different places, as ventilators for the heat to escape; and then, as the cold increases, the covering of straw and dirt is 
to be increased. Access may be had to them, in such case, a1 the southern end, which may be kept fortified against frost by loose bundles of straw packed. In this way, with care, they may be well preserved until spring, and be at hand through the winter for the stock. They may be well kept likewise in bins, in our barns, well packed round, top, bottom, and sides, with coarse hay. This is an excellent and most convenient mode. In our cold climate, the covering must be liberally and carefully returned, if they are opened occasionally for a supply.

I believe our farmers would find a very great advantage in growing esculent vegetables for sheep and cattle, instead of keeping them, as is now done, through our long and severe winters, exclusively upon dry feed. They would be most useful for sheep in the lambing season, and for cows in milk; and though, in fattening properties, I know no article, all things considered, superior to our Indian corn, yet they certainly would come most beneficially in aid of that. I do not assert that turnips are the best crop, for this purpose, which can be grown, but Swedish turnips are certainly among the best. Mangel-wurzel, carrots, cabbages, parsnips, and potatoes, are all useful. I may recur to this subject again; but the conclusion to which I have myself come, and in which I am daily confirmed, and with which I wish the farmers of the United States could be more and more impressed, is, that an abundant supply of succulent food should be provided for their stock during our long winters, — first, as conducive to the health of the stock; and next, as contributing essentially to the improvement of fattening stock, and as enabling the farmer to keep more stock; and lastly, as furnishing him with the best means of enriching his farm, and extending and improving all his other crops. These have been the striking and universally-acknowledged results of such a system of hasbandry here; and I have not a doubt that, in those parts of the United States from which the markets in our cities are to be supplied with beef and mutton, though, from the severity of our climate, it might with us be a more laborious process than here, and we could not have the advantage of feeding off our green crops on the lands where they grew, yet its great benefits would be an ample compensation for any extra expense or labor to which it might, in many situations, subject us. The difficulty and expense of procuring labor may present itself as an objec- 
tion; but that will be constantly diminishing. Improved machinery, and new implements of husbandry, are yearly affording increased facilities in cultivation; and, for our husbandry to be successful, it will require the liberal application of capital, added to enterprise, experiment, effort, and perseverance.

The following result of an experiment, by Mr. J. Bloomfield, of Warham, Norfolk county, to determine the best distance at which plants should stand, was given me by this excellent farmer, and will be curious to my readers. It was made upon Swede turnips. The row was twenty yards long.

\begin{tabular}{|c|c|c|c|c|c|c|c|}
\hline \multirow{2}{*}{$\begin{array}{c}\text { Rows. } \\
1\end{array}$} & \multirow{2}{*}{$\begin{array}{c}\text { No. of Turnips } \\
\text { in each Row. } \\
32\end{array}$} & \multirow{2}{*}{$\begin{array}{c}\begin{array}{c}\text { Distance apart } \\
\text { in the Row. }\end{array} \\
\text { Inckes. } \\
24\end{array}$} & \multirow{2}{*}{$\left|\begin{array}{c}\text { Average } \text { Weight } \\
\text { of each Turnip } \\
\text { in ths Row. } \\
\text { lbs. } \\
\mathbf{5} \frac{1}{4 t}\end{array}\right|$} & \multicolumn{2}{|c|}{$\begin{array}{l}\text { Weight of all } \\
\text { in the Row. }\end{array}$} & \multicolumn{2}{|c|}{$\begin{array}{l}\text { Produce per Acre, } \\
\text { topped and tailed. }\end{array}$} \\
\hline & & & & Stonc. & $\begin{array}{l}\text { lbs. } \\
12\end{array}$ & $\begin{array}{l}\text { Tons. } \\
24\end{array}$ & $\begin{array}{c}\text { Cict. } \\
4\end{array}$ \\
\hline 2 & 38 & 22 & $3_{4}^{3}$ & 10 & 2 & 20 & 1 \\
\hline 3 & 39 & 20 & $3 \frac{1}{2}$ & 10 & 00 & 19 & 13 \\
\hline 4 & 40 & 18 & 3 & 8 & 10 & 17 & 15 \\
\hline
\end{tabular}

Fractions are omitted. The stone is 14 pounds.

9. Potatoes, Bezts, Carrots, Parsinips. - Of these several crops I see nothing pecnliar in the cultivation in Great Britain: which would require me to treat them at any great length.

The potatoes brought upon the table are, in gencial, of a much better quality, drier, and more mealy, than those grown in the United States. The potatoes grown on new land, however, in the Northern States, are excellent; and the potatoes brought to market from the northern parts of Maine, and from Nora Scotia; are not excelled by any which I have met with. Within my own observation and experience, likewise, I have fond that the finest seed potatoes from this country, planted in the United States, with the exceptions above referred to, have, after the firs! year, deteriorated, and become conformed to those usunlly planed in the country. It is demonstrated, therefore, to my mind, that new lands yield potatoes of a better quality than lands which have been long under cultivation; and that a low temperature and damp climate, such as are found in the northern parts of Maine, and the British Allantis provinees of North Ameriea, are favorable to potatoms, white in bot and dry climates the quality of the vegetable is inferior. 
Potatoes are almost invariably planted here in drills or furrows about thirty inches apart. 'The furrow is first opened; the manure laid in it ; the potato planted; and the land reversed by the plough, so as to cover the seed. They are then, just after appearing above ground, often harrowed; and, after getting to some height, the harrow, or cultivator, is passed between the rows; and they are earthed up with a double mould-board plough, or by a single plongh passing twice in the furrow. When ready to be dug, or, as it is here termed, lifted, a double mould-board plough is passed down once, or a single plough twice, through the row of potatoes; those are picked up which are thrown out; and then the whole field is thoroughly harrowed, which brings the remaining potatoes to the surface to be gathered.

Two or three points seem to be well established here; first, that, in planting, it is better to use whole than cut sets; that, where they are cut, the seed end of the potato is more productive than the opposite end, and, while the former is used for planting, the latter may be saved for food; and lastly, that the crop is considerably increased by early plucking off the blossoms. I have already described the lazy-bed mode of cultivation, and the large crops sometimes obtained, in my account of the Agricultural School at Glasnevin. In general, however, the crops are not large, not much exceeding two hundred and fifty bushels to the acre, which, though a respectable, is certainly not a great yield. Potatoes are raised largely for the market in some places; but, in passing through the country, the extent of land under cultivation in potatoes appears comparatively small.

I cannot join with Cobbett in his anathemas upon potatoes, to which a learned agricultural professor here has lately added the force of his denunciations, which are likely to fall harmless under the power of habit and general taste. There certainly can be found, as common consent seems to have established, no more agreeable, and no more nutritious eseulent than a well-cooked potato; and under few crops will an acre of ground yield more food for animals. The disease which has prevailed in the potato - the ravages of which have been so extensive and alarming - will, it is hoped, prove only a temporary evil, or some effectual remedy against it be found. In Ireland, a large number of the population, amounting to millions, depend, almost exclusively, upon the potato for subsistence. The ordinary allow 
ance to a working Irishman is, from fourteen to sixteen pounds of potatoes per day. It cannot be denied, however, in a moral view, that potatoes to the Irish are an equivocal good. In order to improvement, man requires a constant and severe stimulus to exertion. The necessities of men are the excitements to industry and enterprise, and very often the foundation of their virtues. But what hope can be entertained for the improvement of persons content to live upon the meanest fare, and in circumstances of destitution barely compatible with existence, and to go on and marry, and rear children, with no expectation or ambition beyond that of a mud cabin, a peat fire, and a potato diet?

Next to potatoes and turnips, beets occupy a principal place in English cultivation. Of beets, the field cultivation is limited to the mangel-wurzel. These are cultivated in rows, upon ridges, similar to the cultivation of turnips, about thirty inches apart; and though the seed is commonly dibbled in at six inches distance in the rows, the plants are thinned out to a distance of one foot. Deep cultivation is always strongly recommended for all tap-rooted plants. An eminent farmer in Northamptonshire, after having furrowed and manured the furrows for his mangelwurzel, as the wheels of the cart and the trampling of the horses tend to harden the bottom of the furrow, before the land is turned back upon it in order to form a ridge, passes down in the furrow with a miner, that he may loosen and deepen it. A miner is simply the colter of a plough, without the mould-board. IIe speaks of this as being attended with great advantage. No machine has yet been invented which may be safely trusted to drop the seed. A wheel with pegs of about two inches in length, and six inches apart, upon the outside of the wheel, which shall make holes in the ground as the wheel revolves, handles like those of a wheel-barrow being attached to it, is used to dibble the land, into which children, who follow, drop the seed, one being sufficient in each hole, as every capsule in fact contains four seeds. The seeds are then covered with the head of a rake or with the hand. The land between the rows should be kept loose by ploughing, and thrown upon the rows, but not upon the plants, whose nature it is to grow much out of ground. In the latter part of the season, the under leaves may be gathered and fed to milch cows, or sheep, or swine, with sreat advantage 
to the consumer, and, where the crown is left unbroken and only the lower leaves taken, without injury to the producer.

Reports have been furnished me of erops of fifty-eight tons pen acre, and, in other cases, of forty-eight tons, and fifty-six tons; per acre; this, of course, after they were topped and cleaned. 'These, however, are very extraordinary crops, the common yield being about thirty tons. They are much valued for milch cows, and for fatting cattle. Experiments have been made to test the value of mangel-wurzel comprared with Swede turnips in the fattening of cattle. The experiments which have come under my knowledge - the estimate of the increase of weight of the animals experimented upon having been made from external measurement, and not in scales - do not appear to me decisive, but only indicative of considerable superiority in fattening properties of the mangel-wurzel over the Swedes. 'The yield of mangel-wurzel, per acre, under good cultivation, is considerably greater. Caution is to be used in giving them to milch cows, as they are apt to produce scouring. From this effect I have suflered in the free use of them with my own cows. It is strongly advised, likewise, not to use them until the spring or late in the winter; and I have known farmers to keef. them sound and fresh into August. They are considered as not unfavorable to wheat, which may be sowed after them. The seed of the beet should be well soaked before sowing; and it is advised, in the event of transplanting them to fill up vacancies, not to place the plant lower in the ground than it formerly stood, as otherwise, if planted to the top, it will send out shoots from the top, and become seraggy or forked.

Carrots are cultivated to some extent, and much valued. 'There is nothing, however, peculiar in the cultivation. 'T'he land should be deeply ploughed and highly manured. 'They are usually cultivated on a flat surface; but I am satisfied that the ridge cultivation at a distance of two feet, so as to plough between them, would be far preferable. The seed should be sprouted before sowing and mixed with sand, in order to avoid its being sown too thickly. If sowed on ridges, they will be much more easily cultivated and kept clean; and they shouhd lu thinned out to the distance of six inches apart. The Belgian white carrot has come greatly into favor in England. $\Lambda$ dis 
tinguished farmer, in whose authority I place the utmost confidence, pronounces it as thirty per cent. more productive than the common carrots; and I met with an eminent farmer who had grown thirty-one tons seventeen hundred weight upon an acre, and whose crops averaged twenty-four tons per acre. Another farmer informed me, that he usually obtained twenty-five tons per acre. A farmer, at Birkenhead, near Liverpool, who is laying the foundation of one of the most splendid agricultural establishments in England, and whom I had the pleasure of visiting, obtained a crop of a hundred tons from three acres. Much of this was due to the liberal application of guano. Another farmer reports having grown upoin four acres four thousand eight hundred bushels of the white carrot, or twelve hundred bushels per acre, which he fed to his horses, ten pounds each per day, and to his neat cattle, with very great advantage. A strong prejudice exists against the use of white carrots for horses, as injuring their eyes; and the farmer first mentioned above thinks it not without foundation, believing that his own horses had suffered from that cause.

With respect to the common red beet, or the sugar beet, and the parsnip, I have not seen them under field cultivation in England, though the parsnip is said to be largely cultivated, as feed for stock, in the channel islands. The sugar beet is reported to yield abundantly, and to furnish a more nutritious food, better for fattening, and for milch cows, than the mangelwurzel; yet the former has not supplanted the latter. The Jerusalem articholie is often served at table, and is approved by many as food for stock, but is not so palatable or so nutritious as the potato. It grows, however, without much care, and in almost any ground, besides continuing itself in the ground from year to year. Under favorable circumstances, it is said to yield five hundred bushels to an acre, - a statement which I do not give from personal observation, nor receive without some distrust.

10. Cabbages. - Cabbages have been cultivated to a considerable extent in England. There are many varieties; but my province lies only with those which are cultivated for the feed of stock; and this embraces two principal kinds, - those with sirmading leaves, from whoch the leaves are plucked, and the 
others produced, and those which form compact and solid heads such as the drum-head, and the savoy, weighing, in some eases, upwards of forty pounds each, though such must be considered as remarkable. In Scotland, they are rarely cultivated as a field crop. In the south and most temperate parts of England, they may be safely left in the ground, uncovered, through the winter.

The usual course is to plant them in a nursery, and then remove them to a field; and the largest kinds require ample room, and may be planted at three or four feet distance each way. In transplanting, a dibble is commonly used; but, in such case, the root is often doubled up and crowded into the hole, to the injury of the plant. A better way is, to plough a furrow, and, taking the plants singly, cut off a portion of the top, and dipping the root ends in some liquid, lay them at proper distances in the furrow, and then cover them with a plough; having a third person to follow, who may relieve any plants which may have been too deeply covered, and pressing the earth against the roots of those plants which require it.

Cabbages are deemed most excellent food for sheep and stock, though some persons consider them as of too laxative a nature for cattle - a fault which would be corrected by an ample supply of meal, or some dry feed, given in conjunction with the cabbage Oil cake is given with them to fattening sheep, with extraordinary advantage.

Cabbages are considered as great exhausters of the soil ; but where they are consumed upon the farm, they undoubtedly make a full compensation for what they have abstracted. At Ockham Park, in Surrey, the seat of the Earl of Lovelace, which I had the pleasure of visiting, they have been cultivated, for several years, in connection with a crop of beans. The beans are planted in double lines, four inches apart, and with an interval of three feet to the next row. The ground between the rows of beans is then carefully cultivated, until the time of setting out the cabbages, which are then planted, two feet apart, in the rows. The beans are harvested in August, and the cabbages are then ploughed and cultivated, and are ready to be fed off in December. He thinks that he gets as much feed from the land by this crop as he should obtain from a crop of common turnips, though not as much as he would obtain from a crop of swedes; and the crop of beans is not diminished. Indeed, he adds that 
the crop has increased since he began the practice, having been at the outset, for five years before the combination of the crops, about thirty-five bushels to the acre, and, for five years after uniting the crops, at the rate of forty-one bushels per acre.

Our winters in the North United States would present insuperable obstacles to the preservation of cabbages, to any great extent, as winter food for stock; but the same objections would not hold at the south and in the Middle States. The cultivation, however, cannot be said to extend itself in England, the Swedish turnip being generally preferred.

Some years since, an English farmer, by the name of George Adams, published what he terms "A New System of Agriculture and Feeding Stock," for which he obtained the king's letters patent. The pamphlet, though containing only about thirty pages octavo, was sold at a guinea a copy. I caused it to be republished, some years since, in the United States, - not from auy confidence in his plan as being feasible, but as suggesting some hints as to the amount of produce possible to be obtained from an acre, which might induce inquiry and experiment, and, in that way, contribute to agricultural improvement. As the work now is scarcely known on either side of the water, I will transcribe a few passages, which I think will interest my readers.

"By pursuing," he says, "the following directions, a single acre of land will produce a crop sufficient to feed, in one year, twenty-four beasts, or two hundred and forty sheep."

"In September, or sooner, let your land be well manured and properly ploughed, so as to raise a good deal of fine mould; then plant one third of an acre of the land with the large sort of early cabbage plant, viz., the late York or sugar-loaf; one third more, in February or March, with the same sort of cabbage plant; and the remaining third of the acre, in February or March, with the ox or drum-headed cabbage plant. If the land be good, I would recommend that the plants should be set in rows three feet wide, and two feet between each plant, that is, three plants in every square yard. Upon this plan, an acre of ground will require fourteen thousand five hundred and twenty plants, reckoning five score to the hundred; but if the land be poor, it will be advisable to set the plants thicker proportionably, according to the grower's judgment of the quality of his land. By the beginning of Jume, the first crop of cathbages will 
be in perfection. 'Then put either six beasts or sixty sheep, in the manner here directed, according to the plan of the movable houses, herein anuexed, either for cattle or sheep. Let the cabbages and leaves be carefully cut off, leaving the cabbage stalks cut across at the top, to grow again. The cabbages, upon good land, may be expected to average fifteen pounds apiece, which will be, upon the acre, two hundred and seventeen thonsand eight hundred pounds, or one hundred and eight tons eighteen hundred weight, at five score to the hundred weight. Allow to each beast, or ten sheep, two hundred pounds every day and night, which will be twelve hundred pounds a day and night, for six beasts, or sixty sheep; in eighty-four days, or twelve weeks, these will be fat. Then put up six other beasts, or sixty more sheep, which will fatten in the same time and manner, viz., at the end of the half year. Eighty cabbages will have been consumed daily, amounting to fourteen thousand five hundred and twenty cabbages, just the number plauted upon the acre, which, taken at fifteen pounds apiece, amounts to one hundred and eight tons eighteen hundred weight, at five score to the hundred weight; so that the feed of twelve beasts, or one hundred and twenty sheep, stands as under.

Tons. Crot.

For 84 days, or 12 weeks, 6718 cabbages, at $15 \mathrm{lbs}$. apiece, 508

\begin{tabular}{|c|c|c|c|c|c|c|c|c|c|c|}
\hline 6 84 & 6 & 12 & 66 & 6718 & 66 & b! & 66 & 66 & 66 & 50 \\
\hline $13 \frac{1}{2}$ & 66 & 2 & 6 & 1084 & " & 6 & 6 & 16 & 66 & 8 \\
\hline $181 \frac{1}{2}$ & " & 26 & "6 & 14520 & 66 & 66 & $" 6$ & 16 & 6 & 108 \\
\hline
\end{tabular}

As soon as you begin to clear off a few rows of cabbages, after the 1st of June, spread the dung and urine carefully over the ground, leaving alt the cabbage stalks, which will soon sprout again; then with a small hoe work the ground regularly over, so as to cover the manure, and sow turnip seed amongst your cabbage stalks, as you clear off the cabbages, and continue to do so till you have gone all over the ground the first time. About the 1st of November you will have another crop of leep as good at: the first; and then, as you clear off all the cabbage sprouts and turnips, you must again properly apply your manure all over the land, as before, which is now either to be ploughed or dug, and planted as at first. Thus you will have a regular successinn of good keep, and if the winter's produce be what may be expected from good management, the same acre of land will feed, in one 
year, twenty-four beasts, or two hundred and forty sheep. This, like all other crops, will, of course, vary with the season; but, if the weight here mentioned be produced, the number of cattle above stated will hardly get through it. In case of a failure, in the winter, a little hay or corn may be given to supply the deficiency."

Such is the author's account of his scheme, in his own words. It will be seen that he goes into a fraction of time, to meet the exact amonnt of keep which he proposes to obtain from the land. He proposes, as a part of his plan, to keep his beasts and sheep in movable houses or folds, so that they may be placed directly by the feed which is grown for them, and that the most careful provision should be made for the saving of all their manure.

I shall not discuss the practicableness of his plan. I have no confidence in it to the extent to which he proposes to carry it. But it shows the author's strong conviction of the alvantages of soiling, and it leads to that great question, the full answer to which has not yet been approached, What are the productive powers of an acre of land? That cabbages in the Northern United States cannot be relied upon for winter feed, except in a very limited degree, is certain; but where the plants are forwarded by artificial heat in the spring, they may be made to furnish a large amount of antumn feed, and may, in many cases, be cultivated to great advantage. Any methods by which the farmers in the old states, neal the great markets, can increase the means of enriching their lands by the growth of products to be advantageously consumed upon their farms, certainly deserve consideration. They may purchase manure in the cities; but even if the cost of the manure, at first, is small, - and in most cases it is otherwise, - yet the expense and trouble of transportation are always considerable and vexatious. Whether it shall be by the production of milk, by the fattening of swine, of sheep; or of cattle, must be determined by local and individual circumstances. The proximity to a quick market in such cases will always, in respect to many products, give the farmer in the old states, and near the large cities, peculiar advantages. I have some doubts, however, whether, for the purposes of soiling, for milk, or for fattening, any product can be found equal to that of Indian corn cut green. The cultivation of a variety of feed may be advisable, as in the event of the failure of one kind of crop vor. II. 
another kind may succeed; and that animals thrive better upon a variety of food than when confined to a single sort is a point well establin' hed.

11. $\mathbf{R}_{\text {APE. }}$ - This crop is seldom, within my observation, cultivated for seed, but as a green crop, for the purpose of feeding sheep, which are soiled or folded upon it. In some parts of the country it is sown in August, to be fed early in the ensuing spring; but it would not endure our winters. It is most generally sown in May, and at successive times, so as to provide a continuance of the feed, and comes into eating in about three months after being sown. It is sometimes sown broadcast, and left under a slovenly cultivation, to take its chance; but it is advisable to sow it in drills about twelve inches apart, and then the weeds may be extirpated, and it may be kept clean by the hoe. In such case about four pounds of seed are sown upon an acre. Sheep, being folded upon it, gain flesh rapidly; and the ground, in that case, is much enriched for a crop of wheat, or other grain, which may be sown after it is thus fed off. It must be completely fed of before it passes out of blossom. I was told, in Lincolnshire, that the ears of lambs which are thus fed upon it are often made so sore by some acrid matter which proceeds from it, as sometimes to lose their ears; but whether this was stated for the benefit of my credulity or not, I am not certain. I can only say that, if - which I am not willing to believe - it was told me with that view, the relater would himself deserve to have his own ears gently clipped. 'The ear is said to swell, ulcerate, and drop off. Another farmer, on whose opinion I place great reliance, speaks of this crop as too heating to the blood of young sheep, and advises, where they appear affected by it, to hleed them in the nose and give them salt. I always regard a preventive as much more valuable than a remedy; and confess, if such were likely to be the usual effects of feeding upon this plant, I should be very cautious in advising its cultivation. It is much grown, however, for the purpose of feed, in Yorkshire and Lincolnshire, and these objections were not frequently made to it.

When this plant is grown for seed, the yield is represented as about thirty bushels per acre; but it is then deemed a great exhauster of the soil, and will not bear a repetition under five or six years. Cole and rape, though often spoken of as the same 
thing, differ from each other - the cole growing stronger, and ripening its seed much later. When grown for seed, they are cultivated in the same manner, being sown in drills, and the plants thinned to five or six inches apart, and carefully weeded and hoed. The production of seed from cole is more than from rape. When fed upon the land by sheep folded upon them, they enrich the land; but in leases a clause is often inserted forbidding their cultivation for seed, because of their exhaustion of the soil.

In passing through Lincolnshire, I could not help admiring the sagacity of a dog whose business it was, in the character of a rural police-officer, to keep a flock of sheep upon a field of rape, and away from an adjoining field of turnips. I do not know that this sagacity would have been increased had he been withont his posterior appendage, and stood upon two legs instead of four. The learned author of the "Vestiges of Creation" would probably have pronounced him far advanced in the transition state.

12. Mustand. - I found mustard cultivated in some parts of the country, but not to a large extent for the seed. It may be sown either broadcast or in drills, and is gathered by being shaken by hand into a sheet in the field. A good crop is estimated at twenty-eight bushels per acre. A strong prejudice exists against the black mustard, as the seeds remain a long time in the ground, and are with difficulty eradicated. In many leases the cultivation of it is forbidden.

The white mustard is not liable to the same objection; and this is often cultivated for the purpose of folding sheep upon it, and is said to yield a better crop than rape for this purpose. It has been sown in May, and eaten off in July; it has been sown after a crop of oats, and eaten off in October. In all these cases, when fed on the ground or ploughed in, it has proved a great enricher of the land. The amount of seed sown has varied from seven pounds to sixteen pounds per acre. It is recommended by some farmers for folding ewe sheep upou, in autumn, as indirectly assisting the increase of the flock. Neither of these crops requires very high manuring; and they are often grown, with tolerable success, upon land of moderate fertility, never contravening, however, the inviolable rule, that fire is not to be made without fuel, and that good land, good cultivation, and good manuring, are the only certain foundation for expecting good crops of any kind. 
13. Chiccorr. - Chiccory is cultivated in some parts of the country. It was first introduced as feed for cattle and sheep, its leaves being abundant, and very succulent. It could, for such purpose, be cut once the first year, and four or five times a season, after it became established. It was not, however, found superior, as green feed, to other plants cultivated for this purpose, and it was thonght to give an unpleasant taste to the milk and butter. It is now, however, cultivated almost exclusively for the roots, which are used for the adulteration of coffee, and many persons think with advantage. I am not of that number. The land on which it is to be cultivated must be rich and highly manured, as it is important, where the roots are to be used for this purpose, that they should be forced as much as possible the first season, as they become too old and hard in the second year. Chiccory is to be sown in April, like carrots, in drills, kept clear of weeds, and the plants thinned out to a distance of six inches in the rows. In September, the leaves are taken off, and the plants dug with a fork; they are then washed and split by hand, and kiln-dried, and sold to other factors, who cause them to be burnt and ground like coffee, which, in that case, they entirely resemble. They greatly deepen the color of the liquid, when prepared as coffee; and, when mixed in the proportion of a fifth, they communicate no unpleasant taste. Chiccory is deemed very exhausting to the soil, and liquid manure is applied to it, while growing, with great advantage.

The cultivation of woad was pursued to a considerable extent in the same neighborhood; but as this, together with madder, will come more fully under view in my observations on continental husbandry, I for the present pass them over.

14. LuCErn. - This plant is cultivated to some extent for the purpose of soiling, and indeed could not be expected to be cultivated as a field crop. It is undoubtedly a much superior forage to vetches or tares, and is more productive than clover, not yielding more weight at a single cutting, but growing much fuster, and therefore may be cut more frequently. But it is far less cultivated than either vetches or clover, perhaps for the reasons that lucern, though it will bear it even the first year, does not come into a perfect state for cutting until the third year; that it 
equires a good deal of labor at first in keeping down the weeds; ad that it does not take its place in any rotation of crops, it seing expected to occupy the ground for a length of years, where it is once planted.

All agree that it affords a most excellent feed for horses or miich cows; and it is advised that, after being cut, it should be kept over a day before it is given to cattle, as, in that case, it will undergo a degree of fermentation, which will prevent its being injurious to them. The yield of an acre of good lucern, it is said, will fully keep four horses from May to October. The time for cutting it is when it is in flower; and, though it is almost always given green, yet it makes excellent fodder when converted into hay. Some persons advise that the first cutting should be before the plant comes into flower, believing the succeeding crops will be more vigorous for this early cutting. It is commonly believed that a plant is more nutritious when in flower than at any previous stage of its growth; though this conclusion is not conformable to some of the deductions of Sinclair, in his experiments upon grasses at Woburn.

It requires a deep, rich, and dry soil, as it sends down its taproot far into the ground, and in time of drought draws moisture from a great depth, which keeps it in a green state when most grasses fade and are burnt up. The ground should be deeply ploughed, or, better, should be spaded or trenched, and thoroughly drained, as a clayey, wet, or retentive soil is unfavorable to it. Great pains must be taken to keep it clean from weeds.

It is cultivated in two ways - either by being sown broadcast, in which case, where it is kept thoroughly clean from weeds for two or three years, it will acquire such a hold as to dispossess the weeds, but will be benefited by being rather heavily harrowed in the spring; or it may be sown in drills about twenty inches apart; in that case, it may be cleaned by a horse hoe or scufller, and be effectually protected from other plants or weeds. IVhen sown broadcast, it is advised to sow about sixteen punds of seed to an acre, and this may be sown with barley or rye; but when sown in drills, ten pounds of seed are deemed sufficient. 'The broadeast method is likely to give the best crops.

It is said that it will not endure severe frosts, and consequently is not suited to a cold climate; but I have known it cultivated successfully for many years by the late excellent "farmer's 
friend," John Lowell, Esq., near Boston. The great impedıment generally found to its cultivation is the difficulty of keeping it from weeds; but the sowing it in drills will give an advantage in this matter. I have no means of comparing it, in point of value or product, with the Italian rye grass, of which I have given an account; but its reputation has long been established as one of the most valuable plants which can be cultivated for the purposes of soiling. It may be expected to last for eight years, and some persons assert a longer period, and will be benefited by occasional top dressings.

Lucern has been cultivated, with great snccess, by a farmer of the name of Rodwell, whose account I think will be read with interest.

"My growth of lucern this year, (1841,) in a field of eight acres of sandy soil, with a dry, sandy loam for its subsoil, being the third year's growth, (the seed having been sown, twenty pounds per acre, 1838, by a Bennet's seed-engine, with a crop of barley,) produced me, in its first mowing, (which commenced May 24th,) six weeks' entire support for thirty horses, keeping them in good condition and good health, while in constant employment. The second mowing, begun July $3 \mathrm{~d}$, fed me twenty horses for six weeks; and the third, begun September 15th, supported thirteen horses fourteen days; after which, the autumnal feeding with sheep was equivalent in value to the expenses of cleaning, \&c., in the previous spring, which was effected by the extensive use of the Finlayson harrow - a process necessary every second or third year, if upon soils inclined to grass. The only manure used upon this crop has been soot, at about thirty bushels per acre, applied twice since the sowing in 1838." *

15. Sainforn. - This plant is cultivated in localities where a chalk or calcarcous soil prevails, both for soiling and pasturage. It is sometimes, likewise, made into hay, and forms excellent fodder. It is universally understood that a calcareous or limestone soil is most congenial to its growth, and one must hesitate in distrusting the lessons of experience; but the hest crop which I have seen of it - and an admirable crop it was - I found upon an

* Journal of Royal Agricultural Society, vol. iii. p. 238. 
extremely rich loam, which, from its high cultivation, might be called a vegetable garden mould, and to which no lime had been applied, and none certainly was apparent.

It is a highly-productive plant, with small, pointed leaves, rather coarse branches and stem, and bearing a small blue flower. It may be cut twice in a season, and then fed, and will yield, under good cultivation, from one and a half to two tons of dried fodder to an acre; but it is not so productive as lucem. It is not so apt to become heated as clover, not being as succulent: it will grow where clover will not grow; and drawing its nourishment from a greater depth, it is less liable to suffer from drought. It may be cut, and afterwards fed off by sheep the first year of its growth; but it is not in the best condition for mowing until about the third year after planting, and then it will continue for eight or ten years. I have said one of its principal uses is for soiling, and for this it is much esteemed. 'Though it may not be so valuable as lucern, clover, Italian rye grass, or Indian corn, where the latter can be grown, yet there is an obvious advantage in a variety of food; it is more agreeable to the animals themsclves, and some plants will flourish in some seasons, and some soils, in which others would fail. I have seen it cultivated in New England in one case only, and that not with much success; the winter was deemed too severe for it.

The amount of seed sown to an acre is four bushels in the chaff; and it may be sown with barley, or alone. The seed is of very uncertain quality, and should be tried in a pot. Sainfoin is a great exhanster of the soil, when suffered to ripen its seed.

Lord Essex gives an account of curing a crop of sainfoin, which was cut on Monday and Tuesday of the last week in June, when in full flower. It was once turned on Wednesday, and carried and stacked on Thursday and Friday. The weather was dry and hot, but the hay was still so green, that much moisture exuded upon pressure. It was staclied with altemate layers of oat straw. It came ont in the finest condition, and the interleaved straw was much improved. It is well known that, with us, clover is often cut in the morning, turned once merely, in a hot sum, and then packed away, the different lajers being well salted, at the rate of more than a peck of salt to the load. In this way, where the moisture proceeds from the sap, and not 
from rain coming upon it, I have known it effectually preserved and furnishing an excellent fodder.

There are different kinds of sainfoin, some of them distin guished from others by a greater earliness. I saw, in the same. field, side by side, and where both kinds had been once mown at the same time, a second crop coming on, where, in one case, the plant was in full flower, and, in the adjoining land, the plants showed no signs of flowering. I know no means of distinguishing one from the other in such a case, but by actual trial. The farmers who cultivate this crop successfully esteem it very highly. The Messrs. Lawson, of Edinburgh, speak of having, in 1833, introduced from France the double yielding sainfoin, - a very luxuriant growing variety; but $I$ have not seen it.

16. Crimson Crover, (Trifolium Incarnatum.) - This is an annual plant, presenting, in its blossoming, a beautiful crimson flower in the shape of a cone. It is a very productive plant, and is principally valuable as green feed; made into hay, it is deemed superior to the common clovers. Here it is sometimes sown upon a wheat or grain stubble, the stubble being simply harrowed, and the seed sown; and it is then bush-harrowed and rolled. This gives a good crop for green feed the ensuing spring. It is said to be a fortnight earlier than lucern. Few things in the vegetable world present a richer appearance than a field of crimson clover in full flower. It is sometimes drilled at the distance of eight inches in the rows. The quantity of seed is from eighteen to twenty pounds to an acre when sown broadcast ; less would be required when drilled. Its chief value is its quick return; as, when sown in autumn, it may be mowed so early the next season, as to leave a favorable opportunity for fallowing the land for wheat. In this respect, however, I cannot perceive that it has any advantage over our common June clover . and I should hare great distrust of its endurance under the severe frosts of New England. I have tried it myself upon a smal scale, but then it was sown early in the spring.

17. Winn, Furze, on Gonse, (Ulex Europaus.) - This is a coarse, evergreen, prickly shrub, growing, in many cases, to a height of some feet, propagating itself, and spreading over large 
extents of ground which are lcft uncultivated, or kept merely as preserves for game. It is singularly productive; it requires to be gathered only as it is wanted to be used; and, when bruised, it furnishes a most nutritious food. I shall give the directions of one farmer in Worcestershire, who finds his account in cultivating it pretty largely, and whose excellent farming I had the pleasure of inspecting.

It is used more extensively in Wales than in any other part of the kingdom. It proves excellent food for horses and cows. I have not learned that it has been used for sheep. The yield of it is represented, even under unfavorable circumstances, to be from eight to twelve tons, per acre, of green feed, and where the soil is favorable, double that quantity. It may be cut in a year after being sown; but it is deemed advisable not to commence cutting it until it is two years old; and then it may be cut every year, and requires no manuring. Some prefer that it should be cropped not oftener than once in two years; but in that case, the plant becomes woody and hard, and is with difficnlty ent by a seythe.

There are two kinds of gorse; but that which is called the French gorse, is much preferred; the other lind, being shorter, browner, and much less succulent, is used only in times of extreme scarcity. It is advised to be sown in March or April, and either broadcast, or drilled at a distance in the rows of from eighteen to twenty-four inches. When sown on a side-hill, the rows should be made oblique, ratiner than directly up and down the hill. The young plants should be kept carefully wecded, as weeds and couch grass are the great enemies to the successful cultivation of the plant; and they should be protected from cattle. Sand, lime, ashes, and cinders, are applied as manure to the plant; but it grows well without manure. The intelligent farmer, in Worcestershire, whose farm I had the pleasure of inspecting, - Richard Spooner, Lisq., M. P., - grows it upon an old woodland, cleared mp, the soil of which is partly a burning gravel, partly a strong clay, but very dry at bottom, and hilly. The product of half an acre of this land is, on an average, sufficient to keep a cow twenty weeks. On rich, loamy, dry land, he informed me that, in his opinion, donble the quantity might be grown. He has now been in the habit of using it more than twenty years. 
He sows it as he would clover seed, with a crop of barley or oats, and it is fit to cut the November twelve months after suwing. He mows it afterwards, every year during the winter, as wanted, with a common scythe, close to the ground. On good, dry land, he cuts from seven to ten tons per acre. His principal use of it is for his cows; three bushels and a half per day is sufficient for a cow.

It is first cut through a common chaff-cutter, and then bruised in a mill similar to a cider-mill for grinding apples, the revolving fitted wheels, or nuts, being of iron. He has four-and-twenty cows in one house. Besides the gorse, they are allowed nne hundred weight of hay among the whole, - being about four and a half pounds of hay to each cow, - and eight bushels of Swedish turnips, or about twenty pounds of Swedish turnips, to each cow per day. On this, dairy cows are kept in excellent condition, and the butter is remarkably good; fattening-cows on the same allowance will fatten fast. When Swedes are scarce, he substitutes about four pounds of oil cake, per day, to each cow ; and as the fattening-cows get forward, he increases the quantity of oil cake gradually, never, however, exceeding twelve pounds of oil cake, per day, to cows of a large size, and that only for the last month. He advises that the gorse should be well ground, and salt mixed with it, at the rate of four ounces, each cow, per day.

In the communication with which he has favored me, he adds, that "it requires no manure, but in its consumption creates a great deal. It will grow on poor, hilly land, if dry, which will not pay for cultivating. When once sown, and well rooted, it yields a great quantity of food for cattle, at a small expense." He has cut over the same ground now for many years. He mows it as soon as the grass feed ceases, and it lasts until the grass comes again. If there is an appearance of snow, he mows a considerable quantity beforehand, and it will keep, laid loosely down in the yard; but it must be bruised as it is wanted, for it will not keep after being bruised, not even over night.

Furze is prepared, in some cases, by being cut in a common chaff-machine, and then passed through two revolving and matched cylinders of iron, like the nuts of a cider-mill; or it is cut, and then laid upon the ground, and rolled by a stone whecl with a broad, flat rim, somewhat resembling the whecl employed by tamers for crushing or grinding their bark. In some cases, two 
such wheels are fixed to the same axle, which, of course, expedites the work, and both are carried round by a horse or donkey.

An Irish farmer describes his mode of feeding with gorse as follows: "Horses eat it with great avidity, and thrive well on it. I give each working horse a bucket of prepared gorse in the morning, before going out; at dinner time, a feed of boiled potatoes; and at night, two baskets of gorse; neither hay nor oats. Cow-feeding is different; at daylight in the morning, the cattle are driven from their stalls to water - if possible, a running stream. Gorse, if crushed over night, and allowed to lie in a heap, would ferment before morning; the cattle are, therefore, supplied with a feed of mangel-wurzel, while the gorse is undergoing preparation. After breakfast, (ten o'clock, ) they get a feed of gorse - as much as they will eat, (should any remain in the trough, it is taken away;) another feed at two o'clock; at four, are again driven to water; and at six, get a large feed to last all night. Cattle will not eat so large a bulk of gorse as of other food, it being so rich that a less quantity suffices. Gorse, after being once established, requires neither tillagre, manuring, nor weeding, producing the most nutritious food without imparting any unpleasant flavor to the milk, which is rich and creamy. Twenty acres of gorse would support one hundred head of cattle, for the winter six months, without any other feed, save the morning feed of mangel-wurzel, turnips, or potatoes." *

Three modes of sowing it are prescribed - the first, that of sowing it broadcast, when, by some cultivators, seven or eight, by others, twenty pounds of seed are advised to be used. Others recommend to sow it in drills, eighteen to twenty-four inches apart, when, of course, a much less quantity of seed will suffice. Others advise to sow it first in a seed bed, and transplant it, making the drills as above, and setting the plants six inches asunder in the drills. As the seed is a long time in germinating, and much, on this account, is liable to be lost, it is advised to soak the seed four or five days before sowing, and then let it remain a week or more in a heap, being careful to turn it frequently, to prevent fermentation. The transplanting must be as early as practicable, that the plants may get a sure footing for

* Journal of Royal Agricultural Society, vol. vi. part 11, p. 536. 
the winter. Four pounds of seed will be sufficient to supply plants for transplanting.

Having seen the value of this plant, for feeding purposes, on the well-managed farm to which I have referred, I have gone thus at large into its cultivation, believing that the account would be interesting to my American friends. How far its cultivation can be recommended in the United States, experience only can decide. Our severe winters, and deep snows, would be much against it in the Northern States; but there are localities in which, undoubtedly, its cultivation would be beneficial. The obtaining a green succulent feed for our steck in winter, woulc be a most valuable acquisition. The labor required to prepare i would prove a serious objection in a country where labor is difficuls to be procured, and where the almost universal practice is hurry and despatch, and things are but too often only half done.

18. Clovers and Grasses. - The introduction of cultivated grasses, though not recent, is, properly speaking, an improvement of modern husbandry. In British agriculture, various kinds have been introduced; but I shall speak of those which arthe most prominent. For the great mass of my readers, botanica?

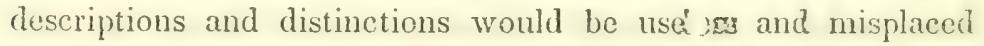
and I shall, therefore, refer to these grasses in terms which are familiar.

In the cultivation of them, two courses are pursued - the one, that of laying down land to permanent pasture or meadow; the other, that of giving them their place for one, two, or three years in a regular rotation. The subject of breaking up permainent pasture, or long-established mowing fields, has been much discussed and controverted; and the decision of the question will depend on many cualifications. The English are strongly opposeci to the breaking up of such lands; the Scotch keep very little land, which is ciprable of being brought under the plough, in permanent grass. Undonhtedly, the largest profit might be obtaineci from breaking up the land, and letting it take its place in the regular course of crops ; but the difficulty to be contended with, where it is to be brought back into permanent pasture or mowing, is that of getting again a firm and substantial sward. 'T'his is not so difficult as is supposed; for I have often seen, where the land is well cultivated, and not too severely cropped, and is laid 
:10wn with a sufficient quantity and variety of seeds, a sward produced by the second year sufficiently compact and strong. One great advantage which would arise from cultivating lands in grass would be, to use up as manure the roots, fragments, and remaius, of tie grass sward, which have been some time accumulating, and which are in themselves the natural means of enriching the land. The produce of such land in grass is generally much inferior in value to what it would be in a regular rotation. Where, however, it lies in the immediate neighborhood of large cities, from which plenty of manure for top-dressing can be procured, at a reasonable expense, the breaking it up might, with much more reason, be objected to. It may be said, likewise, excepting where it is grown for the market, that hay is in much less request in England than with us. Here turnips or other succulent food is in abundance; chopped straw is substituted for hay; and cattle are fatted, and horses maintained, wholly upon turnips and straw. The system pursued on the model farm of Lord Ducie, in Gloucesterșire, is, to have no land in permanent grass, but to bring every portion of the farm under an established rotation of cropping. The same system is pursued in those districts of what may well be called model farming, the comnty of Northumberland, on the border, and the Lothians, in Scotland.

The expediency of breaking up grass or pasture lands, and converting them into arable land, can only be determined by va. rious considerations, and many of them of a local nature. Many of the lands in England, now devoted to the pasturage of sheep, and yielding a very scanty herbage, the soil being very thin, upon a stratum of chalk, and the aspect exposed, would, if brokeu up, produce very scanty crops; and it would require many years to restore them again as pasture lands. There are other lauds, too, of a sandy character, now yielding in pasture very little feed, which would scarcely repay the cultivation, and perhaps be even more impoverished by it. The dairy farmers, too, are generally persuaded - perhips a mere prejudice - that good cheese can be made only from old pasture that has been for years undisturbed. Nor ean it be safely recommended to break up grass land now yielding a tolerable crop of hay, muless the farmer has the determination and means of improving it by thorough-draining and manuring, lest it should be left in a much worse state vor. II. 
than he found it. Indeed, it will be found, in many cases, ar enterprise, of which the result, though often beneficial, may disappoint the farmer, and which is not to be entered upon without judgment and practical skill, and a calculation of the resources within reach for ameliorating the land, and increasing its productiveress.

In laying down lands to permanent grass, it is advised to sow large quantities of seed, - from thirty to forty pounds, - and those of a great variety. In the rotation, the principal plants cultivated are the clovers, and the rye and orchard grass, or cocksfoot.

What is called the cow-clover is a permanent variety, and valued more for being fed or depastured, than for being made into hay. The common red clover, well known in the United States, is that which is cultivated in the rotation. 'This is a biennial; and it is, in general, advised to feed it the first year, and to mow it for hay the second year. I have never seen it so large in England as I have seen it at home, which I am inclined to believe arises from their sowing a much greater quantity of seed to the acre than we are accustomed to sow. The quality of the hay is certainly much better, where it is smaller and finer, than with us. T'wo kinds appear to be cultivated here, as with us the one resembling what is called our northern clover, a coarse and large variety, and the other, what is called our southern or June clover, a fine variety, and well known and valued by our Connecticut River farmers. I have already spoken of the French red or crimson clover, (trifolium incarnatum.) The yellow clover is not valued, though sometimes sown in a mixture of grasses. The Dutch clover is greatly esteemed for pasturage, and, in favorable situations, produces the richest feed possible. The white clover, though excellent as a variety, is not considered the most valuable as a pasture grass; and an objection is made to it, where it too much abounds, that it is apt most severely to scour the cattle.

The making of clover hay, in a climate so variable, or rather so certain, ordinarily, to abound in moisture, requires skill and care. It is never tossed about and spread, but simply turned, and made up, first into small handfuls, and afterwards into cocks; and it sometimes receives many heavy rains without being as much damaged as we should suppose. The low temperature prevents the fermentation which would be likely to take place 
with us. The cocks, or bunches, are never spread or scattered, but simnly turued; and the greatest care is taken that it be not packed arry in the stack when wet. It is often in the stack interleaved with straw, which is supposed to answer the double purpose, that of saving the clover from heat and mould, and that of improving the straw for cattle feed, as in this way it imbibes the odor, and perhaps some of the nutritious qualities, of the clover. It was matter of surprise to some farmers, when I informed them, as I have already remarked, that clover hay, with us, was sometimes mowed in the morning, and carried into the barn in the evening of the same day; there, being salted when stowed away, with about a peck of salt to a ton, it has kept pertectly well, and come out in the spring, green and bright, without mould or smoke. The climate of England would hardly admit of this; and the making of hay, especially in Scotland, is a long process, the haying being often delayed by repeated rains. The hay, in general, on these accounts, seems to me much inferior to the hay with us; but I was surprised to find it so very ruch better, even after repeated wettings and dryings, than I supposed it could possibly be.

Hay, in England, is scarcely ever put in barus. It keeps well in stacks, made up as they are in the neatest manner, and carefully thatched with straw. Nothing can be more beautiful and workmanlike than the manner in which these are made up; and for hay, the long stacks are decidedly preferable to those of a round form, as it is cut down for use, in such case, to more advantage. The formation of a stack, which is often done by women, is a work of much skill, which is the fruit only of practice; the thatching of a stack in the best manner requires both art and experience, and there are men who make it a profession. When well executed, the hay remains for years impervious to wet. During the formation of the stack, - which, when intended to be large, must sometimes wait for several days the progress of the hay-making, - the most careful farmers have a large tarpaulin or canvass covering, to suspend upon poles over the stack, in order to protect it from rain. I refer to these minute curcumstances, to illustrate the extreme carefulness with which many of the operations of hushandry are here conducted. When the hay is to be used, a whole stack is never removed to the stables at once, but it is carefully cut down as a loaf of bread 
might be cut, and always done up and bound in trusses, intended to be of fifty-six pounds each,* and in that way carried to be distributed to the animals. This requires some extra labor; but the farmers find their account in it. How different this is from the careless and wasteful manner in which things are managed with us, where I have often seen horses and oxen standing knee deep in litter of the very best hay, which has fallen and been tossed out of the mangers! 'The consequence of this extraordinary painstaking is, the most economical management of their products. 'The animals have a regular allowance, and are not at one time surfeited, and at another time starved; and not a handful of hay is wasted. I have never been quite able to understand the old proverb, that "a penny saved is twopence earned;" but I quite understand the folly of wasting that which is the product of severe toil and expense, and the immorality of throwing away that which the bounty of Heaven bestows for the comfort and sustenance of man or beast. I once heard a minister say, in his sermon, that some persons were charitable in spots; I think, in a similar sense, it may be said that some persons are economical in spots, and that many persons, who will chaffer and haggle half a day to save a sixpence in the price of an article, will often throw away shillings in their neglectful or wasteful use of it.

The difficulties arising from the humidity of the climate, which the farmers in the north and on the western side of the island have to contend with in curing their hay, are such as to call forth all their energy, patience, and perseverance. I shall best illustrate this by giving an extract from a letter with which I have been favored by the Messrs. Drummond, of Stirling; Scotland, the enterprising founders of an Agricultural Museum, embracing specimens of soils, products, seeds, implements, machines, \&c. \&c., of an almost endless variety, and the inspection of which is full of instruction, and quite worth a journey of hundreds of miles.

"Rye Grass, or Timothy Hay. - For several seasons we have practised a very simple and satisfactory method, which enables us to make hay, not only while the sun shines, but while the rain falls, provided the 'weather be at all breezy.

* Trusses of hay, in Smithfield market, are expected to weigh sixty pounds in the early part of the season, and fifty-six pounds after Christmaz. 
"The mowers are followed by women, who take the newlycut swath up in regular small sheaves or handfuls, tying them near the top, which is done quickly by a few stalks of the grass. The handful is then held near the top, raised a few feet from the ground, and by giving it a quick motion downwards, the resistance of the air expands the bottom, so as to give it a firm position on the ground, thus: form that the rain, as it falls, while the inside is liept perThe process of hay-making ruption, and on the ontside

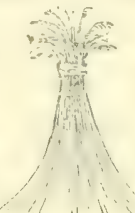

It will be seen from the must run quickly off", fectly dry and airy. then sulfers no interonly during the show ors.

"These small sheaves are very soon, without further trouble, ready for being put together in small cocks, keeping all the root ends outwards, and placing one on the top to throw off the wet. In this way, the lower ends are dried, and the whole, without ruming the smallest risk of spoiling, is soon ready for stacking."

The grass from which it is intended to save the seed, is always done up in sheaves like grain, and remains in small stacks, or, as they are sometimes called, shocks, until it is ready to be threshed.

19. Rye Grass. - The next grass most cultivated here is the rye grass. Of this there are two prominent kinds, the common, (lolium perenne,) and the Italian, (lolium Italicum.) Of the former kind there are several varieties, distinguished mainly by the length of their endurance in the soil, some lasting only for a year, others three or four years, and some producing much more herbage than others. 'The common rye grass has, in my opinion, no advantage over our timothy or herds grass, either in its productiveness, or the quality of the hay. Of the Italian rye grass I have already spoken much at large. It is in high repute, and is invaluable for the alternate husbandry. "Its limited duration, also," says Mr. Lawson, "fits it well for sowing in mixture with the other sorts, intended for permanent pasture, as it dies out, and gives place to the weak and slow-maturing perennial sorts, which are destined ultimately to fill the ground." **

* "In respect to duration it may be termed a sub-perennial, beyond which title even the most permanent varieties of lolinm perenne have no claim. In most cases, two seasons of Italian rye grass are all that can with certainty be depended 
The experiments of Mr. Dickinson, already very fully detailed, would seem to show that he has fallen upon a most valuable variety; and its superiority, to my mind, was decidedly indicated by a comparison of several specimens growing side by side with it in his grounds. The care with which he is saving the seed, and the great demand for it, promise an extended diffusion. It is believed by many that the saving of seed from crops, the first year of their being sown, has induced the habit of an annual upon the plant; and there is reason to think that much has been, and more may still be, dore for the improvement of this, as of other plants, by a careful selection of individual plants which indicate, either greater productiveness, or earlier maturity, or any other valuable property.*

\section{Orchard Grass, or Соскsfoot, (Dactylis Glomerata.) -} 'The next grass much cultivated, and most esteemed, is the orchard grass, or cocksfoot. 'This grass is well known in the United States, having, it is said, been in the first place imported into England from the United States. It is a very quick grower, and makes most excellent feed and hay. The only objection to it is its disposition to grow in patches, which is, in a degree, prevented by its being frequently mown. A new kind of orchard grass has been introduced, which, for its size and prolificness, has been denominated the giant cocksfoot, and has been much commended; but it has not fallen under my observation.

21. Bohmara, on Tree Clover. - The Bokhara or tree clover, it may be expected that I should allude to, from the celebrity which was at one time given to it. I have seen it cul-

on, and, in very wet, cold, spongy soils, it will often exhibit a thin stock the second season. Instances have occurred in which as many as five, or cven six successive years' produce have been reaped from the same field; but this has arisen more from the ground having been resown in the course of reaping the seed, than from the actual duration of the original plants; the steds being remarkably-easily separated from the hay, even though not perfectly ripe, which will always render the harvesting of them an operation attended with considerable care and difficulty." - Laneson.

* "Like all other plants subjected to artificial culture," say the Messrs. Lawson, "the Italian rye grass is productive of numerous sub-varieties, as a proof" of which, we received, in 1838 , specimens of no less than fifty distinct spikes, collected in a field near North Berwick." 
tivated in small patches, merely as an experiment; but it seems to be too woody for feed. Indeed, a stalk of it was shown to me, with a silver head and ferule to it, which made quite a substantial cane, and might have been cousidered much rather as the imb or sprout of a tree, than a stem of grass.

There are many other varieties of grass, which are sown, in some cases, for the sake of the variety. Where land is to be laid down to permanent pasture, undoubtedly variety is to be recommended, as most conformable to the system of nature, - which on uncultivated and wild lands, as on the western prairies, for example, seems to multiply varieties almost without limit, - and likewise as adapted in their different natures to different soils and circumstances of climate and aspect. It can scarcely be expected that I should proceed further in the enumeration. The English are remarkably fond of a close turf, and the compactness of the turf in their lawns, and parks, and pleasure grounds, resembling more than any thing else the close texture of velvet, or a Turkey carpet, is always observed; but in order to produce this, it requires that the ground should be filled with a great variety of seeds.

22. Rib Grass, or Plantain. - I have observed, in many fields, the narrow-leaved plantain, or ribbed grass, cultivated for herbage. It produces its leaves early, and is relished by cattle; horses, and sheep; but I confess I was not favorably impressed with it, as it spreads much upon the ground, and exclusively occupies a space which, with other plants, would certainly have produced a much larger amount of feed. The common parsley, likewise, is frequently sown with other grasses, at the rate of one pound of seed to an acre. It is eaten by cattle and sheep, and is supposed to be a remedy against the liver rot in sheep. Its habits are biemial, but it will in general perpetuate itself by its own seeds.

23. Red Top, Herds-Grass. - That most valuable grass, among us known as the red top, (agrostis vulgaris,) the improved variety of which is the Rhode Island red top, I have not seen cultivated in Fngland; and timothy or herds grass (phleum pratense) is grown, within my observation, to a very small extent. In my opinion, it would be extremely well adapted to 
many of their heavy soils, and be found a most profitable grass. I have known, repeatedly, an average yield of more than three tons of this grass to an acre, in well cured hay, in my own country; and, in one case, more than twenty-nine tons, actually weighed, of well-cured hay; principally of herds grass, obtained from six statute acres of land. In Sinclair's scientific table * of the nutritive value of different grasses, he states that the greatest quantity of nutriment in 'Timothy is found when the plant is perfectly ripe; but the cattle greatly prefer it, when it is cut and cured in the flower; and I am inclined to pay some respect to the decision of judges who seem of right to claim to be competent.

24. Millet. - I have not seen the millet grass (millium effusum) cultivated in England, though ,it might be, in my opinion, to the greatest advantage. I have obtained three tons to an acre, of as good and nutritious hay as can be grown, from this grass; sown in May. I presented some seed to the Royal Agricultural Society, but I have never yet learned its fate; and my principal object, in referring to it is, that I may commend its cultivation.

25. Sowing Grass Seed. - The clovers, are, of course, always sown in the spring, upon the grain. The other grasses are sown very frequently in the autumn, but more often, perhaps, in the spring, with a spring crop of oats or barley, the latter crop being generally preferred in the case, as tending to keep the land more open.

The quantity of seed to be sown to an acre differs very much with different individuals. At Teddesley Park, Staffordshire: where one hundred acres are annually sown with Italian rye grass, three bushels per acre are sown with some clover. Where land is laid down to be kept in grass four or five years, the following proportions of different grasses are prescribed: red clover, $t$ welve pounds; trefoil, four pounds; white, six pounds; rib grass, or narrow-leaved plantain, two pounds; and two pecks of perennial rye grass. I feel a good deal of diffidence in giving these quantities, as the practice of different farmers is so various.

* IIortus Gramineus Woburnensis. 
Wome recommend as much as twenty pounds of each of the red, white, and yellow clovers, with half that weight of rib grass, and three bushels of rye grass, per acre. This, of course, involves a large expense.

One of the most eminent farmers in the kingdom, whose farming seemed to me to combine, in as high a degree as I have any where seen, experience, intelligent observation, and practical skill, Mr. Stirling, of Glenbervie. Stirlingshire, gave me the subjoined list and quantities, as his rule, where land was to be laid down to permanent pasture: nine pounds of fox-tail; two and a half pounds of cock's-foot; three and a half pounds of meadow sescue; four and a half pounds of hard fescue; four and a half nounds of Italian rye grass; three pounds of red clover; four pounds of yellow clover; four pounds of white clover; eight pounds of timothy; two pounds of rib grass; one pound of yarrow. He says that, after repeated trials, he has found this mixture to answer better than any other. He sows red clover, and Italian rye grass, though shortlived grasses, for permanent pasture, because, he says, it is too expensive to sred the land, for the first year; with the perennial grasses, which shecp prefer, and because, in consequence, it carries more stock, and he has better pasture the following year. He is of opinion, that all grasses grow better when red clover is sown among them. The Italian rye grass gives the earliest bite, and helps to occupy the space, which would otherwise be filled with daisies and other weeds. He sows yellow clover, which is not, in general, a favorite grass, because, upon trial, when lie sowed a field of grass, one half mixed with yellow clover and the other with white, the sheep preferred that which was sown with yellow. Fol neat cattle, he says, he should recommend the perennial rye grass, in addition; and he should, for milch cows, omit the yarrow, as, in excess, it imparts a disagreeable flavor to the butter. Mr. Stirling has made some valuable experiments in regard to the depth at which grass seeds should be sown, the results of which I had the pleasure to witness. The difference, in the same field, where the grass seeds were scarcely covered, and where they were harrowed in, was quite obrious, and decidedly against corering them deeply. He says that "a quarter of an inch is too deep for the poa nemoralis, (wood-meadow grass,) and timothy, as they grow more freely when scarcely covered." He 
adds that "grass seeds, in general, are most vigorous at three quarters of an inch deep, with the exception of cock's-foot, rib grass, and red clover." He would recommend, he says, to all who wish to avoid disappointment, to prove all their grass, clover, and turnip seed, before using, by sowing a small weight in a pot, and placing it in a warm situation, and counting the plants which come up; and they will find that a bushel of rye grass seed, weighing twenty-eight or thirty pounds, may be cheaper than one weighing eighteen or twenty pounds; though the price be considerably more.

26. Hops. - The next great article of cultivation to which I shall refer is that of hops. In 1804, the extent of ground devoted to the cultivation of hops amounted to thirty-five thousand acres; and it is at the present time supposed to have greatly increased. In the county of Kent, which is the part of England in which the hop is most extensively cultivated, - said, indeed, to embrace half the land in hops in the kingdom, - the number of acres exceeded iwenty-two thousand. From the immense quantities of beer consumed in England, it is obvious that the demand for hops and barley must be very great. Hops are used in beer for two purposes; - first, to correct the excessive sweetness of the malt, and to give it a pleasant flavor; and second to preserve it sound.

The hop cultivation is managed with great skill in Kent, and in parts of Surrey, where I have had the pleasure of seeing it in its perfection. One individual had one hundred and fifty acres in hops. The ground for hops should be a rich and mellow soil ; and, in general, the farmers are of opinion, that, in order to produce the best quality of hops, the substratum of the soil should be calcareous. That the plant requires a deep culture is evident from the roots having been traced to a distance of twenty feet. The land requires to be trench-ploughed, or spaded to the depth of two spits. The former mode is the least expensive at first; the latter mode will prove the most eligible in the end. The ground, indeed, should be subjected to the best garden cultivation.

The hills are to be marked out in right lines, at a distance of six or eight feet apart. The spot which is to receive the plants should be rendered as mellow and rich as may be, by careful 
3igging. Three $\alpha$ four plants may be placed in a hill. These may be procured from the clippings of the vines, in March; or from what gardeners call layers; or from seed. The latter mode is considered preferable. In hops, the male and female plant are distiuct; but many cultivators reject and extirpate the former as barren. It is necessary that they should grow together - that is, a due proportion of the male plants should be cultivated in order to give "that energy and vitality to the seed without which it would not produce its kind. This it is which gives weight to the hop, which gives the fine aromatic bitter to the production of the vine, and more fully to the seed; - the petal or leaf of the flower containing but little of the astringent quality of the hop. Cultivators of the hop are urged, therefore, to have many male plants on the ground, at least, one to fifty female plants, and 'particularly to encourage them around their plantation, in the hedges, where no ground will be lost.'

"The hop plants raised from seed surpass those which have been raised from cuttings, their luxuriant growth enabling them to withstand the effects of blight. They are found to have a seed at the bottom of every petal of the flower, of a most pungent aromatic flavor; while those hops grown in the usual way, without the necessary quantity of male plants, have scarcely any seed, and they are mostly abortive. In fact, seed gives weight and flavor to the hop, and constitutes the vitality of the plant, or the condition or strength of the hop; and where there is the most seed, there will be the most condition. We therefore say that the grand object in hop-growing should be to get as much seed as possible." * These are the important suggestions of an experienced and competent cultivator.

* "The weight of hop leaves, without the seed, having been accurately ascertained, those grown at Lewisham, being the fourth year from the sowing of the seed, and having a male plant close to them, weighed at the rate of thirty-six pounds per bushel; and the same quantity (by old measure) from Shoreham, raised fiom cuttings, and grown near male plants, weighed at the rate of thirtyfive pounds per bushel. 'The hop leaves without seed, from a place at Oxford where the male plants are always eradicated, weighed at the rate of twenty-two pounds per bushel, when closely pressed."

"Hop seeds being severally put into rainwater, most of those produced by plants raised from seeds, and grown near male plants, sank in the water; while most of those grown in grounds that had not any male plant near them, and whicis nad been raised from cuttings, swam on its surface." - Golden Farmer. 
The vines, or bines, grown from seed will be fit to be poled the third year; those from cuttings or layers, the second year. The business of the first year is, to keep the ground as clean as possible, and the plants well earthed up. Though they are not poled the first year, yet a stick is put into the ground, to which they are tied and trained. The hop is an enduring ylant, and some fields in Kent have been in hops beyond the memory of persons now living; but it is deemed best to renew them once in twelve or fifteen years.

The hills require, every spring, to be opened and carefully trimmed - the last year's shoots to within an inch of the main stem, and the suckers close to it. In some cases, they are manured only once in two years. Farm-yard dung is an excellent manure for them; and the clippings, or waste, of woollen mills, called shoddy, are much valued and used: The land on the borders of the chall formation is much preferred for the growth of hops.

There are several different kinds grown, and distinguished, m different places, by different names. These are the grape, the white bines, and the golden, vulgarly called the goldings. The white bines are most esteemed in Farnham, Surrey, and there are no hops in the market, which bring a better price than the Farnham.

The poles used for the hops are of chestnut, ash, or larch, and are cultivated in plantations, oftentimes, by the hop-growers themselves; and these plantations admit of being cut once in ten years. Beech, birch, and elder, are quite inferior, though sometimes used. The poles are from twelve to sixteen feet; but it is said to be an error to have them too long, as the bine becomes feeble by too much extending itself. With a view to avoid the eflects of violent winds, the plantation is sometimes hoodwinked by a row of trees upon the side most exposed; and to give more firmness, one cultivator has taken pains to have the poles strengthened by an iron wire extending from one to another on the top. The experiment was considered of doubtful advantage.**

* "Improvements in Hop-poling. - Mr. Knowles's plantation (Kent) coissists of about forty-two acres, lying on a very beautiful slope of the Ragstone Hille, having a warm aspect and an excellent soil, which, however, evidently owes much of its productiveness to liberal dressing and spirited cultivatior. Mr. Knowles digs his land twice - once early in the winter, an? again at the : sua. period in the spring 
'The plantations, when it can be safely done, are cultivated by a horse hoe, or plough, and every effort is made to keep the plantation free from weeds. The plant is subject to blight, and destruction from aphides, and a good crop is judged to be obtained scarcely oftener than one year in five. An acre contains about one thousand hills, and the yield may be put down at from five hundred to one thousand pounds per acre. In a series of ten years, from 1835 to 1844 , the return of one plantation, as given in Mr. Buckland's valuable Report on the Agriculture of Kent, is as subjoined:-

\begin{tabular}{|c|c|c|c|c|c|c|c|c|c|}
\hline Cut. & $q r$. & lbs. & & & Cot. & $q r$. & $l b s$. & & \\
\hline .11 & 1 & 23 & per & acre. & $1840, \ldots 0$ & 2 & 15 & per & acre. \\
\hline & 0 & 18 & 6 & 66 & $1841, \ldots 9$ & 3 & 18 & $" 4$ & :. \\
\hline . 7 & 1 & 16 & "6 & 6 & $1842, \ldots 10$ & 0 & 19 & 6 & $\therefore$ \\
\hline .11 & 2 & 23 & 66 & 66 & $1843, \ldots 10$ & 3 & 00 & 66 & 6 \\
\hline $539, \ldots 15$ & 1 & 6 & 66 & 66 & $1844, \ldots$ & 0 & 9 & " & 66 \\
\hline
\end{tabular}

The price of hops fluctuates between very wide ranges. The expense of cultivation in Surrey was stated to me, exclusive of

nidgets or harrows all through the summer, and generally farms upon four good maxims, which perhaps may be more easily remembered by the reader, if thrown into a distich.

$$
\begin{aligned}
& \text { 'Cut early, pick late, } \\
& \text { Well mend, and cultivate.' }
\end{aligned}
$$

'This new plan of poling was exhibited in about seven acres of splendid goldings, at the back of Mr. Knowles's residence. The weather sides of this piece had been poled four hills deep, with handsome, straight, twenty-one feet, large poles, in rows. These were lashed to similar poles placed horizontally across them, about eight feet high, from end to end of the hills; and the rows of hills were similarly bound to each other by poles placed from the outside rows to the inside ones. By this means a phalanx of poles offers a sufficient resistance to the wind to shelter the whole ground. Mr. Knowles was led to devise this plan as a means of shelter. In one year, he calculates that he lost a bag an acre of his goldings, from the effects of the wind-a loss amounting to about one hundred and forty pounds. 'This arrangement has been found a complete protection. Another result has been obtained from it, which was scarcely anticipated, viz., a very great improvement in the quantity of hops grown on the outside poles. In many cases, these poles are covered with from thirteen feet to fourtecn fect of hops from the top, besides the cross poles being clustered most heavily, thus clearly showing the great advantage of keeping the plants and poles firmly fixed. instead of allowing them to swing about. 'The increased expense of poling a ground throughout, in this way, is estimated at about thirty shillings per acre: besides an extra man required in pulling. 'The saving in windy seasons would, doubtless, be very considerable." - Maidsione Gazette.

VOI,. II. 
rent, at thirty pounds, or one hundred and fifty dollars, per acre; but by many it is estimated much higher. T'wenty pounds, or one hundred dollars, are sometimes paid as rent, per acre, for hop land. In spite of all these uncertainties, - perhaps the more on account of them, - men full of adventure plunge with eagerness into the cultivation; and the betting upon the amount of excise duty paid to the government - which, of course, is the index of the amount of product - is prevalent throughout the hop district, from the largest grower to even the lowest picker and packer.

It is desirable that only the same kind of hops should be planted in a field, so that the ripening may be uniform. It is important that the hops should be of a bright golden color, and full of aroma, or what is here called lupulin, which gives its value to the hop. The bines, at the season of harvest, are cut about three feet from the ground, - lower than that is injurious to the plant, from excessive bleeding; - and the poles are then lifted from the ground, and laid upon frames, when the picking begins. This, in favorable weather, is a merry season; and pickers come from distant places, men, women, and children, (many of them of the gypsy race,) encamping in the neighborhood under their rude tents, constructed of hop poles covered with a coarse blanket, with loose straw for their beds; and others, men, women, and children, are glad to find a lodging in some outhouse or shed, like pigs in a sty, with little regard to the decencies of life. In general, they provide for themselves; though the owner is careful to have a good supply of bread and potatoes, as they may be required.

The hops are picked in large baskets, which are gauged by marks; and an accountant is always in the field, to oversee the picking. They are sorted as they are gathered, the discolored and inferior being put by themselves. The price for picking varies from two pence to three and a half pence per bushel, or from four to seven cents. From five to seven bushels is considered a fair day's work, though I saw one woman, who had, in one day, picked eighteen bushels. Whole families, especially mothers and children, capable of doing any thing, are in reprisiiton; and the babies are laid upon the gromd, to take their first lessons in hop-picking, as they may be able to receive them.

The hops, being picked, are at once conveyed to the kilns, or, as they are called, oasts, to be dried without delay. A night's 
delay would be extremely injurious. The most approved kilns are now made of brick, of a conical or sugar-loaf form; "that is, a circular kiln of brick-work, from fifteen to eighteen feet diameter, with rafters, twenty-four to twenty-seven feet long, leaving a round opening in the apex of the roof, surmounted by a movable cowl, (or swinging ventilator, ) the object of which is to allow the vapor of the drying hops freely to escape. The drying-floor should be at least ten or twelve feet from the fires; it is usually made of stout lathes of fir, about two inches apart, covered with a horse-hair cloth, upon which the hops are evenly spread. The improved modern practice consists in having one or more large openings or fires to one kiln, and to admit plenty of cool air from without, the draught being regulated by means of flues and sliding doors. The fuel used in drying hops is, in all cases, charcoal or coke, with some anthracite." * 'They are laid upon the kiln from six inches to a foot thick, and are about twelve hours in being dried.

A large amount of sulphur is now used in drying hops, and is deemed most important to their color. Great prejudices existed at first against its use, but it is not now objected to by the brewers. The hops remain a few days, after being taken from the kiln, in the storehouses, before being packed. The packing has been repeatedly attempted by machinery, but none found equal to the human machine. A bag, therefore, is suspended through the floor of the room, in which the hops are deposited, by a hoop, which forms a temporary rim to it ; two large handfuls are tied up in the corners of the bottom of the bag, to render the handling of the bag more convenient; and the packer then gets into the bag, and draws the hops, - which are shoved towards him, on the floor, by a child, - with his arms, into the bag, and treads them with his feet as closely as possible. This is most severe and awkward labor, and he receives from $9 \mathrm{~d}$. to $1 \mathrm{~s}$. per cwt. for packing. Every part of the body, arms, and legs; is brought into violent motion, and the effort resembles what one would conceive it might be with a man trying to shake off his skin. A bag or pocket contains about $2 \frac{1}{2} \mathrm{cwt}$. 'They have established markets for hops on fixed days, where buyers and sellers attend, and the sample bags are exhibited. The great 
complaint made of the American hops, in the English market, where they are considered greatly inferior to those grown among themselves, - is, that they are not well cured, nor assorted. The profits of the cultivation of hops are sometimes very large. A friend told me that he had known one hundred pounds, as profit, realized from a single acre. But such is a very rare example. Many good fortunes have been made in the business, but very severe losses have been sustained; and the great uncertainties of the result are sufficient to deter any, but the most bold and enterprising.

\section{CVII. - FLAX.}

1. General Views. - The cultivation of flax has prevailed to a very limited degree in England; I saw nothing of it in Scotland; but in Ireland it is pursued to a considerable extent, and yearly with increasing success. Two or three things have served, heretofore, to hinder its cultivation. The first has been the opinion, that it is a very scourging or exhausting crop, and the second, the difficulties of curing it, and the inferior quality of the article, when produced. The want of a market, likewise, for the produce, operated against its cultivation. Out of the cultivation has arisen the market; and the product and the demand appear to be going on with an equal step.

With respect to the exhaustion of the soil, if reliance is to be placed upon chemical analysis, then the fibre of the plant, the llax properly so speaking; is wholly derived from the atmosphere. This is the result come to by the eminent Dr: Kane, professor of chemistry, in Dublin, upon a chemical analysis of the flax plant; and therefore, if the other portions of the plant are, in any form, returned to the soil, there will be no impoverishment, and flax may be as often cultivated upon the same soil as any other crop. How far this question may be considered as settled by such an examination, I shall leave others to determine; but experience proves that, where the land is properly managed, flax may, with success, be much oftener repeated on the same land, than it was formerly supposed advisable to do it. In what form these 
portions of the flax-plant are to be made available as manure, 1 shall presently show.*

The cultivation of flax is very much on the increase in Ireland. In 1841, the amount of crop, as ascertained, was twentyfive thousand tons; in 1843, it exceeded thirty-six thousand tons; and while the quantity produced is constantly on the increase, the quality of the article is decidedly, and very greatly: improved. The flax grown in Belgium, from its fineness and color, has been deemed much superior to any other. Much of the flax now grown in Ireland, of which I saw samples at their great cattle show, is probably surpassed by none. This improvement has been effected, undoubtedly, in a considerable degree, by the establishment of a society for the improvement of the growth of flax in Ireland, composed of some of the first men in Ireland, in point of intelligence, rank, wealth, and public spirit, who have obtained and circulated the fullest information in respect to the growth of flax, and the proper management of the crop; who have offered liberal premiums for the best samples which should be produced, and for improved machines for dressing and cleaning the crop; and who have especially imported several skilful flax-growers and managers from Belgium, in order to give direct and practical instructions to the Irish cultivators, as to the most improved modes of growing, cleaning, and dressing the crop, prevalent in their comntry. No method for the advancement of these objects could be more judicious.

Having seen many of the plantations of flax in Ireland, and believing that the crop may be of great value in the United States. in connection with the proper application of the seed, I shall grive, in as condensed a form as I am able, the information which I have received respecting it. I am quite aware how greatly the

\footnotetext{
* "This fibre, which constitutes the entire money value of the flax crop, is produced during the life of the plant, by the elements of the atmosphere; and the materials taken from the manure and the soil are, in reality, employed by the plant in organizing substances which do not make any return to the farmer, but which are, on the contrary, under certain circumstances, considered to be positively a disadvantage. It is, therefore, of importance, that it should be understood that, by a proper system, the growth of flax and similar fibre crops should be destitute of all exhausting influence; that the materials drawn from the soil by such a crop should be found in the waste products of its manufacture, and should be available by being returned to the soil, to restore it to its original condition of fertility." - Professor Kome.
} 
extended growth and cheapness of cotton has superseded the use of linen; but when the vastly-superior comfort of linen, especially in hot weather, is considered, its greater durability and strength, so requisite for many purposes, its important uses as twine and thread, and its indispensable use in those very delicate fabrics for which increasing wealth and luxury are constantly making new demands, we may expect that the cultivation of it in the United States will be much extended.

2. Soll, and Preparation of the Soll. - The best soil for the cultivation of flax is stated to be a deep, rich loam, with a strong subsoil; and the land should be thoroughly drained, and so laid as not to retain water upon the surface. Wetness of the soil, or standing water upon it, is most fatal to the flax crop. A calcareous soil is never to be chosen for flax, lime being unfriendly to the plant. The best crop to which flax can succeed is a grain crop, such as wheat or oats. It should not be manured the same year in which it is sown, but the manure should have been applied with a previous crop. It is desirable that the land should be deeply ploughed, or subsoiled, as the roots of flax penetrate to a considerable depth, and above all, that it should be thoroughly cleansed from weeds. Fall ploughing is recommended, and two ploughings in the spring, that the land may be bronght into a fine tilth. The land should be well harrowed and rolled; then harrowed with a light or seed-harrow; the seed sown, and again harrowed so as to give it a very light covering, as, if buried deep, the seed will perish; and then again rolled, if the ground is light, but not on heary land, that the ground may be left smooth and consolidated. The rolling after sowing, however, is much condemned by some successful and experienced flax-growers.

3. Seed and Sowing. - The seed should be plump, shining, and heavy, and should be, as far as possible, cleaned from the seeds of all weeds. Two and a half bushels of seed are recommended to a statute acre. I may remark in passing, that the use of American seed is much discouraged in Ireland, and farmers are strongly cautioned against sowing it, as producing a coarse, branchy lind of flax, and of very inferior quality. This fact may prove of great importance to the farmers of the United States. 
The best flax-seed for sowing is reputed to come from Riga, though Dutch seed is much approved. Thick sowing is strongly urged, as it is desirable to have the flax shoot up in a straight stem, with as little branching as may be, for the finer the stem the finer the flax or fibre. Less seed is produced in this way, but the flax itself is more valuable. The eminent manufacturers, the Messrs. Marshall \& Co., of Leeds, give it as their opinion, "that the cultivation of the flax for the fibre is of far more importance than for the seed; and that by sowing seed suitable to produce fine flax, and sowing it thick, (say three to three and a half bushels, per acre,) the farmer, though he sacrifices something in the value of the seed produced, will get a more remunerating crop from his land than he now obtains." This is a manufacturer's view of the question; when the value of the seed for feeding animals is considered, and the contribution which, in this way, it yields to the enriching of the land, the farmer may come to a somewhat different conclusion.

The sowing of clover or grass seed is strongly objected to, as injuring the root ends of the flax. It is desirable to sow as early as convenient, as the earliest sown proves, always, the best crop. It is understood that flax should never follow turnips, or any of the turnip tribe; and it may occur in a rotation twice in ten years, or once in seven or eight years.

4. WeEDrNG. - If the land has been thoroughly cleaned before sowing, the weeds will give little trouble; but the crop will require weeding; and in order to do this, great care must be taken not to twist or bruise the plant, and to weed facing the wind, so that it may assist the plant to recover its upright position. Much injury may be done to the plant by carelessness in weeding, which is performed usually by women and children, creeping upon all fours, and so bearing more lightly upon the plant than if they stood upon their feet.

5. Pullivg. - It is important to determine the best time for pulling the flax. The fibre is of a better quality, if pulled before the seed is quite ripe. If pulled too soon, there is much waste in preparing it; if pulled too late, the fibre becomes coarse. "The best time for pulling is when the seeds are beginning to change from a green to a pale brown color, and the 
stalk to become yellow, for about two thirds of its height from the ground." An eminent cultivator gives this advice, in regard to determining the ripeness of flax: "Try the flax every day, when approaching ripeness, by cutting the ripest capsule, on an average stock, across, (horizontally;) and when the seeds have changed from the white milky substance, which they first show to a greenish color, pretty firm, then is the time to pull. The old prejudice in favor of much ripening is most injurious, even as regards quantity; and the usual test of the stalk stripping at the root, and turning yellow, should not be depended on." The prevalent practice is, almost universally, to overripen the crop.

If the ground has been properly prepared, by draining and levelling, the crop may be expected to be of equal length; but where this is not the case, then the puller should be directed to seize the longest stems in his hand, and, having pulled them, lay them by themselves, and next pull the shorter stems, keeping each handful separate, as it is of great importance to keep the flax of equal length. It is urged, as very essential, to keep the flax even, like a brush, at the root-ends; and in none of the after processes should the short and the long be intermixed.

6. Rippling. - The rippling of flax is a process by which the seed bolls are separated from the stalk. This is done by drawing them through an iron comb, which is formed with iron teeth fastened into a board or bench. 'The seed bolls are sometimes dried in kilns; but by this process they are very apt to be injured, and their valuable properties reduced. They should, therefore, be dried in the sun, and the seed threshed out. The light seed, and the bolls or chaff, are to be used as feed for stock, for which purpose they are eminently nutritious.

7. Steeping. - The rippling or combing off the seed being performed, the next step is that of steeping the flax. This is to be conveyed, then, as soon as may be, to a pond of water, quite free from all impurities, and especially from all mineral mixtures, which are always pernicious to the plant. If the water is spring water, it is advised to let the pond be filled some days before the steeping, that it may have the advantage of the sun upon it. The flax is then to be laid in the pond, two or more layers in 
thickness, and covered closely with sods, that it may be kept down under the water, away from the air and light, yet without sinking to the bottom. In Belgium, crates are used, in which the flax is packed away, in bundles of about twelve pounds' weight each, and these are sunk, and kept down by weights, in the water, with stones underneath, to prevent their resting upon the bottom. It is not objected that a stream of water should pass over the pond; but this, though sometimes recommended, is incompatible with saving the liquor of the steep for manure, for which purpose, as I have seen, it is eminently valuable.

From eight to twelve days is considered a sufficient length of time for the steeping of the plant; though one Irish cultivator states, that where, by accident, some of his flax was left in the water for eighteen days, it was much superior to that which remained only thirteen days. The test given to determine its fitness to be taken out of the water is as follows: "Try some stalks of average thickness, by breaking the woody part, in two places, about six inches apart, at the middle of the stalk; catch the broken bit of wood; and if it will pull freely ont downwards for that length, without breaking or tearing the fibre, and with none of the fibre adhering to it, it is ready to be taken out. Make this trial over, six hours after fermentation subsides; for sometimes the change is rapid." The flax is then to be removed from the pool with great care; and after being set up on end, to drain, for a few hours, by placing the bundles close to each other, it is then to be spread out upon a grass field, not upon the field on which it grew, to complete the process. Short pasture ground is best for this purpose; and it must be spread thinly, so that one stalk may not overlay another, and as evenly as can be done. It is to be turned two or three times, while on the ground, that it may not acquire different shades of color by the action of the sun.

When the wood breaks easily, and separates from the fibre, it is then ready to be taken up. This may be determined by the hand, or by trying some in a machine. It is important, in taking up, to keep the ends even. It is to be tied up in small bundles, and put away in small stacks, loosely built up, or under cover in a barn or shed, ready for being broken and scutched. Some persons attempt to dry their flax by fire; but such a method is 
strongly condemned, as the flax is always injured, its oily portions being dried out by fire.

8. The Courtray Method.-On the Continent, at Courtray, from which some of the best flax is obtained, they practise a method of curing their flax which has been adopted in Ireland, with much success, but which involves more trouble than the usual process. "As soon as pulled, the flax is stooked, without binding it. The handfuls are set up resting against each other, the root ends spread out, and the tops joining like the letter $\mathrm{A}$, forming stooks about eight feet long, with a short strap lieeping the ends firm. In this way it will resist wind and rain well, and dry fast. In eight or ten days, it may be bound up in small bundles, carried to the ripple, and steeped; or it may be stacked in the field or put into a barn, the seed to be taken off at leisure, in the winter, and the flax steeped in the ensuing spring." This leaves the farmer an opportunity of choosing the most leisure and convenient season for attending to his flax product. It is understood that flax improves in the stack for two or three years; but the danger of the flax suffering from being put away, in a stack, green, is to be considered; and the rippling and steeping it immediately after being pulled may prove a considerable saving of labor over that of stacking it at first.

9. Breaking and Scutching. - Machines have been invented, in Ireland, for breaking and scutching, or hatchelling, or swingling, as it is called in the United States, the flax crop. The break seems fitted to do its work well. It is composed of three cylindrical rollers, grooved like the nuts of a cider-mill, and revolving against each other. The scutching machine has several arms made to perform about a hundred and eighty revolutions in a minute; but the objection to it is, that it drives the wood or hull into the flax, and does not leave it in that clean and even state which is produced by the hand. There can be little doubt that experience and ingenuity will improve these, or invent other machines, which may prove more suitable to the object. It certainly wonld not be difficult to make an improvement upon the method of breaking flax practised in Ireland before the improved machines came to be invented, when it was the custom 
to break it with a cart-wheel upon the road, and when they had no wheel, "the cultivator would accost a gentleman, passing in a gig, with a 'Please yer honor, will ye gie uz a rowl?""

10. Uses of the Seed. - I have already suggested the conclusion to which many intelligent farmers have arrived, that flax is not a particularly exhausting crop, when the refuse of the crop is returned to the soil, and the seed applied to the feeding of animals. I saw very remarkable effects produced in a field of oats, where the water in which the flax had been steeped was applicd as a manure. In my opinion, no manure could have been more efficacious; and so it has proved wherever it has been tried. But yet greater benefits are calculated upon, to be derived from the seed when used as feed for fattening stock, and in their manure, for enriching the land. One of the most successful farmers I have met with on this side of the water, and one whose premises, in every department, exhibited the strongest proofs of industry, skill, and intelligence, - and who, more than all this, has risen from the humble position of a tenant farmer, with very small means, to that of an independent landholder, and has bronght up a large family, and planted three sons, as tenant farmers, around him, with ample capital to manage their farms, - attributed much of his successful husbandry to a very liberal supply of linseed oil cake to his fatting cattle and sheep. His farm consisted of two hundred and fifty acres, and he amnually expended two hundred and twenty-five pounds, or more than one thousand one hundred dollars, for oil cake. This enabled him to turn off' his stock in good condition; this gave him ample means of enriching his land; and this laid the foundation of some of the best crops grown in the country. The opinion of an experimenter so observing and successful must have great weight in the case. Many farmers consume fifty and one hundred tons per year, and some, within my knowledge, to the amount of two humlred tons per year. But if the linseed oil cake is valuable, still more valnable is the seed itself, from which the calse is formed, before the oil is expressed. The seed is not a new article to be used in the feeding of stock, and its great efficacy in fattening both cattle and sheep, and in increasing the secretions of milk, when given to cows, I have myself repeatedly experienced. 
11. Mr. Warne's Method. - It is not best, however, to use it in a crude state, but either to reduce it to a rich jelly or mucilage by boiling, or, after having done so, by the addition of meal, to form it into a rich paste, of which cattle soon become very fond. Mr. John Warne, of Trimmingham, in Norfolk county, whom I have the pleasure of knowiug, a highly intelligent and enterprising farmer, has greatly interested himself to induce the farmers of England to cultivate flax largely, not for the fibre only, but for the seed, as feed for cattle, and in this way to obtain the most effectual means of enriching their land, and thus save at home some portion of those immense sums which are now expended upon the importation of manures from abroad.

Having had repeated communications with Mr. Warne, I shall give some account of the management which he pursues in the use of seed for fattening. He has sheds for his stock, which he divides into separate compartments, or stalls, or, as he calls them, boxes. Each box is designed to contain one fatting animal. It is intended to be about nine feet square, and the earth is dug out so as to form a depth of about two feet from the surface, walled in with brick, and the bottom made tight. The animal to be fatted is placed in this box, and copiously littered with straw, of which an ample supply is furnished daily, that he may have a dry bed to lie down upon, and that as much of the manure as possible may be absorbed by the straw. The animal is not taken out of the box during the process of being fattened; and, besides such long feed as may be given, he is supplied with this linseed paste, made after the recipe subjoined.

"Compound for Sheep. - Let a quantity of linseed be reduced to a fine meal, and barley be passed through a crushing machine, with smooth cylinders. Put a lundred and sixty-eight pounds of water into an iron cauldron; as soon as it boils, not before, stir in twenty-one pounds of linseed meal; continue to stir it for about five minutes; then let sixty-three pounds of the crushed barley be sprinkled upon the boiling mucilage, and rapidly stirred in. After the whole has been carefully incorporated, the fire may be suffered to go out. 'The mass will continue to simmer until the barley has absorbed the mucilage; and the compound, when cold, may be given to the sheep."

"For bullocks, the same process is to be observed; but the barley, in this case, must be ground into fine meal, and the quantity of water somewhat reduced. In this case, the fire must be extinguished, for the reason, that flattened barley requires heat to carry on absorption, while meal is sufficiently cooked by inmersion. 
It may be asked, Why should not the compound for sheep be equally adapted to bullocks? I answer," (he adds, " that sheep are close, ruminating animals, and pass nothing undigested, while with bullocks, it is far otherwise. On the compound being removed into tubs, it must be excluded from the air, to prevent its becoming rancid."

I have given the directions nearly in Mr. Warne's own words: but I see no reason why the barley may not, in both cases, be at once reduced to meal, or why the linseed and the grain (whether barley, rye, or maize) may not, in proper proportions, be at first ground together, in which case they are likely to be most intimately incorporated; and the experienced manager will himself soon be able to determine, from his own observation, the quantity of water the meal will take up, and form a suitable and nutritious compound, without diffeulty. The points inportant seem to me to be, that both seed and grain should be ground, and both sufficiently cooked. Mr. Warne adds, in another place, "A bullock may be allowed, in general, to eat as much cake in a day as he pleases; but a nice regard must always be had to the quantity of linseed placed before him, and especially to the oil. Neither oil nor linseed should be used in a crude state, but formed into mucilage, by being boiled in water. The seed must first be reduced to fine meal; one pound and a half of which, stirred into twelve pounds of water, while it is boiling, with four pounds and a half of barley, beans, or pea meal, and given to a bullock of between forty and fifty stone, (fouteen pounds, ) every day, will, in addition to Swedish turnips, bé quite sufficient, or, perhaps, rather more than he would be inclined to eat. This small quantity of linseed will act well on the stomach; and the bullocks will thrive, and fatten, in a degree that can scarcely be credited, except by the person who tries the experiment. The quantity of seed may be increased, after the animal has been accustomed to it for some time, but, I believe, to no great extent." *

I place the fullest confidence in these statements of Mr. Warne. From my own experience and observation, I am convinced that no more uutritious or fattening food can be given to animals, (swine excepted, as it gives an unpleasant taste to the porls, ) than cooked linseed or flaxseed jelly, in certain proportions; and it may be mixed with cut hay, or with various other articles of food, with equal success.

* Warne on the Flax Crop, and Use of the Seed, p. 120.

voL. II. 
One great object in Mr. Warne's arrangements is to secure a good supply of manure. The manure is not removed until the fatting of the animal is completed; and then, if sufficient litter has been supplied, it is obvious that the manure, being protected from the sun and rain, and all its liquid portions being retained and absorbed in the straw, must be of the richest quality. Its very superior efficacy cannot be doubted.

I ought not to quit this subject without reverting to some statements respecting the effect of flaxseed, or rather the refuse, or waste, of flax, upon cows in milk. A respectable Irish farmer testifies that, from one field of ten acres, he had one hundred and eighty-five bushels of bows for feeding, that is, seed in the capsules, and other refuse from the flax. After feeding a cow, which gave only three quarts of milk, a short time, upon this refuse, she soon increased her milk to nine quarts per day. Another farmer testifies to a similar fact, where a cow, which only gave two quarts, was improved so as to give nine; and, upon discontinuing this food, she went back to four quarts. These instances, being well authenticated, seem entitled to consideration.

Many farmers in the United States will, I think, deem this subject worthy their consideration. The cultivation of flax has been very little extended, and within my experience has, proportionately with the population, been lessened. The foot spinning-wheel of the industrious operative, formerly so pleasing an ornament at the cottage door, is now to be found only among the useless lumber of the garret. That, in the present daily increasing triumphs of machinery, hand-spinning, or house-weaving, should ever come back, it would be quite idle to expect. Habits and practices much less useful, and much less desirable, may take their place; but I should certainly be glad to see an increased use of linen fabrics, on the ground both of comfort and durability.

12. Average Produce, and Uses of the Produce. - The average yield of a well-cultivated crop of flax ranges between five hundred and six hundred pounds; and the quantity of secd to an acre may be about fifteen bushels. The chaft and light seed are saved by some, and when cooked are deemed valuable food for stock.

In the reports of the Irish Society for the Growth of Flax in Ireland, a statement is given of the application of the produce 
of three acres of flax, the purposes for which it is used, the processes through which it passes, and the amount of useful and profitable labor which it puts in motion, which I think camnot fail to interest my readers.

"Produce of three Acres of Flax. - 100 stones, at $15 \mathrm{s.},=£ 75$, each stone calculated to produce $5 \frac{1}{2}$ lbs. of dressed flax, - in all $550 \mathrm{lbs}$., - spun to 30 hanks to the $\mathrm{lb}$. will produce 16,500 hauks. About 158 females will be employed twelve months in spinning, at the rate of two hanks per week, (sixteen working days;) wages for spinning each hank, about $1 \mathrm{~s} .8 \mathrm{~d}$. or nearly $7 \mathrm{~d}$. per diem for each spinner. This quantity of yarn would make 210 webs of cambric pocket-handkerchiefs, each web containing five dozen. About 18 weavers would be twelve months weaving this quantity, allowing each man a month for each web ( $17 \frac{1}{2}$ weavers exactly;) wages per web, $£ 2$, or from $9 \mathrm{~s} .6 \mathrm{~d}$. to 10 s. a man, per week. About 40 females would be employed twelve months in needlework, (hemstitch or veining;) each could do one handkerchief on each working day; wages, $8 \mathrm{~s}$. per dozen, or $8 \mathrm{~d}$ per day. The goods, when finished, would be worth $£ 210$ s. per dozen.

" 158 spinners, 12 months, or 52 weeks, at about

3 s. 4 d. per week, . . . . . . . $£ 1,369 \quad 6 \quad 8$

18 weavers, 12 months, 210 webs, at $£ 2$

per web, ............. . . $420 \quad 0 \quad 0$

40 needlewomen, 52 weeks, 1,050 dozen hand-

kerchiefs, at $8 \mathrm{~s}$. per dozen, . . . . . $420 \quad 0 \quad 0$

$\overline{216}$ persons employed. Cost of labor,. . $\overline{£ 2,209 \quad 6 \quad 8}$

Cost of flax, . . . 75000

Profit, . . . . $31013 \quad 4$

Value of 1,050 dozen handkerchiefs, at $£ 210$ s. per dozen, . . . . . . . . . $£ 2,625 \quad 0 \quad 0$

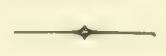

\section{CVIII. - LIVE STOCK.}

I come now to speak of one of the most important topics connected with British agricultural improvement - the live stock of the country. Among the conflicting opinions and estimates 
which prevail, both in this country and the United States, in respect to different breeds, my judgment may be viewed with jealousy and suspicion, and I may have to encounter fierce prejudices, on the part of breeders and speculators. My opinion will be given without any pecuniary bias whatever; and I beg my friends will, in any event, regard it as that of an humble individual, making no pretensions to infallibility of judgment, and anxious only to give the result of his various inquiries and observations, in as impartial and simple a form as possible.

'Two things impress strongly the mind of an observing traveller, in this matter; - the first, the variety of distinct breeds which present themselves; and second, the perfection to which individuals, and large numbers of each of these breeds, are carried. Different localities in the kingdom have their favorite breeds, are tenacious of their peculiar merits, and are sure to prefer them above all others; and, at the same time, the pains and expense, which are bestowed upon their improvement, have been rewarded by many examples, in most of the breeds, of what may be called the perfection of form, and the highest degree of fatness - a degree of fatness transcending the most stimulated appetites of epicurism, and verging, in some cases, almost to disgust.

The science, or, perhaps, it may be called the art of breeding, has been greatly studied. But notwithstanding the success which has attended it, especially with some men, yet, as in respect to most recondite subjects in nature to which the human mind has applied itself, there remains a great deal to be understood and explained; and we, as yet, have only passed the first steps on the threshold. The evidence of this is found in the fact, that the great question of the propriety of breeding in and in, or of propagating within certain lines of affinity, is still a mooted question. High authorities are quoted on both sides. Indeed, it must be obvious, that unless we suppose several distinct individuals of the same race, wholly independent of each other, to have existed at the same time, and to have been the foundation of so many distinet families, there must exist, among the animals of the same race, an inextinguishable relation of aflinity by blood. The whole object of the famous Herd Book is, indeed, to trace back all these diverging streams to a single fountain, and thus, by an uninterrupted descent, to demonstrate the purity of the blood. But our ignorance, and the consequent limitation of human 
power, are evinced by uther facts. Although there are frequent approaches to excellence, yet no human sagacity can command results. Animals of the same family often differ essentially among themselves. Pigs of the same litter seldom fail to present a variety; and twin animals are frequently marked by peculiar and striking distinctions from each other. The famous bull Comet is still considered as the umrivalled paragon of excellence; the celebrated Durham ox remains without a successful competitor; and the brothers and sisters of the vell-known Charlemont ox; shown in various parts of the United States, and afterwards receired in England as an animal of most extraordinary size and fatness, were none of them remarkable for any peculiar excellence. This was strongly evinced at a recent letting of rams, or tups; as they are here designated, which I attended, at the residence of one of the best farmers, and one of the most eminent breeders of Southdown sheep, in the kingdom, Mr. Jonas Webb, of Babraham, in Cambridgeshire. Here were exhibited one hundred and seventy-seven animals of the finest description, bred with all the care which it seems possible to exercise, and with all the skill which great acuteness of judgment and long experience could give. Yet the differences among these animals, in form: symmetry, size, quantity and quality of wool, were so great, that while the services of some of them, for a season, were rater? at five guineas, those of others readily commanded fifty guineas.

But although human sagacity and power can command no more, it should be matter of grateful surprise that so much is within their reach. The great law that like produces like: though it may not be invariable, is, comparatively, of universa! operation. Good qualities are propagated by the union of animals possessing good qualities; and defects, and faults, and infirmities, are, in like manner, extended and aggravated. The application of this principle, or physical law, has, in this comntry; been most marked in its results. From all that I have seen, there seems to me reason to doubt the power of any man to produce what may be called an entirely new breed, or to do any thing more than, by his skill, to modify or improve such as already exist. This, however, is often done in a most remarkable manner. The old proverb certainly holds true, that "a good cow may have a bad calf; " but then it is much more likely that she will have a good one, than that a bad cow will have a good $26 *$ 
calf. The confidence with which some persons speak of what can be done, and what they can do, is often excessive; but what has been accomplished by selection, by crossing, and by the conjunction of peculiar properties, is surprising. There seems a limit, beyond which, perhaps, no person can go. The particular breed may be altered and improved, but an entirely new breed cannot be produced; and, in every departure from the original, there is a constant tendency to revert back to it. The stock of the improved Durham cattle seems to establish this point. If we have the true history of it, it is the result of a cross of a Teeswater bull with a Galloway cow. The Teeswater or Yorkshire stock are a large and coarse-boned animal; the object of this cross was to get a smaller bone and greater compactness. By attempting to carry this improvement, if I may so say, still further, by breeding continually in and in, - that is, with the members of the same family, in a close degree of affinity, - the power of continuing the species seems to become extinct; at least, it approximates to such a result; the race becomes deteriorated. On the other hand, by wholly neglecting all selection, and without an occasional good cross with an animal of some foreign blood, there appears a tendency to go back to the large-boned, longlegged animal, from which the improvement began. One point seems admitted, that, since the days of Mr. C. Colling, the great founder of what is called the improved short horns, though the race has become diffused to an extraordinary extent, and multitudes of fine animals are now produced where then there were few, yet no higher excellence has been reached than that to which he attained. The greatest stress is every where laid upon purity of blood; and yet it is rather an anomalous fact, in this case, that Mr. Colling's famous stock was the result of a cross between a 'Teeswater bull and a Galloway cow; that some of the best animals in the country, for size, and fatness, and milk, have been the progeny of a first cross with a different breed; and that an extreme limitation, in breeding, to the same family has been almost invariably followed by the deterioration of the stock. "There are several instances of superior animals bred in the closest affinity; whilst, in a very great majority of cases, the failure has been excessive and lamentable. It was notorious that the stock got by Comet out of cows that were stran- 
gers in blood, were far superior to those from cows more nearly akin. Mr. Mason, of Chilton, commenced breeding short horns from the same parents as Mr. C. Colling, and, for a certain period, pursued it very successfully; but, being deprived of the privilege of sending his cows to the Ketton (Durham) bulls, he was constrained to use those of his own breeding; and the losses he sustained, in his young stock, were so great that, at one time, his show cows were reduced to four ; but by using the bull Jupiter, whose affinity of blood was supposed to be remote, he again became a successful breeder." * It would be contrary to all observation and experience, to deny the exclusive merits of different breeds, and the tendency of all animals to propagate their like; but it rould be equally so, to deny that extreme results often contradict our expectations, and that both science and observation are, occasionally, at a loss to determine the influences by which these irregularities are brought about, or by what means they may be controlled.

In treating of the live stock of Great Britain, it is obvions, that my remarks must be brief and desultory, upon a subject on which many volumes have been, and still may be, written.

1. Honses. - Among the most improved animals in the kingdom, horses take a prominent place; and a circumstance of difference, in this matter, between England and the United States, which strikes one at first sight, may be called the division of labor among the horses. The American horse, in most of the states, is, generally, a horse of all work. Here, the horses are bred and trained for, and exclusively confined to, particular departments - sporting, pleasure, travelling, draught or agricultural labor; and nothing is more rare, than the transfer of the animal from one department to the other. So we find the race-horse, the hunter, the carriage-horse, the draught-horse, the roadster, the saddle-horse, the pony for children and ladies, the general hack, and the farm-horse. This comes of the immense wealth of the people, and is adapted to give them the best advantages of each kind. It may surprise some of my friends, to tell them, that I have more than once found forty hunting horses in one

* On Short Horn Cattle, by I. Wright. Journal of Royal A gricultural Society. จol. vii. p. 1. 
gentleman's stable, for himself and his huntsmen; and in onc instance, I found a stud of eighty horses, of different kinds, exclusive of the farm-horses. The perfection to which these animals have been brought, the condition in which they are kept, the tenderness, and kindness, and care, with which they are treated, and the admirable manner in which they are groomed, are circumstances, here, all over the country, in the highest degree worthy of remark. I have already referred to them. Their hours of rest, of feeding, and labor, are observed with strictness; their stables are spacious, lofty, well-ventilated, and adapted to preserve, as far as may be, an equable temperature; they are carefully bedded, and cleanly littered, and whatever would be offensive, at once removed; they are thoroughly curried, and brushed, and a horse brought into the stable, in a state of perspiration, is never left until he is completely dried by rubbing; nor, in any case, have I seen a horse left to stand still, exposed to a cold draught of air. The treatment of them is most exemplary and creditable; and is no more than just to animals, incapable of taking care of themselves, to whom we are indebted for so much of pleasure, and so much of profit. At the house of an eminent nobleman, whose hospitality I enjoyed, it was the invariable custom of the family, - ladies and guests, as well as the master, - about nine o'clock in the evening, to go, by a covered passage, into the stables, where thirty horses were kept, to see that the grooms and ostlers were at their post, that the horses were well, and cared for, and the stable in good order. Nothing could exceed the cleanliness and order in which every thing appeared. At one of the principal breweries in London, where forty of the largest size dray-horses are kept, the manager informed me that, after six years hard service, the horses receive their freedom, are sent into the country, exempted from all labor, and kindly cared for during the rest of their lives. I confess, in observing these kind provisions, and this extraordinary care, $\mathbf{I}$ have not been able to suppress the wish, that many of the bipeds, who share with these animals in the labor of the field, - not unfrequently performing the hardest part of it, - could experience, in their own persons, an equal care, and find in their cottages, on their return from a hard day's work, even a moiety of the comforts with which the stables of their co-laborers are provided. It would be doing great injustice, to say that this is not often done 
by many persons, who have no greater pleasure than in providing for the comfort and welfare of their dependants. It is only to be regretted that the practice is not universal.**

In the breweries in London, and in the drays in the cities, horses of an enormous size are employed; and the same kind of horses are employed on many of the farms. The weight of one of them, ascertained in my presence, exceeded seventeen hundred pounds; and he was by no means extraordinary for size. I do not desire to see such horses introduced among the farmers of the United States. Their motion is slow and clumsy, and their keep expensive. In cities, where the vehicles are heavy, and the burdens of coal, and beer, and other goods, very great, they are well suited to the service for which they are used. As far as proportion, color, and action, are concerned, they are, certainly, magnificent animals. With many farmers, these horses are raised, not as being preferred for farm labor, but for sale in the cities; and, after being broken to service on the farm, are, at a proper age, sent to market.

But the horse best adapted to agricultural purposes is of a smaller size, a compact form, short, strong, and muscular limbs, full-breasted, and with round buttocks, of which a favorable representation may be found in the plate accompanying my first report. There are three breeds of horses in the kingdom, distinguished for their valuable properties as farm-horses; these are the Cleveland Bay, a horse of great strength, and good size and figure; the Suffolk Punch, a large and serviceable horse; and especially the Clydesdale horse, almost exclusively

* No person can have passed through the highly-improved territory of the Duke of Buccleuch, in Dumfriesshire, which the public road traverses for more than twenty miles, and observed the clean and comfortable cottages of the laborers, which constantly meet the eye ; nor have seen the almost luxurious provision made by the Duke of Devonshire for his dependants, in his picturesque village of Edensor; nor the humane provision made by the late Lord Leicester for his aged and decayed laborers, at Holkham; nor have witnessed the extraordinary and beneficent exertions of Lady Noel Byron, by allotments, loan, and benefit societies, and industrial schools, for the comfort, instruction, and improvement of her dependants, and the poor; nor the beneficent and parental conduct of many, many others, to whom the strong and unaffected attachment of their laborers and dependants evinces the deepest sense of kindness, but whose names it might seem invidious to mention, - without a grateful acknowledgment of the goodness of Heaven, in making minds so just and generous the almoners of its bounty. 
preferred among the excellent furmers of Scotland, particularly in the Lothians. I have seen nothing superior, in my humble judgment, to the last horse, for farm labor, combining good size, with compactness, strength, and action. In Ayrshire, the farmers, being of an opinion that their fine breed of horses was deteriorating, recently imported a stallion from Flanders. This horse was a model of compactness, and strength. He was fifteen and a half hands high; his girth, behmd his shoulders, was seven feet, four inches, and seventy-five inches round his neck, at the base; he was twelve years old, and cost sixty guineas, in Flanders.

The farm-horses, in ploughing; are never worked more than eight hours a day. The ploughman feeds and cleans them at four o'clock in the morning. They are harnessed, and the plough started, at six o'clock. They are brought to the stable again at two o'clock, and fed, and thoroughly groomed, curried, cleaned, bedded, \&c., and left for the night, at dark. The feed is almost always cut for them, or if given long, given in small quantities; and the oats and beans are crushed. On one farm, the allowance for a farm-horse of the largest size was, two bushels of oats, and one peck of beans, and two trusses of hay; (fifty-six pounds each,) per week, in winter; in summer, green feed, vetches, clover, or rye grass, was substituted for the hay. The general allowance is a peck of grain, half oats and half beans, and from fourteen to sixteen pounds of hay, per day. The army allowance for a horse is fourteen pounds of hay, ten pounds of oats, and seven pounds of straw, per day; "with hard work, less hay, and more corn; with little work, less corn and more hay." The horses belonging to the Queen's Guards, which are often to be seen in the streets of London, and always on state occasions, are beautiful animals, and subjects of universal admiration. They are of a black color, and bred, I believe, on the continent, purposely for the army.

The general rule is, to keep, on arable farms, a pair of horses for every forty acres; in some cases, the proportion of land to the team is larger. One of the best farmers in Scotland allows seven horses for two hundred acres. His land is accessible, and extremely favorable for all farming operations. The cost of keeping a working horse (exelusive of interest or deterioration) he estimates at twentv-five pounds, or more than one hundred and 
twenty dollars, per year. 'These expenses all have reference to the local prices of agricultural produce; and I give them rather as matters of curiosity, than of direct utility to my American readers. The amount of ploughing for a day's work is an acre of land, but, in some cases, an acre and a half. One farmer speaks of ploughing, usually, seven acres in a week, with one pair of horses. 'The furrow slice varies from eight to eleven inches, and the distance travelled, in such case, is from twelve to sixteen miles a day. It does not lie within my province to speak of other horses than those employed in agricultural labor.

Oxen are employed for farm labor to a small extent, and in few counties. On Lord Leicester's farm, at Holkham, so much and so long celebrated, they are used and worked in leather harnesses; and in some places, I have seen them worked singly in harness. 'The general impression is, that they will not do so much work as horses, are not so easily trained, and are more expensive to keep; every one of which positions is, in my opinion and experience, erroneous. I believe these opinions arise out of an entire ignorance of the training of oxen. Nothing can be more awkward than the management of them, which I have seen here. As they are managed and trained in the best parts of New England, their docility is perfect; working without a driver, in the ploughfield, as well as with one; performing as much work as a pair of horses, and performing it as well; costing comparatively nothing for harness, since a wooden yoke and bows, and iron chains, which will last for years, are all that are required; when well cared for until six years old, paying, by their growth, for the feed which they consume; and, when kept in good condition, as they always should be, if ruined for work by any injury, or if at an age to be turned off for beef, exposing their owner to no loss. In every thing but road work, I am quite satisfied that a pair of well-trained oxen will perform as much work as a pair of horses, and at a much less expense. This was the opinion of an English ploughman, who lived some time in my service, and worked wholly with oxen. He had, before this, been used to horses, and a more skiltul ploughman I have never seen on either side of the water. The use of oxen has become much less common than before the introduction of the improved breeds of cattle, which are now brought 
so early to maturity. Formerly, it was not the custom to send oxen to market, before five years old; now the Durham stock, and others, go at eighteen months to three years old. Under this arrangement, there is no opportunity to get any work out of them.

The Scotch plough with two horses abreast, and seldom use more than two. In many parts of England, horses are worked landem; and I have sometimes seen five and six, at length, to a single plough. This is certainly excessive, and the turnings, in such case, most inconvenient; but the motive for putting the horses at length is, that, where the land is heavy, it may not be trodden hard.

2. Neat Cattrle. - There are several distinct breeds in Great Britain, of which I shall not undertake to give a description in full. Such descriptions already fill volumes. The principal breeds which have fallen under my notice are the improved short horns, the Hereford, the North and South Devon, the Staffordshire long horns, the Ayrshire, the polled Aberdeenshire or Galloway, the Kyyloes, or West Highlanders, and the Kerry. There are other breeds, and animals of every cross, variety, and mixture. It would seem that nothing can exceed the perfection to which many of the individuals of each of these breeds are brought. At the Christmas show of the Smithfield Club, they appear in elephantine proportions, like so many moving masses of fat. As I have already observed, the different breeds have their exclusive partisans. That excellent friend of agriculture, the late Lord Spencer, was the great patron of the improved short horns; yet he kept the Alderney to supply butter, and the West Highlanders to furnish meat, for his own table. The late Lord Leicester, so many years at the head of the English farmers, preferred the North Devon. The Duke of Bedford, eminent for his agricultural improvements, and for, perhaps, one of the most complete agricultural establishments in the world, prefers the Herefords; and so with Mr. John Hudson, of Castle Acre, in Norfolk, whose agricultural authority is of the highest character. The farmers who are fatteners of stock are always anxious to purchase the Scots or West Highland cattle, as being always sure of a marliet and of returning a fair profit. 
(1.) The Improved Short Horns. - The improved short horms are a singularly beautiful breed of animals, and, it will be admitted, are the most popular breed in Great Britain. In perfection, they are of large weight, fine-boned, come to maturity early, exhibit great proof upon being killed, and although they are admitted to be great consumers, and require very high feeding, they are considered a very profitable stock for the farmer. They are, it is said, originally of the 'Teeswater breed, imported from Holland, but greatly improved by selection and crossing. 'That an individual, in his lifetime, should effect such improvenents, as all admit Mr. Colling, the reputed founder of the breed, clid, and derive immense profits from his enterprise, is a fact full of encouragement. They are commonly brought to market before three years old, and often at eighteen months. 'The calves often run with the cow six months, and are frequently fed with artificial food from the time they can be made to take it until they are sent to the butcher. The best of these animals, however, have a strong natural tendency to keep fat; but they are not suited to a short pasture, or a scanty manger. It is not invariable, that animals consume in proportion to their size; but it can hardly be questioned, that there is ordinarily some relation between the size and the proportion of food required. It will, I think, not be denied that they are great consumers. An intelligent herdsman, who had been accustomed to the feeding of fattening animals for eighteen years, and, with respect to whose judgment, I know of no private interest to affect it, gave it to me, as his decided experience, that the short horns require a third more food than the Herefords. This judgment must go for what it is worth.

The high-bred animals are not remarkable for their milking properties. There are exceptions, but most of these animals are inferior in the quantity and quality of the milk; though there can be no doubt that both quantity and quality will be affected by the kind of feed supplied them. Individuals of rare excellence, in this respect, may be selected from among them; but the extraordinary accounts which are sometimes given of whole herds or families, must be received with a degree of distrust. 'The finest herd of short horns which met my observation though it must be remembered that, if I have seen many, they are VOL. II. 
but few compared with the whole number to be seen - I found in Lincolnshire, in the possession of one of the best farmers in England, a tenant of Lord Yarborough. They were not in the Herd Book, but had been in possession of the family more than fifty years. A superior lot of cows, in appearance and condition, I never saw, nor expect to see; but they were not distinguished for their milking properties. The property to take on fat is considered inconsistent with that of large secretions of milk. This is not without exceptions within my own knowledge, but is generally true. I shall recur again to the milking properties of the short horns. The beef of the short horns, though good, is not considered of the highest quality. This may be partly ascribed to the early age at which they are killed. It is believed, howcver, that few animals, under proper management, pay better for the care bestowed upon them; and although the prices of the present day are small compared with what they were at one time, this may be traced to varions causes, not implying a lessening of public esteem for the breed. The breed, for instance, is greatly extended, and good animals are not difficult to be procured. The prices formerly given were much too high, owing to the small number of animals to be had, and the much higher comparative prices of all agricultural products, at that time. For labor, as far as my observation goes, they are not used at all.

(2.) Herefords. - The great competing breed with the short homs are the Herefords, which, excepting in Herefordshire and the neighborhood, are not so widely spread as the short horns. It would be difficult to adjust the rival claims between these two great breeds. The Hereford cattle are exceedingly neat in their limbs and form, and of good size. At the show of the Smithfield Club, held at Christmas, the highest prices appear to alternate between the short horns and the Herefords. Under proper treatment, they may be brought to as early maturity as the short horns. I think I have never seen so fat animals as some Herefords; but the fat is not so evenly diffused as in the short horns; and secms laid on in large lumps and patches, which is an objectionable circumstance. They are not so great consumers as the short horns, and their thrift is remarkable. Some farmers in 
England prefer them, as fatting beasts, to the short horns.* 'This may be mere prejudice, - for what class of men, and, in respect to many subjects, what men are free from prejudices? Hy observation inclines me to the belief, that, in equal numbers, there are as many good Herefords as short horns; and the thriftiness of many of them is quite remarkable. A large proportion of the short horns stand too high, and have too long legs. The Hercfords are not exempt from this fault, but have less of it; but they lack substance and breadth behind. In respect to handling, observing persons know that, in this matter, there is every diversity among animals of the same breed, and that it is rather the characteristic of individuals than of a tribe; but I may hazard the general remark, that, as a breed, few animals handle better than the Hereford. I heard from some individuals very much in favor of their milking qualities, but from these persons, though a long time owners of the stock, I could get no authenticated statements. The answer to my inquiries always was, that they kept no exact accounts, but knew their cows were excellent milkers, and gave a very large yield. The habit of praising our cows is, in most cases, very much like men's habits of thought in regard to their children. In this matter, the geese of most men are swans. In general, the Herefords rank low as dairy animals, and are considered inferior. This is the general impression; - as such I give it. Public opinion is not always well founded, and I shall leave to others to determine, in this case, what value to attach to it.

(3.) The Devons. - The Devons, taking their name from the beautiful county of Devonshire, where they are principally found, are of two kinds, the North and the South Devons. The North Devons are a comparatively small race of animals, with long and beautifully-turned horns, of a deep red color, shortlegged, and compactly built, exhibiting, to my eye, the perfection of form and symmetry, with soft, silky coats, and with hair in

* Upon reading the above, a very intelligent and experienced salesman informs me that, although the very best Herefords command as good prices as formerly, yet the ordinary Herefords which come to market are very hard of sale, and are the least esteemed beasts which appear at Smithfield. This he considers attributable to some mistake in their breeding, or to breeding too long in near affinity 
curled and waving lines, in appearance like the most beautiful varied mahogany that ever came from under the plane of the calinet-maker. They do not attain a large size, but they are so compact, that they weigh heavily for their size, and there is no waste in them. 'The South Devons are animals of a much larger frame, often coarse-boned, attaining sometimes to a considcrable size, not remarkable for thrift, coming late to maturity, and, in truth, identical with the great mass of cattle to be found in New England. It is but just to say, in respect to the South Devons, that, as far as I could learn, no particular pains have been taken to improve their breed, and to see what conld be made of them, as in the case of the short horns, the Herefords, and the North Devons.

'The North Devons are, as a breed, most highly and deservedly esteemed. They have the preference of all other breeds for the yoke, being strong, active, and of great endurance; add to this, a remarkable docility, and good temper. It is generally thought that they do not arrive at maturity as early as the short horns or the Herefords; - I do not know that the same pains have been taken to force their progress. An eminent breeder of North Devons contradicts this. $\mathrm{He}$ is one of the most experienced farmers in Great Britain; he has been long accustomed to real them, and insists that more money can be made from them than from any other breed. Of course, this opinion would not meet universal assent, and would be rejected by the advocates of some of the other breeds; but the long experience of this farmer, and his admirable and successful husbandry in every department, entitle his opinions to great consideration; and my confidence in him is such, that, in parliamentary language, in a division of the house, I should be strongly inclined to go into the same lobby with him. They are highly esteemed in Smithfield market for the excellence of their meat, and because its size is more agreeable, on most tables, than the huge joints of some other breeds. In weight, they are much excelled; but the opinion of their advocates is, that more meat can be made from them with the same amount of feed. Of their dairy properties I shall speak presently.*

* A fine example is given of this stock, in the frontispiece to my Fourth Report, vol, i. p. 285. 
(4.) The Ayrshire. - The Ayrshire stock prevails, principally, in Ayrshire, Scotland, and is certainly a beautiful race of animals. It is maintained by some that they are of the same breed, with some slight variations, as the improved Durham short horns. However they may approximate each other in crossing, as races, I believe them to be as distinct as the short horns and the Devons, and a practised eye will easily discern the difierence. They are considerably smaller than the short horns; much lower on the leg; with larger bodies in proportion to their size; not of such length as the short horns; in general, with finer limbs; their faces not quite so long, nor so tapering. Their color somewhat resembles that of the short horns, thongh there is less of white, and the white not so snowy and clear, and none of the roan color, which often makes the Durhams extremely beautiful. They are occasionally spotted with white, as if large flakes of snow, or feathers, had been scattered over them. They are of good thrift, but do not constantly show the same good condition as the best short horns, especially when in milk. When dry, however, they fatten well; and no animals can be more prized than they, in the highly improved and picturesque county of Ayr, where they are principally found. They are chiefly valued for the dairy, and are considered by many persons as, in this respect, excelling all others, - a conclusion to which I demur, for reasons which I shall presently give. I am not about to depreciate them, for a fine Ayrshire cow, with her full udder, is greatly to be admired for her beauty and her product. It is said that they always do much better in their own locality than when they are removed, for examplê, into England. I know other animals who do not thrive so well from home as at home. It is said of the Scotch themselves, such is their native acuteness and enterprise, that they will thrive in whatever country they may be thrown. 'This does not appear to apply to their cows. 'There may, however, be another reason. I recollect a man's having purchased a cow, represented as remarkable for her extraordinary yield of milk, from one of the richest pastures that could be found; and upon taking her home to shorter commons, he complained to the former owner that he had imposed on him. "Sir," said he, in reply, "I sold you my cow, but I did not sell you my pasture."

The Ayrshire cows are extremely thrifty when dry. When fatted, the four quarters weigh from twenty to thirty tron stone, 
of twenty-four pounds each, that is, from four hundred and eighty to seven hundred and twenty pounds. An Ayrshire farmer informed me that he had had cows weigh fifty-one stone, or one thousand two hundred and twenty-four pounds, each. He says, there are no better feeders, and that, when fatted, the beef is as good as that of the West Highland cattle.

(5.) The West Highland Cattle, or Kyloes. - This is a small breed of black cattle, bred in the remote Highlands, and on the northern islands of Great Britain, and brought in immense numbers to the south to be fed. They are short, hardy, thickset, always in good condition, and exceedingly thrifty, when brought from the short feed of the north into the rich pastures and to the abundant mangers of the south. Their size is small, but their weight very great in proportion, as they are extremely compact and solid. Their meat is esteemed of the best quality in the market, and commands, usually, a halfpenny a pound more than any other. They are bought in, at times, quite young, and kept until three years old, when they are sent to market. They are thought, when well purchased, to pay a better profit than any other; and on this account, as well as their symmetrical shape, - for, taking off the head, and neck, and the legs, they would appear to form a perfect parallelogram, - they are universal favorites.* No advantage has come, in any way, from crossing these cattle with any other breed. There is a small kind of black cattle, without doubt allied to the West Highlanders, which are brought to Smithfield market, and there vulgarly known as runts. They cannot properly be called a distinct breed. They are extremely compact and heavy, and their meat excellent. No beef animals in the market sell so well.

(6.) The Aberdeenshire Polled Cattle, near relatives of the Galloway and the Angus cattle, if my memory serves me as to the name, are likewise black in color, and admirable in appearance. They, also, are deemed highly profitable stock both for thrift and for the dairy; and a herd of cows, I believe of the latter breed, horned, entirely black, excepting their ndders, exhibiting the

* A just representation of one may be found at the berinning of my 'Third Report, vol. i. p. 189. 
strongest indications of being most abundant milkers, shown at the cattle show at Dundee, have, in my view, rarely been surpassed. Of the Aberdeenshire cattle, a picture of a superior specimen is given, vol. i. p. 385 .

(7.) The Alderney or Guernsey Cattle. - Of all the cows which I ever saw, the handsomest, - that which gave my eye the most pleasure, that which gave the best promise of being what a cow should be, - was an Alderney, or rather, improved Guernsey cow, brought from one of the Cliannel Islands, and shown at the meeting of the Royal Agricultural Society, at Southampton. She was rising two years old, of moderate size, compact, and well-shaped, of that yellowish dun color which generally characterizes the breed, with a large and golden udder, ears of an orange color in the inside, a clean and thin neck, and the bright eye of a gazelle. This showed to what perfection the breed might be brought; for, in general, they are exceedingly ugly, small, thin, coarse-boned, and presenting little more than the skeletons of animals, covered with a yellowish, flabby, and coarse hide. They come principally from the Channel Islands, Jersey and Guemsey, and abound in parts of Hampshire, and counties most accessible to these islands. They are valued mostly for their milking properties, and not so much, in that respect, for the quantity, as for the extraordinarily rich and creamy quality of their milk, in which certainly they surpass all other breeds. It is stated that no animals will thrive faster, when well-fed and not in milk; and their size is not always inferior. I found at Welbeck, the residence of the Dulie of Portland, a herd of Alderney cows, of the size of ordinary cows, and in good condition.* Few gentlemen or noblemen in England, resident in the country, are without one or more Alderney cows, for the supply of their tables

* 'Two Alderney oxen, fatted by that distinguished and liberal friend to agricultural improvement, Sir Charles Morgan, of Tredegar, Wales, weighed alive, the one, one thousand six hundred and ninety pounds, the other one thousand six hundred and fifty pounds.

This excellent man, now verging towards ninety years old, but retaining in his mind all the elasticity and cheerfulness of youth, has an annual angrultural show on his own estate, free to competition, and, since its institution, has himself given more than five thousand pounds, or twenty-five thousand dollars, in premiums. I have had the pleasure of attending two of these shows, and witnessing the grateful enthusiasm with which this agricultural patriarch is received among his attached neighbors and friends. 
with cream and butter; and I never have had the slightest diffculty in instantly recognizing their produce. They are kept, in some proportion, at some of the large farm dairies in England, for the purpose, by mixing their milk with that of other cows of a different breed, of giving color to the butter, and richness to the cheese; but I was informed, at one of the best dairy farms in Gloncestershire, where forty cows are kept, that a dairy exclusively of Alderney cows "would not make good cheese, or rather would make it too rich;" and that, beyond a certain proportion, and that not a large one, it was not advisable to mix their milk with that of other cows. So difficult, however, is it to determine any thing, that $I$ have found other farmers to state that they have succeeded perfectly in making excellent cheese from the milk of the Jersey cows.

The improvement which has taken place in this breed, in the Island of Jersey, a specimen of which I have given an account of above, is most remarkable; and in their improved condition, for certain purposes, especially for the luxury of cream and butter, it would, I think, be impossible to find a more valuable breed. It is objected to their beef, that the fat of it is too deeply yellow, but otherwise it is deemed excellent in quality.

(8.) Dairy or Milking Stock. - The milking or dairy properties of the different breeds have been matter of much discussion; and it would be difficult to find a unanimous, perhaps not a general acquiescence in any opinion. This should be an argument for forbearance on the part of those persons to whom my judgment might appear erroneous. Mr. Bates, one of the most distinguished breeders of short horns in the kingdom, and a sucessful prize winner for his stock, gave me as his opinion that there were two lines of the short horns - the one large milkers, the other different. No such marked or sectional distinction has come within my observation; but individuals of remarkable productiveness in this respect are constantly to be met with. Few things in this world are without exceptions; but as a general rule, other circumstances being equal, the yield of milk will be in proportion to the size of the animal. The cub of an elephant requires more milk than a calf or lamb, and doubtless there is more provided for him.

The high-bred Durhams are generally poor milkers. 'They 
do not give large quantities; the milk is not rich in butter properties. Now I shall contradict this by some examples, but they, I believe, are the exceptions, and not the rule. A Durham or short-hom cow, owned in Cambridgeshire, made sixteen pounds of butter one week, and at the rate of fourteen for a considerable length of time. I have found several that made twelve pounds and fourteen pounds of butter, a week. These, however, are rare instances. Mr. Bates informed me, that one of Mr. Collins's cows gave at one milling, at night, twenty-six and a half quarts; another gave twenty-four quarts of milk per day; another, nineteen quarts. I did not understand him to make these statements of his own linowledge. His own celebrated cow Duchess gave fourteen quarts at a milking. These are all animals of high blood; but it is the general experience of the keepers of such animals, that their qualities for milk are inferior. Mr. Bates informed me, these were beer quarts. Wine to beer measure is as about four to five.

The Yorkshire or Teeswater cows, from which the improved Durham are derived, are large milkers. It is an evidence of this, that most of the cows kept in the London milk establishments are the Yorkshire. They are, in general, very large animals, and their size for fattening, when their milking is over, strongly recommends them. In condition, they are variable, a cow giving large quantities of milk seldom showing high condition; though even this is not without exceptions. It is rare, however, in any case, to find them in low condition. At a large milk establishment in Edinburgh, kept by a woman, she told me that she had owned a Teeswater or Yorkshire cow, which had given twenty-two Scotch pints, or forty-four quarts, of milk, per day. I was assured of this woman's credibility; but then, with a perfect respect for the conscientiousness and good intentions of the sex, I habitually distrust their arithmetical accuracy, whether in regard to their own age, if they are far on the journey of life, or to other matters. It is not in their way to remember numbers exactly. The great astronomer, Mrs. Somerville, is a rare and magnificent exception.

At a London milk establishment which I have repeatedly visited, the yield in milk is chalked upon a board, over the head of each cow. Miost of them are of the Yorkshire breed. I observed, in my last visit, one yielding twelve quarts per day, one 
sixteen quarts, and one, an Ayrshire, twenty quarts. One cow was shown to me, a Yorkshire, which had yielded twenty-three quarts per day. These were wine quarts, as I understood. Their feed, at this time, was half a bushel ale grains, each, per day; twenty-eight pounds of hay; some potatoes, and newly mown grass, the quantity not determined. Ale grains, it is said, will make more milk than porter grains. This is the opinion of practical men.

At another milk establishment which I have repeatedly visited, two hundred and fifty cows are kept. Here, both Durham and Yorkshire are principally kept. They are preferred, as being best for mill, but especially as fattening easily, when dry. The average yield was stated at eight quarts per day to a cow, through the year, and, before "the disease" prevailed among them, at ten quarts. This is certainly a large amount. The cows are never turned out; water is given to them in their troughs. 'They appeared in very good condition, - certainly much better than the men who attended upon them. They were kept in milk as long as they would pay, though one of them had been in milk three years, and then gave only three quarts per day. They stand upon brick floors. Their feed was one bushel of grains in the morning, and one in the evening, with ten pounds of potatoes, and twenty pounds of mangel-wurzel to each cow, per day. One truss (fifty-six pounds) of hay was divided among ten in the morning, and one truss among twenty in the evening. In the proper season, grass - clover or rye grass - is supplied, but the quantity not determined. In some cases, one bushel and a hialf of grains, forty pounds of mangel-wurzel, and ten or twelve pounds of clover hay, constituted the allowance of each corv. This must be considered as very liberal; and what better repays such liberality than a good cow?

* I may observe, in passing, that two strippers were employed at this establishment to follow the millers; and that a fine of a shilling was always levied upon the millker, when any milk was found after he or she had left the cow. The milk is sent out in sealed or locked vessels, containing eight gallons each, which are carried upon men's or women's shoulders, and distributed over the town. Where the vessels are locked, the milk cannot be adulterated after it goes into the hands of the distributors. What perils it passes through before that time, those who use it can best judge. The labor of distributing seems severe upon wornen, who are much employed for this purpose, and who are principally from Wales; but, in general, they are examples of ruddy health and great muscular 
In St. James's Park, where several very large cows - Yorkshire --are kept tied constantly through the day, for the purpose of supplying a glass of milk fresh from the spring, for those whose unadulterated taste can relish it, and where the cows are petted and highly fed, I have occasionally inquired for the yield. The answer, from an intelligent and civil keeper, has been, sixteen quarts per day, and, within his knowledge, never more.

The first cross of the improved Durham stock with the $\Lambda \mathrm{yr}-$ shire or the Devon has, I may say; almost invariably, produced a fine milking animal. This point may be decmed established. Innumerable instances of this have come under my own observation. I found one instance, in Leicestershire, of a cross between a Durham and an Alderney. The cow, the progeny of such cross, produced sixteen pounds of butter per week, for ten successive weeks, upon grass only. This farmer had twentytwo cows, nearly all of them high-bred Durham stock; but he candidly stated that they were not good milkers.

The Ayrshire stock are generally deemed the best milking or dairy stock in the kingdom. This is a strong statement; my own observations, which were, however, of necessity limited, would make me hesitate in speaking so emphatically. Their general reputation is, certainly, strongly in their favor.

The excellent farmers of Ayrshire - and it would be difficult in any part of the kingdom to find their superiors - are most emphatical in their preference of their own cows for the dairy. Some of the large farmers, under what is called the bowing or boyening* system, let them to smaller farmers, who pay the owner ten pounds a year for the cow. The owner provides for the cow, and incurs all risks of injury or death. The lessee takes the entire care and management of the cow, and generally gets for his profit two pounds to three pounds per cow. This speaks favorably for the stock, though, to ascertain the exact result, the marliet value of the produce, and the price of dairy labor, and other circumstances, should be known.

I visited, in Ayrshire, a principal dairy farmer, of high reputation. His cows are all of the pure Ayrshire; he will have

power. In several parts of London, one is entertained, twice a day, with the cry of "Milk from the cow!" which is the signal that the cow is passing your door, and, if so you please, you may draw the precious beverage from the fountain.

* Boyen means milli-pail. 
no other. They were extremely beautiful animals. His best cows, in the best of the season, gave fifty-four pounds of milk per day. If, as is usually reckoned, a pint is a pound, this would be twenty-seven quarts per day. The average yield was forty pounds per day, or twenty quarts. Yet the amount of butter yielded by them was one pound per day, it requiring forty pounds of milk to produce one pound of butter. They were at grass, and had no extra feed. This was a large proportion of milk for the butter. This farmer was then (September 26th) milking thirty-five cows, from which he sold, the previons week: one hundred and fifty pounds of butter, - not a large amount. It is stated, confidently, upon authority which I personally know is entitled to entire confidence, that an Ayrshire cow has given eighteen Scotch pints, or nearly thirty-six English quarts, per day ; and that a three-ycar-old heifer gave, for six weeks after calving, fourteen pints, or twenty-eight quarts, per day. These were extraordinary animals.

The account given by a celebrated writer on dairy husbandry, that "there are thousands of the best Ayrshire cows, which, in their best condition and well fed, will yield four thousand quarts of milk per year, and produce three hundred and seventy-five pounds of butter each, - and that, in a dairy of sixty cows, every one yielded her own weight, annually, of the best cheese to be met with in Scotland," - must, I think, have been penned some evening when the northern lights, the aurora borealis, were peenliarly brilliant in a Scottish sky. I do not deny the truth of these statements; but my own observation has not confirmed them.

The statement of a farmer in Stirlingshire, of the highest eminence, given to me, was, that his Ayrshire cows, in the best of the season, averaged one pound of butter per day; that he has known two Ayrshire cows to make two pounds two ounces each per day; and that with him sixteen quarts of milk produced one pound of butter.

The North Devon stock have some strong advocates as a milking stock. The most productive cow in butter which $I$ bave found was a North Devon, which, for several weeks in succession, without extra feed, produced twenty-one pounds of butter per week. The character of the owner places the fact beyond a doult. Mr. Bloomfield, the eminent tenant of Lord Leicester, 
after many years experience, states that his North Devon cows will give an average of four pounds of butter per week, through the year. One English pint of milk, as he adds, will produce one ounce of butter; that is, eight quarts will make a pound. I give his statement; but the case will obviously be affected by the length of time which has elapsed from the calving of the animal, by the mode of feeding, and whether it is of the milk first or last drawn from the udder. The celebrated Danvers or Oakes cow, in the United States, which made over four humdred and eighty pounds of butter in a year, - nineteen and one fourth pounds in one week, - and, within my knowledge, sixteen pounds a week for more than three months, and another cow, also within my knowledge, which produced three hundred and thirty-five pounds per year, were evidently of the North Devon blood, though not pretended to be pure. The first cross of the Durham with the North Devon, as I have remarked, produces an excellent milking progeny. Breeding for this object camnot be continued beyoud a first cross with any certainty of success.

The Staffordshire long horns, a race which I have not described, but which have always been eminent as milkers, and with which Bakewell began his celebrated improvements in stock, have produced some excellent milkers, by being crossed with the Hereford stock. Two of these animals, owned by a friend, an excellent manager of his little farm, as well as a most highly esteemed clergyman, in Worcestershire, — two characters not umfrequently united, - produced twenty-five pounds of butter per week.

The Kerry cows, of Ireland, — not the very small stock referred to page 178 , vol. i., — are greatly valued for their millking properties. 'Three of these cows, at a milk establishment near Cork, it was stated to me, yiclded twenty-one gallons per day, or twentyeight quarts each. This was at Blarney Castle, but I did not receive it as "blarney." It was stated to me, on respectable authority, that a reverend gentleman in the county of Kerry had, the previous year, as the produce of five cows, sent to Liverpool twenty-five firkins of butter, of sixty-four pounds each, which would be equal to three hundred and twenty pounds per cow. The cows were fed most liberally upon mangel-wurzel. If there be uo mistake in the size of the firkin, this is certainly a most extraordinary yield.

VOL. II. 
I come, lastly, to speak of the Alderneys as a milking stock. I believe it will be admitted, without a dissentient voice, that for richness of milk, as a race, they are unrivalled, and this with scarcely an exception. I shall state some facts within my knowledge in regard to quantity, obtained without any extra feeding. A farmer in Hampshire owned an Alderney cow, which produced fourteen pounds of butter per week, for a period of thirteen weeks. When I visited him in the summer, he had six Alderney cows, which together had produced fifty pounds of butter per week, during the whole season. Another farmer, whose authority is above question, assured me that, from four Alderney cows, he had made, during the months of May and June, fifty-two pounds of butter per week. Colonel Le Couteur, with whose acquaintance I am honored, states that "the best Alderney or improved Guernsey cows give twenty-six quarts of milk in twenty-four hours, and fourteen pounds of butter from such milk in one week. Such are rare. Good cows afford twenty quarts of milk daily, and ten pounds of butter weekly, in the spring and summer months." *

Mr. Bates, the celebrated breeder of short horns, gave me the subjoined minntes respecting some trials of the quality of milk among stock owned by him:-

One quart of milk, West Highlanders, produced 2 oz. butter.

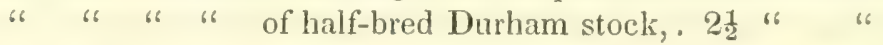
" " " " " average of short horns, . . " 1 " "

Of some select or extra stock, the following was the result:-

One quart of milk, short horns, produced, . . . 221 oz. butter. " " " " " " " 6 of West Highlanders, ...2 " " " "

Of the milk of his famous cow Duchess, a full-bred improved Durham, giving fourteen quarts at a milking, each quart produced one ounce and a half of butter. Supposing the yield at each milking to have been the same, i. e. equal to twenty-eight quarts per day; the amount of butter obtained is shown to have been eighteen pounds six ounces per week. In the case of another cow in his possession, of the same stock, and, I believe, the daughter

* Journal of the Royal Agricultural Society, vol. v. part 1, p. 50. 
of the above, one quart of milk produced two and a quarter ounces of butter, but her yield was not stated.

At Welbeck, at the Duke of Portland's, an Alderney cow, giving three and a half gallons of milk per day, produced fourteen pounds of butter per week. An improved short horn, yielding six gallons per day, produced tivelve and a quarter pounds of butter, in the same time.

In a comparative trial between the milk of the Alderney and Kerry cows, detailed in the Journal of the Royal Agricultural Society, vol. ii. p. 420, the result was as follows, as tested by a lactometer.

$\begin{array}{cccclccc}\text { Portions of cream, } & 100 \text {; May, Alderney, } 25 \text {; Kerry, } & 10 . \\ \text { " } & \text { " } & \text { " } & \text { " June, } & \text { " } & 20 ; & \text { " } & 10 . \\ \text { " } & \text { " } & \text { " } & \text { July, } & \text { " } & 23 ; & \text { " } & 10 . \\ \text { " } & \text { " } & \text { August, } & \text { " } & 16 ; & \text { " } & 13 .\end{array}$

3 pints of Alderney cream gave $1 \mathrm{lb} .8 \frac{1}{2}$ oz. avoirdupois.

" " " Kerry " " 1 " 4 4 $4 \frac{1}{2}$ " "

The farmer attributes "the falling off of the Alderney in cream to their being old in milk, and having cast their calves. The Kerrys came into pasture fresh in milk after their first calf."

At a trial of the qualities of milk, on a farm near Liverpool, which I visited, the milk of the several breeds was, in point of richness in cream, as follows:-

Yorkshire and common cows, as 8 per cent.

$\begin{array}{lllllll}\text { Ayrshire, " " } & \text { " } & \text { " } & 15 & \text { " } & \text { " } \\ \text { Alderney, " } & \text { " } & \text { " } & 23 \frac{1}{2} & \text { " } & \text { " }\end{array}$

There is obviously much uncertainty in these trials, from the different conditions, in various respects, in which the cows might have been, and other circumstances.

The average yield of new milk cheese to a cow, in the different counties, is given with great uncertainty. The tenant farmers are, in general, disposed to conceal the favorable results of their husbandry, from the effect it may have upon their reuts. *

* The precision which one often finds in the information given by interested parties, may be illustrated by a dialogue with a tenant dairy farmer, in the presence of his landlord, to which I myself was a party.

Inquirer. "Will you have the goodness to tell me the average yield in new milk cheese, by the year, of a good cow?" 
The amount given to me in Gloucestershire was three hundred weight, or three hundred and thirty-six pounds, to a cow; on another dairy farm, admirably managed, and where there prevailed a disposition to give the fullest information, three and a half hundred weight, or three hundred and ninety-two pounds. In a report on Cheshire cheese-making, it is represented at three hundred weight, or three hundred and thirty-six pounds. 'The writer says, in a few instances, five hundred weight, or five hundred and sixty pounds, are produced to a cow ; but these cases are rare. The Cheshire cheese, however, is not pure new mill, as some of the cream from the night's milk is abstracted for butter. In the best cheese district in New England, I have known, in a dairy where a good many cows were kept, the average annual yield of entire new milk cheese to have been, in one case, six hundred and twenty-seven pounds to a cow; in another case, six hundred and thirty-one pounds. This was extraordinary, and showed excellent management. The account may be found in my Report of the agriculture of Berkshire. In general the yield with us, as here, does not exceed three hundred pounds to a cow.

The result of a small dairy farm, where twenty cows are kept, as presented in a late Journal of the Royal Agricultural Society,* gives, as the produce of a cow, three and a half hundred weight of cheese, thirty-five pounds of butter, and thirty-five pounds of whey butter. Considerable amounts of butter made from the

Farmer. "There is a great difference in cows."

I. "I understand that, and do not wish to hold you to an exact statement; but please let me have your opinion of the average annual yield of cows as they rise?"

F. " $\Lambda$ great deal depends on their feed."

I. "I am aware of that; but, to be more direct, will a good cow, well fed, produce one hundred and fifty or three hundred pounds of new milk cheese in a year?"

$F$. "That is very difficult to answer."

1. "It may be difficult to answer. I do not expect you to be very exact; but a general opinion is all I want. What do you think? Will it be one hundred and fifty or three hundred pounds?"

$F$. "Some cows will produce more and some less."

I gave up in despair ; and yet this man every year sold all his dairy produce in the market by weight. The secret was, his rent was very low, and he was a tenant at will.

* Vol. vii. part 1, p. 183. 
whey of cheese go to the market, and bring, within about twopence, the price of whole butter.

(9.) Improvements in Relation to the United States. - In thus giving an account of the neat cattle of Great Britain, I have chosen to give my own observations, and facts coming within my own knowledge, rather than to refer to any published accounts. These are as accessible to others as to myself. The facts which an individual circumstanced as I am is likely to collect, unless his attention were exclusively directed to the subject, are necessarily few, and furnish imperfect grounds for him to speak with confidence, which I would by no means be thought to do. That the neat stock of the United States is of a very mixed and miscellaneous description every one must admit. Comparatively few attempts have been made in a systematic manner, and upon an extended scale, for its improvement. Where they have been made, they have frequently failed from want of perseverance, very often from want of encouragement, - and have been sometimes met with the sneers of ignorance, or the derision of envy. The immense improvements which have been made here strike every observer with grateful astonishment, and are evinced by the accounts which I have given of the progressive size of animals in the Smithfield market. Few subjects, in my opinion, more concern the interests of American husbandry than the improvement of our live stock. Much, undoubtedly, may be done by the selection of the best from our own breeds, and by breeding only from the best; but our stock is so crossed, and mixed up, and amalgamated, that it must be a difficult process to unravel the web, and go back to any original breed. We may certainly, with great advantage, avail ourselves of the breeds existing here in the highest state of improvement. I am quite aware that many very excellent animals have been imported into the United States from this country; and I hope these importations will be increased, and that all pains will be taken to preserve the distinctness and purity of the races, and, if possible, improve them. This can only be done by watchful care, good judgment, and liberal keeping.

In making a selection of breeds, it is plain that regard should be had to the locality where they are to be placed. The improved short horns, the Yorkshire, and the IIereford, are best 
adapted to the rich and deep pastures of the Middle and Western. States; the Ayrshire, and the North Devon, seem to me especially suited to New England; while the West Highland cattle would evidently be fitted to the northern, cold, and least productive parts of the country. Great advantages would, in many cases, accrue from a first cross between some breeds. As I have already said, extraordinarily fine milking animals have been produced, in this way, by the crossing of the Durham and the North Devon, and by a cross of a short horn, even, with an Alderney. An eminent farmer in Ayrshire is accustomed to cross his Ayrshire with the improved Durham breed, and steers of this stock, and heifers, after their first calf, have, as I have seen, proved a most excellent and valuable stock. To proceed further than this has not been attended with favorable results, and is never sure of manifesting the best qualities of their progenitors.

Many persons here have accumulated large profits by breeding very superior animals for sale, and the prices have been often exorbitant. The same results can scarcely be expected in the United States, where the means of farmers are very limited, and few can enter into spirited pecuniary competitions for the mere gratification of taste. But a fair and reasonable profit may be expected, under skilful and careful management.

With us, as well as here, the success of farming must mainly depend upon such a conduct of the farm as shall not exhaust its productive powers; or rather, that it shall, from its own resources, furnish the means, not only of recruiting its strength, but of actually increasing its capabilities of production. 'There is no more obvious way of doing this, than by consuming the produce of the farm, mainly, in feeding animals, through whom the riches of its vegetation may be returned in a form to furnish other and better crops. The stall-feeding of beef-animals, if the current prices of agricultural produce are brought into the reckoning, appears, almost always, a losing operation. It will often be a serious one, where the animals so fed are of a poor and unthrifty character, or where, as dairy animals, the product is small in quantity, and inferior in quality. It is plain how much the favorable chances of success are improved, when the stock to be fatted are of a kind to fatten rapidly, and to return large weights, and where the yield of the dairy stock is of the finest quality, and given in abundance. The difference between one 
hundred and twenty pounds of butter and two hundred pounds, as the annual produce of a cow, or between three hundred pounds of new milk cheese and five or six hundred, is of easy calculation. In the attempts to improve our cultivation, to increase our products, and to produce the best, we shall not always succeed; and when we have done all we can, we may fail from causes wholly inscrutable; but we must continually try for success, for we are certain not to succeed unless we do try.

I have never considered farming, under any circumstances, as a source of extraordinary profits, or the means of rapid accumulation; but, under good management, it presents, ordinarily, the means of fair, reasonable, and honest gains. It is a hard case, when, to an industrious and frugal man, it becomes, as it may, a losing concern. Dr. Franklin, with his usual shrewdness, has said, that the thermometer, by which to judge of a man's feelings or enjoyment, is his pocket. When that is empty, the mercury goes down below "zero." With railway speculators, stockbrokers, land-jobbers, and all that class, it may often go up to boiling heat; and in as many instances, it may be found frozen in the bulb. Such extremes disturb all comfort; they always endanger morals; they too often lay waste the human heart, stripping it of its best affections, and make shipwreck of life. With the farmers, at least, I should be glad always to find it, at "temperate." As a means of health, - as a source of rational, and delightful, and innocent occupation, - as a branch of high intellectual philosophy and study, - an enlightened and improved agriculture may commend itself to many thoughtful, and virtuous, and well-governed minds; but to the great mass, in order to stimulate their exertions, and to satisfy purposes which are not unreasonable, it must be a means of comfortable subsistence and profit; and it can only be made so by adopting, pursuing, and, if possible, enlarging by science, experience, inquiry, and practice, the great improvements which have already been made in this first and best kind of human effort.

3. Sheep. - In importance, sheep occupy a high place among the live stock of Great Britain. It would not be easy to make a just comparison between the amount of wool and mutton produced and the product of the dairy or the stall; but the number of sheep in Great Britain is very great. The wool finds a 
demand in the various manufactures of the country; and mutton and lamb make up an extraordinary portion of the food of the inhabitants.

Size, thrift or disposition to fatten, hardihood, early maturity, prolificness, quantity and quality of wool, are matters of great consideration in these animals. It cannot be said that all these properties have been as yet combined, in the highest degree, in any one kind of sheep; perhaps such a combination is impossible; but the efforts for the improvement of the different races, and, in several instances, the success of those efforts, have been as remarkable as in the improvement of neat stock.

There are no fine-wooled sheep in Great Britain. 'The finewooled sheep of Spain and Saxony have not size enough to meet the demands of the markets for mutton; at least, this is the prevalent impression. Perhaps the merino blood might be engrafted into their flocks, to a certain extent, with great advantage; but they fear the diminution of size. Size and fatness are the principal objects of the British farmer; and, in the latter quality, it would be undesirable to attempt any further advance. The fatness of much of their mutton now renders it almost uneatable.

I do not propose to give a particular account of the different kinds of British sheep, but shall speak only generally, with the exception of the two prominent breeds.

(1.) Various Breeds. - The Lincolnshire, the Cotswold, the Dorsetshire, the Gloucestershire, the Oxfordshire sheep, aro large, coarse-wooled, and coarse-boned sheep, which have their partisans in particular districts, and are much crossed and intermixed with others, but have not attained the enviable distinction of being, if I may be allowed the term, cultivated and improved, so as to form a distinct and extensively popular race. Their yield of wool is large, averaging six or seven pounds to a fleece, and in some instances more, and of variable price, dependent, of course, upon the caprices of the market, but, in such a country as this, always in demand for coarse fabrics. Some of these sheep, the Lincolnshire in particular, attain to an cuormons size. I have seen some which, it was calculated, would weigh, when dressed, above seventy pounds per quarter, - the farmer who was feeding them having already killed some which had reached 
that amount. I shall subjoin the authenticated accomnt given me of a Lincolnshire sheep, which will show that I do not deal in exaggerations.* The sheep which I saw in the process of fattening, it was thought, would closely approximate the same weight. I may well say, "they were a sight to behold."

That any sheep should be found of the extraordinary weight of the one given below, will excite the surprise of many of my readers. These sheep, however, as a breed, are not distinguished for their thrift, and are not sought after in the market. A small Welsh sheep, the meat of which is particularly liked, though weighing only about ten pounds a quarter, would sooner find a purchaser, and at a higher proportionate price.

The Dorsetshire sheep have the peculiarity of producing lambs twice in the year. On the farm of an enterprising cultivator in Worcestershire, whose farming is of a high order, $\dagger$ it is the custom to breed from Dorset ewes, twice a year,

"Weight and particulars of "William the Fourth," a two-shear sheep, fed by Henry Healey, Esq., and slaughtered at Brigg, 10th March, 1836.

\begin{tabular}{|c|c|c|c|c|c|c|c|c|c|c|c|c|c|c|c|c|c|}
\hline Live weight, & . & . & & . & . & . & - & - & - & & • & & & & & . & 43400 \\
\hline Dead weight, & - & - & . & - & . & . & - & - & - & - & - & . & - & & $l b s$. & $\dot{0}$ & $304 \quad 10 \frac{1}{2}$ \\
\hline Blood, & . & . & - & - & . & - & - & . & - & - & - & . & . & - & 11 & 0 & \\
\hline Skin, & . & - & . & . & - & - & - & . & . & . & . & - & . & • & 36 & 0 & \\
\hline Pluck, . & . & . & . & . & . & . & . & . & . & . & . & - & . & - & 8 & 4 & \\
\hline Loose fit, & . & . & . & . & . & . & . & . & . & . & . & . & . & - & 34 & 0 & \\
\hline Entrails, & . & . & . & . & . & . & - & . & . & . & . & . & . & - & 26 & 12 & \\
\hline Head, . & . & . & . & . & . & . & . & . & . & . & . & . & . & - & 8 & 12 & \\
\hline Waste, & . & . & . & . & . & . & . & . & . & . & . & . & . & • & 4 & $9 \frac{1}{2}$ & 129 \\
\hline & & & & & & & & & & & & & & & & & $434 \quad 0$ \\
\hline
\end{tabular}

Dead weight, $304 \mathrm{lbs} .10 \frac{1}{\mathrm{~L}} \mathrm{oz}$, or $76 \mathrm{lbs} .2 \frac{1}{2} \mathrm{oz}$. per quarter.

This sheep clipped sixteen pounds of wool the first time he was shorn, and twelve pounds the second time.

† As I may have no better opportunity, I shall digress here to speak of what this farmer has effected, within a few years, by his excellent management. The furm consists of one hundred and seventy-two acres of fair land, with a varied soil, and when he entered upon its improvement, it was quite "down at the heel." He has increased his average product of wheat from twenty-three bushcls to thirty-six bushels per acre, and has sometimes produced fifty-one bushels. His yield of carrots average thirty-six tons per acre, and his mangel-wurzel twentyfive tons. He prefers the Belgian, or white carrot, to any other, being much more productive. This is a general opinion. He keeps twice the quantity of stock which was kept on the farm when he began his improvements; and he sells annually. sixty tons of hay. I refer, in this case, to the farmer who cultivateg gorse 
having two crops of lambs to send to market, the first in December, the second late in the spring. In this case, the ewe and the lamb are both well fed and nourished with much care, as indeed can well be afforded. He stated to me a fact which deserves notice. He has frequently crossed his Dorset ewes with a Hampshire buck; and in this case, the female progeny loses the property of breeding twice a year. I leave the philosophy of this to the physiologists; but the experience of this farmer established the fact. A sheep which will give two lambs a year for the market, and her own fleece, is a profitable animal. The lambs sent to market at Christmas, in a place like London, where persons are always to be found able and willing to pay an exorbitant price for luxuries, can always be sold to advantage.

(2.) Cheviot and Highland Sheep. - The next breeds of sheep which are commonly seen in the Smithfield market, and are bred extensively in their proper districts, are the Highland and the Cheviot sheep, - the former at the north, and the latter at the south, of Scotland. Both of these kinds of sheep are of moderate size, and of good shape, weighing, when dressed, from twelve pounds to sixteen pounds, and upwards, per quarter. Their wool, especially that of the Highland sheep, is of very inferior quality, being worth less than half the price of common wool. The Cheviots are excellent mothers; and both of these kinds of sheep show a remarkable thriftiness, when brought from the north to the rich pastures and turnip fields of the south. Their mutton, of the best quality, always commands a high price in

extensively, for his stock, - of whom I have spoken. This gives him a great amount of food and manure. Besides this, he has the best arrangement for liceping his manure which $I$ have seen in the country. A long shed, open at the sides halfway down, with a floor sunk about two feet in the ground, and the whole walled in at the sides with a brick wall, rising about three feet above ground, with a tight bottom, inclined so that all the drainings of the heap run into a well in the corner, formed the receptacle for his manure. The manure was regularly brought into it from the stables and cow-houses. Thus his manure was effectually protected from the sun and rain, and was accessible, either for deposit or removal. A pump was placed in the well; and as it became full, from the drainings of the heap, the liquid was pumped up, and by a movable trough spread over the heap. It is an important point to secure a manure heap from the drenching rain, as otherwise the liquid running from it becomes greatly diluted, and in such case appears to lose much of its efficacy. 
the market, from the resemblance in its taste to venison, and is much sought after for epicurean tables. The Cheviots are white-faced sheep, and much valued. They are never housed, and are left to dig for their food in the bleak pastures, in the depth of winter. Their wool is coarser than that of the South Devon, and is not used in the manufacture of finer cloth. 'The West IIighland sheep and the Cheviots are valuable races for their hardiness. The Highland sheep have black fices, and are horned. They are long and ill-shaped; and the average weight of wool is about three pounds per fleece. They are deemed even hardier than the Cheviots; but they come to maturity later, and the best of them are not killed until they are three years old.

(3.) Leicester Sheep. - Of the long-wooled sheep, the Leicester take precedence of all others. This race of sheep owes much of its excellence to the sagacity and skill of the celebrated breeder, both of cattle and sheep, Mr. Bakewell. It was his aim, by careful selection, to combine, if possible, fineness of bone, beauty and symmetry of form, tendency or disposition to fatten, with weight of carcass, and a good yicld of wool. In all these respects, it is surprising what he seems to have been able to accomplish; and for roundness and finish of form, flatness and width of back, shortness of neck, fulness of breast, width behind, and depth of fat upon the ribs, the best samples annong them are most remarkable.

The success of Bakewell in breeding his sheep, and raising them to a high degree of perfection, is perhaps in no way more strongly evinced than in the fact that "he let his first ram for the season, in 1760 , for seventeen shillings and sixpence, and in 1789 , he let one ram for one thousand guineas, and he cleared more than six thousand guineas, or more than thirty thousand dollars, the same year, by the letting of others." These fine sheep, either pure or intermixed, are found spread extensively over the kingdom, though they are not well adapted to a cold climate, to short feeding, or to travelling long distances. 'They cannot, I think, be pronounced a hardy sheep; but many of the long-wooled sheep, of various kinds, have been improved by being crossed with the Leicester. Their yield of wool is from six to seven pounds per fleece, and is valued especially for 
worsted yarns, and goes into serges and carpets. They are remarkable for their quiet habits, and seem to enjoy life in eating and growing fat. They are not highly valued in Smithfield market, from their excessive fatness, giving a very small proportion of muscle or lean meat, and a large portion of the carcass being absolutely uneatable, except by the most gross and truly Esquimaux appetites.* The Lincolnshire sheep are larger and coarser; but in tendency to keep, and increase in fatness, the Leicesters are beyond all rivalry; indeed, in respect to almost all the other long-wooled sheep, they have been so crossed and intermixed with the Leicester, that it would be difficult to find a pure animal of any one of the original breeds.

\section{(4.) South Down Sheep. - The South Downs are an admi-} rable race of sheep. The picture in the front of the Sixth Report gives an imperfect idea of their extraordinary beauty; and their value corresponds with their beauty. 'Their average yield of wool is about four to five pounds, of a short staple, and of a tolerably fine, and extremely useful quality. Though they have a great disposition to fatten easily, and come to a good weight, such as twenty pounds per quarter, and often exceeding that, yet their fat and lean are well mixed, and the proportion of one to the other in the same animal such as is desired. They have dark faces, short legs, and stand extremely well upon their legs: are broad in the chest, round in the barrel, most compactly and

* That I may not be charged with prejudice, I shall quote here a letter received from an eminent Smithfield salesman, through whose hands, probably, morc sheep pass, in the course of the year, than those of any other man. "It is necessary that I should qualify my observations by saying that no doubt Leicester sheep have been of immense service; and some of the best of them are now exceedingly good, having the tendency to fatten more quickly than any others. But you will find my dislike of them is shared by almost all practical men. They certainly have degenerated exceedingly, becoming small and light of flesh, and unsalable from these causes - making but little meat per pound, and weighing but very little. 'The average weight of those which come to our market is about eight and a half stone, (eight pounds to a stone,) or seventeen pounds per quarter. The truth is, that some persons have paid such close attention to neatness, symmetry, and comeliness of form, that they have lost size, flesh, and worth. They have, however, their advantages, for such is their aptitude to fatten, that it is only fair to admit that more can be grazed to an acre than of other sheep. The cross of a good Leicester ram with a large-framed Down, makes an excellent sheep." 
strongly built; with flat backs, and broad and square behind; quiet and good-tempered; much more hardy than the Leicesters, though in this respect inferior to the Cheviot and the Highland sheep; capable of being driven, without injury, two, three, or more miles a day, and used often for treading the new-sown wheat where the soil is thin; and doing the most ample credit to any care or kindness bestowed upon them. Their wool is much inferior in fineness to that of the Saxony or Merino; but for quality and amount of wool, for size and weight, for quality of flesh, and for gencral hardiness, it would be difficult to find a superior race of animals.

Jonas Webb, Esq. of Babraham, Cambridgeshire, - whose flocks and excellently-managed farm I have repeatedly seen, having been kind enough to answer fully several inquiries which I proposed to him, I shall give my readers the benefit of his replies. No man is more competent to speak on the subject, for no man's flock in the kingdom has attained a higher eminence.

He has been a keeper and breeder of South Down sheep for nearly a quarter of a century, and laid the foundation of his flock by a selection from some of the best flocks in the kingdom. Since he began his improvements, he has never made a cross with any other breed; and no individual has ever carried off more prizes at the various agricultural and cattle shows, where the premiums are always assigned by judges who are understood to be entirely disinterested, and withont any knowledge of the parties to whom the animals beiong.

"I classed my sheep into three different tribes, according to the different breeders from whom I procured them, after I hat made various experiments with the stock from each, varying, of course, according to the frame and constitution, weight and quality of mutton and wool, and the different character which I might require, always lieeping in view never to breed from an unhealthy animal, however superior he might be in other respects. I have since been rearing a fourth and a fifth tribe, which I am only able to do by keeping a pedigree of each, and by which means $\mathbf{I}$ am able to mix one tribe with another, as circumstances and convenience may require, believing, in most cases, 'like will produce like,' with proper care and watchfulness.

"I consider them to be much hardier than either the Leicester, voL. II. 
Lincoln, or any other white-faced breeds, the Welsh sheep and Cheviots excepted, with quality of mutton and wool superior to any of them. The weekly statement of prices in the London Smithfield market will bear me out in this assertion in regard to meat, and the regular wool market in respect to the wool; althongh, I believe, wool of the first cross between the Leicester and the South Down, from the first clip, is worth, at the present time, fully as much as the pure South Down, for certain purposes. I believe the South Down has more muscle, that is, more lean meat, in proportion to their fat, than any other sheep.

"Their aptness to fatten is very great, at an early age. It has, for many years past, become the custom, in the arable land district, to winter the wether lambs (viz., castrated lambs) upon turnips, rape, \&c., with from half a pint to a pint of corn, (pulse or grain,) or oil cake made from linseed, per day, in the fold on the turnip lands, where they are kept as long as the turnips last, say until the middle of April, when they are clipped and sent to market. Many are sold before that time, so that they are disposed of to the butcher at from twelve to fifteen months old, weighing, upon an average, from eighteen to twenty pounds a quarter. I believe they are capable of walking farther for their food, and bringing it to fold, than any other sheep which can be kept in hurdles, keeping the same good condition. As a proof of this, you may see that my flock of ewes often walk from five to six miles per day, backwards and forwards, to feed upon very, very poor heath or sheep-walk, and have no artificial food.

"The average yield of wool from breeding ewes is about four ponnds each, and from ewe and wether hogs, ${ }^{*}$ from six to eight pounds each, according to their size and keep, and the time of clipping them. On referring to my sheep book, I find the average weight of wool for seven years past, upon sheep of different ages, from one to seven years old, (rams,) varying in number from one humdred and fifty to two hundred, each season, to be about eight pounds each.

"I obtain usually one hundred and ten lambs to one hundred ewes, and often many more. The lambs come generally about the beginning of March. Many persons have them earlier, and

* A sheep, after one shearing, when a year or a year and a half old, is called as shear-hog, or dinmont, or shearling. 
many later; and, in a general way, the later they lamb the more they twin.

"The ewes are first put to the ram at about nineteen months old. I generally put eighty ewes to each ram; sometimes more; often less, if the ram is aged, or according to circumstances.

"I feed my flock ewes upon stubbles from whence the crops of corn (grain) have been harvested, and upon old seed-layers, (lands laid down to grass,) about the time of putting the rams with them. They are generally together about eight or ten weeks, more or less, according to circumstances. The ewes are shifted about from the stubbles in which are the young clovers, \&c., for the following summer, on to old heath, sheep-walk, or pasture, until within a short time of their lambing, if that description of food lasts out, when they are put upon turnips to be eaten off upon the land on which they are grown, hurdled in for that purpose, and receive only a small quantity of them at first, with some hay chaff, or hay and straw chaff mixed in troughs. Some have straw chaff only; or I remove the ewes into a straw yard to pick over the straw, to lodge there at night, and return to the turnip field the next morning. On very bad feeding land, the turnips are often drawn off the land and stored, and the sheep are fed with them upon pastures or in yards. About a fortnight or three weeks after the ewes have lambed, they have what turnips they require, with some hay chaff or straw, and are kept upon them as long as the tumips last, when they are fed with mangel-wurzel, rye sown for spring feed, \&c., until the artificial grasses are ready for feeding, upon which the flock continue until the lambs are weaned. This takes place generally about the latter end of June, or the beginning of July, according to the age of the lambs. The lambs are then put upon after-grass from which hay has been cut, artificial grasses, \&c., until the turnips or rape are ready to be eaten off, when they are put upon it, and are (speaking of my own) never taken off the land upon which that food is growing, until it is all consumed, the following spring, however bad the weather. The ewe lambs intended for stock have some chaff in troughs besides the turnips, which are not cut, but eaten off the ground. The wether and ram lambs have the same treatment, with the addition of a little corn (grain) or oil cake, or a mixture of them, according to the price, and have their turnips cut for them in 
troughs. The corn or oil cake is given in small quantities at first, and increased until each receives one pint per day, which is sufficient to fatten them by the time before specified.

"The ewes are often kept until they are nine or ten years old, but not in the regular flock, as they are mostly brokenmouthed and require nursing, especially where they have been kept much upon turnips. 'The usual time of keeping them, if in a flock, is until they are six or seven years of age.

"I think the first cross with a South Down and a Leicester one of the best I have ever seen, both for mutton and wool, and general usefulness; and as a breeder of South Downs, I recommend to use the South Down ram to the white-faced ewe, as the produce, when fat, is worth more per pound than a cross made the other way, viz., with the white-faced ram and the Sonth Down ewe; but possibly a breeder of Leicester rams would say differently. I believe my assertion will be borne out, that eight lambs out of ten will take most after the male, if a South Down; in color, and a greater number than after the Leicester ram; and the price in Smithficld will determine which description is worth the most per pound, a white or brown-faced sheep. I have stated that the produce, when fat, are worth more per pound, as I consider that all sheep so bred, viz., as crosses, are worth more to fat than for any other purpose, and are certainly excellent sheep. Some crosses have been carried farther to great advantage, withont doubt, but it is the exception not the rule. Little doubt exists in my mind, that the breeders of Leicester and other white-faced sheep can and do use a South Down for one cross only, and then breed on from that cross, not by putting the crosses together, but by putting a white-faced ram to the halfbred ewc, and so keep on, from her produce, with the Leicester or white-faced sheep for several generations, by which means they obtain more muscle, more constitution, quite as much or more wool, (if the selection is properly made in choosing the South Down ram, ) and I believe the brown color of the male would be quite subdued by the second cross, or the third at most; on the other hand, I believe it has been proved that the stain of the white-faced sheep in a South Down flock, where the experiment has been tried, has never been extinguished. Some will come a little different from others in the same lot. Perhaps some individuals may differ from me in opinion. You asked for mine. 
"In making these remarks respecting the South Down sheep, I wish it to be fully understood that it is far from my wish to disparage any other breed of sheep. There may be others equally good for certain districts and localities; possibly better. My object has been to point out the general usefulness of the one, without calling in question the good qualities of any other."

I hardly know what requires to be added to an account of this excellent breed of sheep, so full and explicit as that which has now been laid before my readers, and every word of which rests upon careful and successful experience. Some of the principal breeders of sheep in England have annually a letting of tups or rams, in which their best rams are exhibited, and they are then let, in open auction, to such farmers as choose to hire them for the season, for the improvement of their floclis. I have attended two such meetings, where I found a numerous party of farmers, breeders, and amateurs, assembled, — some coming from a long distance, - the competition spirited, and the hospitalities of the farmer or proprietor, at whose place we met, most liberal.

The first of the two meetings I attended, was at Ingestrie, Staffordshire, the seat of Earl Talbot. The bucks to be let, on this occasion, were superior animals of the Leicester or Bakewell breed, amounting to twenty-four. There were of these twelve shearlings, or animals from whom only one fleece had been taken, and the amounts of these shearings were given as fol-

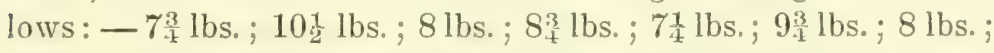
9 lbs. ; 10 lbs.; $8 \frac{1}{2}$ Jbs. ; 11 lbs. ; 9 los. These sheep were all of a high character. In this case the bidding was private, the offer being privately communicated to the agent for the sale, who first announced to the bidder the price at which the individual sheep was held, and then took the highest advance upon that price, the buck too, upon which he bid, being known likewise only to the agent. This method gratified the secretiveness of those who wished to conceal their bargains, and at the same time induced the hirers to name at once their highest offer. The company, which was numerous, afterwards dined together in the palace hall. His lordship himself presided at the dinner.

At Mr. Webb's, at Babraham, Cambridgeshire, the bucks to be let amounted to 177 , which were all numbered and tied upon the ground, for the examination of the company. The number of each sheep was given upon a list exhibited, with his age, the 
amount of wool yielded by him, and the price at which his letting was fixed. At an appointed hour, each sheep was brought into the ring, the lowest price named, and the competition began by an advance upon the price stated. If not taken, his letting was afterwards the subject of private negotiation. In some cases, there was a large advance. After the letting, the company, consisting of more than two hundred noblemen, gentlemen, and farmers, sat down to a bountiful entertainment, provided by the host, in a marquée erected for that purpose. Mr. Webb stipulated to convey the animal sold, at his own expense, half the distance, if it did not exceed one hundred miles, and to take all the ordinary risks. I subjoin the list of 1846 , including number, prices, and weight of wool, thinking it may be curious to my readers.

Number of Bucks, Weight of Wool, and Prices of Letling for the Season, at the Tup Show of Jonas Webb, Esq., Babraham, Cambridgeshire, July, 1816.

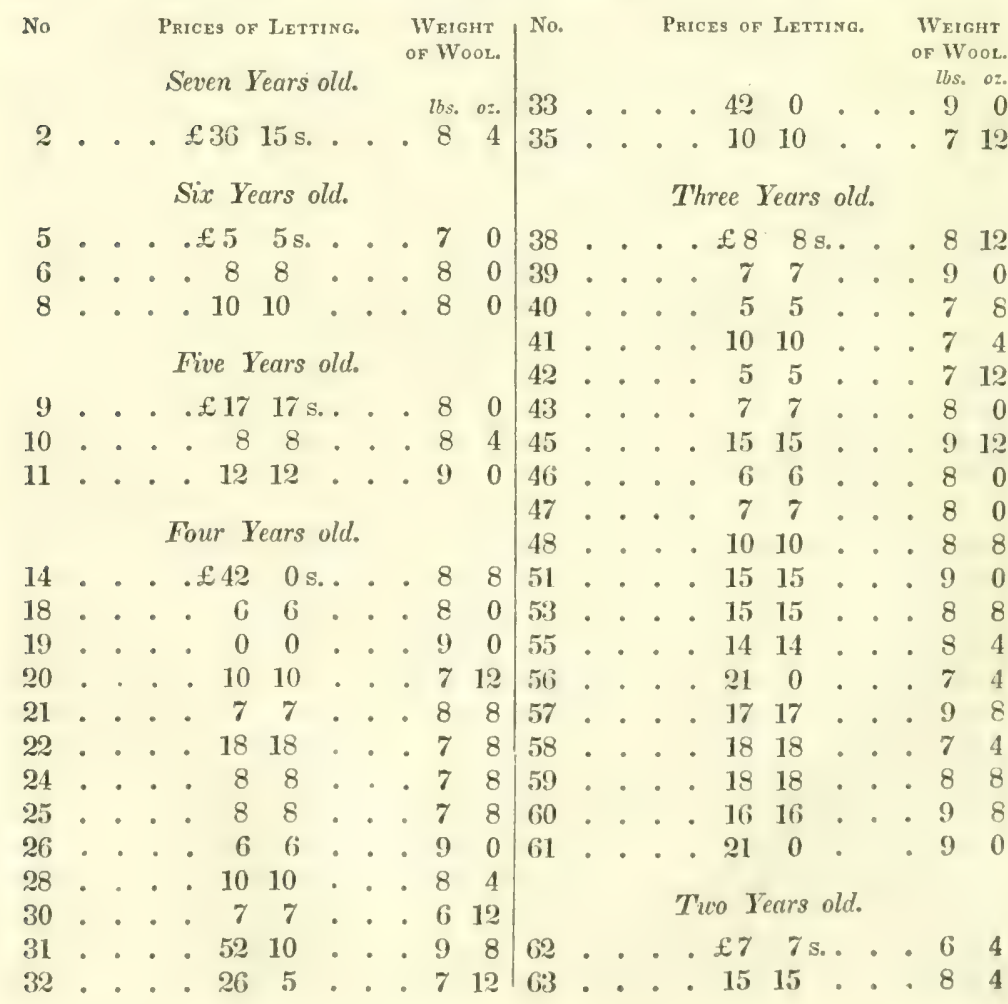




\begin{tabular}{|c|c|c|c|c|c|c|c|c|c|c|c|c|c|c|c|c|c|}
\hline No. & & & Prices or & & & & $\begin{array}{l}\text { Werge } \\
\text { of Wo } \\
l b s \text {. }\end{array}$ & $\begin{array}{c}\text { ont } \\
\text { oor. } \\
\text { oz. }\end{array}$ & No. & & & RICES OF & & & & $\begin{array}{l}\text { WEIG } \\
\text { OF WD } \\
l b s .\end{array}$ & \\
\hline 64 & - & . & . $£ 10$ & $10 \mathrm{~s}$. & . & & . 7 & 8 & 124 & . & . & . $£ 21$ & $0 \mathrm{~s}$. & . & & . 7 & 0 \\
\hline 65 & - & & . 6 & 6 & . & & - 6 & 8. & 125 & . & & - 8 & 8 & . & & 7 & 12 \\
\hline 66 & & . & - 11 & 11 & . & & - 9 & 8 & 127 & & & 11 & 11 & . & & 7 & \\
\hline 69 & & & . 18 & 18 & . & & . 8 & 12 & 12 & 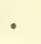 & . & . 6 & 6 & . & & 7 & \\
\hline 70 & . & . & 10 & 10 & . & & . 8 & 0 & 1: & & . & . 11 & 11 & . & & 8 & 0 \\
\hline 72 & & - & 15 & 15 & . & & - 8 & 4 & & & 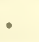 & 8 & 8 & . & & - 8 & 0 \\
\hline 73 & • & . & 15 & 15 & . & • & . 7 & 8 & 13 & & 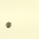 & 8 & 8 & . & & 8 & \\
\hline 74 & & & 24 & 3 & . & & . 10 & 8 & 13 & & . & 11 & 11 & 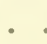 & & . 8 & \\
\hline 75 & & . & 8 & 8 & • & & - 9 & 0 & 18 & & & . 7 & 7 & & & - 6 & \\
\hline 77 & 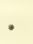 & • & 18 & 18 & . & & - 7 & 0 & 13 & & . & - 10 & 10 & & & . 8 & \\
\hline 78 & & • & . 10 & 10 & • & & - 8 & 0 & & & . & - 12 & 12 & & & 8 & 0 \\
\hline 79 & & . & 10 & 10 & . & • & . 7 & 8 & 14 & & . & 14 & 14 & & & . & 0 \\
\hline 80 & & & 8 & 8 & - & . & - 8 & 0 & 14 & & . & 9 & 9 & & & . 5 & 12 \\
\hline 81 & & & & 6 & . & & - 7 & 0 & 14 & & 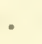 & 15 & 15 & & & & 8 \\
\hline 82 & & & & 6 & . & • & - 8 & 0 & 14 & & 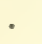 & - 10 & 10 & & & . 8 & 8 \\
\hline 8 & & & 8 & 8 & . & & - 8 & 0 & & & . & . 10 & 10 & & & - 8 & 0 \\
\hline 87 & & • & 16 & 16 & • & & - 7 & 0 & & & - & 9 & 9 & & & . & U \\
\hline 88 & - & • & 18 & 18 & . & • & - 8 & 4 & & & . & 16 & 16 & & & 8 & 0 \\
\hline 89 & . & • & 21 & 0 & . & . & . 7 & 0 & & & 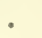 & 26 & 5 & & & 7 & 12 \\
\hline 90 & & & 12 & 12 & . & & 8 & 0 & & & & 18 & 18 & & & • & \\
\hline 9 & & & . $\quad 52$ & 10 & . & & . 9 & 8 & & & . & . 15 & 15 & & & & \\
\hline 9 & & • & - 31 & 10 & . & 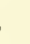 & . 9 & 8 & & & . & - 21 & 0 & & & . & 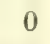 \\
\hline 9 & & • & 52 & 10 & • & . & - 8 & 8 & & & . & 31 & 10 & & & . & 8 \\
\hline 9 & & • & 26 & 5 & • & . & . 7 & 8 & & & . & 26 & 5 & & & - 8 & 4 \\
\hline 9 & & • & 31 & 10 & . & & - 9 & 0 & & & & 31 & 10 & & & , & \\
\hline 9 & & & - $\quad 26$ & 5 & & & - 9 & & & & & 26 & 5 & & & 9 & \\
\hline & & • & 26 & 5 & . & . & - 8 & & & & • & 23 & & & & 7 & 12 \\
\hline 9 & & • & - 42 & 0 & . & & - 8 & 4 & & & • & 15 & 15 & & & 7 & 4 \\
\hline & & . & 21 & 0 & . & • & - 8 & 0 & 15 & & • & 14 & 14 & . & & . & 8 \\
\hline & & & & & & & & & & & & $\begin{array}{r}16 \\
. \quad 0\end{array}$ & & & & • & \\
\hline & & • & . $£ 10$ & 10 & . & & 7 & 12 & & & • & 0 & 0 & & & 8 & 0 \\
\hline & . & . & 5 & 5 & . & • & 6 & 8 & & & • & 42 & 0 & & & . 7 & 12 \\
\hline & . & . & 6 & 6 & . & . & 7 & 4 & & & . & 47 & 5 & $\cdot$ & & - 8 & 4 \\
\hline & . & . & 7 & 7 & • & & . 6 & 12 & & & & 42 & 0 & & & . 9 & 0 \\
\hline & • & . & 9 & 0 & • & & 6 & 12 & & & - & 36 & 15 & & & . $\varepsilon$ & \\
\hline & . & & 13 & 13 & & & 7 & 8 & & & & 26 & 5 & & & • & \\
\hline & & - & 12 & 12 & & & 8 & 0 & & & & 26 & 5 & & & - & \\
\hline & . & . & 7 & 7 & 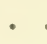 & & 7 & & & & • & - 31 & 10 & & & 7 & \\
\hline & . & • & 18 & 18 & & & . 8 & 12 & & & . & - 26 & 5 & & & . 9 & 0 \\
\hline & . & . & 8 & 8 & & & . 8 & 0 & & & • & 42 & 0 & & & - 7 & o \\
\hline & & & 5 & 5 & 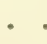 & & . 6 & 0 & 177 & & & 31 & 10 & & & . 9 & \\
\hline 23 & & & . 10 & 10 & & & . 7 & & & & & & & & & & \\
\hline
\end{tabular}

The character of Mr. Webb's flock is above all praise; and I could wish to see this breed of sheep extensirely spread in the United States. Of the character and demand for the wool, the 
manufacturers are the proper judges. As mutton, they are preeminent, - combining with extraordinary fatuess a fair proportion of lean meat, - and in taste, deemed equal to the Highland sheep. We, I think, as a people, have yet to acquire a taste for mutton. In this respect, we differ altogether from the Euglish, with whom, in spite of all we hear about "the roast beef of old England," mutton seems every where the preferred dish. The immense quantities of poultry, likewise, which are brought to our markets, will stand in the way of other meats; yet our markets, especially in our large cities, are likely to furnish a steady and increasing demand for mutton; and wherever they can be reached, I believe that no breed of sheep are so likely to meet and constantly stimulate that demand, as the beautiful mutton of the South Down sheep.

(5.) General Management of Sheep. - I must remind my friends in the United States, that excellence in any department of husbandry has not been reached here, and can no where be sustained, without persevering efforts, and an extreme watchfulness and care. Sheep here are never left to take care of themselves, but have always a shepherd with them, - commonly a boy or an old man, - by day, and are carefully folded at night. The fatting sheep, while the artificial feed remains, are fed in folds.** The general impression with us, I know, is, that they are turned into a field of unpulled turnips, and left to gnaw them into the ground; but this method, unless the turnips are very small, is not much practised or approved. The turnips are generally drawn for them, cut up by a machine, and placed in troughs. This is especially important in respect to Swedes. An experienced farmer in Nottinghamshire informed me that he was averse to

* "It is the custom for almost every grazier to have sheep follow on the grasses after the beasts. It is true, our system of feeding the majority of sheep is much altered. The increased population demands it should be. It was formerly the practice to let the sheep graze, and have the lean nourished by degrees, until they were two years old; but now the plan is, to feed sheep as highly as they will bear, to make them fat as lambs, keep them so, and bring them to heavy weights at one year old. The sheep fed in this way leave a great profit; but the principal inducement to adopt this plan is for the advantage which the land derives. You are aware that nothing will produce such a crop of grain as a turnip field eaten off by sheep folded upon it, especially with the addition of oil cake and grann." - Extract from private Leller. 
giving Swedes to ewes in milk, when their lambs were young, as he found that it made the milk of the ewes too rich for the digestion of the lambs. He therefore aimed to have some white turnips in reserve for the ewes at lambing time. I put this down as the result of his observation, withont any other confirmation of the fact.

Experiments were reported to me, on a farm which I visited, from which it would appear that feeding sheep for fatting in a dry shed, upon a raised floor, and where they were protected from the weather, was attended, on a strict comparison with those fed in an open field, with a great saving of food, and a large increase of weight. Other experiments of a similar kind have not resulted so satisfactorily, as fully to establish this point. The subject deserves further trials. In all attempts to fatten animals, a principal object should be to make them comfortable. Sheep wiil bear, without apparent suffering, almost any degree of cold; but they often suffer from wet, and especially from a wet lodging. Where a shed open at one side, to which they may resort at their pleasure, is connected with a dry fold yard, the best arrangement seems to be attained. Difference in climate is to be considered. In England, the winter is temperate, and generally wet; in the United States, it is dry and cold. In some experiments reported, it would appear that sheep do better when the turnips are given to them unwashed, than when given in a perfectly clean state. I have seen some human lambs, unwashed and uncombed, the very examples of vigorous growth, of muscular energy, and of ruddy health if you could get at the true color of their cheeks. I have not been accustomed, however, to attribute their remarkable healthiness to the dirt in which they lived. The above statement, in respect to sheep, may possibly be true, or it may be a mere excuse to one's conscience, for not an uncommon reluctance to pains-taking and labor.

Of one point I hope my American readers will not lose sight; and that is, that the extraordinary fatness and thrift of the Finglish sheep is not acquired without an abundance of succulent food, and with this their fattening goes on as well in winter as in summer.*

* I have referred several times to the use of oil cake, in fattening both sheep and neat-stock. Perhaps I shall liave no better opportunity of saying, that a 
4. SwINE. - I have seen no individual hogs, and no breed of swine, in any respect superior to those which abound with us. They are not kept to a great extent, or in large herds, and most of them are killed very young. There is no pork, excepting that for navy and shipping purposes, salted and packed down, as with us, in tubs; but with the exception of the lean meat, which is eaten fresh, or made into sausages, the hams are baconed and slightly sinoked, and the sides or flitches, which alone are called bacon, are cured very much as the hams are, and then hung about the wall in the farmer's kitchen, very consolatory under the apprehension of scarcity, but to my taste nowise ornamental.*

The best hogs which I have seen are the Essex White, _ raised by a distinguished breeder, Mr. F. W. Hobbes, - the Berkshire, and the Neapolitan. These are often crossed, and variously intermixed. The hogs of a most successful farmer in Cornwall, to whom I have before referred, were a mixture of the Essex,

valued friend of mine, Thomas Spencer, Esq., of Bransby, Lincolnshire, most kindly remembered by many friends in the United States, has applied, with success, a new article to the fattening of his cattle. He obtains from the greasereceivers and soap-boilers, in London, large quantities of their refuse, with us called scraps, here provincially called brassin, which in the process of manuficture is pressed into cakes, and sent to him in that form. He uses this steamed or heated, and mixed with turnips, chopped hay, and meal, to give to his fattening cattle, and finds great advantages from it. It requires some little time to induce them to eat it. Some of the best feeders of swine whom I have known have always deemed it necessary to give them, with their farinaceous, a portion of animal food. The hog, however, is a universal and indiscriminate gourmand. Cattle being wholly graminivorous, might be supposed to be averse to animal food; but the appetite can be trained; and we may find a solution of the case in the great doctrine, that "all flesh is grass."

* 'The pork which is principally sold in the London markets is very small. A good deal of it comes from Ireland, from the pigs of the poor cotters, who depend upon the pet pig to pay the "rint." A principal dealer informed me, that formerly his customers would be glad of a side of pork which would weigh two hundred weight; now they are averse to it, if it exceeds fifty pounds. This pork is very slightly salted. The hams and flitches are not always smoked, but simply cured and dried, and in that way generally preferred. The American hams are deemed too large for the market, and are objected to as not cut with sufficient neatness.

'The objection to the lard from the United States is, that it is too soft. Whether this be owing to the feed upon which the swine are fatted, or the mode of preparing the lard, it would be worth while to inquire. 'The Irish are said to give hardness to their lard, of which great quantities are imported, by the intermixture of a portion of mutton tallow. From Ireland it usually comes in bladders of five to eight pounds' weight, a form much preferred to kegs. 
the Neapolitan, and a boar which he had imported from the United States. 'They were customarily killed at one year' old, weighing from fifteen to seventeen score pounds. Some which I saw at two years old, he calculated would weigh thirty-five score. He has killed some which weighed thirty-six score. These are very extraordinary weights. His hogs go in the pasture from April until October, and have no other feed. In the autumn they are put up, and fatted with steamed potatoes, mixed while warm with barley meal. Twelve gallons of barley meal he deems sufficient for fattening a hog fed in this way. They are watched by a hind, who supplies them as often as their troughs are empty, and as he can induce them to eat. His practice corresponds with that of a successful farmer in Vermont, which I shall detail to my readers. His hogs were kept in his pastures from spring until autumn, during the grass season, without other food than, at night, the slops or refuse of the dairy. In the autumn they were brought into warm styes, and were continued to be fed upon hay, chopped and steamed for them, with a very small quantity of corn meal mixed with it. In this way he made excellent hogs, and at a cheap rate. One acre of land was sufficient to support six hogs. He occasionally changed their pasture. He deemed hogs kept in this way a more profitable stock than sheep, - a discovery which, I think, will surprise many feeders of swine.

\section{CIX. - DAIRY HUSBANDRY.}

England has long been celebrated for its dairy products, at least for the quality of its cheese; and this is often of a superior description.

1. Butten. - The butter in England is, much of it, delicious, especially that which is made in private families, where it is churned from new and sweet cream every morning, and brought fresh from the churn to the breakfast table; and more particularly when the butter is made from the cream. of an Alderney 
cow. The common market and shop butter, however, is of the same various character with that in our own markets, with no larger proportion of very excellent butter than is to be found in the markets of Boston, New York, and Philadelphia. Indeed, much of the butter found in the market of the last-named city, for its freshness and deliciousness, is no where surpassed. The butter in England is generally sent to market fresh, and you are left to salt it at your pleasure, as you use it. 'The salted butter, in tubs or firkins, is mostly imported from Ireland, or the Continent. Even this, however, is not heavily salted. In most of the markets, a good deal of butter made from the whey of cheese is sold at a reduced price. It is of inferior taste and quality, and is bought by the poor, or to be used in cooking, where, like a good many nameless things, it may be thoroughly disguised, and pass without detection.

The Dorsetshire butter, which stands at the head of the market, comes packed in neat casks of about thirty pounds each; but is very lightly salted, and of course will not keep long. It is likewise sent up to London in lumps, perfectly fresh for the table. Its quality is excellent. The table butter likewise, from Epping, and especially Aylesbury, is of the best description.

The Devonshire butter is almost universally made. by first heating the milk, just so much as to cause the escape of the fixed air. In twelve hours the cream is all brought to the surface, and in a state of consistency to be easily taken off. It is a disputed point, whether as much butter is obtained in this way as by the ordinary mode of letting it stand, without being heated, a much longer time. The butter is thought to acquire in this way a peculiar taste, but it is by no means unpleasant. The skimmed milk remaining is perfectly sweet, and appears the richer for being heated. In this way is obtained the famous clotted cream which is to be found on the hospitable tables of Devonshire, and is a great luxury.

Glass milk-pans, made of bottle-glass, are much approved, and, with proper care, are in no danger of being broken. They recommend themselves by their cleanliness and incapacity of rust, or corrosion, or decomposition. In some dairies I found shallow leaden troughs used for setting the milk, with a tap at the bottom, so as to draw the milk off and leave the cream. Some persons maintain that, the more shallow the pan, the more crean 
in proportion will be obtained; but in a large dairy in Scotland, the milk is always set in deep casks and tubs. Such is the diversity of opinion every where prevalent. 'The Scotch had no fears that the cream would not find its way to the surface unless the principle of gravitation were to be reversed. One of the best dairy women in the country never suffers any water to be applied to the butter when taken out of the churn, a practice not uncommon.

2. Cheese. - English cheese has long been celebrated for its excellence, but it is far from being all equally good. The Stilton cheese stands, by general admission, at the head; the Cheshire, the Cheddar, the Gloucestershire, and the Wiltshire, have their different partisans, and though they differ from each other, are preferred according to the particular tastes of those who eat them. The celebrated Dunlop cheese of Scotland, which is certainly excellent, is made with one fourth part of ewe's milk.

It cannot be expected that I should go into all the processes of the dairy. My remarks must be general. All dairymen seem to agree, that, in cheese-making, much depends on the character of the soil upon which the cows are fed. Wet and low grounds, producing a rank and coarse herbage, are unfarorable, and so are the artificial grasses given to the cows green. An old pasture and a dry soil are most desired; and it is said, that the poorer the pasture, the better the cheese. Wet and cold pastures have been converted into good cheese grounds, by thorough draining and cleaning. The quality of the cheese depends, more than upon any thing else, upon the skilful and careful management of the dairy-maid herself. This is to be learned by practice, and very little useful direction can be conveyed in words. The making of cheese is a chemical operation. We shall be glad when chemistry is so applied as to determine the rules by which success may be made certain.

The average quantity of cheese made is reclioned at one humdiec and twelve pounds to one hundred gallons of new milk. Few cheeses are made wholly of new milk, being, in general, what are called two mcal cheese, and the cream being taken off the previous night's milk, to be converted into butter. In this case, according to the practice of at excellent Vermont farmer VOL. II. 
within my knowledge, the buttermilk would go back to the cheese and serve to enrich it. The cheeses, in general, are made very hard, which is owing, in the first place, to cutting the curd very fine, and next, to the severe pressure which is given to them. The rennets are here called vells; and the best are imported from Ireland. At one of the principal dairies which I visited, it was customary to put six skins, at the beginning of the season, into two gallons of brine, and use this liquid for forming the curd, in such quantities, and at such time, as required. A quantity of lemon was also put into the liquid, to correct the taste and give it a flavor; but I believe with no advantage to the cheese. It is strongly urged not to use the rennets until they are a full year old, as otherwise they cause the cheese to heave and to be full of holes. In most dairies, it is customary to scald the curd with hot whey, but by the best dairy-women this is disapproved, as tending to impoverish the cheese. The coloring the cheese with anatto is not universally practised, nor does it much benefit the sale, where the character of the dairy is known.*

I received from two sources, where the cheese was of the first quality, two recipes for making Stilton cheese, and one for making Cheshire, which I shall subjoin.

(1.) Stilton Cheese. - "To fill one of the Stilton moulds, take nine gallons of new milk, and one gallon of cream. Take

* Several questions have been proposed, by a respected correspondent, on cheese-making. I shall answer to the best of iny information.

The skins for rennet are to be procured a year before they are wanted; to be cleaned of all impurity; to be turned inside out and salted; to be then packed down one upon the other in salt, with a layer of salt between each; and then covered with salt and shut up. As they are wanted, a month before being used, they are to be taken out; the brine drained from them; spread and powdered with fine salt ; rolled out, and distended upon sticks; and hung up to dry.

The temperature of the milk, when the rennet is applied, should be from $80^{\circ}$ to $84^{\circ}$ Fahr. The dairy-women in some parts of the country, who make very good cheese, make their cheeses cold, that is, coagulate at a very low temperature. 'This cheese is said always to meet a quick demand. They likewise salt them but lightly.

'The curd is broken by a machine, being formed of projecting tecth set upon a cylinder; and the curd, being placed in a kind of hopper, passes through them and is ground fine.

An hour, or an hour and a half, is thought the proper time for the process of 
one quart of marigold flowers, and pound them very fine in a mortar, and then stir them into two quarts of boiling water, and let them stand five minutes. Then strain off the liquid into the cream, and pour it into the milk. Put in the rennet. When it has come into curd, take a cheese-cloth and put it into a sieve, and raise the curd with the hand into the sieve, and let it drip until it is firm enough to be put into the mould. When first put into the mould, press it with small weights for two hours; then apply a dry cloth to it, and put it under the press; and salt it every twelve hours for three times. When taken from under the press, put a bandage of calico around it for several weeks, until it gets quite firm."

(2.) Improved Stilton Cheese. - The subjoined is an account of cheese made by a superior dairy-woman in Lincolnshire, in imitation of Stilton, which the writer, a most competent judge, pronounces superior to any Stilton cheese which he ever tasted:-

"The utensils are the same as those used in the manufacture of the real Stilton, excepting the cheese-vat, which in this case is a plate-tin cylinder, without top or bottom, having the sides pierced with holes, to let the whey escape. The rennet is made

coagulation of the milk. If the coagulation is rapid, there will be less curd, and it will be tougher; if slow, more in quantity, and inore tender in quality.

Another machine is used in some dairies, which is called a curd-breaker, being a kind of sieve made of wire with a strong tin rim, as represented in the margin. 'This cuts the curd by being carefully and gently pressed down upon it into the tub. After this, the curd is left for the separation of the whey from it, which is dipped out with a dish, or otherwise removed by the raising of the curd by the gentle lifting of the hand. A board full of holes is made to fit the top of the cheese-tub, and placed upon the curd with a moderate weight upon it, which is afterwards increased, and the tub turned on one side, for the draining of the whey from it. The weight must not be too severe, or the curd will be robbed of its richness.

'To determine when the curd is fit for breaking, is matter of judgment or experience. Fxamination will decide when the coagulation is complete; - the whey becomes of a pale green.

The quantity of salt recommended is one pound to forty-two pounds of curd.

The lever press for the curd, and for the full-formed cheese, is preferred to the screw press, from its tendency to adjust itself.

A full and detailed account of making Cheshire cheese is given in a Prize Essay by Henry White, in the Journal of the Royal Agricultural Society, vol. vi. part 1, which I wish some of our excellent agricultural papers would republish. 
in the same way as usual, only, instead of the stomach of the calf, that of the lamb is used, and, in addition to the usual quantity of salt, a lemon stuck full of cloves adds to the efficacy of the rennet, and gives it a flavor.

"As much as is needed of the morning's milk, as it comes from the cow, and the cream of a fourth part of as much milk of the evening before, are taken to make a cheese. The remnet is put to it in the usual way; and when the milk has become curdled, it is not broken, as here and elsewhere, with a cheeselinife and disk; but the surface of the curd is merely pressed down with a dish, - not broken; and as the whey arises, it is taken off; and this operation is continued until no more appears. The mass by this time is not one fifth of its original size. A long, thin, clean, and dry cheese-cloth is then provided, and the curd is tumbled out of the vessel upon it ; and the four corners of the cloth are gathered together, and tied together, and hung up over the vessel; and the remaining whey is pressed out of it by its own weight. It remains in the cloth for some time, until it gives over weeping, when it is taken out of the cloth, and cut into thin, long, narrow slices, about the size of sticks of sealing-wax. As these are cut, they are placed inside the tin cylinder, which is now placed on one of its ends, on another clean and dry cloth on the table. First, a layer of these slices is placed, filling up the whole of the bottom end; and on the top of this, another layer of slices is placed at right angles to the last; and a succession of others is thus continued, pressing them gently down, till the cylinder is quite full. When this is done, the cloth is gathered round the outside of the cylinder; another person takes hold of the cylinder, with one hand lifting it up, while, with the other, the curd is pressed out into the cloth, which, with the curd in it, is then returned to the cylinder, and pressed down as closely as possible with the hand. Next morning, the whole is taken out of the cylinder, and put into a clean, dry cloth, upside down, and again placed in the cylinder. This is repeated twice a day, always reversing the young cheese in the cylinder. When it becomes so firm as to do without the cloth around it, a wrapper of thin dry cloth is put round it every morning, when it is placed in the cylinder, till it be so dry as to do without the cylinder, when the wrapper only is used, and it is left on a shelf.

"There is a great deal of trouble with this kind of cheese, 
from the constant dampness of the skin; - the sides are apt to get fly-blown, when maggots are the result, and the cheese is injured. The object of cutting the curd into thin slices, and placing them in alternate layers, is, that it may more readily get mouldy, and acquire the peculiar character of good Stiltonbrittleness with softness, richmess, and mouldiness. In Rutland and Leicestershire, where the Stilton cheeses are made, the plan adopted is the same as that of the Dorset farmers in making their poor green Dorset cheese, that is, by inoculating the curd with some old, mouldy cheese. The cheese is of poor character, made up of half-creamed milk.*

"The cheese is salted by rubbing salt in the sides of the cheese, when it has its swaddling bands removed, every day. This cheese takes at least eighteen months before it is fit for the table. The details I have given are those descriptive of the manufacture of the best Stilton." $\dagger$

I shall give next the directions, in her own words, of an excellent dairy-woman, whose produce proves her skill for making

\section{(3.) Cheshire Cheese. - "Take thirty gallons of new milk to} make a grood-sized cheese, and then put the renuet into the mill:. When come into curd, break it up very small; then bring it together into one side of the tub; then dip the whey from it, and put it into the cheese, with a cloth inside of the vat, and

* In my inquiries, in Gloucestershire, of an eminent dairy-woman, what method they adopted to prevent the cheese from heaving or bursting, she, with a little gentle stammering, and rather a threatening scowl from her husband, informed me that "they sometimes put in a little white lead." But "they did not put in much, and they did not know that it did any harm." Of course, as it went to Londorn market, they could not know whether it did harm or good. It might have been well to have inquired of the doctors or the undertakers. Arsenic would have been more certain in stilling all complaints of the quality of the cheese.

In Cheshire, it was much more common than it now js, to put a handful of pins in the centre of the cheese, to create a mouldiness, and give an appearance of age. What would be the effect of the decomposition of the metal in such cases? The chemists might tell us.

With such ingenious medicaments applied to our food, we have great reason to say, in respect to our bodies, with good Dr. Watts, -

"Strange, that a harp of thousand strings Should keep in tune so long ! "

+ Private letter of John Morton, Esq. to H. C. 
put it under the press one hour ; then take it out and break it up very small, and warm a small quantity of whey and pour over the curd, and stir it around; then take the whey from it, and put the curd into the vat again, and squeeze it well with the hand. When putting it in the vat the last way, take a small quantity of salt, and put into the middle of the cheese, and put it nnder the press. Apply dry cloths to it several times, and salt it every twelve hours for four times. A little flour is a very good thing to put in the middle of the cheese with the salt about one table-spoonful."

What the use of the flour is in this case, it would be difficult to say. It may be like the horse-shoe upon the door-post. But I choose to give her directions verbatim and in full. Her cheese is of the best quality, and her dairy-room a model of neatness and order.

A great deal of American cheese has already come, and a great deal more is likely to come, into the English market. Much that has been sent has been highly approved; and the cheesemongers say, there has been an evident improvement in the quality since the first importations; but much of it is disliked, and none of it has yet reached the highest price in the English market. This, I believe, is partly owing to prejudice; for it is very difficult to convince an Englishman that any thing out of his own country, or the product of a foreign country, is as good as that which he finds in it, - a prejudice not exclusively English. But it has some foundation; - the American cheese has too commonly a smartness or acridness, which is disagreeable, and is not found in the best English cheeses; and, in the next place, the cheese-mongers state that the cheese is often heated on its passage, and in that way essentially injured. For the latter evil there would be a partial remerly in packing the cheese in separate boxes, which is now often done, and in not sending them in too green a state. The former evil is in the making of the cheese, and in applying too much rennet. I give this as the opinion of a very competent judge. ITe himself has so well succeeded in the manufacture of cheese, always deemed of the very best quality, that I shall put down, for the benefit of my readers, the suggestions which I have reccived from him in conversation. The subject, in the present open and friendly relations between the 
two countries, is certainly one of great importance to the American dairymen.

He advises, in the first place, that the calf from which the rennet is to be taken should not be allowed to suck on the day on which it is killed. The office of the rennet, or stomach of the calf, is, to supply the gastric juice by which the curdling of the milk is effected. If it has recently performed that office, it will have become to a degree exhausted of its strength. Too much rennet should not be applied. Dairymaids, in general, are anxious to have the curd "come soon," and so apply an excessive quantity, to which he thinks much of the acrid taste of the cheese is owing. Only so much should be used as will produce the effect in about fifty minutes. For the reason above given, the rennet should not, he says, be washed in water when taken from the calf, as it exhausts its strength, but simply salted or dried in the usual way, or otherwise preserved in pickle.

When any cream is taken from the milk to be made into butter, the buttermilk should be returned to the milk of which the cheese is to be made. The greatest care should be taken in separating the whey from the cheese. When the pressure or handling is too severe, the whey that runs from the curd will appear of a white color. This is owing to its carrying off' with it the small creamy particles of the cheese, which are, in fact, the richest part of it. After the curd is cut or broken, therefore; and not squeezed with the hand, and all the whey is allowed to separate from it that can be easily removed, the curd should be taken ont of the tub with the greatest care, and laid upon a coarse cloth attached to a frame like a sieve, and there suffered to drain until it becomes quite dry and mealy, before being put into the press. The object of pressing should be, not to express the whey, but to consolidate the cheese. There should be no aim to make whey butter. All the butter extracted from the whey is so much of the proper richness taken from the cheese. These suggestions seem to me reasonable and valuable. I should be glad if our farmers could send the English even a much better article than that which they produce themselves. I should be glad to overcome every prejudice, on whicherer side of the water it might be found, and transform the union of mutual trade into a perfect union of mutual good-will, between 
two nations; whose joint interests interlock each other in a vast variety of forms, and may be made to fit together like the different pieces of a dissected map.*

* In conversation with one of the largest wholesale cheesemongers and provision dealers in the country, he suggested that there were two great faults of the American cheese, which somewhat prejudiced its sale in the English markets. He is a person in whose character and experience entire confidence may be placed.

He was pleased to say that he had had cheeses from the United States as good as any he had ever seen, and that the general character of the article was greatly improved since the first importations.

But the first fault was the softness of the rind. It often cracked, and the cheese became spoiled from that circumstance. This he considered as owing to the cheese being too rich; if so, it is a fault which may be remedied. The English cheeses soon acquire a great firmness; and I have given above the opinion of an English dairy-woman as to how this is effected. I think proper, however, to add the directions of a most experienced and successful dairy farmer in respect to this matter. He says that the rind may be made of any desired hardness, if the cheese be taken from the press, and allowed to remain in brine, so strong that it will take up no more salt, for four or five hours. 'There must be great care, however, not to keep it too long in the brine.

The second fault is the acridness, or peculiarly smart bitter taste often found in American cheeses. He thought this might be due, in part, to some improper preparation or use of the rennet, and, in part, to some kind of feed which the cows found in the pastures. Both these matters are well worthy of investigation, and that alone can determine.

He was of opinion, likewise, that American cheese would sell better if it were colored like the English cheese. The market for it was fast becoming most extensive.

In respect to American butter, he considered that which usually came here as a most inferior article. (Much of it, I believe, is used, in the manufacturing districts, solely for greasing machinery.) Salt butter, or butter strongly salted, is not salable in the English market; and especially the salt must not appear. I cannot doubt, however, that presently some of our best June or September butter, put up in lumps, would find a good market here, - if, in truth, we have any to export. The very best fresh butter in London market, however, does not bring so high a price as I have often paid for the best article from the county of IVorcester, in Boston market; and I have frequently known the best butter to be sold in Baltimore, and even in Cincinnati market, for half a dollar, a little more than two shillings sterling per pound.

I have seen in England none of the admurable spring-houses which are to be found in Pennsylvania. 


\section{CX. - MANURES.}

The subject of manures, in British husbandry, is one to which I cannot attempt to do any thing like justice, in an cxamination of this nature. It would require a large volume to treat it properly, rather than a few pages of a single report. I shall not enter at all in this place upon the philosophy of manures, but merely refer to some few which are in use.

Of course, under any improved condition of husbandry, all possible pains will be taken, to secure in the best manner the various resources of the farm itself; and yet $I$ have seen here no place in which this provision is complete, or in which more might not be done than has been done.

In most cases, the stable manure is left in the barn-yard uncovered; and I have not met with a single barn cellar for receiving manure, in the whole country. In general, the barn-yards are square, with the sheds extending round three sides of them, and the yard scooped out in the centre; but it is not until recently that they have found the advantage of putting gutters and spouts to their farm buildings, for the prevention of the rain flooding the manure in the yard, and thus exhausting its strength. In only one case - and that I have described - have I seen a shed and pit under it, for the protection of the manure. I have presumed sometimes to describe to the farmers the excellent barn cellars on many of the farms in New England, where the stable is built on a side hill, and all the manure is shovelled through a trap door behind the cattle, into a well-walled cellar, made tight at bottom, and opened by a gate at one side or end, for the purpose of removing the manure; and where a certain number of store swine are kept, who, by constantly rooting among the manure and stirring it, keep it from heating excessively, while they intermix it thoroughly, and reduce it to a fune state; and where, too, the whole is protected from the wasting influences of the sun and rain, and is always in a condition to be applied to the field. Where the flatness of the land and the wetness of the soil would prevent making a cellar, the barn or stable might be of two stories in height, and the cattle kept on what with us is called the sccond story, but here always the first floor. 
In many cases, I have found provision for saving the liquid manure of the stables in a tank or cistern, from which it is either returned to the heap, or carried to the fields in a watering cart. I have already described a prominent example of this kind. The barn manure here is always carried to the side of the field on which it is to be used, and there it is formed into a long heap, in the neatest manner, and frequently covered with earth, so as to protect it from the weather. I have, in no case, seen long manure applied green from the stables. It is not, however, deemed best to keep it too long, or to reduce it to a very fine muck, by which its strength would be exhausted; but it is always shovelled over once or twice, that it may be in a condition easy for distribution. The quantity to be applied to an acre is subject to no fixed rule. The land, as I have described, is well dressed once in a four years' rotation, besides the consumption of one of the crops by folding, and perhaps of another by grazing.

Of the various artificial manures, which are manufactured and usually patented, I shall give no opinion. Any of the advertisements in the papers of the venders of quack medicines, if only the name of the article be changed, would serve for the advertisement of most of the new patent manures, they being adapted to all cases, and certain to cure all diseases. The adulteration of manures is carried on to an enormous extent. No man purchasing a valuable manure one year is certain to find it the same the next. An eminent professor of geology stated, at a public agricultural meeting, that much guano sold was mixed with ninety per cent. of foreign materials. Saltpetre is full charged with common salt; and large amounts of guano, in several of the principal markets, have been manufactured entirely out of home materials. This is not an agreeable picture of the morals of trade, nor should it be inferred that this is a general character; but in so large a commercial country as this, with appetites whetted by gain to the highest degree of voracity, it is not surprising that all kinds of villany should be practised.

1. Guavo. - Guano still maintains its reputation. No new facts have transpired respecting it, but old ones have been confirmed. It continues to be applied, at the rate of two hundred and even four hundred weight per acre, to various crops, with 
signal success, unless its efficacy is suspended or defeated by drought, or unless it comes in immediate contact with the plant, when it proves fatal. It is never safely applied alone, and the preferred mixture is a very liberal proportion of mould. Its mixture with ashes, strongly recommended by some farmers, is, as I have before observed, of questionable expediency. In Devonshire, I witnessed the most extraordinary effects from it, this year, applied at the rate of about tirree hundred weight per acre, upon grass land. The extreme luxuriance and richness of the grass, where it was applied, were most remarkable, especially when seen in contrast with parts of the field not guanoed. Nor is its efficacy limited to one year, but continues for a length of time as yet not determined. But were its obvious effects limited to one year only, yet the increase of crops growing out of its use furnishes, in itself, the means of greatly enriching the farm.

2. The Nitrates. - The nitrates of soda and of potash, from which so much was at one time expected, because so much seemed to have been obtained, are very little used. I found an excellent farmer in Scotland, who applied the former with great success to his potatoes, and I have found farmers in England, whose experience seems to prove the excellent effects of both upon wheat; but the fact that they have geuerally fallen into disuse indicates, whether well founded or not, a strong distrust of their efficacy. One of their acknowledged effects, when applied to wheat, was very much to increase the stalk, without proportionately increasing the grain. The adulterations in these articles have been, I cannot say extraordinary, but flagrant and enormous.

3. Sоот. - Soot is applied, sometimes mixed in compost, at the rate of about forty bushels per acre, and should be applied early in the season. For potatoes, about half that quantity is used, and is deposited in the drill with the seed. With wheat, it is sown broadcast with clover and grass-seed, the ground being first harrowed. It is sometimes sown alone, broadcast, upon grass, and always with advantage. Its effect, however, upon the cereal crops is, to increase the stalls without a correspondent increase of the grain. $A \mathrm{~s}$ it is proved not to diminish the grain, this is to be considered a great point gained. 
In an experiment made in the Lothians, by one of the best farmers in the kingdom, he gave me the following as the result:-

A piece of land, manured at the rate of eighty bushels of soot per Scotch acre, costing threepence per bushel, the product was 7040 pounds of hay per Scotch acre.

A second piece, manured in the same way, gave at the rate of 6671 pounds of hay per Scotch acre.

A third piece, without any top-dressing, produced at the rate of 5280 pounds per Scoteh acre.

The milkmen object to feeding cows upon land dressed with soot, and to using the hay from such land, from its giving a bad taste to the milk. This may be mere prejudice. I give the fact of their objections, without vouching for their correctness.

4. Woollen Rags, - Woollen rags, the clippings of woollen cloth obtained from the factories under the name of shoddy, and wool dust, and woollen refuse of every description, make a most valuable manure. Indeed, none ranks higher in value. Besides its own intrinsic efficacy, it becomes mixed or strongly impregnated with oil, used in the processes of manufacturing. Its effects are not immediate, and therefore it is not to be considered as a forcing manure, but they are very durable; and when spread upon grass land, its efficacy is great and permanent. It is deemed, in the highest degree, rich in all the elements of vegetation. It is considered extremely valuable as an application to hop-grounds. The hop-growers in Surrey informed me that it was to be preferred to any other manure. It is deemed best to mix it very copiously with earth or mould; and in this way it should be repeatedly shovelled over, in order to assist its decomposition.

Mr. Hannam, in his excellent little treatise upon waste manures, states the case of a farmer, who, on applying eight tons of shoddy compost per acre, obtained nine tons of hay, in a small hilly field, which before never gave him four tous. It is tratusported in large sacks, and is a regular article of merchandise.

5. Lrue. - The value of lime as a manure, if so it may be called, is still, with many farmers, questionable. I found an eminent farmer in Ayrshire, who considered its only value to be as a mechanical divider of the soil; and in respect to another 
farmer in Scotland, who, as far as my observation and the character he holds in the county avail, as an intelligent and practical farmer has no superior in the kingdom, he stated to me that he had applied lime to his land liberally; for a quarter of a century, and never saw from it any benefit whatever. On the other hand, the innumerable instances in which it has been obviously beneficial, and where the improvement of the land can be traced to no other cause, compel one to conclude, in reference to its failures, that there must be something in the soil, or in the mode or circumstances of its application, not yet understood. Innumerable instances are found where it has been efficacious at the first application, but its repeated applications have been pernicious. I have already referred to a remarkable fact, that it seems most efficacious upon limestone and chalk soils. MIy readers shall have the benefit of the opinions of one of the most enlightened chemists, which I subjoin in a note.*

* Professor Lyon Playfair, in a manuscript lecture with which he kindly favored me, thus speaks :-

"When a chemist in his laboratory wishes to liberate the potash or silica from a soil which he is analyzing, he mixes it with lime and heats them together. By this means he renders soluble, in acids or in water, all that was insoluble before. 'The farmer performs exactly the same operation as the chemist, when he limes his land. He liberates, by this means, the silica, the potash, and the phosphates, from the soil, and enables them to administer to the wants of vegetation. But by the operation he has furnished no equivalent for that removed by the crops; and therefore it must infallibly happen, that the continuance of the system is merely a continuance of a rapid system of exhausting the soil. A ricli clay, abounding in potash, may long survive the treatment, but is as certainly going on to exhaustion as a granary of corn, out of which you take every day a certain amount of grain, and merely put in its place the key with which you opened the granary door. The lime is the key merely by which you opened the magazine of food contained in the soil.

"I speak of it now in the principal way in which it is used; but it not infrequently happens, that it may itself supply an absent constituent of the soil, especially in cases such as clover and grasses, which experience much bencfit from a top-dressing of this article. I do not say that the former use of lime is illegitimate, because clays often contain potash enough to last for thousands of years, if nothing more than that ingredient were required; but, at the same time, the lime aids the plants in removing sulphates, phosphates, and other ingredients, which may be required for the purposes of their organism, without restoring what is abstracted. I have frequently found, in the examination of some limestones, lauded for their superior excellence, that their action seemed to be due to the presence of some adventitious ingredient, such as magnesia, which could have been supplied more efficiently by other means.

"There is no manure more beneficially used, or more disgracefully abused, than VOL. II. 
6. Sea-Sand. - In some parts of Ireland and England, near the sea-coast, very great quantities of sea-dredge or sand are used, probably very much of the same character as the muscle-bed, much used in some parts of New England, and other maritime parts of the United States.

In Ireland, principally on the western and northern coasts, immense quantities of this dredging are obtained; and the number of one-horse carts, especially near Cork, which I found engaged in the transportation of it, was remarkable. Two kinds of it are obtained, one full of shells, with their living tenants, and consequently abounding in animal matter. "The silicious sand usually amounts to from thirty to sixty per cent ; the shells to from twenty to fifty, and, beside carbonate, yield some phosphate of lime and magnesia. There is, generally, from three to six per cent. animal matter, which yields nitrogen by its decomposition; and from five to ten per cent. of salt water, which holds in solution common salt, and other ingredients of sea-water." *

There is another variety of sand found in certain places on the western coast of Ireland, mixed with a substance resembling

lime. In its principal action, it has no right to be called a manure, for a manure consists in the restoration of ingredients taken from the soil. But lime aftords a key to rob the soil anew, so easily applied that we often find a farmer, who works slovenly, content himself with the application of lime, and by its means obtain the same results - accompanied, however, by a destruction of property - that he would by the drainage of the land, and by a proper system of rotation. Hence, we find it often substituted for the drain; for the disintegration, which the air should effect in a drained field, is obtained by lime in one undrained. But the system, in the latter case, is a ruinous one to the landlord, and even to the tenant, if he remain on the soil; and the cause is obvious, when you consider that he applies the lime without any knowledge of the quantity which should be used; and not following it up by a proper rotation, first to take up the liberated potash, and then the liberated silica and phosphates, a large part of the valuable ingredients of the soil is washed away without any benefit to it.

"I will merely refer to one part of the practice, with regard to the application of lime, because it will confirm still further, that its principal action is what I have described. A favorite mode of applying lime is to mix it, while hot, with earth, and after it has slacked itself, to spread the mixture on the field. By.using the lime in this state, you produce a powerful effect in liberating the alkalies of the earth with which it was mixed, so that, when you spread it upon the field, you, in fact, spread with it a stock of nutriment in immediate readiness for the plant."

I hope it will not be deemed presumptuous in me, to say that these remarkis are extremely rational, sensible, and to the point. The subject, however, is not re lieved of all its difficulties.

* Kane's Resources of Ireland. 
coral, but which naturalists determine to be of vegetable origin, and which is rich in nitrogenous ingredients. This coral contains, likewise, phosphoric acid, and is greatly esteemed as a manure. These various sands are full of comminuted shells, and very rich in animal matter, either living or dead. 'They are applied at the rate of ninety bushels, or even donble that ynantity of bushels, to the acre. "To the large proportion of phosphate of lime contained in the crustaceous remains, and the nitrogenized matters of the fish, much of its importance, doubtless, is due." The farmers in the neighborhood of Cork come ten and twelve miles to obtain it; and "it is dredged in the river from depths varying from ten to thirty feet." This, certainly, speaks strongly in favor of its value.

In Cornwall, England, vast amounts of sand are found near the sea-shore, and are carried into the country. In examining this sand, which is obtained in inexhaustible quantities near parts of the coast, it appeared, in an extraordinary degree, to abound in broken shells. In analytical examination of the sands from different localities, they have been found to abound in carbonate of lime, varying from forty-four to ninety-four per cent. A company has been formed for calcining this sand, which serves to make it more soluble, and renders its action upon the soil more speedy. It is called the Cormvall patent manure; and from the advertisements of the company, it might be inferred that it was exactly suited to all sorts of crops and all lrinds of soils. Its beneficial efficacy in many cases cannot be doubted.

I have referred thus particularly to these manures, that the farmers living in the maritime parts of the United States might be induced to look after resources of fertilizing their lands, within their reach, which may have hitherto escaped their observation.

7. Super-phosphate of Line. - Bones, broken and ground, have been a long time employed as manure in England, and with wouderful efficacy. Indeed, the extraordinary improvements in some parts of the country have been wholly ascribed to the application of bones. It was found, likewise, contrary to all expectations, that bones which had been throngh the hands of the soap-boiler, and from which all the animal and gelatinous matter had been thus abstracted, and that even bones which had been calcined, were of equal effieacy with those which were ap- 
plied in a green state, and fully charged with animal matter. It was also ascertained that bones applied as a manure, beyond a certain point, were not efficacious in proportion to the quantity applied; and that sixty bushels of bones to an acre, produced no more beneficial effect than sixteen or twenty. Here experience and inquiry were confounded, and here science came triumphantly to their aid.

Upon examination, it was ascertained that what gave the efficacy to bones was the phosphorus contained in them, connected with an acid. It was not ascertained that the animal portion of the bones was of no importance; but it was slower in its effects, in ameliorating the soil, than the inorganic portion of the bones; and that what was mainly important, in the application of bones, was to supply this inorganic portion in a form that it should speedily be taken up. In an ordinary state, this phosphorus was combined with lime, in such proportions that it was not easily dissolved; but, Professor Liebig, to whom agricultural science is so greatly indebted, discovered that, by the application of sulphuric acid to the bones, a portion of this lime would be abstracted, and go into another form; and a salt would be left containing a much larger proportion of phosphorus, - and so called the super-phosphate of lime, - which was soluble in water, and would be at once taken up by the plant.

"Phosphate of lime is a substance very difficult of solution; and thus, in a very dry season, the effects of bones are slight and imperfect. Super-phosphate of lime, on the other hand, is extremely soluble, so much so that the vitriolized bones can be entirely dissolved or suspended in water, and thus applied. 'This at once explains the cause of the valuable properties of the preparation. The bones in their natural state are extremely indigestible; the acid cooks them - converts them into a species of soup, which can readily be eaten and digested by the young turnips. The adamantine fetters, with which the various elements composing bones are bound so compactly together, arc by means of this new agent burst asunder - the compact is broken, and each constituent element is left to pursue its own course, and exercise its own natural affinities." *

The effects of this preparation of the bones has answered

* Spooner's Prize Fissay. Journal of the Royal $\Lambda$ gricultural Society, vol. vii. p. 1 
every expectation; and where before sixteen and twenty bushels of bones were applied to an acre, in the growth particularly of turnips, four bushels, prepared with sulphuric acid, are found now to be even more effectual. The advantages of such a preparation are very great, - first, in stimulating and forwarding the growth of the plant; next, in the cheapness of the application; and next, in its so forcing the plant, as soon to place it beyond the reach of the fly, which never attacks it after the third leaf is formed.

The best mode of preparing the manure has been matter of various experiments, and deserves inquiry from the acrid nature of the acid employed - the oil of vitriol. Mr. Pusey advises, to erect a heap of fine mould, and, forming a basin or crater in the centre, to place the amount of bones to be dissolved in it, and to apply gradually an amount of sulphuric acid equal to half the weight of the bones, which, after a short time, will completely dissolve them; and then, shovelling and mixing the mould together, the manure will all be in a condition to be distributed by a machine in the drills prepared for sowing the turnip seed.

Mr. 'Tennait, of Shields, one of the best farmers in Scotland, puts twenty-five bushels of bones into three old iron boilers, and next pours in two bottles of acid, containing one hundred and seventy pounds each, and adds eighteen gallons of water to each boiler. In a day or two, they empty the contents of the boilers into two cart-loads of light mould, with which it is thoroughly intermixed; and, being turned over three or four times, after seven or eight weeks the compost becomes dry-and mealy, and can be spread by the hand.

Mr. Spooner advises, to place the bones in a hogshead, and pour the acid upon them at the rate of one third of the weight of the bones in acid, that is, to one hundred and eighty pounds of bones sixty pounds of acid; and, after it becomes sufficiently dissolved, to mix it with ashes, and apply it in that form. He recommends, likewise, that, first of all, the acid should be mixed with one fourth of its weight of water, or perhaps half as much water as acid, which will raise it to the temperature of $300^{\circ}$ Fahr., and will much assist the dissolving process. Too much care camnot be taken to guard against the effects of the acid upon the clothes or skin of the operator.

The beneficial effects of this application are now beyond ques- 
tion. Mr. Spooner cites a case in which two bushels of vitriolized bones, with ashes, gave as good a crop as sixty bushels of bones unprepared. To Swede turnips it seems more congenial and efficient than to white turnips. Where the crop of turnips is of so much importance as here, this discovery is of immense consequence. Whether it will be equally beneficial to other crops, - to wheat or grain crops, - is to be decided by further trials. 'The experiments reported by one farmer, in reference to a crop of carrots the second year after its application, and to a field sown with barley one year after its application, showed most decidedly, so far, its permanent beneficial influences.

There are other manures used here, which I shall find it more convenient to notice in another part of my work, and which, therefore, I now pass over. Some experiments, however, have been made in Cornwall, with top-dressing land with straw, which I shall refer to, as at least highly curious; and which deserve notice, as possible to lead to most important practical results. They rest upon highly respectable authority. The subject has been frequently referred to in the public papers, but a detailed statement has been given by the secretary of the Cornwall Experimental Club, and published in a late Journal of the Royal Agricultural Society, from which I shall abridge the account.

8. Fibrous Covering, or Gurneyism. - Mr. G. Gurney observed that, "if a bush or other fibrous matter were left lying in a field of grass, the vegetation beneath it wonld soon be observed to be finer or fresher than that around it. This was a fact known to every one, but the agency by which this increase of growth was brought about, evidently involving some great and important but unknown principle, had never been investigated. Flags, rushes, straw, bushes, or, in short, any fibrous covering, would produce a similar effect. Recds, or wheaten straw, applied over grass, at the rate of about a load to a load and a half per acre, would, in a short time, increase the quantity of grass to an incredible extent. The various grasses under it would be found to be healthy, and rapidly passing through the stages to maturity, some growing, some flowering, some speding. Part of a field of grass placed under this operation for one month had increased in weight, over the remaining portion left uncov- 
ered, at the rate of nearly three to one. The green grass from the part untouched, cut at the end of the month, weighed two thousand two hundred and seven pounds per acre; that of the portion placed under the operation weighed five thousand eight hundred and seventy pounds per acre. The grass was weighed as it came from the scythe. During this period, there was not a drop of rain; and guano, nitrate of soda, lime, shell-sand, wood-ashes, and other manures, tried against it, possibly from tho drought, produced, during this period, no very visible action. In this experiment, the fibrous covering was laid on the 15th of April, and the grass cut and weighed the 30th of May. Mall of a hay-field was covered on the $2 \mathrm{~d}$ of May; and a month after, I had cut and weighed, respectively, the portions of the field corered and uncovered, and found that the one weighed three thousand four hundred and sixty pounds per acre, whilst the other weighed only nine hundred and seventy pounds. As to the length of the grasses in the respective pieces, the trefoil in one case measured three and one half inches, whilst in the other it only measured an inch; clover six inches, in the other one and one half." He found, on making the two samples of grass into hay, that the proportionate loss of weight was the same in each parcel, and the difference would be, that in the one case he should get three tons to an acre, and in the other only one. Another most important circumstance in the case was, that when "a certain quantity of stall dung would double the quantity of grass in a given time, when laid on in the usual way, that it would increase it six times, when properly treated with fibrous covering."

These are certainly very curious experiments, and they have been repeated successfully by various individuals. "For an individual to satisfy himself; a bundle of straw, say forty pounds, strewed lightly over two or three roods of growing grass, would in a very short time show the effect, when raked off. In the experiments made, all gave uniform results, when conducted fairly. Some used too much covering, but generally too little. All these experiments showed that the action was general; that the difference in increase of growth, in a given time, was in proportion to the natural fertility of the soil."

"The practical instructions for the use of fibrous covering are few, but essential to profitable results. Straw of wheat, oats, or 
rushos, is to be lightly and evenly laid over growing grass, $m$ the proportion of about a ton to a ton and a half per acre. At the end of a fortnight, it must be raked up in heaps like haycocks, the grass eaten off by cattle, and the covering again relaid. This is necessary in the growing season, otherwise the herbage will grow through, by which the action will cease; the grass will also become entangled with the covering. If the land is good, the grass may generally be eaten off by cattle before the covering is relaid; if not, at the end of the next fortnight (more or less depending on the richness of the land, the season, and the weather,) it should be done, and the covering relaid again; and repeated at about these periods through the season. If straw be the material used, it will last through the whole summer. In the autumn it is the practice to rake it off when dry, carry it away, and stack it for winter litter. Ground under the action of fibrous covering, we find from our returns, will keep three times the quantity of cattle as ground not so treated. This experience seems in keeping with our experiments on weight and measure, of the produce thus obtained."

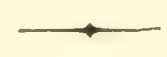

\section{CXI. - GENERAL REFLECTIONS.}

I have deemed it proper to lay these various results, resting as they do upon the most respectable authority, before my readers, to whose knowledge they might not otherwise come. If they have no other beneficial effect, they will stimulate inquiry, and prompt to other experiments. The philosophy of these results is as yet in obscurity. The facts in art and science which are continually disclosing themselves to our investigations are most extraordinary and wonderful, and show that we are yet only in the infancy of knowledge. The glimmerings of the early dawn will presently advance to meridian splendor. It is the province of science to investigate the causes of things; this is the work of the human mind; and how can it be more worthily or rererently employed?

I have been charged, more than once in the progress of these 
reports, with a want of respect for science. I regret if I have given - mwittingly it must have been - any grounds for such a charge. Nothing can be more foreign from the truth. Science, however small my claims to any affinity with her, I love and honor. But mere theory I distrust; self-conceit, which is often harmless, anuses ine; unfounded pretensions I hold at their true value; and low and interested quackery I despise. What is science? Not merely the knowledge of books; not merely a familiarity with the technical rules of any art; not mere hypothesis and conjecture, however subtle and profound. But the observation and the accumulation of facts; the following them out in all their relations and bearings; and the tracing, as far as human sagacity can go, all the circumstances and influences, of which they appear to follow as the necessary consequences and results. This is the work of mind wherever mind is found. This proficiency will be most essentially assisted by the knowledge of facts already established and ascertained; by artificial processes and appliances already invented and familiar to the learned. But let us not consider these investigations as the exclusive business and monopoly of the schools. What I want to see is the universal mind awake. I want that men should every where be induced to open their minds to the beautiful and sublime creation, in the centre of which God has placed them, and seek to understand more of it and of themselves. I want that the man who follows the plough, when he opens the bosom of the bountiful and wonder-working earth, should read lessons of divine wisdom written upon its teeming furrows. I want the sower when he scatters his quickening seed, and sees those diminutive grains which he throws abont him rising from the earth in forms of matchless beauty, gay with flowers, and at last rich in fruits, and pouring into his lap, as the compensation of his toil, the bread which is to sustain and make life happy, humbly but importmately to inquire, How is this miracle effected? I want the farmer, when he sees his recking heap of refuse, now offensive and loathsome to the sense, when cast upon the earth, returning to bless him in the richest products of health, and comfort, and life, to follow out, as far as his sagacity can explore, these subtle and marvellous operations of a beneficent providence. I want men should work with their minds as well as their bodies; and I wish that the penalties of indolence and neglect, in the 
one case, were as severe as in the other. All the practical operations of husbandry furnish ample materials for inquiry and reflection; and inquisitive and reflecting minds, constantly engaged in them, have some peculiar advantages in the study of them, over philosophers exclusively confined to their closets and their laboratories. There is every encouragement to exertion presented even to the most humble. One of the most distinguished ornaments of the school of English chemistry - a man whose attainments would do honor to any country and any age - was devoted, in early life, to a purely mechanical trade, and, by the determined energies of his own mind, has made his way, by universal acclamation, to the proud preëminence which he occupies.* Some of the greatest discoveries in the arts and in science have been made by men of comparatively unassisted genius. I should be too happy, if I could feel that my humble labors had, even in the smallest degree, contributed to induce men to respect their own minds; to lead the laboring portion of the community, while they are working with their hands, to be as active in working with their understandings; and to become ambitious to bring from their own personal inquiry and experience their contributions, however small, to the great and rapidly accumulating mass of human knowledge. So far from contemning science, I reverence it with a species of idolatry - an idolatry, I trust, pardonable, for it is only a form of homage to the great Source and Centre of all intelligence. In the mind of man, enlarged and improved by science, I recognize the proper foundation of moral as well as of intellectual greatness; and I adore with humble gratitude the reflection - very partial and limited indeed it is - of that wisdom and intelligence, which created, guide, arrange, fill, and bless an eternal and boundless universe.

* Professor Faraday. 



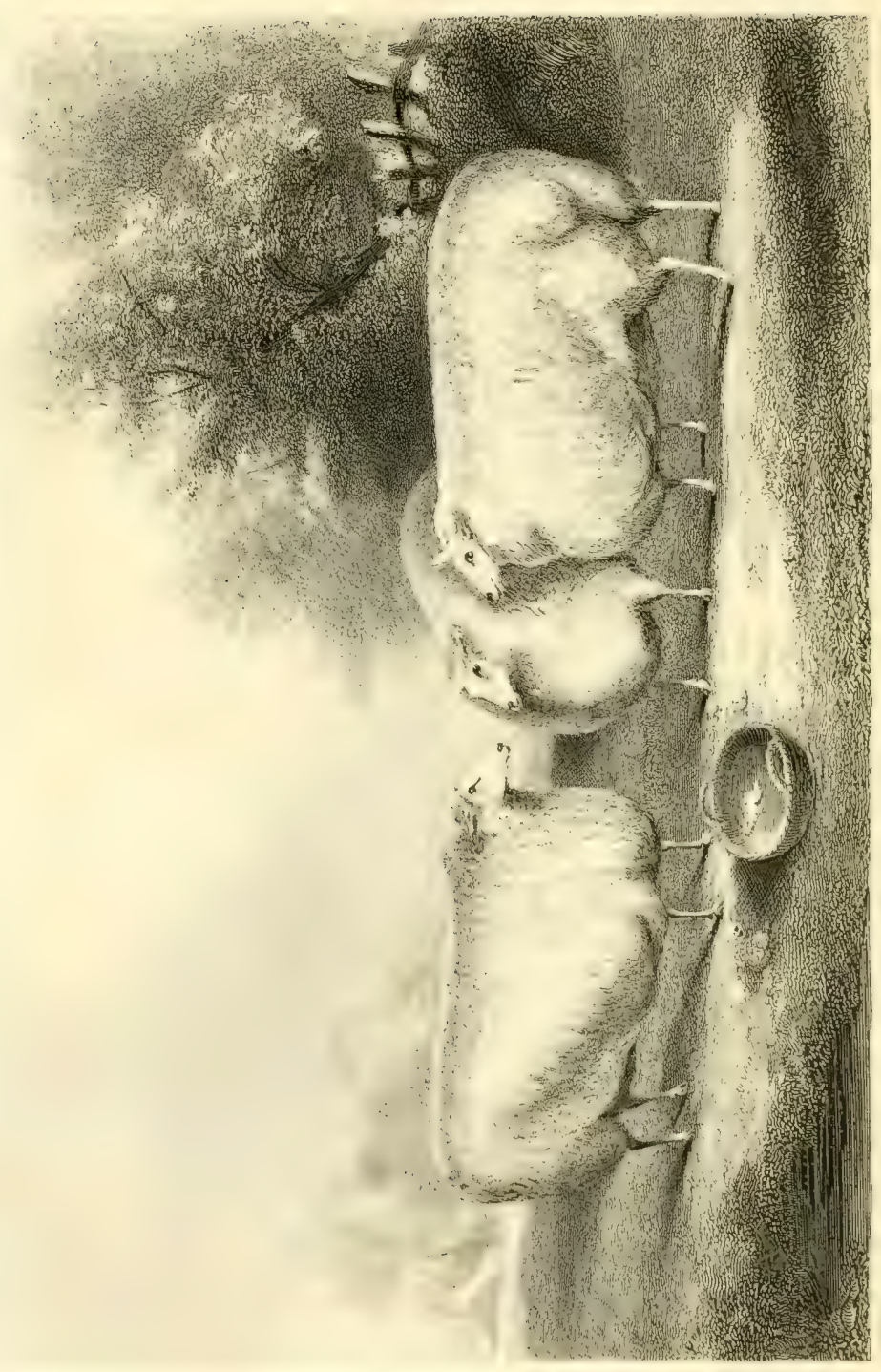




\section{EUROPEAN AGRICULTURE.}

\section{NINTH REPORT.}

\section{CXII.-FRENCH AGRICULTURE.}

The agriculture of France is its great and commanding interest. Its manufactures and commerce are considerable; but its manufactures are mainly concerned in the fabrication, and its commerce in the transportation and exchange, of the products of its own soil. I should have no difficulty in giving the statistical returns of the agriculture of France; but this comes only in a limited degree within my province, and a long table of mere numbers would convey little instruction to my readers. It is of great advantage to France, however, that it procures these returns regularly; and thus, as in the late scarcity of grain and in the failure of the potato crop, enabled the government to provide early, with a humane foresight, against the sufferings which were likely to follow. It is sufficient to say that France has nearly thirty-six millions of inhabitants; and that in ordinary seasons she is able, to a great extent, to feed her own people from her own soil.

\section{CXIII. - SOIL AND ASPECT.}

The agriculture of a country of necessity corresponds to its climate, soil, and aspect. Besides these physical conditions, it 
depends upon many circumstances of a political or moral character, and others which may be termed accidental. The territory of France, stretching through nearly eight degrees of latitude, is susceptible of a great variety of cultivation. On the eastern side, it feels the cold influences of a range of mountains covered with perpetual snow; on its western side, its climate is softened by the vicinity of the broad Atlantic; its northern portions gather humidity from the ocean which bounds it; its southern portions cujoy the sunny influences of an early spring and an almost tropical summer, and of the vapors which rise from that most beautiful of all waters, the Mediterranean, which laves its shores. Its territory is traversed in various directions by several magnificent rivers, the Rhine, the Rhone, the Loire, the Garonne, the Seine; and many minor tributaries, which, if they have not the magnitude of many of the rivers of the western world, afford nevertheless great facilities for inland navigation and transportation; and, at the same time, present on their banks a large extent of alluvial land of the most productive quality.

While the soil of these alluvial lands is most excellent, the soil of the high grounds, as far as it has come under my observation, is of an inferior quality. It is in general strongly calcareous, with the lime or chalk forming almost the entire surface. In dry weather, such lands suffer from the drought, and in wet weather nothing can be more unpleasant to work. Large portions of land likewise are found composed almost wholly of a yellow ochrey sand or gravel, mixed at the same time with an aluminous substance, and apparently highly charged with iron, which constitutes a soil very unfriendly to vegetation. Of soils purely aluminous or clayey I have met with few ; but there are many of a mixed character, with a loam of considerable thickness on the surface. These are capable of great improvement and productiveness. In some parts of the country, lime and gypsum (sulphate of lime) are abundant; and marl of an unctuous and enriching quality is found in many places. 


\section{CXIV. - CROPS.}

The common crops of France are wheat, rye, barley, oats, beans, and potatoes; but its peculiar crops are, bects for sugar, grapes for wine, and silk. Leguminous crops, or esculent vegetables, excepting to a comparatively small amount, for human food, are little cultivated; oats and barley, it seemed to me, only to a limited extent; buckwheat, in the poorer parts of the country, in a small measure; and although the southern portions of France, or more than one half of the kingdom, would produce Indian corn, it does not appear to be largely cultivated, and its value seems imperfectly appreciated. Hay, or grass for hay, cannot be said to be largely cultivated; but there are extensive meadows, which are left in permanent grass. Of the grasses cultivated for feeding, lucern (if it may be called a grass) and sainfoin occupy the first place. The former, when cut green, forms the principal food of the stock during the summer, and when dried makes also an excellent fodder. Vetches do not appear to be extensively cultivated, the preference being decidedly given to lucern. Beans and lentils are cultivated in some districts. Hemp, tobacco, and flax, are likewise grown; but they cannot be considered as prominent crops. Cabbages are sometimes largely cultivated for stock; turnips rarely; and few fields of ruta-baga, of any great extent, have ever met my eye. I have seen large crops of colza and rape, but they do not predominate. It must be understood that I make these observations with great diffidence. France is a large territory: different portions of it, in all their habits, differ much from other portions. It would require years to give a thorough and perfect account of its husbandry, instead of a brief and cursory examination, which is all that my limits admit of.

\section{CXV. - THE FORESTS OF FRANCE.}

In travelling through France, one is constantly impressed with the immense tracts of land which are in forest. The forest conVOL. II. 
nected with the palace at Fontainbleau, only about fifty miles from Paris, is said to contain 35,000 acres; the forest connected with the palace of Chambord, 20,000 acres. There are other forests in France of great extent, some of them being portions of the national domain, and many of them the property of individual proprietors. They are not, however, kept merely for show, or luxury, or sport. 'The heath, or common lands, in France, which remain open and unproductive, are retumed as 19,499,180 acres, or about one seventh part of the whole surface of the kingdom. The fuel generally used in France is wood or charcoal. 'There are, it is said, large deposits of mineral coal in France; but they are not extensively worked, or are not easily accessible, though their value is beginning to be appreciated. Wood, therefore, is grown for fuel, and comes to market by means of the great rivers and canals in the form of wood or coal; so that these forests are regularly and gradually cut off for timber or fuel, and either replanted or suffered to grow again from the old stumps. The law permits the proprietors to cut off their wood only once in eighteen years; and this under the control of a government inspector, who recinires that it should be cut clean, leaving only such trees as may be valuable for ship-timber or for other purposes, which the government claims a right to take for its own uses at an equitable price. Under these excellent arrangements, the supply of fuel is constantly kept good, and the price of wood. has scarcely varied for a quarter of a century. In the cities, and in many parts of France, wood is always sold by the pound; and it is curious in Paris to see the immense arks of charcoal and wood which come down the Seine, and piles of wood in the city, covering acres of ground, and on a level with the tops of the highest houses. The value of the timber in these immense forests is likewise great. Although throughout France the principal and almost universal material for building is stone, yet much timber and boards are wanted for floors and roofs, and various purposes; and many large proprietors think that they cannot make a better provision for their children than by planting forests, or preserving and cherishing such as they already have. 


\section{CXVI. - A FRENCH LANDSCAPE.}

A French landscape is peculiar. A large portion of the terretory is comparatively level, with few great inequalities. The appearance resembles that of some of the large prairies of the United States; for in a great portion of France fences of any kind are unknown. Here and there a large farm-house, or what is called a chateau, or castle, meets the eye, with its customary appendages; but the laboring peop'e chiefly live in villages, which seem scattered about like islands, and are generally known by the spire of the church overtopping the cluster of houses. The French villages more resemble compact towns than country villages; the streets are ordinarily paved; the houses are placed directly upon the street; and though there are usually or frequently gardens attached to the houses, it is remarkable that there are no trees either for shade or ornament in the streets. Yet the great roads through the country, which are usually as straight as they can be made, furnishing a paved way in the centre, and two side paths which are unpaved, are commonly lined with trees on each side for many miles.

\section{CXVII. - THE FRENCH PEASANTRY.}

Excepting with the great farmers, where there are small buildings for the residence of the permanent laborers ordinarily in the court-yard, or immediate neighborhood of the great house, the peasants generally live in the villages, and sometimes go long distances to their work. They rise early, and among their first duties are those of religion; their first visit being, in most cases, to the village church, which is open at all hours. I have often met them there in the morning, when it was scarcely light enough to see the way; and I have found crowds of them in the churches at night, after their return from labor, when, with only one or two lamps burning over the altar in the church, it has 
been so dark that the dress of persons could not be distinguished until you came within arm's length of them. It is the beauty of the Catholic religion, that, although it is in a degree social, it is at the same time individual and personal in its character; that although the ceremonials of the worship are of a splendid, and often gorgeous description, yet the worshipper seems regardless of every thing but his own particular part in the service, which he performs silently, and generally with an intensity and an abstractedness which are remarkable; and in churches whose splendor and magnificence it would require a brilliant pen to describe, I have seen laboring men in their frocks, and with their spades upon their shoulders, and market-women with their baskets upon their arms, go up to the altar, and after performing their devotions, and evidently with no other object in their thoughts, go away to their labors.

In all parts of Europe the women are as much engaged in the labors of the field as the men, and perform indiscriminately the same kinds of labor. Having been much among the peasantry and the laboring classes both at home and abroad, I must in truth say, that a more civil, cleanly, industrious, frugal, sober, or better dressed people than the French peasantry, for persons in their condition, in the parts of the country which I have visited, and especially the women, I have never known. The civility and courtesy, even of the most humble of them, are very striking. There is neither servility nor insolence among them; their economy is most remarkable; drunkenness is scarcely known; their neatness, even when performing the dirtiest worl;, is quite exemplary; cheerfulness, and an innocent hilarity, are predominant traits in their character.

The wages of the French peasantry are in general from a franc to a frane and a half per day to a man, that is, ten to fifteen pence, or twenty to thirty cents; and to women about four fifths of the former sum, or about eight pence, or sixteen cents. In this case, they ordinarily provide entirely for themselves. In harvest, however, or under extraordinary circumstances, they are provided for in addition to their wages. Coffee and tea are scarcely known among them. They drink no ardent spirits. Their usual drink is an acid wine, not so strong as common cider, and this mixed with water; they have meat but rarely; oceasionally fish; but their general provision is soup, composed chictly of 
vegetables and bread. Bread, both wheat and rye, is with them literally the staff of life. With all this they enjoy a ruddy health; and the women are diligent to a proverb. They seem unwilling to lose a moment's time. I have repeatedly seen them carrying heavy burdens upon their heads, and at the same time knitting as they went along.

\section{CXVIII. - SIZE OF FARMS, AND DIVISION OF PROPERTY.}

The size of farms in France has been a subject of much discussion. The right of primogeniture has ceased to exist there: and since the great revolution, the law has ordained that the land possessed by any one at his death should be equally divided among his children. This did not take place without a hard struggle against it on the part of the great proprietors, nor without many predictions of ruin to the agriculture of France, from the infinite subdivisions which the land was likely to undergo, and the small size to which farms were about to be reduced. The law, however, has been maintained, and, as far as I have been able to observe, with the happiest results to France.* It was predicted, that, under such an arrangement, no system of extensive agricultural improvement could be attempted; and that small proprietors being thus multiplied, and the laborers them-

* In France the total number of taxed landed properties is stated, in 1835, to have been 10,896,682, and these were again divided into $123,360,338$ separate pieces of land. It is supposed, however, that of heads of families occupying estates, which combine many of these smaller divisions, and which consequently become merely nominal partitions, there are about 5,000,000. Now, allowing an average of four to a family, it will be seen that there are $20,000,000$ of people in France directly interested in the property of the soil. The number of proprietors of the soil in Lingland, who hold landed property yielding a rent of E100 sterling per year, is stated, at the same time, at 38,000 ; and the whole number of proprietors of the soil in England and Wales is rated at 200,000 , and in the whole United Kingdom at 600,000. The extent of the United Kingdom is about two thirds that of France. - Statistique Génerale de la France, par Schnitzler, tom. iil. p. 11. 
selves becoming proprietors, the lands of the country were destined to go into the hands of men without capital, too ignorant to understand or learn the best modes of cultivation, and withont the power of applying, even if they knew, them.

These objections are not wholly without force; but as this subject possesses considerable interest for many persons, I hope to be excused for enlarging upon it. It happens with respect to many things which are deemed evils, or from which evil consequences seem likely to result, that there is a compensating or balancing power at work, which, if left free to operate, of itself corrects the irregularities, restores the equilibrium, and prevents the evils apprehended. If all France were to be cut up and divided into pieces of ground of the size of a table-cloth, as, from the comments made upon this law by those who know nothing of its actual operation, one would suppose was likely soon to be the case, we should expect a state of things extremely adverse to the national prosperity. But it must be remembered, that while the law requires an equal division of the land among his children at the death of a proprietor, it does not require that the land should remain thus divided. The appropriation of it is left optional with those who inherit it; and in this, as in other cases, they will be governed by their interests, their convenience, and other nameless circumstances by which human conduct is ordinarily infuenced. A father dying and leaving several heirs, sons and daughters, it is scarcely probable that they will all wish to devote themselves to agriculture, and this too when the parts of such property growing out of this division would be, either of them, too small, under any circumstances, for the support of a family. The result is, as we should expect it would be in such case, that some one of the heirs purchases the rights of the others, and the farm remains in its integrity.

What, then, is the advantage of such a law? It is, that it leaves this matter, as it should be left, to the choice of the parties concerned; and that it in fact prevents the too great accumulation of landed property in the hands of individuals. There can hardly be a greater evil, in countries where labor is abundant, and population presses hard upon the means of subsistence, than that immense tracts of land, which might be made productive, should be locked up in the hands of individuals who will neither use the land themselves, nor suffer it to be used by others. It 
seems a violation of natural right, justice, and humanity; and there are many circumstances in the condition of society in the old world, which indicate that it must be modified or abandoned.

One of the first duties of society is, to give to every man a perfect security in the enjoyment of the fruits of his own industry ; but it is equally the duty of society to secure to every man disposed to labor an opportunity, as far as possible, fully and eflectually to exert that industry. The end which goveruments ordinarily.aim at, is the protection of property; and almost all laws, being made by men of property, have this for their great object. But wealth is ordinarily quite able to take care of itself; and the object of government shonld be to protect poverty, which constantly requires protection. The true wealth of a community is its labor, its productive labor. A man is not the richer for houses which he cannot occupy, lands which he cannot use, money that he cannot spend. He might own a continent in the moon, but what would that avail him? He might die of starvation in the vaults of the Bank of England, or in the undisturbed possession of the richest of the mines of Peru. Labor is the great source and instrument of subsistence and wealth. Labor, therefore, honest labor, should be, under all circumstances, the great object of the protection and encouragement of every just government. Laws should be such as to secure to labor, as far as possible, an open field for exertion. Such is the tendency of the laws of France respecting the posthumous division of landed estates. The laws of primogeniture, by which large landed estates go exclusively into the hands of the eldest son, and laws of mortmain, by which lands are forever appropriated to particular uses, are laws of a different description. The law of primogeniture seems to many persous essentially mujust in the favoritisin which it implies, among those who obviously have equal claims upon parental kinduess and impartiality. The law of mortmain and perpetual devises, by which extensive landed estates are locked up and appropriated in perpetuity to particular uses, has met with many warm combatants. They ask, and with what reason I shall leave to the judgment of my readers, Was not the land given to man, that from it, by his labor, he might obtain a subsistence, which, in truth, can come from no other source? Now, shall any man, or set of men, so monopolize and approuriate this laud, that it shall not be available to these objects? It would 
seem that the earth belongs to those who possess it; and that, when a man once quits it forever, his rights in it should cease; yet society admits the remarkable fact, that men who died centuries ago shall determine how the land at present shall be used and appropriated; or that it shall not be used nor appropriated at all.

It does not come within my province to enter upon matters of dispute, which, in a period full of questions and inquiries, seem to be assuming importance, and are becoming matters of private and public discussion. I am well aware of the necessity of giving as perfect a security as human society admits of to the rights of property; but these rights, it would seem, should be held in subserviency to a still higher right, and that is, the right. to live. That which a man produces by his industry or toil, by his skill or genius, exerted without prejudice to the equal rights of another man, is his own; it is his exclusively, and it should be his in perpetuity; that is, the appropriation of it should be his, and should be uncontrolled excepting so far as to prevent its application to an immoral object, to an object prejudicial to health or life, or to the public peace and welfare. But the appropriation of the soil itself to any object in perpetuity, the shutting it up from use, the prevention of its occupation for purposes of human comfort and subsistence, seem incompatible with those natural rights with which the Creator endowed man when he commanded him to till the earth, that he might from it obtain a subsistence. The laws in many of the states of the United States, when the property of a debtor is seized for the payment of his debts, very properly take care to leave him in the possession of the tools of his trade, that he may still provide for his own, and the subsistence of those dependent on him. A law which would rob him of his tools, and, while the community and his duty to himself and his family require that he should by his labor provide for himself and them, should virtually put it out of his power to exert that industry, would be of the same character with that which, under any pretence or form, in the midst of hungry and starving thousands, excludes them from the use of that soil from which Heaven designed they should get their bread, and from which only it can be obtained. It is one of the great effects of the revolution which gave independence to the United States, and of the great French revolution, that 
it broke up these restrictive laws, and in gencral left property in land to follow the usual course of other property; and, above all, made it universally attainable.

In the United States, where land is abundant, and where countless millions of acres must remain for countless years unoccupied, laws restraining the monopoly of land are far less necessary; but even in the United States they should have a care to guard against the perpetual appropriation of land for any objects whatever, whether under the plea of pious or of moral uses, as in fact a direct violation of the rights of every generation to judge for itself, and to judge only for itself, what shall or shall not be maintained; and secondly, as conferring a power which experience shows is liable to gross and injurious abuses.

A principal objection urged against this subdivision of land is, that it prevents any system of extensive improvement of the soil by the great processes of modern discovery, - draining and sub. soiling. This argument has some force; but we may hope that in many cases the owners, seeing their own interests clearly concerned in such improvements, may combinc their forces to effect them. In many of these small holdings, likewise, the cultivation being by the spade, and not by the plough, the land will be trenched as a substitute for subsoiling, and an equal productiveness secured. Where such improvements are obviously demanded, and they might be too great for individual effort to accomplish, there seems no reason why the government itself should not undertake them, assessing the expense upon the different owners of the land in such forms as would be equitable, and made payable at such periods as would render its discharge easily practicable.

It is objected likewise that these small farmers having no capital to apply in the cultivation of their lands, and being of a class not likely to be acquainted with modern improvements in husbandry, their agriculture will probably be of an inferior character. These objections must be allowed some weight; but then the holders of these small parcels are acting under the most powerful of all stimulants - that of their own immediate self-interest. They themselves being the owners of the soil, whatever improvements it receires, and whatever crops it produces, must accrue directly to their own benefit. The holding being small, it becomes the more imnortant that it should be forced to the 
greatest extent, in order to meet their wants. This circumstance will prompt to the greatest exertions in procuring from every available source, and in saving their manure for the enriching of their small farms. Labor and economy, thus applied, may be said in themselves to constitute a valuable and active capital.

But in place of speculations, let us revert to facts, and inquire how this system has actually worked in France. It has produced a great revolution in the tenure of property; but from the best inquiries I could make among the most intelligent and candid, I found a unanimous and emphatical acknowledgment of its beneficial results. In what may most properly be called the rural districts, - that is, a district somewhat remote from large towns and villages, - there are found farms in size from one hundred to five hundred, seven hundred, and a thousand acres, and upwards; and so it seems likely to remain. The law, though it requires a division of the real estate among the heirs, does not make it compulsory to continue such division. The law in fact does little else in stch situations than, so to say, to bring the land into the market, and leave it then to be disposed of according to the circumstances of time and place.

But in cases of partition, we may suppose a farm of twelve hundred acres divided among four heirs; they would have farms of a respectable size; divided again, it would leave farms of seventy-five acres each, which perhaps may be considered the average size of farms in New England, and exceeding the average size of Flemish farms. Even another division of the same number of parts might take place, and twenty acres would correspond with the size of many of the most productive farms in Belgium. Nany persons, in arguing against such an arrangement, proceed upon the supposition that the division is to be infinitesimal. But this is absurd; and, as I have already remarked, the evil of too great a subdivision has already a tendency to correct itself, and to stop where it would become positively mischievous. This is found to be the case, as I have remarked, in the strictly rural districts. But a person passing through the environs of large towns and cities will perceive that the division has proceeded very far; the fields often appear like patchwork, and are cut up into very small pieces. This is exactly as it should be. These pieces are owned by small gardeners, who supply the markets with fruit or vegetables, and 
who, on account of its limited extent, carry their cultivation to a high perfection, and often in the number, variety, and quantity of their crops on these small pieces of ground, astonish one by their success. Very often these pieces of land are owned by persons engaged in severe mechanical trades in the cities, who find health and needful recreation in their cultivation. One thing is quite certain in such cases - that no land thus situated will be left uncultivated; and under the system of minute economy to which it is subjected, will unquestionably be rendered as productive as possible.

If we look at large farms in Great Britain, - I mean farms of hundreds of acres, with the exception of some of the best cultivated districts, such as the Lothians in Scotland, for example, or the counties of Northumberland, Lincoln, and Norfolk, and only some farms in these counties, - we shall find that even these are by no means always fully cultivated; and that, either for want of skill, or enterprise, or capital, large portions of them are wholly unproductive. This is far less frequently the case with small farms, for the simple reason that the owners cannot afford to neglect their land, and that the management is much more easy. It is to be added likewise, that in very small holdings, of six, or ten, or twenty acres, the great expense of a team, and of costly implements, is dispensed with. In some parts of England, though very rarely, but in many parts of the Continent, and especially in Switzerland, the small farmers use their milch-cows for work, thus getting a double advantage from them; and a milch-cow, used tenderly, and treated liberally, may be worked from four to six hours a day without injury to her milk. This saving is a great circumstance. On large arable farms it may be calculated, that from a fourth to a third of the produce must be counted for the support, and equipments, and cost of the teams. The saving of this expense is a great affair; and this is accomplished on small holdings where cows are kept, which pay the expense of their keeping by their labor and their calf; or where, as in many cases, the whole cultivation is performed by human instead of brute labor - by the spade instead of the plough. I believe, therefore, it will be found, that in a fair comparison, the small farms are in fact more productive than the large ones; that they are managed at less comparative expense, and, in proportion, leave more for human consumption. 
If thus much may be said of the economical results, still more may be said of the beneficial moral influences of such a system. Of all the influences which operate to promote exertion, industry, and good conduct, none certainly is more powerful than the hope of bettering our condition; and I may add, without undertaking to give a reason for it, as an established truth, that nothing inspires more self-respect, as connected with a feeling of independence, than the possession of property, and especially the possession of a fixed property in house or land. This effect is constantly seen in the laboring classes among the French. They are extremely ambitious of getting a piece of land; and perhaps too much so, after once coming into possession, of extending their possessions. This stimulates them to industry, and induces the most rigid economy. The subdivision of property or of land in France renders this practicable, which, in other countries, where the right of entail prevails, or where property is held in large masses, and guarded with extreme jealousy, is out of the question. There is a wise foresight likewise, in this matter, in respect to the security of public order and the peace of the country. The persons of all others least likely to engage in projects of revolution certainly are those whose property must iti every case be endangered by such revolution; whose possessions are fixed, and not transferable from one place to another at pleasure. Their estates constitute the strongest pledge of their loyalty and patriotism. The more property is divided in a country, the more equally it is held, or rather, that it should be attainable by all on equal conditions, the greater security is there for the rights of property; the more are concerned in the preservation of the public peace. The humblest agricultural laborer in France may look forward, by industry, sobriety, and economy, to become a proprietor and a holder in fee-simple of some portion of the soil which he cultivates. There is, therefore, the strongest inducement held out to good conduct; and the beneficial influence of this condition of things upon the character of the French peasantry cannot be doubted.

Few things have struck me more forcibly than the difference in the condition of the agricultural population of France and that of Great Britain - a subject to which I have already referred. I have never seen a more healthy, a better-clad, or a happier population, than the French peasantry. Something may 
be ascribed to their naturally-cheerful temperament, and something to that extraordinary sobriety, which every where, in a remarkable degree, characterizes the French people; but much more, I think, to the favorable condition in which this law, which renders attainable the possession of a freehold in the soil, places them.

I am extremely averse to making any unfavorable comparisons ; and I am quite aware that my judgment may be at fault; but I shall offend no candid mind by the calm expression of my honest opinion, The very poor condition of a large portion of the English agricultural laboring population must be acknowledged. The acquisition of property is, in most cases, all but impossible. The great difficulty, where there is a family, is to subsist; in sickness they have no resource but private charity or parish assistance; and they have, in most cases, nothing to which they can look forward, when the power to labor fails them, but the almshouse.

I believe there is an equal amount of philanthropy, and as strong a sonse of justice and humanity, among the English. as among any people; but it is not to be expected, in any country where wealth constitutes the great and most cnviable distinction, and where, by various circumstances, avarice is stimulated to the highest degree, that the great mass of the community should be either philanthropic, or humane, or just. Wealth is almost every where, in what is called civilized, and too often miscalled Christian, life, the great instrument of power. Power is a dangerous possession, and always liable to abuse. The only security against this abuse is the division of power: and to give the humbler classes the means of helping themselves.

In Great Britain, as I have already said, the rural laboring classes are placed in ciremmstances of hardship and disadvantage. It would be ordinarily quite idle for them to aspire to the ownership of land. Philanthropic and benevolent persons, in various warts of the country, have given them small allotments; though some have endeavored to limit these allotments to one eighth of an acre, and many farmers have combined in denouncing the allotment system, and have refused to take leases where the laborers were to be allowed allotments. The beneficial effects of these allotments, both upon the comfort and morals of the roL. II. 
laboring classes, have every where been acknowledged; but under the best circumstances, the allotment system can never be a substitute for that by which the ownership of the land is itself attainable.

I will not contest the point that great improvements can only be expected.to take place on large estates and with the help of large capital; yet, on estates of a medium size, such as a hundred or even fifty acres, these are, perhaps, more likely to take place than on estates of a much larger size, as being ordinarily more within the reach of most men - the majority of farmers being men of restricted capital. The immense improvements in diking and embankments, and in redeeming land from the sea, which have been made in Holland, and in Lincolnshire and Cambridgeshire, in England, could only have been effected by the union of large bodies of proprietors. No single fortune is any where competent to such enterprises.

I will not deny that under a system of large farms more produce may be for sale; and, in a commercial view, more money will be made, and larger fortunes accumulated. But I cannot agree that the wealth of a community, held as it ordinarily is held, is the standard of its prosperity. That undoubtedly is the happiest condition 'of society, where none are over-rich, and none extremely poor; where one is not continually offended by those striking contrasts of enormons wealth and extreme destitution, which some countries present. That condition of society is undoubtedly above all others to be preferred, where the power of bettering our condition is, as far as possible, equally enjoyed by every man, and certainly not denied to any one; and where every possible encouragement and facility are given to the exertion of this power. It is often a great charity to help our neighbor; but the best and wisest of all forms, in which this charity cin be exercised, is that, when a man helps his neighbor to help himself. 


\section{CXIX. - MEASURES OF TIIE GOVERNIENT FOR THE IMPROVEMENT OF AGRICULTURE.}

The measures of the government for the advancement of agriculture have much to recommend them, if they are carried out in an intelligent and faithful manner.

1. Departient of Agriculture. - In the first place, there is a department of agriculture, the secretary or minister of which, being one of the first men in the kingdom, is expected to look after this great interest; to obtain statistical returns of agricultural produce from all parts of the kingdom; to learn what is the condition of the art; what improvements have been made; what improvements are most required; and what is the condition of the agricultural population.

2. Statistical Returns. - The statistical returns of the produce of France have been recently completed, and show a work of immense industry and labor. It is obvious that such a work can present only an approach to exactness; but even that is of great value; and it will be found that some facts have becn brought out, in respect to the average increase of the crops, which are in the highest degree encouraging. These returns have been obtained by a direct application to well-informed and confidential individuals, in different parts of the country, who have made their returns to the central bureau in Paris. $\boldsymbol{\Lambda}$ great variety of subjects have been embraced in them, such as the amount of land in cultivation; the amount of land devoted to different crops; the manure applied; the quantity of seed employed, and the average yield. It extends, likewise, to the number of persons engaged in agriculture, and the number of domestic animals reared or liept in every department, with a great variety of agricultural and commercial information, subsidiary to and commected with the subject, of a very interesting character, and of equal utility. This magnificent work does the highest honor to the govermment, and to the persons employed in its execution. 
3. Inspectors of Agricultural Districts. - The next provision made by the government is the division of the kingdom into four agricultural districts, to each of which an intelligent and experienced agriculturist is appointed, as inspector or commissioner, whose duty it is to go through his district annually at least, observe carefully its condition, and report it to the government; and at the same time, in his journeyings, communicate every where advice and information, as he may see that they are needed. This is certainly an admirable mode of dispensing knowledge and exciting emulation.*

4. Impontation of Improved Stock. - The government likewise have imported from other countries some of the most valuable animals, such as bulls and stud-horses; and stationed them in different parts of the country, that the farmers may avail themselves of the advantages which they offer for the improvement of their stock. On account of the large demands made by government for horses for the cavalry, this becomes a matter of great importance. Whether the keeping of bulls would not be better left to private enterprise, is a question much debated. That which belongs to the public is seldom cared for like that which belongs to an individual; but the government have met this oljection by disposing of their improved animals occasionally. at public sales.

5. Agricultural and Veterinary Schools. - France has likewise several agricultural schools, established in different parts of the kingdom, of which I shall presently give an account, designed to furnish a complete scientific and practical education in agriculture. In addition to this, they have veterinary schools, where comparative anatomy is thoroughly studied, and the diseases of all the domestic animals most carefully treated. These likewise may be supposed to grow in a great measure out of their army, where the medical treatment of their horses is obviously of great importance.

* At one time, several persons were employed by the government to visit foreign countries for the purpose of seeing their improvements, gathering agrirultural information, and bringing home such plants and seeds as were likely to be useful to the country. It is proposed by the provisional government to revive this excellent plan. March, 1848. 
6. Agricultural Societies and Show. - In various parts of the country agricultural societies are established, and assisted by the government, for the purpose of diffusing information; and these will, in all probability, extend themselves. $\Lambda$ society in Paris, composed of some of the first men in the kingdom, meets regularly twice a month for the discussion of agricultural subjects, for the report of improvements, and, at the end of the season, for the bestowal of premiums. An agricultural show was undertaken the last year at Poissy, the Smithfield of France, where some excellent native, and some very good improved stock, though not to a large amount, was exhibited; and here I saw sheep of the very best and most profitable kind, especially for such a country as the United States, where good mutton, and particularly fine wool, are in demand. These were pure Mlerinos, of a very large size, well proportioned and fat, and with fleeces of an excellent quality. I have never seen animals of the kind combining more valuable properties. It is intended that these shows, of which this was a first attempt, should be continued annually.

7. An Agricultural Congress. - Previous to this show, an Agricultural Congress, composed of more than 300 gentlemen interested in agriculture, and sent as deputies from different parts of the country, had been sitting in Paris for a fortnight, to discuss practical questions in agriculture, and likewise political questions bearing upon it; which was done with great ability. At Poissy, the minister of agriculture distributed premiums of large amount; and every circumstance indicated an active, an increased, and increasing attention to this great subject.

8. Conservatory of Arts and Trades. - Paris is, in the next place, distinguished by its direct means of scientific instruction. It has what is called a Conservatory of Arts and Trades. This is, properly speaking, a school for the industrial and mechanical classes. Here is a complete collection of models or of examples of agricultural buildings and implements - to say nothing of other arts - not only of those in use in France, but specimens of the best of every description which are used in foreign countries. Here, under accomplished professors, courses of agricultural lectures, or rather of chemistry and mechanics 
as applied to agriculture, are regularly given, to which access is entirely gratuitous, the professors being supported by the government; so that here is presented to inquisitive minds the best means of learning the application of science to agriculture. Perhaps, in the science which involves the connection of chemistry with agriculture, no country has made so great advances as France, as the labors of Chaptal, Boussingault, Payen, and other distinguished men decisively show. If agricultural chemistry could make men good farmers, the French should take precedence of all others. How far the facts conform to this supposition I shall leave to others to judge; because I have no wish to put my head into the lion's cage; though I am compelled to saty, in passing, that the best arable farming which I have ever seen, the cleanest, the most exact, apparently also the most productive and economical, is in countries where there is no science, technically so called, and implements only. of the most ordinary description; I mean Belgium, Holland, and Switzerland. I shall take occasion to remark upon this fact in another place.

9. Socretr for the Improvenent of Wool. - Besides the Society of Agriculture, which meets in Paris twice every month, and is the centre of the correspondence of all the agricultural societies of the country, there is likewise a Society for the Improvement of Wool, which twice a year bestows valuable premiums upon persons who have made the greatest advances in the improvement of the fleeces of their flocks. This society has its public exhibitions of wool, and has undoubtedly accomplished much good.

\section{CXX. - PARIS MARKETS.}

1. Conn Market. - Paris concentrates much within itself that is extremely interesting to an agriculturist. Its markets are in the highest style of convenience, neatness, and abundance. The market for the sale of all kinds of grain is a circular stone building, two stories in height, and 126 feet in diameter, surrounded by high galleries for the storage of flour, the unground 
grain being in the centre on the floor, and covered in by an iron roof of admirable architectural construction. The building is completely fire-proof. The grain is always brought to market in sacks, and the building, it is said, is capable of containing 10,000 sacks. There are to be found here wheat, rye, barley, oats, buckwheat, beans, peas, lentils, and vetches. Bureaus, or small offices, are ranged round the circle on the inside for the factors, or salesmen; and, as in almost every other department of business in France, women are as much employed in the sale of grain as men; and there can be no doubt they manage with admirable skill and address. Sharp trading seems often the characteristic of the sex; excepting only where the affections are concerned. The Corn Exchange is held here two or three times a week.

2. Meat Markets. - The meat markets are of the neatest possible description; but they are scattered about in shops. The beef in Paris, in point of fatness, is much inferior to the English; yet it is of a fair quality. The mutton is likewise very inferior to the English. Some persons complain of the English beef and mutton, especially the Dishley mutton, as being much too fat, and therefore attended with great waste. Veal, in France, is not killed until it is full six months old, and is of the very finest description. The meat shops in Paris are shut in by doors of iron grating, so as to admit a free circulation of air at night, with cloths covering the meat to ward off the dust; and they are visited every morning by the police, and undergo a strict examination, so that, if there is any meat of a bad description, or which has remained on hand too long, it is at once condemned and seized. The butchers in Paris are licensed, and laid under heavy bonds to conform to the police regulations; and the meats and other articles brought into Paris are subject to a duty; collected at the barriers, which goes towards the improvements of the city.

3. Markets for Eggs, Butter, Cheese, Vegetables, Fruits, Poultry, Fisr, \&c. - The market of the Innocents, "* as it is called, is one of the largest in Paris. This market is to undergo great alterations, and a very large sum is in reserve to build it

* Being the site of an old convent or nunnery. 
upon the most extensive and magnificent plan. This market comprises not only the great fish market of Paris, but also the egg market, the butter and cheese markets, the potato market, the onion market, and the general vegetable and fruit markets. The sellers, with scarcely an exception, are women, very sharp, very busy, and of course very talkative. Looking down upon the whole area from the magnificent fountain in the centre, it would be difficult to find a more gay and animated scene. The fountains in Paris are one of its most remarkable features; and no principal market is to be found without its continually-flowing fountain.

The vegetables, butter, eggs, fish, and many other things, are always disposed of at auction early in the morning to the retail dealers. The vegetables in Paris are excellent. Carrots, and turnips, and onions, are not so large as in England and the marirets of the United States, because the French deem the largesized vegetables not so good for eating as the smaller-sized. It is remarkable, likewise, that there is hardly any season of the year when almost any description of vegetables may not be found in the markets of Paris; and in the middle of December, green peas, aspratagus, string beans, and strawberries, may be purchased in quantities, which shows the perfection to which the art of gardening is carried among them.

The fruits exposed in the markets of Paris are of a superior quality, pears especially, for which the French have long been celebrated. The St. Michael and the St. Germaine pears, which, in the United States, have almost wholly failed, from having, as has been supposed, completed their period, are here still in perfection, which would seem to contradict this theory, and leave some other cause to be discovered for the extraordinary failure of these excellent fruits. I have not been able to ascertain any thing in respect to the culture of any of these articles, which is not familiarly known to all cultivators.

4. Market for Forage. - I have spoken of the grain market in Paris; it has likewise its hay and forage markets, where extensive sheds for protection against the weather are furnished. These articles, as in England, are sold in small bundles of a fixed weight. I shall, perhaps, surprise some of my American readers if I inform them, that hay, in small packets or bundles, 
is often sold in Paris at the groceries. I refer to this fact for an opportunity of making a remark, which, hereafter, if it has not now, will have some importance in the United States; and that is, that where hay, for example, is bought in such small quantities, it is likely to be expended with an extreme economy. No observing American comes from the United States to Europe, without soon becoming convinced, that economy of living is nowhere so little understood as in his own country; and that for nothing are the Americans more distinguished, than for a reckless waste of the means of subsistence. 'The refuse of many a family in the United States, even in moderate circumstances, would often support in comfort a poor family in Europe. When persons buy tea by the ounce, and wood by the pound, and hay by the handful, it is quite obvious that these articles will be expended with far more frugality, than where the store is less limited and seems inexhaustible. While meanness is contemptible, a rigid economy, avoiding all waste, is a great virtue. 'The inhabitants of the United States enjoy an abundance for which they camnot be too grateful; but which is very little understood in Europe, where, with a large portion of the population, including many in the middle condition of life, it is a constant struggle to live, and to bring even their necessary expenditure within their restricted means; and where the constant inquiry is, not what they want, but what can they afford, - not what they will have, but what can they do without.

5. Horse Market. - Paris, besides its grain and cattle markets, has likewise, weekly, its horse market, for the sale of horses, mules, and asses, where immense numbers of every description are brought, and change hands; and where the morality is probably upon a par with that of the trade in horses in other parts of the world, of the green-spectacle character, as exemplified in the Vicar of Wakefield.

6. Flower Markets. - The flower markets are another extraordinary feature in Paris. These are held at all seasons of the year, in three different parts of the city, twice a week, and in the most favorable season comprise a collection of flowers and plants as beautiful as the climate admits of. It is stated on good authority, that occasionally there are exposed in a day, in Paris, 
for sale in these different markets, not less than 30,000 pots of flowers, the value of which is estimated at full 9000 dollars, or $£ 1800$ sterling. With the strict notions of utility entertained by some persons, such facts may seem scarcely compatible; but, if we may judge that to be useful, which gives us a pure and perfectly innocent pleasure, certainly there is no luxury whatever which should be looked upon with more favor. There are distinct markets, held likewise at proper seasons, for the sale of trees, ornamental and fruit-trees, and flowering shrubs and plants, presenting an extraordinary and beautiful variety.

\section{CXXI. - THE CULTURE OF FLOWERS. - BOTANY.}

Perhaps I have already said, in other places, as much as my readers will bear, with patience, of the cultivation of flowers. Yet I must crave a further indulgence. I must urge it on grounds of utility, on grounds of taste, and, above all, on moral grounds. My words will reach many dwellers in the country, who, amidst their daily severe labors and toils, are sighing for some relaxation, and some refreshment of the soul. They want something which shall relieve the dull monotony of their daily toil; something which shall interest their cares, their thonghts, their imaginations, I will add, their affections. 'They require that which, so far from wasting, shall invigorate their strength. They require a pleasure which shall be inexpensive, and easily attainable, and innocent, and which, enjoyed to its utmost extent, so far from satiating and exhausting either the body or mind, shall not weary the former, and shall enlarge, recreate, and elevate the latter, and fill it with the purest delight. All this is at hand in the cultivation of flowers. The taste which leads to it is among the most pure and the most innocent which can be indulged, and where it does not interfere with imperative duties, is unexceptionable.

I cannot say that, as a science for study, botany is ordinarily presented in a form interesting to general readers. 'The general classification of plants, and the scientific distinctions which are 
made between them; the physiology of plants, so far as it is understood, which admits us at once into some of the most wonderful and beautiful secrets of nature; the different modes of culture which different plants require; their peculiar adaptation to various soils and climates, so strikingly as it displays the benevolent adaptations in the works of a wise and omniscient Providence; the acclimation of different plants, and the curious changes which, under such acclimation, they undergo, and by which, like many animals, they are brought from a savage into a domesticated state; the presence of certain plants in certain localities, found nowhere else, and where their presence would seem indispensable to render such places habitable to human beings; the economical uses of different plants for food, for clothing, for building, for mechanical purposes, for naval purposes, for fuel, for coloring, for light ; the medical uses of different plants, so extensive as it is found to be in every pharmacopœia; the infinite variety of fruits, not for subsistence merely, but for luxury ; the uses of plants in the fine arts, for imitation, for adornment, and for taste ; the chemical qualities or properties of plants in their particular uses, and in their general influences upon the atmosphere which we breathe, in the gases which they take in, and those which they exhale; the control and influence which human sagacity and power have been able to exert over the vegetable world in acclimating plants, in propagating them, in fructifying and engrafting, and changing the different species; - all these matters, directly involved in the science of botany, render it one of the most interesting of studies; and, even in its present imperfect state, it is the business of years to master it. The extensive discoveries, likewise, which have been made of fossil plants, in particular geological formations, which, as comprared with present existing species, lead to so many curious induetions in regard to the past condition of the earth, open to the mind many interesting subjects of inquiry. It is as obvious, likewise, that the establishment of a common scientific and technical language, by which the description of a plant, wherever found, shall be every where understood, and the plant, when met with, reeognized, is of the highest importance." But botany, as it is commonly taught in schools, and as it appears in botanical worlis in general use, seems little else than a vocabulary of arbitrary and technical terms, in a language not generally understood, creates 
usually but little interest, and is of little practical utility. Within my limited knowledge, the botanical work is yet to be written, which shall present the subject in that natural, plain, instructive, familiar, comprehensive, elevated, - I hope I may add, without offence to science, - popular form, which would give to rural pursuits and recreations, and to the culture of ornamental as well as of useful plants, an interest, a utility, a delight, even to humble minds imperfectly educated, infinitely beyond what they are now found to have with many persons, in other respects of cultivated taste and enlarged knowledge.

But, putting aside this view of the subject, in which it cannot be expected that the study of botany should become general or even frequent, the simple cultivation of flowers, without any skill or knowledge in technical botany, can scarcely be too strongly enjoined upon the dwellers in the country. While I would urge it upon the wealthy proprietor, if there were occasion for it, I would with still more earnestness press it upon the small farmer, and even upon the cottager and the laborer, who, in the United States, if he will, may always have his house and his garden, humble as they may be, and, I may add, his acres, to devote, as he chooses, to purposes of utility and recreation.

No farmer, in my opinion, should be without his fruit and vegetable garden, to which he should be able to look for a large portion of the daily supplies of his table; for profit, as matter of economy, for health, comfort, and luxury; and a part of this, or a portion additional, should be devoted to the cultivation of flowers and plants for ornament. I do not mean that the great labors of a farm should be intermitted for the care of the garden, as some persons profess to fear that in such case it would be; but they may ordinarily go hand in hand together, and the one serve in truth to advance the other. France is not withont such beautiful examples. On every well-regulated farm there should be hours of recreation, when at least the most severe and? harassing labors of the farm should be for a while relaxed. I know that there are seasons of the year when such a remission could hardly be expected. But there are seasons when there is ample leisure; and in almost every household, and on almost every farm, there are what may be called supernumerary hands, women and children, to whom such cares would always be a welcome occupation and a healthful pastime. 
On grounds even of interest, a proprietor may find, upon consideration, that he is essentially a gainer by every thing which improves the appearance of, or serves to embellish, his estate. This may be a small matter in England, where estates are held to keep; but it is worthy of much reflection in the United States, where almost all estates seem to be held to sell. There may be most expensive embellishments, which should never be undertaken without being maturely considered; there may be embellishments in very bad taste, against which it would be diflicult to prescribe any other remedy than that which improved education brings with it; there may be embellishments of a costly yet of a perishable nature, which certainly are not to be chosen; but embellishments planned in good taste, corresponding with the general character and uses of the property, greatly improve the value of an estate, far beyond their cost. Shade trees, ornamental and flowering shrubs, are always easily attainable, and may be considered as permanent improvements, which give a real and durable value to an estate.

In speaking thus on this subject, among the great variety of tastes which I may be expected to encounter, I know there are many to whom I cannot look for sympathy. They, I hope, will at once turn these pages over, and leave them for persons who take an interest in these subjects. 'These rural embellishments are common in Europe; but they are not appreciated, or, if appreciated, they are not yet so general as they should be in the United States. I wish they might be universal.

1. The Floral Magnificence of Eingland. - In England, they prevail every where, and render the country extremely beautiful. There is not a country-house without its shade trees, its ornamental hedge-rows, its shrubby avenues, its parteres of flowers, its trellises of viues of the most beautiful description; sometimes covering all the sides and the roofs of the houses with their thick matting of foliage, suspending their rich tresses over every door-way, climbing every corner, peeping into every window, and covering it with their graceful drapery as a curtain, and hanging, in thick masses of green and gold, intermingled often with flowers and fruit of the most exquisite richness and beauty, from the edges of the roof, and from every angle and Inojection, where they can fix their grasp. I have seen nothing VOL. II. 
to surpass the admirable and charming diversity, and beanty, and richness, of these embellishments as I have found them all over England; not unfrequently at the residences of the lower classes, as well as those of the rich and noble. I have found often the humble cottage of the humblest laborer adorned with vines of unsurpassed luxuriance; the sweetbrier exhaling its delicious odor under the windows, and roses, and geraniums, and syringas, and dahlias, disputing your passage to the door. These are the petted children of his industrious wife and daughters; and he looks at them with honest pride, and drinks in their odors with the sweeter relish, because they are trained by hands which disdain no useful labor, and can be enjoyed in all their fragrance and beauty without giving pain to a single human being. Better than all this, they are to every passing observer the outivard and infallible indications of the industry, frugality, neatness, and good economy, which reign within.

Wherever circumstances admit of it, every considerable country-house in England has likewise its conservatory, in which, at least, the female part of the household shelter those objects of their care, which are too tender to bear exposure; and find recreation and keep alive the remembrance of the summer's glories and magnificence, when winter utters his hoarse voice without doors, and commands all that has life to retire before his sweeping and icy blast.

2. The Flower Gardens of Paris. - The Garden of Plaxts. - Paris is not only distinguished for its beautiful flower markets, but for its beautiful flower gardens, which may be said to be almost unrivalled. The Garden of Plants, so called, in Paris, in extent, in number and variety of plants, in scientific and instructive arrangement, in the perfect condition in which it is kept, and in the extent of its conservatories, is probably unequalled. It is not only completely adapted to botanical instruction, but likewise to public recreation, combining with these objects as perfect a Flora as science and taste, aided by the ready patronage of the government, have been able to collect and maintain. The most useful as well as the most ornamental flants may here be found and studied in all their aspects and varieties, and in all their habits and uses. 
3. The Gardens of the Palaces. - There are magnificent flower gardens likewise comnected with the national buildings or palaces in Paris and its vicinity, which, with a liberality that eminently characterizes the French in all their public establishments, are open to the public for study, for pleasure, and for recreation; and in pleasant weather are crowded with persons who appreciate and enjoy them. In most of these gardens, the scientific as well as the familiar name is attached to the plant, together with the class to which it belongs, and the country of which it is a native. The gardens attached to the palaces of Versailles and St. Cloud, and more distant at Fontainbleau, are among the great sights of France. They exhibit the most splendid triumphs of genius, skill, and taste, in rendering, as far as these can do it, the beauties of nature even more beautiful, the magnificence of nature even more magnificent; and scem, in their shady avenues and their green lawns, their superb trees and their flowers of superlative beanty, in their statues exhibiting the triumphs of the sculptor's art, - an art all but divine; and in their splendid fountains, combining, wilh the most extraordinary brilliancy, what is most exquisite in design and graceful in motion, to rival, if not to surpass, the splendid and poetical descriptions of the golden age.

4. Rural Embellishments in France, Holland, Belgium, Germany, amd Italuy. - The country in France is very far from being as picturesque and beautiful as that of a great part of England. The deep verdure of England, owing to the constant humidity of its climate, and somewhat to the character of its soil, which is adapted to retain the moisture, is not to be looked for in France, where the soil is to a great extent calcareous, and where the droughts of summer are often long and severe. I have already remarked likewise that the villages in France wear by no means a rural aspect. But France is not without its beautiful country-houses and villas, presenting often, in their construction and adormment, examples of almost unsurpassed taste: and none of then without the charming embellishments of parks and gardens, lawns and fountains, shrubs and flowers. Some of the best farms which I have visited, farms of several hundred acres in extent, have not been without some of these delightiul appendages. 
In passing through Holland, among persons whom we are sometimes pleased to call the stupid Dutchmen - and, in my opinion, there was never a greater misnomer, as I shall presently show - one is charmed with the multitude of residences, ornamented in the highest degree with shrubs, and vines, and flowers of extreme beauty and luxuriance. At Brussels, at Leyden, at Utrecht, are botanical gardens, supported by public munificence, of great extent, and where no pains are spared to carry the culture of plants to the highest degree of perfection. At Antwerp, and at the Hague, there are public promenades, and gardens, and parks, laid out with trees, and shrubs, and flowers, with taste and liberality, kept in the neatest manner, and open constantly to the recreation and enjoyment of the public.

The environs of Frankfort on the Rhine may be pronounced a region of perfect enchantment. The whole city, certainly one of the cleanest and handsomest which I have seen, is surroundec by a wide belt of 'large extent, and furnishing not only many walks, but drives for several carriages abreast, of trees and flowering shrubs, and flowering plants of the greatest variety, combining the richness and glory of the vegetable world as far as the climate admits of it. This charming promenade is open always: freely to the public for health, recreation, and delight. The public, thus freely admitted, never dream of defacing a statue, $\mathrm{ot}$ disturbing a fountain, of breaking a shrub, or plucking a flower. Indeed, I can almost believe, that the richest fruit might hang there untouched - such is the sentiment of propriety in which these people have been trained, and the conviction deeply impressed upon their minds, that what is intended for the common and unrestricted enjoyment of all, should be protected by common consent. In Milan, and Turin, and Florence, and all the principal cities of continental Europe, as far as I have seen, the same taste for rural embellishments prevails, and the same libcrality in opening these grounds and gardens to the free enjoyment of all. In the neighborhood of Rome, a prince, * one of the rich men of the sovereignty, gives up his whole villa, comprising a large extent of the most richly ornamented and embellished grounds, to the free enjoyment of the public.

In England, with the exception of the magnificent parks of 
London, which, for their extent, and in some parts for their beauty, can scarcely be too much admired, these places are not open to the public. The splendid exhibitions of the botanical societies can be shared only at an expense quite beyond the means of the great mass of the community; and are thus arranged with an evident intention to exclude them. If the acquisition of money for the payment of premiums, to encourage emulation, be the object, this object would not be defeated by admitting the public on succeeding days, or on other occasions, freely or for a small fee. The squares in London, full as they are of beautiful shrubs and flowers, are nevertheless all kept under lock and key, and the public are wholly excluded. I must except from these remarks the magnificent grounds of the Duke of Devonshire at Chatsworth, to which access is free; the Arboretum at Derby, of which I have spoken in another place, and which the liberality of a spirited merchant has expressly consecrated to public use; the Royal Gardens at Kew, and the charming grounds at Hampton Court, near London, which are open to the public under proper restrictions. There may be many others, which have not come within my knowledge. A spirit is evidently growing up in England, which will presently show itself in the most ample provision for the gratification of the masses. This great people are not wanting in philanthropy; and though highly conservative in all their arrangements, and phlegmatic and slow in coming to their convictions, are sure to follow them, when they are once determined.

I am aware that most of these squares are private property; but it would be a noble charity, small to those who give, but great to those who receive it, to allow the poorer classes to enjoy them, at least at fixcd times, and under proper restrictions. The admirable police of London would easily guard against any irregvilarity or nuisance; and, indeed, where people are accustomed to such indulgences, no person thinks of committing a trespass. I believe the English people have as high a sense of houor and justice as any people living, where confidence is reposed in them. It is for want of this confidence that persons are often led to do wrong. No better use can be rnade of wealth than to multiply the rational and innocent pleasures of the poorer classes, to improve their taste, and to elevate their characters. A philanthropic mind can find no higher gratification than in giving pleasure to 
others; and the indications of the times strongly show that this use of wealth is becoming as necessary to its security as it is conducive to its true enjoyment.

I must add again, that the parks of London, including Kensington Gardens, for extent and beauty, are nowhere surpassed; and the neatness and order in which the grounds and walks are kept, is, in the highest degree, exemplary. The government likewise have opened a new park of large extent, Victoria Park; in a part of London where the poorest inhabitants reside, for their health and recreation, and are fast progressing in its embellishment and improvement. They have other plans for providing public grounds for the inhabitants, which are as creditable to the liberal views of the government, as they are serviceable to the health, and, I will add, to the moral improvement of the population.

But what are we to say in the United States, where, in a country in which the rapid acquisitions of wealth almost realize the fables of romance, and where old cities are becoming crowded, and cities and towns are fast multiplying, to be filled with the children of industry and toil, there is very little or no provision of this kind for the public health and recreation, or for the improvement of the public taste and education by ornamental and embellished gardens and grounds? This seems to me a cardinal omission; and it is not a little humiliating, that while, under monarchical and despotic governments, the most liberal provision is made for these objects, and the freest liberty accorded, yet in a republican country, where the people have all the power in their own hands, they will do nothing for themselves. It requires no great sagacity to foresee, that, with our rapidly increasing population, this improvidence - to use no stronger term - will be to be deeply deplored, and when those who come after us will learn how much more easy it would have been to prevent than to cure an evil or supply an omission.

This subject is one of great importance, and especially in a country where institutions are in the progress of formation, which are to affect the destinies of unborn millions; and where no childish and slavish reverence for antiquity prevents the inost independent inquiry into what is just, what is expedient, and what is useful. Too much pains cannot be taken, too much attention cannot be given, and scarcely too much expense 
incurred, in providing rational and wholesome pleasures and recreations for the poorer, and especially the laboring, classes of the community. The rich can always find for themselves the means of pleasure and enjoyment. If they do not exist near home, they can seek them abroad; and they are often so crowded and surfeited with them, that enjoyment itself becomes almost a toil. It is wholly different with the pnor and the laboring classes. They are ordinarily fixed in their residence, and have little power of locomotion; their lives are commonly passed in almost unceasing labor; their residences in general, in cities, are in the compact and most crowded quarters, where ventilation is imperfect, and where the cheerful and invigorating light of the sun is often shut out, and where, consequently, strength is more rapidly exhausted; diseases are engendered; the comfort of living is not known; life itself is abridged; the decencies of life are forgotten or trampled upon; moral disease and crime follow in the rear of physical suffering and privation; and a gangrene appears upon the social body, spreading through all the circulations its disastrous influences. Every effort should be made, and all pains should be taken, that these labors may be relaxed; and that some imnocent and wholesome recreation should be provided for these children of severe and almost unceasing toil. Public gardens, and shaded and ornamental grounds, should be established, and every effort be made to render them accessible and attractive. These people are almost in danger of forgetting that there are green fields, and blue skies, and trees which offer a refreshing shade, and flowers which combine the most delicious perfumes with the richest beauties of form and coloring, and warm suns, and glittering stars, and floating clouds of every form and hue, which, in their expansive folds, and in their brilliant and gorgeous coloring, seem the fit emblems of that abyss of glory, where the Divine Majesty has fixed his throne, and into which human presumption has not dared to penetrate. I would do all that can be done to bring these people "out of darkness into this marvellous light."

The recreations of the laboring and poorer classes, especially in cities, are generally of the lowest character. This is particularly the case in England, where large numbers of the laboring population, either in the town or its neighborhood, give themselves up to gross excess. In many of the mechanical trades, 
the workmen, who are usually paid off on Saturday night, do not return to their employment until Tuesday morning, - with their senses stupefied, and, usually, their earnings expended, and their families unprovided with bread. From what I have been able to observe, it is different in France. The public grounds and gardens, of the most beautiful description, are thrown open to the public, and, especially on Sunday afternoons, are crowded with well-dressed men, women, and children. At Versailles, at St. Cloud, in the Champs Elysées, and the Garden of Plants, the Garden of the 'Tuileries, and of the Luxembourg, where not only these beautiful grounds, but the public galleries and palaces, are also open, I have seen several times, on a Sunday, thousands, tens of thousands, twenties of thousands, enjoying the walks, the flowers, the lawns, the shades, the fountains, the statues, the paintings, the most beantiful productions of ancient and of modern art. Here are persons of every grade in society, and thousands of blooming and happy children and young persons; but not a flower is ever plucked, not a twig broken, not a statue defaced, simply because every thing is put under the protection of their honor. Here is not the slightest irregularity or want of perfectly good manners any where apparent ; no erowding, no shouting, no loud talking, no swearing, no drinking, and no drunkenness; and the people at the close of the day retire quietly to their own homes, or mingle in the evening in some innocent festivity. 'This has always given me unaffected pleasure, and I do not know how, by these people, the Sunday afternoon can be more rationally spent.

It is obvious what a gain there must be to public morals, whenever we can draw men from pleasures of a low and purely sensual character, ruinous alike to health and morals, and utterly destructive of all self-respect, and give them a taste for pleasures of a purer, and, I may add, a spiritual and intellectual character. The pure and simple love of nature, so liable to become extinct amidst the harassing cares, and labors, and frivolities, and sensual indulgences of city life, is among the most wholesome sentiments which the mind can cherish. The love of the beautiful, of the curious, of the grand and sublime in nature, can never become injuriously excessive; and as it is, in its own character, perfectly innocent, so we have reason to thank the Great Author of nature, that its resources, and the field of its application, are absolutely unbounded and inexhaustible. 
For my own part, I look upon all these establishments as one great branch of public education. Men are not instructed merely by books and masters, by schools and set lessons, but by every thing which meets the eye and the ear, and especially all which meets the eye and the ear directly, without the interrention of any other agent. Few persons, in even the humblest condition of life, can range through a fine and extensive botanical garden, or through a museum of natural history in any of its forms, without gathering much useful instruction; but especially without having their curiosity excited, some thirst for knowledge awakened and stimulated. This being once put upon the scent, will often pursue the chase with interest and pleasure, and as often with eminent success. What is more gratifying to our self-love than any triumph in such case? and what pleasure is more innocent, more pure, and more intense oftentimes, than the pleasure, under such circumstances, of acquiring knowledge? Compare with such gratifications the purely sensual pleasures and low indulgences which engage a large portion of mankind, how infinitely do they transcend them! The one transient and perishable, always stimulating to excess, and that excess always pernicious, exhansting to the animal vigor, ruinous to health, and but too often the blighting, the degradation, and the ruin of the whole mind. Not so with the pleasures of refined taste, of intellectual progress and attainment. The more knowledge is acquired, the more the capacity and facilities of knowledge are increased. The more the mind is exercised, the stronger it becomes. The more the taste for intellectual pleasures is cultivated, the less likely is man to become the slave of his lower appetites and passions. Then, what a great gain will it always prove to the laboring classes, if labor can be something more than mere mechanical drudgery and toil! What a gain it must be, if, in the midst of almost unremitted labor, requiring only a mechanical dexterity, which practice soon renders easy, there are resources within to alleviate this monotony of toil, or rather to make us less sensible to it; and if, in the intervals of labor, the mind finds means of recreation, intellectual, alluring, delightful recreation, which draw it away from all painful reflections upon what most persons will consider the hardships of a life of constant toil!

I am most anxious that in cities and in the country much 
should be done - indeed, that every thing should be done which can be done - to educate and so to elevate the laboring classes. I want that they should be treated, not as too often they are treated, as mere animals and machines, to be used and applied as we have the power and inclination to use and apply them; but as beings who have minds as well as bodies - minds destined to be immortal; and who should be rendered capable of selfdirection. I cannot think that their duty would be less faithfully, because it would be more intelligently, performed. Whatever benefits the humbler classes must essentially benefit those above them. In agriculture we have learnt one great and important lesson, which seems destined to confer the greatest benefits upon the art, that when, as in subsoiling, the lower strata are loosened, their superabundant moisture drained off, and the air admitted, they become prepared to be mingled with the surface soil ; and thus the whole is enriched, and its productiveness greatly increased: so in society, just in proportion as the humbler classes are educated, improved, and elevated, the whole mass of society is enriched and benefited.

\section{CXXII. - ABATTOIRS, OR SLAUGHTERING IOUSES.}

There are other establishments in Paris which are intimately connected with agriculture; and among these the abattoirs, or great slaughtering houses, deserve to be considered. There are at least five of these large slaughtering establishments for cattle in Paris, just at the barriers of the city. No cattle are allowed to be driven through the streets of Paris, unless it be very late at night, when the streets are empty; and no person is allowed, under any circumstances, to slaughter cattle in the city. These abattoirs are enclosed by high stone walls, excepting at the entrance, where there is a handsome iron paling; and the space covered by each of them embraces some acres. These are magnificent establishments. The enclosure of one of them, for example, — and they are all built upon the same model, though not all of equal size, - is 645 feet in one direction, and 570 in the 
other. I shall take the liberty here of borrowing a detailed account of the arrangement of one of them which I have repeatedly visited. In front of it is a small promenade planted with ornamental trees; and the enclosure contains twenty-three piles of building. At the entrance are two pavilions containing the oflices of those persons who have the management of the establishment. To the right and left of the central court, 438 feet in length by 291 in breadth, are four immense slaughter houses, separated by a road crossing the enclosure; they are each 141 feet long by 96 broad, and include respectively a flagged court. on each side of which are eight slaughter houses for the use of the butchers, by whom the keys are kept. Each slaughter house is lighted and ventilated from areades in the front walls. Above are spacious attics for drying the skins and preparing the tallow: and, to preserve coolness, a considerable projection is given to the roofs. Behind these slaughter houses are two ranges of sheds containing sheep-pens, and at the extremities are stables for about 400 oxen. Each of these buildings contains a loft for forage. These masses of building form the sides of the court. At the end is a commodious watering-place and pens for cattle and sheep, besides two detached buildings, each traversed by a broad corridor which communicates with four melting houses, below which are cellars containing coolers. Beyond these, parallel with the outer wall, are two buildings raised on cellars, in which the slins are kept, and near them, in front of the entrance, is a double reservoir for water, 228 feet in length, built in solid masonry, and resting on arches, which form stands for carts. There is also a Triperie, or building for washing and boiling tripe and calves' feet.

Cattle and sheep, on coming to Paris, are immediately driven to one of the abattoirs, and there kept at the cost of the butcher. The meat is taken to the shops in the city during the night. The slanghtering at one of the abattoirs, for example, may be estimated at a weekly average of 400 oxen, 300 cows, 600 calves, and 2000 sheep. The establishment is superintended by a resident inspector of police, and gives employment, indepentently of the butchers and their servants, to eighteen individuals with their families. Houses for the residence of the workmen and managers are within the court-yard, with handsome grass-plats; trees, and a fountain in the centre. This description gives, how- 
ever, a very imperfect idea of these truly grand, convenient, and useful establishments. The buildings are all of stone, with roofs of brick-tile upon iron rafters, so as to be completely fire-proof; and the neatness is such that, excepting in the boiling houses, one is not in the smallest degree offended by any noisome odor. Every part of the animal is taken care of and turned to some use, and there is no waste of any kind whatever. The blood and waste manure are all received into cisterns, to be applied to some useful purpose; and an abundance of water, always at command, enables them to keep the slaughtering places, which are neatly paved with flagging-stone, entirely clean. The whole is under the immediate direction of the city government; and there are so many checks, that there is scarcely a chance, as there is no motive, for fraud. The salesman finds his animals slaughtered in the neatest manner, and the proper returns accurately made. Such establishments are most important in their bearing upon public health; and I should most truly rejoice to see them taking the place of those private establishments in the neighborhood of our large cities, and in England in the large cities themselves, which are odious in all their relations, and which often poison the atmosphere to a great extent. The public inspection of the establishment by disinterested parties prevents the sale of diseased meats, which there cannot be a doubt is carried to a great extent, and with perfect recklessness, in many private establishments in some countries, where they are secure from observation. Such establishments as these abattoirs would be greatly for the satisfaction, if not the advantage, of the farmers of the United States, who, driving or sending their cattle to the market, must now, in most cases, resign them to the purchaser; and, without any opportunity of seeing them either slaughtered or weighed, must rely upon his honesty for a true return of the weight - a reliance not always of the surest kind.

It is curious to remark, in connection with this subject, the slow progress of improvement, and the obstinacy with which persons adhere to old customs and usages, however objectionable. The abattoirs of Paris have now been established more than thirty years; and yet London, perfectly aware of their eminent advantages, and so distinguished for its social improvements, and claiming a monopoly of what are called the comforts of life, submits to the terrible nuisance of a crowded cattle market in the 
midst of its thickest population, to and from which cattle are driven at all times of day and night, to the great terror, and often at the peril of life and limb, of the passengers. Slaughter houses are to be found in all parts of the city, even the most fashionable, into which cattle are driven directly through the front doors and passages of handsome residences; the Newgate market is completely underlaid with subterranean slanghter houses of an odious description; the blood, and much of the animal refuse, so valuable in an agricultural point of view, passes into the common sewer, either to check the current and produce disease, or it goes on with other filth to poison the waters of the Thames: and in one of the largest and most populous streets in London, for some distance the sidewalk is lined with slaughter houses, where the killing of the animals is open to every passer-by, and where the very gutters, as I have often seen them, are red with blood. The London markets have very imperfect protection against the sale of diseased meats; and diseased animals in Smithfield mect with a quick disposal at a lower price to persons who in various forms disguise the meat, and impose it upon the humbler classes. Indeed, in all that concerns the cleanness, the preparation, and the economy of human food, and the preëminent neatness of those who sell, as much as of the articles which they sell, the French - I speak particularly of the Parisians - are, within my knowledge, excepting only the markets of Philadelphia, without a rival. They are, indeed, scarcely approached. No part of the animal is lost; every part which is capable of being converted into human food, is prepared for use ; and even the cold meats, the fragments and remuants of the table, which are sold in the markets to the poor, are always presented in a clean and inoffensive manner.*

Besides these establishments for the slanghtering of cattle and

* The Londoners, it seems, are just waking up to the utility and importance of establishing abattoirs in the neighborhood of the city ; though, strange to say, they have suffered an admirable establishment of this kind at Islington, conveniently situated and excellently arranged, to lie useless and to go to decay.

Since the above was written, a project for the removal of the Smithfield market has been defeated, and a public dinner been held to celebrate the triumph of the successful party. It ought to have been given in one of the subterranean glaughter houses of Newgate market.

VOL. II. 
sheep, there are abattoirs for the slaughtering of swine, distinct from these, but upon the same plan.

I have observed nothing particular in the mode of killing cattle in Paris; their heads are brought to a ring, and they are then stunned with an axe, and the throat is cut. I do not know that a mode of killing producing less suffering has as yet been devised; but I am not without hope that even this mode may be improved on. When we consider the vast amount of animal life which the wants and luxuries of man require to be daily taken, humanity is greatly concerned in the diminution of the suffering attending it. Since Divine Providence has recently revealed to man an inexpensive method of suspending sensibility, so that the most painful surgical operations are endured without suffering, and even without consciousness, and the first discovery has been succeeded by one as effectual, and even more simple and of more easy application, I see reason to hope that it may be applied to the lower classes of animals, to save them, in the cases referred to, the pangs of death; and thus an immense amount of animal suffering be prevented. If there are any who regard the subject with indifference, and look upon the suggestion as ridiculous or useless, I can only say that with such persons I have no sympathy whatever.

They have a practice in Paris which I have not seen any where else. When the skinning of the animal is commenced, a large bellows is inserted under the skin, by which it is inflated, and becomes much more easily separated from the flesh than by the ordinary process of skinning with the knife.

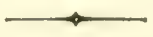

\section{CXXII. - THE FILTH OF PARIS.}

There remains one establishment to be spoken of, directly connected with, and of great importance to, agriculture, as well as to comfort and health; but which, having no other than a disagreeable interest to many of my readers, I forewarm them at once to pass it over; though a French writer humorously observes, that "a book written upon asafotida is in itself no 
more offensive than a book written upon roses." In some respects, the habits of the French, both in their houses and the streets, are execrable and abominable. No familiarity in any degree reconciles a delicate mind to them; and exposures are frequently witnessed in the public streets, which are absolutely brutal, and which in England, (not in Scotland,) and in most parts of the United States, would be regarded as indictable. Yet Paris, in other respects, is an eminently clean city; and even in these matters is evidently improving, and is, with the exception of Milan, Turin, and Genoa, vastly in advance of the Italian cities. Rome, Florence, and Naples can hardly be considered other than as three great public necessaries, where the most sacred places are scarcely free from nuisances, which shock all decency and reverence; and the old town of Edinburgh, and Crlasgow, and Dundee, may fairly claim an unenviable position in the same rank.

This subject, considered in a philosophical and practical view, is of the first importance. It would be altogether a false, in truth, a mere affectation of delicacy, to hesitate to treat it as its importance demands. In all the arrangements of Divine Providence, nothing strikes the reflecting mind with more force than the beautiful circle of mutual dependence and reciprocity in which every thing proceeds; so that the humble elements perform their part, and the most elevated and brilliant can do no more ; and the part of the former is as essential to the common well-being as that of the latter.

Look at a heap of manure, composed of every offensive substance which can be congregated together, reeking with detestable odors, and presenting a mixed mass of objects utterly disgusting to the touch, the smell, and the sight. Yet this is the food of the vegetable world; containing all the elements of richmess, nourishment, health, and beauty. All these the plants know how to separate, to analyze, to digest, and appropriate, and with a skill distancing the sagacity of science, they will return it purified and sublimated in bread, and wine, and oil; in flowers of exquisite coloring and beanty; in perfumes the most odorous which nature's toilet can furnish; in fruits luscious to the taste; and, above all, in products indispensable to life, and full of health and strength. The farmer standing in his barn-yard, knee-deep in its offensive accumulations, may proudly say, "Here is the 
source of my wealth; that which has fed my cattle shall now feed my crops ; that which has given fatness to my flocks shal! now give fatness to my fields." A mysterious power is ever operating in every department of nature; suffering nothing to fail of its use; "gathering up the fragments, that nothing bo lost;" and providing for the various wants of the infinitely varied forms oif life to which existence has been given, and from which, if the Creator should, for one second, withdraw his guardian care, the whole must instantly perish.

The refuse of a city may be considered as of at least five different kinds; first, the ordinary refuse of a house, such as fragments of vegetables, remains of food, bones, rags, and a thousand miscellaneous and nameless substances; second, the remains of fuel, such as ashes and soot; third, the refuse of different trades, of workers in leather, workers in bone, workers in horn, soap-boilers, glue manufacturers, workers in hair and in wool, sugar refineries, and the innumerable other trades always to be found in the busy hive of a city; fourthly, the dung of the domestic animals, cows and horses; and lastly, human ordure or night-soil. I shall say little of some other substances which have been used for purposes of manure; but it is well known that many graveyards have been ransacked for the purpose of gathering up their mouldering relics, and that many hundreds of tons of human bones have been transported from the field of Waterloo to England for the purpose of enriching the cultivation. It cannot be denied in this case to be a more rational, humane, and, I will add, Christian use, than that to which they were put in the bloody arena, where they were first deposited.

In Paris, every species of refuse is husbanded in the most careful manner. No refuse is allowed to be thrown into the streets after a very early hour in the morning, nor until after ten o'clock at night. This refuse consists of what may be called the housedirt, and is laid in heaps in front of the houses near the gutters. A very numerous class of people, called chiffomiers, consisting of as many women as men, with deep baskets on their backs, and a small stick with a hook at the end, carefully turn over every one of these heaps, selecting from them every article of bone, leather, iron, paper, and glass, which are thrown at once into their baskets, and, being carried to their places of general deposit, are there again examined and assorted, and appropriater? 
to any specific application for which they may be suited. 'These jersons appear like a most degraded class; they inhabit particular quarters of the city, and the interior of their habitations is such as might be expected from their occupation. 'The profession descends in families from father to son, and from mother to daughter. They are a most industrious race of people; and many of them may be seen, even at midnight, with their lanterns, taking advantage of the first pickings, and anticipating the labors of the coming morning; and with the earliest slawn they are sure to be found at their tasks. No article of food escapes them; and they call the street their mother, because she often thus literally gives them bread. Though their occupation is necessarily dirty, yet they are almost always comfortably clad, and are never ragged. They never beg, and disdain to be considered objects of charity. They are licensed by the city authorities, for which some trifling sum is paid, and for which they must be recommended for their sobriety and good conduct. They have their particular districts assigned them, and are very careful to prevent all foreign intrusion.

The chiffonniers having done their work, next come the sweepers and collectors of dirt. Every inhabitant of Paris is required, under a penalty, to have the sidewalk in front of his place of business or residence carefully swept every morning. The sweepers of the streets in Paris are almost universally women, who, with long twig or birch-brooms, sweep the streets thoroughly, and all the accumulations are taken in carts to be transported to the great places of deposit. The women assist as much in loading the carts as the men. These women appear to work extremely hard, carrying always a long broom in their hands, and a shovel fastened to their backs, to be used as occasion may require. The gutters in Paris are washed out every morning by fountains, which are placed in every street; and what these sweepers are not able to collect for the carts, they are careful to sweep into the drains leading into the common sewers. I have looked at these people and at the chiffomniers often with great interest; and, filthy and disgusting as their occupration necessarily is, I have always felt in my heart a sincere respect for persons who, poor as they are, would be ashamed to beg; and who, by the severest and most useful labor, are proud to whiain for themselves and their families, though a very humble, 
an honest living. All this refuse is transported to places appropriated for its deposit, where it remains until it is decomposed, and is then sold to the farmers for manure.

\section{$\longrightarrow$ \\ CXXIV. - NIGHT-SOIL. - POUDRETTE.}

The disposal of the night-soil in Paris is a different affair, and occupies a large class of persons. In the crowded parts of London and Paris, such an appurtenance to a house as an open yard is not always to be looked for, and the houses are built in immediate contact with each other. The accommodations for the family are necessarily within doors. In England there are water-closets closing with a trap, and of most exemplary neatness. In Paris, with some exceptions, they are not water-closets, but mere cabinets; and from habitual neglect, which seems too generally to prevail among the middle and lower classes, filling the house with a detestable odor. In many of the houses in the Scotch cities, and houses not always of an inferior description, will it be believed, there are no accommodations of this sort within or without doors? The refuse of the family used to be thrown from the windows at night, not always to the perfect safety of the unwary passenger, and is now commonly carried into the gutters in front of the houses, after ten o'clock at night, to be taken up by the night-carts in passing. Can it be surprising that fever and disease annually remove a large portion of the population of such places?

In London, this refuse passes off into the common sewer,* and from thence mixes with the water of the Thames. It is calcu-

* The extent of these sewers may be judged of from the fact, that one day in London I saw a man emerging from an opening in IIay Street, near Berkeley Square, with a bunch of candles in his hand, who told me he had travelled seven miles under ground. The sewers are about five feet in height, and of a proportional width, being the segment of an oval with the bottom cut off, thus $\square$. This probably was an exaggeration; but it must require a good deal of courage to have ventured even half that distance alone, although it is an undoubted fact, that there are many persons in the habit of daily exploring the sewers, where they sometimes find prizes of value. What an employment! 
lated that this refuse, which may be said to be worse than lost, would be sufficient to manure ammually more than a million acres of land, if it could be applied. I have in another place referred to an association formed in London, with an enormous capital, for the purpose of applying the liquid portions of it; but the progress as yet made does not warrant any public report. The passage of this fecal matter into the sewers does not remove all offence; for in London the odor from the traps or ventilators of the sewers, which are necessarily frequent, is in warm weather disagreeable and odious. Though the habits of the English are eminently cleanly, yet, judging from the sanitary reports, the condition of things in some of the poorer districts of London, and in several of their manufacturing towns, is most oljectionable and degrading.* Paris, in some respects, then, has the advantage of London, and, indeed, of every city which I have been in, excepting the cities of Holland and Belgium - in that all this fecal matter is saved, and certainly with less offence in its removal than could have been supposed possible.

In general it is removed by what is called the atmospheric process. The cart is placed at the door in the street; a long leather hose is extended from the vault to the cart; and, the air being exhausted, the fecal matter, in a semi-fluid state, passes

* The worst parts of Paris and the worst habits of Paris are, however, entirely distanced by some parts of London, eminently cleanly as it is in many other parts. Hear what the philanthropic Lord Ashley has recently said in his place in parliament:-

"He should read a description of a court which he had witnessed himself. It was in such places that a large mass of the community dwelt. In one of these courts there were three privies to 300 persons; in another there were two to 200 people. This was a statement made by a medical man. In a place where these public privies existed, scenes of the most shocking character were of daily occurrence. It would scarcely be believed, that these public privies often stood opposite the doors of the houses; modesty and decency were almost altogether impossible." - Times, of June 7, 1848.

The "cabinets d'aisance sans odeur," which are to be found in many parts of Paris, and which are always kept in the most cleanly condition, but which are often spoken of with sneers by strangers visiting Paris, are to be highly commended as useful and important public accommodations. An eminent medical gentleman once assured me, "that a very large portion of the worst maladies which he had to deal with, arose out of improper neglect in this matter, growing out of inconvenient arrangements or a false delicacy, which should be got rid of." 
directly into the cart. The whole affair is managed, not absolutely without offence, - for that at present seems impossible, but certainly without any offence which is avoidable. The men bring their working-dresses with them, so as never to appear in the streets otherwise than in decent attire. The vehicle in which this fecal matter is conveyed, is a very large, tight cask, or sometimes several tight casks; the horses, harnesses, and the whole equipment are of a neat and perfect description; and in most cases would never be detected by a stranger, if either he were not informed of their uses, or did not read the inscription of the objects to which they are devoted on some part of the vehicle. In no case is any offensive matter left in the streets, or permitted to escape from the carts, until it arrives at its place of deposit.

The carts arrive at their destination before, or as soon as daylight. This place is near one of the barriers of the city. The fecal matter is here suffered to run out upon an extensive piece of ground, flattened and made hard like the bottom of a brickyard. Here it remains until the liquid portion runs off into an artificial basin, from whence as much as is wanted is taken for the purpose of extracting the sal-ammoniac. The rest escapes into the canal in the neighborhood. The solid matter, becoming dry, is then broken up, tumed over, re-broken; and this process goes on until it becomes so dry as to be easily reduced to powder, when it is laid up in heaps, of which immense masses are accumulated. It is thus almost entirely deprived of odor, and may be handled without offence. In this condition it is sold to the farmers, who remove it either in open carts, or in bags or casks. I cannot say that this place, (which occupies several acres of ground,) or its neighborhood, is without offence; but it is inhabited chiefly by persons who get their living by the operation; and to whom, therefore, the offence is not so great. After the first drying, when it forms a thick and hard crust, it is broken up by the plough, and afterwards by the harrow; and this operation is necessarily several times repeated. In the end it passes through a thorough sifting. As many women are employed here as men; and the laborers are principally of the lower order of Germans, whose industry and aequisitiveness are usually remitrable. A great many children are likewise employed; and the search after prizes of value is always animated. As to the health- 
incss of the occupation, its early processes are undoubtedly perilous both to health and life; and many a poor fellow perishes in the vaults, into which they are sometimes compelled to descend; but I found an overseer on the spot, who said he had been constantly employed there for eighteen years, and had never suffered even a day's illness.

The municipal arrangements in Paris seem to me, in various matters, commendable. For effecting the process spoken of, so important and indispensable to health, comfort, and even life, there are three contractors, men of large capital, who take the whole enterprise of cleansing the city in this matter upon themselves. The city is divided into four districts. The contractors are laid under heavy bonds to provide horses, carts, and workmen; never to remit the work excepting one night in seven, Sunday night; and they are paid so much by the cubic foot, by the owner of the house whose vaults they cleanse. They do not begin their work before eleven o'clock at night, and they must leave the city before daylight. The men are divided into parties of five; and each man has his particular office, and is known among them by a distinct name. The corporal, or overseer, constituting one of the five, directs the whole operation, and gives his aid as occasion may require. The man whose duty it is to descend into the vanlt, always does it at the risk of his life from suffocation. They are liable also to suffer from an inflammation of the eyes, which makes them blind for several days, in which they frequently weep blood, and which is attended with extreme suffering. The whole number of persons employed in these services, in Paris, exceeds two hundred. They constitute a people by themselves, and the employment goes down from father to son. Their wages are from twenty to twenty-five francs a week, or from four to five dollars, or one pound sterling. A notice is given at the proper office, by the owner of a tenement, that his vault requires to be emptied, and the service is immediately attended to.

I have gone thus at large into these homely details for sereral reasons; first, for their bearing upon agriculture; for, perhaps. no manure is so valuable. We send ship after ship into the Pacific Ocean, to bring home that for which we have a substitute equal, if not superior, in efficacy, at our own doors. Secondly, because the information how the removal of this mat- 
ter is performed in such a city as Paris, may be of use in other cities, where it is generally left to private enterprise, with very imperfect apparatus and preparations; and is often slovenly and offensively performed. I confess that, in the third place, I have been moved by some moral reasons, because I would lose no favorable opportunity of calling the attention of the richer and more favored classes in society to the condition of their more humble brethren in many departments of human industry, upon the results of whose labor they live; and who peril their lives, and pass their days and nights in the most humble, the most severe, and often the most odious and disgusting services, to secure the health and comfort of those elevated above them; and receive, in the form of compensation for labors so perilous and offensive, that which serves only as a bare subsistence. It is said that the wives and children of the men who perform the most dangerous part of these services, when their husbands and fathers leave home at night, show the same anxiety for their safe return, as if they were leaving upon some perilous voyage by sea.

Various methods have been tried for the purpose of disinfecting this substance; but, either from their inefficacy or the diffculty and expense of procuring them, are seldom used. Quicklime thrown into the vaults is said to destroy the best parts of the manure; but, by many persons, however, it is greatly approved. Charcoal-dust, burnt tan, peat-ashes, the mud from the bottom of rivers or ditches burnt or dried in ovens, have all been used, as it is reported, with success; and may be recommended, not only as disinfectants, but as useful additions.

The Parisian arrangements are far from being perfect. In London, at present, every thing of this sort is lost. In Paris, only the solid portion of the excrementitious matter is saved for manure, whereas there is no doubt that the urine is of far greater comparative value than the solid portions. Various attempts have been made to save this in such a form that it might be casily transported; and in London, manures are sold under the name of urates, which are only urine combined with plaster or gypsum; but the quantity of urine taken up in such cases is so small, compared with the weight or bulk of the article, that in this respect it is considered of little efficacy or value. Chemistry would perform an immense service for agriculture, if it could discover a means of combining this substance in some 
portable form, and in which its efficacy might be preserved. One of the circumstances constituting the great value of guano, and of the dung of birds, separate from the particular food on which they live, is, that their excrements being voided under one form only, the element of urea is inseparably combined with the other matters.

I shall not trouble my readers at present further on this subject; in which I can only say, I have been anxious to give no offence even to the most delicate mind, and must claim their indulgence if I have not succeeded. I shall now proceed to other topics.

\section{CXXV. - AGRICULTURAL EDUCATION.}

The subject of agricultural education has received much attention in France; that attention is increasing, and new institutions are growing up, to which the government promptly lend their aid. The subject is of so much importance, that I deem it proper to give an enlarged account of the leading establishments for this object which have come under my notice.

1. School at Grignon. - The principal establishment for agricultural education is at Grignon, about twenty miles from Paris. It consists of an estate of 474 hectares, or about 1200 acres, with a large dwelling-house upon it, - formerly, I believe, a royal seat, - and other necessary buildings, which have been erected since its endowment. It was ceded by the French king, Charles $\mathbf{X}$., for a term of forty years, to a society of gentlemen specially interested in agriculture, who have the management of the institution, and, by private subscription, have supplied the funds for conducting it.* The government are represented in the management of the estate. They provide all the instruction, by paying the salaries of the professors and superintendent;

* The sum raised by private subscription amounted to 300,000 francs, or about 60,000 dollars, or $£ 12,000$ sterling. The rents paid to the government for the estate are the same as were paid by the farmers who previously held it. The substantial or permanent improvements upon the estate are estimated by a 
and they support some pupils. The pecuniary results for the last few years have been favorable; and all profits go to the support of free pupils, or to increasing and extending the benefits of the institution, which is capable of accommodating seventy pupils. The term of residence is fixed at two years, though it will be seen, from the course of instruction adopted, a much longer time is requisite to acquire a thorough education in the branches prescribed.

The institution at Grignon is designed to supply instruction both in the science and practice of agriculture, and the constitution and arrangement of the school seem admirably adapted to this end. The students in general are from that class in life who depend upon their own exertions for a livelihood. This is as it should be. In the United States we have no other class, and, from the present arrangements of property, are not likely to have. Long may this wise and happy arrangement continue! In a great portion of Europe, a large part of the community are little else than beasts of burden. As long as they live, they must carry upon their backs those who do not choose to maintain themselves. It is a pity they could not put their burden down, and make them "go themselves." Their doom, however, is fixed; and with the present distribution of political power, and the present moss-covered institutions respecting property, there is little chance of an alteration. In England and in France a class exists, of which, at present, in the free portion of the United States, we know nothing; and it may be some time before they are required. These are the persons who manage the estates of large proprietors; who in England are called bailifis or stewards; in France, agricultural engineers. Grignon may be said to be particularly designed to educate this useful class. At the same time, there are among the pupils several who seek this education for the management of their own estates; and these agricultural engineers are themselves, without doubt. hoping presently to become proprietors. In the south of France, land is held generally under what is called the mettayer system, or what is known in the United States as taking land upon

commissioner once in five years, and are to go, at the end of the lease, in acquittal of the rent. The money subscribed by individuals was given to the institution. On this capital, employed on the farm, an interest of sixteen per cent. has been realized, which goes, as above stated, to the benefit of the institution. 
shares. After certain deductions, the half of the produce is returned to the proprietor as the rent of the land. In either case, such education must be highly valuable; in the case of a tonant, that he may be able to obtain the best return from the land, and, in the case of the proprietor, that he may know what to require, and how properly to direct the management of his estate.

The term of residence at Grignon is fixed at two years; but the pupil remains three months after his studies are completed, in order to digest and draw up the entire management of an estate, and describe its details in every department.

The students are divided into classes denominated internals and externals, or resident and non-resident. The former reside entirely in the house, where they are lodged and boarded, and pay about 800 francs, or 32 pounds, or 160 dollars, per year. The externals, or non-residents, provide for themselves, or lodge at the houses of the neighboring farmers, and pay a very small amount for their instruction. This arrangement is particularly designed to benefit poor scholars. Both classes are equally subject to the general discipline and rules of the institution, and are alike engaged in the same works and studies.

There are lectures every day in the week. At the commencement of each lecture, the professor examines the pupils on the subject of the preceding lecture; and they are required often to take notes, and present a written report of the lecture. Besides the professors, there are two monitors, who have been edueated at the school, who labor with the pupils in the fields. They are expected, and it is their duty, to question the pupils on the subjects which have been treated in the lectures; to show their application; to illustrate what may have been obscure; and, in short, to leave nothing unexplained which is liable to misunderstanding or error. There are two public examinations annually, in which the scholars are subjected to a rigorous questioning in what they have been taught. If, at the end of two years, their conduct has been approved, and their examination is met successfully, they receive a diploma from the institution.

They are not only employed in the general work of the farm, but particular portions of land are assigned to individuals, which they manage as they please, and cultivate with their own hands; they pay the rent and expenses of manure and team, and receive VOL. II. 36 
the product, or its value, from the institution. Certain of them are appointed in turn to take care of the different departments of the farm for a length of time - such as the hog establishment, the sheep establishment, the cattle, the horses, the implements, \&c., \&c. They have likewise adopted a practice, which seems much to be commended - that of employing workmen, shepherds, cow-herds, \&c., from foreign countries, - as, for example, from Belgium and Switzerland, - that they may in this way become acquainted with the best practices in those countries.

The time is thus divided and arranged among them: They rise at four o'clock in summer, and at half past four in winter. They go immediately into the stables to assist in the feeding, cleaning, and harnessing of the teams, and the general care of the live stock, according to their respective assignments. At half past five, they take a light breakfast; at six o'clock, they go into the halls of study, and here they remain until eleven o'clock; at half past six, they attend a lecture, or course of instruction, which occupies them until eight o'clock; at half past eight, they are occupied in reading or in making notes of the lectures which they have heard, and the monitors before spoken of are present to render them any assistance required; at half past nine o'clock, there is another lecture or course of instruction for both sections. which occupies them until eleven, when they take their second or principal breakfast. From noon until five o'clock, the pupils are occupied in labor or practical operations. The professors, from time to time, take a section, and employ them in land-sur-. veying, in drawing plans, and in levellings; others are occupied in mineralogical or in botanical excursions, or in inspecting the management of forest lands; others are occupied by their teacher in the practical management of farming implements, in the management of teams in the field, in sowing, and other general operations of husbandry, in a field devoted to these purposes; and a section, to the number of twelve, are every day employed in the direct labors of the farm, in ploughing, digging, harrowing, \&c., \&c. They work in company with the best laborers, that they may observe and learn their modes of executing their work. They are required to be attentive to every operation that is performed, and to present a full report of each day's work to the director-general.

At half past five in winter, and at six in summer, they take 
their dinner. At seven o'clock in the evening, they go again into the halls of study. From seven to half past eight o'clock, there is another course of instruction, or a repetition of what they have had before. Until nine o'clock, they are occupied in their journals, or in making notes of their lectures. At nine o'clock, the sleeping-rooms are lighted, and they retire for the night.

There are several distinct professorships. The Professor of Practical Agriculture gives two courses; the one written, the other oral; and, like the lecture of a clinical professor at the bedside, it is given in the fields. This professor understands not only how a thing should be done, but how to do it; and he can put his hand to every form of agricultural labor, such as ploughing, harrowing, sowing, managing the teams, feeding the animals, handling every instrument of agriculture, buying, selling, \&c. In the words of his commission, his object is at the same time to form the eye and the hand; to teach his pupil how to learn; to command, to direct, and to execute. To this end it was necessary to form a complete agricultural organization for practice, independent of the exercises attached to the departments of the other professors.

The farm is composed of

Arable land, about . . . . . . . 670 acres.

Land in wood and plantations, . . . . 365 "

Irrigated meadows, . . . . . . . . 35 "6

Gardens, including vegetable, botanical, fruit garden, orchards, mulberry plantations, osiers, and nurseries, . . . 28 acres.

Ponds and watercourses, . . . . . 15 "

Roads and lands in pasture, . . . . . 50 "

Occupied by buildings, . . . . . . . 66

The animals on the farm include,

Animals of draught or labor of different kinds, . . . . . . . . . 18

Oxen for fatting, . . . . . . . 20

Cows of different ages and races, and different crosses, . . . . . . . 100

Sheep, embracing the different kinds, . . 1100

Swine establishment, . . . . . 100 
There are likewise on the establishment workshops or manufactories, if so they may be called, -

For the making of agricultural implements;

A threshing-house and machine for grain;

A dairy room, for the manufacture of different kinds of cheese and of butter;

A magnanerie, or establishment for silk-worms;

A stercorary, for the manufacture of compost manures.

To all these various departments the attention of the students is closely called, and they are required to take some part in the labors connected with them.

Besides the farm belonging to the establishment, there is a field of one hundred acres devoted exclusively to the pupils, and principally to the culture of plants not grown on the farm. Here they make experiments in different preparations of the soil, and with different manures.

Two scholars, one of the second and one of the first year, are appointed to attend particularly to the general condition of the farm. Their business is to examine constantly the whole establishment; the works that are going on in every department; to look after the woods and the plantations; the gardens; the horses; the fatting cattle; the dairy; the sheep-fold; the swine; and the hospital; and to attend to the correspondence and the visitors. This service lasts a fortnight, and there is a change of one every week, taking care always that there shall be one scholar of the first and one of the second year associated. 'They attend to all the labors on the farm, and to all the communications between the principal director and inspectors and the laborers. In the veterinary or hospital department of the establishment, they assist the surgeon in all his visits and operations; take notes of his prescriptions; make up and attend to the administration of his medicines; and observe particularly the sanitary condition of the stables and buildings, where the live stock, sick or well, are kept.

On Saturday evening, each scholar, to whom this duty has been assigned, makes to his fellow-pupils a full verbal report of what has been done. This report is transcribed into a journal designed for that purpose; and thus a continued history of the entire management of the farm is kept up. The whole school is divided into sections or classes of twelve each; six of two and 
six of one year's standing; and these sections are constantly under the direction of the Professor of Practical Agriculture.

As the establishment at Grignon may be considered a model agricultural establishment, it may be useful to go more into detail in regard to the course of instruction pursued here.

Once a week there is an exercise, which embraces every thing relating to the management of the teams and the implements.

First, for example, in the different modes of executing any work, and using the utensils employed. The harness, the collar, the traces, and how attached, the shaft-horse or the cattle attached to the load, and the adjustment of the load to their backs; the yoke, the single yoke, the donble yoke; the packsaddle; the harnessing of a saddle-horse; the team for ploughing; the tearn for harrowing; the team for drawing loads; the team for wagons and for carriages with all their appurtenances; - every one of these matters is to be practically understood, as well as the whole management of the team in action.

In ploughing, the turning the furrow, its inclination, its breadth and depth; the laying out of fields; the management of large and small fields; how to make the first furrow, and to finish the last furrow; to lay the land flat, to break it up in clods; to plough it at a certain angle, to lay the land in curved furrows; - these are all considered, and make part of the instruction given. The preparation, equipment, and use of every agricultural implement — such as ploughs, harrows, rollers, scarifiers. cultivators, sowing machines, trenching machines; the practice of sowing, the different modes of sowing, whether broadeast, by dibble, or in drills; the application of manure both as to time: mode, quantity, and preparation, and the composting of mannres. - are matters of inquiry and practice.

The cutting of grasses; the making of hay, and the construction of stacks; the harvesting of grain, by the scythe or by the sickle; appendages to the scythe, called commonly the cradle: and the grinding of scythes; the making of sheaves, and of shocks, or stacks; and the loading and the stowing away of grain, - are matters to be understood.

A practical attention is required to every form of service on the farm; in the cow-house; the horse-stables; the fattingstalls; the sheep-fold; the sties; the ponltry-yard; the threshing-floor; the stercorary; and the storehouses for the produce 
of the farm of every description. The duties in this case embrace not merely the observation of how these things are done, but the actual doing of them, until an expertness is acquired.

Leaving the practical department, we come now to the course of studies to be pursued.

For admission into the institution some previous education is demanded, and the candidate is subjected to an examination before the principal and one of the professors.

First, he is required to present an essay upon some subject assigned to him, that his knowledge of the French language and grammar may be ascertained.

It is necessary, next, that he should be well grounded in the four great rules of arithmetic; in fractions, vulgar and decimal; in the extraction of the roots; in the rules of proportion and progression; and in the system of measures adopted in France.

In geometry, he must be well acquainted with the general principles of straight lines and circles, and their various combinations; and with the general measurement of plane surfaces.

In uatural philosophy, he must understand the general properties of bodies, and be acquainted with the uses of the barometer and thermometer.

Candidates for admission must bring with them certificates of good character and manners, and must be at least eighteen years old. They are rigidly held to an attendance upon all the courses of instruction at the institution, and have leave of absence only on the application of their parents or guardians.

The studies of the first year are begun with a course of mathematics. Geometry and trigonometry are made a particular subject of attention; embracing the study of straight lines, and circular or curved lines, on the same plan; the admeasurement of surfaces; the use of the compass; the recording of measurements; the delineation of measurements; the surveying of open fields, of woods, of marshes, of ponds or lakes; comparison of ancient land measures with those in present use; the use of the square, the chain, and the compass; the elevation of plans; the construction of scales, and the ordinary divisions of landed properties.

The study of various plans in any form; solid measure; conic sections, their principal properties, and their practical application: the theory and practice of levelling; the method of projections 
and their application ; cubic measure of different solids, of hewn stones, of rough stones; the measurement of loose or broken stones, of sand, of lands excavated, of ground filled in, of stacks, and of heaps of manure; the cubic measure of trees standing, and of felled trees, of beams, and every kind of carpenter's work, of firewood, of walls, arches, and ditches or dikes; the ascertaining of the capacity of carriages, wagons, carts, wheel-barrows, pails, troughs, barrels and casks, basins or ponds, and different vessels in use, and of granaries and barns, and the determination of the weights of bodies. To all this is added a full course of trigonometry. They are accustomed likewise to the familiar use of the scale, of the square, of the compass, and of the compasses for delineation, and are often occupied in superficial and in profile drawing.

The next course of instruction embraces embankments, the force of earths and liquids, or their pressure, at rest or in motion.

The materials employed in masonry; their uses and application in building - embracing stones, bricks, lime, sand, mortars, cements, plaster; and all the various modes of building.

The laying of walls for foundations; the erection of walls; the supports requisite; and the construction of passages, enclosures, and arches; the different kinds of woods, their absolute and relative strength; their duration, and the modes of preserving them; every kind of carpenter's work; the construction of floors, staircases, scaffoldings, and exterior supports; the constructions of roofs, in timber, with thatch, rishes, shingles, tiles, slates, zinc, or bitumen; the paving of roads, the formation of bartu-floors, with clay or composition of bituminous substances, which form a hard and enduring surface, - are subjects of incuiry.

Next comes instruction in the blacksmith's shop, in the use of the forge, and the other implements of the trade; and in the various applications of iron and steel, of copper, lead, and zinc.

They are instructed, likewise, in the manufacture and use of leather and cordage; and in the various details of painting and glazing. The prices or cost likewise of all these different processes, are, as far as practicable, ascertained; and the modes of estimating such work are explained.

The next course embraces the elements of natural philosophy; and this includes chemistry, geology, and mineralogy.

First, the general properties of bodies, their divisibility, elas- 
ticity, and porosity or absorbent powers; and the special influence of this last circumstance upon the character of an arable soil.

The following are all subjects of study: bodies in the mass; the weight of bodies; means of determining the density of bodies and their specific gravity; the physical properties of the air ; of atmospheric pressure; and of the construction and use of the barometer.

The study of hydrostatics; the pressure of liquids in their reservoirs, and against dikes and embankments; hydranlics; capillary attraction; the use of siphons and pumps.

The study of heat in all its various phenomena. Its effects upon solid and liquid bodies, and the changes which it makes in their condition ; the phenomena of fusion, ebullition, and evaporation; of vapors; of the hygrometer or measurer of moisture, and the utility of the instrument; the conducting powers of bodies; of metals in particular; of free or radiating heat; application of heat to furnaces or kilns; laws of cold applied to bodies; power of emitting and of absorbing cold; measure of heat; means of determining the mean temperature of any place; influence of heat and cold upon vegetation; means of preserving certain vegetables from frost; construction and use of the thermometer.

Meteorology. Explication of the phenomena of dew; of white frosts; of clouds; of rain; of snow; their various influences upon harvest, and the whole subject of climate.

Study of light. Progress of light in space; laws of its reflection; laws of its refraction; action of light upon vegetation. The subject of vision. The polarization of light; the explication of the rainbow, and other phenomena of light; the prism.

Study of electricity. Conductors of electricity; distribution of the electric fluid in nature; power of the electric rods or points; electricity developed by the contact of bodies; of galvanic piles; their construction and uses. Atmospheric electricity; its origin; the formation of thunder clouds; action of electricity upon vegetation; of lightning; of thunder; of hail.

Chemistry. Simple bodies; compound bodies; difference between combination and mixture; atomical attraction; cohesion; aflinity; what is intended by chemical agents. Hxplanattion of the chemical nomenclature, and of chemical terms. 
The study of simple bodies. Of oxygen; its properties; its action upon vegetation, and upon animal life. Nitrogen, sulphur, chlorine, carbon, hydrogen; their action upon vegetable and animal substances; their uses in veterinary medicine, and their influence upon vegetation.

The study of compound substances. Chemistry as applied to air and water; their importance in agriculture; their influenec upon the action and life of plants and animals; the acids, - the sulphuric, the nitric, the carbonic, the chloric; the alkalies, lime, soda, potassium, ammonia; their application in various forms. The salts in chemistry, and their various applications and uses; their importance as constituent parts of the soil, or as improvements.

The subject of marls and of earths, and of various substances decmed favorable to vegetation. Under the direction of the Professor of Chemistry, the students are taught to make analyses of different soils and marls.

To this is added a course of Mineralogy and Geology. This embraces the general properties of minerals; the physical, chemical, and mechanical character of mineral substances the most common.

The study of the distinctive properties and situation of those mineral substances which are most extended over the globe, and which are the most in use; such, especially, as the carbonate of lime; comprehending stones for building, for the making of roads and walls, limestones, marbles, sulphate of lime, or plaster of Paris; and all the variety of mineral substances ordinarily found, and of use in agriculture or the arts.

A course of Geology follows this, embracing all the leading features of the science, with a special reference to all substances or conditions of the soil connected with agricultural improvement.

In this case, the professor makes frequent excursions with the pupils, that they may become familiarly acquainted with the subjects treated of in the lectures, and see them in their proper localities; so that the great truths of geological science may be illustrated by direct and personal observation.

Next follows a course of instruction in horticulture, or gardening.

Of the soil ; the surface and the subsoil, and practical considerations relative to their culture and products. 
Of the climate; the temperature, the aspect and local condition of the land in reference to the products cultivated; the amelioration of the soil, and the substances to be used for that object, with the modes of their application.

The varions horticultural operations, and implements employed; and manner in which they are to be executed. The employment of water in irrigation; modes of enclosing by ditches or walls; walls for the training of trees; trellises and palings; and of protections against the wind.

The different modes of multiplication; sowing, engrafting by cuttings and by layers, and practical illustrations of these different processes. The culture of seed-bearing or grain-producing plants; the choice of them; their planting and management; the harvesting and preservation of the crops.

Under this head comes the kitchen-garden, and the choice of the best esculent vegetables for consumption; the nursery, and the complete management of trees from their first planting; the fruit-garden, considered in all its details; and the flower-garden.

The general results of gardening; the employment of hand, or spade-labor; the care, preservation, and consumption of the products, and their sale. The gardens at Grignon are upon a scale sufficient to supply all practical demonstrations.

The next division embraces the botanical garden. Here the whole science of botany is treated in its principles, and their practical application. The study of vegetable organization, with a full account of the prevailing systems and nomenclature of botany, and the classification of plants. Vegetable physiology, in all its branches, and vegetable anatomy ; comparison of plants in their native and cultivated states; influence of cultivation in developing and improving plants; the propagation of plants in their natural condition, or by artificial means; the subject of rotation, or change of crops.

The practical application of these botanical instructions; and especially in the examination of plants or vegetables which may be useful in an economical view.

The garden of the establishment embraces what is called a school of trees; a school of plants for economical and commercial purposes; and a school of plants for common use. These are all carefully classed and distinguished by their proper names. The pupils are accustomed to be led into the gardens by the 
professor, that his instructions may be fully exemplified and confirmed.

The next branch of science taught at the school is veterinary surgery and medicine. This embraces a course of anatomy and animal physiology. It comprehends a full description of all the animal organs; and demonstrations are given from subjects, destroyed or obtained for that purpose. The functions of the different organs are likewise described; the organs of digestion, respiration, circulation, and the organs comnected with the continuance of the species.

Every part of the animal, external and internal, is shown, its name given, its uses explained; its situation in relation to the other organs; the good points, the faults or defects in an animal; the peculiarities of different races of animals, with the modes of discriminating among them.

The choice of animals intended for different services, - as in horses, for example, whether for the saddle, the race, the chase, the carriage, the road, the wagon, or the plough. Next, the treatment of the diseases of animals; the medicines in use; their preparation, and the mode of applying or employing them.

The next subject of instruction embraces a complete system of kceping farm accounts and journals, with the various books and forms necessary to every department.

From this the pupil proceeds to what is called rural legislation, embracing an account of all the laws which affect agricultural property or concerns.

I shall give a specimen of some of the topics treated of in this department.

The civil rights and duties of a French citizen, and the constitution of France.

Property, movable or immovable, or, as denominated with us, personal and real; of the divisions of property; of its use and its obligations.

Of commons; of laws relating to forests; of the rights of fishing in rivers; and of hunting.

The laws relating to rural police; to public health; to public security; to contagious or epidemic diseases.

The rights of passage of men or animals over the land of another; if any, and what.

Of erimes. Theft in the fields; breaking or destruction of 
the instruments of agriculture; throwing open enclosures; destruction or removal of bounds. Laying waste the crops by walking over them; inundation of fields by the stoppage of streams, or the erection of mills. Injury or breaking of public roads and bridges. Poisoning, killing, or wounding animals.

The duties of country magistrates; guards or justices of peace. Of courts of law.

Of contracts, general and specific. Contracts of sale and prohibitory conditions. Of leases of different sorts. Of hiring labor; of the obligations of masters and servants. Of corporations, and the laws applicable to agricultural associations.

of deeds, mortgages, bills of exchange, commissions, and powers of agency and attorney; insurance against fire, hail, and other hazards. Of the proof of obligations; written proof ; oral testimony; presumptive evidence ; of oaths. Of legal proceedings; of the seizure of property real or personal, and of bail.

The instruction proceeds under various courses, and I have su far given but a limited account of its comprehensiveness, and the variety of subjects which it embraces.

The study of the different kinds of soil, and of manures, with all their applications, and the improvements aimed at, take in a wide field. Under the head of soils there are the argillaceous, the calcareous, the siliceous, turf-lands, heath-lands, volcanic soils, the various subsoils, loam, and humus.

Under the head of manures, come the excrements of animals, all fecal matter, poudrette, urine; the excrements of fowls: guano; noir animalisée; the refuse of sugar refineries; the relics of animals; oil-cakes; the refuse of maltings; tanners' bark; bones, hair, and horn ; aquatic plants; green-dressings.

The application likewise of sand, clay, marl, lime, plaster, wood-ashes, turf-ashes, soot, salt; the waste of various manufactures; mud and street dirt.

The plants cultivated for bread; wheat, rye, barley, oats, buckwheat, millet, rice, and the modes of cultivating them.

For forage, - potatoes, beets, turnips, ruta-bagas, carrots, artichokes, parsnips, beans, cabbage.

Lucern, lupines, sainfoin, common clover, trifolium incarnatum, vetches, peas, lentils, and plants for natural meadows and for pasturage. 
To these are added, colza, rape, poppy, mustard, white and black, hemp, flax, cotton, madder, saffron, woad, hops, tobacco, chicory, teasels.

The weeds prejudicial to agriculture, and the insects which attack the plant while growing, or in the granary or barn.

The production of milk; and, as already said, the making of butter and cheese.

The production of wool; tests of its fineness; classing of wools; shearing of sheep; weight of the fleece; washing of wool before or after shearing; and every particular in reference to the subject.

The fatting of beef, mutton, and pork. Choice of animals for this purpose; nutritive properties of different kinds of food; in what form to be given; grains entire or ground; roots cooked or raw, green or dry; the value of the pulp of beet-root after the sugar is expressed; refuse of the starch factories; of the distillery; of the brewery; fatting by pasture or in stalls; comparison of the live weight with that of the animal when slaughtered.

Care and management of the various kinds of domestic poultry.

Care and management of bees, with the construction of hives.

Care of silk-worms, and their entire management.

All these studies are pursued in the first year of the course; and the time is so arranged as to afford the diligent pupil an epportunity of meeting his duties, though the period is obviously too limited for the course prescribed.

The second year enjoins the continuance and enlargement of these important studies; the higher branches of mathematics and natural philosophy; an extended knowledge of chemistry; and a thorough acquaintance with mechanics, when the scholars, with their professor, visit some of the principal machine-shops and factories in Paris, or its environs, in order to become practically acquainted with them.

The students are further instructed in the construction of farm-buildings of every description; in irrigation, in all its forms; in the drainage of lands; in the construction of roads; in every thing relating to farm implements; and in the construction of mills and presses.

As I have said, organic chemistry is largely pursued with the VOL. II. 
various manufactures to which it is applicable ; and animal physiology and comparative anatomy are very fully taught.

These studies are followed by a course of what is called agricultural technology. This embraces the manufacture, if so it may be called, of lime, of cement, of bricks ; the preparations of plaster; the making of coal by various processes; the making of starch; the making and purification of vegetable oils; the making of wines, of vinegar, of beer, of alcohol, of sugar from the beet-root, including all the improvements which have been introduced into this branch of manufacture; and the pupils, under the direction of the professor, are taken to see the various manufactories of these articles, so far as they are accessible in the vicinity.

The whole subject of forests, of nurseries, of fruit-trees, ornamental trees, trees for fuel, trees for mechanical purposes, are brought under the student's notice. This is a great subject in France, where wood has an extraordinary value; where immense extents of ground are devoted solely to the cultivation of trees; and where, consequently, it is most desirable to understand the proper kinds of wood to be selected for the purpose in view; the proper mode of forwarding the growth of the trees; and of removing them without prejudice to their restoration. Under this head comes the culture of

Trees for fuel.

Trees for timber.

Trees for house and ship-building.

Trees for fruit, including all the varieties adapted to a particular climate.

Trees for their oily matter; such as olives.

Trees for their bark; to be used in tanning, and other purposes.

Trees for their resinous properties; such as pines.

Osiers and willows for making baskets.

Mulberry-trees for the support of silk-worms.

Noxt to this comes the culture of vines, and the establishment and care of a vineyard - a subject of great importance in France.

I have already spoken of the veterinary course of instruction. 'This embraces the whole subject of the breeding and rearing of animals; their training, shoeing, and harnessing, and entire management.

Under the head of farm accounts, the establishment itself at 
Grignon is made an example; the accounts of which are kept most accurately by some of the students, and open to the inspection of all.

A journal of every thing which is done upon the farm is made up every night; and these accounts are fairly transferred into a large book.

To this is added, a particular account of the labors performed, and the occupation of each workman on the farm.

Next, a cash-book, embracing payment and sales, which are adjusted every fortnight.

Next, an account with the house ; charging every article supplied or consumed.

Next, a specific account of each principal department of the farm; such as the dairy, with all its expenses and returns; the pork establishment; the granary, \&c., which are all balanced every month, so that the exact condition of the department may be known.

As the students are advanced, more general and enlarged views of the various subjects of inquiry are given; such as,

The taking of a farm, and the cultivation or management to be adopted.

The influence of climate and soil.

The crops to be grown; and the rotation of crops.

Agricultural improvements generally.

The devoting of land to pasturage; to dairy husbandry; to the raising of animals; to the fatting of cattle; to the growth of wool ; to the production of grain ; to the raising of plants for different manufacturing purposes; or to such a mixed husbandry as may be suggested by the particular locality.

The use of capital in agriculture; the mode of letting farms: cash rents; rents in kind; rents in service; laws regulating the rights and obligations of real estate: the conveyance of real estate; with the various forms of culture in large or in small possessions, or on farms of a medium size.

I have extended, perhaps bevond the patience of my reader, the account of the Agricultural School at Grignon, and yet have given an imperfect and abridged statement of the subject matters of instruction and study at this institution. The institution at Grignon may be considered as a model establishment; and a thorough education in the various branches referred to, must be, to any young man, an important and invaluable acquisition. 
The question comes up, Will such an education make men better farmers? It must be their own fault if it does not. There may be some branches of the prescribed course, which may not appear to have a direct practical bearing; but there is not one without its use; if not directly, yet indirectly subservient to agricultural improvement; and if not immediately applicable to practice, yet intimately connected with the agricultural profession, adapted to increase its power, utility, and dignity, to elevate and adorn it.

2. Veterinary School at Alfort. - I must not, in this connection, pass over the veterinary schools of France. There are three of these institutions in France, and they furnish all the advantages to be expected from such establishments. The three veterinary schools established by the government of France are at $A$ lfort, Lyons, and Toulouse, and comprise 600 students. The average number of horses kept on them is 1332 ; viz., 838 stallions, 127 mares, 212 colts, 99 fillies, and 56 draught horses.* The one at Alfort is that which I have had the pleasure of inspecting.

This establishment is beautifully situated on the River Seine, near the village of Charenton, about six miles from Paris. The buildings for the different objects of the institution are spacious and well contrived, and the grounds sufficiently extensive and judicionsly arranged. Like other governmental establishments in Franee which have come under my observation, the institution is upon a grand scale, and complete in all its parts. The government of France, in a liberal manner, avails itself of the talents of the most competent men in every department, and of all the advantages which science and art can afford; and it spares no expense in the perfect execution of whatever it undertakes. It adds to all this, as is every where to be seen, a refinement of taste in the arrangement of the most ordinary subjects, which increases the expense only in a small degree, which does not abstract at all from the solidity ard substantial character of the work itself; but relieves that which would otherwise be monotonous, if not offensive, and renders often the plainest subjects attractive.

'The school at Alfort is designed to furnish a complete coursc 
of instruction in veterinary medicine and surgery; embracing not horses only, but all the domestic animals. A student at his entrance must be well versed in the common branches of education; and a full course of instruction requires a residence of four years. The number of pupils is limited to three hundred. Of these, forty are entirely supported by the government. These are educated for the army; and are required not only to become versed in the science and practice of veterinary medicine and sturgery, but likewise in the common business of a blacksmith's shop, as far as it is connected with farriery. Students can be admitted only by the nomination or with the consent of one of the great officers of government, the minister of commerce and agriculture. The expense of board and lodging is about fifteen pounds, or eighty dollars a year; the instruction is wholly gratuitous, the professors being supported by the government.

'The establishment presents several hospitals or apartments for sick horses, cows, and dogs. There are means for controlling and regulating, as far as possible, the temperature of the rooms, and for producing a complete and healthy ventilation. There are stables where the patients may be kept entirely alone, when the case requires it ; and there are preparations for giving them, as high as their bodies, a warm bath, which, in cases of diseased limbs or joints, may be of great service. There is a large college with dormitories and dining-rooms for the students; houses for the professors within the enclosure; rooms for operations upon animals, and for anatomical dissections; a room with a complete laboratory for a course of chemical lectures; a public lectureroom or theatre; and an extensive smithery, with several forges fitted up in the best possible manner. There are, likewise, several stands, contrived with some ingenuity, for confining the feet of horses, that students may make with security their first attempts at shoeing, or in which the limb, after it has been separated from its lawful owner, may be placed for the purpose of examination and experiment.

An extensive suite of apartments presents an admirable, and, indeed, an extraordinary mnseum, both of natural and artificial anatomical preparations, exhibiting the natural and healthy state of the animal constitution; and, likewise, remarkable examples of diseased affections. The perfect examples of the anatomy of the horse, the cow, the sheep, the hog, and the dog, in 
which the muscular integuments, the nerves, the blood-vessels, and, indeed, all the parts, are separated and preserved, and exhibited, by the extraordinary skill of an eminent veterinary surgeon and artist now deceased, who occupied the anatomical chair of the institution, exhibit wonderful ingenuity in their dissection and preservation, and present an interesting and useful study, not to the medical students only, but to the most ordinary as well as the most profound philosophical observer. I have seen no exhibition of the kind of so remarkable a character.

The numerous examples of diseased affections, preserved, as far as possible, in their natural state, strongly attract observation, and make a powerful appeal to our humanity in showing how much these poor animals, who minister so essentially to our service and pleasures, must suffer without being able to acquaint us with their sufferings; and how often they are probably compelled to do duty, and driven to the hardest services by the whip or the spur, in circumstances in which a human being would not be able to stand up. A great number of calculi, or stones, taken from the bladders of horses after death, are exhibited, of a large size, and, in some instances, of a very rough exterior, which must have excessively irritated and pained the sensitive parts with which they came in contact. One of these stones was larger than the head of an ordinary man, and weighed, as I was informed by the attendant, thirty-eight pounds. I am aware how severely this account may tax the belief of my readers, but I assure them there is no exaggeration, though $\mathbf{I}$ shonld have found great difficulty in believing the fact, had I not seen the stone. It is scarcely possible to overrate the suffering which the poor animal must have endured under such an infliction.**

The department for sick dogs, containing boxes for those which require confinement, and chains for such as require to be kept in the open air, and a cooking apparatus and kitchen for the preparation of their food, was spacious, well arranged, and contained

* Facts of this nature strongly demonstrate the inrportance of pure water for our brute animals as well as for ourselves. Such diseases are most likely to occur in a country where the waters are strongly impregnated with lime. In Paris, where, of all places which 1 have seen, they appear least demanded by any excess of modesty, or even sense of common decency, it is said, that since the erection of public urinals along some of the principal streets, the diseases of gravel or stone in the human subject have greatly diminished. 
a large number of patients. Any sick animals may be sent to the establishment, and their board is to be paid at a fixed rate of charges; twelve sous or cents, or sixpence, per day for a dog; and fifty sous or cents, or twenty-five pence, for a horse, including medicine, advice, and attendance. In cases of epidemics or murrain prevailing in any of the districts of France, the best attendance and advice are sent from these schools to assist in the cure, and especially to watch the symptoms and progress of the malady. In countries where large standing armies are maintained, and where of course there are large bodies of cavalry and artillery to be attended upon, as well as wagon-horses for carrying the supplies, the importance of veterinary surgery is vastly increased; but in countries where no standing armies exist, the number of horses kept for use or pleasure, and of other domestic animals, bears a much larger proportion to the number of human beings than we should be likely to infer without inquiry; and renders the profession highly important.

A large and select library belongs to the establishment, and a garden for the cultivation of medicinal plants, and likewise of the grasses employed in agriculture. $A$ farm is likewise attached to the place, on which instruction is given in practical agriculture, and numbers of various kinds of animals are kept for the purpose of breeding the best, and illustrating the effects of crossing. Some selected animals of domestic and of the best foreign breeds, - horses, bulls, cows, and sheep, - are kept for this special object. On one occasion, when I visited the institution, there was a public sale of bulls of the improved short-horns, which had been raised upon the place; and of some bucks of the best breeds of England, the Leicester, the South-down, and others from a cross of the Leicester with a large-sized Merino. I saw at Grignon the cross also of the South-down with the Merino. These: crosses presented examples of improved form, of large size, and of a great quantity of wool of a good, but not of a very fine, quality. These were the result of a first cross; how far it may be successfully continued is not determined. Attempts of this lind to intermix breeds of a decidedly different constitutional charateter, as far as my inquiries have been extended, have not been satisfitctory after a first cross. These animals belonged to the government, and were sold, not with a view to profit, but to the general improvement of the breeds of France. In this excellent 
mode, the government provides, in respect to horses, cattle, anc sheep, for the propagation through the kingdom of the most valuable races. The minimum price was fixed upon the animals as they were brought forward, and they went into the hands of those who made the highest advance, and who were required, under certain conditions, to keep them for the purposes of breeding.* Besides these sales, the best description of horses and neat cattle, studs, and bulls, owned by the government, are at the service of the farmers apon the most liberal terms, for the imjrovement of their stock.

In England, the veterinary establishments are maintained by private subscription. Perhaps, in general, that which is left to private management under the stimulus of personal interest is better cared for than that which is wholly public property; but as in this establishment there is no want of liberality on the part of the government, so there seems to be no want of fidelity and diligence in accomplishing its objects. The students are numerous, and the professors eminent for their scientific and practical acquirements.

3. Agricultural Colony at Mettray. - There are two other institutions for agricultural education in France, which I visited with great interest, and a notice of which will not, I hope, be unacceptable - the one at Mettray, near 'Tours, about 150 miles, the other at Petit Bourg, about 20 miles, from Paris.

The colony at Mettray was founded in the spirit of the good Samaritan, which succors the wounded and forsaken traveller by the way-side, takes him home, and there nourishes and cherishes him. This establishment grew out of the compassion of two gentlemen of high rank and fortune, who were moved to essay what could be done for the rescue of unfortunate, condemned, and vagabond boys, to save them, if possible, from destruction, and give them the power of obtaining an honest living. It is not consistent with my plan, in this place, to go further into the account of the institution, than as a school of agriculture, though the directors propose three objects of instruction - to yualify their pupils for farmers, sailors, or soldiers. The discipline of the

* The expense to the government of supporting the three veterinary schools is said to be about 492,000 francs, or 100,000 dollars, per annum. 


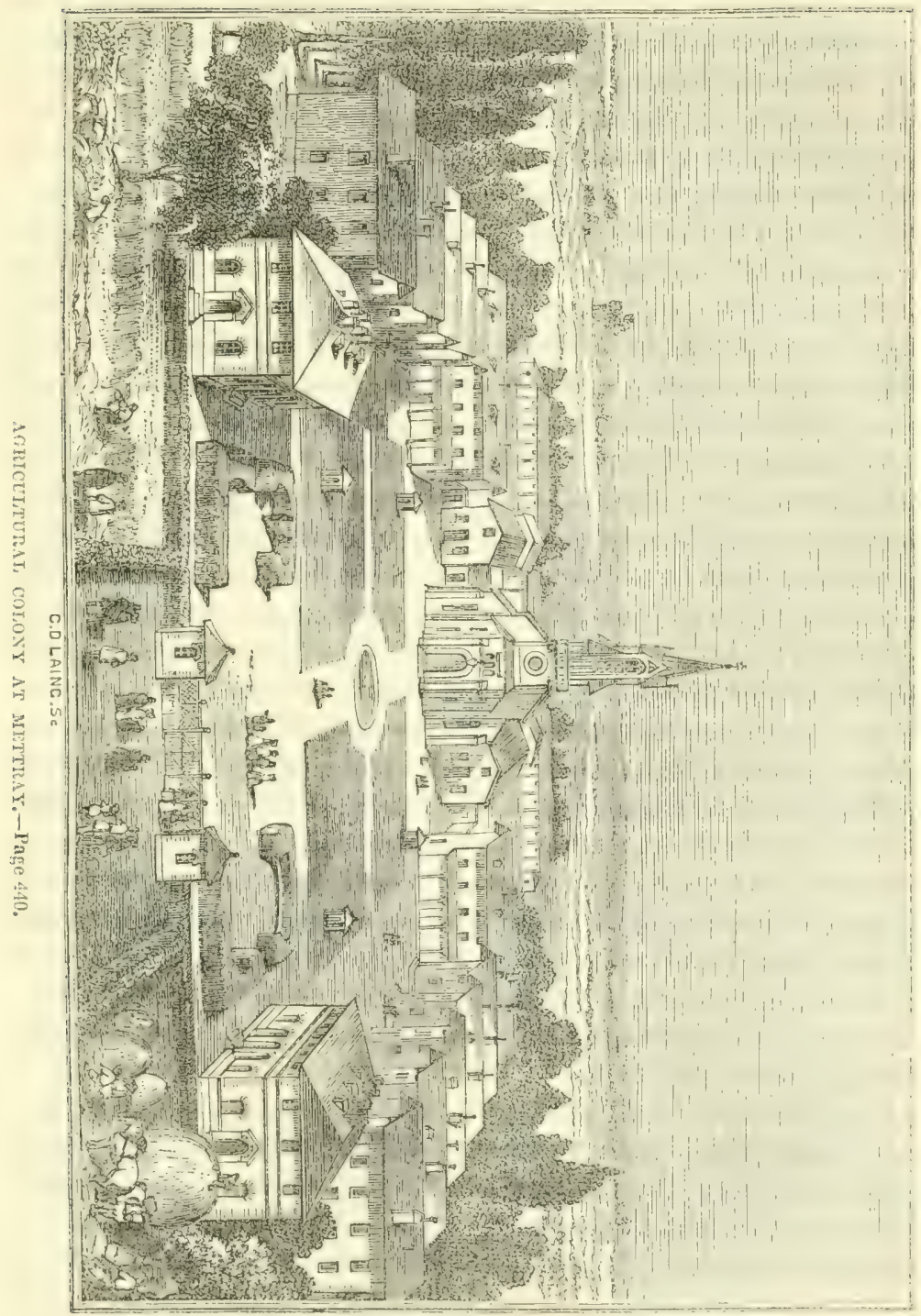


institution is military. They have a full-rigged ship of ample size in the yard, that boys designed for naval life may here take their first practical lessons; and they have a well-stocked farm of five hundred acres, which is under direction to be cultivated by the pupils. The institution is situated in a healthy part of the country, and near a large market-town. They employ an educated and experienced agriculturist as director of the farm. The first object is to render it productive, that it may go as far as it can be made to go towards defraying the expenses of the institution; the second, to instruct the boys in the best and most improved methods of husbandry. The institution had its foundation in private subscription, and though, in its commencement, it had many difficulties to struggle with, it has now a firm establishment.* Besides a farm, there are connected with the institution a large garden, an extensive nursery, and a manufactory for the fabrication of all the implements, carriages, \&c., which are used on the farm. The boys are likewise employed in the making of the shoes, caps, clothes, and bedding, which are required, and many fancy articles which serve for sale, and give them occupation, when by any circumstances they are prevented from out-door labor. The number of pupils is at present 450. It is not intended to keep them after sixteen, but they are willing to receive them at the earliest convenient age. I saw several not more than six or seven years old. They live in families of forty or fifty, in separate houses, under the care of a respectable man and his wife, who give them their whole time. This seemed to me a most judicious provision. They have a guardian with them in the fields, who always works with them. Many of them have been condemned at courts of justice for some petty offence, and many of them, orphans and friendless, have been taken up in the streets in a condition of miserable vagabondage. The discipline of the institution is altogether moral and patemal. Confinement, abstiuence, solitude, and disgrace, constitute the chief punishments; but there are no whips, nor blows, nor chains. It has been so far eminently successful. A

* The Vicomte de Courteilles gave a large estate, and Mr. De Metz, a distmguished philanthropist and a royal counsellor, besides sacrificing his high situation at court, lives among the children, and gives - the greatest of all charities, his whole time - his hand, his head, and heart, entirely to this object. 
hoy; who had been early familiar with punishments and prisons, and now for some time a resident at Mettray, was asked why he did not run away from Mettray. His memorable answer was, "Because there are no bolts nor bars to prevent me."

When one looks at the innumerable herds of children, turned, as it were, adrift in a great city, not merely tempted, but actually instructed, stimulated, and encouraged, in crime, and observes them gradually gathering in and borne onwards on the swift current with increasing rapidity to the precipice of destruction, until escape becomes almost impossible, how can we enough admire the combined courage, generosity, and disinterestedness, which plunges in that it may rescue some of these wretched victims from that frightful fate which seems all but inevitable? I do not know a more beautiful, and scarcely a more touching, passage in the Holy Scriptures than that which represents the angels in heaven as rejoicing over a repenting and rescued sinner. It is, indeed, a ministry worthy of the highest and holiest spirits, to which the Supreme Source of all goodness and benevolence has imparted any portion of his divine nature.

If we look at this institution even in a more humble and practical view, as affording a good education in the mechanical and agricultural arts, its great utility cannot be doubted; and much good seed will be sown here, which, under the blessing of God, is sure to return excellent and enduring fruits.

I should have said before, that there is connected with the institution a hospital, which was a model of cleanliness, good ventilation, and careful attendance; all the services of which were rendered by those indefatigable doers of good, the Sisters of Charity.

4. Colony at Petit Bourg. - Another institution of a similar Lind to that at Mettray, is about twenty miles from Paris, at a place called Petit Bourg. It was once a palace, built by a profligate king for a profligate woman, but now is converted into a school of charity, - certainly a better use. It is not designed for criminals or the condemned, but for vagabond children, fatherless, motherless, and friendless; and is to be regarded as a place for the prevention rather than the cure of crime. 'The farm contains about seventy acres; and though an expensive purchase, and a house much too magnificent for a pauper estab- 
lishment, yet the large rooms in the house, and the various spacious appendages, have been easily converted to the useful purposes of the institution. The neamess to the capital, where the subscribers to the funds principally reside, and therefore can have constant access to it, and a quick market for the produce in fruit and vegetables, are compensating circumstances for the exorbitant cost of the land. No person is received over sixteen years of age, or kept beyond twenty-one. The cost of maintaining a pupil is twelve pounds sterling - sixty dollars; and they are paid for by individual subscribers, or out of the common funds. Seventy pupils are now maintained here; and the applications are far beyond their power of receiving. The children are trained to agriculture, to gardening in its various branches, and some of them to different trades, as tailors, shoemakers, capmakers, blacksmiths, and carpenters. The farming was of a kind to be immediately productive, and was well managed. The cows at this establishment, as, indeed, in most parts of the Continent which I have visited, are soiled, - that is, fed in the stables constantly; and were of a superior description. There were two kinds which particularly attracted my attention, under the designation of Norman and Flemish. In appearance and promise I have seldom seen any superior. I could obtain no exact returns; but the Flemish was remarkable for size, and stated to be equally remarkable for her product in milk and butter.

With a view to encourage their exertions, the pupils have a portion of their earnings put by at interest, for their benefit; and which they receive, if, at the close of their term, they leave the place with honor; but not if they are dismissed for faults or crimes, or if they leave irregularly, and without permission. I hope it will not be deemed out of place if I remark here in passing, that the discipline of the institution is intended to be wholly moral and paternal. Light penalties, which affect the mind, and which are designed to operate upon the self-respect of the offender, and to affect his character and standing, are found much more effectual than any corporal punishments. A public court, at which the master presides, is held among the pupils once a week, when the daily records of the institution are looked. over. Here the deficient or guilty are called to account by their companions, and the penalties decreed. This, which may be called a court of honor has proved signally effectual. 
There are, besides Mettray and Petit Bourg, several other mstitutions on the same plan in different parts of France. They cannot be too strongly commended; and this seems a kind of philanthropy without fault. Let me add, with reverence, that if it were a mission worthy of a Celestial Messenger to seek and to save those who were perishing, what can be more a duty than, in our humble measure, to imitate a divine example ?*

I have deemed it useful to go thus fully into the matter of agricultural education in France, as the subject attracts much attention in England and the United States. The provision made in France for this object is obviously of a most liberal character, and the arrangements are made with equal judgment and wisdom.

I pass now to other topics.

Some of my readers may be interested in the subjoined anecdote, which I received from the benevolent director of the establishment: Among the rewards given at the institution, and those, extraordinary as it may seem, most coveted and deemed most honorable, are what are called tickets of favor. These only entitle the possessor to obtain some mitigation of punishment for an offending companion by bearing it himself. In one case, at the strong solicitation of the parents, a very unmangeable boy had been received into the institution. Silence is always strictly enjoined at meal times. This boy, after repeated admonitions, persisted in violating this rule, when a monitor took him by the collar in order to remove him from the table. The boy instantly stabbed the monitor, so as to endanger his life. For this offence he was sentenced to some months' imprisonment and seclusion, upon short allowance. After being some time confined, the boys solicited his release; the boy who had been wounded among the rest, and who had a right to claim a favor. After repeated refusals, the master at length consented, upon condition that the boy who had been wounded should take his place, and suffer out the time which remained to complete his sentence. This being agreed to, and the wounded boy taking the place and the penalties of the criminal, the culprit was appointed to the duty of ittending upon him by carrying him his food. The confined boy finished the timo to which the criminal had been sentenced. In the mean while, the culprit, witnessing the sufferings of the boy whom he had injured, and his magnanimity in undertaking to suffer for him, and the kind and forgiving conduct of the whole school towards him, was so deeply affected by it, that it appeared to have ... uricul an entire reformation of character, and he became and had continued for a long time one of the best boys in the school.

VOL. II. 


\section{CXXVI. - CROPS.}

The crops cultivated in France are the usual cereal grains, wheat, rye, barley, and oats; but what may be called the peculiar crops, yielding an inmense pecuniary value, are wine, silk, and sugar.

1. Wheat. - In gross amount, the wheat grown in France constitutes an immense crop. With the exception of Russia, from which no accurate statistical returns have been obtained, and in European Russia comparatively little wheat is grown, the bread used being chiefly of rye, it is stated, that more than half of the wheat grown in Europe is produced in France. From the best statistical accounts that can be obtained, the wheat annually produced in the United Kingdom,

England, Scotland, Ireland, is . 111,081,320 bushels. In France it is . . . . . 198,660,000 "

The amount of seed ordinarily sown to the acre is from two to three bushels. The return of crop for the seed sown is represented as, in the best districts, averaging 6.25 for one; in the least productive, 5.40 for one; but the mean average return for the seed in the principal wheat-growing departments is reckoned at 6.07 for one. These accounts must be considered as uncertain. Any person having experience in the case, knows how difficult is even an approach to accuracy. My readers may be curious to know the calculations which have been made in regard to some other countries in this matter.

NORTH EUROPE.

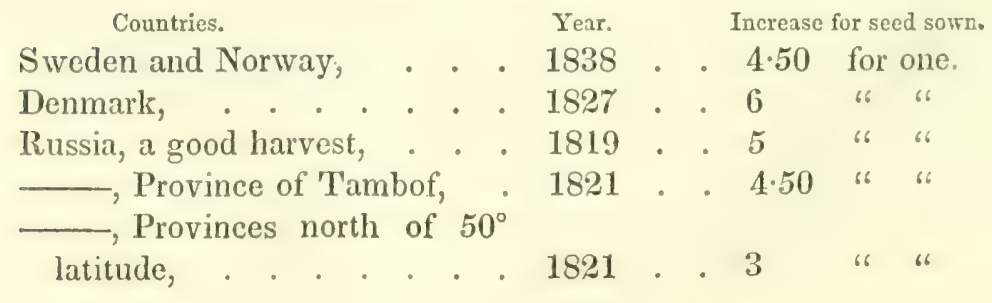


Countries. Year. Increase for seed somn.

Poland, .. . . . . . . 1826 . . 8 for one.

England, . . . . . . . 1830 . . 9 " "

Scotland, . . . . . . . 1830 . . 8 " "

Ireland, . . . . . . . . 1825 . . 10

Holland, . . . . . . . 1828 . . 750 " "

Belgium, . . . . . . . 1828 . . 11 " 6

Bavaria, . . . . . 1827 . 7 to 8 :

Prussia, . . . . . . 1817 . . 6

Austria, . . . . . . . . 1812 . . 7.0: ". ".

Hungary, . • . . . . . 1812 • . 4 "6 66

Switzerland, 182:5, lands of an inferior quality, 3; of a goud quality, 8 ; of the best quality, 12.

France, inferior lands, 3 ; best lands, 6 .

\section{CENTRAL EUROPE.}

Countries. Year. Increase for sced sown.

Spain, . . . . . . 1828 . 6 for one.

Portugal, . . . . . . . 1786 . . 10 " "

Tuscany, . . . . . . . . - . . 10 " 6"

Plains of Lucca, . . . . - - . . 15 "

Piedmont. Plains of Marengo, - . . 4 to 5 " "

Bologna, . . . . . . . - . . 15 " "

Roman States. Pontine Marshes, 20; ordinary lands, 8.

Kingdom of Naples - best districts, 20 ; ordinary lauds, S.

Malta — the best lands, 38 to 64 ; ordinary lands, 22, 25, 30.*

It is obvious how difficult it must be to arrive in this case at any thing like exactness. The quantity of seed employed on the same extent of land is very different in different countries, but the product camot always bear the above proportions to the amount sown. That I may be understood, let us look at Malta, where a return of 64 for one is given for the best lands. Are we to infer that in such case, if two bushels were sown to an acre, the ordinary proportion in France, the product would be 128 bushels per acre? or, if three bushels were sown, as in the best cultivation in England, the crop would be 192 bushels? In

* Statistique des Cereales de la France, par M. A. Moreau de Jonnès. Paris, 1843. 
Ancient Egypt, the return is represented as 100 for one; in Byzantium, as 150 for one; in Ancient Libya, as 300 for one. No certain conclusions can be founded upon such statements. The distinguished traveller, M. Humboldt, states the average product of wheat in Mexico as 25 to 30 for one, and this on table-land clevated 8000 feet above the sea; and that, even on large farms. he found it 50 and 65 for one. In the Antilles he states the production of maize, or Indian corn, as 300 for one. But I have seen in several cases in New England, in the culture of Indian corn, a return of 400 for one ; that is to say, the hills being three feet apart each way, a peck of Indian corn would be sufficient seed for an acre. If 100 bushels of grain are in such case produced on an acre, - and this sometimes happens, - this is clearly a return of 400 for one.

Of the average yield of wheat in France it is not possible to form a conclusion on which entire reliance may be placed. Until a very large district can be taken, and the crops and land actually measured, no certainty can be attained; and then of course it must vary much in different climates, or expositions in different seasons, and under different modes of culture. At present it is altogether matter of conjecture, and it would be difficult to find two men of independent judgment who would agree in the case. The average yield in England I have heard stated by men of political standing, claiming to be well informed on the subject, at not more than fifteen bushels per acre. An eminent agricultural writer placed it at eighteen bushels some years since; men of sanguine temperament rate it at over thirty bushels. These evidently are wholly conjectural estimates. In France it is stated in the best districts to average twenty-two bushels. This rests upon similar authority. It would be of immense importance to any government to know the exact product grown in any country or district, or in the whole country; and this might be obtained by compelling, on the part of the owner or cultivator, an actual return of his crop; but it is of little use to found such returns on estimates purely conjectural. There is another point in respect to this cultivation which the agricultural societies might obtain, and which would be of great importance; that is, first, the smallest yield ordinarily obtained, and, next, the largest yield actually obtained, with a detailed history of the culture in each case; the causes of the 
inferiority in the former, and of the superiority in the latter, as far as they can be ascertained. Reluctant as most men are to state them, yet, as much benefit may be derived from a knowledge of the causes of failure as of success; and in the latter case, every one must see the importance of knowing what can be done, that every stimulus may be given to an emulation which in agriculture is always wholesome, and a great instrument of success. In England, fifty bushels per acre were reported to me, on the best authority, as the yield upon a large tarm in a very favorable season. Nore than eighty bushels have been reported, upon what is deemed ample testimony, to the Royal Society of England, as the product of a single acre.* In France I have had, upon the best authority, reports of forty bushels, forty-four bushels, and seventy-two bushels. It is beyond all doubt that the crops in England have, within a few years, considerably increased; and, by the official returns in France, where much pains have been taken to render them aceurate, it appears that within eighty years, while the population has increased in the proportion of twenty-one to thirty-three millions, the production of wheat has more than doubled; which shows an improvement in the comforts of the people. It is further stated, upon good authority, that the product of an acre of land is ordinarily double what it was three fourths of a century ago; which shows a most gratifying improvement in the agriculture of the kingdom. It is an instructive fact, that the product of wheat in France has increased sixty-three per cent. since the close of Napoleon's wars - a fact which shows, in a most striking manner, the interruption which war brings into the useful arts of life, and the privations and wretchedness which are sure to follow in its train.

There have been in France, as every where else, discussions as to the origin of wheat, many persons maintaining that it is an inferior plant in its natural stite, and that its present condition is

It is almost impossible to get any exact return from an English tenantfarmer of his products, for the reason that he will give no occasion to his landlord to raise his rent. In countries where the amount produced is a subject of such great importance, and where the population is pressing so hard upon the supply, an accurate return of the yearly product should be induced by some pecuniary encouragement, or otherwise made compulsory. 
the result of artificial cultivation. The speculation will do neither harm nor good. There is little reason for the supposition; and it seems extraordinary that similar changes are never witnessed at the present day. It is certain that the wheat cultivated at the present time does not differ from that found in the pyramids of Egypt.

There are nearly thirty different kinds of wheat cultivated in France, including both autumn and spring varieties. In respect to this distinction, there is little doubt that, by a careful selection of the earliest ripe, after a time, the autumn may be converted into a spring wheat; and the spring wheat, being repeatedly sown in the autumn, would presently lose its properties of early ripening. It would be imprudent to prescribe any particular species for universal or for general use, as the different kinds are adapted to different localities, some being much earlier than others, and therefore, though yielding a less product, ripening before the droughts of summer, and escaping, in some degree, the dangers of blight; and others being more susceptible to injury from frost. The white wheat of Flanders is a highly esteemed variety; and is said to be the same as a wheat known in England by the names of the Eclipse wheat, the Wellington, and the Talavera. It is highly productive and beautiful, and is particularly suited to lands of the richest quality. The white wheat of Provence is pronounced the most excellent variety for the quality of its grain; its straw is very tender, and therefore liable to be lodged; and it is too delicate for a cold climate. The Lammas wheat is of an excellent quality; early in its ripening; it sheds its grain easily in the field; it therefore requires to be cut early. It is very susceptible to injury from cold. These are all winter wheats; but what is called a spring wheat in Europe is a wheat which should be sown in February; whereas, in the United States, that only is called a spring wheat which may be sown, with a surety of its ripening, in any part of March or April.

The Tuscan wheat, used in the manufacture of the celebrated and beautiful Leghorn bonnets, is a spring wheat, with very short heads, and produces little grain. The Victoria wheat, of a good quality, and brought to France from Colombia in South America, and represented as ripening in sixty days, was not found, in France, in advance of the common wheats of the coun- 
try. I imported, some years since, a wheat from Spain, highly commended for its rapid growth and early maturity, but in these respects it showed no superiority over the kinds ordinarily cultivated in the country.

We are already, in the United States, in possession of many beautiful kinds of wheat. I can only add, if we could import a few of the French bakers to instruct us in the useful and important art of making bread, it might prove a signal advantage. I believe nowhere is so good bread to be found as in France; and this, not in the cities only, but throughout the country; even at the meanest village tavern you will ordinarily find bread of the best quality.

The Egyptian wheat, which I have seen growing several times in the United States, and which is known by its producing several heads upon the same stalk, is highly productive on rich land. Its flour, however, is not highly esteemed. It does not well bear the cold. It is liable to degenerate, and to produce, at last, only one head.

A large portion of the soil of France is unfavorable to wheat, from its excessive dryness. Though, beyond doubt, a soil partially calcareous is favorable to wheat, yet this quality in excess is unfavorable. The soil for wheat cannot be too good, though it would seem as though there were exceptions to this remark in some of the rich alluvions of the West; but it may be made too rich by manure, and especially by manure applied in too green a state. It is in general the custom to apply the manure to the previous crop, though in many cases, and especially where licuid manure is attainable, it is applied immediately before the sowing of the crop. This was particularly the case in the instance which I have given, of seventy-two bushels being produced to an acre.

A naked fallow is sometimes resorted to in France, especially where the land abounds in weeds, and more particularly the squitch-grass, ${ }^{*}$ which peculiarly infests the old lands in Furope. The quantity sometimes collected from land, in what are called even good farming districts, is surprisingly great, and would lead one to infer, in some cases, that it was the principal crop grown.

As to the crop which is deemed best to precede wheat, I shall 
yive the opinions of the best farmers in one of the best cultirated districts in France. Where tobacco has grown, wheat succeeds to great advantage. The cultivation for tobacco is clean and careful, and the manuring abundant. Wheat follows hemp with equal success, because the cultivation of hemp is equally clean with that of tobacco, and it is even more strongly manured; but the straw of wheat which follows hemp is not so abundant as after tobacco. Wheat after cabbage yields less straw than after some other crops, but more grain.* Beans are by some farmers regarded as a crop propitious to wheat, but not so favorable as those crops to which I have referred; and by others it is believed to produce less grain, and that of an inferior quality. After Indian corn, the wheat gives a good grain, but an inferior amount of straw; but in some localities it is represented as giving an equally good product in grain and straw. After lucern, wheat is cultivated to great advantage ; the lucern strikes a decp tap-root. which greatly emriches the ground when it is turned in. Whoat succeeds well after clover, if the clover is good; if the clover is poor, the crop of wheat is likely to be inferior, which is in other words only saying, if the land is rich, the crop will be good; if in poor condition, the result will correspond. Potatoes are generally condemned as a crop to precede wheat. In parts of France where wheat is grown every second year, potatoes are frequently the intermediate crop; and then the wheat, as well as the potatoes, are manured. After turnips, wheat is stated to be richer in straw than in grain. The rotation differs in many places, sometimes wheat occurring every other year, and sometimes only twice in six years.

I cannot look upon these various statements with all the confidence which some persons place in them. A presumption is always in favor of the general and long-continued practice of any country; yet it is far from being an infallible test of what is good or best, because it is by no means certain to be the result of experiments carefully made, and as carefully noted. Two or three great points, however, seem to be fully settled; that the land for wheat cannot be too deeply cultivated, nor too

* "It is calculated that 120 sheaves of wheat grown after eabbages, will give more grain than 150 sheaves grown after tobacco." - Scherwz, Culture r. Alsace. 
thoroughly manured, in the crop of the preceding year; and that it canmot be too thoroughly cleaned. Mr. Coke, of England, afterwards Lord Leicester, offered a large reward to any person who would discover a single weed among his crops, after their usual cleaning. The wheat plant sends out descending, as well as lateral roots. $\Lambda$ fter land has been thus well prepared, it is not deemed best to plough more than two or three inches for the sowing of wheat. By many persons, in climates where the frost heaves the land deeply, it is deemed best to cover the seed of autumn-sown wheat by the plough. Where the land has been ploughed in the autumn, it is advised only to harrow the land in the spring, and harrow in the seed upon land thus prepared, and press it closely with a roller. Land is frequently, after being sown, trodden by men, but better by sheep - a practice to which I have referred in my remarks upon English husbandry.

In England, certainly by all the best farmers, wheat is sown in drills with a machine. These machines are in general, like many of the agricultural implements of England, where they admit of being so, heavy, complicated, and expensive; but they do their work in an admirable manner; and many of them are contrived so as to sow the manure, when in a state of powder, at the same time as the seed. Many of the French farmers sow their wheat in drills, and by a machine, but not of a very improved character. In Switzerland I found drill machines, invented and made in the country, not expensive, which certaialy performed their work well. Experiments have been made in France of planting wheat in hills, six inches or more apart, by a hoe; making the hole, and dropping several seeds in the hill, as Indian corn is often planted in the United States. There must be obviously a great saving of seed by this mode; and the result has been pronounced successful; but I have not been able to get full information. It was said to be by this mode that a crop of seventy-two bushels to the acre was produced. 'The crop, while growing, was manured with liquid manure, and was kept thoroughly clean. This resembles somewhat the mode of planting by a dibble in England. Such a mode wonld, at first sight, be strongly objected to in the United States, because of the labor which it would require. There is often a difficulty in the United States of procuring labor for any consideration; but, other things being equal, a wise farmer would not ask simply 
what the labor would cost, but whether the result would compensate the labor.

The quantity of seed sown to an acre is ordinarily two bushels, more frequently less than more. The quantity depends somewhat upon the nature of the soil, a larger quantity being sown upon inferior than upon good soils. Somewhat depends likewise upon the time of sowing. If sown early in September, the plants have a longer time to grow, and tiller more abundantly than if sowed later. Early in September is the time ordinarily recommended for sowing wheat, where the previous crop can be got off and the ground be made ready. In situations where the winter is severe, late sowing is strongly recommended, so that the wheat may make little or no progress before the early spring. In this way the crop is secured from the injury of the frost, which, when it destroys the young lateral roots, is extremely unfavorable, if not destructive, to the crop. 'The wheat crop does not sufier from the severity of the cold where it is minterupted, but from alternate freezings and thawings. When the ground is expanded by the frost, the small roots of the young plants are broken and mutilated, and the plants, being often thrown out of the ground, perish.

The diseases common to wheat in the United States are equally common in Europe - the smut, the rust, and the mildew. A remedy, or rather preventive, of the first, in almost all cases sncessful, is well known in the United States - the washing wheat in brine, and sprinkling it with lime. Probably the only advantage of the brine over simple water is, that its adhesive nature makes the lime stick to the seed. A solution of green copperas is equally effectual; and sometimes arsenic is used. The last is objectionable, from the danger of having the substance about the premises. The wheat may be prepared two or three days before sowing, but it must not be allowed to become heated. If laid in a heap upon the floor, it should be occasionally stirred.

The rust and the mildew seem mainly due to atmospheric causes. When the wheat is particularly forced by alternate sunshine and rain, attended with extreme heat, when every species of vegetation is urged to the top of its speed, and especially where the land itself is very rich and the air stagnant or confined, it seems as if more sap were forced into the plant than 
it could dispose of, the vessels burst, and the plant in truth dies of repletion. My own experience and observation seem fully to confirm this theory. The blight of mildew is a diflerent affection. The causes are not well ascertained, and the preventives equally undetermined. A distinguished German clergyman or pastor, - and I may be allowed to add, in passing, that to no profession has agriculture been more indebted for its improvements, after long and careful observation, is of opinion, that three causes may produce it - the state of the atmosphere, when the plant is in a particular stage of its growth; an unfortunate choice of the time of sowing; or the particular condition of the soil. He has found that, in the same neighborhood, the wheat in some fields has been badly affected, while in others it has escaped the mildew. This circumstance seems opposed to the atmospheric theory; yet in the same country, the state of the atmosphere may be different in different positions and aspects of the field. Every one must have experienced this in passing along a public road in an evening; without a thermometer we become sensible, in different places, to great variations of temperature. With us in New England late-sown peas seldom escape the mildew, or what is called the blue mould, which has seemed to me attributable to the heat of our autumual midday sun, followed by the chilliness of our autumnal evenings and their abundant dews. The same theory may account for the facts which he mentions in regard to sowing. He has sown wheat in September, which has suffered slightly from mildew; in October, in the same year, which has suffered severely; in November, which has entirely escaped. The circumstances in these cases are not all given. It is, therefore, difficult to make up a judgment; but one would infer that the late-sown wheat was carried beyond the susceptible season. The influence which the condition of the soil may have upon the health of the plant in this matter, or how far it may be affected by the manure employed, are points not determined. In one district in Alsace it is said the farmers find their wheat liable to suffer from mildew, when it follows clover which has been highly manured; but the manure customarily used in this case is the manure of hogs, to which some are disposed to attribute this result. Nothing seems more uncertain, or rather more imperfectly defined, than agricultural fiets, excepting it be agricultural theories. In order safely to deduce a valuable 
or practical truth from facts, the facts must be accurately and exactly determined and observed; but few men have this patience of observation. All the circumstances under which they occur, likewise, should be known and considered. Few men have the capacity to discover and comprehend them; and, in many cases, it must be confessed that, in our present state of knowledge, they are with difficulty ascertained. This disorder is clearly not propagated as smut is; and liming the seed has no effect in preventing it. This farmer is of the opinion that it does not depend upon the manure employed; at the same time he is in favor of turning in a crop of clover as manure for wheat, rather than to apply animal manure. Some persons confound the diseases of rust and mildew. The result is much the same, the crop being in both cases nearly ruined; but the appearances are different. In the case of rust, the wheat becomes suddenly attacked and the stalks covered with literally a red rust, the grain ceases to fill, and becomes shrivelled. In the case of mildew, the plants become covered with a whitish mould, and the stalks themselves become discolored in various places, and turn black, as in a limb where mortification has taken place.

I have obtained no information as to what is called in the United States the Hessian fly, from the eggs being supposed to have been brought to the United States by the Hessian soldiers, who were the mercenaries of the British government in the American revolution. I cannot learn that it is known here. The grasshoppers, or, as they are here called, the locusts, become destructive to a wheat crop, when the grass fails in the fields. The grain-worm, of which I have given an account in my State Reports, and in other publications, does not appear to be known on the Continent, though they have heretofore suffered from it in England.* Such scourges seem often temporary or periodical.

* I believe there is an effectual remedy against this destructive insect, under whose ravages I have known the most promising crops completely ruined. 'The fly, from whose egg this insect or worm is generated, appears first at the time when the wheat is in flower. If at that time the growing crop is slightly sprinkled with newly-slaked lime sown broadcast over it, it will commonly save the crop. It will either prevent the fly depositing his egg, or by its causticity it will destroy it. The mode is of no importance, compared with the result. The destruction of the crop is not evident until the time for harrest; and then, though the external appearance may be perfect, there will be found in the grain or kernel a small yellow worm or maggot, which has completely destroyed it. 
I have spoken of the quantity and the preparation of the seed. It is said by some that shruntien seed, or seed imperfectly ripened, will germinate and serve for another crop as well as that which is perfectly sound. I believe it may be considered as an established axiom, that perfect seed is always to be preferred to that which has any defect. In many provinces new wheat is always preferred for sowing; but many experienced farmers advise to sow wheat which is a year old, as a security against smut; for though the crop may have been smutty, from which the seed in such case is taken, the smutted ears are said, in the course of the year, to lose their germinating power, and do not communicate the disease to those grains with which they come in contact. A farmer, however, can hardly excuse himself for neglecting to take the prescribed precautions against smut in the preparation of the seed, which have been usually found effectual; and it is obvious that if old seed is used in preference to new, a larger quantity is required to guard against the failure of such as have become eftete. In some provinces, they deem it necessary to change their seed once in two or three years. But the reason given by some persons for this practice is, that the cultivation in these departments is slovenly and negligent, and so the wheat degenerates. I think experiments have fully demonstrated, as applicable to all plants, that where the cultivation is good, and the kind itself good, we have only carefully to select from year to year the very best for seed, and there will be found no necessity for changing the seed; and the crop itself will be likely continually to improve. In some cases, and especially where the cold is severe and the winds are strong, it is advised to plough in the seed wheat to the depth of about three inches. The best cultivators advise this always, especially where the lands are light; but it is a slovenly mode, as practised by some, to sow it upon the stubble of a preceding crop, and merely harrow it in. If nothing else, the benefit arising from the decayed stubble or the clover, when turned under as manure, is thus almost wholly lost. Wheat which is to be sown on a clover stubble * is advised to be sown two or three weeks earlier than

* Wheat manured by turning in a green vegetable crop, is supposed to have less strength, and is therefore more apt to become lodged, than that grown after a crop which has been manured with rich animal manure. 'The occasion of the

FOL. II. 
that which is sown after tobacco or hemp, that it may gain strength; and it is the custom where wheat is sown after tobacco, to spread the stalks of the tobacco crop upon the field, where they remain until the spring, when they are removed. I do not know the advantage of this, unless as a protection against the cold.

Nothing is more prejudicial to the success of a wheat crop, than excess of wet; either stagnant on the surface, or in the soil. I have as yet met with no cases of underdraining or subsoiling in France, but the value of this immense improvement will presently be understood. Where the soil is clayey and wet, wheat is sowed in beds or stitches, and the drains between them kept clear. Experiments have been made in some parts of France for the irrigation of wheat, and with success, where a porous soil or a sufficient drainage immediately carried off the water; but of course it operated most injuriously where the soil or the surface retained too much wet.

The cultivation of spring wheat, unless the land is prepared in the autumn, is liable to many objections. The spring season is crowded with labors which must then be accomplished or not at all. Land plonghed in the autumn, which is, from its position or the nature of the soil, liable to retain the water of winter, is difficult to be worked even by the harrow in the spring, and in an unhealthy condition for being sowed. Spring wheat, though making an equally good flour, and for some purposes more esteemed than any other, seldom yields so abundant a crop as autumn-sown wheat.

In some instances, wheat is carefully weeded and cleaned in the spring; but this, in examples under my observation, has not been executed by a machine, nor very perfectly done. Nothing can be more beautiful than the cultivation, in some parts of England and Scotland, where wheat is sown in perfectly straight lines by a machine, and then carefully cleaned by a horse-hoe. Though I have seen good crops of wheat in France, the cultivation in numerous cases was far from being clean. When the

stalk of wheat being tender, and the wheat therefore more liable to fall, is said to be owing to a deficiency of silex in the soil. But there are few soils where this deficiency exists. I give these opinions as opinions resting upon respectable authority, but without vouching for them. 
carly-sown wheat is far advanced in the spring, it is sometimes mowed; but this practice is not approved. It is sometimes fed down by sheep, and with great advantage; but it is advised not to put horned cattle upon it. This feeding of the wheat should be done, however, only when the crop is very luxuriant, and before May.

The wheat is sometimes manured in the spring on the surface, where liquid manure is easily obtained. Ashes, wood ashes, either crude or leeched ashes, are applied to wheat with the greatest benefit. This is done in the spring, when the wheat is harrowed. The harrowing of wheat in the spring, when it is a fow inches in height, is practised and strongly commended by the best farmers. I have full confidence from experience in its utility. In England, where the wheat is cleaned and cultivated by a horse-hoe or scarifier, this is an effectual substitute; but where wheat is not cleaned by a machine, or where it is sown broadcast, the practice of harrowing it with an iron-tooth harrow of considerable weight, and that two or three times, is strongly commended. This practice is said to have been suggested by accident to a common farmer, who, having sown clover upon his wheat in the spring, was afraid that in some cases the seed would not take, and ventured to harrow it in. He found, to his surprise, that the wheat which he had harrowed was much superior, in the end, to that which the harrow had not passed over. It is a general practice, in some of the districts of France, to sow clover in the spring upon the wheat. This is a well-known practice in parts of New England, where it is sown upon the snow; and, I am sorry to add, sown in many cases in the chaff from the barnfloor, when, of course, a variety of weeds and worthless plants are sown with it. The dung of domestic birds, pigeons, or barndoor fowls, where it can be obtained, is sown with much advantage upon the growing wheat in the spring.

Where spring wheat is sown upon land ploughed in the autumn, which has not suffered from wetness, it is not necessary to replough it, but to put the seed in simply with a harrow and a roller. It has seemed to me that the European farmers sometimes labor their lands too much, as in turning in a clover or stubble crop, or a grass sward, they take pains to break the sward, and bring all the vegetable matter to the surface, to be burnt in some cases, or to be dried and exhaled in others, instead of leav- 
ing it to its natural decay under the soil, and its conversion into food for the growing crop. They are hardly aware of the amount of this vegetable matter, as demonstrated by an eminent farmer in New England, and a farmer who would be eminent any where, who found, by actual measurement and calculation, that the vegetable matter in a common closely fed, field, or meadow, weighing the roots as well as the tops, amounted in an acre to full thirteen tons.**

The manures applied to wheat are a matter of great importance. Different wheats, or wheats grown in different localities, differ very much in their nutritious properties, or in the quantity of good bread which can be obtained from them. The valuable and nutritious qualities of wheat are supposed to depend on the proportionate quantity of gluten and albumen which it contains. This is ascribed by many persons to the nature of the soil in which it has grown, and to the kind of manure which has been applied to it. This theory is altogether probable, and perhaps sufficiently established to induce us to act in reference to it; and, therefore, to apply manures which are likely to contribute to the growing plant the elements required. But many other things may come into operation, such especially as the climate and temperature, and other influences which are as yet imperfectly understood by us. The quantity of flour yielded by different wheats varies considerably, as the millers well understand. A distinguished French chemist, in examining 21 different kinds of wheat, found that the average yield in flour was as 79 of farinaceous matter to 100 pounds of crude grain. But this flour differed very much in its constituents in different kinds of grain. In actual nutritious matter, the difference in different wheats was found to be as 14 to 21 . These were wheats grown in different countries and different latitudes. If this difference depended wholly upon climate, it would of course be entirely beyond our control.

In wine countries, it is known that in different localities the same species of grape produces a wine of an altogether different quality and value from what it does in others. The kind of grape, the mode of culture, the degree of ripeness, the mode of making the wine, the age of the wine, and, doubtless in many

* Mr. Phinney, of Lexington, Massachusetts. 
wists, various artificial processes, affect to a degree the quality of the wine produced; but, beyond all this, there is something in the locality which is believed to determine its character. The colebrated wine, known as Constantia, is the product of a very limited territory at the Cape of Good Hope. In passing up the Rhine, there was pointed out to me the estate of Prince Metternich, where the celebrated Johannisberg wine is produced; and it is produced nowhere else; and from this circumstance its production is a source of immense profit. 'These facts seem to demonstrate the truth of the reply made always to my incuiries in relation to the subject, that there is something as yet unascertained, some peculiarity in the climate, aspect, or soil, from which the product derived its characteristic properties. 'T'he same or similar circumstances may operate upon the quality of wheat; and it is obvious, as far as they are strictly local, dependent upon the climate and aspect, or upon any peculiarities of the soil which do not exist any where else, or upon any causes as yet unascertained, they are beyond our reach.

But that the qualities of the wheat grown depend to a considerable degree upon the kind of manure employed, there can be no doubt. Some experiments, in reference to this matter, made by a German farmer, may be interesting to my readers.

Wheats manured as underneath produced as below : -

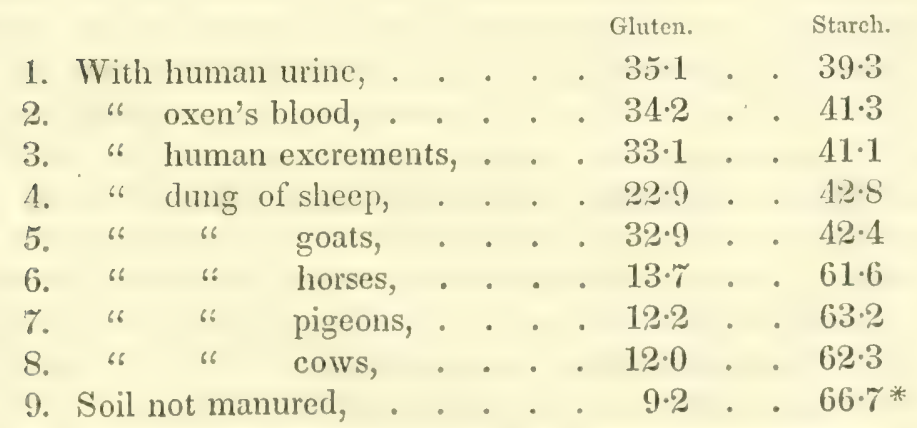

I am unable to say how far these experiments are to be ifepended on; and how far they have been confirmed by other experiments made with the same intention. Two things are

* Cours d'Agriculture, par Gasparin, 
quite remarkable in respect to them; the one is the different qualities of grain grown with manures of the greatest efficacy, and that grown without any manure, being a difference of nine and thirty-five; and the comparatively low result of pigeon's dung, which is generally rated very highly, and supposed to take its place with guano. The manner in which the animals whose manure was used for these experiments were fed, is a circumstance which may have materially affected the results; for the qualities of the manure of the same animals, under different courses of feediug, may be expected to be composed of different elements, and so to give difierent results; so complicated necessarily are all experiments of this kind.

The farmers in France are behind no others in what may be called, technically, agricultural science; and some of those eminent men, who are sometimes called farmers of the closet, have gone into the most exact and minute mathematical calculations as to the actual amount of certain mineral elements, which are supposed essential to the growth of the crop, or of any particulat crop; and next, as to the amount of these mineral substances, which any particular crop carries off in the straw, and in the grain. They then proceed to determine the exact amount of these substances, which must be restored to the soil in order to kcep up its fertility. The first point is determined by analyzing with great chemical exactness a portion of the soil ; the second, by analyzing a portion of the crop, of the straw, and the grain; and these premises being obtained, the third is of course matter of plain inference. These calculations are curious and ingenious, and if vegetation or the growth of plants were as simple an affair, and as well and as easily understood as many pretend that it is, these facts would have a most direct and immediately practical bearing. One of the most eminent of these calculators, however, himself admits that the application of these facts, or rather the rules dednced from them, is an operation difficult, delicate, and which only the most skilful persons can undertake.*

In the present very imperfect state of our knowledge of vegetation, I am free to express my conviction, that they will answer no other purpose than that of mere curiosity and amusement. In the analysis of a soil, for example, if we suppose that a cubic

* Gasparin's Course of Agriculture, vol. iii. p. 405. 
foot is taken, this may be a very inadequate representative of other parts of the field. If the soil is taken from the surface, or that part of the soil which is cultivated, yet there is the soil under this, into which the roots of the plant may extend themselves, and which may contain elements of which we are not apprized. In the chemical analysis of a soil, it is known, likewise, that much of the active portion, all the vegetable portion, is dissipated by heat, and no account is obtained of it but by the loss in weight. The analysis of a soil, likewise, though it may give all its component parts, is sure to destroy their combination, and disturb the relations which they held to each other. There is another great omission in this case. Notwithstanding all the analyses which have been given of soils and products, where the amount of mineral elements removed has been most particularly determined, yet I have met with no instance of the analysis of a soil immediately after the removal of the crop; by which, on comparison with its condition at the time of sowing, the actual loss could be detected. This is a great desideratum, which we may hope will presently be supplied.

I great many exact calculations have been made in reference to the weight of straw compared with the weight of grain, and the weight of stubble, when wheat is reaped with a sickle, compared with the whole weight of grain and straw. These results must, in different cases, be so affected by the seasons and soil, by the amount of crop, by the time which the plant has had to mature itself in, by the height at which the grain is cut, and by the condition of the straw when dry, that it would be difficult to draw any practical rule from them. In ten different experiments made in reference to this point, which have been shown me, no two agree.

In respect to the manures proper for wheat, I shall say somcthing in another place. Every one seems to acknowledge the value of potassium, the principle which is found in common wood ashes. This accords with the result of my own experience and observation; for when called upon, in the way of my official duty, to examine the modes of cultivation and manuring, in no Jess than thirty-six hundred experiments in the culture of wheat, I found that wherever ashes were used upon the field, their efficacy was emphatically commended. The chemical analysis of wheat, taking straw and grain together, gives only a small pro- 
portion of this principle in the whole mass, such as 2 parts in 300 ; but this seems evidently indispensable. Whether it is absolutely necessary in a certain proportion, as food of the plant, or. whether it operates in preparing other matters in the soil to become food for it, I shall not presume even to give an opinion. I must submit to minds qualified by the high attainments of seience, to follow out inquiries so subtile, and at the same time so curious.

I have occupied the attention of my readers a long time on the subject of the culture of wheat, because of its immense importance. In the United States we cannot be said as yet to have known want; but in the years 1812 and 1816 there was, throughout the whole of New England, an almost entire failure of the crop of Indian corn; and it was not until such experience came upon us that many persons were fully sensible how mucl: and how essentially this product entered into our daily wants. The wheat crop has become infinitely more important, for, witl: the exception of the slave states, I do not know a district of the country where it does not form by far the principal food of the population. But one has need to have lived in Europe through a famine to know the immense importance of any great and general article of subsistence; and the suffering among the mass of the community, which follows even its scarcity, still more the miseries and horrors which its total loss brings upon them. It is a fact which, as long as human memory endures, will stand out in bold relief on the darkest pages of history, that, in the years 1846 and 1847, in a country not so large as New England, by the blight of a single crop, not less than 116,000 of human beings actually perished by the awful death of starvation, not to add the thousands, I may add safely the hundreds of thousands. who were swept away by diseases engendered by unwholesome or insufficient food; and not to recur to the awful sufferings of the thonsands and thousands who had strength enough to struggle through this trial, and in the midst of this dreadful shipwreck were just able to reach the shore.

With a rapidly increasing population in all parts of the civilized world, the production of bread is obviously the first object to be sought after, alike by the statesman and the peasant. I scarcely dare give the calculation of the immense amount which would be realized, in any great country, by the single 
saving of a bushel to an acre, in the quantity of seed ordinarily sown.* The same result would follow if an additional bushel could be produced in the ammal average yield of the wheat crop. Even this simple result would be an ample compensation for all the labors and expenses of all the agricultural societies now existing in the world, and the premiums by which, in any country, the government have aimed to enlighten and stimulate production. I have not a doubt that, under an improved culture, not only may there be such an increase as to defray all additional expenses but to add an average increase of five bushels to an acre. It is impossible to exaggerate the advantages which would result from such an improvement.

In looking back upon what I have written on the culture of wheat, it may not be without advantage to revert to some prominent points.

The soil in which wheat is grown to most advantage is a deep aluminous soil, but not so clayey as to prevent its being thoroughly cultivated. It requires, therefore, a good mixture of calcareous or siliceous matter. A soil of excessive lightness or looseness is not favorable to wheat, and a hard and impermeable soil equally uncongenial.

'The soil cannot be too deeply cultivated for wheat. The roots of the wheat plant descend perpendicularly, and spread themselves laterally and broadly in search of food. It would be a mistake to plough too deeply for wheat at the time of its being sown; and it is always useful to roll or tread the soil after it is sown; but it is desirable that it should find a deep mellow bed

* The annual amount of seed for wheat sown in France is estimated at $32,491,978$ bushels.

If we could suppose a third of this saved, the saving would amount to ${ }^{\circ} \cdot \dot{*}^{\circ} \cdot$ bushels per acre, this would give an increase of production of

$10,830,659$ bushels per year.

Add this, under improved cultivation, to the amount of seed saved, and the result would be. . . . . . . . . 65,150,454 bushels.

I believe, under an improved agriculture, this is quite practicable. What economical object could be more worthy of the goverument of a country, than. by every means within its reach, to encourage such production? 
below; and this is the case when it succeeds sucn plants as madder or tobacco, or especially where the soil has been deeply and thoroughly trenched.

Wetness is peculiarly unfriendly to wheat. Surface water, that remains long upon the land, or wetness, which stagnates and remains long in the soil, is highly prejudicial to wheat. This gives the great value to the Deansten system of draining and subsoil-ploughing. The water which falls in such case soaks immediately into the ground and is carried off. Where there is no subsoil-ploughing, and where the soil is of a retentive nature, the laying up the soil in narrow, slightly-rounded beds or stitches, so that the water may pass off at once by the intervals, is highly important.

Wheat land cannot be too clean, or be kept too clean from weeds; and for this reason it should follow a crop which has been kept thoroughly weeded. The small kinds of clover may be advantageously sown with or upon wheat in the spring. This will not impede the growth of the wheat; it in some measure serves to keep down weeds; it protects the ground, in hot climates, from the great power of the sun, after the wheat has been cut; it furnishes some food for stock after the wheat has been harvested; and it enriches the land greatly, when it comes to be ploughed in.

Wheat should be sown in drills four to six inches apart, or better dibbled, or sown in hills, which is not an excessive labor, where it is done by skilful and experienced hands. In any event, whether sown broadeast or in drills, it should be cultivated, and the ground carefully stirred by the harrow or the scarifier.

Early sorving is strongly recommended in warm climates, so that the crop may come off before the extreme heats of summer; but it is advised, in cold climates, to sow wheat quite late, that it may not make any, or but slight progress, so as to be exposed to the severe frosts of winter, but be ready to show itself with the earliest spring. The climate of Great Britain is deemed peculiarly favorable to wheat, because of its equable temperature and its humidity. The plant grows a longer time, and is longer in maturing itself. The harvest in England and Scotland comes off, ordinarily, a month later than in the United States, where the extreme heat of summer often renders the plant 
prematurely ripe. The wetness of the climate in the former, however, makes the harvest more precarious.

Of manures for wheat, it is ordinarily best that they should be given with the preceding crop. Green, or coarse manures from the stables, applied directly to wheat, are universally deemed objectionable. The effects of lime on the soil may be considered as threefold; first, in dividing a tenacious soil, and rendering it friable; second, in preparing the vegetable matter in the soil for the nutrition of the plant; and, in the third place, some portion of it may be taken up with advantage by the plant itself. The principle of potassium in the soil, in the form of common wood ashes or otherwise, seems always highly beneficial, and almost indispensable. Liquid manure, urine diluted with water, is sometimes applied to the growing crop with great advantage. I have known also the water in which flax has been rotted applied with remarkable success.

The harvesting of wheat should take place rather early than late; that is, while there is a degree of greenness about it, rather than to wait until it becomes perfectly dry, as in such case much will be lost in shelling out. In the former case, it becomes ripe in the shock; and it seems well established that, when cut early, it makes better bread, and more is obtained from the same quantity of flour.

These are the great axioms which I have gathered in respect to the cultivation of wheat on the European continent. The importance of the subject will be a sufficient apology for my pursuing it at this length, though I may have added little to the knowledge which exists in my own country; and though, in many parts of the United States, as I well know, the practice may be already highly improved. When all its various uses are considered, the ease of its cultivation, the srreat amount, under good and liberal culture, of its production, and the few accidents or maladies to which the crop is liable, and more than this, the anount which it returns in manure to the land, I know no plant or crop so valuable as that of Indian corn, (maize, ) in countrics where the climate admits of its ripening; but wheat has the universal preëminence in public estimation; its use in civilized countries is daily becoming more gencral, and is taling the place of all coarser grains; and, in a commercial view, as well as an article of subsistence and luxury, it will continue to occupy the highest place among the cereal grains. 
2. Spelt. - 'There is cultivated in parts of France, and in Flanders, an inferior kind of wheat, called spelt, (in French, ipeautre, ${ }^{*}$ ) which mainly differs from other wheat in that it retains the husk on the grain, until separated by a machine. It is in many places used for bread; and in nutritive matter, as far as clremical examination goes, it bears a proportion to wheat of thirty-nine to fifty. It is said to exhaust the soil much less than wheat, but this point is controverted by high authority. It will yield well on a poor soil, and for this it is often chosen; but it will afford, also, an ample compensation for good treatment. The straw is stifier than that of wheat, and, though harder, is preferred by cattle. It will bear to be cropped once or twice in its early growth for green forage, and is deemed excellent for this purpose. It endures the drought like rye, and will grow well upon lands which are too light and dry for wheat. The difference between the weight of the grain of spelt with its husk on, compared with wheat, is as forty-two to seventy-six; and the ordinary difference in price is as seventy-two to one hundred, allowing for the extra expense in hulling and grinding. Under very good cultivation it is stated to yield about thirty bushels to the acre, with the hull, or in the husk.

of this grain there are two kinds ordinarily cultivated, the red and the white. Some of each kind are bearded, and some without beard; and there is a spring and an autumn variety, although, by careful selection of the earliest ripe, the autumnal is without difficulty converted into the spring variety. It is said, likewise, that under a negligent culture, the beardless will become bearded, and that under a good culture and a rich soil, the bearded will lose its awns. The red variety is preferred, as more hardy, and suffering less from wet or cold, as giving a stronger and more abundant straw, being less subject to disease, and producing a better flour.

The quantity of seed required to an acre is double of that for wheat, because it is sown in the husk. A crop of hemp is sometimes taken from the land; if this is got off early, turnips are then sown, and after the turnips, spelt. If the crop of potatoes are kept clean, spelt is sometimes sown after them; in which case the land is not ploughed, but simply dragged or 
scarified, and the spelt merely harrowed in. If it is deemed necessary to manure the land in such case, the manure is spread on the potato ground, the seed then sown, and both thoroughly harrowed in.

With the husks adhering to the grain, spelt is said to furnish a substantial and excellent provender for horses. The straw being very strong, it is much sought after for the manufacture of hats. It is not a salable grain in the markets, because wheat is generally preferred, and because the millers object to the grinding of it.

I have heard of a crop of ninety-four bushels to the acre, but I lack faith in results so extraordinary. In comparing this with wheat, it is to be remembered that this was measured in the husk.

The proportions of spelt in the straw, without taking any account of the stubble, are given as follows:-

$$
\begin{aligned}
& \text { Grain-clean, . . . . . . . } 4638 \\
& \text { Husks, . . . . . . . . . . 15.05 } \\
& \text { Straw, . . . . . . . . } 3643 \\
& \text { Loss, . . . . . . . . . } 214 \\
& 100 \cdot 00
\end{aligned}
$$

And 100 parts of the grain in the husk give as follows:-

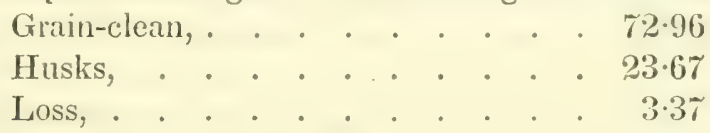

These results can be considered only as approximations to cxactuess, as they must be affected by a varicty of circumstances.

There is a smaller and inferior kind of spelt, which is only cultivated where it is thought too poor even for rye or oats, but which yields very little. The flour of this grain is excellent for some domestic purposes, and it is thought to pay the little care and labor which it receives.

3. RYE. - Rye is very extensively cultivated in Europe - in Great Britain to a small extent; on the Continent, and especially in the northern portions, it forms a principal part of the bread of

\section{* Triticum monococum.}

VOI. II. 
the people. In Germany, in Belgium, in the cold and mountainous districts of France, and in Russia, it is their main dependence. To the Flemish it has been a great source of wealth through their distilleries, not only in the liquor extracted from it, but in the number of swine and cattle supported and fatted in these distilleries, and the abundance of manure in this way produced. There is a debtor side to this amount in the Pandora's box of evils, which such a product always opens upon the cominunity, in the crimes, and misery, and degradation, of which it is the fruitful source; but I shall leave this, as somewhat foreign from my subject, to the sober calculation of my readers.*

The bread from rye is not deemed so nutritious as that from wheat, but it is healthy and good; and a distinguished German maintains that it has a sovereign efficacy for persons whose nervous organization is exhausted or deranged by sedentary pursuits or intense application to study.

Rye succeeds even on a light and dry soil. A clayey, or wet, or calcareous soil is not congenial to it. It grows well even upon a sandy soil, where searcely any other grain will succeed. There is no grain cultivated which yields so large an amount of straw ; and this renders it valuable for litter and for the means of further enriching the soil. The straw is valuable for many other purposes; and particularly for thatching both houses and stacks of grain. In France, vast amounts are used in protecting their wine, when it is transported from one place to another, from the sum, and in covering other merchandise on its way to market. It is said that four crops of rye do not exhaust the soil so much as three of wheat; and, indeed, it has come within my own experi-

* The distilleries in Holland, under the imposts of the government, and the heavy duties upon the introduction of their produce into France, have been almost entirely destroyed.

Each of these distilleries in the course of a year fatted one hundred and eighty head of cattle. The amount of grain consumed at each of them was estimated at 276,765 bushels. These establishments, besides the powerful stimulus which they gave to cultivation, in the market which they afforded for the grain produced, furnished likewise the most abundant supplies of the richest manure.

There was this advantage also arising from them, that in case of scarcity or famine, the immense supplies of grain which they always had on hand, were diverted from the manufucture of gin to the supply of bread for the people. This was giving the loaf instead of the scorpion. 
ence in the United States, that where rye has been cultivated for a considerable term of years successively on the sane land, and early clover has been sown upon it in the spring and plonghed in with the stubble in the autumn at the time of sowing for the next crop, the land, withont any other application, has been in a course of gradual improvement, and the yield of rye continually increased. This is a common practice among the best Flemish farmers, and highly approved.

Of the rye cultivated, there is the winter and the spring rye, which differ from each other only in the time of sowing, excepting that the rye sowed in the autumn is more productive than that sowed in the spring, having a longer time to grow in. The rye, which $\mathrm{I}$ have described in another place as the St. John'sday rye, and which has been receutly introduced into England, is known in France as the multicaulis or many-stalked rye. It is sown in June, and will bear cutting two or three times for green forage, and yet yield a good crop. It has the property of tillering or spreading from the root very abundantly, though it is maintained by some farmers that other kinds of rye, managed in the same way, would show the same properties; and the multicaulis rye sown late in the autumn loses this property. The grain of the multicaulis rye is not so salable in the market as other rye, from its small size.

The general cultivation of rye is so well understood, that I need not enlarge upon it. The best farmers advise not to apply fresh barn-manure to the crop, but prefer that which is decomposed, or that it should follow a crop which has been well manured and cleaned. It does not succeed well on lands subject to fogs, and, therefore, they cultivate little of it directly in the neighborhood of the Rhine. The straw is abundant, but the grain does not fill well.

The principal disease to which rye is subject is the ergot, in which the kernels of the grain become swollen, and form a black, horny substance, well known among medical men as a powertu! agent. This prevails much more in some years than in others; and when care is not taken to separate it from the grain before it is ground, which can be done by careful winnowing or sifting. it is productive of fatal disease, driving often to insanity, and producing mortification in the limbs. The spotted fever, a species of plague which prevailed in parts of New England with 
such a melancholy fatality in 1812 , was attributed to the use of this diseased grain. In 1816 it was fatal in some parts of Germany; and it is said that in one case, where the soldiers in garrison were fed upon bread made from this diseased grain, a tenth part of them died.

The subject of harrowing rye in the spring, so urgently recommended in the cultivation of wheat, is a point contested by intelligent farmers, some strongly recommending, others as strongly opposing, the practice. If the rye is far advanced, it certainly cannot be advisable; but the authority by which the practice is enforced is so high and practical, that I should be strongly disposed to try it, where the condition of the rye admitted of it. The spring rye yields a crop inferior, both in quantity and quality, to that which is sown in the autumn. I have spoken of the multicaulis rye as a valuable forage when sown in June, and cut green. Its earliness in the spring would give it a value in the United States, but later in the season we have a substitute in Indian corn altogether superior.

The ordinary weight of a bushel of rye is from fifty-five to fifty-seven pounds, and the proportion of grain to the straw and chaff is as one hundred to two hundred and ninety-two. These proportions, however, must be obviously affected by the size of the plant, and the height at which it is cut. The culture of rye has seldom had half justice done to it. The color of the product is, I believe, mainly dependent upon the nature of the soil in which it is grown. There is a prejudice against the black bread made in many parts of the country; but the white rye produces a bread scarcely differing in appearance from wheat, and of great sweetness. For feeding animals it is of much value; when cooked, one pound of rye is rated as equal to three pounds of hay; and I have a friend in France, who would be esteemed as one of the best farmers in any country, who keeps a large number of horses, and feeds his horses upon rye-bread, whenever the relative prices of hay and rye render it eligible.

4. BarLex. - Barley is not largely cultivated in France, as wine forms the principal drink of the country. 'The use of beer, however, is said to be extending, and consequently the cultivation of barley.

There are said to be three kinds of barley, in reference to the 
season of sowing; winter barley sown in autumn, spring barley, which is advised to be sown as early as possible on the opening of the spring, and a kind which is sown still later, under the name of summer barley. 'There is also another division into six-rowed barley and two-rowed barley, and these two kinds have their sub-varieties. There is a kind called the celestial barley, to which the husk is strongly attached; but which, when threshed, becomes what is called a naked barley, the husk falling off, and the grain itself being semi-transparent. It is a good bearer, but ripens late; and in general, the naked barleys, though cultivated for soups or for domestic uses, are not much sought after in the markets. There is another kind, called the coffeebarley, which is also a naked barley, the grain of which is stated to be as heavy as that of wheat, but the straw is not strong, and it is liable to be lodged. It is threshed with difficulty, and it is very subject to smut.

The kinds usually cultivated are the common six-rowed and the common two-rowed barley. This latter grain is extremely hardy, and was found cultivated in Lapland, as high as $67^{\circ} 20^{\prime}$ north. The winter barley is said to produce a much heavier crop than the spring-sown; and where the spriug barley is sown, it is advised to get it in as early in March as possible. The quantity of seed employed is one third more than that of wheat. In many rotations it follows wheat; and in such case it is strongly urged to turn under the stubble as soon as the wheat crop is removed. The neglect to do this for any length of time will be greatly to the disadvantage of the succeeding barley crop.

The soil for barley cannot be too rich or too well cultivated; and it should be kept as clean from weeds as possible. No plant is more rapid in its vegetation; and, therefore, if manure is applied to it, it should be in that decomposed state that it may be immediately available for the uses of the plant. This, of course, applies more to spring than to winter-sown barley, which has a longer time to grow in. 'The soil for barley should not be a hard soil, or one apt to be baked by the sun, as the roots of the plant have a tendency to spread themselves, and therefore demand a loose and friable soil. Barley is often taken after potatoes; and, in that case, as soon as the potatoes are removed, the land is turned over with the plough, and in the spring it is again 
lightly ploughed, the barley sown, and covered with a harrow. Clover is sometimes sown at the same time, and a light roller passed over it. For barley sown in the autumn, it is not objectionable that the land should be moist; but when sown in the spring, the land cannot be too warm and dry. If the land is clayey and cold, the barley is not sown so early as in other cases.

The Flemish cultivation of this crop is extremely careful and liberal; and nowhere are better crops to be found. The polders in Flanders are those lands which, by embankments, have been redeemed from the sea, or from the floods of the rivers, and then drained by cross ditches. These lands, being the alluvial deposits of uncounted years or centuries, are extremely rich; and large crops of winter barley are grown upon them. Crops as good, however, according to the testimony of a distinguished farmer, are grown upon lighter lands, where they are carefully cultivated, and liberally manured. The brewers prefer the barley grown upon the light lands to that grown upon the heavier soils; they find the skin of the grain finer, and the grain itself better filled. They prefer, likewise, the winter to the spring barley, because it weighs heavier. It gives, likewise, a larger product.

In the neighborhood of Ghent, where one witnesses the perfection of agriculture, the mode of cultivating this crop is thus in the main detailed by an experienced agriculturist, to whom I have already referred.*

They plough the land twice; they then lay it in beds of about five feet in width; they then go upon the land with a cart of liquid manure, the horse walking in the furrows, and a good deal of the liquid of course falling in the furrows, between the beds; they then level the land with a harrow; they then spread upon the field ten or twelve two-horse loads of rotted manure to the acre, and sow the seed upon the manure; the next step is to clean out the furrows between the beds with a spade, spreading the soil taken out upon the seed, and at the same time covering the manure. The whole field is then trodden by foot, or by a roller drawn by men. The object of this is to retain the hu-

* Van Aelbrocck's Agriculture of Flanders. 
midity in the soil, so that the seed may come up the better. When the seed is two or three inches high, it is then mantred again, with a copions dressing of liquid manure, so that the field is in a condition to bear a crop of potatoes or of turnips the same year. Where the liquid manure is from the privies of the town, it is necessary to dilute it with water. The roots of barley spreading upon the surface, rather than descending deeply, it is not necessary to bury that or the manure deeply, although where barley is sown in the autumu, it is generally advised to plotigh it in with a light furrow. The crops in such cases are very large, averaging more than sixty bushels to the acre. The general cultivation in Flanders is most remarkable for its carefulness, its most abundant labor, and its liberal manuring. I do not know where I should go to find that which is superior to it; and, indeed, it would be difficult to produce its equal. The farmers of the United States wonld be startled at the amount of manual labor bestowed upon their lands by the Flemish. A redundant population gives them the means of doing this with great advantage.

It is well established that barley may succeed wheat, but wheat does not well follow barley. Turnips are often taken after barley, and a crop of rye after the turnips. Beans, likewise, follow with advantage a crop of barley.

5. OAts, - Oats can hardly be said to be largely cultivated in France. They are grown exclusively for the use of horses. This, however, is more in the north than in the sonth. The stimulating and exciting character of oats, as feed for horses, renders them much more useful in a cold than in a warm climate. Oats are supposed generally to be adapted to almost all soils and climates; but, like other products, they repay a careful and liberal cultivation. It is pretended, by some persons, that a crop of oats ameliorates rather than exhausts the soil. This may be the case where oats are grown upon a turfy soil newly turned up; that is to say, it may be the best crop by which to reduce such a soil into a condition for cultivation; but that it otherwise enriches a soil can hardly be believed. It is the opinion, however, of many farmers, that sooner than any other crop, it avails itself of the nutritive parts of the soil, and reduces and extracts manure from ligneous matter contained in the soil, and that it 
will, better than any other crop, bear the application of coarse manure. I give these opinions, as I receive them, from good authority.

There are several varieties cultivated, divided by the French into white and black; by the Flemish, into white, yellow, and black. The white oat is most congenial to a soil which is humid, the black to a dry soil. The black oat, in comparison with the white, is represented as worth an eighth more for use; that is, it is more nutritive in the same weight, and its cultivation less exhausting to the soil.

The Hungarian oat, called sometimes the Tartarian oat, with all its panicles pendent on one side, is here found under two varieties, the white and the black. This species weighs heavier than the white, but not so heavy as the common black oat. It gives more grain and more straw than the common white oat, but it requires rich and strong land.

The potato oat is very little cultivated in France. Indeed, it can only succeed under a far better cultivation than is here bestowed upon the crop. 'The Siberian oat is of early maturity; the grains are yellow and very heavy, but the straw hard and coarse. The growth of this kind is so rapid, that it is said to have been cut when young for a green crop, and afterwards yielded a good grain crop.

There are two kinds of oats cultivated in France, known as winter and spring oats; the former kind being sown in the autumn; but this kind is only safe in parts of the country where the winters are mild, as oats are liable to be destroyed by severe frosts.

The best crops in France, rating thirty-three pounds to a bushel, give about forty-eight bushels to the acre, but a great portion of the crops gives much less; and the average crop is rated at about sixteen bushels per acre, which indicates very negligent cultivation; an eminent French cultivator calls it detestable, but it would not be civil in a stranger to use so harsh a term.

The value of oats, compared with hay, in nutritive matter, is rated at one hundred to one hundred seventy-five. It is strongly advised by the French farmers to use the oats withont threshing, cutting up the grain and the straw together; and by all means, to harvest the oats at so early a season that they may not shell 
out upon the ground; as much is always lost in this way, when they are suffered to become perfectly ripe before cutting. The quantity sown to an acre is four bushels.

'The Flemish farmers obtain very large crops of oats where their land is cultivated with a spade, or otherwise deeply cultivated. With them, the white oat weighs heavier by the bushel, but the yellow oat gives the largest crop, especially on their meadows. They cultivate their oats upon stitches, of a width greater or less according as the soil is wet or dry. They say that oats require not so much manure as barley by one third; but they prefer manure that is well rotted, that the plant may be forced as rapidly as possible. When the plant is a fortuight old, they apply a dressing of liquid manure. Such cultivation is evidently expensive and laborious; but, as in almost all other cases, extra carefulness is compensated by extra product. Sometimes the liquid manuring is repeated, and even more than once. In planting, they are careful not to bury their seed too deeply, two inches being deemed ample.

The great evil to which the crop of oats is subject, is the smut; but for this as yet no preventive has been discovered. The sowing of smutty seed is sure to produce it.

6. Meshin, or Méteil. - The French have a custom of cultivating what they call méteil, but what is called in English meslin; that is, a mixture of wheat and rye. The proportions are not very exactly determined. If the land is more favorable to wheat than rye, more of wheat is sown in the mixture than of rye, and the contrary. It yields a good crop when sown after wheat, when wheat following wheat would not be advisable. This culture is far from being universally approved in France; but some eminent farmers maintain that the crop is more sure than any other; that it is not easily lodged, and that neither the rye nor the wheat is so liable to rust or mildew as when cultivated alone. It sometimes happens, likewise, that the season is not favorable to one of the kinds of grain, when the other yields a crop. It follows potatoes to advantage. It is generally consumed on the farm, in preference to being sent to nuarket; and it makes a wholesome bread.

7. Matze, or Indian Corn. - Indian corn, (Zea mays, here often called Turkey wheat, for what reason I do not know, is 
cultivated to a considerable extent in the south, south-west, and south-east of France, and very much in various parts of Italy. In the richest soils in Italy it presented an extraordinary luxuriance, but nothing could be more slovenly than the cultivation of it, wherever I saw it.

The largest crops, of which I could obtain information, were eighty bushels to an acre; but the ordinary yield was very much less than that, and indeed was quite small. The kinds cultivated were of the small yellow flint variety. The large kinds of gourd-seed corn grown in the Southern States of the United States, or the kinds grown in the Western States, an intermediate kind between the flint and the gourd-seed, would find the climate and soil of Southern Europe favorable, and might be introduced there to great advantage, if, in the present condition of society, the people were capable of any great improvement. They are little accustomed to use it for bread, having no knowledge of the modes of mixing it with rye or wheat; but they use it as a kind of mush or pudding, called polenta. The expense of making it into food among the peasants is strongly objected to, as consuming both fuel and time. It is said that Napoleon used to lament that a laboring man, whether mechanic or peasant, should be accustomed to have a fire in his house for cooking; and the writer who records this fact, sympathizes strongly in this sentiment. That is to say, he would have all their food taken cold, and no time nor money expended in cooking.

I wonder if it never occurred to these men, what an improvement it would have been, if these laboring people, so troublesome and expensive as they are to be fed, and yet so useful and necessary as they are in growing all this bread, conld have been turned out at night like the cattle after their yoke is taken off, to graze in the pasture. This would save bed and bedding, and houserent, as well as food and cooking.

Such sentiments must sound rather harshly upon the ears of American farmers and laborers, who are accustomed, even in the humblest conditions, to sit down daily to a nicely-spread table, covered with a variety and abundance of bread, meat, and vegetables, to which are often added tea, coffee, and beer. 'T'he diet of the laboring poor in Europe is chiefly bread; and this is almost always furnished by a professional baker. During my residence in Europe, I do not recollect a single instance where bread was made in the family. The want of fuel on the Conti- 
nent is a serious necessity. There are no laboring people who live in half the abundance of the laboring people of the United States.

I should extend my remarks much too far if I treated of many of the other smaller crops of the Continent, which indeed present nothing remarkable; and in treating of Flemish husbandry, I shall have occasion to speak of several valuable plants which are cultivated in common by the two countries.

8. Buckineat. - Buckwheat is grown very largely in poor soils in some parts of France, but it seems to be a mere shift to live; and leaves only the regret, that land capable of a much better cultivation should be thus appropriated.

9. Millet. - Millet is cultivated to some extent in parts of France, but almost exclusively for forage, and, in this respect, deserves much more attention than it usually receives. I wish my countrymen were more impressed with the extraordinary value of this plant. I know few plants which make a more abundant return, or which, when it is well cured, give a more nutritious forage, or one more relished by stock. On the intervale lands of the River Loire, where the crops are occasionally destroyed by an inundation, a crop of millet is obtained after the floods have passed off. The crop, under such circumstances, cannot be expected to be large, but it is obtained where no other would be.

10. Clover. - The common large red clover, known in France as the Spanish clover, is cultivated to a considerable extent in parts of France. It has been a long time cultivated in the Netherlands or Low Countries, but was not an established culture in France until about three quarters of a century ago. It is now considered as the foundation of good husbandry. Its foliage is ahundant, and its large roots essentially enrich the lamb. It is sown in the spring, and its seed must not be buried deeply. The mode strongly recommended is to sow it on the wheat in the spring, immediately after the wheat is harrowed; and then to roll the wheat with a light roller.

It comes in, in a regular course of rotation, but it is not allowed to occupy the land more than one or two years; and it 
is advised not to repeat it again under three years. Some English farmers object to its recurring even so often as this. The effect of plaster of Paris or gypsum sown upon it, either when the dew is upon it or the air is humid, is as remarkable as in the United States, though beyond a certain amount it is of no avail. The efficiency or mode of operation of this extraordinary agent seems, as yet, wholly unexplained. The French farmers understand perfectly well the advantages of ploughing-in a clover stubble as a preparation for grain of almost any kind; for lands which are not very rich, it is considered only as an aid, and not as a principal manure.

The small white clover, otherwise called the Dutch clover. constitutes an important element in the rich meadows and pastures of Holland. Clover is cultivated for its seed, in which case, the first crop is taken for forage, and the second for the seed. An eminent farmer speaks of his neighbors having refused to buy his clover-seed because his crop was small and thin ; but; according to his own experiments with this seed, it was preferable to seed from a crop of more luxuriant growth. The probability is, that it was more mature.

Another species of clover, cultivated to a considerable extent, is the trifolium incarnatum, or scarlet clover, of which I have spoken in another place. This appears with a deep red flower; of a conical form and of extraordinary beauty. It endures for one year only. 



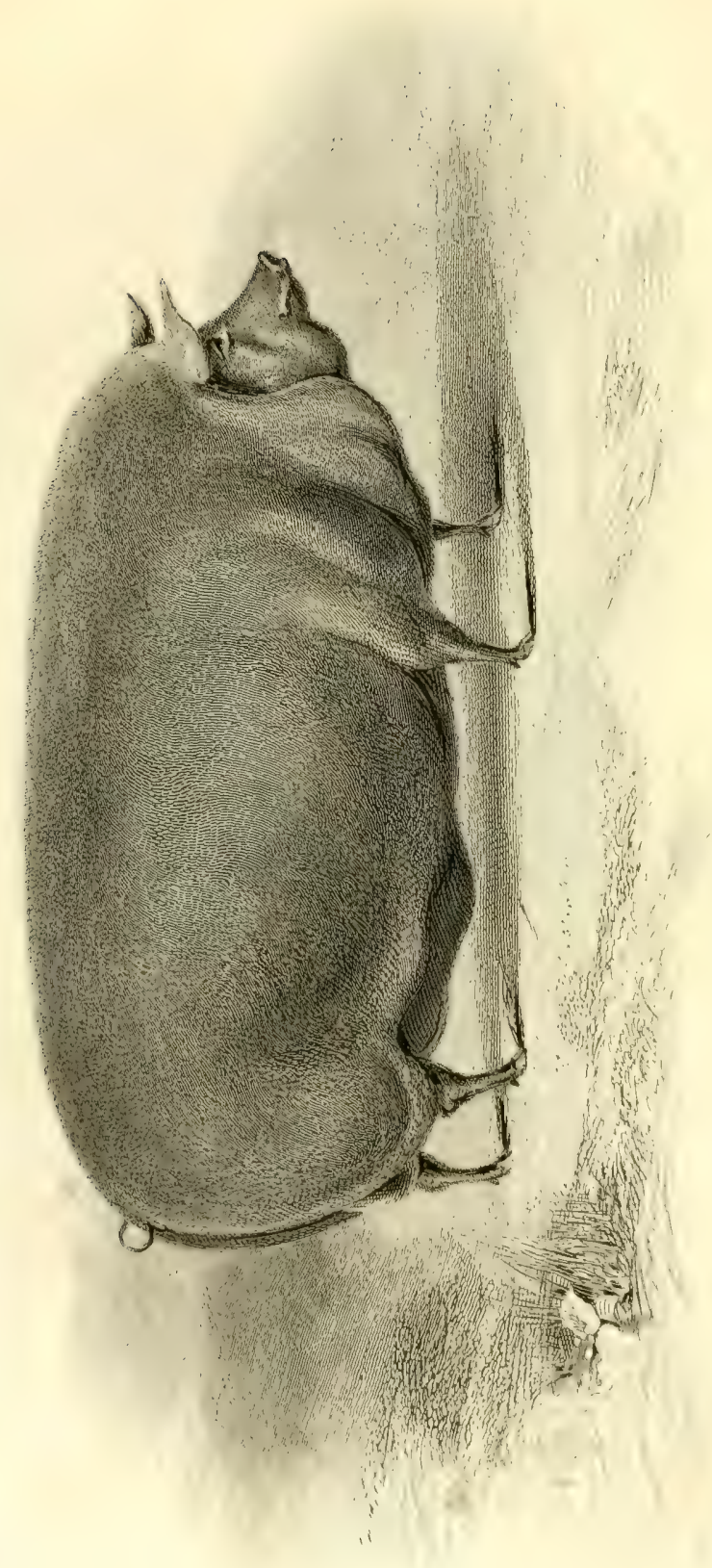




\section{EUROPEAN AGRICULTURE.}

\section{TENTH REPORT.}

\section{CXXVI. - CROPS. (Continued.)}

11. Lucenn. - Lucern is cultivated very extensively in France, and, indeed, may be considered as their great dependence for green fodder. It is a general opinion that no plant will, in this respect, yield a greater return. Indian corn will yield more green food, but a crop of lucern may be got much earlier. Three things are important in the culture of it ; first, that the soil on which it is sown should be rich ; second, that it should be deep, good in the subsoil as in the surface soil; and third, that it should be kept clean from weeds. On my visit to an admirably managed farm, about twenty miles from Paris, where every thing indicated the most exact care and attention, and which might almost be cited as a model farm, the farmer informed me that his lucern, which he cultivated largely, was usually cut three times, and gave him at the rate of fourteen tons to an hectare, made into hay. A French hectare is about two and a half acres, and this would be, therefore, a yield of more than five and a half tons to an acre. A dry season is particularly unfavorable to it. It requires a rich, but suffers from a wet soil.

Lucern is sometimes sown among wheat or barley; but the most certain mode of securing it against weeds, is to plant it in narrow drills, and keep it clean by the hoe for a time, until it becomes well established. About eight pounds of seed - though this is deemed a large allowance - are sown to an acre. It will voL. II. 
bear cutting three times a year, and will endure in the ground eight to ten years. It does not come to perfection the first year ; and the circumstance of its being ordinarily continued in the ground for a term of years forms an objection to its culture, with those who wish to pursue a regular rotation of crops. Gypsum is applied to lucern with the same success as to clover; and the best farmers advise to harrow it in the spring, and, indeed, after each cutting, excepting the last cutting in the autumn.

12. Salnforn. - Sainfoin is the next species of forage most largely cultivated in France. I have already spoken of it, but its value can scarcely be too highly appreciated. It is ordinarily cut only once a year, but in rare cases, twice. It forms a most excellent feed, especially for sheep; and the hay is of the best quality. It will endure for some years. They have had no success in cultivating sainfoin or lucern in Flanders. The prejudice, to which I have referred, that it requires a calcareous soil, is, undoubtedly, not without some foundation.

I come now to speak of the great crops, which may be said to be almost peculiar to France; and if it be proper to estimate the agriculture of a country by the success of its peculiar crops, then the agriculture of France assumes a high rank. I refer in this case particularly to beet sugar, wine, silk, and oil and fruit from olives. These are in France immense products, and of high commercial valıe.

13. Beets. Beets for Sugar. - The history of the introduction of the culture of beets into France for the manufacture of sugar, is well known. The presence of sugar in the beet-root, in an available quantity, was the discovery of a distinguished chemist; and it is among the great obligations under which that science, cultivated so successfully, and with such distinguished talent, has laid the French. The Emperor Napoleon, being cut off by the nations at war with him from those supplies of this article, which the people had been accustomed to receive from their colonies, conceived the plan of their supplying this great necessity from within themselves. It was much ridiculed, but he was not a man to be turned aside from any great project by any minor considerations, where success was possible; his object. to a considerable degree; was accomplished. Since his time, the 
culture and manufacture have been immensely extended, and it bids fair to prove one of the greatest boons that was ever bestowed on agriculture.

There are several kinds of beets cultivated, some of which have been cultivated for a long time. The common red or blood beet, ordinarily grown in gardens for the table, is a well-known vegetable, not, I think, however, so highly appreciated in the United States as in England and on the Continent, where it is much eaten. I have known this cultivated with great success for cattle, adding largely to the product of cows in milk. 'This species, however, is never used for sugar.

The next is a very large kind, growing almost entirely out of the ground, of a pink color and white flesh, known commonly as the scareity beet, or mangel-wurzel, attaining often a large size. and valuable for cattle. There are one or two other kinds, of a yellowish flesh, growing largely out of the ground, and which are considered even more nutritious for stock than the mangelwurzel.

The beet employed for sugar is called the Silesian beet, with a whitish skin and white flesh; but the most valuable kinds have a green neck and yellowish tint on the top. This is full as valuable for the feeding of animals as any of the others, and is decidedly the beet selected for its sugar properties. I have before me the chemical analysis of the properties of the beet-root, but I am unable to derive from them a single practical inference. It may be hoped that chemistry will presently tell us what particular soil is best fitted to its growth, and what manure it peculiarly demands; but this service it has not yet performed. It grows best in a deep, rich, aluminous soil, not a sandy soil, not a calcareous soil, which is unfriendly to it; and it is particularly desirable that the soil should not be liable to suffer by excessive drought, so that vegetation is arrested. It will bear to be well manured, but it is not an extraordinary exhauster of the soil. It returns indeed a large amount of enriching matter to the soil in its abundant leaves.

The land should be well prepared, by being deeply dug $\mathrm{Ol}^{\prime}$ ploughed, and thoroughly manured, and the beets may be either sown, or planted in rows, of about twenty-seven inches apart, and the plants in the row about fourteen inches asunder. $\Lambda$ great advantage comes from growing the plants in a nursery bed, and 
transplanting them. This gives a longer season for the preparation of the land, and the increase of labor in transplanting is compensated by the increased facility of keeping the cultivation clean. The largest crop of which $I$ have obtained any information, was about forty-nine tons to an acre, and this was a case in which they had been transplanted. The ordinary crop does not exceed, and in many cases it falls short of, twenty-nine tons. The amount of seed required for.an acre is not large, and every single seed produces four plants. A large proportion of the beetroot is water, and it is generally estimated that twenty pounds of hay are equal to one hundred pounds of crude beet. In transplanting, it is recommended, instead of doubling it up, to break off the lower end of the tap-root, and to plant it with a picker or a dibble.

In the culture of the beet, many persons have been in the habit of plucking the lower leaves for their stock, maintaining that the growth of the plant was not injured by this abrasion. Experiments fully establish the contrary. An experiment made in Belgium shows, that where beets, from which the leaves were not plucked, produced nine hundred and twenty-five baskets of roots, an equal part of the field, having been plucked once, produced eight hundred and thirty-nine; and another portion, which had been twice plucked in a season, produced only five hundred and thirty-nine. The form in which this experiment is stated is not exact, as a basket itself is an uncertain measure, and the degree to which the plucking extended is not stated, but it seems decisive. The leaves, at the harvesting of the crop, furnish a large amount of forage. If left on the ground, they are reputed highly beneficial as manure, still more so if consumed by animals; and cases are reported in which they have been closely packed away, where the air was effectually excluded, and have yielded a valuable forage for the winter.

That, exclusive of their sugar properties, they constitute a valuable green fodder for cows in milk, and fatting cattle, strongly recommends them to cultivation. They have this great advantage over turnips, that they give no disagreeable taste to the milk; and that when, in the spring, turnips have become corky, and potatoes sprout abundantly, and seem to lose in a great degree their nutritious properties, the beet preserves its freshness, even into June. 
It is not within my province to go into the subject of the manufacture of sugar, farther than as it is connected with agriculture. The greatest profits are realized where an individual unites in himself the character of cultivator and manufacturer. 'The pulp that remains, after the sugar is expressed, is employed in the fatting of cattle and sheep. An eminent farmer, whose cultivation was of the finest description, and who manulactured a large amount of sugar, informed me, that he estimated his pulp, for the feeding of cattle and sheep, as constituting seven-twentieths of the whole value of the crop. It was in June, in that most beantiful agricultural country, French Flanders, when I visited him; and he was then using, and had large reservoirs of, the pulp from the manufacture of the preceding autumn. This he kept sweet and good in large vats, covered with sods and earth so as completely to exclude the air, and guard against a change of temperature. In this case, the beets were not rasped, but cut into small and thin slices by a machine, and then exposed to a hydrostatic pressure. Nothing could be finer than the samples of sugar which he showed me; and I admired, with great pleasure, the high condition of his sheep and cattle fed upon the pulp. He informed me that he obtained six per cent. of sugar from his beets. The chemists say that the beet contains twelve per cent. of saccharine matter, but the amount obtained does not ordinarily exceed five per cent. Whether this proceeds from the imperfection of the manufacture, further inquiries may determine. In general, the farmers are not manufacturers, but sell their crude product to the large manufacturers in their vicinity. In such case, they usually make arrangements to receive back a portion of the expressed pulp. If otherwise, it would clearly be an exhausting process. It is mentioned, that the pulp constitutes a third of the weight of the crop. One hundred pounds of raw sugar give seventy-five pounds of refined sugar, thongh it is stated that, by a recent discovered process, the sugar is bleached without being refined.

The gentleman to whom I have referred above, states that the manufacture of beet-sugar is at present a highly lucrative operation. At first, when the ports were closed to foreign sugars, prices were such, that, even with imperfect modes of manufacture, the business yielded a large profit. Afterwards, when the sugar of the French West India colonies came into competition 
with it in the open market, the colonists found the competition too severe, and thinking themselves on the verge of min, they cried to the government for help and protection. The colonies of Fxance were regarded as so important to its commerce and its navy, that the government laid a heavy impost upon domestic sugar. I believe governments never intermeddle directly in the control of human industry without doing somebody a harm; and excepting where allowed in some qualified cases as the rewards of inventive genius or skill, or as a security to the beneficial uses of capital, which otherwise could not be brought into use, monopolies of every kind combine all the elements of injustice. The effect of this impost was at once to ruin a large portion of the manufacturers of domestic sugar, and arrest the progress of a cultivation destined to exert the most beneficial influence upon the general interests of agriculture. The fixtures and establishments in different parts of the country fell into other hands, at a ruinous sacrifice to their original proprietors. The West India proprietors became more clamorous, for avarice was never yet satisfied with any concession, and the impost was still more increased. The elasticity of skill and genius have defied the pressure. Improved modes of manufacture have been discovered, by which more sugar is obtained from the same amount of the raw material, and obtained at a cheaper rate; and in spite of the heavy imposts, the manufacture is highly profitable, especially to those persons who bought already made to their hands the old manufacturing establishments.

In 1842, the production of beet sugar in France reached the enormous amount of $67,717,685 \mathrm{lbs}$. It had in some years, as it must evidently vary with the seasons, been even more than this; and there is no reason to suppose that it has decreased. In some parts of the country I have seen several factories of recent erection. When the value of the leaves and the pulp for the fatting of animals is added to this actual creation of wealth out of the earth; when the wages received by the innumerable persons employed in the culture of the plant, and the fabrication and refinement of the sugar, are also taken into view; when the admirable preparation which this culture makes for the succeeding crops; when its beneficial influences upon the commerce of the country are considered; and when, especially, the whole is regarded as the product of healthy, well-requited, and free 
labor, and without even the smallest expense or hazard to human life or comfort, - it is impossible to exaggerate the value of this great and increasing product.

A highly-distinguished agriculturist in France, perhaps as competent as any man to speak on this subject, has recently given to the public a statement in regard to it, which must attract particular attention. I shall give his statement nearly in his own words. An hectare (abont two and a half acres) produces in the Isle of Bourbon about 76,000 kilograms (a kilogram is about two pounds and a fifth of a pound) of cane, which will give 2200 kilograms of sugar, and which costs in labor 2500 francs. An hectare of beet-root produces 40,000 kilograms of roots, which will produce 2400 kilograms of sugar, and the expense of the culture of which costs 354 francs. The cost of the cane-sugar in this case is twenty-seven centimes, and of the beet-sugar fourteen centimes only, per kilogram.* These are extraordinary statements, and will be looked at by the political economist and the philanthropist with great interest. There are few of the northern states of Europe, or of the United States, which might not produce their own sugar; and when we take into account the value of this product, even in its remains after the sugar is extracted, for the fatting of cattle and sheep, and of course for the enrichment of the land for succeding crops, its important bearing upon agricultural improvement cannot be exaggerated.

The production of beet-sugar is not by any means confined to France. Large amounts are produced in Belgium, where I found most extensive manufactories, and in several parts of Germany; but in none of these countries is industry in any form unrestricted; and a man hardly dares to be successful in any enterprise, at least to proclaim his success, lest the government, by some impost or taxation, should endeavor to avail itself

* "According to M. Peligot, the average amount of sugar in beets is twelve per cent.; but by extraction they obtain only about five per cent. 'Whe cane contains about eighteen per cent. of saccharine matter, but they get only about seven and a half. The expense of cultivating an hectare of bects, according to Dombasle, is 354 francs. An hectare of cane, which produces 2200 kilograms of sugar in the Isle of Bourbon, and only 2000 in French Guiana, demands the labor of twelve negroes, the annual expense of each of whom is 250 franes according to M. Labran." — Commission of Inquiry in 1810. 
of his success for its own advantages. It is thus that every where industry is checked and hampered, and enterprise scarcely rises from the ground, but is seen fluttering along upon one wing.

14. SiLk. - Silk is another large product in France, giving an humble but honest living to thousands and hundreds of thousands. Its production is greatly on the increase; and the last year it nearly doubled itself.

I know nothing so remarkable, in all its pecuniary and useful results, as the product of this humble insect, the silkworm, whose whole term of being is limited to five weeks. Nothing is to be compared with it in the perfection and beauty of the fabrications of which it supplies the material and basis. What man, woman, or child's dress, in any civilized community, is not in some measure indebted to the labors of this humble insect? and its bearing in a commercial view is an immense affair. In its pecuniary results, with the exception of the article of bread, few things come in competition with it.

It is not merely the value of the product as it comes from the insect which gives it importance, but the extraordinary amount of industry and commerce which its humble labors set in motion. In France, as in other old and populous countries, every branch of industry is divided and minutely subdivided. There is in the first place the grower of the mulberry-trees; who does not always connect with this pursuit the production of silk; but the leaves of his trees are sold in the market as any other forage would be. To him succeeds the grower, or, as he is commonly called, the educator of the silk-worms, who hatches, feeds, and manages the worms until their task is completed, and the cocoons are ready for the market. He is succeeded by the filator, or winder, of the silk from the cocoons, who prepares the crude or raw silk for the manufacturer. Here another and numerous class of operatives is set in motion - the spinner, the weaver, the dyer, the pattern-former, the machinist, and the master manufacturer, from whose hands it proceeds next into the hands of the wholesale dealer, and thence into the hands of the retail dealer, to say nothing of the various forms which it afterwards assumes under the agency of modistes, dress-makers, furniture-makers, hat-makers, and the almost countless operations 
and transformations which it has to pass throngh in the various objects of art of which it constitutes a part. Indeed, it would be difficult to name any single article which plays a more important part in an industrial, economical, and commercial view.

The earliest production of silk is attributed to the Chinese, but the particular date of its origin is lost in the obscurity of remote history. There are many other worms which, in the curious transformations through which they pass, involve themselves, preparatory to their emerging into a new form of being, in a cocoon formed of the finest tissue. But it is the silk-worm, or, as it is sometimes called, the mulberry-worm, alone which furnishes a material of sufficient firmness to be converted into cloth.

The production of silk in France is now carricd to a great extent. Four years ago it was estimated at 1,200,000 kilograms, or about 2,640,000 pounds of raw silk per annum. The last year it was reported to have doubled itself, but, if this should be an exaggerated statement, the production may yet be set down as having vastly increased; and, in a peaceful condition of the country, is likely still more to extend itself. It affords the means of living to many persons, who must otherwise be without resource. In many parts of this culture, the hands of children avail as much as those of men and women, and thus the industry of whole families is set in motion.

The silk-culture has generally been considered as limited to a hot climate, and some have maintained that it belonged exclusively to countries in which the vine could be successfully cultivated. The silk made in temperate climates, and even in the mountainous parts of hot countries, where the temperature is moderate, is esteemed better than that produced in very hot countries. It is difficult to prescribe the exact limits of this production. The mulberry will grow in very high latitudes; but in such cases, it is liable to be killed by the severe frosts of winter, and it is indispensable that the season should be long enough, atter the first defoliation, for the mulberry-tree to renew and perfect its leaves. The worms require a mild and temperate climate; for though they have been grown or reared in rooms where the temperature is, properly speaking, artificial, yet the expense and trouble attending such arrangements are a serious 
abatement of the profits, added to the difficulties of managing such a temperature, and the risks to the lives and health of the worms. It is important to make every effort to keep down the expenses of the culture.

The mulberry may be considered as the only proper food of the silk-worm. Various substitutes have been proposed by the Chinese and others, but wholly without success. 'The worms may be induced to eat, and may be kept alive upon other substances, but they will make no silk. The Chinese have moistened the leaves, and sprinkled them with powdered rice, chicory, and peas, and with the powder of the dried mulberry leaves, so that the worms, in getting at the leaves, were compelled to eat of the powder, but it has been without advantage.

The mulberry is not a tree of difficult cultivation; but, like most other things, it makes a full compensation for particular care and attention. It will grow upon a poor, but it will flourish only on a good soil, inclined to sand, and not humid or heavy. It is advised to train these trees with an open head, that the foliage may be accessible to light and air, and not to feed from them until they are full three years old. The leaves must not be taken from them more than once in a year, and it is desirable to forward the first defoliation, so that the second growth of leaves may become quite matured. Mulberry-trees are set out as ornamental trees by the sides of roads, and in the neighborhood of houses; or, where the business is pursied on an extensive scale, they are planted in rows at a few yards' distance, as is customary with our apple orchards. In many parts of Italy, in Lombardy and Tuscany, the vines are trained to hang in graceful festoons from one tree to another; and when the rich clusters of grapes are seen among the green foliage, it would be difficult to find any thing of the kind more beantiful. An hectare of arable or meadow land, in France, may be valued at 2000 to 5000 franes, or say, 400 to 1000 dollars; an hectare of mulberry-trees in the same locality would, in such case, be valued at 5000 to 12,000 francs, or from 1000 to 2400 dollars. It is calculated that an hectare (about two and a half acres) of mulberrytrees, in full bearing, will produce sufficient foliage to supply the wants of the worms produced by ten ounces of eggs. This would give a product of about 22,000 pounds of leaves.

The mulberry may be propagated by sowing the seed, by 
engrafting, or by layers; the two latter modes are of course the only certain modes of securing the best kinds. The principal kinds propagated in France are four; but they differ somewhat in their product, as the experiments of one of the first cultivators of silk in France, with whom $I$ have the pleasure of an acquaintance, seem to show. What appears to be wanted in a mulberry leaf (excepting for the worms in their first age) is a leaf of a good deal of thickness and weight. The four principal mulberry-trees cultivated in France are, -

Le mûrier rose, or the rose-leaved mulberry.

Le mûrier multicaule, or the multicaulis, well known in the United States.

Le mûrier Moretti, a mulberry, which takes its name from a physician who first produced it.

Le mûrier sauvageon, or wild mulberry, which is our common white mulberry.

The multicaulis is condemned in France in the strongest manner. It is of very easy cultivation; it yields a great deal of foliage; it produces a fair quantity of silk; but it is considered too watery, and to create disease among the worms. One of the most eminent silk culturists in France denonnced it to me in no measured terms. The rose mulberry, is upon the whole, pronounced superior to all others. Its leaves have too much thickness and strength for the worms in their first age; but in such case it is necessary to select the youngest and most tender leaves, and to moisten them with water. The leaves of the common wild mulberry are complained of, as fading rapidly after being gathered, and becoming too soon unfit for use. The time for hatching the worms should correspond as nearly as possible with the condition of the leaves, taking care that the leaves should be considerably advanced, as the consumption of them in too young a state is necessarily wasteful. Experiments have been made to test the comparative value of the different mulberry leaves in the production of silk - I refer to its quality and quantity; but though conducted with much care, they do not appear to lead to any important practical results.

The difference in the worms deserves attention, some producing a large, and others a smaller, cocoon; and some giving, consequently, a larger return in silk than others. This difference is considerable, some producing from a certain weight of cocoons 
ten or twelve per cent., and others eighteen per cent. of silk. The great division of races is, into those which produce a white, and those which produce a yellow, cocoon. It is said that different races of the worm are suited to different climates, either hot or temperate; and the results are always more or less afiected by the mode of feeding and the care bestowed upon them.

The principal of the white races of worms is called the Sina, and this species produces a very fine and beautiful silk. This species was imported from China almost a century since; and its excellence has been maintained, and indeed it is represented to be much improved by care and selection. 'The silk of this species of worm is employed for making the very finest of the white silk fabrics. Ten to twelve pounds of the cocoons produce one pound of silk. 'The cocoons are cylindrical, round at the ends, with a depression or cincture round the middle.

The principal of the yellow races is the 'Turin. 'This is known in Italy by several different names. The form of the cocoon is cylindrical, with a deep indenture or cincture round the middle; the ends are round, and the color is a beatiful yellow. They are esteemed as among the best cocoons known, and furnish a very strong silk.

The Cora is another celebrated race, which is reported to have been the result of a cross between two of the most beautiful and rich of the yellow races, the 'Turin and the Loudun. 'This species yields a large return of silk in proportion to the woight of the cocoons; the cocoons are much sought after, and sell at a higher price than any of the common kinds. As my limits allow me only to refer to the best kinds, I shall not enumerate others, of which there are several sorts, more or less esteemed in different localities.

The ordinary life of a silk-worm embraces five ages, or four important changes. There is a species called the three-change worms; but this peculiarity is considered as the result of a diseased constitution, and the product is comparatively worthless. The worms, by extraordinary feeding, may be forced to finish their feeding in some cases in eighteen days; but this at the expense of a great deal of trouble, and generally at the risk of disease. Their feeding is in some cases extended to fifty days; but this is always owing to scanty and illiberal feeding, and the product is sure to be inferior. The period most to be desired, in 
which to complete their feeding, is twenty-eight or thirty days. This is supposed to depend somewhat upon the peculiar constitution of the race of worms which are fed, but more upon the feeding and management. It is earnestly pressed upon the cultivators to commence the hatching of the eggs as early in the season as the condition of the mulberry leaves will allow it to be done with a certainty of a supply of food. The hatching of the eggs should be artificially forced, in order, as far as possible, to be contemporaneous, as where it is left to take place naturally, there will be a difference in the time of hatching among the worms of several days, which is an inconvenience to be anxiously avoided. It is recommended in the first three ages to cut the leaves fine, and for the very young worms in the first stage, they should be sifted. In order to success, the worms must not be neglected by day or night. In the first age they require twelve feedings in the twenty-four hours; in the fourth age, eight or ten; in the fifth age, seven or eight. The feedings should, in fact, be multiplied as much as possible; as where, with a view of saving time or labor, the food of three or four times is given at once, the worms become disgusted and lose their appetite, a great deal of forage is lost, and bad results are likely to follow. As overfeeding is injurious, so is fasting equally injurious. In order to insure suceess, no neglect must be tolerated. Cleanliness in every department is especially important. The worms must not be crowded. They must likewise be occasionally assorted, placing together those whose progress and condition are most nearly alike; and especially removing at once the feeble and diseased. The best preparation for their mounting, when their cocoon is to be formed, may be termed a small twig broom, inverted and placed so that the upper part may be spread between the shelves on which the worms are fed. The cocoons, after they are completed, reserving those only which are designed for the continuance of the race, are placed, for the destruction of the chrysalis in steam, as being the most certain and eflectual mode. The cocoons, being completed, and the poor tenant of this silken ahode strangled in his own habitation, now pass into other hands for the winding of the silk.

In many parts of Europe, among those who cultivate the silk-worm upon a small scale, some vacant room in the house is occupied for the worms, and very often some vacant barn or VOL. II. 
building is used for this purpose at a season of the year when it is not occupied for other purposes. Where silk is cultivated on an extensive scale, a building is erected for the special purpose of raising the worms, called a magnanerie. The size of this building is of course to be proportioned to the quantity of worms to be raised; and the quantity of worms to be raised must be proportioned to the amount of food to be obtained. Great losses are sometimes incurred by a miscalculation in respect either to the forage or the worms. It is of great moment not to err on the side of too little provision for the feed of the worms, who in their last age consume with almost incredible voracity. Few things are more prejudicial to success than a deficiency of food, or subjecting the worms to fasting.

The magnanerie must, in the first place, supply ample room for the worms; they must not be crowded. It requires a separate room for the hatching of the worms and their feeding during the first age. It must be furnished with sufficient means for heating the apartments in which they are kept. It must have the means of complete ventilation, without bringing draughts of cold air directly upon them. It must be capable of being closed or opened at pleasure, in order to regulate the temperature, which is of great moment. It must be light also, and be capable of being lighted in the evening; for they like the light, and if success is looked for, they are not to be neglected either by day or night.

It has been supposed that the silk-worms are injuriously affected by noise; but this is now deemed an error, as no organs of hearing have been discovered. They are injuriously affected by noxious odors, and this must be guarded against. They are likewise much affected by changes of temperature, and especially by a close and confined atmosphere. The former may, to a certain extent, be regulated by artificial means, and the latter by ventilation. The tables on which the worms are placed, may be made" of canvass on an endless roller, and the worms, being induced by fresh leaves to rise upon a netting made of twine set in a frame, may be lifted up, and by turning the canvass, the litter may be easily removed, and the worms replaced. The legs of the tables on which the worms are fed, should be set in water, so as to prevent the access of ants, which are destructive to them; and every pains must be taken to keep off birds, rats, and mice, which have no hesitation in destroying these industrious creatures. 
There are several serious diseases to which the worms are subject, and some of a fatal character. They are supposed in general to owe their origin to neglect, to insufficient or irregular feeding, to want of ventilation, to neglect of cleanliness, or to too much crowding. The disease called the muscardine is of all others the most dreaded, as it is contagious and generally fatal. The causes of it have not yet been ascertained, and no effectual remedy has been discovered. If it is not caused by neglect, yet the only hope of preventing it is by the most attentive and exemplary care. Where it has once prevailed, it is liable to reappear; and in such places it is advised, as the only certain preventive, to suspend for a time the raising of the worms. It shows itself at all ages of the worms. A large premium has been offered by the Agricultural Society of France for the discovery of an effectual remedy or preventive; but as yet without success. The worms are often injuriousiy affected by thunderstorms or a highly electrical atmosphere; but no human skill affords any protection against this.

Many experiments have been made to get two crops of worms and silk in a scason; but by the most experienced feeders such attempts are entirely disapproved. I shall not attempt any calculation of expenses or profits, these must so vary in different places from the difference in the cost of labor and of land. First, it may be said of the silk culture, that the principal labor which it requires occurs at a season when other agricultural operations are not of a pressing character, and the season is one of comparative leisure. In the next place, the farm buildings, which may be occupied, where the climate admits of it, as a magnanerie, are likely to be vacant, preparatory to recciving the crops. Next, the trees being once planted and matured, and the magnanerie established, they require but little care to preserve them in condition, and a large portion of the expense is incurred. In the last place, the work is of a character to give healthful, useful, and interesting employment to the younger and female parts of the family, whose expenses are sure to go on, but whose labor, for want of some such occupation, might otherwise be lost. The article, when produced, is imperishable, and at present may be considered as sure of a market.

I have only noted the outlines of the subject. I must not go more into detail; but the whole process is simple and intelligi- 
ble, and the details are easily attainable. There is no extraordinary ingenuity in the apparatus or machines connected either with the management of the worms or the unwinding of the cocoons; but I found with Mr. Robinet, of Paris, who has distinguished himself by his attention to this subject, a small and ingenious machine for testing the strength of the raw silk. There was a graduated index at the back of the machine; a strong pressure was made on two threads of the silk suspended from the top of the index, and the degree of pressure or tension required to break the thread indicated of course its actual strength.

I can hardly quit this subject without calling upon my readers to admire with me the wonderful products of this humble animal. The pecuniary value of the product is enormous; its utility is unquestioned and universal; the amount of industry which it sets in motion is immense; and the splendor and beauty of the fabrications, of which it forms the materiel, are unsurpassed.

15. The Vine. - The next great agricultural product of France is that of the vine. The whole extent of land cultivated in vines in France by the last returns was 4,929,950 acres; and there is reason to believe that this amount has been considerably increased since those returns were obtained. The total value of the vine crop in France, reckoning seven gallons of wine as required to supply one gallon of brandy, is estimated at 59,059,150 francs, or, in round numbers, 11,811,830 dollars, or $£ 2,362,366$ sterling. It is supposed that six tenths of the wine produced are consumed in France; the remainder forms the subject of a lucrative commerce.

In a moral view, one would at first be inclined to dread the effects of such a production upon the habits of the people. It would not be true to say there is no drunkenness in France; but, account for it as we will, temperance is preëminently the characteristic of the French people, and I believe them to be without question the most sober of all civilized countries. In the rural districts, wine is the ordinary drink; but this is not in itself a strong wine, and is almost invariably diluted with water. Nuch complaint has been made that snch immense tracts of land are deroted to the production of wine instead of bread; but, in many of the bread-gruwing countries, a far larger proportion in value of the 
product has been devoted to the manufacture of a drink far more intoxicating, and much more fatal to peace, public order, domestic happiness, and all good morals, than the mild and ordinary wines of France; which, when unadulterated, are the pure juice of the grape, and have not the strength of common cider. I was in the vine-growing countries in the season of the vintage, when wine in the greatest abundance was free to all, but there was 110 more excess than at any other season. We could hardly expect these laborious people, whose chief solid subsistence is bread, to limit themselves to water; and I could not but feel grateful that God had given them so innocent and delicious a beverage to cheer and sustain them under their toil. It is not the use but the abuse of these gifts of Heaven, which constitutes the criminality, and converts them into a fatal poison.

Various attempts have been made in different periods to limit the cultivation of the vine. In one case, after a severe scarcity, one of the Roman monarchs ordered the whole of the vines in certain provinces to be destroyed, and more than half the vines in other provinces; and several kings of France have prohibited the occupation of land beyond a certain amount in the culture of the vine, that the people might be compelled to the cultivation of bread. Such interference on the part of governments in private concerns, and such arbitrary measures, seldom effect the desired end. The culture of the bread-grains is, munestionably, always of the first importance; but arrangements of this kind are generally much better left to private interest than to public control. The principal objection to the culture of the vine is, that it is in no respect subsidiary to any other crop; that it occupies the land permanently, without permitting any other crop; and that the vines require much manuring, (though they do not always get it,) without furnishing the materials for producing any minure. Some persons have ploughed or dug in the cuttings and wastc parts of the vine, and it is said with extraordinary success; but the practice is not much extended.

The vines are ordinarily raised from cuttings in a nursery, and transplanted at one year old, generally in rows about four feet asunder each way; but farther when it is intended to plough between them. Generally the land is dug with a spade; the old wood cut away in the spring, and the new trimmed, leaving three buds only. They are then staked, and trained to these 
stakes, which are from four to five feet in height. At the harvest they are gathered with great adroitness, the clusters being cut with a knife or scissors, and carried to the pressing-house in casks or carts. The whole process, afterwards, resembles precisely the manufacture of cider, excepting that I saw no straw used in laying up what is called the cheese, the stems of the vines supplying the place of straw, in giving compactness to the heap; and that there is no breaking or crushing of the grapes, as of the apples, before they are put under the press. The juice, as it comes from the grape, is always white; but it is colored by leaving the stems and skins of the grapes in the vat with the liquor twenty-four hours after it is expressed. The after-management of the wine, where it is kept pure, consists in straining: and different drawings off and bottling, very much like the management of the best cider; above all things, watching over the casks to preserve them from must or any offensive substance.

'The different kinds of wine take their names from the different countries or vineyards in which they are produced. I cannot persuade myself that the grape itself has not much to do with the quality of the wine; but the constant reply to my inquiries was, that the character of the wine depended mainly upon the particular locality in which it was grown, upon some peculiarity in the aspect, or some unknown quality of the soil. I have no doubt the particular quality of the grape has its full share, and other circumstances besides those which I have enumerated. The adulteration of wines, their mixture, and their fabrication out of materials wholly foreign from the grape, are carried on: undoubtedly, to a great extent, especially in the cities; as, indeed, in what country are not such adulterations more or less prevalent, as the condition of the market may render them profitable?

In France the appearance of a vineyard presents nothing very picturesque, though in the season of harvest it is extremely rich. as I have travelled for niniles and miles through vineyards loaded with this delicious fruit. The fields in France are very rarely separated by fences or ditches; but many facts have come to my knowledge, and some within my own personal observation, which convineed me that nowhere are the rights of property more scrupulously respected. In Italy, especially in the fertile plains of Lombardy, the vines are trained from tree to tree, sometimes 
aovering a whole tree with their thick and umbrageous foliage; and the purple clusters of the fruit, hanging over the tree in the richest abundance, remind one of some of the earliest temptations to which our frail race are said to have been subjected.

In passing up the Rhine, after entering upon the highlands, the base of which the waves of this magnificent river have swept for so many ages, one is absolutely struck with amazement at the examples of industry, labor, and enterprise which every where present themselves, in the cultivation of the vine, wherever a favorable aspect presents itself. The steepest acclivities are walled up in successive steps or zigzag lines, from the bottom to the top of very high hills, so as to create or obtain some little flat surface for the planting of the vines, and to prevent the washing of the dirt from their roots. Where there is no soil, soil has been transported on the shoulders of men and women in baskets, for no horse or mule could possibly ascend many of these heights; and where there has been no other method of securing the soil and the vine, these baskets full of soil have been placed, and there remain, that the plant may have a footing. The manure, too, to supply these vines, must be carried up, and the produce must all be brought down upon human shoulders. The labor performed here seems almost incredible. The German wines bear a high price, and these situations produce those of the best quality. The celebrated Johannisberg wine is grown upon the banks of the Rhine, at a magnificent place owned by the distinguished Prince Metternich, and is said to be a source of great profit. The delighted traveller has the opportunity of at least feasting his eyes on this beautiful vineyard, and this rich and picturesque country.

A vineyard, if well cared for, will last an indefinite number of years. The worst wines grown in France are represented to be the most profitable, as they pay either none, or the lightest duties, and being sold at a cheap rate; they never want consumers.

16. Olives. - The cultivation of the olive-tree, both for comfits or pickles, and for the oil obtained from the fruit, is considerably extended in France, and still more in Southern Italy. The extent of land appropriated to the growth of the 
olive in France is stated to be about 303,000 acres. The culture is limited to the southern portions of France, as the tree does not endure any considerable degree of cold. The money value of the product in France is estimated at 22,776,398 francs, or 4,555,279 dollars, for sale; and the value of that which is consumed is reckoned at $23,102,841$ francs, or 4,620,568 dollars, or $£ 924,113$ sterling. This is a great product for a permanent article. The oil-cakes left after the expression of the oil are considered as very valuable for cattle, and their valne defrays some portion of the expense of expressing the oil.

The olive groves or orchards in Southern Italy are very extensive. Looking out from the high grounds in the neighborhood of Florence upon the enchanting valley of the Arno, it appears like an almost uninterrupted grove of olives as far as the eye can reach. It is difficult to conceive of a richer, more beautiful, or more picturesque landscape than is here spread before the eye; combining a chamingly varied surface, with cities crowning the summits, and white palaces glittering among the richest foliage. the river winding its gentle and silver stream through the whole length of the valley, amidst forests and fields of the deepest and most luxuriant vegetation.

The olive-trees are of long endurance. Some orchards were shown me to which tradition ascribes an age of eight humdred years; the condition, however, either from age or neglect, was not flourishing. More than a hundred different kinds of olivetrees are mentioned in France, differing in the quality of their product, and in their adaptation to different soils and temperature. New varieties are occasionally produced by sowing the seed in nurseries. The trees are planted in squares in the fields, at the distance of five or six yards apart, more or less, according as the soil is dry or humid, nearer to each other in the former case than in the latter. The trees should be well manured either with stable manure or compost; it is advised to dig round the trees every spring and autumn. The field should be cultivated, taking care to guard against injury to the roots, with the plough: and, if grain is sown, that portion of the plant near the roots of the trees should be dug in while green, and before the grain is formed.

The great enemies of the olive-trees are the cold, and certain insects. The severe cold in 1820 and 1836 destroyed a great many trees in France. Many insects infest the trees, which 
sometimes prove destructive, against which remedies are preseribed like those employed against the insects which infest the apple-trees. How far it might be successful to introduce the cultivation of the olive-tree into the Southern States of the United States, I must, after the above account, leave the partics interested to judge.

The fig was growing freely in Italy in the open air, and by the road-side. This was in the month of August.

\section{CXXVII.-GENERAL VIEWS OF FRENCII AGRICULTURE.}

I have now gone over the principal crops produced in France, with the exception of some which will come under review in treating of the husbandry of Flanders, where these crops are grown with more skill and success than in France.

I think my readers will have reached a conclusion to which I early arrived, which is, that the agriculture or husbandry of France is a subject of much greater importance, and conducted with much more skill than is generally thought. There are several subjects comnected with it upon which I shall speak hereafter. In many parts, I may add in large parts of the country, the cultivation is inferior, negligent, and extremely discreditable. France, however, is not the only comtry to which these remarks apply; but it must be said of France, that in some of their principal crops, those to which their climate is adapted, to which they have been habituated, and which they have found to yield the largest profit, no persons have advanced further than they. I instance only the production of beet-sugar, which must be taken in connection with the residue or refuse of the manufacture, furnishing so rich and useful an aliment for cattle and sheep. This production is enormous, and constantly increasing; next, the production of silk, which furnishes so valnable and simple a resource for the poor, and which, followed out in its various ramifications, will be found to set so many thousands, nay, hundreds of thousands, of industrious hands in motion; and lastly, its production of wine, so important an article of domestic consumption, and so large an article of commerce. I am not of 
opinion that perfection has been reached in either of these articles of culture, - for to what that is human does that term perfection, in any but the most qualified sense, apply? - but certainly the culture of these articles is pursued with the most exemplary diligence and enterprise; I may add, with as much diligence and enterprise as are applied in any cultivation in any country, and with success.

\section{CXXVIII. - FARM NEAR VERSAILLES.}

I shall hereafter recur to the subject of the agriculture of France; but I may in this place say, that $\mathrm{I}$ have met examples of farming in France, which for excellence of culture and arrangement, and the success of the farming, are nowhere within my knowledge exceeded. A farm in the neighborhood of Versailles, with the intelligent proprietor of which I had the pleastre of an intimate acquaintance, in its excellent management may be considered as a model farm. It consists of about seven hundred acres. The husbandry is of a mixed kind; a large milking stock is kept on the farm, which, though not reared on the farm, are very carefully selected; and kept and fed in well-arranged and capacious stables, where the best arrangements by gutters and cisterns are made for collecting and saving all the liquid as well as all the solid manure. Abundant crops of lucern are grown both for green feeding and hay, and likewise of sainfoin. Good crops of wheat are likewise raised, and of colza. Carrots are cultivated extensively for the stock; and potatoes especially for the manufacture of starch. This manufacture, very simple in its character, constitutes a large object of attention; and what with the potatoes grown upon the place, and those which are purchased, more than one hundred thousand bushels are used in this manufacture in the course of the year. The refuse water or liquor from this fabrication is first collected in tanks or open reservoirs, where it makes a considerable deposit from the matter still floating in it. 'I'he liquid portions are conveyed by small channels or canals on to the grass-fields, which are thus irrigated, and the solid portions are taken out and spread. The effect of this manure is extremely beneficial, and it scarcely differs in strength from the best animal or stable manure. 


\section{CXXIX.-FARMI ACCOUNTS.}

At no place have I seen a more complete system of farm accounts than at this farm. The books are kept with the greatest accuracy; so that the result is seen at once, and any specific loss or gain is traced to its proper source. Through the kind:sess of the owner, I was enabled to procure a form of these accounts. I subjoin it, thinking I can give few things of the kind more valuable to my readers. The great and almost universal fault of farmers is, that through ignorance or neglect they can hardly be said to keep any accounts; sometimes merely a few memoranda in an interleaved almanac, or a few chalks behind the door; or if they keep books, they are often confused, are seldom balanced, and the farmer never arrives at a result upon which he can rely. Often, under these circumstances, he finds hinself gradually declining into hopeless bankruptcy, without being able to ascertain the most active and certain causes. The ship is filling, but he cannot detect the leak, nor consequently the means of stopping it. He may call all hands to work day and night at the pumps, but with little hope of saving the vessel until the fatal inlet is discovered; and that may prove too late.

Under the system adopted by this excellent farmer, an account is kept with every crop, with the stable, the cow-house, the sheep-fold, the poultry-yard, the laborers, and the farm-house. Each is regularly charged with every item on the debit side, and credited with every return which it makes. The whole is then brought into a general résumé; an account of stock is taken; and the books balanced once a year with the accuracy of a banker's clerk.

Take, for example, his Winter In other columns are ar-
Wheat: it is charged with

Ploughing, harrowing, and rolling.

Manures.

Seed.

Reaping, and binding, and stacking.

Threshing, measuring, and storing.

Transporting and marketing.

Rent of land.

Total of expenses.

Expense per acre.
The extent of the land in wheat.

Product in grain and in straw.

Product by the acre.

Value of the grain and of the straw.

Total value of the product.

Value per acre.

Profit of the cultivation, or

Loss. 
The account of each crop is kept in this form in a book ruled in separate columns for this purpose. The history of the crop, such as the time of sowing and of reaping, is given at the bottom of the page; and the average yield of the crop for the ten preceding years.

The account of the Stable is kept in this form:-

\section{Expenses.}

Feeding of the horses.

Utensils and furniture for the stables.

Equipages - Harnesses, saddlery.

Carriages.

Farriery.

Wagoners and ostlers - Wages and expenses on the road.

Board of wagoners and ostlers.

Extraordinary expenses.
Credits to the Stable.

Labors upon the Farm - ploughing, \&c.

"Upon the road.

Manure.

Profit or loss.

The expenses of the Sheep-fold are kept as follows: The account opens with the 1st of July, and finishes with the 30th of June.

Account is taken of the num- A second column gives the ber of

Flocks.

Sheep.

Lambs.

Rams. account of purchases; and another of sales, during the year.

A fourth column gives the number of flocks, sheep, lambs, and rams, at the end of the year.

The next chapter embraces the several items of expense, such as -

Cost of feed.

Medicines or drugs.

Driving and folding.

Hurdles, troughs, \&c.

Transporting and expenses of marketing.

Shepherds - their wages. " " board.

Straw for litter

Total of expenses.
Other columns give the estimated value of the flock at the beginning and close of the year.

Returns from the sale of sheep.

$$
\text { " " " } " \text { " the value of manure. }
$$

Profit or loss. 
The account of the Cow or Milk establishment is kept in the same form; the various items, as follow:-

Keeping of the cows.

Cost of cows.

Care of them.

Utensils.

Expense of the sale of milk.

Litter for the stables.
Number of cows, and their value at the beginning of the year.

Expense of cows purchased.

Number of calves.

Returns from milk or butter sold.

$$
\text { " " calves. }
$$

Value of manure.

The Poultry-yard, embracing also the Pigs, is brought under a similar supervision, and the accounts of the whole year, in expenses and returns, are carefully preserved and adjusted.

The account of manures is likewise kept: - thus,
Manures purchased.
Loading and unloading.
Compost heaps.
Transportation of manure.
Spreading.
Folding.
Straw for litter.
Oil-cakes purchased.

The general expenses of the Farm are then brought into the account : -

Overseers and their travelling expenses.

Bookkeeper, stationery, and postage.

Wages and clothing for the servants.

Journeyings, hunting, dogs.

Time of horse for service of the family.

Insurance against fire and hail.

Taxes.

Utensils and furniture.
Wood and cutting fuel.

Measuring ground.

Mole and rat catcher.

Workmen, by the day or task.

Expense of wagons and farriery.

Saddlery and harness.

Bedding and linen.

Painter, glazier, carpenter, blacksmith. ironmonger.

The specific expenses of the household are next brought into account :

Kitchen expenses.

Cellar.

Eatables.

Groceries.

Butcher.

Baker.

Wood and charcoal.

Household and kitchen furniture.

Beer.

Products of the farm consumed, such as milk and cream, eggs, poultry, mutton, pork, potatoes, fruits and vegetables, butter, and cheese.

Presents to servants.

New Year's and Christmas gifts.

Care and medicine in sickness.

\section{Miscellaneous expenses follow:-}

For the poor, charitable gifts.

Education of poor children.
Meat, bread, wood, medicine, boarding, clothing, fruits and vegetables.

VOL. II. 


\section{Expenses :-}

Civic charges at the mayory.

To the police officers, or country

For a public engine and carriage to watch.

I have thus given the items of accounts kept on this excellently managed estate, not so much to recommend the precise form in which they are kept, as to show their particularity and exactness. The great value of this extreme precision is, that the owner is at once enabled to discover what are the particular sources or occasions of expense, and to determine, if it should be necessary or expedient, what he may at once retrench or forego. The keeping of such accounts requires time and care, and, perhaps, in this case, they may be too much extended. But a careful and orderly arrangement, together with punctuality and exactness, so that the work may never get into confusion or arrears, will overcome much of the difficulty. The satisfaction and advantages arising from it, will be a full compensation for the labor and expense which it may require. I cannot understand why on a large farm a bookkeeper should not be kept as much as in any shop or other trading concern.

I only add, that I have the results of the accounts of this farm from 1816 to 1846 - thirty years ; that the receipts vary considerably, as products and prices vary; but that, in not more than three years in the thirty, was there any loss, and in the other cases a fair and reasonable gain.

\section{CXXX. - $A$ GRICULTURE OF BELGIUM AND HOLLAND.}

I pass now to the agriculture of Belgium or Flanders. My remarks will embrace the whole of the Low Countries, Holland as well as Flanders. 'Though they differ in many particulars, yet they may be considered together. I entered these beautiful countries, beantiful in the eye of an agriculturist from the richness of their crops, and the perfection of their cultivation, in the month of June; and I confess my expectations, excited as they were, were more than answered. 


\section{CXXXI. - 'THE SOIL.}

1 great portion of these countries may be considered as alluvial; much of it formed from the recession of the sea and the elevation of the land; much by the gradual encroachments of the land upon the sea, as where, by the meeting of the tides with the streams of some of the great rivers, which here, by various chanuels, find their passage into the sea, a sand bank is formed, and presently, by successive deposits of mud brought down by the streams, an island or outstretching point is produced, which is gradually raised above the level of the tides; and, lastly, by the actual embankment by dikes of immense tracts, which still remain many feet below the level of the sea, and which form extensive basins or enclosures of almost monsurpassed fertility.

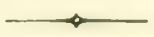

\section{CXXXII - THE DIKES AND POLDERS.}

The extent and magnitude of these embankments is matter of inexpressible surprise; and one is compelled to ask, where and who are the men of such unconquerable and gigantic enterprise as to raise these extraordinary mounds; thus to defy the ocean; and thus to effect conquests, than which none more brave, illustrious, or beneficent, are recorded in history, and compared with which, military conquests seem to deserve only the execration of mankind?

The external dikes are from one hundred and twenty-five to one hundred and fifty feet in width at the bottom, with spacious roads on the top of them; and in several cases the water requires to be lifted twice before it is thrown into the sea. 'These immense tracts of land, which have been thus redeemed from the sea, are denominated polders. 'These polders are said to average more than eleven hundred acres each; and that four hundred and thirty-six polders, embracing an extent of 175,000 acres, are kept dry by eight hundred and fifteen mills. The water to be 
removed is of course the fresh water from rain, or the water from springs, and some, doubtless, from the infiltration of the sea. The work of one mill is required to keep six hundred acres suffciently free from water. The whole amount of this poldered or redeemed land in IIolland is represented to exceed five millions of acres - an amount to be redeemed from the sea scarcely within the limits of credibility. But the original erection of these dikes is not the whole amount of labor which they demand-a demand which knows no interruption nor cessation. It is said, upon competent authority, that had the original dike at Walcheren been made of solid copper, it would have cost less than it has cost in its formation and repairs.

I present here a sketch of the polder of Snaerskerke, given by Radcliffe from the government survey. This polder contains

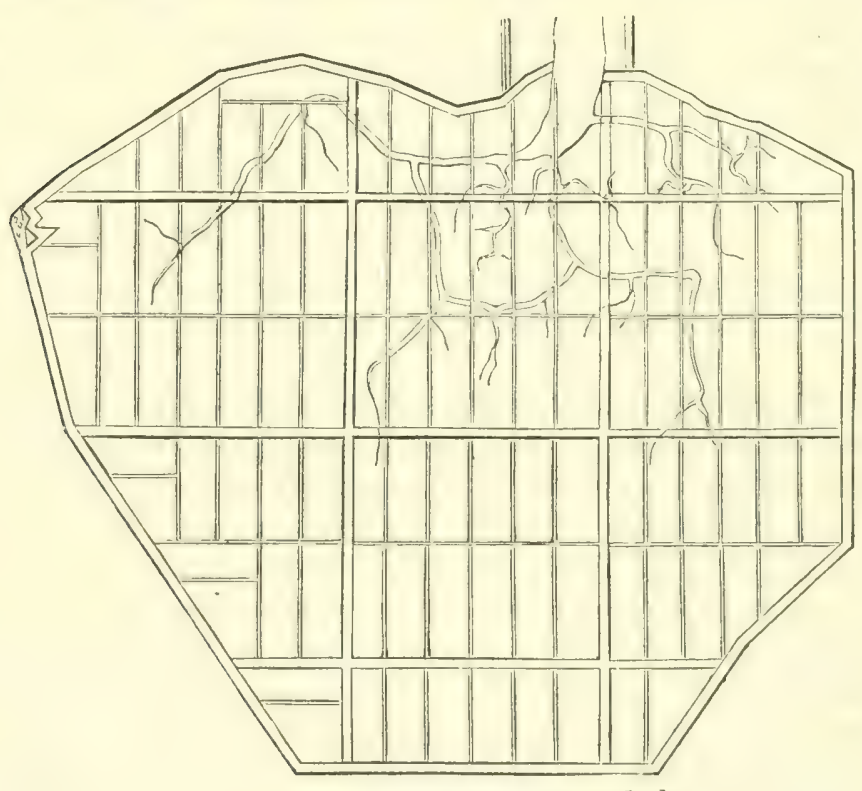

Sketch of the Polder of Snaerskerke.

about thirteen hundred acres, and was drained by order of Napolcon. "The creek, with its minor branches, by which the tide overspread nearly the entire surface, is traced, to point out its original state; but that has now given way to the regular divisions and arrangements marked by the parallel lines, which 
describe the present circumstances and appearance. The facility of this improvement is so obvious, that it is only surprising it should have remained so long unexecuted; the banks of more ancient polders, which nearly surrounded this, huving rendered it unnecessary to do more than to shut out the sea at one point of influx, about fourteen hundred and fifty feet in extent." Let us look next at the pecuniary result of this improvement. "The land which has been reclaimed by it was let for a sheep-pasture, at twenty-five pounds sterling, or abont one hundred and twentyfive dollars, and was thrown up by the farmer as untenable. Upon being dried by this summary improvement, the lots, of which there are one hundred, of thirteen acres each, were sold by auction at an average of $£ 29113 \mathrm{~s}$. $4 \mathrm{~d}$. each, or about 1458 dollars, and would now bring nearly double that sum." **

A great work of this same kind is now going on, which is no other than to drain the Harlaem Lake, and lay the bottom dry for cultivation. This great work has been some time in progress by means of powerful steam-engines, and when completed will lay dry about 50,000 acres. $\dagger$ 'The extent proposed to be drained is said to be seventy square miles. Another tract which has been laid bare contains 18,000 acres. It is impossible to contemplate these mighty and beneficent achievements but with the most profound admiration. But if an immense labor and expense have been devoted to their creation, a corresponding vigilance, a vigilance most laborions, indefatigable, and unceasing, is reguired to maintain them. The inhabitants of this great country sleep always in the immediate neighborhood of an enemy's camp, and are exposed to irruptions and invasions, against which all human power may be unavailing. The recollection of the floods, which have occasionally broken away these barriers, and swept the country, is perfectly terrific. In the course of thirteen centuries no less than one hundred and ninety great floods are said to have occurred in Holland; so that a destructive inundation may be

* Radeliffe's Flanders.

f It is stated, that in order to exhaust the lake, 3000 millions of tons of water must be raised; and in order to keep it dry, 54,000,000 of tons must be raised annually; and sometimes $20,000,000$ of this in one or two months. What a gigantic project!

$\ddagger$ From 516 to 1825 . 
said to have occurred as often as once in seven years, and the years so late as 1808 and 1825 were marked by great floods. In $1230,100,000$ persons are reported to have perished, with cattle innumerable. In 1410, 20,000 persons were drowned; and in 1570 an equal number. In 1717 , the flood is reported to have destroyed 12,000 men, 6000 houses, and 80,000 cattle. The sea has been known, in some cases, to have risen eight feet above the dikes. These events are certainly among the most tremendous in history, and evince the extraordinary courage and perseverance of a people, who again repel the merciless invader, and bravely plant themselves directly upon the recovered field.

\section{CXXXIII. - THE WATER MACHINERY OR MILLS.}

These countries have to exercise a double guard; the first against the irruption of the ocean, and the second against the overflowing of the great rivers, which, fed by streams from mountains covered with eternal snows, here divide into many branches on their way to the ocean; and likewise from the rain which falls, and has no way of escape but as it is pumped up and turned off into the rivers or the sea. In some cases, six, eight, and ten feet of water have been removed; it is stated "that in one case, a depth of more than thirteen feet required to be removed on land more than eight feet below the high water of the river into which it was necessary it should be discharged. It was raised into a reservoir, and let into the river at low water. The water required to be raised by successive lifts twenty-two feet - not an uncommon lift in Holland." The machines by which this water is raised are windmills, made with extraordinary care and expense, and presenting to the unaccustomed eye a peculiar but not umpleasing appearance. I counted more than two hundred in sight at one time, and was told that more than four hundred might be seen. These are variously constructed, some of them with a spiral screw working in a box to which the screw was exactly fitted, and by which large amounts of water were forced up without any heavy pressure upon the machinery. 
In other cases, the water was lifted with a simple paddle-wheel working in a common trough. It is stated that one mill will free six hundred acres from water; but it is obvious that this must depend upon various circumstances, snch as the quantity of water to be removed, and the kind of machinery employed. The most constant vigilance is required to take advantage of all the wind that blows. To give some idea of the expense of these operations, a mill is said to cost from 8000 to 14,000 dollars, or from $£ 1600$ to $£ 2 S 00$ sterling, and its operation costs 300 dollars or $\mathfrak{E} 60$ sterling a year. Many of the persons who have the care of these mills live in them with their families.

These are all windmills. Steam-engines wonld probably be as little expensive, and more under command. Most of these mills were erected before the use of steam in this way was known; but a reason given for preferring wind to steam is, that, as Holland has no coal, in the event of war she might be without fuel, and consequently unable to work steam-engines, the disastrous consequences of which it is not necessary to dwell upon.

Such are the mighty works, as well indeed they may be called so, which arrest the admiration of the visitor to this reclaimed and fertile region, so marked by the most extraordinary enterprise. 'They inspire a profound sentiment of the hardihood and euterprise, the courage and indefatigable perseverance, of the people who undertook, achieved, and have maintained them.

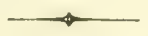

CXXXIV.-FLEMISH AGRICULTURE.

The agriculture of Flanders is chiefly arable. 'To give a detailed account of its various crops and their culture, would be to compose a large work; and I shall therefore limit myself to nnticing those peculiarities in their practice by which their cultiration is distinguished, with such remarks upon particular crops as seem interesting and useful. Flanders itself is to some extent a redeemed country; and the Flemish have also their polders and embankments, canals and dikes. 
I begin by saying that the agriculture of Flanders is superior to that of any country which $\mathbf{I}$ have visited. I do not say that in England, Scotland, France, and Switzerland, I have not seen single farms as well cultivated as any I have seen in Flanders; certainly in the Lothians in Scotland, in Northumberland, in Norfolk, in Lincolnshire, in Bedfordshire, in Berkshire, in Cambridgeshire, in Staffordshire, and in other places, I could single out particular farms and considerable districts where the cultivation is carried to a high degree of perfection and productiveness; but taking into view the large portion of Flanders which I have visited, for neatness, exactness, and thoroughness of cultivation, for the evenness and magnificence of the crops, for the propriety and exactness of the rotation, for the economy and excellent modes of applying their manures, and for the obvious and distinguished improvements made in the soils, this country seems unsurpassed. It is not a little humiliating that this has been done by a people comparatively without education, with no pretensions whatever to what is called agricultural science, and with few implements, and those far from being the most improved. To say, however, that they are without education and agricultural science, is a great misnomer. They have the surest of all science, that which grows out of long experience, and which comes from the application of the mind, sharpened by necessity, to whatever is passing within its own province, and avails itself of all the lessons which that experience suggests. I am far from thinking that with them the ultimatum of improvement has been reached. I should regret to find any where, in any science or art, the door of inquiry closed; but at present they may congratulate themselves with having reached a degree of improvement which many other countries, with superior advantages in other respects, have not as yet approached. Though their implements have been imperfect, there is yet an obvious reason why they have been effectual. The great agricultural instrument in Flanders is a spade. We are contriving all kinds of implements which shall lessen human labor. We want all sorts of machines which shall, if possible, do the work of or by themselves. We want that they should be impelled by wind or by steam, or by brute force; and we would be glad, as far as possible, to dispense with the necessity of personal superintendence. The Flemish farmers reluct at no personal superintendence or 
toil; and eren an inferior implement, with a thinking and directing mind at the end of it, may be more efficient than many a more complicated or better contrived machine, which is expected almost to make its own way.

\section{CXXXV. - THE SOIL; AND SIZE OF FARMS.}

The soils of Flanders are generally inferior' but they illustrate the Latin proverb, that persevering labor overcomes all difficulties. In many instances, the farmers plant themselves upon an almost hopeless blowing sand, which would seem to defy all vegetation. They will begin by planting oats, or ryc, and broom; the oats or rye are used for forage, and so are the tops of the broom, which remains in the ground three years; and is then plonghed in to form and enrich the soil; and when by degrees they can advance so far as to grow turnips or clover, so as to feed a cow, the way of success is open. In such case, all manure, solid and liquid of every kind, is saved with care, and the whole redoubles itself; and after a time is witnessed the conversion of this arid sand into a productive soil.

The size of farms in Flanders is small, in many cases not exceeding fifty acres; often less than this, and not more than six or seven acres. The amount produced, upon even the smallest holdings, is remarkable, and presents an advantageons, and often an instructive contrast with the product of large farms.

CXXXVI. - THE CULTIVATION OF THE SOIL, 'TRENCIFING, PIOUGHING, MIANURING.

1. The first chanateristic of Flemish husbandry is their deep cultivation. In some cases this is done by the spade, in others by the plough, and sometimes conjointly by the plough and spade. The land is gratually trenched to the depth of twenty 
inches or more. 'The land for' grain being laid out in stitches, six or seven feet wide, in the intervals a deep trench or ditch is dug, say of a foot in width. The next year, in cultivating this same land, a foot in width will be taken from the side of this stitch and thrown into the ditch or open space, widening, of course, the next bed to the extent to which it is cut off from the other; filling up the trench of the preceding year, and forming a new trench. This is repeated year after year, until, according to the width of the stitch or bed, the whole ground is gone over to the depth of a double spading. At the same time, as the successive crops have followed each other, the ground has been carefully inproved by manure, until a fine rich and mellow bed of soil is formed. 'This operation resembles subsoiling, with this diflerence, that the work is more thoroughly and carefully done with a spade than it can ever be with a plough. A deep soil, where properly enriched, is obviously most favorable to vegetation. The air itself is a great enricher of the ground; water, another great element of fertility, passes through a well-cultivated soil, leaving its fertilizing influenees, without becoming stagnant, and so injuring the soil. All plants do not equally require deepness of soil, yet even the plants which appear most superficial often extend the fine tendrils of their roots in search of food much farther than the eye can follow, or than is generally supposed. A French farmer states that he has found the roots from a plant of wheat extending five feet. All tap-rooted plants, such as elover or carrots, frequent crops in Flanders, of course demand a deep culture.

The first object, then, of the Flemish farmer, is to get a deep and friable soil, well enriched, and, as far as possible, equally enriched throughout. This is done with great painstaking, and the whole resembles the most beautiful garden cultivation. Liven where it is ploughed, the trenches at the sides of the field, and between the beds, are cleaned out by a spade; what is taken out is laid carefully upon the beds; and the whole executed with a neatnesss and exactness the most particular, and perfectly delightfinl to the eye.

2. Subsoiurg. - 'They have a peculiar mode of working their land in many cases, of which their best farmers think very highly, and which is well deserving of notice. Immediately 
after the plough has opened the furrow, workmen follow with a spade, and take out from the bottom of the furrow large spadefuls of earth, laying them up upon the turned land. IIere they remain in lumps until they are reduced to fineness by the warmth and air, and spread themselves upon the soil. They have an opinion that this is equal to a good manuring. The next furrow slice of course falls into these holes, and to some extent there is a complete inversion of the surface-soil. This does not answer, however, where the land is clayey, or strong and adhesive, as, in that case, water would collect and remain in the holes made under the furrow with the spade. The object of the Flemish farmer is to have the gromd thoroughly enriched and friable; and to give, as far as possible, a quick passage for the water which falls upon it, and free admission to the air.

3. Draning. - Nothing can surpass the painstaking of the Flemish farmer in the preparation of his soil, as the basis of all his efforts, and that on which he rests his hopes of success. I have already said, that with a view to get rid of surface water, he carefully lays his ground in stitches or beds, narrow or wide, in proportion to the quantity of water, which, from the situation of the land, nay require to be disposed of. If the land is made wet by springs, he takes pains to cut off the springs by transverse ditches. These he fills with brush, or wooden boughs, and upon these he lays stones, and then covers with earth, and thus conveys the water into an open side ditch. 'This is a primitive mode of draining, and not the best which could be chosen; but after the wood has decayed, the channel being once formed, it is likely to be kept open for a length of time, by the force of the rumning water. If the wetness of the land proceeds from its low and sunken position, or from springs which cannot be cut off, it becomes necessary then to cut it up by open ditches, which are made at distances varying according to the nature of the land to be drained, and into which the water becomes collected. 'This takes up a considerable portion of the surface, but the compensation is found by the dryness and availableness of the other portions, by which method only these could be secured. This is the universal practice upon the polders, and these principal ditches are often of sufficient width to proceed unon in boats, in 
order to take off the produce to the outer edge of the polder, where it can be removed in carts.

4. Mixing tur Sorl. - If the soil upon which he proposes to operate be composed, as often happens, of different strata of earth, as, for example, of mould, next of a layer of clay, and next of sand, he is careful, by a deep trenching, thoroughly to stir, and by degrees to intermix and enrich the whole. In truth, every effort is made to produce a deep, friable, rich bed for their operations; and by such means soils, which appear at first almost worthless, are made productive. Many soils, which in their original condition were sterile and comparatively worthless, now take rank with the most fertile.

5. Rotation of Crops. - Another great feature of Flemish husbandry is that of a regular rotation of crops. This is exact, and observed with strictness.

What this rotation shall be, must depend on a variety of circumstances. An intelligent farmer will be likely to inquire first; to what crop is the soil best adapted, because of this he is likely to get the largest product; what crop is most required for his own use or for the market; what crop is likely least to exhaust the soil; what crop is he best able to manure; in short, a great variety of inquiries growing out of the nature and particular condition of the soil, which will determine the course of crops to be adopted by the farmer, having in view that which he can obtain with the largest profit, the least expense, and the smallest injury to the land. What are called green crops, with the exception of potatoes, which enter largely into human food, such as carrots and turnips, are grown mainly with a view to the manure, which they furnish by the animals fed upon them. The farm is divided into several portions, and on these different portions distinct rotations are proceeding regularly, the aim of the farmer being to have a variety of crops growing at the same time. In this way he provides best for the supply of his family; having a variety of articles to dispose of, he rums less risk in the fluctuations and caprices of the markets; and he is enabled the better to husband and apply his manures.

I shall here give some examples of these rotations of crops, not as furnishing a rule for other places, which may differ very 
much in various circumstances, but simply as illustrating the practice of these careful husbandmen.

On a soil of a good quality, and on which wheat may be cultivated, the following rotation is sometimes observed:-

1. Potatoes.

2. Wheat, with turnips sowed upon the stubble after the harvest.

3. Oats and clover.

4. Clover.

5. Rye, with turnips sowed upon the stubble after the harvest.

6. In grass, to remain as long as it is profitable.

The farm, in a case like this, will be divided into as many portions as there are distinct crops, so that all will be growing on the same farm at the same time.

The following rotation is sometimes had :-
1. Wheat.
5. Clover.
2. Rye and turnips.
6. Rape.
3. Oats.
7. Potatoes.
4. Flax.

On a very strong soil the following rotation is given:-

1. Potatoes, 2. Wheat, 3. Beans, 4. Rye, 5. Wheat, 6. Clover, 7. Turnips, 8. Flax, 9. Wheat, 10. Oats, 11. Fallow, 12. Tobacco, 13. Rye, 14. Oats.

The following rotation is adopted upon a stiff soil :-

1. Potatoes, with twenty tons of dung per acre.

2. Wheat, with three and a half tons, and fifty barrels of urine.

3. Flax, with twelve tons of dung, fifty barrels of urine, and five cwt. rape cake.

4. Clover, with twenty barrels of wood ashes.

5. Rye, with eight tous of dung, and fifty barrels of urine.

6. Oats, with fifty barrels of urine.

7. Buckwheat, without manure.

On a rich loam the following rotation is pursued:-

1. Turnips, carrots, chicory.

2. Oats and clover seed.

vol. II. 
3. Clover.

4. Wheat. Wheat occurs in this rotation four times in

5. Flax.

6. Wheat.

7. Beans.

8. Wheat. fourth, seventh, and ninth years. The cul-

9. Potatoes. tivation is most careful, and no weeds are

10. Wheat.

11. Oats. eleven years. Clover, which occurs twice, is to be considered as the only euriching crop.

I have given these different rotations from Van Aelbroeck's account of Femish husbandry.

It may not be easy to point out in every instance the principles on which these rotations are founded. With the Flemish farmers they are the result of long experience and observation. Perhaps they might often be changed to advantage. I have known, for example, in some parts of the United States, flax cultivated to great advantage every fourth year; and in some parts of England, wheat grown every second year. But in each case the land was highly manured, and in the former case the land was comparatively a new and unexhansted soil. My object in going into this subject was not to prescribe a particular course, but to illustrate a great principle of Flemish husbandry, which will be fonnd equally applicable to every situation. The necessity of a rotation of crops seems fully established. The kind of rotation to be followed must be determined by the peculiar circumstances of each locality, remembering only that two crops of a similar character must not immediately succeed each other; that the occasional intervention of a cleansing crop - that is, a crop which requires thorough weeding - is indispensable; and that those crops which are to be consumed on the farm serve a donble purpose: in addition to the animals which they sustain, they supply the manure which is demanded. The necessity of naked fallows - that is, of leaving the land wholly unoccupied with any crop, that it might recruit itself, and the weeds be exterminated by repeated ploughings - is no longer acknowledged; and cleansing crops, which are manured, may be substituted, greatly to the farmer's advantage.

6. Manuring. - The next great feature in the Flemish husbandry lies in their system of manuring. In the first place, they manure their land abundantly. In one of the rotations to which 
I have referred, (p. 517,) the first six crops were each of them liberally manured. The seventh, which was buckwheat, and completed the course, was without manure. In the next rotation, (p. 517,) where the rotation extended to eleven crops, five of them were manured. That the manuring was of a liberal character, is seen in the application of sometimes twenty tons of manure to the acre, and sometimes twelve tons, with the addition of fifty barrels of urine. Indeed, the first object of a Flemish farmer is to increase his stock of manure; to this end he suffers nothing which can be converted into manure to be lost or wasted; and besides that which he makes from his savings and his domestic animals, he is always ready to purchase manure, where it can be found accessible - the various canals in the country furnishing great facilities for its conveyance. Perhaps there is only one point in which he is often deficient, and that is, in not raising sufficient green food for the support of cattle, with a view to increasing his manure.

7. Liquid Manure. - It is not merely in manuring liberally that Flemish husbandry is remarkable, but in the particular mode of applying this manure. The great object of the Flemish farmer is to apply it in a condition to be immediately taken up by the plants. Coarse and long manure he ploughs under in the autumn, that it may be in a condition to serve the crop which is to be sown in the spring. Or, if to be applied in the spring, he so works it over and prepares it, that it is in a condition at once to serve the plant. But the distinguishing circumstanice in Flemish husbandry is in the application of liquid manure, both to the lane? before the sowing, and likewise to the growing crop. In such case the growing crop immediately receives it; receives it at a time when, perhaps, the manure first applied has begun to lose somewhat of its efficacy; and in a form that its efficacy is felt at once.

The difficulty of applying this liquid manure to the crops on the land is often considered an objection to its use ; and there is, with many persons, a fastidiousness in regard to the use of it, which is quite absurd, and leads to the sacrifice of the most valnable and efficacious manure which is at the command of the husbandman. In some cases it is turned into the small ditches or furrows between the beds or stitches, and then with a spade thrown on to the beds with some of the soil by which it has been absorbed. In this case a light plough is sometimes passed? 
through these intervals or small ditches, between the beds, so as to loosen the earth by which the liquid has been absorbed. But

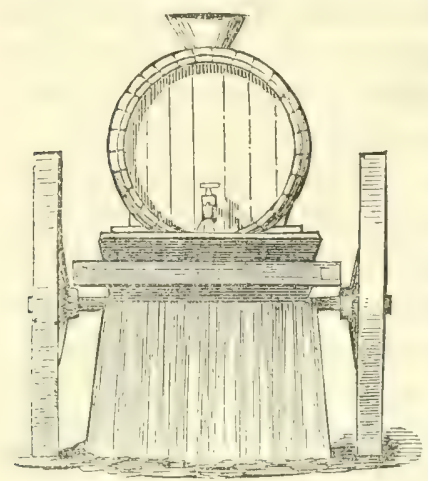

most commonly it is applied directly, by means of a cask constructed for that purpose, resembling the vehicles used for watering the streets of cities.

In the subjoined diagram the liquid from the cask falls into a trough placed horizontally, and pierced with holes, by which means it is very equally distributed.

In other cases, where the liquid is too thick to be distributed through these holes; it is, in passing out, made to strike against a plank or board, by which means it is scattered evenly upon the ground. Thus:-

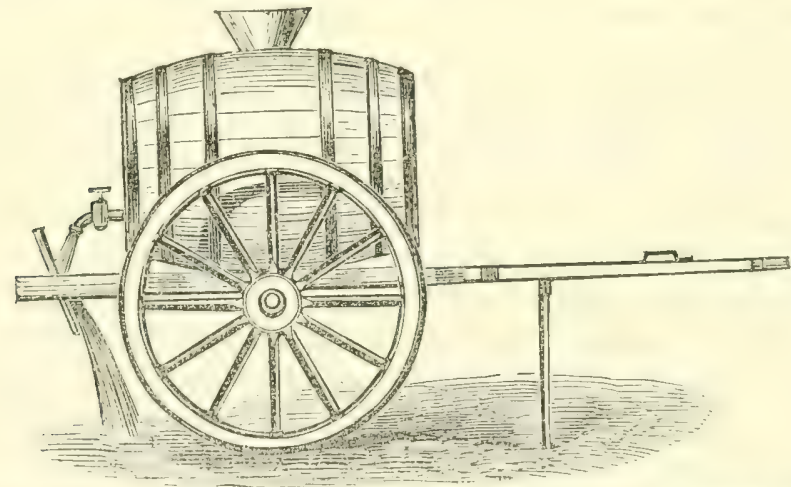

In my opinion, if the liquid was made to fall upon a plank which should be placed behind, at a slight inclination, it would be more effectually spread. Thus : -

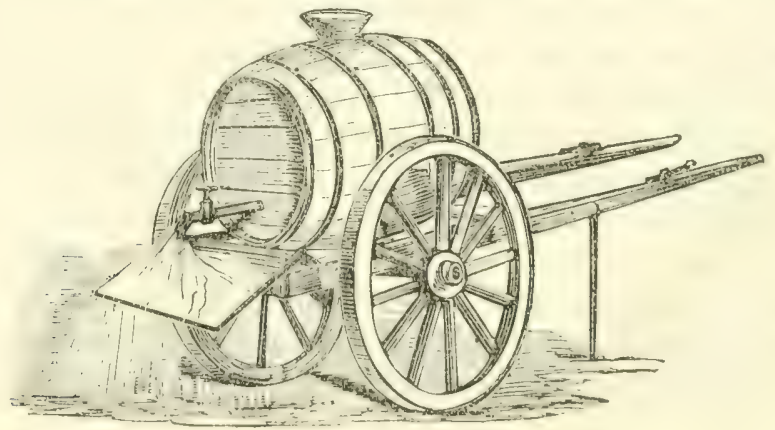


In case of small farms to which this manure is to be applied, and where the cultivator has only his own labor of which to avail himself, he adopts a method of distributing this manure, of which the subjoined cut will give an idea; but which, I can easily suppose, may not be agreeable to persons not accustomed to it. The Flemings, however, reluct at no labor by which their objects may be obtained.

In some cases it is transported into the field by means of a wheelbarrow, with the cask containing the liquid suspended between the shafts. T'here are acknowledged inconveniences attending its application; but many of

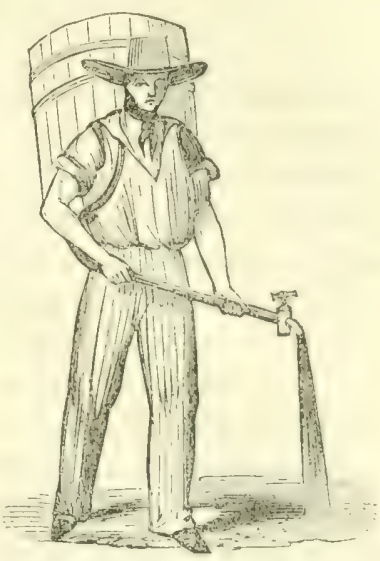
them are purely ideal, and the extraordinary value of the manure, when thus applied, is an ample compensation for any extraordinary labor or expense, which its saving or its distribution may cost.

8. Cleanness of Cultivation. - Another feature in the Flemish husbandry is the cleamness of their cultivation. They spare no pains in the eradication of every weed. They have, in this matter, much to contend with. An old country under a highly-manured cultivation is liable always to be much infested with weeds, and especially with the squitch grass, (triticum repens,) which is their chief trouble. What cannot be accomplished by the plough, or the harrow, or the hoe, is done by hand; and occasional recourse is had to a naked fallow. In such case a fallow crop, that is, a cleansing crop, - a crop the cultivation of which would effectually destroy the weeds, - would be more eligible. The old doctrine, that the land absolutely required rest, with a view to the recruiting of its powers, is now exploded. With ample manuring, and a rotation or change of crops, its occupation may be unremitted. 


\section{CXXXVII. - MANURES.}

I proceed to the subject of manures, as it presents itself in Continental husbandry. The Flemish call manure "the god of agriculture." Of its importance not a word need be said; and the Flemish, in the pains they take in its accumulation and use, evince the estimation in which they hold it. Manure is indeed the foundation of all good husbandry.

1. Mineral Manures. - Manures divide themselves popularly into three kinds - mineral, vegetable, and animal. Of mineral manures, such as lime, gypsum, and marl, the use seems well understood; but, within my observation, they are not applied to so great a proportional extent as in England and Scotland. Lime, or the carbonate of lime, is employed upon lands which are clayey, cold, and heavy; and in such case it answers a double purpose, to divide the soil and render it light and friable; and secondly, to warm the soil. That plants take up some portion of lime from the soil is established; but this is so small an element in their composition, that few soils are found deficient in the necessary quantity. That it should be applied to the land in a caustic or warm state seems likewise an established point. Some of the Flemish farmers advise to the mixture of lime with earth, and to its application in that form; but this seems only an increase of labor without any obvious advantage. Others advise to the mixture of lime with heaps of vegetable matter, so as to reduce it; but, in such case, it is likely to destroy some of the most valuable parts of the manure. The efficacy of a dressing of lime is considered by the Flemings to endure three years; but this must obvionsly depend upon the quantity applied. Thirty bushels of unslaked lime after being slaked is considered by some farmers a proper application; while others advise the application of thirty bushels each year for three years in succession.

I have met with the frequent application of marl to light lands, and to the surface of peat lands, where it soon forms a productive soil. The application of gypsum can scarcely be said to be general. It is sometimes applied in the ground to the seed of 
potatoes in the planting, in which case it is gencrally admitted to improve the quality of the potato; and it is applied also by being sown broadcast upon young clover; in this latter case, ordinarily with success. The philosophy of its operation is still obscure. It is difficult to say why it fails; but it is not less difficult to say why it succeeds. It will sometimes be useful, and at other times without effect, in the same locality. 'This I have myself experienced. A very competent farmer in the United States gives it as his opinion, and the result of his experience, that it sometimes failed of its effects from being too coarsely ground, but that it always succeeded when reduced to an impalpable powder.

Much has been said of the value and efficacy of sea salt as a manure, and in France great complaints have been made of the heavy duty, which in fact prevented its use in this way. A distinguished French farmer and experimenter, who has devoted much time and expense to this subject, and has furnished most cxact accounts of his experiments and observations, has come fully to the conclusion that it is of no use whatever as a manure, and equally useless in the fatting of animals. These conclusions are diferent from the popular notions, which seem always entitled to some respect; but they are fully borme out by the experiments, repeated and varied, of this indefatigable inquirer.

2. Vegetable Manures. - Of vegetable manures I have only to say, that buckwheat and clover are often turned in by the plough, and with acknowledged advantage. The Flemish make a point of collecting every species of vegetable refuse which they can find, all vegetable matter growing upon the sides of the roads, and that which is found in the canals. They are careful likewise to plough in their stubbles, excepting where there is another crop on the ground, such as clover or carrots, which are sometimes sown among the grain soon after the crop is harvested.

Under this head may likewise be placed ashes, of which the Flemish make great use. A large part of the fuel consumed in Holland is peat or turf, and the Dutch ashes are highly valued as dressing for clover. These ashes are imported from Holland into Flanders in large quantities in boats, and always find purchasers. They are applied as a top dressing to dry meadows, as well as to clover, and likewise to flax. It is not well determined on what their particular efficacy depends. 
The ashes of sea coal or mineral coal are likewise used as a manure, but they are deemed very inferior to the Dutch ashes properly so called. Heath lands are sometimes lightly skimmed, and the heath burnt for the sake of the ashes; but if it is intended to cultivate the land or to plant it for trees, it is deemed hurtful to remove the ashes of the surface. Wood ashes and the ashes from the soap-boilers are likewise most carefully saved and applied. Wood ashes are not easily obtained, because of their extensive use in the arts. The ashes from the soap-boilers are much esteemed by the Flemish for strong and moist lands, and have a value from their containing a considerable quantity of lime. The refuse from the bleacheries, which contains a large quantity of soap, is more valued for dry and light lands; both of these manures are greatly esteemed for clover and for dry meadows. Their effects are understood to last for three years, and they are more efficacious the second than the first year.

The cakes from the colza, or rape, which remain after the oil has been expressed, are very much used for manure; in which case they are thrown into the urine cistern, and applied thus mixed. They are supposed very much to increase the efficacy of this liquid manure. Within a few years, however, as I learnt at Courtray, these cakes have been used with advantage for the feeding of cows and swine.

In some parts of France and Belgium the stalks of the colza are ploughed in for manure, and sometimes burnt upon the ground, reliance being placed upon the efficacy of the ashes; and in some of the wine countries, the cuttings of the vines are dug in for manure, it is said, with singular efficacy. It is thus that that which has been taken from the earth for the growth of a plant, is returned to it as a principal element in the growth of the same kind of plant which is to follow.

Soot is likewise used as a top dressing with great advantage, and is considered twice as valuable as ashes. It is applied to the young clover and to garden vegretables, and is estimated highly for its power in destroying insects. Under good management, every article capable of being converted into vegetable food, or of enriching the earth, should be saved as manure.

I have already spolien of the use of the drainings of the fitetory where potatoes are converted into starch; their effects upon grass land were most remarkable. I have in another place 
spoken likewise of the use of the water in which flax has been rotted. I have seen the most beneficial results from it; but I am not aware of its use in Flanders.

From the starch factory this water is conveyed into a basin or excavation, where, after remaining a short time, it makes a considerable deposit. 'This deposit is taken ont and spread upon the land, or thrown into and mixed in compost; and the water is drained off, and conveyed upon the field by small ditches or rills.

3. Animal Manures, - The great reliance for manure, however, every where is upon animal manure, the excrements of animals, and animal substances. One of the most obvious deficiencies in French husbandry is a deficiency in manure. They are not accustomed to folding sheep upon their lands, as is common in British husbandry. They grow very little of esculent vegetable food for their live stock, such as turnips and carrots; and their cattle are kept in the winter often very hardly upon straw. In summer their cattle are much in the pastures, overlooked by a herdsman or a child, so that the manure is scattered.

There is likewise a manufacture of manure called animalice noir, which consists in boiling down the flesh of animals, such as horses, for example, or animals which have died of disease, and are unfit for food; and after it is boiled, baking it in an oven, when it is brought into a state easily to be reduced to powder. There is a manufacture of this same kind of manure in London; but, strange to say, the product is exported to France. The refuse of the sugar refineries, that is, the animal charcoal, or ashes of burnt bones used in cleansing the sugrar, is highly esteemed as a manure; but it is advised by the Flemish farmers to mix it with their liquid manures in the urine vault. This manure is much employed in France. Its chicf value is on heath and moist lands. It does no good on rich, highly cultivited land. It is spread broadeast for grass, and its eflects are surprising. It is applied to wheat land at the time of the sowing of the seed; it is deemed much preferable to apply it in the antumn rather than in the spring. It is applied in France at the rate of four hectolitres to an acre, which would be at the rate of more than eleven bushels. 
The Swiss, likewise, are remarkable for their care of their manures. The heap is usually placed in front of the house, a slight excavation being made for it, so as to form a basin into which the liquids are drained. The long manure is laid at the sides, and doubled in with the greatest care, and no little skill, so as to form a neat and compact pile in a square or oblong form. This seemed to be almost a universal practice; and the neatness and exactness with which it is laid up are quite remarkable. The manure from the stables and the refuse of the house is deposited daily upon it; and the drainings which run down to one end of the basin in which the mantre heap is placed, are often purnped or dipped up, and returned upon the pile. The odor of the heap directly by the door and under the windows of the house cannot be agreeable; but the extreme neatness with which it is formed, and the cleanliness and care which mark ordinarily every thing about the premises, do much to redeem its offensiveness.

In their economy of manures, in their modes of applying them, in their extraordinary liberality in the use of them, the palm must be conceded to the Flemish over all other people. The best Flemish farmers advise against the general mixing of manures. Their doctrine is, that as different animals demand different species of food, as well on account of their habits or constitution as on account of their taste, so different plants and different soils require specific and peculiar manures. I shall not discuss the question how far manure is to be considered as the food of plants. It is enough for us to know that manures are indispensable to their growth, and that different manures are very different in their various properties and effects. The manure of the horse is a powerful and warm manure, and considered as best suited to lands which are cold and moist. It operates quickly; it lightens the soil; but its effects pass off sooner than those of many other manures. 'The manure of horned animals is deemed more substantial, slower in its operation, and more durable in its effects. The Flemish farmers say, that where a second crop is raised upon the ground, the effects of this manure are more apparent in the second than in the preceding crop. It is obvious, however, that the quality of the manure must depend very much on the kind of food upon which the animals are fed. The simplest experiment made with the 
original and most common of all chemical instruments, the human nose, will at once determine the superior efficacy of the manure of animals highly fed with esculent regetables and grain or meal over that of animals fed upon straw only. The manure of swine is considered by the Flemish as of rery little companative value, and where used, in order to produce as much effect, they advise to employ full double the quantity which they would use of cow manure. My own experience has led me to rely upon the dung of swine as among the strongest of manures; and the low estimate which the Flemish farmers place upon it must come from the hogs among them being fed mainly upon grass; and from what $I$ have seen, both in Belgium and France, being very poorly kept at the best. 'The swill pail, which is found at the kitchen door in the United States full of butter-milk and whey intermixed with cooked vegetables, broken pieces of meat and bread, is, alas! not to be found at many cottage or farm-house doors on the European Continent. The whey and the buttermilk are wanted for the table; and it would be a species of sacrilege to give meat, - which a large portion of the laboring people seldom or never taste, - or bread, to the swine. The dung of swine is, however, in the best cases, to be considered as a cold manure, and not easily brought into a state of active fermentation.

The dung of sheep is every where highly esteemed. It is active and powerful; and upon light and moist lands they rate two loads of the dung of sheep as fully equal to three of the manure of other brute animals. It is much used with the oat crop; but it is not advised for flax, as being apt to force it to a premature ripeness. Valuable, however, as is the manure of sheep, I have seen on the Continent no instance of the excellent practice of folding sheep, which prevails so generatly in Whyland and Scotland. In the bergerie, or sheep-house, where their sheep are brought at night, they are careful to spread an abundance of litter, which is generally removed twice a year, in the spring and autumn. They begin with a simple layer, which the feet of the sheep soon reduce to fineness, and so proceed, layer by layer, to a depth of three or four feet, which thus becomes, throughout its whole thickness, thoroughly impregnated with urine.

In some cases, where the farmer does not find it convenient to 
purchase or own a flock of sheep, he receives one to keep or board for another person. In this case he furnishes straw for their litter in the stables on his own account ; and he furnishes what hay, or grain, or pulse, they may consume at the expense of their owner, at the current prices, or such prices as may be agreed upon; and he boards and lodges the shepherd with his two dogs, who has the care of the flock, at about fifty-four dollars, or eleven pounds sterling, a year. He does this for the sake of the manure and of disposing of his produce. In the Lothians, Scotland, I found several instances in which the crops of turnips, or ruta-baga, were disposed of in the field to persons bringing sheep from the interior, to be consumed where they grew. Where practicable, this arrangement is excellent. The Flemish are of opinion that a hundred sheep, well fed, will give, in a welllittered stable or bergerie, from fifty to sixty loads of manure, of more value than eighty or ninety loads of any other stable or barn manure.

I have already spoken of the supply of manure obtained by the Flemish from the numerous distilleries which existed in Belgium, by the immense number of animals which were fed and fatted on the refuse grains of those distilleries. But these supplies are almost entirely cut off.

Another species of manure, much valued on the Continent, and especially among those careful husbandmen, the Flemish, is that of pigeons and barn-door fowls. The superior efficacy of these excrements over most other manures is acknowledged. The excrements of birds are voided only in one form, and may therefore be supposed to possess the greater strength. This manure is saved in Flanders with the greatest care. Contracts are often made with persons who keep pigeons for their manure. A hundred franes, or twenty dollars, is sometimes paid for the manure of six hundred pigeons. 'The manure goes under the name of columbine. The saving of this species of manure requires particular care. It is advised to spread the floors of pigeon-houses and poultry-houses with fine sand, that this manure may be thoronghly intermixed with it, and a fermentation be prevented. If no care is taken of it, it is wasted, or it becomes full of maggots and vermin, which infest the birds. Sometimes it is applied mixed with water, but oftener in the form of powder. The dumg of pigeons is considered more powerful than that of barn- 
door fowls; but the reason is not ascertained. The dung of geese is not so much vilued as either, perhitps for the reason that they feed on grass. The birds, whose excrements form the guano, feed wholly upon fish.

Guano has been used to some extent in France, but its use is much discouraged by the extraordinary adulterations which have taken place in it. These adulterations, according to chemical analysis, have amounted to ninety per cent. Where it has been used, its fertilizing powers have been acknowledged; but the French farmers whom I have met with have not considered it superior in efficacy to poudrette, or dried night-soil. On a visit to a French farmer, about twenty miles from Paris, the state of whose farm would have been creditable in any country, and was certainly inferior to that of few farms which I have visited, he informed me that he had made trial of stable manure, of gruano. and of poudrette; and that he found the guano powerful, that the stable manure produced the largest growth, and that the poudrette produced the best grain. It is obvious that we want many more details and circumstances to form any strong conclusion from this experiment. In all cases, however, anong the French, which came under my notice, I found a strong approval of guano, but the preference given to poudrette. More experience may result in a different verdict.

4. Liquid Manures, and Means of saving thems. - The freparations for saving the liquid manure, which are universal in Flanders, and which are occasionally met with both in l'rance and Switzerland, deserve the most particular mention. There is good reason to believe, that, if it could be saved and applied with equal ease, the liquid manure of an animal is of more value than the solid excrements. The Flemish farmers suliex nothing of this sort to be lost ; and it is stated that in Ghent the servants receive a compensation for saving the waste waters of the house.

On a Flemish farm there is always a urine cistern, usually adjoining the stable or cow-house. A gutter or trough behind the cattle or the horses conveys all the liquids into this cisteru, which is placed outside, rather than immediately unter the calte. that it may be accessible both for the removal, and the mixture of other matters. This cistem is sometimes twenty feet in length, twelve in breadth, and six in depth. It is built of bricks,

voL. II. 
and the bottom laid in cement, so as to be water-tight. It is sometimes divided into two great compartments, and sometimes into several, as in the subjoined diagram.

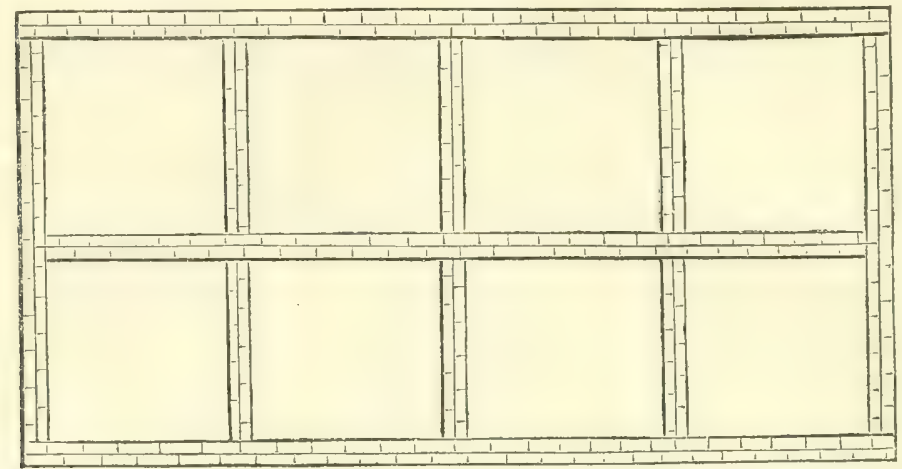

These different compartments are designed to preserve the liquid of different ages separately. Each compartment is accurately gauged, and there is a fixed scale in each compartment, or in the cistern, where it is not separated, by which, from the height of the liquid, the quantity is easily determined. This is necessary for two purposes; first, in case of the sale of the manure, and second, in its application to the soil ; in both which instances it may be important to know the quantity. In addition to the saving of the urine, the stables are frequently washed with water, and this likewise runs into the common receptacle. It is deemed best not to apply the urine until it has some age, and has passed through a degree of fermentation.

In order to increase their stock of manure, the farmers purchase large quantities of manure, such as the emptyings of privies in the cities; and these are carried in boats prepared for the purpose, on the different canals, to the farms which are accessible; and many of these farms have places of deposit, or cisterns for the reception of this manure, directly upon the borders of a canal, that there may be little trouble in discharging the load. This is a double good, to the cities and the country; to the former, in getting rid of their impurities, and preventing the diseases which they might engender; to the latter, in enriching their lands. In many cases these places are used as deposits for the use of manure merchants or dealers, who collect large amounts, and dispose of it in such quantities as may be needed to the neighboring firmers, 
who buy according to their means or necessitics. It is sold by the barrel or tum, and is measured by the scale in the tank, or the vessel in which it is removed. Sometimes the cisterns are covered in with brick, arched, and emptied by means of a pump; in other cases they are cmpticd by means of dippers and bucliets : and it is important that they should be accessible, so that the sediment may be removed as it may collect. Sometimes the cistern is a mere round well sunk in the ground, and empticd by a pump. But the form is of little importance, provided it be secure and convenient, compared with the matter of saving all this refuse, the importance of which $I$ have already most urgently insisted upon. To the great credit as well as to the great gain of the Flemish farmers, nothing of this kind is ever wasted; and the cleanliness of the Dutch towns and cities is certainly not surpassed, and scarcely equalled, by any others.

A good deal of stress is laid upon having the cistern outside of, and detached from, the stable, that the fumes from it may not injure the air of the stable, to the prejudice of the health of the cattle, or those who tend them; and likewise on having different compartments in the cistern, that the liquid may have obtained a certain age brfore it is applied. They are in the habit, likewise, of mixing rape calies, or the cakes which remain after the oil has been expressed from the rape-seed, with the urine, which in this way forms a most efficacious manure. These cakes weigh generally about half a pound, and are sold by the hundred or thousand. The amount of this manure applied to the land is often very large; liberal and ample manuring being one of the great principles of Flemish farming.

5. Compost Heaps. - The Flemish have, likewise, a mode of preparing a compost heap, which is greatly approved annong them. They collect the scrapings of ditches, the vegetable matter which is floating in them, heath, bushes, stalks of regetables, and any waste regetable matter which they can gather; with this they mix a certain quantity of earth or soil, and then add quicklime in about the proportion to the heap of one tenth or one fifteenth. This heap is several times shovelled and cut up with a spade, until it is in a state of sufficient fineness to be applied to the field. In the Pays de Waes, a district of comutry between Ghent and Antwerp, the cultivation of which is not 
surpassed in any part of the country, perhaps not in the world. - for I can hardly think of any culture more exact, more clean, or more beautiful, or any crops more luxuriant than I saw here, - the practice of the farmers is to place this heap near the side of the field intended to be cultivated, and then to pour upon it a copious sprinkling from the cisterns; the heap is then shovelled over, and the whole thoroughly intermixed; in which case it becomes an excellent manure to be applied before sowing.

6. Jauffret's Minure. - The preparation of Jauffret, which has had much celebrity in France, deserves notice here. I have scen one similar applied, and with success, as far as the object aimed at was concerned, in the United States. The object of this invention was to find some means by which straw, brush, ferns, heaths, broom, and other woody substances, might be speedily brought into a state of decomposition, so that the mixture might be applied to the land. He supposes it possible to supply mutriment to the land in this way, without the aid of animals. Tre advises, therefore, to collect a heap of materials composed of vegetable matter, such as straw, ferns, heath, broom, turf, bushes, small branches of trees, stalks, \&c.; and when this heap is made, the articles being intermixed and pressed together, you are then to prepare near it a liquid of the following materials : -

100 parts of fecal matter and urine.

25 " "soot from the chimney.

200 " "gypsum in powder.

30 " 6 "unslaked lime.

10 " " unleeched wood ashes.

A small quantity of salt.

" " " " " refined saltpetre.

25 parts of the drainage of a manure heap, or of liquid fecal matter.

These matters are to be mixed in a place by the heap, with water cnough to make a quantity of liquor sufficient to water this heap, and, in a few days, produce such a state of heat and fermentation as will reduce and wholly decompose it. The plaster or gypsum must be applied by slow degrees and in small quantities; otherwise it would become hard. Near the heap, which should be placed on a piece of ground slightly inclined, 
should be a basin or hole to receive the drainings of the heap, that they may be returned upon it. The washings or applications of the liquid must be repeated, and holes occasionally made in the heap to receive it. In a favorable temperature, it is stated that a fermentation will commence in forty-eight hours, and that in twelve or fifteen days the whole matter will be so reduced as to be in a condition to apply to the land to be ploughed in with advantage.

I am not able to give with great accuracy the various proportions of ingredients which are prescribed; but this general statement will be sufficient for practical purposes, understanding only that there must be a sufficient quantity of the 'iquid thoroughly to impregnate or saturate the heap. Several other mixtures have been prescribed by different individuals, which produce the same effect; the only question is that of cost. I do not deem it necessary further to refer to them, as they have been given in various forms to the public. Any cheap process, indeed, by which such crude materials can be decomposed, must be valuable, especially when the articles themselves, of which the application is composed, are of an active and enriching nature. In general such prescriptions are looked upon as a species of quackery; but Jauffret's method has been much approved in France.

7. General Remarks on Manures. - I have heard from some farmers who claimed to be highly practical and intelligent, great distrust expressed of the value of liquid manure. They have applied to their lands, with comparatively snall eflect, the drainings of their dung-heap; but, as a capital Swiss farmer observed to me, the drainage of a manure heap and the contents of a urine cistern are very different matters. The former is, of course, in strength and efficacy, very inferior to the latter.

The Elemish farmers, in the application of their manures, aim at two objects: the one to have their manure in a form in which it can be immediately taken up by the plant; the other, to apply it at a time when it is directly needed. In a liquid form it is, of course, most accessible to the demands of the plant, and they apply it at the time of sowing; and to some crops repeatedly afterwards, when they are in a growing state, and the eflects of the first application are exhausted. They are, likewise, most $45 *$ 
liberal and indefatigable in the application of their solid manures, not limiting them to the surface, but mixing them with the whole soil by thorough and deep trenching.

\section{$\longrightarrow$ \\ CXXXVII ^ - CROPS.}

I have already treated fully of many of the crops cultivated on the Continent; but there remain some few others, in the culture of which the Flemish distinguish themselves, to which I shall refer.

1. Colza is a plant cultivated largely in parts of France, but very extensively in Flanders, where it may be considered as a standard crop, the culture of which is carried to great perfection. It is a species of the cabbage family, and is cultivated for the oil which is expressed from the seed. It occupies the ground nearly a year, being sown in July or August, or transplanted in September or October, and gathered the ensuing July. The product of a good crop in seed is estimated at thirty bushels. It is considered a great exhauster of the soil, but it returns in its refuse much of what it receives. The stalks are often converted into mantre, and are frequently used as fuel in cooking food for cattle, and in heating ovens. The land on which it flourishes best is a strong, rich soil, rather inclined to sand, yet argillaceous, moderately humid, and with a deep, fertile bed. It must be well drained, so as to allow of no standing water upon it, and it must be well manured. The best preparation is a green sward, or a clover ley broken up; it often, however, follows rye or barley. It is important that the cultivation should be thoroughly clean. When sown on stubble, the stubble is first to be thoroughly harrowed or ploughed to the depth of two or three inches, and then, the weeds being cleared from the land and the manure spread upon it, the whole is to be turned over by the plough to a good depth.

The seed may be sown broadcast, or it may be sown in drills; in the latter case it is more easily kept clean; or the plants may 
be grown in a nursery, and transplanted. In case of tramsplanting, the crop is usually much better, and the oil made from it of a superior quality; but the labor and expense are considerably increased. When sown broadcast it is sown very thin, and cleared out so as to leave the plants about one foot apart. When sown in drills, the drills are more than a foot apart. When transplanted, the plants should first be grown in an ample seed-bed, and set out at the distance of a foot from each other in double rows, the intervals between the double rows being eighteen inches. The land is ordinarily laid in stitches, on which four or six rows may be planted; the land in the intervals dug out with a spade, and laid on the bed in the autumn, and in the spring this dirt levelled, the soil gathered up round the plants, and the whole kept thoroughly clean.

In December, when the ground is frozen, it is sometimes watered with liquid manure from the urine cistern in which the rape cakes have been dissolved; and this manuring is sometimes repeated in the spring, to the great advantage of the crop. 'This liquid manure is sometimes applied most beneficially immediately before sowing the crop. Wood ashes are likewise recommended as a manure; and some farmers in Germany, when the plant presents four or six leaves, give it a dressing of plaster or gypsum. Marl on light soils is likewise extremely beneficial; this is carried on to the land in a season favorable to this work, and then spread and distributed by a harrow.

The seed is often sown broadcast; but it is very prejudicial to the crop to sow it too thickly. There are three different modes of transplanting the crop; first, by a spade, when the workman makes the hole by plunging the spade into the ground to its full depth, when, pressing it from himself, children, who work with him, place two plants in the hole; then, withdrawing the spade, the earth falls back upon the plants, and a pressine of the foot between them finishes the operation. Or a dibble or planter may be used, which makes two holes, into which the plants are placed, and the earth closed up by hand; or a furrow may be struck with a plough, and the plants laid along in the furrow on the side of the furrow slice, and a second passing of the phough will throw the dirt directly on the routs of the ese plants, there being a workman to follow the plongh to relieve plants, which have been too much covered, or to cover those 
which have received too little dirt upon them, and to set up those which have fallen down.

The plants, which are grown in a nursery bed, should have plenty of room ; and soot is recommended as an excellent manure for them, as well as for the field after they have been transplanted. 'The plants, which are designed to be set out, are sometimes kept out of ground five or six days. The design of this is to check vegetation, so that they may not advance too rapidly before the winter, lest the severe frosts should injure them. It is not considered indispensable to manure the field upon which the crop is to be planted, if it is in a good state, or if the previous crop has been manured, though the crop will bear the usual relation to the richness of the land.

The crop follows rye or wheat with advantage, or clover ; but in the case of rye or wheat, the stubble is to be thoroughly cleaned. The crop is to be hoed during its growth, and earth drawn round the plants. The plant has dangerous enemies in flies and bugs which attack it. Against the flies a dusting of quicklime is sometimes of use; but the bugs are with difficulty dislodged, unless by a frost. The frosts, however, when they occur nightly, with warm days, are jnjurious to the plant; much less, however, when the frosts are followed by fogs. It is the habit of small farmers to pluck a portion of the leaves as food for their stock; but this is attended by a diminution of the product.

The harvesting of the crop is a business requiring much care. It must be gathered before it is completely ripe. In good weather it can be laid in small heaps and dried, and then shelled out on cloths upon the field; or it may be stored in a barn after it has become sufficiently dry. In wet weather it may be heared up with layers of straw between the layers of colza, until a return of good weather. If suffered to become too dry, it is liable to lose much by shelling out. In cutting with a sickle, the workman is cautioned against taking too many stalks in his hand at one time, as more likely, by so doing, to shake out the seed.

I have already spoken of the value of the cakes as manure, though they have been much used of late for feeding stock, which they informed me at Courtray was a modern practice. 'The clean cultivation of colza, and the ample manuring, serve eminently to prepare the land for wheat. 
2. Navette. - A smaller kind of colza, called navette, is cultivated. where the land is too light for the larger kinds. It is cultivated for the same purpose, though the produce is seldom more than two thirds that of the other. Its produce is considered more valuable, and sells for a higher price. It is sown broadcast, and requires the land to be well cultivated and manured. The navette, a rape of summer, is sown in the spring, and ripens its seed in September. This kind is much sown in parts of England, as feed for sheep; but is seldom sufiered to go to seed. It produces a healthy feed for sheep, and in good land a most productive vegetation. It sometimes, as I have observed in another place, affects badly the ears of sheep. The navette, a rape that is sown in autumn, has the advantage of bearing the frost well; and is much benefited by being harrowed in the spring.

3. Popry. - The poppy is largely cultivated in Flanders; but I have no recollection of seeing it any where else, though it often appears as a weed in fields of grain, both wheat and oats. It is cultivated for its oil, which, when properly managed, is much esteemed. It is grown in small quantities in gardens for medical purposes as a narcotic; in which case the heads, with a piece of the stalk, are cut off before their maturity, and hung up to dry, and the opium extracted by the druggists.

The poppy cultivated is of two kinds, the white and purple. 'The latter kind produces the larger quantity of oil ; the former, the best quality. There is another difference; the head of one kind being much more open than that of the other: and the former kind is almost exclusively cultivated in Flanders. The soil required for the poppy should be strong and mellow, and, as far as may be, protected from cold. It should be well cleaned from weeds. 'Though ordinarily sown broadeast, it would be preferable to sow the seed in drills, that it may be easily hoed. The plants should be left about a foot apart. It succeeds well to grain, and especially to hemp; in which case the manuring is not required to be repeated. It is especially recommended to follow potatoes, where the ground has been well cultivated and kept clean. When it is intended that the poppy should succeed potatoes, the potatoes should be well manured. When it follows any of the grains, several loads of manure should be given to 
the land for the crop. 'This manure may be applied in the autumn or spring; but in either case it must be ploughed or harrowed, and thoroughly mixed with the soil. There is danger of sowing the seed too thickly, and therefore it is advised to mix the seed before sowing with one portion of earth and two portions of sawdust. As soon as the plants appear, they are to be weeded and cleaned with great care; and when a foot in height, to be hoed and slightly earthed up.

The gathering of the seed of the poppy is to be done by hand, and at different times. As soon as the heads have acquired a degree of ripeness, they are to be carefully shaken over a basket or bag, so as to save the first loose seeds. This is afterwards to be repeated before the general harvest, when the whole is to be gathered by cutting off the heads. The shelling of the seed is afterwards done by hand; for if done by a flail, the seed is cleaned with difficulty; and the pieces of the stalk, which then become intermixed with the seed, give an offensive taste to the oil. The seed may be preserved a long time, but requires to be aired. The oil of the poppy is used both for food and light, and is considered a fifth more valuable than that of the colza. 'The cakes, remaining after the expression of the oil, are valuable for the fatting of swine; and the stalks for fuel. The ashes, which remain after burning it, are of the best kind for manure. If the seed be pressed in a mill used for the colza or other oil, the greatest attention must be paid to cleaning it. The oil expressed in cold weather is much superior in quality to that obtained in warm weather, and the two must not be mixed. The great enemies of the poppy are the field-mice, which eat off the stalls while in a green state, and then destroy the heads. The birds likewise plunder a great deal of the seed.

4. Cameline. - Another plant, called Cameline,* is cultivated, when, for example, the colza fails; as it ripens its seed in three months. The oil is not so valuable as the colza, as it has a bad smell. The plant is not extensively cultivated; but it succeeds well in sandy and inferior land. The stalks of the plant are used for brooms, and some persons cultivate it for this object.

* Myagrum Sativum. 
5. White Mustard. - The white mustard is sometimes cultivated both for the medicinal qualities of its seed and the oil expressed from it, which, though useful for many purposes, is not suitable for human food. 'The great objection to the cultivation of this class of plants is, that it fills the ground with seed which germinates in succeeding years, and is with difliculty eradicated. It is sometimes subject to mildew or rust. It ripens in about fifteen or sixteen weeks. It is liable to be lodged; but this does not ordinarily injure the seed. The plant is eaten as a salad; and it is given to cattle as a change of food, when their appetites become capricious, and require to be quickened.

6. Flax. - Flax is a great crop in many of the northern countries of Europe. It has been largely cultivated in Flanders, both for its fibre and oil. It has been for a long period an important article of commerce, and probably in no country has its culture been carried to such perfection. The value of the crop, and the extraordinary difference in the value of different qualities, amounting in some cases to full one hundred per cent., show the attention it demands, and how liberally it recompenses extraordinary care.

Flax will grow on various soils, but is not indifferent to the character of the soil on which it is cultivated. It requires a rich, sandy loam, and one thoroughly manured. It is advisable, however, with the exceptions to which I shall refer, that the soil should be enriched by previous manuring, rather than in the year of its being sown. The Flemish farmers make flax a crop in their regular rotation, occurring once in seven or eight years; and the manuring of their previous crops has reference to the flax crop, which is to succeed.

There are generally stated to be two kinds of flax. 'The difference does not appear so great, however, but that they may occasionally run into each other. There is a kind which runs upon a single stalk, which is generally preferred, on account of its producing a finer fibre; there is another, of a coarser kind, which branches out at the top, like a tree. They make a distinction in Flanders, likewise, between the plants which bear a close, and those which produce an open or gaping capsule or seed-vessel, the latter being preferred. Experiments hate been made in Germany with seed brought from South Italy. 'The 
seeds were beautiful, and brilliant, and large, yet the plant attained a comparatively small height.

The Flemish farmers approve of changing their seed frequently. It is said that a crop from seed which has been twice sown in Belgium is inferior in quantity, owing to this circumstance. I am an unbeliever in the deterioration of any plant on account of continuing the seed, where proper pains are taken to get, by selection and care, the best seed only from that plant. The seed preferred in Flanders is the seed brought from Riga. There are other places, however, from which seed is brought, the fibre produced from which is said to be finer than that from Riga.

The seed to be chosen should be heavy and brilliant, of a gold color, or a clear brown, and especially clean. It may be tried in water; and if much of it floats upon the surface, it is owing to the imperfection of the seed. It may be tried by throwing some little into the fire, to determine its oily properties; and it may be laid upon a wet blanket or cloth, to determine its germinative powers, Seed which is black, or seed which has been much heated, is wholly unfit for sowing.

The ground for flax cannot be prepared with too much care. A very fine crop of flax is often obtained on grass land, recently turned over, and this even without manure. The land in this case is carefully ploughed, rolled, lightly harrowed, and then sowed, and the seed lightly harrowed or brushed in. The crop which precedes flax is often oats or rye, but especially potatoes. The land, if in stubble or in potatoes, is carefully plonghed in the antumn, and then twice again in the spring; and it requires to be most thoroughly cleaned, and kept clean of weeds.

It is commonly sown thickly. Thick sowing tends to render the stalks fine and straight, without branching. One hundred and sixty pounds of seed is the usual allowance to an acre. which seems a large quantity. The land is sometimes mautured in the year in which it is sown. In this case it is ploughed early, say in March, and thoroughly wrought, and then rolled smooth and hard. The land is then manured with thirty bushels per acre of peat ashes from Holland, or what is called Dutch ashes, and with a good dressing of liquid manure from the urine cistern, in which the cakes of colza have been dissolved; and this is mixed, likewise, with some manure from the 
privies. This makes a strong dressing; the land is then harrowed; the seed sown, and lightly brushed in with a bushharrow, as there is always danger of covering the seed too deeply. Horse manure must not be used for this crop. The effect of marl used as a manure for flax is to injure the color. Pigeons' dung, or what is ealled columbine, and which inchules also the manure of the poultry yard, is pronounced an excellent manure. It is plain that these manures do not favor the production of weeds, as is commonly the case with barn-yard manure; and consequently is much to be preferred. In the neighborhood of Courtray, where much the best flax is grown, they use great quantities of the liquid manure, with the rape calies freely intermixed. A thousand gallons of this liquid manure, with a thousand rape cakes dissolved in it, are sometimes applied to an acre. Besides other crops, flax is said to follow to great advantage a crop of hemp, which is always highly manured, and kept perfectly clean. The dung of sheep is much valued for the flax crop; and especially where sheep have been folded on the land. The general opinion is, that high manuring produces a coarse flax; light manuring produces a flax of a fine fibre. It requires a deep culture, as the roots are supposed to penctrate to a depth equal to half the height: the flax root has been traced much farther than this.

The best flax is produced at Courtray; and it is said that the same pains or manuring will not produce nearly as good in other places: this seems to imply some unascertained quality in the soil, peculiarly favorable to its growth.

The time of sowing flax must be somewhat regulated by the climate or position of the place. It is sown in March, and sometimes as late as May. The earlier sowing is advised, though in the countries of a high northern latitude the rapidity of regetation compensates to a degree for the shortness of the season. Ordinarily in fifteen days after the sowing of the seed the field will require to be weeded. This cannot be too thoroughly performed, and is done by women and children, on their linees, working against the wind, that it may raise the plants which have been pressed down.

Flax is often liable to be lodged, especially if the growth be rapid. Great pains are sometimes taken to prevent this, by placing stakes in line in different parts of the field, and laying

vOL. II. 
poles or bars along upon them, which serve to keep the plant from falling over.

If flax of an extraordinary fineness is required, it is pulled before the perfect ripening of the seed; the superior fineness of the fibre is considered as a compensation for the loss of the seed. But if otherwise, an early is preferred to a late gathering; as the longer it is left to stand, the coarser and harder becomes the fibre. The seed is generally taken off by a comb with iron teeth, made for the purpose, as soon as the flax is harvested; or the whole is stowed away in a barn, to be taken off at pleasure. When the flax is stowed away in a barn, and the seed not taken off until the succeeding winter or spring, it acquires a ripeness which gives it a superior value. After the seed is taken off, the flax is set up in the field in a sort of windrow, the roots upon the gromend, and the tops inclined to each other, until it is sufliciently dried to be placed away in a barn, or stacked with the roots out, or steeped, preparatory to being dressed for the market. The bright and beautiful silvery color of the flax is of great importance, and so is the fineness of the fibre; and all pains are directed to secure these objects.

There are several modes of steeping, or what is termed rotting the flax, that is, destroying the bark of the plant so as to clean the fibre. It is sometimes dew-rotted, that is, left upon the grass, being occasionally turned; it is sometimes rotted in stagnant water; it is sometimes rotted in running water. In Flanders there are persons who are employed as regular steepers of flax; and when the farmer sells his crop of flax before it is dressed to the merchant or manufacturer, these persons dress and prepare it for the market. The inhabitants of Courtray steep their flax in the water of the River Lys, drawing off to the side in an artificial basin, of sufficient depth and width, water sufficient for their purpose. The flax is set upright, with the roots downwards, in a sort of hurdle or basket, and it is with great pains retained in its upright position, as being necessary to prevent its becoming discolored. They are careful to keep the roots at least a foot from the ground, or bottom of the pool. In many cases, instead of water being drawn from the river into a pool or basin, the flax is placed upright in hurdles to prevent its floating away, directly in the running stream, with planks and weights in all cases to keep it under the water, as the tops are longer in 
becoming macerated than the bottoms; and where they are not sufficiently rotted, a considerable loss is experienced. In this case, of course, fresh water is continually supplied to the flax; and the process is completed sooner or later, according to the temperature of the weather. Great skill is required to determine the precise time when the process is finished, and the flax is to be removed from the water, as a few hours are said in such case to make an important difference in the color of the flax. 'I'his must be matter of experience 'rather than of written instruction. In other cases, a pool or cistern of water is formed in a field, in which the flax is immersed, fixed upright, and the bottoms of the plants not touching the bottom of the cistem; and so arranged, that this water can be drawn off and replenished with clean water. It is said that in this way the cleaned flax has more weight than in any other, amounting, it is said, over some methods employed, to ten per cent. This method was at one time considered a valuable discovery in Flanders. It is clearly important in all cases that the water should have no foreign substance in it, which would be likely to give a coloring to the flax. I have already mentioned the value of the water in which flax has been steeped as a manure to land, having seen the most beneficial effects from it. I am informed that a method has been adopted for getting the bark off the flax by steaming the plant, in which case the whole is accomplished in seventy hours, but I am not sufficiently informed to speak of it with confidence. 'The flax being thus rotted, the remaining operations through which it passes are well understood. The operations of heckling and swingling flax, which were formerly performed wholly by hand, are now performed by machinery moved either by steam or water; but it does not enter into my plan to describe these machines.

The seed of flax is of great importance in Flanders for the manufacture of oil. About seven bushels of seed are rated as the ordinary yield from an acre of land. This seems a very small product. The seed, when first taken from the stalks, is carrefully dried and kept in sacks, until it is beyond the danger of being heated. The cakes from the pressed flax seed are highly valued for the fatting of cattle; and the seed itself, being converted into jelly, is capable of being used in this way to great advantage. Indeed, as far as my own experience goes, I know no single article superior to it for cattle or for sheep. 
In Flanders they sometimes sow clover or carrots among the flax, from which they get a crop after that is removed. This should not be done in any event until after the first weeding of the flax. The practice is generally approved. That it is to a degree prejudicial to the flax crop, there can be little doubt; but whether the profits of the clover or the carrots would more than compensate the lessening of the crop of flax, is a matter upon which there exists a diversity of judgment, and, in different cases, undoubtedly a diversity of results.

7. HeMr. - The cultivation of hemp prevails to a considerable extent in Flanders, and is expensive in the preparation of the land, and the quantity of manure required. The value of the crop is considerable; the land, being well cultivated and highly manured, is in a condition for two or three successive crops of grain.

The soil required for hemp is a strong, rich, moist loam, a deep alluvion; and it needs to be deeply cultivated and liberally manured. It is not unusual to plough it eight to ten inches deep, or to trench it with a spade a foot deep or more; and it should be finely divided and tilled. It is ploughed in the autumn, and then again twice in the spring; but it must not be wrought when it is wet, which indeed may be laid down as a universal rule. A sandy clay loam may be considered as best adapted to this culture. It likes a warm exposure and low ground. It succeeds well after clover or potatoes; and in some places it comes as often on the same ground as every second or third year.

The manure which best suits hemp is horse or sheep manure. If the manure is coarse and strawy, it is ploughed in, and often by the first ploughing in the autumn; but if well rotted, it is applied in the spring, and near or at the time of sowing. It requires a warm manure; though the manure of cows, when about a third part is added of night-soil, or manure from the urine cistern, is an excellent application. The manure of pigeons and poultry, ashes, and the cleaning of streets, is much valued. To give a rapid growth to the plant, the manure must be in a condition, that is, well rotted or short, to be immediately taken up by the plant; and with respect to hemp, there is little danger from the seeds of weeds in the manure, as the luxuriant growth of the hemp will overpower them. 
The seed is sown ordinarily about the middle or within the last fortnight of May, and sometimes not until June. 'The seed requires to be watched against the birds; for even after it has made its appearance above ground, they will pull up the plants and take the seed. The plants are to be thinned out to a distance of three or four inches; but if the land be very rich, to a greater, or double the distance. If it is desired to grow a fine hemp for twine, the sowing should be thick; if for larre ropes and cables, it may be sown more sparingly.

The gathering of the hemp is made ordinarily at two different times. There will be found in the field what are called the male and the female plants. Both in Belginm and in France, by a misnomer, the plant bearing the seed is called the male plant, and the plant bearing the flowers for the impregnation of the flowers upon the seed-bearing plant is called the male hemp. It is of no great importance by what term they are designated, provided the difference is understood. The plants which do not bear seed are to be pulled from the field some weeks before the seed-bearing plants; they at that time will give a fine fibre, but if loft until the ripening of the seed, they become of little or no value. The time for pulling them is when the flowers of the non-seed-bearing plants have been loing enough unfolded to shed their pollen upon the male plants, and the top of the stalk becomes of a yellow color; and the part towards the root is bleached. The ripeness of the seed-bearing plants is determined by the maturity of the seed, and the fading color of the stem. The hemp, being pulled, is tied in small bundles; and, after being sufficiently dried by being set up in the sun, the seed is beaten or combed off, and the plant is prepared for steeping of rotting. The hemp pulled first requires not more than eight on ten dilys for rotting; the last pulled, which is drawn, of course, when the weather has become colder, is sometimes liept in the water two months; and it is well for it to remain until the water freezes. The mode of steeping does not differ much from that of flax, excepting that it is not deemed necessary to set it upright in the ivater, and that it is done in a pool or basin instead of the river. The color of the fibre of hemp is obviously of little importanee compared with that of flax, though some of the finest of hemp is sometimes mixed with flax for the making of coarse linens.

Hemp, too, like flax, is sometimes dew-rotted upon the ground, 46 * 
where it is thinly spread out, and occasionally turned. That which is dew-rotted has a superior whiteness and fineness of fibre to that which is steeped, but is not so durable. This dewrotted hemp is therefore preferred for twine, and the other kind for cables and strong cordage. The early-pulled hemp should not be rotted upon the grass, but upon stubble; and it is believed by some farmers, that where it is spread upon a rye stubble to be dew-rotted, it acquires a whiteness above that by any other process. The seed-bearing hemp, when dew-rotted upon grass, must be spread so thinly that one stalk should scarcely touch another.

The farmers of one of the best cultivated districts in Flanders, the Pays de Waes, are averse to planting hemp, because of the great quantity of manure which it requires; but, with the addition of a moderate manuring, they get excellent wheat after it, and sometimes carrots are sown after hemp, and a superb crop of flax is taken from the same ground after the carrots. Two great advantages are said to come from the cultivation of hemp; the weeds are stifled, and the leaves, which fall from the stalks, serve to enrich the land.

The quantity of seed sown to an acre is about half a bushel; and it is advisable to sow it in narrow beds, that when the nonsecd-bearing stalks are pulled, the seed-bearing stalks may not be interfered with. Sometimes a crop of rye or wheat is sown among the hemp plants, while standing, and the extraction of the non-seed-bearing plant serves to cover it. This saves a ploughing.

At the harvest, the plant is usually drawn by the roots, though sometimes cut with a sickle or a knife, and laid on the ground to be dried. The hemp is said to be of a superior quality if thoroughly dried before it is put in the steep. The ends of the seed-bearing hemp are sometimes beaten over the edges of the head of an open barrel, as the seed which comes off in this way most easily is, of course, the most ripe, and the best for sowing. The seed which first comes off in this case is taken for this purpose.

'The roots of the hemp before dew-rotting are cut off with a hatchet, and used for fucl. In pulling hemp, it is important so far to select the stalks as to bring together those which are of the same length, to be tied up in the same bundle. The hemp, after being steeped, must be thoroughly dried; and this is done, 
in some parts of Germany, by a kiln of simple construction for that purpose, which saves much time. 'The hemp, after being dried, is broken by a machine formed by one heavy stone rolling over another, which breaks the bark; and sometimes by mallets, and then the bark is picked off by the hand - a slow process, and prejudicial to the health of the laborers from the dust which fills the room where this is done.

The produce of an acre of hemp is ordinarily about $350 \mathrm{lbs}$, and of the seed from thirty to thirty-five bushels.

There are several other crops cultivated extensively in Flanders; but my object is not so much to give a specific and detailed account of the mode of cultivation of these crops as the general features of the cultivation. Tobacco and hops are grown to a considerable extent; and likewise several plants valuable for their coloring or dyeing properties, such as Woad or Pastel, Weld, and Madder.

8. 'Toвассо.-'Tobacco is cultivated as an article of large consumption and of commerce. It is quite remarkable that a plant so odious and offensive as this, in no respect conducive to health, and in most cases positively injurious, and so nauseous and repugnant to an unaccustomed taste until habit has overcome this repugnance, should have acquired such a hold, that it has become, with a large portion of mankind, almost a necessary of life. There is no hope of a reformation in this respect, and the use is constantly extending itself.

There are two kinds of tobacco cultivated in Flanders - that of Virginia and that of Turkey: the former is estecmed greatly superior to the latter.

It has its place in the rotation of many farmers, occurring sometimes once in four, and sometimes twice in seven years. It will grow well upon most soils, excepting a heavy clay, or at dry sand, or a wet soil; but it requires laborious cultivation and abundant manuring. The erop is stated to be 1000 lhs: : but this much exceeds the amount grown to an acre under the hest cultivation which I have known in the United States: $2000 \mathrm{lbs}$. would, I think, be considered there a large crop, though I have known an average crop of $2700 \mathrm{lbs}$. grown on several aces moled circumstances peculiarly favorable.

The soil is ploughed, and the mannre ploughed in, in the 
autumn, and again ploughed and labored in the spring. The manures used are cow and pigs' manure, and likewise the manure of sheep, which is deemed peculiarly favorable. Malt-dust from the breweries is much valued; and very large dressings of rape cake, sometimes in powder and sometimes dissolved in the urine cistern, are extensively used. If fecal matter is mixed with this, it is essentially improved for this object. The manure of horses, even the urine of horses, is objectionable, as giving a bad taste to the tobacco. What worse taste can be given to it than its ordinary taste, it would be difficult to imagine.

The seed is first sown in a nursery-bed, in a warm and sheltered exposure, in March; the nursery-bed should be wellwrought and manured; and, in case of danger of frost, the young plants require some protection either of bushes or of straw. The transplanting is usually made with a dibble in June, when the young plants have acquired a growth of six leaves. 'They are set out in rows two feet apart, and in the row the plants are fourtecn inches apart. In about fourteen days the plants require to be hoed, and the plantation to be kept clean of weeds. When the plants have acquired a height of ten or twelve leaves, they are then, as it is sometimes termed, stopped, - that is, the topshoot is pinched off, so as to prevent its rising any higher; and all side shoots are broken off, so as to leave only one stalk. In this way the sap of the plant is thrown wholly into the leaves. The tobacco plant is subject to be injured by frosts, especially in low grounds; and is likewise liable to rust, under which the leaves perish and fall to the ground. This depending, as is supposed, upon a bad exposure or a bad condition of the soil, as yet mnascertained, no remedy has been discovered. I have not been able to learn that the tobacco worm, so well known in the United States, and so destructive unless means are taken to remove it, is known in Europe. This is a large green caterpillar, found under the leaves; and sometimes a large drove of turkeys is sent into the plantation, who pick them off and regale themselves upon them. 'I'his is the nearest approach within my knowledge to the use of this weed among the inferior animals; the worms eat the tobacco; the turkeys eat the worms.

When the leaves begin to turn yellow, the harrest begins; they are picked of by hand close to the stalk, and, after a little exposure to the sun, are then tied up in bands and humg up under 
cover for perfect drying. When taken off they are sorted into three qualities - the first, into the large leaves; the second, composed of the leaves next in size; and the last, of the leares which have grown nearest the ground.

9. Hops. - I know of nothing peculiar in the culture and management of hops in Flanders, excepting the production of $1600 \mathrm{lbs}$. of dried hops to an acre, which is a very large yield. 'l'hey are careful not to have the plantations of too large an extent, as it would prevent a free circulation of air; and they manure the ground most liberally with liquid manures. The hops are planted in hills six feet apart each way, and four plants to each hill. A trench is dug round the hill, which is filled with decomposed manure, and in some small measure earthed up. The usual operations of trimming and polng them follow. As no crop of hops is taken the first year, the intervals are occupied by cabbages and other plants.

A method has been recently invented and patented in England for drying or curing hops, by which it is stated that at least fifty per cent. of the fuel ordinarily used will be saved, and a much larger amount of the essential oil of the hops, the lupulin, will be retained in them. The furnace or kin for drying them is of a peculiar construction; and the air used for drying them is made to pass over sulphuric acid or quicklime, by which it is divested of its vatery properties, and comes in upon the hops in a dry and decomposed state. The apparatus is deemed simple enough, and not extraordinarily expensive. The hops dried in this way have, it is stated, brought twenty-five per cent. more in the market than those cured by other methods. I have seen the plans for constructing the apparatus, but further experiments may be desired to determine its advantages. It is said to be applicable to other agricultural purposes, such as malting, and even the drying of hay, so as to expedite the process, and at the same time retan the rich juices of the herbage. It is difficult to conceive that it should be useful in this way upon any large scale. Most patent inventions, however, like patent medicines, are eatholicons.

There are cultivated in Flanders, in France, and in Italy; several plints for the purpose of dyeing or coloring. such as woad. which is used for a blue dye, weld for yellow, and madder for 
red. I was once asked, what bearing had the color of the trousers of a soldier of the French army, which are red, upon agriculture. The answer is obvious; so infinitely diversified and innumerable are the circumstances which affect the various relations and interests of social life.

10. MADDER. * Madder is one of the most important of all the plants used in dyeing, and is cultivated at great expense. It is $t w o$ years, and sometimes three, before the crop is gathered. There are two kinds cultivated - the one with a quadrangular, the other with an hexagonal stem. The former is the most productive; the latter produces madder of the best quality.

The soil required for its production should be deep and rich; a clayey soil will produce good madder, but its working is difficult; a soil, therefore, in which sand enough prevails with the clay to render it friable, is that which is to be chosen. It must be deeply cultivated, as the roots, which constitute the value of the crop, run down very far. A plough will scarcely go deep enough, and the land should be trenched with a spade to the depth of at least three feet. Manure should be ploughed in and dug in until the whole bed becomes most thoroughly enriched. It is advised to plough in the solid manure in the autumn, and in the spring to apply liquid manure, urine and fecal matter intermixed. Cow manure and stable manure are also applied with advantage; and the land should especially be rich from former cultivation, and from having been thoroughly cleaned of weeds. The manure should not only pervade the surface, but be buried deeply, that the roots may not want for nourishment as they go down.

Madder should be sowed in a nursery-bed in a garden, and the seed of the last year should be used, as seed of more than a year old germinates at a very late period after planting. It is well to lay the ground in beds three feet wide, to receive two rows of plants; or in five feet beds, to receive four rows of plants. The plants are to be set in line, a foot apart, and the rows at an equal distance. The intervals between the beds are to be shovelled out, and the ground kept loose by a spade until the second year; when the roots of the plants extend into the intervals, in which 
case they must not be disturbed; they must then be kept a linn. but not dug. Holes may be made for setting the plants, either with a hoe or a spade; they must be taken from the nurserybed, and immediately set out, and not allowed to get dry or withered in the air; they may be dipped in water when transplanted, and great care must be taken to prevent their being injured, and to place them fairly in the ground, bringing the earth and pressing it carefully down around them. Liquid manure may be applied with great advantage in the intervals between the beds. After the planting, it is well to water the plants; and they are to be kept clean, and the intervals kiept loose by a narrow hoe or spade: the spronts thrown ont at the sides of the main stem may be bent down and covered with earth, so as to force the growth of the root. In the autumn the plants should have a slight covering of strawy manure.

The madder which is not taken up until the third year produces much more, and of a better quality, than that which is gathered the second year; but the increased expense and rent of the land are seldom compensated by the increased product.

The harvesting is a work of much labor. The roots, which, in a well-prepared soil, extend to a great depth, must be taken up with much care, and without injury. Sometimes a plough is passed along the line, and then the work is finished by the spate; but generally it is wholly done by the spade; the intervals between the beds being dug ont to the depth of two fect, and the plants carefully displaced and taken out by means of forks or narrow hoes. 'The plants lie upon the ground three or four days, in small heaps, in order to become dry, and in case of rain are covered with straw. They are then carefully housed, and afterwards dried in a kiln for the market. The excellent condition in which, under such cultivation, the land is left for other crops, is a considerable indemnity for the expense and trouble bestowed upon the crop of madder. The rich polders, or redeemed meadows, both in Holland and Flanders, are favorite spots for the cultivation of this crop.

11. WOAD.* - This plant grows wild in various places, but is cultivated for its blue dye. Where indigo is not attainable, it

\section{* Isatis Tinctoriz.}


takes its place; and where indigo is attainable, it is found advantageous to mix a portion of woad with indigo. The use of indigo, however, much interferes with the cultivation of woad. It is sown both in the autumn and spring. That which is sown in the autumn has the advantage of giving a larger crop of leaves, and of sooner getting out of the way of insects. The leaves constitute the value of the crop, and these are gathered sometimes thrice in a season, the first gathering being much the best. It requires a rich soil; and the particular kind of soil is not so important as that it should be deep, to admit of the free descent of the tap-root of the plant. Rich alluvions, which have been well drained, are particularly favorable to it. The land should be manured as well as for wheat; and, above all, it should be kept thoroughly clean. It succeeds well after grain or: after potatoes. It may be sown in drills, or it may be grown in a nursery, and transplanted. The plants require to be from a foot to a foot and a half apart. The leaves are gathered when they begin to droop, and turn slightly yellow; they must be kept free from dirt, and when laid away must be guarded against heat or fermentation. They are sometimes washed, to get rid of any dirt which may adhere to them; and a dry time must be taken for gathering.

After being gathered, they are crushed in a mill, resembling a tanner's bark-mill; they are then made into heaps, where they undergo a fermentation, great pains being taken to close any cracks which may appear in the crust of the heap: after this they are rolled into balls, twice as large as a man's fist, and are then pressed into the form of bricks; and thus are ready for the market. The profits of such cultivation must depend upon the state of trade and the price of indigo. I found this plant cultivated extensively in one part of Lincolnshire, where a large mill had been recently erected for its preparation. The best woad is grown in the south of France, where it is largely cultivated.

12. WELD.* - The weld is cultivated for its yellow color. It is a plant which grows wild in many places, and the smaller kind is known in the gardens as mignonette. It requires a soil dry, calcareous, and well cultivated. It will grow well upon a sandy

* Reseda luteola. 
clay loam. Upon a very rich soil the stems will be proportionally strong and large, but the coloring matter not so goed; upon a poor soil it will not pay the expenses of cultivation; a soil of medium fertility is to be preferred. It should be sown very early in the spring, and the ground should be well cultivated in the previous autumn. It does not require manure when sown upon a soil previously well cultivated and clean. The seed must be covered as lightly as possible, and it is best sowed in line. It will require to be carefully weeded; and when the leaves begin to turn yellow, it should be gathered. In a sandy soil it may be pulled with the roots; in a clay soil, where the dirt would adhere to the roots, it should be reaped close to the ground with a sickle. The plants which are designed for seed should be allowed to remain until the seed is perfectly matured. Fresh seed is greatly preferred to seed more than one year old, which often fails to come up; and when sown, on account of the smallness of the seed, it is recommended to mix it with some fine sand. The plants, when gathered, are to be dried in the sum, and then tied up in small bundles, so overlaying them, that the tops of the plants shall be turned in upon each other, and the roots project at each end of the sheaf. They must then be put away in an airy and dry place, and are ready for sale. It may be cultivated on the same lard once in eight years.

13. Carrots. - I must not quit the crops common in Flanders, without referring to the culture of the white carrot, which is vastly more productive than other sorts. This is sometimes sown among rye or wheat, or colza or flax, after: the last cleaning, and a small crop is obtained in this way, but often at the expense of the crop among which it is sown. When sown as a separate crop, they speak of twenty tons to an acre, or eight hundred bushels. It requires a comparatively light and dry soil; it bears high manuring and deep cultivation; and is considered a profitable crop.

I shall take the liberty of repeating here what I have saicl in another place. The land, after being fully prepared by manuring and fine tilth, should remain until the first crop of weeds comes up, and should be. lightly ploughed, in order to destroy these. F"nrows should then be made upon the field, into which the manure should be placed, and then a back furrow slice VOL. II. 
turned each way upon this open furrow, so as to form a ridge directly over the manure. These ridges should be twenty or twenty-seven inches apart. On the top of these ridges, which should be smoothed off carefully, the carrot seed should be sown in double rows ten inches apart, and as straightly as possible. The carrot seed should be sprouted in wet sand, before sowing, and should early be weeded. The land may then be ploughed between the rows, and kept clean with a hoe. They must be thinned out in the row to about six inches asunder. When ready to be taken up, by rumning a plough directly by the side of the row of carrots, they are gathered with little trouble.

I have now gone through the principal crops grown in Continental husbandry, and though not undertaking to give a fuli detail of the culture, yet I have given all the peculiarities which distinguish any mode of culture, and those general rules and principles which are universally applicable.

\section{CXXXIX. - IMPLEMENTS OF HUSBANDRY.}

In Paris at the Conservatory of Arts and Trades, at Brussels, at Utrecht, I found extensive collections of agricultural implements and models of agricultural tools and machinery. These embraced many of the most improved implements to be found in England or the United States. It may excite a smile of surprise with an Englishman, that I speak of the United States in this connection. But I have seen nothing on the Continent or in Great Britain equal to the collections of agricultural implements which are to be found, for example, in Boston, United States. The English implements are usually clumsy, heavy, and inordinately expensive. In treating of British Husbandry, I have given an account of some of the best of them. They at least answer the purposes of the ingenious mechanics, who understand very well when they have got their pail under a cow with a full udder, and how in the most agreeable manner to abstract the gold from the pockets of enthusiastic agricultural amateurs. Like the Flemish cows, they are carefully fed, not to say llattered, while 
being milked; and finding tools and implements for crery operation, and adapted to all possible shades of diflerence in the mamner of performing it, imagine they have only to purchase the tool to have the operation accomplished. In general they are compelled to learn that it is not so much the tool, as the man who holds it, upon which they are to rely for the proper execution of the work. Of this the Flemings are a striking example; for it is impossible to find agricultural operations better executed, and with fewer and more simple implements.

T'wo ploughs are much celebrated in Flanders, one called the Walloon plough, with wheels to the beam, of which I subjoin a sketch, and which is much used for ploughing deep in heavy lands. It is used with two, three, or four horses, according to the nature of the soil, or the depth to which it is desired to go.

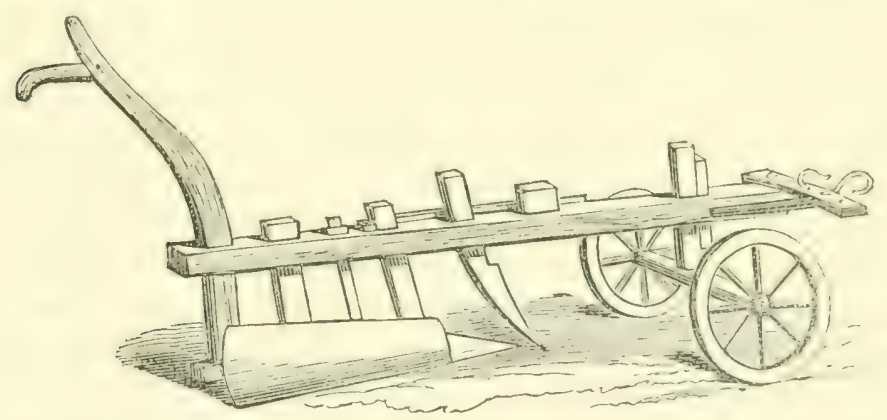

The other is of a lighter description, and is much esteemed as the Dutch plough. It is introduced into France, and there most highly approved. For light lands it is used with one horse, but ordinarily with two. What I have sometimes seen called the Dutch plough has had the mould-board so curved, or rather almost concave, as to offer great resistance; and rather to press the dirt as if with the hollow of the hand, than to turn it over. The common Flemish plough is undoubtedly an exectlent implement. It has a shoe or regulator attached to the beam in front; by which the depth of the furrow is regulated. A plate of it is given at the top of the next page. The Flemings value it not only for raising and inverting the land, but for pulverizing it at the same time.

In the harrows and rollers used in Flanders I saw nothing peculiar. They have bush harrows, and harrows with tecth of iron and of wood. 


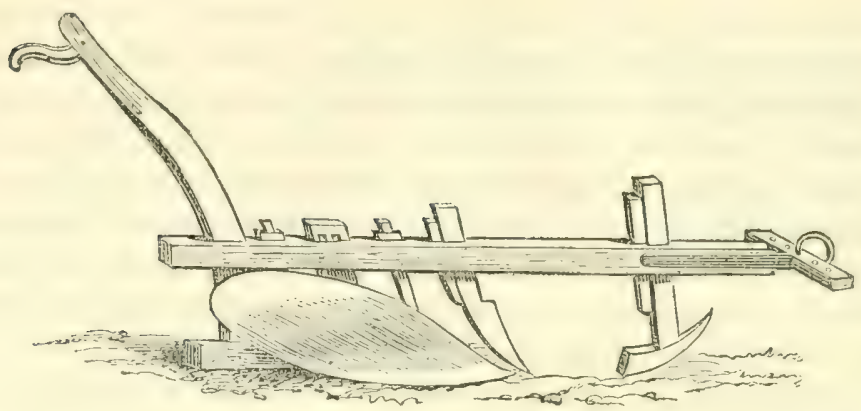

The instrument, which is deemed peculiarly Flemish, is the mouldebart, of which I annex a plate. It is designed for the speedy removal of earth, when it is not required to transport it to a great distance. The horses or oxen are attached to this implement, which immediately dips itself full of dirt, and when full, the handle is then pressed down, that it may slide easily over the ground. When it reaches the place of deposit, the handle is raised, and it empties itself; and the string, which is constantly held by the workman who guides it, is designed to pull it back after it is emptied. It is thus prepared to take up another load. It is a most useful instrument, and effects a great deal of work with a small expense of labor in a short time. It has been used many years in the United States, and is there called an ox-shovel.

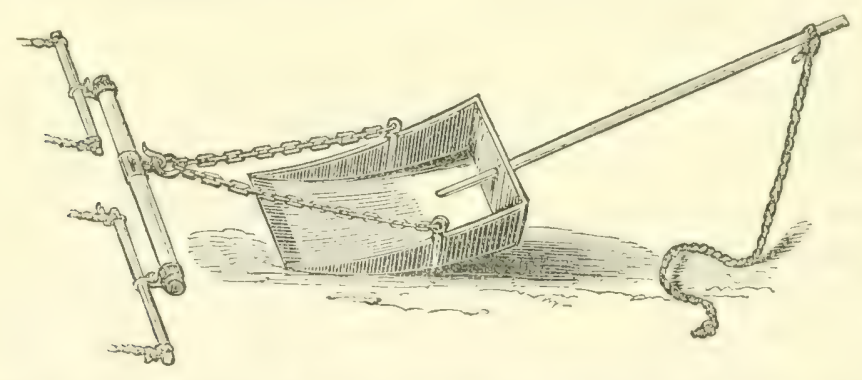

The plough which I saw frequently used in Italy was without a mould-board, and its share resembled the bowl of an inverted teaspoon, only more flat. It simply stirred the ground, but did not invert it.

The spade is an instrument much used among the small farmers of Flanders; and in the best cultivated districts, such as the Pays de Waes, they deem it necessary, once in five or six 
jears, to trench their land completely, to the depth of fifteen or seventeen inches, with the spade.

I saw nothing in the carts, wagons, or vehicles in use on the Continent in any way to recommend them either to Earglish or American farmers. Nothing, however, can be more complete than the fitting out of a E'lemish or Dutch farmer's team. 'T'he equipments in France and Italy are in general wretehed in the extreme. In Italy and in Switzerland, oxen and cows are principally used for draught. In Italy the breed of cattle is extremely beautiful in appearance. The oxen there are often brought out upon the roads to assist in dragging the coaches up their steep hills. They ordinarily draw by the horns or forehead; but where a yoke is used over the neck, I have found a basket of stones hung at the centre to keep it down, that it might not impede the breathing of the cattle. Instead of bows, there were ropes round the necks of the cattle.

The Dutch collar for draught horses has been the subject of much improvement, and the horses used in the Belgian artillery are said to have derived an immense advantage from its improved character. The first object has been to avoid, as much as possible, a horizontal draught; and, therefore, the point of attaching the chain or trace is placed high on the collar, so thit it may not affect the breathing of the animal; the second, to aroid galling the neck of the horse; and for this reason the collars are made open, to buckle at the top, by which means they can be better adjusted to the neck of the animal. Great stress, and I believe very justly; is laid upon having the collars made so as to open at one end at pleasure.

\section{CXL. - SPADE HUSBANDRY.}

An implement which has accomplished an immense amount in some parts of continental Europe, is the spade; and when we reflect upon the actual amount of labor effected by this simple tool, managed by the human hand alone, the elevations which have been levelled, the canals which have been dug, and the mighty embankments which have been raised, we are filled with astonishment at the great eflects which are hrought al)out 
by the most simple means, and at the vast results of combined and persevering labor.

$A$ great amount of land is cultivated by the spade in Belginm, Holland, France, and Germany. Indeed, vast extents of land, especially in the vine-growing districts, on the steep acclivities and on the summits of high hills which are cultivated, are entirely inaccessible to horses or cattle. The ground is tilled by the spade; the manure is carried up, and the produce is brought down on the backs of men or women. It is stated in a statistical work, now in the course of publication in France, that not less than forty millions of acres in that country are cultivated by the spade. This strikes me as an over-statement; yet the amount is, doubtless, very considerable. In Flanders the cultivation is mixed, with the spade and the plough; the land for grain crops is wrought with the plough and laid in beds or stitches, and the intervals are dug out with the spade, and the seed sown on the beds is covered with the dirt thrown out of these intervals. This is all done with the greatest care, and this is the occasion of the extreme neatness and exactness which appear in their cultivation.

In the case of very small farms of a few acres, all the work is executed by the spade or the hoe. It may interest my readers to see the calculation made by the late Rev. Mr. Rham, a gentleman highly estecmed for his agricultural knowledge, and his zeal in agricultural improvements, as to the amount of produce which may be obtained "from fifteen Ghent acres of light land and moderate fertility, which should be cultivated by the spade, with the help of a horse and cart. They will maintain four milch cows, and a heifer, a horse, two or three hogs, and a couple of young pigs; - sending to market, or consuming in the family, the following produce, deducting seed :-

90 bushels of wheat.

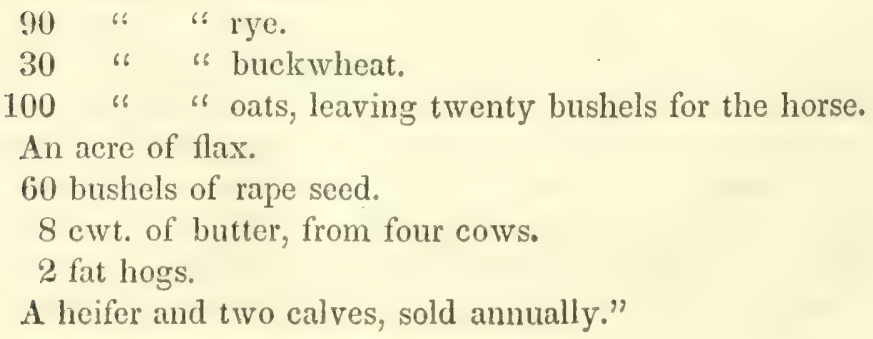


This is an extraordinary amount, and yet I have no doubt it may be realized.

I am not about to enter into a comparison of spade husbandry with that carried on by the plongh and the help of brute labor; but there are many cases in which, owing to the superabundance, and consequent cheapness of hmman labor, it maly present a fortunate alternative. It is stated to require the labor of a man sixteen days to dig an acre, and thirty-two days to trench it, which would be going two spits deep. Labor in Flanders is about ten pence, or twenty cents a day, without feed, which would render it much less expensive than ploughing.

In cultivating land with brute labor, it is to be remembered that on few small farms can a team be kept constantly at labor; but the expense of the keep goes on whether the tean labors of not. The cultivation by a spade is much more thorough than by a plough; much less seed is required, and much better erops are produced. $A$ bushel and a quarter of wheat to an acre is ample, because every seed is carefully covered, and thus secured from the birds, and buried only at such a depth that it rises easily. The cultivation is much cleaner from weeds, and the manure is more thoroughly intermixed with the soil. The lind is made friable, and the deep cultivation gives the roots of the plant ample opportunity to expand themselves. 'The beneficial effects of a good trenching will continue for five or six years. How far it may be expedient to adopt it on any large scale, must depend on a variety of obvious circumstances, which in different situations must greatly vary. The expense of keeping such teams of horses as are kept in England, and in many parts of the Continent, - I speak particularly as to their consumption of food, - to say nothing of their equipments and deterioration in value, is enormous. It seems the great drawback in England to a farmer's prosperity. What might be accomplished where a superabundance of human labor exists, what should be done with a starving population around you, anxious to be employed, and willing to work, are for the consideration of those who find themselves placed in these painful circumstances. Such is the sad condition of many parts of the European continent. 'The example of a Elemish farmer supporting himseli, and wile, and three children, keeping a cow, and fatting a hog, upon the produce of two and a half acres of land, and selling, for various 
purposes, the produce of three and a half other acres, - he being able, with the help of his wife and children, to cultivate well the whole six acres, and to have a great deal of time left for other purposes, - is, I am assured, often to be found in Belgium, and strikingly illustrates the success of quiet and patient industry, joined to temperance and economy.

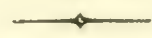

\section{CXLI. - LIVE STOCK.}

In respect to the live stock of the Continent, a traveller perceives at once that, with the exception of horses, little attention has been paid to the improvement of the different breeds. Perhaps I should cxcept sheep likewise, as I shall presently show. In this respect England distances all other countries within my observation; and has displayed a skill, perseverance, enterprise, and success, which are admirable; and which, in enormous prices, have been liberally compensated. A thousand guineas for a bull, six hundred guineas for a cow, or three hundred guineas a year for the service of a ram, ring in one's ears like music from the regions of romance. 'The symmetry of proportion, and the extraordinary degree of fatness to which some animals are forced, as may be seen particularly at the Smithfield Christmas show, in London, and the extreme beauty of the improved stock of England, are most remarkable. Aptitude to fatten, carly maturity, and great weight of carcass, in proportion to the age, and the amount or cost of the food required, are points of great value in any race of animals which are designed for food. But beauty, either of form or color, has only an imaginary value, and no hecessary connection with its product, either in beef or milk; and the extreme obesity of many prize animals is often obtained at an expense to the farmer or amateur much beyond any price which the animal is likely to command in the market. Early maturity is a point of great importance; for, exceptiug where animals are kept for labor, animals kept a day beyond their readiness for a fair market, are almost always kept at a loss. The secret of profit is in general in a quick 
exchange. I have known a farmer to weigh repeatedly two fattening oxen of fine thrift, and size, and extrene fatness, and he discovered that, for a whole month before they were sent to market, they had not gained a single pound. They appeared to have reached their acmi, beyond which they could not be foreed. It is a curious fact in regard to the human animal, that in a condition of health no change of diet and no abundance of diet ever carries him beyond a certain point ; so that every adult man has what he terms his own weight, which does not vary for years. Whether an analogy to this fact is to be found in the inferior animals, would, as far as it is possible to be ascertained, be a curions and useful inquiry. Ordinarily, I admit, not always, animals consume in proportion to their size. I believe it will be found, in general, that two small, or medium-sized animals, of good constitution and thrift, pay the farmer better, in proportion to the amount of food consumed, than one large animal, which would give an equal or superior weight. The English farmers generally consider the small IIighland cattle the most jufitable: for fattening. We know certainly that the milking properties of corvs do not always bear a proportion to their size. The two best cows which I have known - one making $191 \mathrm{lbs}$. of butter in a week, and more than $480 \mathrm{lbs}$. in a year; and the other having produced more than $20 \mathrm{lbs}$. in a week - were two mediumsized cows of the North Devonshire breed; and it seems an established prejudice, if so it must be called, that fatness, and the abundant secretion of milk, in the same animal, at the same time, are to a degree incompatible with each other.

1. Oxen and Cows. - I saw some very large oxen from Normandy in a fat condition on exhibition at Poissy. The cattle, however, most admired on that occasion were a cross of the improved Durham short-horn with some of the best breeds of the country.

The cows, as met with ordinarily in France, are inferior. They show in the early part of the season the effect of bad keeping in winter, and appear scarcely to recover from it during the season. The cows, at several private establishments which I visited, were admirable for their milking properties, but of no particuliar race; though at Grignon, at Petit Bourer, an! gemerally, I found the $\mathrm{Swiss}$ cows held in high estimation. 'The Dutch 
cows have been a long time celebrated for their abundance of milk, which does not surprise one in looking at the rich polders in which in summer they are fed, and where they are often seen covered with a cloth as a protection against both the dampness and the cold. Being unacquainted with the Dutch language, I found it difficult to get as particular information as I desired. Radcliffe, in his book on Flanders, says, that "they are fair milkers; but in this respect nothing remarkable, the average quantity, excepting in the grass districts, where it is infinitely greater, being computed at about seven quarts each cow in the twenty-four hours, through summer and winter." I quote this passage for two reasons ; first, to show how loosely many people speak and write on such subjects, for one is wholly at a loss to know how much a product infinitely greater than seven quarts may be supposed to be; and next, to say that an average yield of seven quarts per day, winter and summer, is a very great yield, and is seldom equalled. There is another report of a farmer at the IIague, furnished to Sir. John Sinclair, where the milk establishment of forty cows produced only about three quarts per day to each cow throughout the year.

The produce of a Dutch cow is rated at about eighty pounds of butter, and one hundred and eighty pounds of whole-mills cheese, in a year, which certainly is not an extraordinarily large amount. They are generally of a black and white color. In some cases they are milked three times in a day. In the greater part of Flanders I found them soiled upon clover or vetches, but principally clover ; in Holland, they remain in the pasture all summer, where they are milked; but in winter they make a part of the family, and, in truth, live in the common eating-room of the family, it being a part of the main house.

The Swiss cows, as far as they have come under my observation, are to be considered of two kinds ; the cows ordinarily kept on the common farms, and the mountain cows. The cows I found at Hofwyl are, from appearance and the accounts I received of them, the very finest of their kind. 'They are large, but not tall; broad in the back, full and square behind; fine boned, and with large udders, giving great quantities of millk. It is diflieult, especially at any distance of time, and when innumerable objects are passing before the mind, to compare two objects, unless they are present; but $I$ think $I$ have never seen fincr animals of the 
lkind. The race is known as the Cimmenthal; and undoubtedly great pains have been taken in their selection and management.

I am at a loss to state the amount of milk given, or butter produced, by these cows, because I do not know the capacity of the Swiss measure; but they are evidently deep milliers, and as well as I could understand, they give from sixteen to twentyeight quarts of milk per day, and about two hundred poumds of butter by the year. These cows were reported to me to weigh from seven hundred to twelve hundred pounds; they were exceedingly broad and round; short and fine in the leg; in high condition, and extremely well covered; and in their whole appearance excelled by none which I have seen. I saw many of these fine animals for sale in the cattle-market at Berne.

There is another kind in Switzerland, which may be called the mountain cow, because I found them principally in the most hilly districts of the country. These were a small-sized animal, of beatiful form, small limbs, exceedingly light of foot, evidently fitted to climb hills and precipices, and with eyes as bright as those of a gazel, and not unlike a deer in their movements. These cows did not promise much in mill.

2. Gonts. - In Switzerland, I found in the mountainous districts large herds of goats, which are brought down from the mountains at night to be milked, and sent away again at daylight in the morning. Many small families keep one goat in their stables to supply the family with milk. They give about one pint of very rich and delicious milk each per day; sometimes more. Among the mountaineers of Ireland, near the lakes of Killaney, I found many families keeping goats for their milk; one family having as many as thirty. These were kept for the comfort and luxury of travellers, who visited these wild and picturesque regions. They are kept at a small expense, and were it not for their wandering and mischierous propensities, a milch goat would be a treasure in the family of a poor man. 'They might easily be fed upon the waste regetables of a poor man's garden or his frugal table; though in most of the poor families in Europe there are other mouths who claim first to be satisfied, and leave little waste of any kind. 'The milk of groats is rich, and is often recommended to invalids by high medical authority. 
3. Asses. - Of all beasts of burden or draught in Europe, asses are, perhaps, the most common. Mules are bred and used largely in Spain, as I am informed; and I found them in the mountainous parts of $\mathrm{S}$ witzerland for the use of travellers in places and passes where carriages cannot be used, and where sureness of foot is particularly desired. But asses are every where common, and, for the purposes to which they are applied, are certainly most serviceable animals. They are in general of a small size, and cost from one to two pounds, or from five to ten dollars; their keep is of the hardest description, and they live to a great age. One was used constantly at Carisbrooke Castle, in the Isle of Wight, for drawing water from a very deep well seventy years, and he was replaced by another, who, when I was there, had been employed for many years. This most useful race of animals presents an example of the humiliating truth, that real substantial merit does not always find its place in this world; that grateful and kind treatment does not always tollow the services rendered; that abuse of power is too common a fault; and that exterior appearance and address are a surer passport to favor than solid and useful qualities. I cannot say, however, that this is withont exception, for I found in some cases in Manchester, in England, among the Irish, the donliey living in the same room with the rest of the family, and sharing in their comforts, such as they were. Whether this was to be considered as an advance upon the usual companionship of an Irish cabin, I shall not determine. It shows at least an amiable thit of eharacter to acknowledge our obligations, and is quite in the equality and fraternity style of the times.

4. Horses. - The Flemish horses have long been celebrated, and most deservedly so, as I have seen for their purpose no horses superior. In France and the Low Countries, horses exchusively are used for agricultural labor. In Flanders, two horses are allowed to fifty acres of land. In many cases the farms are accessible by canals, and manures are brought and produce carried away in boats, which, of course, on still waters are navigated at a small expense. The Flemish horses are of a medium size, compact, active, strong, and extremely well equipped; these farmers being very proud of their teams, as indeed they well may be. Add to this, they are groomed with extraordiuary care. 
Th my journey from Antwerp to Rotterdam by diligenee, it is hardly possible to praise the horses too much for their beauty: speed, and equipments.

The French work horses are admirable, and surprised me by their excellence. I refer particularly to a breed called the Picheron, bred in the interior of France, and used in the diligences and the omnibuses in Paris. The horses generally employed in these cases are unaltered, which elearly does not improve their temper or manners; they are rather under than over size; they are not groomed with much nicety, nor harnessed with any show; they are, however, kept in good condition, and almost exclusively for work; they are small-boned, well filled out, and extremely compact; their usual travelling gait, according to my experience, with immense loads, is from six to seven miles an hour; in the mail coaches in France, the rate of travelling is ten to twelve miles an hour; and nowhere are there more punctuality and despatch. The Flemish carthorse, and the breed of French horses to which I have referred, would, in my opinion, prove a most valuable acquisition to the United States. The Flemish horse is slow in his movements; the French horse extremely active and vigorous: their ordinary height is fifteen and a half hands.

The mode of keeping horses differs much in different places. They are almost universally soiled in summer upon green food, either clover, vetches, or licern. I have already mentioned the case of a large contractor for conveying the mails, who was accustomed, besides straw and hay, to give rye bread in certain quantities, whenever the price of oats or other forage or provender made it upon a fair calculation expedient. For the health of the horses he much approved this food. His stock exceeded four hundred horses; oats are almost always deemed an expensive article; but the best farmers recommend to give them in the straw cut up. Carrots are much valued in Flanders for horses; and considerable quantities of beans are grown in France for horses, and given in a bruised or half-ground form. 'The Flemish give their horses what is called a white drink, that is, water mixed with some portion of rye or buckwheat meal; and sometimes oil-cake is dissolved in it.

In some parts of Flanders, the allowance for a horse is in winter fifteen pounds of hay, ten pounds of straw, and seven voL. II. 
pounds of oats per day. In summer, clover is given instead of hay and straw, seven pounds of oats, and their water whitened with rye-meal. In another district, in winter, about six quarts of oats, thirty-five pounds of hay, or, in place of fifteen pounds of hay, about seventy pounds or a bushel of carrots. In summer, seven quarts of oats; eighty pounds of green clover are given. Instead of the oats, about four quarts of bruised beans are allowed. The Flemish are always anxious to have their horses in the best possible working condition. Excepting only the white drink, the keeping of the French horses does not materially differ from that of the Flemish. The advantages of cutting and mixing food for horses are universally acknowledged, on the score of economy to the farmer, and of utility to the animal fed.

5. Swine. - The swine are almost every where on the Continent, as far as I saw them, miserable; lank, lean, gaunt, and, if they have not a good point about them, they certainly have other points in great profusion. If it was a herd of such swine as one meets with continually in France and on the Continent, which were on one occasion driven into the sea and there perished, the owners certainly could have had little ground of complaint. At Grignon I saw some of the improved breeds of England introduced, and it is to be hoped that they will extend themselves; at present the race seems under a curse.

6. Sheep. - I shall say little of the sheep of the Continent. The sheep seen on the rich meadows in Holland are of a large size, with long, coarse wool and a heavy fleece. The Saxony sheep are well known for the fineness of their wool, their small size, and their tenderness of constitution. I have already said that I found some excellent results at Grignon and Alfort from crossing the Merino with the Sonth Down, but sufficient time has not been had to decide whether it may be persevered in with advantage - a point no where yet determined.

The pure Merino sheep, which were exhibited at Poissy from the farm of Mr. Gilbert, near Grignon, and originally of the stock at Rambouillet, were, beyond all comparison, the finest of the kind I have ever seen; and, I believe, of the very best lind of sheep, for the United States, which could be raised. 'T'hey 
would weigh full twenty pounds a quarter when dressed: their wool is of a fine quality, and their fleeces extremely large and heavy. An intelligent American farmer, who was with me at one time when I saw them, and on whose opinion, from his having been a great wool-grower, I should place much reliatuce, perfectly coincided with me in my impressions of the merits of these extraordinarily beautiful sheep. They are not so large or fat for mutton sheep as the Leicester or South Down of England, in which country mutton, being a favorite food, is much more an object of demand than in the United States; but they are sufficiently large for mutton, and the superior fineness of their wool gives them a peculiar value. There exists with some persons a prejudice against Merino mutton, but it is entirely without reason.

\section{CXLII. - DAIRIES.}

Holland and portions of Flanders are largely devoted to the grazing of cattle, and to the making of butter and cheese. 'The Dutch butter is much celebrated; it is strongly salted and neatly packed, and may be shipped to advantage. Cheese is largely manufactured in Holland. The Dutch cheeses are well known. They are professedly made of whole milk; but I must be permitted to distrust this, certainly in respect to those which I have tasted. They are made in the form of cannon-balls, weighing about seven pounds each. They are an article of extensive commerce, and are sent to marliet as early as they can be got ready. They are exported largely both to France and Eugland. The taste of them is good, but in richness they are very inferior to the best English cheeses.

The Dutch dairy-rooms are models of neatness. 'Lhe French denominate this quality by an expressive word - propricly; and, in the case of the Dutch farmers, it seems impossible it should be exceeded. Their vessels, pans, tubs, presses, shelves, dippers, every thing, in short, connected with the dairy, is marked by a cleanness which seems perfect, and they are bright with excessive brightness. The town of Broeck has been long celebrated for 
its cleanness, and here not a horse ever comes; the streets or passages to the houses are paved with bricks, or with rounded stones from the sea-shore; and a well-dressed lady might almost sit down in the streets without soiling her robes. The neatness of these places is proverbial. I cannot say that I have not seen it equalled in some private examples; and the sect of the United Brethren, otherwise called the Shakers, in the United States, are quite as much distinguished in their houses and settlements for their excessive cleanness; but it is clearly impossible in this respect "to beat the Dutch;" and this most comfortable, agreeable, I will add beautiful, habit of the Dutch, is nowhere surpassed.

The French butter, as found in the markets of Paris, seems the perfection of this article. It is generally sold entirely fresh, and that of the first quality is delicious. It is found fresh in the markets in winter as well as in summer, and is colored with the juice of the carrot. The French offer for sale fifty-three different kinds of cheese. Having tasted of but few, it would be presumptuons in me to characterize the whole. The cream cheese is excellent. The Neufchatel, which is merely the curd, fresh and slightly pressed, is much esteemed. The Rochefort resembles the Stilton, and often equals it. These are deemed the best. I could learn nothing, either in Holland or France, peculiar either in making the cheese, or in the curing or use of the rennet. The $\mathrm{S}$ wiss cheese, called the Gruyere, is manufactured both in France and Switzerland, is much esteemed by many persons, but its flavor is excessively strong and not agreeable. I cannot, however, decide for the tastes of other persons. The celcbrated Parmesan cheese, which commands every where the highest price, is made in a limited district in Italy. The mode of making it is kept a secret. It is of a light green color, and delicious flavor. A distinguished farmer in Switzerland informed me that they had repeatedly endeavored to imitate it, but without success; that the agricultural societies had offered large premiums for this object; and that they had actually sent persons into the district where it is made, but they were unable to get the information. It is conjectured to depend mainly upon the nature of the feed which the cows obtain. The current opinion, that it is composed of a portion of asses' milk, is considered by the best informed persons as without foundation. 
I have gone so fully into the subject of dairying in my observations upon English husbandry, that I shall not extend them. In Holland, the cows are generally pastured and milked in the field. In Flanders, in parts where good pasturage does not abound, they are soiled, and in one of the best districts half an acre of clover to a cow is considered ample for the summer. In winter they have hay, straw, carrots, turnips, or potatoes, in such proportions as a judicious feeder will see to be necessary. But there prevails universally in Flanders a practice of giving the cows a mixture of rye-meal, or the meal of buckwheat with water. This is considered as most indispensable, and, no doubt, contributes essentially to increase the milk. In general, the Flemish farmers prefer a mixture of food both for their cows and their fatting cattle, cutting up straw, hay, tumips, and carrots together.

T'here are modes of management in the Swiss dairies which are well worthy of notice. Where it is desired to avail themselves of the feed upon the mountains, a herd of corvs is driven there in the summer; and some persons - men in the cases which I found - go with them, carrying their provision with them, and, occupying a building which is only habitable in summer, tend the cows, and make the cheese. 'I'hey carry little else than bread with them, and for this they have occasionally to descend the mountain, which, with the return, is no slight task; but bread and buttermilk form their principal and almost sole diet.

In another case, in a small village, consisting, it may be, of fifty or a hundred families, I found an arrangement cortainly peculiar, but which seemed excellent, and capable of being adopted to advantage in many other situations. Some of the villagers kept one only, some two or three cows. A man and his wife, skilled in making cheese, were employed, in a suitable building, with all the necessary fixtures, to make the cheese for the village. 'I'he milk was carried to the place for making the cheese, morning and evening, and there measured and receipted for. Of the whey, each one, when he carried his milk, got his proportion in retum. The eheese was sold on joint account; and, after dedneting expenses, the proceeds were divided anerenting to each one's contributions. This arrangement was excellent; first, for those who kept only one or two cows, and who could not, under the circunstanees, make cheese but to at disad- 
vantage; second, it saved the difficulty and trouble of a dairymaid in the family - a class of persons who are always difficult to be procured; and, third, it assured the good quality of the cheese, by its being made by a person of known and acknowledged skill.

\section{CXLIII. - FARM-HOUSES.}

A Dutch farm-house is a remarkable object. They are seen scattered and alone at considerable distances from each other, over their extensive meadows, generally surrounded by a few trees. At a distance they appear like enormous barns. They are generally square, covering a large extent of ground, of one story in height, and with a roof rising to at least twice the height of the body of the house, gathering in from the four sides of the house, and terminating in a central point at the top, like an Egyptian pyramid. This roof is entirely devoted to the storage of grain and hay. The lower part of the house comprehends a dwelling for the family, sleeping-rooms, and a parlor or drawingroom, which is never used but upon great occasions, such as the death or marriage of some one in the family, and a kitchen, adjoining which is the keeping-room of the family. Adjoining this kitchen, in truth making a part of it, are the cow-stalls; and adjoining this a room for the storage of the cheese, for the milk, the churns, the press, the tubs, and other dairy utensils, which, whether of wood or of brass, are kept in the most polished condition. The cow-stalls are so constructed that two cows'occupy one stall together, tied by chains, with their heads to the wall, and behind them is a deep trench or drain, into which all the solid and liquid manure is received. The solid is immediately conveyed away to the heap outside the door, and the liquid is drained into a covered cistern at the side of the stable, on the outside of the house.

Into this cistern flow likewise all the slops of the house and of the dairy, and the drain is kept constantly clean by water. In summer the cows are kept and milked in the pasture; the stalls are then most thoroughly scoured and cleaned ont, and 
either carpeted or sanded; and exhibit the same perfect neatness as the rest of the apartment in which the family live. In all cases, hoth in IIolland and Flanders, the cow-stalls, while ocenpied by the cows, are frequently washed with water, which, besides the purpose of cleanliness, serves to inerease the contents of the urine cistern; and over every stall is a cord suspended, by which the tail of the cow is tied when milked, to prevent her slapping the face of the milker, or throwing any dirt into the pail. Indeed, the neatness of all their arrangements is perfect. The farmer and laborers have their clean shoes or slippers at the door, where they always exchange their out-door shoes on entering, that they may bring no dirt into the honse. The contrast between a Dutch farm-house and an Irish cabin or wigwam, is most remarkable.

The Swiss farm-house differs entirely from the Dutch. It is a somewhat stately erection, generally of two stories and high roof, with a piazza in front of the second story, to which there is access from the outside by steps. The lower story, or ground floor, is occupied by the live stock; and the sccond floor by the family. This spirit of fratemization and equality, which appears both among the Dutch and the Swiss, in regard to those useful animals upon whom their living and wealth depend, is certainly an amiable trait of character; and is much more harmless in its operation, if we may judge from the results in the two cases, than when applied to human society. The neatness of several of the Swiss farm-houses which I visited, if not so remarkable as that of the Dutch, is really exemplary.

\section{CXLIV.-SWISS FARMING.}

The farming in Switzerland varies very much in dillerent cantons or districts. The soil varies, and the rugged aspect and broken and mountainous character of the country give a variety to their cultivation and modes of life, which at once impress a visitor. The habits and appearance of the population certainly differ much in different parts. 
There are large portions of Switzerland wholly devoted to pasturage, and which, from their inaccessibility to the plough, can be applied to no other purpose. In these cases, where cows cannot go, goats find their way. But wherever the plough or the spade can be used they are diligently employed, and this activity is stimulated in many parts of the country by a dire struggle to procure a subsistence under circumstances most inauspicious and severe. In parts of Switzerland, the melting of the snow on small patches of ground is hastened by throwing small fragments of slate-stone upon it ; such, I may say, is the necessary impatience to get at the ground seasonably to put the seed in for a crop.

In some parts the country is open, and fields of considerable extent are under admirable cultivation; in other places, the smallest nook, the least patch by a running stream, and the most secluded valley, will be husbanded with the greatest care. The valley of Chamouni, enclosed by lofty mountains covered with the snows of untold centuries, and running at the very foot of Mont Blanc, the sublime monarch of these Alpine heights, was green and beantiful, waving with crops of grain; and when I was there, covered with merry hay-makers. I may add, that these haymakers were almost all of them stout and active women, whom I saw mowing as well as making, raking, and loading hay. They were very cheerful and seemed to enjoy ruddy health.

In the arable districts of Switzerland I was told that the farms consisted usually of fifty acres, and many of these farms gave the strongest indications of independence and comfort. The farms in Switzerland are divided by fences; and, with the exception of the loftiest heights, it may be said that a Swiss very much resembles a New England landscape.

\section{CXLV.-HOFWYL。 IRRIGATION.}

I visited in Switzerland the celebrated establishment of the late Mr. De Fellenberg, at Hofwyl, near Berne, for education. No school is better known; and it is believed that none ever 
hetter deserved public esteem and confidence. It does not come within my province to speak of it in this place as a literary institution; but as a farm it may be considered as a model well worth studying. I have already spoken of the cows at this place, of which there were sixty, the superiors to which, in condition and produce, have not come within my view.

The most remarkable improvement which I witnessed in this place was in irrigation. 'The land irrigated was in the shape of a bowl or basin, of which one side was wanting. 'The water, after turning a flour mill, was brought a considerable distance in a raceway on a bank, and then was carried round through successive rivulets formed round the sides of this semicircle or anphitleatre, watering the intervals between these gutters or trenches, and afterwards spreading itself over an extensive piece of thit land; thus, at pleasure, watering one hundred and fifty acres of land. Nothing which I have seen conld be better managed; and the success of the improvement has been a valuable compensation for any expense which has been incurred. The land is lrept continually in grass, and the water is let on several times in a season. It was deemed inexpedient to keep the water on more than half a day at a time.

I shall find no more suitable place than this to montion the irrigation in the neighborhood of Milan. This is a level and most fertile country. A good deal of rice is cultivated in its neighborhood. The fields have their trenches, and cross ditches; and embankments made with great care. The water is brought from a neighboring lake, and these fields are irrigated at phasure. Where there are facilities for it, or where even they can be formed within any reasonable expense, there are no more successful improvements than irrigation. Lren simple pure water is of great fertilizing power; still more when it brings with it the washings of cultivated fields, or other enriching matters, which it may collect in its course. A diversity of opinion prevails as to the length of time during which water may be allowed to remain on the land. The passage of the water over the land is preferred to having it remain stagnant; and an irrigation of a few hours' duration is generally considered more eligible than a longer continuance.

The farm at Hofwyl presents all the improvements which modern ant and shill could bring to it, with the nost impored 
implements in use. Indeed, it may be considered as a model farm. A considerable number of the pupils were lads, who pay the expenses of their education and living by their labor. T'he number of pupils at this institution, which has heretofore been very great, furnished the best possible market for the abundant produce of the farm.

\section{CXLVI. - LODI'S BENEVOLENT ESTABLISHMENT.}

I found one humble establishment of a philanthropic character, of which I deem it my duty to take notice. In a quiet and secluded village in the canton of Berne, I went with some friends to visit an humble peasant by the name of Lodi. He was a man of powerful intellect and extraordinary decision of character. His resolution once fixed, he was not easily turned aside from its execution. His mind from his childhood was profoundly impressed with a strong sense of religious duty, and his heart was warm with sympathy and benevolence for his fellow-men. He had received the advantages of a good common education, and had done much towards improving himself. He had a very small patrimony left to him; he married early, and had one child. He found in his wife a mind and resolution congenial with his own. Looking with pity upon many orphan and forsaken or neglected children about them, he determined to do what he could towards rescuing some of these unfortunate children from the almost certain min which menaced them; and his wife and himself agreed to receive as many of them as would be given to them for this purpose, and as they could possibly support by their united exertions. When I visited them, they had eighteen under their care, whom, in fact, they had adopted, for he made no difference between their treatment and that of his own child; and they were all taught to look upon him and his wife as their parents, and themselves as brothers and sisters. They lived with them, and worked with them as their own children. IIe devoted a certain portion of every day to giving them a useful moral and religious education, and the rest of the 
time was given to work on the land. Industry and useful labor, economy, frugality, contentment, universal kindness and love, mutual affection and forbearance, and the fear of God and an humble and entire reliance upon his providence, formed the great principles which governed the whole household, and which presented themselves strongly illustrated in the eximples of the father and mother of this household. This was exclnsively an agricultural establishment, the girls and boys being tanght and accustomed to all the labors and duties of their condition. He had many difficulties to struggle with in feeding and clothing so large a family; and in the scarcity of 18.16 , from the perishing of the potato, it was a most difficult effort to get through, and he then received some slight aid from abroad. At first his views were suspected, and he was treated with distrust and ill-humor by the villagers. But he had conquered every hostile prejudice; his disinterestedness and philanthropy are universally acknowledged; his children are examples to all, of good conduct and improvement; his neighbors feel happy to render him some aid, and he is known every where as the good father of the village. This is an eminent example of the noblest inilanthropy ; of immense good being accomplished by the most limited and humble means; and of what may be done by heroic self-sacrifice, by noble and generous purposes, by indomitable resolution, and unslacking perseverance. I saw his school, and witnessed his parental deportment among his family; I sat down at his frugal board, and partook of his simple meal of bread and cheese and wine, and I felt myself in the presence of the true nobility of human nature, and that no monarch in Europe had power to confer upon me a higher honor. It is not difficult to be charitable on a grand seale; it is not difficult for a rich man to give away his superfluous thousands to any splendid charity, especially when he can use them no longer; but to devote one's life to the poor, to be willing to share in their poverty, to take the stray lambs of the flock into one's bosom, and to make the orphans, the outcast, the houseless, your own children, and give them, in the midst of poverty, a useful cducation, and to qualify them for the business of life, to be useful and respectable, is an enterprise of the noblest character, conferring immortal honor on him who undertakes it. 


\section{CXI.VII. - INSTITUTION FOR RECLAMMING VICIOUS CHILDREN.}

In the neighborhood of Berne, likewise, I visited another philanthropic institution, in which I was much interested. A few persons had contributed the means of purchasing a valuable and suitable estate for the purpose of establishing an agricultural school for vagabond boys, or those who have been convicted at the courts of law, and who, after suffering the legal penalties of their crimes, and being released from prison without character, without friends, without a home, or the means of procuring an honest living, seem to have no alternative other than that of returning to their former course of idleness, beggary, and crime. This undertaking is thus far eminently successful ; they having found an individual of high intellectual and moral attainments, and of indomitable resolution and great disinterestedness, who devotes himself to the reclamation and education of these poor and wretched children. About sixty individuals are now under his care. The farm is well cultivated, and chiefly by hand and spade labor. The most remarkable features about the establishment are the absence of all peculiar dress or external badges by which the boys could be distinguished; and of all fences or bars by which the escape of the boys might be prevented. The boys are divided into parties of ten or twelve, who work together under the direction of a foreman. The whole discipline of the institution is moral; and their punishments for irregularities, idleness, or other faults, are of a kind much more to affect the mind and conscience of the pupils than their bodies.

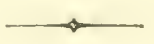

\section{CXLVIII. - CONDITION OF 'TIE POOR AND LABORING CLASSES.}

Europe abounds with philanthropic institutions; and there exists a large demand for them. In Switzerland a society has heen formed in the agricultmal districts, meder the patronage of 
the government, "for the public good," intending especially, under this comprehensive designation, to embrace all means or measures which may relieve, benefit, or improve the character and condition of the poorer and laboring classes.

The condition of these classes in Europe, in general, strongly claims the interest of benevolent minds. Their wages are small; their toil in general hard; their food scanty and mean; and their comforts extremely few. It is one of the monstrous anomalies in the disposition of wealth, that those by whose toil it is created receive the smallest portion of it; and, in the midst of a plenty growing out of their sweat and labor, they are often crippled by want, and perish with starvation.

Philanthropic minds are now actively at work to discover a cure, or at least a mitigation, of this injustice; but it is much more easy to complain of an evil, than to point out a remedy. The Swiss are proposing to give up all the public lands, and individuals with large possessions are offering to relinumish portions of their estates, that land may be given or furnished, on certain reasonable conditions, to the laboring poor, who are fomm to be rapidly increasing among them; and who, in the mountainous districts, in some parts of the country, are as miscrable as the poor Irish. I saw, occasionally, on the Continent, cases of extreme destitution; and, in those places which had been visited the previous year with the potato disease, I saw much and extreme poverty; yet, I confess, I saw nothing on the Continent to equal the degradation, the squalidness, and wretchedness of the Irish, even before that sweeping calamity, which has consigned so many thousands of them to the gravo.

The French have recently proposed violent remedies for these acknowledged evils. The visionary and mad among them have demanded the perfect equalization of property, which, if carried out to its full extent, would result only in universal injustice and pillage. The scheme is as vain and impracticable, as to reduce the Alps of Switzerland to a level with the low countrics of Holland and Belgium. The inequalities in the condition of men do not constitute the great evils which are complained of. I poor man is not in a worse condition because his neighbor is rich, unless the rich man abuses his power to injure him; nor are the poor necessarily the poorer, except by comparison, for the riches of the community in which they live. As far as wealth VOL. II. 
is a stimulant to industry, and an instrument of good, it becomes a universal blessing. The insane, the blind, the deaf and dumb, the maimed, the sick, the old and decayed, the fatherless and friendless children, and, indeed, all who, by the dispensations of Dirine Providence, are deprived of the power of helping and sustaining themselves, should be helped and sustained by the community. But what is to be done for the able-bodied laborers, who are not unwilling to work, but who have no opportunity of exerting their power? This is a great question, and involves immense difficulties in the present organization of society.

I see no grounds to hope for any immediate, speedy, or effectual remedy for the evils which exist. I am not looking for an early millennium. The wealth of the world is every where increasing at a rapid rate, and almost beyond the dreams of avarice. The poverty of the world seems increasing, especially in the old world, in a corresponding ratio. As wealth increases, the value of money is diminished; but as the wages of labor do not increase as the value of money diminishes, and the prices of the articles of human subsistence increase, and as the value of labor is continually diminished by the increase of laborers, and the augmentation of the population goes on rapidly in a state of general peace, the condition of the laboring classes becomes the more straitened, and the great evil of unemployed, though willing labor, is augmented.

One of the first duties of the state should be, not to give labor, but, as far as can be, to secure to every one willing to work, an opportunity of exerting his powers, and, as far as is consistent with the general good, and prejudicial to no just rights of any, to do this in any way or form to which his inclinations may lead him, or to which his talents may be adapted. Monopolies of every description, excepting so far as they may be given as premiums to inventive genius, are to be condemned. The monopoly of land in the old world is a serious evil. The traveller passes over miles and miles of unoccupied and unimproved land, capable of sustaining its thousands and its millions in comfort, and on the borders of these immense tracts finds thousands of human beings suffering and perishing, for the want of an opportunity of procuring their living out of this land, from which they are excluded. This tract belongs to the crown; that tract belongs to the church; these immense domains are held by some 
porrerful individual, who chooses to keep it in its present state for his game preserves; another large tract is deroted to some object, which, if it had its value centurics ago, has now ceatsed to be of use. Is there any reason why this land should not be made available to the support of perishing thousands; whose voluntary labor would make it so available? In feudal times the powerful baron or lord took care of his vassals, and regarded himself as to a degree bound to provide for them from the estate, which they cultivated and protected. Things in this respect are? changed; now, the holders of large estates, who seem every where actuated exclusively by a commercial spirit, feel no futher bound to their laborers, than to manage their estate in the least expensive mode possible, to take every advantage of the competition in the labor market, and get their work performed as cheaply as possible; and then, having got their labor accomplished, and having paid their laborers, in money, the miscrable pittance promised, dismiss them without any further concem for them. This grows out of the modern refinements of political economy, which measures all good and all values by a pecuniury standard A state of South Carolina slavery, as far as the physical comforts of the laborer are concemed, has many advantages over this.

All expectations of any great changes or improvements in the unstitutions of society are, in my humble opinion, vain. There is not wisdom enough, nor virtue enongh, to effect, or, if effected, to maintain them. Ambition, the love of power, avarice, vanity, and pride, those mighty passions which sway the heart, and whose power increases in correspondence with the means of indulgence, impose insurmountable impediments to the progress and influence of the true principles of Christian eyuality; equity. and kindness. Men without power fancy they should not aluse it, if acquired; but the possession soon contradicts this promise. Poor men persuade themselves, if they were rich, their wealth wrould be used only to do good, and make others hitppy; but the accuisition of wealth too often dries up all the spriners of sympathy and kindness, and stimulates inordinately the thirst for further acquisition.

Violent revolutions present remedies full of terror and alarm; sometimes only open new sources of wretchedness, and are but the change of one tyranny for another, and that even more 
severe and terrible. We may hope something from advancing and extending education. This education may improve and enlighten public opinion; and, in the present wide and constantly-extending influence of the press, public opinion seems to present the strongest barrier against the abuse of power, and to be the great exciter to justice and to philanthropic exertion. In proportion as public sentiment is strong, and based upon and controlled by the principles of Christian equity, —alas! so little understood, - we may hope for some substantial amelioration in the condition of society; but this seems at present distant and incertain.

One is consoled in this case by looking at the amount of good which may be effected by such men as the Swiss peasant whom I have described. Suppose him successful in rescuing from wretchedness, and in forming to habits of industry, frugality, and good conduct, only the eighteen children, whom, like an affectionate shepherd, he has taken like lambs in his arms. Imagine these children going out into the world to multiply the good which he has done, and to spread its influences through the various ramifications of society. What a rich harvest will arise, and he the precursor of other and richer harvests from the small seed sown by this disinterested and noble, but poor and humble peasant!

I fear my realers will think me straying from my proper duty; and I have, therefore, cut short these reflections. I could not pardon myself if $I$ could look at the condition of the laboring classes in the old world without the deepest concern. At present, the farmers of the United States have the greatest reason to congratulate themselves, to say nothing of the higher duty of religious gratitude, for the circumstances in which they are placed. There is at present land enough there for all, and open to the acquisition of even the humblest man, who is willing to labor, and to unite with this labor temperance and frugality. 


\section{CXLIX. - IMPOR'TANT' PRACTICAL CONCLUSIONS.}

The great points to which I think the attention of American farmers, and of other farmers, should be called, I shall briefly enumerate.

1. Thorough Draining and Deep Cultivation. - The first of all improvements should be the thorough draining and deep) cultivation of the soil. The Deanston system of therough draining and subsoiling has effected immense benefits in England, and promises to establish itself as one of the greatest single improvements ever made in husbandry. In Flanders, thorongh draining; as it is called, does not prevail ; but their surface-draining is most carefully attended to, and trenching with the spade is even much better, though in most cases more expensive, than subsoiling. Indeed, their land, to the depth of two feet in the best cultivated districts, is completely tumed over, and thoronghly intermixed once in the course of every six years.

2. Manures. - The second great point, and that which almost transeends all others in its claims upon the farmer's attention, is the manufacture and increase of manure. It must be acknowledged that the resources for this object within the reach of most farmers are not half used, and means of creating and accumulating manures are neglected or wasted, which waste, if it could be represented by any pecuniary value, wonld astonish us. On many an English farm there are resources for manure neglected or lost, which would be much more than an equivalent for the rent. Let me here revert to the immense value of liquid manure, and the provision for and means of saving it, which I have treated so much at large.

3. Sorling of Cattue. - The third point of great consideration is that of the soiling of cattle. There are vast tracts of pasture land, to which the plough cannot be applied. Sheep and young cattle may occupy these. But the farmer will find an immense advantage in soiling his beef cattle and cows, and oftentimes his sheep also. They will be fed at less expense; 
they will be more under his inspection and control; they will give him equal, and, according to the opinions of many experienced farmers, greater returns in beef, butter, and cheese, than if kept in the ordinary way. Above all, the extraordinary and valuable increase of his manure-heap and cistern, under such circumstances, is a consideration over all others. Next to labor, manure is the great element of a farmer's prosperity.

4. Improvement of Live Stock. - 'The fourth great matter to which I would call the farmer's attention is the improvement of his live stock. It is difficult to speak too highly of the skill and success of the English in the improvement of their breeds of sheep, swine, cattle, and, I will add, horses. I do not say that their breeds are all such as are best adapted for the United States. I need not repeat the opinions which I have already given in this matter. Different breeds of animals are suited to particular localities; and the extent of the United States presents every variety of aspect, soil, and climate; and is marked by different kinds of husbandry, such as the raising of stock for beef or labor; the growing of wool, fine or coarse, short or long; and the produce of the dairy. These points are all to be considered in the selection of a stock for breeding. An improved Durham short-horn would thrive and develop all his richness and beauty in the fertile meadows of Kentucky and Ohio, and the rich prairies of the west, who would become poor and dwarfish in some of the rocky and almost barren pastures of the north. But that to which I wish particularly to call the attention of the farmers of the United States is, the improvement of their stock by patient care, skill, and selection. They may import animal: of improved breeds to advantage; they may cross the best of their own stocks with the best animals which they can find; and, above all, let them determine always to select the best animals for breeding, and breed only from the best; never sacrifice a superior calf or lamb to the butcher, nor be satisfied with the services of inferior animals for the increase of their stock, under which they would be sure to deteriorate.

5. Improved Articles of Culture. - The next matter to which I beg their attention, is the cultivation of esculent vegetables, the improvement of plants, and the introduction of new 
articles of cultivation. The cultivation of esculent vegetables for stock, such as turnips, ruta-baga, carrots, parsnips, or beetroot, is a matter which I would strongly recommend. Besides its being more conducive to the health of the animals, to their increase in meat and in milk, it will enable the farmer, in the feeding of his cattle, to consume his straw to advantage, and save more expensive forage; and so increase his stock.

The improvement of plants, by the careful selection of the earliest ripe, the fullest and the most perfect plants and seeds, may be carried to an equal extent with the improvement of animals. 'The fine barley called the Chevalier barley, and many of the finest kinds of wheat which are cultivated in Europe, are the product of some individual plants, selected in a large field, and carefully cherished by the cultivator. The difference in the time of ripening, the difference in the amount of product, the difference in the quality of the grain, are all essential considerations.

6. New Articles of Culture. - The introduction of new articles of cultivation is a point of much importance. The flax crop is not by any means so extensively cultivated in the United States, as it may be to advantage, especially when the value of its seed for fatting cattle is taken into the account. No article is more nutritious nor fattening both for sheep and cattle. I am diffident in advising the cultivation in the United States of the oleaginous plants of IIolland and Belgium, such as colza, rane, poppy, \&c. The expediency of doing this can only be determined by experiment. The cultivation of beet-root for sugar, considering the cheapness of the manufacture where it is well understood, and managed on a large seale, and especially in coinnection with the value of the refuse for feeding and fattening cattle, deserves much thought and inquiry. Without reference to the production of sugar, the value of the crop for feeding stock, considering that no crop yields more, is more relished by cattle, or keeps sound to a later period in the spring, is great, and strongly recommends it. Few crops yield more to the acre, when well cultivated, or leave the land in better condition for a succeeding crop of grain. My own views in regard to this crop have most essentially altered in its favor.

Lucern, sainfoin, and vetches, are comparatively little culti- 
vated in the United States. They are all, in proper sitnations, highly valuable. Lucern, in any system of soiling, would be extremely useful as coming early in the spring, and giving under good culture an enormous yield, being at the same time a plant which actually enriches the soil. For later feeding in the season, the farmers of the United States have that most valuable of all plants for its forage and its grain, Indian corn, or maize. I may say, with the great Arthur Young, "that a country is signally blessed above others, which can grow Indian corn." In the Middle States of the United States, sainfoin might perhaps be cultivated to advantage; in the Northern States, experience has shown that the winters are too severe for it. It makes a most nutritious and excellent hay. Vetches yield a large abundance of green feed. St. Johu's-day rye, of which I have spoken, may be cut two or three times, and yield also a large crop of grain. This would make an excellent forage for the purpose of soiling; so, also, the improved Italian rye-grass, which, when properly cared for, bears cutting several times in a season, and yields most abundantly.

I must add, in the next place, that I should be glad to see the cultivation of the vine extended in the United States. In many parts of France, Germany, and Switzerland, it occupies land, steep acclivities, heights wholly inaccessible to a horse or cart, and where the manure is always carried up, the produce brought down, and sometimes the very soil in which it grows, transported by hand. There is land enough in the United States for its cultivation without such extreme toil. $\Delta$ s an article of commerce, it would probably prove lucrative; and as an article of comfort, perhaps few are more grateful and harmless. I speak in this case of the light wines of France, which do not intoxicate unless drunk to beastly excess. The strong wines of Spain and Portngal are made by some factitious process, and charged with brandy; but the light wines of France, being the pure juice of the grape, exhilarate, but do not intoxicate. They take the place of tea and cotfee among the laboring people, and constitute an innocent alleviation of their severe toil. I should be sorry in any way to abridge these comforts, especially as I may say in truth, after travelling a long distance in the wine-growing districts, and at the time of the wine-making, or vintage, when it is to be had in the greatest abundance, that I saw no drunken- 
ness or intoxication in any degree; and I may add, that so far as my observation goes, there is not a more temperate people, than are to be found in the wine-growing departments of F'rance.

I need not add, that under the auspicious circumstances in which the United States are placed, her agriculture must be constantly increasing in importance to the country itself, and to the civilized world, for her commerce penetrates every sea, and her bread-grains, as they have already been, may be of immense importance, and of indispensable necessity, in fecdirg the inhabitants of the old world.

This completes the task which I undertook of giving, from personal observations, an account of European Agriculture and Rural Economy. I commend my work to the indulgence and candor of my readers. It was an undertaking too great for an individual to accomplish as one would desire that it should be done. It must satisfy me, I hope it will satisfy my friends, that I have, with unceasing anxiety, sought to execute it as well as I could. It was not to be expected that I should give a complete system of agriculture; but I have constantly endeavored to collect and present that information which would be most useful; and to convey it in a simple and practical form. I have omitted many circumstances, because they are well known. I have given full details wherever I thought they were required. As to my opinions on any subject upon which I have treated, I can only answer that they are my own; that $I$ am quite ready to yield them, when I find, upon further information, reason so to do; and, above all, that my opinions or judgments do not encroach upon the personal right of independent judgment and opinion in any and all others.

European agriculture lies under many burdens, from which the United States are free, and I pray may long remain so. The weight of taxation in most of the countries of Europe is very oppressive. The unproductive classes are numerous to an excess. Immense standing armies; govermments enormously cxpensive, and in a great measure irresponsible to the people; ecelesiastical establishments, and their altuchés, demanding large contributions from labor, and retuning, in many cases, little more in value than the bishop's blessing in Esop's fable, are all to be sustained from the soil, and by the labor of those who cultivate it. In their 
present exemption from these burdens, the farmers of the United States are greatly blessed. May they duly appreciate their singular advantages, than which none greater ever fell to the lot of man in his social condition. 'To them we may apply the beautiful line of the immortal poet -

O ! ter beati agricolæ, si sua bona nôrint.*

* Thrice happy farmers, if they only knew their blessings. 


\section{A P P E N D I X .}

\section{EXTRACTS FROM THE REV. MR. RHAM'S FLEMISH HUSBANDRY.}

\section{SELECT FARAS.}

I. "A little beyond Courtray is a farm particularly noticed by Mr. Radcliffe. This farm is one of the finest and most compact we have seen. It consists of about one hundred and forty acres, of which about twenty are fine meadows along the river, occasionally flooded in winter, but not irrigated; about ten acres are rich heavy land, adjoining the meadows, in which beans and wheat thrive well; all the remainder, about one hundred and six acres, lie in an oblong field bounded by a hedgerow. A road or path, six feet wide, runs through the middle of the field. The soil of this field is a rich light loam, which lies over a substratum of clay, but at such a depth as to be perfectly sound and dry. It is not extremely fertile in its own nature, but has been rendered so by many years of an improving husbandry. Every part of the land has been repeatedly trenched and stirred two or three feet deep; and the immense quantity of manure, chiefly liquid, put on year after year, has converted the whole into a very rich mould. The strength and vigor of the crops bear witness to the goodness of the husbandry. There were fifteen acres of most beautiful flax, of a bright straw color, and the stems a yard long. This, besides the seed, was worth in the stack from twenty-five pounds to thirty pounds per acre; twelve acres of colza had produced about four hundred bushels of seed; eighteen acres of oats looked so promising, that they could not be set at less than forty-five bushels per acre; eighteen acres of wheat, which stood well with short but plump ears, we valued at forty bushels per acre; eighteen acres of rye, partly cut, with the straw above six feet high, would probably produce rather more than the wheat. There were six acres of white poppy, of which every plant was strong and upright, and the ground under it as clean as a garden: the expected produce would be about twenty to twentythree bushels per acre; six acres were in potatocs, expected to produce three hundred and seventy-eight bushels per acre. A small patch, about an acre, was in carrots, which looked fine and large; twelve acres were in clover, nearly the whole of which was cut green to give to the cows and horses; it produces three good cuts in the year where it is not allowed to go to seed. The ten acres of heavy land were partly in beans and partly in wheat.

"Thus we have one hundred and sixteen acres all profitably cropped, leaving four acres for the roads and farm-buildings. Although this farm is within two 
miles and a half of Courtray, the greatest part of the manure is collected on the farm. Rape-cake is used most profusely, and to this, as well as to the depth of the soil, the beauty of the flax is ascribed."

II. "Near Alost we met with one of the smallest farms, which will maintain a family without other work: it was barely five acres. There was a small orchard of about a quarter of an acre, in which there were some thriving apple and plum trees. The grass under these was good; and the only cow which the man had was led by the wife to graze there for a short time every day, apparently more for exercise than for food. The grass seemed to have been cut for her in another part. The man regretted that he had not the means to purchase a second cow, as he could maintain two very well. Half of the land was in wheat, the other half in clover, flax, and potatoes; so that the clover did not recur sooner than in six years; the flax and potatoes in nine. As soon as the wheat was cut, he began to hack the stubble about four inches deep, with the heavy hoe, and as fust as he got a piece done, it was sown with turnips, after having some of the contents of the urine-tank poured over it; for, small as the farm was, it had its reservoir for this precions manure. Thus a considerable portion of the wheat stubble was soon covered with young turnips of a quickgrowing sort, which, if sown before the middle of August, were fit to be pulled in November, and stored in the cellar for winter use. There was a small patch of cameline, which was sown less for the seed than for the stem, of which he made brooms in his leisure hours, when snow covered the ground. The whole five acres had to be dug in the course of the year, and as much of it as possible trenched; the soil being a stiff loam of a good depth, which was much improved by trenching and stirring. The milk and potatoes fed the family, with the addition of a little salt pork; for a pig was fed on the refuse of the food given to the cow, and a very little corn, and consequently was not overburdened with fat. Most of the wheat and all the flax were sold, and more than paid the rent, which was not high - about ten pounds a year. Incessant labor kept the man in good health, and his wife was not idle. They had two or three young children; but, except the wish for another cow, there seemed no great dissatisfaction with their lot, nor any great fears for the future. They had no parish-fund to fall back upon, not even a union workhouse; but, had they come to want by unfore:cen accidents, they would have found the hand of private charity stretehed out to help them." 


\section{TIRRARI FDITION \\ of \\ STANDARD POETICAL WORKS.}

\section{In Uniform Style.}

TUPPER'S POETICAL WORKS; em. bracing Proverbial Philosophy, Thousand Lines, Geraldine, Hactenus, and Miscellaneous Poems. Complete in 1 vol., $12 \mathrm{mo}$, muslin, fine portrait. Price \$1.00.

COWPER'S POETICAI WORES; with Lise; a new edition, 1 vol., $12 \mathrm{mo}$, with portrait. Prico $\$ 1.00$.

POPE'S POETICAL WORKS; new ellition, containing a Life of the author. Price 81.00 .

BYRON'S POETICAI WORIS; with a Sketch of his Life, in one volume, 12mo, and embellished with a portrait. I'rice $\$ 1,00$.

MOORE'S POETICAL WORKS; an en. tire new edition, in one volume, with porirait. Price $\$ 1.00$.

BURNS' POETICA工 WORHS; embracing 2. Life of the Author, Glossary, and Notes. A new edition, 1 vol., $12 \mathrm{mo}$, with fine portrait. Price $\$ 1.00$.

SCOTT'S POETICAL WORKS; with a Memoir of the Author, embeltished with a portrait. Price $\$ 1.00$.

IIFE, GEMS, AND BEAUTIES OF 5HALSPEARE; all embraced in one volume, ismo, containing six fine engravings and portrait. 23rice $1 \$ .00$.

POETICAL REMAINS OF HENRY KIRli WHITE; containing a memoir of the aushor, with an introductory chapter on his relig. ious and poetical development, by Rev. John Todd. Pricesl.00.
HEMATS' POETICAL WORISS; an en. tire new edition, in I volume, anil illustrates with steel engravings. Price $\$ 1.00$.

HOWITT, COOK $\triangle N D$ LANDON'S POETICAL IVOKKS; a new edition, I volume I2mo, neat muslin. Price $\$ 1.00$.

MILTON AND YOUNG; containing Par. adise Lost, and Young's Night Thoughts, a new edition, complete in 1 vol., $12 \mathrm{mo}$, with portrait P'rice \$1.00.

CROLY'S BRITISH POETS; combining the beauties of the British Poets, with introductory observations by Rev. George Croly, 1 vol., embellished with fine steel engravings, Price $\$ 1.00$.

THE POEMS OF OSSIAN; a new edition, containing ten steel engravings, and printed on fine paper, 1 vol., $12 \mathrm{mo}$. Price $\$ 1.00$.

THOMSON AND POLLOK; containing the Seasons, by James Thomson, and Course of Time, by Robert Pollok, complete in one rolume, $12 \mathrm{mo}$, with portrait. Price $\$ 1.00$.

WORDSWORTH'S POETICAL WCRKS ; an entirely new edition, from plates just exereo. typed, complete in 1 rol., $12 \mathrm{mo}$, with portrait. Price $\$ 1.00$.

CAMPBELL'S POETICAL WORKS; including his "Pleasures of Hope," Theodoric, and Miscellaneous Poems, many of which are not contained in the former editions. Complete in 1 vol., $12 \mathrm{mo}$, with portrait. Price $\$ 1.00$.

The above poetical works are uniform in size and binding, and are sold sep. arately or together. Their size and style considered, they are the cheapest lit rary editions of the same authors before the Americar public. 


\title{
PHILIIPS, SAMPSON \& CONPANYS
}

\author{
PUBLICATIONS OF \\ STANDAD WORES
}

\section{IUPE AND WACAULAI'S \\ HISTORY OF ENGLAND. BOSTON LIBRARY EDITION.}

\section{PHILIIPS, SAMPSON \& COMPANY}

Are now publishing HUME'S HISTORY OF ENGLAND, from the Invasion of Julius Cæsar to the Abdication of James II., 1688, and continued from that time by

$$
\text { T. BABINGTON MACAULAY, }
$$

with notes and references; being an accurate reprint from the Standard English Editions. The above works are published in large crown $12 \mathrm{mo}$. form, bound uniform in muslin and sheep binding, printed from good clear type, forming altogether the cheapest and most perfect Library Edition of the two authors, ever issued from the American press.

Each volume contains over five hundred large duodecimo pages, and are sold separately or together at 62 cents per volume.

Extract from the North American Review for October, 1849.

"'The best advice that can be given even now to the diligent student of English history, is to read Hume first, and Henry, Lingard, Hallam, Brodie, Guizot, Aikin, and a host of others, afterwards. Any one of these later candidates for public favor may be omitted without material loss; IIume alone is indispensable.

But the greatest compliment that Hume's work ever received, is that which has just been paid to it perforce by the most brilliant and captivating of English writers of our own day. The all-accomplished Mr. Macaulay, who seems to have been born for the sole purpose of maling English history as fascinating as one of Scott's romances, durst not enter into competition with his great predecessor, but modestly begins his history almost at the point where Mr. Hume's terminates. Mr. Macaulay evidently prefers to be a continuator of Hume, rather than to wrestle with him on his own ground. 


\section{COMPIETE}

\section{LIBRARY OF NATURAL HISTORY.}

\section{ILLUSTRATED WITH

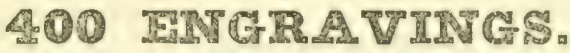

This work was carefully compiled by A. A. Gould, M.A., from the works of Cuvier, Griffith, Richardson, Geoffrey, Lacepede, Buffon, Goldsmith. Shaw, Montague, Wilson, Lewis and Clark, Audubon, and other eminent writers on Natural History.

It is all comprised in one imperial octavo volume of about 1000 pages, handsomely bound, and is in itself, as its title indicates, a complete library on this subject. Price $\$ 3.00$.

\section{SHAKSPEARE'S DRAMATIC WORKS;}

Complete in seven volumes, imperial octavo, of nearly 550 pages each; forming in all nearly 4000 pages. The above edition of the great dramatist is known as the "magnificent Boston edition," being celebrated for its transcendent beauty of typography; and in this regard altogether the finest American edition extant.

\section{PROVERRIAI, PHILOSOPHY:}

A book of thoughts and arguments, originally treated. BY MARTIN FARQUHAR TUPPER.

First and second series, complete in 1 vol., $12 \mathrm{mo}$, with a fine portrait of the author, and bound in various styles.

\section{THE MIOENANTCS' TEZT-EOOII, AND ENGINEERS' PRACTICAL GUIDE;}

Containing a concise treatise of the nature and application of mechanical forces; action of gravity ; the elements of machinery ; rules and tables for calculating the working effects of machinery ; of the strength, resistance and pressure of materials; with tables of the weight and cohesive strength of iron and other metals. Compiled and arranged by Troms KELT, of the Gloucester City Machine Company. Complete in one volume, $12 \mathrm{mo}$.

To the eareful mechanic, the above will be found a work of invaluable daily :eference. Price $\$ 1.00$. 


\section{MUSIC B00KS.}

\section{White's Chureh Melodist.}

A new collection of Psalm and Hymn Tunes, adapted to the wants of Choirs, Singing Schools, \&c. By Edward L. White, Editor of "The Modern Harp," "Melodeon," "Sacred Chorus Book," \&c.

\section{American Collection; \\ (1) BY EDIVARD HAMILTON, Esq.}

The greater portion of the music in this book is entirely now, and of a very high order; and Choirs will find it a rich accession to their musical libraries.

\section{Congregational Singing Book; OR, VISTRY COMIPANION.}

The music in this book is composed entirely of old choice standard tunes, such as will be familiar to all. They were carefully collected and edited by Asa Fitz, Esq.

\section{Common School Song Book.}

This will be found to contain a very choice collection of simple, and, for the most part, familiar airs, beautifully adapted to the wants of Juvenile CHorrs, the Private Circle, or the School Room. Edited by Asa Fitz, Esq.

\section{Sabbath School Minstrel.}

This little volume is especially adapted, in its Music and IIymns, to the service of the Sabbath School. It has been much admired wherever it has been used. Edited by Asa Fitz, Esq.

\section{GREEK COURSE ON STUDIES.}

CROSBY'S GRAMMAR OF THE GREEK LANGUAGE.

CROSBY'S XENOPHON'S ANABASIS.

CROSBY'S GREEK ILESSSONS : consisting of selections from Xenophon's Anabasis, with Directions for the study of the Grammar, Notes, Exercises in Translations from English into Greek, and a Vocabulary.

CROSBY'S GREEK 'TABLES, for the use of Students.

*** 'The above are by A tpineus Crosby, Professor of the Greek Language and Literature in Dartmouth College. They are very highly recommended, and are already extensively in use, as text-hooks, in the different colleges and classical schools of the country. 





APR 25194 


LIBRARY OF CONCRESS 